
gyt 





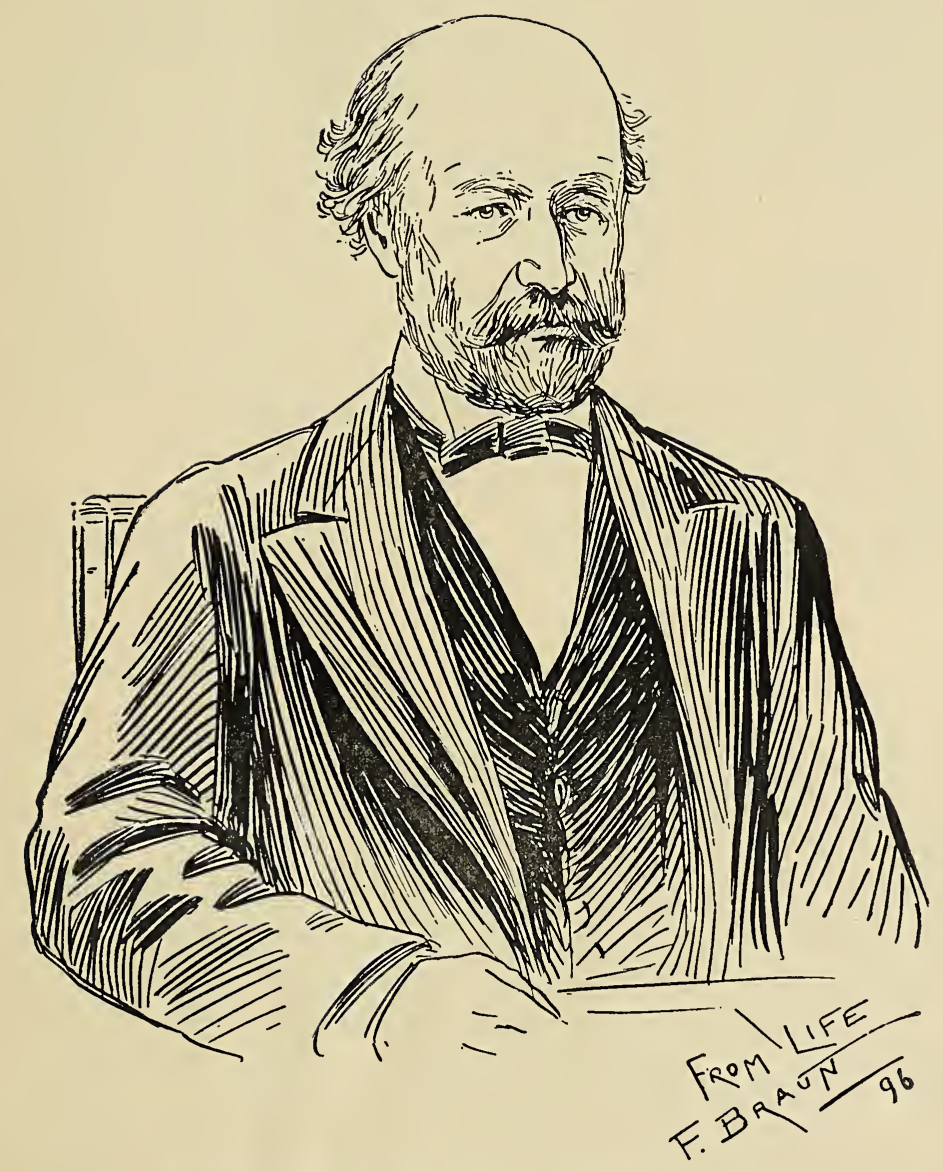

THE RIGHT HON. LORD TWEEDMOUTH,

Chairman of the Inter-Departmental Committee on Post Office Establishments. 



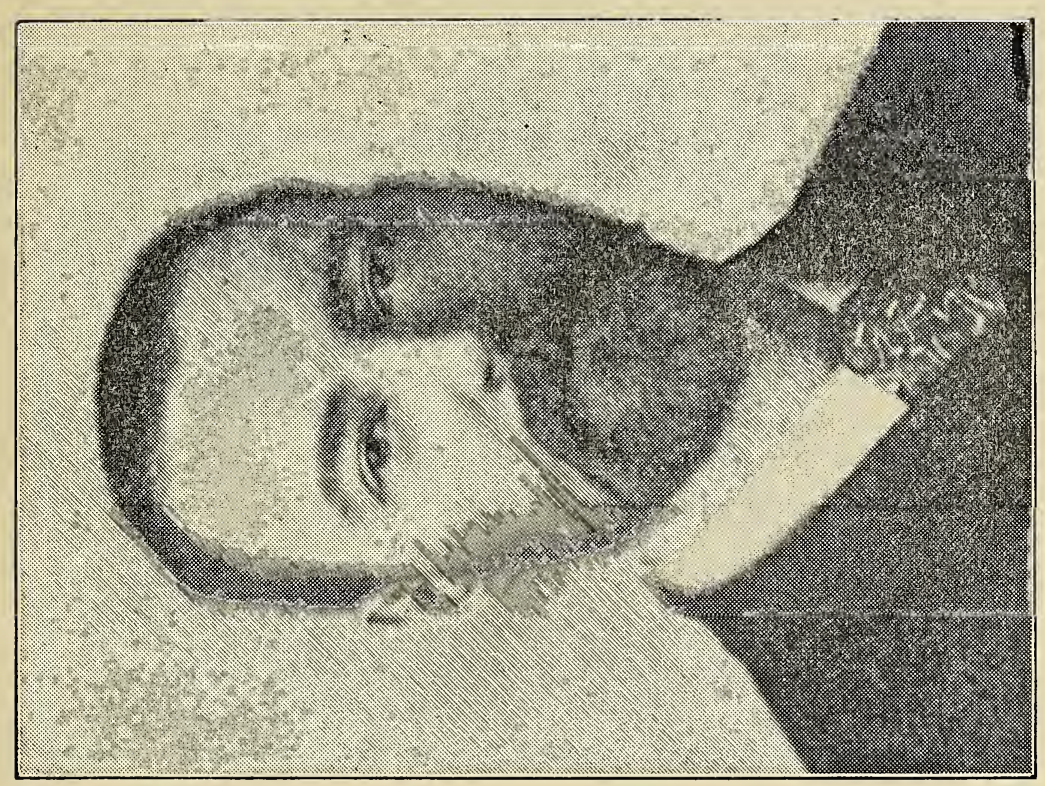

प

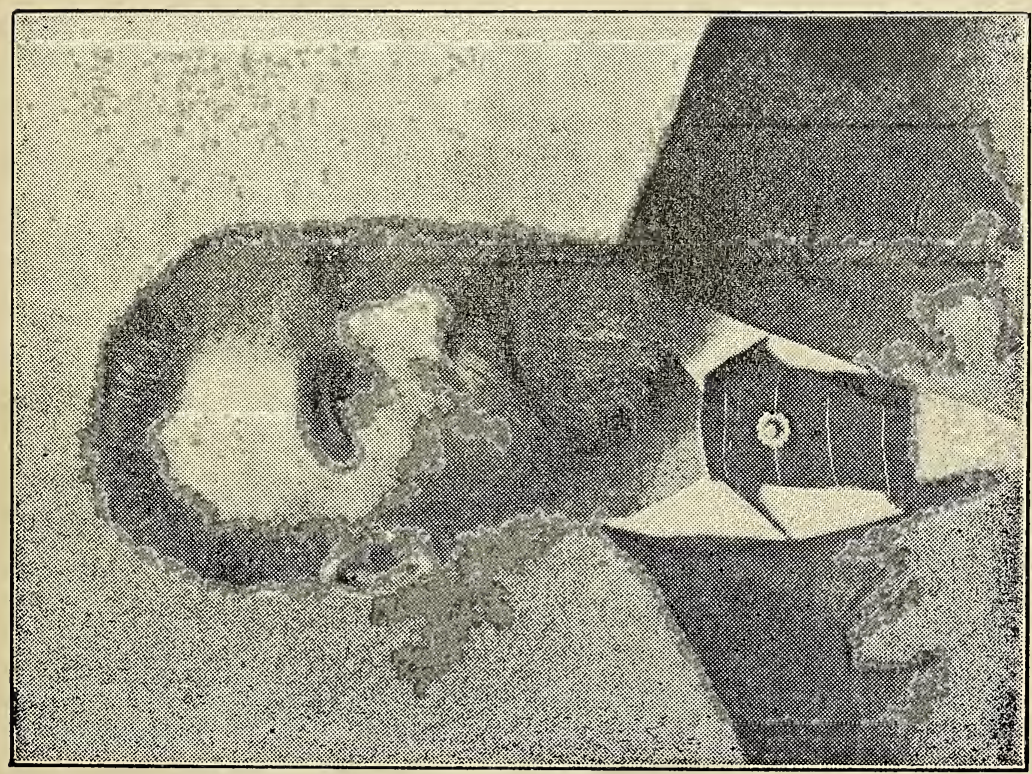

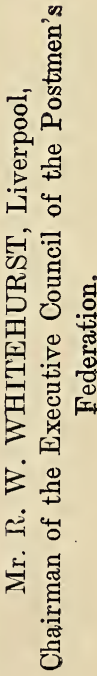





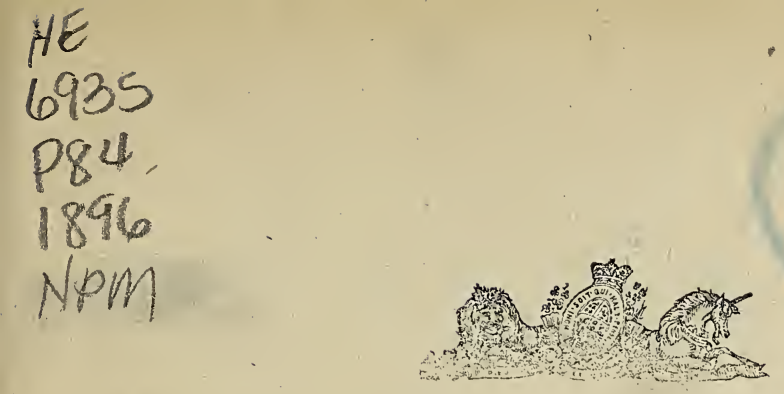

THE

\title{
INTER-DEPARTMENTAL COMMTTTEE
}

ON

\section{POST OFFICE ESTABLISHMENTS:}

\author{
BEING
}

A VERBATIM REPORT OF THE EVIDENCE GIVEN BEFORE LORD TWEEDMOUTH AND COMMITTEE BY THE REPRESENTATIVES OF THE POSTMEN'S FEDERATION.

Postmen's Federation

PUBLISHED BY AUTHORITY OF THE POSTMEN'S FEDERATION. FOR PRIVATE SALE.

[COPYRIGHT.]

Printed by Alex. MAlcolm \& CO., 34 Ann Street, City, Glasgow; and $1 \& 2$ Bouverie Street, Fleet Street, London, E.C. 
THIS BOOK

IS RESPECTEULLY DEDICATED TO THE

\section{POSTMEN WITNESSES}

WHO SO FAITHFULLY AND WELL

DISCHARGED THEIR DUTY TO THEIR COMRADES

THROUGHOUT THE UNITED KINGDOM

IN SUBMITTING THE

POSTMEN'S CASE FOR ENQUIRY

TO THE

INTER-DEPARTMENTAL COMMITTEE ON POST-OFFICE ESTABLISHMENTS, PRESIDED OVER BY

THE RIGHT HON. LORD TWEEDMOUTH.

JAs. C. BRown, Editor "Pcstman's Gazette." 


\section{PREFACE.}

-

THE history of the birth and growth of the movement for an amelioration in the condition of that important body of Civil Servants - the Postmen of the United Kingdom - is contained in this volume; and constitutes a magnificent record of what may be accomplished by steadfastness of purpose and unity of forces. The events which led to the formation of the Postmen's Federation, and the labours of that body when established, compelled the abandonment by the higher officials of the Service of that old-time Conservatism - and here we speak not of politics, but of policy - which treated the rank and file as mere machines, with no power to think or act for themselves, and no right to combine in order to secure the redress of their grievances. But the old order of things has now almost disappeared. The advance of democratic sentiment has gained for all working men-be they State servants or in private employment - the right to join hands for the common good. Combination has, in fact, been legalised, the claims of manhood have been recognised, and the Englishspeaking working man to-day stands proudly before the whole world the possessor of privileges and the holder of an independent position which mark him out for the envy of his :lass in all foreign countries. The accompanying volume contains a faithful record-reproduced in larger measure from the "Postman's Gazette" - of the work done by members of the Federation, jointly, as well as individually, on behalf of the Postmen of the United Kingdom. It will constitute a permanent memorial of the painstaking and unwearied efforts of the witnesses who were selected to lay before Lord Tweedmouth's Committee on the Post Office Establishments the various Branches of the Postmen's case; it shows with what 
unexampled care facts were collated and marshalled so as to enable the witnesses to successfully withstand the searching cross-examination of the highly-skilled Treasury and other permanent officials who were associated with Lord Tweedmouth in the Inquiry; and, above all, its pages contain ample proof of the justice of the claims put forward, and of the necessity of the investigation in those columns which are devoted to the Evidence of the Departmental Witnesses who felt it their duty to recommend many alleviations in, and improvements of, the Postmen's lot. Time alone will show the real extent of the success achieved. Much, however, has undoubtedly been gairied, and in this should be found an incentive to even greater effort in the future. It is in tho hope that every Postman - old and young - will acquire a copy, will read, mark, learn, and inwardly digest its contents, and will benefit by the morals to be drawn therefrom, that the Editor of the "Postman's Gazette" has prepared this book for publication.

Glasgow,

19th September, 1896. 


\section{A CHAPTER}

OF

\section{POSTAL SERVICE HISTORY.}

\section{(FROM A POSTMAN'S POINT OF VIEW.)}

So far back as 1860, the Times gave a dismal account of the condition of the Past Office Service, and warmly espoused the cause of the London letter-carriers. It said: - "Hard-worked and ill-paid, these men are! all discontented and sullen; they are irdifferent to the proper performance of their duty, and hold the threat of dismissal in utter disdain, feeling sure, as they say, that even stonebreaking at the roadside would not be harder work and scarcely less remunerative." Through lack of data, however, we are unable to follow up closely the various movements that have been afoot since then for the amelioration of the conditions of service of the postmen's class. Many of these movements would appear to have partaken largely of a local character - that is, the different offices attempting separately. The earliest traces of united action of which we have any record date from 1879, when the established letter-carriers of certain offices were threatened with a reduction of 2s. a week. It appears, in June, 1874, when for a time wages ruled high, a provisional allowance of $2 \mathrm{~s}$. a week was granted to each established postman in certain large towns. As far as can be ascertained, this allowance was given to all appointed postmen-to those at the maximum and intermediate figures, as well as to those at the initial wage. The allowance appears to have been given to new entrants till the end of 1876, or the beginning of 1877. Those who had been in receipt of it, however, were allowed to retain it till 1879, when for af few weeks it was withdrawn, but only to be renewed very shortly, in consequence of the widespread dissatisfaction caused by its withdrawal. In defending: themselves against loss of allowance, extensive correspondence took place between the letter-carriers of the principal towns in the United Kingdom. In addition to being successful in getting the allowance restored, this correspondence served to awaken the letter-carriers to the fact that their conditions of service were not what they might be. That there was reasonable ground for complaint may be gathered from the naive admission contained in the Budget speech of $\mathrm{Mr}$. Gladstone on 24th April, 1882. Speaking on the Post Office, he said:-

"I think I ought to state, in justice to all parties, that great care appears 
to have been taken by the late Government in restricting the extension of the establishment. The pressure since we came into office has reached a point which is extreme, and although, I hope, the Post Office will go on increasing, yet the percentage of the cost for collection of revenue, I am afraid, will show some increase also."

By 1881, the disaffection in the ranks of the letter-carriers began to find vent in petitions to the Postmaster-General. The general petition of the London letter-carriers was dated 26th April, 1881, and petitions from other towns came pouring in about the same time. After considerable waiting, without signs of an answer, the matter was taken up in Parliament by friendly M.P.'s, amongst whom the memory recalls with gratiotude the following names:-Schreiber, Summers, M'Culloch-Torrens, Macliver, and Biggar.

In the House of Commons, on 10th July, 1882, the Right Hon. H. Fawcett, Postmaster-General, said, in reply to a question by Mr. Summers, M.P. :- "Without troubling the House as to detail, I may sìte generally that the effect of the decision will be, as regards the majority of letter-carriers employed in London, to raise their scale at the maximum by $2 \mathrm{~s}$. a week, and to substitute an annual increment for a triennial one. In the country the scales will be reduced from 27 in number to 7 , and these are in every case higher than those they supersede. The system of good conduct stripes, carrying with them allowances of 1 s., 2 s., and $3 \mathrm{~s}$. a week, will be extended to the country (provinces?), and in this respect the suburbs of London will be placed on the same footing as London proper is now. In the case of the auxiliaries in London whose time is only partially occupied by their official duties, their pay for the early morning delivery will be raised from 10d. to 1s. a morning, and after they have served five years as auxiliaries, it is iny intention, provided that they fulfil the conditions prescribed by the Civil Service Commissioners, and are eligible in other respects, to promote them to the establishments as opportunities occur."

In reply to a further question, Mr. Fawcett said:- "The reviøion will date from the time the docision was arrived at-that is, from the end of last week."

Mr. Callan, M.P., wanted to know "why the new scale for letter-carriers was not retrospective, the same as in the case of the sorters and telegraphists." In reply, Mr. Fawcett said:- "I halve to state that, having fully considered the memorials of the letter-carriers, I procured the assent of the Treasury to the scheme, and which, I trust, without retrospective payment, meets the merits of the case."

In connection with the Fawcett Revision, the following points are worthy of note :-

(1) The postmen in receipt of the 2s. provisional allowance did not really get " their scale increased at maximum by 2s. per week." They simply got the provisional allowance converted into permanent wages.

(2) From 1882 to October, 1891, the number of good-conduct stripes allotted to each locality was limited; so that many men who had duly qualified for stripes haid to wait a further indefinite period for vacancies to occur. 
(3) By the Fawcett Revision the boon of annual holidays was extended to rural postmen for the first time-but only a week.

(4) The intention of Mr. Fawcett with regard to the London auxiliaries does not appear to have been given effect to in its entirety.

The movement which culminated in the Fawcett Revision originated with the large towns-those towns that were affected with the loss of the 2s. allowance. After the movement had begun a few of the smaller towns joined in. At that time the necessity for a letter-carriers' society became apparent. Partly through fear of victimisation of its leaders, the proposal to form a society fell through. Doubtless the soothing effect of the Fawcett Revision also helped the proposal to fall to the ground; for revisions, even of a moderate character, go to allay discontent.

The Parcel Post was commenced in August, 1883. Originally, town postmen were to have bsen exempted from parcels work; but the extortionate charge exacted by the railway companies for the carriage of rail-borne parcels was such that it seriously threatened the success of the new venture, as the Post Office would have to work it at a big loss if they carried out the original intentions. As a mode of economy, the Parcel Post delivery was saddled on to the ordinary letter-carriers without any extra payment. At this juncture it once more became apparent the mistake which the lettercarriers had made in no't forming a society to watch over their interests. The existence of a well-equipped letter-carriers' society at this period could easily have compelled the authorities to have made better arrangements for the Parcel Post than obtained during the first few years after its introduction. To prevent the regular letter-delivering force from having grounds to object to do Parcel Post work, the class designation was changed from letter-carrier to postman. This change of name was approved of by a meeting of Surveyors, and was put in operation in October, 1883.

For the next few years matters were drifting from bad to worse. The rates of postage had meanwhile been reduced and popularised. This resulted in a great increase of work, but there was not a corresponding increase of force. The result was that all over the country postmen were overworked, and had very bad hours of attendance. The employment of unestablished labour was systematically and extensively resorted to. In this way the postmen did not reap the benefit they expected from the Fawcett Revision.

A Royal Commission on the Civil Service, under the chairmanship of Sir Matthew White Ridley, was appointed in 1886. (?)

The order of reference of the Ridley Commission was in the following terms:- "You will state whether in your opinion the work of the different offices is sufficiently and economically performed; whether it might be simplified; whether the method of procedure cam be improved and the system of control is deficient or unnecessarily elaborate. As ten years have now elapsed since the adoption of the scheme of organisation recommended by the Playfair Commission, the time has come when the working of the scheme may with advantage be reviewed. You will therefore report whether the scheme has been fairly tried; whether its provisions have met with the 
approval of the Service; and whether modifications are needed to give it complete development."

In common with other branches of the Civil Service, the Post Office servants were invited to submit evidence. Accepting the invitation, the postmen of many towns prepared a statement of postmen's case, and applied for an opportunity: to give oral evidence, and even going to the extent of naming their witnesses. But the Commissioners got tired of their work long before the "manipulative branches" of the Post Office Service could be reached. So the postmen had no innings before the Ridley Commission.

About this time a society known as the United Kingdom Postmen's Association was formed. Its affairs were managed by an Executive Committee of London postmen, with Tom Dredge (of N.W.D.O.) as general secretary. For some time this society showed considerable vitality, and it had branches in the principal towns throughout the country; and in connection with it was a fortnightly journal called the "Postal Service Gazette," which enjoyed considerable vogue.

In addition to the summary dismissal of Dredge, some of the other men who had taken prominent part in the agitation suffered persecution through espionage and consequent trumphed-up charges. The success of the great Dock strike, however, suggested new possibilities for trade unionism among postmen. If the dockers could be led on to victory through the instrumentality of the "nasty outside agitator," why not postmen? A postmen's society, officered largely by outsiders, could act with greater boldness than a society on the so-called constitutional lines, for at that time the conditions of service were so irksome as to call for a bold adrocacy of the postmen's cause. As a result the Postmen's Union was formed. This society was a child of the "New Unionism." In its rules and constitution it more closely resemibled the recent labour unions rather than the older and more staid trade Sccieties. The General Secretary, Mr. J. I. Mahon, was an engineer to trade, and received his trades union education in the Amalgamated Society of Engineers, one of the most complete in all the trades unions. The majority of the Union Executive were also men connected intimately with the "New Unionism" movement. Hence the policy of the Union was modelled on regular trades union lines, looking towards a strike as an ultimate weapon to force its claims. That these were altogether wrong lines to conduct a postmen's movement is now pretty well admitted. But with all its faults and shortcomings, the Union movement did immense good service for the postmen. Even as remote from the centre of the agitation as Glasgow the postmen were much more considerately treated since the Union movement loomed large. Formerly human flesh was scarcely a factor to be considered at all by the Department. At the commencement of the Postmen's Union Dredge.was a member of its Executive, but he soon had an opportunity to get re-instated in the Service, on writing an apology, which he did. From his re-instatement he would appear to have severed his connection with the Union.

In his capacity as general secretary, Tom Dredge convened a mass meeting of the London postmen to take place in the Memorial Hall, Farringdon Street, for the purpose of discussing their grievances. This action was re- 
garded by the authorities as a breach of the old rule which prohibited the holding by officers of the Department any meeting beyond the walls of the Post Office for the discussion of official questions. This rule was made by Lord Stanley of Alderley so far back as 1866, and its existence was entirely unknown to many in the Service. Even those who knew of its existence regarided it as a dead letter, seeing it had been promulgated twenty years previously, and had since been allowed to fall into disuse. Dredge was dismissed the Service. About this time, also, the "Postal Service Gazette" got into trouble. It had become involved in an expensive libel action, and, as a result, ceased publication. With Dredge's dismissal and the stoppage of the "Gazette," the U.K. Postmen's Association gradually collapsed.

The following article, written by a well-informed and-on the whole-an impartial writer, is culled from the 1891 issue of "Hazell's Annual." As it is admitted by competent authorities to be the best history of the Union movement written, no apology is made for quoting it pretty fully:-

"The Postmen's Union was formed in October, 1889, with a man named Mahon as secretary and an Executive, including a man named Donald. When the Union took a workable form it was freely joined by the postmen. - . The programme laid down by the Union was-First, that the rule prohibiting the right of postal employees to meet and discuss their grievances in public be cancelled, and that the Postmen's Union be recognised by the authorities in matters of dispute as to wages, working hours, etc.; second, that the normal eight hours' working day shall be worked as nearly continuous as possible, and in no case shall it be spread over more than twelve consecutive hours; third, that all time worked over eight hours per day be paid for at the rate of time and a half; fourth, that the auxiliary staff be added to the established staff, that the wages for all men starting shall be 24s. per week, and that an annual increment of $1 \mathrm{~s} .6 \mathrm{~d}$. should be paid to all men until 40 s. $6 \mathrm{~d}$. be reached. Meetings were frequently held, and the Department soon made it known that its policy was not to recognise the Union, and to enforce the official rules as to the non-discussion of Departmental matters in public. Men were punished for attending meetings of the Union, and this action gave impetus to the membership. But it was not till June that the agitation assumed a serious aspect. Meanwhile, it should be stated, the sorters had formed thernselves into a Fawcett Association. The first meeting was held outside the Post Office, and without official sanction, and took place at the Memorial Hall, Farringdon Street, on 10th February, 1890. It was a meeting of sorters, whose special grievances were set forth in detail. They, claimed that they were entitled, on the basis of the Fawcett scheme, to insist upon such a classification as would ensure payment of work according to quality. Resolutions were passed regretting that the Postmaster-General had not given consent to the appointment of a Committee to inquire into the Fawcett scheme, threatening that if the usual methods failed to secure them the fulfilment of that scheme they would communicate with the Treasury, and forming an association for mutual benefit of the sorting force, called the Fawcett Association. The action of this body was subsequently of first importance, as will be seen later on; 
but it is sufficient now to state that there were two organisations within the London postal ranks-one known as the Postmen's Union, which was officered and worked by outside agitators; and the other, the Fawcett Association, consisting of sorters and officered by men within the Service. When postmen were suspended and had their pay reduced for attending meet. ings, the Union became more aggressive. On June 20th, the .Union issued an appeal to the public, setting forth that the Postmaster-General had repeatedly stated that they were entitled to form in a trade union; that for six months the rule forbidding postmen to attend meetings for discussion of questions of work and wages elsewhere than in the Post Office itself had been allowed to remain a dead letter; but that an order had now been issued allowing outside meetings, only on condition (1) that notice was given to the postal authorities; (2) that none but postal employees be present; (3) that an official shorthand writer be admitted. The Union claimed that these conditions made combination impossible: On the occasion of the Guildhall Banquet to celebrate the Jubilee of the Penny Post, a procession of postmen had been broken up by the police, and had held a meeting at Clerkenwell Green. At this meeting the representatives of the authorities had taken the numbers of men attending, and these men had been suspended until they gave an apology for attending the meetings of the Union, and promised not to repeat the offence, and had been punished by deprivation of pay and by reảuced wages consequent upon the cancelment of good conduct stripes. The Union denounced this conduct of Mr. Raikes as tyrannical, and appealed for support to Trades Unions and the public, on the principle that the postmen had unrestricted right to attend public meetings of the Union for the ventilation of their grievancès.

Up to this point the public had not taken a keen interest in the quarrel, which was, however, brought prominently to their attention by a riotous meeting in Hyde Park on Sunday, June 20th, when men who were supposed to be Post Office spies, attending for the purpose of taking the numbers of men for further punishments, were mobbed and ill-treated by the crowd. Nine men were' suspended for attending this meeting, and asked to say why they should not be dismissed the Service, the reply being that when they were off duty they could attend what meetings they liked.

"On July 7th, a mass meeting of about 2,000 postmen was held in the Holborn Town Hall, when the following demands were unanimously formulated:-(1) That all Departmental limitations as to the right of meeting be cancelled; (2) that all men reduced or suspended should be reinstated and their stoppages of pay refunded; and (3) that in matters affecting the rate of pay the Department should deal with the Postmen's Union. It was also decided that the intervention of the London Trades' Council be accepted, and that no further action be taken-if the result was reported within twelve days, and if the Department took no steps with a view to supplanting the labour of the men then in the Service, in the event of failure of negotiations. In preparation for a strike the authorities had called in much of the reserve labour of the Department, and as the agitation developed, it was seen that 
the non-union and the union men were fairly equally balanced in the point of numbers. The Union made strenuous efiorts to increase its membership, and succeeded in many districts, although they were unable to induce the "blacklegs," as they called them, to retire. Mr. Raikes, who was at this period often questioned in the House of Commons by Mr. Conybeare, M.P., who was associated with the Union, stated in the House that the question would never have assumed its then proportions had it not been for the uncalled-for interference of professional agitators; that the disaffected men were not indispensable to the Department, and that he was fully prepared to efficiently maintain the Postal Service in the Metropolis. He declined to receive a deputation from the London Trades' Council. On the morning of the 9th, the authorities having still further strengthened their position by chrafting non-union men into the Service, there was a free fight in the Parcel Post Depot at Mount Pleasant, Clerkenwell Green, and the unionists succeeded in driving the non-unionists out of the building. Their success prevented an immediate strike at the General Post Office. The work of delivery was, however, seriously delayed; and, with the object of averting a crisis, the authorities intimated to the men of the E.C. district that if they would sign a declaration not to strike, they would undertake to dismiss the relief men. The postmen wanted, however, to fix a date (July 21st), and the proposal fell through. On the evening of the day a mass meeting was held on Clerkenwell Green, and Mahon instructed his men, among whom were delegates from the various divisions, that if on the morrow morning they received messages that Mr. Raikes had consented to dispense with the "blacklegs," they were to continue work, but they were to take out no letters until they received this message. During July the Postmen's Union had maide every effort to persuade the sorters' organization to act with them, and it was stated that they were joining the Union in large numbers. But on this night (July 10th) a largely-attended meeting of the Fawcett Association was held in the General Post Office, at which a communication was read from Mr. Raikes, stating that the petitions dealing with the grievances of the sorters had been handed to the Treasury, and were being favourably considered. This announcement was received with loud cheers, and though there was a suspicious minority, the tone of the meeting made it certain that the sorters would not join the postmen in a strike. This meeting greatly'strengthened the hands of the authorities, and at 3.30 the succeeding morning, Sir Arthur Blackwood, the Secretary to the Post Office, accompanied by a posse of police, went to Mount Pleasant Depot, and dismissed about 100 of the men concerned in hustling the non-unionists out of the building. The point of interest now was whether the postmen would make the first delivery on the 10th. Fvents showed that the authorities had not miscalculated the incapacity of the agitators to bring about a simultaneous refusal to work in ail the offices. There had been a disturbance at the Central Office the previous day between the unionists and the non-unionists; but on the morning of the 10th the co-operation of the police with the Departmental chiefs was so effectual that a repetition of scenes within the Central building was impossible. On this eritical morning the leaders of the 
agitation seemed to have lost their nerve, and so lamentable an exhibition of organising incapacity was made that the men in the various districts did not know whether they were expected to strike or not. No communication was made to them, and the result was that the Union, considered as an instrument for united action, was completely disorganised. The men, as a whole, solved the difficulty as to the indecision and the panic of the Union Executive by taking out their letters as usual; but at Holloway, Finsbury Park, in the Eastern and East Central and West Central districts many men refused to take out the letters. The authorities followed up this revolt by at once dismissing all men who had struck and were otherwise insubordinate. In the afternoon, these dismissed men, headed by Mahon, marched to the Post Office, with the object of bringing out the men, but the building was guarded by the police, and their anticipations that several hundreds would join them in the strike were destroyed. Similar efforts made at the district offices to even then bring about a general cessation of work failed, and by midnight, in spite of a meeting at Clerkenwell Green, in which the certainty of success was insisted upon by the agitators, it was known that the movement had utterly and hopelessly collapsed. Though there was considerable sympathy with the abstract principle that the men had a right to hold unrestricted public meetings, public opinion was dead against the movement as soon as there was a prospect that inconvenience might result from it. The places of the dismissed men were at once filled up. Only in the East End of London, where the sympathy of the roughs was naturally on the side of the insubordinate, was there any difficulty in the delivery, of letters. Here, to avoid molestation of postmen who remained at work, and of "blacklegs" who were engaged, each postman was accompanied on his round by police. By the 12th of July many of the men who had struck had renounced the Union and the agitators at its head, and were appealing for reinstatement. But the latter made one last effort on the 11th to induce the East Central men to come out, by making a formal declaration of a strike of all postmen, "to last until the right of public meeting and free combination is recognised by the authorities." Had this declaration come on the morning after the Clerkenwell Green meeting, and had it been simultaneously known at all the district offices, there can be little doubt that a general strike would have taken place. But the tactical opportunity had been missed, and the declaration came off after a decisive defeat. The men had been cowed by the prompt dismissal of the insubordinate colleagues and the adequate preparations to permanently fill their places; and the result was that, instead of the strike manifesto being obeyed, the men who had already struck appealed for forgiveness at the hands of the authorities. The various 'Trades' Unions in London, through the Trades' Councils, seemed likely to make common cause with the postmen on the abstract question of the right of meeting and recognition of the men's Union; but the postmen themselves had no courage left in them, and the disgust of the Trades' Council and the incapacity of the Union Executive, which had so grossly mismanaged the agitation, was so great that nothing was done.

In all, 425 men were dismissed the Service. Mr. Raikes claimed to have 
made a personal investigation into the circumstances of each case, with the result that fifty men were reinstated, leaving 385 men finally dismissed. A committee was formed subsequently for the purpose of relieving the men (the Union having no funds worth speaking about) and obtaining re-employment for them in the Post Office; but Mr. Raikes resisted all pressure for the re-engagement of men who, he considered, had behaved in a manner destructive to discipline in the Service. A Postmen's Union is, at the time of writing, nominally in existence, but soon after the disastrous collapse of the agitation Mahon retired from it."

The Postmaster-General's annual report for 1890 contains the following reference :-

"Much time and labour have been devoted during the past year to the arrangement and organisation of the numerous branches into which the great Department is divided. An extensive scheme for adjusting the duties of the sorting clerks and telegraphists throughout the kingdom has been carried into effect. Important changes were made affecting sorters in the Metropoli$\tan$ offices, and various other organisations were effected.

"I regret to state that while the representations of a large body of London postmen were in process of examination, a number of misguided officers abandoned their duty on the 9th of July, 1890, and refused to obey orders.

"I was compelled at once to take stringent measures to restore discipline, and found it my painful duty to dismiss from the public service in one morning about 450 men.

"I felt that after this occurrence it was impossible to proceed at that time with the various questions affecting postmen which were engaging my attention, and $I$ therefore had to defer until the autumn the appointment of a Committee to examine the subject. I also decided to extend the inquiry into postmen outside of London."

The Committee of Inquiry referred to was the 1890 Committee on Postmen. It will be observed it was only appointed in the autumn, that is, after the Union movement had culminated in the July crisis. This Committee was a purely Departmental one, and Mr. Herbert Joyce was the chairman. Mr. Hill was a member, so also was Mr. Badcock. In addition to considering the case of the London postmen, it took up the case of the 52 towns that had petitioned in April, May, and June, 1890. Representatives from Edinburgh and Glasgow were allowed to give oral evidence before the Committee. The other 50 provincial towns appear to have been visited by Mr. Lewin Hill, who seems to have held a sort of special roving commission.

Unlike the Tweedmouth Committee, which has been so fully reported in the "Postman's Gazette," the Joyce Committee was conducted in private, so that the postmen throughout the country were completely in the dark as to the nature of the evidence. Although the Committee reported in favour of even more concessions than have been granted, it is quite clear that it approached its work already prejudiced against the postmen's claims.

In his examination before the Tweedmouth Committee, Mr. Lewin Hill 
made an admission which is both interesting and instructive. He said:'When the Committee on Indoor Staff, under Mr. Raikes, in 1890, considered their proposals, which were adopted, the opinion was expressed by the majority of the Committee that if these concessions were made that would end the agitation."

As the Committee on Indoor Staff did not consider the case of the postmen at all, it is now quite evident that the Raikes' Revision of 1891 was not given voluntarily by the Department as a spontaneous act of justice. It is quite clear that if the postmen had meekly borne the bad conditions that then existed there would have been no Raikes' Revision for them.

Although we did not expect the Department to own up so candidly as $\mathrm{Mr}$. Hill did, we have all along suspected the sweating and beating-down motives actuating the chief advisers of the Postmaster-General, for on the 14th March, 1890, in reply to a question by Mr. Fenwick, Mr. Raikes stated:- "It is quite true that the initial wages of the second class of London postmen have been advanced to $18 \mathrm{~s}$. a week, and at the same time the Lords of Treasury did indicate their opinion that any further claim from the postmen could nat be entertained. Their Lordships regard the wages paid to the first class, with the other contingent advantages of good-conduct stripes, uniform, sick pay, gratuitous medical attendance and pension as affording adequate remuneration." However, the rapid growth of the Union movement served to force the Department to look seriously at the question. So much was this the case, that the claims which were scouted in March were in the following July, "in process of examination."

In the ordinary sense of the word, the Postmen's Union movement was a complete failure. Still, beneficial results were obtained. Since the Union movement loomed large, postmen have been more considerately treated. It also suggested the idea of concerted action. This is how 52 towns petitioned almost simultaneously in 1890. For although only a few of these 52 towns were directly connected with the Union, they, nevertheless, owed the inspiration to the Union movement. It may here be proper to point out that the line of policy approved of by some of the provincial branches of the Postmen's Union differed somewhat from the line pursued in London. The London men had discarded the petition method as being antiquated and effete. Some of the "country" branches were not quite so distrustful of the official channel. Naturally, the policy of the London men was largely influenced by the views of the Executive of the Union, who were outsiders unaccustomed to the ways of the Post Office.

By February, 1891, the postmen began to wonder when the Joyce Committee was going to report upon its labours. In March the monotony of waiting was relieved by a lively debate in the House of Commons on the occasion of Earl Compton's motion:- "That in the opinion of the House it is desirable that a Select Committee be appointed to inquire into the administration of the Post Office." As a peroration to a vigorous defence of his own administration, Mr. Raikes appealed to the House "not to encourage by any uncertainty in their decision that night any recrudescence of that unfortunate feeling of discontent and dissatisfaction which was now at an almost 
vanishing point in the Service. The noble Lord was doubtless unaware of it, but he was being put in motion by the expiring Committees of the old agitation, who did not represent any general feeling in the Service. $\mathrm{He}$ thought it had shown to the House that the Post Office, the Treasury, and Her Majesty's Government have given the most careful consideration to all grievances which had been brought before them, and had afforded most substantial, and, he believed, complete relief."

On Wednesday, 22nd March, 1891, the Glasgow postmen held an indignation meeting in the Post Office, at which the following resolution was unanimously carried:- "That this meeting resolves to testify its great astonishment and regret at the long-continued delay in receiving an answer to the petition for redress of grievances presented in May, 1890, and that in consequence of said delay, widesprcad dissatisfaction and discontent prevail among the officers of the Department, and that even a feeling of dismay has been the general result of the perusal of certain portions of the speech of Her Majesty's Postmaster-General in the House of Commons' debate last week. It is further resolved that our Vigilance Committee be empowered and desired to draw up a memorial to this effect, addressed to the Postmaster-General, and that copies of motion be sent to Earl Compton, Mr. Lockwood, his seconder, and to the M.P.'s for Glasgow."

In reply to their memorial of remonstrance, the following reply was conveyed to the Glasgow Committee :-

"Mr. Hobson,-

"You will, by the Postmaster-General's direction, be good enough to inform the memorialists that they are right in supposing that the remarks Mr. Raikes made had no intention in prejudicing the case of the postmen, but that he cannot too severely reprehend their action in thus animadverting upon what the head of the Department was pleased to say in the House of Commons ; though in doing so they altogether mistake their position, although on this occasion he is willing to overlook their conduct, believing, as he does, that they erred through ignorance, but he desires that they may be emphatically cautioned against the repetition of so grave an impropriety.

"1st May, 1891."

Meanwhile the postmen's case was being kept to the front by Parliamentary friends. Amongst the M.P.s who, from time to time, questioned Mr. Raikes, the following names are readily recollected:-Sir Thomas Esmonde, Dublin; Messrs. Cross, Liverpool ; Schwann, Manchester ; and Provand, Glasgow.

On 8th June, 1891, Mr. Cross, M.P., asked the Postmaster-General whether he was able to give an answer to the petitions recently addressed to him by the postmen of Liverpool and other places?

In reply, Mr. Raikes said:- "The memorials to which my hon. friend refers emanated, I think, from the postmen employed at 52 offices, were referred by me in October last to a strong Departmental Committee, who have made them the subject of an extensive enquiry, which, owing to the large number of witnesses to be examined, extended over six months. The report of the Committee was submitted to me in April last, and as soon as I had been able to consider it with due care, I forwarded it to the Treasury 
on the 13th of May last, together with my recommendations as to the course to be taken. I hope as the matter is one of the greatest importance to a very large number of deserving officers, no long time will elapse before $I$ am favoured with their Lordships' reply. As soon as this reaches me I can assure my hon. friend that I shall lose no time in giving effect to it."

In the House of Commons on July 17th, 1891, the Right Hon. H. C. Raikes, Postmaster-General, said in reply to a question by Mr. Cross, M.P. for West Derby Division of Liverpool._- I am now able to give an general outline of the new arrangements which, with the sanction of the Treasury, $T$ am now prepared to make. In London the two classes of postmen, wherewer two classes exist, will be amalgamated into one class, so that men, instead of waiting for vacancies to occur in the higher class, will be able to progress without interruption from the minimum to the maximum of their scale. The scale, moreover, in the case of each of what are called the four suburban divisions, will, at its maximum, be raised by 2 s. a week. Thus, more than 600 men who now rise on two classes to 30 s. a week, will henceforth rise on ai single class to 32s., and more than 700 men, who now rise on two classes to 28s. a week, will henceforth rise on a single class to $30 \mathrm{~s}$. Similarly, 300 men whose maximum is now 24s. will rise to $26 \mathrm{~s}$. An increased rate of pay per hour will also be given to auxiliary postmen, and some of their number will be granted a week's leave in the course of the year. In the country (provinces?), as in London, the division into two classes, where two classes exist, will be done away with, and the scales will at their maximum be raised in no case by less than $2 \mathrm{~s}$. a week, and in some cases by more. This applies to town postmen. The rural postmen-that is, the postmen who ply between town and villages-have hitherto received fixed wages. For the future they, like town postmen, will, with few exceptions, be paid on scale, and their wages will rise considerably above what they have hitherto been. In the case of rural postmen, moreover, the period of their annual leave of absence will be extended from one week to a fortnight. Another alteration of great importance, applicable to all country (provincial ?) postmen alike, is that they will henceforth be paid extra for all work done on Sunday, and the payment will be at the rate of one hour and a quarter's pay for one hour's work. Thus, not only will they for six days' work be paid higher than they have hitherto been for seven, but, if employed full time on Sunday, they will receive pay for a .urther additional day, and that at a somewhat higher rate than for ordinary days. Yet one more alteration I may mention-an alteration which is applicable to all postmen in London and the country alike, both town and rural. Their uniform hitherto has not included boots, and boots will henceforth be supplied, or rather an allowance in aid of boots. As regards good-conduct stripes, the regulation of which, I am aware, has not given entire satisfaction, I am not yet prepared to announce a decision; but good-conduct stripes apart, I cannot but think that the concessions already announced, the cost of which will considerably exceed $£ 100,000$ a year, will appear to the House as not unhandsome, and will be accepted with satisfaction by the persons concerned."- "Hansard." 
On the occasion of a debate on Supply a fortnight later, Mr. Pickersgill, M.P., said :- "The Right Hon. gentleman claims that he has made the postmen a handsome concession. Now, I demur somewhat to the use of the word 'concession' in such a case, though I am not at all surprised that the Postmaster-General makes use of it, because his views of the relation between the employer and the employed are rather the views which obtained in the eighteenth century, than those which characterise the last years of the nineteenth century. But the announcement thus made is of extreme importance from another point of view. It is a distinct admission that: when trouble occurred in the Post Office last year, the postmen had reasonable grounds for $;$ complaint. I do not wish to review the circumstances of the trouble of last year, the serious breach of discipline-for strilke it can scarcely be called-it was a breach of discipline, followed by a lockout on the part of the authorities. I never defended the conduct of the men, it was indefensible; but as I pointed out then, and now repeat it, the men were precipitated into their misconduct owing to the unconstitutional conduct of the right hon. gentleman in interfering with their right of combination to protect their own interests. Some men were dismissed. A large number of these have emigrated, and a considerable number are without employment, or are only casually employed. On their behalf, I appeal to the right hon. gentleman for their reinstatement in the Service, a: all events when an opportun ty presents itself. I ask, also, that those who have been punished by degradation, or otherwise, should be reinstated in their original positions."

Amongst the decisions contained, in the Revision, and not alluded to by Mr. Raikes in his statement to the House, the following are the principal:-

\section{(1.) Overtime.}

"It is, as you are aware, a rule of the Service that postmen are not paid overtime. This is a very necessary rule, and as general relaxation of it would offer a premimum upon dawdling. At the same time, the Postmaster-General recognises that there are certain exceptional cases, cases not resting on the mere word of the person interested, but coming within the personal knowledge of his superior officer, in which it is only just that overtime payment be allowed. When, for instance, a postmen is kept waiting for a train which is late by as much as two or three hours; or when he is detained by heavy snowstorm; or has an extra delivery to make, you are at liberty to authorise his receiving overtime payment on being thoroughly satisfied that it is deserved. Payment, when allowed, should in all cases be according to the wages of man who receives it-at rate and a quarter for each hour."

\section{(2.) Definition of what Constitutes Whole-Thme Duty For a Rural Postman.}

Surveyors were enjoined:- "You will not fail to see that a rural postman before being placed on a scale must do ai full day's duty: and this he cannot be considered as doing unless he fulfils one of the following conditions:-

"(a.) That he wallss as much as 15 miles a day.

"(b.) That he walks as much as 14 miles a day, and is absent from headquarters for not less than 8 hours. 
“( $($.) That he walks as much as 12 miles, and is absent from headquarters for not less than 10 hours."

\section{(3.) The Case of the London Town Postmen.}

The London "town" postmen did not wish to get a "rise" by the Raikes Revision. Presumably this was a sort of penalty for having nurtured the Positmen's Union in their midst.

\section{(4.) Reductions of the Commencing Wages.}

By the Raikes Revision the lot of the new entrants was made much harder. Not only was the period of after-appointment probation extended from six months to two years, but the initial wages of the scale were reduced. In his statement to the House of Commons, Mr. Raikes carefully avoided mentioning this important fact; neither was it clearly stated in the inspired press notice of the Raikes Revision which appeared in most of the newspapers. This was a very sore point. In Glasgow, for example, young men of 21 and 22 years of age, and with three to four years' service as Auxiliary Postmen felt it a hardship to be asked to take 17s. a week instead of the old 18s. rate. It was not surprising therefore that when the Glasgow postmen attended a meeting to consider the situation, the following resolution was unanimously carried:- "That this moeting of postmen of Glasgow, after considering the terms of the revised Scale of Pay, declares its dissatisfaction with same, and maintains that the statement of the scheme, as reported in the newspapers, was misleadin $;$, inasmuch as that it left an impression in the mind of the public that postmen were to benefit to a greater extent than is actually the case."

In contrasting the niggardly revision given to the postmen with the Raikes Revision of 11th July, 1890, to the Sorting Clerks and Telegraphists it was felt that there was room for discontent. The following motion was therefore passed as placing on record the mind of the meeting on the matter :- "That we assert the moral claims of postmen to share equally with all the other employees of the Department in the advantages of the abundant revenue which our combined labour is instrumental in producing."

Following up in the same direction it was also agreed:- "That this meeting considers that the time has now arrived when an organisation of postmen of this country is indispensable to an extensive and permanent improvement of our condition, and pledges itself to do all that is possible to establish such an organisation."

From correspondence with other towns it was found that somewhat similar lesolutions had been carried at some of them. In the experiment of again trying to organize postmen, London led the way. At first the Londoners intended that their proposed new society should be of a purely local character. It was to be a sort of Vigilance Association to watch over the London post. men's interests. The supporters of the new movement seemed to think that the aspiration towards a society on a rational scale entertained by the late Union to have been of too high-มiown an order. But largely through the advocacy of Mr. Rouse, postman in E.C.D.O. (now Overseer), it was decided to make the new society a national affair. That officer had been a delegate 
to the Glasgow conference of the Northampton Society. There he met postmen-delegates from other parts of the country, and naturally enough they talked about the fiasco of the 9th of July, 1890. Although the Union had signally failed, the consensus of opinion was decidedly in favour of forming some sort of society to watch over postmen's interests, and be ready on emergency to advise and direct united and concerted action. Thus through having been present at the Northampton Society's Conference, Mr Rouse was enabled to gauga the feeling that was abroad favourable to another attempt being made to organize postmen on a national scale. Fortified with this knowledge he strongly advised the London men to let their "country" brethren have an opportunity to join, which was done. Thus in September, 1891, the Postmen's Federation was first established. At the outse' it was decided to keep free from the toils of the "nasty outside" agitator so much dreaded by officialdom $\rightarrow$ alf-promise having been given that if the postmen would keep by themselves there would be no official interference. The Federation was therefore officered entirely by bona-fiae postmen. For the first year a provisional Executive of London postmen managed the affairs of the society. The important post of General Secretary was filled up by a postmen of the E.C. District -Mr. Churchfield - who still holds that office at time of writing. At an early stage the need for journalistic connection became apparent. For a time the difficulty was tided over through the courtesy of the editor of the "Post" (the official organ of the Fawcett Association) who allowed about a page of each issue for the postmen. As a quid pro quo the "Post" enjoyed an increased circulation through postmen buying it for the salke of the "Federation Notes." However, this arrangement was on the face of it a mere make shift. Very soon the editor of the "Post" had other clamant calls made on his space, so the postmen were crowded out. The Federation was by this time a society having considerable connection in the provinces. A young growing society without any adequate magazine to express its aspirations is like an army without either bugle or drum. The Postman's Gazette was therefore commenced in May, 1892. The editorial duties were undertaken by the General Secretary, Mr. Churchfield, who was assisted by another E.C. postman, Mr. A. R. Wilkin. To start a postman's newspaper with a postman editor was a bold, venturesome enterprise attended with numerous uncertainties. In the first place it was uncertain how the Department would jump, so to speak. For at that time rule No. 52 (in the metro. politan postmen's rule-book) said :- "A postman is forbidden to write to the press on official matters." It was also an uncertainty whether a postman's paper could command a paying circulation. Then again, with reference to news-items, the machinery for collecting suitable "rews" was of an elementary character. Contributions written by busy men in their remnants of spare time could not be expected to have that literary polish which a trained journalist could bestow on his work. At first Branch Secretaries were inclined to insert too much smoking concert reports, etc. But in spite of these difficulties the "Gazette" made headway, and it has been a potent instrument in spreading a knowledge of the Postmen's Federation and its aims: 
The first annual Conference was held in the Old Friend's Hall, St. Martin's Lane, London, W.C. This Conference adopted a rallying platform, the main planks of which consisted of the principal improvements which the postmen desire to see effected in the Service. It did more. It welded the Federation into a real living society-not one merely existing on paper. At the time of the first Conference the membership was under 3,000. It is now near 15,000 .

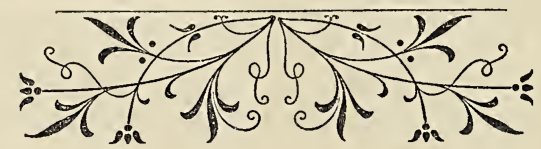




\section{POST OFFICE AD MINISTRATION.}

\section{IONDON:}

C. CHURCHFIELD, E.C.D.O., General Secretary.

\section{Wages-Minimum-Sanitation-Recognition of the Federation.}

\section{WestMinster, Feb. 3, 1896.}

The Committee appointed by Mr. Arnold Morley, the late PostmasterGeneral, to inquire into the grievances complained of by the employees in the Postal Service, resumed its sittings at the House of Lords' Committee Rooms under the presideney of Lord Tweedmouth. The other members present were Mr. Walpole, Sir F. Mowatt, Sir A. Godley, and Mr. Llewellyn Smith. Evidence as to the London Postmen's grievances was first taken.

Mr. Charles Churchfield was examined by the Chairman as follows :-

Q. You are a postman?

A. Yes, my lord.

Q. What is your term of service?

A. Nineteen yearsølast February.

Q. In what way did you enter the Service?

A. As an assistant letter-carrier.

Q. As an auxiliary?

A. No; as assistant.

Q. How long were you before you became a postman?

A. One year and ten months.

Q. Is that included in your nineteen years of service?

A. I was promoted to the first class after one year and ten months' service.

Q. And what rate of wages are you now receiving?

A. Thirty-four shillings a week, and three shillings stripe money.

Q. You are also General Secretary to the Postmen's Federation, are you not?

A. Yes, sir.

Q. And I suppose you have been largely responsible for the preparation of the evidence which is to be laid before us on behalf of the Federation?

A. Yes. I have assisted my colleagues in London in preparing it.

Q. May we take the evidence which is to be submitted by the twenty-two witnesses who are named to us by your Association as fully representing the case for the whole country?

A. I speak on behalf of Liondon only.

Q. That is not my point. You are the General Secretary of the Postmen's Federation, are you not?

A. Yes, sir.

Q. And therefore you speak on behalf of that Association?

A. Yes, my lord.

Q. Are we to consider that the 22 witnesses named by that Association represent the whole case of the Federation?

A. Yes, my lord. 
Q. Have you, may I ask, had any complaints from any parts of the country as to any special district not being sufficiently represented?

A. Some few months ago we had complaints from Scotland; the question was brought up at the Annual Conference and fully threshed out, and the Scotchmen were unanimous that the representation was satisfactory.

Q. I believe Mr. Maclaren will be able to state the case for Scotland, will he not?

A. Yes, my lord.

Q. And with regard to Ireland, have you had any representations from there on the subject?

A. From Dublin we had a request that they might be attached to our deputation, but we could not see our way to take them in, we having made our arrangements before they made their application to us.

Q. Then is the Irish case not represented by any of these witnesses?

A. I take it that we represent the postmen of the United Kingdom?

Q. Then you do say that in the opinion of the Association there is no necessity for any special representation of the Irish case by Irishmen?

A. I should say not, my lord.

Q. Is that the opinion of your brethren in Ireland?

A. It is the opinion in the majority of the towns-in Belfast and Cork, and smaller towns.

Q. Is it not the case there is a strong feeling in Dublin that they are not arequately represented?

A. No ; it is only the opinion of a part of the Dublin staff.

Q. What is the particular subject on which you yourself are going to speak?

A. On the minimum wage for the Isondon postmen.

Q. Have you prepared a statement which you wish to read to the Committee?

A. Yes, my lord: but before I read it I should like to put in two statements on behalf of the Postmen's Society.

The Chairman : Very well, put them in.

The witness then handed in the following prepared statement, viz.:-

\section{THE FEDERATION.}

As General Secretary, I have the honour to ask that the Postmen Federation, which has a membership of 12,000, and which is managed solely by postmen, should be recognised as the oficial channel of communication between the Department and postmen. The Federation was established in 1891 on lines which, it is believed, met with the approval of the late $\mathrm{Mr}$. Raikes. In the first year of the existence of the Federation it had $a_{0}$ membership of 2,000 ; in the second year, 5,000 ; the third year, 3,000 ; and at the present time it has a total membership of 12,000. It has ever 330 branches distributed throughout the United Kingdom. At each of the four annual conferences convened by the fifederation, resolutions have kifen unanimously passed asking for the official recognition of the society. It is the feeling of postmen that grievances afrecting their class, as a whole, could be dealt with more effectively by an officially recognised body, haviny branches all over the United Kingdom, than by individual postinen, Tho do not have the facilities or the opportunities for making an appeal to the Department a unanimous one. Moreover, the Executive of the Federation, feeling that the Department was anxious to meet them in every reasonable way, would put forward those questions which, after carefinl examination and inquiry, seemed to them to require adjustment. It is apparent that the advantages of a direct channel of communication between the Department and the men are many and great, inasmuch as there is no fear of any disquieting rumours being circulated regarding various offices. as has been the case in the past. The Postmen's Fecleration has, in a 
sense, been recognised by the Department as the mouthpiece of postmen, for at the Newcastle Conference, in September, 1894, several delegates had been refused leave of absence to attend at Newcastle. On those assembled at the Conference becoming aware of this fact, I was instructed to at once telegraph to the Postmaster-General asking for leave to be granted them. A reply was soon afterwards received from $\mathrm{Mr}$. Walpole stating that, under the circumstances, the postmen in question had been granted leave of absence. I may mention that the Executive of the Postmen's Federation endeavoured to approach the late Postmaster-General (the Right Hon. A. Morley), in regard to the grievances of postmen, but owing to some breach of official etiquette, Mr. Morley would not receive or recognise us as a representative body, consequently, as no hearing could be obtained, pressuro was brought to bear in Parliament to obtain this Inquiry. Our pectition, signed by the whole of the Executive of the Postmen's Federation, embodying the statements our witnesses are now placing before you, was forwarded by registered post to the late Postmaster-General, after all official methods of approaching him had been resorted to without suecess. In the first place, the petition was handed to the superintendent (Mr. Hitchcock), who, after an interval of three days, returned it with a notification that he did not feel justified in forwarding it to the P.M.G. The petition was then handed by us to $\mathrm{Mr}$. Briggs (then acting for $\mathrm{Mr}$. Saunderson, sub-controller). Mr. Briggs would not accept it, and stated that he was fully acquainted with the circumstances of the case, that the superintendent had already submitted it to him, and that owing to official etiquette not having been abserved, he (Mr. Briggs) could not put it forward. Our deputation, however, urged that the petition should be put before Mr. Badcock, the Controller. This again was refused, and, consequently, no other course seemed open but to forward the petition direct to the Postmaster-General by registered post. On 10th May, 1894, Mr. Badcock sends for me, and, to my surprise, tells me that he had never seen our petition, and acquaints me with the answer of the Postmaster-General to the effect that our petition was declined "owing to its informality, as though promoted by London men, it is signed by postmen in other towns, and embraces matter with which the London postmen have no concern." At the request of the Department, all the arrangements as to witnesses and evidence for our case have been conducted through the Postmen's Federation, which latter body has collected a vast amount of evidence, and entire confidence is shown in the Federation by the fact that the membership is still increasing, and is likely to increase. In conclusion, I trust that this request will receive your earnest consideration, and, I think, I cannot close this appeal with more fitting words than those uttered by your lordship's colleague, the Right Hon. Sir William Harcourt, who said in reference to combinations of workers: "Combination is the duty of all workers, and Civil servants will no doubt derive benefit from mutual agreement and co-operation in the same manner as other workers have."

\section{SANITATION.}

The second statement put in by the witness was on the subject of sanitation, and was as follows:-

In Submitting to your Committee for your kind consideration the question of the unsatisfactory state of sanitary arrangements in the postmen's offices in London, I should like to call your attention to the following complaints :-

(1) The postmen's office at Mortlake, S.W., is built in the back garden of the East Sheen Receiving House, and is composed of corrugated iron outside, and wood inside, the measurement inside being 16 feet 10 inches by 14 feet. The staff of postmen at this office is fifteen and upon the G.P. duty there is an insufficient supply of seats by two. There are two gas 
burners for lighting purposes, and, these being in centre of office, each man sits in his own light. It is, stated that in the winter the office is intensely cold, and the heat in summer almost unbearable. There is no kitchen provided, so that the men have not the least accommodation afforded them for the purpose of drying their clothes. In the rainy season the wet frequently comes through the glazed portion of the roof. Another want which is greatly felt is the need of an official clock, as the watches of the men frequently differ from that of the officer in charge. To approach this office, the men have to travel over a roughly-stoned roadway, which is frequently covered with vans, etc., and is the private property of the owner of a forge adjacent, or to use their right of way, which is usually muddy, and the latter part of which is only three feet ten inches wide. Within a few yards of sorting office there are no fewer than nine w.c's. belonging to the adjacent houses, which cause a very disagreeable smell, and which every man from time to time has complained of. It is believed by the men attached to this office that the medical officer (Dr. Macintosh), assistant to the Barnes and Mortlake medical officer, has reported upon this subject several times. I now call attention to the temporary office, which was engaged for the Christmas pressure, 1894. This room had been shut up, and upon the men entering it, at once noticed a very fusty smell, and that the walls were streaming wet, which, in the opinion of the men, hastened the death of a brother officer. He, doing an inside duty, had to spend a large number of hours in this room, after which he fell upon the sick list and died on the 14th February, 1895. During the early part of November, 1895, the men forwarded a petition to their Postmaster, asking that a more realthy room should be engaged for the Christmas pressure; and they complain that after waiting about a month for a reply, their inspector ( $\mathrm{Mr}$. Grigg) walked into the office and spoke most severely to first one man and then another in turn, saying that the Department would not be dictated to, and that there was a great deal of feeling in the matter. The same room was again used for the past Christmas pressure, but was not in quite such a bad condition, owing to the fact that the windows had been kept open for some considerable time previous to their going in, but the damp upon a part of the wall was still to be seen.

(2) Inadequate sanitary accommodation.-I should like to call your attention to the arrangements at Sydenham S.O. This office, with a staff of 50 men, has two w.c's. and two urinals. One w.c. only is available for the men, the other being reserved exclusively for the overseers' use. This office, which was formerly a ground floor of a warehouse, contains no kitchen or second room of any kind for the use of the staff. Another office (Anerley, S.E.) is placed in a worse predicament. The men there have no kitchen for their use, and the officers have their meals while sitting at their desks and when on duty. Until about twelve months ago the w.c. and lavatory were attached to the office, but since alterations, the w.c. has been removed to a stable-yard adjoining, and lavatory basins have been taken away altogether, so that the men have no opportunity of washing unless they use a pail, and then they find their own soap.

(3) Want of retiring-rooms, and, where they exist, the insufficient accommodation for the staff employed.-In addition to the offices above-named, I should like to point out my own office (Maida Hill), to which I have been attached since February, 1878. When first appointed to Maida Hill, the office was held in the first floor of a receiving house, with no accommodation for the men but one w.c., which had to answer the purpose for the staff of about 24 men, and eventually for a number of telegraph messengers who afterwards came there. About 13 years ago, owing to the increase of work, our present office was taken; this office is situated in a mews, and at the present time has a staff of $57 \mathrm{men}$. It is held in what was the first floor of a brass foundry; the lower part is at present used for cab-building purposes. It has a skylight in the roof which can be opened, 
and is used for the purpose of letting out the hot and foul air. There is no kitchen for the use of the men, so those men who have their meals at the office are obliged to sit in the S.O. while another duty is going on. I am very glad to say that a new office has been erected for us, and the men are most anxiously looking forward to the day when they will be transferred, which it is hoped will be very soon. At several offices where kitchens are supplied-namely, Notting Hill, West Brompton, and South Kensington, they are underground, and generally in an unsatisfactory sanitary condition. At Notting Hill, although the kitchen itself is a good size, it has sitting accommodation for only eight men, although the staff is about 90 in number. It is underground and very dark, so that the gas has to be used all day. The only means of getting daylight into it is through one window, which opens on to a yard about three feet wide, and surrounded by walls about $40 \mathrm{ft}$. high. Directly facing this window are the urinals, and joining these are the w.c's., which cause a very bad smell to enter the kitchen.

West BRompton.- - It is complained that the urinals are only separated from the kitchen by a door, and as somebody is continually going in and out, it causes a very obnoxious smell to enter, especially as one of the urinals was without water a short time ago. It is stated that the kitchen is much too small, and is filled with smoke almost daily.

Sodtr Kensington.--The kitchen at this office is also underground, the gas having to be kept alight the whole of the day. The ceiling is about 7 feet high, and the ventilation is also bad, as when the windows are open they are in a line with the back of a man's neck, and, rather than get a stiff neck, the windows are more closed. The dust-bin, although not actually in the kitchen is under the same roof, and with the smells from the w.c's. which, it is stated, are often out of repairs-the place is a most unpleasant one to be in, especially when the men are having their meals.

Before bringing my case to a close, I should like to call attention to the Holloway S.O. This office, with a staff of 84 men, is supplied with three w.c's. and urinals; the state of the latter is very defective, so much so, that with an extra flush or overflow, the water runs over the floor, and finds its way through the ceiling of the S.O., the kitchen and urinals in this case being above the office. The coal-cellar, which is also used as a lamp-room, was, after a heavy storm we experienced last year, found to be covered with a quantity of sewage matter which had exuded through the brick floor of the same, and was allowed to remain for the space of two weeks, notwithstanding it had been reported several times; and the smell arising from the same was very obnoxious, and it is feared the same thing will occur again upon the first heavy storm we may experience.

\section{(Signed) G. KING,}

\section{Maida Hill.}

\section{THE MINIMUM WAGE.}

Mr. Churchfield, continuing his evidence, said:-I have the honour to submit, on behalf of the postmen of the whole of London, the case for an increase of the minimum wage. My colleague, Mr. T. G. Barnes, who will follow me, will deal with the question of increase of annual increment, of maximum wage, and of the abolition of the zone system. It will be my object to show that the present minimum wage is not in keeping with the progress made by other branches of the Public Service, and as it is generally expected that a postman should maintain a respectable position in the world, it will not be difficult for me to prove conclusively that on the present minimum it is hardly possible to live decently, and absolutely impossible to live comfortably. Other classes outside the Post Office receive a higher minimum, and we consider that the Post Office, the largest revenue- 
earning service of the country, should take a higher view of the treatment of its hardest worked servants than it has done in recent years, and make even the postman's position an appointment to be coveted. The following are the reasons adduced for an increase of the minimum wage:-

(1) That the duties are of an important and responsible character.

(2) That the work cannot be compared to " unskilled labour," a large amount of sorting being performed by postmen in addition to their ordinary duties.

(3) That a vast responsibility is incurred in connection with the delivery of registered letters.

(4) That the duties of a postman involve strain, exposure, and break of rest. (Vide P.M.G's. Report, 1895. Pages 12 and 14). And

(5) That rents in London are excessively high, and continue to increase.

The Chairman : Niay I ask. Mr. Churchfield, where the most of you live?

A. We live in all parts of London.

Q. Can you give the average distance of your residences from the offices in which you work?

A. I should say it ranges from 4 or 5 to 7 miles.

Sir F. Mowatt: Seven miles from the office where the men have to attend? A. Yes.

Mr. Walpole: I presume you are taking the case of the E.C. postmen?

A. Yes; I am speaking for the City men. As to the district men, I should think that the majority live from 25 minutes to three-quarters of an hour from their offices.

1Q. Are those the men included in Zone 1 ?

A. Yes; and in Zones 2 and 3.

Q. Do you mean to say that the postmen in Zone 2 live 25 minutes away from their offices? Take South Kensington, Earl's Court, and West Brompton: would you say that the men at the offices there live 25 minutes away?

A. Yes; I should think they lived fully that distance from their offices.

Q. Then toke the case of Notting Hill and Maida Hill: those offices are in Zone 1. Do the men employed there live 25 minutes away from their offices?

A. I should say so, sir.

The Chairman: Where do you yourself live?

A. I live at Manor Park.

Q. How long does it take you to get from your own house to the General Post Office?

A. Travelling by train, I can reach the G.P.O. in three-quarters of an hour.

\section{RESPONSIBLE CHARACTER OF THE DUTIES.}

Continuing, Witness said: As showing the importance of the duties, I would mention that on joining the Service there is first to be read, and carefully observed, the Postmen's Book of 60 Pules, which shows that the duties are by no means few or simple. It cannot be denied that great trust is at all times necessary to ba reposed in postmen, inasmuch as letters and articles of great value pass through their hands. While on this head, I would refer to one of five causes mentioned by Adam Smith as accounting for higher wages being paid in certain employments-namely, "The small or great trust which must be reposed in those who exercise them." Referring to this cause, the late Right Hon. Henry Fawcett says, in his "Manual of Political Economy" (pp. 136 and 137): "With regard to the fourth cause mentioned by Adam Smith, it may be remarked that, when a great amount of trust is requisite to be reposed in an employee, his wages are, of course, higher. An employee, when he has demonstrated that he possesses such qualities as will cause his employer to place confidence in 
him, can claim higher wages, and the employer who gives these higher wages is abundantly recompensed." That this principle of paying a higher minimum to postmen has been recognised by the Department in the past, I will prove by the production of a circular issued by the Circulation Department, dated March, 1855. This document, after referring to the then classification of the new establishment, states that the minimum for the 4th class is 19s. And again, in March, 1865, a further circular issued by the Circulation Department fixes the minimum wage at 20s. ; it will be seen, therefore, that so far as the minimum is concerned, the postman's position lias been one of retrogression.

It has been suggested that, if the minimum were raised to $24 \mathrm{~s}$., a difficulty might arise with regard to telegraph messengers coming into the postal service. The question would be asked-Should they, being mere lads, receive $24 \mathrm{~s}$. per week on their entry into the Postal Service? Would not this high wage cause them to lose their heads, and to become improvident, etc. This point has been considered by us, and our suggestion is, that the present maximum of telegraph messengers should be raised to 15s. (as was paid under Mr. Fawcett's scheme), and that they should he allowed to remain on as telegraph messengers until the attain the age of 19 ; this, it is believed, they would readily do if they could look forward to a prospective 24s. per week on entering the Postal Service. Arrangements could also be made for the telegraph messengers to qualify for appointments on a shorter probationary period than two years. I am desired by my colleagues to call attention to the fact that a large nuinber of telegraph boys are occasionally employed in the sub-offices to work the holidays and illness of established men, and althongh doing a full day's work, do not receive more than $12 \mathrm{~s}$. per week. Even in 1858, the Department were cognisant of the fact that some of the young men then in the service of the Department were the sons of elder letter-carriers, and that they lived at home with their parents; and, as will be seen from the official notice above referred to, the age of entry was but 17, and the minimum wage 19s. This minimum of $19 \mathrm{~s}$., it must be understood, was given at a time when the work of the Depariment was not of so heavy and important a character as at the present time. I may mention that the late Postmaster-General (Mr. Arnold Morley), in replying to a deputation from the Permanent Committee of the organisation of the unemployed on 2nd Dec., 1892, said: "I am not going to use the market rate of wages as an argument; I recognise it is not the standard by which a Government Department or any employer of labour ought to be guided. The Post Office, I admit, ought certainly to set an example to other employers, bearing in mind, of course, the duty it owes to the public and the considerations of administration for the Exchequer, by whose decisions it is bound. You are probably aware that Parliament has practically settled the question of the rate of wages so far as Government contracts are concerned. I have already had under my notice the case in which I shall certainly do all I can to act up, not only to the letter of the law, but also to the spirit of the regulations passed by the House of Commons." This extract from the ex-PostmasierGeneral's speech bad, I believe, reference to the contract for the mail-carts.

\section{THE NATURE OF THE WORK.}

Mr. Churchfield, dealing with this point, said: Postmen are generally informed that, in deciding as to the amount of their wages, due regard must be had to the fact that their labour is "unskilled." This is an injustice to the postman, as it will be found on inquiry that at the various post offices, postmen are daily sorting the district work of London. No offices in zones have any sorters, and the working duties must be necessarily done by postmen, who, in fact, make up all despatches to the chief district offices. Now, this sorting work can hardly be classed as "unskilled," and, for this reason among others, it is asked that postmen should receive an 
increase of the minimum wage. I would also mention that the heavy work of sorting and delivering hundreds and thousands of circulars, which are annually dealt with, is performed mainly by postmen, young and old, which circulars are at times even kept back by the Department in order that the bulk of the sorting may be done by postmen. Moreover, it cannot be said that the postmen, whilst on sorting duty, is favoured or excused for any mistakes he may make, for he stands on the same footing as sorters as regards penalties for "mis-sorts."

\section{REGISTERED LETTERS.}

I will speak now as regards registered letters, and the method in which they are handled by the officials. I wish also to draw attention to the injustice suffered by postmen in the heavy responsibility thrust upon them in connection with the delivery of the registered letters. I would point out that the registered letters are received by the sorters in sealed bags, and signed for by them. They arrange the slips for the postmen's deliveries, and hand the registered letters to the postmen. For this duty, sorters in the City receive an allowance, whilst the postman, with from 50 to 100 registered letters, in addition to ordinary mail matter, goes into the streets alone, and for performing his part of the duty-a very important one -receives no allowance whatever. I may mention that it is the practice of the Department in the E.C. District, where the registered letters are known to contain enclosures of great value, to supply a guard to walk with the postman. On the 15th November last, one postman signed for two registered letters which had been insured by the senders for a sum of no less than $\$ 80,000$. To insure the safe delivery of these two letters, the Department furnished two men to act as guards. It is no uncommon occurrence for postmen delivering certain walks through London to have sometimes 20 to 30 registered letters of the value of many thousands of pounds each. I would mention the Hatton Garden robbery, where a postman, engaged on his day delivery, was set upon by thieves, who, after administering chloroform to him, decamped with registered letters containing large sums. I mention these facts in the hope that they will receive consideration in determining what increase of the minimum wage should be given. It cannot be urged that only men of long service and good conduct are selected for this work: the first man available, whether with two or twenty years' service, is liable to be called upon to take out deliveries, including the registered letters, in the absence of the regular men through illness or holidays.

\section{DUTIES OF AN ARDUOUS CHARACTER.}

This is another strong reason, I think, for better treatment as regards rate of pay, and also prevents comparison with other employments. It has been stated in the House of Commons by successive PostmastersGeneral, that the whole of the Postal staff should, as far as possible, be in attendance at the various post offices as early as 5 a.m., and that the conditions of the Service prevent the duties being continuous to any extent. In fact, it is stated by the Right Hon. A. Morley in his Report of 1895 (p. 12), that, "The circumstances of employment under the Department indeed necessarily impose a severe strain on the stafi undertaking the duty. The public expect to receive their letters as early as possible in the morning, and to post them as late as possible at night. . . . On both sides of the Service, therefore, there is every necessity for very early and very late attendances, which are not usual in private employment." And again, in same Report, page 14, it is stated-“. . . The Post Office population is distributed unequally among different ages and between both sexes, excluding the very young and the very old. It consists of selected lives, candidates being required to pass a medical examination before they are 
admitted to the Public Service. And the nature of the work varies from duties of a light and pleasant character to some which involve strain, exposure, and break of rest." I maintain that the heaviest duties are performed by postmen. Yet, when they ask for an increase, they are told their wage compares favourably with those given in private employment. No con pas iscn should, I think, be made, as it is pointed out in the Postmaster-General's Report above that the conditions of work are different from those which prevail in private employment. The postman at the present time receives a lower minimum in proportion to the importance of the duties performed by him, and the exacting physical conditions of the Service, than is paid by other public bodies, such as the London County Couscil, and H.M. Office of Works. In fact, the Right Hon. Herbert Glaistone (then First Commissioner of Works), in reply to a deputation to him on the minimum wage to Park-keepers (Royal), said that he had recommended to the Treasury the raising of the minimum to $24 \mathrm{~s}$., and they had agreed. Of course, a good many workmen received more, but he would like to point out that the work was continuous.

Mr. Smith: Are you not using the word "minimum" in two different senses? The minimum wage for the park-keepers was a minimum for adults, and not a minimum which was to increase.

A. I am dealing with a minimum scale of increases. You will see that Mr. Gladstone qualifies the word "minimum" in the particular case I am citing.

Mr. Smith: I do not think you see what I mean. I would suggest you are using it in a dual sense in this case. In the case you name it is a mirimum for all adult workmen.

A. It is a provision that none shall be paid less than 24 s. weekly.

Sir F. Mowatt: What is the average age of park-keepers? Is it not about 30 years?

A. They rise to 28s. There are different classes of them.

Sir F. Mowatt: And they do not rise so high as you do?

A. That is so.

Mr. Walpole: But do you know at what age they enter that particular service?

A. They are mostly taken from the ariny, and are consequently middleaged mien.

Q. Do you know the average age at which men enter your own Service?

A. When they are transferred from the Telegraph Service the age would range from 18 to 20 ; but when they come from the army they are admitted at as high an age as 32 .

Q. Then in your own Service a postman would receive, under your proposal, a 24s. minimum at the age at which the park-keepers receive $24 \mathrm{~s}$. ?

A. Yes; that would be so ; but it would be after many years' service.

Mr. Walpole: Do you know the hours worked by the park-keepers?

A. Yes ; eight.

Q. Are you sure of that?

A. Yes; it is eight hours a day. That is the Government system.

Mr. Smith: What is the limit of age for entrance as postmen?

A. I have said that a man who comes from the army can, if he has served

12 years with the colours, be admitted up to the age of 32 .

Q. Do a good many come into the Service after being in the army?

A. There has not been a very large proportion during the last 12 months.

But in the time of Sir James Fergusson a good many did come in.

Q. Did they come in at a minimum of $18 \mathrm{~s} . ?$

A. Yes.

Mr. Walpole: Is it not the case that since Sir James Fergusson's tine

the r.ule has been altered so as to give preference to telegraph messengers?

A. Yes.

Mr. Smith : Does the 18s. minimum apply to all these men? 
A. Certainly, except in one or two instances where auxiliary postmen were appointed to the staff at a minimum wage of $24 \mathrm{~s}$.

Mr. Walpole: That would be after many years' auxiliary service, would it not?

A. Yes.

Mr. Smith: Did you enter as a telegraph messenger?

A. No ; I came from the outside public.

Mr. Waipole: What was the age of your entry?

A. 18 years. There is one other point I should like to put forward refelring to the severe character of postmen's duties. The following statement, made by Sir W. B. Richardson, taken from "Longman's Magazine," shows that the work is of no ordinary character:-

"There are some callings which, on account of their monotony and steady wear and tear from constant work, require regular limitation of time. The postman is an excellent example of this class of workers incluced under this head. Th: work of a postman is one continuous busygo-round; he is always on his feet during the whole of his working hours. The resulb is that the postman rears out fast. The late Meclical Officer to the (xeneral Post Office, Dr. Waller Lewis, was fully alive to the fact. $\mathrm{He}$ referres to it in his reports, and he spoke several times to me about it. 'There weie some men, he told me, who sustained the tedious labour fairly; but none bore it well, and the weaker ones badly. The effect was generally to produce premature cld age; in other words, shortening the life of the worker."

The above statement, made on the althority of one so well-known, merits earnest cossideration, and the taxpayers of the country will surely not grudge the increase asked for by the postmen. On the statement, too, of Dr. Wilson, the chief Medical Officer of the Department, the Postal Service, with its split duties, is not conducive to goo d health. In fact, he states"The duties are arduous and trying, even to the strongast." This in itself is sufficient reason for the Department paying a good "living wage."

\section{EXCESSIVE RENTS IN LONDON.}

Another point I wish considered in dealing witl the question of the minimum is the very heavy rents that liave to be paid by those residing in London. In a pamphlet, published by Mr. Stanley Boulter, entitled "Free Homes for the People," reference is therein made to the Report of the Royal Commission on the Housing of the Working Classes, as follows :-

"The Commissioners found that the $r \in n$ ts in the congested districts of London were gradually getting higher, and wages were not rising. At Prospect Terrace, in South St. Pancras, 4s. a week was paid for one room $10 \mathrm{ft}$. by $7 \mathrm{ft}$. ; the same was the case in Derry Street. In Wood Strest 6s. Was paid for a single room, and if cheaper quarters were needed, an underground kitclien must be sought. which commanded a rent in this neiglibourhoor of 2s. 6d. a week. At Steplen Street, Tottenham Court Road, $5 \mathrm{~s}$. a week was paid for a single room in great decay. In Chapel Row and Wilmington Place, Clerkenwell, 3s. 9d.. 4s. 6d., and 5s. were the rents for single rooms. In Spitalfields the average rent for one room was from $4 \mathrm{~s}$. $6 \mathrm{~d}$. to $6 \mathrm{~s}$. a week. These instances might be multiplied. The Con:missioners stated that the highness of rent in proportion to earnings was undoubtedly a potent and principal cause of the condition in which the poor are housed. An inquiry extending-over nearly a thousand dwellings, taken at ravdom in different poor parts of the Metropolis, showed that 46 per cent. of the poor population pay from one-fourth to one-half of their ineome in rent."

This statement, based on the most reliable evidence obtainable, is one we feel merits your serious consideration in determining and fixing the future minimum wage of postal officials. 
In addition to the above point, regard must be had to the travelling expenses incurred by postmen owing to the numerous attendances that must be made to perform the daily duties. In conclusion, I would just state the number of men who will benefit by this increase, if granted. The P.M.G. stated in the House of Commons in 1893 that there were then 4,937 postmen who received $24 \mathrm{~s}$. per week, or less, and those were adults and on the staff. It is estimated that about 60 per cent. of the established classes would benefit by an increase of the minimum, and we earnestly hope that your recommendation will be a favourable and a just one. I thank you for your courteous attention.

The Chairman: I understand what you have come to ask for is an increase of the minimum; you do not say anything about the maximum?

A. My colleague will deal with that; as I have already pointed out, he will take the case of the annual increment and the maximum wage.

The Chairman: What are more especially the grounds on which you ask for an increase of the minimum?

A. We ask it for the simple reason that $18 \mathrm{~s}$. a week is such a small sum for a man to start upon. I should impress upon the Committee the fact that a young man, having entered the Service, takes up the responsibility of manhood at once. Though he may be living at home, he feels the responsibility that is thrust upon him of earning his own living.

Q. Take the case of a lad of 18 . Is not 18s. a week as much as he would get in any other employment to which the class from which postmen are usually drawn are accustomed?

A. But we are asking that the age should be raised at which telegraph messengers should be transferred.

Q. Postmen are not solely drawn from telegraph boys?

A. And that is the reason we are asking for an increased minimum. We have men entering the Service at the age of 25 and $30-$ men who have passed through the army.

Q. Surely no man would come in from the army at the age of 25 . You told us that he must have 12 years' service with the colours before he could come in?

A. He must have 12 years' service with the colours if he is to come in at the age of 32 ; that is a privilege specially extended to those men.

Q. Then after one term of service with the colours a man might come in at the age of 25? Do you say that a man coming in at that age starts equally with the others at 18 s.?

A. Yes.

Q. And whether he be 25,26 , or 32 , he still gets $18 \mathrm{s.?}$

A. Yes.

Q. Then I understand your suggestion is that the age of telegraph boys who are transferred should be raised to 20 ?

A. Yes, or 19 if promotion is thrown open to them. Supposing they come in at 19 they would be 20 or 21 before they got on to the establish. ment.

Q. At present it is open to them at 18 , is it not?

A. Yes; but as I say, we suggest that the age shonld be raised.

Q. What is the minimum you propose?

A. 24 s. a week.

Q. Would you propose that a telegraph boy coming in at the age of 19 should receive $24 \mathrm{~s}$. at once?

A. Yes.

Q. You propose to raise him from 15s. at one jump to $24 \mathrm{~s}$.?

A. Yes.

Mr. Smith: Do you propose that the minimum age for postmen should be raised to 19 , or simply that the maximum age of telegraph boys should be raised to 19 ? 
A. The age at which a postman may enter the Service has been fixed by the Department at 32.

Q. But that is only in the case of men who have served 12 years with the colours. Is it not the fact that the minimum age at present is 18 , and that you now propose to raise it to 19 ?

A. Yes.

Sir F. Mowatt: And you say that no one should be admitted before they are 19 ?

A. That is so.

Mr. Walpole: In practice that is what is occurring in the Department. We keep the telegraph boys on till they are 19, and then they become postmen, so that really we are doing what you ask.

The Chairman: I do not want to put it to you in an unfair way, but, taking an average young fellow of the class from which postmen are drawn, does not 18s. represent a much larger wage than usually is paid to one of that age?

A. I take it it is not so, my lord. I think it is only the prospect of the future that keeps these young fellows in the Service. I believe they would get the same wage elsewhere.

Q. But they would not get more on the average, would they?

A. I take it that they would, sir. Look at a young fellow who has learned a trade.

The Chairman: Yes, by all means take such a case as that. A young fellow is apprenticed to a trade at the age of 18 . Surely he would not be earning so much money?

A. No; but after having served five or seven years, as the case may be, he would rise to his maximum at once.

Q. But the maximum pay even then would not be more than the minimum of 24s., would it?

A. On the contrary, I take it that a good workman receives on an average from 38s. to $40 \mathrm{~s}$. a week.

Mr. Smith: But not at the age of 18 ? At that age he certainly would not be getting more than we give, and surely that would be a big jump?

A. There is another thing ought to be borne in mind, and that is that there is no permanency in the Post Office employment for the first two years a man is in the Service.

The Chairman: What do you mean by that?

A. A man has to do two years' probation, and, if he fails, he is not put on the establishment. By that time he will have reached the age of 21, and will have to look for employment elsewhere.

Q. Do many men fail on their probation?

A. Not a great many.

Q. Is it not a rare thing to fail?

A. Well, I take it that the Department have fully analysed a boy's life and strength during the time he is in the Telegraph Service. Then if he is a man who is brought in from the army, he is a man who has also been well tested.

Sir F. Mowatt: Therefore the service during the first two years is practically if not theoretically permanent?

A. Yes.

Mr. Smith: Substantially, the grievance you represent is that adults of 21 and upwards are getting less than $24 \mathrm{~s}$. a week?

A. Yes; including the army men I have referred to.

Mr. Walpole: Do you know how many army men have been admitted int) the London Postal Service during the last 12 months?

A. I should say about 300 .

Mr. Walpole: Including the auxiliary classes?

A. Yes.

Q. In the London Postal Service? 


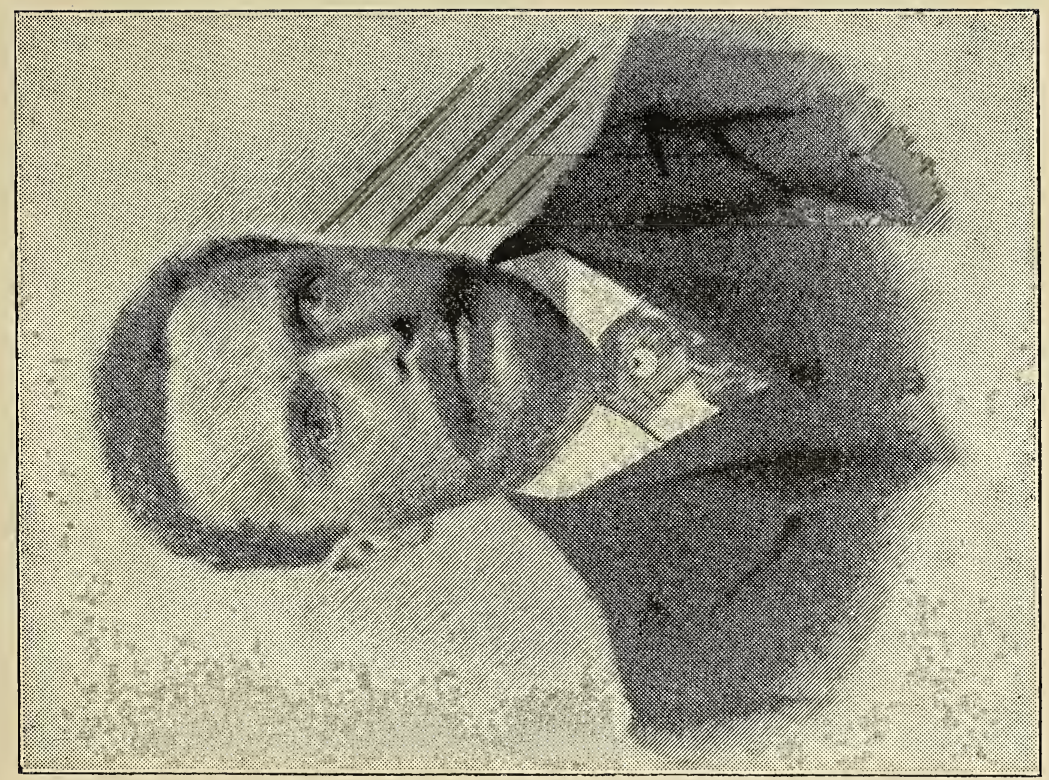

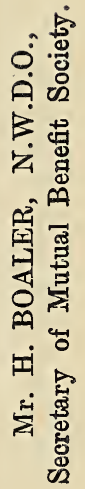

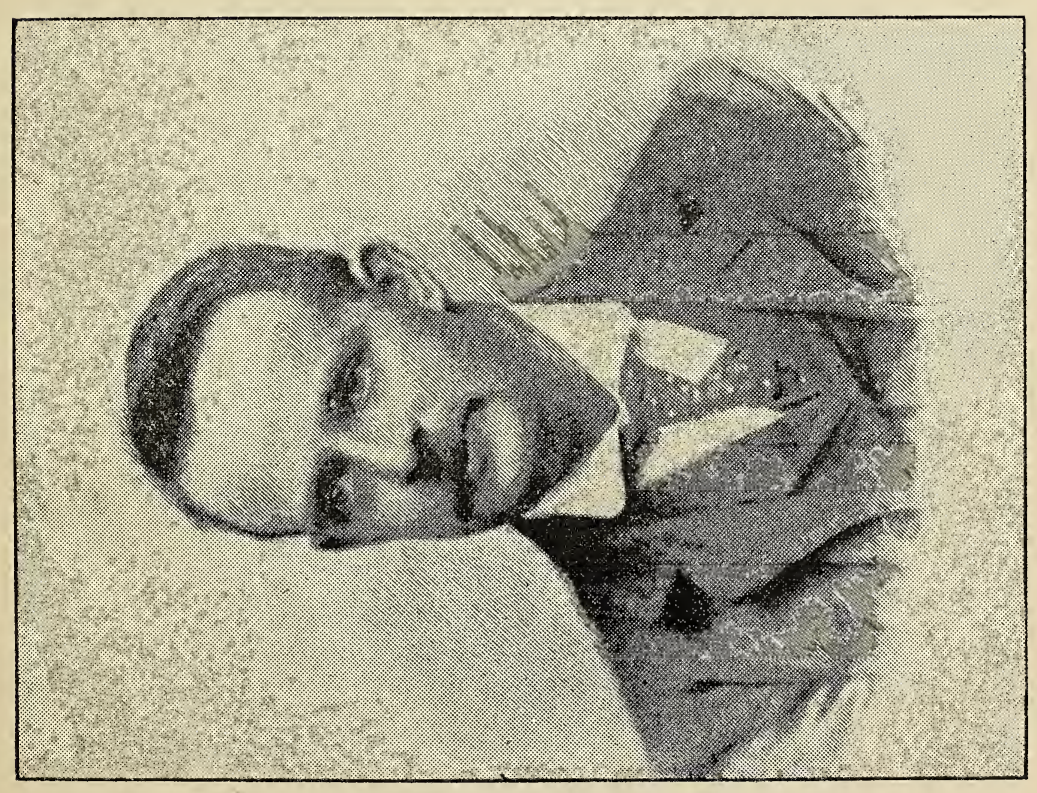

要 

A. Yes. Let me add that the men do not enter at the age of 18 if they enter through the auxiliary service; they are taken on at any age.

Mr. Smith: And they all come in at the minimum wage of 18s.?

A. Yes; the wage is 18 s. a week.

Q. And if they come from the auxiliary to the permanent staff they still get 18s.?

A. Yes; except in such cases as I have already alluded to.

Q. You have mentioned in the course of your evidence the case of telegraph messengers taking the place of established men during the holidays and in absence through ill-health. Are we to understand you put that forward as a grievance?

A. It is not regarded altogether as a grievance, but we maintain that there should be a certain staff attached to the offices to take up the vacancies as they occur; for instance, in the various zones if a man is absent for any cause, and fails to come on duty they simply get a telegraph boy from the depot, and get him to do the man's work till he returns. They have no reserve staff. At Christmas time telegraph boys are drafted into the different districts, and do men's work for four or five days, and then they are sent back to their various stations.

Q. But the Post Office work, being in its nature fluctuating, can you aroid anything of that kind?

A. It could be avoided by young fellows qualifying during the period set apart for probation. They could then be taken on the staff.

The Chairman: They are learning what their future work will be during that time, so it is good for them as well as for the Department?

A. Yes; but some of the auxiliaries serve eight or nine years before they get on the staff, and even then they have to go through two years' probation.

Sir F. Mowatt: If he does the work of a probationer for two years surely it cannot do him much harm. If he fails it is a proof that the probation was necessary. But if be does not fail how does it really affect him?

A. It affects him in this way-If a man has done seven years' service before he gets on the establishment, and then has two years to do as a probationer, he may, in the course of that two years, contract some complaint which would disqualify him from further service, and the Department would then have the privilege of dispensing with his services.

Mr. Walpole: I presume, Mr. Churchfield, that if unfortunately a man, after he had done his two years' probation, contracted a complaint that would disqualify him from further duty, he would have to retire, and he would not be entitled to any pension. Therefore he would be in exactly the same position, would he not?

A. That is so.

Q. Then where would the difference come in?

A. We are asking that these men should go direct to the staff. We maintain that they have qualified during their auxiliary service.

The Chairman: I do not think you grasp the point. You do not make out any strong case of grievance on the part of the probationers. You do not say that many of them are rejected, or that they are rejected on improper grounds?

A. One of my colleagues will deal with that point.

Q. You are not prepared to go into it?

A. No, sir.

Mr. Walpole: There is one question I want to ask you. I think you are under a misapprehension. You said something about 300 army men coming into the London Postal Service last year. I think you would probably like to modify that statement. I am advised that it is not a fact.

A. I am speaking of the Service generally, including auxiliaries.

Mr. Walpole: I assure you you are wrong. I am told that there were 
300 in 1893 and 1894 combined, and that when Sir James Fergusson's rule was in full force. As a fact, very few came in in 1895.

A. In that case, sir, I shall be very glad to modify my statement.

Q. You are including auxiliaries as well?

A. Yes, sir.

The Chairman: One of your friends is going to speak on the zone question, is he not?

A. Yes, sir.

Mr. Smith: In fixing on the particular sum of 24s., have you done so because other public bodies pay that sum?

A. Yes. Such bodies as the London County Council pay it. It is the standard rate of wage in London.

The Chairman: Do they give it to people so young as boys of 18 ?

A. I take it they make a rule not to employ men under a certain age.

Mr. Smith: It is the standard rate, but you would not like to accept it as your fixed wage, would you?

A. Not as a fixture.

Q. Is the analogy not rather a dangerous one for that reason?

Witness: I take it that the County Council have power to raise the maximum.

Mr. Walpole: You mention that in your earlier years of service the minimum wage of postmen was higher than it now is?

A. Not in my time, but before my service.

Q. Was there not a class of assistant-postmen at that time?

A. There was a fourth class, but there were no assistant-postmen.

The Chairman: Was there no classification among the town postmen at ail? A. No.

Q. Is there anything else you wish to say?

The witness then withdrew.

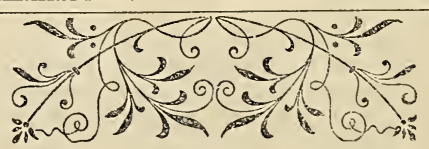


I. G. BARNES, S.E.D.O.

Wagns-Annual InCRement-Zone System-Maximum.

Westumster, February 3, 1896

The next witness was Mr. T. G. Barnes, of the S.E. District Office.

The Chairman: What is your service? 1879.

Witness: I entered the Service as an auxiliary in the month of June,

Q. And then?

A. I was an auxiliary for nearly 12 years, and came on the establishment at the end of 1890 .

Q. How old were you when you entered the Service?

A. Between 18 and 19 . I was 30 by the time I got on to the establishment.

Q. What pay did you get as an auxiliary?

A. I was getting 12s. as an auxiliary for a few hours' duty.

Q. 'Then you only devoted a short time to the Service?

A. Yes.

Q. And you employed the remainder of your time in other ways?

A. Yes.

Q. That was until 1890. You are getting 23s. a week now, are you not?

A. Yes.

Q. Have you got any stripes?

A. No, my lord, not yet.

Q. You want more especially to talk about the annual increment, the abolition of the zone system, and the maximum wage?

A. Yes, my lord.

Q. Well, tell us what you have to say.

Witness : In bringing before you the question of the inadequacy of the annual increment for postmen throughout the whole of London, we feel convinced, that, as this question has never been seriously considered by the Department upon our several petitions, this opportunity, long desired by the men concerned, will have the effect of producing, through an impartial tribunal such as this Committee, the recognition of our claim to the same treatment as other branches of the Postal Service. The claim that the annual increment of $1 \mathrm{~s}$. is inadequate cannot, in our opinion, be considered an unreasonable one, seeing that it has not been increased one halfpenny during the past 30 years, though, at the same time, great improvement in this respect has taken place in other classes. In March, 1865, a Circular Memorandum, issued by command of the then P.M.G., laid down the status and pay of the Liondon staff.

Mr. Walpole: What is the date of the memorandum? 
A. 22nd March, 1865. It gave the following information :-

\section{CIRCULAR MEMORANDUM.}

Upon the recommendation of the Postmaster-General, the Lords of the Treasury have now sanctioned as a permanent arrangement the following wages for the Minor Establishment of the Post Office:-

180 Sorters with wase rising by $1 /$ - a week from $40 /$ - to $50 /$ - a week.

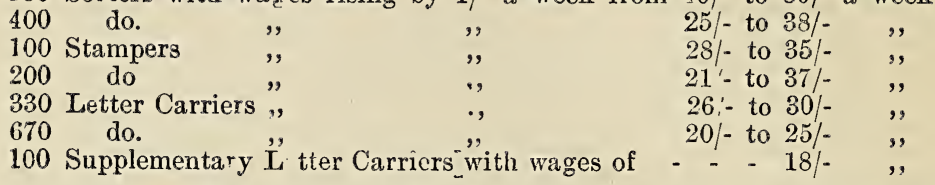

In communicating this decision to the men it is necessary to remind them that, though their wages alone, looking to the general rate of wages, might be considered to remunerate them sufficiently, the benefit of their places is by no means confined to their bare wages, and that this is especially so in the case of the letter-carriers.

To all, pensions are granted on their retirement from age or sickness. All have a fair chance of rising to the several classes above them, the entire establishment being recruited from the supplementary class. All have a fortnight's holiday every year on full pay. All have medical advice and medicine gratis, and, when the medical officer reports it to be necessary that they should absent themselves from duty, they still receive two-thirds of their wages, and all have assistance in the insurance of their lives to the extent of one-fifth of the premium. Beyond this the letter-carriers are supplied with uniform clothing, the money value of which is equal to at least 1s. 6d. a week, and they receive from the public in gratuities at Christmas a sum which, if divided equally and spread over the whole year, would produce on an average $5 \mathrm{~s}$. a week to each man.

The places, therefore, of the regular letter-carriers-1000 in numberare worth upon an average from $26 \mathrm{~s}$. 6d. to 36s. 6d. a week, apart from the other advantages.

In comparing, too, these wwages of the Minor Establishment with the wages of artisans, it must be borne in mind that they go on continuously throughout the whole year, and that the work in the Post Office is not liable to fluctuations which necessitate frequent change of abode.

By command of the Postmaster-General,

W. Bozknham, Controller.

Circulation Department, G.P.O., March 22, 1865.

Witness, continuing his evidence: The Controller distinctly lays it dowu that all have a chance of rising, as the entire establishment is recruited from the supplementary class. It will be seen by this that letter-carriers at that time had the opportunity of rising from 20 s. to $50 \mathrm{~s}$. per week, without, I presume, undergoing any further examination than that required on their entry into the Service.

The Chairman: Surely the figure should be 30 s., and not 50 s.?

A. No, my lord.

Mr. Walpole: You mean that the letter-carriers might ultimately rise to first-class sorters?

A. Yes.

Q. I presume that in the one sense they have got that prospect now?

A. Just so; but the prospect of a man rising to $50 \mathrm{~s}$. a week is not very bright. He is more likely to remain a postman. 
Q. And in those days it was very unusual for a postman to become a firstclass sorter?

A. In those days the Service was developing very rapidly, and it was necessary to increase the staff more rapidly than at the present time. Therefore the men had a greater chance of rising.

Mr. Smith: Do you know if, as a matter of fact, they did rise in that way?

A. No, sir; I cannot say I do know that. But I am aware that men who came in at that time to supplement the letter-carriers are now holding positions as inspectors and first-class overseers. In my own case, even if I came in as a sorter at the present time, I should never reach that, nor do I think half the men in London would do so. But that is a question of promotion, with which Mr. Harris will deal.

Q. The figures you have just given us are not the limits of the scale for postmen, but they are the limits which, in your opinion--

The Chairman: They are the limits for the whole Minor Establishment of the Post Office, are they not?

A. Yes. As a matter of fact, there are a large number of sorters in the E.C. District at the present time who came in as postmen. I am informed that is so, but I cannot speak to it from personal knowledge. It was clearly understood that the contingent advantages, such as uniform, sick and annual leave, pension and Christmas boxes, were even at this time of day taken into account. We contend that the wages of postmen should be considered on all fours with that of the sorting class, with whom, working side by side, doing exactly the same work, we yet present the extraordinary spectacle not furnished in any other trade or profession in this country-of one man receiving double the yearly increment of the other. This state of things cannot be thought, by any stretch of imagination, to conduce to that feeling of contentment amongst the large class I represent, which is essential to the well-being both of the Department and of the public. Whilst our petitions have time after time been ignored, we have seen other classes not only receiving an increașe on their maximum, but having their increments raised, while at the same time that of the postmen has remained stationary. Why, I cannot find out, but the fact has been gradually borne on us that postmen are considered the pariahs of the Postal Service.

Mr. Walpole: The what?

A. The pariahs of the Postal Service. (Laughter.) I mean by that that the revisions of 1881 and 1891 did not benefit the postmen to the same extent as they did other classes. Why, we have not been able to find out, except that they are a larger class, and if their demands were conceded it would absorb more public money than would be required for the other classes. I will now proceed with the reasons why the increment should be raised to 2s. per week per year. They are:-1st, The similarity of the work performed by postmen and sorters; 2nd, split duties; and 3rd, the exceptionally long period now in rogue before reaching the maximum. With regard to the first point, I wiil take leave to mention the famous statement of the late Mr. Fawcett, on the intelligible principle of paying for work solely according to its quality, and we assert the work of a postman is more arduous and equally responsible as that of a sorter. This should be taken into account when adjusting the scale of wages; and, further, that had the postmen received the same consideration as other classes under the revisions of 1881 and 1891, they would now be in receipt of what they now claim. The work of a postman and sorter is so similar that it is difficult for me here to state where the difference comes in, but it will be sufficient for any purpose to state that both classes have to pass an examination which consists as a rule of what is known as primary sorting, which necessitates an intimate knowledge of the whole of the British Isles. This in itself shows that postmen are as equally capable as sorters, seeing that their appointment is not only deferred, but the annual increment as well, 
until they can prove themselves efficient. So far, the treatment is equal, but. in the event of both passing, the sorter will, after the first two years, receive an increment of $2 \mathrm{~s}$, , and the postman will receive only 1s. Besides sorting, postmen are expected and are called upon to open and despatch bags. They have, too, other duties, which in some, and principally in the head offices, are performed by sorters. In addition to these must be added the responsibility of deliveries, which includes letters, parcels, charges on unpaid letters and registered letters, which we contend is equal in importance to the Service and to the public with any duty performed by a sorter. I think, without any further showing, it will be seen that the duties, as far as the inside work is concerned, are analogous, whilst the postinan has in addition to his responsibilities by the deliveries and consequent dealings with the public which has tended to make the Service so popular in the past, and which will have the effect of still further doing so in the future. With regard to split duties, much has been given in evidence on this point, and, without a doubt, the system stands condemned, but postmen have been, and are, at the present time, working split duties which have the effect of spreading the eight hours' work over 12, 14, and 16 hours per day. This entails upon us the going to and from our homes between each spell of work, and presses hardly upon a class of men, who, owing to the smallness of their wages, are compelled to reside at some distance from the office; and we submit that not only the divided attendances but the expenses of travelling are a sound reason for an increased increment.

The Chairman: What are your travelling expenses on the average?

A. My travelling expenses are nil. I finish practically at my own door. Mr. Walpole: Where do you live?

A. In the S.E. District. The bulk of the men there live a considerable distance away from the office.

Sir F. Mowatt: It is not a question of the distance from the office. It is rather one as to the distance from where the round ceases that determines how far the men have to travel.

A. Many men-in fact, a majority of them-endeavour as far as possible to get on walks which finish as near their homes as possible. But unless men pay a heavy rent they cannot possibly live near the office.

Q. You have to start from the office?

A. Just so, sir.

Q. And you have to go from your homes to the office?

A. Yes, sir.

Q. And you try so to manage it as to end your circuit near where you live?

A. Yes, sir; but the bulk of the men are not able to do that. Take the district offices. The men have to live in what are termed suburban districts, and that, of course, entails their travelling half or three-quarters of a mile before beginning each delivery.

The Chairman: And what should that represent in money?

A. I find that on the average with the men in my own office they spend 2s. a week on travelling.

Q. Roughly, £5 a year?

A. That is the men who are doing three deliveries a day.

Q. On 'bus, tram, or train fares?

A. Yes; some travel by 'bus, some by tram, and some by train. It includes all sorts of travelling. Coming to the third point of the smallness of the increment of postmen, in no other trade does such a long period obtain as that to which we are subjected-viz., 1s. per year for 16 years before reaching the maximum of 34s. per week. I can conceive no defence to this system, even taking into consideration the Departmental view of contingent advantages. A statement of the rates of pay of various trades has already been submitted in evidence to this Committee. I would add the fact that most of these trades have an apprenticeship attached of five 
or seven years, at the expiration of which the youth becomes a journeyman, and at once claims and receives the current wages of his trade, which, in a number of instances, ranges from $34 \mathrm{~s}$. to $40 \mathrm{~s}$. per week. Add to this the fact that the knowledge he has obtained will procure for him the employment in one shop as well as another, and compare it with the position of a postman of five or seven years' service of work, which is one of no earthly use to anyone outside the Post Office.

The Chairman: At any rate, postmen are not liable to have to seek work elsewhere so long as they stick to the Post Office?

A. Just so.

Q. Their employment is permanent, whereas other employers may fail. Consequently a journeyman's employment is much less certain?

A. Yes.

Q. And considerations of weather come in?

A. Just so, sir.

Q. Take the building trade. A great portion of his time, especially in a very hard winter, a man might not be employed at all?

A. Certaini? ; but it will be readily seen that a greater inducement should bo held out to men to make themselves proficient, both for their own sakes and that of the public service. The Government rate of pay should be a model to all other employers, instead of which we find that the arduous duties of our class are paid for at a rate which barely suffices to keep body and soul together, the smallness of the increment granted not being sufficient to keev pace with the increasing responsibilities which the years bring upon as, id the slow, tedious, dragging existence eventually reducing men to mere a'itomatons, knowing, as they do, that, however proficient they may become, the only inducement held out to them is the paltry rise of 1s. per wee.s per year.

Sir F. Mowatt: That represents 22 12s. a year. I think one may be a little deceive by the mention of the shilling. That is a small sum, but \&2 12s. is a considerable amount. It is always the case with weekly increments that iney seem much smaller than they really are.

Witness : What I have to submit is that the postman, considered officially, is altogether a superior class to outside workers, and is expected by his ability, good conduct, and high character, to set an example as a State servant, both on and off duty. He is, before being placed on the staff, subjected to an extremely rigid medical examination, which is so peculiarly exacting that men have, before now, been rejected by the medical officer as unfit for the Postal Service, and have afterwards successfully passed the medical examination for the army. We have, also, a searching investigation into our past life from childhood upwards. We have a probationary period of two years, during which a man is constantly under special supervision before the confirmation of his appointment. We have a stringent code of rules, numbering 61, as to what we should and should not do, besides other orders issued from time to time to govern our conduct. We have recently an order issued, whereby any man misconfucting himself when off duty is to be immediately reported. We have early and late attendances, in which our work must be performed. We have the varying influences of the English climate to contend with, the heavy work of responsible deliveries, the continued good health required to cope with the strain the work inflicts, the high standard of character and good behaviour demanded on and off duty as long as uniform is worm, and these things are rewarded at the end of each year by a rise of 1s. per week. The public expect the work that it gives its servants to do should be done well, and we believe they are also in favour of a fair and proper wage being given for services rendered. More especially is this the case with postmen, who emerge into the street entrusted with thousands of pounds' worth of public property without the slightest supervision. Work of this nature should be amply recognised where well done, and in asking that the annual increment 
should be raised to $2 \mathrm{~s}$. for the reasons I have stated, I have every hope that this Committee will recommend the same on behalf of a deserving and painstaking class, who have been called, and justly called, the backbo e of the Postal Service.

The Chairman: And now come to the question of the

\section{ABOLITION OF ZONES.}

Witness: Yes; I now come to the question of the abolition of the zone question. In dealing with this subject, I will endeavour to be as brief as possible, inasmuch as the glaring anomalies of the present system do rot require at my hands much explanation to sbow you that the circumstances under which the zone system was introduced years ago, do not, as far as I can see, hold good at the present time. That the appellation London an 1 its suburbs was at one time correct I admit, but the rapid growth of the population, and the vast increase of factories and workshops on grounds which, within my own recollection, were fields and gardens, has gradually swallowed up every inch of space to build upon. That being so, streets and roads now in existence in, as it were, the heart of London, have produced, so far as the wages of the London men are concerned, the most peculiar results. I will give you a case in point. Supposing the Committee were to get on an omnibus for a 1d. ride at Hyde Park Corner; you will proceed down Brompton Road, which on one side is delivered by town postmen at a maximum of $34 \mathrm{~s}$., the other side of the road being done by men of Zone 1, reaching 32s. You will then come into Fulham Road, and by crossing Stamford Bridge, find yourselves in Zone 2, where the maximum is 30 s. Thus, in the course of a 1d. ride, we are enabled to show you a specimen of the system under which the postmen of London are paid. I could multiply this illustration from any other district in London, but I think I have said enough to convince you that this state of things is not a fair, just, or reasonable one. Why the people living on one side of Brompton Road should have their letters delivered by a postman who only reaches 32s. per week, whilst they on the other side have a man with a maximum of $34 \mathrm{~s}$., is a question it would be very difficult for an intelligent Londoner ${ }^{+} ?$ answer. Such, however, is the case, and I ask that this unfair system sirould at once be done away with, and in its place there sinil be one class receiving the same wage from start to finish with the sano prospects in view.

The Chairman: Would you apply that to the whole of the London district?

A. Yes, sir.

Q. That is, the whole of the five zones?

A. Yes.

Q. I suppose it is a fact that the process of delivery is more severe in the City than it is outside?

A. We do not admit that, sir.

Q. But is there not more to do in the way of getting upstairs to deliver letters at offices in the City?

A. We do not admit for a moment that a man in the City or S.E. District works harder than a man at Peckham or Clerkenwell or Kensington and other so-called suburban offices. Indeed, the contention will be put to you that the men in the suburbs work harder.

Q. I should imagine that one of the principal grounds for saying that some of the City and town deliveries are more severe than others is that they involve such an amount of stair-climbing. Is not that so? Would it not be the general opinion of Liondon postmen that that is so?

A. Yes; but in comparing the deliveries you must take into consideration that in the suburbs men have long gardens to traverse before they reach the door. 
Q. Yes; but in the City a man may have to go up half-a-dozen flights of stairs in one building. That shows an increased difficulty of delivery, does it not?

A. Yes; but I am informed by Mr. Churchfield that the walks in the City are smaller, and there are more men to cover them.

Q. But are there not a good many more deliveries?

A. Yes.

Q. Then your opinion would be, speaking for your Association, that the extra difficulty of delivery in the town districts is more than compensated by the larger staff of men to perform the delivery?

A. That is so.

Q. And your opinion is, too, that so far from having harder work to do they have easier work?

A. Not necessarily. They have the same responsibilities.

Q. I am not speaking of responsibilities-they would perhaps be about the same-I am referring to actual physical labour.

A. I think if that question were put to a suburban instead of to a town man, he would emphatically answer that heavy physical labour devolves more on a suburban than a town man.

Mr. Walpole: Why?

A. In consequence of the length of the deliveries, and, as I mentioned before, the long gardens to be traversed before reaching the doors at which the letters are to be delivered.

Q. A man in the suburbs only works eight hours. Is not that so?

A. And it is the same with the man in the City.

Q. And there is no increased labour in walking up and down gardens than in walking along a straight delivery?

A. That is so.

Q. But surely there is greater labour put upon a man who has stairs to travel up and down?

A. In a sense it does not entail more physical labour than is undergone by a man in the suburbs.

The Chairman: I would sooner walk on a level all day than go up and down stairs. (Laughter.)

Mr. Walpole: Is it not a fact that the men in the City are put to an expense for travelling to and from home which does not fall upon a man in the suburbs?

A. Yes, sir.

Q. Would it not be very unjust not to give some consideration to a City man who is living six or seven miles from home? Should he not have some advantage over a man who lives probably within a mile of his work?

A. In a great many suburban districts in London the expense of living near the office is quite as great as in the City.

Q. I am not defending the present zone system. Do you propose to sweep away all the zones, and not give some consideration to postmen who are compelled to live a great many miles from their work, and are, consequently, put to travelling expenses?

A. Well, sir, if we take into consideration this, that if our claims are conceded and the weekly increment is increased to $2 \mathrm{~s}$., we should be able to pay a little more for house rent than we are able to pay at the present time.

Sir F. Mowatt: Although you may pay more house rent, surely those who are put to heavy travelling expenses would object to receiving the same rate of wages as you, would they not? We have had this pressed upon us strongly by the sorting class, and, indeed, one of your own witnesses read out a list to-day of the high rents paid for single rooms in the City. That would not be the case at Fendon, Finchley, and Edmonton. A man would not have to pay $6 \mathrm{~s}$. a week for a single room there.

A. But take the West End of London, North-West of London, South 
Kensington, and Hampstead. Men cannot live near their offices there. Rents are far heavier than in the City or South-Eastern District, and, consequently, men have to go outside even their own zones to reside. Yet these places are suburbs, and are included in Zones 2 and 3.

Mr. Walpole : Take Mr. Churchfield's own case, Mr. Barnes. He told us that he lives at Manor Park?

A. Yes.

Q. And he is bound to travel to and from Manor Park every day of his life?

A. Yes.

Q. And if he has split duties he must travel more than once daily?

A. Yes.

Q. Would it be fair to pay him only the same wages as are paid to a postman living at Manor Park and delivering theie?

A. Manor Park is outside London.

Q. No; it is in Zone 4.

A. In asking for the abolition of zones we do not so much take travelling expenses into consideration as the similarity of the work that we all of us perform. That is our belief. The work in South Kensington is similar to that in the City.

Mr. Smith: Would you extend that to the provinces? Would you have one rate of wages over tho whole country?

A. I must leave that in the hands of the witnesses from the provinces.

Q. You have put forward a case of absurdity in which men delivering letters on different sides of a street receive different rates of pay. Are there not roads one side of which is in London while the other side is out of the London district?

A. Very probably, and evidence will no doubt be laid before you on the point. There is no reason, in our opinion, why a man at Newcastle-on-Tyne should receive an increased mazimum as compared with men on the other side of the water at Gateshead.

Q. Then you are prepared to go very far in the direction of the abolition of differences in the rates of pay to London postmen?

A. Yes.

Q. Your argument is that increased rents and the cost of travelling acts rather in an opposite direction?

A. I base my argument on the fact that a man as a postman has the same responsibility, no matter what expenses he may be put to. The remuneration should therefore be the same.

Q. Remuneration after all is what you get; it is not money alone, but clothing, accommodation, and other things. All this must be taken into account. In some places it is possible to get better accommodation for less rent than in others, and if a man is put to less expense this way surely it may be argued his remuneration is quite as high as that of the man who has a higher wage, but has to pay heavier rents?

A. I do not think that would apply in a great many cases.

Q. I quite understand your argument. But might not the difficulty be met by a re-arrangement of the zones?

The Chairman: As I understand it, what you are asking is that in future the mininum wage of postmen should be $24 \mathrm{~s}$. a week, and that it shail rise by annual increments of more than 1s. a week. What increase do you suggest?

A. I suggest the increment should be 2s. a week.

Q. And then it should go up to 40 s. Is that the request put forward on behalf of the Association?

A. Yes, my lord.

Q. And that that should apply to the whole suburban district without any distinction?

A. Just so. 
Q. You do not speak for any ontside the suburban district?

A. No, my lord. I speak for the established postmen of London. I am not laying before you the case of a square mile of this important city, but that of the whole of London-Greater London, I might say-where men breathe the same air.

Sir F. Mowatt: Had you not better modify that statement. (Laughter.)

Witness: Well, perhaps I had better cut those words out. I am speaking on behalf of men who pay the same for food, clothing, light, and rent, have the same responsibilities, and the same drastic rules to govern them, and yet have a difference in their maximum of 2,4 , and 6 shillings a week. Such offices as Peckham, Hampstead, Kensington, and others, with a staff of postmen of 100 and over, cannot surely be considered inferior in any respect to the one in which I am engaged myself, where the numbers are not very much larger, With these oliservations I will leave the matter of the abolition of these distinctions in your hands, confident that, however strong may have been the necessity for them in the past, London is at the present time such a huge network of streets and roads, with very little difference one from the other, that it is absolutely essential that the same rule and the same system should apply to all.

\section{INCREASE OF MAXIMUM.}

In asking for your recommendation that the wages of London men should reach a maximum of $40 \mathrm{~s}$., I do so on the following grounds :-Most of the arguments in favour of an increased increment apply equally to this question, and I beg to advance the following additional reasons, viz:-

(1) That this is the maximum of a 2 nd class sorter; (2) lack of promotion; and (3) heavy strain of work, precluding men from receiving benefit from the Superannuation Act. With regard to the first point, I have already adduced in favour of an increased increment the argument that the work of a 2nd class sorter is practically the same as that of a postman, and as their maximum is $40 \mathrm{~s}$., we reasonably expect the same amount. This statement I may strengthen by mentioning my second point-lack of promotion. Whereas the 2nd class sorter has a superior class to go to after reaching the $40 \mathrm{~s}$., the postman is in a sense stationary when he attains his present maximum. This question will be more fully gone into by mycolleague, Mr. Harris, on promotion, but dealing with the question as it presents itself to us at the present time, we have, with very few exceptions, nothing further to look to than the present maximum. The third point is the heavy work and consequent break-up, both physically and mentally, of the system long before it should be, thereby rendering the Superannuation Act to a large number of men inoperative. More so, as the wages of postmen as so small and so long before what I may term "decent," that it is well-nigh impossible to save anything for the time when the breadwinner is taken away. This we contend should not be. The maximum asked for is not only a fair and reasonable one, but is warranted by the fact of a man being through it enabled, as the years tell upon him, to provide himself with additional comforts, and will thus not only prove an incentive to good for junior men, but a more substantial benefit for the older ones. Another point that should be considered in relation to this question of maximum is that the average weekly wage for the whole 16 years, during which a man is qualifying for his maximum, is only $26 \mathrm{~s}$.

The Chairman: In that do you include any allowance for stripes?

A. No, sir ; they are not wages.

The Chairman: What?

Mr. Walpole: What are they?

A. It is an emolument given by the Treasury for good conduct. You cannot, therefore, call it wages. A man cannot claim a stripe the same as he can claim an increment.

Q. A man of good conduct gets a stripe as a matter of course? 
A. Just so, sir. In regard to the maximum, I would like to mention a statement made by the late P.M.G. in his speech in the motion which resulted in the appointment of this Committee. He states that the maximum wages of sorters before the revision of 1881 were, 1st class 45s. per week, and 2 nd class $25 \mathrm{~s}$. They are now 56s. and $40 \mathrm{~s}$. respectively. Further, the maximum of the postmen of London was 30s. per week, and have sinee been raised $4 \mathrm{~s}$., making $34 \mathrm{~s}$. total; but at the same time as this statement was made in the House of Commons, no mention was made of the fact that Mr. Fawcett, at the time of increasing the maximum by 2 s., took it off the minimum, thereby making the new entrants pay for what was granted
to the senior men.

The Chairman: It hardly paid for it. New entrants would only be kept there a certain time.

A. Just so.

Q. And, therefore, it is not quite a set-off?

A. But it did not prove such a great boon to the postmen as was represented at the time. We contend it was not. During the last 30 years the only increase the postmen have had has been this $4 \mathrm{~s}$., and of that 2s. was granted by Mr. Fawcett, who at the same time took 2s. away.

Q. That is what you call the set-off?

A. Yes. I would also draw your attention to the fact that the difference between the maximum of a 2nd class sorter and a postman before 1881 was $5 \mathrm{~s}$. in favour of the postman, but now the difference is 6s. in favour of the 2nd class sorter, making their increase 15s. to the postman's 4s. It will thus be apparent to all that the claim for equal treatment with other classes on this subject is both right and reasonable.

The Chairman: How do you make the 15s.? I only make it 11s.

A. The pay of a 2 nd class sorter before 1881 was $25 \mathrm{~s}$. maximum, now it is $40 \mathrm{~s}$. The difference represents the $15 \mathrm{~s}$.

The Chairman: Oh, yes; we are striving at exactly the same thing.

A. The 2nd class sorter's increase is 15s., as compared with the postmen's $4 \mathrm{~s}$. I do not treat the postmen as two classes. It amounts to this, that while we have received an increase of $4 \mathrm{~s}$. to our maximum, our increment has not been altered in any shape or form, while in the case of the sorters it has been altered first, from $1 \mathrm{~s}$. to $1 \mathrm{~s}$. $6 \mathrm{~d}$., and then from $1 \mathrm{~s}$. 6d. to $2 \mathrm{~s}$. Ours, I repeat, has not been altered a farthing. Yet they have received the huge addition of $15 \mathrm{~s}$. to their maximum. The wages question, I may say, is the crux of the whole grievance of the London men. They consider that they have been treated unfairly in the past, and that they have seen classes which, in a sense, are junior to them, reaping large benefits, while nine out of every ten postmen in London have to be contented with a maximum of $34 \mathrm{~s}$. a week, and have no hope of anything else. They ask that this state of things should be altered, and that they shall receive equal consideration with other classes for the work they perform.

Mr. Walpole: When you say they have no hope of anything else, have you not left out the hope of promotion to overseerships?

A. I think the figures Mr. Harris will give on the question of promotion to the overseers' class will still further bear out what I have said. In my own office there have been two promotions of postmen as overseers during the last 20 years. There are 150 men before me, so when it will become my turn I cannot make out. (Laughter.)

Sir F. Mowatt: Is there no other promotion of any sort?

A. The other promotions are to lobby officers. But there are none such in the suburban districts. We contend that taking a man from the S.E. District Office and civing him a hear postmanship at New Cross or Blackheath is unfair to tho $\mathrm{Xew}$ Cross and Blackheath men.

The Chairman: Surely the effect of your scheme would be to put all districts on an equality, and thon there would be no question of hardships with regard to transfers?

A. Not at all. Every man would take his turn according to seniority. 
That would be much better than the present system. [Mr. Harris sends me a note that I am not to go into this question. (Laughter.) $\mathrm{He}$ will do that.]

Mr. Walpole: Do you happen to know the maximum pay of police constables in London?

A. $32 \mathrm{~s}$.

Q. That is the maximum pay?

A. Yes.

Q. Their attendances are somewhat similar to your own?

A. Yes, sir; but there are greater incentives to a policeman to make himself efficient than there are in the case of postmen. I was asking a policeman the other day, and he told me their minimum was $24 \%$. and the maximum 32s. But every man has an equal chance of being promoted to the rank of sergeant and inspector. The same system applies to the whole police service.

Q. You think their prospects of promotion are better?

A. Yes, sir. If we received the same incentives I do not think we should object to a minimum vastly different to our own.

Q. I presume the age entrance is different?

A. I think it is very little higher than our own. It is 21.

Q. Very few constables go on at 21 surely?

A. I have seen some I have thought younger than that. I should like to add in regard to the zone system that I might have brought into comparison the case of the police at such places as Sutton and Croydon. They are in the Metropolitan area, and the men there receive the same consideration, as far as pay and everything else is concerned, as those who work at Bow Street or in the Borough.

Mr. Smith: The City police force is, of course, a different force?

A. Yes, sir. In bringing my remarks to a close on the wages question, I trust I have said sufficient to show you the necessity for the same amount of justice, treatment, and equality as those have already received whose responsibilities and work are no heavier or greater than ours. In the questions I have had the honour to lay before you, I am proud to say that I represent the whole of the London postmen-some 5,000 in numberwho are anxiously and expectantly looking forward to a better condition of things, with brighter prospects for all concerned.

The Chairman: Thank you, Mr. Barnes.

Sir F. Mowatt: I should just like to ask exactly what the witness is asking for. I understand it is that the men should enter at $24 \mathrm{~s}$. practically at 19 years of age?

A. Yes.

Q. And rise by annual increments of 2s. a week until they reach a maximum of $40 \mathrm{~s}$.? That would make eight years?

A. Yes.

Q. What stripes could a man earn in that time?

A. One stripe.

Q. A shilling a week for each stripe?

A. Yes.

Q. And, in addition, the emoluments of the office are uniform, pension, and care during sickness?

A. Yes, that embodies our claim. We want a minimum of $24 \mathrm{~s}$. a week, rising by annual increments of $2 \mathrm{~s}$. weekly to $40 \mathrm{~s}$., and with stripes that would give us $43 \mathrm{~s}$. I find the minimum age for the City Police is 19 years and the wages 25s., with a rise of 1s. 6 d. yearly to the maximum.

Mr. Smith: So that they are on a higher scale in the City?

A. Yes, sir. I sincerely hope that although I have not gone so fully into the case as I might have done, the gravity of the wages question will appeal very forcibly to you. The established men of London atre looking forward very anxiously for your decision. 
C. J. WARNER, S.W.D.O.

WAGES-CHRISTMAS Boxks.

Westminster, February 3, 1896.

Mr. C. J. Warner, of the S.W. District Office, was next examined :The Chairman: You are a postman in the S. Western District?

A. That is so, my lord.

Q. How did you come into the Service?

A. I entered on the 20th April, 1876, as a boy-sorter. I was promoted to be second-class letter-carrier on the 18th November, 1878, and further promoted to first-class town postman on the 1st July, 1883.

Q. Then you are at your maximum?

A. That is so, my lord.

Q. You want to speak more especially about Christmas boxes. Will you tell us what you have to say?

A. Before I commence my statement I should like to say I believe that this question is one that has caused a great many other grievances, arising from the fact that it has lowered the status of postmen in the eyes of the Department, and thus caused them to be looked down upon. It is a fact that Christmas boxes have been, and still are looked upon as a source of which the wages of postmen are supplemented, year by year, a view taken both by the postmen and the public, and which is also, I believe, shared by the Department, inasmuch as we can conceive no other reason for the gxeat disparity which exists between the amounts paid respectively to postmen and to other classes in the Postal Service. If this view is correct, as I shall endeavour to prove, then it can easily be understood why postmen should seek to obtain a fixed in preference to an unknown quantity; I say "unknown," because persons who give this year may, and often do, refuse the next. It has been estimated that the postmen receive in Christmas boxes as much as would equal 5s. per week per man. This I shall prove is the amount estimated by the Department, and, we believe, taken into consideration by them in fixing the amount of our wages.

Mr. Smith: Are you referring to a document read by a previous witness?

A. Yes, partly so; but I have some other evidence. The Department have not shut their eyes to the fact that the postman, in addition to his wages, receives annually from the public something which makes his income larger than which he receives from the Department. This is easily proved by the fact that in provincial towns postmen who perform duties other than those of the delivery of letters, receive allowances which are, in some cases, as much as 7s. per week, and which allowances were at one time stated (on the wage sheets) to be in lieu of Christmas boxes; this shows that at least the Christmas boxes are recognised as emoluments. But, whereas the man who rëceives the allowance in lieu gets the benefit of it in superannuation, the one who receives the astual thing does not: I shall now show bot the 
Department recognise and foster the system. The rule sanctioning the practice is as follows :-

"Although you are allowed to receive, and, indeed, respectfully to ask for Christmas boxes, you are not to demand them, and any well-founded complaint of importunity towards the public will be very seriously dealt with. Unless you agree with the other men on the walk as to the division of Christmas boxes, you will be required to furnish the Postmaster with a detailed. statement of the several amounts you have received from each person or firm, and to submit to the decision of the Postmaster as to your share."

Sir F. Mowatt: Are the boxes shared among the men in each district equally?

A. On each walk.

Q. But if one walk produces more than another, is not an average drawn for the whole district?

A. No; only for each walk. The rule continues:-_You are strictly forbidden to solicit gratuities on account of the delivery and collection of parcels." This seems to show that the Department recognise, as it were, that the letter-carriers have certain vested interests, while at the same time they also recognise the evils of the system, inasmuch as they will not allow any extension of it by allowing men who deliver parcels to solicit gratuities. This is obviously unjust, because there is no difference in the status of postmen who deliver letters and parcels respectively, yet men have been punished and rendered liable to dismissal from the Service for doing what other men have done year after year, and are still allowed to do. Of course, we agree that it would not be right to allow the system to be extended; indeed, the general public would not stand it. Still, a man who delivers parcels is supposed to receive as much wages as one who delivers letters, whereas, taking Christmas boxes into consideration, he does not. In connection with this I may quote a statement made by the late Mr. Raikes, when Postmaster-General: "It has appeared both practical and advisable to prevent the extension of it to other classes, and, with this in view, the solicitation of Christmas boxes by Post Office servants, other than lettercarriers, is prohibited at pain of dismissal." I would here point out that the distinction above, i.e., letter-carrier, no longer exists, all being designated postmen, and if I use the word "letter-carrier" again, it will be merely to distinguish between men who deliver letters and those who deliver parcels. In the 5th Report of the Postmaster-General, 1859, appears an appendix headed, "To the London Letter-Carriers," and dated "G.P.O., 29 September, 1858," and signed by the Controller of the Circulation Department, of which the following is an extract:- "The lowest wage of any London letter-carrier (this being obtainable by a youth of 17-often the son of an elder letter-carrier) is 19s. a week, advancing with every year's good service to 23s., while those who are willing and able to become sorters may rise into classes receiving $25 \mathrm{~s}$. to $30 \mathrm{~s}$. a week, from $32 \mathrm{~s}$. to $38 \mathrm{~s}$., and from $40 \mathrm{~s}$. to $50 \mathrm{~s}$. (this is a point I wish most particularly to impress upon the Committee), though some of you appear unwilling to become regular sorters, since that office entails the loss of Christmas boxes (averaging, it is believed, more than $£ 8$ per year, and on some walks exceeding even £20) which are given to letter-carriers." I will quote another extract from a Memorandum Circular, dated 22nd March, 1865:- “They (postmen) receive from the public in gratuities at Christmas a sum, which, if divided and spread over the whole year, would produce, on an average, $5 \mathrm{~s}$. a week for each man." Further, I may state that the Postmaster of one of the largest districts in London has decided that in the case of postmen recently deceased, the surviving relatives are to receive the amount of the share to which those postmen would have been entitled, had they lived. Again, in a footnote to a recent order, restricting leave of absence, it is distinctly stated 
that the restrictions do not apply to leaves of absence granted to postmen for the purpose of collecting Christmas boxes. This is, I think, sufficient to show that the Department have, and still do, recognise the system. I now come to the moral aspect of the question. The postman is the outward and visible sign of the inward and invisible (to the public)-(laughter) -working machinery of the Post Office, an institution of which we as postmen are proud, and justly so, considering the very large share we bear in keeping the machine in perfect working order. I mean by outward and visible sign that the postman is the only one who is known to the public. That is due to the fact of his wearing a uniform, whereas there are other classes in the Post Office of whom the public know nothing. As postmen, and more so as men, we feel that it involves a loss of self-respect and dignity, as uniformed Civil servants, to go annually from door to door, book in hand, "respectfully" begging a gift of money. We also consider that it is not worthy of such a grand civilising agency as the Post Office that this barbarous system should exist. In 1881, the late Mr. Fawcett (then Postmaster-General) said: "I believe that, in the majority of cases, Christmas boxes are not given reluctantly. I certainly think that if they were prohibited the public would still continue to give them. Under these circumstances, I am not prepared to advise their prohibition, but I fully recognise that it would be undesirable for any letter-carrier to solicit Christmas boxes with impunity." I differ from the late Mr. Fawcett when he says "the majority of cases"; it would be more correct to say "some cases." We are deeply sensible of the liberal and generous manner in which a portion of the public respond, and believe that they are sensible of the heavy responsibilities we incur, and are pleased to reward us in that manner; but it is the system of which we complain, as it is obvious that if a man is allowed to ask the well-to-do, the man who delivers in a poor neighbourhood has as much right to increase his wages by this means as the former, and will exercise his right in the same manner. Hence we have the degrading spectacle of uniformed Civil servants going from door to door, flom the large tradesman to the small shopkeeper, from the mechanic's house to the labourer's tenement, "begging," and authorised to do so by the largest revenue-earning Department in the State. Even among the well-to-do we find a growing tendency to revolt against the system, as witness the correspondence in the "Morning Post" and other papers during the past Christmas, but I submit that, whether given freely or grudgingly, or whether refused altogether, the fact that solicitation is authorised and carried out systematically condemns the system on its moral aspect.

The following are the reasons which I adduce for abolition:-1st. That the system of tipping is against the spirit of the age, as can be seen by the number of restaurants, theatres, and other large establishments where gratuities are prohibited, where, formerly, attendants, etc., had to depend largely on tips for their wages, which now are paid by the proprietors. 2nd, That the State should not follow but lead the way. 3rd, That prohibition by the Post Office of gratuities would be the downfall of the entire system-(laughter)-as large corporations, vestries, councils, water companies, etc., would follow the lead given by them, and also prohibit their servants from soliciting Christmas boxes, and thus a great boon would be conferred on the general public. 4th, That the system, "which has no parallel in the Civil Service," is a standing blot on the administration of one of the most important departments of the State, and for this reason alone should be discontinued. 5th, That it is opposed to the best principles of political economy. 6th, That it is unjust to allow one postman to solicit and receive this emolument, and to punish another for seeking to obtain the same. 7th, That it saps the independence of the man and brings the Department into contempt; and, to sum up, it is degrading to the postman, humiliating to the Department, and exasperating to the public.

Sir F. Mowatt: You draw a distinction between the man who gets a 
Christmas box for delivering letters and one who gets it for delivering parcels. Does not the same man deliver both parcels and letters?

A. No, sir; not as a general rule. A letter-carrier is a man who should only deliver letters. But since the institution of the Parcel Post, a number of parcels have been put on to him to help the parcel-man out. That is a question that will be dealt with by a subsequent witness.

The Chairman: There is a separate parcels delivery.

Sir F. Mowatt: I've seen the man who delivers my letters coming up the road laden with parcels. (Laughter.)

Witness : I now come to the last and most important stage of my case, viz. : compensation. I have endeavoured to show the evils of the system, and also reasons why it should be discontinued, but, in asking for the abolition of the system, it should be distinctly understood that the postmen are not prepared to sacrifice the pecuniary benefit derived from it without receiving compensation, as it is easy to see that, without compensation, the postmen could abolish the system by refraining from solicitation. But it would not be in human nature to expect that this should be the case. I will premise that, from long usage, we have certain vested interests, which it is necessary in the public interest that we should forego, and we are in the position of those whose property is required to be taken for a public improvement. (Laughter.) The course always followed in such cases is, I believe, to buy the property owners out. I believe that a large majority of the public are in favour of the abolition of this system, but I am certain that very few would be unfavourable to compensation, and if, as I contend, this would be of benefit to the greater number, then the greater number should pay. The postmen would have asked for the abolition of Christmas boxes years ago, but there has been a fear that they might get them taken away and receive nothing in lieu thereof. I, however, refuse to believe that such an injustice would be perpetrated. Our case is that the Department have, as I have shown, estimated this emolument at $5 \mathrm{~s}$. per week per man, and we are therefore justified in believing that our wages have been fixed as plus this amount; therefore, in asking that this solicitation of Christmas boxes should be prohibited, we ask at the same time that such allowance should be made (by an increase of wages or otherwise) as would compensate us for the loss we should otherwise incur. I respectfully submit that public opinion is ripe for the settlement of this most vexatious question, and that it should be settled on these lines; and, although I would not urge that we have any strictly legal rights in the matter, I do submit that we have very strong moral rights, and that it is not the practice of this mighty and wealthy State to disregard its moral obligations. With these reservations, I confidently leave the Christmas box question in your hands, believing that you will make such recommendations as will do justice alike to the postmen, the community, and also the State.

The Chairman: What would you put the average value of the Christmas boxes at?

A. I put mine at over $5 \mathrm{~s}$. a week.

Q. You do?

A. Yes.

Q. You are in the South-Western District?

A. Yes.

Mr. Walpole: Are you in Zone 1 or 2?

A. I am a town postman.

The Chairman: What guarantee could we have that the public would not continue to give these Christmas boxes, as Mr. Fawcett suggested that they probably would?

A. I am afraid I cannot give a guarantee for the public.

Q. It would be rather hard on the public for it to have to pay twice over? A. It is the system of solicitation that we object to. I do not think 
that many of the public would give Christmas boxes if they knew it was prohibited and if the postmen were receiving an equivalent. They would continue to give, however, if the men received no equivalent.

Q. As to the $5 \mathrm{~s}$.: can it be certain the State would get the advantage by putting an end to the practice?

A. I think the heads of the Department might be trusted to see that that was done.

Sir F. Mowatt: Do railway companies prevent their guards and porters taking tips? (Laughter.) Their case is very similar.

A. I presume that in the event of solicitation being prohibited the Department-that is, the Postmaster-General for the time being, and the Secretary-would see that the order was carried out, and would at once issue a notice prohibiting the practice. After that any man soliciting would be liable to dismissal in the same manner that a parcels delivery man is liable now.

The Chairman: Do you suppose that in many cases in London the amount that a postman gets out of the Christmas boxes is of the value of $5 \mathrm{~s}$. a week?

A. It may be; but that is hardly our case.

Q. It is a part of the case with which $I$, as chairman, have to make myself acquainted.

A. You are taking London as a whole. But there are many men who, from the nature of their duties, never receive the boxes. Men on collecting duty get none. I was seven years before I had any share.

Q. Before you had any share?

A. Yes; but that is gradually being altered.

The Chairman: It seems rather hard that a postman who collects on a particular walk should not receive a share as well as the man who delivers.

A. It is a custom which has obtained among postmen themselves, and to a certain extent it has been sanctioned by the Postmasters.

The Chairman: I thought the Christmas boxes were divided on a plan laid down by the Department.

A. The division is made on each walk separately.

Q. Surely it is strange that a postman collecting on a particular walk should receive no share, simply because he does not happen to deliver letters at the doors?

A. It has been looked forward to as a kind of promotion. A man looks forward to the time when he can increase his maximum in that way. The same system does not obtain in two offices alike. The distribution goes more by the custom of the particular office.

Q. Then they are not divided equally amongst the men on the same walk? On your own walk how many men are there who receive Christmas boxes?

A. Four.

Q. How many men are there on the walk altogether?

A. I can hardly say. There might be from eight to ten. The other compromise the matter by receiving a certain sum from the walk to be divided amongst them at Christmas.

Q. There are eight or ten men on the walk, and of them only four receive a share of the Christmas boxes?

A. They receive the largest share.

Q. Tell us the exact rule on your own walk.

A. The rule has been up to this Christmas-it will be altered nexi Christmas-to divide them among the four senior men.

Q. And they take the whole?

A. No; they have to contribute so much to the assistants' fund. There 
has been a dispute at our office, and the Postmaster has decided that there shall be a different mode of distribution next year.

Sir F. Mowatt: None of the money goes to the parcels men?

A. Not for the letter-carriers. "Ihey are another branch. Most of the parcels men are in depots at separate offices. The system of Christmas boxes was in existence long before the Parcel Post was instituted.

The Chairman: Is your wn personal objection to Christmas boxes founded on the fact that next Christmas you will receive a much smaller share than last Christmas?

A. Not at all.

Q. You will receive a lesser share next Christmas?

A. Yes; but that does not alter the fact that the men have been estimated by the Department to receive an equivalent of $5 \mathrm{~s}$. a week.

Q. I do not care a button about the Department. I want to know what the facts are. If you don't choose to give me the facts I cannot form a sound judgment. I do not want to tali about the Department. I want to know absolute facts as to what occurs in the Service. I press you for them. If you do not choose to tell me the facts, I repeat I cannot form a sound judgment.

A. If the Christmas boxes were put into a heap and divided equally between all the men who wear the postmen's uniform, they would not equal 5 s. a week.

Mr. Walpole: How do you know that?

A. I give it simply as my opinion.

Q. It is a guess. You do not know what the amount really is?

A. No; I do not.

Q. Cannot you possibly tell us what it would average?

A. Not within a very large margin.

Q. Can you give us the amount on your own walk?

A. I do not know the amount this year. We have not yet shared it.

I believe it will be greater than laš year.

The Chairman: What was it last year?

A. I received $\$ 15$ last year.

Q. That is $\$ 60$ among the four of youl. What did the assistants get?

A. Each of the four paid 10s. into the assistants' fund.

Q. Then only $£ 2$ went to the assistants?

A. Yes; but some of the assistants only do one delivery or part a day. That is really not the point. We claim that the Department has estimated the value of the Christmas boxes to each man at $5 \mathrm{~s}$. a week, and that, conseguently, our wages are $5 \mathrm{~s}$. a week less than they would otherwise be. For the purpose of our argument it does not matter what the Christmas bexes really amount to.

The Chairman: But another part of your argument was that, taking the thing as a whole, the system must be given up, and that would involve to the whole of the men a certain loss which the Department ought to make good.

A. Yes, quite so; but we add that whatever a man is paid by the public would only be paid by the public still, although in another way. The men would not then be allowed to go round with books.

Mr. Walpole: I should like to ask the previous witness-Mr. Barnesa question. When you asked for a scale of wages going up to 40 s., did you intend that to include Christmas boxes?

Mr. Barnes (the previous witness): No, sir; I was only dealing with the wages question.

Mr. Walpole: Then let us understand what it is you really want. You want a minimum of $24 \mathrm{~s}$. plus $5 \mathrm{~s}$, or $29 \mathrm{~s}$. in all, rising by annual increments of $2 \mathrm{~s}$. to a maximum of $45 \mathrm{~s}:$ ?

Mr. Barnes: No, sir: 
Mr. Warner (witness): I am authorised to say that if the postman get their whole demand upon the wages question conceded they would be willing to forego the Christmas boxes, provided they received an immediate rise of $2 \mathrm{~s}$.

The Chairman: All round?

Mr. Smith : The existing men?

A. The existing men. I think that the increment of $2 \mathrm{~s}$. would compensate those men who only had it in prospective.

Mr. Smith: What proportion of the whole staff are sharing in the Christmas boxes, taking into account those who are not acting as lettercarriers and those who are parcels postmen?

A. I think in several offices they share equally.

Q. The parcels postmen?

A. Not the parcels postmen.

Q. You cannot answer the question perhaps, but, speaking roughly, what would be the proportion of the whole of the postmen of London who at ary given time would receive nothing?

A. It would be less than one-fifth. I was particularly asked a question as to my own office. That office is an exception to the rule. Among suburban offices and district offices the rule is for every man who delivers letters to take a share.

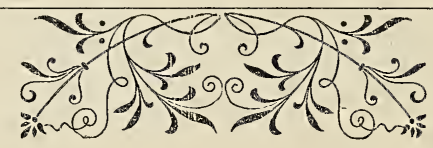


D. S. BOSTON, Kentish Town.

\section{Hours of Duty.}

Westminster, Monday, February 10, 1896.

Mr. D. S. Boston (Kentish Town) gave evidence as follows :-

The Chairman: You are a London postman?

A. I am, my lord. Perhaps, before giving my evidence, I may be allowed to say, in reference to the statement made by Mr. Walsh as to the sorters being too highly paid, and his suggestion that they should be reduced to 45 s., that that is not the opinion of the London postmen. They do not complain of the high rate of wage of any class in the Service : they only complain that the channel is not open to them to rise in the Service.

Q. What is your length of. service?

A. Nineteen years.

Q. Did you enter as an auxiliary?

A. I was four years a messenger from 1872, and became postman in 1876 .

Q. Are you at your maximum?

A. Yes, my lord.

Mr. Walpole: Have you any stripes?

A. Yes, sir ; three.

The Chairman : Are you going to speak entirely on London?

A. Yes, my lord, entirely on London.

Q. Have you a statement?

A. I have.

Q. Then read it, please.

\section{LONG HOURS OF DUTY.}

Witness : In placing before you the long hours of the postmen, I respectfully ask your kind indulgence. I am sure, gentlemen, you will agree with me when I say that they are the mose extraordinary hours that any public body of servants ever worked. In a large portion of London-or, I may say, in a considerable portion of the Postal Service-the duties extend to some fourteen and sixteen hours per day-from 4 and 6 a.m. until 8 and 10 p.m. By working these long hours in the winter a man is deprived of all home comforts, and is almost prevented from any social intercourse with his family. These arduous duties tell so much on the man that in a few years his constitution is, in many cases, completely underminedso much so, that from time to time he feels bodily and physically unfit t) perform his duty, and is thus compelled to see the doctor, and go off ill, so that he may get the rest that is so necessary for all who have to face the bitter weather early and late. In a large number of cases the duties are too much for the men, and result in their being off ill a number of times, which eventually leads to their being certified unfit for further service, 
thus compelling them to take their bonus, which only makes the case worse, as they are deprived of the pension which they might have otherwise enjoyed had their duties been arrangd so that they could have obtained the rest and recreation that nature requires for every man. A postman's duty keeps him employed morning, noon, and night-no time for any little

- pleasure that he sees thousands of his fellow-men enjoying who are in a less responsible position than himself. What is possible for large employers of labour is surely possible for the Post Office-that is, to arrange the work of their employees so that they may be able to enjoy the comforts of home in the winter, and share the enjoyments of the summer evenings in the many open spaces that are now at the service of the working classes, so that they may breathe the pure air that is so necessary for those who are employed all day in the busy and crowded streets of London. To make it clear that these long hours do exist, I will give you a few instances:At the E.C. there are such duties as follows: Attend office 5 a.m., 10.50 a.m., and 5.20 p.m., finishing at 8 p.m., time covered 15 hours. Another duty at same office: 5 a.m. to 7.30 a.m., 2.30 p.m. to 8 p.m., time covered 15 hours. W.D.O. attendance, $G$ class, 4.45 a.m. (4 a.m. Mondays) to 8.30 a.m., 4.45 p.m. to 7 p.m. delivery, finishing 8.30 p.m., time covered $15 \frac{1}{2}$ hours ; $\mathrm{C}$ classs, 5 a.m., 12 noon, 4 p.m., finishing at 6.20 p.m., time covered 13 hours 20 minutes. S.W.D.O., B class, attendance 5 a.m., 12.25 p.m., 4 p.m., finishing 6.20 p.m., time covered 13 hours 20 minutes; C class, 5 a.m., 1.25 p.m., 5 p.m., finishing 7.20 p.m., time covered 14 hours 20 minutes; $G$ class, 4 a.m. to 7 a.m., 4 p.m. to 8.40 p.m., time covered 16 hours 40 minutes. In the N.W. District at Hampstead A class duty G.P. 6.15 a.m., 10.50 a.m., 3.50 p.m., 7.50 p.m., finishing at 10 p.m., time covered $15 \frac{3}{4}$ hours ; B class duty, 6.15 a.m., 11.45 a.m., 3 p.m., 5.30, finishing at 8.15 p.m., time covered 14 hours ; $\mathrm{C}$ class, 6.15 a.m., 11.40 a.m., 1 p.m., 7 p.m., finishing at 10 p.m., time covered $15 \frac{3}{4}$ hours. At Kilburn, B class, 6.25 a.m., 1 p.m.. 6 p.m., 9 p.m., finishing 9.45 p.m., time covered 15 hours 20 minutes ; $C$ class, 6.15 a.m., 11.20 a.m., 3 p.m., 8 p.m., finishing 10 p.m., time covered $15 \frac{3}{4}$ hours. I may say that this is not all. At a number of other offices in London the postmen are at the present time perfoming these long hours. That it is possible to alter this sad state of duties is clearly shown in offices where the revision has been granted.

Mr. Walpole: As a matter of fact, the case of Hampstead is under consideration is it not?

A. Yes; it has been under consideration.

Q. It has grown extremely rapidly?

A. I do not say extremely rapidly.

Q. But, as a matter of fact, it has grown very rapidly?

A. Yes, sir; it did grow so six years ago when a revision was first promised.

Q. Is that your own district?

A. I was there ten years. I know it had grown considerably then, and that in the last six years it has continued to grow, although not so rapidly as previously. I shall give a statement as to why the revision was promised six years ago. It has since been under consideration, and how long it will continue under consideration I am unable to say. It is only those men like myself who can feel the great benefit to be derived from the change of duty. I am pleased to say Kentish Town was granted the revision some two years ago. It can hardly be stated what a benefit it was to the men the new arrangement of their duty, viz., 8 hours in 12. My only regret is that there should be any offices where such long hours still exist. It cannot be urged that the outlay cannot be spared, as each year thousands of pounds are added to the annual millions of profit of the Post Office, and which profit no other class in the Service helps to build up like postmen; 
Mr. Walpole: Do you admit that eight hours is reasonable?

A. Yes, sir.

Q. You have no complaint to make as to the hours?

A. No, not as to hours. In my further statement I shall have to complain of the large number of attendances. As for the 8 hours in 12, the men are very well satisfied; they like the change very much. The fact that we help to build up the profits of the Service only makes our case the more deserving. It may be said that the public, as taxpayers, must be considered. In answer to that,. I can only say I wish the public had to give their opinion. I should be certain then there would be no more long hours for the postmen. The public support, I am sure, we have had for years past, from their various expressions of sympathy for the postmen, who have to wade through the bitter cold and snow and rain of the winter, often getting drenched to the skin, and arriving home late, tired, and footsore, and again facing the same bitter weather in the early morning with aching limbs. In urging our case, we are only asking the Department to carry into effect the mandate of the Postmaster-General in 1890, which mandate I will explain. A deputation which waited upon the PostmasterGeneral (the Right Hon. Cecil Railes) in July, 1890, in reference to the long hours, received from him the following statement: "With regard to the hours over which your attendance is spread, I can tell you frankly, and I do not in the least mind saying it, on that point $I$ am entirely with you. I think it a very great hardship the hours over which your attendance is spread should be anything like 16 hours. I will use my best endeavours to bring the 8 hours within the 12." I can only say, gentlemen, that the best endeavours of the Department have been very bad indeed. Six years have passed away, and many are still awaiting anxiously for the promise to be carried out. I can only hope that the time is near at hand when this cruel injustice will be done away with, I trust for ever. Things are certainly not looking any the brighter, for we have recent instances which go to show an even longer extension of hours than 16-the midnight staff dutties. Some are as follows: - South Kensington, midnight collection, 2 p.m. collection, 3 p.m. delivery, 7,8 , and 9 p.m. collections, five men employed. I can even illustrate worse cases: Kilburn, N.W., midnight collection, commencing 11 p.m., 10.30 a.m. collection, 4 p.m. delivery, 6 o'clock bye bag, 8 p.m. collection. You will see by that that the man is employed all night. When he gets his rest I am unable to say. The midnight commences at 11 p.m., and then he is on duty again at 10.30 a.m.

Mr. Walpole: When does the 11 p.m. collection finish?

A. I should say about 1.10 a.m. I take it that the man would have to go to Cricklewood or Child's Hill. The despatch from Kilburn is, I think, at 1.10 or 1.15 . Then he has the $10.30 \mathrm{a} . \mathrm{m}$. collection, the $4 \mathrm{p} . \mathrm{m}$. delivery, the 6 o'clock bye bag, and the 8 p.m. collection. He has not very long in hand before he commences again. Here is another case-S.W.D.O., midnight collection, 12 midnight till 4 a.m., 4.45 till 3 p.m., time covered 20 hours; 12 midnight till 4 a.m., 6 p.m. till 9 p.m.; 12 midnight till 4 a.m., 7 p.m. till 9.45 p.m. You will see that the man is at work all night. It is not quite so bad as the last case, but still, according to all reason, when he works at night he should not be called upon to work in the day.

Mr. Walpole: He is off at 4 in the morning till 4 or 5 in the afternoon?

A. Admittedly, sir.

Mr. Walpole: If you count the duties from 4.45 in the afternoon they spread over $11 \frac{1}{2}$ hours.

A. Yes, sir; but the Department does not count in that way: it counts from midnight.

Sir F. Mowatt: His work per day is within 12 hours.

A. Yes, sir; in the night it would be within 12 hours. 
Q. There is a break?

A. Yes; but our contention is that these things could be arranged better, and all we want is that they shall be so arranged.

Mr. Walpole: The man has from 4 in the morning till 6 at night, and on another duty, as you show, it is from 4 a.m. to 7 p.m. that he is off. That gives an interval of 14 hours in one case and 15 in the other.

A. Yes; but there are two duties, and I an showing that they could be better arranged. One man does his time right off. He works at night, and has his rest in the day. These things, I say, are badly arranged, and it is possible to arrange them better. 'The duties I have quoted apply also to other districts, and clearly show that both day and night are broken into. So where the rest for these men comes in I am unable to say. It must be clear to your minds, gentlemen, that this system of long hours is thoroughly bad. If Dr. Wilson condemned the system of split duties, his opinion upon this question is beyond a doubt. Before I conclude this question I wish to make it perfectly clear that what is asked for is that the 8 hours of the postmen may be worked within the 12. I can, I am sure, now leave this question in your hands, and only hope that you will be able to see your way clear to advise the immediate change of these long hours, and thus throw light and happiness into the homes and lives of the postmen.

\section{NUMBER OF ATTENDANCES.}

The next grievance of the postmen that I have to bring before you is the large number of attendances that the men have to make to complete their day's work. In a number of instances they have to attend as many as five times, and there are instances of six and seven times. As to the last mentioned I will explain, as I have no wish to mislead you on that point. I wish to qualify the statement by saying that they are separate attendances in this way-each attendance is ticked off, although some of the duties follow on each other. Still it is possible for a postman to sign six or seven times a day for being late. It renders him liable, therefore, to excessive punisbment for coming on late. At Churton Street, S.W.-

Mr. Walpole: Churton Street does not exist now, does it?

A. Yes; it is in conjunction with S.W. At Churton Street, S.W., there is a duty which is made up as follows : -8.40 a.m. collection, 10.40 a.m., 11.40 a.m., 1.40 p.m., 2.40 p.m., 3.40 p.m., and 6 p.m.

Mr. Walpole: How long does the collection take?

A. Just under an hour.

Q. And are these all collections?

A. Yes, sir.

Q. But surely Churton Street does not exist any longer, does it?

A. It is still in existence.

Q. At the South-Western Office? Are you sure of it?

A. Yes, sir.

Q. How long does the 1.40 duty take?

A. I should say three-quarters of an hour.

Q. Then practically the 1.40 and 3.40 duties would be continurus duty, and the interval would be allowed as part of the man's working time?

A. Yes, sir.

Q. Do you see any hardship in bringing him on thus, seeing that the interval of rest is allowed for as part of his working hours, and he is paid for it?

A. Yes, sir ; it makes seven attendances in a day.

Q. But if the Department pays for the whole time from 1.40 to 3.40 it practically is one attendance?

The Chairman: the point is that at each of the hours named he can be fined for late attendance. He can have seven fines a day.

Mr. Walpole: If he is paid for attendance at the office there can be no question of his coming on late. 
Sir F. Mowatt: You have given us seven attendances, and you say that they are practically three-quarters of an hour each?

A. Yes, sir.

Q. That makes the duty a little over six hours?

A. Yes; but then-

Mr. Walpole: Where the interval is under a half-hour or approaching it it is paid for as part of a man's duty, is it not?

A. I have explained in the early part that I wished to qualify the statement.

Sir F. Mowatt: Then you complain not of the fatiguing number of attendances, but of the signing of the book?

A. It malkes him compete very unfairly with other men, as he has the possibility of signing the late book seven times a day, and therefore he is liable to excessive punishment.

Mr. Smith: Have you known excessive punishment coming from that?

A. Yes; it is looked upon as a very serious offence in the eyes of the Department to be late in attendance. It prevents a man getting his rise or stripes.

Q. But in this particular case in which you divide what appears to us to be a continuous duty into seven parts, and call them seven attendances, you say the point is that on each the man can be fined for being late. But his whole time is at the service of the Department. During the period he can wait at the office in the intervals, and therefore it is difficult to see where the opportunity of being late comes in.

The Chairman: It would be considered four attendances in the eyes of the Department?

A. Yes, my lord. But the man is not obliged to remain at the office. If he has 20 minutes' interval he may go away and then he runs the risk of being late.

Mr. Walpole: Yes?

A. He will be supposed to return at a given time, and, as a previous witness has shown, men are called upon to sign the late book for two minutes.

Q. Do you really mean to say that this man goes on duty at 1.40 , again at 2.40, and again at 3.40, although the Department pays for the whole of his time, from 1.40 to 3.40 ? That being so, is there any grievance whatever in saying that the whole time being paid for the man should be considered on duty?

A. I am not saying that. What I am pointing out is that this man can sign the late book seven times. He has to make seven separate attendances. He has to be in the office seven separate times, and may have to sign the late book each time. That added up in the course of the year is a very serious thing.

Sir F. Mowatt: But that is the price he pays for availing himself of the intervals between the collections, for which time he is paid by the Department?

A. He does not want it. He does not look at it in that way.

Q. But it is the way in which I look at it. This man is really paid for his attendance from 10.40 to 3.40 .

A. But he goes out -

Q. He may if he likes. Although he is paid for the time he can get away?

A. Yes, sir.

Q. And when he avails himself of the opportunity of going away, although his time is paid for, you talk of it as a hardship that he should have to sign the book when he comes back.

A. Quite right. But it is all very well to say that the Department pays for the intervals. But the man has to go to his collection every time; he has to make a journey that occupies a certain amount of time, and sometimes by the time he finishes one collection it is time to start on the next. 
Q. If he has no time on his hands then it is continuous duty, is it not? Then he would not have to re-sign: that is only done when he has time on his hands and goes away?

A. That is the point. A man has to sign for every separate collection, and he may have to sign the late book if he is only two or three minutes late.

Q. But he would not be late unless he took the time himself. You say there is more than time enough for delivery between each collection.

A. There is time enough, I take it, between. But various causes of delay occur. Lots of things happen which are not expected by the Department, such as difference of time by the clocks. Perhaps a man may be kept a minute or two at a receiver's office. All these may contribute to late attendance, and I say that in such a case as that with which we are dealing a man would be very heavily handicapped as compared with a man who has to put in fewer attendances. I wish to make this as seven separate attendances only in the sense I have explained, viz., that there are seven separate possibilities for the postman to sign the late book; the same would apply to the six times in a great number of cases. The above fact is alone sufficient to show that there is just reason why the attendance should be considerably less. Four attendances seem to be the recognised fair number by the Department, but the postmen think differently. The attendances are in most cases made up of collections, which often means walking a mile and over each time to commence his collection, thus compelling him to start some 15 or 20 minutes before his actual duty commences. It will be readily seen that this means a man working an hour over his time every day. The injustice of this cannot be denied. And in fairness, I ask that these number of attendances be reduced to two or, at the most, three attendances per day. These attendances are a very serious thing for the postmen in many ways. He often gets wet through, and is compelled to remain in his wet clothing because there is not time to go home to change, and in a number of cases he is obliged to get some of his meals out of doors, or put to the expense of riding to and fro, which makes inroads into his already insufficient wage. No better support can be given to this grievance than the statement of Dr. Wilson, who condemned the system of repeated attendances as injurious in every sense to the constitutions of the strongest men. What it must mean to the weakest can readily be imagined. What is asked for by the postmen is that the attendances shall not be more than two. In speaking of split duties, the Medical Officer of the Department condemned them in the strongest terms; what, then, must be the strain upon men who have to make three, four, and five attendances a day, and who have all kinds of weather to contend with in performing their duties? In asking that two attendances shall be the limit, I may say that this question is a burning one in a large number of offices throughout London, where the men are anxiously looking forward to these two attendances being carried into effect, and that these attendances be within the 12 hours. I may add that at the second largest office in London, viz., W.D.O., a scheme was. submitted by the men embracing an entire two-attendance duty, but I regret to say nothing has been heard of it from the Department, now eight months past. There are offices enjoying this privilege, and there can be no just reason why the whole of Iondon should not have the same. Gentlemen, I now leave this in your hands, feeling sure your decision in this matter will be in favour of less attendances than are in force at the present time.

Mr. Walpole: A previous witness compared postmen's duties with those of policemen. You know the latter have two duties?

A. Yes; but I do not think this is a very fair comparison for postmen.

Sir F. Mowatt: A postman has not to fight for his life three times a week?

A. No, sir; but he has to figl'; for health, because he is on both early 
duty and late duty; he may get drenched through, he gets home late, and this is repeated day after day.

Sir F. Mowatt: A constable has also to do that. A postman is not very often hit on the head with a brick. (Iuaughter.)

A. No, sir; I am very glad to say he is not. The last witness, in speaking on the question of leave, did not speak on behalf of London; he did not understand our system. The allowance off duty is always left in the hands of the overseers of the various offices, and they have been in the habit of giving the leave if they thought the men really wanted to be let off, but now the Department has laid down a very stringent rule that a man'shall not be absent from duty more than three times in one month, although the absence may refer to only one collection in the day. I have known men in my offece get off their first duty in the morning simply in order that they might secure an extra hour in bed.

Mr. Walpole: Is not the rule this, that a man shall not be off duty more than three times in one month without showing good cause for his desire to be off duty. Have you not left out those words?

A. I think the rule reads "without special application to the Postmaster."

Q. But the overseer has the power without reference to the Postmaster to let the man off not more than three times in a month. Do you not think that power is very liberal?

A. It may be liberal to a certain extent, and it has not been encroached upon. The men look upon the rule as an unfair interference. During the winter months they like to get an additional rest.

Q. Do you know of any case where an application of that kind was unfairly refused?

A. No, sir ; I do not.

The Chairman: The last witness asked that the Department should lay down strict rules by which the Postmaster should be guided in regard to this question. It appears that in London the Department have laid down a rule, and you object to it. Yor think that this is a matter which should be left entirely to the overseer's discretion?

A. Yes, sir; the men are placed entirely in the hands of the overseers, and $I$ have never heard of a case in which advantage lias been taken unfairly. During the winter months the men ought to get the benefit of additional rest, and I have not the least doubt that when the duties are better it will not be thought so much of. There can be no objection to leave the matter in the hands of the overseers.

Q. But is not the present rule infinitely fairer? Was it not a fact that under the old rule some of the overseers dealt laxly with these cases, and others were much more strict?

A. No, sir, not within my knowledge; and, even if such a state of things existed, it should be remembered that the overseers are in the hands of the Department just the same as the men.

\section{HEAVY WINTER WORK.}

This is the next question that I have to place before you. I want to point out the great difference of the work in the winter, it being very much heavier, while the late arrivals of the carts and trains, caused by the severe weather, snow, fog, etc., is the means of the postmen getting out on their deliveries later. That, taken with the very bad and slippery conditions of the roads, pavements, and steps, is often the cause of the men working one and two hours over their time every day. Although this is clearly shown in books kept for that purpose, the men are told they will get nothing for protracted duties, meaning, in other words, "We know you work over your time, but we will not pay you for it." I think that a previous witness supported that view; I believe you asked him the question. The reason for bringing this matter forward is this-that the Department have thought fit to bring in a strong order that nothing shall be allowed for protracted 
duties. We contend that is very unfair. Some few years ago the men received payment for protracted duty in consequence of the very severe weather-when a very heavy fall of snow lasted longer than usual-but the Department have since thought the practice of that year was a mistake, and I am sorry to say they went so far as to send notices this Christmas stating that no allowances would be given for the New Year's protracted duties, the Depar'ment knowing well that it is impossible for the men to finish their deliveries in anything like their proper time. The excuse that is offered by the Department is that the expenses must be cut down; but, gentlemen, is it honest, is it just, that knowing these men are compelled to work hours over their time, yet refuse to pay them?

The Chairman : Are not extra men put on at these times?

A. They have been put on until this year, but not this year. But even when it has been done in previous years, overtime has had to be worked. Perhaps it will be said that the men have been paid, so I had better tell you some men were paid: the postmen received 6d. for the night delivery on New Year's Eve, and 6d. for New Year's Morning General Post. This was the only allowance made. It can clearly be shown that men worked two and three hours over their time, and only received 6d. for it; and when speaking about it, they are told they will receive nothing for the overtime done. I have here a few instances of where payment of the $6 \mathrm{~d}$. in question was made, and where nothing was granted for the overtime done, as stated before as being clearly shown in the book. I will take the case of my own office, and I can show that this applied to the whole of the N.W. District, and, I think with two exceptions, to the District Office itself. Whether it applied to other districts I am unable to say. This statement shows that the men worked from one to three hours and received nothing for it, while others worked the same number of hours and received 6d. for it. This applies to the established class as well as to the auxiliaries. 'The auxiliary class work in the morning two hours' overtime on the first post, and received 6d. for it, that being less by $6 \mathrm{~d}$. than the sum they should have received. This applies to the whole class in the N.W. District of London. Whether other districts sufiered in the same way I am not in a position to say. but I am inclined to think they did, or if not, this system is the beginning of a most unfair and unjust system that they have in their minds to adopt in the future. I don't know what your opinion may be on this subject, gentlemen, but I myself cannot think that the Postmaster-General wishes that the men shall do the excess of the work which he knows must be done in heavy seasons like the New Year, and receive nothing for it; that surely cannot be the way in which the Postmaster-General intends the expenses to be cut down. In concluding, gentlemen, the question of the heavy winter work-I would only ask you to kindly look fully into this question, more especially the New Year's system of paying the postmen. The men are looking anxiously forward to get the payment they are entitled to, and I wish respectfully to impress on your minds that all the postmen ask for is that they be paid for the work they honestly perform over these eight hours. I may also add that it goes to show that the duties of a postman should be estimated under eight hours in order to allow for the expansion caused by some of these circumstances. I think, my lord, I heard a question put to the last witness to the effect that if these men had applied for overtime would they not have been paid for it? Now, I can show that in this particular case the claim was made out for these men and sent to the Postmaster, but that it came back with the amount scratched out, and $6 \mathrm{~d}$. substituted for from one to three hours' overtime. I think that does away with the idea that the Department do pay when overtime pay is applied for.

Mr. Walpole: But they were paid 6d.?

A. Yes; for from one to three hours' work. The men are entitled to considerably more than that. I cannot understand why the Department only paid $6 \mathrm{~d}$. It is quite a new idea to me. 
Q. I presume the reason was the Department does not pay ordinary overtime to postmen. It is the usual rule only to pay for excessive overtime. As one witness said, if the Department undertook to pay overtime to postmen it is feared that that would encourage dawdling?

A. That does not apply to ordinary overtime.

Q. No, not ordinary, but for excessive-such as Christmas Day, is it not usual to pay for that?

A. No, sir.

Q. But on this occasion 6d. was allowed for an exceptionally heavy delivery?

A. Only $6 \mathrm{~d}$. was allowed for the last delivery at night, and $6 \mathrm{~d}$. for the delivery in the morning, and on each occasion the time sheets showed that these men worked from one to three hours' overtime. As a fact, the first postmen did not finish till 10.15 or 10.30 , instead of 8.30 . The established men, if they had been paid pro rata with their wages, should have received considerably more for overtime, but they did not get it.

The Chairman: At what rate do you claim they should be paid?

A. In many cases it would rank from 6d. to 9d. Under Mr. Raikes's scheme a rule was laid down that the men should be paid pro rata $\rightarrow$ so much an hour according to their rate of wages. Previously to that, a fixed sum was laid down, and it was not allowed to be exceeded. Since the rule came out, the practice has been as far as possible to put the junior men on overtime, so that the benefit seldom reaches the senior men, and the Department pays less now than it used to.

\section{CIRCULARS.}

The next question that I have to place before you is that of the circulars. The last few years the circulars have become a very great grievance to the postmen, as they are compelled to take them out with their ordinary work, instead of being sent out specially. This entails a large amount of extra work for the postmen, as when a large number of circulars come to the office they are worked out with the deliveries. 'The result of this system is that the postmen have to take them to work out on two and three deliveries a day, thus compelling them to work over their time each delivery, and, in addition, delaying the public's important correspondence throughout the day, and also delaying the circulars as well-sometimes until the next day. Each time a man takes out circulars on his delivery it makes lim later. If a large number of circulars came in this afternoon to be worked off, they would not be all delivered at once, but some would be left over for to-morrow. That may be a considerable saving to the Department, but it is a considerable loss to the postman.

The Chairman : Why?

A. Because he has to do it for nothing, instead of getting a special delivery. It is asked that, as this is a special work apart from letters, they be sent out as such, or, if the postmen be compelled to take them out, they may do them after they have done their ordinary work, and be paid for them. It may be said that some specials are sent out, but, gentlemen, I assure you since the great question of cutting down expenses has been before the officials, a special is a very rare occurrence. Large firms when they have a rush of work pay their workmen for the overtime done; it is only just and fair that the Post Office should do the same. As an instance to show that this is looked upon as extra work, I may tell you that when a postman is tested on his delivery he is not allowed to take out circulars. Again, if a postman raises the question he is working over eight hours, the Department test him, and should it happen that there are circulars on that special delivery, he is not allowed to take them out.

Mr. Walpole: You mean heavy circulars. He would take out the ordinary amount, but not large trade circulars?

A. Not large trade circulars such as "Warner's Safe Cure" or "Mother Siegel's." He would not be allowed to take them out if he were going 
to be tested. Therefore the Department must look upon it in the light of extra work, and we ask to be paid for it as such. This clearly shows that the Department consider it extra work apart from the ordinary; that being so, I hope, gentlemen, you will sce your way clear to advise payment on special delivery for the same, at the pro rata rate of wage; and not for the cutting down rate that is now paid to the postmen in those instances where a special delivery is done. I might qualify my statement by saying there have been instances where established postmen took these out specially and only got a shilling for it. A special delivery constitutes two hours, and perhaps the wages of the postman would amount to 1s. 4d. or 1s. 6d., but he would be told he would only get a shilling for this special delivery, and, rather than take the circulars out for nothing with his ordinary deliveries, he would accept the shilling.

The Chairman: Is it not rather difficult to draw a sharp dividing line as to what is a circular and what is not?

A. Not in the ordinary sense. We do not suggest that every circular coming from various sources should be dealt with in this manner. The men take them out in the ordinary way; but when we have large batches of circulars come in from firms like Jones and Crisp, of Holloway; Marshall and Snelgrove, Peter Robinson, "Warner's Safe Cure," and "Mother Siegel's," we contend that they are sufficient for special delivery, and should be treated accordingly. To pass them through the ordinary delivery inflicts a great hardship on the men, especially as most of them are sent in during the winter time. In the winter months there is a large rush of circulars from drapers and fancy stationers, especially in the three weeks or month before Christmas. The men are asked to take these out on their ordinary deliveries, and, if they are compelled to do so, it causes a great deal of friction with the overseers. The Department says that a man may be compelled to take out 60 circulars with any delivery. Of course the men grumble if they have to do that when they know that there are sufficient circulars for a special delivery. It is a serious grievance in every way, especially when these circulars are mixed up with the letters for the delivery. The letters are apt to get in between the circulars, and the men have to do all the sorting of the circulars, no matter how many there may be. They are then divided into batches, and the delivery is spread over perhaps for a week. All this entails a lot of extra work on the part of the postmen.

Sir F. Mowatt: But sometimes a man gets a shilling for taking them out?

A. Yes; but only sometimes.

Q. Is that according to any fixed rule?

A. No; I do not think it is according to any fixed rule. At one time when a batch of circulars came in the overseer would specially engage a number of men to take the whole lot ont at once, and thus clear them off.

The Chairman: The postmen would do that in addition to their ordinary work then?

A. Yes. Supposing a man finished his ordinary delivery by 4 o'clock, the overseer would tell him to take these circulars out, and would add, "I shall only allow you a shilling for it." The man would do them after he had done his ordinary work. He would tie them up in bundles, and deliver after he had finished delivering his letters. He would have to start back again to deliver the circulars. The object would be not to delay the ordinary delivery.

The Chairman: You, mean that he takes them out, and, after the delivery of the ordinary letters, he works back again?

A. Yes, sir; if the bag is not too cumbersome. The men would rather $\mathrm{do}$ this for a shilling than get nothing for it; but they contend that it is not enough, and that, according to the rule laid down by the Department. they ought to receive an allowance pro rata with their wages for the time occupied in their delivery, more especially as some men are getting full pay for overtime. 
H. M. WILSON, Hampstead S.O.

Iondon Auxitiaries' Case.

Wrstumsiner, Monday, February 10, 1896.

Henry Mark Wilson next gave evidence as follows :-

The Chairman : You are an auxiliary postman at Hampstead, I believe?

A. Well, I am in rather a transition stage just at present. I joined the Service 17 years ago as an auxiliary, and last year, in July, I received my appointment to the established class, and commenced with an initial wage of $24 \mathrm{~s}$. a week in consideration of the services $I$ had rendered. Of course, I am serving two years' probation at the present time, in the same way as a lad would who is just coming into the Service.

Q. You had been 16 years an auxiliary before you were appointed?

A. $16 \frac{1}{2}$ years.

Q. At what rate were you paid as an auxiliary?

A. At different rates at different times. I was receiving as an auxiliary, at the time I was appointed on the staff, 28s. 6d. a week, with a week's holiday during the year, and boot allowance. That was because I was doing full time as an auxiliary. That arrangement came into force under Mr. Raikes's scheme; he made a provision to the effect that where an auxiliary was doing full-time duty he should receive a week's holiday during the year without loss of pay, and, in addition, boot allowance.

Q. What was the boot allowance?

A. A guinea a year.

Q. Then you absolutely lost by going on as an established postman in regard to your present rate of pay?

A. Practically speaking, at the present time I am losing 4s. 6d. a week.

Q. But then you have the prospect of a rise, as well as pension, and all that sort of thing?

A. Just so; but I may say that the complaint always put forward on the part of an auxiliary postmen is that the time they serve in that capacity is not acknowledged by the Department. Therefore, if it had involved an even greater loss of pay, I could not consistently have refused my appointment to the establishment when it practically complied with my own request.

Q. Did you have uniform as an auxiliary?

A. Yes, sir.

Mr. Walpole: How many hours a day did you work as an auxiliary?

A. My duties were to start with the $3 \mathrm{a.m}$. collection, and then $\bar{I}$ had a continuous duty until I finished the General Post duty at 8.30 o'clock. Then I had the 10 minutes to 10 collection, which lasted until a quarter to 11 ; and finally $I$ had the last delivery at night, which occupied me from 8 till 10.

The Chairman: At what time did you start again?

A. With the three o'clock collection in the morning.

Mr. Walpole: And then you were on from 3 till 8.30 ?

A. Yes, sir.

Q. And again from 9.50 till 10.45 ?

A. Yes, sir; practically an hour, 
Q. And then again on the 8 p.m. delivery until 10 at night?

A. Yes, sir.

Q. You were working about $8 \frac{1}{2}$ hours a day?

A. Just about that, sir. I did not get so much for that duty until Mr. Raikes's revision came in, and under that I got $3 \mathrm{~s}$. a week addition.

Q. How long were you doing that duty?

A. I can hardly say how long, but it would be eight or nine years.

The Chairman : Are you doing that duty now?

A. No; they have taken off the last delivery.

Q. Then you are doing from 3 to 8.30 , and from 9.50 to 10.45 ; is that your duty?

A. Yes; and I go right on as a rule.

Mr. Walpole: 'Then you have only $6 \frac{1}{2}$ hours' duty?

A. Yes; but you must take into consideration it is night work.

The Chairman: You practically have a continued duty from 3 to 10.45 ?

A. I do not complain of my duty; I am highly satisfied with it. I wish every man had the same. I do not complain about my duty in the least now. Of course, having been an auxiliary for so many years, the auxiliaries of London have placed their case in my hands, and I am fighting for them now.

Mr. Walpole: With regard to the interval between 8.30 and 9.50 : the Department pays for that time, does it not?

A. Yes; it just gives me time for breakfast.

Q. But the Department pays for it?

A. Yes; according to the rate they are paying me now.

Q. When you were first appointed auxiliary, did you do any work outside the Departmental work?

A. Yes; when I was first appointed I only had a 12s. 6d. duty. I did the quarter to 1 collection for that (that was in the middle of the day), then I also did the 4 p.m. and 8 p.m. deliveries.

Q. What are you besides?

A. I am an engraver by trade.

Q. Are jou still an engraver?

A. Yes; when I can get it to do, which is very seldom. My trade is a luxury, and luxuries are things which always suffer first and foremost. It is only wealthy people who can afford to have engraving done. I have had to suffer in that way during the time I was an auxiliary-I found the trade going off. I have done a great deal of work for Hampstead Vestry, and that is how I filled up my spare tims in order to get a decent living.

The Chairman: Proceed with your statement, please.

Witness: I wish to submit the case of the London auxiliary postmen. First, I will deal with its importance. In approaching the auxiliary question, we feel that it is one of the utmost importance both to the Department and to the employees, as it is the sphere from which many charges of sweating are brought against the Department; therefore, we feel compelled to emphasise the principle enunciated in our "National Petition "- That the terms of service of this deserving class are not creditable to any Government, and we are convinced that to do them anything like justice they should immediately be added to the established force at an initial wage according to their length of service." In confirmation of that statement perhaps I may be allowed to read an extract from the current number of "Truth," as I should like to show that a similar feeling to that existing in the Department is, if we take "Truth" as an exponent of public opinion(laughter) -also existent among the public:- "The position of these auxiliary men, both in town and rural districts, is a disgrace to the Department. large numbers of them have to spend the best part of their lives at their present work, and have grown old in the public service, yet the very telegraph boys who are taken on in the manner above described, will, in a 

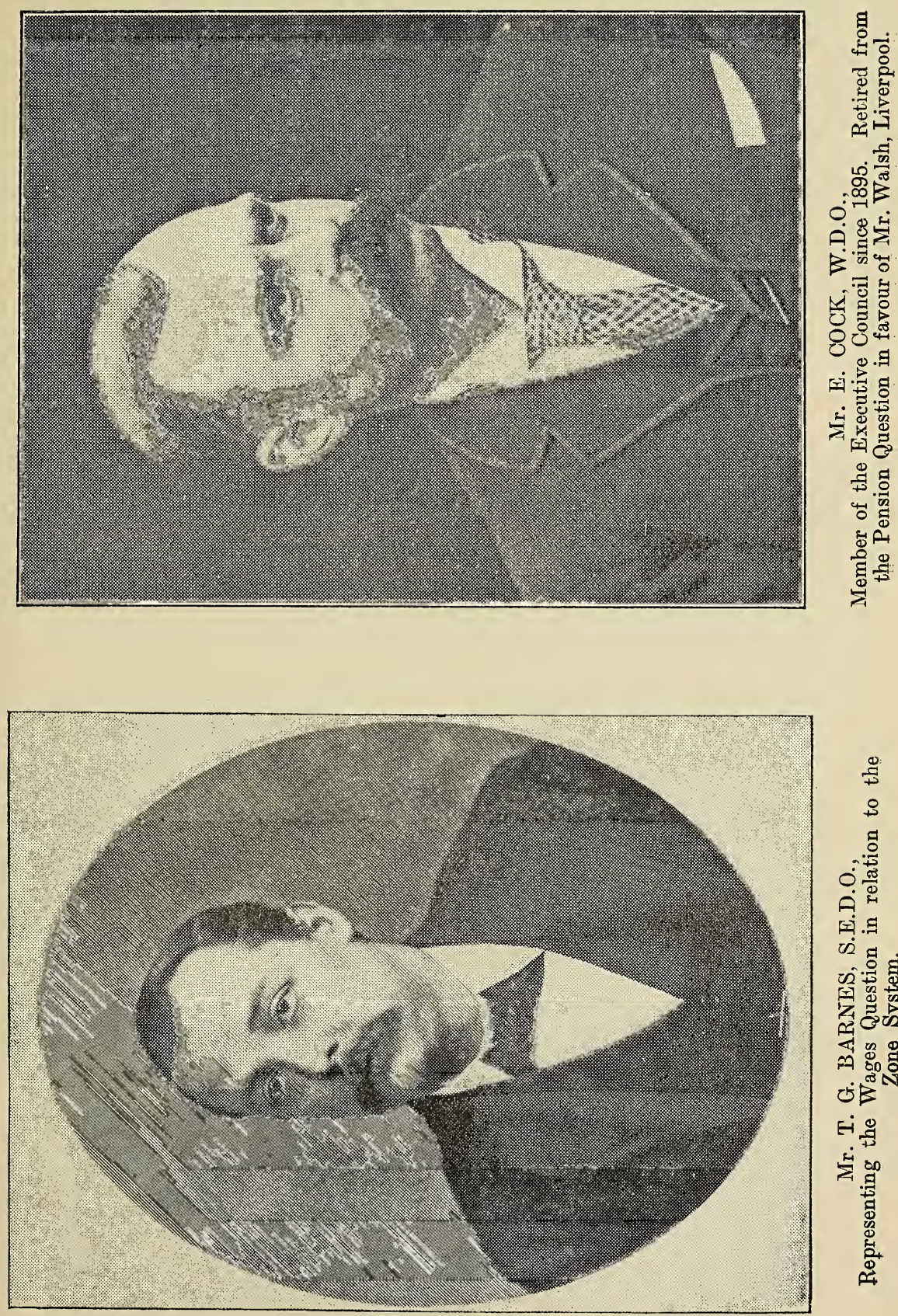

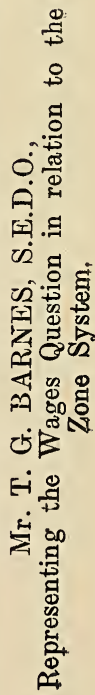



very short time, pass over the heads of the auxiliary men who are now engaged in teaching them. It may be right to classify men according to the age at which they join the Service, but to first lay down an age for joining, and then to take on at an older age large numbers of men who are prematurely excluded from obtaining a footing on the established service is as unjust as it is stupid."

Mr. Walpole: Many of these auxiliaries are men like yourself, engaged in other trades, are they not?

- A. Granted, sir.

Q. And do not wish to be taken on as established men?

A. Yes, sir; they do.

Q. You think there is a great competition among men engaged in other work to take service under the Department?

A. I must qualify that. I will deal with that in its proper course.

Q. But is it not a fact tha.t these men are engaged in other trades?

A. Yes; where they are able to get the work to do.

Q. But is it not the rule that they must be able to?

A. It is the rule, and I wish to emphasise this very emphatically. I shall show later on how very unjustly the men are dealt with by the Department on that head. The Postmaster-General (the late Right Hon. H. C. Raikes) in his reply to our "National Petition," and also in answer to questions on the subject in the House of Commons, said that he much preferred, where the circumstances admitted of it, that men should be employed who, giving their whole time to the Service, are borne upon the establishment, and received the established rate of wages and consequent advantages; but with the most scrupulous care in adjusting the work, some duties would always remain which could not by themselves, or in combination with others, be constituted whole-time duties. While readily admitting that the Postmaster-General was expressing his candid opinion on this point, and with every desire to carry it into effect, we submit this theory is not carried into practice to the extent that it could be, and that the proportion of auxiliaries in comparison to the established class is not governed so much by the difficulty of arranging full-time duties for them as by the fact that auxiliary lahour is cheaper and more advantageous to the Department on the seore of economy, as the saving effected in comparison to an established force (in the shape of pension, sick pay, holidays, etc.) is very considerable. I have chosen Hampstead simply because I can speak from personal experience. It is the office I lave been at all the time I have been in the Service. In proof of this contention, at one of the largest residential suburbs of London-viz., Hampstead-the staff there consists of 112 men, only 39 (or one-third) of whom belong to the established class, the remaining two-thirds being auxiliaries, a clear proof that no attempt is here made to carry the Postmaster-General's asserted preference into force, as it must readily be admitted that ample scope is afforded for a considerable proportion of these men to be supplied with full-time duties, and this is continued in spite of the protests of the staff and the promise, extending nearly two vears backward, that the duties should be revised. This system is more or less prevalent tilroughout London. I have here a list of the duties, which I shall be very pleased to hand in. It will show how at Hampstead the duties have been extended, and what occurs at Hampstead takes place at many other offices as well. I shall have to refer to these in the course of my statement, and I would like here, if I may be allowed to do so, to introduce another point. The last witness was asked whether it was not a fact that Hampstead was under a revision. I believe it is a fact, but unfortunately the revision has been pending six or seven years, and it seems to be no nearer reaching the climax than at the first start. That is why we take this point so very strong. A promise has been made over and over again that if the men asked to have their duties revised, it should be done. But when these applications are made the reply always is 
that the revision is pending, and, I repeat, it is still pending, and is no nearer fruition as yet. While readily admitting there is considerable diffculty in the total abolition of the auxiliary class, we cannot allow that it is impossible, because in important centres like the E.C. in London, at Liverpool, and Newcastle, there are no auxiliary postmen employed, therefore what is possible in such important commercial localities as the abovementioned is also possible elsewhere.

\section{TERMS OF SERVICE NOT UNDERSTOOD.}

Another statement of the late Right Hon. H. C. Raikes, in reply to a petition from the London auxiliary postmen, in August, 1887, was-" That the applications for employment under existing conditions are exceedingly numerous." This statement we must respectfully protest against, for, as a matter of fact, the existing terms are not made clearly understandable to the applicants, and this fact is most tterly complained about, more especially by the army reserve men, to whom the Postal Service has been recently thrown open, who contend they are inveigled into the Service under a false impression. I am informed, my lord. with regard to the army reserve men, they all contend that the conditions are not explicitly laid down, and that the offer to them to come into the Post Office, made to them while they are still in the army, has not been explicitly carried out. They thought they would be put on the established class. It is implied in a certain way. They are given to understand that they are going into a Government Department, and that, by good conduct and merit, they will be enabled to rise in the same way as they can in the army. I may also quote my own case in proof of the statement that the terms are not very clearly understandable. I was educated at the Duke of York's Military School, at Chelsea, and when I produced my testimonial from that school to Mr. Oakshott, the superintendent of the N.W. District at that time, he made the remark, "You are quite aware what discipline is?" I replied "Yes, I am thoroughly aware." Then he said, "You know it will be the same here as where you have come from, and where you have been educated: by merit, ability, and general good conduct you will be able to get along." I was three months in the Service before $\bar{I}$ actually knew that I was at a stagnant wage. I found it out by reading the Rule Book. I happened to make a remark to one man, "When does the time for a rise of salary date from?" Ho replied, "You will never get a rise so long as you are here."

Mr. Walpole : But when you were appointed an auxiliary, did you not sign a form?

A. I signed several papers.

Q. Do not all auxiliaries sign forms setting forth the conditions of employment?

A. I have no recollection of signing one.

Q. Are you aware that auxiliaries now have to sign them?

A. I believe there is a form that has to be signed.

Q. Do you know what the form is? Does it not state that "I am fully aware I have been appointed at such-and-such wages, and that no advantage or payment other than those wages attaches to the appointment; that my services may be discontinued at any moment, and that when they are discontinued, whether after a long or a short period, I have no claim for the payment of compensation, gratuity, or pension. I fully understand the character of these terms, and annex my name thereto." Is it possible to make terms and conditions more intelligible than that?

A. I admit that that is rather more explicit than what I was told when I entered the Service. I had no such paper.

Q. You say we do not put fairly before the men the conditions of the employment. Now, could they be put more fairly? 
A. If the men are allowed to read that paper in the first place, before they sign, it is explicit.

Q. And they sign it?

A. Well, there are a number of rules and regulations in the Service which are laid down, but which are not always carried into effect. We are desirous that the Postal Service should be put upon all fours with the other public services as regards the position of these men-that is, in the army, navy, or police.

\section{ASSIMILATION TO OTHER PUBLIC SERVICES.}

When a recruit enters either of the above services, he enters upon the same conditions as every other man in the same service, and knows that by merit, ability, and good conduct the higher grades are open to him, and not as the condition of those men who enter the Postal Service as auxiliaries, who are almost in a condition of stagnation as regards promotion to any higher rank; in fact, in numerous cases, men after 20 to 28 years' faithful and meritorious service are in a far worse financial position than they were upon their entry into the Service, and there have been instances where these men have been turned off without any provision whatever, for no other offence but old age (not decrepitude); and it has been only by appealing to a generous public that they have been saved from ending their days in the workhouse - a state of things not at all creditable to a Governmental Department. In confirmation of this statement, sir, I may say that a man at my own office, whose name was Joseph Noyes (he has been dead now for nearly 18 months) was thus dismissed, after having been an auxiliary, I believe, for about 25 years. During the greater part of that long auxiliary duty he had to perform what are termed A class duties at Belsize Park. which walk is one of the most aristocratic and important in Hampstead Parish. He had to do the A duties, which are, as a rule, allocated to established men. He was responsible for charges, etc., and after taking on his shoulders that duty, he did the General Post delivery in the morning from 6.30 to 8.30 , and then he did the 2.40 collection in the afternoon. Next he took out the 4 o'clock delivery, which lasted until after 6 o'clock, as Belsize Park is a very heavy walk. Then he had the 8 o'clock delivery at night, which lasted until after 10 , and in many instances until 11 . I have myself worked on it many times until 11. All this man received for these important duties during all these years was $14 \mathrm{~s}$. $6 \mathrm{~d}$. a week.

Mr. Walpole: Do you say he did this until a year and a half ago?

A. No, sir; he died about a year and a half ago. His wages were reduced when a revision took place at Hampstead, and some of the duties were taken off. He was given the first delivery in the morning and the last at night, and his wages fell to 12s. This was a fair rate of pay for the duty, but the point is that, after many years' service this man got into a worse financial condition than when he first entered.

Mr. Walpole: This is not an existing grievance. Do you now know any case in which an auxiliary working such a number of hours is paid anything like so small a wage as $14 \mathrm{~s}$. 6d.?

A. I think I could give evidence of some cases. I have them tabulated here, and I shall be able to produce them presently when I speak on the rate of wages.

Q. London cases?

A. Yes; and when this man reached his sixtieth year-the limit at which a man is considered capable of doing delivery duty-he had to leave, and there would have been nothing for him if it had not been for a subscription got up by the inhabitants of Hampstead, who raised something like $£ 200$, which lasted just exactly until his death, Had it not been for 
that he would have had to go into the workhouse after having given 25 years' faithful service to the Government.

Q. What do you mean by having to leave?

A. He was told he must resign his position as auxiliary because he was 60 years of age.

Q. Who told him that?

A. The order was given to him at Hampstead that he must resign his position. Another man who had been an established postman, but then performed auxiliary duty in order to make up the small amount of pension he got to something like a living wage, was told the same thing. They were both 60 years of age, and both had to resign solely on account of their ags being 60 , and not because they were incapable of doing the work. The men did their work, and no complaint was made against them.

Mr. Walpole: I cannot understand $i^{2}$

A. It is a fact, I assure you. I do not wish to mislead the Committee.

Q. What was the name of the second man?

A. The name of the second man, who was a pensioned postman, was Whickers. Both men are dead now. Both have died since.

Q. How long ago did this hannen?

A. Not more than three years ago.

Sir F. Mowatt: Was Noyes not put on half-time when he got to be 6i) years old?

A. No, sir ; he was discharged.

Q. Then when was he put on shorter time?

A. That was when the revision took place a few years previously.

Mr. Walpole: I think Whickers was not very efficient at that time, was he?

A. Well, he was gettirg on that way, but he contended that he was copable of doing a small duty.

Q. He was a pensioned man and past work?

A. He had a very small pension.

Q. But was he not past work?

A. I should not like to say for certain. He did his work.

Q. Were not some people very high in the Post Office interested in him, so that he had every chance of his case being thoroughly considered?

A. I believe he had considerable interest among the high officials in the Post Office. I am not quoting his case as a hardship, but only as showing that the man did have to leave at 60 years of age. It fortifies Noyes' case. I will call attention to the case of another man-Burridge-in the N.W.D. Office. That man has done 29 vears as an auxiliary postman, and before the revision took place in the N.W.D. Office, three or four years ago-I would not like to say for certain the number of years-he was having altogether 22s. 6d. a week, but when the revision came about his duties were reduced. and he is only taking 15s. 6d. now. That is the reward he has got for 29 years' good and faithful service.

The Chairman: He is doing less duty, is he not?

A. Yes; but lis age is too great to tempt him to find other employment. This man was made use of by the N.W.D. Office for everv duty it was possible for a postman to do. He was competent to do any duty that could bə placed upon him in the office. He could be put on any walk at a moment's notice, and he would do it just as thoroughly as the man permanently on it. That man's services could be utilised at any time. He was called on to do sick duty or anything of that sort: when there was a pressure in the office they always turned to him, and he always gave great satisfaction, and he put his time at the disposal of the Department. Many auxiliaries find it better to thus make themselves serviceable to the Department, and consequently give up other work. Therefore they have to rely on the Department. When they are getting well on in vears it is impossible for a nan tro save anything on such wages as are paid. 
The Chairman: What is his age now?

A. Not quite 60 . He is getting close on it.

Q. Had he any trade?

A. I believe he was a bootmaker. I am not quite positive as to that, but I am certxin he had some other calling; what it was I cannot possibly say.

Mr. Smith: As a mattrr of fact, has he not gone back to his trade since his duties were reduced?

A. He has not been able to.

Q. Does he, as a matter of fact. live on his reduced pay?

A. As far as he possibly can. He says he is only existing.

Q. I am not asking whether lie lives well or not; but has he to live on that pay?

A. Yes; that is a positive fact. I am not quite certain whether he entered under the age at which it is possible to get on the establishment. I have two or three other cases here. There is that of a man named Bristow, of Kentish Town. He has done 24 years' service, and he was 19 when he entered it. When the Kentish Town revision took place some time ag $\mathrm{J}$ his wages were reduced from $£ 16 \mathrm{~s} .6 \mathrm{~d}$. to $15 \mathrm{~s}$. Here is a man entirely eligible to go on the establishment. He was only 19 when he entered the Service, and has been in it 24 years, and after all that time his wages are reduced. It cannot be said it is dune on account of old age or inability to do the work.

Mr. Walpole: What is his name?

A. Bristow, of Kentish Town.

Mr. Smith: Is it a comon practice for an auxiliary to drop other employment and practically give continuous service to the Department?

A. Where a man sees a fair opportunity to be of use to the Department it is a custom prevalent in all offices in London to do so.

Mr. Smith: It is a risky thing to do.

A. At the same time you must take this fact into consideration, that although these men are supposed to have other employment, practically speaking it is difficult to get it, as the competition is so great.

Q. Then how do they get on?

A. Well, some who have no fixed trade pick up an additional revenue in the way of window-cleaning; but this is a very precarious thing. They have to hunt it up, and if a duty crops up in the office-if there is a vacancy for a certain time and a certainty of pay-they prefer to take it. What we are complaining about is that these older men who have been so many years in the Service are treated in the way I have described.

Mr. Smith: I see the point of your complaint. What I want to know is whether it is possible that a man drops entirely out of his original trade and becomes solely dependent on the Department?

A. If you will kindly reserve that question till a little later on I will deal with that point.

Mr. Walpole: Do you happen to know if Bristow would have taken a place on the establishment if it had been offered to him?

A. Not at the initial wage of 18 s.

Q. He would prefer auxiliary duty at 15 . to established duty at $18 \mathrm{~s}$. ?

A. Certainly; because if he takes an appointment on the staff at 18s. the Department would require the whole of his time.

Mr. Walpole: I am only asking the question.

Witness : He is quite willing to take an appointment on the establishment if the Department will take into recognition his number of years' service, and give him an initial wage somewhat in accordance with it.

Sir F. Mowatt: Do I understand you to say that this man has been unable to get anything to do since?

A. No, sir; I did not say he was unable to get anything to do, but 
that he does not know where to look for anything. On account of the age he has reached, he thinks it would be impracticable for him to seek employment in any other way.

Q. Still he would rather have $15 \mathrm{~s}$. than $18 \mathrm{~s} . ?$

A. No, sir; you are mixing two men up. The man who would rather have 15s. as an auxiliary than 18s. as an established postman is Bristow. Burridge is the man who thinks he is too old to get other employment.

Sir F. Mowatt: Well, either you or I have been mixing the two men up. (Laughter.)

Witness: I might say the same in my own case. I have been offered an appointment on the staff 10 or 12 times of my period of service, but I could not take it on the terms of 18s. a week. I am a married man with a family dependent upon me, and I certainly could not take it upon myself to give up the whole time at my disposal to the Department for 18s. It would be utterly impossible to keep a wife an. family on that and remain an honest man. I take it that making such an offer at all to a man with a wife and family is nothing more nor less than putting a premium on dishoresty. A man must live, and he will not see his wife and children starve. I think it is an unfair position in which to put a man after he has done a number of years' service, for the Department to ask to be allowed to avail itself of the whole of a man's time for the small sum of 18s. a week. I may point out very emphatically that the Department itself admits that these men are not paid a wage sufficient to keep them above temptation, because it will not allow an auxiliary to do the 7 p.m. collection in London, during which he has to call at the receivers' or branch offices to receive the remittances for the day for transmission to the Accountant Receiver-General. The Department will not allow an auxiliary to go on that duty at all, if the collection has to be made at a receiver's or branch affice. If this is done for any other cause than to keep the men out of tenystation because their wages are insufficient, why cannot they do this riuty as well as the established postmen, especially bearing in mind the fact that he has on his deliveries to deal with valuable registered matter? This property is entrusted to him just in the same way as it is to the established postmen. I have another case here-that of a man name.. Johnson, in the same office. $\mathrm{He}$ had done 15 years previously to the same revision, and his wages were reduced from $£ 15 \mathrm{~s}$. 6d. to 15s. Then there is the case of a man named Lewis, which is peculiar, and of another man named Beeby, who has had two or three years' more service than Bristow. This man was allowed to retain his full-time duty after the revision, receiving $£ 1$ s. a week wages, boot allowance, and a week's holiday. The other men want to know why they cannot be treated in the same way. Why should the privilege be given to one man more than to another? If the Department could work a duty of that description in one instance with very little trouble it might do it in other cases. Surely we are deserving of it after giving all these years' service. That is a point I wish to bring strongly before your lordship; but it is a difficult matter to bring out unless I have the particulars of individual cases substantiated.

At this point the Committee adjourned until Thursday, Feb. 13, the witness not having concluded his evidence.

Westminster, Thursday, February 13th.

The Inter-Departmental Committee on Post Office Establishments held its twenty-eighth meeting at Westminster on 'Thursday, February 13th, there being present the Right Hon. Lord 'Tweedmouth (chairman), Sir Francis Mowatt, K.C.B., Spencer Walpole, Esq., Llewellyn Smith, Esq., Si: Arthur Godley, and Robert Bruce, Esq. (secretary). 
Henry Mark Wilson was re-called and further examined :-

Sir F. Mowatt (who temporarily occupied the chair): Will you please continue your statement from where you left off at our last meeting?

A. I had got as far as the case of the dismissal of a man at 60 years of age, and where it was only by appealing to the public that he was saved from going to the workhouse.

Q. I think you were dealing with the terms of service not being made explicit?

A. I had gone a little beyond that.

Q. The next question is stagnation of promotion.

A. That is the point now, sir.

Q. I don't want unduly to compress your evidence, but please recollect that six days were to conclude the evidence of the postmen; we have already had three days, and we have not got quite so far through as we had hoped. I don't want to stop you saying anything you think necessary, but will you kindly bear this in mind?

A. I will not say anything unnecessary, but I hope you will not compress me on this auxiliary system, because I think that is the most disgraceful point in the whole of the Postal Service. I would like, if I might be allowed to do so, to make a remark with regard to a document which Mr. Walpole produced here upon my former evidence as to the terms of service not being made explicit to these men. The army reserve men in particular bitterly complained that they have been beguiled into the Service on something like false pretences, and Mr. Walpole produced a document which I urderstood him to say exch man is called on to sign when engaged, explaining the terms of the Service. At my office at Hampstead, we have rather an undue proportion of these reserve men. I have made a personal application to each of these men, and each one emphatically denies ever receiving such a paper or signing it on his engagement. They say they never saw such a paper until five months ago, when a paper was sent round to them and they had to sign it; but there was nothing of the kind on their entering the Service. One man goes so far as to say that he not only had no paper of explanation, but that he was led to understand that lie came into the Service as an auxiliary at 15s. per week, and that at the end of 12 months he would receive an estabiished appointment. 'That man is stili in the Service.

The Chairman: Did he say who he received that promise from?

A. He received it, he says, both at the barracks and at the District Office -at the North-Western District Office-where he made his application for employment as an auxiliary. Of course, I told ...m distinctly that I should bring this evidence before the Committee here this morning, and that if he was not prepared to stand by it he should not make the statement.

Mr. Walpole: I will look into the facts.

Witness: The next point to deal with is the remedy. We would suggest, as a remedy for this state of things, that as vacancies occur upon the established class the preference should be given to men serving as auxiliaries before any other person, and that their initial wage should be in proportion to their term of auxiliary service; for instance, if an auxiliary has served three years, he should commence three increments in advance of a new entrant into the Service. In asking for this, we are simply asking for a privilege to be restored to this class which they were in possession of 31 years ago, for we find by an Official Circular, issued on March 22nd, 1866, it was there officially laid down, "There should be three classes of postmen, viz., first class, second class, and a supplementary class at a fixed wage of 18s. per week, and that all vacancies in the higher grades should be reeruited from the ranks of the supplementary class, or, as they are now known, auxiliaries; and we would further point out that this method would meet Dr. Wilson's suggestion of raising the age of entry to the minimum that he advocates, as in most instances those men are above 25 
years of age, and have given practical proof of their ability to stand the wear and tear of the work of the Department.

Mr. Walpole: What would you do with the telegraph messenger boys?

A. I would introduce the old class of boy sorters that was in existence some years ago, so that they would be gaining their instruction, and if the boys are kept on to the age advocated-that is, up to 19-they might take turn and turn. I don't consider that even, a telegraph messenger, provided he has only a year or two's service, has a right to be put on the establishment before an auxiliary who has sometimes 15 or 16 years' service. Let them take turn and turn about. If the telegraph boy has senicrity of service over the auxiliary let him be put on the establishment first, but let the auxiliary have some sort of chance according to his period of service, so that when a vacancy occurs, if his conduct has been satisfactory, he shall be put on the establishment, instead of being left as he often is at present, without any hope.

The Chairman (Lord Tweedmouth): Do I understand that no auxiliaries are appointed as postmen?

A. Oh, yes ; there are some appointed, but the cases are very few and far between indeed, in comparison with the number of men taken on the establishment. I can give you instances of men who have done 28 or 29 , or even 30 years' service, and, so far as their wages are concerned, they are in a far worse position now than when they first entered the Service.

Mr. Walpole: I suppose tliese are men who have some other employment?

A. You may naturally presume that, because all auxiliaries are supposed to have some other employment.

Q. Many of them would not wish to be put on the establishment?

A. Many of them would.

Q. Not the whole of them?

A. I think the majority of them would be only too glad to accept an appointment if th:y were started at a fair initial wage; but, of course, an adult who his a wife and family dependent on $\mathrm{him}$ does not feel inclined to take an appointment at $18 \mathrm{~s}$. a week, where the Department would occupy the whole of their time, and lie does not eare, under such conditions, to give up such supplementary employment as he may have.

Mr. Llewellyn Smitlı: Will you explain whether the remedy you now suggest is only a temporary one as a means of absorbing the present auxiliaries, or is a permanent proposal?

A. I merely suggest it so far as the existing force is concerned; my contention is that there should be no auxiliaries at all.

Q. You are not making a proposal for the future, but simply suggesting a method of absorbing the present staff?

A. Just so, sir. I have combated the suggestion that it is necessary that men should be employed as auxiliaries at all, and we contend that as in E.C., London, and Liverpool, and Newcastle, there are no auxiliaries employed, it should be possible to do without them elsewhere. My suggestion was in view of the fact that a certain number of auxiliaries are in existence at the present time, and should be absorbed in the permanent staff. I mean to show-and I hope I will be able to expound my idea in the matter clearly to you-that we are of opinion that there is no necessity for an auxiliary class at all. The late Postmaster-General (the Right Hon. Arnold Morley), in his defence of the employment of auxiliary labour, further stated:- "These men are employed not for full day, but only part of a day, and the Post Office does not profess to give them a full week's wages. The wages they receive are in the nature of piece-work, and the question for the Postmaster-General's consideration is, not what sum in any particular ease this payment amounts to in a week. but whether it is a fair rate per hour, and sufficient to command the services required." This opens up the question apart from that of their absorption into that of the established force, whether these men are paid at a fair. rate of wage for the services 
rendered. Allowing that owing to the accumulated pressure of work on the first and last deliveries, it is necessary to employ a certain proportion of auxiliary labour, we submit that even then they are not fairly dealt with, as, although the late Right Hon. H. Cecil Raikes laid down the rule that no man should be employed at less than sixpence an hour, in numerous instances they are paid much less.

Mr. Llewellyn Smith: In London?

A. Yes; I am speaking for London. I will give you a case in point at Hackney Office in the Eastern District. It is the case of a man who does the General Post delivery-by which we mean the first delivery in the morring; then he has a collection at 10 a.m., and at 11 a.m., and another collection at 1 p.m., for which he gets $14 \mathrm{~s}$. $6 \mathrm{~d}$. per week-that is, $6 \mathrm{~d}$. per week less than he should have at the auxiliary rate of wages laid down by Mr. Raikes.

Mr. Walpole: Can you give us the hours he works?

A. He does the General Post delivery, as I have said, which, taking the official time laid down, is supposed to last two hours. Then he does the 10 o'clock a.m. collection, which, I presume, would take an hour, with a similar time for the later collections at 11 o'clock and 1. o'clock.

Q. You presume they take an hour?

A. Mr. Raikes laid down the dictum that no delivery was to be paid for at less than 1s., which would represent two hours, and no collection at less than 6d., which would represent one hour's duration. I go upon these lines.

Q. You mean that he ought to have 15s. a week instead of 14s. 6d.?

A. Quite so, sir.

Q. Can you give me the name of that man?

A. B. J. Berry, a man of longer years' service than myself. I have done 17 years, and $I$ think he has done three or four years more. The next case I would like to mention is that of a man named Jones. He does the General Post delivery, the 10 o'clock collection, the 11 o'clock collection, an.l the 1 o'clock collection, but he only gets $14 \mathrm{~s}$. a week, so that he is a shilling short.

Q. You assume that the General Post delivery takes two hours?

A. I don't assume it; I take it as a Departmental rule.

Q. Quite so; you are quite right. Jones only gets $14 \mathrm{~s}$. a week?

A. Another man, Hill, does the same duties, and gets $14 \mathrm{~s}$. $6 \mathrm{~d}$. a week

Q. Do you know whether they have drawn attention to their case?

A. Repeatedly.

Mr. Llewellyn Smith : Do you know what the reply was?

A. The reply was that that was all they would get.

Mr. Walpole : By-whom was the reply given?

A. By the overseer at the Hackney Office.

The Chairman: I understand these men are all of the Hackney Office?

A. Yes ; I am giving instances from that office. There is another case of a man named Baulsen.

Q. Same office?

A. Yes. He does the 10 o'clock collection and the 11 o'clock collection; from 6.40 to 7.15 he does the late-fee collection, axd then the 8 p.m. delivery, for which he gets 14s. 6d. per week, whereas, according to the Raikes' scheme, he should be receiving 16s. He does three collections and one delivery.

Mr. Walpole: Should he not get 15s.?

A. I think, according to the official times laid down, he should get 16s., but he gets 1s. 6d. less.

Q. That seems to be a similar case to Berry's-three collections and one delivery?

A. Yes; but $I$ think the late-fee collection extends a little longer. 
Q Have these men appealed from the overseer to the Postmaster ?

A. Yes; they appealed to the Postmaster, and in the first place sent their appeal through the overseer, and the answer was that they cannot receive any more money than they are receiving at the present time.

Q. Do you know when that appeal was made?

A. There have been repeated appeals made. I know that for a fact, because this man Berry came to see me personally, and I produced to him the official statement of Mr. Raikes, showing the money he should receive. I believe Mr. Churchfield can bear me out that Mr. Berry went also to him, and that he gave him an official copy of Mr. Raikes' scheme as laid down for Londen, and he produced that before his superintending officer, but still he only gets $14 \mathrm{~s}$. $6 \mathrm{~d}$. a week, or $6 \mathrm{~d}$. less than the scale. I might also mer.tion the case of a man named A. A. Smith, who does the 11 o'clock collection in the morning; then he does station duty from 12.45 to 1.45 . I carnot inform you exactly what he does in that duty.

$\mathrm{Q}$ Is this still Hackney?

A. Yes; and the same man does duty from 5.20 to 6.15 every other week.

Q. Is that station duty?

A. I don't know, but that is on alternate weeks. Then he does parcel collection from 7.30 every evening until probably 9.30, and for that duty he gets 13s. 6d., whereas he should get 15s.

Q. For all these duties?

A. Yes. Another man at the same office, A. W. Allen, does the 11 a.m. collection, the 1 o'clock collection, and is on duty from 7.30 to 9.45 , dealing with parcels, and he gets $12 \mathrm{~s}$. a week, which is $1 \mathrm{~s}$. 6d. less than the official rate as laid down by Mr. Raikes. I am not sure whether the 11 a.m. duty that I have mentioned is a collection or delivery, but at all events he has a duty at that hour. I do not know whether it is necessary to go into all these cases, but there are four men at the same office who actually get $2 \mathrm{~s}$. 6d. per week less than the offieial rate.

Q. Why have these men not appealed to the Controller? Because men ars. so far as I know, not very diffident about appealing to hesdquarters.

A. That depends upon who the man is. I should not be diffident myself, but many men are; and not only that, but you may not be aware that where a man inakes himself importunate with the superintending officers who have sole control in his particular office, that makes matters very unpieasant for him-that is, if he is too persistent. I know this case has been pit forwari two or three times through the proper official channels. The Department lays down a rule that a man must only make application through his immediate superior, and this man has done so, and the result of his application-or rather of their applications-was nil. If these men go and apply in any other way than through their superiors, they are asked why they have departed from the official course laid down for their guidance. Tlerefore there is not much encouragement for a man to go further after he has received an answer from his immediate superior purporting to come frem the liead of the Dopartment.

Q. You know the superior is bount to sond on to his next superior officer any appeal against his own decision?

A. Dacidedly we know that; bit experience has taught us that it is absolutely useless. We find by experience that the immeriate superior officer's dictum becomes law. It is like ruming your head against a brick wall to go against that, and the chances against it are very small.

Q. At any rate these cases s'all be looked into now.

A. Thank you, sir.

Q. I don't understand you to object to the Raikes' scale if it was carried out?

A. If it was carried out in its entirety I think the suxilip ries would be 
content with it, but that does not put aside our objection to their always remaining auxiliaries.

Q. I was talking about the scale.

A. Yes. Again, when they enter the Service they have to make a declaration that they have other employment, but, in many cases, their duties are so extended over the day that it is impossible for them to follow any other employment; and where it suits the convenience of the Department, the other employment of these men, which the Department insists at other times upon them being in possession of, is on these occasions utterly ignored and thrust upon one side. Again, to meet the increase of work in growing districts, isolated duties are created and given to these men, until such time as it becomes necessary, owing to the congested nature of the increased work in the district, to re-arrange the whole of the duties at their office, which is accomplished without any consideration for them, notwithstanding the fact that to meet the exigencies of the Service they have arranged their other employment (or in many cases given it up altogether) to do these duties, and then they are deprived of them altogether and given any duty at any part of the day which the Department in its wisdom (or crassness) think proper to allocate to them, thus making them suffer a double pecuniary loss by depriving them of the remuneration they were receiving for the duty of which they are deprived, and by dislocating their spare time, so that they very often lose their other occupation through inability to adapt the time at their disposal to it. This same injustice applies also to such offices as have season duties, bringing these men on duty at any time of the day while the pressure lasts, and then depriving them of the said duties when it falls off. Now, sir, I would like to give you soma evidence on that point, because I do not wish to put forward a bald assertion without being able to support it. I would like to point out here that not only do the auxiliaries have to sign that they are in possession of other employment when they take office under the Department as auxiliaries, but every year a form is sent up to them, and this is a copy of the form:- "I do hereby declare that I have other means of subsistence than those derived from my employment as auxiliary postman, namely (here a blank is left for the employment), and that my total earnings from private sources and official wages are not less than 18s. per week." Now, if any auxiliary postman should at any time be without other means of subsistence than those derived from his employment as an auxiliary postman, he must report the circumstance to the Postmaster of the office which he attends. Now, sir, I contend that that document is a great inducement to men to make false declarations, because through some unforeseen circumstance over which a man may have no control, he may just happen to be deprived for a short time of outside employment exactly when that document is placed in his hands.

Sir F. Mowatt: Once a year, is it?

A. Yes.

Q. At a fixed time of the year?

A. Much about the same time in the year. I don't know that there is any fixed date. Supposing a man were to go and report, as the official document required, to his immediately superior officer, that he has no other employment but the auxiliary postmanship, he would naturally suppose, as it has always been understood through the Service, that he would on that account be displaced from his position as an auxiliary postman. I would put it to the Committee that this is rather a hard strain on a man, to require him to make a declaration informing his superior officer of the fact that he has only but half a loaf, with the expectation that when he makes that statement he will be deprived even of that half loaf; that is a very false position to put a man in, and a very hard line of conduct altogether on the part of a Government Department like the Post Office. You see the man is 
naturally tempted to hide such a fact if he is without additional employ. ment, in case he should get discharged from his position as an auxiliary, and thus be deprived of anything at all. When a man in such a position has a wife and family depending on him at home, it is not much use talking to him about moral obligations, especially if he fancies that those depending on him are likely to be deprived of food and sustenance. Altogether that is a point I wish to bring very strongly before the Committee, because it is a great hardship of the auxiliaries, and doubtless puts some men to the absolute necessity of telling falsehoods.

Mr. Walpole: I see your point, and extremely sympathise with it. On the other hand, don't you think it would be very undesirable for the Department to be employing a large number of men at a very low scale of wages without seeking some assurance that they would have the means of subsistence?

A. I do think it would be very undesirable, but where these men have been several years in the service of the Department, and the Department is thoroughly conversant with their efficiency and honesty, I think this is a very unfair imposition to place upon them. The officials know that these men are thoroughly honest, straightforward men, who have always done their duty to the Department, and we think they ought not to be handicapped in the way I have described.

Mr. Llewellyn Smith: I know your position is that these auxiliaries ought to be abolished, but, supposing the class to be detained, do you see any other way in which the Department could satisfy itself that the men had some other sources of income? Have you any suggestion to make on that point?

A. Yes; I would like to point out to you the inconsistency of the Department in sending such a notice to be signed by these men whilst the postal authorities themselves have given the men such work to do extending over the day that it is in many cases an utter impossibility for the man to have other employment.

Q. Do the postal authorities force these duties on the auxiliaries.

A. No ; but I put it to the Committee as men of commercial experience and knowledge whether a man having a regular job which brings him in so much per week, and having also more precarious employment, would not be likely to give up the more precarious employment if necessary rather than sacrifice the more permanent work?

Q. You mean that there is a continual inducement to the men to depend on the Post Office and drop their outside work?

A. Yes. Here is the case of a man at my own office at Hampstead, a man named Frederick Davey, and the duty he does is as follows:-6.15 a.m. to 8.30 a.m., General P.ost delivery; then he does a collection at 2.40, and one at 4.20 ; then he is occupied from 4.40 to 5.30 carrying bags, after which he has the $8 \mathrm{p} . \mathrm{m}$. delivery, lasting till $10 \mathrm{p} . \mathrm{m}$. I would like to ask you, gentlemen, where the spare time is that that man has to devote to other employment, and where is the employer of labour who would employ him at such dislocated times?

Q. We know that there are some casual and occasional means of earning a little money at some employment or other.

A. That is what he has to depend upon.

Q. That is what they do depend upon, I suppose, a good deal?

A. Yes.

Sir F. Mowatt: Am I right in taking it that the interval between 4.20 and 4.40 , being under 30 minutes, is all paid for with the time work; that is is he paid for the whole time from 2.40 to 5.30 ?

A. I think not. But at the present this is not a question so much of these men's wages. I will admit that at Hampstead we receive the Raikes' scale, and we are on the whole satisfied as to the rates of pay that the auxiliaries 
get, but I wish rather to draw your attention to the inconsistency of the Department in insisting that these men shall have other employment, and expecting them to make a declaration to that effect, when the officials know that the duties are often such as to leave t:e men little or no time to attend to any other employment.

Q. Do you know what the man Davey gets?

A. Yes; $£ 1$ 0s. 9d.

Q. Then that in itself enables him to sign without any hesitation the statement that his earnings exceed 18s.?

A. Yes; but I presume you would not consider that enough to keep a man and his wife and two or three children?

Q. I am only speaking in reference to your complaint as to these men signing whether they have got more than $18 \mathrm{~s}$. per week.

A. I am not speaking so much about the wage as that he has very little time to attend to any other employment, which the Department nevertheless insists upon him having.

Q. When he was engaged?

A. Yes; when he came into the Service.

The Chairman: They only require to be satisfied that he should have $18 \mathrm{~s}$. a week?

Sir F. Mowatt: Do you know of any case of a man dismissed because, having 18s. or less as an atixiliary, he had no other outside employment?

A. I cannot say that I have a knowledge of such cases.

Mr. Walpole : As a matter of fact, he would not be dismissed?

A. I should hardly think so.

The Chairman: Are auxiliaries frequently dismissed through not having extra outside employment?

A. They never give the Department an opportunity of dismissing them on that ground, for they are always careful of liaving some extra work; they have always got something or other-a.t least I presume so.

Mr. Walpole: What is this man's trade?

A. He has got no trade; he was a manservant, and he fills up what spare time he can get by cleaning windows, besides keeping a sweet-stuff shop.

Q. He would have some time in the morning for cleaning windows?

A. He is done about 8.30 ; but by the time he gets his breakfast there is little time to clean windows.

Q. Thiere is a break of six hours?

A. Hardly that, I think.

Q. From 8.30 to 2.40 .

A. But he must get lis meals, so that the whole time inot at his disposal.

Q. As a matter of fact, does he not get other employment?

A. I am not saying that this particular man does not get employment; I am only desiring to show how his duties are spread over the greater part of the day.

Q. As a matter of fact, I understand that a gentleman in this room does employ this man.

A. 'That may be; I don't doubt that for a moment. I don't know who may employ him.

Q. At all events he has other employment?

A. Yes. Here is a typical case of a man named Joseph Powell. His pay amounts to $15 \mathrm{~s}$. a week, so that he comes within the 18s. limit, and I would really like for some member of the Committee to point out where the opportunity arises for that man to increase his income beyond the $15 \mathrm{~s}$. by outside employment. He has a collection in the morning at 8.50 , extending to 9.45 , and he has a 12.45 collection and a 1 o'clock delivery, which extends to 3 in the afternoon. He then does the 4 o'clock delivery, lasting till 6.15, for all of which he gets 15s. a week. Practically the whole of that man's time during the day is taken up by his duties as an auxiliary, 
and I cannot see where any opportunity presents itself to him to enable him to add anything to his $15 \mathrm{~s}$.

Q. What is he by trade?

A I cannot answer for that, but, fortunately for himself, he is a single man. Here is the case of another man in the same office, Henry Walte:'s; he does the General Post delivery in the morning from 6.15 to 8.30 official time; he is again on duty from 12.46 till 3 o'clock, and then has a delivery from 8 p.m. till 10 at night, for which he gets 15s. 9d. I believe that 9d. is given to him for taking a bye-bag to St. John's Wood and Kilburn between the other deliveries with mis-sorted letters. The Hampstead, Kilburn, and St. John's divisions are so mixed that it is practically impossible for each man in sorting always to know exactly where the respective divisions end, and so, in order that there may not be any delay $w^{\circ}+h$ the correspondence, this man is paid $9 \mathrm{~d}$. a week for taking that back all the week backwards and forwards.

Q. Do you know what he is?

A. $\mathrm{He}$ is a reserve man. I am not aware whether he has finished his time in the reserve, but he came in from the army. I have also a memorandum of the case of a man named Hartley, who I find has now left the Post Office anil gone into the army.

The Chairman: The pay which the other man received as a reservist would count with him as other employment.

A. Yes; if he has the reserve pay. Hartley, whom I have mentioned, came in as a telegraph messenger, and although he has now left another similar officer is doing the duty which he had; it is done by a former telegraph messenger called Ramscart. This is the duty he does:-8.40 a.m. to 9.45 a.m., collection ; then again, 1.55 to $2.40,4$ to 6.30 , and 9 to 9.45 , for wages to the amount of $15 \mathrm{~s}$. per week. Now, there is a duty extending practically all over the day, and yet as an auxiliary he is supposed to have other employment, though he came from the Telegraph Service in common with many other auxiliaries.

Mr. L. Smith: Do you know what his other employment is?

A. I should say that practically he has no other; I don't see how he can; he cannot have a trade at his fingers' end, having come from the Telegraph Service.

Mr. Walpole: Was he a telegraph messenger?

A. Yes.

Q. Was he living at home?

A. I don't know.

Q. As a matter of fact, a telegraph messenger employed as in auxiliary duty and living at home is not required to sign the form you have mentioned?

A. I have not known of any auxiliary to be exempted from it.

Q. I believe that telegraph messengers who are auxiliaries and living at home are not required to sign it?

A. That would be known to you, sir, but I have no knowledge of it. Then I would like, gentlemen, to give some evidence in respect to this point: that whilst the Department expects these men to have other work it does not take into consideration that fact in so allocating their duties-I mean their postal duties-so that they may fall in with their other duties. I have a case in point, and I think it is a very hard case. It was either at the latter end of 1887 or in the beginning of 1888 , but that can no doubt be ascertained from the office. There was a revision of duty in the Northern District Office, and several of the auxiliaries had been employed from 6.30 in the evening until 10 o'clock at night, for which they got 10s. a week; and here I am not complaining about the wages. They came in for a collection at 5.30, and were on sorting duty and despatching duty until it was time for the 8 o'clock delivery, which they took out, which as a rule kept them occupied until 10 o'clock or even a little later; that gave these 
men the whole fore part of the day for other occupations, but at the time of the revision to which I have referred their duties were altered, and they were brought in for a collection at 10 o'clock in the morning, actually breaking into the very central portion of the time which the men had previously devoted to their private employment. Though they protested strongly against it the Department would not make any alteration. They told these poor old auxiliaries that unless they choose to accept that duty they must go.

Q. How long would the duty last from 10 o'clock?

A. It is not a question of how long it would last; the grievance is putting this duty right in the centre of their time, when men had already made arrangements to devote the earlier part of the day to their private occupations. In spite of protests on their part, the Department would not alter this duty, but told them that unless they accepted it they must go, and they did go. I think they were entitled to some consideration, aspecially when $I$ mention that the aggregate term of service of these men amounted to 120 years.

Sir F. Mowatt: How long were they employed from 10 o'clock?

A. I cannot give you an answer to that. I don't know how long the duty lasted, but the objection was to depriving them of the time most advantageous to them for other business.

The Chairman: Was it a collection?

A. I think so.

Mr. Walpole: But it would not last an hour?

A. Probably not; but you have to take into account the time occupied in going and coming. A man might be deprived in that way of from 2 to $2 \frac{1}{2}$ hours. In my own duties there is no account taken of the fact that I have goi nearly three-quarters of an hour's walk in the morning before I can start at $3 \mathrm{a.m}$. to make my collection, and it is the same at the 9.45 ccllection, or rather I have then 25 minutes before I can get to my first bcx; I have a corresponding distance to come back after that from the office, and, though I am not complaining of my duties, yet, as the remark was made that I was only working about $6 \frac{1}{2}$ hours, I thought it as well to note that the Department occupies my time for at least 8 hours. At South Kensirigton these auxiliaries are brought in for season duty at a certain time of the year, and then deprived of it after a time.

Q. Deprived of what?

A. Deprived of the season duty, there being no necessity for it.

Q. Not when the season is finished.

A. I am speaking rather of the hardship of them being called in to do this extra duty for a time.

The Chairman: Do you mean that it is an irregular form of duty which prevents them pursuing other callings with the same advantage?

A. Just so, sir.

Mr. Walpole: In a case like South Kensington, where there is a large season pressure, what is the Department to do? It must cope with the work, and don't you think it must employ temporary inen?

A. I will show later on that if the Department took proper lines there would be no necessity for it.

Sir F. Mowatt: Do you complain that when there is this extra work to do the Department employs men to do it?

A. They are only extra men in a certain sense; they are the same men who are already employed in the Department. I should like here to mention the case of a man at Blackheath, who is a waiter. He states that on Saturday, 13th July, which was, I suppose, the time of the General Election, they had an election there, and an order came down to the office to say that no man, not only no establishment man, but no man was to be let off that day owing to some thousands of circulars that were expected, and that must 
by delivered the day they came. 3,600 circulars came, and as this man had an afternoon job offered him that day for 7s. 6d., he spoke to the overseer anil asked whether he could not be allowed to go to that job, but he writes that the overseer said "No, you cannot get off." He entreated the overseer to let him go, and offered to come down for the 10 o'clock delivery and again in the evening, and then by that means lie was let off, otherwise it would not have mattered what that man's otlier employinent was, for it was only at the discretion of the overseer that he was allowed to go; that was only after making repeated applications, and showing what he would lose, and offering to come at another time for extra duty.

Sir F. Nowatt: Are you giving us an instance of an overseer helping a man or refusing to help him?

A. I am giving this as an instance of the way in which the Department utterly ignores the other business which they assume these men to have.

Q. But the man was let off?

A. The official dictum did not let him off.

Q. He was let off at the discretion of the overseer-that is, the Department met his requirement.

A. If there had been any delay in the delivery of these circulars I fancy the overseer would have had his knuckles rapped.

Q. The instance you lave quoted shows that the overseer gave him the cbance of earning the extra 7s. $6 \mathrm{~d}$. outside.

A. Yes; but utterly irrespective of the work which the Department insists upon these men having outside. An order is issued that no man is allowed to be away on a certain occasion.

Q. But an exception is made to that order when a man wants to get away?

A. I am afraid I could not fall in with that view, for in many offices the overseer would stand by the red tape rule, which he would hold could not be departed from.

Q. At this office the man was allowed to go?

A. Yes.

Mr. Walpole: Was not that his regular duty?

A. No, sir.

Q. You don't mean to say that the Department would have refused him leave outside of his regular duty?

A. Yes ; there was an order-no man was to be allowed off dutv.

Q. Off duty means off the duty to which he is assigned, not that the man is to be detained in the office all dav.

A. I know that when an order of that kind is received no man is allowed away.

The Chairman: Whether lis duty is over or not he is kept in all day?

A. If an order of that kind is received a man is detained.

Q. Has it ever happened to you?

A. No.

Q. Have you ever been kept all day waiting for extra duty?

A. In connection with the battle I am fighting for the auxiliaries I can safely say that I have myself met witl exceptional and kind treatment on the part of the Department; I have had nothing to complain of personally, but these cases have been brought before me, and it seems to me that if a man's wants and requirements can be met in one instance they might be met fairly all round.

Q. I quite grasp your point, but I think you should have given us an instance in which the auxiliary bad suffered; in the case you quoted they did not suffer.

A. He suffered by having to come down later for extra duties, and was only allows.l off on that condition.

Q. After all he was paid for the later time he worked, and he also got the 7s. 6d, in the afternoon. You have quoted an instance where hardship 
was avoided by the discretion of the overseer; I should like you to quote us a case where an auxiliary suffered through being kept in attendance through the day.

A. I can give you an instance in my own office. On Boxing Day, two or three years ago, there was a great delay in the matter of parcel delivery; we were fairly inundated with parcels at the office, and after finishing his delivery the inan was ordered back to assist with the parcels. The question whether he had any other duty or not was not taken into account, and many of the men were kept at work until late in the afternoon.

Q. They were paid overtime for it?

A. I am only speaking of the system of bringing these men at certain periods when it suits the Department, although the Post Office insists upon them having otlier employment.

Q. Did any of these men ask to be let off because of other employment?

A. I should think they would not have other work on Boxing Day, but if they had asked I am afraid they would not have got off, for the rule would have been like the laws of the Medes and Persians.

The Chairman: If he had no other work to do, in many cases they would probably be glad to come in and earn overtime?

A. Yes. Allother grave injustice imposed upon the auxiliary class is the performance of sick duty ; that is, when an established man is ill his inties cccupying 8 hours per day-are in many instances allotted to an auxiliary jostman to perform at a wage of $18 \mathrm{~s}$. per week, or $4 \frac{1}{2} \mathrm{~d}$. per hour (which cannot by any stretch of the imagination be termed a fair rate of pay for such important work), and this notwithstanding the fact that the established man may be receiving as much as 36s. per week for the same Juties. Now, I don't wis! to make that statement without giving some evidence on the point. I know that the Department is adopting a plan whereby reserve men may in some instances do this sick duty, and some telegraph messengers may do it, but in my own district in our office at St. John's Wood last week an auxiliary was called on to take sick duty for an established man named Moore, and got 18s. The duty he had to do was the General Post delivery, for which he arrived at the office at 6 a.m., a 9 a.m. collection, an 11 a.m. collection, and a noon collection, and a 3.10 p.m. collection, and a 4.45 collection, remaining at the office until after 6 to make up the G.P.O. bag. The man further qualifies this by stating that he has to walk 15 minutes for the 9 o'clock collection before he can make a start, and so with the other collections except the one at 4.45, which is around the office.

Mr. I. Smith : How many hours does he work?

A. First from 6 to 8.30 , then the 9 o'clock collection, which would be one hour official time, and as he does not finish his first duty until 8.30 he is practically away the whole time from early morning. After 10 o'clock he has to look forward to the 11 o'clock collection, which would take him till 12, irrespective of the time coming and going, and the 1 o'clock collection would take him till 2 o'clock. Then the 3.10 collection would take him,

believe, till 4 o'clock, after which he has the 4.45 collection; but he remains till 6 to make up the G.P.O bag.

Mr. Walpole: It just makes it uuder 8 hours' duty?

A. And the man, according to Mr. Raikes' scheme. should be paid 24s for it.

Mr. I. Smith: And he is paid 18s.?

Mr. Walpole: Mr. Paikes' scheme did not apply to auxiliaries on fulltime, did it?

A. Well, so much the better for the auxiliaries on full time.

Q. Is it not the case that it applied only to isolated postmen, and not to men working the full eight hours?

A. Oh, yes, sir. I got a rise of $3 \mathrm{~s}$. myself on that aeeount:

Q. Did yon get $24 \mathrm{~s}$. a week? 
A. I was getting 25s. 6d. a week before Mr. Raikes' scheme came on, and when it came in it made me up to 28s. 6d. per week.

Mr. Smith: How long did that sick duty last to which you referred just now?

A. The man only did it for one week, and then he refused to do it any longer.

Q. Do you know what his employment is outside?

A. He is a man who has been in the army, sir. If he has any employment it would be of a casual character-whatever he can obtain. I do not think he has any trade.

Q. Do you know what particular work he was doing outside? Have you any information as to that?

A. I believe he is a handy man in gentlemen's houses. He has got a decent little sort of connection.

Q. When he declined to go on with the sick duty did he go back to his ordinary work as an auxiliary?

A. I presume so.

Q. He was not discharged?

A. No.

Q. Then it was quite at his option?

A. Yes, sir. But it comes to this-that when the Department empioys a mall to do duty my contention is that they should pay him a proper rate of wages. I submit that this is a case of sweating on the part of the Department.

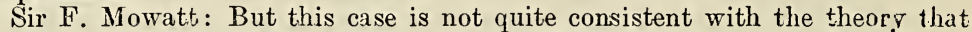
a man is obliged to take additional work if additional hours of attendance are offered him. I thought I understood you to state that any auxiliary to whom additional work was offered was obliged to take it?

A. Not obliged to take it except in such an instance as I have stated on the morning of a Bank Holiday, when every man was ordered back for a parcel delivery. He would be compelled to do that then.

Q. Otherwise, in the ordinary way it is quite within the option of an auxiliary to refuse to do the duty?

A. We are not complaining that the Department compels a man to do the duty. We are complaining that when they offer the duty they offer it at a sweating wage.

The Chairman: Do you suggest it should be paid for on the continuous scale at per hour?

A. Yes; we contend that in all instances Raikes' scheme should be put in force where auxiliaries are employed.

Q. Exactly-at 6d. per hour?

A. Just so, sir. Next I wish to point out the advantages they should participate in. Now, considering that the work demanded of these men is identical with that performed by the established class, it is only just that while they are employed as auxiliaries they should receive some of the contingent advantages of the former class in the shape of holidays, sick pay, stripes, boot allowance-at least, in a reduced ratio. We claim that ihe Raikes' scale affecting the auxiliary class should be carried out literallythat is, they should receive payment at the following rates:-From 5 a.m. to 10 p.m., 6d. per hour; from 10 p.m. to midnight, 8d. per hour ; from midnight to 5 a.m., 9d. per hour ; and for all Sunday, Christmas, and Good Friday duty 1s. per hour. I may inform you that these auxiliary men consider that the work they do is identical with that performed by the established class in every respect, and in numbers of suburban offices throughout London these men are doing all the making up of the bags and despatching, and everything else just the same as an established man. In that office, practically speaking, the Department are requiring work from these men which the other men at other places are receiving a maximum of 56 s per week for, whereas the Departmant is now only paying at the 
outside 6 d. per hour, and in many cases less. In addition to that, the men get no holidays at all, no sick pay, and there is no question of stripes nu matter how long they serve. They have no boot allowance, too, and, indeed, no advantage of any sort or description. In laying down 6d. per hour as the minimum rate these men should receive, we would point out that this is the dock labourer's wage; and anything below that amount is, as stated by Mr. Booth in his evidence before the Royal Commission, below the poverty line; and as the dock labourer requires nothing but physical strength, and the auxiliary postman must be possessed of honesty, integrity, and a certain amount of educational ability, he is at least worthy of the same rate of wage. We would furthermore suggest, in counting the time employed, that any time between two duties of less than one hour should be considered as a continuous duty, as where a man has to make two or three attendances daily, the time occupied in going to and fro is a considerable loss to him.

\section{HOLIDAYS.}

In the matter of holidays (as before mentioned) many of these men perform duties so extended over the day that practically their whole time is involved, and as they are continuously at work the whole year through, it is only right and necessary, as regards health, that they should receive at least one week's holiday without loss of pay during the year. More especially in the matter of Bank Holidays are the auxiliaries unjustly dealt with, as a man upon the establishment is either paid extra for the duty he performs on a Bank Holiday, or is allowed a similar time off duty upon some other occasion; and as the Legislature has decreed these days shall be public holidays, we fail to see why the auxiliary postman should be singled out for its deprivation without any recompense, more especially as no recognised annual holiday is granted to these men should they receive the Bank Holiday concession in common with the men upon the established class.

\section{SICK ALLOWANCE.}

The question of sick allowance is a most important item with this class, and we contend that while these men are exposed to the same risks from inclemency of our very changeable climate, and while no special effort is made to protect them from any contagious disease or epidemic that may be raging, some allowance should be made to them when they succumb to the effects of these contingencies; and as the established man is allowed full pay during sickness, we would suggest that the auxiliary should be allowed at least half. I put it down to half because I cannot see how I can consistently ask that an auxiliary shall get the whole of his pay during illness. $\mathrm{He}$ devotes only a portion-as a rule about one-half-of his time to the Department. But we do contend that while an auxiliary has to go into the same infected neighbourhood as the established postman, and is subjected to the same inclemencies of the weather, when he succumbs to themwhich is often the case on account of the pressure of the work of the Department-he should be allowed half-pay.

Sir F. Mowatt: About the holidays: Do I understand you to say that when an auxiliary is at work full hours continually he does not get any holidays?

A. Yes, sir; he gets one week's holiday during the year; that is all, when he is doing full-time duty the same as an established man-that is to say, 8 hours.

The Chairman: And anybody not doing 8 hours gets no holiday?

A. No holiday of any sort or description. Now I come to the question of 
good conduct stripes. The good conduct stripe question is one that bears very hardly and unjustly upon the auxiliary class, and also indirectly subjects them to a very grave suspicion in the eyes of the public, as the public are always informed that stripes are issued solely on account of good conduct, and they (having no means of judging the difference between an established postman and an auxiliary) seeing a lad enter the Service, and after five years receive a stripe, and an auxiliary whom they have known as postman for perhaps ten or even twenty years without such a distinction, raturally come to the conclusion that the auxiliary must have misconducted himself in some way or other-a very undesirable impression to create in the mind of the public in respect to a man who has to fulfil so important duty as the safe-guarding and delivery of important documents, and in many cases very valuable property; putting on one side that it is quite as important in a public department like the Post Office to encourage good conduct in the whole of its staff, as it is in a section. We would suggest (if it is desirous of showing a distinction between the two classes) that as the established man wears lis stripes horizontally, the auxiliary should wear his in perpendicular position. (Laughter.)

The Chairman: You are determined not to mislead the public?

A. Yes; I think t'e public would make inquiry why one man wears the stripes in one position and one man in another, and then they would get some logical idea of what the position of an auxiliary postman is. They get no chance of that now. Whenever an answer may be given to questions to the Postmaster-General in the House of Commons, it is to the effect that stripes are not considered as wages but are the reward for good and meritorious conduct, we contend that the Department ought to encourage good conduct as much in the auxiliary staff as they should in any other class. This is a matter which rests entirely with the Department. It is not like a pension scheme, for which an Act of Parliament has to be obtained purposely, but it rests solely with the Department and the Treasury. I take it it is just as necessary that good conduct should be encouraged in an auxiliary as it is in the case of an established man, seeing that the same responsibilities are put upon bim, and that the same amount of valuable property is entrusted to his care.

Mr. Walpole: Would you give stripes to all the auxiliaries, irrespective of the amount of duty they do?

A. Yes, sir; I should not make any distinction on that point. Provided that a man does his duty properly, honestly, and straightforwardly, I think the Department should encourage him even although he has only one duty to perform instead of four. I do not mean to put forward a claim that they should have it for a less term of service than the established men. You see that auxiliaries stand at a stagnant wage. There is no prospect of that wage increasing in any shape or form, and it would be a certain amount of recompense for the stagnant position if a man could improve his position by an addition of from 1s. to $3 \mathrm{~s}$. a week to his wages by deserving it for meritorious conduct. Again, some concession in the way of boot allowance would be a great boon to these men, as the nature of their work naturally bears very heavily upon this article of clothing, and we would suggest that they be granted one pair of boots annually, or half the amount granted to the established class.

Mr. Walpole: Some have an allowance, have they not?

A. Yes; half the amount granted to the established class. There are two points I should like to mention to you which I have not dealt with in my statement, and one is with regard to the men not being entitled to any pension. We certainly advocate an amendment of the Superannuation Act. I did not put that into my statement, as Mr. Walsh, of Liverpool, was dealing with the superannuation question, and I am satisfied with the way in which he put the case of the auxiliaries forward. I am prepared to leave that matter in his hands. Bat there is another question which has been 
brought before you-that of Christmas boxes. In most of the suburban offices in London the auxiliaries have a fair share of the Christmas boxes. according to the deliveries they do. As a rule, for each delivery a man does on a walk he gets a share of the Christmas boxes. I will make my case clear to you. Say that there are three established men on a walk, presumably one of them does. four deliveries a day, and the other two will do three. The number of duties necessary on the walk are made up by the auxiliary postmen, and the shares of the Christmas boxes are determined according to the men who do the deliveries. The money collected is divided into so many shares, and if an auxiliary does one duty ho gets one share; if two he gets two shares, and the established men receive in the same proportion.

The Chairman: They are exactly the same?

A. Yes, according to the duty they do. Of course, the contention has been put forward that these Christmas boxes should be abolished. I am certain that the auxiliary postmen will quite agree with that as much as the established men. It is a degrading system to be subjected to-to go round like licensed beggars to do what any man in private life would be locked up for doing. At the same time, like the established men, as these Christmas boxes have been recognised as part of our wages, we do not feel inclined to lose them without some recompense. On that score the established men have put forward a claim, and it has been suggested that they would be willing to drop them if they were to receive an immediate rise. Now, as the wages of an auxiliary man do not rise, the question comes in, how is he to be compensated for the loss of the Christmas boxes should they be prohibited, and he be unable to solicit them any more than any other man? His wages do not increase, and I can hardly see where the remuneration is coming in. The suggestion I put forward on belalf of the auxiliary men is that, provided the Department abolish Christmas boxes, each auxiliary should receive $1 \mathrm{~s}$. per week additional for each delivery he does. That is, making $£ 212 \mathrm{~s}$. for each delivery in lieu of a share of the Christmas boxes, and as, practically speaking, most of the auxiliaries only do one delivery, or at the most two, and as the Department have computed that a man receives $£ 5$ a year as Christmas boxes, I think to claim $£ 212 \mathrm{~s}$. for the auxiliaries is a very moderate request.

$\mathrm{Mr}$. Walpole: You suggest 1s. per week each for each delivery?

A. Yes, sir.

Q. You have given us some cases in which the auxiliaries are doing two and three deliveries a day?

A. Yes, sir; two deliveries.

Q. And then that would represent an increase of over $£ 5$ ?

A. Yes, sir; $£ 54 \mathrm{~s}$. If you make an allowance to the established men who get an increasing wage, I take it that as an auxiliary lias a stagnant wage, it is not too much to ask for this concession.

The Chairman: Do you think that represents the average sum received by the auxiliary?

A. As Mr. Warner told you, it is a difficult matter to fix an average sum. Some of the walks are very wealthy walks, and the average rate the men would receive from them would be far in excess of the amount obtained on a poor walk. It is therefore a very difficult matter to estimate what is the average rate a man receives in the shape of Christmas boxes. If they are abolished, I certainly put it forward in all good faith and conscience that I lo not think it would be an exorbitant demand on the part of the auxiliaries that they should receive 1s. additional per week for each delivery.

Mr. Walpole: Do- you think that if the Christmas boxes were abolished the public would cease giving?

A. Yes, sir; in 99 cases out of 100.

Q. Do you really think that?

A. Yes, sir ; I do. 
Q. And that is your opinion?

A. It is, sir.

Q. But it was not the case when railway porters' tips were abolished?

A. I do not know anything about railway porters' tips. I have never been in that line of business. I have been an auxiliary postman for 16 years, and $I$ know as a positive fact that if $I$ did not ask for Christmas boxes I should not get them in many instances. I do not know whether the person whom I ask is short of coin at the time, but the reply often is, "Do you mind calling such-and-such a time?" Sometimes I do call, and $I$ find if $I$ do not call a second time $I$ never get anything at all. That is the case in 99 times out of 100 , I never have them offered to me.

Mr. L. Sinith : In what district is that? Is it Hampstead?

A. Yes, sir.

Mr. Walpole: As a matter of fact, the Scotch postman does not ask for Christmas boxes?

A. So I see.

Q. And yet they do get Christmas boxes.

A. I wish that happened in London; they are very fortunate there.

Mr. L. Smith: You mean you wish you could do without asking for them?

A. Yes, sir. These matters that have been laid before you are some of the most burning and important grievances that the auxiliary class are suffering under (wlich can be substantiated-as I think I have shown-by evidence), and we feel assured that when you have given them your careful and earnest consideration we can confidently leave the issue in your hands, and that you will allow they are well-founded and deserving of material alleviation, and trust the few auxiliaries that are unavoidably retained will receive a higher rate of remuneration and a greater share of contingent advantages, but that the class will be merged into the establishment as far as practicable.

The Chairman: I think you have another point to raise about the two years' probation. I think you may as well go on and finish your evidence.

Witness : Do you prefer to take that now?

The Chairman: Yes; I think we may as well do so as you are here now. I was going to ask you a question. You have told us several times is the course of your evidence when you were asked what remedies you proposed, that you would deal with them later on. I do not think you have as yet given us those remedies.

A. I do not think that I have. My remedy is the absorption of the auxiliary class into the established class. I contend, the same as Mr. Barnes contended over the zone system, that London itself should be one whole, and that all within the Metropolitan area should be treated in the saine way as they are treated in the City. I contend also that greater postal facilities should be given all over London, and that one part should have equal treatment with another part. I think a plan ought to be adopted all over the Metropolis by which there should be a delivery and collection pretty nearly every hour per day. I know very well it may be contended that that would be difficult, and that there would not be a corresponding amount of work to be done, but I submit that the work would be spread more equally over the day. At the very office at which I amat Hampstead-when I first went there, there were only six deliveries a day. I am not quite certain what were the number of collections; I do not think there could have been more than half the present number. Now we have practically a collection every hour throughout the day. We have also had an additional delivery put on at 3 p.m., as there used to be no deliverv between 1 and 4 . We have found by experience that since this fresh delivery, and since these additional collections have been instituted, the work has been more equally spread over the day. Experience shows that when the public get to have a thorough knowledge of the arrangements 
in regard to collection and delivery, the work, instoad of becoming lighter by reason of the increased number of deliveries, increases correspondingly, and it is only when the public are thoroughly well aware of the existence of these postal facilities at certzin times during the day that they make use of them. If there were more in existence $I$ believe they would be used equally as much as the present ones; that would mean an increase of income to the Post Office and an additional amount to hand over to the Treasury which would enable them to pay the expense of the further duties I am adrocating. I think that the question might be met in that way.

Q. You would increase the number of deliveries and collections, and in that way find full employment for the whole of the auxiliaries; you would also take them on the regular staff?

A. Ies, sir.

Q. Where will you stop? Would there not then be something more wanted?

Mr. Smith: If you go on like that you might have a delivery or collection every minute of the day.

A. You could not possibly do that: time would not admit of a delivery and collection every minute.

Mr. Walpole : Is it not the fact that in the City the work is so heavy anil the correspondence so great that we are forced to have balf-hourly collections, or the letter-boxes would be crammed up in the middle of the day? Surely you do not suppose the same difficulty. would arise in the outlying parts of Hampstead?

A. I think, sir, if you were to pay a visit to Hampstead, you would find that the collections were pretty heavy, and that the men's bags were filled up to the top.

Mr. L. Smith: How would you get rid of the anxiliary force?

A. There would in the future be no necessity to engage an auxiliary force : every man would be on est.zblished duty.

Q. Would not the difficulty in getting rid of the auxiliary force arise from the fact that the work is of a fluctuating character at different parts of the day?

A. The work of the morning delivery and of the last delivery at night is rather heavier than at other times of the day, but at the same time I maintain my contention that there would be sufficient work during the whole of the day if these additional postal facilities were given to the public. As a matter of experience, we know that where new duties are created, there is a corresponding increase in the amount of correspondence. I feel sure that the public would avail themselves of increased facilities. At the present time they cannot do so because they are not in existence.

Q. And you think that then there would cease to be a difference between the duties at different times of the day?

A. Just so.

The Chairman: How long are you likely to be with the probationers' case?

A. I have not a wonderful lot, but I am afraid I shall bring in some contentious matter. The prolongation of the term of probation-

The Chairman: When was the change made.

A. I hardly know the date. It was three or four years back. Mr. Maclaren tells me it was a year later in the provinces than in London. The prolongation of the term of probution for all entrants into the Postal Service from six months to two years is opposed to all sanse of reason and justice. Taking into consideration the severe medical exa ination that a candidate has to undergo, it is obvious that the original probation of six months is quite sufficient time in which to test the stamina of the candidate as to his capabilities of physical endurance for the work required, as it is certain if there was the slightest doubt in the medical officer's mind as to his fitness he would reject the candidate forthwith. The hardship of the two years' 
probation is very pronounced in the case of candidates coming from the position of telegraph messenger, as most of the telegraph messengers have done four or five years' work in the service of the Department after undergoing a previous medical examination, and this at a time of life when other lads are learning a trade or profession, and if, after a further two years' service, they fail to pass the second medical examination, they have then reached an age too advanced to begin acquiring the knowledge requisite for a trade or profession, and are consequently thrown into the ranks of the flotsam and jetsam of the commercial world, and become waifs and strays, and lead a life of chronic pauperism to the end of their days; whereas, if the prcbation only extended to six months, as formerly, they would have a reasorable chance of acquiring a sure and certain means of obtaining a decent and respectable position in society.

The Chairman: Have you gone through four years' probation? Did you have first to go through two years' probation as an auxiliary, and then two more years in order to get on the establishment?

A. I will deal with that presently.

Q. But is it so? As an auxiliary did you have to do two years' probation?

Mr. Walpole: An auxiliary does not have to do that; it is only when he applies to go on the established class that he has to do the two years' probation.

The Chairman: Then an auxiliary has no probation to go through?

A. No, sir.

Mr. Waipole: And an auxiliary is not medically examined, is he?

A. No, sir.

Mr. Sinith: Have you had two years' probation yourself?

A. I am doing that now, sir. We would further point out that the two years' probation for these lads is not a just test, seeing that a practice is now introduced of placing them on a midnight duty lasting until $7 \mathrm{a} . \mathrm{m}$., thus putting an unnatural strain upon them by confining them in the heated atmosphere of the sorting office for three hours, and then sending them out on a bitter winter morning for a 3 a.m. collection, this, instead of developing any latent disease, sowing the seeds of it. In the case of the candidate being recruited from the ranks of the auxiliary postmen, the two years' probation reaches the height of absurdity, seeing that these men have been performing postmen's duties for a number of years, and yet to get permanently placed upon the established class they are compelled to undergo a two years' probation to ascertain if they have sufficient physical endurance to perform work which they have been actually doing for, in some instances, as many as 15 or 16 years or more.

The Chairman : Can you give me any cases of men being rejected on their two years' probation, after having passed through the auxiliary service?

A. I will give some cases presently. I am dealing with them with my statement. The evidence of Dr. Wilson before this Committee fully demonstrates the fact that in the case of the auxiliary the probation is unnecessary, as he has given proof of his physical fitness to perform the work required of him, and shonld have his appointment confirmed forthwith, upon his passing the necessary medical and educational examinations. I should like to make out my own case. And not only my own, but also that of three other men in the same office as myself. One man has done two years' more service than I have, as an auxiliary, making him 19 years. I have done 17 years' service, and another man has done something like 14 or 15 years' service. You must take this point into consideration, that each onë of us men has been doing full-time duty for the last eight years. We have not been doing a portion of the duty, like most of the auxiliaries, but we have been doing actually the same amount of work as an established man is required to do, the same amount of strain is put upon us, and, indeed, it has been rather worse, because our hours of duty have been from 3 o'clock in the morning, fnishing practically at 11 o'clock-a continuous duty- 
and then in each case we have had to go on at the last delivery at night, or at least the last collection, making it turned 11 o'clock before we got to bed. I think we have given fair proof of our stamina, and shown that we are capable of doing the work. The doctor has passed us without any objectionable comment upon our physical abilities, without any shape or form, yet we have to do two years' probation to show that we are capable of doing the work we have been doing the last eight or nine years.

Sir F. Mowatt: You do not object to the medical examination, I suppose?

A. No, certainly not. It is a proper protection on the part of the Department to have it. I do not think that a man should be put back even if the doctor is against him. The doctor has known me all the time I have been at Hampstead; he has known me both personally and otherwise. Last week I had to go to him at the end of six months for a further examination, and I shall also have to go to him at the end of two years. He made a remark to me- "Are you on two years' probation?" I sail "Yes." He said, "I never heard such an absurd thing in all my life."

Mr. Walpole: It didn't do you very much harm?

A. It does not do me any good.

Q. What harm can it do you?

A. I will point out where the harm comes in presently. I have a case here which I have taken from that point of view, and I think I shall be able to show that in all probability it may do a man harm. At any rate there is a chance of it. The all-round injustice of so long a term of probation is self-evident when the fact is taken into consideration that each individual candidate has to undergo a most severe medical examination upon his initiation to the ranks of the established class, thus conclusively showing that he is physically qualified to bear the computed strain expected to be placed upon him; and then, after two years' experience of a postman's arduous duties, and the constant exposure to all the inclemency of our very variable climate, to be subjecter to the same test, or, in most instances, an even more severe one, than when-in the majority of cases-he was fresh and untried, is, to say the least, a very unjust competition between the laws of nature aud economy. Another reason why the probationary term should revert to the original period is the great difficulty experienced in gaining other employment when it is ascertained that the reason for leaving the Postal Service is medical disqualification. Very naturally, other employers of labour look askance at employing a man whom they legitimately look upon as an invalic ; and this injustice is made more unbearable by the unreliable nature of the examination which disqualifies a man, as there are numerous cases on record where men have been disqualified by the Departmental medical officer, and then they have presented themselves and successfully passed the medical examination for the army, and this test, as is very well known, is as severe a one as any man can undergo. I can give the names of two men from the N.W. District Office who were refused by the medical officer at the end of two years. One is now in the marines, and the other in the Army Medical Corps, and both these corps hare as severe a test as any other corps in the British army.

The Chairman: What are the names of the men? A. Akerman, who is in the marines, and Hunt, who is in the Armz
Medical Corps.

Mr. Walpole: The medical officer in the N.W. District happens to be an army surgeon, does he not?

A. That I cannot answer.

Sir F. Mowatt: What did he reject them for? A. No satisfactory reason was given to the men; t!ey were simply
medically disqualified.

Mr. Walpole: Just repeat the names of the men.

A. Akerman and Hunt, sir.

Mr. Walpole: I will look into their cases. 
Witness: I have also another case I wish to bring vefore the Committee in order to show the unreliable nature of the disqualification. It is the case of a man at the Walthamstow Office. He was an auxiliary, and he was offered an established appointment. He went through the Civil Service exumination, and was examined by the doctor, and then he received the following communication from the Civil Service Commission:- "Sir, I am directed by the Civil Service Commissioners to acquaint you that on the evidence before them they were unable to certify having ascertained that you were free from any physical defect or disease which would be likely to interfere with the proper discharge of your duty, and they have therefore been unable to grant a certificate of qualification." Upon the man receiving this he thought, as he was unable to tell from it what his physical disqualification was, so he went to the London Hospital, in Whitechapel Road, on August 10, 1891, and he obtained the following certificate from the medical officer who there examined him:- "This is to certify that George Emeny, 20, is free from any disease of the lungs." This certificate was signed by A. C. Elsmore, M.D.

Mr. Walpole: That is only a certificate that he is free from disease of the lungs.

A. Wait a minute; I have another one here. It is dated August 24, and reads :- "This is to certify that George William Emeny, 20, is free from any organic disease.-A. C. ELSMore, M.D."

Mr. Walpole: We don't know why this man was disqualified?

A. That is just the point.

Q. I presume the man had a right of appeal. He could appeal against our decision.

A. He might have done so ; but then an auxiliary is heavily handicapped in that respect by having to fish out the sum of two guineas for the medical referee's fee. It is a hard job for him to do that.

Q. Do the Commissioners charge two guineas fee on appeal?

A. Yes; in the Official Circular it is stated that the men have a right of appeal on payment of two guineas. Why I know it is a fact is because our Federation, in a case where a man has been medically rejected like this, has now adopted the rule that we will provide the fee for the man to appeal. The Department refund it if the man passes the examination. We propose to provide the fee for any member of the Federation who is medically disqualified, and to put the matter to the test.

Sir F. Mowatt: You say the man got that communication from the Civil Service Commissioners?

Mr. Walpole: The Civil Service Commissioners use our Departmental officers for the purposes of examination.

A. It slipped my memory for a moment, but I believe that at the time this man was examined he had no right of appeal.

Mr. Walpole: I think you are mixing up two things. There was always a right of appeal.

A. The Civil Service Commissioners wrote to this man that they could not issue a certificate of qualification to him to the effect that he was free from physical defects, yet he goes to the London Hospital and is there examined again, and declared to be free not only from disease of the lungs, but from any other organic disease.

Q. But organic disease and physical defects are not always the same thing.

A. The man is not informed what is the matter with him.

Q. It does not state what is the physical defect, but it is pretty evident that the examination the man had undergone must have disclosed something; perhaps it was a case of "flat feet."

A. Don't you think, sir, that when this man presented himself for examination at the London Hospital, with the knowledge that that is one of the reasons for disqualification, he would have subjected his feet to examination, as we:i as other parts of the body? 
Q. It is not enough that the certificate does not cover that.

A. I should imagine from the fact of the man presenting himself for examination in that way, and undergoing it, there was really nothing whatever the matter with him. I know that if I were an insurance agent, and qualified to give certificates, I should feel myself justified in recommending him as a first-class life. Another and final point is the undesirability of leaving so unjust a means of retaliation upon a man in the hands of the Department, as a man in two years discovers many anomalies in the Postal Service which his sense of right and wrong induces him to endeavour to get remedied, and in this way (although doing his duty efficiently and giving every satisfaction otherwise) makes himself very objectionable, and this medical examination is a very excellent extinguisher for him.

Q. That is a very serious charge. Can you give us any case?

A. I will bear out the statement if you will allow me. Doubtless this statement will be looked upon with a certain amount of suspicion, as it will be thought that a man engaged in the honourable profession of a doctor would not be amenable to official pressure in this manner, but evidence can be supplied of cases where men have been too ill to attend for their tirst duty (officially known as the G.P. duty), and when they have received 2 n order to visit the doctor, they have been informed that it is officially marked "Absent from G.P. duty," and, therefore, he cannot have a certificate to say he is unfit for duty, whether such is the fact or no; and, therefore, if medical officers are open to pressure in such cases, irrespective of their professional judgment, they are just as amenable to official pressure in other cases.

Mr. Walpole: Where does the medical officer come in there?

The Chairman: The medical officer, it is suggested, puts on an official mark?

A. The rule of the Department is that a man shall not see the doctor without an order from his immediate superior. In district offices the inspector on duty superintends, and when this man went to the official medical oflicer the latter knew from the mark on the order that he had not been on the General Post delivery, and he therefore told the man, "I cannot give you a certificate relieving you from duty on account of being ill to-day, because you were not on General Post duty." That is an intimation, or rather an insinuation, I suppose, that the man was a malingerer. That, as a matter of fact, he had overslept himself, and that it was only a subterfuge to get off duty.

Sir F. Mowatt: You are not now speaking of the medical examination when a man joins the establishment, but only when he is asking for sick leave?

A. I am only speaking of the pressure that is brought to bear on the doctor. This is a corollary of my statement that I brought forward, that this is an unjust weapon in the hands of the Department to be used against the men.

Mr. L. Smith: What is?

A. This medical examination at the end of two years.

Q. Would it not apply to the examination of any time?

A. Certainly, whenever a man was ordered to undergo one.

Q. But you object to the medical examination?

A. No, sir; I do not object to it in the case of new entrants in the Service. No reasonable men would raise an objection to being examined again at the end of six months, but to extend it over two years is very unreasonable, especially in the case of men who have given 15 or 16 years, service to the Department, who have during that time been doing full-time duty, and who have passed the first examination. I contend there should be a custom that for those who have thus undergone it, it should be sufficient. I am qualifying this part of my statement as to the unreliable nature of the 
medical disqualification at the end of two years. I say it is a great injustice; it means retaliation in the hands of the Department if a man makes himself objectionable. Naturally gentlemen of high and honourable position, such as doctors, would be supposed not to allow pressure to be brought to bear on them, and I have brought this case forward to show that where a man wishes to get a certificate, official pressure may be brought to bear on the doctor, and if it is done in one case, it is just as likely t) be done in another.

Sir F. Mowatt: I do not see where the pressure on the doctor comes in. Do you mean that because a man did not attend the General Post delivery the intimation of that is the pressure?

A. No, sir. The pressure is this : a man is supposed to present himself if he is too ill to attend the first delivery-he is supposed to present himself at the office as soon as possible, or if he is too ill to do that, to send word so that a doctor may be sent down to see him. That is, supposing he is too debilitated to get up in the morning and come to the office. Probably the man will reach the office about 9 or 9.30 , and he will get an order from the superintending officer to visit the doctor. When the superintending officer gives him the order to visit the doctor be marks in the corner that the man was absent from General Post delivery, and when a man gets to the doctor, the latter, directly he sees that mark, refuses to give him a certificate that he was ill.

Sir F. Mowatt: However ill he may be?

A. Yes; pressure is put by the official mark on the paper.

The Chairman: Your allegation, Mr. Wilson, is that there is an official rule that any man going to a doctor for a certificate, who brings on the order for the interview a notice that he has missed the General Post duty, then, as a matter of course, he gets no certificate?

A. Yes ; it is taken for granted that he is a malingerer.

Sir F. Mowatt: Is that so? It is a tremendous accusation.

A. Yes, sir; I lave a case here to show what it amounts to. On Jan. 21. 1896, a man named Harper, belonging to the S.W. District, failed to attend the General Post duty, and arrived at 9 a.m., and asked for an order to see the doctor. The inspector endorsad the order, "Absent from General Post duty."

Mr. Walpole: And that was correct?

A. Yes; I am not questioning the correctness of it. He saw the doctor, who, after asking him a few questions, stated that on the face of the inspector's endorsement of the order, unless the man was seriously ill, he could not grant him a certificate. He told him to get some poppy heads, anil to make a poultice, and finally, after various statements, granted him two days' leave, which was subsequently extended to five days. This man, I should have said, was a postman.

Sir F. Mowatt: This is like the case of your waiter; the man got exactly what he wanted.

The Cliairman: What was the matter with him?

A. I presume it was face-ache or neuralgia.

Sir F. Mowatt: At any rate the doctor let him off attending duty, and later lis leave was extended.

A. Afterwards, but not in the first place. If the man had not contested the point, the doctor would, as he told him, have refused to grant a certificate on the face of the inspector's endorsement.

The Chairman: It does sometimes happen that people do oversleep themselves, and try to get off the penalties they thereby incur by endeavouring to get a medical certificate?

A. Well, I have never done it myself.

Q. But these things do occur sometimes?

A. I should not like to answer for it; I do not mind taking responsibility upon myself for things I actually know, but I cannet say that I have any 
positive knowledge that this does occur. All I can say is that I have a list of men here from the S.W. District Office who were refused. I do not know why : I have tried to find out, but I have not got the information.

Sir F. Mowatt: This accusation is a very serious one, but I must point out that the case you have adduced, as far as it goes, shows that the doctor on examination did, in spite of this endorsement, give the man two days' leave, which was subsequently extended to five.

A. I have had the man's duties handed to me, and I do not think there is any likelihood of his malingering. He has been on at 4 a.m. for two years, and has only been late eight times. The longest he has been late has been 40 minutes. He never missed a duty before.

Sir F. Mowatt: That very man?

A. Yes, sir.

Q. But he got his certificate?

A. Yes, sir; but he would not have done had he not contestcd the doctor's opinion. The doctor told him that on the face of the endorsement of the order by the inspector he could not grant him a certificate. It was only after a protest on the man's part, and on lis insisting on an examination that the doctor did examine him; otherwise there was a prima facie case against him, as the certificate was sufficient to enable the doctor to refuse the leave.

Mr. L. Smith: To refuse it unless he had reason to suppose that the man was ill. Is that not a reasonable position to take up?

A. I do not think so.

Q. You understand that you are basing upon this a tremendous charge against the medical officer?

A. It is a thing commonly done in all the districts.

Q. The charge you are basing on this is the inproper withholding of medical certificates for entrance into the Service?

A. I am only showing the probability that pressure will be brought to bear to that extent.

Mr. Walpole: Have you any evidence whatever of the improper withholding of certificates after probation?

A. The unfortunate part is that the withholding of a certificate disqualifies a man.

Q. But have you any case where a man, after probation, has becn rcjected without good reason?

A. I take it that the fact of a man passing into the army is sufficicnt evidence that he was not properly disqualified?

Mr. Walpole: I understand he was rejected on appointment, and not after two years' probation?

A. Yes; it was after two years' probition.

The Chairman: Were both men you have named auxiliaries?

A. I do not know whether thcy were auxiliaries, or whether thcy came from the Telcgraph Service. They were appointed the same as I am at the present time, but at the end of two years' probation they were rejected. I have the case of another man in the same office-a man namerl Duncan. He was disqualified, and entered the army, and then he was bought out by his friends. He is serving as an auxilizry postman at the present time.

Mr. Walpole: He seems to have had a cliequered career. What office is he in?

A. He was in a N.W. District office. He was put upon two years' probation, but he was disqualified by the medical officer, and thereupon joined the army.

Q. Do you know the date of this?

A. No doubt it can be ascertained. I believe it was two years ago.

Q. What regiment did he join?

A. I have not that information.

Mr. Churchficld: He passed into the Marine Artillery. 
Mr. Walpole: I wonder he joined us again after his experience.

A. So do I, sir.

Q. He evidently thought better of us than you do.

A. I do not know, sir. We would further impress upon you that candidates for appointment have, with the exception of a very few cases, already served from four to five years' probation, either as telegraph messengers or auxiliary postmen. We therefore trust you will give this question your earnest consideration, and that you will see your way clear to recomm.nd that the old six months' probation be reverted to.

Mr. Walpole: Have you any evidence of any case where a man who has made himself inconvenient to the Department has been medically rejected?

A. No, sir; I make no charge of that sort. I am only saying it is very clear that such a thing might hang over a man.

Q. I understand you make that as a complaint. You see it is a serious charge to make against our medical officer.

A. All I can say is that I know that in former years men have bsen discharged. I do not mean that the Department have deliberately gone out of their way to do that, but still there is a risk of its occurring. Now, the man I was speaking of the other day-Whickers-declares he had to take his pension sooner than he otherwise would have done, for the simple reason that he took part in the agitation in London when stripes were first issued to postmen.

Q. How old was Whickers when he was pensioned?

A. I do not know.

Q. Do you happen to know that he was 70 years of age?

A. He was nothing like that, sir, when he was pensioned. I do not think he was more than that when he died. He was serving as an auxiliary in the Post Office when I entered it 17 years ago.

Sir F. Mowatt: When did he die?

A. Not more than two years ago at the very outside.

Mr. L. Smith: Your suggestion is that the medical officers were tampered with by the Department?

A. No, sir; oh, no, not in the least! That is the statement put forward by the man himself. Mr. Walpole asked me if I could give any instance of a case where pressure was brought to bear, and therefore I named this case. The man always asserted it.

Q. You do not yourself adopt that view?

A. I do not adopt that as a hard and fast line.

Q. In this particular case do you suggest it occurred? You are making a very serious charge, and you must either make it or withdraw it.

A. In this particular case I do not suggest it.

Mr. Walpole : Did you know Whickers?

A. Yes.

Q. At the time when he was got rid of as an auxiliary?

A. Yes; he was then in a very infirm state of health.

Q. Then where does your charge come in?

A. I think you are under a misapprehension as to the facts.

Q. Do you suggest that he thought he might have gone on?

A. Not as an auxiliary, but he thought so when he had to take his pension as an established man. At that time he thought he might have been kept on some years longer.

Q. When was it he took his pension?

A. I cannot say. He was in the Service as an auxiliary when I came in. How long before that he took his pension I cannot say, but it was previous to 1879 . Mr. Churchifield tells me that it was 17 vears ago that he took his pension. I came into the Service in February, 1879. He was an auxiliary then, and I presume he had just taken his pension.

The Chairman: Thank you.

The witness then withdrew. 
H. BOALER, N.W.D.O.

Pancel Post.

Westminster, Monday, February 17, 1896.

Henry Boaler, of the N.W.D.O., was next examined as follows :-

The Chairman: Are you a parcel postman or a letter-carrier?

A. I am a letter-carrier.

Q. And you are going to give evidence from the point of view of the ordinary letter-carrier, and not of a parcel postman?

A. Yes, my lord.

Q. How long have you been in the Service?

A. I entered as a telegraph messenger in 1872. I was appointed secondclass letter-carrier in 1875, and first-class in 1879.

Q. Then you are at your maximum now?

A. Yes, my lord.

The Chairman: Then go on with your statement.

Witness: My.lord and gentlemen, you have heard the statement of the previous witness with reference to the separation of the letter and parcel branches. The statement that I have to make is upon the same subject, bit from a letter-carrier's point of view. I say "letter-carriers," gentlemen, because prerious to the establishment of the Parcel Post that was our designation. I myself was appointed first a "second-class letter-carrier," and then a "first-class letter-carrier." Perhaps it would be well for me to explain how we lost that title, and how we came to be burdened with the delivery of parcels. I say "burlened," gentlemen, because tle late Mr. Raikes (P.M.G.) recognised them as a burden. In an interview upon the same subject at G.P.O. on July 24th, 1890, he remarked-"The parcel question is no doubt a great one. I should be extremely glad, so far as postmen are concerned, if they had never been burdened with them. I always think they were introduced hastily, and the whole system being done in a hurry, has perhaps not worked quite so smoothly as was intended in the first instance." On the 1st of August, 1883, the Parcel Post was established, and, as is usual when special and important duties are to be performed, letter-carriers were called into request. They were the pioneers of the movement, performing the whole of the sorting and delivering, and finally instructed the new entrants, which at that date were unestablished men; and so well did they perform their duties that they were afterwards rewarded with a new title-" postman "-which brought with it the grievance flom which we are now endeavouring to get relieved, viz., the delivery of parcels. This had been feared, but an assurance was given that it would not interfere with the duties of a letter-carrier. This, I am sorry to say, has not been the case, as I will endeavour to prove. This branch was established to supply a public want, therefore a public convenience. But, gentlemen, it is now my duty to explain that in a great many instances it is an inconvenience--1st, to letter-carriers, and 2 nd, to the public. It is an inconvenience to letter-carriers for the following reasons: It is detrimental 
to the proper performance of their duties, owing to the fact that the greatest number of parcels for delivery fall upon the two and the most responsible duties of the day, viz., the first and last. In my own office, for $8 \mathrm{n}$ instance, N.W.D.O., 200 parcels on a G.P. delivery is a common occurrence, and during the Christmas pressure as many as 800 per day were delivered by letter-carriers. The heaviest periods of the year for letters are also the heariest for parcels. And the men who suffer most are those who are on the most responsible and heaviest in the delivery of letters. The inconvenience to the public is caused in the following way:-Although the number of parcels to be dealt with is limited to five on the G.P. delivery, five parcels will often add 10 to $15 \mathrm{lbs}$. to an already heavy delivery of letters, and must of a necessity, when it is considered that every parcel causes a stoppage of from two to three minutes to dispose of, and in many cases they have to be returned through being unable to obtain an answer, which thus causes a delay of at least 15 minutes.

Sir F. Mowatt: You say they have to be returned very often. Is it a very common thing?

A. Yes; it is a common occurrence, because at the early morning dolivery business shops are not always open by 8 o'clock. And in other cases thic servants are not up, or if they are you cannot get people to come to the door to take the parcels. They think it is a letter, and can be put in the box. I have frequently had to take parcels back.

Mr. Walpole: But you would not take parcels out to shops not likely to be open?

A. If we know that shops do not open until a certain time we should leave the parcels behind.

Q. I presume that postmen would know better than any one else what time the shops open?

A. There are a great many cases in which it is not safe to leave the parcels behind. We inay think the shop would not be open, and very likely it might be a very important parcel. Yet by the time a man returned from hi; finst delivery it would probably ba time for him to start out again, and then he would be called upon to explain why he had left the parcel behind.

Mr. Walpole : But don't you constantly leave them behind?

A. YEs; in well-known cases. where we are sure the shop would not be open, but in doubtful cases we take them out. This delay of at least 15 minutes to a most important class-sity gentlemen and local tradesmenis of great moment. The former by liaving to leave by certain trains to attend business, and who do not receive their letters until their return at night, and the latter in carrying out the orders of his customers. It is not an unfrequent occurrence that our deliveries are not finished at 10 minutes or a quarter to nine, and gentlemen often come to me and ask if there are any letters for them, as they liave to catch a certain train and get into the City by a given time. This is not only worrying to the postman, but it is annoying to the gentlemen themselves. The postman gets discreait for being late. $\mathrm{He}$ is often threatened to be reported foi loitering; but we cannot possibly lielp it owing to the delay caused by these parcels. It is only upon those walks where a number of parcels are taken out by the men that this annoyance exists.

Sir F. Mowatt: Do you say that the average number of parcels taken out is more than five?

A. We never take out more than five.

Q. Then the delay is caused by the delivery or non-delivery of five parcels?

A. We cannot get rid of parcels as quickly as we can letters. Anyhow, it takes at least two minutes to get an answer at the door. The servant does not always come to the door the first time of ringing or knocking, thinking, probably, that a letter has been placed in the box. In nine times out of ten we have to knock or ring twice. I have timed myself times after 

times, and I find that it takes two or three minutes before I have been able to dispose of the parcel.

The Chairman: But the same thing occurs when you have to collect extra fees?

A. Yes, my lord; and all these things help to make us late.

Q. Have you not to collect fees much oftener?

A. Yes; we are continually dealing with registered letters, and collecting fees for insufficient postage, etc. The postmen are consequently continually finishing late, and $a_{\text {a }}$ certain amount of pressure is brought to bear upon hin so that he shall finish the morning delivery by a certain time in the morning. If he is after a given time he has to write and explain the reason why. It is rather a critical thing to say, but I believe that a number of the men, sooner than write and explain, will falsify their time in the books, because all explanations as to finishing late go against them. It will, therefore, be seen that to a letter-carrier with a heavy delivery of letters, five parcels is a great consideration, as when thus encumbered and hurrying to prevent a late finish may, in a great many instances, account fo: the mis-delivery of letters. I should like to substantiate this to a certain extent. There are a great number of matters for which a postman may be punished by loss of stripes, extra duty, etc., and this is one of the chief causes. We have to carry parcels, books, etc., and often a man's bag is filled up to the top. He can only just catch hold of the top of it, and yet he has to carry it from the bottom to the top of warehouses. It is bulky and heavy, awkward and inconvenient, and he cannot get hold of it properly. When he is lumbered up with parcels he is apt to overlook the letters, and put them into the wrong boxes. I believe myself that this is a great cause of mis-delivery of letters. A man might easily overlook a post card or a thin foreign letter, and they find it very difficult to sort these things out; they get mixed up together, and it makes it very easy for them to put letters in the wrong boxes.

Mr. Walpole: But whether he has parcels in his bag or not, he may do that?

A. There would not be the same possibilities as when a man is lumbered up with parcels and books. Probubly both his hands will he full, and he would not have an opportunity of looking at the letters so thoroughly as he could wish. The carrying of parcels is also dangerous to correspondence, as in the instance of such parcels as tin, wooden, and cardboard boxes, butter, Devonshire cream, fruits, flowers, etc. And I have instances of game, partriages, rabbits, fish, and the whole of these have to be carried in the same bag as the letters. It is really dangerous to the correspondence. And any damage, such as tearing, soiling, etc., is seriously noticed if reported. I might say that during the fruit and flower season we have to carry cardboard boxes and such things containing strawberries, cherries, and flowers, which are all mixed up in our bags. The weight may be light, but it is the mixing up with our bundles of letters and book packets that we complain of. I have had boxes burst and the juice pour out upon the letters, then it has been necessary to explain to the public how this has occurred. I have had, in consequence, to stand bullying, and have been threatened to be reported. I do not think that these reports are really made, but if they were $I$ believe the Department would find some means of dealing with the difficulty. In the suburban offices parcel duties are still heavier, letter-carriers taking out 6,8 , and 10 parcels on one delivery. During the Christmas pressure, at one of these offices the parcels were so numerous that they had to make a special delivery of them before they could cope with the letters. 'They also have to make up and receive parcel hampers, and are held responsible for their contents, also their safe despatch. They have further to advise and despatch foreign parcels, collect parcels on six collections out of eight, "there being only two made by the parcel postman." As many as fourteen are collected with the letters by 
one man, and the fact of his doing this is greatly detrimental to his keeping his proper time. He has to sign for the parcels, and that will occupy a minute or two, so that he loses time upon his collections. The whole of the above duties carry with them responsibilities, and with them the possibilities of ircreasing the already numerous chances of punishment. I may also add that in the year 1891 parcel postmen were made an established class, and this, with the erection of large depots in various parts of London, goes to prove the enormous increase in the number of parcels, and the necessity of picperly dealing with them. In conclusion, gentlemen, I therefore hope that, as our duties as letter-carriers are of such a responsible and arduous nature, which the numerous witnesses you have heard have tried to prove, you will give your strongest recommendation for the separation of the letter and parcel branches.

The Chairman : How many men are there in your own office?

A. On the General Post I speak of there are 66.

Q. In the N.W. District Office?

A. Yes.

Q. How many deal with the Parcel post alone?

A. The whole of thern. But parcels are only dealt out in the most responsible walks, while in the poorer walks there would be hardly any parcels at all. It is on the most responsible walks that the difficulty arises.

Q. Are there any men in your district office who deal with the Parcel Post alone?

A. There are some at the depot branch, where they deal with the larger parcels, those, for instance, weighing $4 \frac{1}{2} \mathrm{lbs}$. charged over. We get them up to $4 \frac{1}{2} \mathrm{~d}$., but at the depot they send them indiscriminately up to the full charge. Sometimes we get a $6 \mathrm{~d}$. parcel, but it would be a small one; in fact, we get the smaller parcels.

Mr. Walpole: Then you only get small parcels?

A. Yes.

Q. And a $4 \frac{1}{2}$ d. parcel would weigh 2 lbs.?

A. Yes, sir.

Q. Can you give us any case where a man has been overburdened with parcels?

A. In the suburban offices at Hampstead and Kentish Town, men frequently take out parcels up to the price of $9 \mathrm{~d}$. and $1 \mathrm{~s}$.

The Chairman : We only want your experience in your own office.

A. Yes, iny lord; 1 have stated what goes on there.

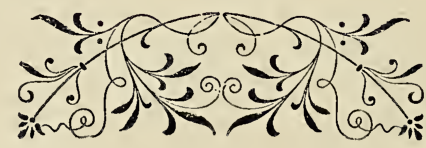


GEORGE HAROLD STUART.

\author{
Parcel Postmen's Cask.
}

Westminsten, Monday, February 17, 1896.

\author{
Mr. George Harold Stuart called and examined :-
}

The Chairman: I believe you are in the Parcel Post department?

A. Yes.

Q. In the S.W. District?

A. Yes.

Q. How long have you been in that office?

A. I have been in the S.W. Office since last November twelve months; but I have been in the Service altogether over five years; I have been appointed about five years.

Q. Did you begin as an ordinary letter-carrier?

A. No ; I began as a parcel postman.

Q. Have you been in the Parcel Post department all through?

A. Yes. I began as an unestablished man in the Leicester Square Paroel Depot, and at the period when the parcel postmen were established I gained my appointment.

Sir F. Mowatt: In 1891 then?

A. Yes.

The Chairman: What is your particular duty? Do you deliver parcels, or do you deal with them in the office?

A. I deliver and collect, and assist with the sorting for parcel work generally.

Q. Do you deliver with a cart?

A. I do with a hand-cart. Of course, many deliveries are done with vals ; others, on the contrary, are done with a hand-cart. The first question $I$ have to bring before the Committee is the Christmas box question as affecting parcel postmen. In bringing before you the case of the establishid postmen on parcel duties, it may be as well for me to state that there is no difference in rank between established letter-carriers and established parcel postmen; in fact, the terms letter-carrier and parcel postmen are siruply matters of convenience, the whole body being classed under the heading of established postmen. Similar examinations have to be passed; wages and increment are identical ; and the same rule governs all. It is one of these rules-No. 44-which causes what I may term the chief special grievance under which we labour. This rule, while permitting letter-carriers to solicit Christmas boxes, contains the following clause: "You are strictly forbidden to solicit gratuities on account of the delivery or collection of parcels." It will, of course, be ovious that this places the parcel postmen at a considerable pecuniary disadvantage; for example, should two men enter the Service at the same time, one of whom is employed as a letter postman while the other is appointed to the parcel branch, the letter man will, in the course of his service, receive a considerable sum more than the parcel man. A question on the subject of parcel postmen being forbidden to solicit Christmas boxes was asked in the House of Commons by Mr. 
Cunninghame Graham, on February 21st, 1890, and the then PostmasterGeneral said in answer :- "The custom of letter-carriers receiving Christmas boxes is a very old one, and, so far as they are concerned, the Department recognise the difficulty that would attend any interference with it. But it has appeared both practicable and advisable to prevent the extension of the custom to new classes, and with this view the solicitation of Christmas boxes by Post Office servants other than letter-carriers is prohibited on pain of dismissal." I admit that this reply fairly states the state of affairs at that period (1890); but it must be borne in mind that a most material change has been effected in the parcel staff since that date, the work being then performed by unestablished men whose duties were comparatively of but small responsibility. In 1891, owing, no doubt, to the increase in the number of parcels dealt with, the extension of the Foreign and Colonial Parcel Post, and the introduction of the registration system in the Parcel Post, which made our duties, always quite as arduous as letter duties, equally responsible, all unestablished men who were eligible received appointments as second-class postmen, and were thus placed on an equality with letter-carriers. Shortly after, classification was abolished, an! all-letter-carriers and parcel postmen-became one class. By thus raising us from the new classes to which the Postmaster-General alluded to the classes which are allowed to solicit Christmas boxes, I contend the Department incurred a responsibility which it has made no attempt to meet-the responsibility of allowing us to solicit Christmas boxes or of granting us an allowance in lieu of that permission. I have no desire to question the wisdom of the Department's policy in seeking to limit the practice of Christmas boxing, but I certainly think it should be definitely laid down as a first principle that the cost of this should fall upon the Department itself, and not upon its servants or any section of them. The natural and inevitable results of what is considered an unjust and unfair rule are to be observed almost every year. Men try to evade and defy it, and, should the breach of discipline be discovered, are severely punished by suspension, infliction of punishment duty, reprimand, etc., to which is added the galling circumstance that other men of the same class are permitted, and indeed encouraged, to do what they have been punished for doing. I may mention that there is a circumstance which sorely tempts parcel postmen to break Rule 44. Certain firms and others put aside sums each year as parcel postmen's Christmas boxes. Now, the only way to get them is by asking for them, for people naturally wait to be asked, thinking that by so doing they ensure the gift falling into the right hands. We are thus placed in a most invidious position. If we ask for what is practically our own we risk dismissal ; if we do not, we lose a most desirable addition to our wages. Gentlemen, it is dishonourable to the Department that poor men should be placed in such a position. To conclude, I would remind you of a remark which fell from your lordship during Mr. Warner's case. Y $Y u$ said it seemed hard that men on collecting duties should receive no Christmas boxes. If it is hard for these men who have this emolument to look to in the future at any rate, I put it. to you that it is very much harder for us who not only receive nothing now, but have no prospect of ever doing so, and I confidently ask you therefore to recommend that an allowance be granted us so that parcel postmen may at length reap all the advantages to which, as established officers, they have a right.

Q. As a matter of fact, I fancy that parcel postmen do receive a considerable amount of Christmas boxes?

A. Not a considerable amount without endangering their situation.

Q. I am not talking about endangering their situations, but I happen to have made some private inquiries on the subject, and I have been surprised to find that in almost every case where a considerable Christmas box was given to letter postmen, a sum was also given to the parcel postmen; that is so, is it not? 
A. It is not so generally, but it is so in some cases. I think that shows conclusively that this rule is unjust and unfair.

Q. I understand the rule only prohibits solicitation?

A. Exactly.

Q. It does not prohibit the reception?

A. No. That, of course, is so, but then you cannot get them very well without asking for them. People do not run in the street after you with the money. That is the position the Department places us in.

Q. What I wanted to find out is, whether your experience as a parcel postman is such as to justify you in the belief that if the solicitation of Christmas boxes were prohibited to the letter postmen, the public would cease to give?

A. I think they would, because the public do not recognise these differences which the Department make; in fact, we ourselves cannot understand why they should make any difference. We contend that our work is in every respect equal to letter work. I will deal with that portion of the question later on, but I will say now that the public do not recognise these differences, and if they cease giving them to letter-carriers, they would cease giving them to us as postmen. Therefore, if the letter-carriers receive compensation and we do not, we should be unfairly treated.

Q. If it could be told us that it was the invariable rule that the parcel postmen got nothing, that would be a very strong argument in favour of the idea that the public would cease to give to the letter postmen if they were prohibited from soliciting; I am afraid that argument will not hold good, quite?

A. The public give Christmas boxes to parcel postmen, not out of generosity, but simply out of a sense of justice; they do not think it is right that the Department should make these invidious distinctions. I remember myself a man asking me why I had not called in for my Christmas box. I said, "I must not do so ; the Department do not allow me to solicit." "As a matter of fact," he said. "I suppose you receive more money than the letter-carriers?" I said. "No." "Do you mean to tell me that you do not receive more money than the letter-carriers, and that you are not allowed to solicit? I bolieve they get a great deal." I said, "We do not receive any more," and, as a matter of fact, his remark then was, "I never heard sucl damned cheek in my life."

Q. I hope he acted up to that opinion?

A. You see our case is that the letter men are asking that these Christmas boxes should be abolished. and that they should be granted compensation. If compensation is granted to the letter postmen, and we receive nothing, we do not consider that would be fair. Of course we admit that the public do, to a large extent, give us these gratuities. even in face of this rule; but the men have to break the rule and to risk dismissal, and men have been dismissed for breaking this rule and frequently otherwise punished. You ses it is not necessary for the public to report the man for importunity as in the case of a letter-carrier. If, through anv circumstance, it comes to the knowledge of the Postmaster or any official of the Department that the man has solicited, he may be reported and severely punished. As wo are established men, and in other points equal to letter-carriers, we do not consider that this is fair to us. We consider that all the advantages which letter postmen have we should receive; and exactly the same with compensation-if any compensation is granted to the letter men with regard to this matter, we consider that we have a right to be considered accordingly.

Mr. Llewellyn Smith : Are the parcel postmen interchangeable with lettercarriers? When you get into the Service, when you are once a parcel postman are you always a parcel postman?

A. That is so in the chief depots; it is so in Mount Pleasant, and I 
believe it is so in Bird Street, but at the South-Western Office it is not so. At the South-Western the men are allowed to go upstairs into the letter walks, but we object to that system. I have a case in point, and I can go into the details of it. A man has four or five years at the rough work of the parcels, and then he can go upstairs, but certain restrictions are placed upon him. There has to be a certain time on town duty; that is to say, on the reserve upstairs, and consequently we would lose our seniority up to that time.' We object to going on the other branch altogether.

Q. In spite of the Christmas boxes?

A. We hope to get compensation.

Mr. Walpole: Still there has been no question of compensation up to this, and you still prefer to remain as parcel postmen?

A. We should not prefer it if the letter men received compensation and we did not. We contend that we have a perfect right to receive just as much money as any other postmen.

Q. As a matter of fact, what are your Christmas boxes worth-your own I mean?

A. My own?

Q. Yes.

A. Without solicitation?

Q. Without solicitation; I assume you obey the rule?

A. About 1s. 6d.

Q. What! 1s. 6d. a year?

A. Yes; without solicitation.

Q. Then the whole compensation we have got to give you is 1s. 6d. a year?

A. Nothing of the kind. I contend, as a matter of fact, that the Department has robbed us during the years we have been established by not allawing us to solicit.

Q. The Department has made a rule, and you entered the Service with the full knowledge of that rule?

A. But when we entered the Service we were not told whether we were to be parcel postmen or letter men; we had to go where we were put.

Q. You entered as a parcel postman, did you not?

A. I entered as an unestablished parcel postman.

Q. You were then made an established parcel postman?

A. Yes.

Q. So the Department has kept faith with you all the way through, has it not?

A. No, I do not consider they have. When I entered the Service as an unestablished parcel postman it was a regular thing, after a certain amount of service in the parcel post, to be drafted as an established man into the letter post; and then, of course, you would get these advantages of the Christmas boxes. When we were established, however, we were not allowed to do so. We had been in the Service some time then, and I contend that the Department actually had no right to make this rule without giving us compensation.

Q. Do you think the Postmaster-General has no right to make a rule which applies to all the letter-carriers all through Scotland at the present moment?

A. I believe the Postmaster-General has no right to make a rule whichweli, robs one section while it gives unfair advantages to another.

Q. Even though that is a rule which the whole of the letter-carriers of London have asked him to make apply to them now?

A. Yes; but they have asked for compensation. I contend that as postmen we have a perfect right to receive everything which every other postman receives, and if you grant compensation to the letter men, I contend that we have a perfect right to receive it also.

Q. That is your contention?

A. Yes。 


\section{HAND-CART ASSISTANTS.}

Witness : The next matter to which $I$ have to refer to is the request that assistants be allowed on all hand-cart deliveries and collections. This is a grisvance which, I am isure, will be at once remedied when its nature is understood. At the large depots, whenever a delivery or collection is made involving the use of a hand-cart, two men are sent with it, both of whom assist in its propulsion. Having regard to the weight of the handcart when loaded with parcels, to the fact that it is often impossible to fasten down the lid owing to the bulk of the contents, and also that these contents are of considerable value, generally including registered and foreign parcels, it is of the highest importance that two men should accompany each hand-cart. At some of the minor offices, however, notably the NorthWestern and Hampstead, men are often sent on hand-cart deliveries or collections without anyone to assist them. If these were accidental occasions due to stress of work or some unforeseen contingency, the case would be bad enough, but this is not so. Men have to do this daily as part of their duty. Some flagrant cases are where men have to attend the office at 4 p.m., take a hand-cart, make a 4.30 p.m. collection, bring it in, take out a delivery at 5 p.m. which will last till nearly 7 p.m., and then bring in a 7 o'clock collection, the whole of this being performed single-handed. Were this performed upon level ground the strain would be very great, but for a man to have to do this among the bills of North-West London involves a strain of a heavy and injurious character. As an example of the nature of the district, I may say that in Camden Road, which has to be traversed by some of the men of whom I speak, an extra horse is allowed by the Tramway Company for their trams, but, as I have shown, no assistance is granted the postmen. I may say with regard to the North-West that they have applied for assistance, but it has been refused. At Hampstead the men applied for assistince when the snow was on the ground, and the answer they received was that they did not encourage laziness in the Post Office.

Q. Who gave them that answer?

A. The overseer, I presume. Another matter which should be considered is the insecurity of the parcels under this system. A man is often obliged to leave his hand-cart unguarded whilst engaged delivering or collecting, by night as well as by day. It is true locks are placed on the hand-carts, but they are of very simple construction, and may easily be turmed. During the absence of the postman, which may last several minutes, especially if he has a registered parcel to deliver, or one about which he has some inquiry to make, it is quite easy for anyone so disposed to abstract a parcel or parcels from the hand-cart. Of course, it is quite impossible to take a hand-cart everywhere you go, and you have to leave your handcart when you go up to the top of buildings or something of that kind. In the City, of course, there is a great deal of stair work in the offices; and in all other districts, too, although there the offices are far less numerous. But there are many blocks of mansions and buildings, and, of course, all these liave to be climbed; and it generally follows, as a matter of course, that when a man has a parcel sent him, he takes care to live on the top of these buildings, and you have to go right to the top and wait there till the slip is signed, and it may be that several minutes elapse while you are away. It is, therefore, quite easy for anyone to abstract a parcel from the hand-cart, which, of course, means loss and annoyance to the addressee.

Q. Do you know of any case where a parcel has been abstracted from a hand-cart while the postman has been going upstairs?

A. No; it is impossible to say-

Q. As a matter of fact, has there been any case brought to your know. 
leäge of the loss of a parcel left in that way while the postman was going upstairs?

A. I am about to answer if you will allow me to. I say it is impossible to say exactly, because if a parcel is lost from a hand-cart, and the man comes back and reports it, he cannot say how or where he has lost it.

Sir F. Mowatt: He would find out, would he not, if his lock had been broken?

A. These locks are somewhat similar to railway carriage locks, and you simply turn them by inserting a piece of steel. I have seen them turned by a piece of wood being inserted. When the man came back and reported the loss, he could not be certain how he had lost it; for instance, he might think he had left it behind in the office.

Mr. Walpole: Will you accept it from me that, as far as the Department knows, no parcel has over been abstracted in the way you have mentioned?

A. I will accept it from you bacause, as I say, it is impossible to say. I only point ont that it is quite possible that parcels may be lost in this way, and that they ought to be safeguarded, so that this risk should not be run. As I say, this means loss and annoyance to the addressee and to the Department, and, moreover, the postman is liable to punishment for losing the parcel, although it will be seen that it was impossible for him to prevent the theft. These evils would be obviated were it laid down as a strict rule that all hand-carts must be accompanied by two men. Another question which is very much interwoven with this is the limit of weight on bag deliveries and collections. In some offices where they are not allcwed any assistants, and where they know they have more than they call carry, rather than take a hand-cart they overload themselves. Another thing: it is a temptation for a man to delay parcels in a case like that. If a man has as much as he can carry, and he gets another parcel which will necessitate his taking a hand-cart, it is a very great temptation to that man to put the parcel out of the way if he possibly can do so. I do not say it is done; I believe it is not. I only point out the temptation which it is to the men to do this kind of thing. If it were laid down as a strict rule that two men should be sent with each hand-cart, this sort of thing could not be done. Of course, with regard to the big deliveries and collections, assistance would imply that two men would be sent with the handcart in this particular case. There is a rule laid down in the Rule Book that if you have more than $35 \mathrm{lbs}$. on a collection you can ask for assiatance; but I say that rule does not practically apply to parcel men, because if they ask for assistance in most offices they are told to take a hand-cart. At some depots the weight a man is supposed to carry is the same as in the letter branch, viz., $35 \mathrm{lbs}$., but at others this limit is not recognised, and the men are much more leavily laden. I think it should be clearly defined what the weight limit really is, and this definition should be printed in the postmen's Rule Books.

\section{OVERALLS.}

Now I have to deal with the question of overalls. I do not wish to put this as a grievance. It is not a grievance. The idea of asking for these things has been mooted on several occasions, but it never assumed any distinct form until after this Committee was appointed; then we understood that the official channel was closed-

The Chairman : No.

A. And that anything we required was to be brought before this Committee. This request for overalls is a request for a small addition to our uniform. Parcel work, consisting, as it does, of a large amount of handcart propulsion necessitates, of course, much walking in the roadway. The condition of London streets in wet and muddy weather needs no 
enlarging upon. In such weather our trouser legs become saturated with water, and no matter how good our boots may be, it is impossible to keep our feet dry, as the water splashes over the tops of the boots and runs inside. It is often some hours before we can change or properly dry ourselves, and the results frequently are that men contract colds, rheumatism, etc. This matter would be easily and effectually remedied were overall leggings, similar to those issued to the Metropolitan Police, issued to us. The cost would not be large, and the Department would, I am confident, be recompensed by the decresse in sick pay which would follow. I may mention as a not unimportant matter that we should be able to keep our uniform much smarter and cleaner than at present were this request granted. With regard to the cost, I have not been able to find out what the police officials pay on their contract price, but I believe you can obtain a very good pair of these overall leggings for about 7s. 6d., and they would last a couple of years at all events, so that the cost would really be very small indeed. I am informed that the cost would be much less than 7 s. $6 \mathrm{~d}$. a pair.

Q. It would rot help your boots; you would get your feet just as much wet through if you had overalls?

A. No; they come down very low over the laces of the boots, so that the water would not get inside so readily at all events. It would be a great advantage in that respect.

\section{SEPARATION OF BRANCH.}

Now I have to deal with the separation of the branch. I would urge upon you that the parcel branch should be entirely severed from the letter branch. A strong reason for this separation lies in the fact that the present system engenders an opinion that our branch is an inferior one. This opinion, which seems to be shared by Mr. Badcock, judging from the evidence he gave upon the sorters' case, is an incorrect one, and cannot fail to have a bad effect upon the parcel staff. The canse of this opinion is probably that the Parcel Deportment is of recent establishment, and I am afraid youth and inferiority are often held to be synonymous terms. It is to this opinion being held, no doubt, we owe the fact that on one or two occasions men have been temporarily transferred from letter offices to parcel depots as, punishment for miscondudt, a proceeding we strongly object to. Again, should a parcel man perform a superior duty, such as a lobby officer's in the absence of that official, not only would he receive no addition to his wages while doing so, but, should a vacancy arise, the position will be given, not to the man who has performed the duty at inconvenience and possibly expense to himself, but to a letter man, who may have had no experience in parcel lobby work. I contend that this is unfair; if a man undertakes 2 position of responsibility to oblige a department, he should be able to look forward to a substantial benefit, as he receives nothing at the time. The system of treating the parcels branch as an inferior one has peculiar and far-reaching effects. It is doubtless the reason why we are not allowed to solicit Christmas boxes; it may even be the reason why some men at Waterloo have to be on duty $56 \frac{1}{4}$ hours per week instead of 48 . These men are coach guards, and I have here a statement from one of them. On the Wallington coach, he tells me he goes on duty at $5.15 \mathrm{a} . \mathrm{m}$., at 5.52 the coach departs, and he calls at South Lambeth, Clapham, Balham, Tooting, Mitcham, Sutton, and Carshalton; at 7.59 he arrives at Wallington, his destination. When he arrives at Wallington he is about 17 or 18 miles away from his base-his home-and he is put off duty from 7.59 a.m. till 12.11 p.m., or about that, and he receives no allowance or anything of that kind; and while he is actually put off duty, there is no accommodation for him at Wallington, and he cannot get any food or anything lik 
that, but has to go back to Carshalton, a distance of about a mile, to get his breakfast in the stables there. At 12.11 p.m. he leaves Wallington and calls as before.

Q. Does the coach put up at Carshalton then?

A. Yes; and through the kindness of the driver he goes back on tho coach. As a matter of fast, I think he ought not to do so, but the driver brings him back. At 2.17 p.m. he arrives at Waterloo, and is then employed opening baskets, etc., until 4 o'clock. He is actually on duty, I contend, for $10 \frac{3}{4}$ hours. I think when a man is taken away from his home at a distance like that, the Department ought not to consider that he is off duty for this space of four hours very nearly, for the man cannot do anything, because, of course, he cannot come home. In the case of a long distance guard, they get an allowance, which $I$ think is called a sustenance allowance, of 3s. per day. This man, although he is put to not as much expense, but still to a great deal of expense, receives no allowance, and that, I contend, is unfair. I cannot see any reason why that should be so.'

Q. Is he a postman, technically speaking?

A. $\mathrm{He}$ is a postman. This system of treating the parcel branch as an inferior one may also be the reason that two parcel postmen at Hampstead, although in the Service for some years, have never received any uniform or boot allowance. I have received particulars of their case from these men. These men, it appears, have been in the Service for over three years, and they have never received any boot allowance or any uniform.

Mr. Walpole: Are they established postmen?

A. They are not. They do not exactly know what they are, and they want to know. They seem to think that they are first-class sorters.

Q. If they are first-class sorters what has it got to do with your case?

A. They would like to know what they are. They are termed casual postmen employed on parcel duties. They tell me they do all the recording, despatching, and entering of foreign, colonial, and registered parcels. That, of course, is first-class sorters' work. But t'iese men are really parcel postmen.

Q What is their pay?

A. They are paid 18s. a week, and they receive no advances in money whatever. They are not supernumerary postmen, because, if they were, they would, of course, have received some small advances; they have been there for three years and have received nothing at all.

Q. These are, as a matter of fact, full-time supernumeraries, are they not?

A. No, they are not. They have been in the Service three years, and have received no advances in their pay. They have been told they were casual postmen, and if they were full-signed supernumeraries they would receive boot money and their uniform, which, as a matter of fact, they have not. There are three other men in the office styled the same, viz., casual postmen, who do receive uniform, but who do not receive boot money.

Q. Are these men employed on indoor duties?

A. On both indoor and outdoor duties. At any rate, no other reason than the system of treating the parcel branch as an inferior one can be assigned for these things. I beg to assert most positively that our work is every bit as responsible as letter work, and in proof of this assertion I would like to call your attention to the nature of a parcel postman's duties. In addition to his work of sorting, collecting, and delivering parcels, he performs a considerable amount of clerical work, as each parcel has to be recorded on lists provided for that purpose. I have provided myself with lists (producing and explaining same). You will perceive there that in entering a parcel you have to enter the name and address, and the name of the office of origin, and also whether by coach or rail, and other par. 
ticulars. You see great care has to be taken in entering these parcels for fear that the railway company should be paid too much. That is a sample of the clerical work which a parcel postman has to perform.

The Chairman: Have these two sheets been done by yourself?

A. Yes. As a matter of fact, they are not done with pen and ink liks these; they are done with lead pencil.

Q. Have you filled this in yourself?

A. Yes.

Q. Just as a sample?

A. Exactly; to show how they have to be done.

Q. This is not an actual list, but it is just a sample to show us what you have to do?

A. Yes; it is exactly the same as the lists we do:

Q. I imagine you have made it as elaborate as you can?

A. No.

Q. I see jou have got parcels from Egypt and from Oxford on it?

A. If you were to go through the whole of our lists, you would find that it is not by any means elaborate.

Q. Is it not?

A. No; in fact, I have left out several that I might have put in. I think I have been very fair to the Department in that. With regard to Kingston an 1 suburban places, you do not enter the postage as a general thing, but sometimes you do for parcels. To continue with my statement. This portion of the duty is, I believe, performed by sorting clerks in the provinces, but in London is almost wholly done by postmen. Great care must be exercised when recording, for the name and address of the addressee, the name and code of the office of origin, and the amount of postage, must be distinctly shown. In the case of foreign, colonial, and registered parcels, still other particulars must be given. The postman making these entries is wholly responsible for their correctness, and is liable for punishment for errors committed. When the number of places which are named alike, but which have to be shown differently, are remembered, it will be seen that this responsibility is a very real one, and that errors may easily be made. The parcel postman's clerical work does not end here, for he has to fill in a "to whom delivered" column on his list, with the description, or, if possible, the name of the person who has received the parcel he has delivered. Charged parcels, too, cast great responsibility on parcel postmen, as the charges sometimes, in the case of customs dues, amount to several pounds. These things, I contend, make our work in every way equal to letter work, and I maintain our duties cannot fairly be said to be inferior to letter duties. I am dwelling somewhat on this inferiority business, but my excuse must be that the matter is keenly felt by us, and we are convinced that separation is the only remedy. With regard to this inferiority, it is rather unfortunate for a branch when a. Department gets hold of that idea. I may point to a case in point: the Department held the idea that sorting work was superior to postmen's work, or, at least, I believe so; and the consequence was that the sorters' maximum was greatly raised, while the postmen's maximum was left almost stationary, or was not raised very much at all events. We do not want anything like that to happen to us; we want to guard against anything of that kind.

Q. Still, you do want to be separated from the letter men altogether?

A. Yes; so far as the working is concerned. I think it would be ad. vantageous to the working. I have said, I trust, sufficient to prove that this inferiority does not exist, at least so far as postmen's work is concerned. I now turn to another strong argument for separation, viz., the great and ever-growing importance of the parcel branch. In the first com. pleted year after the establishment of the Parcel Post, I find that the number of parcels carried was 22,910,040. In the year ending March 31st, 1895 , the number is given as $57,135,841$, or considerably more than double 
the quantity carried in the first year. I find also that the number of res gistered parcels last year was 590,788, and a calculation of the number of parcels registered to letters registered, shows that a far larger proportion of parcels are registered to lettars. I have not in that calculation included the number of insured parcels, which amounted last year to nearly $60,0 \mathrm{c0}$, which is a great increase, and which would make t'e comparison more favourable to us. The number of foreign and colonial parcels exchanged in the same period was $1,557,831$, and their value $£ 2,031,255$, or an average of $£ 16 \mathrm{~s}$. each. That is a rough average, but it is rather more than $£ 16 \mathrm{~s}$. each. The value of the inland parcels it is, of course, impossible to give, but as nearly every purcel carried has a distinct monetary value, it must be enormous. In making this comparison respecting the proportions of letters and parcels registered, I have no intention of undervaluing letter work. I only wish to show the value of our own work, and to argue from that stand. point that a separate branch is desirable. To some extent we are separated by the establishment of such depots as Mount Pleasant, Bird Street, Waterloo, and I ondon Bridge, which have their own staffs, reserves, etc.; but at other offices the branches are worked conjointly, one reserve staff serving the whole, and this often throws an unfair amount of work on the parcel postmen, as a man from the letter branch where the sorting is different and the system of delivery entirely different, will need almost as much tuition as a new man. Even men who have some knowledge of parcel work find themselves greatly handicapped after a short absence, owing to the frequent changes in the sorting. In fact, the system seems to me entirely faulty, as postal work requires not men who have a good general knowledge of the work, but rather men whom I may term specialists. Men who are employed on one kind of work one day and on another the next cannot be so efficient as if they were kept on one kind always. On the matter of difference in the nature of the work, I should like to quote Mr. Badcock's answer to a question from your lordship. He said, "The experience that a nian gains in Parcel Post work would be of no use to him in a letter office." His answer, of course, referred to the sorters, but it will apply equally well to the postmen. Entire separation would tend to secure greater efficiency in both branches, and would be welcomed by both letter and parcel staffs. It may cost a little more to work the branches separately, but I am confident the increased efficiency will more than recoup the Department for the outlay. I ask, therefore, that parcels be exclusively dealt with by parcels men; that each parcel depot shall have its own staff, and that all promotion in parcel offices shall be res?rved for parcel men. Of course, on such a thing as wages we claim entire equality.

Q. Exactly; your case is the same there. But do you not see a great difficulty in separating the work of the two classes in the country generally; it may be possible in big centres, but surely it must be quite impossible in the country districts?

A. I only represent London, and I do not see any difficulty as far as London is concerned. With regard to the country, I think that difficulty will diminish, because as the parcel work increases you will find that it will naturally separate itself. What I mean to say is this, that if a numbrr of parcels are being delivered in a place, and they find they are increasing rapidly, as a matter of fact they will have to employ a separate staff. Of course, it will not do away with the difficulty in remote country districts; you never will be able to do away with that difficulty at all.

Mr. Walpole: Would it not be utterly impracticable in the country districts to separate the services?

A. It might be in remote districts, but $I$ am speaking of London.

Q. Would it not be very difficult in the suburbs of Lon!on to separate the two services?

A. I do not think so. It would be a little more expensive than at present, but I say that the natural growth of the Parcel Post will necessitate this 
sort of thing being done, and that, as a matter of fact, I am simply forestalling the Department in asking for this. I think you will have to do this kind of thing in some years to come. It would be desirable and better for the parcel branch, and it would conduce not only to greater efficiency, but it would make the branch more elastic.

The Chairman: We heard from the last witness that even in London the delivery of parcels was practically confined to certain walks in one district, and that the parcels in the poorer districts were very rare?

A. That particular office would require a less number of parcel men, that is the only thing; the districts would be exactly as they are now. A parcel walk is far longer than a letter walk. It would simply work out to the same thing in that respect.

Mr. Walpole: If you separate the two staffs as you propose, do you propose to have two separate supervising staffs also?

A. I do not see that that is necessary; there is not a separate supervising staff for the sorters.

Q. Would you put the letter-carrier and the parcel postman under the same overseer?

A. Yes; that would apply to the case where the parcel men and the letter men were in the same office, but it would not apply to places where they had separate depots, certainly not. They would be just the same as sorters and postmen under the same overseer. That, my lord, is my case.

The witness withdrew.

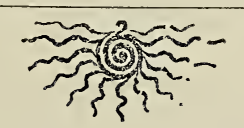


HENRY BOALER, N.W.D.O.

Punishments-Discipline.

Westminster, Thursday, February 20, 1896.

The Committee resumed its sittings at Westminster on February 20th, there being present the Right Hon. I jord Tweedmouth (Chairman), Sir Francis Mowatt, K.C.B.. Spencer Walpole, Esq., Sir Arthur Godley, and Rohert Bruce, Esq., Secretary.

Henry Boaler was re-called and examined on the question of punishments, as follows :-

The Chairman: I think you want to speak upon the question of punishments. Will you go on with that?

A. Yes; I want to make a statement on the subject of excessive punishments, and I make it on behalf of the London postmen. We claim that it is excessive punishment where men are punished during the whole period of their service.

Mr. Walpole: How do you mean by "punished during the whole perio 1 of their service."

A. I will shortly explain and illustrate that in my statement.

The Chairman: I spppose you mean that the record mounts up against them?

A. Yes. The first case to which I would ask your consideration is that of J. Chapman and W. Howell of the Western District Office, who, in the year 1891, were punished with the loss of class, which to a postman is monetary loss.

Sir F. Mowatt: Loss of class?

A. Yes, sir.

The Chairman: You mean that they were degraded by being put back in their class?

A. Yes, my lord. In this instance their loss is estimated at about $£ 40$ at present, and they will continue to lose at the same average until they reach their maximum. Their offence is one which we have the highest possible authority for saying is no offence, and which there is no rule against, viz., combining for remedy of alleged grievance. These men were appointed as auxiliaries in 1886, and appointed 2nd class postmen in 1888. In 1890 they joined the Postmen's Union, and were elected by the members of the Branch as local secretary and collector. During Oetober, 1891, nearly two years 1.iter, and at the time of the abolition of the classes, 52 appointments to the 1st class were to be made, which should, in the ordinary course of events, have included these men by virtue of their service and fitness, each having over three years, and whose conduct had never been questioned. But this was not so. They were excluded, and the reason given by the Postmaster was that they were prominent members of the local branch. Therefore, gentlemen, these men were passed over by a number of their juniors, which vot only meant an immediate.loss-3s. per week-but the loss of seniority, which also acts to their detriment in the choice of walks, holidays, etc. 
The Chairman: Has the particular case of these men been raised before?

A. Yes, my lord; I believe it has been reported to the Comptroller several times. They can get no remedy.

Mr. Walpole: Did not these men attend a meeting outside of the Post Office for the redress of grievances contrary to the then existing regulations of the Department?

A. I have a quotation here from one of the best authorities we can getthe late Mr. Raikes-who, when Postmaster-General, said, "There is no rule forbidding Post Office employees to combine for the purpose of remedy. ing alleged grievances."

Q. But was not such a rule in force at the time these men combined?

A. We are given to understand that there never was such a rule.

Q. Is it not a fact that at the time these men met there was a distinct rule of the Department forbidding them to meet outside the Post Office to discuss their position? I am not saying whether the rule was right or wrong, but was not that the case?

A. Yes; it was the case.

Q. And these men disobeyod that rule?

A. I have no evidence that these men disobeyed the rule, and, moreover, the Department never called upon them for any explanation of the matter.

Q. As a matter of fact, they did attend a meeting at Clerkenwell, did they not?

A. No; I am not aware of that. I am told that they did not. Even if they had attended such a meeting, which I am empowered to say they did not, as the rule has since been done away with, we think their punishinent ought to have been done away with also. The effects of the punishment should not continue as they do to the present day.

Q. The punishment was a punishment for the transgression of the rule. I am not interested in defending $a_{i}$ rule which did not exist after I became Secretary. But is not that the fact?

A. I believe it is.

The Chairman: Have they had no promotion since?

A. Yes; they have had their good conduct badges. They are good conduct men, as proved by the fact that they have got all their increments and stripes and everything up to date. What they complain of is that the junior men are receiving $3 \mathrm{~s}$. per week higher wage, and also enjoy the privilege of preference for certain walks, and that is an advantage to them in regard to Christmas boxes, which is part and parcel of our wages. They also get the choice of holidays.

Q. What you mean is that these men by their disobedience of this particular rule lost a certain amount of seniority?

A. Yes; and an immediate loss of $3 \mathrm{~s}$. a' week.

Q. That was involved in the loss of seniority, was it not?

A. Yes, my lord.

Sir F. Mowatt: You say that the matter has been represented to the Comptroller, and that it is not a fact that these men attended any meeting outside the Post Office?

A. Just so.

Mr. Walpole: Were there three or two men?

A. Two men-Howe and Chapman. I have a statement here which will explain the whole of Chapman's case, if I may have permission to read it. It is from himself.

The Chairman: I don't think you must read it. I think you must only use these cases as illustrations. We are not here to inquire into the grievances of individuals, but rather into the grievances of all classes in the postal service, and the only way in which you can bring in any individual case is as an illustration of what the whole class is liable to be subjected to. I am quite ready to hear anything you may have got to say on behalf of your class, but with regard to the long statement as to the individual case of 
Chapman I think it would be better if you simply handed it to the Secretary of the Post Office.

Mr. Walpole : Please hand it to me, and I will take care that it is looked into.

Witness: The statement will practically cover the case of the two men I have mentioned. I should also state that it is not a personal matter merely. Until we get a proper ruling on this question we don't know how we stand, and even witnesses before this Committee may perhaps have some doubt as to whether they may not ibe subjected to the same sort of thing themselves. I mean loss of class or something like that. We want the rule properly defined.

The Chairman: You may be quite sure that you will not suffer loss of class or any other damage whatever through anything you may say here. You and the other witnesses may make your minds ciuite easy on that point.

Witness : That suggests one point why we would like to ask you to accept evidence in support of the recognition of our society. We think our society should be recognised by the Department. These men have been punished, and are being punished unjustly, and I must ask that in common justice you will recommend that they be recompensed and placed in their proper position in the Service.

The Chairman: I do not think that we are empowered to interfere in matters of discipline that are past. All we can say is that evidence we have received makes us think that such a rule as you have referred to does not work well with regard to a whole class of individuals, but we are not a court of appeal from the astion of the Postmaster or the Postmaster's suborclinates in the past. I want to make that quite clear.

Witness: I quite understand that, but I think that if the rule has been done away with the punishment should not continue, as at the present time, and that these men should be recompensed by being restored to their seniority.

Mr. Walpole: I think it is only fair I should say that I cannot accept that view. Disobedience of a rule that exists at a certain time does not seem to ine to be condoned by the fact that the rule is afterwards altered. 'The punishment is imposed for disobedience of an existing and well-known rule, cyud here I am not expressing any particular opinion on the merits of these individual cases.

A. We have no proof that these men broke the rule. They were elected by their comrades as the local secretary and collector of a branch to solicit small subscriptions, etc., to keep the branch in order, and I believe it was stated by the Postmaster that the punishment was imposed because they were prominent members of their branch. I understand that to be the only cause really why they were reduced, and they were given no opportunity of explaining whether they had broken any particular rule or done anything like that. They were never called upon to make apy statement whatever with regard to their position. The next subject $I$ have to deal with is that of excessive punishment. We maintain that the system of punishing men three and even four times for one offence, extending in many cases over five years, is excessive punishment.

Sir F. Mowatt: How does that occur?

A. I will explain. The punishment inflicted on postmen most seriously affect their good conduct bariges and promotion, as well as the system of receiving increments. That, we think, is cruel and unjust, considering that the Department is put to no monetary loss by the offences for which these punishments are inflicted, although sometimes the stripes are withheld for offences spreading over as long period as five years. If a man is a little late, or commits any other trifling offence, it may be brought up against him even five years afterwards, when a stripe becomes due.

Mr. Walpole : If a man has lost an increment on account of his conduct during the preceding five years, he is not eligible for a stripe.

A. Yes. 
Q. Is not a stripe a reward for good conduct?

A. We regard it largely as wages.

Q. But it is a reward of good conduct?

A. It carries certain extra wages with it.

Mr. Walpole: You had better get that idea out of your head. We regard stripes as a reward for good conduct.

Sir F. Mowatt: Some of the other witnesses disclaimed regarding the stripes as wages.

A. I have heard it stated that it is a rule in the book of instructions issued for Postmasters that no man is to be punished with the loss of stripes unless he has been late in attendance sixteen times, I think, during the course of the twelve months.

Sir F. Mowatt: Now you are speaking of late attendances.

Mr. Walpole: That does not touch the question we were discussing. No main loses his increment for a small number of late attendances.

A. We have really no definite rule as to the number of times, and we don't always understand what a small number is.

Q. Have you known any cases where a man's increment was arrested unjustly for late attendance?

A. Yes; I have several cases which I will read later on. The very fact of the punishment complained of goes to prove the responsible and important nature of our duties, so much so that in no other branch of the Service are the possibilities of punishment so great as in the postmen's ranks. We would therefore ask that the arduous and varied nature of these duties bo taken into consideration. I will now read a list of the duties of postmen, as it will assist me later on with my explanations : -1 , The collection of correspondence ; 2 , the delivery of same; 3 , the whole of the inward sorting; 4,75 per cent. of the outward; 5 , dispatching railways ; 6 , responsible for the whole of the news dispatch; 7 , receiving and dealing with district bags; 8, dealing with removals and re-directing same; and 9, to assist in the collection and delivery of parcels. The whole of the duties named carry with them responsibilities, and any mistake in the performance of them is a punishable offence. All little mistakes are brought up as evidence against the men when applying for their increment or stripe. The punishment of which we complain most is the punishment for late attendance. In the instance of a man who may unfortunately have been say from 12 to 18 times late in the course of 12 months, no matter how little the time lost, he is punished with the loss of his increment when that becomes dué, and in the event of the man being entitled to a good conduct badge by reason of his service, that is also withheld. And in some instances men are punished with extra duty also, although the time lost has, however small, and in every instance, to be worked out, usually by a special attendance and at the convenience of the Department.

Sir F. Mowatt: I thought there was a limit of three or four minutes allowed which did not count as late attendánce?

A. No, sir. I have known men having to sign for one or two or three minutes late. Each counts as a late attendance.

Mr. Walpole: Does anything coint under five minutes?

A. Yes; from one to four minutes count.

The Chairman: Does one minute count?

A. Yes ; I have known a case where a man had to sign the late book for one minute, and two minutes is a comparatively common occurrence.

Mr. Walpole: Are men punished for that?

A. It is recorded against them the same as if they were an hour late.

The Chairman: But they are not fined?

A. We have no fines, but these late attendances are all totalled up against them, and may interfere with their increment. In the case of collections I think they are regarded as even more serious than in the case of G.P. deliveries, for they are mostly written in red ink. 
Q. What is the exact measure dealt out to a man who is late? I mean what is generally done in London, because I assume you must have had some experience?

A. Yes; I have experienced a lot of that. In the first instance, at the end of the month the total of a man's lates is made up, and he has to give an explanation why he was late, and the amount of time, be it 20 minutes or half-an-hour or more, has to be worked out by special attendances at the convenience of the Department. He may have to come back after he has done a delivery in order to work out his time, or he may have to attend at three or four o'clock in the morning for the purpose. At the end of tweive months, if he has been on an average 12,15, or 18 times late, his increment is stopped.

Mr. Walpole: Is it not a fact that a man must have been late more than three times in a month before it affects him?

A. Oh. no, sir.

Sir F. Mowatt: You say that 12 late attendances of one minute in a year will disquailify him?

A. I have not any record of a man being punished for having 12 late attendances of one minute each.

Q. But you say each late attendance of one minute counts?

A. Yes, sir.

Mr. Walpole: Can you give me an instance where a man has been punished for being twelve times three minutes late on the average?

A. I have not such a case here; but that makes no difference in the office. It is no great encouragement to a man when he knows that a few minutes la'te will for a long time tell so seriously against him. It does not encourage him to strain every nerve or use extra energy to get to the office in time.

Q. Can you give me any instance where a man has been punished for 12 late attendances?

A. I have been punished three years in succession for late attendances.

Q. How many late attendances?

A. Eighteen times the first year.

The Chairman: Do you know the total amount of your lateness?

A. I did not keep a record of it, not knowing that this Inquiry was coming on, but I had to repay the time.

Q. What was your average?

A. I should say I was late on the average about 20 minutes each time.

Mr. Walpole: Each time?

A. Yes. I am speaking of the early hours of the morning.

The Chairman: That is 360 minutes in the year.

$\mathrm{Mr}$. Walpole: That is a very different case from what you brought forward about punishment for being late two or three minutes.

A. I said it was possible to have to sign the book for being late even one, two, or three minutes.

Q. But where does the punishment come in?

A. During the time I have mentioned I hove had to sign for as little as five minutes late, and some have had to sign for three minutes.

Sir F. Mowatt: How many times were you late the second year?

A. Twelve times.

Mr. Walpole: Do you know how much you were late on the average?

A. I did not keep count.

Q. Do you suppose it was an average of 20 minutes?

A. Yes; I should say that was about the average.

Sir F. Mowatt: And in the third year?

A. I was ten times late.

Mr. Walpole: With the same sort of average?

A. I should say so, but I did not keep count.

Q. You will mit that lateness for 20 minutes involves very serious dis-

organisation of our deliveries and collections? 
A. Yes; we quite understand that punctuality is necessary in the Department, but we complain of the excessive nature of the punishments. $\mathrm{We}$ want a proper and clearly known code of rules laid down with regard to punishments.

Q. What was your punishments in these cases?

A. I lost 1s. a week each year.

Q. Your increment was arrested for three successive years?

A. I obtained my' increment last year.

The Chairman: Was it arrested altogether for three years?

A. Yes; it was first arrested for one year, and then there was an ims. provement in my late attendances, which fell to 12 , and it was again arrested for further improvement, as it was considered that once a month late was a very bad average for a postman. My attendance then improved. being reduced to six during the next 12 months, and $I$ then received my increment.

Mr. Walpole: Your increment was arrested for three months, was it not? A. For six months in the first instance.

Q. In 1893 was there not another incident that I do not want to refer to further, which rather affected the question-in fact, were you not reprimanded afterwards?

A. Yes; but still I think I explained that pretty well at the time, and I was not informed that it would be held in evidence against me. I was not informed that it would.

Q. At any rate you were warned, if not reprimanded?

A. Yes ; but I was not warned that it would affect my increment. The incident arose out of a mistake which any one might have fallen into at the time. It is true I wass warned about it, but I was not informed that it would tell against my increment. I was not so instructed.

The Chairman: I understand you complain now that you were not made aware of the exact rule under which the Department proceeds in the case of these punishments. I understand that to be the point you wish to make?

A. Yes, my lord.

Q. I understand you aidmit the necessity of punishment, but that you wish a regular scale or rule to be made known, so that you may know exactly what you are incurring for a particular offence?

A. Yes. We ask that a proper Departmental code of rules should exist whereby the men should know what they are to be punished for, and what the punishment will be. But we think that stopping a man's increment is cruel and unjust, not only to himself, but because it may deprive his wife and family of some necessaries. The system I would suggest, and I believe the Department would admit it to be more effectual, would be a system of extra duty or something like that, instead of stopping a man's increment or wage.

Q. You have extra duty now in such a case?

A. No; we merely work out the time we lose.

Q. Are you' not punished by extra duty as well?

A. Yes; I have instances of that: instances of men being punished by extra duty as well as loss of increment.

Mr. Walpole: Where your increment is merely deferred, you don't ultimately lose the money, do you?

A. Yes.

Q. I understand that where it is arrested you lose the money, but where it is deferred for three months, if your conduct is good during these three months you get back the arrears?

A. This is a matter of late attendance, and not of general good conduct.

Q. I suppose the senior officer has to sign a certificate that a man's conduct and attendance has been good?

A. It is a matter of attendance; for a postman may be the best conducted man in the office, and if he is late, that late actendance will affect him just as much; no consideration is given in such a case to general conduct. 
The Chairman : I think it is obvious that a series of late attendances might put the whole working of the general delivery tremendously out of gear?

A. No; it does not.

Q. How?

A. Well, if there are three men on the walk and I am late, the other men do my work, and the Department does not suffer in any shape or form. The other men have to buckle to and do the work till I come, so that there is no loss to the Department.

Q. But it is conceivable if there was laxity about insisting on regular attendance that all three men on that walk might be late or absent some morning.

A. Not likely; and $I$ think it would have a much better effect if we had a system of punishment for late attendances different from witholding of income.

Mr. Walpole: You say the Department does not suffer, but do not the public suffer from late deliveries if only two men are delivering on a walk instead of three?

A. I was rather speaking of sorting work and similar duties. Two men would not be sent out to do three men's deliveries.

Q. But the public must suffer if only two men are doing the work instead of three?

A. I have never known despatch to be delayed by a late attendance during the whole time of my service.

Sir F. Mowatt: You mean that the other two men are not fully occupied unless the third man is late?

A. No; but a man can always strain a nerve when he is put to it to assist another man. Late attendance may be accounted for as in the following :- Over 50 per cent. of the postmen have to be on duty at an early hour - from 3 to $6 \mathrm{a.m}$. (this all the year round). It is in the early ahtendances where men are mostlyi late, but it is also possible to lose a few minutes upon collections. Owing to the exigencies of the Service, collections are regulate 1 to a minute; therefore to a man who may, through no fault of his own, not be in possession of a watch, and who has to depend upon the uncertain method of collecting by guess, a church or public-house clock is at the best a most dangerous system. (Rule 45.) Our duties last all the year round. We do not rotate. We have a rule (No. 45), which states that we must not under any circumstances collect a minute or even half a minute before our time; we must wait until the exact time. But there are some places where one cannot readily see a clock, and many of the young men cannot afford to be the possessors of a watch, so that they have to guess the time, and they may chance unfortunately to collect. a minute before the proper time, which, if it were known, would incur official displeasure, and call for explanation. If, on the other hand, they collect a little late, they are thrown late in their arrival at the office. Now, these collections take from 30 to 40 minutes, and the man in his round may have to make four to ten. or perhaps thirteen calls, and he has to regulate his movements during all the time, keeping an eye all the time on some clock. It is not always easy to keep exact to the minute in a half-hour or forty minutes' collection at many different places, where there may be a little delay even by the public asking questions or that sort of thing, so that men have often to use extra energy to arrive at the proper time. Therefore it will be seen that with the usual chance of a heavy collection, and sometimes hampered with bulky parcels, it is quite possible for a man to lose two, three, and even four minutes, which loss is recorded against him, although I am very pleased to say that this is not a common occurrence. When there are a number of people in the receiving office buying stamps, etc., or signing for registered letters, it is often difficult for a man to get forward promptly to sign the book. I have been delayed myself. Late attendance is not caused by want of energy, but through the mental and physical strain following a tiring and 
worrying day, causing a man to occasionally sleep through the unnatural and artificial means employed to wake him at an early hour of the morning. When a postman retires to bet he is a tired man, physically and mentally. The means omployed to wake a man early being usually an alarm clock, although clocks are not always to be depended upon, as it occurs occasionally that even they fail in their duty by stopping in the night, and when that is not so it is possible and does occur that a tired man may fail to hear it, his sense of hearing having got used to the noise, particularly if a man has a cold, "a common occurrence with postmen," or is otherwise unwell, although not sufficiently ill for him to go off duty.

The Chairman: I think the tendency of ordinary human beings is to wake at about the same hour every morning, even without the aid of an alarm clock-at least that is my experience.

A. It would no doubt be my experience, too, if I had not to turn out as a rule at such an extremely early lour; but some have to get up at halfpast 2 o'clock in the morning, and I have to get up at 4 o'clock every morning, summer and winter.

Q. I expect that if you found yourself in bed some day without actually having to get up at that hour, you would probably wake all the same at 4 o'clock.

A. All I know is that I very seldom wake at 4 o'clock on a Sunday morning. It is nearly 8 or 9 o'clock before I wake up on a Sunday morning. If a man is late it is usually not his own fault, and it is as much an annoyance to himself as it is to the Department. Besides, when he goes into the office late the fact is noted by his brother officers, and all eyes are turned on him, and it makes him feel very uncomfortable, for he is watched, and remarks are passed. If a postman can avoid it, he will not make a late attendance. Again, a man may be unwell and oversleep himself, although his illness would not be sufficient to excuse him. Postmen upon an average make 1,000 attendances in the course of 12 months, 700 of which he makes during the day time, with an average of only 1 per 1,000 lates. The same applies to men who are on day duty, and it is a fact that men on this class will not, if they can possibly help it, perform an early duty owing to the severe punishment for late attendance. A number of men when once they get on a late duty will not, if they can help it, take early morning duty, especially if they have in view any increment or stripes that might be endangered. They will rather keep to the late duty, and I can mention cases in which men have lost an increment or a stripe for late attendance, have not been allowed to exchange to late duty. I have an instance in my own office. It is that of a young man who has had 12 years' service, and who should have two stripes, but has not got them owing to being unfortunate in getting up in the morning. There is a vacancy in the late delivery for which he made application to the Postmaster, owing to his being a bad timekeeper, and hoping that some man might take the early morning deilvery who could give better attendance, but he was required to continue at the early morning duty, so that his arrears rather tend to increase.

Mr. Walpole: Don't you think we should have many more late attendances if it was understood that all the men who were late in the early morning would be transferred to the pleasant mid-day duty.

A. I don't think so. If the punishment for late attendance was not so severe, we would get better men to come on the early class, but now they will not do so. The chief reason why some of them come on early duty is that they may get a better share of the Christmas boxes; but I think that is rather short-sighted policy, for what they gain in Christmas boxes may be lost and more than lost through late attendance in respect of their increment and stripes. When you consider that a man may lose his increment for two or three years in succession for late attendance, and that in any case it must take him at least sixteen years to reach his maximum, it may be almost a lifetime under certain circumstances before he does attain that maximum in his class. 
Mr. Walpole: As a matter of fact, even taking the extreme case in which the increment is arrested, if it is arrested for a year, and the man gets his increment the following year, does he not get his double increment, so that the time of reaching his maximum is not delayed?

A. Yes; if he so improves in the second year as to get the back money, but if he does not show a sufficiently? marked improvement-and we don't always know what a sufficiently marked improvement is-he would not get it; but that is only where a man's increment is deferred. If it is arrested the first year he never regains it?

Q. Although he may lose the money during one year he may still reach the maximum at the same time?

A. Yes; but he would have lost the $£ 212$ s., and we complain that for a man to lose $£ 212 \mathrm{~s}$. for an average of something like twelve late attendances is cruel and severe.

Q. That is an extreme punishment. The more usual punishment in such a case is for the increment to be deferred merely for three months, and as a rule I suppose these men can regain it?

A. If a man's increment was deferred for six months and his record improved, he might possibly get the back money.

Q. He would get the back money?

A. Yes; but if his record did not greatly improve he would lose it. I quite understand that punctuality is a very necessary qualification in all postal employees-postmen in particular-but would ask exceptional considerations owing to them performing exceptional duties. The system of withholding a man's increment when due 1s. is a strong cause of complaint, when it is taken into consideration that it takes a man 16 years to reach his maximum, so that during that time a man has only been receiving the mean average of $£ 16 \mathrm{~s}$. per week. The loss of $1 \mathrm{~s}$. is a serious one, especially to men with families, but the loss does not end here. The question of punishment to which my statement refers is to postmen a most serious one, affecting as it does our wages, our good conduct badges, and promotions. The system of arresting increments which we claim as wages, is cruel and unjust, considering that the Department is put to no monetary loss for the offence for which this punishment is inflicted; also, the system of withholding stripes, which is looked upon as a source of wage, as a further punishment for offences occurring as long back as five years. I have a case in point here. A young man in the Service married and his wife was an invalid, and he had to sit up at nights often with her, which caused him to lose a lot of time in his morning attendance. She died after a time through this illness, nevertheless he lost his increment during that year. Afterwards he so made up the time that he regained, as Mr. Walpole has suggested, the double increment. However, he lost the back money, but the case did not end there. Three years afterwards the matter was brought up against him when his stripe became due, and owing to his having lost his increment three years previously, his stripe was withheld. In another five years a third stripe was due, and he made application for it, but he was told that he would have to serve six months more probation on account of the same circumstances which had led to his loss of increment and to the delay of his second stripe, so that his third stripe was delayed for what occurred some six or seven years previously. He says that during the five years he wrote two explanations for late attendance, and was five times late during the whole period, and that he had one year and eight months without being late at all. but when he applied about his stripes he was told that there were several things against him.

Mr. Walpole: Where did this man come from?

A. Blackheath.

Q. Do I understand you to say that the man was punished by lass of increment for five late attendances?

A. No; that was his record during the five years from the time his in- 
crement was arrested. The original bad attendances were due to his being unable to afford a nurse for his sick wife, which made him late in the morning; but after his wife died he was able, as I have said, to make much better attendances.

Q. What is the name of this man?

A. P. H. Cox.

Q. Did he represent to his superiors that he had been late through sickness at home?

A. I don't know.

Q. But you know that the Department always takes into consideration when there is such trouble at home, does it not?" (Cries of "Oh, oh.")

The Chairman : Order, order.

A. No, sir ; a man might be sick himself, but he would have to come in the morning and report the fact, even if he had to go back on account of his illness, and if he came five or ten minutes late he would have to sign the late book all the same when he did. attend, and it would count against him. I have mentioned that in the case of Cox he was told that there were several serious complaints against him. The first and second of these had reference to the fact that the letter-carrier who assisted him in the parcels duty arrive 1 at the S.O. fifteen minutes earlier than himself, and made up a parcel hamper, labelling one empty, although there was a very small parcel left in it unobserved from the general post delivery. The assistant in his explanation had stated that it was entirely his fault, as Cox did not arrive in the office until ten minutes after he had made the hamper up, and this occurred twice. The third complaint was that the assistant, having a lot of large parcels to deliver on the general post delivery, did not arrive at the S.O. till four minutes before the dispatch, with the result that a train was lost, and that was brought against Cor as a reason why he should not receive his stripe.

The Chairman: That rather goes against your argument that the late attendance makes no difference to the punctuality of the dispatch of the deliveries.

A. It was not this man's fault; it was his assistant who was late.

Q. I don't say it was his fault, but the inference is all the same if it was the other man's late attendance that caused the missing of that particular train. You tolid us just now that you never had known a case of late attendance delaying deliveries or interfering with the puolic convenience.

A. I was speaking then of the general post delivery. We don't have any trains to catch in the general post delivery, for a man has simply to come in and sort and arrange his letters before taking them out, so that there is no possibility of a man missing a train in the general post delivery. The fourth complaint against Cox was for delivering a letter torn at one end, and the fifth was advising a C. docket instead of a despatch note for a foreign parcel, although we maintain that this is sorters' duty. Postmen have in such a case to take the responsibility of some sorters' duty without the recompense. The sixth and seventh complaints against Cox were for not sending up a bill in the roard respatch of parcels, and he adds on this point, "The other letter-carriers saw me make it out, and I am certain I put it in." These are the charges on account of which this man's third stripe is being withheld for six months in order to see if he makes any other trifling curors.

Mr. Walpole: You have given us no instance of a stripe being stopped for eight late attendances in twelve months.

A. There is a case of a man named Buchanan in the E.C. Office, who has been waiting for his stripe since June, 1895, because he was eight times late in the year. This man's father was a postman before him, and died in the Service after 30 years' work.

The Chairman: Can you tell me what is the sum total of his late attendances? 
A. I cannot. But as a rule my experience is that the Department makes no difference whether it is five minutes or an hour.

Q. Do you mean that the Department would make no difference whether this man's late attendances amounted in all for that year to forty minutes or to eight hours?

A. It would still be counted against him as late. I may add that when a man has a good conduct badge due to him at the end of five years he often does not receive it for periods of from three to eight months after that time, and during the interval he is put under supervision and watched to see whether any little case crops up against him that would enable the stripe to be witliheld.

Q. I suppose that is where there has been some doubt whether his conduct has been previously sufficiently good to entitle him to the stripe?

A. No ; it is a general practice. The stripes are held back for five or six months.

Mr. Walpole : Is it not a fact that these stripes are sent out periodically in batches to the Postmaster-General for approval, and that when they are delivered after they have become due they are ante-dated. to the time when they became due.

A. Yes; but during the interval a man may be two or three times late, which would be sufficient to stop him receiving his stripe, whereas if he had received the stripe at the proper time the same offence would not have been sufficient to justify it being taken away from him. I have a case here of a three years' auxiliary postman appointed in October, 1888, on a 16s. scale.

Mr. Walpole : Where is this man?

A. It is a man at Clapton.

Q. An auxiliary postman?

A. He entered as an auxiliary; his name is Robert Charters. He entered at the time of the 16s. minimum, so that a stripe became due on October 1 st, 1893.

Q. His second-class service would not count for a stripe, would it?

A. Oh, yes.

Q. I think you are wrong. I believe that in 1888 the second-class service did not count for a stripe.

A. I believe that rule refers to the $14 \mathrm{~s}$. scale, and not to the $16 \mathrm{~s}$. I got fìy second stripe in my assistant letter-carriership.

Q. The Report of the Postman's Committee in 1891 states that in London and some of the provincial towns where two classes of postmen exist, service in the second class has not been allowed to count for good conduct stripes. $\dot{I}$ know that was altered on this Report after 1891 . $14 \mathrm{~s}$.

A. I think the rule to which you have referred dealt with the juniors at 1891.

A. Yes; I think I. have a case here.

Q. When this Report was written I believe the minimum was 18 s.

A. I have a letter here which says, "With respect to your application, I have to request that you will state what is your height in your boots, and if your are eligible in this respect, whether you are willing to accept nomination as a junior letter-carrier with wages commencing at $14 \mathrm{~s}$. a week, and increasing by 1s. a week to 18s.?"

Q. What is the date of that letter?

A. 1881.

Q. But we were talking of a much later date than that:

A. I understood you to say, sir, that nev̄er was a 14s. minimum.

Q. I said there was not at the time you spoke of.

A. I was speaking of a $16 \mathrm{~s}$. man.

Q. You said my observations as to a certain rule applied to a 14s. minimum, and not to the $16 \mathrm{~s}$. rate-that is what I understood you to say.

A. A number of men in the E.C. District who have idone 15 years' service, 
and have earned their second stripe, are now informed that they are not entitled to the third stripe owing to their havin entered the Service at a 14s. minimum. This proves that these men received their first and second stripe at the $14 \mathrm{~s}$., and it is only on the third stripe becoming due that they are told the period of service at $14 \mathrm{~s}$. does not count.

Q. I don't accept the statement that it proves that.

A. There are 20 men in the E.C. District now waiting for stripes.

Q. When was the answer you have quoted sent?

A. As late as last month.

Q. They complain, I understand, that at the end of the five years and ten years' service they got their stripes, but that now at the end of 15 years they are told that they must wait an indefinite time before they are entitled to their third stripe.

A. They did not receive the first stripe at the end of the five years, but they received two stripes at the end of ten years, which amounts to pretty much the same thing; bu't now at the completion of 15 years' service they are informed that the junior service does not count, yet they received their first and second stripes on that score.

Mr. Walpole: Perhaps you will give me the names of these men and I will look it up?

A. I am afraid I cannot; there are 20 of them. Mr. Churchfield will supply the names later on.

The Chairman: May it not turn out that the result of this Inquiry will show that they ought not to have received two stripes at the end of ten years?

A. I hope not, or else I shall be a sufferer as well.

Q. But it may be the case that so far from having been damnified by not getting their third stripe now, it will come out that at the end of ten years they got something more than they ought to have had?

$A$. If so the Department should have found this out before, and not waited till now. I think that is all I have to say with reference to excessive punishment. I am informed there are men in the room at the present time who received the first stripe at the end of five vear's' service, including secondclass service as well. In conclusion. I would ask that as the exigencies of the Service demand punctuality, and naturally a punishment for any departure from it, all cases of late attendance be punished with extra duty, and in extreme cases by the loss of the G.C.B., but even then for the space of one year only, as I feel sure thait the system of withholding them for such a length of time as five years tends ito defeat rather than support the object it has in view, as a man who knows that it is quite impossible for him to obtain or regain them when once lost under five years, loses heart; but on the other hand, as in the army and navy, make it possible for him to regain limself in 12 months, he would with renewed energy? try to do so. I should say that if a man loses his stripe or increment, and knows that he has five years in front of him, during which it may be impossible for him to regain it, he loses heart and energy becaruse of the obstacles in his way.

The Chairman: You would punish late attendances by fines?

A. I think that would be a better system. It is practised by the police. If a policeman is late he may perhaps lose a day's pary. That would be better than losing a year's increment.

Q. Is not that very often the practice in the provinces with regard to postmen?

A. Yes, my lord; I think it would prove a better system. It would have a better effect on the men if they lost money. It would not affect them in the end, because they would keep better time. The present system as it stands carries with it a double punishment. It affects a man in the matter of both increment and stripes, which we look forward to as part of our wages. In any event, they are held out as part of our wages.

Q. A't the same time you will admit that a man who is guilty of persistent late attendance could hardly be considered a man of very good conduct? 
A. No; not if he is persistenly late. But when a man is only late from 10 to 18 times in the course of 1,000 attendances in all weathers and all seasons of the yeasr, I do not think that is persistent late attendance. Seeing that a man may have to sign for two minutes late, and he must not be 18 times late in the year, I do not think if he keeps within that rule he can be considered a bad attendant, or a man of bad character. There is another little question that I should like to refer to, and that is with regard to the third stripe. The first and second stripes are unlimited in number, but in the matter of third stripes the percentage issued to men in one office must not exceed 30 per cent. That is to say, if there are a hundred men in an office, no matter how many are entitled to the third stripe, no more than 30 can be issued. I have not found many offices where the men are suffering from this, but still there is a possibility of a man after completing 15 years' service having to wait for a vacancy-for another man to die. I think that a man after 15 years" service is quite as much entitled to a little encouragement in the shape of an additional stripe as a man with 10 years' service. It would not be a great matter for the Department to grant this concession. It is not one which would affect thousands of men, but it would apply to a few here and there, and I think it is a concession that might easily be granted by the Department. it?

The Chairman. Do you know of any cases where men have failed to get

A. No, my lord; I do not. But still there is the possibility. Personally I have never come across a man who has thus suffered.

Mr. Walpole: Is not the probability very remote indeed of a loss of that kind?

A. I think it is myself.

Q. Is it not a fact that many hundred third stripes are vacant in London at the present moment?

A. Yes; it is a fact. It is very seldom that 30 men out of 100 live to do 15 years' service. I have just been informed there are three full-time men at Hampstead waiting for their third stripe owing to the 30 per cent. being filled up.

Q. But is not Hampstead a part of London?

A. Yes.

The Chairman:I understood the witness to say the system applied to individual offices.

Mr. Walpole: I think London is taken as a whole.

A. No. I am informed the percentage is taken for individual offices, and that is how it is that three men are waiting for the stripe at Hampstead.

Q. But in Liondon, as we all know, there is a large number of vacancies?

A. Yes; but this difficulty only exists at a few offices where there are a large number of senior men. I am also asked to mention that a number of men in the City are waiting for their stripes, and have been waiting nearly 12 months. They have made application, and have been informed that they will be down in due course. It is the system of withholding stripes for 12 months which is a real cause of grievance. A man thinks that having a record of good conduct for five years he should have his stripe at once, and not have to wait 12 months for it.

The Chairman : They will date back?

A. Yes; but the possibility is that during the 12 months some little thing may crop up which will take it away from them. Really, a man has to serve six years' probation instead of five for a stripe. In thanking you, my lord and gentlemen, I should like to express a hope that you understand our feelings as did the late Mr. Raikes, who, in a speech at the G.P.O., in July, 1890, remarked-" I can quite understand the feelings of men who think one punishment ought to suffice for an offence. When you have paid the penalty of the enormous crime of sleeping a few minutes too late, it seems hard that the matter should be again brought up against him and so be made a permanent offence." Thus Mr. Raikes saw the hardship of our position, and said he considered it was a hard system of punishment. 


\section{ALFRED F: HARRIS, W.D.O., General Treasursor.}

Promotion.

Westminster, Monday, Feb. 24, 1896.

Lord Tweedmouth's Committee resumed its inquiry on Monday, February 24 , all the members being present, and the room being crowded by postmen, who are taking a keen interest in the proceedings from day to day.

The first witness called was Alfred F. Harris, who was examined as fcllows :-

The Chairman: You are a postman in the Western District Office, I fancy?

A. Yes, my lord.

Q. How long has your service been?

A. $19 \frac{1}{2}$ years.

Q. What is the particular point you are going to talk about?

A. The promotion question, my lord.

Q. Have you a statement prepared for us?

A. Yes, my lord.

The Oiairman : Very well, read it.

Witness : With your permission, sir, I wish to preface my remarks on promotion by touching on the wages question. I find on perusing the Estimates the following curious facts, that notwithstanding that other branches of the Service have advanced in the matter of wages during the past ten years, the wages of the postman has materially decreased, although there has been an increase in the maximum of $2 \mathrm{~s}$. per week.

Mr. Walpole: Are you speaking for the London postmen?

A. Yes, sir. In 1886 the sorting staff numbered 2,227, with wages amounting to $£ 191,288$, or a mean wage of $£ 113 \mathrm{~s}$. $2 \mathrm{~d}$. The postmen numbered 2,760 , with wages amounting to $£ 191,280$, or a mean wage of $£ 16 \mathrm{~s} .7 \frac{1}{2} \mathrm{~d}$. In 1896 the sorting staff numbers 4,251, with wages amounting to $£ 389,908$, or a mean wage of $£ 116 \mathrm{~s}$. 2d., whilst that of the postmen number 5,198 , with wages amounting to $£ 352,818$, or a mean wage of $£ 1$ 5s. $115 \mathrm{~s}$., thus showing that whereas the sorting staff mean wage has risen by 3 s. per week, or an increase of $£ 33,15716 \mathrm{~s}$. per year, that of the postmen has decreased by $8 \mathrm{~d}$. per man per week, meaning a saving to the Department of $£ 9,009$ 17s. 4 d. per year.

Mr. Walpole: Are you taking established postmen only, or postmen and auxiliaries?

A. Established postmen.

Q. You are dealing only with established postmen?

A. Yes ; in this case.

Mr. Walpole: That is all I want to know?

Witness: I wish to hand in two tables which will bear out my statement. 


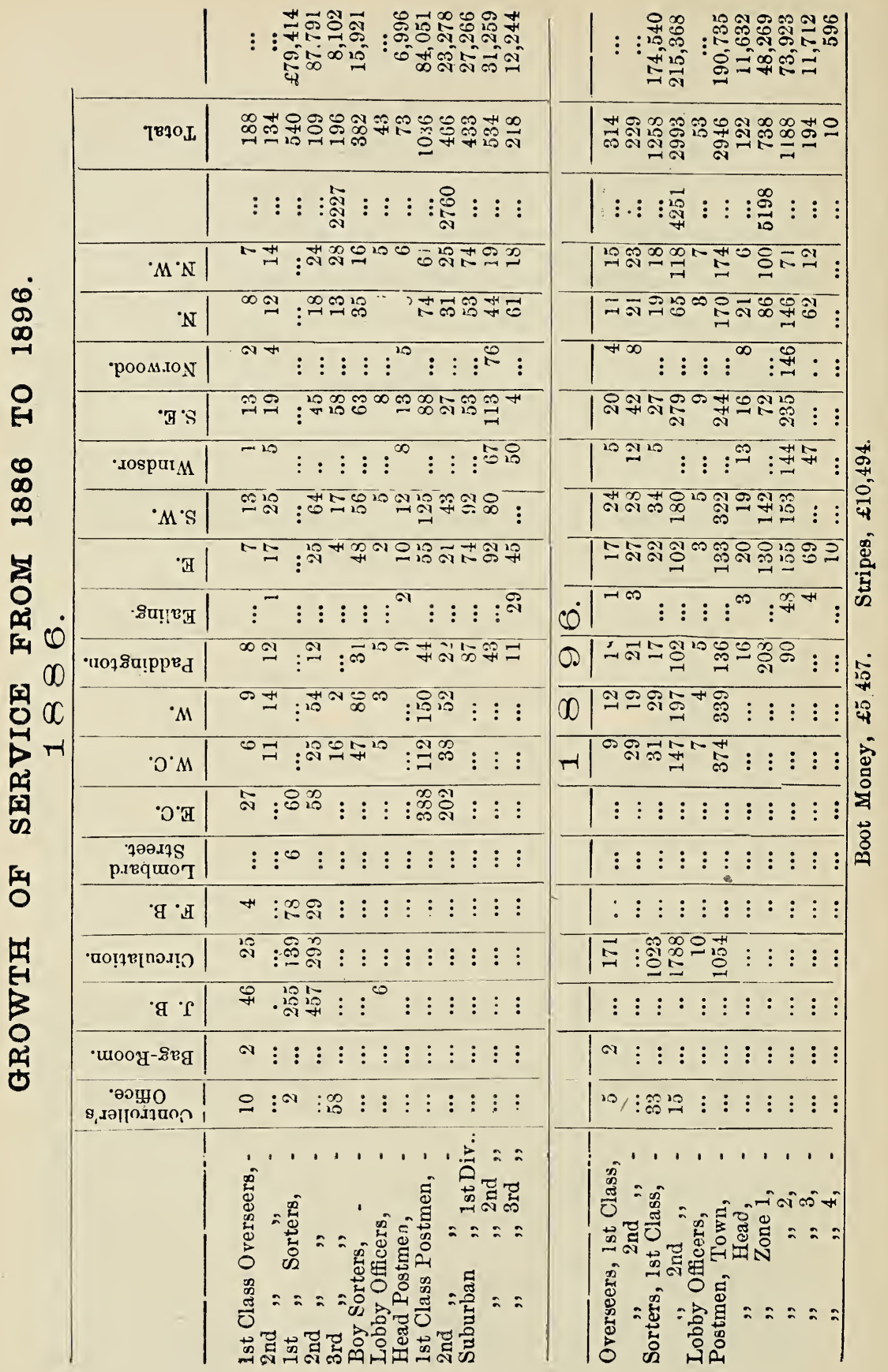


The Chairman: How do you account for the alleged decrease, Mr, Harris?

A. I cannot account for it at all.

Q. The wages have risen?

A. It must be the increase of the staff and the larger number of new entrants, I think.

Q. A larger proportion of junior men?

A. That is exactly the case, I think, my lord.

Q. Are you including in your statement with regard to sorters the overseers?

A. No, sir.

Q. Not the wages of the overseers?

A. No, sir.

Q. And you wish us to assume from these tables that although other brauches of the Service have gone forward, the postmen have gone back?

A. Yes.

Q. You prove that by your statement without these tables?

A. Yes.

Q. And I do not know that the tables could prove more?

A. No, sir; but they give you figures which I have summarised in the statement in a tabulated form.

Q. But still your statement summarises the argument which you wish to bring out?

A. Exactly, sir.

Mr. Walpole: What do you make the wages of the postmen now?

A. Giving the whole sum?

Q. Yes. What were they last year, for instance?

A. $£ 352,818$. I might explain here that that includes boot money and th: stripe allowances.

Mr. Walpole: Just so ; that explains the difference, as the figure I had was $£ 336,000$. Is it not the case that during the last 15 years the minimum of the postmen's wages has been raised?

A. Yes.

Q. And is it not the case that the maximum has also been raised?

A. Yes; in one case, however, the minimum of the postmen was lowered.

Q. But the minimum used to be $16 \mathrm{~s}$.?

A. It was 18s., then it was lowered to $16 \mathrm{~s}$., and then again raised to $18 \mathrm{~s}$.

Q. And the maximum was also raised?

A. Yes; by $2 \mathrm{~s}$.

Q. Must not the decrease of the average wage be due to the large increase in the postmen's force, and the consequently large number of men low down in the scale?

A. Exactly so ; but should not the same be the case in the sorting staff. Their force has been increased in the same proportion as the postmen.

Mr. Llewellyn Smith: Your point is that this comparative statement of the scales of pay shows that the postmen's scale has not advanced so much as that of the sorter?

A. Exactly.

Q. And not that the postman has been reduced?

A. That is so. In speaking on the question of promotion, the Committee will have gathered that it is one of the chief grievances of the Postal Service. In 1886 the staff of postmen in London numbered 2,775; at the present time the staff consists of 5,210 , or an increase of 2,435 ; thus in 10 years the staff has nearly doubled itself. I may explain here that throughout my case I have taken an average of 10 years. For years past postmen have brought the matter of future prospects up again and again, but with little success, not because their claims were not reasonable, but simply because the Department would not recognise them. In 1892, on this 
question, postmen petitioned the Right Hon. Sir James Fergusson, M.P. (H.M.P.G.), in the following terms :-

"Your petitioners are reluctantly compelled to express their surprise that after the repeated applications they have made for the removal of the present unfair system pursued by the Department respecting their promotion, it should be necessary to approach you to affect a reform so urgently needed, not only in the interests of your petitioners, but also of the Postal Service. The defects are :

"(a) The habitual violating of the agreement made with most, if not all of your petitioners when they entered the Service, mainly brought about through allowing new entrants into the Postal Service the first opportunity to compete for superior appointments.

"(b) The long probation which those officers who are fortunate enough. to be nominated for promotion have to serve at a personal loss, and a profit to the Department.

"(c) The absence of information respecting the appointments and qualifications for higher grades of the Service."

An answer to the foregoing was received in June, $1892:-$

"As regards the request that postmen working superior duties should receive an allowance during their probation, Sir James Fergusson observes that postmen, like other Post Office servants, are tried on superior duties before promotion; but that, of course, promotion-which the grant of a special allowance would practically be-cannot be given to them until they have proved their fitness.

"(3) Promotion.-A list of appointments to which postmen, among other officers, are eligible for promotion is appended :-

\section{APPOINTMENTS FOR WHICH POSTMEN ARE ELIGIBLE.}

\begin{tabular}{|c|c|c|c|c|}
\hline Appointment. & \multicolumn{3}{|c|}{ Scale. } & Qualification. \\
\hline 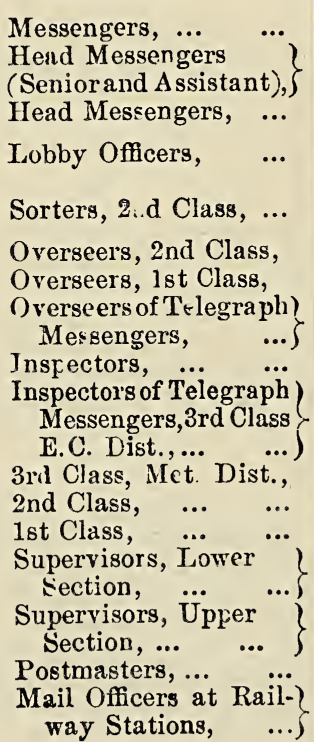 & $\begin{array}{l}21 /- \\
45 /- \\
50 /- \\
\left\{\begin{array}{l}20 /- \\
30 /-\end{array}\right. \\
\begin{array}{l}18 /- \\
\text { then } \\
40 /-\end{array} \\
56 /- \\
20 /- \\
£ 175 \\
30 /- \\
32 /- \\
40 /- \\
50 /- \\
£ 175 \\
£ 175 \\
\text { at va } \\
30 / 1 \\
\text { and } 5\end{array}$ & $\begin{array}{l}1 /- \\
1 / 6 \\
2 /- \\
1 / 6 \\
1 / 6 \\
1 /- \\
2 /- \\
2 /- \\
2 /- \\
1 /- \\
£ 10\end{array}$ & $\begin{array}{c}40 /- \\
50 /- \\
60 /- \\
38 /- \\
45 /- \\
20 /- \\
40 /- \\
56 /- \\
68 /- \\
30 /- \\
£ 280\end{array}$ & $\begin{array}{l}\text { Usually selected } \\
\text { from men not } \\
\text { over } 40 \text { years of } \\
\text { age. } \\
\text { Examination by } \\
\text { Civil Service } \\
\text { Commission. } \\
\text { Limits of age, } \\
18-21 \text {. }\end{array}$ \\
\hline
\end{tabular}


The Committee will observe that this list is open to postmen, "among other officers"; practically this list is misleading to a postman (with one exception, i.e., 1st class sorters). These appointments are the only ones open to the postmen in conjunction with other classes. It may be mentioned that two appointments that were open to postmen 10 years agoi.e., countermen and writing assistants-have been erased from the list. Now, I will consider in detail the list of appointments as given. Messengers form the first item. Postmen have taken, and do take, advantage of this appointment, but they are only successful after many applications. There have only been five postmen at the W.D.O. in 15 years who have been thus appointed, two of whom applied 18 months previous to promotion. I may state that of those who applied when the list I have just read was placed up in the office, none got an appointment at the time, but since this Committee has been sitting three or four men have been appointed. The second and third items are head messengers, which are only reached through the aforesaid appointment. The fourth item-i.e., the positions of lobby officers, of which there are but 53 in London-are generally obtained by postmen on their maximum, or after they have been in the Service over 20 years. As to the fifth item-i.e., 2nd class sorter-reference will be made to this later. 1st and 2nd class overseers are usually appointed from lobby officers and head postmen, and a few-a very few-from the ranks of postmen. It is to be noticed that it is in the E.C. District that the promotion to overseers is obtained by postmen to the 1st class in the Metropolitan districts being limited to that of the 2nd class. My lord, we consider this a distinct grievance, seeing that the postmen perform the same duties in the Metropolitan District as they do in the East Central District. We think that 1st class overseerships should be open in the same proportion to the Metropolitan District officers as to those in the City.

The Cliairman: I suppose that postmen who are appointed 2nd class overseers rise to the 1st class overseers, do they not?

A. Exactly so, sir. But I may state that we only had one postman appointed overseer at the Western District Office ever since $I$ have been there.

Sir F. Nowatt: But a postman can become a head postman and then an overseer?

A. There is no such thing as a head postman in district offices. They are only to be found in suburban offices. With regard to overseers of telegraph messengers, it is unnecessary to say anything beyond this, that their maximum pay is lower thian that of a postman. Inspectors-These positions, which properly enough were formerly within the reach of, and were obtained by postmen, are now practicably unobtainable by them owing to the larger share of promotions falling to the lot of the sorting staff. Inspectors of telegraph messengers-Whence come the inspectors of telegraph messengers is a query. That they do not come from the ranks of the postmen is a certainty, now this class has been made redundant to postmen for some years. Supervisors (upper and lower)-The statement with regard to inspectorships applies equally to supervisors. Postmasters-This position is not on record as ever having been reached by a postman in London, I may state. Mail officers at railway stations-The number of these officials is nine, all of whom are promoted from the inland branch porters. Thirty years ago all promotions were open to letter-carriers, but at the present timc but few are so, owing to certain anomalies of the Service. The numbe! of promotions is insufficient for the large and ever-increasing staff; the increase of the former is not in proportion with that of the latter. Especially in the case of postmen is this most noticeable; for instance, if we take the staff of Dublin and that of the London W.D.O., and compare the superintending officers:- In the Dublin sorting office there are 57 superintending officers to a staff of 529 , while in the W.D.O. the proportion is 39 to 657 . I beg to hand in a table showing this : 


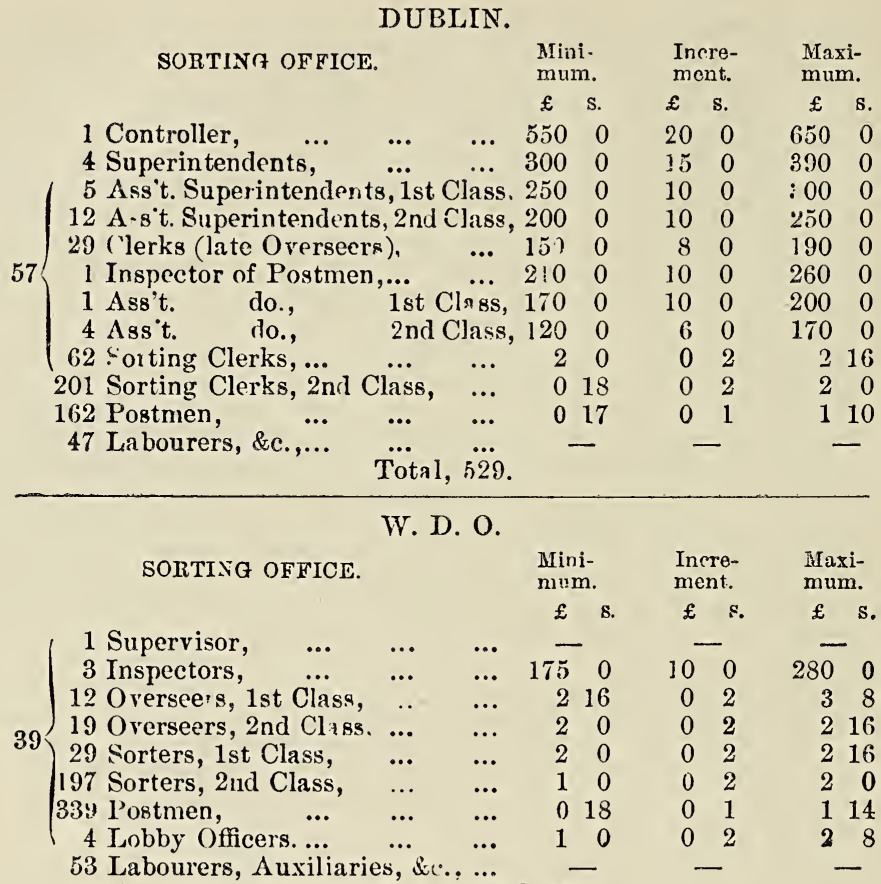

Total, 657.

In 1886 the superintending officers at the W.D.O. were as 1 in 15, at the present time they are as 1 in 17. The appointments have gradually diminished to postmen, and proportionately increased to the sorting staff since the Fawcett scheme revision-the proportion of appointments to overseers was defined as two to sorters and one to postmen, but it is found that this has not been adhered to, inasmuch as in the past ten years the promotions to overseerships hare been as follows:-

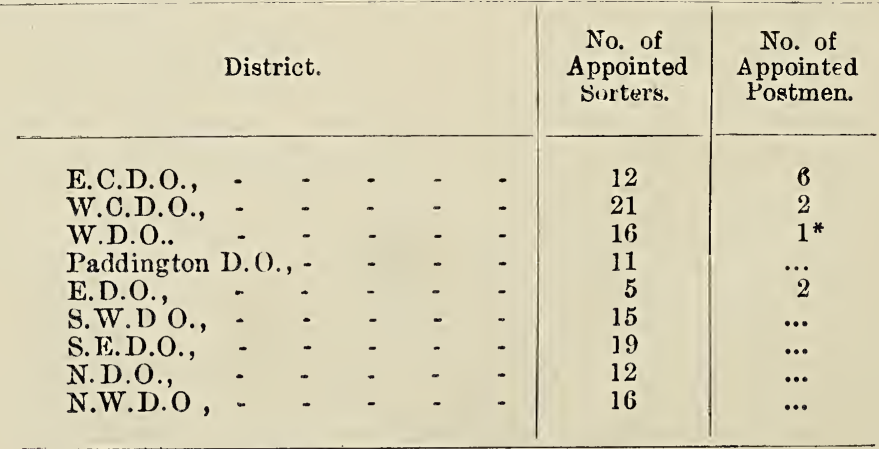

* 'This one I romoted to Sub-Office. 


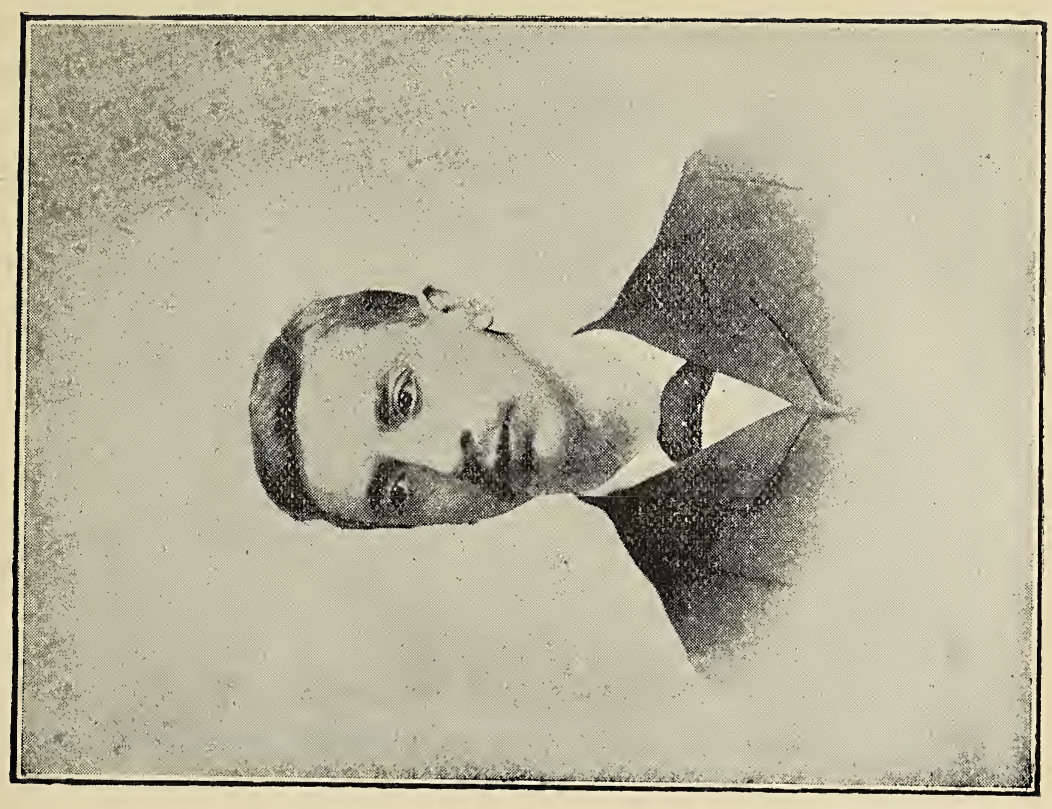

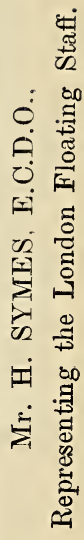

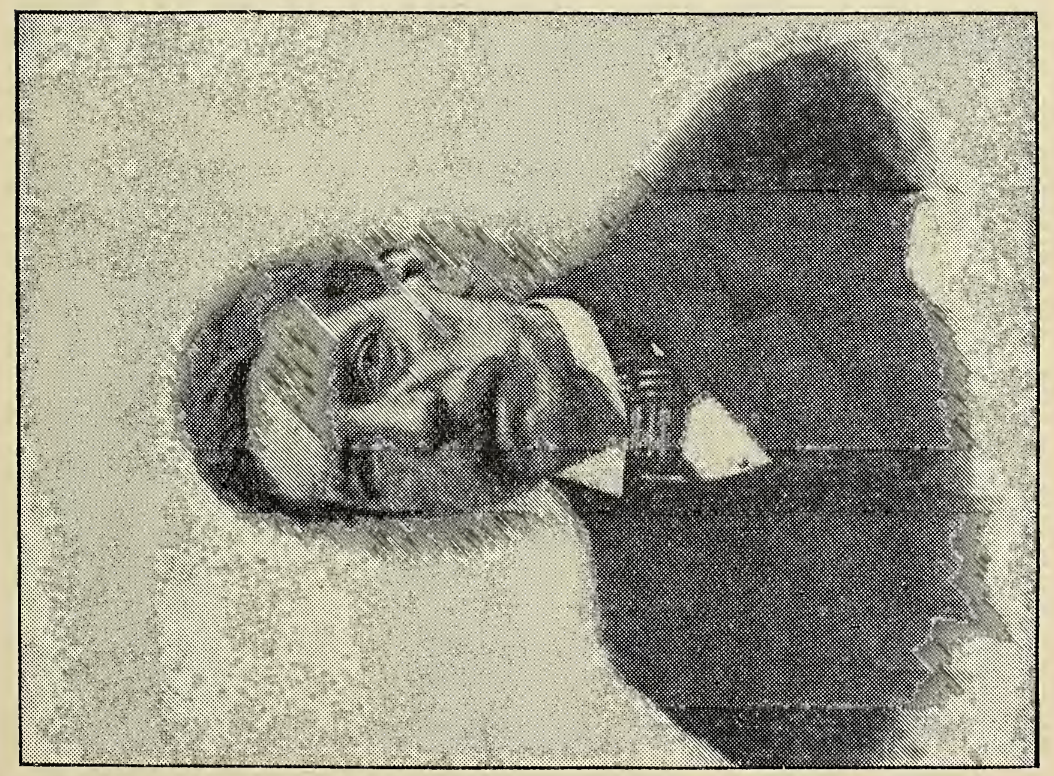

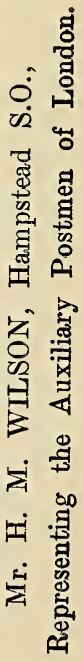



Mr. Smith : In the E.C.D.O. the proportion is two to one, is it not?

A. Yes; but it is only in the case of the City that that has been carried out. The City postmen seem to be favoured in that respect.

Q. When you said just now that the proportion was defined to be two to one, I did not understand you to state by whom it was defined. Is it to be found in any official document?

A. Yes, sir. In 1884 a deputation waited upon the late Mr. Jeffreys, then the controller, and after listening to them he sanctioned it.

Sir F. Mowatt: Who?

A. The late Mr. Jeffreys.

Mr. Smith: Have you a copy of the order issued, or of any official document showing it?

A. No, sir; I have not been able to get it.

The Chairman: Was it said by Mr. Jeffreys in answer to a deputation?

A. Yes, my lord; and in proof of it we find that in the City it is faithfully carried out.

Sir F. Mowatt: And you complain that it is not carried out in the other cases you have quoted?

A. Yes, sir.

Mr. Smith : Was it not rather an expression of hope that he would be able to carry it out in general than a definite undertaking?

A. No, sir; it was a definite undertaking.

Mr. Smith: There must be a record of it somewhere, then?

Mr. Walpole: Are you sure it was a record reduced to writing, or was it a suggestion based upon what had taken place in the past?

A. No, sir; I have only this to go by, that it has been faithfully carried out in the City.

Mr. Walpole : "Faithfully carried out" by people who did not know of its existence. The present controller does not know of the existence of this regulation.

A. I am informed it is part of the Fawcett scheme which was brought in at the time of the sorters' revision.

The Chairman: Were the postmen to receive promotion over the sorters?

A. Yes.

Q. What proportion of the whole staff of London postmen have received promotion during the last two years?

A. Do you mean the number, my lord?

Q. Yes; you have about 5,000 postmen in London, and I want to know how many promotions they have had?

A. There have been 38 appointed as lobby officers, 13 messengers, and 126 in the suburban districts.

Mr. Walpole: As what?

A. Either head postinen or overseers. If they had been appointed over. seers they have previously been head postmen.

Q. That is within the last year?

A. There have also 15 been appointed in the district offices.

The Chairman: Do you mean they were all promoted in one year-last year?

A. No, they are the number in 10 years; the whole of my arguments are based on a 10 years' average, and we find that in the suburban offices there have been 126 appointments, a list of which I have obtained. There are 69 offices.

Q. According to your figures the average of appointments have been 20 a year?

A. Yes, for the whole staff.

Q. That has been the average for the last 10 years for the whole staff?

A. Yes; and we find it very difficult in the case of the sorting staff. I might state that in the suburban offices there is no one but postmen to proniote; if they were sorters in those offices undoubtedly they would 
have received many of the appointments which have been given to postmen. I have here a table showing the number of appointments obtained by postmen at the suburban offices I have alluded to:-

Table Showing the Number of Apponntments obtained by Postmen in the Suburban (or Zones) of London during the past Ten Years.

\begin{tabular}{|c|c|c|c|c|c|c|c|}
\hline SORTING OFFICE. & & 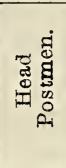 & & rerseers. & 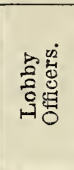 & 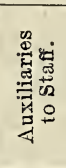 & 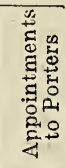 \\
\hline Acton, W., $\quad \ldots$ & ... & 2 & 1 & & .. & ... & ... \\
\hline Anerley, S.E., ... & ... & 1 & & ... & $\ldots$ & $\ldots$ & ... \\
\hline Blackheath, S.E., & $\ldots$ & $\cdots$ & 1 & 0. & 1 & $\ldots$ & $\cdots$ \\
\hline Barnes, S. W., ... & $\ldots$ & 1 & & ... & ... & $\cdots$ & 3 \\
\hline Balham, S.W.,... & $\ldots$ & $\ldots$ & 2 & & $\cdots$ & $\ldots$ & $\cdots$ \\
\hline Bethual Green, E., & $\ldots$ & 2 & & $\cdots$ & $\cdots$ & $\cdots$ & $\cdots$ \\
\hline Catford Bridge, S.E., & $\ldots$ & 1 & & $\cdots$ & $\cdots$ & $\cdots$ & $\cdots$ \\
\hline Chel:ea, S.W.,... & $\cdots$ & $\cdots$ & & ํㅡㄴ.P. & 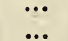 & $\begin{array}{c}. \cdot \\
\ldots\end{array}$ & $\begin{array}{l}\cdots \\
\ldots\end{array}$ \\
\hline Chiswick, W., ... & $\cdots$ & $\ldots$ & $\begin{array}{l}1 \mathrm{ft} \\
2\end{array}$ & om K.1. & $\begin{array}{l}\cdots \\
\cdots\end{array}$ & $\dddot{4}$ & $\dddot{4}$ \\
\hline $\begin{array}{l}\text { Clapham, S.W., } \\
\text { Clapton, E., ... }\end{array}$ & $\begin{array}{l}\ldots \\
\ldots\end{array}$ & $\ddot{2}$ & & $\ldots "$ & $\ldots$ & $\ldots$ & $\ldots$ \\
\hline Deptford, S.E., & $\cdots$ & $\ldots$ & & $\cdots$ & .. & $\cdots$ & ... \\
\hline Dulwich, S.E.,... & ... & 1 & 1 & & $\cdots$ & $\cdots$ & $\ldots$ \\
\hline Ealing, W., & $\cdots$ & $\cdots$ & 2 & ," & $\cdots$ & $\cdots$ & $\cdots$ \\
\hline Earl's Court, S.W., & ... & $\cdots$ & & $\cdots$ & $\cdots$ & $\cdots$ & $\cdots$ \\
\hline Fulham, S.W.,... & $\ldots$ & 1 & & $\cdots$ & $\cdots$ & .. & $\cdots$ \\
\hline Finchley, North, N., & $\cdots$ & $\cdots$ & & $\cdots$ & $\cdots$ & $\cdots$ & $\cdots$ \\
\hline Finchley, East, N., & $\cdots$ & $\ddot{i}$ & & $\cdots$ & $\begin{array}{l}\cdots \\
\ldots\end{array}$ & $\begin{array}{l}\cdots \\
\ldots\end{array}$ & $\begin{array}{l}\cdots \\
\ldots\end{array}$ \\
\hline Forest Gate, E., & $\begin{array}{l}\cdots \\
\ldots\end{array}$ & $\ldots$ & & 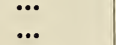 & ... & ... & $\cdots$ \\
\hline $\begin{array}{l}\text { Hammersmith, W., } \\
\text { Greenwich, S.E., }\end{array}$ & $\begin{array}{l}\cdots \\
\cdots\end{array}$ & $\cdots$ & 2 & , , & $\ldots$ & $\ldots$ & $\ldots$ \\
\hline Hackney, E., ... & $\ldots$ & ... & 2 & & ... & $\ldots$ & 1 \\
\hline Hampstead, N. W., & ... & ... & & $\cdots$ & $\cdots$ & $\cdots$ & $\cdots$ \\
\hline Hendon, N.W.,... & $\ldots$ & $\cdots$ & & $\cdots$ & $\cdots$ & $\because$ & … \\
\hline Herne Hill, S.E , & $\ldots$ & $\cdots$ & 1 & , & $\cdots$ & 2 & 2 \\
\hline Highbury, N., ... & ... & 4 & & $\cdots$ & $\cdots$ & $\cdots$ & $\cdots$ \\
\hline Highgate, N., ... & ... & 3 & 1 & & $\cdots$ & $\cdots$ & $\cdots$ \\
\hline Hclloway, N., ... & ... & 2 & 1 & & $\cdots$ & $\cdots$ & $\cdots$ \\
\hline Homerton, E., ... & ... & $\cdots$ & 2 & & $\cdots$ & $\cdots$ & 2 \\
\hline Hornsey, N., $\quad \ldots$ & ... & 1 & & $\cdots$ & $\cdots$ & $\cdots$ & $\cdots$ \\
\hline Kentish Town, N.W. &,$\ldots$ & 1 & & $\ldots$ & $\cdots$ & $\cdot \cdot$ & $\cdots$ \\
\hline Kensington, W., & ... & $\cdots$ & & $\cdots$ & $\cdots:$ & $\cdots$ & $\cdots$ \\
\hline Kilburn, N.W., & $\cdots$ & 1 & 1 & & $\cdots$ & $\cdots$ & $\cdots$ \\
\hline Lee, S.E., $\quad \ldots$ & $\because \cdot$ & $\because$ & 1 & & $\cdots$ & $\cdots$ & $\cdots$ \\
\hline Lewishain, S.E., & $\ldots$ & 2 & & $\cdots$ & .. & ... & $\cdots$ \\
\hline Leyton, E., $\quad \ldots$ & $\cdots$ & 1 & & $\cdots$ & $\cdots$ & $\cdots$ & $\cdots$ \\
\hline Leytonstone. E., & $\cdots$ & 1 & & $\cdots$ & $\cdots$ & $\cdots$ & $\cdots$ \\
\hline Maida Hill, W., & $\cdots$ & 2 & & $\because$ & $\cdots$ & $\cdots$ & $\cdots$ \\
\hline Mill Hill, N.W., & $\cdots$ & $\cdots$ & & $\cdots$ & $\cdots$ & $\cdots$ & $\cdots$ \\
\hline $\begin{array}{l}\text { Mortlake, S.W., } \\
\text { New Cross, S.E. }\end{array}$ & $\cdots$ & $\ddot{2}$ & 4 & & $\cdots$ & 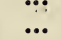 & $\begin{array}{l}\cdots \\
\ldots\end{array}$ \\
\hline $\begin{array}{l}\text { New Cross, S.E., } \\
\text { New Wandsworth, S. }\end{array}$ & W., & ... & & $\cdots$ & ... & $\cdots$ & $\ldots$ \\
\hline $\begin{array}{l}\text { New Wandsworth, S. } \\
\text { North Kensington, W }\end{array}$ & & $\ldots$ & 2 & & $\cdots$ & $\ldots$ & ... \\
\hline North Woolwich, E., & $\cdots$ & $\cdots$ & & $\cdots$ & $\cdots$ & $\cdots$ & ... \\
\hline Norwood, S.E.,... & & 5 & 5 & , & $\ldots$ & $\ldots$ & $\cdots$ \\
\hline & & 37 & 33 & & 11 & 16 & 12 \\
\hline
\end{tabular}


TABLE SHEWING NUMBER OF APPOINTMENTS-Continued.

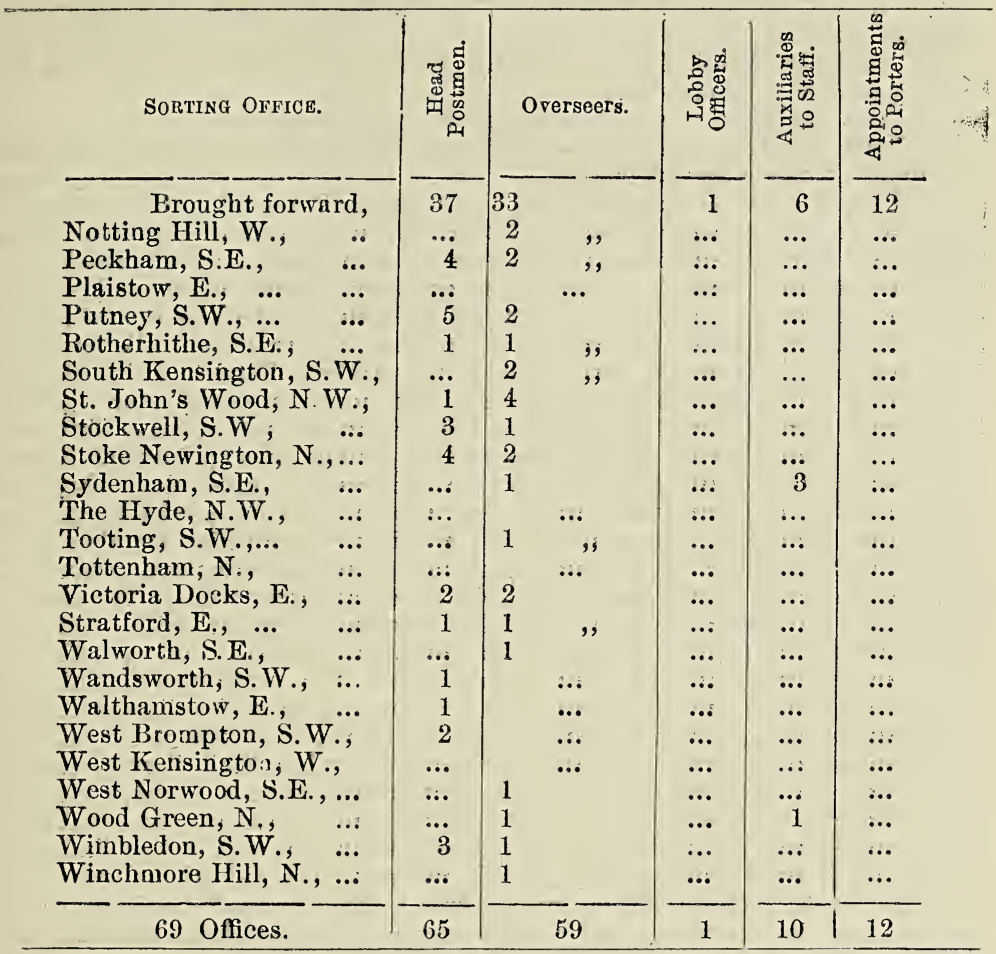

1 Telegraphist.

69 Offices obtains 126 appointiments-an average of 2 to each Office, or 1 Postman promoted every five years.

1,258 Suburban Postmen in 1886. 2,252 ditto in 1895.

With the exception of the E.C. and W.C.D.O., these postmen are prorisoted to suburban offices. In reference to the list of overseers' appointments, it will be found that whereas postmen have oinly received 15 appointments to overseers, in the case of the sorters the number of appointments have been 127, showing that the sorters have received more than eight times the number of appointments than postmen, and proving that a great injustice has been done us. There are in London 684 officers wearing three stripes, 475 wearing two stripes, and 1,023 wearing a stripe, who have practically only lobby officers and a few messengerships open to them for promotion, and scarcely any one of these officers considers that a 2nd class sortership would be promotion, owing to the fact that they would forfeit their seniority and go to the bottom of the class. This was altogether different previous to the introduction of the sorting staff, and postmen were then in receipt of 45 per cent. of the appointments, thus sliowing that a junior staff has been introduced to the detriment of the senior staff. I may state that messengerships are open to porters, and that they obtain a large number of the appointments. There are only 44 
messengers in the whole of the London district, and 53 lobby officers, so that will give you some sort of idea of the number of appointments there are open to postmen.

Mr. Walpole: What do you mean by junior staff? Do you mean that the sorting staff is a junior staff?

A. Yes, sir ; they have been established since the postmen.

Q. Then you mean that they are junior in respect of the date of their aplointment to the establishment?

A. Exactly. On the authority of Mr. Salmon, Postmaster of the Western District, it may be stated that the latter was in a peculiar situation, seeing that there were no suburban offices to appoint postmen to, but this by the foregoing figures seems to be the case of every district office, and even if this were not so, unless an amalgamated seniority list had been established, it is decidedly against the suburban postman to promote a district man over his head. This has been done in the various districts, with the excej:tion of the three I have mentioned. No doubt it would assist greatly if I pointed out the method adopted with regard to promotion. Two lads passing a Civil Service examination and obtaining an appointment termed boy sorters (since redundant) enter the Service the same day, they run side by side for three years, when they should both be on the verge of a 2nd class sortership, but owing to there being no vacancies for this class, and a large number of vacancies for 2nd class letter-carriers, these lads are told to make an application for the latter appointment-or the chances would be that their services would have to be dispensed with. One lad under protest applies, not wishing to lose his situation, and speedily obtains the position of 2 nd class letter-carrier. The other (presumably not caring whether he stayed in the Service or not, because he disregarded the instructions given to him) stays on as a boy sorter, and before long obtains the position of a 2nd class sorter (without a further Civil Service exam.), and when the Metropolitan districts were placed upon a footing with the E.C. District by the Fawcett scheme coming into operation, he obtained a 1st class sortership (without exam.), and finally he reached a 2nd class overseership (still without exam.). To revert to the lad who obtained the position of 2nd class letter-carrier, after a given period he is promoted as 1st class letter-carrier, and is now wearing three stripes, showing that he performed his duty in a proper and efficient manner. If this man seeks promotion now, he is told that he can apply for a 2nd class sortership (which the had had a right to, and had almost obtained), and must go through a Civil Service exam., in itself a difficult matter for a lad fresh from school, who had been coached on the various subjects to pass, and, if successful, go behind all the numerous entrants on that class during a period of over 16 years. This would be a retrograde movement, seeing the duty he would be called upon to perform would be precisely the same as when he entered the Service in 1876 at a wage of 9s. per week. I may state, gentlemen, that there was a lad who obtained promotion to the 2nd class of sorters from the postman's class. He was appointed to the City, and his duties for the first three weeks were merely to pick up the paper, string, etc., from the floors. That will give you an idea of the work that 2nd class sorters might be expected to perform.

Mr. Smith: Do you suggest that as a typical case of the duties of 2nd class sorters?

A. It was so in the case of this man.

Sir F. Mowatt: How long did this work go on?

A. About three weeks. The sequel to the cases I quoted just now, my lord and gentlemen, is that whereas the lad who disregarded his instructions in the earlier part of his career is now in receipt of a salary of $50 \mathrm{~s}$., with an allowance of $5 \mathrm{~s}$., making a total of $55 \mathrm{~s}$. per week (with a chance of ultimately reaching an inspectorship, $£ 175$, by $£ 10$, to $£ 260$ ), the postman's maximum pay is $34 \mathrm{~s}$, , and $3 \mathrm{~s}$. three stripes, a total of $37 \mathrm{~s}$., or at 
the present time a difference of $18 \mathrm{~s}$. on the wages, and no prospects of proniotion. Yet the superiority in one case is no more than in the other, seeing that the two officers only passed the one examination. I would like, sirs. if it were possible, for you to call in at the Western District Office, where I am employed, between 6 p.m. and 8 p.m. any evening and see for yourselves the way letters are dealt with; I venture to think you would come away greatly enlightened as to the relative work of postmen and sorters. A little illustration as to the course of a letter from the time of posting to its delivery will perhaps be out of place here.

Sir F. Mowatt: What do you mean by "the course of a letter from the time of posting to its delivery?"

The Chairman: The witness evidently wishes to show the life of a letter between the time of postage and delivery.

Witness : In the case of a local letter it frequently occurs that during its progress through the Post Office it does not pass through a sorter's hands at all. Should the letter be going to a neighbouring district the letter would probably pass through two sorters' hands-it is only when the letter goes into the provinces that it goes through a number of sorters' hands. In the first place, the letter is collected by the postmen, brought to the office, turned out on a facing table, there to be faced by postmen, stamped ditto, primarily sorted by postmen, then the sorter checks the postmen's sorting and bags the letters to the district for which the letter is intended at the other end, a sorter opens the bag and signs the letter bill, and there the letter passes out of the sorters' hands, for the postman stamps, primarily sorts in walks, then into streets, and finally disposes of the letter by delivering the same.

Mr. Walpole: That is a letter for another district in London?

A. Yes. That a postman may be promoted to a 2 nd class sortership is but a dubious benefit (with a few exceptions), and the examination to be passed in order to obtain this advantage-if such it be-is made deterrent by its requirements. That an anomalous state of things exists here is very apparent.

Mr. Walpole: What do you mean by the words "made deterrent by its requirements?"

A. By the examination postmen have to pass.

Q. Have you a list of the subjects in which they have to pass?

A. Yes, sir.

Q. Read them out, please.

A. One subject is arithmetic, but first a man has to copy on a form a passage in his best handwriting, and to do as much as he can in 30 minutes. $\mathrm{He}$ is told that it is desirable that the passage he is copying should all be got on one page, but that he may, if necessary, use the other page. Special importance is attached to the clear and good formation of figures, and then he is examined as to returns of articles of export from during the year 1889.

Mr. Walpole: You are reading an actual examination paper, are you not?

A. I was just reading the headings.

Q. Just give us the headings of the examination, please.

A. Arithmetic (the first four rules, simple and compound), English composition (that is writing an essay), and geography generally.

Mr. Walpole: And that is all?

A. Yes.

Q. And that is what you call a "deterrent examination"--the first four rules of arithmetic, English composition, and geography.

A. It is, sir, for a man of years. If you take my own case, for instance ; I am just on 35 years of age, and I think $I$ should break down in an examination of that sort. I do not think really and truly that $I$ could do it. The fact of the matter is. I have a child at school. She has been educated at a board school, which they term a higher grade school. She 
is now in the 7th Standard, and is passing into the $7 \mathrm{X}$ Standard. I put some of these subjects to her. With regard to the sums she could answer about 6 out of 12, but when it came to the geography, although the children are taught by memory maps; it was impossible for her to answer the questions.

Q. But any child in the 7th Standard ought to be able to do any sum in the first four rules of arithmetic, ought she not?

A. She ought; but in answer to that I may explain that if you look at the school-books which they use, you will find on the back of them intimations from teachers who undertake to coach pupils in these various subjects. At the school which my child attends, after they have passed the 7 thX Standard they are educated further, to enable them to pass the various Civil Service Examinations. It is the same with regard to the boys; they are taught side by side with the girls, and the boys could not be expected to do any better than the girls.

Mr. Smith: I understand your chief objection is not so much that the standard of examination is too high for a lad, but that a postman would have forgotten some of the things he had learned at school, and would cosisequently find it more difficult to go through his examination with credit? Is that your point? Is it a question of age rather than of standard?

A. My point is that every postman has passed a Civil Service examination when he enters the Service, and I think that that is all that is necessary for him. When he becomes a 2nd class sorter, he ought merely to have to pass a sorting examination.

Mr. Smith: That is quite a different point. You may take the whole examination and say it is too hard, but that would apply to the sorters as well as postmen. "Do you think the standard ought to be lowered for sorters? It is the same examination for sorters as for postmen, is it not?

A. No ; I would not suggest that the standard be lowered. I should like to point out that all officials in the Post Office, no matter what position they have attained, have had to pass only one Civil Service examination.

Mr. Smith: That is not an answer to my question.

Witness: You asked me whether I would have the standard lowered?

Mr. Smith: The reasons you first gave for your objection were based chiefly on the ground of age. You suggest that the men might possibly find it difficult to go through the examination, although they are fully com. petent. But when you give an illustration of the examination, and state the subjects, I understand you to argue that a boy or girl who passed through the 7th Standard at a Board school could not, nevertheless, pass this examination. Surely that would tend to show that the whole thing is too hard for anybody?

Witness: May I point out that I myself passed an examination for a sortership. I have never passed any examination to become a postman. Presumably my appointment is still that of a sorter, although I am acting as a postman.

The Chairman : You were appointed as a postman and sorter?

A. Yes, iny lord. What I would suggest is this, that postmen should not be expected to pass this examination on appointment as 2nd class sorters, but that, with regard to new entrants, or those coming from the street, as the saying is, they should pass it as a matter of course.

The Chairman: What you would say is that, having passed an examination, and having become a postman, your experience as a postman qualifies you to become a 2 nd class sorter, provided that you show your competency?

A. Exactly so, sir.

$\mathrm{Mr}$. Walpole: Then would it not be necessary to stiffen the examination for postinen?

A. Exactly so, sir; and we would suggest that tor.

Q. At present the examination for postmen is in the simplest possible form, is it not? 
A. Yes; the examination for postmen at the present time has been lowered, and that has acted to the detriment of the men who are now in the Service.

The Chairman: Practically you want to merge the classes of postmen and sorters?

A. Exactly so. While I am on this point I should like to speak on the question of the "dual certificated" men.

Mr. Walpole: We have had that.

Witness : I have here a case from Dublin. Now, Dublin is not represented at this Inquiry, and in the Dublin office there are a large number of men who have passed this dual certificate. During the period between 1885 and 1887 a number of men were examined before the Civil Service Commissioners and qualified for the dual position of "sorter and postman"; they were instructed to take up duty as postmen. After some time a number of them individually applied for a transfer to the S.O., and were granted permission to enter on their Civil Service certificate; the remainder waited some time longer, confident that the Department would transfer them as vacancies occurred, but not hearing anything, decided on making application, with the result that they were refused admittance to S.O. by Mr. Arnold Morley, on the ground that the educational standard had been raised, although they pointed out to him in their petition that men already in the S.O. had qualified at the very same time, and on the very same Civil Service certificate as themselves. This they feel to be a great injustice, as having qualified for a position whose maximum is 56s. per week, besides other advantages, such as increased annual holidays and annual increment, they think it decidedly unfair to keep them on a class whose maximum is $33 \mathrm{~s}$. per week, less holidays, and less annual increment. As showing that the Department recognised their claims to sorterships, they in 1890 issued a notice to the effect "that all applicants for sorterships from postmen will be required to undergo the Civil Service examination now prescribed for sorters, except those who have obtained the dual certificate of sorter and postman." (Vide W. J. Landray's evidence before I. ord Tweedmouth's Inquiry.) Now I come to the case of the London dual certificated men.

'The Chairman: Are you one of these yourself?

A. I have been forced into the position of a postman.

Mr. Walpole: You took a postman's place voluntarily, I suppose?

A. No, sir; I was forced to take it. It meant my taking it or leaving the Service. That was not the terms on which I entered the Service. The inducement I was offered was that I should get in time $45 \mathrm{~s}$. a week, and I see no possible chance of doing so. There was a class of men who entered the Service between 1879 and 1882 with a dual certificate as junior lettercarriers and sorters at the wage of $14 \mathrm{~s}$. per week, who had to attend a sorting school in their own time, and pass primary sorting three times, as well as learning the routes and duties in connection with the Parcel Post. Men who made applications for sorterships had to follow behind men as much as ten years their juniors, and passed no examination in the E.C.D.O. and other branches. Those men who started the Parcel Post at the E.C. Office were informed by the overseer (Mr. Blake) from the chief of the Department that in return for their endeavours, if the appointments were placed on the established staff as sorters, they should be the first to receive that appointment, as only those men who had not received their appointments as 1st class letter-carriers were drafted into that service. This promise was confirmed in the presence of the late Right Hon. H.' Fawcett by Mr. Jeffreys, the then controller, and Mr. Hunter, and if that promise had been fulfilled they would now be performing the duties of 1st class sorters at the Parcel Post Depot, and other branches, to which these men were afterwards drafted. The advantage of men joining the Service as 2nd class sorters is that they are placed on their seniority without passing 
any sorting examination, but a letter-carrier, although having passed all through the examinations, has to pass again for the 2nd class sorterships, known as a Departmental examination. At present at the Parcel Post Depot, Mount Pleasant, there are men who are four years junior to the men who started the Parcel Post in 1883, and came as auxiliary postmen, working the duties that were promised to the men who first worked the duties in that branch. The abolition of this sort of friction is a desideratum. It might be suggested that 1st class sorterships should be within reach of the senior men of the postmen's class equally with those who are of the 2nd class sorters, thus making the two brancles equal in aim and status. In a probationary stage, when a postman has been performing the duties of one in a higher grade, such performance of such higher duties should receive corresponding increase of pay. Postmen have performed superior duties without this increase. In common with other branches of the Service, we deprecate the system of devolution. In 1865, in the Official Circular dated March 22nd, and signed by the then controller (Mr. W. Jokenham) we find the following:- "All have a fair chance of rising to the several classes above them, the entire establishment being recruited from the supplementary class." Of this class there were 100 men termed supple. meltary letter-carriers. This promise was faithfully carried out on the Department, for to-day most of the inspectors, supervisors, and overseers were postmen at or about that time. On the institution of the Parcel Post the whole of the initial work was done by letter-carriers; these men were promised appointments, but this promise was not carried into effect, outsiders and sorters taking these appointments, and the letter-carriers being drafted back to their original duties without any recognition.

Mr. Walpole: When you say you were promised appointments, what vere you promised appointments as?

A. We were promised appointments as sorters, sir.

Mr. Walpole: Have you any evidence of that?

A. Certainly, sir. I wish to put in this letter :-

To the Controuler,

F.C.D.O., September 27th, 1895.

Sir,-In answer to your inquiry as to who gave the promise in question, I beg to submit that when we were selected to learn the routes in connection with parcel duty, under Mr. Blake and Mr. Chamberlin, we were informed by the former from the chief of the Department that we should forget all about the letter post, as our appointments would be in the Parcel Post if that department was placed on the established staff, as only those men who had not received their appointments as letter-carriers were selected for duty in that department. I also beg to refer you to $\mathrm{Mr}$. Hunter and Mr. Blake, who were present with the late Right Hon. H. Fawcett and Mr. Jeffreys, the then controller, when all the officers of the Parcel lost were assembled and informed by them that we were the men appointed to work that department, and its progress was ours in that service. Had their promise been fulfilled we should be performing the duties of 1 st class sorters.

On behalf of the Petitioners,

I am, Sir,

Your obedient Servant,

R. W. Neale, Postinan, E.C.

Mr. Walpole: What rank did Mr. Blake hold in the Service wien he gave this alleged promise?

A. Well, sir, lie was an overseer at that time, and he has since been transferred to be chief inspector at Mount Pleasant. 
Q. Do you think your overseer had any right to give a promise of that kind? Do you attach any importance to a promise so given?

A. I do not know that; but you must remember that the overseer was our immediate superior officer.

Q. Who was Mr. Hunter, the other gentleman who gave the promise?

A. I am informed that he introduced the Parcel Post under the Fawcett scheme.

Q. Is it not a fact that he denies any knowledge of this interview?

A. The men sent this letter in, and they have received no reply.

Mr. Walpole: Do you mean that this letter has been sent to the Department?

A. Yes, sir.

The Chairman: Do you look upon the Parcel Post Service as a better one than the letter branch?

A. Oh, no, sir; but they are part and parcel of the office work. But what we do say is that these men who have chiefly brought about the Parcel Post were sent to work these duties, and, in fact, taught the 2nd class sorters their duty; they went into the office, they brought the thing about in its initial stage, and they consider that as a promise was made to them it should have been carried out.

Mr. Walpole: I understand you to say that these men were promised distinct advancement for working the Parcel Post?

A. Yes, sir.

Q. Ard I think that the promise on which you rely is an alleged promise by an overseer? That, as far as I understand it, is your case?

A. Yes, sir.

Sir F. Mowatt: What was the promise?

A. They were promised that they should be made sorters. These men urge in support of their claim that they are dual certificated men.

Mr. Walpole: Has that anything to do with the promise? That is another thing altogether.

A. No, sir; these men think it adds to the obligation to appoint them.

The Chairman: Were all these men taken to work the Parcel Post in its initial stage, as you mentioned just now?

A. Exactly.

Mr. Walpole: But at that time, when they were taken to initiate the Parcel Post, and when the alleged promise was given, there were no sorters employed in parcel work, were there?

A. No, sir.

Q. And there was no intention of employing them, was there?

A. I do not know, sir; but even if that were so, when the intention to employ sorters was carried out, the men who held dual certificates thought that as they were perfectly competent to perform the duties, and as they were promised the appointment to sorters, they ought to have received it. Undoubtedly the promise was made in good faith.

Sir F. Mowatt: I do not understand you. When these men went to the Parcel Post were there no sorters there?

A. No, sir ; there were no sorters there.

Q. And I understand you to say that the promise was that they should remain in the department and become sorters?

A. Yes, sir.

Q. But if you have no sorters in the department, how then could they remain and become sorters?

A. They held dual certificates. They could work either as postmen or sorters, and they were waiting for appointments to sorterships.

Q. Do I rightly understand you that these men think when they were set to Parcel Post work they were promised that they should be made sorters, although there were no sorterships in the Parcel Post to which they could have been appointed? 
A. Yes, sir.

The Chairman: You also wish to insist upon the fact that the particular men chosen for this duty were dual certificated men, and therefore had more of the sorter element attaching to them than the ordinary postman?

A. Exactly so.

Mr. Walpole: Are you quite certain that all the men chosen were dual certificated men?

A. I am informed so, sir.

The Chairman: How long were they kept at the work before sorters were introduced?

A. I should think twelve months or two years, sir.

Q. Where did the men come from who initiated the Parcel Post?

A. The Paddington Depot. They were there nearly eight months. They had a sort of idea that they were tried on these duties in order to test their fitness, and after they had performed them for a long period they were sent back.

The Chairman: Do you know why the change was made? Was it the case that the men were found not to be thoroughly competent to do the work?

A. Oh, no, sir; these men must have been competent to do the work, or they would not have been kept at it.

The Chairman: They were apparently not kept at it.

A. I mean for so long a time. These men were promised this thing in good faith, but the promise was not fulfilled, and they were kept waiting for appointments as 2nd class sorters.

The Chairman: I am afraid you have broken down a little. It appears to me that you have not very clearly made out the promise. I quite understand you have so far established your case that a number of men were taken from the letter side of the Postal Service for the purpose of carrying out the Parcel Post service, and that the whole charge of that service was in their hands for a considerable number of months?

A. Yes, sir; and then when naturally they might have been kept on at that particular service, they were sent back, and sorters were brought in to do the work.

The Chairman: I think you have made that out pretty clearly, but I do not think you have made out a clear and definite promise to these men that they should become sorters. They may have thought there was an implied understanding from the fact that they were kept at the work, but I do not think you have shown any strong proof that they were promised they should become sorters.

A. I do not think there was any necessity for the promise; they were entitled to it by right.

Q. That, I think, is a matter you may fairly put forward in your evidence, but you founded your statement upon a definite promise, which I do not think vou have shown us was made. I must say that.

Mr. Walpole: As to the fairness, and as to what they might have expected, I presume that when the Parcel Post was established it was necessary for the Department to get up a "scratch team" for the new work. I am not using that term offensively.

A. Yes.

Q. And because they swept together a number of men who seemed likely to be qualified for the work, surely you do not hold that the Department was bound in honour to keep those men at that work for all time?

A. Well, sir, these men were dual certificated, and should have taken precedence.

Q. I have no doubt the men you represent were dual certificated, but you must give me leave to doubt whether all the men put to that service were so.

The Chairman: Were none of these men kept on? 
A. There is nothing here to indicate that any were.

Q. Can you tell me whether the whole of these men so taken were sent back again to their letter work, or what proportion were kept on?

A. I cannot tell you, sir. As a further illustration of the way promotions are dealt out, Mr. F. A. Gill, a postman, in 1892 applied for a clerkship, and no notice was taken of his application. In Feb., 1893, he successfully passed the sorting examination, obtaining the 18th place out of 100 vacancies, and shortly after (in 1895) he applied for the clerkship again. This time his application was granted, and he entered a competitive examination for the same and passed, he being transferred to the controller's office.

Mr. Walpole : Do you mean clerkship or sortership?

A. Clerkship. The point is this, Mr. Gill could equally have passed for a clerkship as a sorter, yet as a postman he was not allowed the privilege. Here is distinctly a class grievance. We consider that, providing a postman can pass the examination, no barrier should be put in his, the postman's way. 'This class distinction is an anomaly that wants serious attention. You, sir (Mr. Walpole), I have to thank for the admission, miade on Dec. 18th, I think, that there are no major or minor establishmients, and hope in future that when a postman seeks to enter a competition witl others, no matter his age or service so long as he is on the establishment, he shall be permitted to compete.

M.r. Walpole: These are limited competitions, are they not, for which a man must be nominated by lis superior officer?

A. That is for clerkships.

Q. Yes ; clerkships.

A. I do not know, sir. All we do know is that a notice is put up to the effect that "applications are invited."

Q. But it would be subject to a recommendation from a superior officer, would it not?

A. Yes, sir. But I am pleading for the postmen who are kept out of them.

Q. I a.m not saying that postmen ought not to be recommended, but surely there ought to be some recommendation on the ground of good corduct and efficiency?

A. Quite so, sir ; and postmen, I should think, would be able to stand that. Mr. Walpole: Quite so.

Mr. Smith: I want to get this a little clearer. Do you mean to say that under no circumstances is a postman allowed to compete for a clerkship?

A. Yes, sir.

Q. Is that so? Not even if he gets a recommendation?

A. Yes. Whatever qualifications he may possess, he cannot get into this limited competition. He can only compete in the outside market-in the open market.

The Chairman: Have you got any instance of a postman having been made a clerk?

A. No, sir. We only know that they have repeatedly applied for these clerkships, and there is no instance of a postman ever getting one.

The Chairman: You said they had never been allowed to compete.

Mr. Smith : Excepting in open competition.

Mr. Walpole: I am informed that the practice of the controller is to ask Pastmasters to nominate the most suitable men in their offices, and that no restrictions are imposed as to whether they are postmen or sorters. That is the rule.

Witness: All I can say is that postmen are never recommended. I do not know whether it is thought they are not competent. I have another illustration here from a suburban office. E. G. Smith entered the Post Office as telegraph messenger on the 28th January, 1877; he was appointed as assistant or 2nd class letter-carrier on the 18th August, 1878, and as a 
suburban letter-carrier on the 13th November, 1881. As a result of an application made by him for promotion on the 9th January, 1893, he was sent on trial to Wandsworth, and there acted as head postman. From there he went to Mortlake on the 14th July, remaining there till the 29th of the samc month. On the 8th September, 1893, he was sent to Barnes, where he remained till October 8th, when he was told to return to Putney and take up his own postman's duties. Since then he has been called upon from time to time to do head postmen's duties while head postmen are away on holiday. I have another case:-J. P. Worth has been working head postman's duty on and off for the last nine years. The last time he did it for a period of three years, and each vacancy has been filled up by men from the District Office. He has two stripes, and is a thoroughly capable man, who understands every part of his duties. This is at New Cross.

Mr. Smith: You say he has been unfairly passed over?

A. Yes, I should think so. He has been working on these duties for nine years, and surely he is competent by this time to perform them. I have an illustration from my own office as to the way vacancies, are filled up. Quite recently an official intimation that clerkships were vacant was placed on the notice board in the offices. A considerable number of postmen, among other officers, applied for the position, but were doomed to disappointment, for in every instance their applications were ignored. Six years ago a lobby officer's position was vacant in the W.D.O. This position was not notified to the postmen (nor are any, as far as that is concerned, with the exception of 2nd class sorters). This was offered to and accepted by quite a junior man, and, although a man many years senior to the recipient applied, his application for the position was not noticed. I may state there were over 50 men between the senior who applied and the man who obtained the position.

Sir F. Mowatt: You say a senior man applied?

A. Yes, sir; senior men did apply. This shows it was a case of distinct favouritism.

Sir F. Mowatt: I cannot see that.

Mr. Walpole: Will you give me the name of the man? I will look into it.

Witness: The name of the man who applied for the position was W. Coslett; he is the senior man. I think he has been in the Service nearly 35 or 36 year's.

Q. What was the name of the man who got it?

A. Bruton, sir; he has been appointed about five or six years.

Q. Then this is a case five or six years old?

A. Yes, sir. The senior man has never been offered an appointment. I may state that for over five years in the Western District Office there has not been an opening for postmen at all. All the promotions have gone to the sorting staff.

My Lord and Gentlemen.-The foregoing statements are the result and outcome of careful thought and documentary research. The object aimed at has been to make clear that the grievances to which your attention has been called are real ones, and call for remedial measures. Our one desire is to work in a spirit of unanimity with the slightest possible amount of friction. You will observe that special mention is made of the difficulty existing between ourselves and that branch of the Service-2nd class sorters. We claim equality with the latter staff, also an equal proportion of appointments, and that appointments to the higher grades be open to us in equal ratio. I may also add that we would further recommend amalgamated seniority lists, the same as in the case of 2 nd class sorters in the Metropolitan District.

Mr. Smith: When you say "open to all in equal ratio," you mean "competent in equal ratio," I suppose?

A. Yes; I used the wrong word perhaps. This would go to still a large 
and ever-increasing feeling of discontent that exists. Without further troubling you, my lord and gentlemen, and feeling that our case will be justly and liberally dealt with, on behalf of the London postmen I thank yo'ı for your courteous attention.

Mr. Walpole: What do you mean by amalgamated seniority lists?

A. Amalgamated seniority lists for the whole of the London postmen, including the City postmen.

Q. Do you mean irrespective of the zones? You know that in London postmen are paid on different scales according to different zones?

A. Exactly so.

Q. And you would take no account of that?

A. No, sir; I would take the man as he comes into the Service.

Mr. Walpole: I only wanted to know what you mean?

A. Yes, sir.

The witness then withdrew, having been under examination over an hour.

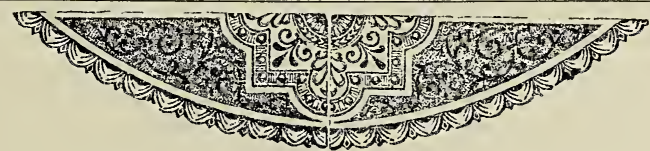


H. SYMES, E.C.D.O.

\section{Abolition of Classification.}

\section{Floating Staff.}

Westminster, Monday, March 2, 1896.

Mr. H. Symes, E.C.D.O., examined:-

The Chairman: Are you a postman in London?

A. Yes, my lord.

Q. In what part?

A. The E.C. District.

Q. Are you at your maximum?

A. No, my lord; I have 24s., with a stripe. I have seven years' service.

Q. Are you speaking for the junior men?

A. I am speaking from the point of view of the men who suffered by the abolition of class ; they were deprived of the appointments they should have received.

Q. Are you going in favour of the re-introduction of classification?

A. No, my lord; I will deal with that presently. You will see by my opening statement what my complaint is.

Mr. Walpole: What are you yourself?

A. I am an established postman.

The Chairman: With seven years' service? 1889.

A. It is $6 \frac{1}{2}$ years' service; I made a mistake. I joined on August 12th,

\section{ABOLITION OF CLASSIFICATION.}

The case which I have to submit to your consideration arises from the revision scheme which came into operation on August 2nd, 1891, under the regime of the late $\mathrm{Mr}$. Cecil :Raikes. Prior to that idate the postmen of London were divided into two classes, respectively termed the 1st and 2nd classes. By a clause of the Railkes' Scheme, however, this system of classification was abolished, the two classes were amalgamated, and a division made into zones, the said zones taking as their basis the respective districts in which the men were stationed being introduced in its stead. In every district of London a large section of the men consider that a serious injury was inflicted upon them by the manner in which this abolition was carried out, and Ihave, in consequence, being one of them, been deputed to lay their case before you. Before proceeding to do so, however, I desire to point out that the fact that exception is taken to the manner in which, in a specified instance, a principle is carried out, does not necessarily imply any disapproval of the principle in itself, and that the men whom I represent do not object to the abolition of any arbitrary class distinctions which may exist between men whose duties are of a similar or of an identical nature. Quite the contrary: they regard any such abolition, when properly carried out, as a desirable reform. But they contend, and I will presently endeavour to demonstrate to you the justice of their contention, that the manner in which the Department, by the scheme of 1891, feebly attempted to reduce this principle to practice, involved in the process the infliction of a serious and lasting injustice upon them, the violation of official rule and precedent, and the creation of a tendency-in addition to those previously existing-towards disorganisation in the postal service, as a natural consequence of giving just and reasonable grounds for discontent to a section of 
its employees. Having made this prefatory statement in order, at the outset, to render our position alear, and to obviate the possibility of giving rise to any misunderstanding concerning our attitude towards the subject of class abolition in general, I proceed to lay down, as a definite premise, the principle that it is a guiding rule of official procedure that-"No person or persons entering the postal service under stated conditions as to pay, promotion, etc., shall, at any period subsequent to that entry, have those conditions altered in such a manner as to deprive them of any of the advantages which they would have received by their original agreement with the Department being fully carried out."

The Chairman: What is that quotation from?

A. I have not quoted anything. I $\mathrm{a}_{\mathrm{m}} \mathrm{m}$ going by precedent.

Mr. Walpole: Then it is your own statement?

A. Yes, sir ; but it is borne out by many other statements.

Q. I am not disputing it.

A. Oh, you do not dispute it, then?

The Chairman: In the copy you have given me of your statement yos have placed these words 'in inverted commas, and therefore $I$ thought it was a quotation?

A. No ; it is not a quotation. The abolition of classification involves many intricate matters which it is difficult for outsiders to understand. It is hardly necessary for me to dilate upon the obvious necessity for the adoption of such a principle by a great public department such as the Post Office. Moreover, it has for years past been tacitly accepted in written and verbal statements by successive chiefs of the Department, as will, for instance, be sufficiently demonstrated by a retrospective examination of the evidence which has already been placed before the Committee by our present chiefs, in which evidence it will be perceived that they have not even attempted to refute this principle, but have always contented themselves with the endeavour to prove that it has not, in any specific case with which they were dealing, been violated. The principle of continuance of primary advantages being, I think, firmly established, the question which naturally presents itself on endeavouring to apply this principle to the case of those who complain of the manner in which classification was abolished in 1891 is, "Under what conditions did they enter the postal service?" These conditions, in so far as they concern the case in question, may be roughly divided into three, viz. :-The minima-In this respect the men concerned form two classes, the first entering the Service between 1887 and November 9th, 1889, and having a minimum of $16 \mathrm{~s}$. weekly, whilst the second, entering the Service between November 9th, 1889, and August 2nd, 1891, received a minimum of 18s. In all other respects, however, their conditions of service were identical, the second being "That they should rise from their respective minima by annual increments of $1 \mathrm{~s}$. per week until vacancies in the 1st class occurring, they should fill those vacancies at a minimum wage of $24 \mathrm{~s}$. weekly." The third condition was "That they should, having received their 1st class appointments, rise by increments of $1 \mathrm{~s}$. weekly (the first increment being biennial, the rest annual) until they reach their respective maxima."

Mr. Walpole: As the Department has not disputed the principle is it worth while to continue this?

A. As the principle is accepted I will not. Now, the raison d'être of such a system of classification as that laid down by these conditions must naturally, in the first place, have been a performance of duties of $a_{1}$ different character, those of the first being considered superior to those performed by the second class. As a matter of fact, I find it was originally intendel that the duties of the 2nd class men, then termed assistants, should be confined to collections, it being apparently considered that the responsible and arduous duties of delivery constituted work of a distinctly higher character, demanding higher remuneration. After a time, however, the growth of the public business seems to have necessitated a further division of walks, and these assistants were introduced among the letter-carriers, carrying out 
(although in a sense different to that in which it was first applied) the signification of their title, by taking a portion of two or more walks. This process went on in a greatly increased degree, until the majority' of these assistants gradually fell into much the same position as the ordinary letter-carrier, although they did not receive a corresponding increase of pay in return for the performance of these superior duties, which had primarily been the raison d'être of a superior class. Although, however, the 2nd class evolved in this species of laissez faire manner into a kind of probationary class, locking forward to the period when they would be receiving the higher wage of the 1st class as a recompense, at least in part, for their then inadequate remuneration for the performance of 1st class duties, a certain numerical ratio was, in spite of their anomalous constituent elements, always preserved between the two classes, and, whenever there was any delay in the issue of 1st class appointments, that delay was accompaniod by, and due to, a general insufficiency of staff. This cursory examination into the evolution of the system of classification leads us to the conclusion that the creation of 1st class appointments was dependent, in the preservation of the numerical ratio between the classes of which I have spoken, upon the development of the Service, and the accompanying increase of staff. To come now to the period between 1887 and August 2nd, 1891, although, in the first half of this period, appointments were sometimes delayed for some considerable time, owing to the fact that the staff had not been increased in proportion with the work, during the second half appointments were grantsd after a period of service almost as short as those which haid previously-as I will presently demonstrate-been the rule instead of the exception; so that some of us were brought, by the natural evolution of the system, to such a position that we should, at some time during the year 1891, have received our 1st class appointments, with a consequent rise to $24 \mathrm{~s}$. per week. As an example of what that mean't to us all, I will remark, eı passant, that my own wages during the first ten months of that year were 19s. per week. In order to show by how small a turn of what might be termed the official "wheel of misfortune" some amongst us lost these expected appointments, and to demonstrate how suiddenly the decision to abolish classification was arrived at, I should like to ask whetlier or no a paper was forwarded in May, 1891, in response to a Treasury minute authorising the creation of 65 appointments, containing a list of that number of names of men who were recommended by the responsible officials as fit recipients of those appointments? If so, whether that list has been preserved, and also whether it is not a fact that my name appeared upon that list amongst others, and that it was subsequently removed in order to make way for others whom it had originally been intended to punish by a temporary suspension of their appointments, which appointments the responsible officials, when it was determined to abandon the system of classification, did not care to entirely deprive them of, and therefore included their ndines in the list of those qualified, to the exclusion of others, such as myself, to whom they (the officials), being enamoured of Departmental economy, did not see fit to extend the same measure of justice?

Sir F. Mowatt. The maxima were 32s. and 30s., were they not?

A. Yes, sir, at that period. I may point out that the increase of the maximum did not date from this; it occurred in the following May, and had nothing to do with it.

Mr. Walpole: The maximum at that time in the London town district was $32 \mathrm{~s}$., and in tle provincial town districts 30 s.?

A. Quite right.

Mr. Smith: Were any passed over at the maximum?

A. I beg your pardon; I do not understand.

Q. Were any passed over who were at the maximum of the 2nd class?

A. Yes; when the increment becomes due men are passed over for bad character. To resume: Some amongst us were then, just prior to August 
2nd, 1891, anxiously, yet confidently, expecting our appointments, never dreaming but that, as we had properly performed our duties, the Department would honourably adhere to its engagements. Bu't the ways of the Department are past finding out, and often disappoint the most reasonable expectations. The Departmental coup d'etat was sprung upon us, and in all parts of London men who, like myself, were expecting almost immediate appointments, i.e., a rise from $19 \mathrm{~s}$. or $20 \mathrm{~s}$. per week to $24 \mathrm{~s}$, as well as those who followed them, the whole of whom, as the development of the staff has since that time sufficiently shown, would have received similar appointments at some time within the two years following that period, found that prospect suddenly snastched from them, and themselves left without hope of ever being able, unless they now receive through your recommendations the reward of patient endurance of injustice, to retrieve their lost position. I thought I would state this, as it proves how utterly it was outside the system that we should suffer as we did. Although there had been no communication between the various districts, petitions were forwarded from all parts of London, but it would be impossible for me to deal with them all, and therefore my remarks will be chiefly confined to those efforts to obtain redress which emanated from my own district, the E.C., because, coming as they did, under my immediate notice, I am better acquainted with their details. But what is to be said concerning the E.C. applies in nearly every particular to the whole of London.

Sir F. Mowatt: You have not stated what the hardship is yet?

A. I thought that could be seen. I have laid down here the principle for continuance of primary advantages in conditions of service. We contend that in consequence of the manner in which classification was abolished, and by reason of the introduction of a new scale, the men already in should have been continued on the old scale until they had received all the advantages they had a right to expect.

Sir F. Mowatt: What advantages have they lost?

A. They lost $5 \mathrm{~s}$. a week, which would have been a great advantage to them; I will deal with that later on.

Mr. Walpole: May I ask you this? We have had an application, I dare say you know

A. Oh, yes.

Mr. Walpole: You had better wait until you hear what I have to say. We have had an application from the sorting clerks throughout the country for the abolition of classification.

A. Yes, sir.

Q. And, in my opinion, undoubtedly the abolition of classification will be a serious injury to some of the 2nd class sorting clerks. Do you think the Department is precluded from conceding the wish of the sorting clerks generally to abolish classification because it would undoubtedly injure many of the 2nd class sorting clerks?

A. Not in the least; I think you should take into consideration the principles laid down by the Treasury in regard to this. When the Department abolished classification our men asked for an increased increment as compensation. But the abolition of class has been carried out, and we have not had the increased increment, but we have actually lost money through the abolition of class.

Mr. Walpole: But the ultimate advantage was to increase your maximum?

A. I will deal with that presently. I will show what it meant.

Q. But your maximum was increased?

A. Oh, yes, but not very considerably. But that was on general grounds. At the same time other branches of the Service received still greater concessions. Surely you ought not to contend for one moment that this concession granted to the large body on general grounds was a particular concession in our case to compensate us for the loss we had to sustain by the abolition of classification? 
Mr. Walpole: I am not contending anything; I only want to bring out the facts.

A. I quite agree with your facts, but they may be put in another light. It all depends in the way you put them.

Sir F. Mowatt: Your maximum was raised by 2s. ?

A. Yes; but it would take nine years to get it. It was no compensation for us. On April 4th, 1892, a meeting of the men affected in the E.C. District was held, at which meeting three delegates were elected for the purpose of laying the case before the Controller. These three drew up, and on April 7 th forwarded a written request for an interview with the Controller, which request I will now, with your permission, read to you.

\title{
(Copy.)
}

To the Controller,

$$
\text { E.C.D.O., April 7th, } 1892 .
$$

Sir,-At the meeting of the E.C. postmen, who suffer by the abolition of classification, held on Monday, April the 4th, the following resolution was passed:-

"That this meeting respectfully asks the Controller if he will bo good enough to receive a deputation of three, to lay our case before him?"

We, the undersigned, were duly elected by the meeting, and respectfully ask that you will grant us the favour of an interview, that we may discuss the following points with you:-

Firstly-That we are under the impression that it is an official principle "That no individual should suffer by the introduction of a new scale of promotion or wages."

Secondly-We are prepared to show that we do, and shall suffer material pecuniary loss by the abolition of class, amounting in some cases to about $£ 100$ by the time the maximum is reached. (It is more than that in some instances.)

Thirdly-We would earnestly point out for your kind consideration that, before the last revision, although we were receiving inaidequate wages for our needs, we were buoyed up by the prospect of obtaining a 1st class appointment and consequent rise to $24 \mathrm{~s}$. per week. In conclusion, believing you liave the interests of the men under your charge at heart, and if we fully convince you of the existence of a real grievance, we feel sure we shall gain your valuable recommendation towards establishing a better condition of things.

We are, Sir,

Your obedient Servants,

\author{
W. JoHNSON, \\ C. Clark, \\ H. Srmes,
} (Postmen).

Now, considering the nature of this application, it might have been expected that the Controller, seeing a large number of men under his charge so thoroughly convinced thait they are suffering from an injustice, would have gladly seized the opportunity of meeting their delegates, thereby either satisfying himself that their complaints were unfounded, with the possibility of proving it to the men, or, on the other hand, discovering the real nature and extent of their grievances, and, in the interest of the Service generally, removing the causes. But it seems that the representatives of the Department, their protestations to the contrary notwithstanding (and we must judge them, as we would others, by their actions instead of by their words), have determined, as a principle regulating their attitude in such cases, never to give al moment's careful consideration to the alleged grievances of their subordinates, if the position of those subordinates be such as to render possible the assumption of a dignified appearance of accurately estimating the whole situation at a glance, without the trouble of inquiry. They find this attitude so much easier than the careful consideration of facts and argu- 
ments, which might render invalid some of the conclusions to which they had arrived, as a consequence of comfortably viewing the alleged causes of these grievances through the stained glass spéctacles of bureau calculation.

The Chairman: I am afraid that the Inquiry now sitting rather upsets that contention.

A. This Inquiry was granted in consequence of the refusal of the officials of the Department to hear our complaint.

Q. This is an Inquiry by! the Department itself?

A. At the request of Parliament. I am afraid we should not have got it without. I do not want to press this further and run the risk of running counter to the officials. There are ways of punishing men unknown to you, my lord. This view of the matter seems to afford the only adequate explanation of the Controller's refusal to hear us, and to discuss the point we had advanced. Naturally, the men could not rest satisfied with this result, and a memorial was drawn up, duly signed by the men and handed to the superintendent, together with a written request to forward it to the Postmaster-General, on September 14th, 1892. Some time afterwards what was termed a reply to their petition was received by the men, which reply, strange to say, bore the date of September 15th, the day after that on which the memorial had been placed in the hands of the superintendent. It seems to me somewhat extraordinary, considering the habitual, and perhaps necessary, slowness of official procedure, and also the fact that the memorial would have to be read and reported upon by several persons before it could reach the Postmaster-General, that, in the space of 24 hours it could have gone through the usual routine and have been received, carefully considered, and replied to by him.

Mr. Walpole: Have you got the reply?

A. Yes, sir; I have it. I will read it presently.

Q. Are you sure of the date of the memorial?

A. Yes, it was September 14, 1892.

Q. I have a petition before me dated 19th September.

Witness: The 19th! That makes it still more remarkable.

Q. Is this not a reply to something else?

A. If the petition is dated the 19th I am five days better off than $I$ thought I was.

Q. On the contrary, it shows that this reply cannot possibly refer to your petition.

A. It shows that our memorial was never considered.

Sir F. Mowatt: Is that so?

A. Yes, that is so ; they replied to our arguments before they, knew what we had got to say.

Q. When you say you sent in a petition on the 14th, and got an answer 24 hours later, do you know i whether any other petition had been sent in prior, and that the answer therefore might have not applied to yours?

A. It was handed to us some months later-this answer to the petition.

Q. Then you did not get it within 24. hours?

A. I am only mentioning the date it bore.

Q. You did not get an ahswer until some months after the petition had been sent in?

A. Certainly not.

Mr. Smith. It was posted up, you say?

A. Yes; posted up.

Q. Do you say it was posted up before your petition went in?

A. No; I beg your pardon, I had better read that part again. "Some time afterwarids what was termed a reply to their petition was received by the men, which reply, strange to say, bore the date of September 15, the day after that on which the memorial had been placed in the hands of the superintendent."

Sir F. Mowatt: Then you got the answer some time after the petition was sent in? 
A. I do not wish to convey the impression that the reply was posted up on the 15th ; I merely stated that it bore that date. You will note I used the words "Some time afterwards." The petition was practically a repetition of the former paper. However, in order that you may be able to judge how far the character of the official notice indicates a careful consideration of our case, I will, with your permission, read both the memorial and the notice to you.

\section{(Copy.)}

To the Right Honourable ARnoud MonLey, M.P., Her Majesty's Postmaster-General.

The petition of the town postmen employed in the Eastern Central District Office, in London (being those who entered the Service before the revision of August, 1891, and have not received 1st class appointments) sheweth as follows :-

That your petitioners are under the impression that it is an official principle "That no individual or class shall suffer by the introduction of any new scale of promotion or wages." Therefore, they are grievously disappointed at the revision of August, 1891, which abolished classification without making provision that those who entered the Service under the old conditions should not suffer loss. Your petitioners would point out that we do and shall suffer material pecuniary loss. Men invariably received their 1st class appointments before reaching the maximum of the 2nd class. Those who, in the ordinary course of events, would have received the substantial rise to $24 \mathrm{~s}$. per week during the past year (some of whom entered on the old minimum wage of $16 \mathrm{~s}$.) had that prospect taken from them without any compensation whatever, and have now to wait at least another three years before reaching the minimum of the old 1st class, viz., 24s. Further, your petitioners would earnestly point out for your kind consideration that, before the alteration, although receiving inadequate wages for our needs, we were encouraged by the prospect of receiving a 1st class appointment within a reasonable time. Your petitioners therefore pray that you may be pleased to grant a continuance of 1st class appointments until all those who were already in the Service before August, 1891, are receiving the higher rate of wages, viz., 24s.

\section{Appended is a copy of the notice which was afterwards posted up:-}

\section{NOTTCE.}

The Postmaster-General has carefully considered the memorials from certain postmen in the London districts, who represent that, by the improved organisation of the postmen's force, which now allows all postmen to rise without break to their respective maxima, they, as individuals, can no longer expect that rapid promotion from 2nd to 1st class which sometimes accompanied any large augmentation of force consequent on growth of business. The Postmaster-General thinks that the revision of 1891 must be looked at as a whole, and that the substantial improvement conferred on the whole body of postmen must not be overlooked. A higher maximum has been granted, postmen are no longer liable to be kept waiting for an in. crement, an allowance for boots has been granted, the number of stripe allowances has been added to, the regulations as to sick pay have been modified in their favour, and, generally, their position is better, while the system is fairer to all. The unusually rapid and accidental promotion of some, owing to exceptional circumstances, was never intended, and the old system could not be defended as equitable. It appears to the Postmaster-General that the advantages of the new system more than outweigh the disadvantages referred to by the memorialists, and he does not see his way to make the changes suggested.

I.P.S., 15th Sept., 1892.

(Signed) A. Pamphilon, Vice-Controller. 
The Chairman: Were there any other memorials from your class prior to the 15th September?

A. Oh, yes, sir; there would have been some memorials from other districts of London possibly to the same effect, but not from the E.C. District. We had no reply to them. I am informed that 10 months previously one was forwarded from the S.W. District, and the reply to our memorial was really a reply to their memorial, but I repeat that this shows that our memorial was never considered.

Sir F. Mowatt: 'Then didn't you get an answer to your memorial?

A. That reply was given to us as a reply to our memorial.

The Chairman: Is not the explanation possibly this-Certain memorials had gone in from different parts of London, and the Department drew up an answer in reply to them. Your memorial came in four days after the time the question had been decided, and as it raised a similar question-

Witness (interrupting) : But

The Chairman: Do let me finish. May it not have been the case that as your memorial raised a similar point to those raised by the other memorials it was considered thait the answer given to the first memorial was also an answer to yours?

A. It might have been considered so, but the unfortunate part is that we raised the question from a different standpoint.

Q. Don't you think it is right that the Department should be able to judge for itself what it considers a sufficient answer to a certain memorial? You have it that the Department came to the conclusion that the answer had been giren in reply to other memorials, and that it must be taken as applying to your case. Were not the Department justified in referring you to their former answer? It does not seem to me you have any great grievance because the Department did so. I am not saying anything with regard to the question raised, I am only dealing with the question as to how your memorial was answered.

A. I think I shall show that the Department did not consider the matter from our standpoint. Now that you have heard our position and its soidisant answer, probably the first thought which occurs to you, as it occurred to me upon the occasion of my first comparison of their relative characteristics, is that the fundamental contention of the memorialists, i.e., the claim for the eontinuance of primary advantages, is not even alluded to by the defenders of the official position. The only conclusion possible is that they found it convenient to ignore this contention because, having already committed thomselves to its acceptance by numerous actions and statements, they found themselves on the horns of a dilemma presented by the fact that if they, in this notice, definitely stated their acceptance of the premise, they would have found it very difficult, if not impossible, to refute the arguments which the memorialists had deduced from it, and if they definitely denied the premise, they would at the same time be denying their own previous attitude.

Mr. Walpole: I only want to put this absolutely right. Your memorial was sent in on the 19th September, and I find that my predecessor submitted the matter to the Postmaster-General on the 6th December, 1892, that it was fairly and thoroughly considered at that time, that Mr. Morley approved the recommendation the same day to refor to the Controller for information, and that the memorials were answered on the 12th January, 1893.

The Chairman: In those terms.

Mr. Walpole: Very much in those terms.

Sir F. Mowatt: Then it is as the Chairman suggests, that this is a reply to a previous memorial, and that the Department indicated that they simply adhered to their decision on the point.

Witness : They did not notice our primary contention.

The Chairman: But even there, Mr. Symes, it is pointed out that you have had "unusually rapid and accidental promotion?"

A. I will deal with that presently. 
The Chairman : Wait a minute. The reply told you that "The unusually rapid and accidental promotion of some owing to exceptional circumstances was never intended, and the old system could not be defended as equitable." Surely that from the official standpoint of view absolutely traverses your contention that the agreement :was you should have continuous promotion. What the Department say is that they consider you misinterpreted what the primary advantages were. It was never intended to have this constant rapid promotion.

A. They do not say that.

Q. They say so distinctly.

A. I don't think so.

Q. It certainly appears to me that they do. I am not now raising the question whether the Department were right or wrong, or whether you were riglit or wrong. I am only saying that it strikes me as an outsider, looking at the two documents, that the answer to them, rightly or wrongly, absolutely meets all the points you raised.
A. Well, sir-
The Chairman: Go on with your statement.

Witness: We may therefore regard this silence as an admission that the contention is indisputable. The statement contained in the second clause of the petition, to the effect that the revision of 1891 abolished classification without making provision that those who entered the Service under the old conditions should not suffer loss, forming, the first contention admitted, the basis of the complaints submitted to the Department by the whole of the postmen in London who are affected by the abolition in question. I will now, with your permission, endeavour to show you how much weight can be attached to the statements; which the Department placed before its petitioners in 1892 as a conclusive refutal of the arguments advanced by them, and as sufficient reason for refusing to entertain their complaints.

The Chairman: When you joined the Service did you expect as one of the incidents of your service that you would make an extraordinary and rapid jump from the 2 nd to the 1st class?

A. I certainly expected that I should, my lord. There was no reason to suppose at that period when I joined the Service, seeing that it was absolutely necessary from the nature and condition of the office that the Department should increase the staff to a large extent within a very short space of time, I say there was no reason to suppose I should not have that jump.

Q. Would it not be possible for the Department to merely increase the number of 2 nd class postmen?

A. No, sir; because they got a statement upon which they based the ratio. I applied to the Department for a copy of any orders modifying the system of classification between 1869 and 1889. Mr. Hitchcock objected to it on the ground that it was absolutely absurd to ask the Department to rummage over the papers for a period of 20 years.

Mr. Walpole: This statement was drawn up later than 1884?

A. The question is, how did they arrive at their ratio?

Mr. Walpole: There is nothing at all to show that there was any pledge by the Department of any kind in regard to the proportion between the 1 st and 2 nd class.

A. But they must have had something to work on.

Mr. Smith: What pledge did they give you?

A. That whatever appointments were open should be open to me.

Mr. Smith: Was any statement ever made to you as to the proportion between the 1st and 2nd class? If so, when and how?

A. No more than what was going on under the system of classification.

The Chairman : It is perfectly open to the Department to put its men into whaterer class it chooses. 
Witness: Mr. Badcock spoke differently upon that point when he was speaking of the newspaper men. He said they had a grievance if there really had been abolition of classification, but he endeavoured to prove that it had not been abolished, and that, on the contrary, it was merely an amalgamation of the districts. In order to facilitate this examination I will, with your permission, reduce this rather rambling document to something like order by placing the statements therein contained in logical sequence, so that my answering arguments may be clear and to the point. I shall, however, be exceedingly careful not to ignore any one point. I therefore deduce from the notice the following statements :-

(1) That cases-similar to those referred to by the memorialists-of what the notice terms rapid promotion were accidental, owing to exceptional circumstances, and were never intended.

(2) That what is described in the notice as "the disadvantage referred to by the petitioners" is more than outweighed by the following advantages :- (a) A higher maximum; (b) postmen now rise without break to their respective maxima; (c) postmen are no longer liable to be kept waiting for an increment; (d) an allowance for boots; (e) increase in the number of stripe allowances; and (f) favourable modifications in the regulations as to sick pay.

(3) That the abolition of class improved the pay and position of postmen, and that the present arrangement is fairer to all.

Now, in order to correctly estimate the value of the fist assertion (that rapid promotion, by which the Department means giving $24 \mathrm{~s}$. a week to men performing arduous and responsible duties, and who were at the time mostly more than 21 years of age) was accidental and owing to exceptional circumstances, I will quote a few cases from the E.C., showing the length of time elapsing before, and the age at which appointments were obtained during the 20 years preceding the abolition of 1891 . I will divide this 20 years into periods, giving a few examples in each, stating the conditions of service, the average time elapsing between the date of entry and that of receiving 1st class appointments, and the age on receipt of these appointments, as follows :-

E. C. D O.

1871 to 1875 .

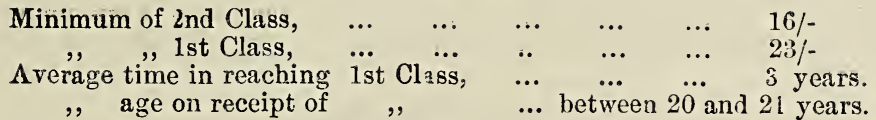

\section{EXAMPLES.}

Kirkham e.tered Aug. 6th, 1872; Received 1st Class, Nov. 6ih, 1875. Herd " July 21st, 1874; ,, , June 21st, 1877.

\section{$18: 5$ to 1879.}

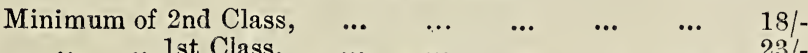

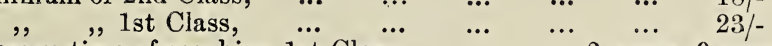

$\begin{array}{cccc}\text { Average time of reaching } 1 \text { st Class, } & \cdots & 2 \text { years, } 9 \text { noonths. }\end{array}$

\section{EXAMPLES.}

Dunsmore entered May 3rd, 1875 ; received 1st Class, Nov.20th,1877. Brown, W., ,, March 17th, 1876; ,, ,, Feb. 1st, 1879.

The Chairman: When you take your averages do you strike them merely upon the examples you have given us, or do you take them on the whole lot? 
A. No, sir; I have my figures here; it is roughly drawn up.

Q. Upon how many men did you strike your average?

A. On the whole, as far as possible.

It may be here remarked that during this period men were frequently passed over for 1st class appointments owing to their being, at the time these appointments became due to them, under the age of 20 , the limit set by the Department. This occurred in two of the cases quoted above, viz., those of Brown and French.

1879 to 1882.

Minimum Boy Sorters and Assistant Letter-Carriers, $\quad \ldots \quad 14 /$ -

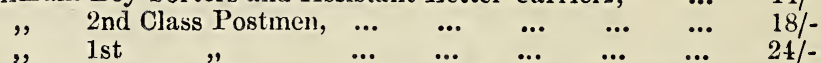

A verage time as Boy Sorters and $L$ tter Carriers, ... about 1 year.

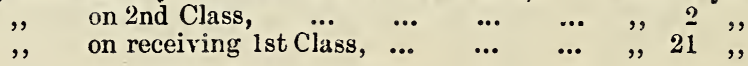

\section{EXAMPLES.}

Entered.

Guillan, Geptember 9th, 1879,

Parr, May 24th, 1880,

Haggar, April 11th, 1881,
Appointed 2nd Class. Beceived 1st Cluss. April 8th, 13:3.

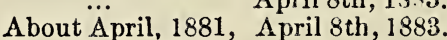
,, July 1882, Nov. 9th, 1:84.

I draw your attention to the fact that at this period of combined initial service at a minimum of $14 \mathrm{~s}$., the age limit was 16 years.

The Chairman: When these boys received 14s., they did not do a full day's work, did they?

A. Oh, yes, my lord.

Q. A full eight hours' day?

A. Yes, my lord; the age limit was low then, and they were presumably qualifying for the position of either sorter or postmen; in fact, some of them became sorters. Our age limit is practically 19, although theoretically it is 18. Taking this into consideration, and seeing that the Department has recently stated to some of these men who applied for third stripes that their service as postmen commences with the date of and class appointment, my average of two years is rather under than over the mark. It should also be noted that during this period also men were frequently passed over because they were under 20 years of age. Examples: Guillam and Parr.

Jude, entered Nov. 11th, 1877, received 1st class June 20th, 1880.

French, entered June 25th, 1877, received 1st class Nov. 1st, 1880.

The Chairman: You come in about this point yourself, do you not?

A. Yes, my lord; the last man who received the appointment entered in 1889, a few months previous to me, although there are men who did not get appointments who entered earlier than that.

1882 to $18 \cdot 9$.

$\begin{array}{ccccccc}\text { Minimum of } 2 \text { nd Class, } & \ldots & \ldots & \ldots & \ldots & \ldots & 16 /- \\ ,, \quad, 1 \text { st Clas }, & \ldots & \ldots & \ldots & \ldots & \ldots & 24 /- \\ \text { Average time in reaching } 1 \text { st Class, } & \ldots & \ldots & \ldots & 4 \text { years. } \\ ,, \quad \text { age on receiving } \quad, & & \ldots & \ldots & \ldots & 23 \frac{1}{2},,\end{array}$

We have a case of a man with a 1st class appointment in the W.C. District; he is 54 years of age, and cannot possibly reach the maximum before he is retired on account of age. At the period to which I refer 
that the staff was insufficient is proved by the complaints of the men, that they were working a considerable amount of overtime without payment.

\section{EXAMPLES.}

Galbee, Eldridge, Hyatt, Harrowing, Mann, * Johns,
Entered.

September 3rd, 1883.

December 12th, 1835 .

July 13 th, 1886 .

March 21st, 1887.

April 25th, 1887.

April 25th, 18.9.
Appointed 1st Class.

December 16th, 1888 .

November 5th, 1889.

March 23rd, 1890.

February 22nd, 1891.

May 17th, 1891.

July 26 th.

* This was the last man appointed.

The average during this period is somewhat longer owing to the insufficiency of staff to which I have before alluded. The examples which I have quoted are fair representative instances, and you will find, if you inquire further, that though they are, for the sake of convenience, taken from the E.C., yet they can be substantiated for London in general. You are now, then, with these examples before you, in a position to judge whether the statement of the notice concerning the rapid promotion (i.e., as defined by the men's petition appointment to the 1st class some considerable time before reaching the maximum of the 2nd) being accidental owing to exceptional circumstances, and never intended is or is not in consonance with fact. Is the natural evolution of the Service through which men received their appointments in periods varying from 1 year 9 months to 5 years a matter of accident? (In one case it was a year and three months.) As for being exceptional, I have proved, and not merely stated, that on the contrary the reverse, i.e., the delay of appointments, was the exception. And with regard to it being never intended, what the Department calls rapid promotion occurred almost uniformly during 20 years. In this connection the question naturally presents itself, "How long does it take the Department to discover its own intentions?" (Hear, hear.) Now, with respect to the second statement, that what is spoken of as the disadvantage referred to by the petitioners is more than outweighed by a list of advantages, real or ostensible, I will consider these advantages one by one, in order to arrive at a just estimation of their relative values as compensation for the loss incurred. Clause 3 of the notice states, "A higher maximum has been granted," as though that higher maximum had formed part of the scheme of August 2nd, 1891, and had been given to the petitioners as compensation for their loss. As a matter of fact, however, the rise in the maximum (2s. weekly) did not take place until May, 1892, or about nine months after the abolition of class, and thus formed a separate grant.

The Chairman: Now the 2ad class town postmen were only first introduced in 1885 , were they?

A. No, sir; in 1869. There was a classification of duties. They underwent various changes, but I have not been able to obtain the particulars. Moreover, this higher maximum was given to all London postmen alike, and, therefore, cannot be regarded as compensation to men suffering under a special loss, unless, indeed, it is contended that a small concession of this description granted to postmen as a body from eonsiderations of justice at a time when other branches of the Service received increases not only in their maxima, but also in their increments, can be regarded as justifying the violation of official procedure which is involved in the confiscation of a portion of the emoluments due to a section of that body. And, moreover, apart from these considerations, the value of even this slight incrcase is greatly diminished when the number of ycars which must necessarily elapse before, under the most favourable circumstances, this maximum can be reached, is taken into account. To take my own case, it will take me. 
at the present rate of progression, nine years from the 9lk of November next, and 14 years 3 months from August 2nd, 1891 (the date on which, as I will show, I should under the old conditions have received my 1st class appointment) to reach this maximum. I think, therefore, that I may dismiss the first so-called advantage as untenable, firstly, because the number of years before it can be obtained, and the fact that it is not available at the time when it is most needed, render its compensation, if admitted at all, exceedingly small, and secondly, because a grant to a body of men given on general grounds cannot be regarded as compensation for sectional loss. The second advantage is far more apparent than real. The notice states "postmen now rise without break to their respective maxima." You will remember that, in enumerating the "conditions of service" which existed under classification, I stated that the first increment of the 1st class was biennial, i.e., that after a man had received his 1st class appointment he was compelled to wait two years before receiving his next increment, this custom apparently having its origin in the period when the line of demarcation between the two classes in the matter of duties was distinct, and having its raison d'être in the fact that the man was supposed to be qualifying for his new duties. Of course, any pretext for this delay was utterly destroyed when postmen became one class. In order to set a just value upon this advantage, it is necessary to remember that, as I liave already shown, during the 20 years prior to its existence men reached the wage of $24 \mathrm{~s}$. after periods of service ranging from two to five years, whilst those who now enjoy this great advantage have had to wait from six to eight years to attain to this weekly wage. Allowing one year to be added to the former periods, the respective number of years becomes :-

$\begin{array}{ccc} & \begin{array}{c}\text { Under } \\ \text { Tro Classes. }\end{array} & \begin{array}{c}\text { Under } \\ \text { One Class. }\end{array} \\ \text { Shortest periods } & \text { 3 years. } & 6 \text { years. } \\ \text { Longest ,, } & \text { 6 years. } & 8 \text { years. }\end{array}$

And this in spite of the indisputable fact that the question of the Service generally, leaving postmen out of the question, has improved. With regard to the third statement of advantage, viz., "That postmen are no longer liable to be kept waiting for an increment," I must confess that I am somewhat at a loss for an explanation of its meaning. I have not yet heard of anything whatever which, under the old system, would have caused an increment or appointment to be arrested or suspended which will not to-day do so. Indeed, this is so to a greatly intensified degree. A few years ago it was not common, as it is now, for a man whose annual attendances were 900 , a third of those involving departure from home at 4 a.m., to have his increment or stripe stopped because he was eight times late during the year, because he had been punished once or twice for some venial offence, or because he had been reported without seeing the report or being told who reported him, for that indefinable offence technically known as "lack of erergy." These things are common now, and have been for the last three or four years. On these grounds, then, pending some explanation of its meaning, I may dismiss the third advantage as unproved. The fourth ad. vantage is an allowance for boots. Like Mr. Maclaren, I am not aware that this allowance can be counted as wages. This allowance (one guinea a year, or rather less than $5 \mathrm{~d}$. a week) seems a somewhat small recompense for our loss, and, moreover, it must be dismissed as having no bearing on the case in question, being granted to all postmen in tardy recognition of the fact that the nature of their duties involves some considerable expense in shoe leather, an expense which it is obvious the sum granted by no means fully defrays. The fifth advantage- "Increase in the number of stripe allowances" -is of the same character, being small in comparison to our loss, and having no bearing upon our case, because it was granted to all 
as a tardy recognition of the fact that men who had fulfilled all the necessary conditions were sometimes kept waiting a considerable time for their stripes because the number of those stripes issued had not been increased in such proportion as to meet the requirements of a continually increasing staff. The sixth statement of advantage is to the effect that the regula= tions as to sick pay have been modified in our favour. This, I presume, is meant to refer to the fact that formerly a third of an officer's pay was stopped when he was absent on sick leave, whereas since June, 1890, full pay has been allowed. Unfortunately for the argument, recent sad events have effectively demonstrated that it is now more difficult than ever to obtain that sick leave, and may be taken as an indication to you of what is well known to anyone acquainted with the undercurrent of official procedure in the Post Office, that the fact of full pay being given has been made an exeuse for making it so difficult to obtain leave that many men (who, in employment in which sick absence meant nothing but monetary loss; would certainly take a rest) go about in suffering because they know that the official medical officer, unless their complaint be infectious, or renders their continuiance on duty an absolute impossibility; will certainly not give them leave, and if they venture to hint their need of such leave or to apply to an outside medical man, that they will lay themselves open to a suspicion of malingering which will probably lead to an interpretatior: of perfectly innocent acts into a justification of that suspicion. This is the explanation of the fact that, despite the prevalence of the influenza during the years on which he reported, Dr Wilson was able to state, in his evidence to you, that the percentage of sick absences was considerably less than formerly. Thus, then, this sixth advantage appears in the light, not of a benefit to the men, but of an official economy. But, even if this were not so, every argument which applies in the other cases with respect to their being granted to all sections of postmen, applies with greater force in this instance, as this full sick pay was given to the entire Postal Service. We thus see that the whole of these soi-disant compensatory advantages vanish into thin air on being subjected to critical investigation.

Mr. Walpole: Am I to understand you to say that as postmen you received no compensation that was not included in what was given to the Service generally?

A. Yes. Other men who reached their maximum in a certain period have got the increase of the maximum wage, and it is not fair to judge us from that standpoint, as it makes us appear before the public in an artificial light as receiving advantages which we never got. That is why we ask compensation. We are now enabled to accurately estimate the value of the third assicrtion contained in the official notice, viz., "That the abolition of class improved the pay and position of the postmen, and the present arrangement is fairer to all." But now I have already demonstrated to you that neither the rise in the minimum nor that in the maximum can be, by any stretch of the imagination, considered as having any connection with class abolition. I have shown that formerly men attained to something approaching a living wage much more rapidly than is possible to even the most favourably situated now. It is easy to see from the figures I have quoted at the former rate of progression the average length of time required to reach the present maximum would be somewhat less than 14 years, whereas now even those who entered the Service after Nov. 9th, 1889, will be 16 years in reaching their maximum, whilst those unfortunates who entered prior to that date will be from 16 to 18 years - a somewhat long apprenticeship.

The Chairman: The maximum would be $4 \mathrm{~s}$. more?

A. Not nesessarily so. A number of men entered between 1882 and 1891. and all these men rose straight to the present maximum. The others could not. Their rise to the higher maximum would be more than compensated for in the earlier years, when life is hardest. Then, as to it being fairer to all, that may, I venture to think, be doubted, but if that means that it is 
more certain I readily admit that. The present arrangement is certaincertain in its slowness-while that formerly existing was uncertain, inasmuch as it afforded the prospect of frequently rising at a considerably quicker rate than is possible at present, this prospect, however, being tempered by the certainty of never rising at a slower rate. Before quitting this document, there is one remark contained therein that I should like to notice, i.e., "The Postmaster-General thinks that the revision of 1891 must be looked at as a whole, and that the substantial improvement conferred on the whole body of postmen must not be overlooked. I have already shown the value of this substantial improvement, but were it real instead of fictitious, I should still think it somewhat a new departure for a public department to ask a section of its employees to console themselves for a special loss by the exercise of altruism. Official altruism is somewhat of a revelation to psychologists. I will now, with your permission, draw your attention to a few anomalies selected from amongst many which exist to-day in London as the direct result of the irregular manner in which classification was abolished in 1891 . The first instance is that of the men who, entering under classification, obtained a transfer to some other district. Now, when this transfer is official, the rule is that the men shall be placed in order of seniority behind all other established officers at their new office.

Sir F. Mowatt: Are these transfers made by the Department on its own initiative, or on the application of the men?

A. I really cannot say about that; I merely point out the fact. I am not going to enter upon the whole subject of their position. I am merely going to point out that the abolition of class deprives them of what they might reasonably have expected from the Government in the shape of appointments. I am told that the transfers are made on pcrsonal application, but that in some cases it has been the act of the Department itself. I cannot, however, vouch for that from personal knowledge. Many men of this class were at the time when class was abolished expecting their appointments, but the manner in which this abolition was carried out deprived them of all hope of obtaining these appointments, and they were thus punished, although they were men of good character, by the loss of a portion of their wages. As cases in point I may mention Thomas Knill, Earl's Court, and Weinberg and Martin, E.C.D.O. The second anomaly consists of the position in which two men of the W.D.O. (Howe and Chapman) find themselves now that the abolition of class has deprived them, although men of good character, of a chance of getting on a level with their juniors in the Service. The circumstances of the case are these:- In the days of the Postmen's Union one of these men was secretary, the other a collector for the local branch. This appears to have given umbrage to Mr. Lorraine, then chief clerk of the district, the result being that het declined to recommend them for their 1st class appointments when these became due. Since then, however, they have made repeated applications concerning the matter, and have been informed that their records were good, and the officials can find no proper explanation of the fact that they were passed over, but no further appointments having been sanctioned, their grievance cannot be remedied.

Mr. Walpole: We have had this case before us.

A. Yes, sir. These men suffer a continued loss. The next paragraph in my evidence is rather a divergence. Shall I read it?

The Chairman : The appeal for the men's reinstatement?

A. Yes, my lord.

The Chairman: You had better not go into that.

Witness: Very well, my lord, I will pass it over. The third anomaly consists of the fact that all those men who, like myself, were among the first in the order of seniority entitled to 1st class appointments are to-day receiving sums ranging from $3 \mathrm{~s}$. to $5 \mathrm{~s}$. per week less than men who entered the Service under precisely the same conditions some three or four months 
before them. To take my own case as an example, I received my 2 nd class appointment on August 12th, 1889, while the man immediately preceding me, leaving out of count those passed over, received his on April 8 th in the same year. My weekly wage is $24 \mathrm{~s}$. My increment dates from November. The wage of my senior by three months is $28 \mathrm{~s}$., the increment dating from July. That means that rising by annual increments of $1 \mathrm{~s}$. per week his original seniority of three months has become four years four months, and instead of being on the same wage as myself for eight months in the year, and 1s. in advance during the remaining four months, the difference has become $4 \mathrm{~s}$. during eight months, and $5 \mathrm{~s}$. during four months, or an annual difference of $£ 114 \mathrm{~s}$.

Mr. Walpole: 3s. to $5 \mathrm{~s}$. did you say?

A. Yes; I have quoted an example.

Q. That man must have got rapid promotion?

A. Yes; extraordinarily rapid promotion, owing to the rapid developmient of the Service.

Q. After three years in the second class it should be an addition of 2s.?

A. It would be more than that. It took me six years to get to the $24 \mathrm{~s}$.

Mr. Walpole: I make it $2 \mathrm{~s}$. in three years.

A. I entered in August, 1889, and during the first three months' service I got 16s. Another anomaly arising from the irregular manner in which classification was abolished, the effects of which anomaly are felt in most of the London offices, is expressed in a communication submitted to me br the men affected in the E.C.D.O. This communication I will now, with your permission, read to you, as follows :-

We, representing a large number of postmen at the E.C.D.O., desire to submit to the consideration of the Inter-Departmental Committee a serious grievance from which we are still suffering, in consequence, we contend, of the remains of a formerly existing class system, the anomalous distinctions of which still make themselves felt to us by means of the duties we perform.

At the E.C.D.O., and we believe, to a great extent throughout London, a large proportion of the walk sections are distributed by means of a system of levying, i.e., a species of auction, in which the seniors have the preference. But we, the junior men at the E.C.D.O., have never been permitted to enjoy the privilege of participating in these levies, a consequence of the class system which existed prior to 1891 , under which system the character of the work performed by the two classes was, in the first place, different. But although the distinction in title and work has disappeared, we are, in consequence of the unfair manner in which the change was introduced, still labouring under the following disadvantages:-

(1) We are not allowed to choose our duties in accordance with our scniority, which is obviously a great inconvenience, seeing that it exposes us to the risk of being placed upon a walk situated possibly in that part of the district which is the most distant from our homes, and we thus have both expense and inconvenience thrust upon us.

(2) Having no choice of duty, we are compelled to remain indefinitely upon either the floating staff or upon duties which do not finish till between 9 and 10 p.m., although there are many other duties in existence, and many older men would gladly exchange their duties, which involve early morning attendances, if they could at the same time preserve their right of choosing and fixity of tenure in the said duties. This is more especially a great hardship to young men.

(3) We are precluded by this arrangement from taking a fair share of the Christmas boxes, although the Department, in fixing the amount of our wages, has taken these Christmas boxes into consideration, We are thus deprived of a portion of our wages. 
We would therefore urge that the system of levying, which has, wherever it has been adopted, proved so satisfactory an arrangement, should be extended so as to include all duties, whether at present termed assistant or no, in its scope.

The Department having, in merging the clasises, already recognised that the work performed by all sections of the men is practically identical in character, should, we contend, to be logical, abolish this remaining class distinction, so that we may all be, in fact as well as in theory, one class, i.e., postmen.

Signed on behalf of the men concerned,

Hew Price, Postman.

J. Frampton, Postman.

H. J. MoLie, Postman.

All these anomalies, as well as others, are obviously due to the fact that, in violation of all precedent, the Department ignored the principle of the continuance of primary advantages when introducing the scheme of 1891 . I now come to the consideration of an admission by the Department which somewhat contradicts the notice of Sept. 15th, 1892. You will remember that, despite its appeal to altruistic sentiments, the general tenour of that notice indicates that we were mistaken in supposing that we had lost anything by the abolition of the classes, and that, on the contrary, we gained by it. Well, on March 21st, 1895, in reply to another attempt on our part to get a hearing, the controller, whilst referring us to that very notice of 1892, at the same time submitted to us the official estimate of the amount lost in the case of 22 men attached to the E.C.D.O. The question arises as to whether the Department is really sure of their attitude on the subject, except so far that it is determined, for reasons of economy; to prevent us obtaining redress. At any rate, we have the Departmental admission that we did lose, and that is something. The only question then is, how much? I here recall to your memory that in my own case, which I will here, for the sake of clearness, use as an illustration which applies, in greater or lesser degree, to all the other men concerned. I should-if my questions concerning the projected appointments of May, 1891, are, as I have reason to believe they must be, answered in the affirmative-have received my appointment at that date. If this be not admitted, then, as 65 appointments. were authorised by the Treasury minute of May, 1891, and as these must-the number of men eligible for these appointments taken into consideration-have included men three or four months my seniors, I should thus have received my appointment about August of that year. If, again, we take the Departmental statement, it would have been November. We have thus three dates in 1891, viz., May, August, and November. In estimating our loss, however, another fact has to be taken into consideration, viz., that under classification men had to wait two years after receiving the 1st class minimum before their first increment became due. I see that the Department, in the estimate submitted, has taken this fact into consideration. But I would point out as an argument against this calculation that the men who are our seniors by three or four months waited only 12 months after the receipt of their 1st class for their increment, and, moreover, as it was only after great pressure being brought to bear upon the Departiment that these appointments were sanctioned in December, 1891, and, as they were dated from July, although they should have been issued in May, it seems but just, taking into consideration the fact that, had these appointments been granted in May, the preservation of the ratio between our service and theirs would have caused the first amongst us to receive appointments to August of that year, that in estimating our loss, if the wait for increment is taken into consideration, the calculation should commence from August, and if the difference between our service and that of the 
aforementloned seniors is taken as dating our appointments from November, that we should, in justice, receive the same benefits as those seniors received, and not be compelled to wait for our increment. I will now proceed, with your permission, to give you some idea of the amount of our loss, taking 1st, the Departmental calculation; 2nd, the calculation from August; and 3rd, the calculation from November, without the wait for increment.

Mr. Walpole: When was this Departmental calculation made?

A. In 1895.

Q. At youx request, or in answer to a memorial?

A. It was submitted originally to the superintendent, and we were not intended to see it.

Q. It was a paper worked out by the superintendent for the purpose of his report, was it not?

A. It was in his hands at the time of his writing to us; I applied for it.

Q. It formed no part of the reply of the Department to your memorial, did it?

A. Not in the least; but it showed that the Department admitted our case, for they drew up the calculations; otherwise they could not have had the basis to work upon. I will, taking these three calculations as a basis, show, 1st, the loss we shall sustain before attaining to our maximum; 2nd the amount lost by us up to the present time, and will, as usual, take my own case as an illustration:-

Frcm Novemb: $x$, 1891, to November, 1905 (date of Maximum).

\section{On the Departmental Calculation.}

11 years at $4 /$ - per week, ...

$\begin{array}{llllllllll}1 & \end{array}$

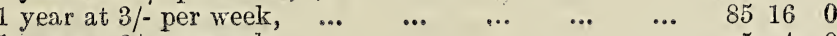

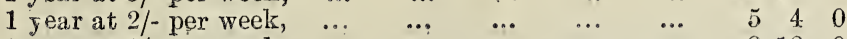

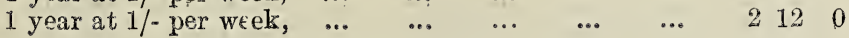

Total Loss by date of Maximum, $\ldots . \quad \ldots £ 104 \quad 0 \quad 0$

From August, 1891, to November, 1905 (date of Maximum).

Allowing Two Years to receipt of First Increment.

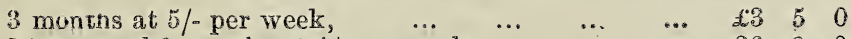

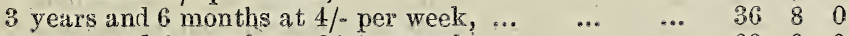

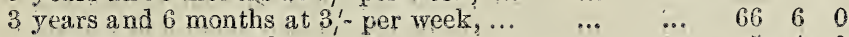

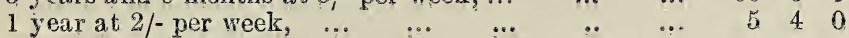

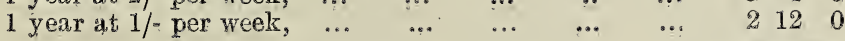

Total Loss by date of Maximum, $\ldots \quad \ldots \quad \$ 113 \quad 15 \quad 0$

From November, 1891, to November, 1905.

Without waiting for Increment.

11 years at $4 /$ - per week, ..

$\begin{array}{llllllllll} & & & & & & & \end{array}$

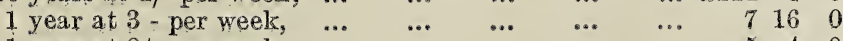

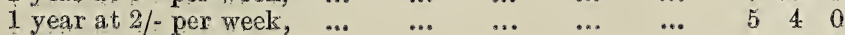

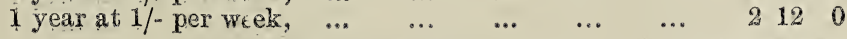

Total Loss by date of Maximum, $\quad \ldots \quad \ldots £ 130 \quad 0 \quad 0$ 
From November, 1891, to February, 1:93.

On the Departmental Valuation.

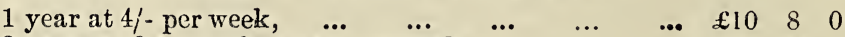

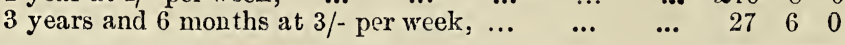

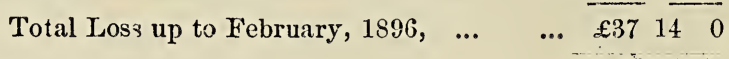

From August, 1891, to February, 1896.

All wing Two Years to Receipt of First Increment.

$\begin{array}{llllllllll}3 \text { months at } 5 /- \text { per week, } & \ldots & \ldots & \ldots & \ldots & £ 3 & 5 & 0\end{array}$

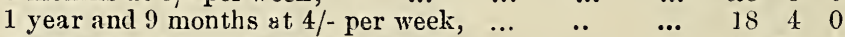

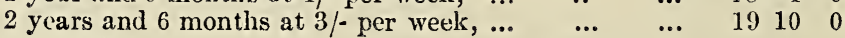

Total Loss up to February, $1896, \ldots \ldots$

From Novemker, 1891, to February, 1896.

Without waiting? for Increment.

4 ycars and $3 \mathrm{n}$ cnti.s at $4 /-$ per week, ... $\quad \ldots \quad \ldots \quad \ldots 44 \quad 4,0$

These figures apply, with some slighit variations, to the whole of those who were, in August, 1891, on the eve of receiving their appointments ; the latter sums represent the amount they have already earned, and which, in consequence, is owing to them by the Department.

The Chairman: How many were there of this sort?

A. That is a difficult question to answer; they, are scattered all over London. The number of men more or less directly affected would be about 500 . In my own office there would be somewhere over 100, but I do not know the exact figure. I did not think it necessary 'to get that. Naturally, having shown our loss, you will expect a suggestion as to remedy. It seems to me that the whole tenour of my evidence indicates that there can be but one adequate remedy, i.e., carrying out, in this instance, the principle of continuance of primary conditions of service, by granting 1st class appointments to all concerned at periods regulated by the ratio formerly preserved between the classes. Also, in my judgment, the justest calculation to adopt is the last I have mentioned, because it would give to us the same relative position in the Service as men who entered under exactly the same conditions. Justice also, it seems to me, could only be satisfied by the payment of back money in full, as, if my interpretation of official procedure and my reasoning therefrom are correct, that money has already been earned by us. I think I may claim thas I have fully demonstrated the departure from the rule, and $I$ would here point out the necessity, for the sake of the preservation of Departmental honour, of a close adherence to it. We have committed our futures to the keeping of the Department. At a period of our life's history when we haid to deltermine our course in life, we surrendered whatever opportunities might have fallen to our lot of rising by energy, ability, or even by lucky chance, to a position higher than any possible within the narrow, inelastic, and necessarily slowly developing limits of Departmental promotion, in exchange for what we were led to believe was a certainty of such regularity in conditions of service as excluded the possibility of retrogression in those conditions. We have been sadly deceived," and having spent the best years of our lives in acquiring an aptitude for work which is not, outside the Service, of a marketable nature, we have seen the years passing by whilst we- some of us with growing families (I myself am not married)are still some years distant from the attainment of what. Mr. Charles Booth has called the minimum living wage in London-30s. per week. It is not 


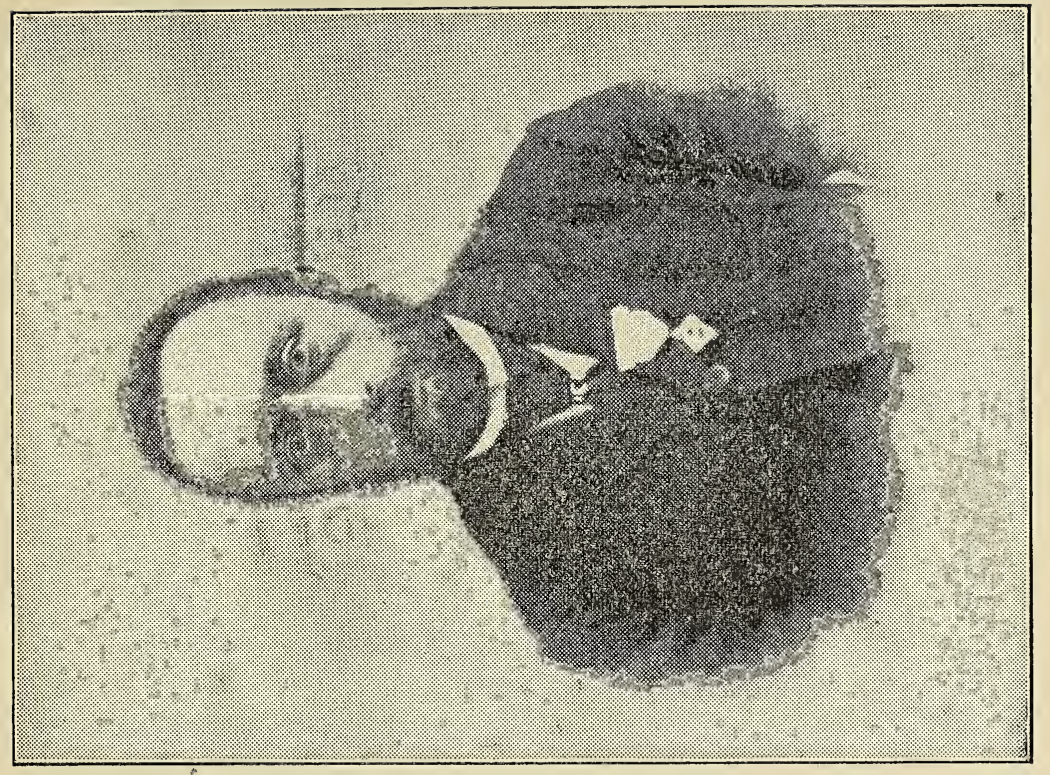

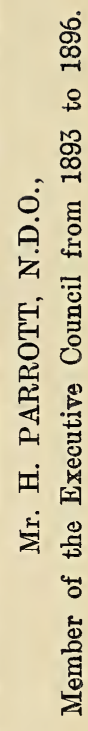

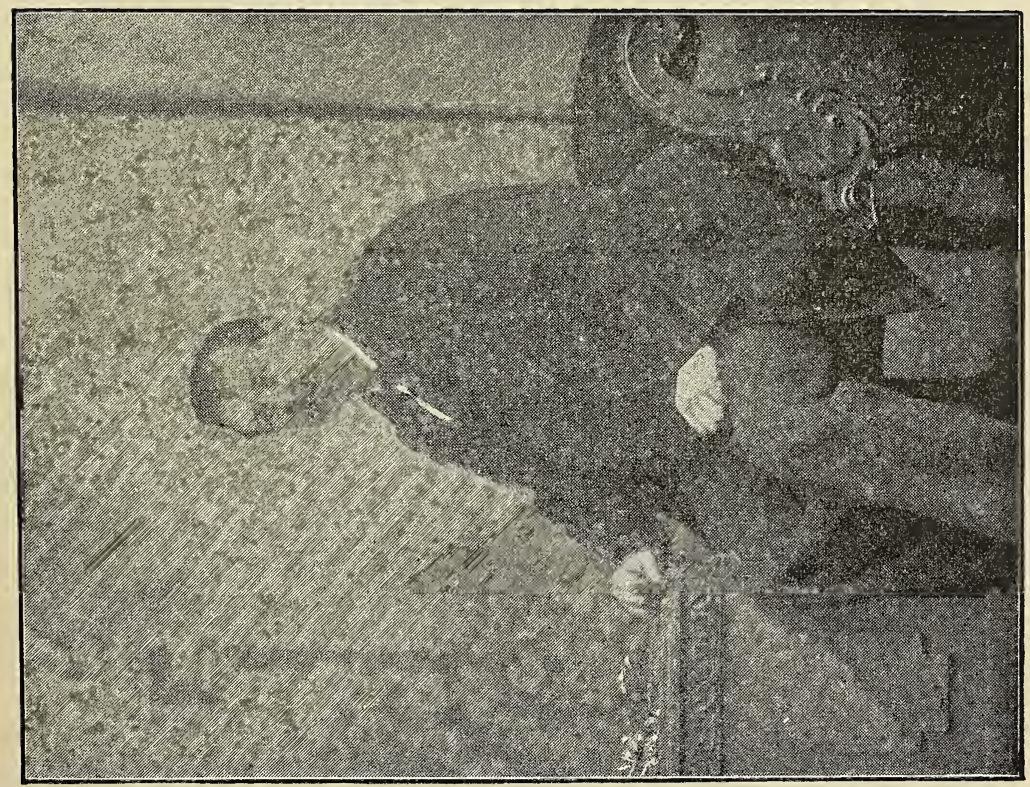

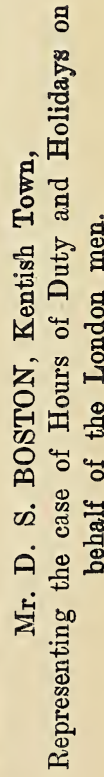



for the benefit of the Department that such just cause for discontent should be given, the Departmental machinery must suffer through it, and both inside and outside the Service the impression is spread, and sunk deeply into the minds of all, that once a man commits himself to the tender mercy of the Department, that Department will, for the sake of economy, stretch its power to the utmost limit. I need say no more, feeling convinced that after the evidence laid:before you, your sense of justice and of what is due to Departmental honour will lead to a favourable recommendation. My lord and gentlemen, that is my case on "Abolition of Classification."

The Chairman:' Do you know where the remark about a living wage is a quotation from?

A. From Charles Booth's "Life and Labour in London."

Mr. Walpole : Are you certain of your quotation?

A. Yes; he makes 30 s. a living wage, and $24 \mathrm{~s}$. a poverty wage.

The Chairman: That is for a man with a family?

A. Yes; but a large number of our men have families. I am sufficientiy old myself to be married. I shall be 26 in April, but I only get $24 \mathrm{~s}$. a week, and should not like to marry on that.

Sir F. Mowatt: I am afraid if you were to get all you are now asking for you would be tempted to marry. (Laughter.)

A. Well, I should have been getting another 4 s. a week.

\section{FLOATING STAFF ALLOWANCE.}

I will now submit to you the case of the London floating staff, i.e., that portion of the postmen's force which, in every London office, is kept in reserve, or floating on the erratic tide of official exigencies for the purpose of filling vacancies caused through sick absences, annual leave, etc. These men are strongly of opinion-and I may here state that the postmen as a body share that opinion-that their duties are of such a nature as to entitle them to special recompense, preferably in the form of a monetaryl allowance. In support of this claim they contend that the nature of their duties places them in a position of considerable disadvantage in comparison with other postmen. I will deal with this contention under the five following headings :- -

(1) The increased expense incurred by the men through the uncertain nature of the hours of attendance.

(2) The increase of responsibility through the multiplicity of the duties performed.

(3) The increased risk of ill-health owing to the irregulapr habits caused through frequent changes in the hours of attendance.

(4) The increased difficulty of keeping a clear record for punctuality owing to these changes.

(5) Personal inconvenience, by which I mean the difficulty of disposing of their time.

In order that my arguments may be clearly understood, I will, prior to entering upon the consideration of these five points, read to you representative statements of duties performed, which statements have been furnished by members of the floating staff attached to the E.C.D.O.:-

"I am a junior postman earning $22 \mathrm{~s}$. weekly. It is my duty, as one of the holiday working staff, to perform an officer's deliveries or other duties during his absence on annual leave, which necessitates a fortnightly change of attendances at the office. After the holiday season is endeI I am placed on what is called a reserve staff, from which I am liable to be placed on any duty made vacant by sickness or official leave of the proper officer. These duties may vary daily, which the following eight days of my attendances will show:-

"On Friday, 17th Jan., I commenced duty at 5 a.m. till 9 a.m., after which I attended at 9.50 a.m. for the 10 o'clock delivery, and $12.50 \mathrm{p} . \mathrm{m}$. for 1 o'clock delivery. I was instructed to attend the following day (Satur- 
day, Jan. 18th) at 5 a.m., and performed 5 till 9 a.m., and 4 till 8 p.m.thus the duty extended over 15 hours. During this later duty I was employed both in sorting letters and wheeling truck-loads of papers through the office. On Monday and Tuesday (20th and 21st), 12 p.m. till 8 p.m. I attended 5 a.m. the following morning (Jan. 22), performing the general post on one walk, and attending aggain at 9.50 a.m., anẩ 12.50 p.m. for 10 and 1 o'clock deliveries on another. The next morning (Jan. 23) 5 a.m. for general post on entirely different walk, and again another walk for the 4 o'clock delivery. Next day, 5 a.m. till 1 p.m.; finishing the week (25th) by attending at $5 \mathrm{a.m}$. for G.P. delivery, and $2.30 \mathrm{p} . \mathrm{m}$. for 5 o'clpck delivery. It is a frequent occurrence to receive a note after having arrived home informing me of my duties for the following day."

Mr. Smith : Do all these duties begin at 5 in the morning?

A. I am not quite certain.

The Chairman: There are two in the middle of the day.

A. They are very moderate examples of duty. I have some worse ones here. To continue the statement-

"In some cases I have received these notes ais late as 7.30 p.m., with instructions to attend the following morning at 5 . In one instance I left the office understanding I was to attend the following day at 12 noon. On arriving home late that night I found a note had been delivered instructing me to resume dutyl again at $5 \mathrm{a} . \mathrm{m}$. through the sick absence of the proper officer, thus depriving me of a reasonable night's rest. I have been three years now on this staff, and am unable to claim a settled duty on accounti of my general knowledge of a great many duties. Should a man show aptitude for learning new duties he is retained on the staff, while other men are allowed to remain on one setitled duty for years, thus, of course, receiving a reward for not showing special aptitude. (Laughter.) The general feeling of the men of my class is one of dissatisfaction at the loss of those privileges which other postmen, both senior and junior, enjoy. The irregular meal times and rests which this system creates are, in our opinion, detrimental to physical health, domestic comfort, and economy. My 22s. weekly wage is inadequate to the increased demands made upon it by these conditions.

$$
\text { J. Frampton, E.C.D.(O). }
$$

Week ending Oct. 26th, 1895:-Mondar, 5 to 9 a.m.; 9.50 for 10 a.m. deliveries; 12.50 for 1 p.m. deliveries-Ḧolborn.

Tuesday, G.P., commencing at 5 a.m.; 1.15 for 4 p.m. delivery-Clerkenwell Green.

Wednesday, G.P.; 1.15 for 4 p.m. delivery-Clerkenwell Green.

Thursday, 5 to 9 a.m. ; 2.50 for 3 p.m. delivery ; 5.50 for 6 p.m. delivery - Queen Victoria Street.

Friday, 5 to 9 a.m.; 10.50 for 11 a.m. delivery; 5.50 for 6 p.m. delivery - Mark and Mincing Lanes.

Saturday, 5 to 9 a.m. ; 10.50 for 11 a.m. delivery-Mark and Mincing Lanes. 3 to 5.30 , Sorting Office.

Week ending November 9th, 1895 :-Monday, 5 to 9 a.m. ; 10.50 for 11 a.m. delivery; 2.50 for 3 p.m. delivery-Moorgate Street.

Tuesday, 10.50 for 11 a.m. delivery ; 2.50 for 3 p.m. delivery-Moorgate Street. 6.50 for 8 p.m. delivery-Hatton Garden.

Weidnesday, 5 to 9 a.m. ; 10.50 for 11 a.m. delivery; 2.50 for 3 p.m. delivery-Moorgate Street.

Thursday, 5 to 9 a.m. ; 4 to 8 p.m.-Postmen's Office.

Friday, 5 to 7.30 a.m. ; 2.30 to 8 p.m. - Sorting Office.

Saturday, 5 to 7.30 a.m.; 2.30 to 8 p.m.- Sorting Office.

Week ending Dec. 7th, 1895 :-Monday, 11.30 for 2 p.m. delivery-Finsbury Cicrus. 5.50 for 8 p.m. delivery-Myddleton Square. Two points in one district very widely apart.

Tuesday, 9.20 for 10 a.m. delivery; 1.50 for 2 p.m. delivery-Finshury Circus. 5.50 for 8 p.m. delivery-Myddleton Square.

Wednesday, 5 to 9 a.m.; 9.50 for 12 p.m. delivery-Finsbury Circus. 
Thurstay, 11.30 for 12 p.m. delivery; 3.20 for 4 p.m. delivery-Mincing Lane. 6.30 for 8 p.m. delivery-Myddleton Square.

Friday, 12 for 12 noon delivery; 3.20 for 4 p.m. delivery-Queen Victoria Street. Finished inside at 7.30 .

Saturday, 12 to 8 p.m.-Postmen's Office.

\section{G. A. Langston.}

These statements may be regarded as clearly showing the nature of the duties referred to, and as they are quite ordinary and representative, and, although taken haphazard from the E.C.D.O., they embody the variations and attendant inconveniences which characterize the duties performed by the London floating staff as a whole. I now proceed to deal with my first contention-"That increased expense is incurred by these men through the uncertain nature of their duties." The examples I have quoted indicate, in some slight degree, the meaning of the phrase "uncertain nature of their duties," but in order to grasp the full significance of this phrase it is necessary to give due weight to the fact that these examples are but general outlines, and are subject to endless variations in accordance with the exigencies created by the necessity of rapidly and efficiently filling the place of any part of the complex and interdependent Departmental machinery which may suddenly break down. The question now arises-In what manner do the obviously uncertain duties cause increased expense? To which question I reply: 1st, with regard to food. In the economy? of a working man's household there is no room for waste. But the nature of the duties performed by these men renders the avoidance of waste an absolute impossibility. Take, for instance, a man who, say, at the E.C.D.O., is instructed to take up duty at $5 \mathrm{a} . \mathrm{m}$. for the purpose of working a sick vacancy, the duty consisting of first delivery, 2 p.m. delivery, and 5 p.m. delivery. Naturally he arranges for breakfast to be prepared at home, but at some time during the morning either the man whose place he is filling may arrive or it may be necessary to place him on another duty, no other man being atvailable. In either case he is frequently compelled to incur the expense of purchasing his breakfast at the office refreshment bar, thus providing for it twice. On the other hand he may attend at $5 \mathrm{a}$.m. either without fixed duty or expecting to per form a duty which would enable him to reach home in time for dinner, but being contrary to his expectations, placed on say G.P., 11 a.m., and 3 p.m. deliveries, or some other duty which prevents him reaching home until the evening, he is compelled, in like manner, to purchase another dinner. It is obvious, and particularly so in the case of these men who are mostly but a few stages from the minimum wage, that a postman's wages are not sufficient to keep pace with the expense involved in the continual purchase of food from irefreshment rooms which these erratic duties necessitate. Add to this the waste which I have referred to, and the increased expenditure on food is clearly proved. The second increased expenditure incurred by some of these men is in travelling. Most London postmen are compelled to live at a considerable distance from the office, and travelling expenses consequently form no inconsiderable item in the household budget. More especially is this so with men employed on the floating staff, for finishing as they do at all hours, at widely divergent points, and often, on two 'consecutive days, at two extremities of the respective districts in which they are employed, they are frequently thus debarred from becoming season ticket holders, from taking advantage of workmen's trains, and from practising that economy which cam often be effected by regularly riding from a given point and using the same method of conveyance. Also, wearied by the strain of wandering over great buildings such as, for example, Mansion House Chambers, or up and down boscure streets, in the tedious endeavour to discover names and places which are frequently imperfectly known, harasse 1 by the worry generated by the consciousness of the increased risk of misdelivery, with all its attendant consequences, they are frequently compelled, through sheer physical and mental exhaustion, to cast considerations of 
economy to the winds, and wilfully launch into an expenditure of travelling of which the items, small in themselves, collectively form sums which make considerable inroads upon their meagre wages. Having shown how the uncertain nature of floating staff duties involves increased expense, I come to my second point, viz., the increase of responsibility through the multiplicity of these same 'duties. In this connection there are several minor details which need but a passing reference, such, for instance, as the difficulty which a man suddenly instructed to collect from a box, whose position is imperfectly known to him, has in collecting and returning to the office exactly in the time allowed, and the consequent risk he incurs of being reported.

Mr. Smith: Are men reported and punished for being late as severely as if they were on their regular duties?

A. The unfortunate part is that from the character of the explanations received, the officials who have to receive them may not be aware of the duties the men are working.

Sir F. Mowatt: Do you mean that the men do not explain the duties they are working upon?

A. I am afraid the explanations receive but scant consideration. (Hear, l.ear.)

Sir F. Mowatt: That is not my question. Do they, when giving explanations which they are called upon to give, state the duties upon which they are employed?

A. Probably they do; but as a matter of fact these men are punished to the same extent as other men.

Mr. Smith : And you mean to suggest that due consideration is not given to their explanation?

A. It cannot be when they are punished to the same extent as other men. I was only alluding to this incidentally.

Mr. Smith: I quite understand; I only wanted to know.

A. I am not making a special point of it. Then again, in some offices, such as the N.D.O. and the N.W.D.O., postmen on the floating staff are employed to work sorters' vacancies. From the Departmental standpoint these men are working superior duties, but we, the postmen of London, do not concur in that opinion. We contend, on the contrary, that in many respects our duties are identical with those performed by sorters, and that, where these duties differ, those of the postmen are of the most responsible character. I will not adopt the Departmental view and contend that these men, performing duties classified as superior and involving, according to the Departmental superstition, an increased responsibility should, on that account, receive increased pay. I will content myself with pointing out in this connection that the Department can, when convenient, disregard in this matter of duties the anomalous distinction between sorter and postman, although, at the same time, it does not forget to preserve the still more anomalous disparity between their respective scales of remuneration. I come now to the sphere in which the onerous nature of this increased share of responsibility is most acutely felt, i.e., in performing delivery duties. Roughly speaking, there are two factors in the creation of this increased responsibility. These are-Increased risk of overlooking removals and walk instructions ; increased danger of mis-delivery. With regard to the firstthe increased risk of overlooking removals and walk instructions-you will probably remember one evening in last summer visiting the E.C.D.O., upon which occasion what is termed a "walk-book" was shown to one of you. You, will doubtless recollect the size of that book, and possibly you may even recall the varied nature of the numerous instructions which it contained. Our rule book informs us that we must make ourselves thoroughly acquainted with removals, orders, etc., and recent official notices have stated that no excuse will be accepted for ignorance in this respect, and that, as often as our walk is changed we are to make ourselves acquainted with all the orders or removals contained in the new walk-book. But if this 
is a trying task to the ordinary postman, how much more must it be so to the men employed on the floating staff, who, changing day after day, and often two or three times in one day, from one walk to another, always having but a slight knowledge of these walks, and sometimes even compelled without instruction to deliver a walk entirely new to them, are nevertheless held responsible for the due observance of these orders?

Mr. Walpole: Have you any instance of a man being punished for not knowing the removals on a walk upon which he has just been put?

A. I have an instance of a man punished for not knowing the removals.

Q. That is not what I ask, still, I will take your point.

A. I have an instance of a man being punished for that. A man named Wolferton was punished with two hours' extra duty for delivering a letter for a certain firm into a box on the ground floor, when the firm's box was on the first floor.

Q. Had he worked that walk before?

A. Yes, very rarely; but he was not acquainted with the walk. He had worked a good many walks in the interim.

Mr. Smith: Then he was on the floating staff?

A. Yes ; in the E.C. District.

Mr. Walpole: When did this happen?

A. Here is the paper- "For mis-delivering a letter, two hours' extra duty." This letter was simply put in the wrong box.

Q. I asked you the date?

A. It does not say the date. I think it was about 18 months ago; it was not more than two years ago at any rate. It is not so much the work wo complain of as the fact that a consequence of reporting these things against us is that they appear in the records, and when the officials are looking over the book for a man's record, it is hardly possible for them to understand whether he is on the floating staff or otherwise, and stripes and iucrement are considered from that standpoint. Each record is a factor in coming to a conclusion whether or not a man should have his increment or stripes. That is the point I wish to urge.

Q. You have not given us a case which bears out your argument. You told us in your evidence that a man was punished for mis-delivering letters when on an entirely new walk?

A. Quite right, sir; and I will give you a case of that kind-a case of a walk served by a man who received no instructions and was punished, although it was a new walk to him. It was a man named Farrant, and the walk was in the City Road. His stripe has been stopped, and he put it down to the fact that he had mis-delivered a letter. Of course, I cannot say if it was so. It has been overdue six months.

Sir F. Mowatt: What is that case?

A. It is the case of a loss of stripe being inflicted for a man working a walk the wrong way, and causing a delay in the delivery of the correspondence, which, I believe, is sufficient to justify the loss of stripe. This man was never on the walk before. There was no one in the office to give him instructions, and it was entirely left in his hands to dispose of the correspondence the best way he could. His name was Farrant, and he was in the E.C.D.O.

The Chairman: What is the date?

A. I have not the date. It must be recent. The stripe was due in March last year, and it has been stopped, for other men have received theirs since. One man whose stripe was due on Sept. 29 has got his, so it must be stopped.

Mr. Walpole: Was no punishment given at the time?

A. No; but he was severely cautioned. I have a ease of a man being punished.

Mr. Walpole: Oh, that is quite enough. 
Witness: Imagine the difficulty experienced by a man on a walk with which he is imperfectly acquainted sorting his General Post delivery at the rate of about 30 letters a minute, with no time to overhaul his work, and with the additional distractions of unpaid and registered letters, in duly remembering removals, re-directing letters, and obeying special instructions concerning specified firms. The character of these special instructions is varied, such as orders to deliver letters to the care of certain persons other than those to whom they are addressed, to deliver them in certain boxes in specified offices, or to avoid crossing the correspondence of two persons or firms whose names are identical. In this latter connection an instauce, and not by any means a rare one, came under my own notice a short time ago. In Sun Street, Finsbury, there are two firms whose correspondence is frequently directed, "Jacobs, Sun Street, Finsbury," without any indication of the particular Jacobs for which it is intended. Their letters were, in consequence, frequently crossed, and some barl feeling seeming to exist between the firms, several postmen who have exercised their discretion and delivered the correspondence wrongly, as it afterwards turned out, to the firm they had believed it to be intended for, have been reported for their trouble. En passant, I may mention an extraordinary example of official unreasonableness which arose from this incident. Shortly after these occurrences a letter arrived addressed as before, "Jacobs, Sun Street, Finsbury." The man into whose hands it came, not knowing under the circumstances what else to do, endorsed it as insufficiently addressed. To his surprise, a few days later, he was called ${ }^{4}$ upon to explain why he had done so-an instance of the sweet reasonableness of official procedure. Of course this has nothing to do with the case of the floating staff. However, to return to my instance, a man suddenly placed on this walk to fill a vacancy would almost certainly commit some mistake in such a matter as this, and in consequence be reported. Being reported means either punishment by the imposition of extra duty or a caution. In either case the matter stands in the official records, and when the granting of increments, stripes, promotion, etc., is being considered, this kind of thing is a determining factor in the calculation.

Mr. Walpole: I suppose there was some rule in the Department under which $\mathrm{Mr}_{\mathrm{r}}$. Jacobs should have had his letter?

A. There was no rule at that time.

Q. But the man was reported for departing from the rule?

A. Our point is not so much that the man gets punished but that the matter appears in the office records. It is like a continually dropping stone.

Mr. Walpole: You mean like water continually dropping on a stone?

A. Yes, sir. I beg your pardon. I am not used to this sort of thing. Now with regard to the second factor in the creation of this extra responsibility, viz., the increased danger of mis-delivery. You will remember I have already pointed out that a man, after sorting lis General Post, or, I may add, his 8.15 p.m. delivery at the average rate of about 30 letters per minute, frequently has no time to overhaul his work before leaving the office. The comparative infrequency of mis-deliveries under such circumstances, in my opinion reflects great credit upon the postmen as a body, but the risk incurred is obvious. But the postman who is regularly attached to one walk is in this respect to some extent safeguarded by an automatic correctness in sorting his delivery, engendered by the habit of dealing with the same names and streets, and by the fact that his familiarity with the relative positions of the houses and streets served by him makes it possible for him to deal with his work in the most regular and methodical manner. Not so with the man employed on the floating staff. In his case the risk of mis-delivery is increased a thousandfold by lis necessarily vague acquaintance with these details. More especially in the disposal of registered correspondence is this increased risk incurred. Frequently a man has from 20 to 40 registered letters, which he ties up with his ordinary 
work. It is comparatively easy for him, in the stress of duty, with an imperfect acquaintance with the names and addresses, to cross or misdeliver one of these registers, thus causing him great worry and annoyance, and in the event of the register being, as is quite possible, altogether lost, he will become an object of suspicion to the authorities, who, knowing they pay the man wages inadequate to his needs and duties, naturally, if the register contain valuables, as is frequently the case, and if the man be unable-as in such a case he almost certainly would be-to render a clear account of the occurrence, come to the conclusion that the man must be watched, and when being watched under such circumstances the most innocent acts are viewed from a prejudiced standpoint, and it is thus easy, without being able to commit a man, for the officials to become convinced of his dishonesty. From time to time men are dismissed from the Service on suspicion.

Mr. Walpole: Have you any instance of a man being dismissed from the Service on suspicion?

A. Oh, yes; certainly, sir.

Q. Do you know of any man having been dismissed on mere suspicion?

A. Yes, sir; that at any rate was the reason given for it. A man named Morris in the E.C.D.O. was so dismissed 18 months ago. I do not know what was the cause of it.

Sir F. Mowatt: Was suspicion the ground alleged by the Department for the dismissal?

A. Yes, sir. That is the only reason we have heard. How far such circumstances as those of which I have spoken contribute to these dismissals, it is, of course, difficult for me to say, as in such cases the Department keeps all details strictly secret. In the Registered Letter Branch of the G.P.O. sorters receive, in addition to a wage considerably larger than that of postmen, allowances varying from 3s. to 10s. per week, solely because they are intrusted with valuable register correspondence. I do not complain of their receiving this allowance, because I believe that the nature of the duties fully justifies it, but I should like to point out that every reason which can be urged in its support can also be urged with greatly increased force as affording ground for extending this concession to the postmen's floating staff. In so far as the receipt of registered correspondence is concerned, the responsibility of sorter and postman is equal. They both give in exchange for this correspondence a receipt to persons employed in the Post Office, for the accuracy of every detail of which they are held responsible. But here the equal responsibility ends, for in the disposal of his work the sorter has the advantage of receiving, in exchanga for every letter, a receipt from a man in uniform, the receipt containing the man's name and number. Thus the sorter is sure that, should the letter be subsequently inquired after, he can-the man to whom he has given the letter being in the Postal Service, and consequently easily tracedclear himself. But the postman who is delivering $a$ walk strange to him is compelled to give these same letters to persons absolutely unknown to him, and having no connection with the Service, merely because they happen to be somewhere on the premises to which these letters are addressed. But these persons may be parties in a fraud, of which the postman would become the victim. Viewed in this light, the fact of the postman on floating staff duties receiving no allowance corresponding with that enjoyed by the sorter, to compensate him for his obviously great responsibility in connection with the disposal of registered letters, is a decided anomaly. I will now read a statement furnished me by one of the floating staff, which shows clearly my statement concerning the rate at which walks are prepared for delivery, and the insufficient time to examine the work, bearing in mind the dangers to which the floating staff are exposed from 
easily committed mistakes, the committal of which may have serious consequences on their present or future position in the Service.

On February 1st, 1895, whilst working a vacancy on Lrombard Street walk, I delivered a registered letter from Germany at the offices of the Hong Kong Bank on the ground floor, instead of leaving it at the AngloAustrian Bank on the first floor, to which it was addressed. The correspondence which these two banks receive by this mail is similar in appearance, and I unfortunately threw the letter off in the wrong place. Hence the mis-delivery. However, I obtained the usual signature, the mistake not being noticed by the head messenger who took the letter. About a week afterwards I was called upon to give an explanation, which I gave, and some time later I was cautioned and reprimanded in severe terms, and warned as to the future. I naturally took this to be my punishment, and concluded that the case was settled. I was mistaken, however, for in the following September, seven months later, I was called upon to sign the order book, containing another severe reprimand, caution, warning, etc., together with instructions to the effect that I was to be punished with four hours' extra duty, and the information that the letter had been lost, without explaining how, and that the Department had paid 50 francs indemnity. A stripe was due to me in March, 1895, but as I have not yet received it, $\mathbf{I}$ prosume that it is stopped. (This is similar to Farrant's case. Other men have received stripes which were due at a later date.) Thus, for a mistake which it was so easy in the hurry of duty to commit, I was twice reprimanded, punished with four hours' extra duty, and my stripe has been stopped-a loss of $£ 2$ 12s. per annum.

BOYLE, E.C.D.O.

This case will serve to illustrate to you the possible serious effects of the grave responsibility which, in a greater or lesser degree, is thrust upon every member of the floating staff.

The Chairman: Would you be satisfied if I had the rest of your evidence printed without now reading it? I have given you a long, long time. I do not think you have drawn it as short as you might have done.

A. I have cut it shorter than my case justified-much shorter.

The Chairman: Well, we will print what remains of it. You will not have the chance of being pulled about over it.

Witness: But if I read it I might have the chance of making some additional points. One never knows. (Laughter.)

The remainder of the statement, as follows, was taken as read:-

Witness: I will at this point, with your permission, make a slight digression in order to draw your attention to the claim put forward by the men performing deliveries by special register carts. I have here a tabulated statement of the numbers of registered letters delivered by these carts in the E.C. during the week ending Feb. 22nd, 1896. A reference to this statement will show that the number of registered letters thus disposed of is frequently very large, and as the places to which these letters are directed are, for the most part, banks and large commission agents, and consequently this registered correspondence is both very bulky and very valuable, it will be readily perceived that these deliveries involve a great deal of arduous labour and heavy responsibility. This duty, commencing at 7.30, and finishing about 9 a.m., is performed under great stress. The bags have to be sealed, signed for, checked by several different persons, arranged for delivery, and often delay is occasioned through the proper persons not being at hand to receive and sign for them at the places to which they are addressed. Consequently hurry, strain, and heavy responsibility are involved in the disposal of these bags. The sorters who have the first handling of these valuable and important letters receive, and rightly, I think, a compensatory allowance, and it seems but fair that a similar allowance should be granted to those who have them under their charge outside the office, and who incur the additional responsibility of deliver- 
ing them to persons outside the Service. On these grounds I ask for your careful consideration of their claim. To return to the floating staff, I have no less than eight instances in which these register cart duties have been performed by men on this staff, owing either to a vacancy suddenly arising, or to its being necessary, through stress of work, to increase the number of carts. Coming now to my third point, viz., "The increased risk of ill-health owing to the irregular habits caused through frequent changes in the hours of attendance," I will preface my argument thereon by a few extracts from the evidence laid before this Committee by Dr. Wilson on Friday, Dec. 6th, 1895. I quote from the "Telegraph Chronicle" of Dec. 13th :-

"The Chairman: Then you find the greatest amount of sickness amongst classes in which the men are younger?

"Witness: Yes; especially when they are engaged on split duties.

"The Chairman: Do you think that split duties affect young men more than others?

"Witness: Yes; I feel sure they do. My opinion is that the sick absence is higher in the class of young men who do split duties because it affects their health more than it does the health of older men. My point is, that the split duties given to the men up to the age of 25 do affect their health.

"The Chairman: You do not think there is any particular predisposed cause of phthisis in any of the various classes of employment in the Post Office?

"Witness: I think the split duties have a tendency to affect the record in regard to health.

"The Chairman: So far as we have got, however, you attribute the really worst part of the remediable ill-health in the Post Office to the existence of split duties?

"The Witness : I do, sir. My view is that split duties are not conducive to good health. They are arduous and trying even to the strongest. That is obvious to anybody.

"The Chairman: Do you see much sickness attributable to irregularity of meals?

"Witness: Of course irregularity, like excess, leads to ill-health if continued for any time."

Here Dr. Wilson clearly and emphatically states that split and early morning duties, as well as irregularity in meals, are injurious to health. I think he might have added, if the duty be split up into three or four attendances spread all over the day, it is obviously more injurious than two attendances, as it deprives a man of rest. He might also have added as a factor in the creation of ill-health-irregularity in duties, and the consequent variation in, and frequent insufficiency of hours of rest. Now the floating staff, by its very nature, is compelled to suffer all these hardships in the most intense degree. They are compelled to perform duties commencing at 5 a.m., or even sometimes earlier, and involving three attendances or more, such attendances being in many instances so spread over the day as to deprive them of mid-day rest, whilst at the same time compelling them to work early and late-veritable slavery. And the character of the changes in these duties prevents the statement made by Dr. Wilson concerring the telegraphists- "That although a man's duty may vary considerably in point of time, the time of taking food need not vary"-from appiying to them. For, when a man attends the office at 5 a.m., in most cases it is necessary for him to leave home at 4 . If he follows Dr. Wilson's advice he would take a meal before leaving home. Should he go on with the first delivery it will be 9 o'clock when he gets his breakfast, Dr. Wilson's interval-5 hours - thus elapsing. But a man on the floating staff is frequently during the course of a morning changed to another duty, as, for example, the second delivery. This means $10 \mathrm{a.m}$. before it will be 
possible for him to obtain breakfast, and, leaving out of count the difficulty lie will then experience in obtaining that breakfast, that makes an elapsing period of six hours, during which he has been performing continuous labour involving a large expenditure of energy. But it may be objected that it is usually possible to obtain 10 minutes' interval during the course of the morning, during which refreshment might be taken. That is so, but first, the 10 minutes dwindles into 5 , or even less, by the time refreshment has been obtained, a hardly sufficient time; and second, taking refreshment in this interval is doing what Dr. Wilson strongly deprecates, i.e., cramming two meals into a period of four hours. Take again some of the duties I have quoted-for example those worked by Frampton. On 13th January attending the office at 9.50 he would breakfast about 8 a.m. Attending again at 12.50 p.m. he would dine about mid-day, with barely four hours' interval. Attending at 5.55 p.m. he would take his tea about $4.30 \mathrm{p} . \mathrm{m}$. The next day attending at $5 \mathrm{a} . \mathrm{m}$. he would breakfast at $4 \mathrm{a} . \mathrm{m}$., and again at 10 a.m., an interval of six hours; and as he attended again at 4 p.m. he would have to dine about 2, leaving to chance all prospect of getting tea. Again, a man is frequently summoned after performing a full day's work to attend a.t 11 p.m. or midnight, in order to work a vacancy on the night staff. What sort of regularity in meal times and hours of rest can be observed under such circumstances? These examples might be multiplied to infinity, as will be perceived on examining the lists of duties submitted to you by various witnesses, all of which duties, as well as many others not mentioned, are at various times performed by members of the floating staff. The erratic nature of the demands upon these men's services, the natural consequence of the variable character of the vacancies they are called upon to fill, involving, as it does, wide divergencies in the amount of time elapsing between meals, and in the respective hours of the day at which these meals can be taken, as well as the continual changes in the hours of attendance, rendering their periods of rest irregular, and even to a greater extent than with the general body of postmen insufficient, obviously constitute a serious menace to their health. And to this must be added the fact that, with very few exceptions, the men on the floating staff are considerably beneath Dr. Wilson's 25 years of age. My fourth point is-" The difficulty of keeping a clear record for punctuality owing to these changes." If it be-as it undoubtedly is-difficult for a man whose day's duty regularly commences at 5 a.m. to keep up to the official standard in this respect, this difficulty is considerably increased when the hours at which the day's duty is commenced are continually changing. For instance, I myself have for some years past regularly attended at $5 \mathrm{a.m}$. I have in consequence become so used to preparing my alarm clock that it is almost impossible for me to forget to do so. But a man whose use of the alarm is irregular is much more likely to omit this. Or, again, a state of nervous restlessness during sleep engendered by the continued, halfunconscious dread of the morning, with its utter weariness and painful endeavour to keep fully awake is, with the postmen on early morning duty, what mar be described as chronic nightmare, haunting, with the exception of the middle period of his annual leave, his most profound slumbers. But it is obvious to anyone who is in the slightest degree acquainted with the character of these nervous phenomena that any cessation for a period of the habit of early rising would greatly increase the tensity of the manifestations, as I myself have experienced after, for instance, a period of annual leave, having on several occasions, after a fitful night's rest, finally fallen so soundly asleep that the alarm only partly roused me, and, in consequence, I have been under the necessity of understudying a running man in order to reach the office in time. The floating staff duties involving, as I have already shown, greatly differing hours of morning attendance, as well as night duty, the men employed on that staff obviously run a greatly increased risk of being late, with all its consequent danger of loss of stripes, incre- 
ments, etc. My fifth contention-" That floating staff duties render the disposal of the men's time when off duty a matter of considerable difficulty and uncertainty" -needs, after what has preceded it, but little said in its support. A man who but rarely knows whether his next day's duty will commence at midnight, 5 a.m., 8 a.m., or 10 a.m., or at what time between mid-day and $10 \mathrm{p} . \mathrm{m}$. he is to finish, is obviously precluded from making those preliminary arrangements which are so necessary to either the useful or pleasurable disposal of the off-duty time. Many men on the floating staff have complained bitterly to me that for years they have been, in consequence of these duties, deprived of that social intercourse which is so necessary and so welcome a relaxation from the monotonous performance of their official duties. Others who find their relaxation in studious pursuitsand amongst postmen there are many such-complain of the difficulty of pursuing their studies in a methodical, orderly manner in consequence of their duties rendering it impossible either to regularly attend classes or to make arrangements amongst themselves for mutual assistance. Life under such circumstances becomes a monotonous, grinding, tedious round, unsweetened by social intercourse, unillumined by the light of knowledge, and can only be fitly described as slavery. I think I have demonstrated that the work performed by these men is of a special character, and I will now quote a few instances in which such work is already rewarded with a special duty allowance. The T.P.O. sorters receive allowances to recompense them for increase of expenditure and inconvenience, but I have already shown that this increased expense and inconvenience is incurred by the postmen's floating staff also. The registered letter sorters, G.P.O., receive allowances in recognition of the responsibility incurred in dealing with valuable correspordence, but the postmen's floating staff, who deliver this same correspondence under circumstances which, as I have shown, seriously increase the risk and responsibility, receive nothing. This is a distinctly anomalous condition of things, which becomes worse when we consider that these same floating staff duties are in Liverpool, Glasgow, Edinburgh, Newcastle, and many other provincial towns, rewarded with allowances varying from three to seven shillings per week, whilst in London, the Metropolis, where the inconveniences attendant upon the performance of these duties are necessarily felt in the most extreme degree, not a single cent is thus paid. The existence of this staff is an absolute necessity; the men employed on it are chosen for their special abilities and general adaptiveness, and, in accordance with the oft-quoted principle of paying for work according to its quality, I ask that these men, whose wages range between 18s. and $24 \mathrm{~s}$. per week, should have that sum supplemented by a special duty allowance similar to that given in the cases I have quoted. That, gentlemen, is my case on behalf of the London floating staff.

, The Committee adjourned until Monday. 
WILLIAM MORGAN SHEPHARD, New Cross.

The Case for the London Supernumeraries.

Westumnster, Monday, March 9, 1896.

Lord Tweedmouth's Committee on the grievances of Post Office employees resumed its sitting on Monday, March 9th, there being present:- The Right Hon. Lord Tweedmouth (Chairman), Sir Francis Mowatt, K.C.B., Sir Arthur Godley, K.C.B., Spencer Walpole, Esq., H. Llewellyn-Smith, Esq., and Robert Bruce, Esq., Secretary. lows :-

William Morgan Shephard, the first witness called, was examined as fol-

The Chairman: You are a supernumerary postman?

A. Yes, my lord.

Q. How long have you been in that position?

A. Five years last December.

Q. In what capacity did you begin your service?

A. I was an auxiliary in the first instance.

Q. Then you became a supernumerary?

A. No, my lord, I became an unestablished postman at a stationary wage of $18 \mathrm{~s}$.

Q. What wage do you now receive?

A. $£ 1$ 0s. 3d. per week.

Q. Why that amount?

A. I will explain that later on; the $3 \mathrm{~d}$. was given in accordance with an order made on the 13th June last, and I helieve it is a decimal fraction of what we will get in June next to make us up another 1s. a week, so that we shall then be getting 21 s.

Q. Are you not on a scale with a minimum of 18s., rising by 1 s. to $26 \mathrm{~s} . ?$

A. No; that was in accordance with the last order dated 13th June last. As we first signed for and undertook the duty, the maximum attained next December would have been 21s.

Mr. Walpole: Your maximum is now increased to $26 \mathrm{~s}$.

A. I have heard so.

Q. The 3d. is paid rather as' an adjustment of increment?

A. Yes, I understand so.

The Chairman. You have also a fortnight's annual leave, have you not?

A. Yes, sir.

Q. And half-pay when on sick leave?

A. Yes, sir.

Q. You have no pension?

A. No; no pension; ro stripes; no gratuities; no bonus; and no hopes of any kind beyond what I have staited.

Q. And no share of Christmas boxes?

A. Yes, if we are fortunate enough to secure a good walk where they are obtainable.

Q. What do you consider your own share of Christmas boxes?

A. That would vary according to one's luck in having a good walk.

Q. But I mean your own experience? 
A. I am taking my seniority under an old dispensation, but when the next revision comes on I shall probably be knocked out of that.

Q. That is not the question I am asking. I want to know what do you calculate to be the value of your own share of Christmas boxes?

A. $£ 710$ s.

Q. Per annum?

A. Yes. I propose now to proceed with my statement.

Q. I ought to say that we must really finish with the postmen's evidence to-day, and if any of you are not heard to-day, I shall simply have to tell you that I carnot hear you, as we have already given a very large share of the time to the postmen, so please be as short as you can in any statement you have to make.

A. I shall be very short, indeed. In subniitting the case for the supernumerary postmen, if I do not deal with it at the length it deserves, I lope that its brevity will not in any way detract from its gravity: and seriousness. About the end of 1889 a number of auxiliaries in the various districts of London were asked to take on a new class called the "unestablished," i.e., to do a regular staff man's duties of 8 hours, 12 days" holiday, and 18s. per week wages. In November, 1890, a form was issued to this class by the Controller (Mr. R. C. Tombs), on behalf of the P.M.G., stating that their employment as unestablished postmen must cease, and giving them a fortnight's notice and an offer to join the new class called "supernumerary postmen" (unestablished) on the following terms, viz.- "The attendance required will be about 8 hours-between 5 a.m. and 11 p.m. Wages 18s. per week, to rise 1s. every 2 years to 21 s., provided you give satisfaction in the performance of your duty, and that your conduct is good. The first rise to 19s. after the completion of 4 years' continuous service, if that should occur before you have been 2 years on the supernumerary class. Annual leave of 12 days (working). Medical attendance in sickness, and half-pay during absence. Uniform in every respect similar to a staff man. You are also given to understand that in your future employment you acquire no claim to be appointed a permanent Civil servant, having passed no literary or medical examination. And if you can obtain other employment with advantage to yourself you should do so, and when your services are discontinued, which they may be at any time, you will not be entitled to pension, gratuity, or compensation." As far as we know, there are very few of this class-some 50 or 60 -in the whole of London, and only those malle in 1890 and 1891 are in the Service, as the class is redundant, and as we die or leave, the vacancy so caused is made a staff appointment.

The Chairman: It seems as though the Department in making you this offer did it rather by way of compassion than otherwise?

A. I do not take it as any compassion at all.

Q. Was not the alternative to turn you adrift altogether. You were not qualified any of you by examination for the post of regular postmen?

A. I will show you later how, in my case, the ground has been shifted.

Q. What was the difficulty in your case?

A. I was too old.

Q. Either the men were too old for appointment or else they failed to pass the examination, is not that the case?

A. Yes, some of them failed to pass some examination, and some were too old, but others were too short.

Q. In stature?

A. Yes, sir.

Q. They do not come up to the Departmental requirements?

A. Yes; but some in our office failed in that respect.

Q. Then all belonging to your class were men who for some reason or another failed to come up to the standard prescribed by the Department as necessary for the appointment of the regular staff?

A. Yes, that is so.

Q. Then it was rather by way of compassion that you were kept on at all? 
A. No, sir. A't the end of 1889 a revision took place which reduced my wage as an auxiliary from 16s. to 11s. I had been doing 3 duties at 16s. I had a shop at that time, but there was plenty of overtime, etc., and while I was putting it in, the shop was allowed to fall into a failure. I was frequently called upon, as men who know the walks are, to do other duties, and my wages were made up to 27s. per week. I had had 16s. for 3 duties; I did the G.P., the delivery at 10 in the morning, and one at 8 at night, so that $I$ had from about 1 o'clock in the day till 8 at night to do my own work. But when a revision took place, most of these superfluous duties of auxiliaries were made into staff appointments, so that I was pulled down to 11s.

Q. You had then only 2 duties?

A. Yes. Being a man with a family I was disposed to accept the new terms offered in November, 1890, as representing an immediate and permanent rise with the idea in my own mind that it might be a stepping-stone to the establishment. I thought so then. I think so now, and I don't despair of it even yet.

Q. But you were told very distinctly in the form which you signed that it would not be such a stepping-stone to the establishment.

A. Other men have been told so just as distinctly in former years.

Q. But you signed this form and accepted the specified conditions?

A. I have had 9 years service as an auxiliary.

Q. I am not denying that. In signing this you accepted the conditions of the Department, one of which was that this appointment was not a steppingstone to the permanent established service.

A. Nevertheless, we cherished the idea that it might become so, as we had seen others advance before us. Our grievances are:-(1) Insufficient living wage : to obtain our maximum of $5 \frac{1}{4} \mathrm{~d}$. per hour, we must have done at least 8 years' continuous service. And that is $\frac{3}{4} \mathrm{~d}$. per hour less as is laid down by the "Raikes" revision for unestablished labour. The present maximum $\left(5 \frac{1}{4}\right.$ d.) is less than the recognised pay of the docker, and it is almost impossible for us, as responsible servants of the Crown, to do our duties as citizens and parents, and we therefore think that our present position is not one to be coveted.

Mr. Walpole: Now, I suppose you wish to amend that, as you know the maximum of the class is 26s.?

A. Yes, but I will deal with that later on. I acknowledge the increase. There is an unfortunate man in our head district office who received $£ 10$ s. 3 d. a week, and he pays 9s. for rent. He lives close to the office; he has 5 of a family, and has had 30 years' service; he failed in the examination through not being able to pass something in arithmetic. There are also three men in West Brompton of 23 years' service who are in a similan position, and they get no Christmas boxes. This means slow starvation for most of us. When quite one-third of our money goes in rent, it means where there is a young family food in the shape of bread and treacle, or boiled rice for a change for dinner, during the week; this is not quite the state of things that should be expected in the case of a responsible man, who has given faithful service, no matter whether he is a supernumerary or a regular postman, for we all wear the same uniform and perform the same duties, and have the same responsibilities and penalties, so that I think we are not only the worst paid, but the worst treated class in the Service.

Mr. L. Smith: Why do the men you have mentioned not get Christmas boxes?

A. The walks go by seniority, and owing to their position they are given the worst walks.

Q. Where there is not much chance of getting Christmas boxes?

A. True. We are debarred from good conduct stripes through no fault of our own, and the public, not understanding that we are not entitled to them, think that they are withheld from us for misconduct, etc., and, of course, draw their own conclusions when they observe senior men without 
them. We consider that no age or condition of service should prevent $\approx$ supernumerary receiving good conduct stripes. We cannot see that good conduct stripes should depend upon any conditions as to age or failing to páss examinations, medical or otherwise; as $I$ have been getting on for 16 years in the same office, and everybody knows me very well, you will understand that since we wear exactly the same clothes as established men unlike the auxiliaries, and that we wear the red collar in the summer, it is a common reproach to us and destroys our self-respect that we cannot get stripes. People ask us often why we don't get stripes, but we cannot argue with the public, and explain to them the ins and outs of the service, or say: "I ain just an inch too short, or a fortnight too old, or I could not do a fourth division sum." As one previous witness suggested, that the stripes of his class might be perpendicular, so I might suggest that we might have silver stripes, if you like to denote that we are an intermediate class between the auxiliaries and the established men. (Laughter.) I hope that in this matter something practical will be done for us. I do not say that a supernumerary postman has all the virtues, but he has not all the vices either. (Hear, hear.) Our duties are exactly the same as the staff men, some being attached to the parcel duties, others do the sorting and railway districts side by side with the staff men; and as our 8 hours' duty extends over nearly 12 hours, we have no opportunity of augmenting our wages, as some of us have to come in 4 or 5 times a day. In the case of the parcel men at the Depot, they have to pay railway and tram fares, which on their small wage is to them a serious matter. One of my colleagues dispatches a delivery and a 9 o'clock collection, that is making of bags, register bills, etc., which a regular man on the staff gets a $3 \mathrm{~s}$. allowance for, but my colleague, because he is a supernumerary, gets inothing extra, and some of our men have to come in 7 times a day.

The Chairman : Have to come 7 times a day into the office?

A. Yes, a man in West Brompton does that.

Q. Do you mean that he has 7 duties?

A. Yes, 2 deliveries and 5 collections. At Blackheath there is a man of our class doing 2 deliveries and 4 collections, and another man in the SouthEastern District Office who has 8 collections, and has had 30 vears' service; he comes in 8 times, and if he is late for any one of them he is liable to have his increment stopped, and to suffer penalties. These duties; if paid at the auxiliary rate, would represent $27 \mathrm{~s}$. per - week.

Mr. Walpole : When you speak of a man doing 8 collections, you mean that it is one continuous duty, do you not?

A. Yes, sir.

Q. One continuous duty comprising 8 collections?

A. Yes, sir.

Q. That is not a baid duty, is it? But rather a good one as duties go.

A. Yes, in some respects, but a man has got 8 times the chance of being late to another man's four chances.

Q. My point is that instead of representing 8 split duties it is a continuous duty?

A. Certainly, sir. If the men at West Brompton were paid according to the Raikes' revision for an established or anxiliary labour he would get $2 \mathrm{~s}$. $6 \mathrm{~d}$. for the five collections, and $2 \mathrm{~s}$. each for the two deliveries, making an addition of $4 \mathrm{~s}$. $6 \mathrm{~d}$., but we are not so well off.

The Chairman: You will come very near that when the maximum of $26 \mathrm{~s}$. is reached?

A. That is only a boon recently granted. I think since this Committee came into existence, it has taken !a little bit of the wind out of my sails. (Laughter.)

Mr. Walpole: I think I am right in saying that it was done before this Committee was thought of.

A. This Committee was appointed on May 17th, and on the 13th June this boon was given to us. As to the loss of seniority, being supernumeraries, 
the most serious thing is that we have no rank, all staff appointments ranking senior to us. We are at the bottom of the list, both as regards holidays and the choosing of duties. It means as to holidays, we have to take them either at the beginning of March or the end of October, and never take a holiday in summer. And it is rather hard, too, to see young men of only a few weeks' service pick duties in front of us, leaving us the worst and hardest walks; and in the case of reserve men without walks, they have to work vacancies, and receive no Christmas gratuities. We should not mind all this if there was only a possibility of being promoted to the staff, but there is none. We only know that after a long period of service, we have still the certainty of the worst duty in the office. One of the unfortunate supernumeraries in my own office commenced his holidays in February, and in my own case I had to come back from mine in November.

Q. You get the last fortnight in October?

A. Yes, I should not get very much sunburnt then, and there are no excursions running into the country either in February or November.

Q. But you would start rather sunburnt. (Laughter.)

A. It is a drawback having to start when the excursion season is over, and we have to pay the full fare, which gives us very little chance of ever getting outside of London.

Mr. Walpole: Your unfortunate colleague commenced his holiday in February.

A. Yes, he commenced on the 22nd February.

Q. Then he finished last Saturday.

A. Yes, and he is not sunburnt, I assure you.

Q. It was rather unfortunate weather last week for the purpose.

A. It seems rather an unjust thing that while others are by their seniority climbing upwar'd, we are left struggling, and are rather going backwards; indeed, I have only to outlive my juniors in order to get the worst duty in the office and lose all Christmas boxes, which is certainly enough to destroy as man's spirits. I am myself on midnight duty, and have been so for over 3 years with no hope, as far as I can see, of ever getting, an evening off in the week, although I should like to have the pleasure of going to a meeting sometimes, or of enjoying some personal recreation. I am, however, debarred from that. There is no chance for me, I have always to be on duty at night,

The Chairman: What is your duty?

A. I come on at 1 o'clock in the day and remain until 3 in the afternoon; then $I$ go on about 6 until 10 minutes to 8 , and then go on at 9 o'clock. I am responsible for district sorting in London, and I go on again at midnight, finishing a little after 12.

Q. You do that every day regularly?

A. Every day bar Saturday. It is a burning question with us, because we have had our rights to seniority, but now the system is very much cut up in the various districts of London. In the Waterloo depot they pick their holidays and their duties-that is, ithe supernumerary men do just the same as the established men, and so it is in Brompton, but in other districts they are served as we are. We know there is no chance of our getting a better duty.

Mr. Walpole: Would you be satisfied if we let you rank above new appointments when the men below you fall out?

A. Certainly; we make that a great point. We think that all men appointed after November, 1889, should take duties and holidays junior to us.

Q. I will look into that with the Controller, and see what we can do.

Witness-Two years ago, the men in the S.E. District made an appeal to our Postmaster, that, being regular men, and having staff duties, we should have seniority in picking duties and holidays. These concessions were granted us, and remained in force until about three months ago, when, on the application of the junior men to a new Postmaster, it was decided to reintroduce the old order of things. We pray that we may be restored to our seniority. I may point out tha our supernumerary colleagues at the Parcel 
Depot (Waterloo) are allowed their seniority as regards duties and holidays the same as the staff, and in addition, they change their duties with established men month about, thus giving them ai chance of recreation, which is denied to us. In times of sickness, another hardship is added to our lot, as only half-pay is given us, and at a time when, in fact, we want more. It is in my own personal experience and knowledge that men have been out on duty when they should have been in bed, but were compelled to remain on duty for fear of being put on the sick list and on half-pay. Seeing we have passed a medical examination, and have the same work and weather to go through as the established class, we ask for the same advantages as they" enjoy. With regard to medical examinations it has been suggested, I think, that we are not supposed to vass an examination, but I must tell you that 3 colleagues and myself were stripped naked before a doctor and were passed as fit. I was at that time 42 years of age, and I think it was a little almost too bad to strip me, and then tell me I was too old to pass, because they previously knew my age, as my birth certificate had been sent in.

The Chairman: A good many of your class have not passed the medical examination.

A. A few, but I think there are fewer rejected on that ground than on almost any other; sometimes it is a question of age or of height, and in some cases it may be a literaryi difficulty, but very few because they fail to pass the doctor.

Q. Do you mean to say that they have all passed the doctor?

A. No, I am only stating my own case and those of certain colleagues who are known to me.

Q. But perhaps your case is rather an exception.

A. Possibly, but there are four of us in our office who have passed.

Q. You say the fact of your age was known before you were examined?

A. Yes, I had sent in my certificate, and we were vaccinated; two of us had bad arms, but we were in clubs and got sick pay, although one unfortunate man had not the same advantage, and had to work on. There was one of our class at West Brompton who was laid up with a bad foot contracted while on duty, but only half-pay was given to him while away from duty. I also recollect a case of an officer who died on the 12th January last, aged only 31; he was taken ill on duty with pneumonia. Another man found him standing up against a fence unable to proceed with his duty, and his colleague took his duty. He lay a week ill, then died, without receiving his money or anything, although he providentially belonged to a Wandsworth club, and his mother got $\$ 38$ from it.

Mr. Walpole: Did he not get his half-pay?

A. Yes, but only for 1 week. Owing to the Christmas pressure he could not take his usual meals at home, and in the bad weather of last winter he contraicted this pneumonia whilst on duty. There is no mistake about the case. He was a comparatively young fellow. One of the many hardships of our class is that we are entitled to no pension or bonus; all other branches of the Service doing a full day's duty have one in prospect, but we, receiving the least wage of all, have no means to save for old age, and when we are past work, notwithstanding our long and faithful service to the State, we are turned out on the world either to join the miserable army of unemployed, or to go to the workhouse as an expense to the ratepayers. It does seem hard that having the lowest wage, we have no pension, seeing that those in the Service who have the highest wages get afterwards a good pension. Our only hope is that we may die before we become too old to discharge our duty.

Mir. Walpole: You know the difficulty in the way is the law; I fear we have no power to give you pensions, as you have not passed the Civil Service exarnination.

A. We have had no chance of passing that; unfortunately, I seem to have been born too soon; I am just reminded that there is a compassionate fund of which we might get some benefit. 
Q. I wais only touching on your point as to the difficulty of granting you pensions. It is not in the power of the Department.

A. With regard to myself and my 3 icolleagues in the office, if $I$ could by any means have taken a little bit of their youth, and they could have taken a little bit of my height, we might all 4 have passed and got on the establisliment; if we were combined, I dare say we could pass, that is if you stivuck an average. (Laughter.) In a letter from the Right Hon. Arnold Morley (late P.M.G.), dated General Post Office, 2nd February, 1893, he says, in reference to our class, "Some are past the prescribed limits of age, or for other reasons are unable to pass for the establishment, but had the Department possessed the power, they would long ago have been incorporated into the establishment." But as to age, we had no chance for the staff. The age limit has, however, been altered to 32 , but to time-expired soldiers only, who have served 12 years with the colours. We beg most respectfully to ask, if it has been altered for one class of the community, why should it not apply to some of the most deserving Civil servants? Mr. Morley also, in the same letter, mentioned that he was considering if it were not passible to procure for us some advance in wages, but we heard nothing till the 28 th December last, when we received $7 \mathrm{~s}$. $1 \frac{1}{2} \mathrm{~d}$. back money, being $3 \mathrm{~d}$. per week rise from the 13th June last, and we have also heard that we rise in future 1 s. per year to a 26s. maximum. Twenty years ago, if a man was in his 25th year he had no chance of passing, but that was altered 20 years ago to 30 , which is just where I was put out, but now I see that by an order, which must have been issued in the beginning of September, 1892, it was provided that the maximum limit of age for appointment as postmen or porters should be extended from, 30 to 32 , so as to aidriit a number of timeexpired soldiers. In reading Mr. Morley's letter, one would imagine that the age limit was, like the laws of the Medes and Persians, never to be altered, but it has been altered.

Mr. Walpole: What was your age when you joined tlie Service?

A. 32 and three weeks.

Q. A little over 32 . And then I am afraid you only joined as an auxiliary?

A. That was all, sir.

Q. And then you were 37 before you became a supernumerary postman?

A. I was more than that. Of course, new entrants should conform to all the new regulations, but surely old servants who can show themselves able to do all the duties of the junior men should have the option of joining the establishment now. It would be a doubly serious thing for us if we are not put upon the establishment, and if this Committee were to recommend the abolition of Christmas boxes, and to prohibit these being: solicited, as we shall not share the advantage claimed by the staff of $2 \mathrm{~s}$. immediate rise. I therefore desire to back up my colleague, Mr. Wilson, in asking that the supernumerary postmen should be allowed 1s. per duty, and that if such an officer has 2 collections, these should be counted as one duty. This is the suggestion $\mathbf{I}$ throw out as a substitute for our Christmas boxes. Our remedy, for our grievances is, that we shall at once be put on the staff, and that our minimum shall be $24 \mathrm{~s}$. a week, and that our increment, sick pay, and choice of duties be in every way the same as the established men.

The Chairman: Why do you select $24 \mathrm{~s}$. as the figure?

A. Because we are all adult men, and many of tis have families, and if we had risen at the rate of $1 \mathrm{~s}$. a year, as we think we ought to have done, we should have just about come to the $24 \mathrm{~s}$. now.

Q. You take no exception to the maximum of $26 \mathrm{~s} . ?$

A. We take no notice of that.

Q. But I mean do you accept it?

A. We are bound to accept it; it is already an established fact.

Q. You do not ask for an increase of the maximum?

A. It will be another five years before we get it. We only rise 1s. a year.

Mr. Walpole: Christmas boxes are worth about $\$ 710$ s. a year to yon? 
A. Yes, on myl present duty; but on the next levy I shall lose that.

Q. Is that last year's amount, or the average?

A. I think it is about my usual amount; I do nearly 1500 separate tenements. A good deal has been said about the dangers of some of the duties of the polioe, but we also have some dangerous duties with regard to some steps which I have to use constantly. It is the case of a man who was killed $\rightarrow$ neighbour of mine-as you will see from the print which I have in my hands.

Q. Was he a postman?

A. No; unfortunately for our case he was a civilian. (Laughter.)

Q. This poor civilian seems to have fallen down thirteen steps about 8 feet?

A. Yes, sir.

Q. And he had just had two glasses of mild and bitier as well as $2 d$. worth of gin?

A. That would not be excessive, sir.

Q. But it might contribute to the danger?

A. It is a dangerous place, as certified by the coroner's officer. There is also 2 cottages, but before reaching them you have to go over a fence and pass where there are some signal wires low down, and cross two lines of railway, where there is shunting being done. At Christmas time an auxiliary sent to deliver parcels there brought them back and said he could not find the place. I do not wonder at it. I could find it because I know to my cost where it is. As the parcels were perishable we could not leave them till next day, though the weather was foggy. It is a very dangerous walk.

Q. The coroner's court recommended the railway company to put a handrail across and to light the bridge; has that been done?

A. It is private property, and the railway company say that if we go there we go at our own risk.

Q. Have they fixed the hand-rail?

A. No, sir; nor the light. In conclusion, it would have been out of all order if we had not been last. It is only consistent with our present position as supernumeraries that you have heard our grievances at the end of this long Inquiry, but as we are last we hope we shall not be the least in your favourable consideration. We look forward with confidence to your verdict, knowing that we are the worst paid and in many respects the worst treated of the classes covered by this Inquiry. We thank you for the opportunity yon have given us of expressing our views. If you will allow me I should just like to add that I am desired by the established men in the S.E., with regard to the evidence given by Mr. Symes on classification, to state to you that the conditions explained to you relating. to the E.C. of the injustice done to a number of postmen affects men outside the City to a far greater extent than has been shown to you. That is, the average time served on the 2nd class in the S.E. was three years, and therefore the loss to the district men was much greater than that of the City men.

The witness then withdrew. At this stage someone in the room asked to be allowed to give evidence respecting the case of the supernumerary parcels postmen, but the Chairman declined, saying that that had been sufficiently covered already. Later in the day the Chairman expressed his willingness to hear the witness, but he had then left. 
GEORGE CORBET, of Woolwich.

Special Case for the Woolwich Men.

Westumnster, Monday, March 9th, 1896.

George Corbet was next called and examined:

The Chairman : You are a postman, I believe?

A. I am an auxiliary postman, my lord.

Q. You want to tell us the case in regard to the Woolwich men, don't you?

A. Yes, my lord. I might say in commencing that I am an auxiliary postman of 29 years' standing, and my own case is that simply I have never had an opportunity of being made an established postman.

Q. Have you got some other occupation?

A. Yes, my lord, I have to have. I do not see how I could have got on without it. It has been my ambition ever since I entered the Service to get on the establishment, but I have never yet attained that, because, unfortunately, as one of my colleagues said just now, I was born too soon. The scale of age when I entered was 25, and I was 26, and although it was extended some nine years later, when the new Woolwich office was opened, we did not get the benefit of it. I and some 20 others sat for examination with a view to a permanent appointment, but I was told I was ineligible on the ground of my age. Unfortunately, I had grown no younger, but still I am waiting on and hoping to be considered. I may say-for I wish to conceal nothing-that I have a break in my service, which, no doubt, has been a great hindrance to me. I had, after taking all the senior duties I could, repeatedly applied for promotion, and our late Postmaster at Woolwich, after making the applications, and having them refused, declined to send any more forward, as he said it was quite useless. At that time I did what was possibly a foolish thing. I wrote direct to our late Secretary, Sir A. Blackwood, and I made up my mind that, if nothing came of that, I would resign. Hearing nothing for some months after I did resign, but I soon found out my mistake, for, having had so much outdoor exercise, my health was not sufficiently good to enable me to stick solely to my occupation. I was a bootmaker by trade. I applied consequently to be reinstated. I sent in the application on the Thursday, and on the Monday the Postmaster sent for me, and said he had recommended me to be reinstated. I have been in the Service ever since.

The Chairman: At any rate, your experience of the Service is that it does not wear a man out.

A. It has not worn me out so far.

Mr. Walpole: And when you went back to the Service did you regain your health?

A. Yes, sir. I do not know that, so far as my own case is concerned, I have anything further particular to say, only I would like my service to be recognised in some manner. 
Q. What is your pay as an auxiliary?

A. Now it is 11s. per week.

The Chairman: For two duties?

A. Yes. I might have had more duties than that, but as I found that I could not get on the establishment, or even on the unestablished class, which I had already applied for, I took a duty which best suited me, so as I could follow another occupation better. I may say that our Postmaster sent for seven of us, and, as far as my memory goes, he asked each of us if we would take up a full duty providing it was offered to us. The wages, he said, would be $18 \mathrm{~s}$. to $£ 1$ per week; and he also promised that efforts should be made to give us this full duty. He added that he could not promise anything in the way of privileges, but that that matter must be left in abeyance. I believe that each man sent in a reply that he would accept the duty, presumably under the idea that ultimately he would be recognised by the Department. We think that after 29 years' service as auxiliaries we really deserve some recognition.

Q. How long was the break in your service?

A. Six months, sir, and I was reinstated without being recommended in any shape or form, and even without being medically examined. As far as my memory serves, I do not think I had to go before the magistrate again.

Mr. Walpole: I do not want you men to be under any misconception as to your application. I am afraid we have not the power to do as you suggest.

Witness, No, sir; I am afraid not. I will now proceed with my statement. In asking that the statement from the Woolwich men might be heard separately, we do not wish you to infer that we are not satisfied with the way in which the questions affecting the general body of postmen have been placed before you, as we fully appreciate the conduct of the rase by our able colleagues, but, feeling that our case is purely local, and this question of provincial control having excited so much dissatisfaction at Woolwich, we decided to approach this Committee separately. Previous to April, 1875, Woolwich, for postal purposes, formed a part of the SouthEast London District, at which date Woolwich became a district Head Office, embracing the sub-offices of Charlton, Belvedere, Erith, Bexley Heath, Bexley, Crayford, Welling, and Shooter's Hill, but was still incorporated in and controlled by the London Postal Service until the 1st September, 1879, when, for some reason or other unknown to us, it was suddenly transferred to the control of the South-East Provincial Surveyor. Tis is transference caused great dissatisfaction to the staff at the time, a dissatisfaction which has existed ever since, and has constantly broken out in recurring attempts to obtain retransference to the control of the London Postal Service, and we hope to establish proof that we have some grounds for being dissatisfied with provincial control. Woolwich is for all practical purposes a part of the county of London; it is represented in Parliament by a London member; it is also represented on the London County Council and London School Board; it has its Metropolitan Fire Brigade and Metropolitan Police, exactly the same as the parishes of Westminster and St. George's, Hanover Square. In fact, for all official purposes it forms a part of London, but for postal purposes it might as well be as far away as Land's End, and, when any question arises such as the giving of an increased maximum of pay to postmen, comparisons are made between Woolwich and Brighton or Newcastle-on-Tyne. Comparisons, my lord, are sometimes odious, and I have no doubt that the senior staff at Woolwich would be very glad to have their salaries put on a level with the senior staff at Newcastle-on-Tyne, seeing that the Postmaster and chief clerk get nearly double the amounts paid to the same officers at Woolwich, and so on downwards, in proportion to the rest of the staff. We respectfully submit that Woolwich should be controlled by the London Postal Service, and that wo 
be paid the same rates of pay and enjoy all the privileges pertaining to the London Postal Service as those men in the adjoining parishes of Blackheath and Greenwich, where both the minimum and the maximum pay are higher than at Woolwich, viz., 18s. by 1s. to 30 s., whereas ours are $17 \mathrm{~s}$. by $1 \mathrm{~s}$. to $24 \mathrm{~s}$. , and 17s. by $1 \mathrm{~s}$. to $28 \mathrm{~s}$., the lower rate obtaining at the sub-offices only. Thus we have men at the Charlton sub-office whose deliveries cover a good part of the parish of Greenwich, yet they are on a scale of pay, the maximum of which is some 6s. per week lower than at the two offices named. We submit that this classification be abolished, and all men doing eight hours' duty may receive the same scales of pay. We also submit that the auxiliaries here may be paid the same as in London, as promised by the scheme of the late Mr. Raikes, viz. :- not less than 1s. for a delivery, and not less than 6d. for a collection, their duties being in no way dissimilar. Being under provincial control bears harshly upon us in another direction, viz. :- Promotion, which at Woolwich is absolutely at a standstill. The appointment of head postman was abolished some three years ago, and there are only two appointments to which about 40 established postmen may aspire, viz., an inspectorship and assistant-inspectorship, and under the provincial system these appointments are very frequently given to sorting clerks and telegraphists, thus the maxim that "once a postman always a postman" is in a fair way of being carried out. Whereas in London there are numerous positions to which postmen may hope to obtain, such as head postmanships, lobby officers, overseers, and sorterships, promotions to which opens up a brighter prospect to the men, there are no such openings existing at Woolwich, and it deadens hope, and frequently sours the disposition. My lord, we submit that house rents and the cost of living is as high here as at Blackheath or Greenwich, and the competition for housing accommodation shows no sign of diminution, nor is it likely to do so, and there is no prospect of rents going down. Our duties are no less onerous or responsible, our hours of duty are no less than those of the men at Blackheath and Greenwich, the requirements of the Service are in every way the same, and we feel no reluctance in pressing our claim for reincorporation in the London Postal Service. My lord, this question has been a bone of contention for the last 15 or 16 years, and has created more discontent at Woolwich than almost all the other grievances. Several attempts have been made at removing it, but, up to the present, we have not succeeded. We now appeal to you and this Committee to urge upon the Department the desirability of placing Woolwich in the position it formerly occupied in the London Postal Service. The great majority of the inhabitants of the parishes of Woolwich, Plumstead, and Charlton are in favour of it. and we hope our appeal to this Committee will not have been in vain. I might say in addition, my lord, that we have several men who formerly were in the S.E. district office, both auxiliaries and established men-I think there are seren or eight-and we were informed, although I have no evidence of the fact, that Mr. Fawcett stated that no man should suffer by the change which resulted in transferring the S.E. district to provincial control. They have, however, suffered.

The Chairman: I want to know why you were selected to represent this Woolwich case?

A. I do not know, my lord, any further than this, that I am one of the oldest servants in the office. I rather pressed upon them to send another man.

Q. It seems to me rather curious to have selected an auxiliary who was not affected by this particular case, rather than one of the established men who was affected.

A. I quite thought so, my lord, and pressed them to send somebody else, but they persisted in sending me if I would go.

Q. Then they had such confidence in you? 
A. I suppose so.

Mir. Walpole: You are affected by it in the shape of auxiliary wages?

A. Yes, sir; there is only one man in the Woolwich office of that description, so that in the Service I can give the senior established man eight years, and then be senior. I have felt aggrieved that I could not get on the establishment. I may say that cne time I was offered an appointment, and I took one as a rural postman in the Beckenham district, from Hayes to Down. At that time I understood it was to be an established appointment, but after taking it up I was given to understand that it would not be so, on account of the break in my service, and as I had a sickly wife and six young children to keep, I did not think that 18s. would be sufficient, and therefore I gave up the appointment. Any step I have taken with regard to my service has been taken honourably, and if I acted unwisely, as I am sorry to think I did, still there was nothing dishonourable.

Mr. L. Smith: Is this grievance which you speak about confined to Woolwich, or do you speak on behalf of other suburban districts as well? Is Woolwich the only place where the grievance prevails?

A. There is Woolwich and Charlton, and other districts.

Q. I am not asking as to the extent of the Woolwich district; we know that it embraces Charlton and other places, but I am asking, are there any other districts in the outskirts of London like Woolwich in this respect?

A. I believe there are. I have a statement here from Croydon, which bears upon the point. Shall I read it out?

The Chairman: I understand that Woolwich is the only case in the London district where this grievance occurs?

A. I think Croydon is a similar case.

Q. Can you tell us the name of any other districts?

A. I know of no other cases personally except this one at Croydon.

Mr. Smith: Is it the same at Kingston, Richmond, and Kew?

A. No, sir.

Q. You have not got up that case apparently?

A. No, sir; but I shall read the Croydon case?

The Chairman: I think not if it is on the same point. We need not go into details. If there are any other cases of a similar character, you can simply give us the name.

A. I cannot say that there are. I will hand in the Croydon statement.

The witness then withdrew. The Chairman, looking at the Croydon case, said it bore upon another point altogether. 


\section{CHURCHFIELD-RE-CALLED.}

\section{Supplementary Case.}

Westminster, March 19th, 1896.

The Post Office Departmental Committee resumed its sitting at noon to-day, all the members putting in an appearance during the course of the day. Lord Tweedmouth again presided.

Mr. C. Churchfield (E.C.D.O.) was re-called and examined as follows :-

The Chairman: I understand you have some case you wish to bring before the Committee in which you think that one of the men has been injured in consequence of some evidence that has been given before this Committee?

A. Yes, my lord.

Q. Will you state what you have to say?

A. Yes. It is the case of G. J. Roberts, an auxiliary postman in the N.W. District, whose case was mentioned before this Committee.

Mr. Walpole: When?

A. By Mr. Boaler. It is the case of a man who had no uniform, and was doing Parcel Post duty.

Q. What day do you say was mentioned?

A. I cannot say the day, but Stewart also mentioned it.

The Chairman: Was the name of the man Roberts mentioned?

A. No name was given in the evidence, but he is the man who supplied it, and I think it is generally known he is.

Q. It is as regards the supernumerary postmen, is it not?

A. Yes.

Q. Then what does he complain of?

A. He informs me that he has been called upon to resign his position of auxiliary postman owing to the fact that a parcel docket which he reported to the second-class overseer as missing had been found under the string of a parcel on delivery. The case was reported by the first-class overseer to the Postmaster, who said that, owing to the numerous complaints referring to this man Roberts, he had better look out for another situation. The man informs me that there is nothing whatever against him, that the complaints are of a simple and trifling character, and he can't understand why, for the loss of a docket which had to do with sorter's rather than postman's work, he should be dismissed. I should like to hand in his letter, my lord.

The Chairman: Very well.

The following is a copy of the letter:-

\section{Queen's Crescent, Haverstock Hill, London, N.W.}

\section{Mr. Church field, -} 16th March, 1896.

Dear Sir,-Being a member of the Postmen's Federation, I wish to draw your attention to what I was told last Saturday. I am one of those parcelmen at Hampstead with no uniform, and also was the one that collected the evidence for Mr. Stewart of S.W.D.O. Last week on G.P. I reported an "N. bill" missing to the second-class overseer. So the firstclass overseer fetched me back and asked me why I did not report it to him, at the same time saying he would make a special report of it. When I returned to the office at $1 \mathrm{p} . \mathrm{m}$. he had left an explanation, saying that the 
bill was found under the string of a parcel while out on delivery, which I found was correct. The answer came back on Saturday to my explanation that, owing to so many reports, the Postmaster said I had better look out foi other work. Take it altogether, I don't think that I have any more than anybody else, and when I do have them they are over paltry things like the above ; in fact, they are not about postmen's work, but sorters', such as to do with foreign and registered parcels. This very overseer that reported me is the one that was spoken of at the Inquiry, he being the man who, when assistance was asked for by the parcel postman, saying that laziness was encouraged in the Post Office. And my opinion is that he heard that $I$ sen' this evidence down, and, this being the first chance, he has rapped this report in and made it worse than what it is. When he told me this I said to him: "This is a fine thing to tell me-after nearly three years and a half service." I hope and trust you will try and do something for me. I have been in the Federation nearly since it started. I am also a member of a mutual benefit society.

A man at our office left a parcel on the wall the other day, and they did not say so much to him as they did to me for failing to see the "N. bill." Please excuse writing, as I have a gathered finger.

I remain, your obedient servant,

G. J. Ronerts,

Hampstead Parcel Postman.

Witness : Roberts informs me that he is prepared to stand by this letter.

Q. The only wealiness in it is that I do not think you have connected this with the evidence upon his case in any way.

A. I would like to impress upon you that we can only connect it with thi, evidence that this man has furnished to us.

Q. But it seems to me that the evidence was of the most harmless character?

A. I beg your pardon; I think you will find that there are only a few of these men that were mentioned.

Q. But the general complaint is that they do not receive boot money and uniforms, as I understand it?

A. I beg your pardon; but I think you will find that there are very few of these men in London.

Q. The complaint made on behalf of this man was simply that he did not receive certain advantages.

A. Yes ; that he did not receive uniform and boot allowance.

Q. Surely for a statement of that sort the Department could not bear any grudge against him?

A. Do you not think so, my lord?

Q. Well, I am looking at it from a most ordinary point of view.

A. Will you be good enough to read the man's own opinion, my lord?

Q. Well, he says in his letter, "My opinion is that he heard that I sent this evidence down, and this being the first chance he has rapped this report in and made it worse than it is. When he told me this, I said to him: 'This is a fine thing to tell me after nearly three and a half years' service." He expresses a hope also that you will do something for him, $\mathrm{Mr}$. Churchfield. I do not think that really indicates any feeling on the part of the Department against the man for giving the evidence.

A. I would point out to you, my lord, that there are very few men of this class, and if this man is dismissed the Service for the trifling offence of omitting to report to the proper officer-and I think in this case he did report in the right way, for he reported to his immediate superior officer who is the second-class overseer-I say that if he is dismissed for this trifling offence the men will only be able to entertain one opinion as to the cause.

Q. That is not the question. Roberts may have been hardly used with regard to this particular lapse of duty; I think that that is possible, but 1 
know nothing about it. I do not think you have given us any shadow of proof that he has been dismissed on account of supplying evidence.

A. But if there is nothing whatever against the man, does it not appear to you that the very fact he has furnished the evidence would constitute a reason?

Q. I do not know what is the cause of his dismissal, but I cannot conceive it possible the furnishing of such evidence as I see here would constitute any ground of complaint.

Mr. Walpole: Is it not a fact-does he not show it in his letter-that there are several things against him?

A. Also for trifling offences.

Q. What he says is, "Owing to so many reports, the Postmaster said I had better look out for some other work"; he does not contradict the fact that there are several reports against him. Then he goes on to say, "I don't think $I$ have any more than anybody else, and when I do have them they are over paltry things like the above; in fact, they are not about postmen's work, but sorters', such as have to do with foreign and registered parcels." He does not think, apparently, that that is proper work to give him, but he does not deny the fact that there are many reports against him?

A. Quite right.

The Chairman: I will take the opportunity of asking Mr. Badcock about it at once, so that he may tell us what the Department has to say about it.

Mr. Walpole: Mr. Churchineld, the members of your Federation have had very full opportunity of giving evidence here, have they not?

A. Quite right, sir.

Q. And have you any other case in which there has been any act of intimidation against any of these men?

A. I have a case from. Windsor, where I am informed that the men are suffering from a sort of petty intimidation. They are being watched about, I am told.

The Chairman: Thank you, Mr. Churchfield.

Witness: I wish to thank the Committe for the manner in which they have dealt with our witnesses. 


\title{
PROVINCIAL CASE.
}

\author{
ALEX. M'LAREN, Glasgow. \\ WAGES- \\ Christmas Boxes-The Initial Wage. \\ Wristminster, Monday, February 3, 1896.
}

Mr. Alexander MTaren was next called:

The Chairman : You are in the Glasgow Post Office I believe?

A. Yes.

Q. And been there all the time of your service?

A. Yes.

Q. When did you begin?

A. In May, 1885.

Mr. Walpole: As postman?

A. Yes, as postman.

The Chairman: Under what circumstances did you come into the Service?

A. I was a tèlegraph clerk with the Glasgow and South-Western Railway

Company.

Sir F. Mowatt: What was your age?

A. Almost 17. I do not know that the circumstances of my way of entering the Service were in any way typical of the average case.

Q. How did you enter?

A. I entered as a postman. In the first years of my service I did not hold any appointment. I was an unestablished postman.

Mr. Walpole : Is it ai better thing to be an auxiliary postman than a telegraph clerk?

A. In my particular circumstances it was. I wass as tall at 16 years of age as $I$ now am. My wages as a telegraph clerk on the raflway were certainly not a man's wages, and I thought it was necessary to get more.

Q. What wages haid you?

A. I had 9s. al week.

Q. That is the ordinary pay of a telegraph clerk on the railway?

A. Yes, for a lad of 16 .

The Chairman: I suppose you were only a learner?

A. No; I had had two years' experience. I wais doing postal work as well as railway work. I was two years a telegraph clerk at St. Enoch's Station, and then I bègan to think I was too big for the wage I was receiving. When I began at the Post Office I got 18s. a week for substitute's duty, but after I had been at the work eight or nine months, they found out that I was under 18 years of age and said I was too young to be receiving such a wage, so they put me on auxiliary duty at $14 \mathrm{~s}$. a week.

Q. How many hours' duty?

A. Nominally six, but in the reas the reality was much more than six. It was really the full time of a postman.

Q. It was in 1885 that you joimed the Service?

A. It is utterly impossible for me to give the different dates that $I$ was full-time postman and auxiliary postman.

Q. How many years were you in that transition stage?

A. Three and a half years. It was November, 1888, that I was added to the established staff as a second-elass postman at 18s. $a_{\text {e }}$ week, 
Sir F. Mowatt: You were then 20 years of age?

A. Yes; I was then 20 years old.

The Chairman. You are going to speak on the whole Scotch case?

A. I intend to cover in my statement the case for all the provincial offices, English and Scotch. In beginning I would like to say; that when we first became aware wo were to be allowed a hearing, there seemed to be great importance attached to the separation of the case of the London men from that of the provincial postmen. The reason for that I do not know. There has been some misunderstanding. Only at the last moment I became aware that the cases were to be taken jointly (although it had been my view all along that it should be so), and it may, therefore, be necessary for me to overlap some of the evidence given by the London men. If I do, I would pray for some consileration on that account. The provincial postmen are the largest class in the Service. I believe there are 20,000 established postmen, and I suppose that the auxiliaries number 5,000 more. It is difficult for us to get information on that point except by application to the authorities.

The Chairman: In the case of points, already sufficiently dealt with, you will pass them over.

A. I should prefer to be permitted to read my own statement.

The Chairman: As fully as you like. I only suggested that where you could cut down you might do so.

A. I have already cut out several pages. The wages question, on which I propose more especially to speak, is one which gives room for debate, and on which there is a great deal to be said. Nowadays when labour matters are of such interest to the general public and are discussed everywhere with avidity, there is no more outstanding division exists in the ranks of the workers, than that which exists between what is called "skilled" and "unskilled" labour. Whether these idistinctions are in themselves just or unjust is a disputed point with writers on labour-politics. For present purposes, however, it is sufficient for me to state that it depends very much under which of these headings a man is ranged, whether he shall or shall not receive pay proportionate to his work. Therefore it follows that any class of men prefer to be placed rather in the "skilled" than the "unskilled" list, as thereby they become entitled to a higher scale of pay. The work of a postman, with which we have at present more particularly to do, is viewed by the Department which controls the Service as belonging to the unskilled class, and this view is admitted to have, to a certain extent, an influence on the rate of wages. I would point out, however, that the work of a postman cannot fairly be classed as unskilled labour. There is skill required to properly transact the duties, there is intelligence required, there is experience required, quite as much as in the case of professions generally considered more difficult. Besides, the statement that a postman's work is " unskilled" is contradicted by the Service itself; as, if it be a fact, how then can the work of those above him in rank-even postmasters and surveyors-be classed as skilled and paid as such? It is plain therefore that it.cannot be said with any degree of consistency that a postman's wages should be low becauso his work is "unskilled." Another factor which in many cases settles the rate of wages in other lines of life is the so-called "law ' of supply and demand." This, for various reasons, cannot be used as a just standard in the case of the postal service. The Post Office is a State monopoly; there is only one master, therefore a postman cannot change positions as he could if engaged in any ordinary occupation. Rather is it the case that the Post Office service is so exclusively a branch of Government work as to be altogether outside the range of the law of supply and demand, and consequently should not be guided by the rules of the ordinary labour market.

The Chairman: But then the employment is permanent?

A. I will deal with that presently. If a young lad is going to learn a trade he has his craft behind him, but if a man goes into the Post Office he 
has no craft. There is no post office across the road where he can go and get a job. (Laughter.) Post Office work is so nearly allied to the Civil Service that the regulations which fix the rates of wages in the latter might also be fairly applied to the former. Evidently the law of supply and demand is not recognised in other branches of the Civil Service. If it were, how can you account for 500 applications for 30 places in open competition? It would, we contend, be nothing more than fair that postmen's wages should be fixed, not with reference to the rates paid outside Government service but rather that the conditions of employment should be assimilated as much as possible to those obtaining in other branches of Government employment - particularly of other branches of the postal service where work is of a similar character. It might also be said in a general way with regard to the law of supply and demand. If that law is a Divine one, what about the unemployed?" I do not know how many that class number: Mr. Smith probably is better versed on that point.

The Chairman: A Post Office servant,does not run the risk of being unemployed?

A. We do not accept the law of supply and demand as applying to the Post Office.

Mr. Walpole: What is your authority for calling it a Divine law?

(The question was not answered.)

Witness. Many years ago, when the sorters and letter-carriers were rated by the Department as being on a footing of equality, the letter-carriers considered that they had a grievance in, being called upon to do the inferior work of sorting.

The Chairman: I suppose they cut down the districts and got less Christmas boxes?

A. I do not know. To get over the difficulty the authorities established the "dual certificate," and changed the appointment designation from "letter-carrier" to "sorter and letter-carrier," so that the postmen might be available for either indoor or outdoor duty, if necessary. Men constantly employed on sorting duty were paid at a higher rate than those who were always on delivering duty. This was not on account of any supposed superiority of the work, but rather in lieu of uniform, and also because they had no opportunity of getting Christmas boxes. This has already been treated of. I am only mentioning it in the way of giving an historical retrospect, so as to mark the disparity between the wages of sorters and postmen.

The Chairman: Do you agree with Mr. Warner as to the Christmas boxes?

A. Partly, but I did not understand it all.

Q. Will you tell us where you differ from him?

A. I look on Christmas boxes as one of the emoluments of the office. Perhaps I had better read my statement. That these were the reasons for the difference in pay is partly shown by a quotation from the "Memorandum Circular," dated 22nd March, 1865, in which letter-carriers were reminded that: "They received from the public in gratuities, at Christmas, a sum, which if divided and spread over the whole year, would produce, on an average, 5s. a week for each man." By this extract it will be seen that Christmas boxes are approved of by the Department and actually recognised as part of the postmen's wagest. I will, however, have occasion later on to refer more fully to this phase of the question. Mr. Arnold Morley, the late Postmaster-General, speaking on the wages paid in the postal service, said that-" Before the date of the revision by Mr. Fawcett in 1881, the maximum salary of the London Sorters of the first class was $45 \mathrm{~s}$. per week, and it is now 56s.. The maximum for sorters of the second class was then 25s. It is now 40s. With postmen there had been a corresponding increase. The maximum salary for first class postmen in London had been increased from 30 s. to $34 \mathrm{~s}$. per week, and in the suburban districts from 28s. to 32s." This statement on being examined shows that the increase of the maximum to 
postmen was only $4 \mathrm{~s}$., against $11 \mathrm{~s}$. to the first class and $15 \mathrm{~s}$. to the seond class of sorters. This certainly could not in fairness be called a corresponding increase to both branches of the Service.

Mr. Walpole: If Mr. Morley had said there had been "an increase" instead of "a corresponding increase," he would have seen accurate.

A. I am taking the report from the London "T:mes."

Mr. Walpole : Quite so.

Witness: Granting then that improved condi'sions of service are required by the postmen, our proposal is to replace the existing scales of wages by the following:-(a) For principal towns s.nd their immediate suburban vicinity-Minimum 20s., increment 2s., and maximum 40s. (b) For smaller towns, a proportionate increase provided that no postmen doing full time duty (whether town, sub-office, or rural) should be placed on a lower scale than-Minimum 20s., increment 2s., maximum 30s.

The Chairman: Have you any estimate as to what that would cost the country?

A. Mr. Walsh is going to deal with that more particularly.

Sir F. Mowatt : I understand you to draw a deduction between the largest and the smallest towns as regards the maximum. You put one at 40 s. and the other at 30 s.

A. We ask that the men in the large towns should rise to 40 s., ant for the smaller towns a corresponding increase providing they are not to be less than 30s.

Q. You are adopting the word "corresponding" perhaps not quite accurately. You objected to the late Postmaster-General using it.

A. Yes, and the objection can be brought out as well founded by rule of three.

Q. You suggest for the largest towns 20s. to 40s., and for the smallest 20 s. to not less than 30 s.?

A. I am not dividing them into two classes. I am leaving it for the Department if it chooses to arrange an intermediate class.

Q. Still you say the smallest towns up to 30 s. and the largest up to 40 s.?

A. Yes; but there might be an intermediate class. In my istatement I am merely naming the largest and smallest towns. These proposals are not put forward without due consideration. Postmen who are at present being paid at very low wages would, it is true, get by this scheme a very considerable advance.

The Chairman: I suppose the second scale would cover all the rural postmen?

A. Not altogether. Another witness will deal with their case. If rural postmen are really located in a town they ought to have the town rate of wages.

Q. Can you, without reference to particular rates, tell me what your own view would be of the different cost of living? What would be the variation in the cost in a big town, in a small town, and in a mural district?

A. There is a difference, and sometimes it happens that the existing classification does not meet the, necessities of the case.

Q. What in your opinion is the difference? Can you form any opinion yourself as to how much greater expense one is put to by living in a large town than a small one, or how much more expense in a small town than in a rural district?

A. I have not been able to form any precise judgment upon that point. I have, however, asked for information upon it, and I find that the cost of rent is not exactly in proportion to the population of the place.

Q. Yet it can only be by some sort of population test that a classification could be fixed at all.

A. We prefer that we should be divided into districts. There is the Tyne district, for instance, and the cost of living in the towns round about there is practically the same as in Newcastle itself, and therefore the wages ought 
to be the same. Yet under the existing arrangement the cost of living in these towns is reckoned on a lower scale than in Newcastle itself.

Q. But you cannot tell me anything which will enable me to form a judgment of your view as to what the difference would be in the cost of living in these various districts?

A. No; it would be impossible without having to produce such a volume of evidence as we should never ge't through.

The Chairman: You might boil it down before you come here and give us the results.

Witness: We will now consider the mode of entering the Service and tho initial wages paid to postmen on whole-time duty. The postmen's class is chiefly recruited from the telegraph messengers-a state of matters of which we quite approve. The present commencing wage of the established class is $17 \mathrm{~s}$. per week-in most provincial towns there are, of course, lower classes - and if a lad of 16 or 17 years of age gets this rate immediately on leaving the telegraph messengership, there would not be quite so much room for complaint. This, however, is not the case. The terms of service of new entrants are at the present day much worse than they were about 20 years ago. At that time the qualifying age for appointment was 16 , and the appointment was confirmed in six months. Now the qualifying age is 18 , ant the newly-appointed postman has to undergo a further probation of two years before his appointment is confirmed. We do not object to the raising of the age. On the contrary, we approve of it, because we maintain that letter delivering is not an employment in which boy labour should be used. Before a lad can be entrusted with the delivery of letters he must have arrived at years of some discretion. The authorities, fully alive to this, do not care to employ any one under 18 so long as a sufficient number who are over that age are forthcoming to fill up vacancies as they occur. The following extract from the "Book of Rules for Postmasters" is interesting as throwing some light on this phase of the question:- "No person under 16 years of age can be permitted to hold any situation in the Post Office, or to have access to letters, with the following exceptions:-(a) Persons employed with the consent of the surveyor in rural districts or in times of great pressure. (b) Persons employed exclusively on telegraph hisiness." These would be telegraph messengers, of course. We would naturally expect that the raising of the qualifying standard would be accompanied hy a corresponding improvement of the initial wages. This, lowever, was not the case. Instead of getting an improved initial wage, the rate of pay was actually roduced from 18s. to $17 \mathrm{~s}$. per week. In Glasgow, some years ago, a new entrant was placed on the establishment within a few weeks of his joining the Service. In that case he had an increase of pay shortly after completing one year's actuasl service. At present a new entrant has to wait for years before being appointed. For example, a young man entering the Service has to go through all the vicissitudes of auxiliary postmanship for three or four years before his turn for taking up whole-time duty comes. During this time his wages may be $8 \mathrm{~s}$. or $14 \mathrm{~s}$. per week, according to the number of hours which he may have to work daily? The time so served does not count as service for pension, stripes, or anything else. After taking up whole-time duty, he may be months ibefore being added to the established class at 17s. per week. This prolonged unestablished service is likely to continue as long as the present system of employing a large auxiliary force exists. We contend that paying low wages is not consistent with the duty of the Department to the public, and the validity of our contention was practically admitted by the late Mr. Raikes, who said:- "Postmen occupy an important public position of great trust and responsibility, and I consider 18s. per week too low a rate of pay for postmen who are of mature age." I may say that this statemen', made in the House of Commons, le 1 us to hope we should get an increased commencing wage rather than a re: duction. 
The Chairman: The men must be of a mature age?

Witness: I will deal with that later on. As we have seen, the commencing wage has been decreased instead of increased. It is our desire to see established a living wage for all postmen who do a full day's work. By the term "living wage" we do not mean a wage on which a man may simply exist, but on which the postmen can live in a healthy, decent house, adequate in size for a normal family. And when I say "normal family," a postman of 18 is not expected to have a large family. (Laughter.)

The Chairman: I hope not. (Reneweld laughter.)

Witness: But he may be expected to support his parents.

The Chairman: Or help towards it.

Witness: Yes. It is necessary a postmam should be able to supply for himself, his wife, and children, sufficient food and clothing, and surround them with a certain amount of domestic comfort. If we were speaking of the case for Glasgow alone we would claim even a higher initial wage than that stated - that is, higher than $£ 1$ a week. But we are bearing in mind that the representations we are now making are on behalf of the whole country, and that it may perhaps be necessary, in the case of large towns, to subordinate their interest to some extent so as to secure a measure that could be uniformly applied throughout the country. Another matter in connection with which postmen consider they are not treated so liberally as the circumstances warrant is the matter of increment. The rise from a low wage to a respectable living watge is, in our opinion, too slow. Assuming, for example, that a lad of 17 enters the Service at Glasgow, and that after a lapse of four years he receives his appointment, the pay obtainable by him after seven years' actual service would only be 20s. per week. Considering that he will by this time be 24 years of age,that he will take ten years more to reach the maximum pay, this rate of increase is, in our opinion, altogether inadequate.

Sir F. Mowatt. Is not, four years rather longer than the period which usually elapses between a lad joining and getting his appointment?

A. It depends very much mpon whether there, is an auxiliary class to be travelled through before it reaches the full-time class-whether, in fact, there is a buffer class. I am well aware that Glasgow is to some extent not altogether a typical case. T have gone over the evidence that has been supplied to me, and $I$ find it is a very general custom for the buffer class to be exhausted-for it to be travelled through before a man gets an appointment. It is quite a common thing for a new entrant to have two and even three years' service before being added to the established class.

Sir F. Mowatt: If he goes in at 17 they would put him before 20 on the established class. You have been using the figure 24.

Witness: I will repeat my statement.

Q. You said two or three years' service just now?

A. Yes. In Glasgow we have 524 established and 202 auxiliary postmen.

Q. You said two or three years, and you have also put it at four. I want to know which is the period you rely upon?

A. I can only repeat my sitatement. (Repeated part of last paragraph, beginning with the words "Assuming, for example," and ending "altogether inadequate.") Continuing the witness said:- In putting forward a plea for improved wages, we are not unmindful of the advaintages of Post Office employment, nor do we desire to overlook them. We would point out, however, that these advantages, while in themselves real and of direct benefit, coupled as they are with the rates of wages, do not represent so much as they seem to do. In the first place, we have sick pay. Thait we have in common with many other branches of the Civil Service, and it has not yet been pointed out as an argument in favour of low wages to other sections of the Government service. We have also uniform and boot money. On this question $\mathrm{I}$ am not opposed to a nominal value, as wages, being set on the boot money and uniform. But I think the Department, seeing they must 


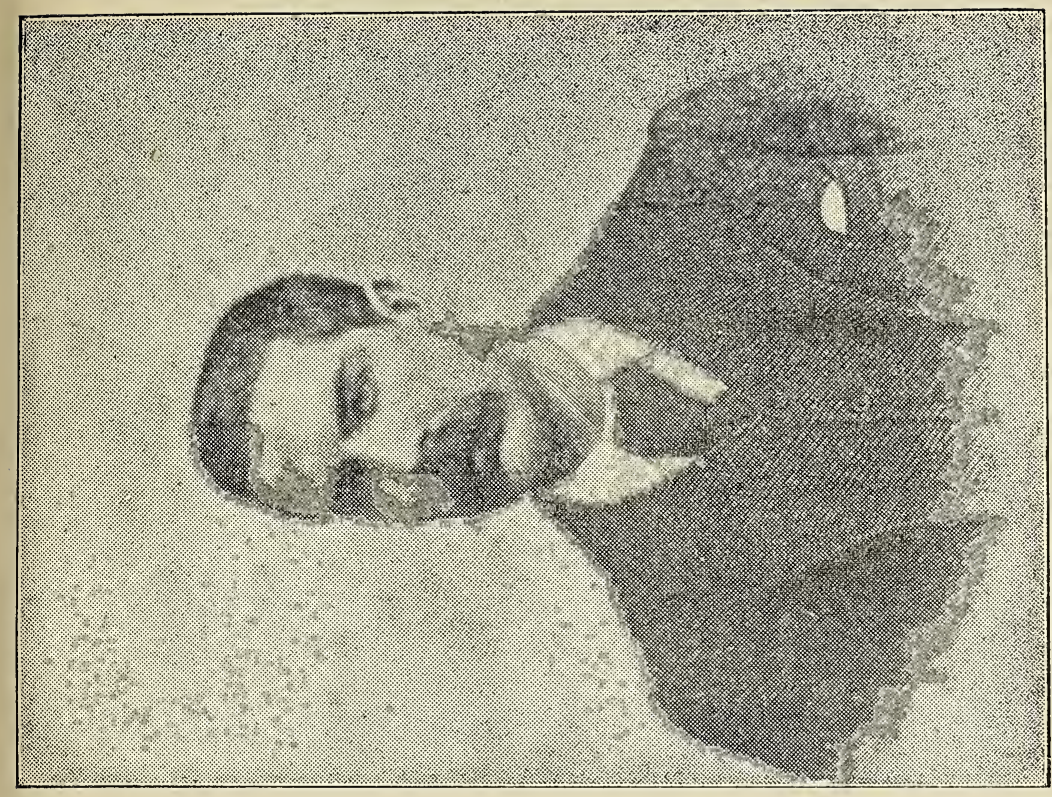

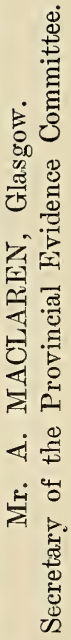

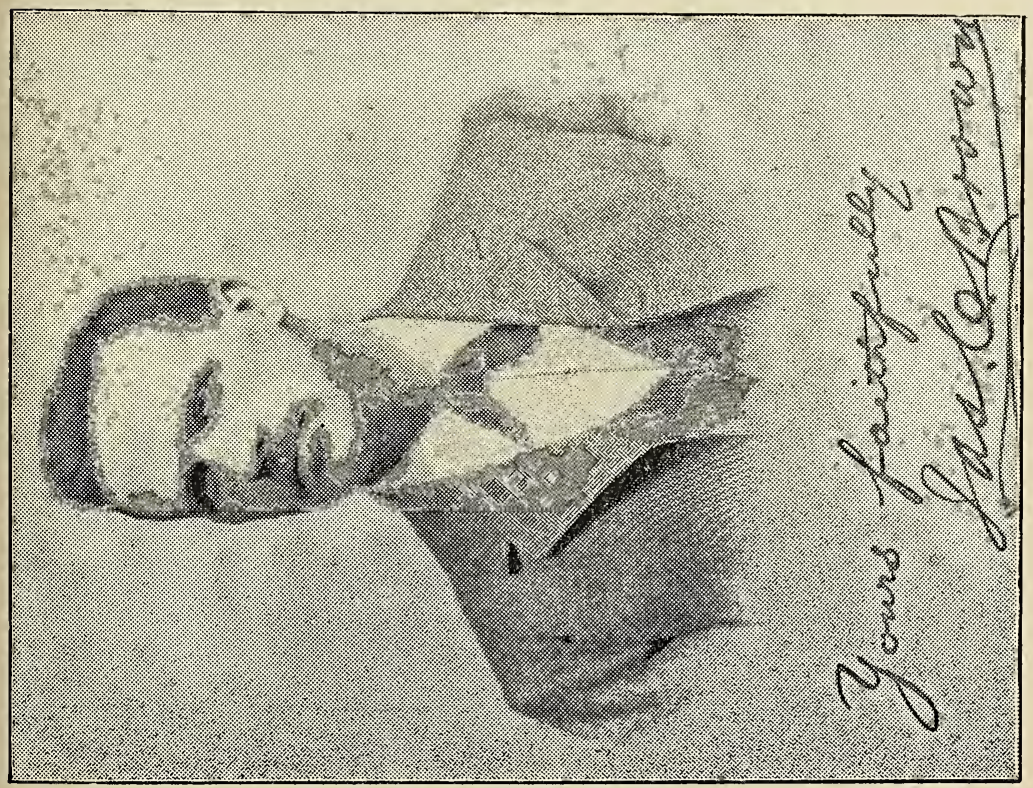

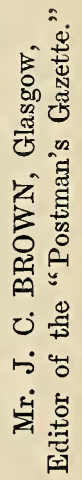



provide some badge of office to distinguish us from the general public, should not regard as wages the full cost of the articles. The subject of pensions is one which I do not propose to discuss, as I am confident that a subsequent witness will show how infinitesimal are the average postmen's prospects of a pension. A subsequent witness will also deal with the general question of promotion. So I will confine my remarks to a consideration of the prospects of promotion as enhancing the average postman's position-a matter alluded to by the late Postmaster-General (Mr. Arnold Morley). It ma.y turn out that the postmen have in the past been deprived of their proper share of promotion, and I hope that that will be one of the results of the Inquiry. But it is scarcely possible that such a large increase will be made to the postmen's list of higher appointments as will secure to every postman pro. motion as a matter of course. My own impression is that the conditions are such that $90 \mathrm{per}$ cent. of the postmen will end their service with the postmen's uniform still on their backs. I think the proportion would be more accurate if it were put a little higher. In Glasgow there are 524 established postmen and 202 auxiliary postmen, while, if we include sub-office postmen (i.e., postmen not employed at head office) we have 800 postmen at Glasgow. It seems highly improbable that there will be such a change from the existing order of things as to give promotion to even a small proportion of these without making sinecure posts. We cannot be parties to the advocacy of creating additional higher appointments, even though they should be intended to afford promotion to meritorious officers, unless such additional superior appointments are required in the public interests. With regand to Sunday pay, many men would rather be free on the Sunday and have the Day of Rest to themselves than have work, even though they are paid for it. Then, with reference to the regular nature of the employment which is urged as an advantage of the Post Office service, I would point out that, while to a man of reliable character the situation is permanent and the wages regular, there is the great fact remaining that we often have irregular and undesirable hours of attendance, and have frequently to attend to our official duties in time which ought properly to have been our own. This detracts considerably from the satisfaction of being in receipt of regular wages and in a permanent situation.

The Chairman: But think how many in outside employment have the same disagreeables to face.

A. Quite so. This is our staternent to the Department. There is no evirence of the uniformity of the application of the principle of the value of permanent employment in dealing with the cases of men inside and outside the Department.

Q. Take the case of a policeman. He has worse hours than you have?

A. Yes, partly so; his hours are not quite the same.

Q. And he has as responsible a place?

A. Even more so. He has to exercise so many functions. There is still another matter which is of interest to all postmen, and it is looked at by the Department as one of the most important emoluments connected with that branch of the Service responsible for the delivery of the letters-I mean the question of Christmas boxes. This, in my opinion, and in the opinion of very many of those most directly concerned, instead of being looked on as an advantage, should be treated as something entirely different, and openly discouraged, if not totally prohibited. For one thing, we submit that a system whereby the servants of the State receive private gratuities, which are looked as part payment for public services, is altogether wrong in principle, and ought to be abolished. This view was borne out by Mr. Raikes, who said:- "It has appeared both practical and advisable to prevent the extension of the system to other classes, and with this end in view the solicitation of Christmas boxes by Post Office servants other than letter-carriers is prohibited on pain of dismi Isal." This shows that exceptional legislation is made in the case of postmen which they do not altogether appreciate. 
The Chairman: Is the sum raised in Glasgow a very considerable one?

A. It varies very much according to the districts. In some of the higher districts it reaches $£ 16$, while in the lower districts it is not more than $£ 3$.

Sir F. Mowatt: Does that represent the two extremes- $£ 3$ and $£ 16$ ?

A. Well, in one or two cases it may be a little higher. We have no data to go upon.

The Chairman: Do you think the public would cease to give Christmas boxes if it were prohibited?

A. If they were prohibited I think they would. Glasgow's case is somewhat different from London. There we have no house to house canvass with a book.

Q. It is purely voluntairy on the part of the public?

A. Yes.

Q. Are the boxes asked for?

A. Not to a very great extent.

Q. Does not the postmen call at a house and say to the servant, "Will the master give a Christmas box this year?" I expect he does-(laughter).

A. It may be indirectly asked for, but it is considered mean to ask for it. It is preferred that it should be purely spontaneous on the part of the public. Perhaps this accounts for the lowness of the Glasgow rate. I believe that, taken altogether, the average will not exceed $\$ 5$ per man. The postmen on collecting duties have no Christmas box at all. I am only giving my own opinion. In dealing with this question I tl:ink that the general custom in Glasgow and other towns in Scotland that I am;aware of is not to allow solicitation. Many of us did not know it was allowed until rule-books were issued to us a few years ago, and in then we found it stated that it is allowed. Formerly our view was that we were allowed to accept but not to solicit. That the time has come for a change is shown by the fact that the public are allowing the custom to fall into disuse. They realise that the postman is a servant of the State, and doing the work of the State, and they argue, not unnaturally, that he should be paid altogether bys the State. Then, again, the system is not at all fair to the men themselves. Nowadays, with an increased number of deliveries, some districts may have three or more postmen in the course of the day. In London they have more, but I am referring to Glasgow. The public, of course, do not recognise one postman more than another, or at least. will not consider themselves indebted to one postmar. more than another. They cannot, therefore, be expected to give a tip to every postman, neither can book-sharing among the men themselves be expected. I may tell you that in Glasgow postmen do not share out the Christmas boxes.

The Chairman: And each man gets what he can?

A. Yes. It is quite true that the senior men on the walk consider that they have the first claim, as a matter of custom. The postmaster, not later than last week, said he would be disinclined to interfere in any dispute of the kind. In London, the postma/sters do adjudicate on these disputes.

Mr. Smith: Is there any agreement among the postmen as to who shall call at a particular house, or is there a sort of race between them?

A. There is no race. The man who goes there the most frequently in the day is probably the best-known and gets it, but it is a matter of chance in many instances. If only one gratuity is given at a house it is a matter of chance who gets it. It sometimes happens that an auxiliary going only once a dav may get as much as the regular postman who goes three or four times a day.

The Chairman: Perhaps he has got a friend in the house-(latughter).

Witness: The result is that the monies received as Christmas gifts come to bê very unequally distributed, and while they represent something to some men, they mean very little to others. Of course, that they may be partly accounted for by the absence of that continual reminider, "the book," which perhaps might keep them up to the standard of $5 \mathrm{~s}$. a week all round. There has been a large increase in the number of postmen. But there has 
been of late years a large shrinkage in the value of the Christmas boxes, both in respect to the amount of the individual "tips" and in the proportion of the public who continue the custom. Speaking in July, 1890, on the value of Cliristmas boxes, the lafe:Mr. Raikes said:- "I have been informed that very large sums fall to the lot of lucky postmen, and I have heard the average estimated at $£ 15$, and rising, in some cases to $£ 75$ a year."

Mr. Walpole: Is that so?

A. I have taken it from Hansard. Perhaps this accounts for the Raikes revision to postmen being less liberal than his revisions to other branches. I believe, however, that Mr. Raikes' information was greatly in error, and that the value of Christmas boxes was on that occasion over-estimated, at least, so far as some towns were concerned. Another decided disadvantage pertaining the system is that Christmas gifts are sometimes used as bribes to induce men to break the rules of the Service in various ways, such as giving letters in the street, even registered letters; putting letters under doors; giving information as to the affairs of business people; divulging removals of debtors; or otherwise exceeding their duties. For instance, if a man is in the habit of giving a $5 \mathrm{~s}$. Christmas box and he comes up to me in the course of the y/ear and wishes one of those things done, it would take far more nerve on my part to refuse him than to refuse a man who was not in the habit of giving anything. The system is nothing more or less than indirect taxation, of which the general public ought to be relieved, and which should be borne solely by the Department. For instance, there isI can speak only for Glasgow and not for the rest of the country-only a portion of the publia who give these Christmas boxes. They are, by this practice, paying a double share if it be the case that the postmen are receiving $5 \mathrm{~s}$. a week less by reason of this system, for that $5 \mathrm{~s}$. goes to the general revenue.

Mr. Smith: You say 5s. per week per man. You also told us the aqverage was $£ 5$ per man.

A. The Department estimated it at $5 \mathrm{~s}$. per week per man.

Mr. Walpole: Do you think the tendency is towards a shrinkage in the Christmas boxa?

A. Yes; if they are not asked for.

Q. And if they were worth 5s. a week in 1865, and there has been a shrinkage since, they are not worth it now?

A. They may be worth it in towns where they are collected with a book. But where they are not so collected they are shrinking. The Department might deliver a notice to the public to the effect that they were expected to make up the $5 \mathrm{~s}$. and advise them accordingly to pay it up-(laughter). Of course, I an not putting that forward as a practical suggestion. Still it is the logical outcome of the system. This system operates unfairly towards younger men and in poor districts, while the men in rich or business districts do well. I presume the theory of the Department is to show no favour to either rich or poor, so far as the Post Office is concerned. If this system is to be used in any way as a bribe to influence the manner in which a postman discharges his duty, it is quite possible that the officers in the richer districts would even exceed their duties as compared with the men in the poorer districts. Many men overwork themselves in order to keep walks which have grown to be too much for one man, becıuse thereby they have more opportunities of getting Christmas boxes. I have no doubt that if inquiry is instituted on this point by the Department confirmation will be forthcoming. The increase of 40s., which we now ask, if given, would willingly be accepted in lieu of Christmas boxes-I am, as to this, speaking on behalf of the provinces-and by this means the Service would be rid of a glaring anomaly and the men, while equally well paid, would be, all on one footing, and would have no inducement to favour one more than another of whom we serve. Since the introduction of the penny postage, the prepaid letter had been the staple 
source of revenue to the Department. In connection with the Post Office there is no other efficient class of men than the postmen. They form, indeed, the backbone of the Service, without whom it would be impossible to carry on the work. Again-I am speaking particularly of my own office at Glasgow-I maintain that the postmen's staff are as efficient in their duties as any other branch of the Service. Their wages, however, have not kept pace with the improvement made in the wages of other classes. This, to a certain extent, is due to the existence of the Christmas-box system, which I have already spoken of. Another probable reason is that the postmen are numerically a very large class, and to grant them even a small increase of pay involves considerable expenditure. And it so comes about that the Treasury, when the subject of rates of pay is under consideration, always seems to give a less liberal revision to postmen than to the other branches of the Service. That seems to be the objection, anyway. Any proposal to increase the wages of a small class seems to meet with less difficulty than is the case with such a large class as the postmen. There are so many points to be weighel up in the postmen's case that do not seem to be considered in the case of other classes. I have now endeavoured to show that the increase of wages is demanted by the nature of the work, is deserved by the way in which that work is performed, and by comparison with the other branches of the Post Office Service, and is required in order to replace what in former years was calculated as part payment, but is now being seen to be not only unjust to the great mass of the men and humiliating to the independence of their nature, but is also of less real value than it was some time ago. That finishes the statement I have prepared.

The Chairman: Have you not formed any opinion as to the amount it would cost?

A. Mr. Walsh is dealing fully with that.

Q. He has formed an opinion, then?

A. Yes. I may say the reason I am not dealing with that in my evidence is that we were working on different data and arrived at different figures. Approximately they are the same, but I should prefer to have only one set of figures used.

The Chairman: It has been calculate 1 to amount to about $£ 270,000$ a year.

Witness. Is that for provinces alone?

The Chairman: Yes : for the provinces alone without Iondon.

Witness: Yes; I believe it would come to that.

The Chairman: 'The provincial towns and the rural districts as well?

Witness : Yes.

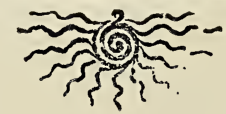


JOHN WALSH, Liverpool.

\author{
WAGES- \\ AgGregate-Speclal Cases-Liverpool.
}

Wesminsten, Monday, February 3, 1896.

Mr. John Walsh was next called.

The Chairman: You are a Liverpool postman, I believe?

A. Yes, my lord.

Q. How long have you been in the Service?

A. I joined in February, 1877.

Q. As an auxiliary?

A. I joined as an auxiliary. I was offered an appointment about five months before ait Aintree, but I refused it. I subsequently joined as an auxiliary at 18s. per week. I served in that capacity about five months. I had an understanding that I should be appointed postman, and was appointed on the 3rd August, 1877, also at 18s. a week. I got up to 20s., and then became a sorting postman in 1882, so that wages now, with allowances, are 41s. a week.

Q. You have three stripes?

A. Yes, I have three stripes afier 19 years' service.

Mr. Waipole: What allowances have you?

A. Ts. as a sorting postman, $1 \mathrm{~s}$ for each of three stripes, and $1 \mathrm{~s}$. for sorting. () 11 investigation in $188 \mathrm{i}$ it was found that Liverpool did more sorting than any other town in the United Kingdom. A gentleman was sent down from London to investigate the matter, and that was his report, and we consequently got a shilling increase all round. It was suggested that that should be withdrawn in 1891 .

Q. You get $7 \mathrm{~s}$. for indoor service and 1s. for sorting?

A. Yes, but a shilling will die out with the present holders.

Q. At any rate you get 41 s. a week now?

A. Yes.

Mr. Smith: How did you get up to that?

A. I entered at 20s. minimum. At that time 2s. were in jeopardy. The maximum for the whole Service was 26 s., with 2s. temporary. That was temporary then, but it was soon after made permanent.

The Chairman: What are the particular points you are going to take up?

A. I am first dealing with the wages question, mostly in the aggregate.

I will also deal with the pension question. To begin my case I have gone slightly out of the ordinary, as I wish to detail a special case in connection with the head office at Liverpool, which points to some of the difficulties of our work.

The Cliairman: Is it illustrative of the case of any part of the country?

A. I dare say it is to a great extent.

The Chairman: Your Liverpool business is, of course, different to the business in other parts of the kingdom, on account of the great amount of American mails to be dealt with.

A. Yes.

Q. Do these mails go into the hands of the postmen? 
A. Yes; we have to deliver the mails, and that increases our work. The men have a grievance on that score. They get no extra pay for overtime. The work is crushed into our ordinary work. Mr. Dowling will deal with that point more extensively. I have to complain that the work at the Head Office, Liverpool, is murderous. About eight months ago I substituted James Elliott on $12 \mathrm{C}$ walk (see b) ; the man was regarded as one of the strongest men in the Service. He died after about a fortnight's illness. I asked his sister what was the cause of his death; she told me the doctor put it down to hear't disease, but that he told her and the doctor that the heavy walk was killing him. She said from the time he went on $12 \mathrm{C}$ walk a few months before, he had vomited up his food through severe work. I did not find the walk above average in the mornings, but after a day's work on it I was only fit for bed.

The Chairman : Let us hear where this walk is, and what makes it so exceedingly hard.

Witness: I propose to describe the nature of the work at the head office later on. The point is that I can name more than one walk in the same predicament.

Sir F. Mowatt: You have been doing this walk?

A. No, sir; only on the occasion I have mentioned. I go from walk to walk. On the B side of the same walk the inspectors watch little committing suicide day after day in trying to cope with two men's work. I hold the man as guilty of dishonesty who presses the work of two men on one, as is a man who takes wrong change from a counter. Little carries from 40 to $90 \mathrm{lbs}$. of letters out on his delivery, and has had one hour extra duty for leaving this immense weight at the bottom of some stairs while he served the top offices. He has been operated on for a twist in the bowels at the Royal Infirmary. On one occasion, when the man was off, about six men, including inspectors, had to help the walk out.

Mr. Walpole: Has Little applied for relief?

A. He could not have relief. As Mr. M'Laren has told you also, one reason why the men thus sacrifice themselves is for the sake of the Christmas boxes.

Q. But assuming that he had applied for relief, would it not have been given him?

A. I am quite sure that it would not under the old regime, which has just passed away.

Q. Is it not a distinct rule of the Service that it shall be given?

A. I find that in London and Belfast the regulation is that in making a collection $35 \mathrm{lbs}$. shall be the maximum. That regulation is applied to walks in London and Belfast. It is not so in Liverpool. I was substituting on 14 $B$ walk, and weighed the bag on the first delivery for a week. On the 29th of November I had 47 lbs., on the 1 s't December 63 lbs. I was late' getting out, and was due to collect at 8.30 . I did not finish the delivery till near 9 a.m. I had to run for the collection, and was covered with sweat when I arrived at the office.

\section{Mr. Walpole: Did you apply for relief?}

A. I would not attempt to apply for relief or raise any difficulty. In Liverpool the rule has been to deny the postmen everything that they ask for. On the 3rd of December it weighed $58 \mathrm{lbs}$, , on the 4 th $59 \mathrm{lbs}$., on the 5 th $76 \mathrm{lbs}$., on the 7 th $58 \mathrm{lbs}$. I was so exhausted after these first deliveries that I could not sleep in the interval between deliveries, and on one morning had to take a bath to refresh myself for the work which followed. I had the bag on $16 \mathrm{~B}$ weighed on the 29th ; it weighed $63 \mathrm{lbs}$; on the Saturday it was over a hundredweight; on the 6 th it weighed $90 \mathrm{lbs}$., and on the 8th December $120 \mathrm{lbs}$. The inspector helped the man to lift it on his shoulder on the 8th December.

The Chairman: Are you quite sure of these facts? 
A. Yes, my lord. I have in each case a witness to the weighing of the bags. I am sure of the facts. They have taken the average weights in Liverpool over and over again, and I believe you will find that the whole office average over 40 lbs.

Mr. Walpole: What distance do you go to these deliveries?

A. The walk is about seven 'or eight minutes' walk from the post office, bnd we have to carry the bag up and down the stairs, for if we leave it at the bottom the outdoor inspector, who is on the watch, will get us from one to three hours' extra duty, for the risk we have run.

The Chairman: Can you give me the exact distance of the three several walks, the names and places where they start and finish?

A. That would only be giving the distance the bag has to be cavried. I cannot estimate the distance up and downstairs.

Q. I want you to give me some street to begin with?

A. From the head office to Dale Street is about seven or eight minutes' walk; that is $14 \mathrm{~B}$. Then $12 \mathrm{~A}$ is just at the back of the Exchange-0ld Hall Street it begins at.

Q. Where does it finish?

A. It serves Old Hall Street, Queen Street, and Brook Street, and, on the other side, Old Hall Street; $12 \mathrm{C}$ serves Edmond Street and Ormond Street.

Q. How long does it take on the average to complete the delivery on the $12 \mathrm{C}$ walk?

A. I should say it takes from about half-past seven to a quarter to nine. The work has grown up immensely in Liverpool, so that the men have had practieally to bulk the letters into the boxes without looking through thøm outside.

Q. Then the first delivery takes about an hour and a quarter?

A. $\mathrm{Yes}$, sir.

Q. How many deliveries are there on that walk in the course of the day?

A. Three deliveries.

Q. And what length of time do the following deliveries take?

A. There is a mid-day and an afternoon one. For the former we are due at the office at 11, and we finish it just on one.

Q. How long would you be kept before you get the letters?

A. No time at all. They are ready immediately we go back to work.

Q. Do you mean to say that the mid-day delivery takes two hours?

A. C duty commences at 11 and finishes at one.

Q. You take two hours to do the same duty in the middle of the day for which you take only $1 \frac{1}{4}$ hours in the morning?

A. The carriers take a double proportion in the day-time.

Mr. Walpole: A longer walk?

A. Yes, a longer walk but less letters.

The Chairman:: Were all these heavy weights on the early morning do. livery?

A. Yes.

Q. And what length of time does the evening delivery take?

A. About the same; we finish at five or half-past. We are due to collect at 2.45 , and finish at half-past five.

Q. What really occurs is that you have the first delivery, then a collection duty, and then a delivery duty? Is not that so?

A. Yes.

Q. And only three duties a day?

A. Yes.

The Chairman: Then the distance of these particular walks from the head office is not very great.

A. No, the distance of none of them from the head office is great. Nearly the whole of the heavy work of Liverpool is centred in the western district.

Q. How many flights of stairs are there to go up?

A. I cannot answer that question. 
Q. Weuld it be 50 ?

A. I am not prepared to say. I should think that on this walk there are about 400 lots of letters to deliver, and there is a tremendous lot of stair climbing.

Q. You heard some of the evidence received to-day, which rather disputed that a stair-climbing walk was more fatiguing than one on even ground. Is that your opinion?

A. I should say stair-climbing would be more exacting, but I see no reason why there should be a difference in the payment. I should say that the physical strain would be much greater. As a matter of fact, we have had several men at Liverpool sent by the Medical Officer to recruit their health on walks where there is no stair-climbing. On the 5 th $\mathrm{I}$ had $1 \mathrm{~A}$ weighed; it weighed $63 \mathrm{lbs}$. Man after man has told me he would sooner be dead than the present slavery should continue. I have to ask that the door at the east entrance of the Hearl Office, Liverpool, be opened for men coming in with collections. This imposes an extra minute or two in walking on the men, which has not been added to the times allowed for collections. I have to request that the postmen doing most walking work be situate on the ground floor in the new office, or that a hydraulic hoist be provided. Men now have to carry from 40 to $120 \mathrm{lbs}$. of papers and parcels up a long flight of stairs. I have to request that stone tables be dispensed with in the new office for men to eat from, and that the kitchens have fires in winter, as have the clerks; the indoor men are now starved to death in winter. I must point out that conviction for irregularities is made easy in the postmen's branch by the documents relating to the cases being withheld. The sorting clerks and indoor postmen are furnished with the whole of such documents, and the postmen claim similar treatment. A few years ago I had an explanation in C.B. for mis-sorting a letter. I looked up the case and found, though a postman in W.D. had regretted the error, etc., the letter could by no possibility have reached the man's hands. In another case I had an ixplanation for mis-sorting to E.D., but on opening the case $I$ found the letter had not been mis-sorted, but dropped in ine E. district. Had I been an outdoor man I would not have seen the papers, and, as is usual, would have regretted, etc. I ask that the outdoor inspectorship be abolished as an anomaly and canse of unnecessary irritation to the men. Only about three or four towns have these positions yet, the remainder ido very well without them. The spy system lately introduced in the American P.S. is causing unlimited vexation and confusion, and I have here a paper containing extracts from independent American journals in regard to this. I call attention to slight offences of postmen being exhibited on notice boards, while no such usage is in practice ast regards clerks, also that men are subjected to petty annoyances. I have here a docket which I offer as an illustration. You will observe it is marked in blue lead pencil, while the postman has to mark in his walk in red ink before he goes out. If he takes out the docket without having on it the blue lead mark, or without himself marking it with red ink, an explanation will be called for, so he has to walk back perhaps a mile and a quarter to get it marked.

The Chairman. But surely it is not a difficult thing to carry out that instruction?

A. No, but it causes unnecessary irritation.

Q. Why?

A. That he should have to do it. If a man in the office takes out the docket without being so marked he has to give an explanation. Only the other day a man was so vexed by this red, white, and blue business that he spoke rather impertinently. That was no doubt caused by irritation.

Q. Where does the irritation come in?

A. At having to do this thing. 
The Chairman : But unless the docket is properly numbered it would be of no use.

A. Under the old system we could mark the dockets outside on the wallss, or when we had finished, in pencil, and it is quite sufficient.

Q. What is the grievance?

A. The inspector writes on it in blue, and the man has to put the number of his walk and section in red ink. If this condition is not complied with the man has to give an explanation.

Q. The inspector does the blue figure?

A. Yes, and if the man takes the docket out without that blue figure on it he will be punished. This system only appertains to one office-the Head Office in Liverpool. It is not common to the remainder of Liverpool.

Mr. Walpole: What occurs is that the inspector serves out the delivery return in blue, and the man has to fill it up in red?

A. Yes.

Q. And the grievance is that?

A. I am only giving it as an instance of the petty annoyances the men are subjected to.

Q. Do you mean that the annoyance is the requirement to write in a particular coloured ink?

A. It is having to do something exceptional.

Q. The requirement to write in red ink?

A. Yes; a man cannot have red ink on his walk, and if it goes in without red ink it is a proof that the condition has not been complied with.

Sir F. Mowatt: If he does it in red ink before he starts there is no diffi. culty?

A. No; but then it is possible for human nature not always to remember.

Mr. Walpole: Do you put that grievance on the same level as the carrying a weight of 120 lbs.?

A. No; I only give it as a small matter.

Q. You do not attach equal importance to it?

A. No, sir. Mr. Bednall asks for 2s. allowance to sorting clerks while performing night duties. The highest rate of night duty in the C.B., Liverpool, is worked by sorting postmen. The head office men work 14 weeks out of 24 on night work, that is 58 per cent., yet have only 12 idays' annual leave. In addition, they are ordered, when required, to work overtime after night duty on one of the monster walks I have described. There is an instruction by the late Postmaster to superintendents in C.B. not to work a night officer on overtime after his night work, yet this is no protection to sorting postmen. Manchester and Birmingham, by a little forethought, do without making their night duty men take out walks. Early in '91 a Secretary's order was issued in Liverpool informing us that Bank Holidays, when they began or ended the annual leave, would be allowed for by an extra day being added to a man's leave, but not when they occurred in the middle of such leave. This order was observed in Liverpool till last year, when the holidays were changed to begin on Sundays instead of Mondays, to do us out of the day. We found London and Dublin were honourably observing the Secretary's order, but Liverpool were treading it under foot. We had one of our M.P's. to intervene, and the old state of things was ordered to be restored, yet, to our amazement, the August batch were actually changed from the Monday to the Tuesday. I ask how we are to know where twe stand if local authorities act in this manner? We have sent on about 40 names of Postmasters and superintendents who have sons and daughters in the P.O., Liverpool, in higher positions as compared with about three children in of the postmen. We do so to show that a public benefit is being used for private friends. A case has been told me of an inspector making an offer to a foreman in a telephone company to befriend his son, on condition the foreman gave employment to the inspector's brother. Overtime for Sundays, 
Christmas, and even the boot allowance is held over and paid with the wages in order to have a penny stamp out of postmen. The reverse treatment is meted out to the sorting clerks at Liverpool.

At this stage the Committee adjourned till Thursday.

Westminster, Thursday, 6th February, 1896.

The Departmental Committee on Post Office Administration resumed its sittings to-day (Thursday) in the House of Lords Committee-room. Lord Tweedmouth again presided. All members of the Committee were present, and the room was crowded by Postmen, who evinced a lively interest in the proceedings. The whole day was occupied with the taking of the evidence of Mr. J. Walsh, of Liverpool, and the proceedings proved pretty lively at times, as the Committee objected to receiving certain evidence by means of which the witness sought to rebut the claims of another class of P.O. employees.

Mr. Walsh, having taken his seat at the witness table, was examined by Mr. Spencer Walpole as follows:-

Mr. Walpole: You said on Monday, "About eight months ago I was substitute for James Elliott on $12 \mathrm{C}$ walk. He was regarded as one of the strongest men in the Service. He died after about a fortnight's illness. I asked his sister what was the cause of death, and she told me the doctor put it down to heart disease." Do you know the circumstances of Elliott's death?

A. No more than that, sir.

Q. Do you happen to know that a few weeks before his death he suffered from a very severe attack of influenza?

A. No, sir.

Q. Then you do not know that he resumed duty against the express advice of our medical officer?

A. No, sir, I do not.

Q. And you do not know that he died of bronchitis?

A. I only go by what his sister told me, sir.

Q. Will you accept it from me-and I have it in the report of our medical officer-that the cause of death was bronchitis, contracted through resuming duty too soon after an attack of influenza?

A. I will accept it. Of course I rely upon the statement given to me.

Mr. Smith: Do you mean to say that you have any: evidence to support it?

A. I have only the statemen't of the sister. Of course we know all about Elliott. I worked with him and saw him.

Mr. Walpole: Do you know his sister?

A. I had never met her before, nor have I done so since.

Q. Do you know anything about this particular walk on which Elliott was employed?

A. Yes, I do.

Q. Do you know he was put on it on his own application?

A. I do, sir.

Q. Do you know he never made any complaint that the walk was too heavy?

A. I can quite accept your statement, that he would not, sir.

Q. Are you quite aware he never made the slightest complaint, either to the inspector or the medical officer, that the work was too heavy?

A. If he did not make it to the medical offeer, then his sister's statement in that particular must be wrong. 
Q. I am advised that he could have had a lighter walk if he had so desired, but that he never gave the slightest hint to the inspector or the medical officer that the work was too hard. Will you accept that statement from me?

A. Yes, sir, I will.

Q. It was the $12 \mathrm{C}$ walk he was on, was it not?

4. Yes, sir.

Q. Do you know the man employed on it now?

A. I do, sir-Richardson.

Q. Do you know he has told the inspector that he has not any fault to ficul with the walk as regards the first delivery, which is heavier than the subsequent deliveries?

A. That is my own statement, sir; but I say that the work for the whole lay is too much for one man.

Q. You say, further, that on this walk there is a great deal of climbing staircases.

A. No, sir. That is on the other side of the same walk.

Q. It is waik $12 \mathrm{CI}$ am referring to.

A. Yis: anc: a man would have to do the other side at the mir-day delivery. He would then take both sides and have a tremendous lot of stairclimbing.

i). Lit 1 am advised that this walk is particularly free from stairs?

A. I told you in my opening statement, sir, that $I$ did not find it ahove the arrege.

Q. 'Tisen upon that point you have been reported inaccurately?

A. That was my statement-that it , was not above the average in the morning.

11. Now let us come to the B side of the same walk.

4. It siluuld be A side.

Q. But I ou say "On the B side the inspector watched Little commuring suisicle""

A. I should have said the A side.

Sir F. Mowatt: Is that the walk of which you have been speaking?

A. Yes, sir; it is the same walk. It has four different sides.

Mr. Walpole: You say that Little carries from 40 to $90 \mathrm{lbs}$. of letters on the delivery, and has had one hour's extra duty for leaving that immense weight at the bottom of some stairs while he served the top offices. Do you know that of your own knowledge?

A. Little communicated to me that he had had an hour's duty for the bag being found at the bottom of the stairs. What weight was in it, when it was found, I do not know. It is generally said by the men that the outdoor inspector, in order to make sure of a conviction, allows the men to go over the heaviest portion of the walk, and then will find the bag at the bottom of the stairs, when it is light 'enough to complete the charge against the postman.

Q. Are you rightly reported in saying Little was punished with an hour's extra duty for leaving that "immense" weight at the bottom of the stairs?

A. Yes, sir, I am rightly reported.

Q. Are you aware that, at the time, the bag did not weigh above $20 \mathrm{lbs}$.?

A. I was not aware of it at the time, but I have heard it since.

Q. Will you accept the statement from me?

A. I will accept it, sir.

Sir F. Mowatt: Then, since you made that statement, the "immense weight" has come down to $20 \mathrm{lbs}$.?

A. Allow me-

Q. Answer the question first, please. You said he had "an hour's extra duty for leaving that immense weight at the bottom of the stairs." Do you think you were justified in describing 20 lbs. as an immense weight? 
A. Will you allow me to complete my statement? When I said that an immense weight was left at the bottom of the stairs I was not aware at what point the inspector found the bag. I have been made aware of it since by a communication from Liverpool.

Q. Have you been made aware since that the man on that occasion was not going upstairs at all, but was simply going down to the basement?

A. That makes very little difference. He would have had to climb the stairs again. Even if the baig only contained $20 \mathrm{lbs}$. weight, that does not completely explain the case, because, when he left it at the bottom of the stairs, the man would probably have had to take three or four bundles of letters in his arms in order to deliver at the different offices, and therefore the weight of those bundles ought to be added to the weight of the bag.

The Chairman: He would have served probably the whole building above before he went to the basement, surely?

A. It is not my? custom. I do not know what Little's custom was, but I served the basement first in order to get rid of the stuff. Of course I do not know what little's mode of doing the work was.

Q. But he would not take down to the basement the bundles he was afterwards going to take to the top of the building?

A. Yes, he would probably do so in order to save opening the bag a second time. In order to facilitate delivery he would talke out of the bag all that was required for the building he was about to serve.

Mr. Walpole: Are you aware that the place where his bag was left was an exposed place, and that the bag might easily have been taken by any: passer-by?

A. That is not what I am complaining about.

Q. Do: you think there is anything unreasonable in punishing a postman for leaving a bag $20 \mathrm{lbs}$. in weight in a place where any passer-by miglit take it?

A. My complaint against the authorities is this-they are well aware that these heavy weights are now being carried, and they know it is impossible for the men to carry them up and down the buildings, yet they send round an outdoor inspector to lash the men into doing what is an impossibility".

Q. Are you aware that I had the bag on that particular walk weighed yesterday, and that it weighed $53 \mathrm{lbs}$.?

A. I an: and I have a telegram here giving to-day's weights as tested by the men on duty.

Mr. Walpole: Your allegation was that the bags weighed from 40 to 90 lbs.?

A. That was an approximate statement.

Mr. Walpole: I edmit that $53 \mathrm{lbs}$. is too heavy; I am not justifying it.

A. Thank you, sir.

Q. You said that Postman Little had undergone an operation for a twist of the bowels, but you omitited to state when that was?

A Voice: About two years ago:

Q. Do you happen to know that it was five years ago?

A. I cannot fix the time. I merely made the statement as it was given to me. It was generally' believed by 'the men at the office that it was due to overwork.

Q. Do you happen to know that Little, at that time, was away for rather over two montlis, and that he lias not been absent a single day through illness since?

A. I cannot say as to that; but I myseri have only had six days' sick leave in 19 years. I do not believe in sickness ; I believe only in being a dead man or a live man. I think the evidence which has been given about sick absence is not worth considering, nor is it a fit basis for statistics.

Q. I am not desiring to defend excessive work; I am only anxious to correct any misapprehension which might arise from what has been said. 
A. And I, too, hope that you will kindly accept my statement that $I$ am only anxious to get at the truth, and if there is any defect or error in my statement I shall only be too pleased if it can be found out. I do not want you, gentlemen, to act on anything but the truth.

Q. Now I come to your own case-to your own experience on the $14 \mathrm{~B}$ walk. You told us that the weight of ithe bag on that walk on the 1st December was 63 lbs.?

A. No, sir. The first date I gave was when the weight was $47 \mathrm{lbs}$.

Q. Very well, I will take it your way. On the 29 th November the weight was 47 lbs.?

A. Yes, sir.

Q. And on the 1st December it was $63 \mathrm{lbs}$.?

A. Yes, sir; but I may possibly be wrong in my dates.

Q. As a mitter of fact, you were not on duty on the 1st December, were you?

A. Possibly I am wrong in my dates. I took a very hurried note.

Q. It is quite natural you may have made a mistake as to the date. Now, dil you make application for relief on any of those days?

A. No, I did not; but I wals assisted on one occasion, not because of the heavy weights, but because the inspector thought there would be reports through late delivery. I was assisted on that one morning, but I never asked for assistance, as I do whatever work is set me.

Q. Why did you not ask for assistance?

A. Well, when assistance is given it does not produce a proper state of things. There are men in the Service, especially in Liverpool, who take everything they can get in the shape of big walks, and farm them out to assistants in order that they may get all the Christmas boxes. I believe it will be admitted by the authorities in Liverpool that they have actually had to punish men for trying to get more than their own walks to deliver. I want this state of things to be thoroughly understood. I want it to be realised that the system of Christmas boxes act against the men as well as against the Department.

Q. Then, it was the knowlelge that a portion of the Christmas boxes would be forfeited that prevented you applying for assistance?

A. No, sir. I do not get any Christmas boxes at all. It affects some men, but it does not affect me.

Q. Then why did you not apply'i for assistance if you had no interest in the Christmas boxes?

A. I did not apply for assistance simply because the Inspector in all probability would have said to me, "Walsh, if one man can do this work, you can." I feel that I must not be behind others in doing my work.

Mr. Smith: You think it would have been refused?

A. It would have been refused or reflected upon.

Mr. Walpole: Now I come to the 16 B walk, which you refer to.

A. Yes, sir.

Q. You state 1 that on the 29 th the bag weighed 63 lbs.?

A. Yes, sir.

Q. And that on the next day it weighed one hundredweight?

A. Yes, sir.

Q. And that on the 6 th it weighed $90 \mathrm{lbs}$., and on the 8 th December it weighed 120 lbs.?

A. Yes, sir. I did not weigh the bags myself, but the man who was on the walk did so, and it was witnessed by another man. I believe that on the first occasion, when it weighel 63 lbs., I did weigh it.

Q. Quite so ; but again I think, probably, you have made a mistake, as the 8th December was of Sunday?

A. I have very probably made some mistakes in the dates, but not in the weights. I took very hurried notes. I was overworked at the time both 
Hby the severity of the work of the office and the getting up of this case. Still, that is a small matter in connection with this general statement.

Q. I believe it is perfectly true that this walk is a very heavy walk, but is it not a fact that there is always a hand-cart available for the postmen on duty?

A. That has not always been the case. It has only come into operation in late years.

Q. But you are talking of last autumn. Was not the hand-cart available at that time?

A. Certainly the men had a hand-cart on the mornings I speak of, but by the rules of the Service we are, obliged to take the bag up and down the buildings. The hand-cart is not always supplied. I believe it is only available two or three mornings a week, and if a man comes out before the handcart starts or after it leaves, he has to carry the bag himself. On the $14 \mathrm{~B}$ walk, as I mentioned before, I had to carry the bag every morning.

Q. Is it not a fact that on all these occasions that you mention in December last the hand-cart was available?

A. Yes, and I believe it was used.

Q. Is it not a fact that on all these occasions, and especially on the 5th and 8th December, when there was these very heavy weights, the handcart could have been used?

A. Yes, probably that would have been the case.

Q. I admit it was a very!heavy weight, but was it not due to the fact of the arrival of the American mails?

A. Yes; and during the two months preceding Christmas the work was very heavy.

Q. Is it not a fact that the men on duty have only to carry the bag from the first floor down to the ground floor, and then out to the hand-cart, and that they do not have to carry it on any other occasion?

A. They have to carry it from the first floor to the ground floor, and then to the hand-cart, but after that they wh with it upon their delivery.

Q. I am advised that they only have to carry it from the first floor to the ground floor.

A. But in addition to that they have to carry it while serving their walk. The Chairman: Then how does the system work?

A. The han 1-car't only goes as far as the Exchange, and then the man takes his bag out of it. It is only for a few very heavy bags.

Q. What is the object? Is it to take the bags from the office to the commencement of the walk?

A. Yes, sir.

Q. And at the commencement of the walk the postman takes the bag on his shoulders and goes up and down each staircase with it?

A. Yes, sir.

Mr. Walpole. Then it is not the same as the Parcels Post, in which the postman takes the hand-cart from house to house?

A. No, it is not, sir. The postmen sometimes find it of very little use, because it starts before they come out. It only takes six or seven bags.

Q. You also stated that you never think of applying for relief in Liverpool?

A. Yes, sir.

Q. And you add that "The rule there has. been to deny everything the postmen ask for"?

A. Yes, sir.

Q. Do you adhere to that statement?

A. I do, sir. I adhere to that statement.

Q. Do you mean that everything the postmen ask for is refused? 
A. My own experience is that there is a set "No" to every application from the men. I have spoken to many of them, and that is the invariable answer I have received.

Q. Does that apply to everything?

A. I do not say that.

Q. Is it not a fact that you applied in May last for special leave to attend a postmen's meeting in London?

A. With regard to personal matters of that kind I have been rather kindly treated.

Q. Is it not a fact that you tendered a vote of thanks to the Postmaster of Liverpool for lis kindness on one occasion?

A. Yes; and I am glad to tell all that can tell in favour of the Postmaster as truly as all that tells against him.

Q. But in your last evidence you did not tell very much in his favour.

A. But my evidence wants to be completed. I do not think that you will feel that the condition of the Liverpool Head Office is one that particularly reflects credit upon the responsible authority. I am very sorry indeed to make this exhibition of the office.

Q. You say, "I have to complain of the work at the head office as murderous"?

A. Yes, sir.

Q. Is it not a fact that no man at the head office works more than eight hours a day, and tlat the average amount is rather less?

A. That may be the amount of attendance, but the men live a great distance from their walk, and they feel that they ought to have some credit for that. I do not think the work is over the average in point of hours.

Q. Then it is not "murderous" in respect to the length of the work?

A. No, sir; it is the severity of the work.

Q. Is it not a fact that the men on the two heaviest walks have been on the same duty, one for twenty and the other for thirty years?

1. Do you mean Little and Morrison?

Q. I do not know the names, but is not that the length of the service?

A. I know that the man on A walk is periodically away for three, or even five weeks during the heaviest seasons-during the principal seasons for the fruit and provision trades, and one merchant said to the substitute that he did not know how it was that the Department allowed this kind of thing to igo on year after year, without taking notice of it, for he, as a provision merchant, was considerably inconvenienced through new men coming on to the district so frequently.

Q. I want to ask one other question. Will you take it from me that all the bags were weighed yesterday morning?

A. Yes, sir; and I have a telegram saying that they were weighed again this morning.

Q. Is it a fact that no bag weighed above $68 \mathrm{lbs} . ?$

A. I have not the figures of yesterday. I have only those for this morn. ing.

Q. Will you take it from me that the average weight of all the heavy bags was only 39 lbs.?

A. That would be a very moderate statement. I think my statement ir my own evidence was that it would be about $40 \mathrm{lbs}$. One ought to do these things very deliberately in order to arrive at the truth. The weights should be taken regularly for weeks and even for months, and should include the first and last days of the month, and first and last days of the quarter. In the present instance things have been done much more rapidly.

Mr. Walpole: You will quite understand why we have done things rapidly. I was anxious to test to-day the evidence you gave on Monday, and, there. fore, it was necessary to be rapid.

A. Not, I liope, anxious witl the intention of getting the upper hand of me, or of tripping me up? 
Q. You will have seen by the questions I have asked that I have tried to put it fairly?

A. You liave, sir.

Q. And I/have taken steps to give relief where relief is required.

A. Thank you, sir.

The Chairman: I suppose it is only on individual walks that individual men have to carry these heavy weights?

A. It is very general in the head office. There are very few exceptions.

The Chairman: You told us in your evidence that the average weight of the bags is $40 \mathrm{lbs}$. If the average weight is $40 \mathrm{lbs}$. it stands to reason that there cannot be a very great number of heavy bags. Is not that; so?

A. Well, it stands to reason that the heavy bags must be very heavy, as there are some walks where a man has to carry only 7, 11, or $13 \mathrm{lbs}$, , therefore the other bags must be wery heasy.

Q. There cannot be very many of them. How many bags go out?

A. I should say that the whole of the second section was very heavyNos. 9 to 16.

Q. How many bags do you include in the number on which you take your average of 40 ?

A. Roughly, I should say 16.

Mr. Walpole: Do you mean that, roughly, 16 were over the average?

A. Yes.

The Chairman: You yourself use the term "average," and put it as $40 \mathrm{lbs}$. per bag. Do you take that average from a series of 16 bags?

A. With 16 bags the average is $40 \mathrm{lbs}$.

Sir F. Mowatt: But there are more than 16 bags carried through Liverpool, are there not?

A. Oh, yes, sir.

Mr. Smith: The point is not quite clear yet. Do you mean that the average of $16 \mathrm{batgs}$ is $40 \mathrm{lbs}$, or that there are $16 \mathrm{bags}$ with $40 \mathrm{lbs}$. and upwards?

A. I am giving the average in every case.

Q. Then there are some less and some more than $40 \mathrm{lbs}$. in those 16 bags?

A. I go farther than that, and say I believe there are certain mornings when the ifverage iweight for the whole office and for every man would ba 40 lbs.

Q. That is on special days?

A. Yes, sir, and at certain times of the year.

Q. And you say that would be the average weight for the ; whole office, taking the light walks as well as the heavy walks? And on ordinary days you say the average would hold good for at least 16 bags?

A. I think so, sir. I have here a telegram which I received just now, giving the result of the weighings of the bags this morning. It is as follows :

"Men weighed bags this morning. Result-Walk $13 \mathrm{C}, 39$ lbs.; $8 \mathrm{C}$, 36 lbs. ; 9 A, 52 lbs.; 11 C, 40 lbs.; 9 B, 43 lbs.; 12 A, 50 lbs.; 9 C, 60 lbs. ; 10 C, 53 lbs. ; 11 B, 75 lbs. ; 13 B, 46 lbs. ; 15 B, 43 lbs. ; 4 B, 43 lbs. ; $1 \mathrm{D}, 57 \mathrm{lbs}$; $12 \mathrm{C}$, (the walk about which there has been so mucl talk), 54 lbs.; $9 \mathrm{E}, 43$ lbs.; $16 \mathrm{C}, 40$ lbs.; 14 B, 52 lbs.; 14 A, 42 lbs. ; $10 \mathrm{~A}, 70$ lbs.; $16 \mathrm{E}, 49$ lbs. ; $1 \mathrm{~B}, 53 \mathrm{lbs}$; $16 \mathrm{~A}, 49 \mathrm{lbs}$. ; and $16 \mathrm{~B}$ (the walk as to which I stated the weight was $120 \mathrm{lbs}$.), was this morning 103 lbs."

Mr Walpole: It was 62 lbs. yesterday.

A. Yes, the last bag weighed to-day was $11 \mathrm{~A}, 53 \mathrm{lbs}$. There are some words attached to the telegram which I do not quite understand, and, therefore, I will not put them in.

The Chairman: What, in your opinion, would be a weight which a man could satisfactorily deliver? 
A. Before I answer that question I should like to clear up a misapprehension which has arisen from the way in which the press reported my evidence last Monday.

Q. But what do you think would be a fair weight?

A. I think $30 \mathrm{lbs}$. would be a fair weight.

Sir F. Mowatt: Is not that the general limit?

A. I think $35 \mathrm{lbs}$. is the limit in Belfast and London.

Mr. Walpole: You do not think that the Department enforce that limit unreservedly in London and the rural districts?

A. No, sir, I do not think so. Bu't the Chairman is asking me to indicate if there could be any set weight.

The Chairman: It is absolutely impossible to say that a bag shall weigh so much and no more, morning after morning.

A. Will you permit me now to correct a statement which has been reported in the press, and has given rise to some misapprehension? It is as to bulking letters into the letter-boxes. The statement in the press was given as if the practice of bulking the letters into the boxes applied to one particular walk. It appeared as if it only applied to $12 \mathrm{C}$ walk. As a matter of fact, my experience in Liverpool during 19 years is that it is the common practice. There are more letters to deliver now than at the time we were accustoined to look them through. The work has grown so greatly that we have had to put the letters in bundles in the boxes, for, if we were to attempt to go through them at the doors it would be 10 o'clock before the first delivery was finished, instead of 8.30 or 9 .

The Chairman: But before you start you tie up the letters in bundles, do you not?

A. Yes, sir.

Q. Before you start from the office?

A. Yes, sir ; we sort them all there.

Q. And therefore all you fail to do now is to check that sorting at the particular house of delivery?

A. Yes; we do not go over it again. Sometimes the sorting has to be done under an artificial light in the sorting-office, and therefore it is a great advantage to check it in the clear daylight outside.

Q. Still, I suppose you will not say that $40 \mathrm{lbs}$, or even more, would be too great a burden to put on a man ion one of these comparatively short walks from time to time?

A. Well, it, would be better in order to safeguard the man to make it $35 \mathrm{lbs}$. The rule not to exceed that is strictly carried out both in London anl in Belfast. There, whenever the bag is over 35 lbs., assistance is given.

Mr. Walpole: Of course, thait is subject to the possibility of affording assistance. It is not always possible, even in London, to help a man on the occasion of a heavy delivery?

A. No, sir, and we do not want to handicap the Department unduly.

Mr. Walpole: I only want to correct an impression you have probably given rise to. There are occasions when it is impossible to give this relief.

1. Well, if there is a set rule we should try to work up to it.

'The Chairman: You had better proceed with your statement now.

Witness : My lord, in assisting Mr. M'Laren to lay before you causes why postinen throughout the country should have better wages, I ask only justice and not privilege. Justice is represented by a pair of scales; the Government employer I regard as the balance; if the balance favour the right side or the left, it is the cause of deprivation to the side not favoured; if its lines or laws are not straight, and subjects at a distance suffer by reason of the greed of opposing sections, the balance, by being rightly informed by the sufferers may, if willing, again become a true dispenser of justice. My lord, justice can know nothing of privilege. The judge who hangs one criminal and favours another by dismissal from punishment, for a like offence, 
murders the one he has executed. I find there are 24,556 postmen established in the United Kingdom, and that their arerage wages at the maximum is $£ 1.5 \mathrm{~s} .5 \frac{3}{4} \mathrm{~d}$. a week, their minimum $16 \mathrm{~s}$. $0 \frac{3}{4} \mathrm{~d}$., and their mean wages $£ 10 \mathrm{~s}$. $11 \frac{3}{4}$ l. per week. There are 500 at fixed wages, whose average is $14 \mathrm{~s}$. a week; several of these receive $10 \mathrm{~s} .6 \mathrm{~d}$. and $11 \mathrm{~s}$. per week, and two at Kendal get 3s. 6d. per week each, while one at Clitheroe gets 4s. a week. I take these from the estimates. There are 9,900 postmen at a maximum of $22 \mathrm{~s}$. $p$ mun of $15 \mathrm{~s} .4 \frac{1}{2} \mathrm{~d}$., and a mean wage of $17 \mathrm{~s}$. $7 \frac{1}{4} \mathrm{~d}$. per week.

Mr. Walpole. Are you dealing solely with established postmen?

i. Yes, solely with established postmen. I have nothing to do with the auxiliaries at this point.

(). And you are dealing with the whole of the United Kingdom?

A. Yes, sir.

Q. I suppose there are allowances?

A I was under the impression that in the estimates no man was included unless he was an established postman.

Q. Bit, the auxiliary postmen certainly must come in.

A. I believe that in the estimates for the provinces so much is allowed for auxiliaries, but so far as Iondon and Dublin are concerned the auxiliaries are nalueri.

Q. A man at 4 s. a week must be an auxiliary ; that stands to reason.

A. I simply go upon the estimates. On communicating with Clitheroe I found the man got 9s. for doing extra deliveries. We complain that men are taken on at very small wages, and then some other allowances are piled on them in respect of which they get no pensions. I have here a letter from the place stating that it is correct that this man got an allowance for doing two extra duties.

Mr. Walpole: He must be an auxiliary?

A. Well, I do not think anyone is included in these estimates except those on the establishment. I believe the heading is "Established Postmen." I find inconsistencies neither based on reason or justice, in the aimless method of paying postmen doing similar work in the various towns dis-similar wages. At Harrogate, the most wealthy and fashionable inland watering-place in the kingdom, with a population of 20,000 , swollen in summer to 40,000, which increases the cost of living and rents, the established postmen number 20, and they are paid a maximum of $22 \mathrm{~s}$.

Mr. Walpole: Are you sure of that?

A. That is the statement I get from Harrogate. The very lowest rented houses to be had there are $6 \mathrm{~s}$. $7 \mathrm{~d}$. per week. The rates of wages in Harrogate are: Joiners, $8 \frac{1}{2}$ d. per hour; bricklayers, 9d. ; slaters, $7 \frac{1}{2} d$. ; painters,

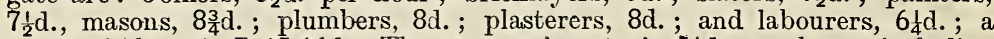
mean of these is $715-16 \mathrm{~d}$. The postmen's rate is $5 \frac{1}{2} \mathrm{~d}$. per hour, including emoluments. At the mean, that is:2 7-16d. per hour less than the other rates.

The Chairman: Including emoluments. Does that include stripes?

A. Yes, I believe it includes everything the postman gets.

Q. Does that include uniform?

A. I cannot say that.

Q. When you sayr emoluments and use the word as an inclusive term you should be prepared to tell us what the emoluments are?

A. I should say they include all Sunday pry. Probably postmen do not think the uniform is an emolument.

Q. Does it include stripes?

A. Yes, sir. The men hold the view rather that they should be paid for wearing the uniform instead of being taxed for it. One section of clerks at Liverpool refused to wear blouses because of their pride, yet, when they compare our position with their own, they include in our emolu- 
ments our uniform. There are 30 towns with less population and less - established postmen than Harrogate receiving $24 \mathrm{~s}$. and 26s. minimum. There are 11 towns with larger populations but less established postmen receiving 24s. and 26s. per week. There are 12 watering towns with about the same population, but again less postmen getting 24s., but to cap all there are 16 towns in the Harrogate surveyor's district (N. E.) with less population or less established postmen than Harrogate, receiving 24s. and 26s. maximum. The infiux of extra work performed by men situated in these pleasure resorts, under the sweating system of extended delivery, makes their summer a perpetually recurring Christmas, without the Christmas overtime. This is a point that constitutes a very sore grievance among the Liverpool men, but as it will be dealt with by $\mathbf{M r}$. Dowling I will simply put in Mr. Rich's statement upon it.

The Chairman: What do you nean by "making summer a perpetually recurring Christmas"?

A. It is the heavy work.

Sir F. Mowatt: And it does not carry with it Christmas boxes-(laughter)?

A. No, sir. This is an account of an interview I had with Mr. Rich on the subject, ${ }_{i}$ and I put it in becarse I think it indicates ai way out of the difficulty.

The Chairman: Who is Mr. Rich?

Mr. Walpole: The postmaster at Liverpool.

Witness : It is a vexed question, and I think Mr. Rich's remarks are as good as any that could be offered. I wish to put in this statement now of his views. Mr. J. D. Rich's views on overtime, stated just before the deputation $r e$ the unemployed an overtime to the late Postmaster-General, are accepted as a fair solution of the extended delivery difficulty by Liverpool postmen, but were never fulfilled. After the said unemployed deputation, Mr. Rich sent for me and said, "If I do not observe strict economy, I am myself to blame; when there is extra work I expect men, as in all employments, to put forth extra effort to cope with it. Yet, I do not think high pressure the ideal state. If a man he've an unusual amount of work for a delivery, he must not be his own judge, but must call the inspector's attention to it; and the inspector, agreeing that there is work to detain him an hour over his 8 hours, he will be paid extra for it. If I were an inspector," continued the postmaster. "and a man represented he had one hour's work extra, and I was of opinion he had only fifteen minutes, I would place on his walk a good worker, instructing him to do the delivery fairly, and then if I found it took this man only fifteen minutes, I would punish the first man for falsehood-firstly, in the public interest, and secondly, in his own, so that he should not make himself liable to prosecution for wilful delay of letters. If an inspector acts unfairly, it is open to a man to seek reAress ; and if a doubt exists in the mind of an inspector as to the sufficiency of the overwork, I desire the benefit of such doubt to be given in favour of the man." In practice this , has been entirely repudiated; an appeal against an inspector we would not think of, as the superior must be upheld, and, in all cases, sided witk; but sweating by overwork being crushed into the ordinary work was never greater than since the unemployed question in Liverpool.

Witness (continuing his statement): In London, Liverpool, Glasgow, Manchester, and Dublin, there are no junior postmen. In Birmingham, Leeds, York, Southport, Portsmouth, Southampton, Middlesboro', Twickenham, Stockton-on-Tees, Leicester,-Kingston-on-Thames, Hull, Croydon, and Chester there are. Even in these latter there are four different rates of minimum, and two of maximum:-1, 15s.; 1, 13s. ; 4, 14s.; and 8, 12s. ; Birmingham, 17s. maximum; the remainder 16s.

Mr. Walpole: You mean 17s. minimum, surely?

A. No, maximum; 15s. is the minimum. 
Q. Then you are referring to the junior postmen?

A. Yes, sir.

Wituess: Why is the minimum more in Birmingham than in Leeds and York? Why is it more in Portsmouth than in Southamptor? Why have Birmingham junior postmen while Liverpool, Manchester, etc., have none? Why had Manchester 27 per cent. of its appointed postmen paid less than 24s. a week, while London has hardly 1 per cent., Liverpool $3 \frac{1}{2}$, and Glasgow $11 \frac{1}{2}$ ?

Mr. Walpole: Are these the percentages of the junior postmen to the regular staff?

A. Oh, no, sir. I am giving the rate of wages in the towns I have named.

Q. Really, it is a series of conundrums you are asking us-(laughter). What we want are facts.

A. And I want to prove the inconsistency of the whole situation.

Q. But you say only 1 per cent. of the postmen in London are paid less than 24s. a week. The state of things is absolutely the reverse. It must be.

A. I am taking the rates from the Estimates, and I say that the maximum rate is less than 1 per cent.

Sir F. Mowatt: You particularly distinguish between the appointed postmen and the juniors?

A. Yes, sir.

Q. And you say only 1 per cent. of the London appointed postmen are receiving less than $24 \mathrm{~s}$.?

A. I take it from the Estimates.

Mr. Walpole: Are you taking the maximum scales?

A. In this case I am. At Manchester 27 per cent. were paid less until the present Postmaster-General raised the maximum to $30 \mathrm{~s}$. And these were men living almost in Manchester itself.

Q. But that has all been altered during the last twelve months?

A. Quite so.

Q. And the whole question falls with Manchester?

A. Oh, yes.

Q. I really thought you meant they were now getting less than 24 s. ^ week. Now I understand you mean they were till recently?

Mr. Smith : How many men are paid on a scale which does not rise above $24 \mathrm{~s} . ?$

A. I should prefer my statement going in as it is.

Q. But it is not correct.

A. Oh, yes, it is. I think you will find consistency in it. Why are bag men, mèssengers, etc., paid wages from 38s. to $45 \mathrm{~s}$. in London, Edinburgh, and Dublin, while in Liverpool, Manchester, Glasgow, Birmingham, etc., men doing similar work are paid by the miserable method of allowance which they may hold for twenty years, and then be deprived of, when about to be pensioned?

Mr. Walpole: There, again, you are making a most confusing statement. Of course no bagman in London goes above 38s. You join the different ciasses together.

A. I have to do that.

Q. But it does not make it clearer. You know it is not quite true.

A. You cannot adduce any reason why men should be paid wages in London, Dublin, and Edinburgh, and why the men in the provinces should be paid less for the same work, and then only in the form of allowances. The only reason is that it may give the Department the advantage of being able to deprive them of the allowance when it chooses.

Mír. Walpole: There are a certain number of postmen who get an allowance for bagman duty in addition to their wages, which brings the total up to nearly the same scale. 
Wages-Aggregate.

A. Quite so, but we want it in the form of wages and not allowances.

Sir F. Mowatt: Is this going on now, or is it something that occurred two years ago?

A. No, sir; this is not old history. (Laughter.) At Liverpool three men on the door of the Parcel Post Office are rotating and doing the same work. One of the three gets only 3s. allowance, the other two 5s. each. About five ytars ago, in drawing up a petition to get sorting postmen paid sick pay on allowance, $I$ found that men doing similar duty had been receiving what we were asking for, for years previously at Manchester and Birmingham; they were also getting pro rata their allowance in overtime pay. We were immediately granted the same, although we had tried previously and failed. The old method was "Don't tell the postmen at Manchester what you are getting." Keep it dark, so to speak, but we looked upon this deprivation as a gross injustice, and the men at Manchester got raised to the 30s., while their colleagues in Manchester and their fellow suburban men at Liverpool have had it for years, have been dealt with previously in a way in which I trust the Department will in future be asliamed to deal with its men. I may mention that the very reverse is now taking place in Manchester. We were then without sick pay on allowances. They are now without it, although several other towns are getting it. Manchester is actually in the position we were a little over five years ago.

\section{ARMY TREATMENT OF POSTMEN.}

This is the subject dealt with in the third branch of my remarks.

Mr. Walpole: What do you mean by "army. treatment?"

Witness: Mr. Badcock, in his evidence, compared the overseers with the non-commissioned officers in the army. The order, uniformity, and philosophy in governing the army and producing its contentment would fit the Post Office about as well as the postman's uniform fits him, that is, where it touches. The purchase of human energy, bone, and sinew in the cheapest market, and the sale of it in the dearest, with its privilege and depression, forms a perpetual lever for unsettlement and contention, and would, if applied to the army, as it exists in the Post Office, lead to mutiny or even chaos.

The Chairman: I think you are going a little away from your case. What we want to hear is the postmen's case, and what they have got to say. We do not want to go into a general disquisition.

A. I shall bring it to a crisis. I am dealing with the conditions of our work.

Q. But what Mr. Badcock said in his evidence was with regard to the condition of the sorters. We have now got to a separate class of the Post Office altogether. I do not think it comes within your office to criticise the evidence given on another subject altogether.

A. Independent though these sections may appear of each other, they can hardly be separated. It is the only way of doing us justice.

Q. We want to hear everything you have got to say on behalf of the postmen.

A. And I shall bring it in with regard to postmen.

The Chairman: I have given you a considerable amount of latitude. You must not abuse that.

A. I hope I shall not do so. I am only dealing with this point in order to introduce another subject. The great army of postmen outnumber the otlier sections combined, yet they, their overseers and inspectors, are despised and insulted by the privileged sections. Mr. Walpole sympathised with Mr. Nicholson in his loss of dignity when supervised by a female. Is the Secretary aware that, though there is nothing relating to it in our rule books, we are compelled to "Mr." provincial sorting clerks, even while they are mere boys? Is he aware that, in every instance where an official 
document is headed by the title "Mr.," the "Mr." is struck out before it is handed to a postman for use, so that the doctor, who, before would have treated one with the respect due to any well-behaved person, is relieved of this necessity when he sees that the official desire is that the postman be called in the manner convicts are called, i.e., Number so-and-so, Postman Walsh. My lord, I do not think that you have suffered either in dignity or manhood by treating us in this Inquiry as men. I have seen the notice put up for a man's funeral minus the "Mr.," although the corpse of the dead soldier is saluted by his officer.

\section{HOW AMERICAN POSTMEN ARE TREATED.}

I asked the secretary of the American letter-carriers whether the need to earn one's bread, as a postman, subjected the men there to these insulting methods. In his country, he answered, such usage was unknown; they "sir-ed" no clerks there; indeed, the precarious condition of their clerks needed the carriers' pity. I have known junior clerks checked for speaking to postmen because of their superior position. I have heard of sorting clerks demur to being compelled to sort beside postmen, and being upheld. I have seen them risk delaying a despatch and stand idly by, waiting for a postman to tie and seal their bags, because it would degrade them to do such work. The vanity and dignity of these clerks costs the country dearly, for much of the indoor postmen's work consists of waiting on them. The London sorters are a useful body of men; I have seen them at work sorting and pulling bags about and mixing generally up with the work. I am one of a number of postmen at Liverpool who took over the city sorting thirteen years ago. I have been doing it ever since. I can speak for the usefulness of this class at Liverpool. It was introduced against the opposition and prejudice of superintendents and sorting clerks, and, I believe, supported, for a time alone, by Mr. Rich and Mr. Fardo. We were for years insulted and badly treated, but have lived it down, with the result that the superintendents who were most opposed have over and over again praised our work. Now, the sorters complain, in evidence, that much of their work is porters' work, and they wish to be relieved of it, and be called sorting clerks. Notice, it is not division of labour for efficiency but for pride, in order that the said porters may wait on them. Thus section after section of men begin, create privileges, impose the hardships and indignities on new-comers, make secure the ramparts surrounding their privileges, and draw up the ladder that others may not enter.

Mr. Walpole: Is it necessary for your case that you should abuse your co-officers?

A. I hope I am not abusing them. I am showing the distinctions that are drawn. Postmen have suffered greatly through them, and have been looking forward to this exposition 30 years to my knowledge. Thirty-one vears ago all entered as first, second, third, and fourth class sorters. Throughout the country the most fitted for certain work were, for the most part, put to it. The sorters became consolidated into a separate section, known now in the provinces as sorting clerks. The supervisors, in most cases, were chosen from them, and between the supervisors and these clerks they have managed to completely oust the postman from almost every position and emolument in the Service.

Mr. Walpole: You are representing provincial postmen. Where are the supervisors at Liverpool?

A. I speak for every section.

Q. But you are now speaking of a section with which you have nothing to do?

A. I am comparing our case with theirs.

Q. Supervisors do not exist in the provinces? 
A. We use the term in regard to the superintending and governing staff in the provincial offices.

Mr. Smith : You use it in a general sense in all provincial offices?

A. Yes; we so describe the governing power in all provincial offices. The sorting clerks have petitioned over and over again that the sorting postmen be abolished, not in the interests of efficiency or public good, but in order that one first-class clerk may be created to every second-class one made to fill our places. Mr. Rich told me, on one occasion, that they submitted to him a scheme showing how much could be saved by turning the postmen out. The everlasting bid for privilege by these sections having been ever readily conceded is the cause of the gross injustice of which postmen to-day complain.

Mr. Walpole: When you say "readily conceded," is it not a fact it has not been conceded, and that you remain as sorting postmen at Liverpool still?

A. Oh, I will show that they have lots of privileges.

Q. But you are referring to a particular demand for the abolition of sorting postmen?

A. I am referring to the privileges in general, sir. It is the knowledge that hard work and new inventions in discipline are for postmen, while the notice board is continually covered by the promotions of small and already overpaid sections, that has filled postmen with sullen discontent, and made them in Liverpool, of late years, refuse testimonials to high official after high official.

\section{EDUCATIONAL TESTS AND GRADE DEFERENCE.}

The clerks asked for a higher educational test for entrance, and it was granted, though 10 per cent. of the clerks at present in the Service could not pass it; but it was required to keep postmen down, and it has acted. If it had not another barrier could have been made, and, indeed, has been added, namely, the candidate must be under a certain age, and if this fails there is still another expedient. At present, in Liverpool, four postmen have passed the preliminary examination, but they are kept back, while boys from the telegraph branch are transferred to fill up the vacancies in C.B. To show the vagaries of this class of business, the assumption of the Department is that a higher education is necessary to efficiently manipulate letters, therefore postmen camlot sort without it. The sorting postmen referred to took the work over from the clerks, nearly all of whom are now superintendents and clerks, while the sorting postmen, with the exception of six young men, are stationary as postmen. I remember when the clerks did the sorting; two sections-sixteen men-were frequently kept from walks sorting an hour at the clerks' mis-sorts. Two postmen can now keep the mis-sorts and re-directed clear. I have been ordered by Mr. Richardson and other superintendents, at Christmas time, to show up letters posted, or going through Manchester on the 22nd and 23rd of December, and getting into our hands on the 26th of December. I inquired of the Manchester postmen if they did forward sorting at Christmas to any extent, and was informed that they were not allowed, except what was known as four-lotting. Nine-tenths of the forward primary sorting at Liverpool is done by postmen, and Mr. Rich never allowed dignity to keep the public four days without their letters. He swarmed the sorting desks with postmen, and for nineteen years, with Liverpool's inconvenience of office and fittings, I have never known a letter to be kept behind, without it was a mis-sort to the locals, which, of course, were not sorted till later on. I must qualify that statement. Last year was, unfortunately, an exception to the case, but if postmen were admitted into the despatching rooms and made acquainted with the work there, the difficulty could soon be got over. About four first-class sorting clerks at a maximum of 56s. per week deliver 
letters from the box; these are merely postmen whom the public come to, instead of their going to the public. Send them to try the doubtful letters of box firms and do the out-door delivery, and they would receive $30 \mathrm{~s}$. instead of 56s. A large sum is paid to have a London mail due in Liverpool at 6.10 a.m., met at Crewe and sorted, in order that merchants may be convenienced at Liverpool. Three sorting clerks are put on this work, some of whom do not know the main streets in Liverpool. They object to stamping and tieing up when at the head office, but there is a 12s. allowance for travelling, so they pocket their dignity, and stamp, seal, and tie up. Should the train be iate, these men have the extra time of the delay, but they are helpless; they cannot sort the west or commercial portion of the city into walks. The train arrives at 7 a.m., or five minutes past, but the letters are not sorted, and the postmen have to be despatched without, while two sorting postmen have to be paid overtime to sort the mail. I sort for a whole night, bag off papers and parcels, and enclose the register bag and unpaid, fill in the time bill, and despatch the van, but a firstclass clerk has to come and sign for the unpaid and register bag. The postman's intelligence is not adequate to initialling the bills, so a 56s. man's time must be wasted.

\section{POSTMEN VERSUS SORTERS.}

The Chairman: It seems to me that your evidence amounts to this-You think that the difference between the sorting clerks and the postmen should be abolished, and that postmen and sorting clerks should be interchangeable?

A. Quite so ; and I maintain that I can establish that by figures as I go on. It is the claim of the London postmen also. For 14 years I have been about 10 months a year at local sorting, but I must admit that my intelligence, presence of mind, and judgment have never been taxed to the same extent at sorting as on delivery. Take one walk-for example, Old Hall Street-for the first delivery. Little will have to go through 2,000 letters in putîing up his walk, and again arrange 1,200 for delivery. To do this, he must sort at the rate of 35 a minute, without allowing any time for re-directing letters, taking charge, getting keys, etc., and after this he has to take out from 40 to 60 lbs. weight. He will not, as the sorting clerk, have a dozen bundles to finally dispose of, but 300 or 400 lots to finally dispose of. Let his mind be off his work one moment, and a misdelivery is made of which he will hear, and for which he will be punished more severely than a sorter, because it causes complaints direct from the public, and the clerks hear mostly from the official at the office to which letters were mis-sent. The nicest discrimination and judgment are required in claiming badly initialled and illegibly addressed letters for his clients, and an intelligent postman causes many valuable letters to reach people which never would do so were it not for his diligence and risk. I have known postmen say they could tell by the industry, the district, or even the colour of the envelopes, if the letter belonged to their firms.

The Chairman: You are going into figures, I understand?

A. Yes, my lord.

Q. Can you instance any foreign country which adopts the system of making sorters and postmen interchangeable?

A. No, I cannot, sir. Under the American system the postman, however, is much better treated. You find that he is guaranteed his situation, whereas the clerk is merely taken on hire.

Q. But in this country both postmen and clerks are guaranteed, are they not?

A. We are much more old-fashioned-much surer and better.

Q. I say that both classes are guaranteed. You say that in America the clerks are only taken on temporarily? 
A. Yes ; in this country we are both guaranteed, but $I$ want to point out that, as a matter of fact, the American system to some extent suffers by the absence of interchangeability. On the occasion of a strike in America, the postmen, in view of the position they occupied, having their position guaranteed by law, refused to interfere with the sorting of the mail, and stood idly by while the clerks were over-pressed.

Mr. Walpole: You say that the American postmen liave a guaranteed position. Do you know that of your own knowledge?

A. To a very great extent.

Q. Is it not a fact that the American postman is not eligible for a pension?

A. Quite so, sir.

Q. Is it not a fact that his service does not count for pension?

A. I will come to that presently. I have liere some printed extracts upon the point to prove my case, but $I$ do not intend to inflict them on the Committee unless it is necessary, I assure you.

\section{COMPARISON WITH POLICE WAGES.}

The condition of the postman is held by the Department to be one of luxury compared with other workers. I find the postmen compared at Liverpool with the local police stand thus:-Postmen's minimum, 17s.; policemen's, 24s. 6d. Joining the service together the postman loses the first year at 7s. 6d. per week, $£ 19$ 10s. ; second at 6s. 6d., $£ 16$ 8s.; third at 6s. 6d., $£ 16$ 18s.; fourth at $6 \mathrm{~s} .6 \mathrm{~d} ., £ 16$ 18s.; fiftl at 6s. 6d., $£ 16$ 18s.; sixth at 5s. 6d., £14 6s. ; seventh at 4s. 6d., £11 14s.; eighth

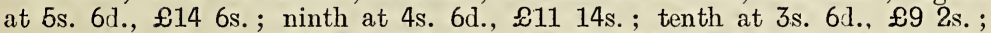
eleventh at $2 \mathrm{~s} .6 \mathrm{~d} ., 28610 \mathrm{~s}$; twelfth at $1 \mathrm{~s} .6 \mathrm{~d}$. , $\$ 318 \mathrm{~s}$; thirteenth, at $6 \mathrm{~d}$., $£ 1$ 6s. The postman, therefore, loses in thirteen years $£ 159$ 18s. This loss to the men is a gain to the Post Office, if applied to the 24,556 postmen, of $£ 3,926,504$ in 13 years, or $£ 302,038$ 16s. per year.

Mr. Walpole: You have omitted the whole question of Sunday duty, have you not?

A. Yes.

Q. You are aware that the police do Sunday duty?

A. Yes, I am.

Q. And if you do such duty you are paid extra for it?

A. Yes, sir.

Q. And you have not brought that into your calculation?

A. No, I have not.

Q. Surely it is a very essential element?

A. Yes; but on the other hand I have not brought in to my calculation the fact that promotion up to sergeant and superintendent is open to every constable.

Q. Have you brought into your calculation the fact that the police have to submit to a deduction from their wages for pension?

A. Of $2 \frac{1}{2}$ per cent. No, I have not.

Q. And to make your calculation accurate both those elements slould be introduced, should they not?

A. It is a very slight matter, but I propose to deal with the question of pensions presently. Had I not better go on with my statement?

Q. There is a qualification of height refuired in the Liverpool police, is there not?

A. Yes.

Q. They are required to be 6 feet high, are they not?

A. No; only $5 \mathrm{ft} .7 \mathrm{in}$.

Q. I think you are wrong. 
A. I can also prove that a height and chest measurement qualification was required from the Liverpool postmen. The height was the same as in the police. I find a joiner receives $37 \mathrm{~s}$. $10 \mathrm{~d}$. per week; a policeman averages 27s. 6d. per week; carters, 27s. and 30s.; dockers, 27s. and 33s. per week; scavengers, $21 \mathrm{~s}$ per week. A mean of these gives $29 \mathrm{~s}$. $0 \frac{1}{2} \mathrm{~d}$., which is 8s. $0 \frac{3}{4} \mathrm{~d}$. a week more than the postman's mean average.

Mr. Smith: How do you get at the dockers' wage?

A. Of course the wages of these men are precarious.

Q. But how do you get at the figure?

A. From a return.

Q. Is it what the men would earn if they were on full work?

A. Yes; and if they are not at work they have the time to employ as they choose.

Mr. Smith: Oh, but perhaps they would prefer the work and not the time?

\section{POSTMASTER DAYTON, OF NEW YORK, ON BRITISH POSTMEN.}

Postmaster Dayton, of New York, interviewed, during his recent visit to London, is reported to have said of British postmen :- "Very little is expected of your letter-carrier, and he is paid accordingly. We pay our letter-carriers $£ 20$ a month, but they are worth it. We expect our men to keep track of removals, ferret out obscure addresses, and so on." Postmaster Dayton had a difficult task to perform. He had to depress our men's service to the level of their starvation wages, and elevate his own to the level of their's. The task was impossible without a mis-statement, and Postmaster Dayton is either grossly imposed upon or a willing victim to an error which suits his case. To imply that British postmen do not keep track of removals or ferret out obscure addresses is untrue; they not only do so, but, with the exception of a few letters disposed of by the blind clerk and the first-class clerks doing postmen's work in the box office, are the only individuals allowed to re-direct, trace, and finally dispose of letters as dead.

The Chairman: You need not make this Committee the means of answering Postmaster Dayton. We do not care about his views.

A. I am working a comparison.

The Chairman: Please leave him out of the question. I do not care a snap for him.

Witness: It upsets my statement.

The Chairman: I must have him knocked out.

Witness : There are parts which bring in the question of the educational test. It is very important, and I should be very sorry to omit it.

The Chairman: If you have any representations to make with regard to the educational tests required of postmen, you can tell us without bringing in Mr. Dayton.

Witness: But I can proye it with more force in this way.

The Chairman: I do not think you can. Tell us, please, what your opinion is.

Witness: We make the mistake, says this gentleman, of demanding all sorts of irrelevant acquirements in our candidates for minor places. The American postman passes an examination nearly similar to the extmination lately introduced here to prevent postmen becoming sorters, and Mr. Dayton admits it is a mistake. But a greater than he showed in his essays, years ago, that lawyers, doctors, and professional men in America were not 
less capable but more capable since examinations for these professions had been depleted of the dead languages; I refer to Emerson.

Witness here put in the following quotation from Emerson upon "New England Reformers," in regard to "Superfiuous Education":- "But in a hundred high schools and colleges, this warfare against common sense goes on. Four, six, or ten years, the pupil is parsing Greek and Latin, and as soon as he leaves the University, as it is ludicrously styled, he shuts those books for the last time. But is not this absurd, that the whole liberal talent of this country should be directed, in its best years, on studies which lead to nothing. If the physician, the lawyer, the divine, never use it to come at their ends, I need never use it to come at mine. So they jumped the Greek and Latin and read law, medicine, or sermons without it. To the astonishment of all, the self-made men took even ground at once with the oldest of the regular graduates, and in a few months the most conservative circles of Boston and New York had quite forgotten who of their number was college-bred and who was not." I claim that postmen are fitted to do every function now done by sorters. The Department, like the scientist proving that Stephenson's train could not run, as smooth wheels could not revolve on a smooth surface, will answer "Impossible." but with Stephenson we answer, "We can do these things, for we are doing them and have done them." No Trade Union in the country would suffer lads from school to be jumped in over their experienced workers, for the purpose of filling all the higher positions of the craft.

Sir F. Mowatt: A sorter passes an examination as well as a postman, does he not?

A. Yes.

Mr. Walpole: And what examination is there to prevent postmen be. coming sorters?

A. I am giving the postmen's opinion.

Q. Are you dealing with the exuminations of postmen or of sorters?

A. I say the educational test has baen raised.

Q. For the sorters?

A. Yes, for the sorting clerks.

Q. And what is the objection to raising it?

A. I think it is an injustice to the postmen throughout the country. They can perform the duties without it, and they have work sufficient to occupy their whole time without being called upon to prepare themselves for an educational test which is unnecessary.

Q. Do you mean that we have too high a test for: sorting clerks?

A. Yes ; that is our opinion, and it is also our opinion that it has been introduced in order to keep the postmen out.

Q. But the examination has been fixed, has it not, to suit the capacities of a child educated at an elementary school, and who has passed the 6 th Standard?

A. I do not know that.

Q. Is it too high a test if that is so?

A. It is unnecessary for the performance of the work. Continuing his statement, witness said:- In America postmen are paid two rates. In towns where the population is over 75,000 postmen are rated first-class; they receive the first year $\$ 600$ or $£ 125$, the second $\$ 800$ or $£ 16613 \mathrm{~s}$. 4d., and afterwards $\$ 1,000$ or $£ 2086 \mathrm{~s}$. 8d. In towns under 75,000 the rate is second-class. The second-class men get first year $\$ 600$ of $£ 125$, and afterwards $\$ 850$ or $\$ 177$ 1s. 8 d. American postmen have no sick pay, no uniform provided, and no pensions. Their uniform costs from $£ 210$ s. to 
$£ 3$ per annum. Suppose we allow $£ 54 \mathrm{~s}$. for uniform and boots, $£ 212 \mathrm{~s}$. for sickness, and $£ 5$ 4s. to form a pension fund, their minimum rate minus $£ 13$, would be $£ 112$, which is $£ 578$ s. a man more than the British postman's mean average.

Mr. Walpole: You referred just now to examinations in the dead languages. There is nothing of that in the P.O. examination?

A. No; but there is in other professions, which it is admitted can go on quite as well without them.

The Chairman: As to American postmen's wages, is it not a fact that the general rate of wages is higher in Anierica than here?

A. I believe it is.

Q. And is not the cost of living considerably greater in America?

A. My brother-in-law says the difference is not very great. House rent and clothing are dear, but food and general utensils in the house are much cheaper.

Mr. Walpole: As a matter of fact, meclanics in America get two or three times as much as they do in England. Is that not so?

A. I believe that in some trades they do.

The Chairman: If you could say that the rate of postmen's wages in other European countries was higher than that paid here it would be a very much stronger case from your point of view.

Witness: As a matter of fact, with regard to European countries, they are all military-ridden, and cannot be compared with a commercial country. I want to point out, as this gentleman has pointed out, that the rates for the higher officials in the English Post Office are much higher than for those in the American office, while the English postmen have much less than the lower grales in the Anerican Post Office.

Mr. Smith: You are assuming that the level of prices is the same in the two countries?

A. Quite so.

Q. But it is not, is it?

A. Let me give an illustration. The American postmen are so much better off that they can afford to come over here to spend their holidays, whereas the British postman can hardly afford to take his annual leave. I have not been able to go out of Liverpool more than three or four times during my service.

'The Chairman: Is it not a fact that the hours of American postmen are much longer?

A. No. They have alisolutely eight hours. The American Treasury has had to pay over $\$ 100,000$ for overtime, and if the British authorities could be fined for infringing the eight hour rule, I fancy there would be a much heavier claim against the Government. A mean of the American four scales-£125, £166 13s. 4d., £177 18s., £208 6s. 8d.-is £169 5s. 5d. Deduct from this the $£ 13$, and still America pays her postmen $£ 1565 \mathrm{~s} .5 \mathrm{~d}$., or an average of $£ 101$ 14s. 6d. more per man than England. That is a. profit to England compared to America of 186.6 per cent. out of her postrinen. In 40 years the American gets $£ 5,09013 \mathrm{~s}$. 4d. more than the English postman. England gets three postmen for what America pays one. Our free delivery system, and our annual $£ 3,625,000$ surplus are liad, for the most part, out of our poor underpaid postmen.

\section{THE MINIMUM.}

I should like here to put in my letter of engagement as a letter-carrier offering me a minimum of $£ 1$ per week. (Letter put in.) Nineteen years ago I received $£ 1$ a week on joining the Service. A return furnished to 
the House of Commons on the 1st July, 1890, shows the minimum for first-class postmen in London to have been $23 \mathrm{~s}$., and in Liverpool, Manchester, Edinburgh, and Glasgow, 22s. per week. Take Liverpool as an example of the immense supposed benefit to postmen the raising of the maximum to $30 \mathrm{~s}$. and the reducing the minimum to $17 \mathrm{~s}$. has been. A mean of the wages of 634 establisled postmen at Liverpool now gives $£ 7419 \mathrm{~s}$. per week. In 1890 there were 389 first-class men at 22s. to 28s., 161 second and twelve sub-office men at $18 \mathrm{~s}$. to $21 \mathrm{~s}$. If these increased in their then

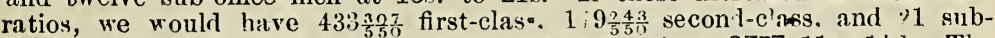
office men, which at the mean of the old rates gives $£ 73711 \mathrm{~s} .1 \frac{1}{2} \mathrm{~d}$. The stupendous increase in postmen's wages then is really $£ 41 \mathrm{~s}$. $7 \mathrm{~d}$. per week at Liverpool. Now, if I mention that 389 were reduced 1s. or their successors you will see that there is a nett gain out of the men of $£ 5$ to $£ 16$ per week.

Mr. Smith : Do you mean the reduction of $1 \mathrm{~s}$. was on the maximum or on the minimum?

A. On the maximum, working out of London.

Q. But that particular shilling was a special thing in Liverpool, was it not?

A. It was, sir.

Q. Was it only given to a portion of the postmen?

A. No ; it went to the whole of the postmen.

Mr. Walpole: Were all the postmen employed in sorting?

A. Yes; we were all doing sorting.

The Chairman: This return does not give the present position?

A. I am comparing it with it.

The Chairman: It is prior to the revision of 1891 ?

A. I am comparing what happened after the revision of 1891 with what was the position before it.

Mr. Smith: The result of the 1891 revision was an increase, was it not?

A. Yes; it was an increase to the older men at the expense of the new entrants into the Service. It was a kind of Peter and Paul business; you took away from Peter in order to pay Paul.

\section{COMPARISON WITH TELEGRAPHISTS AND SORTING CLERKS.}

Mis-statement is made in the House constantly, putting increase of staff forward as increase of wages. Mr. Tipping, second-class telegraphist, said at five years' service (21 years of age for telegraphists) a wage of 28s. instead of $24 \mathrm{~s}$. should be given. The present wages were about those of a stoker on the Midland Railway, and the increment of 2s. per week was so small as to be difficult of realisation. I have inquired of a stoker on the Midland, and find he gets 21s. per week, and that his average attendance is 10 hours per day, and that it takes three to five years to get 27s. per week.

Mr. Walpole: That is one fact we have got about the wages for other labour in this country. Am I right in saying that a stoker for 21s. a week works 10 hours a day?

A. Yes, sir. The misfortune is this: you have got a powerful Government here controlling matters, which ought to do what is right. You have got capitalists outside doing pretty well what they like, and operating upon the men as far as they like to go. We expect more humane and better treatment from the Government than would be expected from a private employer. But suppose their wages (stokers and telegraphists) the same, Mr. Tipping, to be paid at the stoker's rate per hour, would only receive 
16s. $93-5 d$., and to compare the after stages would be ridiculous, while the stoker may be far the more useful public servant of the two. I have been to the telegraph room over and over again when serving it, or sent on messages, and have also inquired from others, and have found quite half of the tolegraph stafi sitting idle awaiting work.

The Chairman: Then you have no objection to telegraphists being paid stokers' wages?

A. I want to prove that they are not entitled to an increase, and that we have suffered by the increases they have already had. I will prove that later on. It is alleged that it is only when young and supple of joint the telegraphist's business can be learned ; this applies to pianists, drummers, acrobats, tailors, and others, but the power manifested in statesmen, generals, and wise thinkers of nots, does not depend primarily on suppleness of the fingers, and is possible at the grey-laired stage. The fact is, being a stoker, a postman, or a telegraphist, depends on influence or chance. The poor telegraph lads, who have to sigu on entering they have no claims on the Service after a spell of good service, and are sent away because of no vacancies, would fill, and more than fill, all the vacancies filled now by favoured lads direct from school. The army and navy do not, once lads have passed a medical examination, send them adrift after keeping them in service when they should have been at a trade. Now, if $28 \mathrm{~s}$. a week can be used up by a youngster of 21 , his wants will not be satisfied by $£ 3$ a week when lie has a family to support. I think the Department entirely wise in this graduated method of payment, as it is a better means of distribution. It frequently happens that these young men live with their parents, several of them making a big salary to swell the family coffer. But extremes can be reached, and are, when young fellows, appointed at 21 and 22 , receive only $17 \mathrm{~s}$., and increase not by $2 \mathrm{~s}$., but by $1 \mathrm{~s}$. annually.

Mr. Smith : Is that the average age of appointment-21 or 22 ?

A. Yes, sir; I have a scheme prepared which shows that.

The Chairman: A previous witness put it at 19.

Mr. Walpole: At hiverpool boys are not kept as telegraph messengers beyond the age of 19 , are they?

A. 'They are sometimes made acting postmen.

Q. But they must begin a postman's duty at 19 , must they not?

A. Yes; they are not kept in the telegraph branch after they are 19.

Q. 'Then they must go through the auxiliary stage?

A. They do not get appointed postmen until they are 21 .

Q. Do you know of your own knowledge any telegraph messengers in that position?

A. I have a return of the average service, and what they do as telegraph lads. Some of them, marrying eirly, are kept by this initial low wage in poverty ever afterwards. Our relief force at Liverpool, doing about twothirds of their work by sorting outwards-the class of work named superior -have all had from five to seven years' telegraph service at wages of from $5 \mathrm{~s}$. to $12 \mathrm{~s}$. per week, and are beginners with a prospect of fifteen years before them, at 21 years of age, until they can reach the maximum and stripes.

Mr. Walpole: Some of these are not telegraph messengers in the ordinary sense. They are older men.

A. I told you they were auxiliaries.

Mr. Smith: And therefore they are exceptional and not typical,cases?

A. They all rise to that condition, and then would become typical. It is about that age that the telegraph lad becomes a postman.

Mr. Walpole: And he would carry his wage of $18 \mathrm{~s}$. with him?

A. No; he would only get $17 \mathrm{~s}$. ; he would drop a shilling. 


\section{POSTMEN IMPOVERISHED BY BIG WAGES IN O'THER BRANCHES.}

I will now compare the wages of the postmen to these badly-treated telegraphists, and at the same time answer the sorting clerks as to the pseudo gain the Department were to have in turning the postmen away from sorting :-

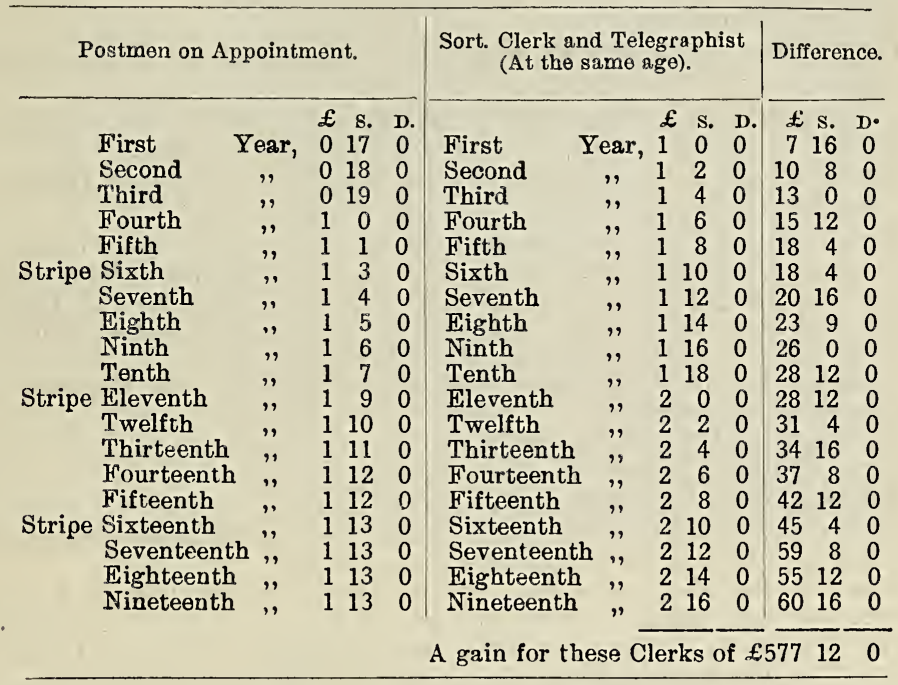

This does not include the jumps they have been describing to the Committee. Suppose a postman to get a sorting postmanship at four years' service; 7s. a week amounts to $£ 184 \mathrm{~s}$. a year, and this for fifteen years to $£ 273$, so that the sorting clerk still gains $£ 304$ 12s.

Mr. Smith: Do you make any allowance in the comparison for Christmas boxes?

A. No, sir; I cannot. I now propose to reply to Mr. Lascelles.

Sir F. Mowatt: Who is Mir. Lascelles?

A. $\mathrm{He}$ is a sorting clerk who has been giving evidence against the postmen.

Mr. Walpole: He has not been giving evidence against the postmen.

Sir F. Mowatt: I have heard no such evidence.

A. It is an illustration of our whole case.

The Chairman : I should just like to know what you want to do?

Witness: I want to prove that Mr. Lascelles' statement with regard to the comparative amounts expended on postmen and clerks is false, and also that several other of his statements are untrue.

The Chairman: But we can deal with these things ourselves.

Witness: It is a question between the two sections. You cannot deal with it without hearing our case.

The Chairman: We are not here to decide between the two sections. We have heard their case, and we are now hearing yours. Don't suppose we take as Gospel everyt ing that is told us.

Witness : But without hearing our reply to their statement you cannot meet the case of our class. I want to show that the amount expended on postmen and that on the sorting clerks compare very differently. 
Mr. Walpole: We can work that out for ourselves.

Witness: You might say you have been doing that in our office, but look at the condition of affairs at Liverpool which I have exposed.

Sir F. Mowa'tt: Would it be wise to base your case and evidence on a proposal to reduce the salaries of the sorters? The result would not appear to be very fortunate.

A. No,-it would not.

Q. Have you put in any claim that the sorters shall not have an increase of pay?

A. I shall prove it most clearly that they are not entitled to one, and that they are getting too much at the expense of the postmen.

Mr. Walpole: That would be, valuable evidence from a Post Office point of view. (Laughter.)

The Chairman: But it has nothing to do with the postmen's case. Whatever you have to say about Mr. Lascelles, it must be something directly affecting the postmen. If you insist on saying it-and I do not think it is necessary-we must consider the point, but I cannot allow you to answer Mr. Lascelles on behalf of the Liverpool men.

Witness : I have already spoken of the foolishness of the Department in employing men as sorters-

The Chairman: I must lay it down absolutely that I can only hear you on matters referring to the case of the postmen.

Witness : Well, this refers to it.

The Chairman: No, it does not. It is a question as between two classes of the men. It is not a postman's question at all.

Witness: He asked as to the sorting. I am showing that the Liverpool postmen are as capable of doing it as the clerks.

The Chairman: Wait a moment. Mr. Lascelles, as far as I can see, does not go into the question of the postmen at all.

Witness: Yes, he does.

The Chairman: He does not.

Witness: He names certain postmen in Liverpool, and speaks of 24 being occupied on sorting duty.

Mr. Walpole: The sorting postmen at Liverpool have never been employed on the T.P.O.

Witness : No; but Mr. Lascelles is setting up a claim that the thing we complain of should become common to the whole Service.

The Chairman: Your case is that you want to merge the classes of postmen and sorting clerks?

A. Yes ; and I can prove his statements and caleulations to be absurd and false. He has been ready to make an attack upon us, and I think it would only be fair for the Committee to liear the other side. (Cries of "Hear, hear.")

The Chairman: Order, order! So far as your statement relates to the postmen I have nothing to say, but you cannot go into the general case of the distribution of work between the various classes. I cannot allow you to do that.

Witness: We say we are as fitted for the work as they are. Will you not allow me to illustrate our capability for that?

The Chairman: You cannot go into Mr. Lascelles' evidence with regard to that. I am quite ready to hear your statement that the postmen are fully capable of doing the work of sorters.

Witness : I have a lot of evidence mixed up with this part-evidence sent on to me from other towns. They are in fear of this work being taken away from them, and they want to prove their capacity for it.

Mr. Walpole: It is not to be taken away from them. They are not employed on it. 

Witness : They want to show their capability and their right to claim it.

Sir F. Mowatt: The Cliairman is quite willing to hear any statement showing your capacity for the performance of a particular work.

The Chairman: Yes; but without entering into a controversy with $\mathrm{Mr}$.

Lascelles.

Witness then commenced to read the statement, which mentioned a public apology from Mr. Lascelles to other clerks for false statements on a previous occasion.

The Chairman: I will not receive that.

Witness: I want to slow the statement was false.

The Chairman: Whatever he says about the sorting clerks is for these clerks to answer. It is not for you, as a postman, to answer wliat he said about a clerk at Liverpool.

Witness : He asks that the clerks-

The Chairman: Please stick to the postmen. I will not have evidence from you with regard to the sorting clerks.

Witness: In dealing with the Foreign Office work he takes credit for express letters. At Liverpool the

The Chairman: I wish you to keep to the postmen. This is a question of grinding at the sorting clerks.

Witness : They are getting superior pay and position because of their clerical duties, and I want to show that those duties are not exceptional.

The Chairman: I am quite willing to hear you if you say the postmen are fully competent to perform these duties; but what I do not want. and what I will not allow, is you to enter into an argument as to how far sorting clerks are competent to do their work. You can make your cusse out that you are competent, but leave the sorting clerks out.

Witness: I am not saying they are incompetent. I am saying that they claim certain privileges on certain grominds, and that on their own evidence they belittle those grounds.

The Chairman : Do keep to your own case.

Witness again commenced to read.

The Chairman: You will not do as I tell you. I shall have to have it all cut out.

Witness : Let me read it and then cut it out.

The Chairman: Why should I allow the Committee's time to by wasted in that way?

Witness : I am giving evidence as a postman.

The Chairman: You are master of your own case. Tell us what affects the postmen.

Witness again suggested reading from the docunent, and was referring to the clerks.

The Chairman: I must stop this altogether. Put that paper away altogether, please. Now, I will ask a question or two on wliat I believe to be your point. You consider that a postman is fully capable of doing the work of a sorter?

A. Yes, sir.

Q. And you think that it would be an advantage to the Department that the postmen should do that work?

A. Yes, sir.

Q. And you think that for that work you are entitled to be paid on a scale similar to that which is paid to the men who now do it?

A. Yes. I say that the sorters are deserving of no be:ter pay than we for the work they do.

Q. Do you consider your pay is sufficient for that work?

A. Well, I am getting allowances. I should say that $45 \mathrm{~s}$. a week for the indoor men, including clerks of the $£ 190$ and $56 \mathrm{~s}$, a week class, wouid be a proper rate. 
Q. You think it is not necessary to pay more than 45 s. a week?

A. That is my contention.

Q. You consider the practice of employing postmen to sort at Liverpool is based on a good principle?

A. I do, sir.

Q. And you consider it a practice which should be extended to other parts of the United Kingdom?

A. Yes, sir. I should also like to ask for the abolition or modification of Rule 162, which preserves certain sorting duties for clerks, and disallows them for postmen. In the case of a strike the clerk might refuse to do postmen's work; therefore I think the rule should be altered.

The Chairman: And you think, as I understand it, that the present rule with regard to the examination of sorters is an unfair rule-that it is too severe?

A. Yes, sir ; I do.

Q. What qualification do you think the Department ought to require of postmen who are to be employed on sorting work?

A. I should think, sir, that the qualification now required of postmen on entering the Service ought to be the examination for both sorters and postmen, and that it ought to be required to be of an excellent character.

Sir F. Mowatt: That the subjects should be the same, but the standard a little higher?

A. Yes; it ought to be a most excellent production.

Mr. Smith: What subjects are they?

A. The four first elementary rules, dictation, and reading addresses.

Q. What are the extra subjects for the sorters' examinations?

A. Percentages.

Mr. Walpole: What?

A. Percentages, and decimals, and geography generally. This is, of course, hardly educational at all. It is merely cramming a youth with a lot of matter of very little benefit either to him or to the Department. The knowledge gained through sorting is quite sufficient.

The Chairman: Is it not a fact that already a considerable number of postmen become sorters every year?

A. Yes, sir; but that does not satisfy the general body. Very often an experienced postman who has really served as a sorter is not eligible for promotion because he has passed a certain age.

Q. Have you formed any opinion, or have you any scheme to propose to the Committee as to the method by which the aspirations of the postmen in this way could be satisfied?

A. Do you mean merely for the work?

Q. You have two bodies now-sorting clerks and postmen?

A. Yes.

Q. Have you got any scheme by which the desire of the postmen to be amalgamated with the sorting clerks could be carried out?

A. No; I have not any precise scheme. I think if you make the condition of the postman outside similar to the condition of the clerk inside at once it would do away with the desire on the part of the postman to get in, and would make it no degradation to the clerk to go out.

Q. But you now have two bodies on a different footing?

A. Yes.

Q. And a great number in both of the different classes?

A. Yes.

Q. Yes; if you make a change you must have some way of starting it?

A. Yes; but the change would have to be as all things are-gradual. I think if you give $45 \mathrm{~s}$. for the indoor staff and $40 \mathrm{~s}$. for the outdoor staff, and allow stripes as well as so much for uniform and boot allowances, the extra $5 \mathrm{~s}$. to the sorters would place them on an exact level, and then the 
desire of the postmen to get indoor and to outdo the clerk would not be so great as at present.

Q. Your idea is to reduce the salaries of the sorters and sorting clerks?

A. Yes; and to make the higher class redundant.

Sir F. Mowatt: What you suggest is that the existing rates of pay should be continued to the present staff, but that future entrants should be subjected to the scale you mention?

A. It would be a reduction of the mininum; we are asking for 20 s., and a maximum of $40 \mathrm{~s}$.

The Chairman: I am talking about the sorting classes.

A. I would make the two classes redundant, both the $£ 190$ and the $56 \mathrm{~s}$. men, and I would give an increase to the second-class of $5 \mathrm{~s}$.

Q. You would abolish the first-class sorting clerks-the clerkships?

A. Yes ; and I would have it consistent all through.

Q. And you would raise the wages of the boys?

A. Yes, in the larger towns.

Q. And you would expect the two classes to be interchangeable?

A. I should, of course, expect the most intelligence and the greatest capability. I should want to develop to the greatest extent the capacity of the men, instead of keeping them at mere mechanical and irresponsible work. I should want to find out if they were capable of other work.

Sir F. Mowatt: You do not consider now that the postman is simply kept to mechanical and unintellectual work?

A. I say he is denied an opportunity of acquiring a knowledge of other work in the Service, but I do not say that he is doing merely mechanical work. What we complain of is that he is denied the opportunities of making himself acquainted with this work.

(The Witness then asked the Chairman if he would take the statement which he had proposed to read in reply to Mr. Tascelles' evidence and look through it himself.)

The Chairman : I should be delighted to look at it.

Witness : I hope your lordship will also look at the case of the stampers, which I propose to hand in.

(Statement handed in.)

The Chairman: Have you got any estimate of the cost of what you propose?

A. Yes.

Witness : The sorting postmen are but $10 \frac{1}{2}$ per cent. of the postmen in Liverpool. The work of postmen, we contend, in every respect is as important and responsible as that performed by sorting clerks, and is indispensable to the Service and the public; neither will boy labour, nor woman labour, which suffice for telegraph work, do for it. Dealing with the public, it needs a person who has attained years of discretion, also mature age, to stand the constant physical strain of the work. I may say that Sir George H. B. Macleod has reported that, such is the difficult nature of the service, that men in the best of health have entirely collapsed after a year or two, in consequence of the hard nature of the work to which they had been unable to become inured.

Mr. Walpole: Can you give us any reference to that?

A. No, sir; that is the statement given me from Glasgow.

Q. Do you really expect us to accept a hearsay statement from Glasgow, not fortified by any data or reference?

Mr. Smith: In order that we may attach any weight to a statement of this sort, we must know the circumstances under which it was made and the authority for it. Cannot you give us that?

A. No, sir. Perhaps Mr. Maclaren can substantiate it in some way.

The Chairman: Then why did not Mr. Maclaren put it forward? 
A. It was in obedience to a request made that one witness should not overlap the ground covered by another witness.

Mr. Maclaren : I may explain that, in consequence of that request, I cut out of my statement those parts which were to be covered by Mr. Walsh, and one of them was a comparison with the work of the sorting clerk.

Mr. Walpole: This has nothing to do with the work of sorting clerks. It is an alleged statement by a medical officer that the work broke the men down. Can you tell us where it came from?

Mr. Maclaren: The statement was shown to me.

Sir F. Mowatt: When was it made?

A. I should think about 25 years ago. (A laugh.)

Mr. Smith: Who is the authority for it?

A. Sir George Macleod, a former medical officer.

Q. Where is the document? What is it?

Mr. Walsh: I will withdraw the statement.

Mr. Maclaren : I have endeavoured to find official confirmation of it at Glasgow, but they tell me they have not the data so far back as that.

Mr. Smith : Where did you get it from?

A. When instituting inquiries among the older men in the office.

Mr. Walpole: And somebody told you then that Sir George Macleod stated something 25 years ago. That is all?

\section{A. Yes.}

Mr. Walsh, continuing his evidence, said:-At Liverpool, eleven years ago, men had to be $5 \mathrm{ft}$. 7 ins. in height, and at least 34 ins. round the chest, to be employed at the head office. The efficiency of the Service rests even more with the postman than the sorter.

Sir F. Mowatt: Is that now required?

A. No ; I believe it has lapsed now.

Q. It is not required now, then?

A. It used to be, but not now.

Mr. Walpole: There is no such rule now, in fact?

A. No; but it was enforced at one time at the hearl office.

Q. How long ago was that?

A. Eleven years ago. It was maintained five or six years, and then it lapsed.

The Chairman: And even then the height measurement was four or five inches below the standard required for the police?

A. I believe it is 5 feet 10 inches for the police.

Mr. Walpole: Did you say the chest measurement was 24 inches?

A. No; 34 inches.

Mr. Walpole: I beg your pardon. I thought you said 24.

Witness (continuing): The postman collects the letters and again delivers at destination-the all-important part, which needs quite as much intelligence in doing it well as a sorter's duty calls for. A postman's position is one of even greater trust and responsibility than that of a sorter, because a sorter works constantly under a supervisor, and a postman does not. I have had as many as 74 registered letters on one delivery. In America the force of this is admitted, postmen there being better treated than clerks or indoor officers. A high standard of health and strength is demanded to begin with, a rigid medical examination, and, in after service, the work demands a continuance of this strength and a high standard of character and good behaviour. I have here an extract from "Truth" showing the absurdity of the grade business, and I wish to put it in in evidence.

The Chairman: This is not even quoted from "Truth."

Witness : It is taken from another paper, but it was copied from "Truth" into that paper.

The Chairman: It does not show the letter to "Truth." 
Sir F. Mowatt: It appears to have been inserted in the interests of the postmen.

Witness: It seems to have been something sent to the editor of "Truth," Mr. Labouchere, I presume.

The Chairman: Very well, the extract can be put in.

\section{EDITOR OF "TRUTH'S" OPINION OF THE PLAYED-OUT GRADE SYSTEM.}

The following paragraph, inserted in "Truth" in the interests of postmen, tells its own story:-

"At Liverpool, it appears, 600 postmen, whose salaries never rise above $£ 70$ a year, have nothing better open to them than 21 'inspectorships,' and doubtless in many other parts of the country there are men quite as badly off. In these days of advanced, and still advancing, popular education, the system of dividing employees into grades separated by impassable barriers is utterly indefensible. There is nothing, for instance, in the duties of a 'sorting clerk' which any board school youth who has passed the seventh Standard ought not to be equal to; and it ought to be possible for any postman who can show the requisite qualifications to advance either to this or to any other higher grade."

Witness: The whole grade business is hateful and unnecessary. Men are intelligent enough now to know that obedience is as honourable as command. The hazard of dismissal is sufficient to insure men doing the work set them, without the foolish faith in Helotry as a necessity and sound method of discipline.

Mr. Smith: What?

Witness: Helotry: the Greek system of having slaves.

The Chairman: Is it not a fact that many postmen show the requisite qualifications for sorting clerks?

A. No; it is not.

Sir F. Mowatt: You said just now that the examination was equal to the sixth grade; should it not be the seventh grade?

A. The Secretary said it was the sixth.

The Chairman: But suwely it is a fact that the postmen are satisfied?

A. No, it is not. The age limit prevents them coming in.

Q. But that is one of the qualifications required?

A. We say that our experience is practically the same as that of a sorter, and that our work is inseparable.

Sir F. Mowatt: Not inseparable, because it is separated now.

A. We ray that experience is part and parcel of the qualifications for this office.

The Chairman: But the Department must be the judge whether an individual is qualified?

A. Quite so.

Q. Now, supposing that then postmen could satisfy the Departmentand I am not raising the question whether the Department requires too great a qualification or not-supposing, I say, that the Department is satisfied with regard to the qualifications of any particular postman, I suppose you suggest that he should become a sorting clerk at once?

A. We contend that the present barrier is impassable. It ensures to certain people certain privileges which are conserved. I will give an illustration. The police enter at one standard. They are selected for important duties. I have been through the office of the Liverpool Police force, and, from a humble postman's point of view, I must say that the work seems to be excellently done, and quite equal to anything I have seen in the Post Office. The men in the police office are selected from the ordinary police force; the examination required of them is about the same as that 
we go through, and I would suggest that all the work required in the Post Office could be done by men selected from those who possess the ordinary qualifications and pass the ordinary standard, although, as I have already suggested, I would recommend that that standard be made excellent.

The Chairman: Do you mean that the sorting clerks should be recruited from the ranks of the postmen?

A. I do, sir. And we made a similar appeal to the Ridley Commission.

Q. And did the Ridley Commission make any recommendation?

A. No ; they did not touch it. We also presented a petition to the same effect in 1892. I would sooner be a member of a crew of slaves than of wrangling pirates, incapable of cohesion and obedience. As the army, navy, and police are on a common level to all, except officers when beginners, so should the Post Office be, so that preferment shall be common property to all who merit it, and authority be held by no man over another, except in the case of persons promoted to supervise.

\section{BIG WAGES TO SOME THE CAUSE OF SMALL WAGES TO OTHERS.}

I have said the high wage paid to high officials is one of the chief causes of discontent. I will add -and of low wages to postmen. Suppose a sum divided into three equal parts, one for the workmen, one for supervisors, and one as surplus for the nation; you cannot increase the amount for supervision without diminishing the amount paid to the workers, or that set aside as surplus, without reducing workers and supervisors, and so on; but the very reason for supervision is that it is capable of getting more work out of the workers, and it will be pressed by the defenders of the surplus to do this, or be depleted itself. Therefore it will endeavour to cut down force or lessen wages. The same holds with the different branches of the Service. Unduly pay telegraphists and it will be at the expense of other workers or the surplus; unduly promote them to postmasterships and these are lessened to others. This is illustrated in the treatment of the great army of postmen, for, like those who shared among them the garments of Christ, the clerks and telegraphists share between them or tear from each other the privileges of the Service, and the army of postmen are sent empty away. (Laughter.) The first 32 men at the head of the Post Office receive $£ 501$ 2s. 6d. average salary; that is, about the pay of majors-general in the army. Fancy, 31 majors-general as head clerks! But I am not sufficiently acquainted with the Secretary's office to be able to say if about two supervisors or more would be adequate to that building. $\overline{\mathrm{I}}$ do know, however, something of the excess of supervision at Liverpool. 'In two small rooms with through doors there are one chief clerk at $£ 600$, one superintendent at $£ 310$, two clerks at $£ 190$ to supervise three telegraph lads, one sorting clerk, and each other. (Laughter.) In another small room (survey branch) there are one superintendent at $£ 400$, one at $£ 310$, and one at $£ 260$, and two clerks at $£ 190$ to supervise five firstclass sorting clerks, three second-class ditto, and a telegraph lad. In another small room with partitions there are one superintendent of accounts $£ 400$, one at $£ 310$, two at $£ 260$, and four $£ 190$ men to supervise two first-class clerks, the Postmaster's servant, and a telegraph lad. In another little room sits the chief superintendent at $£ 500$, another superintendent at $£ 260$, and one clerk at $£ 190$ to supervise one second-class clerk and a telegraph lad. In another room there are one superintendent at $£ 260$, one clerk at $£ 190$, and two first-class sorting clerks. At the counter, head office, for the important and intricate work of selling penny stamps, money orders, etc., there are two superintendents at $£ 260$ and four $£ 190$ men to control about four first-class and five second-class clerks. 
The Chairman: You must be perfectly aware that that is altogether an exaggerated description of the state of affairs in Liverpool?

A. No, sir; it is a true description.

Mr. Smith: Do you ask us to believe that the sole duty of these superior officers is to keep in order that small number of people?

A. I give it as an illustration, sir.

Q. Answer my question, please. Do you ask us to believe that the sole duty of these supervising officers is to keep in order this small number of persons?

\section{A. Oh, no. I do not say it is.}

Sir F. Mowatt: Then what do you mean?

A. I will explain it. Will you allow me to develop the point? A superintendent is added for governing or commanding when there is no commanding necessary in this particular branch of official work.

Mr. Smith: Then it is a question of title, not salary?

A. It is a question of both. If you were to put an artist in the corner of the room it surely would not be necessary to give him the title of general? There is not in any private firm in Liverpool anything approaching this gross waste, this fearful extravagance of public money. I have observed in my 19 years that about half the time of countermen is unoccupied. I inquired of one of the hall porters, a man of the most reliable and official type. He informs me, from years of experience, it would be understating their idle time to put it down to three hours out of eight. They are provided with seats, and I find Mr. Walsh, the senior counterman, only claims compensation to be added to his $£ 190$ a year for the injury done to his dignity by wearing uniform; he puts forward no claim on the ground of injury from the chairs being uncushioned. (Laughter.) It will be news to postmen in Liverpool, who were turned aside by Mr. Evans, superintendent, from entering objection notices, as too important for postmen, to learn from Mr. Walsh that positions at the counter were open to, and had by postmen in London. There are at Liverpool 79 positions at a mean average of $£ 2246 \mathrm{~s}$ open to 265 first and second class sorting clerks, or one to 3.4 ; seven positions would make a supervisor to every three clerks. The gross amount, not including the Postmaster's salary, expended on these few men in supervisors, at the mean, is $£ 17,720$. There are 37 positions at a mean average salary of $£ 23010$ s. open to 310 telegraphists, some of whom are boys; that is one to 8.4. The gross amount of the mean for these supervisors is $£ 8,530$. There are 22 inspectorships at mean average salaries of $£ 15013 \mathrm{~s}$. open to 634 postmen; the gross amount at the mean for these supervisors is $£ 3,315$. The other staffs combined number 575-59 less than the postmen-yet the amount paid for control alone amounts to $£ 26,250$. These are the men with pitiful complaints who want more-ever more, it matters not at whose expense, postmen's or country's. Our committee complained some years since of undue preference to a certain man; they had an answer from the then Postmaster-General that the higher authority never interferes in the Post Office with the recommendations of subordinate superiors. Again, more recently, the answer was repeated in another formthat the Postmaster's recommendations were always satisfactory, and the Postmaster-General saw no reason to interfere. I have here a letter dated 18th March, 1887, in which the following appears :- "The rules of the Post Office are, as you are aware, so strict that it is difficult for me to speak to Mr. Raikes without mentioning names, and might do harm to the individuals.

"I have spoken to him, however, generally, and he contends for a principle of selection for certain offices, and says that seniority cannot be the 
rule in such a service as the Post Office, or they might have men appointed who were not qualified for the offices.

"If, therefore, the Postmaster of Liverpool represented to him that the two men appointed were the best suited, I am afraid, from what he said, that he would not interfere further, as he says that it is a rule to trust to the judgment of the Postmaster, and that as a rule Mr. Rich's decisions have given satisfaction at the Post Office.

"With regard to the appointment in Lark Lane, I understand the man was one of the seniors, and no a junior; and in this case there was no passing over, as he was well acquainted with the district, and was an old officer."

Mr. Smith: It amounts to saying that as a rule he trusts the Postmasters?

Witness: Yes. The superiors are relied upon, and increase of salary, and increase of supervision initiated on their recommendation, and so we have the above picture of wanton expenditure at the expense of the poorest paid men and the nation. The higher officials regulate their own duties, a we have the spectacle of two superintendents- $£ 400$ men---in C.B., Liverpool, on early duty together when there is practically nothing doing. I have seen them chatting and wasting valuable time for half-an-hour at one spell, and becoming suddenly busy, accompany with a third superintendent at $£ 310$ one solitary stamper to the door with the outgoing London or Isle of Man mail.

Mr. Walpole: What o'clock was this?

A. It would be about 11 o'clock. I should propose, in the interests of the ration and the weaker servants, that a committee of three members of Parliament and three elected postal pensioners assist the Postmaster-General to hear appeals, make grants, and accept or reject proposals for increase and decrease of salaries. together with receiving tenders for contracts at whatever distance from London.

Mr. Walpole: One of the duties of the Postmaster-General is to receive tenders.

The Chairman: Surely you are going outside your case again?

Witness: It is only by the wav of reference. You see what a protection this would have been to Mr. Morley when he said he. dreaded to take over the mail-carts service, because of the expense of highly-paid officials. and it was no dotibt on this account he was prevented from relieving these poor scarecrow men and horses from the sweaters.

Mr. Walpole: Mr. Morley never said anything of the kind.

Witress: I now come to the estimate of the demands put in by telegraphists, and propose to show how postmen fared in '91, after the other's had been dealt with.

Mr. Smith: What is this about?

Mr. Walpole: Telegraphists' wages.

Witness: It is really a summary of what it will cost and how we fared in consequence of the other increases. I will go into that later on. I notice that there is no tangible estimate by the telegraph and other highlypaid sections. Mr. Fischer not even affording an approximate estimate of the cost of the required additions. Well may the revenue, like Mercutio, complain that an attempt is made to scratch it to death. I will roughly summarise the telegraphists' requests, together with their probable expense to the country. They want seven hours a day instead of eightone-eighth of the salary of the first and second classes. They want an extra week annual leave-one fifty-second of the same. The first and second 
classes in tondon and the provinces number 6,221, whose mean wages are $£ 572,8948 \mathrm{~s} \frac{1}{8}+\frac{1}{52}=\frac{15}{104}$, and $\frac{15}{104}$ of $£ .572,8948 \mathrm{~s}$. is $£ 82,62818 \mathrm{~s}$. $10 \frac{1}{2} \mathrm{~d}$.

Mr. Scott asked that $4 \mathrm{~s}$. extra be given at five years' service.

To affect those also who have passed the "jump" stage, say one-half of the second-class at $£ 10$ 8s. per man (£114 8s. per man in 11 years), - - - - . $£ 22,60912 \quad 0$

Mr. North wants a proportionate increase for the seniors, based on $£ 148 \mathrm{~s}$. and $£ 6$ enjoyed by first and second 一that is, $£ 1510$ s. 7d. for 213 seniors, - - -

$\mathrm{He}$ also complains his $\mathrm{C}$ division has only one-third of the number it should have-he does not say they are required, or that there is work, but on this point he provides a remedy in suggesting that their hours be shortened; this little increase would cost - - -

The abolition of classification raises the mean from $34 \mathrm{~s}$. to 38s. per week, a difference per year of - - -

$£ 24,140 \quad 0 \quad 0$

$£ 41,740 \quad 8 \quad 0$

They want pension after 25 years' service, also heirs provided for-say one-half present telegraph pension charge, - - - - - - - - - -

The telegraph branch cost the paying part of the Post Office last year to make up deficit, - - - -

All these little items give a prospect of debt for next year of - - - - - - - - - - - while less than 7,000 telegraphists only will have been appeased, 11,626 female telegraphists, sorting clerks, and sorters remain to be dealt with.

The Chairman: Had you not better leave aione the other branches of your own service, Mr. Walsh, and confine yourself to explaining the wants and demands of the postmen, and the estimated cost of satisfying those demands?

A. This is a point you cannot get over. If you increase the salary of one branch it is frequently at the expense of another, and we believe it has been repeatedly at our expense that the other sections of the Post Office Service have had their salaries increased.

Mr. Walpole: You want strongly to urge on this Committee not to increase any salaries in the Postal Service except those of postmen?

A. Yes, sir, I do.

Mr. Smitlı: Is that not enough, without going into the question whether the estimates are sound or unsound?

A. I am not saying whether they are sound or unsound.

The Chairman: Your evidence cannot be of much value unless you give us your estimate of the cost of your proposal. Lots of time has been consumed.

A. I will supply our estimate.

Q. Give us the estimate for your own particular branch. I do not want your estimate with regard to other parts of the Service.

A. You do not think I am capable?

The Chairman: I do not think you have the necessary knowledge.

A. The only way to deal with the subject is that which I have adopted in my statement, which $I$ hope you will allow me to read.

Q. When do you suppose we shall finish this Inquiry?

A. I will not take very long. I am simply giving the result.

Mr. Smith: Your items cannot be verified or discussed. They refer to another branch of the subject, on which you cannot have the data for forming an estimate. It does not affect your case. 
Mr. Walpole: I hope you will confine it to your own opinion. I trust it is not the opinion of postmen generally.

Witress: It is our general opinion that other classes have received increases of pay at the expense of the postmen. Perhaps it is not apparent how postmen suffer by these lavish salaries to telegraphists and others. A postman at Aberayon-the father of five children-gets $7 \mathrm{~s}$. per week, say for 48 hours' hard work. A telegraphist at the same place gets, say 40 s. for 48 'hours' work.

Mr. Walpole: Do you know that postman?

A. I put it in hypothetically. As a matter of fact, I have had information that it is so.

Q. I am quite sure it is not so.

A. Very well, sir, I will accept that; but I may suggest that it may occur in other parts of the country.

Mr. Smith: Do you really believe there is any postman doing 48 hours a week and only getting $7 \mathrm{~s}$.?

A. It came out before the late Postmaster-General that such things occurred in Ireland and elsewhere.

Q. Do you believe that at this moment there is a postman in this country doing 48 hours a week and receiving $7 \mathrm{~s}$. ?

A. I hope not.

Mr. Walpole: Then why do you put in this case?

A. I am putting it in hypothetically.

The Chairman : We do not want hypothetical cases.

Mr. Smith : If you don't believe in it, it amounts to nothing.

A. I am simply telling how the postmen suffer. The postman returns to the shopkeepers who supply him with bread, meat, and vegetables, $7 \mathrm{~s}$, or 48 hours' hard labour. The telegraphist gets 7s. worth of service from the shopkeepers, etc., similar to the postman, and pays the community with 8 hours 24 minutes' labour. The clerk's comparative luxury, if properly understood, is the cause of a postman's misery. Let a rich farmer pamper one child and unduly stint others of his family, and the law will and has interfered. If a contented and happy Service is desired, there will be only one class in the Service below supervisors, and postmen will be of that class. Instead of this 56s. and $£ 190$, if all workers, outdoor and indoor, rose to 45s. per week in all towns where postmen are paid 24s. now and upwards, uniformity and contentment would be possible, which never will be attained by favouring one section at the expense of the other.

Mr. Walpole: I deny that.

Witness : All right, sir. I may add that I estimate the saving to the Department by the arrangement I propose at $£ 186,87616 \mathrm{~s}$.

\section{BENEFITS TO THE SERVICE.}

Transfer from telegraphist or clerk to outdoor officership, by men unfit for indoor work, would be an easy matter, as it would carry with it no pecuniary disadvantage or disgrace, and indoor work ceasing to be regarded as a preserve of privileges would not be coveted by postmen as it now is. A more healthy state would accrue; postmen trusted more and thrown on their own resources would develop qualities (for deficiency of which they are blamed, though they have never had an opportunity to cultivate them), and clerks, finding the Department no longer forcibly keeping down the great mass of their fellow-workers, that they might more easily and as a matter of course attain promotion, would exert themselves to compel it by merit. 


\section{MR. MORLEY'S PROPORTIONATE INCREASE TO POSTMEN.}

Now, as to Mr. Morley's statement that postmen got an increase of wages proportionate to other classes in the Service, bear in mind, my lord, my illustration of the pseudo benefit conferred on Liverpool postmen. That illustration points to what we have believed all along, that the supposed increases of salary are often increases of staff.

Mr. Smith: When did Mr. Morley say that?

A. It was said in the House of Commons. I do not know the date.

Mr. Walpole : He said "correspondingly."

A. It amounts to practically the same thing.

The Chairman: I think you should quote Mr. Morley's exact words.

Mr. Walpole: As a matter of fact, he said nothing of the kind you have stated. What he did say was that certain increases had been made to certain branches, and then he said that the postmen would get a corresponding increase.

A. Yes, yes. The Postmaster-General's report states that since 1881 $£ 747,980$ has been granted, and of this supervisors, sorters, and clerks have received $£ 492,330$, and postmen, etc.. $£ 255,650$, a difference of 90 per cent. in favour of the upper sections, who are in number 73 per cent. less than postmen. In '91, after the other sections had received Sunday pay and other splendid advantages granted, and just two or three months before we got our revision, we received a letter at Liverpool in Mr. Raikes' own handwriting, stating that he had no intention whatever to alter in any way the pay or other conditions of postmen, but, thanks to the power of Parliament, he had to change his attitude towards us. The letter read:-

Dear Whrthey,-The scheme improving the position of employees in this Department, which has recently been promulgated, had reference mainly to the sorting clerks and telegraphists, and it has not been proposed to make any change as regards postmen, but I am glad I have been able to obtain the consent of the Treasury to enable the postmen to participate in the Bank Holidays, or receive pay in lieu of them. The memorial from the postmen, to which you call attention, is receiving consideration.

We had at this time no Sunday pay and only 4d. per hour for overtime.

The Chairman: But you have Sunday pay now?

A. Ol, yes; but I am only showing what has happened, and how it was intended to treat us until we brought the power of members of Parliament to press our case on the authorities.

The Chairman: You had a revision?

A. Yes; twelve months after the clerks.

\section{FINAL APPEAL.}

In pressing the Committee to recommend that the postmen's increment be increased from 1s. to $2 \mathrm{~s}$., I but ask what the telegraphists regard as an imperceptible increase; our men have the same necessities, and, losing a greater amount of physical energy, require better nutriment to sustain the strain. Compare for one moment our younger men to American postmen-our youıg fellows work side by side with senior men, and do similar work, but receive only half the wages, and have 15 years to run the gauntlet of satisfactory conduct as well as wear and tear before they receive the maximum. Two years after appointment the American receives the splendid maximum of 2208 6s. 8d. It cost America in salaries this year for 12,744 carriers $£ 2,451,19410$ s. $2 d$., and $£ 66,375$ to substitute these on annual leave. Our 24,556 established postmen cost at the mean $£ 1,338,554$ 8s., a difference of $£ 1,112,6402 \mathrm{~s}$. 2d. expended by America (without the money on substitutes) on her postmen, which are a little over half our num. 
ber. So much for the generosity of Great Britain to her workers. Our claim for 22 a week all round would increase the anuxa] cost :£576,813 12s., or by giving towns now receiving 248 . and upwards $£ 2$, and those receiving $22 \mathrm{~s}$. and under $30 \mathrm{~s}$. (the lower rate would affect $9.900 \mathrm{men}$ ), and the cost would then be $£ 448,53010$ s., a reduction of $£ 128,700$. Men work to live, and should have the means to live a healthy and comfortable life. The amount we ask seems large, but it is less than our just dues. The population is about 40,000,000; suppose one in five taxpayers, the cost to each would not amount to 1s. 2d. a year. Take income tax as a basis ; in 1889 taxed incomes amounted to $£ 645,000,000$ on incomes of $£ 160$. It would amount to $2 \mathrm{~s}$. $2 \frac{1}{2} \mathrm{~d}$. a year, and for these fractions of charge 24,556 postmen, with about twice their number depandent upon them, could be made comfortable and happy, and even this infinitesimal charge to each would almost disappear if organising capacity were displayed in paring down gross extravagance in the Post Office. I may tell you, my lord, that the estimate you mentioned on Monday is nearly right. It is the difference between two means I have given; yours is the annual cost.

Mr. Walsh, in the course of his evidence, also laid before the Committee the following table, giving

A Few Specimen Cages of the Reliff Force Men, Liverpool, and Showing the Age of Men on Appointment.

\begin{tabular}{|c|c|c|c|c|}
\hline Names. & $\begin{array}{c}\text { Date of } \\
\text { Appointment. }\end{array}$ & $\begin{array}{l}\text { Age when } \\
\text { Appointed. }\end{array}$ & $\begin{array}{l}\text { Service 2s } \\
\text { Telegraph } \\
\text { Messengers. }\end{array}$ & $\begin{array}{l}\text { Wages as Tel. } \\
\text { Messengers and } \\
\text { Assist. Postmen. }\end{array}$ \\
\hline $\begin{array}{l}\text { A. E. Peck, - } \\
\text { R. O. Parry, - } \\
\text { J. W. Gregg, } \\
\text { J. Nixon, - } \\
\text { J. Richardson, } \\
\text { W. J. Hind, - } \\
\text { W. Price, - } \\
\text { Average, - }\end{array}$ & $\begin{array}{r}\text { 11th Aug., 1892, } \\
\text { 10th Nov., 1892, } \\
\text { 5th Jan., 1893, } \\
\text { 19th April, 1893, } \\
\text { 16th May, 1893, } \\
\text { 16th June, 1893, } \\
\text { 10th Nov., 1892, }\end{array}$ & $\begin{array}{l}21 \text { years, } \\
20 \frac{1}{1 \frac{1}{12}} \text { years, } \\
20 \frac{1}{4} \text { ye } s r s, \\
20 \frac{1}{2} \text { years, } \\
20 \frac{1}{4} \text { years, } \\
20 \frac{1}{2} \text { years, } \\
19 \frac{1}{\frac{1}{2}} \text { years, } \\
20 \frac{1}{3} \text { years, }\end{array}$ & 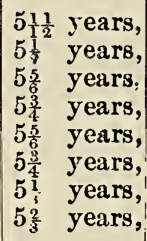 & $\begin{array}{l}\text { 18/- per week, } \\
18 /- \text { per week, } \\
\text { 18/- per week, } \\
18 /- \text { per week, } \\
18 /- \text { per week, } \\
18 \text { /- per week, } \\
18 /- \text { per weok, } \\
18 /- \text { per week, }\end{array}$ \\
\hline
\end{tabular}

WAGES.

\begin{tabular}{|c|c|c|c|c|}
\hline Names. & $\begin{array}{c}\text { Wages on } \\
\text { Appointment. }\end{array}$ & $\begin{array}{l}\text { Age when 21/- } \\
\text { will be had. }\end{array}$ & $\begin{array}{c}\text { Age when } 30 /- \\
\text { and stripes will } \\
\text { be had. }\end{array}$ & Rem trks. \\
\hline $\begin{array}{l}\text { A. E. Peck, - } \\
\text { R. O. Parry, - } \\
\text { J. W. Gregg,- } \\
\text { J. Nixon, - } \\
\text { J. Richardson, } \\
\text { W. J. Hind, - } \\
\text { W. Price, - } \\
\text { Arerage, - }\end{array}$ & $\begin{array}{l}\text { 17/- per week, } \\
\text { 17/- per week, } \\
17 /- \text { per week, } \\
17 / \text { - per week, } \\
17 /- \text { per week, } \\
\text { 17/- per week, } \\
\text { 17/- per week, } \\
\text { 17/- per week, }\end{array}$ & $\begin{array}{l}25 \text { years, } \\
24 \frac{1}{r^{2}} \text { years, } \\
24 \frac{1}{4} \text { years, } \\
24 \frac{1}{2} \text { years, } \\
24 \frac{1}{4} \text { years, } \\
24 \frac{1}{2} \text { years, } \\
23 \frac{1}{2} \text { years, } \\
2 \frac{1}{7}_{7}^{2} \text { years, }\end{array}$ & $\begin{array}{ll}36 & \text { years, } \\
35 \frac{1}{1^{2}} & \text { years, } \\
35 \frac{1}{4} & \text { years, } \\
35 \frac{1}{2} & \text { years, } \\
35 \frac{1}{4} & \text { years, } \\
35 \frac{1}{2} & \text { years, } \\
34 \frac{1}{2} & \text { years, } \\
35 \frac{2}{7} & \text { years, }\end{array}$ & $\begin{array}{l}\text { These men average } \\
\text { about } 2 \frac{1}{2} \text { years on } \\
\text { this relief force, } \\
\text { during which their } \\
\text { Xmas Boxes do not } \\
\text { amount to much. } \\
\text { Serrice as Tel. Mes. } \\
\text { and Auxiliary is not } \\
\text { inoluded in the Tel. } \\
\text { Mes. Service. } \\
\text { These men lose 1/ on } \\
\text { appointment. }\end{array}$ \\
\hline
\end{tabular}

\section{SUPERANNUATION-LONDON AND PROVINCIAL.}

Before beginning my statement on the superannuation question, I may mention that I am speaking upon it for the whole country. My colleague in London has retired, and the London representatives have passed a vote 
of confidence in me as capable of dealing with this question for the postmen generally.

The Chairman: I must ask you to compress this sufficiently to enable you to finish to-day. I really cannot go on after four o'clock.

Witness : Of course not.

The Chairman: And I cannot take you as a witness on another day.

\section{WHAT THE POSTMEN DESIRE.}

Witness : After wages there is no subject of such consequence to postmen as per.sions. The Committee, therefore, over which your lordship presides, in addition to being regarded by postmen as a judgment seat for the righting of long-accumulated wrongs, is an object for anxious speculation and hope as to it: recommendations on this question. We think your counsel should make an Act of Parliament possible to lessen our qualifying period of service, so that some vitality may remain to allow of our enjoying a pension; also, that such pension shall be sufficient to support a man with some degree of comfort without competing with other workers; and, lastly, that some provision shall be made for our wives and children in the event of our death. The profit made on our work can and ought to admit of provision such as we ask. Concede this, and the prospect of security from want in our old age (with the knowledge that death will not condemn our wives to the degradation of charing, or hateful outdoor relief, but enable them to cherish and bring up healthy and sturdy British children) will do much to enhance our lives, and content a body of workers who are the mainstay of the Postal System. Mr. Boulden, telegraphist, made a claim on behalf of the telegraph section for exceptional treatment, and your lordship entered a caveat, as I understand, at the lameness of this sectional method. If there is a body in the Service which deserves exceptional treatment, both on account of the meagreness of wages making provision for old age impossible, and on account of the grinding character of the work, that body is the postmen; but in claiming just treatment postmen do not desire unjust treatment to any other section of workers. If, as British citizens and tax-payers, we should limit or suggest a limit to the application of our scheme, we would draw the line at men receiving over $£ 300$ per annum. For what has been already said as to the unequal advantages of the few, lessening to starvation point the wages of the many, applies with greater force to the distribution of the pension fund. My figures and comparisons are, of course, to build up and sustain the postmen's case. The superior knowledge and intelligence of the other sections will enable them to investigate these matters and devise their own remedies. Our scheme is simple, direct, and easy of application. It is the result of due deliberation and unanimous approval on the part of the late Conference of postmen, and I can say will be a satisfactory solution of the pension question. It will, if granted, set at rest the just claims of postmen for the present generation. It is as follows :-

That the postmen of the United Kingdom be allowed to retire after 30 years' service. The rate at 30 years' service, and at all periods at which pension is granted, to be 1-45th instead of 1-60th of their wages for each year served, and widows of postmen who die in the Service, or, after being pensioned, provided they were married to the said postmen before their retirement, or had been two years married prior to the husband's death while le was in the Service, to receive pensions of $10 \mathrm{~s}$. per week during widowhood, children to receive $3 \mathrm{~s}$. per week each up to 15 years of age. I am informed that postmen were the last in the Postal Service to receive a pension, the solicitude of the heads of the Postal Service, in former times as now, being entirely absorbed in looking after the pensions and emoluments of the higher officials. 


\section{POSTMEN'S PENSION AS COMPARED WITH ENGLISH, WELSH,} AND IRISH POLICE.

The police have been and are much better cared for. Parliament, since 1839, has passed no fewer than nine Acts in the interest of the English and Welsh police. These number about 80,000 , and all are enabled, by Act of Parliament, to retire at 25 years' service, the scale being at 25 not less than $30-60$ ths or more than 31-50ths of their wages; that is to say, the maximum of police wages being about 30s. per week throughout the country, and in no instance touching the low level of the postmen. The policeman retires at 25, as though he had 30 years' service as a postman; and if the police authority like to award 31-50ths, their wages supposed the same, viz., $30 \mathrm{~s}$. per week, the postman would receive $12 \mathrm{~s}$. 6d. while the policeman would receive 18s. $7 \mathrm{~d}$. per week pension for the same service. In Liverpool and many other towns the police retire at 26 years' service with two-thirds pay as pension. In case of accident or disablement the policeman may be awarded full pay as pension at any period of his service. The wives and children of police officers are pensioned, the widow $£ 15$ per annum, and the children $£ 210$ s. a year each, that is if the husband has been killed in the Service. In case of constables who die from natural causes in the Service, or after being pensioned, gratuities are granted at a rate of one month's pay for each approved year's service to the widow and children. The Royal Irish Constabulary, over 12,000 strong, and directly employed by the Government, is still more favourably treated. At 26 years' service constables can retire on 30-50ths of their pay; that is, at 25 years an Irish constable retires with the same pension as the postman has to serve 36 years for. At 28 years' service he receives two-thirds pay as pension. There are no deductions from the pay of Irish constables who have joined since 1883. There are exceptional rates for constables injured in the Service, and widows and children in case of the constable's death by violence receive pensions-the widow during widowhood, and the children up to 15 years of age. The widows and children of constables dying after 15 years' completed service are also pensioned, though the constables die from natural causes. It is inexplicable that the postman worker, whose vitality is consumed at such a rate, should have no adequate provision made for the wrecked and used-up part left him of life, when the country has had its pound of flesh, while such jealous care is taken of the unused and able-bodied policeman, who may be said rather to have rusted than worn in his country's service.

The Chairman: Is it not the case that the police have to contribute a certain amount to the superannuation fund-that it is, in fact, held back from his weekly wages?

A. In the case of the Irish police they do not, but in the case of the Finglish and Welsh police they do. I thoroughly believe-and I shall be coming to that later on, at the end of my statement-that our men, rather than that the present state of things should continue, would, if their demand for £2 be granted, be willing to make the slight contribution necessary for the pension.

Sir F. Mowatt: Have you finished your comparison with the police? You are aware, I suppose, of the great risk to life which they run in view of the circumstances under which they carry out their duties, the frequency with which they are injured, and the manner in which their vitality is used up, while, as a rule, the postnien do not get assaulted two or three times a week?

A. No, sir; but, as a matter of fact, assaults on the police are not frequent. Young constables are mostly put to the rough work on that account. 
Sir F. Mowatt: You are quite in error. I sat on a Committee which considered the question, and the qualification for this pension was entirely the frequency of assaults and the manner in which policemen are used up by them. After 25 years' service they are quite unable to go on.

Witness : I think I could demonstrate a different state of things.

Sir F. Mowatt: That, at all events, was the ground upon which the pension was settled. If that was wrong, then the Committee came to a wrong conclusion.

Witness : As a matter of fact, after they are pensioned they occupy some of the best positions open to working men.

\section{NATURE OF THE POSTMEN'S WORK.}

If we suppose in a community of four, one man to sow, reap, and thresh corn, grind it and make it into bread; another to make wool and fibrous material into clothes; another to kill cattle, provide meat, and make boots from the hides; and the fourth set over the other three to keep them peaceful and honest, we shall understand that three are engaged in hard labour to provide themselves and the policeman bread, meat, boots, and clothes, and that his return service of watching is the easiest and least laborious. But what would be thought of those from whom the severest service was exacted, if they were fools enough to almost neglect provision for their old age and offsprings in comparison to the lavishness of their provision for those of the policeman, who had always been a cause of greater exertion or service to them? Now, in the present complex state of society our return service to the community calls us forth at all times of day or night, to face all weathers, storms, frost and rain, to be often drenched to the skin two or three times in one day, to cross bleak mountains and marshes, becoming benumbed and frozen to carts.

Mr. Walpole: Does that occur in Liverpool? (Laughter.)

Witness: I am speaking for the whole country. We are sometimes benumbed and frozen, even to the extent of being unable to dismount until lifted down. We have to enter fœtid slums and climb hundreds of stairs with loads of from 30 to $95 \mathrm{lbs}$. weight-I think I have sufficiently demonstrated this-and all the time the strain on the mind never ceasing, for tliere are inquiries to make here, and answers to give there, charges to collect, and, above all, a far-reaching code of discipline to comply with. This service makes it unnecesary for the farmer to leave his plough to take his message to the town; the lawyer need not use valuable time carrying a message to his client; the nobleman need not leave his chateau, nor the cotter keep from his work to carry a message to a distant friend. The community go on oblivious that they are spared all this exertion and more, by the efforts of their postmen. But if we do good and necessary service, we require an equitable and honest order in the shape of money to obtain a return service from the community, such as shall not only keep us in comfort and health when working, but sustain us and those dependent upon us th our old age. Our treatment in the past is not creditable to those who should have taken care of us, nor does it reflect well on ourselves to be practically in the position of the three workers I lave described, without intervening our intelligence to bring about more equitable treatment as regards pension. I see Dr. Wilson's salary is $£ 930$. I suppose his work is from 4 to 6 hours a day. In all instances of men so salaried and so worked I observe the difficulty is to get them to retire from the Service. Dr. Wilson's evidence beats anything I have ever read, even in the care for and treatment of slaves. The evidence in the Maybrick case as to how a man's liver should be pounded was human in comparison.

The Chairman: Please do not go into those matters. 
Witness (continuing): First British lads, the sons of working men, are engaged to work, and if the severest form of work in the country does not wreck them in six months it may be it will in two years; if not, then five years will tell a tale. I am glad this Committee was appalled by such evidence. You are first to squeeze out of the lads all the energy possible, then throw away the husk. The reverse operation, however, he recommends at the other end. You are to keep thein in harness while the slightest energy remains until they are killed off. Does our country need all this ; must a copper or two per head be saved at the expense of human life?

Mr. Walpole: Dr. Wilson said nothing of the kind that you are putting into his mouth.

Witness : I had better finish it.

Mr. Walpole: We have got his evidence.

Witness : But he implies what I suggest by not wanting to limit the terin we have to serve for pension. He wanis to keep us as long as he can, in order that we may be killed off. He siys 4.2 per 1,000 is extremely low for a death rate, but that 6.39 , the postman's death rate, is high in comparison to the Registrar-General's returns ; yet his is only a return of men serving, and does not include the deaths of the pensioned. He says one-fourth of the candidates are rejected at the first examination, and that the final examination is not quite so high-say for the intermediate and final anotlier fourth-that is 50 per cent. rejected. He has not got his probation extended to five or ten years yet. Well, note, the weak or dying branches are lopped off at both ends, and then this fair and impartial statistician compares the sound lives after the unhealthy have been extracted, with unselected lives, cripples and diseased of all trades, yet the postmen's death rate is high in comparison to the Registrar-General's returns. I find his pensioned of 6.3 per 1,000 is more favourable to a pension scheme than my $T^{7}$ per cent., the difference of $\frac{3}{100}$ of a per cent. between us, is, no doubt, through my including porters and labourers in my pensioned, though $I$ do not include the body of labourers from which they were drawn to base them on.

\section{SIR W. B. RICHARDSON ON POSTMEN'S WORK.}

To show the effect on life of the service we render, I quote Dr. Sir W. B. Richardson, one of the first authorities of the day on such a subject. This evidence is the more valuable from not having been procured. It was given as part of a lecture in August, 1893, before the Sanitary Institute at Brighton. "There are some callings," siid Dr. Richardson, "which on account of their monotony and steady wear and tear from constant work require the same regular limitation of time. The postman is an excellent illustration of the class of worker included under this head. The work of the postman is one continuous busy-go-round; he is on his feet during the whole of his working hours. The result is that the postman wears out fast. The late medical officer to the General Post Office-Dr. Waller Lewis -was fully alive to the fact. He referred to it in his reports, and he several times spoke to me about it. There are some men, he told me, who sustained the tedious labour fairly, but none bore it well, and the weaker ones but badly. The effect generally was to produce premature old age ; in other words, shortening the life of the worker." The telegraphists make a strong point of their sedentary occupation and cramped position at work predisposing to respiratory disease. Let them have a turn at stairclimbing with heary loads, and tiley will begin to know something of hard work, wear and tear, and the long lifo Dr. Richardson refers to, as reserved for postmen whose oceupation is not sedentary. 


\section{COMPARISON WITH OTHER POST OFFICE PENSIOŃS.}

My experience is that so-called sedentary occupations in the Post Office are closely allied to, if not synonyms to express "light work, abnormally" high wages, and long life." In the 1893 and 1894 Estimates I find 44 Post masters, surveyors, and secretaries were pensioned. 'Their average ages were 66.6 , their average pensions 62.6 per cent. of their own wages, $66 \frac{2}{3}$ being the highest point obtainable, and 28 of them, by overstaying their pensionable age and servics, relieved their country of no less a sum than $£ 38,722$ 2s. 1d. Only one of the 44 is given in the death column of the same Estimates, that is 2.3 per cent. In the same vear 156 postmen were pensioned, averaging 55.8 years of age and 27.4 of service. Their pensions were only 45.6 per cent. of their wages. There were seven deaths of these pensioned in the same year, that is 4.5 per cent., or nearly double the Postmaster's death rate. In 1894 and 1895 there were 14 Postmasters pensioned, and no deaths of these in the same year. The postmen numbered 166 , but 14 of them, or 8.4 per cent., died in the same year. In 1895 and 1896 the Postmasters pensioned were 19; of these no denths are recorded. There were pensioned in the same year 160 postmen; of these pensioned 11 again were dead; that is, 6.8 per cent. In four years-' 92 , ' 3 , ' 4 , and ' 5 -there were pensioned 109 Postmasters, surveyors, and secretaries; of these two died in the year they were pensioned. In the same four years 635 postmen wers pensioned; 37 died in the year they were pensioned, a difference of 4 per cent., or an accelerated death rate of 4 to 1 in the first pensioned vear for the postmen pensioners.

Sir F. Mowatt: Do you mean 37 of the identical postmen who were pensioned in that year?

A. Yes.

Mr. Sinith : And they died within the year?

A. Yes; they died within the year.

Sir F. Mowatt: And how did you ascertain that?

A. It is in the Estimates.

Q. Are the particular men named?

A. Yes; I am prepared to put in an explanatory table if necessary. In the four vear's referred to the pensions of 12.3 per cent. of the postmen were under 6s. per week, and an additional 24.8 per cent. of them under 10 s per week.

Mr. Smith : Do these figures refer to the London staff?

A. No; to the whole country.

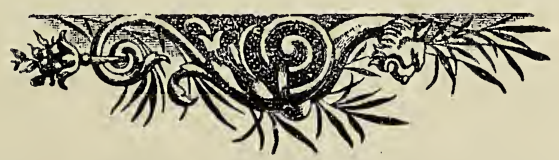


This is the explanatory table:-

\begin{tabular}{|c|c|c|c|c|c|c|}
\hline 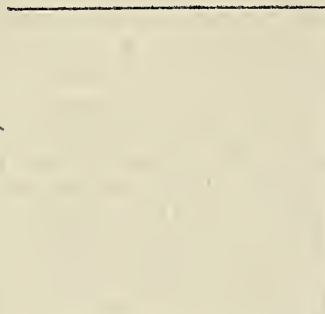 & 离 & 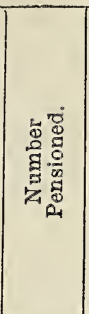 & 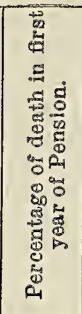 & 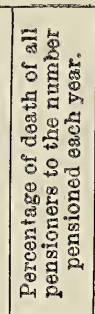 & 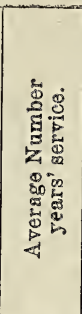 & \\
\hline Male Telegraphists, & $\begin{array}{l}1892-3 \\
1893-4 \\
1894-5 \\
1895-6\end{array}$ & $\begin{array}{l}19 \\
11 \\
21 \\
16\end{array}$ & $\begin{array}{r}14 \cdot 7 \\
9 \cdot 1 \\
19 \cdot 0 \\
6 \cdot 2\end{array}$ & $\begin{array}{l}26 \cdot 3 \\
81 \cdot 8 \\
52 \cdot 4 \\
43 \cdot 8\end{array}$ & $\begin{array}{l}22 \cdot 6 \\
25 \cdot 5 \\
22 \cdot 9 \\
22 \cdot 1\end{array}$ & $\begin{array}{lcc}5 & \text { s. } & \text { D. } \\
50 & 14 & 47 \\
49 & 17 & 8 \frac{3}{4} \\
49 & 19 & 5 \\
48 & 14 & 11\end{array}$ \\
\hline & Mean & $16 \cdot 7$ & 122 & $51 \cdot 1$ & $23 \cdot 3$ & $49 \quad 1 \quad 4 \frac{1}{4}$ \\
\hline $\begin{array}{l}\text { Female Telegraphists, Re- } \\
\text { turns and Counter- } \\
\text { Women, also Women } \\
\text { Supervisors, }\end{array}$ & $\begin{array}{l}1892-3 \\
1893-4 \\
1894-5 \\
1895-6\end{array}$ & $\begin{array}{l}14 \\
31 \\
28 \\
37\end{array}$ & $\begin{array}{l}\dddot{6} \cdot 4 \\
3 \cdot 5 \\
2 \cdot 7\end{array}$ & $\begin{array}{r}14 \cdot 3 \\
6 \cdot 4 \\
39 \cdot 3 \\
13 \cdot 5\end{array}$ & $\begin{array}{l}18 \cdot 8 \\
21 \cdot 6 \\
18 \cdot 6 \\
20 \cdot 8\end{array}$ & $\begin{array}{rrr}29 & 1 & 5 \frac{8}{4} \\
38 & 10 & 2 \frac{3}{4} \\
33 & 11 & 0 \frac{3}{4} \\
39 & 1 & 11 \frac{3}{4}\end{array}$ \\
\hline & $M=\operatorname{an}$ & $27 \cdot 5$ & $3 \cdot 1$ & $18 \cdot 4$ & $19 \cdot 9$ & $\begin{array}{lll}35 & 1 & 2 \frac{1}{4}\end{array}$ \\
\hline $\begin{array}{l}\text { Overseers, Sorters, and } \\
\text { Sorting Clerks, - }\end{array}$ & \begin{tabular}{|l|}
$1892-3$ \\
$1893-4$ \\
$1894-5$ \\
$1895-6$
\end{tabular} & $\begin{array}{l}21 \\
28 \\
33 \\
28\end{array}$ & $\begin{array}{r}4 \cdot 7 \\
7 \cdot 9 \\
6 \cdot 0 \\
17 \cdot 8\end{array}$ & $\begin{array}{l}90 \cdot 5 \\
27 \cdot 3 \\
51 \cdot 5 \\
78 \cdot 5\end{array}$ & $\begin{array}{l}29 \cdot 7 \\
31 \cdot 0 \\
30 \cdot 9 \\
26 \cdot 5\end{array}$ & $\begin{array}{rrr}73 & 19 & 1 \\
76 & 4 & 9 \frac{1}{4} \\
77 & 6 & 8 \frac{1}{4} \\
60 & 17 & 10 \frac{1}{4}\end{array}$ \\
\hline & Mean & $27 \cdot 5$ & $9 \cdot 1$ & $66 \cdot 9$ & 295 & $\begin{array}{lll}72 & 2 & 1 \\
\end{array}$ \\
\hline Postmen, & \begin{tabular}{|l|}
$1892-3$ \\
$1893-4$ \\
$1894-5$ \\
$1895-6$
\end{tabular} & $\begin{array}{l}153 \\
156 \\
166 \\
160\end{array}$ & $\begin{array}{l}3 \cdot 2 \\
4 \cdot 5 \\
8 \cdot 4 \\
6 \cdot 7\end{array}$ & $\begin{array}{r}103 \cdot 9 \\
91 \cdot 0 \\
101 \cdot 8 \\
86 \cdot 8\end{array}$ & $\begin{array}{l}28 \cdot 8 \\
27 \cdot 4 \\
27 \cdot 0 \\
28 \cdot 8\end{array}$ & $\begin{array}{ccc}31 & 8 & 5 \\
29 & 3 & 0 \frac{1}{4} \\
32 & 11 & 11 \frac{1}{2} \\
35 & 17 & 4\end{array}$ \\
\hline & Mean & $158 \cdot 7$ & $5 \cdot 7$ & $95 \cdot 8$ & 28 & $\begin{array}{lll}32 & 5 & 2 \frac{1}{4} \\
\end{array}$ \\
\hline $\begin{array}{l}\text { Average for first three- } \\
\text { divisions, - }\end{array}$ & $\ldots$ & 239 & $8 \cdot 1$ & $44 \cdot 1$ & $24 \cdot 2$ & $\begin{array}{lll}52 & 1 & 6 \frac{1}{2}\end{array}$ \\
\hline Difference, $\quad-\quad-\quad$ - & $\ldots$ & 134.8 & $2 \cdot 4$ & $51 \cdot 7$ & $3 \cdot 8$ & $19 \quad 16 \quad 4 \frac{1}{4}$ \\
\hline
\end{tabular}

\section{A Comparison with the Sorters.}

To increase $£ 325$ s. $2 \frac{1}{4} \mathrm{~d}$. tc $\frac{28}{45} £ 1015 \mathrm{~s} .0 \frac{3}{4} \mathrm{~d}$. w ould be required.

The total, $£ 43$ 0s. 3d., would be still $£ 9$ 1s. 3td. short of the sorter's and C's. average. The postmen ask forty-fifths instead of sixtieths to be their rate of pension; the average of the above divisions, taken separately, is already more than postmen are asking for. The postman gets $£ 325 \mathrm{~s} .2 \frac{1}{4} \mathrm{~d}$. for 28 years' service; for 24.2 years' service (the other sections' average) he would only get $£ 2717 \mathrm{~s} .7 \frac{3}{4} \mathrm{~d}$, , or $\$ 24$ 3s. $10 \frac{3}{4} \mathrm{~d}$. less than those named, for the same number of years' service. My former contention, and Dr. Richardson's also, that postmen wear out fast, and are dying when pensioned, is 
borne out by the percentage of deaths to the number pensioned. The other sections have 2.4 per cent. more deaths in the first pensioned year, but in the annual death rate of all the pensioners as a percentage of the pensioned in the same year, they are 51.7 per cent. better off than postmen.

Sir F. Mowatt: You say their death rate is 51 per cent. better than that of the postmen?

A. Yes; the difference of percentage as against the postman is 51 .

Q. The postmen die faster?

A. Yes.

Mr. Smith: The percentage is the percentage of deaths of pensioners, calculated on the number, not of all the pensioners, but of t'.ose pensioned in a particular year?

A. It would be the same thing if I based it on the total number. I do it the same as in the Estimates. The pension of the other sections then, being already nearly double that of postmen, it favours an addition being given only where it is badly needed. Attempting to satisfy the craving for money of highly-paid officials simply places a larger amount of capital in the hands of men with safe incomes to enable them to compete against business men who have no security. It is unnecessary, and will not even satisfy. To illustrate this let me cite a case:-Mr. Banning ceased receiving pension in '91, the cause being his having committed suicide because his investment in salt shares had not turned out profitable. His pension was $£ 1,133$ 19s. 3d., his salary, therefore, $£ 1,700$ 17s. $10 \frac{1}{2} \mathrm{~d}$. $£ 1,000$ of this sum saved for ten years would have given him a capital of $£ 10,000$, which, at 4 per cent., would have yielded $£ 400$ to add to his pension, or even at the low rate of $2 \frac{3}{4}$ per cent. Consols at 98 , would have insured to him and his heirs $£ 28012 \mathrm{~s}$. per annum of a perpetual pension. My lord, it is mockery of our condition to cite a case or two, as Mr. Morley did, of men who had entered as postmen leaving the Service with good pensions as Postmasters, thus leading the strongly imaginative to assume that this is the normal wind-up of a postman's life. Whether one or twenty men entering as postmen leave as Postmasters is but cold comfort to about 80 per cent. of postmen doomed to premature old age and death in the postmen's ranks, with the inadequate provision made for postmen in such events. In Appendice A Postal and Telegraph Vote, 1895 and 1896 Estimates, we find that 723 surveyors, secretaries, controllers, and clerks receive in pension $£ 99,549$, while 2,246 overseers, sorters, and postmen receive $£ 70,593$; that is to say, a number less than one-third of the sorters, postmen, etc., receive a sum equal to them and $£ 28,956$ over. The heads of the Department allow high wages to be paid their own class, and that class is abnormally swelled, hence the magnitude of the gross amount paid in pensions, and the shudder of Ministers at the bare idea of imposing more burdens on taxpayers in order to increase the pension of Civil servants. The list by adjustment may not need an increase at all to give postmen a look in. Parliament by cutting down lavish salaries and sweeping away surplus controlling power will confine pensions to enabling all worn-out faithful servants just sufficient to maintain them in comfort, a limit beyond which pensions should not go.

\section{APPLICATION OF SECTION X. SUPERANNUATION ACT, 1859.}

Section X. of the Superannuation Act, 1859, provides for the production of a medical certificate to the satisfaction of the Commissioners of the Treasury, showing that the person is incapable from infirmity of mind or body to discharge the duties of his situation, and that such infirmity is likely to be permanent; without this the grant shall not be lawful under the Act. Has this Act been complied with in the case of Mr. Johnson, Postmaster and Surveyor of Manchester, who was pensioned between ' 91 and 
'2 at 2460 per annum, and appointed Postmaster of Hastings in the same year at a salary of $£ 540$ ?

Sir F. Mowatt: That case is new to me.

Witness: Or in the case of Mr. Tombs, controller, pensioned on $£ 400$ per annum at the same time, and within the year appointed to the Postmastership of Bristol at $£ 800$ per annum? What of the infirmity, in these cases, of mind or body being permanent? There is no evidence here of coming back for the love of being of service, else these men would serve at the pensioned rate. The proof is all in one direction; that is, benefit of self at the expense of the nation. The country is paying for these jobs $£ 860$ per annum without a demur, while worn-out postmen, their widows and children, are in workhouses, orphanages, and other dependent positions.

Mr. Walpole : The country is not paying anything extra for this.

A. Yes; in both cases.

Q. How?

A. If they were on their pensions other men would be employed in their place.

Q. Yes; but the salary paid would be more than the sum they are now receiving?

A. No, sir; it is exactly the same amount. Their places would hare been filled up. I may say that all sections in the Service look on this in the same way.

Mr. Smith: I do not understand. What do you mean by losing anything? It may be unjust, or it may be right or wrong-as to that I say nothing-but: where does the loss come in?

A. It is keeping another man out of the position.

Mr. Walpole: That may be so, but it is not a loss to the public.

A. I would like to consider that point again. My mind is too much engaged to deal with it now.

(I sent on an explanation, which has been entered in my evidence, to the following effect:- The loss occurs by these men being placed on pensions at all, when they were fit to serve. The salaries paid now at London, Manchester, Bristol, and Hastings are the same in amount as the salaries paid when these men served in London and Manchester. The amounts paid in pensions are, therefore, a loss to the nation.)

Mr. Walpole: The case happened before I became Secretary to the Post Office, and from my own experience I cannot tell exactly what occurred. I believe this is it, however. Mr. Tombs broke down in a very onerous office, and was not able to go on. But he was able to take a less onerous post, and he received a pension, together with a salary for the less onerous office, reduced in comparison with what an outsider would have been appointed at. His salary and pension were not to exceed the salary of his former office. It is, therefore, a saving to the public.

Witness : But it keeps out another man.

Mr. Walpole: Some other man would have had to be appointed to the office.

Sir F. Mowatt: And at the expense of the public.

Witness: Still, it is generally regarded as a not very good job. Compare these two cases with some I have here. There is $\mathrm{Mr}$. Timney, 7 vears auxiliary, 20 years appointed, 4s. 1d. a week, in Lurgan Workhouse. One poor fellow, J. Bulyer, is allowed, after 17 years' service, 4s. 8d. per week. He is blind, and in the workhouse of Athy; another in the same place is luxuriating on $5 \mathrm{~s}$. $4 \mathrm{~d}$. per week, after 28 years' service.

Mr. Walpole: Do you mean by the "same place" the workhouse?

A. No, not the workhouse, but in Athy.

Q. How many years' service, did you say?

A. 28 years' service for $5 \mathrm{~s}$. $4 \mathrm{~d}$. a week. At Liverpool 95 per cent. of the widows of postmen are wrenched from the care of their little homes and children to become charwomen. 


\section{PLEA FOR AUXILIARY POSTMEN BEING BROUGHT WITHIN THE SCOPE OF THE PENSION ACT.}

It must be sl.eer misconception of its obligations which blinds the wealthiest Government in the world in dealing with its children, to cause it not or.ly to neglect its parental solicitude for the weakest subjects, but actually to use their helplessness to oppress them by giving unremunerative labour. I speak of the auxiliary class, probably one-third of the postmen of the United Kingdom. The labour performed by this class in every instance is identical in importance with that performed by established postmen. In Liverpool, Newcastle, and througlout the large towns, we have whole sections of established postmen performing duties once performed by an auxiliary class; but there is need that the great profit made by the Post Office should not be diminished, and the late Postmaster-General has informed us that the supply of labourers exceeds the demand, so that the poorest, most helpless, and least able to provide for themselves in old age, needing paternal care, offer themselves for employment, and by a trick of trade are classed auxiliaries in order to save the revenue pensions. A kind of sentimentality has devised compassionate allowances for young lady telegraphists, children of supervisors in the Post Office and middle class people, on their leaving the Service to marry. But there is no compassion for poor old Bradley, an auxiliary at Maghull.

Sir F. Mowatt: Where is Maghull?

Witness : Outside Liverpool. This man has served his country in hail, rain, and snow for forty years. Nor is there any for hundreds like him. The law, it is true, will provide is workhouse for him and his poor old wife, and fill the minds of his relations, unable to keep him out, with the misery of the spectacle.

Mr. Smith: Has he gone there?

A. I have a letter from him, in which he says:-_"The distance I walk in one day is about 20 miles, as near as I can reckon it. When I first carried letters I had to go from 30 to 40 miles a day, viz., through Maghull, Melling, Netherton, Thornton, Sefton, and Lunt, and only received a 1d. a letter, paid on delivery. After I had been on a while they rose me to 9s. per week, at which I was kept for 9 or 10 years. Then they gave me 11s. 6d., then 13s. 6d., then $15 \mathrm{~s}$. , and about three vears ago they gave me 18s. I first carried letters in 1846.'

Q. Was he serving full time at $9 \mathrm{~s}$. a week, or only as an auxiliary?

A. As an auxiliary.

Mr. Walpole: Do you seriously believe any man, even in the old days, had to walk 30 or 40 miles?

A. I am giving his statement.

Q. Have you ever in your experience come across any case approaching that of a man walking 30 or 40 miles a day being subseqnently raised to 9s. a week?

A. I do not know that I have.

Q. Do you know anything of a case like it?

A. No.

Q. Do you believe that to be true?

A. I should rather not express an opinion. I am only here to give evidence.

Mr. Walpole : I only asked what your belief was?

The Chairman: It is a serious thing for a man to come here and give evidence and not be responsible for that evidence.

A. I should say it is too much on the average. I should say 20 miles or a little over it would be nearer the mark. I have had country walks my-
self as a substitute.

Mr. Walpole: Have yon ever had to walk 20 miles a day? 
A. I should say nearly that. One round I had was five miles, and that liad to be walked three times a day.

Q. But three times five is only fifteen?

A. Quite so; but there is the calling in and out. His letter concludes:-

"Altogether I have been off ill about six or seven times. In my younger days I had very good liealth, but the last few years I have not been so well. I will be 64 years of age in February. I am told I am not entitled to a pension, and I really den't know what to do when I am forced to retire. I lost the use of one arm when two years old. I have had one leg broken in three places, and now ons leg is shorter than the other, so you will see what my prospects are. I had a son, a postman here, who died four years ago through illness brought on by exposure to the weather, so I have no one to help me. I have received Sunday pay for about two years now. I must now conclude, hoping you will be able to do something for me, and with very many thanks to you for your great kindness.-I remain. yours sincérely,

Edmund Bradley."

Mr. Walpole: Then this old gentleman was 50 years at work, and is still in tolerably good health?

A. Yes; but he expects to go on the parish.

Mr. Smith: That is the case of an auxiliary?

A. Yes.

Q. Does your next evidence apply to auxiliaries?

A. Yes.

Q. Are the people in the Irish workhouses auxiliaries?

A. No; they have pensions.

Q. Do you of your own knowledge know anything about these men?

A. No; I only receive the statements.

Q. Have you any means of telling us of any other causes for their being in the workhouses-other than the lowness of their pensions?

A. No ; only their poverty.

Mr. Walpole: In fact you don't know as much as you know from the letter of Mr. Bradley?

A. Nothing more.

Mr. Walpole: Not so much.

Witness (continuing) said: Much is made of the disgraceful condition of the broken-down heroes of war, the sufferings and exertions of whom, in some cases, were confined within a very few years; but the misery and poverty of the used up worker has not sufficient poetry nor power in it to awaken those in whose service 40 or even 50 years' faithful drudgery has been done to a sense of their duty to maintain their servants in old age. This case has been before the present Secretary:-W. Nicholson, 30 years' service, Gateshead ; broke his service twice, retired ill-health, probably to die in workhouse. J. Cartwright, auxiliary, Oldbury, $23 \frac{1}{2}$ years' service, made the ordinary declaration before a magistrate when he joined the Service, and was for some time under the impression he would receive pension. His not being established, he says, was due to some error on the part of his then Postmaster; about ten years ago, however, he was asked to sign a paper disclaiming all right to pension when too old for work; another man at the same office was at the same time forced to sign a similar paper or quit the Service in 14 days, but breaking down soon after, Sir B. Hingley, late M.P., pressed the peor fellow's claim, and after several refusals by Mr. Morley to lay the case before the Treasury, succeeded in getting 6s. per week pension for him. I may qualify that statement, perhaps. I do not know whether the refusal was by Mr. Morley to lay the case before the Treasury, or whether it was a refusal on the part of the Treasury to grant the pension. 
Sir F. Mowatt: Better put it on the Treasury. These things are always put on the Treasury. (Laughter.)

Witness : I would remind the Committee that a few cases of auxiliaries receiving pensions appear in the Estimates. I quote a few cases from the 1893 and 1894 Rowland Hill Annual Reports, which will make it clear that the Department has little sliame either in the matter of allowing Christmas boxes to answer as wages, or charity as pension.

1. Late unestablished postman, London, 72 years of age, past work; donation.

16. Late unestablished postman, Clifden, Co. Galwayy, aged 70, paralysed (man and wife destitute); donation.

23. Retired rural postman, unestablished, Broadford, N.B., aged 80, living on two daughters (domestic servants); donation.

142. Late rural postman, unestabliṣhed, Poole, aged 76, unfit for further work; donation.

169. Late postman, unestablished, Brading, Isle of Wiglit, age 67, blind, wife bedridden; donation.

188. Late auxiliary postman, Alresford, aged 77, no pension; he combined the occupation of postman, astronomer, lecturer, poet, and cobbler. Now in receipt of parish relief.

190. Late unestablished postman, Gravesend, aged 65, spinal disease, almost blind, wife also biind.

1894.-71. Late rural postman (unestablished), Malden, self and aged wife dependent on charity.

174. Late rural postman, Recess C. Galway, aged 66, crippled by rheumatism, wife deaf mute; both in misery.

196. Late unestablished rural postman, Llandudno, work given up through incurable disease, four children dependent on him.

224. Late unestablished postman, Hackley, aged 79, unable, to work; no means.

272. Late unestablished postman, Lowestoft, aged 77, not entitled to pension.

283. Late auxiliary postman, Ware, aged 66 , disabled by rheumatism; an applicant for parish relief.

Nor are many of the pensioned preserved from want, while the mass of misery to orphans and widows can only be faintly conjectured, bearing, as it does, sad contrast to the mitigation by Government of like misery to policemen's widows and children.

4. Retired rural postman, Holywell, aged 63, small pension, son blind, wife prostrated with rheumatics; relieved.

7. Rural postman, Gloucester, disabled by rheumatism, man and wife dependent on small pension; relieved.

26. Retired postman, London, aged 80 ; small pension.

Retired postman, Liverpool (consumption), wife and two young children dependent on small pension; relieved.

46. Retired postman, Glasgow, chronic invalid, four young children, small pension; relieved.

61. Retired postman, E.C., aged 83, pension 58. per week, only son unemployed ; relieved.

66. Late parcel postman, Exeter, disabled by accident, small compassionate allowance; relieved.

73. Retired postman, Pembroke, aged 85, small pension; relieved.

119. Retired postman, Callan, pension $5 \mathrm{~s}$. $4 \mathrm{~d}$. per week; relieved.

177. Another postman, Callan, pension $4 \mathrm{~s}$. 7d. ; relieved. 
280. Retired rural postman, Basingstoke, aged 101; a soldier who fought in the Indian campaigns and Waterloo, guarded Napoleon at St. Helena, and served 21 years in the Post Office; his pension is so small that he is receiving parish relief; relieved.

1. Rural postman, Kingston, pensioned on 8s. per week, wife and three children to support; relieved.

2. Postman, Ipswich, aged 83, pension insufficient for his support; relieved.

7. Postman, Edinburgh, too ill to work, wife and child dependent on small pension; relieved.

- 12. Postman, Preston, spinal disease and partial blindness, 6s. per weck; relieved.

28. Rural Postman, Batl, aged 73, pension $£ 17$ a year; relieved.

24. Postman, Oldham, wife and three children depending on a pension of less than $5 \mathrm{~s}$. per week.

59. Retired station messenger, Gosport, aged 70, retired through injury on duty, wife a lunatic, compassionate allowancs of 5s. 111. per week; relieved.

63. Rural postman, Cupar Fife, paralysis, wife and self dependent an small pension; relieved.

76. Rural postman, Wantage, blind wife and six children dependent on small pension.

110. Postman, London, aged 64, wife and invalid daughter to support o I small pension; relieved.

124. Rural postman, Carlisle, pension $£ 10$ a year, dying of heart disease, two children dependent on him; relieved.

27. Rural postman, Brockley, aged 82 , wife 86 , pension small, children unable to help.

\section{WIDOWS AND CHILDREN.}

54. Widow of postman, E.C., four young clildren; relieved.

92. Widow of postman, Thurso, five roung children to support out of ber earr.ings as charwoman.

97. Widow of postman, London, 73, in receipt of parish relief.

98. Widow of postman, Southampton, four young children, in receipt of parish relief.

25. Widow of postman, Chatham, aged 87, bedridden and helpless, dependent on charity.

48. Widow of mail porter, Lonlon; husbanl died of injuries sustained in rescuing a woman from fire. Widow in delicate health, with a family of five young children.

78. Widow of rural postman, Grampoand Road, left with two children, in receipt of parish relief.

119. Widow of rural postman, Southampton, with six children under 12 etc., etc., ad infinitum.

In the ' 93 report 155 cases of destitute postmen were treated, 53 per cent. of the whole. In the ' 94 report 173. or 58 per cent. Gentlemen take more care of a favourite horse when it is no longer serviceable than is taken of numbers of our broken-down postmen. Tender children and poor women are left neglected to starve, and the nation reaps the seed sown in weakness and ignorance.

\section{POSTMEN'S WAGES THE BASIS OF CALCULATION.}

My lord, Sir F. Mowatt and yourself, when Mr. Boulden was being examined, asserted that a sum equal to 12 per cent. of the salary list is the pension charge of the Department, and you gave 12 per cent. of $£ 120$ 
salary as an example of cost. Let us see on whose salaries that 12 per cent. is, or how much of this comes to postmen :-

In the 1892 and 1893 Estimates 153 Postmen were pensioned, average $28 \cdot 8$ service.

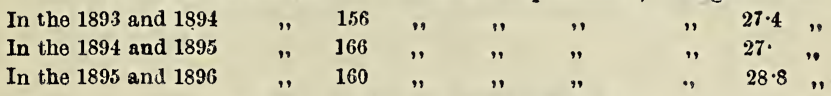

A mean of theso four yours gives 28.0 .

In '92 \& '93 the pensioned Postmasters numbered 32, with an av. service of $41 \cdot 6$ year.

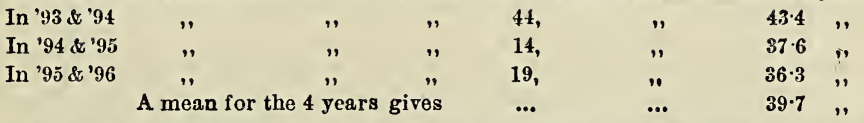

This shows a difference of 11.9 years in the capability of Postmasters to serve longer than Postmen.

In 1892 and 1893 the pensioned Pustmasters were 3.4 per cent. of those serving

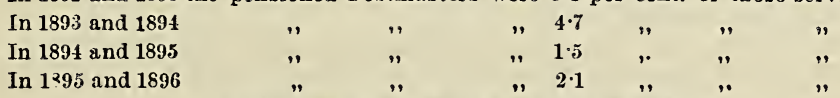

A mean again for 4 years gives $2 \cdot 9$ per cent.

The peusioned Postmen in 1892 and 1893 were 0.7 per cent. of those serving.

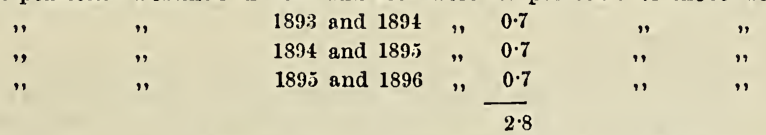

A mean for four years gires 0.7 to the hundreds of postmen serving.

This shows that four times the number of Postmasters are pensioned in proportion to the number of Postmasters serving than postmen in proportion to the number of postmen serving. I have already shown that the pensioned postmen die the first year of pension in the proportion of 4 to 1 of the Postmasters, so we shall presently discern the phantom pension is to the great body of postmen.

Mr. Walpole: Have you taken the established Postmasters at the head offices and included the sub-postmasters?

A. No; I have not included the sub-postmasters.

Q. In taking the postmen have you included the auxiliary postmen?

A. No, sir, I lave not. To continue-suppose $£ 500$ to represent these pensions per hundred of each for one year; the Postmaster's share would be $\frac{29}{10} \times \frac{39}{6}$, and the postmais $\frac{7}{10} \times \frac{28}{6}$; that is. $£ 4263 \mathrm{~s}$. for the Poitmasters, and $£ 7217 \mathrm{~s}$. per pensioned fraction to the hundred postmen. Remember this takes no account whatever of what each is entitled to by reason of large or small salaries. It simply shows that the work and condition of service can be relied on to kill your postmen off, so that it is only possible for them to serve in the above porportion to Postmasters, just as it is calculated with certainty that a tram-horse is used up in four years, while it takes twenty to use up a carriage-horse, or that insurance companies receive thousands from the poor, who can be calculated on to lapse pay. ments and forfeit benefit, so may postmen open their eyes to the fact that, under present conditions, but $\frac{7}{10}$ per cent. of their number will ever receive a pension; and that, if pension is a deduction from pay by a percentage similar to all grades, their deductions are going to the most highly-paid officials in the Service. Should pensions be increased by stoppages in future, the same holds good; postmen's interests will be safer in being separately treated, especially as to funds. Now, my lord, instead of 12 per cent. of 
their wages, I find the pensions of Postmasters, in the Summary Appendix A Estimates, 1892 and 1893, to be 14.3 per cent. of the wages of the Postmasters of the United Kingdom. In '93 and '94, 18.7 per cent. In '94 and '95, 18.3 per cent. ; and in '95 and '96, 18.8 per cent. I find the pensioned postmen, sorters, messengers, overseers, etc., in '92 and ' 93 to receive an amount equal to 4.1 per cent. of the wages of these classes ; in ' 94 and '95, 3.8 per cent. ; and in '95 and '96 3.7 per cent. I have not included the amount of Postmasters' pensions in Appendix B against the wages of the Postmasters, though $I$ have included the amount of pension in Appendix B paid to overseers, sorters, postmen, etc., against the wages of these classes.

The Chairman: Does that not arise to a considerable extent from the fact that these classes are mostly made up of young men? There has been a great extension of numbers among the postmen and sorters, and the consequence is that the average age of that particular class is a low one.

A. Yes; but I will give other comparisons in order to show that my remarks are quite applicable.

The Chairman : But you admit it?

A. Yes, to a certain extent.

Q. And, taking the average of the postmen's class, it is a low age?

A. Yes. It is a monetary consideration, however, and I am recapitulating this mostly in view of deductions being made from pay.

Mr. Smith: The Postmasters, many of them, have served in these lower places?

A. Yes; I admit that.

Q. And that being so, they get the pensions which sorters and telegraphists got? Their pension fund is part of the sorters' pension fund?

A. I am showing how it is we are disadvantaged from a monetary point of view. In arriving at the gross annual wages of postmen, I have taken a mean of the provincial postmen's wages, and the actual wages paid to postmen, overseers, sorters, and tracers in London, Edinburgh, and Dublin. I have not included any man's wages who is not established. I have not included the wages of inspectors, sorting clerks, paper sorters, and labourers; although I am of opinion some or all of these are included in the etcetera after overseers, sorters, and letter-carriers, otherwise they do not appear; clerk and C. I take to mean the major establishment. I can qualify that on account of the Secretary doing away with the major establishment, or at any rate giving it a final damper. I have not included allowances to mail messengers, sorters, sorting postmen, stampers, etc. I have not included boot money outside of the three cities mentioned, yet the pension only averages 3.8 per cent. Instead, then, of having to pay $£ 148 \mathrm{~s}$. on $£ 120$, it would only require $\$ 411$ s. to secure the present pension.

Sir F. Mowatt: The explanation is that the number has greatly increased. The pensions are pensions for the smaller number, and the salaries salaries for the larger numbers.

Mr. Smith: And the only pensions taken in are the pensions of postmen, and not of those who have gone up into the higher grades.

Witness: The postmen, etc., get 8.2 per cent. less than your average amount, and the Postmasters 5.2 per cent. above it. My own impression is that $2 \frac{1}{2}$ per cent. on postmen's present wages is more than sufficient to pay the whole of the postmen pensioners.

\section{COST OF PENSIONING POSTMEN AT THEIR PRESENT RATE.}

For four years the average has been $\frac{7}{10}$ pensioned to th e hundrid postmen, with an average service of 28 years, and a pension of $£ 325 \mathrm{~s} .2 \frac{1}{4} \mathrm{~d}$. per man. Take now 100 postmen, and allow 30 years to extinguish them from the Service- $r^{7}$ of a man for 40 years gives 28 men, which at 
$£ 325 \mathrm{~s} .2 \frac{1}{4}$ d. amounts to $£ 9034 \mathrm{~s}$. $8 \mathrm{~d}$. Suppose the pensioned to average seven years on pension (which I do not believe they do), a sum of $£ 6,322$ 12s. 8i. would be required, which could be raised by the hundred men, at an average deduction of $1 \mathrm{~s} .2 \frac{3}{4} \mathrm{~d}$. per week, paid during 20 years' service. 'This is on the building societies' plan.

Sir F. Mowatt: But you are assuming that they will only remain seven years on a pension?

A. By the number of deaths in the first pensioned years you can pretty well gauge what the postmen's pensions are worth.

Mr. Walpole: You are assuming, first of all, that a man is pensioned after 28 years' service?

A. Yes; on the average.

Q. And his age would then be only 48 , and consequently you are assuming that the average life of a man at 48 is only seven years?

A. No, sir.

Q. It is opposed to all experience.

A. You must take it that they are played-out men at 48 . They are not healthy.

Mr. Smith : 5.7 per cent. died in the first year?

A. Yes.

Q. That is about 1-16th?

Sir F. Mowatt: When men retire from sickness the great number of deaths occur in the first year, but it would reduce the percentage in subsequent years.

A. The number I have given in this estimate is one-fourth too much, and $I$ have done so in order to cover any contingency of that kind.

Sir F. Mowatt: I listened to your figures.

Witness: To change our rate of pension from sixtieths to forty-fifths would increase the pension charge by one-third of itself, and to confine this operation to postmen alone would, as the above illustration shows, entail but a very small cost; while the reduction in service to 30 years would not at the outside bring the yearly average over 1 per cent., or an increase of $\frac{3}{10}$ per cent. This latter would be in the Department's favour, as it would get rid of tottering, feeble men at the maximum, and employ young men of vigour at the minimum in their stead. Take the 3.8 per cent., I find by the Estimates it cost to pension postmen, etc., 1.3 per cent., or about $3 \mathrm{~d}$. per week from a man receiving 20s. wages would provide for us the increase we ask. It will occur to the Committee that postmen, through their combination, can do this for themselves. We hold it is the duty of the Government, as employer, to provide for the worker in disablement and olil age, and every function our combination performs of the Government's duty weakens the power and authority the Government should liave. My lord, I ask you to imagine the misery entailed on the families of those men pensioned in a dying condition, as shown by 6 per cent. of deaths in the first year. I am a little over the estimate here. An addition of one-third of their meagre pension added would do much to provide dying men with comfort, and this state is common to most pensioned prematurely. Whiat we ask is not privilege or luxury, but bare necessity. In the name of the widows and orplians of postmen I also appeal. I find by the RegistrarGeneral's returns that the married males are 33.1 per cent. of the male population. Taking marriageable males from 20 to 95 I find the married ones are 70 per cent. of these. Suppose postmen married to be 70 per cent. of postmen, I find the males to disappear between the same ages at the rate of $1 \frac{3}{8}$ per cent., but some of these will be infirm, and some emigrants, therefore we will place the rate at 1 per cent. for postmen, including tlieir pensioners. We are asking for $10 \mathrm{~s}$. per week for the widow, if she have been two years married to the postman before his death, or if in the case of a deceased pensioned postman, she shall have 
been married to him before he left the Service. Our reason for naming two years is, that the husband cannot out of his wages leave his wife anything to maintain her. She is less eligible for marriage, and in most instances will have a child to maintain. We only ask this provision during widowhood. We ask for $3 \mathrm{~s}$. a week for children until they reach 15 years of age, as less would not support children in large towns, if they have to be placed out in respectable families. Suppose this to average 13s. per week per widow, the yearly money being about the same as the postman's average pension; we might put it thus-if it takes 3.8 per cent. to pension pcistmen, what would it take to pension 70 per cent., implying widows and children, and I get answer 2.24 per cent.

\section{HOW OUR PROPOSAL COMPARES WITH THE TREATMENT OF POLICE, AND FALLS SHORT OF THE SAME.}

I beg the Committee to keep in mind the favourable terms granted by Government to the police, and compare with their system our request. We do not ask about two-thirds at 26 nor at 28 years' service-terms granted to the English and Irish police-but at 30 years' service. We ask terms a little more favourable as regards our widows and children, but the difference between 26 and 30 years' service would more than cover this. We do not believe in placing men with any amount of unused energy in them on pension that they may compete in an overstocked labour market with other workers, and hence have not asked for pension at 21 years, as in the army and navy, nor at 25 , as in the police; but after 30 years of work infinitely more exacting than either. We would be willing that the law should prevent pensioners with two-thirds pay for 30 years' service receiving other wages from other employment, provided high and low are subjected to the same restrictions, and that breach of the Act should subject the pensioner to return to the work of his calling for a period to be stated at no wages but his pension. We think pensions should not be forfeited except for treason (dividends and other incomes are not), but simply suspended or forfeited to Government during the period a pensioner might be imprisoned, in order that men prone to enrich themselves beyond their needs by trading might not have insecurity of income as an excuse.

\section{UNESTABLISHED OR AUXILIARY POSTMEN, ALSO TELEGRAPH BOYS' SERVICE BEFORE APPOIN'TMEN'T AS POSTMEN OR SORTERS.}

I ask that the poor auxiliaries be placed on the pension list, in order to prevent the sad spectacle of these poor men working while body and soul cling together, eager rather to die at work than in the workhouse. If they have not served full time, pay them at least for the time they serve, made up into eight hour days, etc. I ask on behalf of postmen who have been telegraph boys that their telegraph service counts towards pension. Boys' service in the army and navy counts towards pension. But in the event of our scheme being recommended, and becoming law, fifty years ought to be the age of retirement for these.

\section{CHRISTMAS BOXES.}

I also ask that the value set on Christmas boxes, viz., 5s. a week, be included in the postmen's wages as a basis for pension.

Mr. Smith : Is that your estimate- $5 \mathrm{~s}$. a week?

A. Yes; I concur in it.

Q. And you think we should be justified adding it?

A. Yes. Stampers and indoor men generally are pensioned on the allowance received in lieu of Christmas boxes. The Department permits the public to pay part of the postmen's wages direct to the postmen, and be- 
cause of this irregular method reduces the postmen's pension. The young ladies in the Service have compassionate allowances or dowries to marry when leaving the Service of their own accord, amounting to $£ 70$ and $£ 80$ a case. They have not families to support, therefore their incomes are not distributed to support as many individuals as men's salaries. They have not to collect part of their incomes from the public at Christmas, hence though they only arerage 20.8 years' service-in the ' 95 and ' 96 Estimates that is one-fourth less service than the postmen-their average pension is $£ 39$ 1s. $11 \frac{3}{4}$ d., or $£ 616$ s. $9 \frac{3}{4} \mathrm{~d}$. per lady more than postmen, who are for the most part fathers of families. Of course this claim falls to the ground in the event of a just equivalent being granted in lieu of Christmas boxes.

\section{SUMMING UP.}

My lord, in conclusion, I may say that postmen throughout the length and breadth of the land look to this Commission with a sanguine hope of amelioration on this question, and should we, as workers, continue to be denied the treatment meted out to the police, so vital is this question, that I believe the men would submit to a small deduction from their salaries rather than that the pension should continue the unreality it is to the great body of postmen. One word more, and then I will finish. I have stated that 95 per cent. of the widows of postmen are charwomen. I may siy that the Post Office, particularly in Liverpool, and I believe in other places, has been good enough to accept the wives of postmen as charwomen. I ask, as the husbands of these have had nothing given to them in liou of their services, that these women may also be taken on to the pension and treated in the same way as other pensioners, that is, after ten years' service to be pensionable. This would apply to only a very few. I thank you very much for your kind attention. I have had a very heavy case to put before you, and I am sure you have stood it well. (Laughter.)

The Committee then adjourned till Monday. 
STEPHEN DOWLING, Liverpool.

Hours of Duty-Holiday and Casual Leave.

Wrastumster, Feb. 10, 1896.

The Departmental Committee, presided over by Lord Tweedmouth, which is inquiring into the grievances of the Post Office servants, resumed its sittings in the House of Lords' Committee Room on Monday, February 10th.

The first witness called was Stephen Dowling, who was examined as follows :-

The Chairman: You are a Liverpool postman, I believe?

A. Yes, my lord.

Q. What is your length of service?

A. I joined as an auxiliary in April, 1877.

Q. And then?

A. I was appointed in September as a regular man.

Q. In the same year?

A. Yes; and now I receire 31s. a week, which is the maximum pay of a postman at Liverpool.

Q. Have you any stripes besides?

A. No. The 31s. inclurles an additional one shilling allowance.

Q. What is the particular point to which you wish to call our attention?

A. The particular point is the hours of duty. I shall also deal with kindred questions, such as holidays and leave.

Q. Have you prepared any statement?

A. I have, my lord.

The Ohairman: Proceed with it, please.

Witness: I approach this question of postmen's hours of work with a feeling akin to amazement that such a state of things as I am now about to disclose should be permitted to exist in the present advanced stage of development of so vast a revenue-producing Department of the State as the Post Office. The health, the leisure for recreation-for the intellectual advancement and home duties of the toiling masses are questions that are now almost engrossing the attention of economists, legislators, and, in fact, the public generally. But in stating this case for the postmen I regret to have to say it is my opinion-and that opinion is shared by the whole of my class-that these most vital questions cannot have received from the Department, or the Treasury, or both of these, the consideration, the attention they demand, else the present condition of postmen's hours of labour would never have been allowed to survive whilst there remained a single penny surplus profit derived from the system to be poured into the State coffers. Our grievance in its general aspect comes under the head of

\section{SPLIT DUTIES.}

From the very nature of our work, the fact that we are public servants in the employ of a great Department, the work of which is in some stage 
ot progression during the whole 24 hours of each day, we cannot ever expect to obtain such desirable hours as, for example, the bank clerk. But, on the other hand, neither is it necessary that our hours should be oppressive, and spread over too long a period of the day; that, in fact, we should be comparable rather with the unfortunate 'bus conductor than with any other class of employees in the Department.

The Chairman: Do you put it forward as your case that you should have no split duties at all, or would you consider them almost inseparable from a postman's duty? Do you think it is necessary that there should be a certain number of split duties?

A. I admit it is necessary there should be some, and you will see as I develop my case that that will come out. Indeed, I do not know a single fnstance where that victim of dividend-making concerns has his time and labour exploited to the extent of 16 and 17 hours per day. But this is the fact in the case of postmen, where there is no competition and no genuine public benefit to be gained from such a state of things.

Mr. Walpole: Are you going to give concrete examples?

A. Yes, sir. For example, a man makes four attendances in the interval of $16 \frac{1}{4}$ hours, as at Devonport, or within 16 hours, as at Bristol.

Mr. Walpole: Have you the Devonport case with you?

A. Yes; I have an exact statement of the duty.

The Chairman: State it, please.

A. The first attendance is from 6 a.m. to 9 a.m., 3 hours; the second attendance from 11.15 a.m. to 1.45 p.m., $2 \frac{1}{2}$ hours; the third attendance from 6.45 till 7.45 p.m., 1 hour; and the fourth attendance from 8.15 p.m. till 10.15 p.m., two hours, giving a total attendance of 8 hours 30 minutes.

The Chairman: Spread over what time?

A. Spread over $16 \frac{1}{4}$ hours.

Mr. Walpole: Can you tell me at what distance from the office the man doing this duty lives?

A. I cannot say exactly as to Devonport, but I know that in many cases, even if they do not live a long way from the office, our men are taken long distances to the finishing points, and they would have a long way to walk back to the office.

Mr. Walpole : It is a fact, is it not, that it is some time since there was a revision of these duties at Devonport?

A. Yes, sir.

Q. Is it not a fact, do you happen to know, that at this present moment these particular duties at Devonport are being revised?

A. I did not know that they were being revised; if anything had happened that was of importance I think I should have been informed. I do not think that any revision has been effected yet.

Q. No revision has been effected; but is it not a fact that they are under revision?

A. I do not know that.

Q. I presume you know from your own experience that the duties always look worst immediately before they are put under revision; that they must be the heaviest under the maximum?

A. I presume that is so; but I think that, generally speaking, unless pressure is brought to bear upon the Department in a powerful form the revision would not come about.

Q. Will you accept my statement that, before this was mentioned at all, the revision in this case was actually under consideration?

A. I will accept your statement, certainly. I now come to cases of five attendances in the interval of 15 hours 5 mins., as at Cambridge ; or within $15 \mathrm{hrs.}$, as at Birmingham.

Mr. Walpole: Have you the attendances in the Cambridge case? 
A. No, sir ; but I have a similar one of five attendances within 15 hours from Birmingham, which works out as follows:-First attendance, 5.15 a.m. till 8.15 a.m., 3 hours ; second attendance, 9.25 a.m. till 10.30 a.m., 1 hour and 5 mins.; third attendance, 11.30 a.m. till 1.30 p.m., 2 hours; fourth attendance, 5 to 5.45 p.m., 45 minutes; and fifth attendance, 6.30 p.m. till 8.15 p.m., 1 hour and 45 minutes; total attendance, 8 hours and 35 minutes.

Mr. Walpole: I suppose you are aware that in the case of Birminghamperhaps you have seen a report, however-an inquiry was made into the pestmen's duties some years ago, and that the statement is that the men's atterdance could be kept within 12 hours only by relieving men from part of the early morning delivery, and that to this the men themselves objected, therefore these attendances at Birmingham were kept on to this extent purely at the desire of the men themselves. Will you accept that statement from me?

A. I do, sir.

Q. And, therefore, I presume that probably has something to do with the state of affairs at Birmingham?

A. Yes; but if some way could have been shown by which these men could have been relieved at night, I am sure they would have agreed to have their duty compressed within 12 hours. Next I come to cases of six attendances in the interval of 14 hrs. 55 mins., as at Aberdeen (Woodside S.O.); or within $14 \mathrm{hrs}$. 45 mins., as at Louth. I have here the six attendances at Louth, and they are as follows:-1st, 6 a.m. till 8.30 a.m., two hours and a half ; 2nd, 9.35 a.m. till 10.20 a.m., 45 minutes ; 3rd, 10.30 a.m. till 12.45 p.m., $2 \frac{1}{4}$ hours ; 4th, 2 p.m. till 3.15 p.m., $1 \frac{1}{4}$ hours ; 5 th, 4.45 p.m. till 5.55 p.m.. 1 hour 10 minutes; 6 th, 7 till 7.40 p.m., 40 minutes ; total, 8 hours and 35 minutes.

Mr. Walpole: I suppose you have no personal acquaintance with Louth, have you?

A. No, sir.

Q. It is a small town, is it not?

A. It is, sir.

Q. The men very probably live very close to their work?

A. Yes, sir; probably not far away. But still they may be taken a long way from their work to their finishing point, and in the case of the attendance from 9.35 till 10.20 it would not afford much time to get back in order to put in the next attendance. You will see, sir, that there is an ivterval of 10 minutes only between this attendance and the next at 10.30 a.m., which can hardly be counted as an interval at all, but is counted, so to make it appear a shorter day.

Mr. Smith: You mean it is not counted in the hours of attendance?

A. It is not counted in the hours of attendance, and they check off all short intervals, consequently reducing the men's actual hours of work. If they were counted as continuous duty the men would have no complaint to make.

Mr. Walpole: Probably a short duty of that kind is a station service, is it not?

A. I am not aware that it is a station duty. I understand that these mien are doing ordinary duty. You see, if they were not checked off for these short intervals, the total of the day's work would come to considerably more than it ought to do. It is already over the 8 hours a day.

Mr. Smith: And, of course, that is a grievance in this particular case?

A. They have not stated it as a grievance, but I presume it is a grievance everywhere where they are checked off for such short intervals.

Mr. Walpole: In regard to Birmingham, I should like to read another paragraph from the Report to which I have already alluded. It is to the 

effect that attendance can only be kept within 12 hours by employing a sufficient number of auxiliaries on morning duty, and the postmen object to being taken off the morning delivery because of the loss of Christmas boxes. There is no alternative therefore to spreading the duty over 15 hours.

A. A case of that kind was met at Liverpool by the older telegraph boys acting as auxiliary postmen from 6.15 at night to do the last delivery. We had precisely the same difficulty to contend with in Liverpool, and it was met, although all the duties in Liverpool are not yet compressed within 12 hours. Then there is the case of eight attendances in the interval of 14 hrs. 25 mins., as at Rawtenstall.

Q. Part of these attendances are on station duty, are they not? Have you got them?

A. I have not the exact table.

Q. Where is it that this nccurs?

A. At Rawtenstall. I have corresponded, and found it to be absolutely correct, although they have not sent me the exact statement.

Mr. Smith: There is no objection, then, on the part of the Liverpool postmen to the older telegraph boys taking part in the last delivery? I understood from a previous witness that some complaint was sometimes made that the older telegraph lads were used for auxiliary postmen's duties?

A. I think I heard what Mr. Walsh said about that, but he was referring chiefly to the fact that they had their wages reduced when they were made postmen.

Mr. Smith: I think it was Mr. Churchfield that made the observation to which I allude, but it does not matter. I suppose I may take it that in this particular case there was no objection raised of that kind?

A. No objection was raised at the time, but an objection has been raised since that the postmen should be partially employed as telegraph boys.

Q. 'Then it did not meet with entire approval?

A. No, sir.

Q. But I understood you to recommend it?

A. No, sir; I did not propose it in any tangible form. I said it was met in that way at Liverpool.

Mr. Smith : You do not absolutely suggest it, then?

A. No, sir. It cannot be said with any. show of reason, although the actual time of work in these cases may amount to a total of from 8 to 9 hours only, that the man performing such duty has an 8 hours' day; that he has even proper time for food and rest, not to mention those other objects which go to render his life endurable. How much actual work must these $3,4,5$, and 6 , leaving out of the question 8 , attendances entail besides what can be shown on time sheets? These men cannot reside on the premises of their offices; and if they could many long walks would be recessary to reach collecting points, to attend station duties, and to return from finishing points. The lives of such men are those of dogs, stealing a nap between duties, with one eye closed and the other on the clock.

\section{EFFECT OF THESE TOO NUMEROUS ATTENDANCES ON TIME-KEEPING.}

The ill effect of these too numerous attendances will be readily understond from the fact that postmen have the worst late rate in the Service.

The Chairman: What do you mean by late rate?

Witness: The number of late atterdances. Thre is no difficulty experienced in tracing the cause to this, as will be seen by placing the number of attendances required from postmen opposite that required from, for instance, sorting clerks. 
TABLE OF ATTENDANCES.

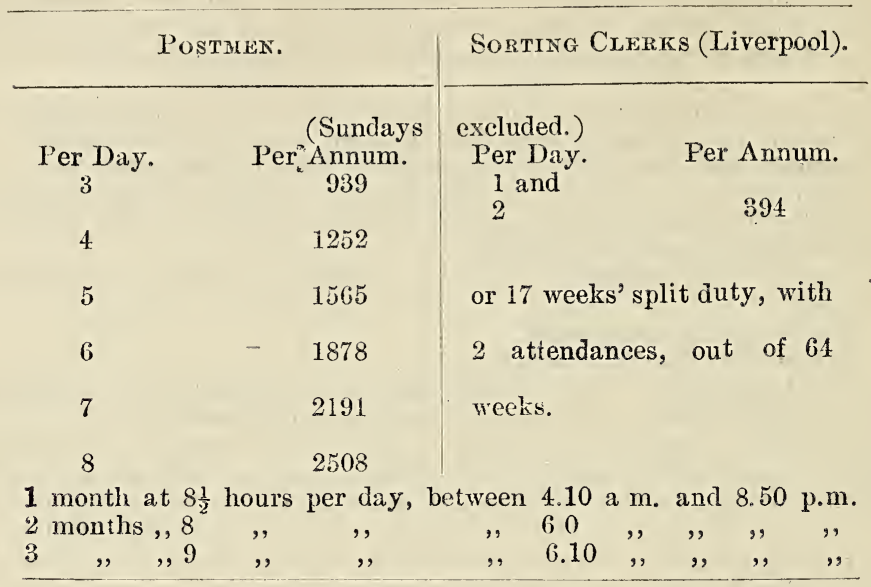

I admit that sorting clerks in the smaller towns put in more attendances than I have given in the foregoing table, but still it is nothing like the number of attendances we have to put in. Notwithstanding the enormous disparity in these figures, there is no corresponding latitude in point of discipline; for whilst the number of lates in the case of the sorting clerk may reach 15 or 20 times per annum, that of postmen must not exceed the latter without incurring the arrestation of increments-12 times is the limit for stripes-despite his exceptional hours of attendance, such as $4.10 \mathrm{a} . \mathrm{m}$. 4.45 a.m., 5 a.m., and late nights.

Mr. Walpole: Do you say that 12 is the limit for stripes? Is that the rule at Liverpool?

A. Yes, at Liverpool; I believe it is something less at other towns. I lave given the outside figure. Twelve late attendances in a year debar a man from stripes, and, out of such a number as 1,252 attendances which are necessary in the case of a man having to put in four attendances a day, the 12 late attendances give a very narrow margin.

Mr. Walpole: But is not the official rule quite different from that? Is not the rule to the effect that the question of withholding stripes shall be enforced if a postman has been late 16 times during the year, or 20 times in the case of attendances between midnight and 6 a.m., and that the circumstances shall be taken into account in coming to a decision? Is it not the case that the question is not raised at all unless the officer has been late 16 times on day or 20 times on night attendances?

A. Against that I have to oppose the facts that in Liverpool men who lrave had nothing else against them, and who have had their stripes withheld, have been told that 12 times is the limit for stripes. In many towns men have had their stripes withheld for having been eight times late in the course of a year.

The Chairman: Not on that account only, surely?

A. 36 times in three years is what we are told is the limit in Liverpool, and if a ma.2 gets over that limit he immediataly becomes ineligible for stripes.

Mr. Walpole: But the rule I am quoting is in existence, and it is really in force? 
A. We have frequently urged that the limit should be 16 , and when the stripes were first granted that was the limit, but the practice has been in Liverpool to arrest a man's stripes if he has been late 12 times.

The Chairman: What constitutes a late attendance?

A. A few minutes.

Q. How many minutes?

A. $2 \frac{1}{2}$ minutes, but in some places even a late attendance of one minute is entered; in other places, however, as much as $2 \frac{1}{2}$ minutes is made the limit. All this, we urge, points to a lack of consideration, and causes many a postman to have a bad record and be branded as a man of bad condict, who, if he had the duties of the sorting clerk, would have no such record, suffer no such stigma. I have here a case in Cork, where a man starts uuty at 1.20 a.m., and has three attendances, and is not finished till 10.20 the next night.

Mr. Walpole: You must take that in another way.

Witness: If you take it another way the duty is over 14 hours, but we are not in the habit of counting night duty from mid-day.

Mr. Walpole: I should like to see these attendances.

Witness: I will let you have them, sir. When a man has only one, or, cccasionally, two attendances to make each day, he can brace himself up for punctuality; but when his duties are spread out over the whole dayand sometimes part of the night-his energies naturally flag.

\section{NUMEROUS ATTENDANCES AND BAD WEATHER.}

Then thers is the question of bad weather to be taken into consideration in cornection with these numerous attendances. When Dr. Wilson, giving eviderce before this Committee, animadverted on split duty and its ill effects, he must have had in his mind our unlimited attendances, which are without equal in the Service. Imagine, my lord, the postman going into his home $3,4,5$, and as many as 8 times per day, drenched with roin, or his boots penetrated with snow. Setting aside the hardships endured through exposure and its consequences to health, as shown by Dr. Wilson's statement that the death rate amongst the postmen's class. was the highest in the Service, I ask you to consider how much comfort there can be in a small dwelling where an attempt has to be niade to dry clothing so mary times a day. I know in my own case the very appearance of bad weather is dreaded. Or, worse still, picture him when he cannot get home remaining in wet clothing all day long. And this region has its share of humidity. Yet in spite of working early and late under these conditions in one day, the postman has to rise early on the next, gather together all his parts, and prepare for a fresh attack, perhaps under similar circumstances. And this, year in, year out. Or, think of him working under the fierce rays of a suminer's sun, in the hottest part of the day, when others are seeking shelter, walking along dusty, country roads, in the streets, in loathsome slums, among insanitary dwellings, climbing hills, and mounting stuffy buildings-with heavy loads and hung all round with parcels. All these things we submit for your consideraticn, in the hope that you will urge them as potent reasons for a swceping reform of our duties. They point to the urgent necessity of concentrating day's work within narrower limits, so as to afford us proper time for rest between the completion of one day's work and the resumption of that of the next. We ask you to recommend that no duty shall extend beyond the limits of 12 hours and two attendances; that no period of duty which necessitates an attendance shall be reckoned as less than one hour.

The Chairman: Will you state how that can be effected?

A. I have a proposal to make later on.

Mr. Walpole: You do not mean to say that the attendance should be brought within eight hours? 
A. I suggest that the duty should be campleted within eight hours.

Q. Do you mean that the actual attendance of eight hours should be spread over a longer period?

A. I mean that we should only have one attendance, if possible.

Q. But you know that witi the great mass of postmen that is utterly irmpracticab?e?

A. I have admitted that for a great number it may be impossible, but then we ask the Committee to recommend that no duty shall extend beyond the limit of 12 l.ours' attendance. I have not asked that our duty be worked as an eight lours' duty in every case.

Mr. Walpole: Are there not a great miny cases in which the men object to liringing their duty within 12 hours?

A. I intend to deal with that later on.

Q. Do you think that the Department should bring it within 12 hours against the strong remonstrances and desire of the men?

A. There is an argument against that. Frequently when there have been attempts to bring the duties within the limits of 12 lours, there have equally been attempts to crush the old number of attendances into the narrowed linsits, and that has always made the duty worse than before. If you have the attendances, as I suggest, within 12 hours, and lessen them instead of crushing the same number within that period, then I am sure our men would urarimously agree all over the country to bring in the day's work within 12 hours. By this, however, we do not imply that all our duties should be spread over 12 hours; on the contrary, we ask that we may have duties which can be properly termed eight hour's' duties-worked in the limits of eight hours; to be placed in fact, on an equality with sorting clerks, who have, at Liverpool, 47 through duties out of a total of 64 duties. We would like to make it clear that it is as necessary to cut down the number of attendances as to contract the covering time. Indeed, attempts have already been made to narrow the extremities of duties which have resulted in utter failure to improve them. In all these cases either the number of attendances has been increased or the same number has been crowded into the narrowed limits.

Sir F. Mowatt: But if a certain number of attendances have to be covered, and if they are to be put within narrower limits, the men must expect to do little nivre than if they are allowed to extend over wider limits. I understand you to say that they want eight hours' work?

A. I believe that in many cases if the attendances were properly compressed, the duties could be worked through without any break, or with two attendances at most, and the men would not complain about that. It is when the men are thrown off for very short intervals between their three and four attendances, which are spread over 12 hours, that makes it so rtuch worse than when the attendances are spread over 16 Lours, with longer intervals for rest. I admit it would be quite impracticable to compress the duties in many country places and small towns within eight hours. I am chiefly referring to larg 3 towns.

Sir F. Mowatt: I lid not quite follow your argument.

Mr. Walpole: Do I understand you to say the desire of the men is to have a continuous duty of eight hours?

A. Yes, sir.

Mr. Walpole: But I am informed and advised that the men consider that a continuous duty of eight hours would be exceedingly fatiguing?

A. I propose to deal with that later on. I will not be a moment before I come to it. Referring to this point of short intervals, a correspondent fron a small town wrote me as follows-and I am quite satisfied from the tone of the letter that the humour escaped the writer unwittingly:"When the new surveyor came he revised our duties. They were bad duties extending over 15 hours each day. Now we work them with more attendances within $13 \frac{1}{2}$ hours. But, to give the surveyor his due, the duties were 
not much better before the revision." It has been objected that the nature of our work renders it impossible for us to do a continuous duty of eight hours. This is actually so in such cases as Scottish towns, where, unfortunately, the Dutch tenements-of-flats' system of building prevails, and in parts of large commercial centres where stair-climbing enters largely into the work. - But I have never heard it suggested that it was impossible tor any other class in the Service to perform eight hours' consecutive work, which goes far to admit that in such cases our men are doing exceptionally hard work, and should, consequently, have shorter hours than those with lighter occupations, such as sorting clerks, or be allowed short rests out of their eight hours.

\section{INTERVALS.}

In many instances the intervals between the parts of our long duties are frittered and whiled away in the streets-often, I regret to have to say (and this, I think, it reflects rather on the Department than on the men), in public-houses. These very intervals have been the cause of many a man's ruin in the way I have just mentioned. I would point out that if a man had better duties he would make his way home instead of loitering about as he has to do in many towns, to spend his spare time. He would be glad to do his duties in a more compressed period, and then wend his way home to his wife and family. Some men spend their spare time on the premises, when there is convenience, such as a kitchen. This is especially so at the Liverpool Head Office; where, on certain duties our men never see home from the time of setting out in the morning till the time of reaching there after the completion of all their attendances, owing chiefly to the fact of residence being so far from the centre of the city. At a few offices men are regularly on duty six hours at a time without time for a meal, as at Lark Lane, Liverpool. Here, as is often the case, if the men had an interval for food, there is no culinary convenience. Until the last few weeks there was not even a liettle to boil water. Recently the sub-postmaster has supplied one, with a capacity for abont a pint of water, to supply 17 men. (Laughter.) Further, this office is insanitary. The men feel really ill after remaining in it for any length of time. There are two or three men at Southport Office who commence duty at 11 a.m., and work through till 4 or 4.30 p.m. with no interval for dinner. I should like to say that this is the second attendance.

Mr. Walpole: Where is this?

A. Southport.

Q. Is not that a decisive objection to the proposal for a continuous eight hours' duty, that the men would have no interval for dinner?

A. But those who do eight hours have intervals for meals.

Q. Then you mean to suggest that, if the work were compressed, you should have intervals given you for meals out of the eight hours?

A. Yes; in precisely the same way as other officials in the Department get them. The sorting clerk and telegraphist get half an hour for dinner and 20 minutes for tea if they are working continuous duty. I may tell you that this state of affairs in Southport has arisen through the walks being enlarged. They have taken in some of the rural districts. Previously 28 men did the Southport district alone. Eleven years ago 28 men were set on this duty by a revision which was brought about, I believe, by Inspector Appleyard. There are now only 23 men in Southport doing what 28 men did eleven years ago, notwithstanding that there are about 2,000 odd more houses to which deliveries have to be made.

Q. Were those 28 men full-time men?

A. Y'es, sir.

Q. Are you certain of that?

A. I am artain of that, sir. 
Q. Were they full-time town postmen?

A. Yes, sir; the town postal radius has been enlarged, and two or three places have been taken in, in addition to there having been a growth of over 2,000 houses within the old radius.

Mr. Walpole: But it seems incredible that 23 men are doing now what 28 men did before?

A. It is in the day-time, and in that case the men have no interval for dinner. There are 27 or 28 men on the deliveries still, but some of them are put on the extended districts. No corresponding increase is made for the inner circle. Frequently the interval between two periods of active duty is so short as not to permit of sufficient time to go off the premises, as at Burnham, R.S.O., where men are checked off duty twice a day for the short space of 20 minutes, between 8.30 and 8.50 a.m., and 5.30 and 5.50 p.m. The Department would never dream of offering such treatment to sorting clerks and telegraphists, who claim 30 minutes' meal time out of their eight hours. Contrast the checking off for short spaces of time with the rule which obtains in Liverpool, O.B. If a sorting clerk at Liverpool be required for overtime his time is not broken unless more than two hours elapse between the time of finishing his proper duty and the time of taking up overtime. That is, he is credited with and paid for such intervening time whether he works it or not.

Mr. Walpole: What is that?

Witness : If he commences duty at 8 a.m., and finishes at 4 p.m., and is required for overtime at half-past 5 or a quarter to 6 , he is not checked off fo: the interval, but is paid for it.

Sir A. Godley: Do you say that his time is not broken at all, but that he is regarded as having worked all that time, and is credited with and paid for such intervening time whether he works it or not?

A. Yes, sir.

Mr. Walpole: At overtime rate?

A. Yes, sir.

Q. Are you certain of that?

A. Yes, I am certain of it.

Sir F. Mowatt: He is paid overtime between 4 o'clock, when his ordinary duty ceases, and 5.30 , when he is again required?

A. Exactly.

Q. The hour and half, or however long the may be doing nothing, is paid for as overtime?

A. That is so, sir.

Mr. Walpole: I wish you could give me a statement to that effect. I will inquire into it. It is a surprise to me.

Witness : I think my present statement is fairly clear to you, sir?

Mr. Walpole : Very well.

The Chairman: At what particular place does this occur?

A. At Liverpool, my lord. Continuing his statement, witness said:-It is obvious these are the breakfast and tea times of the men at Burmham Office, and that the motive for casting them off duty for these short intervals is to reduce, by a paring-off system, the totąl amount of actual duty, which, notwithstanding, is at least 8 hours 20 minutes. If 30 minutes for meals is allowed in the instances adduced, that, at the very least, ought to be allowed the postman out of his eight hours for breakfast, for he has generally to perform the heaviest portion of his day's work before that, and requires a substantial meal. We ask you to recommend that no interval of less than one hour shall interrupt the reckoning of any duty as continuous.

\section{INEQUITABLE METHOD OF RECKONING A POSTMAN'S DAILY WORK.}

The present method of reckoning a postman's time is quite exceptional, and against exceptional treatment we urge our remonstrance. We are not 
allowed the time taken up in going to and coming from the various starting and finishing points. For example-In the suburban district of Hillhead, Glasgow, a postman finishes his delivery at a distance of two miles from the head office. He has to traverse these two miles three times daily, in his own time; total, six miles, for which he gets no compensation. This inequitable method of reckoning a postman's time obtains in a greater or lesser degree all over the country. In Southport men are booked off duty at a distance of $1 \frac{1}{2}$ miles from their office. They have to return in their own time. I have shown how few split duties are performed by sorting clerks at Liverpool, yet, though those duties only entail two attendances, six of them are compensated by half an hour for tramping time.

The Chairman: And when a man finishes his delivery two miles from the the head office, how far is he from home?

A. He may or he may not be a long distance.

Q. Is it not a fact that, as far as possible, the rounds are arranged so that a man shall leave off as near as can be to his own home?

A. It is not always the case.

Sir F. Mowatt: But he makes his own home near where he is likely to leave off, surely?

A. $\mathrm{He}$ cannot always arrange for that. He cannot always get what he wants. In Liverpool it is not the case. I am informed that, in this par* ticular case, the postman could not obtain a dwelling at Hillhead. It is a suburban and aristocratic district, and he would have to go back to the office to get near his home.

The Chairman: Then he would live near the office?

A. He might live near the office, or within a reasonable distance of it, but, supposing that a man lived near his walk he would have a long distance to go to the office, and he would be required to cover that three times a day, so that it amounts to precisely the same thing.

Q. Do you use the trams at Liverpool, or not?

A. No, sir.

Sir F. Mowatt: I think you finished the last sentence in your statement by saying that the sorting clerks were allowed half an hour for "tramping time"?

A. Yes ; on split duties they are allowed half an hour for tramping time, but only when they have to attend on such duties.

Q. And is that allowed as part of their day's work?

A. Yes. As a matter of fact, their day's work comes to $7 \frac{1}{2}$ hours.

The Chairman: Does that practice also prevail in Liverpool?

A. Yes, my lord.

Q. And, besides that, do they have meal times allowed them?

A. I do not think so in that case. Neither do we have meal times allowed us, my lord, so that the two cases are precisely analogous in that respect. These anomalies work out to the great disadvantage of the postman, who, according to the method of reckoning I have just referred to, would be giving as much time to the Department as the sorting clerk if he could show only six hours per day on the time sheet. We trust, my lord, that the members of this Committee will be able to fall in with our view, which, we submit, is only a reasonable view, that all time taken up in going to stations, to make collections, in returning home or to office from finishing points other than that necessary to make first attendance, and to retum home after the last, be accredited to postmen.

The Chairman: You are willing to do two journeys in your own time?

A. Yes, my lord.

Q. You will give twa journeys free?

A. Yes.

Q. But any more you want to be allowed for?

A. Yes, my lord. 


\section{OVERTIME.}

But what will be said to the fact that the great bulk of our men work time in excess of eight hours' actual duty, in spite of this paring system. I find that in most offices the time worked is at least $8 \frac{1}{2}$ hours on the averagethat is, as far as I have been able to ascertain. I think it is a pretty fair average. I have got papers from most of the towns all over the country, and I do not think that if I got any more it would make much difference in the average. I find that men, especially in the smaller towns, are over eight hours every day, in spite of this paring system. In many instances it exceeds nine hours, as at Stalybridge, where a man works 9 hours 20 minutes' actual duty every day in the year-Sundays excepted-between 10.30 a.m. and 12 midnight; also at Dingwall, where the actual duty performed is, at ordinary times, 8 hours 30 minutes.

Sir F. Mowatt: What do you include in "actual duties"? Do you include the walks?

A. No, sir. When I say "actual duty" I mean without making any allowances, not even counting time for "pouching."

Mr. Walpole: Have you any proof of this?

A. I can send it to you. It is part work in the office. This duty will, I think, be admitted. There is no chance of completing it in any other way. The duty is chiefly station duty at the office, and all of it would be signed for on the sheets.

Q. And you say it is a regular duty of 9 hours 20 minutes at Stalybridge?

A. Yes, sir, every day; and for it the man receives no overtime. Again, at Liverpool (Lark Lane), a section of men perform every alternate week 8 hours 50 minutes-often over 9 hours. The alternate duty is one of 8 hours and 10 minutes. At Newcastle-on-Tyne an entire section of men perform, the whole round, 8 hour's 30 minutes' actual duty every day, between 6 a.m. and 9 p.m. At Birmingham men are performing 8 hours 35 minutes without any compensating duties. At Louth the following duties are worked:-

1 month at $8 \frac{1}{2}$ hours per day, between 410 a.m. and 8.50 p.m.

2 months , 8 ", ", , 6.0 , , , ,"

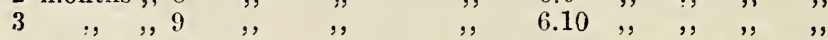

Thus at this office, apart from times of pressure, overtime is worked during cight months out of twelve without extra pay. We heard no such complaints from witnesses belonging to other classes before this Committee. The burden of the complaint of those witnesses was to the effect that 8 hours was too long. On the contrary, we will be absolutely content with the condition of duties about which the other classes have complained, and we won't be happy till we get it. (Laughter.)

The Chairman : You will be then?

A. Yes, my lord. (Fienewed Laughter.)

Q. Of course, you have one advantage over the sorters. You have not to attend at such unearthly hours as they have?

A. I think that absolutely the reverse is the fact, my lord. We find that our men have to attend at all hours of the morning, and at all hours of the night.

Q. Do postmen attend between 10 at night and 5 in the morning?

A. Well, we would not think that at all a very bad duty. It is a fact that our duties are spread over 16 or 17 hours a day.

Q. I am speaking of the absolute hours. You do not have to attend in the dead of night, do you?

A. Well, here is the case of a man at Cork who attends from 1.20 a.m. to 10 p.m. His duty is spread over all that time.

Q. I suppose his are collecting duties in the early hour, are they not?

A. Yes, my lord.

Mr. Walpole: I should like to look into that Cork case.

A. Of course; it might be put differently. 
Mr. Smith: It might be represented as a duty from 10 p.m. to 1.20 a.m.?

A. No; but it might be represented as a duty from 1.20 in the day till 4 the next morning.

Mr. Walpole: Yes ; the man at Cork is doing from 1.20 p.m. to 4 a.m.

The Chairman: Tell us your own experience. What have been your worst attendances of that character?

A. My worst attendances have been from 6 a.m. to 9 p.m.

Q. Have you had any midnight attendances at Liverpool to do yourself?

A. No, I have not; but we would not regard such attendances as bad at all, so long as we put the time in within reasonable limits. In the case of the sorting postmen who have to work night duties, and in the case also of the stampers, their duties only range about $7 \frac{1}{4}$ hours. We do not look upon that as a great hardship a* all. What we complain of is the fact that our duty is spread over the greater part of the day.

The Chairman: That point I quite understand. You complain that your duty is spread over a great number of hours. I was only quoting the case of the sorters to point out that their duty, to a large extent, has to be performed at a time when people generally were in bed.

A. Well, I shall be able to show that a large percentage of our men do night duty. I propose to do that when I am dealing with the holiday question.

Sir F. Mowatt: Do you suggest that they do a larger percentage of night duty than the sorters?

A. Yes, sir; a much larger percentage.

Q. Night duty-at what hours?

A. After 10 p.m., at midnight, and in the early morning. I shall be able to show that they have a greater percentage of night duty at Liverpool than have the sorting clerks. I refer, of course, to our indoor staff and the sorting postmen, who all rank as postmen.

Q. What is the latest collection at Liverpool?

A. Ten o'clock.

Q. And is no pillar-box cleared after 10 o'clock?

A. No. sir.

The Chairman: When is the first one in the morning?

A. Five o'clock.

Mr. Smith: Just refer back for a minute to the Cork case. It appears to me to be quite clear that the real limits of that man's duty are from 1.45 in the afternoon till 4 in the morning?

A. Yes; you can take it that way.

\section{PROTRACTED DUTIES.}

These are caused by late trains, large influxes of circulars, and heavy mails-such as American mails arriving at large centres like Liverpool. Here we have a very deep-seated grievance. By a rule of the Service laid down by Mr. Raikes, no extra pay is granted to postmen for "mere protracted duties," as that would "put a premium on dawdling." But whatever charge of "dawdling" might be made in the case of a late train could scarcely be laid at the door of the postman. Delays caused through late trains are almost the rule in many small towns. Take Dingwall as an instance. There men are frequently compelled to be in attendance 1,2 , and 3 hours in excess of their time without pay. When a large American mail arrives at Liverpool a great amount of overtime is incurred in C.B., where it is all paid for ; but no corresponding overtime is paid to the postmen who deliver it. Why we are unable to conceive. If overtime is paid for in one branch it is anomalous, unjust, and illogical that it should not be paid for in another. Were it only possible, my lord, for the members of this Commission to witness for themselves the pressure under which the men at Liverpool Head Office have to work at such times with heavy loads of letters which have to be deposited on the ground at every call until they are considerably lightened, after starting from the office at something near the time at which they ought 
to finish-they would ridicule the idea of "dawdling." Then there is the case of large influxes of circulars. I suppose it will go without saying that an amount of work is indispensable to their delivery. It is also as indisputable that that work must be, at least, tenfold what is necessary to sort them; yet it is of common occurrence that the sorting of them is paid for at overtime rate, whilst no pay whatever is made for their delivery. These circulars are not delivered in proper course, but are detained and spread over a number of deliveries. It is sometimes nearly a week from the time of posting before the delivery of a large influx of them is completely effected. I have abundance of correspondence from towns large and small, throughout the provinces, complaining bitterly that every time the men arrive on duty, for periods extending over two or three weeks, certain advertising circulars await disposal. They are doled out for delivery in portions until the stock is exhausted. Extra time is incurred at every delivery, but not enough perhaps to set up a claim at each several delivery, yet if the aggregate day's time were taken, a claim could be established. But postmen are debarred from making such a claim. In this our treatment is without parallel in the Service. The following is the manner in which an overtime claim was treated at Manchester Office. I will read the claim and replies. Perhaps it will not be necessary for me to mention the man's name, if I hand the papers to you afterwards, iny lord. He wrote to the surveyor as follows:- "On the 26th Oct. last I had a number of letter circulars to deliver along with my 2 p.m. delivery, which I did not finish until 5.25 p.m. I handed to the charge-tk.ker the orertime claum erclosed, which he returned to me, stating it was a prolongel delivery, and the claim was not aliowed. On the 6th November I had again a number $0^{+}$letter circulars, anci I did not finish until 5.15. The overtime docket is enclosed. In support of the claims I respectfully submit that, on the above duties, I was detained on duty after the usual time of finishing them, for periods exceeding one hour, and having, according to rule, drawn the attention of the charge-taker to the exceptionally heavy nature of my deliveries, I am entitled to the overtime claimed. The overtime for the 6th November is 1 hour and 20 minutes, and for the 26th October 1 hour and 15 minutes." He was requested to answer the following explanation:"With reference to the claim made by you for overtime on the 26th October and 6th November, the charge-taker considers that the extra circulars were not sufficient to cause the deliveries to be unduly prolonged, therefore you are called upon to explain why so much time was occupied in delivering them." The reply from the postman was as follows:- "The charge-taker has only been at this office a short time, and therefore is not sufficiently conversant with my walk to be able to express a qualified opinion. On having made my first claim he did not question me as to the time occupied by me in the delivery. On the 26th October it was 2.50, and on the 6th November it was 2.55 before the sorting and setting were finished, and, these having taken so long-I submit that the time occupied in the delivery was very reasonable.' Whilst in the office I was, in the first place, under the supervision of the charge-taker, and, in the second place, under the supervision both of the charge-taker and inspector, and I have not until now been taxed with wasting time. I submit there is no reason for a charge of this description after so long an interval, simply because I have made a claim for overtime, and that, therefore, I am not receiving that fair treatment I have a right to expect from the Department." Then the man was requested by the inspector to explain why he was so long sorting and setting on 6th November, the demand continuing-"You acknowledged to me that it was not the number of circulars which had caused you to be so late, so much as the fact that they were spread over your double walk; but if they had been only for one or two streets they would have been disposed of in much less time." The answer to this was that "the sorting and setting referred to was done, so far as I was concerned, without any loss of time, and, as I have before mentioned, under the supervision both of the charge 
taker and the inspector. If there had been any time wasted, you, as inspector, would have pointed it out at the time. I am still of opinion that neither sort: $\cdot$ g, setting, nor delivering would have taken so long if they had been confined to one or two streets, instead of being spread over the whole district." The decision of thè chief clerk was that the se were unduly prolonged deliveries, and also that he was not satisfied that the postman "had made exertions to finish earlier." This is the way in which most of these claims are dealt with. We never get any satisfaction for these prolonged deliveries.

Mr. Smith: Would you prefer that these circulars should be sent out altogether in a batch, and not spread over a period?

A. Yes, sir; I am about to suggest that view. Here I would like to draw the attention of the postal authorities to the immense debt the Department is contracting, the consequences of which might some day be very serious. I refer to the possibility of the postmen's claim for overtime pay passing into law as in America a few years ago. There th'se claims were met by retrospective legislation, and the men had only to present their claims at the law courts in order to render the Department a debtor for all overtime from the date of each man's entry into the Service.

The Chairman: I should think that law was made shortly before a Presidential election. (Laughter.)

Mr. Smith : When was that Act passed?

A. Only a few years ago. I have not the exact date. I will let you have it.

Mr. Walpole: I suppose that, as a taxpayer, you are not very anxious about such an Act passing in this country?

A. Well, sir, I should think that the small quota I pay in the shape of taxes would be more than recouped were I to be paid for all overtime I have worked since I have been in the Service. At Hebburn, R.S.O., the duties at ordinary times extend over a period of 14 hours 30 minutes daily $6.30 \mathrm{a.m}$. to 9 p.m.). The men there are often employed delivering circulars one liour extra each day for two or three weeks together, for which they do not receive pay.

Mr. Walpole: You mean by that, I presume, that their deliveries have been protracted in consequence of having to deliver the circulars?

A. I meas to say that the deliveries take up 8 hours without having the circulars thrown in, and we consequently get no pay for delivering the circulars.

Q. And the result is that the deliveries are protracted by the circulars?

A. Yes, sir.

Q. The ordinary delivery includes the customary amount of halfpenny niatter, does it not?

A. Yes, sir; but I am referring to the advertising circulars which cone in in large batches. Within the past few months the men at the Southport Office have worked overtime with circulars on different occasions witlout fay. Here the inspector has considered it necessary to make special provision for the delivery of these large quantities of circulars, but on presenting the claim, the Postmaster has refused to meet it, and the inspector has been obliged to pay it out of his own pocket.

Mr. Walpole: Where is this case?

A. At Southport.

Q. And do you believe an inspector has paid the men out of his own pocket for working the circulars? Did you find it out from the inspector?

A. I got it from two or three men of long standing. I got it at a meeting of the men-from some of the most respectable men in the Southport. Office.

Q. Do you really believe that the inspector paid a large sum of money out of his own pocket?

A. I mean to say that two or three men have told me that the inspector, when paying the postmen, said: "The Postmaster has refused your claim 
for overtime, but never mind, I will pay it out of my own pocket." That is the evidence I rely upon. Instructions are laid down to the effect that these circulars are to be delivered, but that no overtime is to be incurred; which instructions, however, I confess never to have been able to grasp. 'The only logical conclusion seems to me to be this-that if men work $8,8 \frac{1}{2}$, and 9 hours without them, it is impossible to deliver these circulars, however skilfully they may be insinuated into the deliveries, without working overtime.

Mr. Walpole: When you say that the men work $8 \frac{1}{2}$ hours and 9 hours, do you not know it is a rule of the Department that they shall only work 8 hours?

A. Yes, sir; but they are compelled to do it, as the circulars are pressed on them.

Q. You are making a sensational statement that the ordinary time of working is 9 hours.

A. And I have shown you that in many cases and in a great many towns it is so.

Q. Is it not the rule of the Department that whenever the duties exceed 8 hours a revision shall take place?

A. It is, sir. But then a revision does not take place until we have brought an immanse amount of pressure to bear upon the Department.

Sir F. Mowatt: Then you assert that the general work of the postman exceeds 8 hours?

A. I think it generally does.

Mr. Walpole: Give us your own hours?

A. I commence at 9.45 a.m.

Q. Are your hours the same every day?

A. Yes, the same every day. I commence at 9.45 a.m., and work till 11.15 , and sometimes till 11.30 a.m. I have worked till 11.40 , but 11.15 is the official time. It is the recognised time. I am due again at 12.15, and I am considered as off duty only that short interval.

Q. You are an hour off?

A. Yes; I am supposed to be. Then my work lasts till one. I believe the official time is recognised as 1.15 . I go on again at 5, and then my duty is continuous till almost 11 o'clock.

Q. What is the official time? When should it end?

A. 10.45, but it is frequently 10.50. I may tell you I have an interval in this case. It is the only case of the kind we have in Liverpool. Generally speaking. I have an interval of half- an hour for a meal.

Q. Half-an-hour?

A. Yes; and sometimes a little more.

Q. At any rate put it at half-an-hour?

A. Yes, sir; put it at that.

Q. And, therefore, your actual duty, excluding that half-an-hour interval is $7 \frac{3}{4}$ hours?

A. I believe I have left out a quarter of an hour because it is recognised by the Department as an eight hours' duty.

Q. Well, practically you have an eight hours' duty?

A. Yes, sir; but I am giving you cases in Liverpool and elsewhere, where the men have more?

Mr. Walpole: Quite so.

Mr. Smith: You do not say that these duties much exceed eight hours, do you? Would you say that they do in the majority of cases?

A. I think they do exceed it in the majority of cases.

Mr. Walpole: What time do you spend in the day going backwards and forwards between your own house and the office?

A. I should say about an hour and a half.

Sir F. Mowatt: Altogether?

Mr.Walpole: Does that include coming on in the morning? 
A. I live rather near my work. Men from distant wallss have to cross where I live.

Q. Practically you do not go home between 11.15 and 12.15 ?

A. Yes, sir, I do. I live close to the work. The 12.15 is a collecting duty near my walk.

Q. You would not call your duty a particularly severe one?

A. No, sir; only in regard to the circulars. It is of the circulars delivery that I complain.

Q. The normal duty is not a very heavy duty?

A. But I do not know how to separate it from what would be called an abuormal duty. It is an aristocratic district, in which advertising circulars are almost the rule. We have an enormous amount of these circulars.

Q. The effect of it is not apparently to extend the time?

A. It does extend it, however. I frequently finish 25 or 30 minutes after the time on each delivery. I am sometimes 40 minutes after the time without any pay.

The Chairman: Then on those occasions is your bag a very heavy one when you start?

A. No, sir; it is not a very heavy one. The fact of my not doing the first delivery accounts for my not having very heavy bags, unless it is with parcels at night. Frequently I have beavy parcels, and have to set my bag down in order to serve a few houses, keeping it under my eye during the time I am going backwards and forwards. The witness to whom the case for the weights and parcels is entrusted will tell you something about that later on, and I am therefore not touching that question. There is, moreover, the pressure at such times to be taken into consideration. Our duties are so clut up and their parts so unsvmmetrical that 30 minutes' extra work at a delivery is frequently sufficient to prevent a man going home in an interval. 'This is often the case at Liverpool. I have heard, however, from a great many other towns that they have similar cases. Thus, in addition to the heavy strain put upon a man by these protracted deliveries, he is deprived of the full value of an interval, and, as a consequence, is put to the expense of purchasing food out, whilst his proper meal is spoiled and wasted awaiting nim at home. I trust I have made this grievance clear, for it is a very sore one, the feeling regarding it being very strong throughout the whole country. If I have failed to impress it duly on this Committee, there will be much disappointment felt by my comrades in all parts. Besides the grievance is growing and becoming more inte use in proportion to the increase in competition and consequent advertising. We would point ont that our men do not solicit this overtime, even were it paid for. Our experience is that a postman's daily work is arduous enough without it, and we would hail with gratification any schems the object of which would be to relieve us of it. But we regard it as an extreme hardship to be compelled to work time for which we receive no pay, and this hardship is intensified by the fact that all indoor officers are paid for all time in excess of 8 hours. At the Liverpool Office there is an almost regular influx of advertising matter on Fridays. This is spread over the Saturday deliveries which are heavier than those of ordinery days apart from circulars, but which, with this extra work, are rendered so oppressive as to leave our men unfit even for recreation on completion of their duties.

Mr. Walpole: Have you no Saturday relief at Liverpool?

A. No, sir. On New Year's.Day last, at Wolverhampton, every postman due at first delivery and having no collection to make, was ordered to attend duty at 5 a.m., which, for most of the men, was one hour before the proper time. This is of annual occurrence. The men there have never received extra pay for such time. One of the men who should have been due at 6 a.m. Was brought on duty at 4 a.m. He was paid for the first hour, but was treated like his fellows for the second-that is, he was not paid at ail. On Christmas Eve, men at the same office worked five or six hours' 
overtime, for which they were not paid. Some of them performed $16 \frac{1}{2}$ hours on that day. Bad weather often impedes progress. A man cannot make the same speed during hail, rain, or snow storms, or when the ground is overlaid with ice, No compensation, however, is made for overtime incurred at such times. On the contrary, a lack of consideration is often shown, and men are fined for short delays wich collections, etc. On Sunday, January 13th last year, also at Wolverhampton, there was a heavy fall of snow; in some districts the men were compelled to make long deto urs to aroid the drifts. The whole of them were late in returning to the officein some cases as much as three hours. No overtime was paid.

Mr. Walpole: Before you go on to another point, I wish to ask you as to the attendances-the long attendances-at Christmas time, extending over 16 hours.

A. Yes, sir.

Q. Have you any doubt that that would be considered as overtime by the Department?

A. I have no doubt. It is one of the cases in which we are paid overtime, but it is not the case that it is paid at Wolverhampton.

Q. Are you sure of that?

A. Yes, sir.

Q. Is it not the fact that you are paid at Liverpool, and is it not the intention of the Department that you should be so paid?

A. I believe stich is the intention of the Department, but the men frequently cannot get what the Department allows.

Sir F. Mowatt: Do you know whether at Wolverhampton any claim was made for it?

A. It is not necessary to make any claim; it is quite a recognised thing at Liverpool, and the sheets are put accordingly.

Q. I presume the men are dissatisfied that they were not paid; but did they not make any application for it?

A. Frequently at these small offices men have a special dislike to claim even their rights.

Q. But did they make any claim?

A. I do not know whether they did.

The Chairman: Is it not the case that at all offices an exact record is kept of every single hour's attendance by postmen?

A. Yes, sir; they are supposed to keep one.

Q. But don't they?

A. I do not know that they sign special overtime sheets.

Q. But is not every postman's daily record kept?

A. Yes, sir ; it is kept.

Q. And therefore you can see at once what overtime a man does?

A. Yes; you can see it on the sheets.

Mr. Walpole: You have no doubt that the practice pursued at Wolverhimpton is not general throughout the country?

A. Yes, sir ; I have no doubt about that.

Q. And the case of Wolverhampton is an exceptional one then?

A. It is an exceptional case, but thare may be one or two other places where a like course is pursued.

Q. You do not know whether the Wolverhampton men made any claim?

A. I do not.

Q. Do you know whether, by any chance, the Christmas overtime claims from Wolverhampton have not yet keen passed? You must remember it is not very long since Christmas.

A. Well, we have had ours a long time at Liverpool. I have heard that the Wolverhampton men have been treated in this way for years.

Q. But is it not a fact that soms of these overtime claims are not passed till some time after Christmas? 
A. It is a fact; but I repeat it has been the rule at Wolverhampton not to pay them.

Mr. Smith: In previous years?

A. Yes, sir.

The Chairman: Whose practice was that?

A. It will lie with the Postmaster, my lord. The men in these placesin these small places-are not able to bring their cases forward so forcibly as we would be able at Liverpool. I am quite certain, from the nature of the complaints I have had from Wolverhampton, that the case has, in all possibility, been put before the Postmaster ; of course, I cannot be certain of that, but I should judge it from the bitterness of the way in which the complaints have been made in this matter.

Sir F. Mowatt: Before you come to another head of your evidence, there is one point on which I had intended to ask you a question when you were putting forward a claim for the time the men spend in going to and from their deliveries to their homes. You said you thought it should be allowed with the exception of one journey to the office in the morning, and a journey home in the evening. Have you thought at all how that should be estimated? You do not suggest, I suppose, that a man might reside where he likes, and then be able to claim whatever time he occupied in going backwards and forwards?

A. No ; but I should say there should be a reasonable average time allowed. I would not let a man reside where he liked, but we do want some reasonable allowance made in these cases.

\section{UNVARYING LATE DUTIES.}

In addition to what I said about long duties earlier on, I have to draw your attention to the fact that many of these duties, performed by numbers of men at offices belonging to different groups, are unvarying late duties. At Newcastle-on-Tyne an entire section of men perform a stationary late duty, the covering time of which is about 16 hours-from 5 or 6 a.m. till 9 or $9.15 \mathrm{p} . \mathrm{m}$. That is all the year round. At Liverpool a complete section at three district offices perform an unvarying late duty between 9.45 a.m. and 10.45 p.m., without even a nominal relief-that means without Saturday relief or anything of the kind. These men may change duties for an "early day" if they wish, once a week; but the conditions under which this early day is taken render it a most undesirable change. After working till 10.45 on the previous night, this change necessitates a reappearance on duty at 6 a.m. to perform a heavy day's work with three attendances, extending till 5 p.m. or later. It will be seen from this that a short night's rest and a long day's work would not conduce to a condition favourable to making private use of the evening-the object of such a change. There are men at liverpool Office who have performed this or a similar late duty for the past six years, and whose prospects of a change are so gloomy that, the present stagnation of promotion to senior sections continuing, they are certain to find themselves still on it six years hence. It is argued that these are young junior men; but there is every probability of their mending of that fault whilst they still find their duty unchanged, unless more disposition is shown by the officials at Liverpool to improve things. But I submit that it is jast because they are young men that they should not be called upon to make such a sacrifice. Environment is row busy moulding their characters and ir:delibly labelling them for their life-jourrey; yet here we find these young fellows on the threshold of their career beset by the gloom of a persistent late duty-cut off from that proper social intercourse whose influence is so essential a factor in brightening their ycung lives and producing better and hajpier men. This state of things is demoralising. I tremble for the future of these young fellows. Many of their walks lie in squalid districts, where they have to work at nights amidst brawls and drunkenness on every hand. Is it a matier for wonder that they themselves should, in turn, take to drink? 
And this is the painful fact. I warn the Liverpool officials that unless they speedily alter the conditions of duty of this section, from which the other sections are recruited, they will have in future such a rate of drunkenness as they have never yet known. Punishment will be no deterrent. Men grow sullen, reckless, apathetic under it. Better remove the cause.

\section{EARLY DUTIES.}

Hitherto I have confined myself to examples of long split duties. I now give an example of a shorter split duty at Liverpool District Offices.

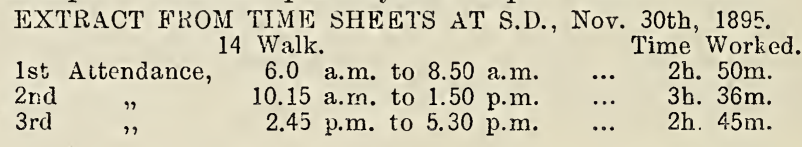

Total, $\quad \ldots \quad 9$ h. $10 \mathrm{~m}$.

The men are paid no overtime for working on these duties. This is an extract from the time sheets at S.D. It is a day when the men worked under pressure. It was the 30th November, and the walk I have taken was a moderately light walk.

Mr. Walpole: Then these are exceptional attendances you are going to give us-attendinces under pressure?

A. I asked one of our men to give me an account of his time and he took a day of pressure which happened to be the dlay before I asked him.

Q. But still you admit it is a day of pressure?

A. I do, sir. I now come to-

7 Walk, W.D., Nor. 30th, 1895.

$\begin{array}{lrrrrr} & & & & \text { Time Worked. } \\ \text { 1st Attendance, } & 5.30 \text { a.m. to } 9.15 \text { a.m. } & \ldots & 3 \mathrm{~h} .45 \mathrm{~m} . \\ \text { 2nd } & 10.45 \text { a.m. to } 1.16 & \text { p.m. } & \ldots & \text { 2h. } 30 \mathrm{~m} . \\ \text { 3rd } & \quad, & 2.45 \text { p.m. to } 6.5 \text { p.m. } & . . & 3 \mathrm{~b} .20 \mathrm{~m} . \\ & & \text { Total, } & \ldots & 9 \mathrm{~h} .35 \mathrm{~m} .\end{array}$

No time is here allowed for "pouching." This, too, is one of the lighter walks at the head office. I may say thit one or two occasions that the time the men start on the collection is not on the sheet. But still the time is indisputable. It is a set time at which he has to make the collection, and I am thersfore taking $i t$ as the time of attendance, and taking his time of fir.ishing from the sheet.

Mr. Walpole: 'Tliat is a day of pressure again?

A. Yes, sir, it is. I believe it was a day of pressure. We have many of them.

The Chairinan: Have you got the official times that the men should have worked on those days?

A. No, my lord, I have not.

Q. But it is rather important, is it not? Is that not really the important thing?

A. No, my lord; I think that these days come a great deal oftener than is admitted. There are many days of very heavy pressure, and I think ir was necessary for me to take a day of pressure to show what we have to do sometimes; we are frequently told that we have lighter days, when wo do not complete our eight hours' actual work, but this applies equally to other bianches of the Service, the men in which are never asked to work overtime in times of pressure without getting paid for it. I think that a day of pressure like this is the best possible example I could give. Not withstanding the arduous nature of this duty at W.I)., there is an arciitional collection imposed, by rotation, at 9.45 a.m. - the man s liealifist time. It is true that this collection does not often fall to a man's turn; but each nian has to make it for a week when it reaches him. 
Sir F. Mowatt: How often does that duty reach a man?

A. It revolves around 16 walks, and I should think it would not reach a man more than once in eight months, but when he has to do that particular duty the work becomes unendurable. He has to do it for a week. It really amounts to this-he comes on from 5.30 until 1 o'clock, and does not get any proper time for breakfast.

The Chairman: I do not quite understand how you make that out?

A. Perhaps I misiead figures.

Sir F. Mowatt: What I take you to say is this-that this occasionai delivery occurs between 9.15 and 10.45 ?

A. Yes; and a man has frequently to run round his walk in order to complete his first delivery in time to make the $8.30 \mathrm{a} . \mathrm{m}$. collection, which he has to bring in before h" can get his breakfast.

Q. What is the man doing at 5.30, when he goes in?

A. He at once begins to sort his walk.

Q. And when does he begin the actual delivery?

A. Some time between seven and eight.

Q. And then what is he doing from 8 till 9.15 ?

A. $\mathrm{He}$ is out on his delivery; he does not start until between seven anex eight, and the question is whether he will be able to finish in time to do this collection. The quantity of correspondence is very heavy sometimes, and a man may not get out on his delivery until 8 o'clock in the morning.

Mr. Walpole : He has only to sort his own walk?

A. Well, there are sometimes three, four, and even five sides to a walk, and the four or five men who are engaged upon it would commence by dividing the correspondence into five parts, and when they had sorted those parts they would exchange them according to the particular sides which they would have to deliver. It would be perhaps 7.30 or 8 o'clock before they go out, and, at a rush, it takes a man till after half-past eight to finish his delivery; then he has to go right away and make his collection and bring it in. That would occupy him until 9 or 9.15. On his return he might have a few bad letters to deal with, or something of that sort, but I have not counted that in at all. He will then have to leave the office again at 9.30 to make this additional collection, and he returns downstairs to the Circulation Branch about five minutes past ten. He will be due on again at 10.45, and, consequently, he is deprived of any proper time for breakfast.

Mr. Walpole: That happens once in six months, you say?

A. It revolves round 16 walks, and it occurs once in eight or nine months.

Sir A. Godley: And then it lasts for a week?

A. Yes; and then it makes the duty unendurable. I wrote out a petition myself, and all the men signed it with the object of getting the collection taken off, as we found the duty very heavy without it, but it was opposed by our inspector, and we were unable to get rid of it. Add to this duty the time taken up going to and from points of starting and finishing, and we get a result of a sweating duty. At the end of it study with a view to advancement or recreation-they are luxuries for others, not for postmen. For them-bed! At this office men on first delivery carry out from 30 to $90 \mathrm{lbs}$. -scmetimes as much as 120 lbs. - and are worked all day at the highest pressure; in the mornings, in fact, at fever heat. They have to climb the numerous flights of stairs in the chambers of our busy commercial centre without any assistance to carry their loads, and as it would be impossible to unanipulate their letters with these loads on their shoulders, serious risk is run by depositing the bags of letters on the lower stages of buildings, wh:ere they are exposed to the danger of being stolen.

\section{PRESSURE CAUSED BY COLLECTIONS OR STATION DUTY BEING ATTACHED TO DELIVERIES.}

Where collections are attached to the end of a delivery, it is commonly the case that the time allowed for such delivery is so narrowly defined that, 
under the least pressure, men are greatly harassed to complete it in time to make the collection. At the Southport Office men have been obliged to make provision themselves for a collection under such circumstances, by paying a substitute. Southport men have paid cab fares themselves in order to reach the office in time with these collections. At Hebburn, R.S.O. (Durham), men have to meet trains at the end of their late delivery, and in consequence of late despatches, which are common at certain times of the year, they have to turn themselves into harriers in order to be in time for their bags at the station. In such cases, at Liverpool Office, men are instructed to break off their deliveries in time to collect. But if this is done at the evening delivery we are compelled to go to complete the delivery in the meal time, which keeps us on duty for about six hours without food. I may explain that or the 6.15 delivery under such cireumstances the delivery is not completed until nearly 10 o'clock at night. A man has to do his collection, and after that has to return to complete his delivery. In the meantime another man goes out with the later delivery, some of the letters of which may be delivered before those of the earlier delivery. We submit that it is a bad system to have a collection dependent on the finishing of a delivery, which, in spite of all gauging, is a variable quantity.

\section{CASE FOR THE JERSEY MEN.}

The hours of the Jersey postmen are very uncertain, and extend over from 12 to 18 hours per day, owing mainly to the irregular arrival of the mail boats. Some of their duties commence at 6.10 a.m. and extend till 11.30 p.m., a covering time of 17 hours 20 minutes. They have three, four, and five attendances per day, subject to arrivals of boats. These arrivals are rarely-if ever-at advertised hour, as shown by the following table, which states the actual times of arrivals for the most favourable month of the year-July:-

HOURS OF ARIIVA, OF SOUTHAMPTON MAIL BOAT AT JERSEY FOR THE MONTH OF JULY, 189,.

\begin{tabular}{|c|c|c|c|}
\hline 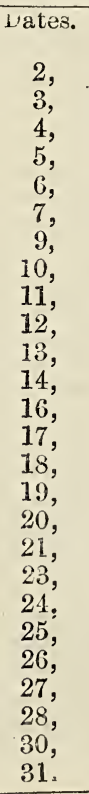 & 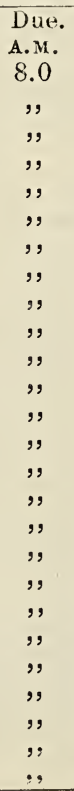 & $\begin{array}{c}\text { Arrival. } \\
\text { A.M. } \\
10.30 \\
9.35 \\
9.50 \\
8.45 \\
11.30 \\
8.35 \\
8.20 \\
8.50 \\
8.15 \\
8.10 \\
9.15 \\
835 \\
8.55 \\
8.45 \\
9.30 \\
9.30 \\
11.50 \\
9.35 \\
8.55 \\
11.35 \\
8.55 \\
\ldots . . \\
10.40 \\
8.55 \\
9.10 \\
8.50 \\
\end{array}$ & $\begin{array}{l}\text { Arrival. } \\
1 . x . \\
\ldots \\
\ldots \\
\ldots \\
\ldots \\
\ldots \\
\ldots \\
\ldots \\
\ldots \\
\ldots \\
\ldots \\
\ldots \\
\ldots \\
\ldots \\
\ldots \\
\ldots \\
\ldots \\
\ldots \\
\ldots \\
\ldots \\
7.10 \\
\ldots \\
\ldots \\
\ldots \\
\ldots \\
\end{array}$ \\
\hline
\end{tabular}


Months could be given showing four arrivals after mid-day. Now, the men's duties are based on the arrival of the boats at their advertised hour8 a.m. From that hour they have to be either within call or on the premises. Thus they are kept in attendance many hours beyond their proper time, almost every day, for which they are not, paid. Between periods of active duty all time is checked off, even to five minutes, although the men be unable to leave the premises.

The Chairman: But the men have a good deal of latitude, have they not? The boats can be seen a long wayi before they come in. They are signalled, are they not?

A. There are some parts-La Roque, for instance-where they cannot get a signal at all; in this case it protracts the duty. The men get a very small amount of pay, and it prevents them doing anything else.

Mr. Walpole: Is it not the case that when the boats arrive exceptionally late the men are always paid overtime?

A. No, sir.

Mr. Walpole: I have an idea that it is.

A. I am told by the Jersey men that it is not so ; they are paid sometimes when they get a supplementary delivery.

Q. Do you mean to say that if men are kept in attendance awaiting a boat, the arrival of which is protracted, they are not paid overtime, and have no right to it?

A. No, sir ; they get no overtime for it.

Q. I think you are under a mistake.

A. Wlell, I've written two or three times, and I have been informed that they do not get paid; the only time when they get overtime is for supplementary delivery.

Q. And do you say that where the boats are exceptionally late they get no overtime?

A. Yes.

Q. Well, I think you have been misinformed.

A. Well, the men tell me they are quite satisfied if the boats arrive before 10 a.m. That is to say, they would be satisfied to be detained for two hours over their proper time, but ask to be paid overtime when it exceeds two hours late. I should take it from that that they were not receiving overtime. It is only in the cases of supplementary deliveries that they do so. I am not speaking of those deliveries, I am speaking only of the ordinary deliveries which are delayed by the lateness of the boat.

Mr. Walpole: Well, I think you are under a misapprehension.

Witness: The men at St. Heliers have no Sunday relief, and they get neither pay nor relief for working Bank Holidays. These protracted dúvies are sufficiently trying to the regular men, but to the unfortunate auxiliaries and sub-office men-who receive pay as low as 6s. per week in return for six or seven hours' work per day, and who are dependent on other employment to eke out their miserable pittance-to these they spell starvation, since, on account of the uncertainty of the hour at which they are freed from duty, it is next to impossible to obtain regular employment. We submit that these conditions of work are discreditable to the Service. I do not think it is either in the interests of the Department or of the men, in so urgent a case, to clothe the naked truth in euphemisms; therefore I declare openly that the Department is here guilty of sweating. These men are badly paid-some of them-badly clothed, and-I was about to say badly fed, but I am unable to conceive how certain of them are fed at all after house rent, etc., are cleared.

Mr. Smith: Who do you say are working six or seven hours a day for 6s. a week?

A. I should have said that they were sub-office postmen whose work averages from six to seven hours a day.

Mr. Walpole: Where is this? Is it at St. Heliers? 
A. No. I should say it was some small part of Jersey-some small office there.

Q. What do you say they are paid? Is it only 6s. or 7s. a week you suggest?

A. Yes; but some of the auxiliaries have had a revision lately, they have had a slight increase, but that only affects one or two men in Jersey. These men are attached to La Roque, Upper Trinity, etc., which are very small offices.

Q. But when you say that the men at St. Heliers have no Sunday relief, are you referring to the cases of established town postmen?

A. Yes, sir.

Q. Are you certain of that?

A. They tell me it is so ; I must rely on them.

Q. But you know it is against the ordinary rule of the Department?

A. I admit it is, but it is a very similar case to that at Wolverhampton.

Q. But is it not the case that if no boat arrives at Jersey on Monday morning there is no duty that morning?

A. I know that their duties are lighter on Mondays than on other days, through no boat arriving.

Mr. Walpole: Let us go back to the Southport case for a moment. You said you had known officers take a cab on their own account. Are you acquainted with Rule 58 affecting town postmen? Does not that rule provide that a town postman may be allowed to employ a cab or other conveyance when the weight of his collection exceeds 35 lbs.? But that if he emiploys a cab he must obtain a ticket from the driver, and hand it to the proper officer? Does not that rule apply to the men at Southport?

A. I was not speaking about the weight of the collection; I was showing that the men were working there under pressure, that they were not able to complete their deliveries in time, and that they had consequently to take a cab to get to the office in time with their collections, quite irrespective of the weight of their bags.

\section{PROPOSAL FOR THE UTILISATION OF POSTMEN'S SPARE TIME.}

It is admitted that eight hours is a fair day's work, provided that it is accompanied by suitable conditions of attendance. It is also admitted that very considerable difficulty may be experienced in cutting out an exact eight hours' day for every postman. If the Department credit postmen with working intervening time it is only just that they should be employed on some useful work. This proposal involves the re-organisation of the Service, so that more of the sorting work should fall on postmen. As an inustration I will take Liverpool. In Liverpool C.B. there are about 25 sorting clerks employed on primary sorting, including newspaper sorting. This lighter form of work could easily be performed by postmen, and alternated with the heavier outdoor work. We do not anticipate any difficulty through failure on the part of postmen to make themselves efficient. In support of this view we would point out that the greater part of the primary sorting is now done by postmen at Liverpool with a fair rate of efficiency, which would increase with the greater practice accruing from the scheme we suggest; also that in many towns the complete devolution of duties obtains, under which system postmen substitute clerks during annual or sick leave. We urge that this would place a greater reserve force at the command of the Department for times of pressure, and would result in the greater efficiency of the Service, and, in the long run, even in economy. It would also create a training ground for postmen with a view to their advancement to sorterships, which, as my friend Mr. Walton will tell you, is urgently needed, the low percentage of promotions from our ranks being unparalleled in the Service-a condition of things not calculated to stimulate to that healthy emulation without which the best qualities of men 
cannot be evolved-a condition, too, which is solely accountable for the apathy of our men.

Mr. Smith: Your argument seems to be that distinction should be abolished altogether?

A. I suggest there should still remain sorterships, the duties of which should be performed by postmen. The men could then pass from the outdoor to the indoor department, according to practice.

\section{HOLIDAYS.}

(On behalf of London and Provinces.)

The subject of holidays is one of most vital importance. We are of opinion that the time over which this annual relaxation from work extends is based on a thoroughly unsound principle-that of wages or salary. It seems to us that it ought to be based rather on the more just principle of the nature and quantity of work performed. It is an indisputable fact that under the present system those who have the shortest hours and the lightest work have also the longest holidays. Dealing with the hours of attendance, I went fully into the nature of our work; what I said then applies equally to holidays. Long hours, early mornings, late nights, hardships and delays arising from atmospheric and other causes, divided attendances and consequent irregularity, sometimes amounting to almost entire absence of time for food and rest, heavy loads, responsibilities (and it must be acknowledged that there is no duty in the Service more responsible than that of the final disposal of letters, including registered and other valuable and important communications). For instance, a mistake in the circuiation of a letter may be-and is often-easily rectified. But a mistake made by the postman-the mis-delivery of a missive to any other than the proper addressee, is not easily set right, and may have very grave consequences. The postman has to deal finally with all communications for his walk, search directories, order books, etc., and attend to the clerical work of re-direction; his work, in short, is the consummation of the undertaking of the Department to convey missives to their destinations, and demands an amount of intelligence and judgment which is only too often under-estimated by the authorities. That work involves, as we have seen, not only physical but mental strain, and entitles him to more consideration from the Department as regards recuperation and relaxation than those whose work is less exacting and who have shorter hours. Instead of this the postman has two weeks' holiday, whilst sorting clerk and telegraphist have three weeks. At times of pressure, such as Christmas, neither of these undergoes the strain which is put on the postman; the telegraphist has no pressure to compare with it, and the sorting clerk finishes his work just when the postman is about to start on the heaviest part of the whole pressure, after working side by side with the sorting clerk through all the earlier stages. I do not fear contradiction when I state that a whole month's work is compressed into the few days of the Christmas pressure. Therefore we think our claim modest when we ask that our holidays be extended to three weeks on grounds of equality with sorting clerks. It may be urged in support of continuing the difference now existing that the sorting clerk has a sedentary, indoor occupation, with a large amount of night duty. But it is the fact that there are postmen also employed on this kind of work, yet they are not thought to require an extra week's holiday, and do not get it. At Liverpool, for example, there are about 152 sorting postmen. stampers, mail messengers, and parcel postmen. all of whom perform indoor work with an enormously larger percentage of night duties, as shown from the following:-

\section{Night Duties (Iiverpool).}

Sorting Postmen, 58 per cent., or 14 weeks out of 24.

Stampers, \&c., 25 ,, 1 week , 4.

Sorting Clerks, $18 \quad, \quad 11$ weeks ," 64.

50 per cent. of the work of the London Postmen is indoor. 
Mr. Smith : Are these indoor duties performed by the same postmen?

A. The sorting postmen do both outside and indoor work, but the stampers, mail messengers, and others, are always employed on what are called indoor duties.

Mr. Smith : But I am referring to those on sedentary duties.

A. Well, though a stamper is not, in a literal sense, on a sedentary duty, in the same sense as a sorting clerk standing at his desk also is not on a sedentary duty, but these are usually called sedentary duties. I may say I am told that in London 75 per cent. of the postmen's work is indoor.

Q. Then you wish to correct your statement on that point?

A. Yes, sir.

Mr. Wlalpole: We ars to take it that 75 per cent. of the work of the London postmen is indoor?

A. Yes, sir.

Mr. Smith: And you want to substitute the figures 75 for 50 in your evidence?

A. Yes, sir, since I have to take this evidence from the London postmen; I am speaking on their behalf in order to save the time of the Committee.

Mr. Walpole: What you really mean is that 75 per cent. of the time of the postmen in Iondon engaged on deliveries is employed on indoor work? Does that exclude collections?

A. I cannot quite say, sir. In this connection I would point out that a great disparity exists in the amount of time rendered by sorting clerks and that by postmen to the Department annually. At Liverpool C.B., on the "A" section, sorting clerks perform 35 hours 30 minutes per week for seven weeks out of 26-that is, they get a relief on Saturdays of 2 hours 30 minutes. They have six split duties at 7 hours 30 minutes per day. On these split duties we may allow them one hour for going and coming to and from home, making their split duty stand at 8 hours 30 minutes. Take a postman from the same office, and average his day's work at 7 hours 45 minutes-I want to ba here under the mark if possible. We have allowed the sorting clerk one hour for his duty of two attendances, and therefore allow the postman two hours for his three attendances. Roundly speaking, we find that the sorting clerk works about sixteen days less in the year than the postman-the extra week's holiday and the meal time of 30 minutes not included. This is independent of all the unpaid overtime I have shown to be performed by our men. By making the concession of three weeks we feel assured the Department would be partly recouped by the consequent improved standard of health. It is an all-important matter that a postman should be in a robust state of health to enable him to cope with his exacting conditions of work, and to resist any incipient infection during his visits to slums and fever-haunted dens. Sir W. B. Richardson says: "Some men are kept too long engaged in what many consider light work, but which by its persistency tells rapidly on the constitutional power. Postmen are good illustrations of this. The automatic rapidity with which the postman does his work so cleverly and, as a rule, so admirably, is, I believe, in every case too prolonged each day to be consistent with the health of the class as a whole. To be constantly on foot and in rapid motion, as the postman is, is to be subjected to a strain that must needs be limited in its duration. The labour of a postman stops from necessity much sooner than it need do, and much sooner than it ought to for the advantage of the public. A postman who knows his district perfectly is an invaluable public servant, and he ought to be kept at his work as long as possible. It would be more expedient, indeed, both in regard to public expense and convenience, to employ a greater number of hands in the Postal Service than to force an excess of labour out of the few."

The Chairman: Surely in regard to what you quote as to the postman being constantly on foot, you are rather arguing against what you have already said? 
A. I was then referring particularly to the Liverpool and London men, in the country it is very different. I have shown you that the men in Liverpool and London are not considered to require three weeks' holiday, although a great percentage of them work indoors, and a large percentage are also on night duty.

Mr. Walpole: It appears to me that Sir W. B. Richardson, when he wrote that paragraph, did not seem to have been aware of the conditions under which Liverpool and London postmen did their duty.

A. I should say he took the postmen in a general sense, and I should say that, in a general sense, they do more walking than sorting. The members of the Royal Irish Constabulary get one month's holiday. We appeal to you to recommend that Mr. Morley's wish to "arrange, whenever it could be done without considerable charge to the taxpayer, that postmen's annual leave should be granted for the period exclusive of the winter months" be carried out. We feel confident there are few offices where this could not be done under the conditions laid down by Mr. Morley. It is our opinion that due efforts have not been made in many offices to give that desired effect. Liverpool and Birmingham, for instance, are offices belonging to the same group; but whilst, I am glad to say, Liverpool has succeeded in obtaining this arrangement, Birmingham has been refused it. A deputation of Birmingham postmen waited on their Postmaster with the object of pressing their claim, but they were met with a refusal on the grounds that it would incur extra expense. Such anomalies, we feel satisfied, will not be brought under the notice of this Committee in vain. It is obvious that what can be done in Liverpool could also be done in Birminghain. The Oldham postmen presented a memorial before their Postmaster in December, 1892, asking this concession. The request was granted and came into operation; but the arrangement not having been set forth in a document, the old system was reverted to on the advent of a new surveyor. I am informed that the 8 months' system would work out with very little additional expense there. In many small offices-such as Chathill (R.S.O.)-a grievance is experienced which deprives men of the full value of their holidays. I refer to the insufficiency of the allowance made for substitution. The minimum pay only is granted to substitutes. As a consequence, the men have to put their hands into their pockets to add $4 \mathrm{~s}$. per week before they can find a substitute willing to act.

Mr. Walpole: Can you give me an instance where that is done?

A. Yes, sir; I have one or two letters to that effect at home, where the men say they have had to do it. I can send the letters on to you if necessary.

Q. You say they have to pay a portion of the substitute's salary?

A. Yes, sir.

Q. Do you know whether these men have drawn attention to the fact that they have had to pay money out of their own pockets?

A. I can only surmise so from the nature of their letters.

Q. Do you know that if they had drawn attention to it the money would have been repaid as a matter of course?

A. No, sir, I do not.

Q. Will you take it from me that it is so?

A. Of course, I will take it from you; but in the meantime I will send in a written statement to you. This is felt very keenly, more so as that is the time above all others when men want all their savings for meeting the expenses which are inseparable from holidays. This insufficiency of allowance applies also to Bank Holidays. The men at Chathill are compelled to take a day's leave in lieu of pay for working on those holidays. But they have to add about $8 \mathrm{~d}$. per day to the allowance before they can get a man to work in their stead. At Cork 24 outdoor men perform on an average four hours' duty every Bank Holiday, and instead of pay being granted, they are relieved in the following way:-On five successive Mondays the 24 walks are compressed into 19. "Thus, in order to relieve the remaining 
five men, additional work is thrown on each man for 20 days in the year. This, practically speaking, means no Bank Holidays for the Cork man, since the day he takes in lieu thereof is taken at his own expense. I thinl: that the London postmen have a great grievance as to Bank Holidays. On those days they are required to perform duty

Mr. Walpole : Are you going to speak on bahalf of the London postmen?

A. Yes, sir. The London postmen have a great grievance as to Bank Holidays. On those days they are required to perform duty for from four to five hours. Instead of pay, as at Liverpool, they are allowed time off, and instead of getting a clear day, as is the case in many towns, the men only get the actual time off which they have worked. This is regarded as very unfair, since at other Government offices a full day's leave is given in lieu of Bank Holidays, although the time of actual work may not have amounted to one hour. We urge that the time on such days is of greater value than that at ordinary times; for example, there are advantages to be gained from excursions and facilities of that sort which would be of great benefit to a London man. We also urge that, as in the case of Sundays, the time or pay given in lieu ought to be at an increased rate, and we would ask this Committee to recommend that a full day be given to the London men for time worked on Bank Holidays.

\section{SATURDAY HALF-HOLIDAY.}

We hail with delight Mr. Morley's concession of Saturday half-holiday, and would be glad if the principle were extended to every part of the country. We think, however, the condition laid down by the late Postmaster-General, "that the local town or county council signified its approval of one of the Saturday afternoon deliveries being suspended," might, without fear of causing any serious inconvenience to the public, be deleted. Many of us have vivid recollections of all the barriers that were placed in the way of suspending deliveries on Bank Holidays. The idea was absurd-could not be entertained-the public would not submit to it-business would be brought to a standstill next day-and so on ad infinitum. I myself have worked from early morning till late at night on Bank Holidays, when there was no relief whatever. In spite, however, of all these gloomy prophecies, we have obtained Bank Holiday relief, and plenty of it, especially since the Department undertook to pay us extra for work on those days. And the Department did not ask town or county council to signify their approval before making the concession. They simply ordered it by one Departmental coup, and never a murmur was raised, and the public fell imperceptibly into the the ways of the Department. 'The main objection to extending this relief to Liverpool was that American mails frequently arrive on Saturday evenings, and that as a consequence of suspending one or two evening deliveries the public would suffer the inconvenience of delay in the delivery of important business correspondence till the following morning. But these mails arrive during the day on Bank Holidays, and there is no serious complaint at the public not getting their letters on those daysnotwithstanding that the delay is much greater than it would be on Saturdays.

Mr. Walpole: I suppose that on Bank Holidays all the offices are closed, are they not?

A. The same applies to Saturday afternoons, sir.

Q. But if an office is expecting correspondence by the American mail, they would not close? Would they not wait for it on Saturdays?

A. I think they would; and the same would apply to Bank Holidays, if they knew they could get the letters. But knowing they cannot get them they do not wait. Every one of these barrier's raised is a barrier of gauze the colour of iron, which will be no let to our progress if only the Department will march abreast of us. We ask you also to consider the 
ripening of public opinion and the recent attempts at Parliamentary legislation in your determinations.

Mr. Walpole: It is a fact, is it not, that when the postmen applied at Liverpool for this relief on Saturday afternoon, we referred it to the local authorities?

A. Yes, sir ; it is a fact.

Q. And we asked them whether there was any objection locally to our giving you the boon asked for?

A. Yes, sir; and most of the local authorities were agreeable to it. It was only when some one brought pressure to bear on the Chamber of Commerce that that body used its influence to prevent the Town Council deciding in our favour.

Q. Do you think that the Department should override the wishes of the local authorities?

A. It does not consult them in many cases; it is only in a case like this that it does so. In the case of Bank Holidays it certainly did not question them.

\section{SPECTAL LEAVE.}

By this we mean leave requested for a day or part thereof. You have been told of the terrible nature of the work at such offices as Liverpoolhow that work has put, and is putting, men into their graves-and here I must corroborate everything told you by my colleague, Mr. Walsh-a man of the highest personal integrity in the office, and whom I have never known to be capable of even the shadow of an untruth-who is known at Liverpool by the name of "Honest John." I knew Postman Elliott, whom Mr. Walsh referred to, well. In reference to this case I should like to make a remark or two. (To Mr. Walpole) I beard what you said to Mr. Walsh the other day. As a matter of fact, although I knew that, at the last, there was a complication of influenza, and, finally, of bronchitis, that was only the beginning of the end. I knew that he had been failing a long time before the influenza set in, and his sister told me that his work was killing him. He used to come home in a very exhausted condition, and he had been for a long time in a very low state.

Q. You knew his sister?

A. Yes, sir.

Sir F. Mowatt: It has also been stated that he had heart trouble?

A. Yes, it was so stated; but that also was a later development. $\mathrm{He}$ had been bad for a very long time by reason of the difficulties of his work; all these were later developments.

Mr. Walpole: You know that he actually went on duty against the advice of the medical officer after he had had an attack of influenza?

A. Yes, sir, I believe it was so. Seventeen years ago I worked with him side by side on the same walk. I knew him then to be in robust health, and to be a man who husbanded that health, as he did-as far as he could under the wretched conditions of his work-until the day of his death. All that his sister told Mr. Walsh she told me. She said that her brother had been worked unto death in the Liverpool Post Office. I can also testify to what was said about the number of men it has taken to perform the work of one on the heavy walks of Liverpool. I have had a short experience of walks of this nature. All this has been put before you vividly, accurately, and truthfully, therefore I need not trouble you with reiteration. But I will further point out that our work is very confining in naturethat we have not that liberty to absent ourselves for a day or part thereof enjoyed by others, and by artisans in particular. We are quite satisfied that the nature of our employment could never admit that liberty; yet we are of opinion that. provided a man is prepared to pay for qualified sub. stitution, no obstacle ought to be thrown in his way by the Department. Instead of which we have to complain of the inordinately inquisitive in- 
quiries made by some supervising officers before they allow a postman to have his work performed by a deputy - even for one hour. Men at Windsor, for example, have been repeatedly and persistently refused leave for a small portion of the day, and have been told this is a rule of the Service. One man at that office was refused leave in this way, although it was asked for the purpose of firing his class, he being a member of the Windsor Volunteers. His Postmaster informed him he would never get such leave from him (the Postmaster) if he (the postman) were under him for 20 years. We submit that the time has arrived when such arbitrary power should be taken out of the hands of Postmasters, and some definite ruling laid down in its stead. The members of the Liverpool Police force have one day's special leave every fortnight. In the United States a postman may take a day's leave at any time by simply providing a deputy.

The Chairman: You understand that the decision must eventually rest with the local Postmaster?

A. Yes, sir ; I think so.

Q. You could not refer it to the head office, or even to a district office?

A. No, sir; but you might have some definite ruling on the point for the guidance of Postmasters.

Mr. Walpole: Do you think it is a fact that Postmasters do throw unnecessary obstacles in the way of special leave?

A. In the case I have sdduced it was done. I know that very frequently the supervising officers have made inquisitive inquiries which are quite unnecessary.

Q. In your own experience have you ever had occasion when you have been refused special leave unfairly?

A. I have been frequently asked when I have been taking leave-even for an hour or two-what I required it for?

Q. And you think that is unreasonable?

A. I do, sir.

Q. Do you happen to know on how many occasions in 1894 and 1895, up to the 31st of March in the latter year, you yourself were granted special leave?

A. I am not complaining now about that.

Q. But I am asking about it, and I want to get at the facts.

A. I am not complaining specially about the Liverpool office; I know there are a great many smaller towns worse than that.

Q. But $I$ want an example in the other direction, and $I$ therefore ask you how many times you have been granted special leave?

A. I myself have had a great many special leaves.

Q. Is it not a fact that you were granted it on 10 separate occasions in ono year?

A. Possibly, sir, but mostly for work in connection with our Federation.

Q. In the present year, which has not lasted very long, is it not a fact that at the end of January you applied for three days' leave to be able to deal with your correspondence? I do not mean the letters you deliver, but your own correspondence, which you said had assumed proportions quite in excess of your anticipations? Were you not granted that special leave?

A. Yes, sir; and when I have applied for anything in connection with the Federation every facility has been placed in my way. I have nothing to complain of in that regard. What I am complaining of is that when a man merely wants to make an exchange of duties, he is asked the reason for it. That has occurred at Liverpool, and the rule has been really irritating to the men. They may have wanted to get free for a night, and I do not think that inquiries of that nature should be made.

Q. But how is it irritating? Is it irritating because a man who is asking special leave which upsets the work of the Department is required to state why he wants to go away?

A. But he provides a qualified substitute, and so it would not upset the special work of the Department. 
Sir F. Mowatt: Then you would suggest that whenever a man desires to take part of a day as special leave, he should be allowed to do so if he provides a substitute?

A. Provided that it does not occur too often. I do not think I should have been allowed anything like the liberty I have had in that respect if I had wanted it for any other reason than to attend to the work of the Federation.

Q. But is not that a very good reason for asking what the special leave is wanted for?

A. There might be some reasons quite as important to a man and his family as attending a Federation meeting.

$\mathrm{Q}$. And you object to be asked for those reasons?

A. There are many private reasons a man would not care to state on paper ; indeed, some of them would almost look ridiculous.

Mr. Walpole: But people in a much higher class than that in which you yourself live are accustomed to state the reasons for which they are asking special leave.

A. I am not aware of that, sir. I think the inquiries are unnecessary in the cases I am dealing with. If a man requires a change of duty, and can effect an ordinary exchange, I do not see why he should be asked to state what he wants that exchange for. He is not putting the Department to any inconvenience, because he is probably exchanging it with the officer who rotates with him on that particular duty, and who will consequently be agreeable to take it for him.

The Chairman: Thank you.

Witness: I thank the Committee very much for the patience with which they have heard me. 
Zachariah Howe, of Sheffield, was the next witness called.

The Chairman : You are a Sheffield postman, are you not?

A. I am, my lord.

Q. You are an auxiliary now, are you?

A. Yes, I am.

Q. How long have you been an auxiliary postman?

A. 24 years next March.

Q. And what other occupation have you followed?

A. I am a small shopkeeper, sir. By trade I am a brush-maker.

Q. Then you have three methods of earning a livelihood at this moment?

A. My wife looks after the shop. It is a small hosier's, draper's, and fancy stuff business.

Q. And you make brushes?

A. I have been out of employment in regard to brushes these 10 years.

Q. And not carried on your trade at all?

A. I have not carried on my trade at all simply because I could not get work. I worked for one firm in Sheffield over 20 years, but foreign competition and the importation of foreign goods has spoilt the brush-making industry, and I have had to get a living as best I can.

Q. Did you carry on the brush-making, when you had it, at your own house?

A. No, sir ; at my employer's.

Q. How did that fit in with your Post Office work?

A. It fitted in very well. I had nothing to complain of.

Q. What time used you to be employed on this occupation?

A. When I first joined as an auxiliary the work went by seniority, which, I may say, gave great satisfaction to the auxiliaries at Sheffield. When I first joined I lial allotted to me the first morning delivery at $9 \mathrm{~s}$. for seven days. Then there was a collection which the auxiliaries were allowed to do. They were paid at that time practically by piece work.

Sir F. Mowatt: How long did the morning delivery take?

A. From 3 to $3 \frac{1}{4}$ hours. From 6 o'clock till 9 or 9.15. Then if I did a collection $I$ had 3 s. a week, which brought my wages up to $12 \mathrm{~s}$., and if two collections I had $3 \mathrm{~s}$. for each, and got thus $15 \mathrm{~s}$. a week.

Q. So for the delivery you got only 9 s. a week?

A. Yes.

Q. At what hour did you get to the brush factory?

A. After 9, when I had done my delivery; I used to be at work between 9 and 10. As my seniority went on I got collections, one at first, and then two-the 6 and 8 o'clock collections at night. Practically I worked at the brush factory from between 9 and 10 in the morning till nearly 6 at night. I found my occupation on the delivery very beneficial.

Q. You were practically receiving 15 s. a week?

A. At that time I was, sir.

The Chairman : What particular point do you wish to speak about?

A. Well, if you have no objection, my lord, I would like to give my own experience as an auxiliary with regard to the rise and fall of wages. In March, 1872, I joined as an anxiliary, working from 3 to $3 \frac{1}{4}$ hours per day for seven days, or 23 hours per week (about) at $4 \frac{3}{4} \mathrm{~d}$. per hour. I had also a collection at $3 \mathrm{~s}$. a week ; that brought it to $4 \frac{1}{2} \mathrm{~d}$. an hour. In doing two together I had $41 \frac{1}{2}$ hours for $15 \mathrm{~s}$. a week, equal to $4 \frac{1}{2} \mathrm{~d}$. per hour. Speaking from memory, in 1874 or 1875 - as a result of a petition-we got a shilling extra per week for the delivery and a shilling for the collection, thus bring- 
ing the pay for the $41_{\frac{1}{2}}$ hours occupied in the delivery and collections to $5 \frac{1}{4}$ d. per hour. At that time $I$ had the morning delivery at 10 s., and two collections at $4 \mathrm{~s}$, each, making $18 \mathrm{~s}$. a week. After the morning delivery I used to go to work until 6 o'clock at night, and then do the two collections. I thus had a lapse of from 8 to 9 hours for other employment. In the spring of 1887 the Ridley Commission sat at 2 Victoria Street, London, S.W. A correspondence sprung up in a number of towns throughout the country with regard to our contentions. We in Sheffield did not consider ourselves so badly paid, but our grievances were-no stripes, Sunday duty all the year round, no holidays, no pay for overtime, and no boot allowance. In 1889 an anomalous revision took place, and, speaking from my own experience, if I could have obtained other employment I would have left the Service. It was what we older men termed, when talking to one another, an Irish revision. It meant more work and less money. There are only two of us left who were in the Service then.

The Chairman : You mean, of course, at Sheffield?

A. Yes, sir. It drove all who had other employment-and they were the best of the men-out of the Service. And how we were cajoled by our superior officers-the superintendents-to join the established class I will point out. We were having $18 \mathrm{~s}$. a week at $5 \frac{1}{2} \mathrm{~d}$. per hour-and this is an anomaly, sir-four men were now paid $14 \mathrm{~s}$. a week, and the remainder 12s., all, however, doing the same work-six hours per day as formerly.

Mr. Walpole: Do you mean that all the men were doing the same work?

A. I mean that those who had 14s. were doing the same work as those who had $12 \mathrm{~s}$.

Mr. L. Smith: You say that it meant more work and less pay?

A. It meant that we still had the same work to do-the morning and midday deliveries, and one collection, for less pay.

Mr. Walpole: Who were the four men?

A. I cannot tell.

Q. Are they in the Service still?

A. No, sir. I wrote to Sheffield for the information, but have not received it. I can vouch for it that they were all doing the same duty.

Sir F. Mowatt: Didn't you say you were enticed to join the establishment?

A. I will explain that as I go on. Our duties were at this time, as I have said, the marning delivery of two or three hours, and the collections at night, thus leaving every facility for other employment. Then we got a reduction of wages. As near as I can remember-

Mr. Walpole: What do you mean by the established class?

A. The established class of postmen.

The Chairman : You did not join it?

Sir F. Mowatt: You resisted the cajolement?

A. No; listen to me, sir. How they persuaded us to join the established class

Sir A. Godley: Tried to persuade you?

A. They took the men, from the senior auxiliaries downwards, and asked them to join the establishment. I will give you the names and length of service as near as I can. Henry Hall, 49 years of age 21 years' service. I believe the Department lately had his case under consideration; what decision they have come to I am not in possession of.* Arthur Ouseley, 50 years of age, 21 years' service; Z. Howe (myself), 51 years of age, 17 years' service; and G. Stanyard, 46 years of age, 14 years' service. We were all solicited to join the establishment. I was asked, and at first consented, but went home and reconsidered it. I well weighed the matter up with my wife, and decided not to join. I wrote thanking them for their kind offer,

\footnotetext{
* Hen y Hall has sin e received a full appointment and $£ 10$ back pay, app int-
} ment to date back to the revision of 1889 . 
and declined on the ground of age. The superintendent and other officials again solieited me. I was taken before the Postmaster, explained to him my age, and, more than that, told him it was not a fair bargain. That was the ground for my declining. After putting in 17 years' service to be asked to go on the established class as a new entrant, I thought was not a fair bargain; I was being unjustly dealt with, and that I would try to seek occupation in other ways. If I could have found other employment I should have left the Service.

Mr. Walpole: No constraint was put upon you to join?

A. No, sir.

Q. Then I do not know what you mean by being cajoled?

A. I will tell you. We all four said we were too old. I said, "I beg your pardon, I was above the age when I joined; I shall not get in." The Postmaster replied, "Oh, yes, you will." I was flattered at their opinion of my ability. All the years I had been in the Service I had never experienced such flattery. I would not have believed it. That was the kind of cajoling that was done to bring us into the Service. I asked, "If 1 am refused shall I forfeit my seniority in the auxiliary class?" "No," was the answer. Now, as auxiliaries, we considered that by seniority we had the choice of duties and collections. We considered that a great favour. For years I had been striving to get two collections. The then Sheffield Postmaster said to me, "No, Howe, I don't see why you should." I said, "What about the pension?" He said, "I wlll do all I can to help you to get your former time to count." That was 17 years. Well, gentlemen, we all four laid our cases before the Department, and we were refused. Ouseley, since deceased, was one who was refused. We were kept doing full duty for a few weeks. I cannot say from memory how long we were kept doing full duty. As unestablished town postmen we had 18s. per week, no holiday, no increment, no sick pay, and no boot allowance. I asked to be replaced, and to take my seniority as an auxiliary, but they refused me. Then I was asked if I would be removed to Hillsborough. I strongly objected, and said, "Let it go by seniority." Ultimately another man accepted. I could not see sacrificing my home and business.

The Chairman: I think you are rather dealing too much with your own case.

Witness : I was put back as an auxiliary at 12s. a week, and forfeited seniority. I strongly objected, as it gave me no facility for other employment. I was asked to sign a document. I at first objected. I asked the superintendent if there was any possibility of being replaced senior at $14 \mathrm{~s}$. He distinctly said, "No." Ultimately I had to sign what we call "the piece of blue" for $12 \mathrm{~s}$. a week.

Mr. Smith: When did you have to sign that?

A. I am speaking of 1889.

Mr. Walpole: You signed something of that kind six years ago?

A. Yes ; I do not think those papers have been introduced long.

Q. But you signed it yourself in 1889?

A. Yes, sir.

Q. Then it was introduced before 1889 ?

A. Yes, sir.

Q. You said you were restored at 12s. a week. Your present wages are $14 \mathrm{~s}$. , are they not?

A. Yes; I will explain that. A change of Postmaster took place in 1881, from Mr. Mawson to Mr. Stephenson. In 1892 the first opportunity I had with Mr. Stephenson, who is now at Newcastle-on-Tyne, I explained to him my position. He remarked that he would take up my case for me and help me. On June 27th, 1892, we were all placed on an equal wage of $14 \mathrm{~s}$. per week. I asked Mr. Stephenson, "What about my back pay?" He said, "Howe, I cannot assist you. I was not in Sheffield at the time; I was not Postmaster." Thus I lost about $£ 15$ through being solicited by my superior officers to join the established class. I tried in vain to get my 
case through the official channel. This is what occurred among the auxiliaries. When you offend a superior officer it is a losing game. It is like running your head against a brick wall. You don't know where it will end. I think from my own experience of such anomalies as this cropping up that the executive of the Federation should be accepted as the channel of communication. I have said that in 1887 a Royal Commission sat at 2 Victoria Street, and that this brought about a correspondence in many towns throughout the country. I have the correspondence here.

The Cliairman: I think we will not go into that. We had better come to the case of the provincial auxiliaries, I want to get on with your evidence.

Witness: In presenting for your consideration the case of the auxiliary postmen in the provinces, I should mention that I am an auxiliary at Sheffield of 24 years' service, and would preface the matter that I have to present to you by the remark that discontent has prevailed amongst this class ever since I entered the Service, and I have no doubt many years previcusly, as I found it existed upon my entry. I would further point out that in spite of repeated attempts to obtain reform. on our part, we are in a worse condition to-day than we were some 21 years ago. At the time when the Ridley. Commissien was appointed, hope entered our breasts that an opportunity had arisen to have our case tried upon its merits, and with this object in view an amalgamation was attempted between Newcastle, York, Leeds, Bradford, Hull, Nottingham, Derby, Leicester, Birmingliam, and Sheffield, for the purpose of electing and sending a representative before the Ridley Commission, but, unfortunately for us, the labours of that Commission ended before reaching the Post Office, thus was hope once more banished from our hearts. The points I wish to speak on are:-1st.- The irregular rate of payment adopted towards this class throughout the country. 2nd.-The uncertain and undefined method of promotion to the ranks of the established class. 3rd.-The custom of requiring Sunday labour from a large proportion of the auxiliary class without any payment for the same. 4th.The absence of participation in any of the contingent advantages of the established class, such as holidays, sick pay, stripes, and boot allowance. The first point to be considered, viz.:- The irregular rate of payment adopted for work of the same class and importance tends to breed discontent amongst the ranks of the auxiliary class, and places a severe strain upon the discipline so necessary in an establishment like the Post Office; as, when men in some towns gain the knowledge that for exactly the same nature and length of time occupied in the work performed they are paid at a less rate than their confreres in other towns, this feeling of discontent must naturally arise. When it is pointed out that the rate of pay per hour for this class of Post Office servants only reaches an average througliout the country of $4 \frac{1}{2} \mathrm{~d}$. per hour, and when the responsible nature of the work entrusted to them is taken into consideration, and the fact that no matter how many years' service they devote to the Department as auxiliaries, they receive no increase in their wages, it cannot be considered an extravagant request to ask that the minimum rate of pay be $6 \mathrm{~d}$. per hour from 5 a.m. to 9 p.m., and from 9 p.m. to midnight, $8 \mathrm{~d}$. per hour, and from midnight to 5 a.m., $9 d$. per hour, as these latter periods are night work, and should be paid at a higher rate than day work, as is the custom in all callings, trades, etc. I have already spoken of the anomalies with regard to the pay of the auxiliaries. In Cambridge there are four men during the College term who are putting in seven attendances, and working from $9 \frac{1}{4}$ to 10 hours a day for $19 \mathrm{~s}$. a week.

Sir F. Mowatt: Seven attendances?

A. Yes, sir.

Mr. Walpole : Are all those men you refer to auxiliaries?

A. Yes; they are auxiliary postmen, employed during the College term. Sir F. Mowatt: For from 9 to 10 hours a day?

A. Yes. $9 \frac{1}{4}$ hours is the lowest, and 10 hours is the highest. They are 
on first at 6.45 a.m., and at night until 8.45 or 9 . I will give you the attendances : -6.30 to $8.30,9.15$ to $10.45,12.30$ to $1.20,2.30$ to $3.30,4.15$ to $5.30,6$ to 7.10 , and 7.15 to 8.45 . This is during the term, which lasts, I believe, 32 weeks. Thus four auxiliaries working $229 \frac{1}{2}$ hours, at $4 \mathrm{~d}$. per hour, earn between them the weekly wage of $£ 316 \mathrm{~s}$. The same men during the vacation at Cambridge do one collection and one delivery. The delivery is 6.30 to 8.30 , and the collection is 6 to $7.10 \mathrm{p.m}$.

The Chairman: And what do they get for that?

A. 10s. a week. Between them they put in $78 \frac{1}{2}$ hours, and the wages work out at $6 \frac{1}{2} \mathrm{~d}$. per hour. Here is an anomaly. During the vacation they get $6 \frac{1}{2} \mathrm{~d}$. per hour, and during the term, when the heavy strain is put upon them, they only get $4 \mathrm{~d}$.

Mr. Walpole: During the vacation they only have one delivery and one collection?

A. Yes, sir, for 10 s. a week.

Mr. Smith: Do you know how they fill up their time on the vacation?

A. I do not know, sir; but from the correspondence I should say they have nothing to do. They complain very much about that.

Q. But they have something to do.

A. Well, these men have not.

Q. How do they spend their time?

A. Sit at home, I suppose.

Q. They have to certify that they have something to do?

A. From the correspondence which reaches me I judge that they have nothing to do.

Mr. Walpole: Do you think that they have signed the blue form?

A. I have not asked that question. I have not the correspondence here, but the men complain of the low rate drawn by the auxiliary as compared with the established class.

Mr. Smith: I have just been informed that the rule requiring auxiliarie; to have other employment has not been applied outside London.

Witness: That is so. I will touch upon that later on. I believe that at least 75 per cent. of the present auxiliaries, earning $12 \mathrm{~s}$. or $14 \mathrm{~s}$. per week, depend entirely on their income from the Department. In Sheffield, for instance, but one other man to my knowledge does anything else for a living. The older men were driven out as I have explained by the revision. In Windsor- -

The Chairman: Is this blue paper signed by the auxiliaries in the provinces now?

A. Yes, sir.

Q. Are you sure of that?

A. I had a copy of what was sent to the postmen at Sheffield. I was not aware that we could write to the Postmaster for information or I should have been writing to them all up and down the country-(laughter)I thought such action would have been treated as insubordination. I have at home a copy of the letter I sent to the Postmaster asking for a copy of the document which I signed.

Q. You mean the one the auxiliaries have now to sign in the provinces?

A. He sent this one to me as the one I had signed.

(Document handed in.)

Q. Is it the one that has to be signed now?

A. It is a long time since I joined. The last one I signed was in 1889 .

The Chairman (to Mr. Maclaren): Do you know if this is the form the auxiliary postmen have to sign in the provinces now?

Mr. Maclaren: I don't know. I have been appointed for seven years.

Mr. Smith: I am told it is practically the same thing.

Witness: In Windsor there are three auxiliaries, who work the duties $\mathrm{by}$ rotation. These duties start at midnight. The first is 12 to $1.45,6.15$ to 9.15 a.m., 6 to 8 p.m., and 8.45 till $11-9$ hours per day. The ques! 1 on is when does the man who does that duty get lis sleep? The second duty is 

12 to $1.30,10$ to $12.15,6$ to 8.10 , and 8.45 to 9.45 . This man puts in 6 hours 55 minutes per day.

The Chairman: Is that at Windsor?

A. Yes. There are three duties on which the men rotate. The third duty is 6 to 9 a.m., 10.20 to 11.10 , and 6 to 8.15. That represents 6 hours 5 minutes, whereas the first duty is 9 hours. But it is spread ove: about 17 hours. All these are done at 15s. a week; thus, 132 hours per week at $4 \frac{1}{8}$ d. per hour gives the total wages of the three men, viz., $225 \mathrm{~s}$. per week. But in addition I have another anomaly which exists at Windsor, and has done so for many years, according to my correspondents. A. Young, a rural auxiliary, works from 6 till 10, four hours on the morning delivery, doing 24 hours per week for $9 \mathrm{~s}$., or $4 \frac{1}{2} \mathrm{~d}$. per hour. In addition to that, during the College term he is called upon to assist with the duty from 6 to 8.30 p.m., for which he receives no pay. I received this last August. The statement is, that in 1893 he thus worked 174 days; in 1894, 234 days; and up to August, 1895, he had put in 139 days, or a total of 547 days, at two hours per day, representing 1094 hours, or 22 weeks 4 days and 5 hours at 8 hours per day, for which he has received no pay.

Mr. Walpole: Why does he do it?

A. He does it under pressure.

Q. What is the man's name?

A. A. Young. Since I have been in London, I wrote to know if this existed now, and they have sent me word, "Yes, it does."

The Chairman: Is there not a fixed rate acknowledged by the Department for provincial auxiliaries in the same way as in London?

A. No, sir; I wish there was. That is what we are fighting for, of course. I have given you two college towns. I will now take the case of a third. Men at Oxford are receiving $5 \frac{1}{2} d$. per hour on the average. The letters sent to me say how satisfied they are as things are going on, compared with the case of their brethren at Cambridge and Windsor. The only complaint from Oxford is that they have to work $1 \frac{1}{2}$ hours on Sunday. That is the principal complaint. They are getting near on 6d. per hour.

The Chairman: Is that including the Sunday duty?

A. No, sir.

Sir F. Mowatt: Do you say they are not paid for working on Sundays?

A. Yes, sir; I will touch upon that presently. Another anomaly exists at Ramsgate. The first duty is 5.30 to $7.30-\mathrm{a}$ two hours' duty with one attendance. For this the wages are $6 \mathrm{~s}$., or $6 \mathrm{~d}$. per hour. Next there aro two duties combined, 6.30 to 8.30 , and 5.30 to 7.30 , or four hours at $13 \mathrm{~s}$. per week. Here comes in the anomaly. There are four men, two of thein doing the duties I have named. Then there is an intermediate duty during the day: one from 9.30 to 12.30 , and the other from 3.15 to 5.30 . The men who do all these duties have 13 hours a day; while still another duty from 11.15 to 1.30 brings it up to $13 \frac{1}{2}$ hours per day. The two men who do these identical duties get a reduced pay of $4 \frac{3}{16} \mathrm{~d}$. per hour. Thus, the more bone and sinew you give to the Department, the less wages you receive. For another duty a man receives $14 \mathrm{~s}$., or $4 \frac{1}{8} \mathrm{~d}$. per hour. These are anomalies which exist, and which cause great discontent. The next case I must allude to is that of Warrington. Here the men have greater facilities for other employment than any town I can name, and I think I have had from 200 to 300 papers submitted to me.

The Chairman: How is it they get those facilities?

A. I cannot tell you that. I have not been there.

Q. Can you tell us in what particular trade they are employed?

A. It used to be pin manufacture when I was a lad. At school we were taught, "Warrington for pins." Now I will give you another anomaly. There is a man named Ashbrook doing duty at Warrington from 6.30 to 8.30 p.m., at 8 s. per week.

Mr. Walpole: That is $8 \mathrm{~d}$. per hour.

A. That is where the anomaly comes in. 
Q. Is it not an anomaly on the right side?

A. Yes ; but, according to the correspondence I have received-and I had some only this morning-there are four other men doing the delivery from 6 to 9 a.m. and receiving 9s. per week, or $6 \mathrm{~d}$. per hour. Then there are six men doing the two deliveries together for 12s. a week, and you thus see, my lord, that for doing them jointly they get only $4 \frac{3}{4} \mathrm{~d}$. per hour, while when they are separated for one the men get 6d., and for the other $8 \mathrm{~d}$. per hour.

Mr. Walpole : I am afraid these are anomalies you had not better draw attention to.

Witness : They are pointed out to me in the letters I have received.

Q. Apparently in the cases of the separate deliveries we are giving much too much.

Witness : Next I come to Shrewsbury. There are three duties of, 7.45 to $9.15,10.45$ to $11.50,4.10$ to 5 , and 6 to 9 p.m., involving four attendances, 14s. per week. There are other duties, 6 to $9,10.40$ to 11.50 , and 7 to 8.15, for 12s. per week, and there are six duties from 6 to 9 , and 10 to 11 , at $9 \mathrm{~s}$. per week. This is the nearest approach to the case of men working in one town for a similar wage. The three men at $14 \mathrm{~s}$. a week get $4 \frac{3}{8} \mathrm{~d}$. per hour ; the two at $12 \mathrm{~s} ., 43 \mathrm{~d}$., and the six at $9 \mathrm{~s} ., 4 \frac{1}{8} \mathrm{~d}$. per hour. I will not trouble you with any more anomalies. But there are several towns, as I have pointed out, where auxiliaries do intermediate work or other service. I admit there are some towns where the man can do work outside the office, but I may instance the case of the Sheffield duties, and ask where a man under this revision has a chance to earn anything outside whatever. In some towns-in Southport, Leeds, and a few other towns, there is a lapse of six or seven hours per day, but there are not many like that. There are several towns where the duties are arranged as at Sheffield, where the auxiliaries are called upon at all hours of the day. This is an argument why the auxiliaries should be drafted into the established class. As an auxiliary myself of many years' standing, I look upon it that if you call upon me to do a day's delivery I should be drafted into the established class.

The Chairman: Have you any claim for any particular rate of wages to put forward?

A. Yes, my lord, 6d. per hour. But before I proceed to deal with that, I wish to give some anomalies as to Sunday pay. I believe it was stated the other day you could hardly credit that men put in three or four attendances for 12s. and 14s. a week. Now here is the case of Berkhamsted, where men put in four attendances for 12s. and 14s. a week. Again at Sheffield, a rural auxiliary is working for 12s. a week.

Mr. Walpole: What is his name?

A. Mappin. He is in the same office as myself. He takes his delivery into the country and returns with a collection, and I cannot see why men, living in the same town, and doing practically the same work, should not have the same compensation. G. Mappin had been a telegraph messenger.

Mr. Smith You say he is a rural auxiliary?

A. Yes, at 12s. per woek. He is due at the office at 6 o'clock. He goes into the country to deliver, and gets back at 12 o'clock. On Sundays his duty is from 6 to 11 . That goes on all the year round, and he gets no pay for the Sunday duty. He does not get a day's holiday in the year. He does every week 41 hours at $35 \mathrm{~d}$. per hour.

The Chairman: Do you know that the man is employed on Sundays without pay?

A. Yes.

Q. Are you sure about it?

A. Yes. I should only be too glad if he were paid. It would make a great difference to the Exchequer if every one were paid.

Mr. Walpole: How old is this man who was a telegraph messenger?

A. 19 years of age.

Q. Then he has just been put on the duty? 
A. No; he has been on the duty some time. He states that he has been five years and six months in the Service.

Q. Very likely, as a telegraph messenger.

A. He was a telegraph messenger, but now he is a rural auxiliary.

Q. If he is only 19 years of age, he carnot have been auxiliary 5 years.

A. He has given up his telegraph uniform.

Sir F. Mowatt: Is it not a fact-as I am assured it is-that the wages are fixed to include Sunday work? If a man does no Sunday work he gets less; if he does he gets more?

A. No, sir ; I can prove to the contrary.

Q. Is not 7s. a week for 6 days, and 8s. per week for 7 days, including Sunday? The authorised rule is that a provincial auxiliary occupied on one duty for three hours shall receive 7s. per week if employed 6 days, and 8s. per week if employed 7 days?

A. I can prove very different to that, my lord, by the papers which have been sent in to me.

The Chairman: How about Sheffield?

A. That is, I believe, the only town in the country where the men for Sunday duties receive 1s. 6d. I believe other towns have petitioned for it. I believe that last September the Southport men petitioned their Postmaster and they got it.

Q. Are you aware of any cases of men who are doing Sunday duty getting the same wage as men who do no Sunday duty, and both doing similar duty in the week, getting the same rate of wages?

A. No, my lord.

Mr. Smith : They must be paid for Sunday duty then?

A. No, sir.

The Chairman: Do you, of your own knowledge, know any cases of men doing the same duties on week days, but one doing Sunday duty also and the other not, receiving the same wages?

A. I should think I could point out cases in different towns.

The Chairman : Very well, point out a case then.

Mr. Walpole: In different towns the rates of pay may possibly differ.

Witness: There are auxiliaries in Sheflield getting 10s. a week and 1s. 6 d. for Sunday duty.

Sir F. Mowatt: Then they do get paid for Sunday duty?

A. I believe Sheffield is the only town in the country that got Sunday pay at the time of the revision. When we got a new Postmaster he wanted to know how it was that the auxiliaries were paid for Sunday duty.

Mr. Smith : Can you give me the name of any town where they are not paid?

Witness : I could have brought you dozens. I have given you the case of Oxford.

The Cinaurman: The postmen there said that their wages were good; the only difficulty was that they had to do an hour an a half's duty on Sunday without pay.

A. Yes, sir.

Q. Can you, from your Oxford information, give us the case of two men, one of whom does duty on Sundays and the other does not, who receive the same pay?

A. Two men receive 12s. doing Sunday duty.

Mr. Walpole: Sir F. Mowatt suggests I sliould state what I know the rule to be. It is that in fixing the remuneration of the auxiliaries we always take into consideration the Sunday duty as well as the week-day duty. That is the rule of the office.

The Chairman: I see, even in this paper which you have handed in, that at Oxford a man named Hallett gets a shilling extra for a Sunday collection.

A. But that is not a morning delivery, my lord. Collections are paid for. I am speaking of deliveries which are not. Collections are generally paid for. A man who does a morning delivery in Sheffield gets 1s. 6d. 
Mr. Walpole: I presume the Sheffield man is a substitute for an established man. Is it not an established man's duty done by an auxiliary?

A. When is it an auxiliary duty?

Mr. Walpole: I say that from the fact of its being paid for. I assume it is the case of an auxiliary being substituted for an established man. Would that not be the rule of the office?

A. It would be for a collection.

The Chairman: In the Oxford case is it not the complaint, not that the men are not paid for Sunday duty, but that they get nothing extra for it?

A. My claim is that six days shall constitute a week.

The Chairman: The men at Oxford are paid so much an hour for their duty whether it be on Sundays or other days. Their complaint is that they do not get anything extra for Sunday duty.

A. That is a general complaint, my lord.

Q. What do you ask they shall be paid extra for Sunday duty?

A. We ask the same as established men-ratio and a quarter. Some time ago, I was following an established man in the work I did, and while I received 1s. 6d. for what I did on the Sunday, he got $2 \mathrm{~s}$. 9d. for it.

The Chairman: Then the complaint is not that you don't get paid for Sur:day work, but that you only get paid at the same rate as on week-days?

A. In some towns the men are paid and in some they are not. We want that six days shall constitute a week's work.

The Chairman: And that then any work on a Sunday shall be paid for, not at the ordinary rate, but at rate-and-a-quarter?

A. Yes, my lord.

Q. That is quite different from what you said at first. What you first said was that you objected to not getting any pay at all.

Mr. Walpole: I assure you there is Sunday pay, whether it be sufficient or insufficient. Sunday work is taken into consideration when the pay is fixed, and if a man has to work on Sundays that fact is considered.

The Chairman: In Sheffield a man gets 1s. 6d. extra for a Sunday delivery, and 1s. for a Sunday collection, does he not?

A. Yes; and the anxiliaries do both.

Q. And get 1s. and 1s. 6il. respectively?

A. Yes, iny lord.

Mr. Walpole: Is it not the case that the men who receive these payments are acting as substitutes for established men on their alternative Sunday leaves?

A. I cannot answer that. You have heard me speak about the Cambridge men. They attend twice per day-6.30 to 8.30 , and 7.15 to $8.45: 3 \frac{1}{2}$ hours. They have no pay on alternate Sundays. At Windsor they average $3 \frac{1}{2}$ hours, and get no pay on alternate Sundays.

The Chairman: But these hours are counted in the weekly wage?

A. We want them not to be counted. We want six days to constitute a week's work.

Sir F. Mowatt: Are you complaining that Sunday is included in the wages? Do you want it excluded so that you may charge extra for it?

A. Yes.

Q. But you began by saying it was not included in the wages. We have got it now that it is.

A. At Ramsgate they do 3 hours at $5 \mathrm{~d}$. per hour; at another place they do $3 \frac{1}{2}$ hours without pay, and at Shrewsbury they are on from 5 to 10 .

Mr. Walpole: As a matter of fact, the Cambridge men, when the wages were fixed, had Sunday duty every Sunday, had they not?

A. I do not know that.

Q. And since then their wages have not been altered, but they have been relieved of duty every alternate Sunday?

A. I am not aware of that.

Q. And no reduction has been made in their wages?

A. I am not aware of that. 
Q. Will you take it from me that it is so?

A. Oh, yes. But, as I said, at Shrewsbury they do duty from 5 to 10 on Sundays and get no pay. At Barnett they do $2 \frac{1}{2}$ to 3 hours on Sundays without pay. At Leeds they do 2 to 3 hours on Stindays alternately without pay. And with regard to your argument, my lord

The Chairman: I am not arguing. I only want to arrive at the exact facts.

Witness: At Southport they work $3 \frac{1}{2}$ to 4 hours on one Sunday and have pay. The next Sunday they have not.

Mr. Walpole: I think that on the Sunday they are paid they act as substitutes for established men, while on the other Sunday they are working as auxiliaries and doing their own duty.

A. We ask that we may be paid for all Sunday work. To emphasise our claim for increased pay. we would point out that 6d. per hour is the minimum rate of wage almost universal t'roughout the country, which is paid by corporations and municipal bodies to their lowest class of labourer. Another reason why this rate of pay should be adopted is, that the practice has grown to extend and spread many men's duties over such a large proportion of the day that it is impossible for them to add to their small wages in any other direction as they formerly could, and we suggest that as, in the exigencies of the Service, it is necessary to employ a certain amount of auxiliary labour, their duties should be apportioned to the morning and evening, and so abolish the erratic distribution of duties at present in vogue. As an instance of the injustice done to the auxiliary by this custom of lengthened duties, I may refer to a case in point, where a duty of 3 hours in the morning is paid $9 \mathrm{~s}$. per week for, and one in the evening of 2 hours is paid 8s. per week, when performed by two separate men (making a total of 17s. per week for the two duties). When two similar duties are combined and performed by one man he receives a wage of 12s. per week, or $5 \mathrm{~s}$. less. Similar instances can be produced from Ramsgate, thus showing the necessity for a uniform rate of wage throughout the country; and we would furthermore urge that no interval of less than one hour between duties be reckoned off. In asking for a more certain and defined method of promotion to the ranks of the established class, we would point out that the nature of the work performed by an anxiliary is exactly the same as that performed by an established man, viz. :- -delivery, collections, station duty, stamping, etc., and they are often called upon to perform holiday work and sick duties in the absence of their established colleague, thus showing that their labour is, as far as the Department is concerned, equally as useful to them; and they are as skilled as the established men, although receiving a lower rate of wage than the latter, and none of the other contingent advantages, and with no prospect of an increase as long as they remain auxiliaries. This stagnant state of affairs is not conducive to that interest in the work of the Department which ought to be cultivated in every public service, and we suggest that as the work of the district increases in bulk, it should be met by instituting established duties, to be given to those men in the order of their seniority, in preference to meeting the contingency by making more auxiliary duties, as is the custom at present. I would suggest that the vacant established duty and two auxiliary duties be added together, and two auxiliaries be fully appointed. The men at Sheffield are practically working all hours of the day.

The Chairman: Your plan would reduce the total number of men employed?

A. Yes.

Mr. Walpole: I have before me the hours worked by the men at Sheffield.

Most of them are not working between 9 in the morning and 6 at night.

Witness : I have a long tabulated statement, which does not bear that out.

Mr. Walpole: Oh, I admit that some of them are.

(Low wages handed in as read.)

Witness : Furthermore, we would point to Dr. Wilson's evidence before this Committee as proof that this method would be in the best interest of 
the Department, as it would avoid the evils that he deprecates, viz., the early age of entry and the uncertainty of new entrants being able to bear the strain of the work of the Department, as the auxiliary has given tangible proof of his stamina, and brings practical experience to bear upon the work required of him. We would further urge that he should commence at the initial wage in accordance with his previous services, and not on the level of new entrants. I see no objection to joining the established class, although I did refuse once. The third point for consideration, viz., the custom of requiring Sunday labour to be performed by the auxiliary postmen, without in many cases any remuneration for the same, cannot, in our opinion, be defended upon any ground, as it is opposed to all rules of honesty to take anything from a man without returning him an equivalent for it. The Department themselves evidently feel that this is an injustice that cannot be defended, or why do they pay for the labour in some instances, and not hold to the hard and fast line that they are justified in demanding this labour from the whole of the auxiliary class without any payment whatsoever? Furthermore, we desire to point out that this is a distinct violation of the pledge given by the late Right Hon. H. C. Raikes, in the House of Commons in 1887 or 1833, "that in future all Sunday work would be paid for." These words I am giving from memory. It may be urged that this statement may have referred to men upon the establishment, but, if it is admitted that it is an injustice to demand Sunday labour of an established postman without paying for the same, how much greater is the injustice to the auxiliary, who is doing similar work for far less remuneration and out of whose labour the Department is making the greater part of their large annual surplus, of which they are so proud (and justly so). Therefore, we feel justified in asking that Sunday labour should be taken from the auxiliary class, or that they should be paid at the rate stipulated for by Mr. Raikes, viz., time-and-a-quarter rate; and when it is pointed out to you that this Sunday work (without pay) often extends over 4 or 5 hours, thus depriving a man of the best part of the day, which has been set apart for rest by laws both human and Divine, we feel assured you will readily admit the justice and consideration of this request. The fourtl point for our consideration is the absence of participation in any of the contingent advantages of the established class, such as holidays, sick pay, stripes, and boot allowance. Holidays are recognised as an absolute necessity in these days of high pressure business requirements, and it would certainly tend to the advantage of the Department if the auxiliary class were granted an annual holiday, to relieve them in some sort from the dragging, monotonous routine of their duties, as they would return to those duties recuperated in vital energy, and with a more cheerful disposition to cope with them-more espiecially should this concession be granted, as in many instances the time given by these men is very little short of that given by the established class, and they are fully as capable of appreciating a little relief as are the men in the last-mentioned list. An allowance in sick pay is necessary to this class, as they have all the risks to contend against that the established class have, in the shape of inclement weather, contagious diseases, or epidemics, and, as no special provision is made on their behalf against such contingencies, it is only right that they should be recompensed to a certain extent when they succumb to them. In the matter of good conduct stripes, in our opinion it is essential in the best interest of the Department, and as an encouragement to good behaviour, diligence, and disciplinary rules, that the auxiliary postmen should be rewarded for these attributes the same as the established men, and that they should receive a good conduct stripe (when merited) every five years, to carry with it 1s. per week addition to their wages. I have been for 20 years on the same walk. I am often asked by gentlemen why I lave no stripes, and when I have pointed out my length of service and explained that they are not given to auxiliaries, disgust has been expressed with the system. The stripes, we contend, would be an advantage to the Department and to the public, inasmuch as that the 
main cause of the great surplus revenue of the Post Office is the confidence that the public place in its working, and so making use of all the facilities offered them; but if they once conceived the idea that the work was entrusted to a large class of men of an indifferent character (which they would be perfectly justified in thinking, by the absence from these men of any distinguishing mark of good conduct), that confidence would be considerably shaken; they would become timorous of utilising the facilities offered them to the extent they now avail themselves, and the inevitable consequence would be a vast diminution in the revenue which is so acceptable a boon to the Treasury. Lastly, seeing that many of the auxiliaries are walking for six or seven hours daily, which must of necessity cause a great wear and tear of boot leather, we are of opinion that an allowance should be made to those men for the provision of boots, in proportion to that allowed to the men on the establishment, according to the ratio of time demanded of them in common with the established postmen. I know I am on my feet about six hours per day, and to do me justice I ought to have at least an allowance of one pair of boots a year. In conclusion, I would thank this Committee for the attention they have given me, and would remind them in considering their decision upon this question that they are adjudicating upon-I think I may venture to term-almost the worst dealt with of any class of public servants; but I feel assured that the merits of the case will receive your full oonsideration, and we may safely leave the issue in your hands.

The witness, who was under examination about an hour and twenty minutes, then withdrew. Mr. Wilson's evidence, commenced on the Monday and finished this day, occupied nearly three hours.

The court adjourned at 3.50 . 
ALEX, MIAAREN, Glasgow.

Auxiliakiks' Case.

Westurinster, Monday, 17th Feb., 1896.

Present:-The Right Hon. Lord Tweedmouth, Chairman; Sir Francis Mowatt, K.C.B., Spencer Walpole, Esq., H. Llewellyn Smith, Esq., Sir Arthur Godley, and Robert Bruce, Esq., Secretary.

The Chairman: I understand you have a little more to say to complete the case of the auxiliaries.

A. Yes, my lord. In going over the evidence already given, I find that it does not quite complete the case of t'. e auxiliary postmen, and I desire to complete it. In doing so I wish to follow the order of headings already supplied, and I would also like to say that I regret that the evidence should be unduly prolonged on any point, but seeing that there is sucl a very large number of men involved, namely, about 10,000, according to the Postmaster-General's report, I consider it is our duty to see that their case is fairly put. In our national petition about three years ago we asked, among other things, that the auxiliaries be merged in the established force, as it seemed to us that only by s'lch a course could justice be done to this hitherto neglected class. In rep'y the Postmaster-General vouchsafed unto us the following decision:- "Auxiliaries are not on the establishment because they do not do for it a full day's work. As soon as their work grows into a full day's work, they are incorporated into the establishment, provided, of course, that they fulfil the prescribed conditions. It is obvious that men who are only in part servants of the Department cannot be accorded the same privileges as those who are wholly so. But the PostmasterGeneral is anxious, whenever the circumstances make it possible for him to do so, to convert an auxiliary duty into an established appointment." About the same time, Mr. Geo. Lansbury (on behalf of the Unemployed Committee) drew the Postmaster-General's attention to the case of the auxiliaries. In reply, Mr. Lansbury received a letter signed by Mr. H. Joyce (of G.P.O.) which contained the following important statements:- "Mr. Morley cannot help thinking that the conditions of the auxiliaries' employment are not fully understood. These men are not employed for a full day but only part of a day, and the Post Office does not profess to give them a full week's wages. The wages they receive are in the nature of payment for piecework, and the question for the Postmaster-General's consideration is not to what sum in any particular 
case this payment amounts in the course of $t^{1} \mathrm{e}$ week, but whether it is a fair rate per hour, and sufficient to command the services required." Again, in the same letter- "Mr. Morley much prefers, where the circumstances admit of it, that men should be employed who, giving their whole time to the Service, are boine on the establishment, and receive the established rate of wages and contingent advantages; but witl the most scrupulous care in adjusting the work some duties will always remain which cannot by themselves, or in combination with others, be constituted into whole-time duties, and where this is so the employment of auxiliaries is unavoidable." The status of auxiliaries is further defined by the following rule of the Service :-_ Auxiliaries, in whatever capacity employed, may be dismissed on the autlority of the surveyor, and in this respect, as well as in respect of requiring no Civil Service Certificate before employment, and not being entitled to leave of absence at the cost of the Department, or to pensions, they are on a different footing from established officers." In the matter, however, of legal penalty from misconduct, they are in the same condition as established officers. The Postmaster-General's last annual report states:- "An auxiliary postman, in the sense in which the term is applied by the Department, is a man employed for a less period than 8 hours a day. In London auxiliaries are usually drawn from two classes: (1) Telegraph messengers awaiting appointment as postmen; (2) persons having occupations of their own, whose total earnings both from the Department and their own affairs amount to at least $18 \mathrm{~s}$. per week. The pay of auxiliary postmen in London is $6 \mathrm{~d}$. per hour during the day, and $9 \mathrm{~d}$. and $10 \mathrm{~d}$. at night. The pay of an auxiliary postman in the country averages from 4d. to 5 d. per hour." I presume that in the postal nomenclature the word "country" covers the provincial towns. Auxiliary postmen's terms of service were also alluded to by Mr. Morley in the House of Commons as follows:- "Auxiliaries in provincial towns, in addition to their wages, were provided with uniform, free medical attendance in cases of sickness, with extra payment for Christmas Day and Good Friday, together with any allowances for any other duties they performed, so that the statenient that the men's wages were a certain amount was not an accurate statement of the emoluments which they received. They had these and other advantages which he had mentioned, and were of a fairly substantial kind." I suppose the other advantages referred to must be the Christmas boxes. Of late vears there has been a disposition on the part of the Department to allude to them by indirect reference rather than by direct mention. I suppose the authorities wanted to slide altogether out of the recognition of them. In the foregoing I have endeavoured to state fairly and fully the official view of the case, and, having done so, we have now to consider the following questions :-

(1) Is the employment of auxiliaries really unavoidable?

(2) Assuming, for argument's sake, that it is impossible to dispense altogether with auxiliary labour, is the proportion of auxiliaries not needlessly high at some towns?

(3) Even if it be shown that the exigencies of the Service require the employment of auxiliary labour, we submit that they merit better conditions of service.

With reference to the first point, I must frankly admit that the arrivals of mails at Glasgow and some other towns are such as to cause the pressure of work to converge on the first delivery in the morning and the last delivery at night. It must also be admitted that the Department would have considerable difficulty in providing a full day's work for all the 202 auxiliaries at Glasgow. But I see no bona fide difficulty in incorporating at least 25 per cent. of them into the established force. I believe that in many other towns there is a greater amount of auxiliary labour employed than is absolutely 
necessary, and $I$ think this will be admitted on a careful scrutiny of the following table:-

TABLE SHOWING THE PROPORTION OF AUXILIARY POSTMEN TO ESTABLISHED POSTMEN IN CERTAIN TOWNS.

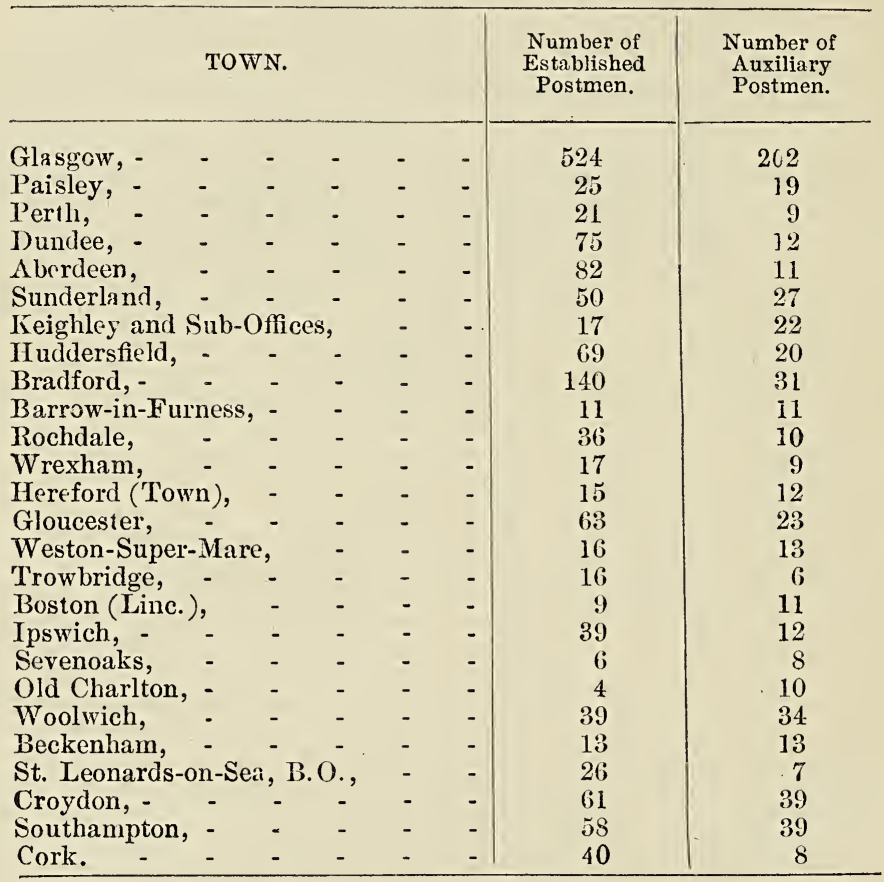

Mr. Llewellyn Smith: When you say that 25 pei cent. should be incorporated, do you mean that 25 per cent. should be got rid of and their place taken by a smaller number of established postmen, or that 25 per cent. of these auxiliaries should be made established postmen?

A. I think there is a good deal in the evidence of Mr. Wilson which suggested that public facilities should be increased at certain periods of the day, and in that way many of these auxiliary duties would be erected into full-time duties.

Q. By making more work?

A. Yes.

Mr. Walpole : Even if there was no necessity for it?

A. Not exactly. In making that statement $I$ had in view the case of Glasgow, where there are certain postmen who consider they have a grievance in being kept on perpetual late duty. At a meeting we held a petition was drawn up showing how the unvarying late duty could be abolished, and at the same time admit of about 25 auxiliaries being converted into the whole-time men, besides facilitating the work of the Department.

Q. What became of that petition?

A. It was only addressed to the Postmaster, and I presume he did not require to pass it on any further. The chief objection to the prayer of that petition being granted was that established labour is paid at a bigher rate than auxiliary labour, and it would involve an incresse of about 
$\$ 300$ a year to convert these 25 auxiliary duties into established appointments, because some of these auxiliaries were only on 8s. duty.

The Chairman: If you make a larger number of full-time men, would not that reduce the number of men employed on short-time duty?

A. Yes; but I think that the postmen, taking them all over the country, pretty closely approach a full day's work of eight hours; I mean the established postmen.

Q. But if you increase the number of full-time duties that would surely reduce the total number of men employed on short time.

A. Yes, it might; but some of our established men have a collection in addition to their deliveries, which does not harmonise with the other parts of their day's work, and we would propose to relieve the delivering postmen of that part of their work. I don't think we have much ground for complaint at Glasgow as to established men exceeding their ruota of 8 hours. We don't make complaint on that score, although Mr. Dowling, who has scrutinised the papers received on this subject of hours of attendance, assures me that it is quite a common thing for the hours of established postmen elsewhere to considerably exceed their proper quota of 8 hours per day.

Q. How many established postmen have you in Glasgow?

A. 524 .

Q. And how many auxiliaries?

A. 202.

Q. If you were to add 50 auxiliaries to the established postmen class that would practically involve a re-distribution of many of the duties, would it not?

A. There has been an additional delivery put on; it was added in the second week of January, and is being provided for by temporary methods; but we are anzious that where there is a revision of that sort it should not be provided for: by auxiliary labour, or by temporary methods, but that it should be erected into a whole-time duty.

Mr. Walpole: I suppose that a large number of the 524 established postmen in Glasgow are employed on indoor duty?

A. Yes; I think there are 36 stampers and about 40 messengers.

Q. Then a considerable number are employed on station service?

A. Yes; about 40.

Q. Then there are rather over 400 employed on outdoor duties?

A. Not so many, I think.

Q. I am advised that there are 414, which no doubt would be about right, for you said the total number was 527, and you have otherwise accounted for a little over 100 ?

A. Yes; I believe that would be so. It did not occur to me that there were quite so many on outdoor duty, but apparently I neglected to take into account those at Govan or some other suburban districts.

Q. None of the auxiliaries are employed at more than two duties?

A. Not at Glasgow.

Q. They have none of the long six hours' duties of which we have heard?

A. Not at Glasgow; but cases have been brought under my notice from other places.

Mr. Llewellyn Smith: I understand that the 5 or 6 hours' duties for auxiliaries are what you object to most?

A. There are 147 of our auxiliaries employed on 6 hours' duty, and the remainder on $8 \mathrm{~s}$. duty, which covers the morning deliveries.

Mr. Walpole: There are only two deliveries?

A. Yes; but they are the two heaviest of the day.

Q. Do they take 3 hours each?

A. I have here a typical case of the attendance of an auxiliary postman on two duties; it is as follows : $-5.45 \mathrm{a.m}$. to $9.15 \mathrm{a.m}$., and then 6.45 p.m. to 9.15 p.m.; that is a typical case. Total daily work 6 hours, 
covering a period of $15 \frac{1}{2}$ hours, and with an interval between of about $9 \frac{1}{2}$ hours ; wages $14 \mathrm{~s}$. per week, being about $4 \frac{1}{2} \mathrm{~d}$. per hour.

Q. The man has practically a whole day free between his two duties, namely, from 9.15 a.m. to 6.45 p.m.

A. Yes ; but other work is not practicable in such a case. It must be remembered that most of these are lads of from 18 to 21, who have not always reached their full bodily strength or maturity, and having in view the extraordinarily fatiguing nature of the work at Glasgow, which is mostly stair-climbing, as any of the Committee may know who have visited Glasgow, such youths are not fit for much other. work in the interval. One high official in the Post Office-I think it was Mr. Trollope-when he was in the Service, visited Glasgow to investigate the case of the postmen; the postmen of that day insisted that he should travel up and down the long flights of stairs with them, and he stated that he had never worked so hard in his life, although, of course, that was not such hard work as the postmen had, because they had also to carry their bags of letters. In view of the kind of work which the young men have to do during their two duties, it is quite evident from the letters which we have received t'lat they cannot in the intervening hours of the day engage in anything but work of a light character.

Q. Are these lads waiting for established appointment?

A. Yes; waiting for appointment. Out of the 202 I don't suppose that there are more than two dozen who liave other regular employment throughout the day, and these are most probably men who don't look forward to an established appointment.

Mr. Llewellyn Smith: The majority of the young fellows who are auxiliaries at Glasgow are, I suppose, looking forward to an appointment?

A. That is so.

Mr. Walpole: I suppose they are ex-telegraph messengers?

A. Yes. The Service is mostly recruited from the telegraph messenger branch, and we quite approve of that. There seems to be some discrepancy on this point as to the practice in London and the provinces, for I believe that in London the auxiliaries do not form the avenue from which the regular postmen are recruited; they are outside of the regular line of promotion, whereas in the provinces the auxiliaries are considered to form the recruited field for the established class.

Sir F. Nowatt: Being themselves recruited from the telegraph messengers?

A. Yes.

Mr. Llewellyn Smith: Then they are an intermediate class between the telegraph messengers and the established postmen.

A. Yes. We have no complaint to make on that score at Glasgow, for during the last ten years at least the vacancies have been filled up in that way very fairly. When a telegraph messenger is taken on for auxiliary duty in the letter-carriers' department, his name is entered in a book kept for the purpose by tle head inspector, and that records his seniority, so that except in cases where a man has something against him, such as too many late attendances, lhe is not passed over when his turn comes for an opening. I am glad to be able to state that we can congratulate our inspectors on the impartiality with which they give established appointments to auxiliary postmen in turn, but I understand that in London the auxiliary postmen are not considered the proper recruiting field for the established class.

Mr. Walpole: With regard to the 147 who are doing 6 hours' duty, you added that the remainder are on $8 \mathrm{~s}$. duty; are these chiefly ex-telegraph messengers waiting for appointment?

A. Yes. Most of those on the 8s. duty are younger lads. They either do morning delivery or do two attendances, Parcel Post, or whatever is required, because those who usually assist with parcels may be sent out with circulars if there are no parcels for them. 
Mr. Llewellyn Smith: Then they are not adults, but boys?

A. Yes, that is so; those who receive $8 \mathrm{~s}$.

Mr. Walpole : Confining yourself to Glasgow for a moment, do you object to this system of employing telegraph messengers waiting for appointment as auxiliaries?

A. I don't object to it; I regard it as being the best method by which the Service could be recruited.

Q. Is there anything in connection with the system to which you object?

A. Yes; the treatment meted out to these men.

Q. As to their pay, or their work, or in what respect?

A. In almost every respect they are an outcast class.

Mr. Walpole: You have told us that in Glasgow they are mostly boys waiting for established appointments?

The Chairman: You can hardly describe boys in that transitional state as being an outcast class?

A. I have a vivid recollection of my own experience in the matter.

Sir F. Mowatt: But you were not an outcast, for here you are as an established postman giving evidence.

Mr. Walpole: You admit that they are added in due course to the established class; and now please tell us in what respect do they suffer?

A. In having none of the contingent advantages of the Service.

Q. Do you mean that they are outcasts because they don't get holidays, an I bist allor:ance, and sick pay?

A. Yes: and considering also the bad hours they have to work.

The Chaimman: Your idea apparently is that they ought to be put upon the estallishment much quicker?

A. Perhaps I will make the point more clear if I proceed with my statement. Apart from the question of partial absorption of the auxiliaries in the established force, the question arises as to what should be done with those remaining in a state of auxiliaryship? For even the most thorough of the Departmental apologists could scarcely have the heart to say that their condition requires no amelioration. A scrutiny of the papers seems to show that their average all over the country is about $4 \frac{1}{4} \mathrm{~d}$. per hour; but I was not sure how they stood with regard to Sunday duty, so could not tabulate that in exact figures. The present rate of pay-average $4 \frac{1}{2}$ d. per hour-might be considered sufficient under very exceptional circumstances, such, for example, as mere lads of 16 or 17 employed on light duties, and that they had promotion to better wages after a definito period. Although a lad of 16 or 17 might reasonably be contented with $4 \frac{1}{2} \mathrm{~d}$. per hour light work, he soon outgrows this rate of pay. Besides, an auxiliary postman's duty cannot fairly be described as work of a light character. For in Glasgow and most of the towns that I am acquainted with, the auxiliaries have to carry the same loads as the appointed men. The $4 \frac{1}{2} \mathrm{~d}$. per hour is irrespective of the lightness or heaviness of the work, and also irrespective of the age or length of service of the recipient. Letterdelivery is physically heavy work, and of a responsible character, which clearly marks it off as being unsuited for boy-labour. Having in view that it is adult work of a severe character, we feel quite justified in asking for the present $4 \frac{1}{2} \mathrm{~d}$. rate being superseded by the following improved rates-6 $\mathrm{d}$. per hour for day duty and 9d. per hour for night duty and Sunday duty, and the Sunday duty to be paid separately. In reply to the deputation from the Unemployed Organisation Committee, the Postmaster-General said, among other things:- "I am not going to use the market value of wages as an argument. I recognise that it is a standard by which a Government Department or any employer ought not to be guided. The Post Office, I admit, ought certainly to act as an example to other employers, bearing in mind the duty it owes to the public, and the consideration it must have for the Chancellor of the Exchequer, by whose decisions it must be bound." (Dec. 1892.) I wish to do Mr. Morley every justice, because his attitude 
on this question is considered very satisfactory; it is decidedly an attitude towards progress, and the only thing we have to regret is that it has not been possible to make more progress in the way of establishing, as far as possible, the auxiliary class. To ensure the equitable reckoning of an auxiliary postman's attendance we desire to see the following conditions observed :-

(a) Any interval less than one clear hour not to be booked off.

(b) No single attendance to count less than one hour.

Mr. Walpole: Are you talking of the whole country?

A. Yes.

The Chairman: Is it not half-an-hour now?

A. I am not aware of any definite rule.

Mr. L. Sinith: You don't recognise local differences in these cases?

A. I have endeavoured to keep in view the ca'se of the whole country. In Gloucester we liave a number of men doing collection duties spread over the whole day-five collections at 12s. per week.

Mr. Walpole: You are talking abont auxiliaries?

A. Yes ; I don't know how long a collection lasts, but we desire that no single attendance should be counted less than one hour.

Q. Five collections, assuming them to take one hour each, wonld mean 30 hours per week, paid at 12s.?

A. Yes.

Q. That is nearly $5 \mathrm{~d}$. an hour, is it not?

A. Yes; but we want them to be paid 6d. per hour, and if there is only 1d. of difference it seems to me that what we are asking is very moderate compared with some claims put forward by other sections of the Service. In case of men whose daily work is spread over more than two attendances, and thereby spoiling their chances of obtaining other employment, we desire that such cases should invariably be paid higher than 6d. per hour in order to compensate them for the broken nature of their day's work. It ought to be considered by the surveyors or whoever deals with these questions whether the man should not get a higher rate than $6 \mathrm{~d}$. an lour in the case of broken duties.

Mr. Walpole: Supposing an auxiliary is an ex-telegraph messenger, what would you say to it then?

A. We say that it is work that ought not to be performed by boys at all.

Q. But I understood you to approve of the Glasgow plan of ex-telegraph messengers being employed as auxiliary workers?

A. I admitted in the early part of my statement that it might be a fair reasonable wage for an ex-telegraph messenger in the first instance, but what we object to is the stationary condition in which he remains; he may be 20 years at the same rate of wages, and the same wage would not be adequate for him after 20 years' service, even if the work remained the same.

The Chairman: What is the average time a telegraph messenger remains as an auxiliary in Glasgow?

A. From $3 \frac{1}{2}$ to 4 years, but the man signing 202 nd on the auxiliary list would have the prospect of being stagnated much more than 4 years.

Sir F. Mowats: But not longer than 20 years?

A. It is hard to say; but it could not be 20 years, because the hard work of the postman kills them off quicker than that.

Mr. Walpole: You are judging somewhat from the experience of the past; I think you have been some little time without a revision of the outdoor force in Glasgow?

A. I think it was in October, 1891

Q. Glasgow has grown rapidly, and there is a revision pending, is there not?

A. I am not aware; I am not taken into the confidence of the Postmaster. 
Awother reason why the work has increased is that the general public are finding out that the Post Office is one of the best mediums for advertising. The recent gold boom and other things of the kind has largely increased our work, apart from the growth of the town. It may seem that paying 6d. per hour auxiliary labour would involve some inequality, seeing it is a higher rate per hour than the initial wage for the established class. The distinction is intended. For in some towns, at any rate, auxiliary labour appears to be employed not so much because it is unavoidable, but because it is cheaper than established labour. Besides, we regard it as only fitting that the auxiliaries, whose labour is in a manner casual, should be paid at the higher rate. The following rule of the Service is instructive as having a bearing on this point:- "Except in the case of auxiliaries, the power of dismissal rests with the Postmaster-General alone, and no one once dismissed can be employed in any capacity without the special authority of the Postmaster-General." It will thus be seen that the auxiliaries have not got the same security of office-tenure as the established officers have. We are asking $20 \mathrm{~s}$. per week to commence with, and at the rate of $6 \mathrm{~d}$. per hour it might seem that we ought to be asking $24 \mathrm{~s}$. per week, but this distinction is intended, for in some towns auxiliary labour appears to be employed, not because it is the most suitable, but because it is cheaper. It may be advanced by the Department that the work is not casual, that the men have some security of work during good behaviour, but their other employment is casual.

Mr. Walpole: It may be difficult to answer the question, but can you give us any case where the Department has deliberately preferred aux iliary labour to established labour because it is cheaper?

A. I cannot say that, but I will mention the case of a few towns where the proportion of auxiliaries employed seems to be larger than is necessary. Take the case of Paisley, where there are 19 auxiliaries and only 25 established postmen, or Keighley, Yorkshire, where there are 22 auxiliaries and only 17 established postmen; Bradford, where there are 31 auxiliaries to 140 established postmen; Barrow-in-Furness, where there are 11 of each class; Worcester, 69 established postmen and 33 auxiliaries; in Cheltenham there are 53 established postmen and 32 auxiliaries; in Bath 80 established postmen and 24 auxiliaries; in Newport, 42 established postmen and 31 auxiliaries; in Belfast, 131 established postmen and 34 auxiliaries. In all these cases I cannot see how it is that the exigencies of the Service require such a large proportion of auxiliary postmen. I have been in communication with all of these districts.

The Chairman: The proportion is not so great in many of them as it is in Glasgow?

A. No ; but take such a case as Barrow-in-Furness.

Mr. Walpole : Will you accept it from me that, so far as the PostmasterGeneral is concerned, every revision of the outdoor force that comes up, an endeavour is made to place as many establisher men as it is possible to find established duties for?

A. I gladly accept that statement, but I would like to add also, that in a large service like the Post Office, ramifying throughout the whole country, it is not at all to be wondered at if in nooks and crannies of the system you find some men in authority who are rather antiquated in their notions.

Q. You mentioned the case of Paisley, and I happen to have here a report to the Secretary at Edinburgh. It is as follows :-

"The employment of so many auxiliaries at Paisley is no doubt open to objection, and I have more than once discussed the subject with the Postmaster with a view to the employment of more men on full duty in place of a number of auxiliaries. A revision of the whole outdoor daties is now before me, and a report will reach the Secretary shortly; but unless the day's work is spread over too long a period, I fear it will not be possible to reduce the number of auxiliaries." 
Will you accept that from me as evidence that we are trying to reduce the proportion of auxiliaries?

A. Yes ; and I recognise the attitude that Mr. Morley took up. I accept that as the wish of the Department, but in some towns we find it is not accomplished. I have no doubt that when these auxiliary duties were first commenced that the plan was adopted for purposes of economy.

Q. I am only hoping that you will make some allowance for our great difficulty in dealing at once and rapidly with thousands of different towns?

A. Yes ; I am making due allowance on that account. I must admit also that within the last two months, indeed since this Committee was established, there has been a considerable brushing up, and I hope it will continue.

Q. I was not aware of that; in fact, I rather thought that in some cases we were perhaps a little disposed to take a more severe view in prospect of the Committee's work.

A. Perhaps it would not have done to hold over the worst cases for the Committee to deal with. With regard to the auxiliary postman's opportunity to get other employment, I now wish to deal. Unlike London, it is not compulsory in the provinces for an auxiliary to have other employment; and, for various reasons, it is difficult for those wishing other employment to get it. In Glasgow, for example, the majority of our auxiliaries are young men from 18 to 21, who have previously been telegraph messengers, so that they have been in the Post Office since leaving school. They have, therefore, no trade on their hands to which to turn during their disengaged time. But even suppose they had another trade to which they could turn, they would be seriously hampered by the nature of their official duties. The fatiguing character of their official duties would prevent them from engaging in any but the lighter and more crowded occupations, such as clerking. The following quotation from a Shrewsbury correspondent shows some of the difficulties that beset an auxiliary postman in his endeavour to obtain other employment:- "If one goes to look for employment the first question he is asked is, 'Where were you last employed?' and when he states he is employed in the Post Office he is straightway asked what more he would like? It is very hard to get steady employment outside the Post Office while the official hours are so awkward. It is not everybody who will take a man for a few hours a day, and not even then certain of having him regularly, for the Post Office authorities may send for him at any time to do a collection or deliver a parcel." As bearing on this point, I would wish to quote the following rule of the Service:-

\section{DEVOLUTION OF DUTIES.}

"In the case of superintendents or clerks:-When an officer belonging to any of these grades is absent, his duty should devolve upon the officer next below him, provided he is competent, and the duty of the latter upon his immediate inferior, subject to the same conditions of competency, and so on to the lowest class.

"In the case of postmen:-When divided into classes, a postman of the lower class is to act as a substitute for a postman of the higher, an auxiliary for the lower class, the auxiliary's place being supplied by an extra man employed temporarily."

I wish to draw particular attention to the latter portion of this rule, by which it is implied that an auxiliary must hold himself in readiness to sacrifice his other employment when the Department requires his services for whole-time duty. Auxiliary postmen, practically speaking, have security of tenure during good behaviour, although, according to the strict rule of the Service, they do not have it; they may be dispensed with at any time. For instance, I remember a young lad who was along with me as an auxiliary postman, and he was told to take a month to look out for another situation, as he had not sufficient chest measurement to be a postman. 
I suspect that stair-climbing had kept him from becoming sufficiently stout to become a postman, but that, 1 admit, was an extreme case, and I am not quoting it as typical.

The Chairman : It night have been a kindness to him?

A. Yes.

Mr. Walpole: You don't object to a minimum chest measurement?

A. No; but it is a standard of efficiency which is not exacted from other departments. It shows that the postman's work is really more important than some of those more highly-paid departments.

Q. Than some other departments of the Post Office?

A. Yes.

Q. You think the importance of tie work is to be gauged by the chest measurement of the persons performing it?

A. Not exactly; but there is a greater degree of efficiency and more conditions exacted from the postmen, although their wages are lower.

Q. Is it not a fact that in almost every branch of the Service, including the sorting clerks, etc., in London the medical officer insists on chest measurement?

A. It is not laid down by the rules of the Service.

Q. But it is the practice, is it not?

A. It may be the practice in London, but 1 don't think medical officers throughout the country insist on it. I cannot, however, speak with confidence on that. I know that men whose stature would not admit of their being postmen have got employment in the telegraph and sorting branches. With regard to auxiliaries getting extra outside employment, I may say that the whole of our postal work depends very much on the English Mail Selvice, and if the English mail is late the postmen may be kept beyond their usual time, and that might be very inconvenient for a man who is employed, say, to keep an office open for a commission agent or anything of that sort.

Mr. Walpole: I presume in the case of these ex-telegraph messengers it is not desirable that they should have other employment? Six hours' duty as an auxiliary postman is enough?

A. Quite enough.

Q. And it is better to employ them as auxiliary postmen until they get more mature and strong?

A. Yes ; if the Department paid the auxiliaries better for their work, and gave them a reasonable wage, we would be quite satisfied to discouraging them from undertaking any outside employment.

Mr. Llewellyn Smith: As a matter of fact, have many of these men outside employment?

A. Perhaps 10 per cent.; about two dozen out of 204 .

Q. They do something else?

A. Yes; but usually of a light character. There was a case brought under my notice where an auxiliary postman who had a duty to finish rather earlier than the others was able to take a situation as shorthand clerk with a firm of engineers, but he made himself prematurely old by trying to work two days' duties in one day.

Q. Are we to understand that the larger proportion of these auxiliaries who have 9 hours' interval between their postal duties do not engage in other work?

A. The work was so hard that when I had such an interval I had to go to bed. There has been a revision since, but even in view of that $I$ consider the best thing the youths can do in their interval of leisure is to get rest.

Q. I was asking not what they ought to do, but what, as a matter of fact, they do?

A. The fact is that a comparatively small section of them have other employment, which is usually of a light character, such as keeping an office open to something of that sort, which does not involve heavy work. I have 
already read out the rule of the Service laid down for the guidance of Postmasters and others that the auxiliary is the proper substitute for a whole-day postman, and that the auxiliary must hold himself in readiness for such business.

Mr. Walpole: I presume that among the 200 or more auxiliaries at Glasgow there must be many who are always ready and glad to undertake such extra duty?

A. I don't quite catch your point.

Q. Then I will put it in another way: that it cannot be the practice to select some extra auxiliary and inflict this extra duty upon him whether he likes it or not?

A. In Glasgow their complaint rather is that they cannot get enough of that extra work.

Q. That would be the case in London also, would it not?

A. I have not gone into the case of London.

The Chairman: I think you will find that the cases are very exceptional indeed where an auxiliary is forced to take an extra duty against his will?

Mr. Walpole: Even the man mentioned at our last meeting-the man who was a waiter-suffered, I am told, no kind of compulsion whatever-that he was let off when asked?

A. Although there may be no compulsion in the strict sense of the word, still, if an auxiliary is not pretty attentive to the suggestions that are made to him by his immediate superiors, he may be passed over when a vacancy occurs in the established class.

Q. That would not be the case in Glasgow?

A. No; there we have no complaint to make on that score. We wish to acknowledge the impartiality which the Glasgow authorities have shown in selecting men in accordance with their seniority, but I should like to hand you a statement-(statement here handed in)-with reference to St. Leonards-on-Sea.

Mr. Walpole: There is nothing here showing pressure. The paper you have handed in to us gives the answers to the questions you put as to the official hours of attendance of auxiliaries filling up their spare time with other employment, and it is stated that the auxiliaries act as substitutes for the town postmen, and that with regard to their own duties they rotate so that they cannot well take other employment. There is nothing in this paper as to undue pressure.

A. No; but there are seven duties having various hours of attendance, and they rotate, so that only one week in eight there is a man with the same duty, and it would be out of the question for him to engage in any other employment, unless it was something like collecting for industrial companies ; and it is a moot point whether that is not forbidden to auxiliary postmen.

Q. That may be so; but you mentioned St. Leonards-on-Sea as a case where auxiliary postmen were forced to accept duty against their will so as to enable them to obtain other employment.

Sir F. Mowatt: We had that put before us as evidence that an auxiliary should not be called on to take any but his regular specified duties?

A. I only wish to bring out the truth. There has been no case brought under my notice of an auxiliary having been compelled to relinquish his other employment.

The Chairman: I understand you to say that the practice of St. Leonardson-Sea is so to distribute the duties as to make it impossible for a man to take other employment?

A. Yes; it is not quite conducive to efficiency and good discipline that an inferior officer like an auxiliary should argue with his Postmaster the point whether he is bound by law to do this or that thing. When a thing is suggested to an auxiliary, even without any threat whatever of consequences in case of refusal, the fact of its being suggested to him in that way by a superior officer I take to amount in itself to a certain amount or kind 
of pressure, having in view the proper regard that must be had to the authority of the superior officer.

Q. I quite understand that from an opportunist point of view it is best for the auxiliary to take the work suggested to him.

A. Not exactly opportunist. I do not care about that term altngether; I am not quite sure what it maans.

Q. I mean from the point of view of a man's own advantage, namely, that if a man does suggest the work suggested to him he is more likely to stand well with his immediate superiors.

A. I don't wish it to be understood that he accepts the work in the way of currying favour with lis superiors.

Q. Oh, no; but it is natural with everybody to wish to stand in good favour with superiors?

Mr. Llewellyn Smith: A man who raises objections to particular duties does not get on quite so well?

A. No ; a man does not care to raise obstacles which may possibly in some way hinder his progress in the Service.

Mr. Walpole: I should like to ask you with reference to a vacation at St. Leonards: has that rotation not been arranged to suit the views of the men themselves?

A. No; I think not.

Q. Is it not a most unusual practice for auxiliary duties to rotate?

A. It is unusual; there are only comparatively few towns where it seems to be done.

Q. Would you not infer that it has been done in these towns to meet the wishes of the men themselves?

A. Not always; the rotation may have been fixed in order to equalise the duties, and so long as the men are paid equal wages there might be no reason why they should not rotate. In continuing my statement, I wish to put in a plea for the contingent advantages of the Service. First, with reference to the annual holidays, it has been advanced, of course, that an auxiliary, seeing that he does not do the same amount of work in a day as an established postman, should not get the same privileges. That may be quite so, but I want to bring out what is the practice in Glasgow. In doing so I may say that I quite concur with what Mr. Dowling said with regard to the basis upon which the holiday arrangements are fixed. The basis of wages is unwholesome; it ought rather to be a basis of work. A telegrapb messenger in Glasgow gets a fortnight's holiday every year, with wages. His wages are reckoned at $8 \mathrm{~s}$. per week, although some, of course, get more and some less. But as soon as a telegraph messenger comes to be promoted to an auxiliary postmanship-doing far more responsible and fatiguing duty-he gets no holidays. He may be in this position four or five years without getting any holiday. This constitutes a sort of imprisonment for one who, after all, is a growing lad. We want that such lads should get a 'fortnight's holiday. Of course, it might be said that if a man who did not do an eight hours' duty got a fortnight's holiday, he would be getting more than he was entitled to. But that is scarcely correct. In giving a fortnight's holiday to a postman who works 48 hours a week, you give him, in fact, 96 hours' holiday, and, in the same way, if you give a fortnight's holiday to a man who works only 36 hours a week, you give him 72 hours' holiday. I think that a very fair case can be made out for giving the same amount of holidays to auxiliary postmen as to the established men. I think, indeed, that they need it more on account of the effect of the permanent injury to their health through being as long as four and even five years without any holiday at all. I know that when I was in that position and experienced it, I felt it as an imprisonment. Then, with regard to stripes, I am quite satisfied with the case Mr. Wilson has put forward. He has put the points clearly, and it is unnecessary for me to dwell further on the subject.

Mr. Walpole: I should like to ask you one question. You do not, I 
suppose, advocate that a man should be kept as an auxiliary for so long a period as to entitle him to stripes?

A. No.

Mr. Llewellyn Smith: Would you give them in proportion to the number of hours worked, and spread them over a longer period when a man works a shorter number of hours?

A. It has been so frequently impressed upon us that stripes do not represent wages, but represent so many years' good conduct, that I think an auxiliary ought to have the benefit of the doubt, even although he does not do a full day's work. If he does a fair day's work, and his conduct is good, he should have stripes; that is my view of the subject.

Q. Then you would take the same period?

A. Well, as to that, it is not a point on which I have consulted my colleagues. They may differ from me, but I do not think it is very materiai. With regard to Sunday pay, the general rule of the Service is that a postman whose week's work includes Sunday work has no extra payment for Sundays, but he does if his week's work is based on a week-day duty, as is the case at Birmingham and Glasgow. Our auxiliaries do not do any Sunday duty at all, but if they did they would be paid extra for it. That is a point upon which I had some difficulty in getting information. Even our Postmaster could not tell me the position of the auxiliaries in regard to Sunday labour. Nobody in the Glasgow office could tell me.

Mr. Walpole: Who does the Sunday work at Glasgow?

A. The established postmen. The question has never arisen there. The general rule seems to be that a postman having a Sunday delivery in addition to a week-day delivery is not paid for it. But in some towns they have adopted a system which we call sweating. by substituting auxiliaries for established postmen. For instance, at Southport, instead of giving the auxiliary $3 \mathrm{~s}$. $6 \mathrm{~d}$. or $4 \mathrm{~s}$. for a Sunday morning delivery, as the established men would liave, they bring in an auxiliary, and only give him 1s. 6d.

$\mathrm{Q}$. That is an auxiliary acting as a substitute for an established postman?

A. Yes; but he is not paid at the same rate. He is only paid on the $4 \frac{1}{2}$ d. rate.

Q. And he is also paid the $4 \frac{1}{2} \mathrm{~d}$. rate for his ordinary week-day work?

A. Yes, as far as I can make out.

Q. The 1s. 6d. payment on Sunday is not for a regular auxiliary duty, but for a duty as substitute for an established postman, is it not?

A. I do not understand the intricacies of the case. It seems to me that if an auxiliary postman is brought on to do a dav's work for which an established postman gets $3 \mathrm{~s}$. $6 \mathrm{~d}$. or $4 \mathrm{~s}$, , and the auxiliary only gets $1 \mathrm{~s} .6 \mathrm{~d}$., there is a decided unfairness about it.

Q. The established postman gets whatever may be his rate of pay, plus stripes and his other advantages?

A. For Sunday work he gets rate-and-a-quarter.

Q. But his pay would depend on his position in the Service and the number of stripes he has, would it not?

A. Yes.

Q. While the auxiliary would be paid at the lower rate, he would be paid on the minimum scale, would he not?

A. Yes; but the work is the same.

$\mathrm{Q}$. The work may be the same, but is it not the fact that some postmen get $34 \mathrm{~s}$. and others $18 \mathrm{~s}$, , according to the time they have been in the Service? That is so, is it not?

A. Yes.

Q. They are paid at different rates?

A. Yes.

Q. Must that not always be the case that men who are doing the same work are paid at different rates?

A. Yes; but I do not see any justification for such a great disparity. There is another point in connection with this which emphasises the 
opinion that this system is scarcely a fair one, and that is the auxiliary's wage is a stationary one, while the postman has an ascending scale, with the prospect of reaching the top. Now I come to the question of sick pay.

The Chairman: You said in the earlier part of your evidence that your idea was that Sunday labour ought to be paid for at the rate-and-a-half, whatever a man was getting?

A. Yes.

Sir F. Mowatt: Is it not a fact that in the case of established postmen they are paid a rate-and-a-quarter?

A. Yes ; in my office it is rate-and-a-quarter. It was so when Raikes's revision came in force. But it may be higher in some offices.

Mr. Walpole: For Sunday work?

A. Yes; rate-and-a-quarter, with stripes.

Q. Before you leave this point let me ask you another question. You say that at Southport the established postmen are paid 3s. 6d. for Sunday duty. I doubt if that is so. Have you any information on that point? The mean scale of the Southport established postmen is $5 \frac{1}{2} \mathrm{~d}$. per hour against the auxiliaries' $4 \frac{1}{2} \mathrm{~d}$. I do not think there can be all that difference in the Sunday pay?

A. They have not as many postmen on Sunday duty as on week-day duty, and it therefore takes longer to do the morning's work.

The Chairman: Each postman has a longer walk?

A. Yes; I have information on that point.

Mr. Walpole: Even if a Sunday delivery occupied 4 hours, the pay would only amount to $2 \mathrm{~s}$.

Sir F. Mowatt: That is on the mean scale?

Mr. Walpole: And if you take it at the maximum, it won't come to more than half-a-crown, will it?

A. I think the delivery takes about five hours.

Q. The morning's work?

A. Yes; I am not quite sure until I can scrutinise the papers from Southport.

Q. I know of no delivery occupying five hours; still, I do not want to press that point.

Witness: With regard to such pay, while we claim that the auxiliaries ought to have a condition of service more approaching the conditions of service of the established class, we do not want to press it on the point of sick pay, because although a man may be employed at the Post Office he may bring on his sickness through overwork in other employment, and then it would scarcely be fair that the Post Office should be called on to support that man during a sickness so incurred. I think that if an auxiliary postman who does six hours a day had two-thirds of his wages as sick pay that would meet the needs of the case. I do not think it is fair that we should have no sick pay at all. A man might break down through his work at the office, even although he is an auxiliary.

Mr. Smith: Do you mean he should receive sick pay to the extent of two-thirds of what he is receiving from the Post Office?

A. Yes; an established man gets full pay during sickness, while an auxiliary postman at the present time gets nothing. I would give an auxiliary two-thirds of his wages. I now come to the question of service being allowed to count for pension. The rule of the Service in the Post Office is that no service counts until after the date of the Civil Service certificate. I have instituted inquiries on that point, and I have come to the conclusion that the Superannuation Act would warrant a more liberal interpretation than has hitherto been placed upon it. I think in the past it has been the custom not to recognise any service where the wages have been as much as 10s. per week, or the work six hours per day, with six days to the week. That has been the custom in some other branches of the Civil Service.

Sir F. Mowatt: You might qualify that statement a little. There is a clanse in the Superannuation Act which says that when the service done 
before the issue of the certificate is of the same class, and is full-time service, then it may be counted in calculating the pension; that is to say, that if an auxiliary served as many hours before he got his certificate as he did afterwards, and if his work were identical both before and after, then it could be counted for perision.

A. I was unaware of the distinction, of course, but I would ask it to be considered whether the Superannuation Act, even apart from the representations made by Mr. Walsh, could not possibly be more liberally interpreted by the Department. I have a case in point. I said in my evidence that most of our auxiliaries are young men, and in saying so $I$ was quite right; but $I$ think we have one old man whose age is 66 years.

Sir F. Mowatt: Then that is not the case of the postman who died before he could serve 20 years?

A. No; it was Dr. Wilson who said in his evidence that the severity of the Post Office work killed the men off more quickly than the work of any other branch.

Sir F. Mowatt: I am rather glad there is a survivor. (Laughter.)

Witness: I should like to give the particulars of that case. In Glasgow there is a man named M'Alpine, who joined the Service in 1859, and he has been almost continuously in the Service since then. I have known him since 1885 , and he has been working six hours a day. He has put in about 35 years' service. There was a broken interval of nearly 10 months, but he never had any holidays, and if that interval were written off as a holiday, his service might be put down as a pretty continuous one since 1859 . Now, that man, notwithstanding the valuable service he has done, may be turned adrift by the Department without a ponny of compensation for his work.

Mr. Walpole: Has he any trade of his own?

A. Yes; he is an exception to the rule in that respect. $\mathrm{He}$ is the only one of the old men left who were foolish enowgh or inclined to do two day's work in one. He must have had a cast-iron constitution or he would never have stood it.

Mr. Walpole: I am afraic that inder the Superannuation Act that would be a fatal bar to his being granted a pension.

Sir F. Mowatt: Yes; that is so.

The Chairman: What is his occupation?

A. He used to assist in a baker's shop when I first knew him. I cannot say for sure what his occupation is now. I think he works in some warehouse or other. Another point which I wish to bring under the notice of this Committee is with regard to the subsequent service of auxiliary postmen. I pointed out in my statement o; the wages question that it takes an auxiliary postman an average of seven years before he gets $20 \mathrm{~s}$. a week; that is the case in Glasgow.

Sir F. Mowatt: Before he gets 20s.?

A. Yes.

Mr. Walpole: Including his auxiliary service?

A. Yes, including that, and I submit that it is not at all fair.

Q. You say the men would be four years in the auxiliary service?

A. Yes, four years in the auxiliary; and I say that $20 \mathrm{~s}$. is not a fair wage after seven years' service. It only takes seven years for a man to learn. a trade, and then he would get at once full wages.

Mr. Smith : How old would he be when he got the 20s.?

A. Well, he goes in at 17 , and that is putting it very low. Our Postmaster will not take them under 18 if he can possibly help it. The inspector does not like to employ lads so young if he can get older ones, and we quite agree with the reasonableness of that view. But there are times of great pressure, such as election times, when they are compelled to take boys who are not more than 16 years of age. As a rule, however, it is between 17 and 18 years of age that boys leave the telegraph department for the letter-carrying department. Thus, a lad of 17 entering the Service must take seven years before he becomes a postman at the wage of $£ 1$ per week. 
In my statement on the Wages Questinn I stated it took a new entrant seven years' service to attain the wage of $20 \mathrm{~s}$. per week. For the purpose of illustrating the slowness of the rate of increment, and that the case of Glasgow is by no means an isolated one, the following tabular statement has been prepared. This table shows the number of postmen who are employed on full-time duty and in receipt of less than 24s. per week. (Date of information, August, 1895) :-

\begin{tabular}{|c|c|c|c|c|c|c|c|c|}
\hline \multirow{2}{*}{\multicolumn{3}{|c|}{ Towss }} & \multirow{2}{*}{\multicolumn{2}{|c|}{$\begin{array}{l}\text { Number cf } \\
\text { Postmen } \\
\text { on Whole } \\
\text { Time Duty } \\
\text { and in } \\
\text { receipt of } \\
\text { less than } \\
\text { 24s. per } \\
\text { week. }\end{array}$}} & \multicolumn{2}{|c|}{$\begin{array}{l}\text { Average Service } \\
\text { (including } \\
\text { Auxiliary } \\
\text { Service, but } \\
\text { not Telegraph } \\
\text { or Messenger } \\
\text { Service). }\end{array}$} & \multirow[t]{2}{*}{$\begin{array}{l}\text { Average } \\
\text { Weekly } \\
\text { Wages } \\
\text { (includ- } \\
\text { ing } \\
\text { Stripe } \\
\text { Money). }\end{array}$} & \multirow[t]{2}{*}{$\begin{array}{c}\text { Average } \\
\text { Age. }\end{array}$} \\
\hline & & & & & Years & Months. & & \\
\hline \multicolumn{4}{|c|}{ Birkenhead and Sub-Ofices, } & 94 & 4 & 4 & $19 / 1$ & 25 \\
\hline Bradford ( & (York: & s), - & & 53 & 5 & 2 & $20 \%$ & 23 \\
\hline Brighton, & - & - & - & 20 & 5 & 8 & $20 /$ & 27 \\
\hline Bristol, & - & $=$ & & 151 & 4 & 7 & $195 \frac{1}{9}$ & $25 \frac{1}{3}$ \\
\hline Cambridge, &,- & - & & 11 & 5 & 6 & $19 / 2^{2}$ & $25 \frac{1}{3}$ \\
\hline Cardiff, & - & - & - & 77 & 4 & 11 & $19 / 10$ & $24 \frac{2}{4}$ \\
\hline Grimsby, & - & - & - & 20 & 4 & 7 & $18 / 10$ & $22 \frac{1}{4}$ \\
\hline Harrogate, & & - & & 18 & 4 & 6 & $18 / 2$ & $27 \frac{2}{3}$ \\
\hline Hull, - & - & - & - & 20 & 5 & 2 & $18 / 10$ & $23^{2}$ \\
\hline Leeds, & - & $-\quad-$ & - & 167 & 4 & 6 & $18 / 7 \frac{1}{2}$ & $24^{4}$ \\
\hline Nottinghan & $m$ and & IS.O.S. & - & 69 & 4 & 4 & $17 / 6 \frac{3}{4}$ & $26 \frac{1}{5}$ \\
\hline Plymouth, & - & $-\quad-$ & - & 39 & 7 & 5 & $18 / 6^{4}$ & $23 \frac{1}{2}$ \\
\hline Portsmouti & & - & - & 24 & - & - & 19,11 & -2 \\
\hline Reigate, & & - & - & 16 & 9 & 10 & $21 / 1$ & $29 \frac{3}{4}$ \\
\hline Southport,, & & - & - & 24 & 5 & 3 & $20 / 6$ & $27 \frac{3}{4}$ \\
\hline Stafford, & - & - & - & 20 & 4 & 9 & $19 / 3$ & $29^{4}$ \\
\hline Stockport, & - & - & - & 19 & 7 & 2 & $20 / 5$ & $27 \frac{3}{4}$ \\
\hline Worcester, & , - & - & - & 20 & 4 & 2 & $18 / 2$ & $1\left[23^{4}\right.$ \\
\hline Worthing, & & - & - & 20 & 9 & 9 & $20 / 8$ & 28 \\
\hline Edinburgh, & & - & - & 114 & 3 & 3 & $19 / 1$ & $21 \frac{3}{4}$ \\
\hline Aberdeen, & - & - & - & 36 & 4 & 11 & $19 / 3$ & $24 \frac{3}{4}$ \\
\hline 1)undee, & - & - & - & 17 & 4 & 4 & $20 / 4$ & $\therefore 22 \frac{1}{4}$ \\
\hline Inverness, & - & - & - & 27 & 4 & 3 & $19 /$ & 24 \\
\hline Paisley. & 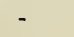 & - & & 17 & 5 & 3 & $19 / 2$ & 25 \\
\hline Belfast, & - & - & - & 40 & 4 & 3 & $19 / 2$ & $23 \frac{1}{2}$ \\
\hline Cork,-- & - & - & - & 16 & 7 & 11 & $17 / 6$ & $25 \frac{3}{4}$ \\
\hline
\end{tabular}

Mr. Walpole: How many auxiliaries are there at Glasgow with four years' service?

A. I do not know definitely.

Q. Would there be 50 ?

A. No; I think not.

Q. What service has a senior man?

A. He has over four years, I think. A number of the senior men are employed on full-time duties as substitutes, but months may elapse before a vacancy arises in the established class.

Mr. Smith: Is it a common thing for auxiliaries to refuse established appointments?

A. No; it is not a very common thing; but cases have been known where the men prefer to leave the Service rather than take an established 
appointment. Of course, it must also be admitted that some men become auxiliary postmen who have no intention whatever of giving their full time to the Department. Cases have been known of students attending Giasgow University who have found it convenient to be auxiliary postmen. These are not typical cases; they are exceptions to the rule. We do not want to legislate for exceptional cases, but rather for the average typical case. We think that the service which an auxiliary postman puts in should he reckoned, and that his initial wage as an established postman should be increased in proportion to the auxiliary service. In the list of headings which I submitted, I put it down that he should at once have two years' increment, and $\mathrm{I}$ find that some of the men in the correspondence before me support that view. But in other towns there is not unanimity of opinion upon the point. My own view is that is would be a very fair concession to make, that if an auxiliary postman works as much as six hours a day he should have two years' service reckoned to him for each three years' employment he has done before getting on the established list. That would mean as a rule that his initial wage would at once have two increments added to it.

Mr. Walpole: Then you would give him two years out of three?

A. Exactly.

Mr. Smith: Are there many postmen in Glasgow who get on at the initial rate without going through the initial stage?

A. None at all, except at some of the Glasgow sub-offices, and that is a sore point with our auxiliaries, because in some of the Glasgow suboffices ariny reserve men are drafted straight in, and in a manner passed over the heads of the auxiliary, postmen. There seems to be some discrepancy on this point in the Postmaster-General's annual report, for it would seem to be suggested that the soldiers have the first claim, even apart from the claims of the auxiliaries. Now, I am advised by the local officials in Glasgow that telegraph messengers have the first claim.

Mr. Walpole: I rather think that the reference in the report affects London. It is pointed out that it is impossible to enforce the rule where there are a large number of auxiliary men.

Witness: Practically this is what takes place in Glasgow-in the suboffices around Glasgow-vacancies are given to army reserve men. I do not say it is the custom, for I have no statistics to put in. But it frequently occurs that army reserve men are appointed in preference to auxiliary postmen.

Mr. Walpole: You can take it from me that the rule is to accept the senior in the Service.

A. And as far as the head office in Glasgow is concerned, I am satisfied that that rule is carried out. I make no complaint about that, and I would not care to suggest that it should be literally carried out in the suboffices also. As illustrating the long time which our men in Glasgow take to reach a fair living wage, I have compiled a tabulated statement here. which I propose to put in. I find that in Leeds there is not only an auxiliary class, but there is an intermediary junior class, which further imperles progress.

Mr. Walpole: We have practically decided to abolish that.

Witness: I am very glad to hear it; but it does not alter the fact that a. number of those at the foot of the established class have taken a very long time to get to a decent wage.

Mr. Walpole: Yes; that is so.

Witness: In Leeds, I am informed that in August, 1895, there were 167 established postmen getting under $24 \mathrm{~s}$. a week, and that the mean of the whole lot of wages was 18s. $7 \frac{1}{2} d$., the average age of the men being 24 years of age. Of course, in stating that I include wages only; I do not include the other contingent advantages. I do not think that $18 \mathrm{~s}$. $7 \frac{1}{2} \mathrm{~d}$. a week for a man 24 years of age is by any means an excessive wage, and I am glad to see that the Committee are admitting some of our points. 
Now, with regard to postmen having other employment, I think there is another point of view in which that might be looked at. Personally $I$ do not think it is very desirable that postmen or other men in Government employ should be allowed to crowd the unemployed market, for it may be the means at times of the Government coming into direct conflict with the organised labour of the country, and with the great Trades' Unions. I do not think the Post Office should foster this system of a man having two jobs at the same time. It would be much better did he get an adequate wage for one job, and I should say that when an auxiliary postman does $6 \frac{1}{2}$ liour's' duty per day lie should have the benefit of the doubt, and be allowed to call it an eight hour duty, especially in Glasgow, where the work is so very hard. I think I have exhausted my statement now, and I have to thank you, gentlemen, for the very patient hearing you have given me. I hope that one result will be that the conditions of service for auxiliary postmen will be made to approximate more nearly to the conditions that obtain in other classes. I beg to hand to the Committee a list of typical cases of duties which I should like to see incorporated in my evidence, as they go to show the bona fide character of the evidence which I have given.

\section{TYPICAL CASES OF PROVINCIAL AUXILIARY DUTIES.}

GLasGow.-524 established postmen, 204 auxiliary postmen. ExampleTwo attendances, viz., 5.45 a.m. to 9.15 a.m., and 6.45 p.m. to 9.15 p.m. : total daily work about 6 hours ; covering time about $15 \frac{1}{2}$ hours ; wages $14 \mathrm{~s}$. per week, being about $4 \frac{1}{2} d$. per hour.

PaIsley.-Example-One attendance for morning delivery from 6.15 a.m. to 9.15 a.m.; total daily work about 3 hours; wages 7 s. per week, heing about $4 \frac{1}{2} \mathrm{~d}$. per hour.

Aberdeen.-Example-Two attendances, viz., 6 a.m. to 9 a.m.. and 6 p.m. to 8 p.m.; total daily work about 5 hours; wages $12 \mathrm{~s}$. per week.

DundeE.-Example-Three attendanees, viz., 6 a.m. to 8.30 a.m.. 12.15 p.m. to 2.30 p.m., and 4.30 p.m. to 6.30 p.m. ; total daily work $6 \frac{3}{4}$ hours ; wages $14 \mathrm{~s}$., being about $4 \frac{1}{4} \mathrm{~d}$. per hour.

PerTH.-Example-Three attendances, spread over the whole day, as follows : 7.30 a.m. to 10.30 a.m., 4.20 p.m. to 6.30 p.m., and 7.30 p.m. to 9.30 p.in.

Southamptor.-Example-Two attendances, viz., 7.45 a.m. to 11 a.m., and 5.30 p.m. to 8 p.m.; total daily work $5 \frac{3}{4}$ lours; wages $13 \mathrm{~s}$. per week.

Boston (LINC.).- Example-Two attendances, viz., morning delivery and night collection; total daily work about $4 \frac{1}{4}$ hours ; wages $8 \mathrm{~s}$. per week.

Croydon.-Example-Two attendances, viz., 6 a.m. to 8.30 a.m., and 6 p.m. to 8 p.m. ; total daily work about $4 \frac{1}{2}$ hours: wages $12 \mathrm{~s}$. per week.

KEIGHLEY.-Example-Two attendances, viz., 6.15 a.m. to $9.15 \mathrm{a.m}$., and 6.15 p.m. to 8.45 p.m. ; total daily work $5 \frac{1}{2}$ hours; wages $12 \mathrm{~s}$. per week.

BRADFotR (Yorks.).-Tixample-Two attendances, viz., 9.35 a.m. to 12.45 p.m., and 6.40 p.m. to 8.20 p.m.; total daily work $4 \frac{3}{4}$ hours; wages 13s. 6d. per week.

Barrow-In-Furnass.-Example-Two attendances, viz., 8 a.m. to 11.15 a.m, and 5.45 p.m. to 7.45 p.m.; total daily work $5 \frac{1}{4}$ hours; wages $12 \mathrm{~s}$. per week.

SundERland.-Example-Two attendances, viz., 5.50 a.m. to 9.15 a.m., and 5.50 p.m. to 8 p.m. ; total daily work about 5 lours; wages 12s. per week.

Rochdale.-Example-Two attendances, viz., 6 a.m. to 9 a.m., and 6.40 p.m. to 9 p.m. : total dailv work about $5 \frac{1}{4}$ hours; wages $12 \mathrm{~s}$. per week.

Wrexham.-Example-Two attendances, viz., 6 a.m. to 9 a.m., and 7.35 p.m. to 8.35 p.m. ; total daily work about 4 hours; wages 10 s. per week.

HudDERSFIELD.-Example-Three attendances, viz., 6 a.m. to 8.45 a.m., 6.30 p.m. to 8.20 p.m., and 8.40 p.m. to 9.30 p.m.; total daily work $5 \frac{1}{4}$ hours; wages $12 \mathrm{~s}$. per week. 
Beckenham.-Example-Three attendances, viz., 6.30 a.m. to 8.45 a.m, 4.30 p.m. to 5.30 p.m., and 7.55 p.m. to 11.15 p.m.; total daily work $5 \frac{1}{2}$ hours; wages $15 \mathrm{~s}$. per week.

WooLwICH.-Example-Three attendances, viz., 6.35 a.m. to 8.20 a.m. 1.55 p.m. to 4 p.m., and 7.50 p.m. to 10.20 p.m.; total daily work about $6 \frac{1}{4}$ hours ; wages 16 s. per week.

Seven OAKs.-Example-Three attendances, 10.10 a.m. to 11.45 a.m., 4 p.m. to 5.50 p.m., and 7 p.m. to 9.20 p.m.; total daily work $5 \frac{3}{4}$ hours; wages 13 s. per week.

Old Charlion.-Example-Three attendances, viz., 6.50 a.m. to 8.20 a.m., 10.50 a.m. to 12.15 p.m., and 7.40 p.m. to 9.50 p.m.; total daily work about 5 hours; wages 12 s. per week.

WeSTON-SuPER-MARE.-Example-Three attendances, viz., 8 a.m. to 12.30 p.m., 6.15 p.m. to 7.30 p.m., and 8.30 p.m. to 9.45 p.m. ; total daily work about 7 hours; wages $13 \mathrm{~s}$. per week.

HereFoRD.-Example-Three attendances, viz., 6 a.m. to 9.15 a.m., 6.15 p.m. to 7 p.m., and 7.30 p.m. to 9.45 p.m.; total daily work about $6 \frac{1}{4}$ hours; wages $14 \mathrm{~s}$. per week.

GLOUCESTER.-Example-Five collections about an hour each, spread over the whole day; wages $12 \mathrm{~s}$. per week.

Trowbridge.-Example-Four attendances, viz., 8 a.m. to 9.10 a.m., 12.5 p.m. to 12.50 p.m., 1.30 p.m. to 1.50 p.m., and 8.20 p.m. to 9 p.m.; total daily work about 3 hours; wages $9 \mathrm{~s}$. per week.

Cork.-Example-Two attendances, viz., 7.30 a.m. to 10.30 a.m., and 2.45 p.m. to 5 p.m. ; total daily work $5 \frac{1}{4}$ hours ; wages $12 \mathrm{~s}$. $6 \mathrm{~d}$. per week.

St. LeonardS-oN-Sea.-Example-Three attendances, viz., 6.45 a.m. to 9 a.m., 9.30 a.m. to 11.30 a.m., and 12.15 p.m. to 2.30 p.m.; total daily work about 6 hours; wages 15s. per week.

\section{AUXILIARY POSTMEN (PROVINCTAL).-TYPICAL CASES OF EXTREMELY LOW WAGES.}

Case No. 1.-Llanelly-Attendances 6.15 a.m. to 9 a.m., 9.30 a.m. to 11.30 a.m., and 6.45 p.m. to 7.45 p.m.; total amount of work daily $5 \frac{3}{4}$

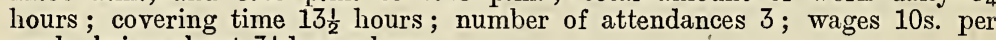
week, being about $3 \frac{1}{2} d$. per hour.

Case No. 2.-Cosham (HaNts.)-Attendances 6.30 a.m. to 8.30 a.m., 4.30 p.m. to 6.30 p.m., and 7 p.m. to 7.40 p.m. ; total daily work $4 \frac{3}{4}$ hours ; covering time 13 hours; number of attendances 3 ; wages $8 \mathrm{~s}$. per week, being about $3 \frac{1}{2} \mathrm{~d}$. per hour.

Case No. 3.-BALA, R.S.O.-Attendances 6.45 a.m. to 9 a.m.; total daily work $2 \frac{1}{4}$ hours ; wages $4 \mathrm{~s}$. per week, being about $3 \frac{3}{4} \mathrm{~d}$. per hour.

Case No. 4.-BASINGStOKE-Attendances 6.30 a.m. to 8.30 a.m., 9.30 a.m. to 10 a.m., 10.30 a.m. to 3.30 p.m., and 8 p.m. to 9 p.m. ; total daily work $8 \frac{1}{2}$ hours; covering time $14 \frac{1}{2}$ hours; number of daily attendances 4 ; wages $11 \mathrm{~s}$. $6 \mathrm{~d}$. per week, being about $2 \frac{3}{4} \mathrm{~d}$. per hour.

Case No. 5.-Portsmodth-Attendances from 8.45 a.m. to 12 noon, and 5 p.m. to 7.15 p.m.; total daily work $5 \frac{1}{2}$ hours; covering time 7 hours; wages $10 \mathrm{~s}$. per week, being about $3 \frac{3}{4} \mathrm{~d}$. per hour.

Case No. 6.-Galashiels-Attendances, 1.50 p.m. to 2.30 p.m., 3.15 p.m. to 5.45 p.m., 6.15 p.m. to 6.50 p.m., and 9 p.m. to 10.30 p.m.; total daily work $5 \frac{1}{4}$ hours ; number of attendances 4 ; covering time 10 hours; wages 9s. per week, being about $3 \frac{1}{2} \mathrm{~d}$. per hour.

Case No. 7.-Dunblane, N.B.-Attendances, 6.45 a.m. to 12.30 p.m., and 6 p.m. to 7.45 p.m.; total daily work $7 \frac{1}{2}$ hours; covering time 13 hours; number of attendances 2 ; wages $14 \mathrm{~s}$. per week, being about $3 \frac{3}{4} \mathrm{~d}$. per hour.

Case No. 8.-Bridgnorth-Attendances, 5 a.m. to 9 a.m., 4.30 p.m. to 6 p.m., and 6.45 p.m. to 8.15 p.m.; total daily work 7 hours; covering time 15 hours; number of attendances 3 ; wages $12 \mathrm{~s} .6 \mathrm{~d}$. per week, being about $3 \frac{3}{4}$ d. per hour. 
WILLIAM MARTIN, Manchester.

\author{
Parces Post.
}

Westurnster, Monday, Feb. 17th, 1896.

The next witness called was William Martin, postman, of Manchester, who was examined as follows:-

The Chairman: You are a Manchester postman?

A. Yes, my lord.

Q. I understand you mean to speak about the Parcel Post system?

A. Yes, my lord.

Q. Are you a parcel postman yourself?

A. No, my lord.

Q. Then you are an ordinary postman, I suppose?

A. I am an ordinary postman substituting for other postmen.

Q Are you in the auxiliary or the established service?

A I am acting as a substitute for a town postman at Manchester.

Q. Are you an auxiliary then?

A. No, my lord.

Q. Then you are on the established service?

A. Yes, my lord.

Q. How do you mean you act as a substitute?

A. I do substitute duty for men who are away for sickness and other reasons.

Q. You are a sort of reserve man then?

A. Yes, my lord.

Q. Do you get a regular rate of pay for that?

A. Yes, my lord, together with an allowance of $5 \mathrm{~s}$. a week.

Q. What is your period of service?

A. I was appointed in January, 1874.

Mr. Walpole: You say you are on a regular scale of wages, and get in addition an allowance of $5 \mathrm{~s}$. as a substitute?

A. Yes, sir.

Q Are you kept continuously substituting for other men?

A. Yes, sir.

Q. What have you to tell us about the Parcel Post?

A. $1 \mathrm{t}$ is in regard to the Parcel Post work done by letter-carrying post. men. Our complaint is about the weight we have to deliver. The Parcel Post was established to meet the public convenience, and the railway companies were guaranteed 55 per cent. of the postage received of the rail-borne parcels. That has proved much too high a rate for the service performed, and the consequence is that the Parcel Post Service has been crippled by the large percentage paid to the railway companies. Where the Parcel Post is established it was begun separately from the letter delivery, but shortly afterwards it was found that the Parcel Post was not paying, or that it was not working satisfactorily, so the separate basis of work was done away with, and the duty was imposed on the letter-carrier postman.

T.he Chairman: But there is a strict limit as to the amount to be carried by them, is there not? 
A. I am sorry to say it is not so in practice; it varies considerably in placis. Originally the intention was to have the parcels delivered separately froin the letters. But since then they have been superadded to the work of letter-carrying, and the result has always been considered a very great haidship by those who have to do the work. The remedy adopted by the Department was to put this extra work on us, and we say it is a very untair remedy. I would venture to point out that a contented service is an efficient service, and that contentment cannot take place until the grievances of our class are materially decreased. Now, I wish to lay before the Committee the public view of the subject, and I may say at once that the public are quite in accordance with our view on the matter. In the first place. they recognise that the combined delivery materially delays the delivery of the letters, which are infinitely more important. I have here a list of 118 offices where all the parcels are delivered with letters. I propose to put that in. The offices are-Ayr, Aberfeldy, Alva, R.S.O., Antrim, Appleby, Abbeyleix, Acock Green (Birm.), Apgarth, R.S.O. (Yorks.), Blaydonon-Tyne, Bexley Heath, Busby, Blantyre, Ballindalloch, R.S.O., Broomboro, Beccles, Broughty Ferry, Broadbottom, Rothesay, Brighouse, Batley, Bar!'staple, Bedale, Bathgate, Bridge of Allan, Burgess Hill, R.S.O.., Bala, R.S.O., Betty's-y-coed, Bingley, Berkeley, Comrie (Perths.), Coatbridge, (astle Douglas, Chumleigh, Chathill, Chichester, Cosham, R.S.O., Corris, R.S.O., Cambuslang, Dartmouth, Dudley, Droitwich, Dungannon, Dudley (Worcs.), Drymen, Dalkeith, Dumbarton, Dukinfield, Enniscorthy, Erith, S.O., Fakenham, Godalming, Guernsey, Gravesend, Garstang, Garth, Gosforth, Hallkirk, R.S.O., Heckmondwicke, Helensburgll, Holyhead, Heywood, Hollingworth, S.O., Harrington, R.S.O., Horncastle, Hamilton, Harwich, Henley-on-Thames, Ipswich, Irvine, Invergordon, Jarrow-on-Tyne, Johnstmue, Kendal, Kildare, Kink's Langley, Lockerbie, Leek, Louth, Lyndhurst, Larne, Llanwyllog, R.S.O., Loftus, R.S.O., Mountain Ash, Maybole, May, Maryhill, Malton, North Walsham, Newnham, Nantyglo, R.S.O., Norbeth, Nantgaredig, Omagh, Old Charlton, Pantardulais, Padstow, Prestwich, Palfield, R.S.O., Portadown, Perth, Pentre, Queenstown, Rutherglen, Renfrew, Rawtenstall, Roscrea, St. German's, St. Asaph, Selly Oak, Swinton, Salt Ash, Spilshy, Slough, Stretford, Sowerby Bridge, Staly: briılge, Shipley, Stirling. A few of the above offices give assistance if over $35 \mathrm{lbs}$. Next, the public realise that this combined delivery endangers the safety of the letters when the delivering bags are too full to be fastened. The public have been heard to cry "Shame" on the system that requires us to be laden like donkeys. I liave here a letter from Crediton bearing out that statement, and I can quite believe it from my own experience.

'The Chairman: Tell us something about your own experience.

A. At Manchester, where I come from-and I cannot speak with authority ust now, because a revision lias just been commenced-ap till now thi system of working has been altered so frequently that I do not know ex. actly what it is. A fresh plan was commenced only last Monday.

Mr. Walpole: What was it last month?

A. At the beginning of this month the men had to take out very frequently as many as 14 or 15 parcels, and, as Mr. Maclaren has described, the work is macie very laborious.

The Chairman: Can you tell me at all the weight you had to take out on any specific occasion?

A. I cannot recall to mind any particular occasion.

Q. Do you know of any particular occasion on which you had been unduly laden?

A. I have not taken any note at the time, because I never anticipated the question would be asked.

Q. Is there no practice of giving relief to postmen when they make complaint of having too heavy burdens?

A. Yes ; but I think nine times out of ten it is refused. Of course, it is 
not always exactly the weight we complain of-it is the bulky nature of the parcels. They may be band-boxes, or umbrellas, or fishing-rods, or other parcels which are awkward to carry. There may be eggs, and all that kind of thing. Parcels sometimes contain fruit.

Mr. Walpole: But the average weight of the parcel will not be great?

A. Well, parcels may be carried up to $11 \mathrm{lbs}$.

Q. But the average weight of a parcel is under $3 \mathrm{lbs}$, is it not?

A. Well, in a manufacturing district like Manchester I should think it would be heavier than that as a general rule.

The Chairman: Don't you know of any general rule about the weight to be carried in Manchester?

A. Frequently we are told when we are applying for relief that there is nobody at liberty to give us relief. As I say, in a manufacturing district the average weight of parcels would be higher than the general average for the country.

Q. Is it not the ordinary prictice that the postmen shall only carry narcels where there are only a few to go out, and that when there is a considerable number to be carried, special means are taken for their delivery?

A. I have a case where a man refused to take them out on principle, in orde to test what the rule was. He refused to carry $40 \mathrm{lbs}$. weight, and was reprimanded by the Brighton Postmaster, and threatened with severe consequences if he repeated the attempt. I am not defending his action in refusing to carry the parcels out; but he did it on principle, and that was the result.

Q. Are not the parcels at Manchester generally delivered in a special delivery?

A. In the centre of the town, I believe. At the present moment there is a parcel delivery by hand-cart immediately after the first letter delivery, but after that hand-cart delivery the parcels are supposed to be taken out by the letter-carriers, while in the suburbs of Manchester these letter-carriers carry out parcels even with their first delivery. The work, as I say, is ver $y$ laborious indeerl. I understand that Manchester is the most important postal centre out of London. I have a complaint from Torquay on this point. The District Council memorialised the Postmaster-General with regard to the heaviness of t. e postmen 's burlens, and one statement in the memorial was to the effect that it was painful to witness postmen struggling under their loads. They added that they were in favour of the parcels being delivered separately.

Mr. Walpole: What was the date of the memorial?

A. I have not the date, but it can be obtained from the official records. It must be pretty recent, because the District Council has not been estab. lisherl very long. Postmen are tempted to lighten their loarls by delivering parcels out of the course to unauthorised persons, and to deviate from the prescribed route. That, of course, is a serious matter in postal work, where regularity is so essential. A man will deviate from his route in order to gec rid of a heavy parcel, and consequently he delays the delivery of ietters. Postmen must deliver the surplus parcels the best way they can, or if they do not do that, they leave them over till the next delivery, and I say that that is a very impropar method of disposing of the parcels.

Mr. Walpole: Where have you got your facts from?

A. We sent out a schedule asking how the parcels were disposed of, an 1 correspondents have sent me statements on the subject as to how these things are done. I do not know it from my own knowledge ; I merely repeat the information supplied to me. Here is a list of 20 offices where postmen must deliver surplus parcels the best way they can, or leave them over till next delivery :-Burgess Hill, R.S.O., Castleford, S.O., Fernda'e. R.x.O., Fakenham, Holyhead, Hooley Hill, King's Iangley, Limavarly, I:?westoft, Larne, Ovoca, Pontardulais, R.S.O., Porthcawl (Glam.), Rosine, Selly Oak (Birm.), South Shields, Stone (Staff.), Stafford, Todmorden Watford. 
Sir F. Mowatt: Do you say these are places where the postmen are told they must deliver the parcels the best way they can?

A. Yes; that is the practice.

'The Chairman: And supposing there are more than a man can carry out on his first delivery, do you say he has to take them out during the day?

A. Yes.

Mr. Walpole: I do not think that can be so?

A. The supervision must be very lax, or these things would not occur.

Q. You liave no knowledge from your own experience of any such case, liave you?

A. No; but I am speaking for the provinces, and it is on their behalf that I am putting these matters forward.

Q. Do you believe that at any large place, such as Stafford or Watford, postmen would be allowed to deliver parcels the best way they can, or even to leave them over for a later delivery? Do you suppose the Department would stand that for one moment?

A. I quite believe it. I have a letter here where assistance cannot be procured because the payment allowed by the Department is not sufficient, and then the Parcel Post is growing so rapidly that the arrangements made some time ago may not be very suitable for the present time, and may not suit the present exigencies of the Service. I believe the public, in nine cases out of ten, will not make formal complaint out of sympathy with the postman, who is obviously overworked. Again, parcels of objectionable odour and liquids liable to escape are carried in contact with letters, causing public annoyance. I have had to deliver a parcel of raw rubber; the stench was unendurable, and my bag was scented with it for days afterwards.

Mr. Walpole: But is not raw rubber prohibited from being carried by the Parcel Post?

A. Yes; but unless you open a parcel you cannot tell what it contains. The rubber may be wrapped up in such a way as to prevent any smell escaping at first, but when the parcel gets into a heated office the probability is that it will begin to smell. Another complaint of the men is that of pushing heavy laden carts to railway stations through mud, etc., whilst in uniform. They say it is degrading in the eyes of the public, and not calculated to enhance his cleanliness. Parcel delivery by hand is antiquated ; all other parcel-carrying concerns employ almost exclusively horses and vehicles; their long experience and commercial predilection is thus in strong contrast to the method adopted by the P.O. The system is unbusiness-like, and, we consider, wasteful, inasmuch as horse-flesh is cheaper than human flesh. Besides, if parcels are delivered separately from letters, the deliveries need not be so frequent. From Worksop I have a note to say "It is not infrequent for us to start on our afternoon walks loaded like packmen, with our bag full of letters and parcels, and parcels slung across our shoulders." From Old Charlton I have information to the effect that the delivery of parcels by letter-carriers not only makes the work more fatiguing for the men, but keeps them much longer on their walks, and my correspondent adds, "I have seen men come out of the office with their bags full, and parcels tied round their bodies." A postman's legitimate work of collecting and delivering letters, etc., is being constantly extended and increased. Parcels have increased during the past 11 years in round numbers from 23 to 54 millions, and consequently justify a reversion to the original method of collection and delivery separately. I have a case here-typical of many others-from Crediton, a town of 4,000 or 5,000 inhabitants, constantly extending by the erection of new buildings. There are only two postmen to deliver the letters and parcels; they deliver about 20 each daily at the same time as the letters, and the public are loud in expressing condemnation of the overworking system. This typical case from Crediton shows how the work is done in many small towns. My correspondent there writes to say"Our work is very heavy. We take from our office to be delivered day by day, parcels as well as letters. There are only two postmen at Crediton, 
and some days we have to deliver nearly 40 parcels between us. This makes our work very hard. We are often wet through with sweat, and our arms get dead with the weight of the parcels hanging on them. The public when they see us thus laden, cry, "What a shame it is to load the men in such a manner!" "

Sir F. Mowatt: But if there are four deliveries a day, that only amounts to five parcels each man for each delivery?

A. I question whether there would be so many deliveries at a place like Crediton. There might possibly be only two or three. Now, at Brighouse, the letter-carrying postmen three years ago used not to deliver parcels, but now the practice has been altered, and they are required to deliver them, which necessitates a lot of extra work on them. The same practice is in force at Manchester. Here, as at Brighouse, we are not allowed to deliver parcels in the private boxes at the P.O. The postmen have to carry them out and deliver them at the offices, and this in many cases may entail numerous journeys in order to catch the people at home; it may necessitate calling three or four times a day.

Mr. Walpole : But these calls are all included in the 8 hours' day, are they not?

A. Exactly; but very often the 8 hours' work extends to nine, and, as has been pointed out by Mr. Dowling, this, to a great extent, is the cause of the difficulty. I have here a copy of a notice exhibited on the board of the Postmaster's office at Newcastle-on-Tyne. It is as follows:- "Serious complaint is made that frequently parcels brought in by the collectors from the town and receiving offices are in a damaged condition. There can be no excuse whatever for damage to parcels whilst in the possession of the collectors, and they must so arrange as to prevent breakage with hard substances, or in placing their bags on the ground. Also, special attention must be given to the condition of each parcel when received, and the attention of any sub-postmaster must be drawn to any damage. After this notice, if any parcel is damaged whilst in the possession of the collector, he will probably be called upon to pay the cost, and further punishment for carelessness will assuredly follow." "We contend that damage is inevitable whilst we deal with them in the present method. Parcels are damaged by too much handling, especially edibles or breakables, whilst many other kinds of parcels when crushed in satchels or carried by hand are damaged thereby. Parcels are damaged by exposure to weather by being set down in the street to open a gate or pillar-box. They may have to be put down in the snow or rain. The carrying of parcels up and down stairs in towns, and swinging about suspended from shoulders for long distances in suburban or rural districts is also liable to cause damage. Parcels are also damaged in crowded streets when hurrying along. The removal of these objections would undoubtedly witness a vast increase in the number of parcels despatched. That, of course, is a matter of opinion. It is my opinion, and the opinion of a good many people, that parcels-especially those containing eggs, flowers, and fruit-are damaged in the crowded streets. Frequently persons used to send fruit by Parcel Post, with the result that the juice ran out and damaged everything in the bag.

Sir F. Mowatt: I have known even the fruit itself to disappear from the parcels. (Laughter.) Do you mean to say that the limit of the parcels' weight is 11 lbs.?

A. Yes.

Mr. Walpole: That is the limit of weight for individual parcels?

Mr. Smith: What do you consider should be the limit of weight that a parcel postman should be expected to carry?

A. I have cases where there do not appear to be any particular limit at all. Postmen have to do the best they can.

Q. Do you mean to say you never heard of a limit of that kind?

A. I am referring to places where there is no limit. Even in places wher 
there are limits, they have no balances on whic! $l_{1}$ the bags of the postmen can be weighed.

Q. I thought you said there were no limits?

A. I said there were not limits in all cases.

Q. Is there a limit in Manchester?

A. There is no fixed limit there. We were told that we would only have to take out a few parcels, but I find that in many cases a man has to take out eight or nine, and even more than that.

Mr. Walpole: I suppose that a great many of the parcels that now go by Parcel Post used to go by Book Post? I am referring to the very small ones. Books, etc., can now be sent more cheaply by Parcel Post, can they not?

A. No doubt.

Q. In the old days there was no Parcel Post, and then the parcels went by Book Post, did they not?

A. Yes; but they were frequently sent by railway as well. I should think there was only a small portion then by Book Post of what now goes by Parcel Post. I have been in the Service 22 years or more, and I do not remember anything like the same proportion.

\section{SUGGESTED SCHEME OF RELIEF.}

In towns and populous centres horses and vehicles should be employed almost exclusively on Parcel Post work. Rural railway stationmasters should deliver all parcels within a short radius of their location, in consideration of the large revenue derived by them from the carriage of post parcels. This would not be so much of an innovation when it is understood that stationmasters at most stations already transact certain postal business. The rest of the district should be served by mounted postmen.

Mr. Walpole: Perhaps the railway people would object to that.

A. They have been forced before now to do things - they ought to do what is right. I would suggest that balances should be supplied at all delivery offices, and that no postman on a near walk be permitted to take out more than $35 \mathrm{lbs}$. weight, including both parcels and letters, or $25 \mathrm{lbs}$. on a distant walk. At many offices there is no means of accurately ascertaining the weight, consequently there is much doubt and diversity of opinion on the subject.

Sir F. Mowatt: What is your suggestion about these two weights?

A. I would suggest that no postman be permitted to take out a comlined weight of more than $35 \mathrm{lbs}$. for a near walk, or $25 \mathrm{lbs}$. on a distant walk. I hear from Prestwich that their great grievance at the office there is that the men have no means of ascertaining the exact weight they are called upon to carry. The delivery of parcels greatly impedes the delivery of letters, and the postmen cannot get back to the office by the right time when they are burdened by parcels.

\section{POSTMEN'S REASONS FOR EXEMPTION.}

Parcel Post work militates against a postman officially because mistakes therein are recorded against him. Where parcels are numerous some postmen leave them in the office till they have completed their deliveries, then return to the office and deliver surplus parcels generally in their own time; others, to avoid the double journey, overburden themselves, thus inflicting physical injury on themselves; whilst others deviate from prescribed routes by permission. In any case, it is discreditable to the Department. I have here a list of 45 offices where spacial delivery of parcels is made after completing ordinary delivery-generally in man's own time-when parcels are 


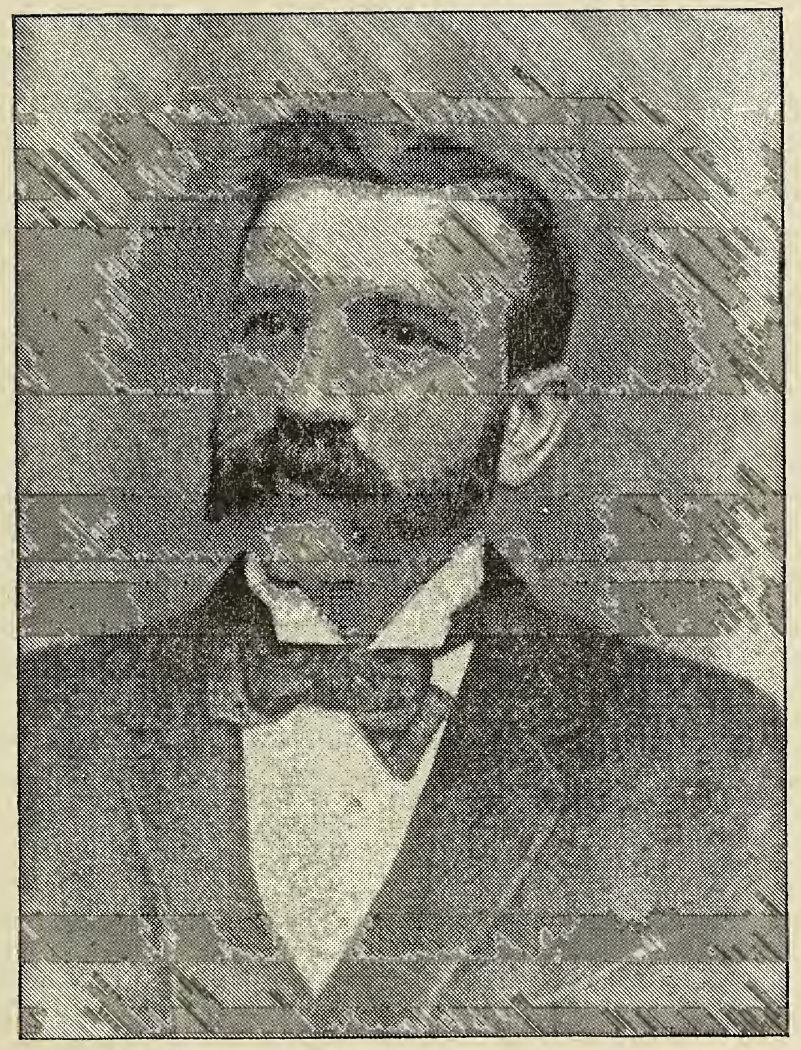

Mr. S. WRIGHT, Loeds,

Representing the case of Promotion and Junior Postmen. 

numerous. They are:-Ayr, Ashby-de-la-Zuuch, Aberfeldy, Aigburth, Broughty Ferry, Broadbottom, Bridge of Allan, Berkeley, Coventry, Castleford, S.O., Chorlton-cum-Hardy, Cookstown (Ireland), Dartmouth, Enniscorthy, Eccles, Heckmondwike, Harrington, R.S.O., Huntly, Irvine, Jarrowon-Tyne, Johnstone, Kildare, Loughboro', Luton, Liverpool (in some cases), Lockerbie, Leek, Louth, Ludlow, Leominster, Llanwyllog, R.S.O., Melton Mowbray, Maybole, Portadown, Perth, Pentre, Queenstown, Rothesay, Renfrew, Swinton, Salt Ash, Uddingston, Widnes, Walsall, Yeovil.

Sir F. Mowatt: What do you mean by that? What do you mean by saying they are delivered in a man's own time? Does it not all come within the 8 hours' work?

A. No, sir; a man has to do it after he has completed his ordinary work. He has to go out again in order to deliver the parcels.

Mr. Smith: Do you mean that in these offices it is a regular thing, at certain periods of the year, such as Chrisimas, etc., for the men to have to do this?

A. I believe it is a regular thing that whenever it happens there are too many parcels for a man to take out on his ordinary delivery he has to return after that delivery and take out the surplus parcels.

Mr. Walpole: Do you know that of your own knowledge?

A. I do not. It is simply information supplied to me.

Q. Now, in the information supplied to you, does it not say this, that it is only done when the parcels are numerous?

A. They are my own words-" when the parcels are numerous."

Q. And, therefore, it is limited to cases when there is pressure?

A. I have here a list of 31 offices where the men deviate from the ordinary route in order to dispose of heavy parcels, thus causing irregularity of service. I will put it in. List of 31 offices where men deviate from ordinary route in order to dispose of heavy parcels, thus causing irregular service:Busby, Beccles, Blackburn, Bradford (Yorks.), Burslem, Bacup, Barnard Castle, Cosham, Devonport, Dalton-le-Furness, Darlington, Dukinfield, Felixstowe, Galashiels, Kilmarnock, Kendal, Kildare, Motherwell, Maryhill, Northampton, Norwich, Newton Abbot, Oban, Prestwich, Plymouth, Perth, Portsmouth, Taunton, Weston-super-Mare, Worksop, Walton-le-Edge. Here also is a list of 56 offices where undelivered parcels frequently cause special journey back to office:-Ayr, Ashby-de-la-Zouch, Aberfeldy, Adgburth, Blaydon, Tyne, Brighton, Bathgate, Bettws-y-coed, Bury, Barnard Castle, Bournemouth, Belfast, Coatbridge, Castle Douglas, Crieff, Chorlton-cumHardy, Cookstown (Ireland), Dartmouth, Dudley, R.S.O., Droitwich, Dungannon, Dudley (Worcs.), Dalton-le-Furness, Dalkeith, Dumbarton, Enniscorthy, Eccles, Hollingsworth, Huntly, Henley-on-Thames, Irvine, Invergordon, Liverpool (C.), Lockerbie, Louth, Ludlow, Larne, Long Eaton, R.S.O., Maybole, Maryhill, Newark, Newton Stewart, Nantyglo, Oban, Prestwich, Porth (Glam.), Perth, Spilsby, Taunton, Tiverton, Uddingston, Ulverston, Windsor, Wrexham, Walton-under-Edge, Worksop. This is a very serious matter. The men are not allowed to deliver parcels in the ordinary way like a letter, and consequently they are bound to bring them back to the office, and in many cases they have to cover long distances in order to bring them back to the office, whereas, if it had been a letter and not a parcel, they could lave dropped it into the nearest pillar-box. In some cases where assistance is allowed it is not procurable because of the smallness of the authorised allowance, viz., $4 \mathrm{~d}$. per hour, for which a speed of four miles per hour would be required. That is contained in a statement from Colis, Merionethshire.

The Chairman : Do you mean to say that a speed of four miles is required from the men?

A. That is the general speed.

Q. Four miles required from a man who is on his feet delivering parcels?

A. Yes; it is not laid down in any rule book that it should be four I 
miles an hour, but it is generally understood that the men should cover four miles in walking.

Q. How can a man who is delivering parcels and letters go four miles an hour?

A. He can if he is a good walker.

Q. He could walk all right four miles an hour, but he could not stop to deliver parcels and letters as well, and go at the rate of four miles an lour?

A. It is not said that he is expected he would do so, but it is presumed that would be the official distance required of him.

Mr. Walpole: Is it not the case that the official rate is a maximum of three miles an hour?

A. I have never heard that maximum stated; it is generally understood to be four miles.

Q. But you must know that four miles is an impossibility for a man thus engaged?

A. In a place like Colis there would not be many calls to make.

Mr. Smith: When a postman fails to deliver a parcel, what does he do with it?

A. He has to bring it back to the office as a rule. At Manchester we can take them to a receiving office.

Q. And if it is a letter you can drop it into a pillar-box?

A. Yes ; we drop it in, in a return letter pouch.

Q. Is it a rule to leave the parcels at a receiving office?

A. Yes ; at Manchester it is ; but in this list of cases I have given it is necessary to return to the head office.

The Chairman: That is because there is no receiving office?

A. Yes, sir; and therefore it is a great hardship to have to deliver these parcels at all, because it imposes this duty upon the postman. I have a communication from Luton, which complains that they do not think that enough pay is given to enable them to obtain relief when an extra weight has to be carried. Then I have a statement from Halkirk, Caithness, which says that, "Owing to the length of the journeys, the men find it impossible to carry the weight in parcels and letters combined without keeping ponies and traps, for which nothing is allowed by the Department for the support of the animals or other expenses connected therewith."

Mr. Walpole: Do you know of any case where a postman is required to keep a pony and trap for which he gets no allowance?

A. He is not required to keep it; but he finds it impossible to do his work without having a pony and trap, and for that he gets nothing from the Department. I have another case in which there are often 24 parcels a day to be delivered.

Mr. Walpole: But they would be spread over several deliveries, and with six men that would only mean four each man?

Witness : But 19 out of the 24 parcels might come on one man's walk. At Formby parcels are delivered and collected together with letters without regard to weight; half-a-hundredweight is frequently carried over two miles, two-thirds parcels. At Waterloo and Aigburth it is somewhat similar. T'he men ask that there shall be no compromise on this question, and they warn me not to ask any money equivalent; all they want is to get rid of the work. I have some more cases here as illustrating our complaint. At Gateshead the parcels are delivered by four men after completing their letter deliveries ; 15 minutes interval only is allowed between in three cases, and 30 minutes in the other; the district is very hilly, and the work very laborious. A horse and van should be used. At Huddersfield the district is very hilly; number delivered by van weekly, 1,113 in 1886; the number in 1894 by hand-carts was 2.157 ; work very laborious. Thus, although the work has very nearly doubled, the man who had a horse to deal with fewer parcels has this extra labour thrown on a few hand-carts. At Newcastle-ón-Tyne the collectors strongly complain that no additional time 
is allowed when heavily burdened with parcels. Pontardulais, R.S.O., in Wales, the postman carries parcels $9 \frac{1}{2}$ miles in a very mountainous district, ani "Can't keep up to time or keep dry." At Hassocks (Sussex), G. P. Locke refused to carry $40 \mathrm{lbs}$. on delivery, three-fourths parcels, on the $31 \mathrm{st}$ December last, the bulk of which had to be carried three miles. $5 \mathrm{lbs}$. were taken off, and he was reported to the head Postmaster at Brighton, who reprimanded and threatened him with severe punishment if he repeated the offence.

Mr. Smith : That is the case you have already mentioned?

A. Yes.

Mr. Walpole : And it occurred at Christmas time, did it not?

A. Yes; on the 31st December. At Rochdale the " $Z$ " delivery dockets are unsatisfactory, irasinuch as the honesty of some of the men was doubted because they could not identify the recipients of the parcels two weeks later, although the dockets were filled up in the manner required by rule. I have the names of the postmen here to which that refers. Although I do not think any record is required, the public should be called upon to sign forthwith, and not to leave it to the man to write the name of the person who receives the parcel. We do not know of any other concern that adopts this method. At Harrogate, in the season, postmen make a parcel delivery after the first letter delivery; if late (which occurs often in the season) then there is no time for breakiast. At Fakenham Postman Wright walks $19 \frac{1}{2}$ miles daily, serves seven parishes, and has an average weight of $30 \mathrm{lbs}$. At Hull, Worcester, etc., parcel postmen are prohibited from soliciting Christmas gratuities, while at Manchester it is permitted. At Roscrea the work is very hard; the death of the late postman (who wheeled the baskets) is locally attributed to overwork in this connection. Assistance was given and was considered permanent, but it has been again withdrawn. At. Roscrea the arrangements have been altered pretty frequently. But the report made to me is-" With regard to town work, it is hard for one man to bring two or three heavy baskets on a hand-cart, and mails besides. I may mention it was counted too heavy some time ago, and the late town postman got help at mid-day, but this has been discontinued in consequence of a new mail-cart contract, which brings an early bisket in the morning. All the same, I often have three baskets. The amount paid for extra help was $2 \mathrm{~s}$. per week, which goes to the new contractor. Such heavy work wrecked the late postman's life, and sent him to an early grave. Help was given to me for some time, and then taken away altogether." From Chathill, R.S.O. (Northumberland), comes the report-." Application was made for hand-cart, which was refused on the ground that the distance from post office to station was only a short distance. The refusal to grant a hand-cart requires the attendance of three postmen where one could do." From Wicklow the complaint is of having to wheel heavily laden hand-carts from the post office to the railway, a distance of nearly one mile. My correspondent adds"I suppose we are not alone in having to do this, but I would say that it is a disgrace to ask men who have to keep themselves respectable to wheel a truck for a mile of road, all through the dirt and mud. The very poorest merchant living in a town like this would not ask his drunken yardman to wheel a truck to the railway station without providing him with some assistance." I do appeal for a return to original methods.

The Chairman: You put it forward that all parcels under all circumstances should be treated separately?

A. Yes.

Q. But surely in country offices, where there are not many parcels to deliver, you could hardly expect to have a separate delivery for parcels?

A. In that case it would be difficult to make the arrangement, but in large centres there ought to be no difficulty whatever. The Parcel Post work is increasing very rapidly. In the rural districts the men might be mounted, especially if the suggestion to raise the weight of the parcels is adopted. 
Q. But in a very large proportion of the rural districts now the postmen do have carts?

A. But not in all. That is where the hardship comes in.

Q. May I take it your demand is that all parcel deliveries should be separate in large centres, and that in rural districts and sparsely inhabited places arrangements should be made so as to relieve the men to some extent without giving an absolutely separate delivery?

A. We should like all parcels to be treated in a separate delivery. That vould be the only safe rule.

Q. Do you think that that is possible?

A. I think it could be done by mounted men, if the weight of the parcels were increased.

Q. Why is it not possible to compensate the postmen for it?

A. In a great many instances the postmen object to the work, even with compensation. They consider it is too laborious, and they want to be relieved of it. In my case, when I began to work for the Department there was no parcel delivery, and I consider it has been imposed upon me. Had I known that I should have been required to carry parcels out like a porter I don't think I should have taken the situation. But the work was imposed upon me many years afterwards.

Q. Have you understood that you were expected to carry only a certain weight?

A. But if a man is travelling along like a pedlar with all sorts of things hung around him, he does not hold a very elevated position in the eyes of the public and of the people amongst whom he lives.

The Chairman: Thank you.

The witness then withdrew. 
JOHN SHIELDS SMITH, Newcastle-on-Tyne.

\author{
Citizen Rigitis-Recognition of the Federation-Late Attendances- \\ Excessive Punishments.
}

Westminster, Thursday, Feb. 20th, 1896.

John Shields Smith, of Newcastle, was next called and examined, as follows :-

The Chairman: You are a Newcastle postman, I think?

A. Yes, my lord.

Q. How long have you been in the Service?

A. Twenty years on the 15 th of this month. I came into the Service as a telegraph messenger-on the 15th February, 1876, and I entered the Post Office in March, 1879, as a relieving postman, receiving my appointment on the 11th August, 1881.

Q. Of course you are at your maximum?

A. Yes, my lord.

Q. Have youl got your three stripes?

A. No; I have two stripes, and th third will not be due till August.

Q. You have not been in the Service quite 15 years?

A. No; I have only been in 14 years and 6 months.

Q. What is your par?

A. T'wenty-eight shillings and two stripes.

Q. You wish especially to speak on the punishment question, do you not?

A. Yes, my lord. I am repiesenting the provincial postmen on matters appertaining to discipline.

Q. You have heard the last witness's evidence?

A. Yes, my lord.

Q. I understand that the system of punishment in the provinces is quite different to what it is in London?

A. Quite so; in fact, I do not think that even the greatest authority on punishment can give any decided opinion as to which is the prevailing system of punishment, there are so many different systems of punishment throughout the United Kingdom. These are matters I wish to dwell upon, and as my evidence is quite different from that of Mr. Boaler, I should like to say I consider you will come to the conclusion that his evidence is watery as compared with what I will lay before you. (Laughter.) I do not wish to minimise Mr. Boaler's case; it is strong enough, I admit.

Q. But you have a stronger case? Can you tell me what the rule is in the provinces, say at Newcastle, as regards punishment?

A. I can give you the rule at Newcastle and some other towns.

Q. Will it come out in your statement?

A. Yes, my lord. Previous to commencing that statement I may say I was instructed to read up the question of citizen rights, and I did so in order to enable me to bear out the contentions which I have to put forward, but I have since learned that your lordship will not entertain that question, and I was informed, after I had read it up, that I should not be allowed to put it in. But I saw in Tuesday morning's "Times" an intimation to the effect that the scope of the Committee's Inquiry has been extended so as to embrace the question of citizens' rights. 
The Clairman: - What I have said more than once is this, that we are not empowered to go into questions which affect the Civil Service as a whole; but if you can show us any point on which the Post Office Service stands at a disadvantage as compared with other branches of the Civil Service, that would be a matter for our consideration. What we have to look into are cases of exceptional treatment in regard to Post Office servants. They undoubtedly can rightly be brought before us. We are not appointed to inquire into matters affecting the Civil Service generally.

A. Yes, my lord; but I am informed that a paragraph appeared to the effect I have stated in Tuesday morning's "Times."

The Chairman: You must not take everything that appears in the "Times" as gospel. (Laughter.)

Mr. Walpole: I saw the paragraph to which you allude. I think it was an account of a meeting of the Fawcett Association. So far as I know, there is no authority whatever for the paragraph.

The Chairman: I shall be happy to read your statement on the question of citizen rights if you will hand it to me.

Statement put in as follows:-

\section{CITIZEN RIGHTS.}

My Lord and Gentlemen,-The grave importance of the subject-citizen rights-ombracing as it does the civil liberties, increased duties and responsibilities of Civil Servants, demands the earnest consideration of all who conscientiously desire the development of moral rectitude and intellectual culture. The anomalous position of Civil Servants has been discussed with more or less ability by many distinguished men inside and outside the Imperial Parliament. Before I enter into the subject it will be necessary to define a citizen and his position in the State. I will take for a definition"A citizen is an individual having a share in the government of the State, and the State is a number of citizens associated together for mutual benefit." Our Government being, as it is, essentially democratic, elected by the people, it naturally follows that the Government is just what the people make it, and the only way to secure good government is to have good citizens, and to make good citizens it is necessary to give them absolute freedom of association with their fellows, and cultivate and encourage the development of the physical, moral, and intellectual faculties, in order that they may exercise the franchise honourably and justly.

Bosanquet, speaking of the Greek cities, says : "Citizenship was obviously and visibly a life, your whole life, with common dangers, common responsibilities, common enjoyments, and common ambitions. Your happiness was to fill satisfactorily,, a recognised place, and to be acknowledged by your fellows as doing so."

I heartily concur in these sentiments, believing as I do that it is the duty and the common amibition of every good citizen to be honoured with the confidence of his fellows, and to actively assist in building up a sound and healthy State.

This is a privilege enjoyed, and the rightful inheritance of every citizen in the United Kingdom except Civil Servants.

I could quote extracts from many eminent authorities, such as Ruskin, Bright, Socrates, Butler, Cicero, and others. I refrain, because I feel the right of our claim cannot be disputed.

This brings me into the heart of my subject-the disabilities of Civil Servants. Rule 81 in Town Postmen's Rule Book reads :- "You are allowed to record your vote, if you have one, at a Parliamentary or Town or County Council Election; but you are not allowed to take any active part in an election, or to serve on any committee having for its object to promote or prevent the return of any particular candidate, and you are also prohibited from becoming a candidate for the County Councils."

I respectfully submit that this rule takes away from Civil Servants the privileges and rights enjoyed by the vast majority of citizens. It narrows 
and warps our judgment by confining our aspirations and actions within the narrowest limit. It denies us the right of becoming useful citizens by preventing us from participating in that which is ennobling and elevating, i.e., the association with men of lofty ideals, and actively pursuing a life of usefulness.

The mischievous effect of this rule cannot be over-estimated; its whole tendency is degrading and paralysing, crushing worthy ambition instead of fostering and encouraging its healthy outlet.

I have never seen or heard any sound reason given as to why Civil Servants are deprived of their civil liberty. Three antiquated arguments have been advanced, i.e., (1) State-paid servants; (2) the inducement to divulge official secrets; (3) advance selfish interests. These are arguments that have been urged against our claim; they are as unsound as they are ridiculous.

(1) The State is a number of people associated together for mutual benefit; Civil Servants form a portion of the State, as such perform a particular work for the whole of the community, for which they receive a prescribed stipend. After a servant has rendered the particular service required of him, the Department has no right to control his actions in other spheres of life, so long as his actions are not detrimental to the Department in which he serves, or against the laws of the country. Had this been in the Middle Ages,' and chattel slavery predominant, the autocratic action of the Postmaster-General would not be questioned. But we are supposed to be living in an age of enlightenment and liberty, and are subjected to the same rents, rates, and taxes as other citizens. The same penalties are inflicted for infringement of Imperial laws and municipal bye-laws. We are compelled to pay the aforesaid rates and taxes for the government of the people. Yet we are not permitted to take an active interest in the spending of the same. If it is right that we should pay rates and taxes, it is equally right that we should have a say in the spending of our money.

On the other hand, if the Department is right in withholding our citizenship, the Department ought to pay our rates and taxes. This will be considered an impracticable idea. It is sound logic all the same, because I hold that it is the duty and right of every citizen to see that he is not taxed unjustly, or made to pay more then is necessary. If the Department denies us the right to become active and responsible citizens, the Department ought to pay the penalty.

As to the secrind reason-that of inducement to divulge official secretsI wculd respectfully point cut the sophistry of such an argument. (1) There are sufficient laws and rules to protect the Department, and punish anyone who betrays the trust reposed in him; (2) were men inclined or tempted to do so, the present disabilities will not prevent, but tend to induce; (3) the longer men are held in bondage the keener they feel their sores, and, in consequence, will do in secret what they dare not do openly; (4) if secrets are not betrayed now they never will be by the extension of citizenship, because the more liberty men are given the more loyal they become, duly recognising their responsibilities and endeavouring to discharge them.

Dealing with the last reason-" The using of our power to advance selfish interests" -I may say this contention is utterly untenable, and can only be looked at as an attempt to undermine and foil our endeavours after more favcurable conditions. All progressive movements have been represented in unlovely guise by reactionary opponents, but as the movement progresses the moral sense of the people is being educated to regard the ideals aimed at as worthy of attainment. Civil Servants claim to be as loyal to our institutions, as zealous in seeking the welfare of the people, and equally as unselfish as any other section of the community. They are now possessed of the power to advance their own interests; they are wise to avail themselves of the opportunity. It is the successive Postmasters-General who are responsible for this seeming selfishness by exercising arbitrary power over free citizens, thus throwing them into a narrow groove of self-seeking.

Give them their rights and. allow them to carry their ideas further, by 
educating themselves into the pros and cons of government-it will then be found that they possess the requisite energy and ability to rise to a full comprehension of their duties and privileges. John Knox says: "A fullyequipped citizen needs less governing than au inferior one. The higher the standard of citizenship the less governing it will require, and the ideal State undoubtedly is one in which government is reduced to a minimum."

Although in recent years there has been some concessions granted to Civil Servants, i.e., Parish Councils Act, postmen have shown their sincerity by becoming candidates, suveral of whom have been elected councillors, and discharge their new duties with distinguished ability. Still there is an incalculable wrong perpetrated by Parliament allowing the head of a State Department to over-ride its lawful Acts, and autocratically prevent thousands of lawful citizens from exercising their undoubted rights.

On June 20th, 1892, Sir Jas. Fergusson said-"He was asked by what law or right he did so. He did it by right of duty which belonged to the head of a great public Department." In April, 1893, Mr. Arnold Morley, replying to Mr. MacNeil, said-“"There was no actual Treasury minute on the subject." May, 1893, the Solicitor-General said, in reply to Mr. MacDonald-" That, so far as he knew, there were no Acts of Parliament unrepealed which dealt specially with the electoral privileges of Civil Servants. Whatever regulations were made with reference to the action of subordinate officials in the Civil Service were made not under the authority of any section of an Act of Parliament, but under the inherent authority of heads of Departments, to make regulations for the discipline and government of those under their control."

The foregoing answers amply demonstrate the legality of our claims. We are deprived of our rights' in the interests of discipline. I gravely question whether it has the desired effect. To my mind the result is quite the reverse; it is a bad example for a disciplinarian to violate Parliamentary laws. A great State Department and the laws of the country ought to be in harmony, not in antagonism; a power exercised under such conditions cannot command that respect and obedience that it otherwise would do.

I confidently leave the question in the hands of this Committee, believing that you will base your recommendations on the fundamental principle of justice, and give to Civil Servants full opportunities to develop the gifts of nature, and become useful citizens.

\section{RECOGNITION OF THE FEDERATION.}

On behalf of the provincial postmen, I am requested to urge the claims of the 'Postmen's Federation for official recognition. Taking a retrospective view of postmen's agitations previous to the establishment of the Federation, when postmen deplored and deprecated the conditions of their employment, when all means of ventilating their grievances were closed, when they performed their duties in an insipid sort of manner, and anxiously looked for some redress of their many grievances, the appointment of the Ridley Commission in 1887 raised a feeling of hope, and numerous were the grievances showered on the heads of that Committee, and great were the expectations of redress. On its being made known that the Committee would not inquire into the administration of the Post Office, a strong resentment was rampant. It was then efforts were made to organise. Here and there groups of postmen were banded together, and agitations of a confused description were the order of the day. It was not until the formation of the Postman's Union that any real attempt was made to unite postmen into one solid organisation. The disastrous failure of that Union taught postmen a lesson which they have not been slow to profit by. The Postmen's Federation sprang into existence in 1891. Without going into the history of the movement, I feel some pleasure in saying that its claims for recognition are justified by the beneficial influence it exercises over its members.

The untold advantages to be derived from such recognition are apparent. Grievances that are now allowed to lie in abeyance would be dealt with effi- 
ciently and satisfactorily as soon as they were felt, and in dealing with questions as they crop up, the Society is doing a public duty. If unredressed grievances are allowed unduly to accumulate there is always a danger of the Service falling into a state of chaos.

As it is the duty of every workman to protect his labour, our society, from the nature of things, partakes of the character of a vigilance or protective association rather than a regular trades union. That being so, the Federation is in a position to disabuse many of the misconceptions and imaginary grievances against the Department, and advance the real burning questions that ought to be considered.

Many large employers of labour and many large trades unions find that it is to their mutual advantage to form conciliation boards and boards of arbitration, as witness the formation of conciliation boards with the Northumberland and Durham Miners' Unions and the Masters' Associations-the respective representatives meet and discuss matters of dispute without resorting to a calamitous social war.

From personal experience I can vouch for the advantages of an exchange of opinion between the official representative and the postmen's representatives. The late Postmaster of Newcastle-on-Tyne, Mr. Thos. Hunter, and the present Postmaster, Mr. Thos. Stevenson, have always received the postmen's representatives courteously, and discussed questions at issue thoroughly, thus gaining the respect of the men represented, and arriving at a true conception of the deportment of the officers under their control. Our late Postmaster-General (Mr. Arnold Morley) has stated on several occasions that wo enjoy the same privileges as other trades unions; had this been so there would be no necessity to plead for official recognition.

I refer to a letter to the Elen Club on February 14th, 1895, and a letter to J. A. Murray MacDonald, April 1st, 1895, from which I have extracted the two following passages:- "All the privileges which trades unionists enjoy, and, in my opinion, rightly enjoy-are thus accorded to the unions of postal officials." ... "I trust that you will see from the whole tenor of my letter that while I am bound to act on the rules which prevail through the whole service of the Crown, I am anxious, as far as possible, to afford all classes of employees in the Postal Service the fullest opportunity of approaching me on any subject which they may think affects their position, their pay, or the conditions of their employment."

Undoubtedly there has been some liberty extended to Civil Service organisations, but our liberties are nothing in comparison to the privileges $€ n$ joyed by other trades unions; at the same time I am of opinion that the recognition, we are now pleading for would have been granted by our late Postmaster-General had it not been for what he considered the etiquette of the Service. I submit that it is not conducive to good discipline that any false notions of etiquette should stand between the rank and file and the heads of a great State Department. The concessions already granted have in no way been abused; we have studiously encouraged officers to show becoming respect to their superiors, and to serve the Department to the best of their ability; we have always used our power to advance the interests of the Department by seeking the redress of its servants' grievances. Therefore, I submit that it would be an additional source of efficiency to the Service, and give general satisfaction to the men, were the Postmaster. General to receive a deputation of postmen's representatives every six months for the purpose of discussing grievances of a general nature. I sincerely hope that this Committee will make this suggestion the basis of thei recommendations.

Witness: I will now proceed to deal with matters of discipline. In dealing with matters of discipline it will be my duty to point out to you the diverse and numerous forms of punishments for precisely similar irregularities, the effect upon the efficient performance of public duties, and the utter hopeless and depressed condition which it imposes upon the offenders 
affected, and whilst I candidly acknowledge that discipline is necessary and desirable for the good government of a large body of men, and the infliction of some form of punishment advisable for the maintenance of such discipline, I emphatically protest against the present confused and vexatious methods adopted for punishing men for the most trifling irregularities, and, according to the evidence I will lay before you, it will be demonstrated beyond question that the Postal Service is in a state of chaos so far as its servants are concerned, which calls forth a searching inquiry and the vigorous action of this Committee to place the Service upon an equitable basis, which will command the respect and obedience of all right-thinking men who desire order. The greatest discontent prevails throughout the Service because of the want of uniformity in the application of punishment. Sometimes an offence in one case is met with undue severity, another case under identically the same circumstances is treated in quite a different manner, therefore it is obvious that so long as this haphazard system of administrating punishment remains extant, so long will it engender resentment, and militate against efficient service. And when it is remembered that postmen are working in absolute ignorance of the maximum penalty for many of the multifarious offences they may commit, our grievances will be all the more apparent.

\section{LATE ATTENDANCE.}

'There are several different modes of punishment for this irregularity. For illustration and brevity I will name three different towns, i.e., Cork, Newcastle-on-Tyne, and Liverpool, where the punishment varies. The towns I have mentioned are by no means isolated in their peculiar method of awarding punishment. They are, indeed, typical cases.

Conk.

A late attendant at Cork is immediately penalised by the infliction of a fine at the end of the quarter, the time lost by each man is added up, the delinquents are then called upon to perform extra duty to the extent of double the time they have lost. The following cases, which occurred quarter ending September 30th, 1895, will convey a correct impression of the punishment-meted out :-

$\begin{array}{lcccc}\text { Names. } & \text { No. of Lates. Aggregate Loss. } & \text { Fine. } & \text { Extra Duty. } \\ \text { J. Roche, } & 5 & 28 \text { minutes } & 10 \mathrm{~d} . & 1 \text { hour. } \\ \text { S. Horgan, } & 5 & 32 \text { minutes } & 10 \mathrm{~d} . & 1 \text { hour. } \\ \text { J. Johnson, } & 5 & 40 \text { minutes } & 1 /- & 1 \text { hour. }\end{array}$

The Chairman : In each case a fine of $2 \mathrm{~d}$. is inflicted for a late attendance? A. Yes. They are also liable to having their increment arrested and their service stripe being withheld. I respectfully submit that the punishment is out of all proportion to the crime, and beg to draw your attention to a statement made by our P.M.G. in the House of Commons on December 7th, 1893. He said- "The rules differ in different offices, at some a fine, and at others extra duty is imposed for late attendance, but at no office, so far as I am aware, are both fines and extra duty imposed for the same offence.

The Chairman: Of course you do not object to making up the time that has been lost?

A. Certainly, my lord. If the Department keeps the money from the men I do not see any necessity for them to work up lost time as well.

Q. These men suffer nothing with regard to increment or stripes, do they?

A. I have not inquired as to that, but I am told that every one of them, according to the number of times recorded late, would suffer in the matter of increments and stripes.

Sir F. Mowatt: With regard to this list of late attendances at Cork, I find they run to 28,32 , and 40 minutes; they therefore do not include late attendances of less than five minutes, do they? 
A. I cannot say that, sir, but I can give an instance from other offices where men have got two hours' punishment for being three minutes late.

Mr. Walpole: Do you know when these late attendances occurred at Cork? Are they moderm instances?

A. They were in the quarter ending September 30, 1895.

Q. I see the striking thing brought out in the Cork case is that the men are fined and also get extra duty for late attendance?

A. Yes, sir.

Mr. Walpole : I will look into that question. It ought not to be so.

Witness: Thank you, sir. I may add that it is the same in other places which I am going to mention.

The Chairman: Is there a time limit in the provinces at all for late attendances?

A. No, my lord.

Q. Are not two minutes allowed as a period of grace?

A. Two minutes is allowed in Newcastle, but it is not so in other townsLeeds, for instance.

Mr. Walpole: Is there not a universal rule that two minutes shall be allowed?

A. We never see the rules of the Service. I am going to deal with that point later on in my evidence.

Q. I have no objection to saying that the rule runs that for "each late attendance exceeding two minutes and not exceeding fifteen," etc.

A. I admit that we get two minutes' grace at Newcastle. I do not wish in any way to exaggerate my case, my lord; I wish to keep within the line if I can possibly do so. I do not wish to damage the men whom I am representing by hot-headedness, and $I$ do desire to state my case as calmly and as deliberately as possible.

\section{NewCastle-on-Trne.}

Postmen in Newcastle are obliged to make three separate attendances per day, commencing at 5 a.m. And you must remember there are 900 attendances in the year. Should a man be 10 minutes late he will be called upon to perform 30 minutes' extra duty. As all lost time is allowed to accumulate to the end of the quarter, a man may be four times 10 minutes late, total time lost 40 minutes. For this he will be specially called upon to work two hours' extra duty, or 120 minutes for the loss of 40 . The men are seldom called upon to do their punishment duty until there is an influx of circulars, then all the men available for punishment are called upon, generally speaking, without previous warning, to reduce as much as possible the extra pressure by stamping, sorting, and delivering these circulars, thus saving the Department from employing extra hands or paying overtime. The late General Election furnishes a case in point. There were five Parliamentary candidates for Newcastle, who sent their election addresses to each of the electors. Postmen were compelled to do extra duty in order to dispose of the abnormal amount of posted matter. The men did their work cheerfully, expecting to be remunerated for their labours at overtime rate of pay. Two days afterwards a notice was displayed upon the postmen's notice board, signed by the inspector, informing the men that any man who had punishment duty to perform would not receive overtime pay. (Cries of "Oh, oh.")

The Chairman : Order, order.

Witness: But the time he had worked would be deducted from his punishment duty. Thus, a man who had been 20 minutes late, and worked an bour delivering Parliamentary addresses, would get nothing for his labour; another man who had not been late would receive overtime pay at the rate of time-and-quarter. Not only does the Department punish the late attendant with three times the amount of time he has lost, but in this instance it deprived him of what he was justly entitled to-extra pay, or an equitable diminution of his punishment. Should any man be late when on Sunday duty 
the time he has lost is deducted from his Sunday pay, and in addition to that he has to perform the aforesaid punishment duty. The anomaly does not cease here; at the end of the year his conduct and nature of attendance is reviewed, and if it is not to the satisfaction of the Department he invariably has to suffer further punishment in the arrestment of his increment for an indefinite period, and at the end of five years he is again punished by his service stripe being withheld. We consider this mode of punishment to be hard and unjust, more especially is it so when it is taken into consideration that when a postman is late the Department loses nothing; the man has the same amount of work to perform, although less time to do it in, consequently he punishes himself by throwing an extra amount of vigour into his work to make up for lost time-in many cases the severe strain is felt for days afterwards. The existence of this obnoxious punishment, calculated by the Department to effect punctuality and punctility, on the other hand, is the most prolific source of discontent, and injurious to the true interests of the Service. Furthermore, I am of opinion that this mode of punishment is not in accordance with Rule 8 in Town Postmen's Rule Book, where the following scale of punishment for late attendances is laid down for the guidance of postmen :-

\section{RULE 8.}

"(A) For every late attendance you may be fined according to the following scale, viz. :

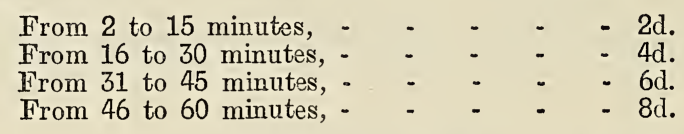

"A late attendance beyond one hour will be specially dealt with, and in addition to being fined as above, you will be liable to be called upon to make up the time lost, or to be otherwise punished. (B) At the end of each quarter the produce of the fines will be divided amongst the men who have not been late four times in the quarter. (C) All cases of late attendance will be specially noticed, and if they should be numerous and without excuse, they may lead to the arrest of your annual increment for 12 months, to suspension of pay, or possibly to your removal from the Service."

The Chairman : Are these fines not inflicted at Newcastle at all?

A. No, my lord; I submit that any other form of punishment than that laid down in Postmen's Rule Book is an infringement of the said rule, and local Postmasters are equally responsible to the P.M.G. for the efficient carrying out of the rules, therefore the precedent established whereby local Postmasters infringe the rules is a bad example from a disciplinary point of view.

\section{LIVERPOOL.}

A postman in Liverpool is fined for every late attendance at the rate of 8d. per hour: if late 15 minutes or part thereof he is fined $2 \mathrm{~d}$., if late 1 hour he is fined 8d., and is specially called upon to work an hour extra in lieu of the one he has lost; if late four times in the quarter he is fined for each offence, and is obliged to work up the broken periods he has lost; if five times late he has to pay his fines, work up all the time he has lost, get a special report, and a record in the black book is made. He is also liabie to have his increment arrested, and if 36 times late in three vears his stripe is stopped, a loss of 52s. a year, and what little chance he had of being promoted is blighted. Although the punishment meted out in Liverpool differs in some respects from that meted out in Cork and Newcastle. it will be observed in every case that the Department is not content with its pound of flesh, but must inflict several punishments for the one offence. 
Throughout the various offices in the United Kingdom different systems of punisliment for late attendance are in operation, all more or less stringent; silme a.1 punished with fines, others with extra duty, and, notwithstanding the disclaimer to the contrary, both fines and extra duty are inflicted, as is the case in Cork, Newcastle, and Liverpool, to which I have just referred.

The Chairman: Not at Newcastle. You said there were no fin's there?

A. Certainly, my lord; but a man there loses his Sunday pay, and is punished with additional duty.

Q. He los:s an amount of Sunday pay in proportion to the time he is absent from duty?

A. Yes: it a man is late half-an-hour, and his pay is at the rate of 1 nd. an lour, he loses 5d., and is called upon to do punishment duty as well.

Q. I uu raisc, no objection to a fine, do you?

A. No, my lord; I think it only right that if a man loses the time of the Department, his money for that time should be kept from him, but as the Department is so scrupulous in insisting on punctual attendance, I think it should exercise some care in seeing that the men are not compelled to work over eight hours. I will give an instance of what I mean. A man with whom I work side by side is not a very good attender. I do not wish to defend any man who infringes the rules of the Service, but I do wish to point out that excessive punishment does more harm than good. This man may have been 20 times late in one year, and although he has to work overtime in order to make up for the late attendances, that is not all the punishment. He is losing by arrears of increment, and by being deprived of good conduct stripes, 2s. a week. I consider it very hard thus to punish him especially as he works nearly nine hours per day instead of eight. If the Department makes it a binding rule, and takes stringent measures to carry it cut, it should exercise some care that the men are paid for the work done in official time.

Q. Don't you think that a man ought to receive some more punishment than the mere loss of wages for the time he fails to attend at the office? As far as I understand your point, you admit that if a man is late, it is quite fair he should not be paid for the amount of time he has failed to put in the office?

A. Yes, my lord.

Q. Well, you can hardly call that punishment?

A. Well, I do not think it is right that the Department should swell its revenue by the misdeeds of postmen.

Mr. Walpole: What do you mean by that?

The Chairman: But, as far as I understand it, the money paid for fines is distributed amongst the other postmen?

A. Yes, my lord.

Q. And therefore the Department is not a gainer by them?

A. No, my lord.

Q. The men are the gainers-those who put in good attendances?

A. Yes, my lord; I admit it is an inducement for a man to be a good attender; but, on the other hand, when the Department is gaining by a man working overtime, it is an inducement for the officials of the Department to be more scrupulous, especially at the present time, when the economy craze is so prevalent.

Q. I wish it were. (Laughter.)

A. I consider that if a man does wrong it is not right or fair for any one else to benefit by his misdeeds.

Q. You are mixing up two points. You are mixing up the question whether it is right for the Department to take advantage of a man working beyond eight hours without being paid for it. That is one question. Do not mix it up with the question of fines or punishment. It seems to me, I must say, that you are not quite fair in your contention that a man should 
suffer nothing more for late attendance than merely not being paid for the time he failed to put in. If that were all, it would be no punishment at all.

A. I admit, my lord, that stripes are given to postmen for good conduct, and I think that the Department is quite right in withholding the stripe from bad attenders; but I also think that, in justice to the men, the Department should let them know how many late attendances will prevent them getting the stripe.

Q. One difficulty about that is that late attendances cover such a margin of offences. You cannot possibly put five or ten minutes lateness in the scale against a late attendance of one hour?

A. That is immaterial, my lord. You will observe that the scale of punishment at Newcastle is the same up to the half-hour. A man who regularly attends late is a man who dwindles five or ten minutes. $\mathrm{He}$ is the man who is most frequently late. If a man is late over half-an-hour then he has to put in double time, so it does not make any difference whether a man is five minutes or half-an-hour late. I really think the better plan would be for the Department to stop the amount from a man's wages, and to fine him according to Rule 8. Then lay down a stipulated time, and if any postman goes beyond that, he does not get his good conduct stripe. I think such a rule would give general satisfaction, and would do away with the dissafaction caused at present by the men being kept in the dark.

Q. I quite understand you ask for exactly the same thing as Mr. Boaler, that there should be an absolutely clear statement, showing what punishment a man is going to incur. You also want that the rule shall be uniform throughout the Service?

A. $\perp$ es; I am informed that in many towns the fines are distributed among the local cliarities. I believe that is done in Glasgow, for instance, instead of distributing them among the men who have put in good attendances. I prefer the plan of distributing them among the men, as I think they constitute an inducement to the men to be punctual. It is, of course, left to the wish of the men whether the money shall be distributed among themselves or given to a local charity.

Mr. Walpole: It is only given to the local charity at your own wish then? A. Yes, sir.

Q. There have been cases, have there not, where the fines have been returned to the men who paid them?

A. Yes; that happens in some instances. I will give you an illustration. Rule 8 says that no postman shall share in the distribution of the fines if he be late oftener than three times in a quarter, and if I, for instance, were late but triree times, the proceeds of the fines, supposing they amounted to 6d. per man, would enable me at the distribution to get the 6d. back which I had paid for the three late attendances. This plan is enforced at Liverpool and Cork. There the men share in the fines, but at Newcastle, if a man is once late, he is humiliated and degraded in the same way as a man who is twenty times late. He is brought up to do punishment duty, and held up to ridicule among his fellow-workers. I think that is most humiliating to a man. A man may strive to do his best to put in good attendances, but a time may come when, owing to an accident-and accidents will happen in the best regulated families-when he is late, and I think it is scarcely fair for any postman under such circumstances to be paraded before his colleagues as a delinquent. It is like a culprit being paraded before a. lot of fellow-citizens, who are told to look upon him as a man who has been convicted of some offence.

The Chairman: You think that a strict enforcement of the fines is scarcely a proper way of dealing with the subject of late attendances?

A. Yes; but I would abolish the latter part of the rule, and I will tell you why later on. The one thing the Department is unanimous upon is the repetition of punishment. Instead of the offences after punishment sinking into oblivion they are kept on hand until another favourable op: 
portunity appears for the Department to revenge itself. In consequence the men are kept in a continued state of uncertainty and unrest as to the safety of their annual increment or good conduct stripes. If the far-reaching detrimental effect of this cumulative system could be fully realised it would not be tolerated a day longer. It is for this and other reasons that I respectfully urge that some means should be adopted to banish the general discontent that is now prevalent through the administration of excessive punishment, and the arbitrary actions of some who do not hesitate to abuse the power with which they are vested, and instead of fostering and encouraging that spirit of respectful obedience by which alone good government can be secured, they create a feeling of retaliation which tends to promote thrat spirit of insubordination which usurps all discipline. The foregoing remarks do not apply to every Postmaster or officer in authority. I know there are conscientious officers who strive to do their duty to the Department and mete out justice to those under them; because of this I am desirous of drawing your attention to the many inequalities that postmen are subjected to by having men placed over them who do not or will not understand the proper functions of a superior officer. I have in my possession many cases of exorbitant punishment that have been inflicted upon postmen for late attendance and other irregularities, some of them of the most trifling nature.

\section{EXAMPLES OF HARSH PUNISHMENT.}

With your kind indulgence I will quote a few typical cases, firstly, to substantiate my previous statements; secondly, to acquaint you with the terrible hardships to which a postman can and does suffer when left at the mercy of an individual, who may be imbued with an old-standing antipathy or deep-seated prejudice against postmen as a class; and thirdly, to show the absolute necessity of some authentic instructions being issued from headquarters, laying down the maximum penalty for all forms of irregularities. These are the cases:-

William Woodhouse, appointed postman at Norwich in Jan., 1872, has thus been a postman for 25 years. The early part of his career was characterised as being indifferent; he was suspected and charged with writing direct to the Secretary concerning a shady proceeding in the payment of junior postmen's wages. On two occasions he has been suspected and charged with communicating to the press; on the first occasion the Pesto master expressed his regret that it was not in his power to dismiss ha-, and on the second occasion he was told that he would never be recommended for any promotion. This latter threat has been consistently carried out, although Woodhouse strongly protests against the charges laid against him, and earnestly declared his innocence, and still adheres to his former protestations. The last 17 or 18 years of Woodhouse's official career have been of a most exemplary description: a good time-keeper and zealous in the discharge of his duties, and yet, though he has been a postman for 25 years, he has never been the recipient of a conduct stripe! By this means he has been deprived of about $\$ 90$, truly a great loss for a postman to suffer through liaving this vast sum deducted from his wages. It needs no words of mine to point out the great injustice that has been inflicted upon Woodhouse. Any little irregularity that may have occurred (such as bad timekeeping, which is admitted) in the first seven or eight years of his service, has been amply atoned for by 17 or 18 years' punctuality ard excellent behaviour.

J. Saunders entered the Service at Norwich as telegraph messenger on July 6th, 1872. Took up duty as an auxiliary postman 1875, received his appointment as letter-carrier 1878. He has now served 17 years as a postman, and has an unblemished record. For some reason or other he has never received a stripe. The only instance wherein he may have incurred the displeasure of those in authority is in 1885 (ten years ago). One of the postmen 
was charged witl coming off his delivery in a state of intoxication. The postman in question made a charge against the chief clerk of being intoxicated on several occasions. Mr. Forest (surveyor) came to investigate the case. Saunders and a postman named Fish were sent to give evidence. The result of the trial was, the postman charged with drunkenness was dismissed the Service and the chief clerk retained his position. Immediately afterwards papers were sent to all the senior postmen asking them if they had at any time heard Saunders or Fish making use of obscene language in the postmen's sorting office. Two old men replied in the affirmative. Saunders and Fish were reported and fined three days' wages. That is (so I am informed) the only record against Saunders. He has since made application for his conduct stripe, and waited twelve months without receiving a reply. He then forwarded a second application. The Postmaster sent for Saunders, told him he had no right to send in applications for stripes. He might be the best conducted and most punctual man in the office, but that did not constitute his right to a stripe. Stripes were given as an act of grace, not as a right. That, my lord, is the expression of opinion on the part of the Postmaster at Norwich.

The Chairman: Does it lie entirely with the Postmaster of a particular office whether a stripe is awarded or not?

A. Yes, my lord.

Q. And is there no sort of appeal beyond him?

A. There may be in the eyes of the Department an appeal from the Postmaster, but the postmen look upon it as sacrilege to go above the Postmaster.

Mr. Walpole: Still, there is an appeal?

A. Yes, sir; you will understand that some postmen can state their case pretty fairly, but other postmen can not. He who can state his case in a proper light is better looked after by the Department than the man who is unable to do it. That is one of the reasons why we are pressing for an official recognition of the Federation.

The Chairman: I should imagine that in this sort of case the Federation would help a man to state his case?

A. Yes; if we are allowed to do it, we are quite eager to undertake it.

Mr. Walpole: Surely it can draw up a case for the men, and then let him send it forward through the prescribed official channels. Is there any difficulty in that?

A. I believe it is done in some cases, but you must understand that it is against the rules of the Department for the Federation to interfere between it and the postmen, therefore a man must state his case himself.

The Chairman: But the Department does not ask the man who drew up his case for him, does it?

A. It is very often suspected, and I have heard cases in which the inspector has remarked to the men, "The Federation has had a hand in this apparently." I may say, speaking of the town from which I come, that I have had occasion to appeal to my Postmaster two or three times, and I have expressed myself as highly satisfied with his decisions.

Mr. Walpole: Do you refer to Mr. Hunter or Mr. Stevenson?

A. To both; I have, in fact, made representations to both of them, and they have always been ready to listen to the men.

Q. Then you have no complaint to make against your own Postmasters, either late or present?

A. Not as regards receiving the men and listening to any grievances they may have to put forward. They have always willingly and courteously received the men, and endeavoured to understand the question at issue.

Q. Have you any reason to think that in the great majority of cases that is not the rule among Postmasters?

A. I believe there are cases here and there where it is not. I shall be able to show that some Postmasters have a very antiquated idea, as Mr. 
Maclaren has previously stated, of their duties towards the men. Indeed, some of the inspectors also have antiquated ideas; they talk to the men in unnaturally loud tones, and in a strained voice. They talk in the same way as an officer in the army would give the order, "Right about turn!" I do not think it adds to the dignity of any official to put on an assumed voice when speaking to the men. 1 think in the minds of intelligent persons ridiculousness is thereby exposed, and that such conduct is calculated to bring the positions of Postmaster and inspector into contempt. I have another case which I wish to lay before you; it is that of a man named Arthur S. Carter, of Norwich, and I propose to put it in in order to show the enormous responsibilities postmen incur, and also to show how a little slip may entail severe punishment being inflicted upon a man. I also want to point out that in the matter of wages a postman is looked upon as being at the bottom of the ladder, but that when it comes to any mistake in the performance of his duties, he receives the strongest punishment. Therefore 1 think that although the Department does not admit by the amount of wages it pays that the postmen are performing the most responsible work of the office, yet they do concede that by inflicting upon them the heaviest punishment for derelictions of duty.

Arthus S. Carter was appointed in Norwich Post Office as postman on July 23rd, 1883. Received his first stripe 1889, with back pay from date due, entitled to his second stripe July, 1893. He waited several months. The expected stripe not being forthcoming he made inquiries through the proper official channel. After receiving many evasive replies he was eventually informed that his stripe was arrested owing to the mis-delivery of two letters in 1891 by Carter, addressed to Messrs. Smith and Son, Thorpe, to Messrs. Smith and Son, Norwich. Carter explains that he has between forty and fifty letters every morning for Smith and Son, Norwich.

Now, I should like to point out that the sorting clerk was more to blame than the postman, because the sorting clerk must look at the names the town to which letters are addressed, and in this case he evidently mistook Thorpe for Norwich. It was a case of gross negligence on his part. When a postman gets many letters for delivery, he seldom looks at the name of the town, he just looks for the name of the firm ; for instance, in my own case, I have a large number of letters to deliver to the firm of Messrs. Stephens and Mawson, shipbrokers, who have an office in Cardiff as well as at Newcastle. They have posted letters at Newcastle addressed to their Cardiff office, and yet those letters have been delivered to them in Newcastle again. That is a very simple mistake for a postman to make, and he does not, I repeat, look at the names of the towns. He looks mainly to the name of the firm.

The Chairman: In that case the letter ought not to come into your hands at all?

A. No; it ought not to come into my hands; it ought to have been forwarded on by the sorting clerk.

Q. Do vou say that the sorter in this case practically escapes punishment, and that the postman is called upon to suffer by being fined?

A. Yes.

Q. But in this sort of case. do you not, when you return to the office, call attention to the matter? Don't you report the facts?

A. I do not; but probably Messrs. Stephen and Mawson do.

Q. Don't they hand the letter back to you?

A. No; and even if they did hand them back to me, I probably should not report it; $I$ would in all likelihood keep it dark.

The Committee then adjourned for luncheon, the witness's examination not having been completed.

Mr. Shields Smith resumed his evidence when the Committee returned from luncheon. He wished, he said, to give a case typical of the severe punishment inflicted for late attendance. It was as follows:-

W. H. A. Jordan has been an established postman in Torquay 12 years, 
and he received his yearly increment up to 1887. In the year 1888 he had 22 late attendances recorded against him, and in consequence liis increment was stopped. In 1889 he was 18 times late, and his increment was again stopped. He was also due for a service stripe, and that too was withheld for his late attendance. In 1890 he made a great improvement on his timekeeping, having nine records against him. He received his increment of $1 \mathrm{s.}$, and made application for his stripe, but was informed that he would have to serve five years of uninterrupted good conduct before his stripe could be granted. Now, this man's punishment in addition to local fines has been, through arrestment of increment in 1838, £2 12s., and in 1889, £5 4s., loss of stripe for six years, $£ 15$ 12s. ; a total loss of $£ 238$ s.

Mr. Walpole: But then, Mr. Smith, we do not admit that loss of stripe is loss of pay. The stripe is a reward for good conduct.

A. Yes, sir.

Q. And this man's conduct was not good. His attendance was late?

A. Yes, sir; but his income was less too.

Q. I was only talking about stripes.

A. It is a loss to a man if he does not get it.

Q. But a stripe is only a reward for good conduct. It has nothing to do with a man's pay?

A. I admit your point, sir; but at the same time my contention is that the punishment was excessive.

Mr. Walpole: That is quite another point.

Witness : The conduct of Jordan (on the admission of his own Postmaster) has been in all respects satisfactory, and yet, although he has served 12 years, he did not receive his first stripe until April last, and is still being punished at the rate of $1 \mathrm{~s}$. par week through retention of his second stripe. He has made a second appeal for it-up to the present unsuccessfully: (I am now told that it has since been granted.) He makes three attendances per day, commencing at 6 a.m., and his record for the last six years reads1.890, 9 times; 1891, $15 ; 1892,6 ; 1893,4 ; 1894,2$; and 1895, 2 ; total for six years 38 .

Mr. Walpole: And has no notice been taken of these 38 lare attendances?

A. The man has only got his stripe now, after being 12 years appointed.

Q. You said just now that he had got his second stripe?

A. Yes; but that only recently, and this man has been losing money all this time. Why did the Department keep his stripe from him? If he deserved it he ought to have had it. I have the particulars of cases in which two hours' punishment has been inflicted on men who have been very few minutes late. A man named W. Harrison was onca late 3 minut?s, and his punishment was two hours' extra duty. Allen was a minute late seven times; he also got two hours' extra duty, as did Lee, who was twice late and lost 25 minutes. I have to bring before your notice the case of Evan Rees, town postman, of Barry Port. He has been fined two years' increment and three days' pay for missing; a mail due at 4.30 a.m., and he writes to me: "I can conscientiously say there has been no wilful neglect on my part, and on each occasion the failure was due to my having overslept myself."

The Chairman: How often did he miss the mail?

A. Twice, my lord.

Q. Was he taking letters to the mail then?

A. Yes; he was a mail messenger. He had missed the mail on two oceasions, and at the time he was fined three days' pay, which I consider sufficient without being fined two years' increment.

Mr. Walpole: Is that an apparatus station, or was it merely a case of taking letters to the mail?

A. I cannot say.

The Chairman: But his missing the train involved the delay of the whole mail? 
A. Yes, my lord; and that is another consideration of the importance of the postman's duties.

The Chairman : Oh, yes.

Mr. Walpole: We are on another matter just now.

The Chairman: It is also a demonstration of the importance of a postman failing to do his duty.

Witness: The next case is that of Philip Briers, town postman, of Loughborough, who for late attendances amounting to 40 minutes was required as punishment to perform a Sunday morning delivery of 3 hours and 50 minutes. He has also been informed by his Postmaster that in case of any more late attendances his good conduct stripe will not be recommended. Mr. Walpole: Do you know the date of that?

A. I have not the date, sir, but there is nothing behind it; it is quite a genuine case. The men held a meeting of indignation about the punishment meted out to this man, and I have had several letters on the subject.

Mr. Walpole: I will take the name. I should like to look into the case. Let me look at the letters you have on the subject

Witness: I have numerous other cases in which we say the punishment has been excessive. I am informed one man's stripe was arrested for losing the mail ; one man's increment and stripe were arrested, and he was six days' fired-one, two, and three days respectively-for losing the mail arriving at $4.25 \mathrm{a} . \mathrm{m}$. on four occasions; one man's increment was arrested for six months, and he was fined one day's pay for putting a letter under a door where there was a letter-box.

The Chairman: You had better give us your most typical cases.

Witness : I have a good number.

The Chairman: I do not think you will strengthen your case by giving innumerable illustrations. If you give us three or four typical cases, that is all that is necessary for our purpose. Just give us selected cases which will bear out your statements.

Witness: Well, here is a case from Oldham, which I really think is a very hard case. Postman W. E. Jones has had two stripes withdrawn on the charge of losing a registered packet. On returning from his delivery on August 3, 1893, he reported having a registered receipt for which he had no registered packet. Search was made for the missive, but without success. Two days afterwards the packet was found in a wall box quite clean, and bearing no marks of rain. On the particular morning-the postman goes on to state-when the packet is supposed to have been lost, it rained heavily, and was very dirty underfoot. Further, the packet was found in quite another direction to the postman's walk. The case was reported to headquarters, and the verdict given before the postman had an opportunity of making any explanation on paper. It is now over two years ago, and he has made two requests that the case be reconsidered. The postman states that he did not handle, or even see the registered packet until its restoration.

Mr. Walpole: But he handled the receipt for it?

Witness: Yes, and I will take even the Departmental view of this case, and will say that the man signed for the letter. The man says himself that he has not seen the letter, neither did he sign for it. I have come to the conclusion that he must have left it in the office, and even taking the view that as soon as he signed for it he became responsible for it - the Department is responsible to the public, and the postman is responsible to the Postmaster if anything goes wrong-I do not see any necessity why the Department should take away a stripe from the man. The method of reporting a man is one which ought to be condemned. Very often an anony. mous person writes a letter to the Postmaster to the effect that Postman Soand-so, doing a certain thing. The Postmaster says to the postman, "You were seen doing it." The postman denies the charge, but is refused the name of the informant, which the Postmaster declines to divulge, and the result usually is that the postman is severely punished on a complaint against which he has no means of defending himself. I consider that no court of 
justice, and, indeed, no other tribunal in England would convict any man, or body of men, on such evidence.

The Chairman: But this man whose case you are referring to, was, so to speak, self-convicted; he signed for the letter and then did not deliver it. Witness: But he denies ever having seen the letter.

The Chairman: But still, prima facie, there is a strong case against the man.

Mr. Walpole: I will look into the case. I feel sure the punishment was not given for simply losing a registered parcel.

Witness: I thought there was something behind the case, and I wrote for further information, and I got it by express letter the other day. I am really not surprised at anything that Postmasters do.

Mr. Walpole: But your own experience has been very favourable?

Witness : Yes, in my own office. I have had a case brought before me where the Postmaster acted as matrinonial agent.

The Chairman : The Postmaster?

Witness: Yes, sir; and I consider it a gross breach of the rules of the Service for a Postmaster to interfere between a postman and his sweetheart. I have here a copy of the letter sent to me by the postman, and also of the one written by the Postmaster of Widnes to the young woman. Here is a case which I wish to bring before you to illustrate the custom which is becoming general of compelling the men to proceed from the office in single file. The Postmasters in certain towns insist on the men all leaving the office together, and in single file. They have all to be ready at the same time, and when the word is given for despatch they have to march out in order. Now, it is really an impossibility for all the men to be ready at the same moment. There are some who have two or three times as many letters as others. Those who have the smaller quantity of letters to deal with are, of course, ready first, yet they have to wait until the others have completed their sorting, in order that they may emerge from the office in single file. This often puts the men to great inconvenience; it makes them lose trams and 'buses in towns where they are allowed to ride free. I have a case from Tunbridge Wells, where the men are obliged to walk through the streets to their respective walks in single file. They are subjected to ridicule consequently from the public, and, as there are some young men amongst them, they resent that ridicule. On one occasion, according to the report I have received, two senior auxiliaries walked out of the line, and were reported by a sorter-clerk who had been sent out for the purpose of watching them. The result is that these two auxiliaries have been refused any promotion, and they have suffered great punishment thereby. I do not propose to go into all the cases I have had submitted to me, but I will suggest that if there is any charge I have made, or anything I have said, which you do not think I have substantiated by facts, I shall be pleased to answer any questions any member of the Committee may wish to put to me.

Mr. Walpole: The gist of your evidence is that the Department ought to lay down strict rules measuring the exact punishment for late attendance?

A. Yes, sir.

Q. Did you hear Mr. Boaler's evidence?

A. Yes, sir.

Q. Did you hear him instance the case of a postman who was late on several occasions in consequence of the illness of his wife?

A. Yes, sir.

Q. Do you think it would be fair to punish in the same way a man who was late through serious illness at home, and a man who had no excuse whate $\overrightarrow{\mathrm{ve}}$ for being late?

A. That is a matter which the Department must guard itself against. of course these things are open to great abuse. If I were late in the morning, and felt I had a good excuse, I should avail myself of the opportunity. If the Department would lay down a rule which tould enable 
a man to know that lateness would mean loss of stripe, or would prevent him getting one, he would endeavour to keep good time. In the majority of cases illness does not stop the men from going to their walks; indeed, the Department will not accept it as an excuse. In fact, we do not know what excuse the Department will accept. I do not think it will take any.

Mr. Walpole: I am only asking whether it will not act harshly in many cases if the Postmasters are allowed to exercise no discretion in late attendance where there is really a bona fide excuse?

A. We do not wish to curtail any discretion on the part of well-intentioned Postmasters. We wish all possible latitude to be allowed to those who understand the government of men, but we want restrictions put upon those who control the men under them with undue harshness.

Q. But if the Department laid down absolute rules never to be departed from, would not well-intentioned Postmasters, as well as other Postmasters of whom you do not think so well, be bound to follow the rules strictly?

A. Yes; and that would be better than leaving the men at their mercy.

The Chairman : You would like a fixed rule laid down as to the maximum punishment to be given?

A. Yes, my lord.

Q. With regard to the minimum punishment, you would leave that to the discretion of the Postmasters?

A. Yes, my lord; I believe that harshness has been tried long enough, and that the time for kindness has arrived. I made a statement just now to the effect that hundreds of men are waiting for their stripes. This is from personal observation. Men are never informed whether or not they will get their stripes. They may make inquiry of the inspector, and he tells them that he does not know ; then they may apply to the Postmaster's clerk, and he can give them no information; in fact, they are kept in the dark, and it is like having a sword suspended over their heads. I do not think this is good for the Department. I have here a letter I have received from Worthing, where nine men are waiting for their stripes, and can get no information about them.

The Chairman: Are a good many men waiting for their stripes at Newcastle?

A. Yes, my lord. I will now give you some typical cases of men being reported by anonymous writers. Here is a case of a man engaged as a sub-office postman, who has been deprived of his good conduct stripe through being reported for intoxication. His name is Nevins, and the facts are these : Shortly after Christmas Nevins received a report from our Postmaster saying that he (the Postmaster) had been informed that on Bank Holiday Nevins had been seen in the public streets in a disgraceful state of intoxication. In reply, Nevis admitted having had some drink, and that whilst off duty, but he emphatically denied being drunk, and offered to name several credible witnesses in proof of his assertion. Nevins had the report returned to him, on which the Postmaster had written that the plea of being off duty could not be accepted, as whether on or off duty he was still a postman. He was also asked if he had anything further to say for the information of the surveyor. Nevins repeated his previous statement, and shortly afterwards he was informed that he was to be punished by the loss of his good conduct stripe, this being the decision of the Postmaster-General. Nevins considers that he has been most unfairly dealt with. $\mathrm{He}$ has requested the name of the informer who gave evidence against him, but this is refused by the Department. He has petitioned the Postmaster-General to have his case reconsidered, and has received in reply the information that the Postmaster-General is unable to alter his decision. Whatever may be thought as to the truth of Nevins's statement, there can be but one opinion as to the most unfair and un-English-like policy of punishing a man without letting him know the name of the person who has given evidence against him.

Mr. Walpole: Why, in the case of a man charged with being drunk in the streets, is it necessary to produce the witness? 
A. If I were charged with knocking a man down, do you think it would be fair for me not to be brought face to face with the informer, so that I might know where the information came from? Do you think it would be right for me to be convicted on evidence which I could not test?

Q. The two cases are not, I think, parallel. One is a question whether a man was or was not drunk; that is not like a question of assault.

A. The man said he was not drunk.

Q. But when a man who is charged with being drunk admits he had had drink, it is.

A. I beg your pardon; that is not the question at all. I have been charged with drunkenness, and have never tasted intoxicating drinks in my life. I am a life-long teetotaller.

Q. Have you ever been punished?

A. I have never been punished, but if I had not indignantly met my accuser face to face I might have been.

The Chairman: You found out who your accuser was?

A. I did, my lord. I have another case here. A Cardiff man was charged with drunkenness by his inspector. The man indignantly denied it, and brought forward witnesses to prove he was not drunk. He brought forward Mr. Shepherd, the president of the Cardiff Branch of the Postmen's Federation, who was called upon to send in a written statement. That statement completely exonerated the accused. Shepherd was sent for by the Postmaster. In the room with the Postmaster were his wife, his chief clerk, and the chief inspector. The Postmaster asked him what he knew of the affair. Shepherd gave him a copy of the statement, and having read it the Postmaster deliberately tore it into pieces, and told Shepherd he did not believe him. A witness because he gives evidence in favour of a man is practically told that he is a liar. The accused postman offered to bring forward other witnesses to prove his perfect sobriety, but he was not allowed to. Insteat he was called upon to say why he should not be dismissed from the Service. This is only a sample of the treatment the postmen get in these cases, and I think it is time it was stopped.

Mr. Walpole: What date was that?

A. It is not dated. It is the case of Hughes, postman, of Cardiff. I am informed it occurred six months ago. I am awaiting further particulars of the case. Here is the case of a Manchester postman, which is typical of the manner in which postmen are tried and condemned. It is the case of F. W. Dain, who has been an appointed town postman in Manchester for 34 years. He writes:-_ On the 19th Nov., 1895, I was reported for being drunk and using abusive language to a person on my walk. These are the facts of the case:-I was going up his stairs to his office when I caught my foot in the stairs, which are in a very dilapidated state, and grazed the skin of my leg, which brought blood and gave me great pain. Smarting under this, I came out with the words, "Why the devil don't you get the stairs mended?' I admitted in my explanation at the time what I had said, and also that I had three glass of beer that day. But my complainant stated he had seen me drunk many a time. I sent in a petition from about 20 persons and friends on my walk who had known me from 3 years up to 28 years, and who certified that they had never seen me drunk once. I have been over 34 years appointed, and am now turned 58 years of age, and this is the first time I have been reported for an offence of this nature. My punishment has been loss of one good conduct stripe, viz., 1s. a week. I had been in possession of three stripes ever since they were first issued in Manchester."

Mr. Walpole: What is the man's name?

A. Dain. For one report he has been deprived of his stripe. It does not seem to matter who makes a complaint against a man. If the complaint comes from the outside it is taken as Gospel against him, and nothing he can hring forward to refute the charge against him is accepted. I submit 
that as the men are under the control of the Department it should form its own opinion on the evidence for and against, and not merely accept the complaint from outside.

Q. Is it not possible that the Department may have had this man under its eye for many years? I do not suppose you have the same opportunity as we have of knowing the facts.

A. The Department may.

Q. You have not seen the case that was brought before the Department. According to your own showing the man confessed he had been drinking to a certain extent?

A. Yes; he said he had had three glass of beer.

Q. That is his own confession?

A. Yes ; and it is proof of his honesty that he admitted it. He might have said that he had had no beer. Here is another case-that of Postman Thomas Etheridge, who was deprived of first stripe for five years for an offence committed by him during his holidays. It appears that he, with some companions, became a little uproarious at a country-side inn, and, in consequence, was arraigned before the local magistrates and fined. Notwithstanding the fact that the offence was committed by him during his annual leave, and some considerable time before the order was issued warning the post officials, he has been made to suffer the loss of his stripe, the local Postmaster taking to himself the discretion of allowing him the benefit of receiving another when due.

Mr. Walpole: This occurred during the man's holidays, and he admits he was drunk?

A. Well, I consider the Department has nothing to do with a man when he is on holidays.

Q. Don't you think that the Department in awarding stripes for good conduct has to consider what a man's conduct is at all times?

A. Not if he does his duty to the Department. When the Department engages a man they do not buy his body and soul. They buy his labour, and that is what he sells to the Department. As long as he gives that labour honestly and faithfuliy to the Department I do not consider it has a right over his proper time.

Q. But if the Department gives a reward for good conduct, don't you think it has a right to take into consideration his conduct during the whole of the time?

A. No, sir; I do not think it has. This is a question very keenly felt throughout the United Kingdom. If the Department looks at a man's pri. vate affairs and follows up his private life, I think it will prove an encouragement to hypocrisy. If a man knows he can get a stripe by going to church or wearing a blue ribbon, or by joining some religious body, he will be apt to do these things, not because he is honestly convinced that his action is right, but because he thinks the Department will look upon him with a favourable eye. I think it is an infringement of a man's liberty for the Department to consider his conduct when he is out of uniform.

Q. But this is not a case of a man being punished for not going to church. $\mathrm{He}$ was punished apparently for being drunk and disorderly at a public-house?

A. Yes ; and I consider the Department had nothing to do with it. $\mathrm{He}$ was not in Departmental clothes at the time.

Q. Do you know that?

A. Yes; I know that for a certainty. He was on his annual leave at a country-side place. He went into a public-house and got a little uproarious, as a man is likely to do when he is relieved of the restraint of uniform. I have a note here saying that $I$ am championing the "boozers" too much. Now, no man condemns drink more strongly than I do. It is a curse to the country; but $I$ think it is carrying things too far to put a restraint upon a man outside office hours. For instance, suppose I were to go to a friend's 
house to a wedding or to a christening, and they were to prevail upon me to take a glass of whisky. I have little doubt it would make me drunk, and then some officer of the Department might say I was drunk, and I should at once be put down as a drunkard by the Department. It might be the means of injuring one who is an honest and sober man.

The Chairman: Your point is that the Department should not punish a man merely on the strength of anonymous evidence against him?

Mr. Walpole: This was a case of conviction for drunkenness.

The Chairman : That is different, of course.

Witness: It is a case which I should have dealt with under the head of "Citizen Rights."

The Chairman: Supposing a man is guilty of theft at a time when he is not in the employment of the Post Office, would you have the Department look over it?

A. That is not a parallel case. That is very different. A man may get intoxicated but may not violate any law of the land. Yet if he is seen in a state of intoxication that is considered sufficient for the Department to record it against him.

Mr. Walpole: But surely your own view is that the Department must be wise in trying to encourage by all the means in its power sobriety and good conduct amongst its servants?

A. Yes ; I think that.

Q. Does it not add to the reputation of the whole Service?

A. Yes.

Q. And was not the Department wise in noticing the case of this man who was convicted?

A. I do not think it was right in punishing him. I do not think it was wise in that respect. I shall not give any more typical cases, as I have driven home the point I wanted to. But I should like to contrast the punishment meted out to postmen with that awarded to sorting clerks. I am not saying that it is too slight in the case of the latter. It is, I assert, too severe in the case of postmen. This is the case of Postman J. Webster, of Liverpool, with a list of his offences:-Offence, July, 1883, wilfully delayed three letters; first time of misconducting myself after eight years' service. Punishment, deprived of my stripe. Offence, July, 1886, suspended for being under the influence of drink; punishment, removed from my walk and placed among 'junior men' on the 'relief force,' thus being deprived of participation in Christmas boxes, being a great loss to myself and family. I still remain without my stripe, and an additional one is due; in November, 1896, I should get a third."

Mr. Walpole: Where does this case come from?

A. Liverpool. Now, I will contrast his case with some examples of Mr. Freeling's conduct while in the C.B. as second-class sorting clerk:-

"21st Sept., 1891-For having mis-sent 4 letters to Lincoln, and on same date mis-sent 74 letters to Northampton, and on the 24th, 93 letters to Nottingham; punishment, 1 hour extra duty.

"23rd Oct., 1891-Mis-sent 6 letters to Lincoln Sorting Tender, and on the 24th, 6 letters, and on the 25th, 5 letters to the same office, and on the 26th mis-sent 23 letters to Northampton; punishment, 1 hour extra duty.

“27th December, 1891-Mis-sent 36 letters to Wavertree; punishment, 1 hour extra duty.

"28th March, 1892-For neglecting to forward newspapers, etc., to Maghull and Melling when despatching; punishment 1 hour extra duty.

"25th April, 1892-For having arrived late on duty nine times during the quarter ending 31st March ; punishment, 1 hour extra duty.

"19th June, 1892-Missing 6 newspapers to H. and K. packet, and on the 21st, 14 newspapers to Exeter; punishment, 1 hour extra duty. 
“18th June, 1892-Mis-sent 8 letters, 3 post cards, and 3 circulars to Birmingham ; punishment, 1 hour extra duty.

"25th July, 1892-Mis-sent 10 letters to Newcastle-on-Tyne, addressed to various places; punishment, 1 hour extra duty.

"9th Oct., 1892-Failing to forward two bags received from London for Southport on the 6th inst.; punishment, 1 hour extra duty.

"19th Dec., 1892-Mis-sent 26 letters to Wrexham addressed to Bangor; punishment, 1 hour extra duty."

Mr. Walpole: In the case of sorting clerks they have no stripes, have they?

A. No; but they get promoted in spite of the mistakes they make. This man has been taken into the surveyor's office.

The Chairman: You had better return to your case, Mr. Smith.

Witness : Certainly, my lord. I wish to thank you for the latitude you have given me. To prevent any exaggerated views being advanced before this Committee, the Postmen's Federation have made every exertion to obtain reliable evidence. With that object in view we sent letters to almost every Post Office in the United Kingdom, asking for particulars as to their conditions of employment and general grievances. Some of the letters have not been returned, others have been returned in such a manner as to raise suspicion as to whether they had fallen into the hands of those for whom they were intended. One of the letters returned from Formby, a sub-office under Liverpool, throws some light upon the manner in which our private communications have been dealt with. This letter to which I refer was addressed to the senior postman at Formby, and contained the following communication:- "Please inform me for the purposes of the Committee of Inquiry, before whom I am to give evidence-1st, The number of parcels per day to each man at your office, together with their approximate weight, and the longest distance they have to be carried; 2nd, the number of auxiliaries and postmen, their attendance and rate of wages; 3rd, a list of your duties, showing conspicuously duties covering over 12 hours; want of convenient and proper medical attention, or any other matter of which you feel aggrieved.- Yours sincerely, JoHN WALsF, Secretary, Postmen's Federation, Liverpool." The letter was returned with the following intelligent answer written by the sub-postmaster of Formby:-_ "Formby has nothing to do with this agitation. One thing I know, a good many of the postmen are not worth the money they get.-Formby, 12th August.-R. Alexander."

The Chairman : How did the letter fall into his hands?

A. I will explain. We instructed our representative, Mr. John Walsh, of Liverpool, to go to Formby and inquire into this case. His report shows that Mr. Alexander acknowledged opening the letter, and wrote his opinion without consulting any of the postmen. All the postmen were interviewed by our representative, and all of them were quite ignorant of the letter in question.

The Chairman: Why did not Mr. Walsh bring this case forward in his own evidence?

A. This portion of our case had been placed in my hands, and the instance I am dealing with comes, of course, under the head of discipline. The men have many grievances that require redress; for example, want of proper accommodation, as they are compelled to sort their letters in a temporary shed erected in the back yard for that purpose, as $\mathrm{Mr}$. Alexander cannot tolerate the postmen going through his house, consequently the men are almost perished. with cold in winter. Empty barrels are provided as seats, the table to sort the letters on is described as being like a potato trough. The postmen have not an official medical officer; they complain of being overloaded with parcels, and insufficiency of pay. Had a postman taken the liberty of opening a letter addressed to another person, he would be liabie to punishment by fine or imprisonment, or both, according to Section 25 of the Post Office Offences Act. In my humble opinion the same punishment ought to be meted out to this sub-postmaster for opening our 
private letter, and so cowardly replying thereto, as we understood from our late Postmaster-General (Mr. A. Morley) that every facility would be given, and postmen would be encouraged to come forward to give evidence. We know not how many Mr. Alexanders there may have been trying to frustrate our efforts.

Mr. Walpole: The sub-postmasters are equally liable to punishment?

The Chairman: Who was this lotter addressed to?

A. The senior postman at Formby.

Mr. Walpole: If the sub-postmaster did open it, it was a very grave offence.

A. Yes, sir. The Postmen's Federation have every reason to thank the Department for the facilities which have been granted them in collecting the evidence.

Q. Was the postage paid on that letter?

A. Yes; it was paid. This is not the only instance of the sort where statements as to evidence have been withheld from the men, and that is the reason why $I$ am bringing this case forward.

Mr. Walpole: I will inquire into the case. Of course this could not have been done at the wish or with the knowledge of the Department?

Witness: I do not wish to impute anything against the Department. In fact, speaking on behalf of the Postmen's Federation, I may conscientiously say that the Department have not interfered in any way with our getting information. I have thought it my duty to take care, on behalf of the men I represent, that the conduct of this Postmaster should be brought before the Committee.

Mr. Walpole: You said he was a sub-postmaster just now?

$A$. Yes; he is a sub-postmaster, but the men are under him.

The Chairman : It is not a very big office, is it?

A. No.

Mr. Walpole: He is probably a local tradesman.

A. Yes, he is. There is also the question as to the shelter afforded for the men.

The Chairman How many men are there under him?

A. Ten, I believe. The papers that were sent out to collect information contained the following questions:-(1) State the number of times late in a year which debars a man from getting his increment; (2) State the number of late attendances in five years which debars a man from getting his stripe. Out of 286 replies receired there are 230 who cannot give the desired information, and only 56 offices where the men have any knowledge as to the number of times they have to be late before their increment or stripe is arrested, and these vary from 4 to 24 for arrestment of increment, and from 25 to 60 for prevention of receiving stripe. This state of affairs is manifestly unfair to the men, and is not at all creditable to those responsible for the maintenance of discipline, nor yet is it to the interest of the Department to allow men who are performing an important public duty to remain in ignorance of the penalty they incur by unpunctuality, or any other irregularity that may be punishable. Rule No. 8 in the Postmen's Rule Book, under which punishment for late attendance is served, is of such a vague character as to give little short of infinitive power to local Postmasters in administrating punishment for this sometimes unavoidable offence. So long as this rule exists, the comforts and happiness of postmen's homes will be at the mercy of the fluctuating temperament and erratic judgment of the many arbitrators. As to the vagueness of this rule, line 3 reads :- "A late attendance beyond one hour will be specially dealt with." Here unbounded authority is lavished into the hands of the official authorities. Again (Clause C) says :- "All cases of late attendance will be specially noticed, and if they should be numerous and without excuse they may lead to the arrestment of annual increment, etc." How are we to know from this abstract language the number of times they countenance as numerous or the kind of excuses 
they consider plausible? So far as we are concerned, it is immaterial as to the cause of late attendance; a certain number of times late entails always the working of extra time minus pay-in addition to stoppage of increment and exemption from stripes.

The Chairman: As I said before, I do not see how it is possible to put all late attendances on the same footing, and that is where it seems to me your argument breaks down. I do not see how the Department can say that so many attendances shall involve a certain punislıment, because there is great variety between late attendances and the length of time a man may be late. It may be the case that he does not get up sufficiently early in the morning, and it may be that he delays a collection through some unforeseen event.

Witness: Yes; but the Department at the present time do not take into consideration anything a man may urge against being fined.

The Chairman: I am not able to say whether that is a fact or not. It is not what the Department says; it wishes its representatives at the various offices to take all these things into consideration.

Mr. Walpole: Will you accept it from me that I have discussed this matter with some of the leading Postmasters, and they assure me that they do take these things into consideration in dealing with these matters, and awarding the fines. They tell me they do take care, where a man is not wilfully or culpably late, to mitigate the fine, and where the lateness is wilful or inexcusable they increase the fine.

Witness: You put the question to me in a very unfair manner.

Mr. Walpole: I have not put a question. I have merely made a statement.

Witness: You put me in a peculiar position. My experience teaches me that what occurs is quite different.

Mr. Walpole: But you admit that your own experience has been favourable both in regard to your late and your present Postmaster?

A. Yes; in respect of receiving applications from the men. I do not think that a man ought to work more than 8 hours a day. If he does not get a natural rest he cannot return to his work in due time next day. I have been informed that 12 times is the official limit for late attendances.

The Chairman: I think it is 16.

Witness: I lrave been informed it is 12 . I can speak from personal experience, and I know that the postmen at Newcastle have been told that 12 times is the official number. We earnestly request that the last four lines in Section A be expunged, as it is totally unnecessary to punish men twice for the one offence. We also ask for the entire abolition of Section C. It is couched in most ambiguous language, a standing menace to all whom it refers to, and one of the greatest factors in creating discontent. In support of this request I may say that no other body of men in the Service is subjected to sucl a rule. It is not to be found in any other rule book. Men who are under one and the same Government, belonging to the same class, and performing work of the same nature, ought not to be governed by different sets of rules. There should be one set of rules printed in one form by one printer. The present plan is to have one set for London and another for the provinces. I hope in the future the Department will have a uniform code of rules for all classes of postmen. We do not crave any privilege; we only want to be treated as men in a proper manner. I have here the book of rules for London postmen and provincial postmen. There are 136 rules for provincial postmen, and only 61 for the London men; thus there is a double number for the provincial men. I cannot see any reason why we sliould not all be treated alike.

The general rules of the Service are embodied in the Book of Rules to head Postmasters - a book to which very few postmen have access. I have been 20 years in the Service, and had never seen one of the extracts which were supplied to me by a postman in another town. Rule No. 1 of this 
book says:- “This book of rules is intended for the use not only of Postmasters, but, so far as may be, for other officers who are equally bound to observe them. As no breach of rule will be excused on ground of ignorance, it is the duty of the Postmaster to take care that his subordinate officers acquaint themselves with the rules affecting their respective classes." Again, Rule 5 says:- "For the purposes of these rules every person is deemed an officer of the Department whose employment is recognised by the PostmasterGeneral." So far as the majority of the postmen are concerned, the general purport of these rules is a matter of conjecture. It may thus happen that postmen infringe the rules of the Service quite unwittingly. Besides, some of the rules in the Postmasters' book admit of an interpretation of an oppressive character. For example, Rule 26 says:- "Although a Postmaster whose whole time is not at the disposal of the Department may be permitted to hold a news agency, he is not allowed to be the proprietor, either wholly or jointiy, of any newspaper, or to take part in editing one." The same rule also states:- "The permission to hold a news agency does not extend to postmen."

\section{"THE POSTMAN'S GAZETTE."}

This rule, under a reactionary Postmaster-General, might be construed as prohibiting postmen from having any connection with the press. We view the existence of such a rule with some apprehension, as we don't know how soon it might be cited as the authority for suppressing the "Postman's Gazette." I may explain, my lord, that the "Postman's Gazette" is the official organ of the Postmen's Federation. Its articles are written exclusively by postmen, and do not, I hope, exceed the bounds of fair criticism. Moreover, the "Postman's Gazette" has always striven to inculcate in the minds of its readers a sense of the duty they owe to the State and a spirit of loyalty to the rules of the Service. The "Postman's Gazette" is not a newspaper in the ordinary sense of the term. It is edited by a postman, and published fortnightly for circulation among officers of the Department only. It is not for sale to the general public. In fact, so far as those responsible for its issue are concerned, such a practice is condemned, and were it known that any postman sold "Gazettes" to the public his action would at once be repudiated, and immediate steps taken to stop further supplies.

The Chairman: Surely there has been no attempt to interfere with your "Gazette" or with the part postmen take in it?
A. Yes, my lord.
Q. Are you sure?
A. Yes.

The Chairman: What is the complaint you have against your own superior officers in regard to this?

A. Under that rule?

Q. Yes; I want to know what has been done under that rule?

A. They have been called upon to give explanations.

Mr. Walpole: Who has been called upon to give explanations?

A. Those who have been in connection with the "Gazette," sir.

Q. What explanations have they been called upon to give?

A. As to why they had connection with a newspaper. We contend that it is not a newspaper in the ordinary sense of the word.

The Chairman : Are you certain of your facts?

A. Yes.

Q. You have not given us any instances of interference with you.

A. I will give you the facts of the case in writing, my lord.

The Chairman : All right.

Witness: I may inform you that the information I got was confidential, but all the same it is authentic, and I can vouch for the accuracy of my statement. 
Sir A. Godley: Do you wish us to understand that you have no access to the rules?

Witness: Well, I think the men can see them if they make application to the Postmaster; but the majority of them are not aware of the existence of this rule book. I say I have not seen it all the time I have been in the Service. Perhaps I may be partly to blame for not sending in an application to look at them; at any rate, I have not been conscious that such a book was in existence.

The Chairman : You have been a very good officer; you are at the maximum of your class; you have got two good conduct stripes, so that your lack of knowledge of the existence of the book has not interfered with your progress very much.

Witness: I may have been a very lucky individual. Here is another man who has been in the Service 25 years, and has never seen it.

Mr. Walpole: What?

A. The Postmasters' Rule Book.

Q. He has seen the Postmen's Rule Book, has he not?

A. Yes; but many of the rules in the Postmasters' Rule Book are not in the postmen's.

Mr. Walpole: Don't you think it is a great advantage to the men to have this small book, which contains all that is necessary for their information, instead of the larger one provided for Postmasters? I am ashamed to say I have not read through the larger book myself.

A. The rules I have quoted are not in our rule books at all.

The Chairman: But you will remember that Postmasters have a great many duties to perform which do not relate to postmen at all?

A. This postman says that the rule he quoted did not refer to Postmasters alone, but it referred to all the officers of the Department.

Mr. Walpole: The object is to save the postmen the trouble of reading a voluminous book of which only a small fraction refers to them.

Witness: But I have quoted a case in which a postman has been called upon to give an explanation as to a matter which was not contained in the rule book supplied to him.

Mr. Walpole: Can you give us any case where a postman has been punished, or even called upon to give an explanation for breaking a rule which is not contained in his own book of rules?

A. Yes. A postman at Widnes, in Lancashire, took a licence out for a public-house, and put his brother in to manage it.

Q. Is he the licensee, then?

A. Yes; that man has never seen the rules.

Q. What happened to him?

A. I am quite aware that a rule on this matter does appear in the rule book, but this man had never seen it.

Q. Do you say he had never seen the rule book supplied to postmen?

A. He says he has not.

Q. Are not the rules available for all postmen?

A. Yes.

Q. And can be seen in all offices?

A. I do not know.

Q. Is it not the presumption that every postman has access to these rules?

A. I presume so.

Q. And is not one rule to the effect that you are forbidden to be connected directly or indirectly with the ownership or management of a publichouse?

A. Yes; but I say the man was ignorant of the rule, and he cannot be expected to act on presumption.

Q. But you were complaining that this man was punished for breaking a rule in the Postmasters' book which he had never seen, and I am pointing 
out that the rule is contained in the postman's own book. Is that not the case?

A. My point is that the man was in actual ignorance of the rule. $\mathrm{He}$ did not know that it existed.

Q. Is it not your business as a town postman to be acquainted with the book of rules?

A. I cannot become acquainted with the rules if I have no access to them.

Q. Have you any doubt that it is a practice in every post office that the postmen shall have access to the rules?

A. It may be the practice, but this man tells me he never had the book; I do not know why, and I do not know whether it has now been supplied to him or not. I was five or ten years in the office before I got a book of rules.

Q. You had access to them, I suppose?

A. I cannot say that I had, but I may have had access, and I did not think there was any necessity to see them. I had no idea what the rules of the Service were until a book was supplied to me.

Q. Is it not the case that every postman actually signs the book of rules and puts his signature to this: "I have carefully read these rules and understand them?" Have you any doubt that this man at Widnes did that?

A. I have grave doubt. He says he had never seen the book. I may tell you the books were never received until about three years ago, and I was all that time in the Service without seeing any rules. I simply signed a declaration that I would not steal, or open letters, and that was the only rule I was acquainted with. Being such an exemplary character, I managed to steer clear of everything. (Laughter.) We therefore feel some justification in asking this Committee to recommend that such antiquated rules be rescinded. We also desire that better opportunity be given to postmen to know the rules which they are required to observe.

\section{GOOD CONDUC'T STRIPES.}

Crood conduct stripes with a special allowance are awarded to postmen who prove themselves deserving after five, ten, and fifteen year's service. Any man who aspires to obtain a stripe must prove to the satisfaction of his supervising officer that his conduct for the last five years has been of an exemplary description, punctual and exact in attending to his duties, diligent in discharging the responsibilities appertaining to his position, which involve faculties, mental and physical, under which might be mentioned assiduity, punctuality, sobriety on and off duty, honesty, tact, civility, unqualified subordination to superiors, avoid violating any of the 136 rules laid down for his guidance, which constantly brings into play the faculties just mentioned, and in all respects prove himself worthy of any honour the Department may think fit to confer upon him. One would think that after a man had successfully served under all these strictures, and received his stripe or stripes, he would be entitled to some consideration, some leniency from the Department he had served so well, but this is not so; the practice appears to be directly opposite, and the utmost harshness is used. I have been inundated with bitter complaints from men who have been deprived of their stripes for some error of judgment. Without dwelling upon the sympathetic side of the hardship imposed upon the man affected, I will endeavour to point out the injustice of adopting such stringent measures. A. has to serve fifteen years; his conduct and time-keeping has been of an exemplary description before his stripes are obtainable; should he, after obtaining his stripes, take one false step, commit some irregularity, in view of which his superior recommends strong punishment, he is immediately deprived of that which has cost him years of much personal effort and abnegation. This entails not only official humiliation and public suspicion, and perhaps to a certain extent evasion, but, worst of all, a reduction of his 
already-too-meagre earnings. This extreme punishment is most unjust, the severity of which not only falls upon the man, but also on those who are depending upon him for their living. I consider that any crime or irregularity committed by a postman that does not warrant dismissal is amply atoned for, and the Departmental dignity upheld, by depriving the offender of his last stripe, and in the case of a man with two stripes offending, his first offence should affect his third stripe; in the case of the offender holding one stripe bis crime ought to be laid against his second, and no punishment should exceed 12 months' duration. This method of distributing the stripes is very unsatisfactory, inasmuch as they are seldom, if ever, given to the men when due. There are hundreds of men at the present time with good records anxiously awaiting for their overdue stripes.

Mr. Walpole: You said that a man was lightly deprived of his stripes? Is it not a fact that a local Postmaster has no power whatever to deprive a man of his stripes, and that every case of deprivation must come before the Postmaster-General?

A. I did not know that. We are learning a lot now about the rules of the Service which we did not know previously. So far as we knew, the Postmaster was the authority in this matter.

Mr. Walpole: As a matter of fact, these cases come before the Postmaster General personally.

A. We deal with the Postmaster, and we know nothing about the Postmaster-General. If we send in a petition we never see the reply of the Postmaster-General. What we do see is the interpretation of that reply by the local Postmaster. We never receive any communication from headquarters, and we have to take for granted that what the local Postmaster tells us is correct. The me cannot obtain any information as to their detention or relief to their apprahensions. They are kept in a state of mental suspense for months, sometimes years, without any satisfactory explanation. I consider this a cruel and unwarrantable action, which could easily be avoided by informing each man as his stripe becomes due whether the report of his conduct sent forward is of a satisfactory nature or to the contrary. Were this done, it would allay much of the present discontent, and add to the complacency of the men.

\section{RECOMMENDATIONS.}

Again I urge the necessity of uniformity in awarding punishments. It is most essential for the well-being of the Service that uniform regulations should be drawn up and issued in book form to every postman, containing all information and instructions appertaining to his conditions of service, i.e., wages, increments, stripes, allowances, pensions, promotions, hours of duty, overtime, holidays, punishments for late attendances, intoxication, and other irregularitiss, methods of appeal, petitions. Much can be said of the advantages of adopting this suggestion; primarily, it will dispel a great amount of ignorance, and enlighten the men as to their prospects; they will be able to see that there is such a thing as promotion for a deserving postman, and know what to look forward to as regards pension. They will be acquainted with penalties for breach of regulations, know how to appeal if dissatisfied with decision of local Postmasters, and petitioners will see the Postmaster-General's reply to their petition, or any exact copy of the same, not the local Postmaster's version.

Now, my lord, the case that I was instructed to lay before you is completed. I have studiously avoided indulgence in extravagant language, or in any way exaggerating the evils strewn in a postman's path. I have strictly adhered to facts, believing that they would convince this Committee better than any eloquence of mine, therefore I consider I would be wanting in my duty were I not to remind this Committee of the keen economising competition that is now raging between Postmasters, each striving for an economic supremacy. The efforts to economise would be laudable were it not that 
postmen are very often the instruments used in this inhuman competition. All punishment duty worked, all increments arrested, all stripes stopped, adds to the economising glory of the postmen's judge. I ask is it right that the true conceptions of economy should be prostituted in this manner? Is it right that the surplus of the Post Office should be swollen by the misdeeds of postmen? Is it right that men should be trebly punished for late attendance, and never get a farthing for overtime worked? Does the severe punishment add to the discipline, contentment, or benefit of the Service? These questions I confidently leave in your possession, believing they will meet with your impartial consideration, and justice will be the outcome of your deliberations. I hope I have been sufficiently concise to your lordshif in pointing out the various recommendations so that they may meet with the sympathy and approbation of this Committee, and ultimately secure recognition and adoption by the Department. Such will cordially meet the object for which I am present before you-that of seeking redress on some of the present ignominies existing among postmen, adding to and strengthening the efficiency and discipline of those of whom I have the honour and pleasure to be a representative.

This concluded the evidence of the witness, and the Committee adjourned until Monday.

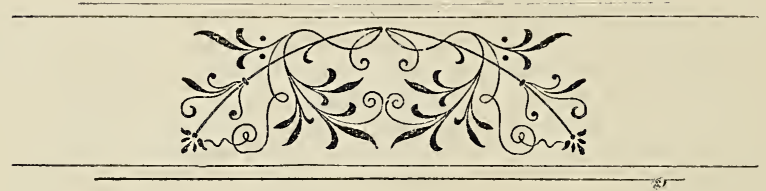




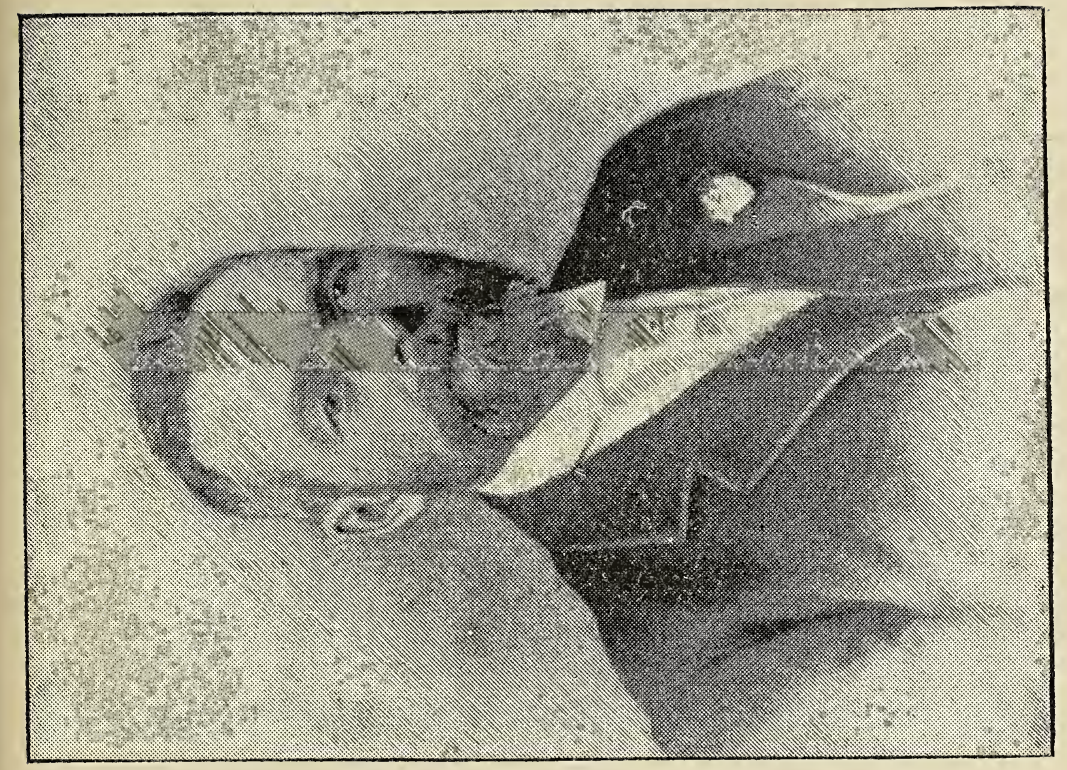

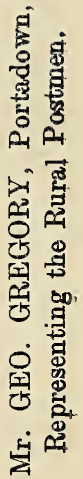

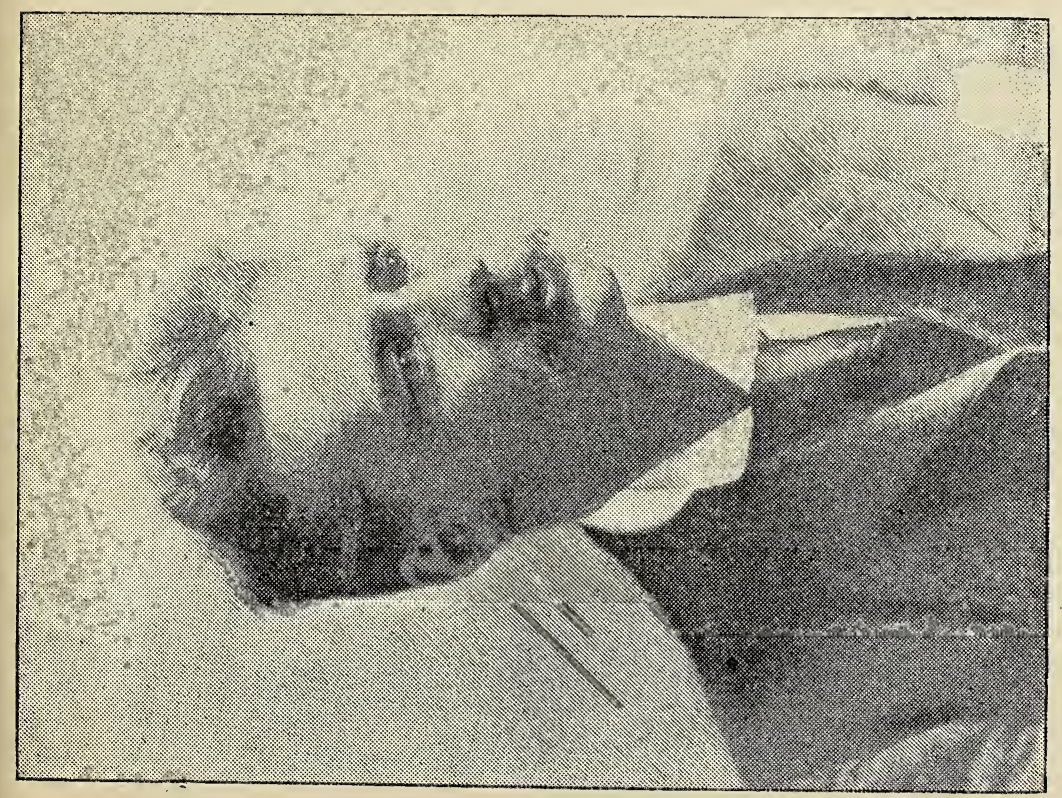

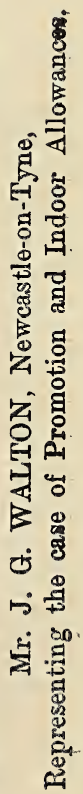



J. G. WALTON, Newcastle-on-Tyme.

\section{Promotion.}

Westminster, Monday, Feb. 24th, 1896.

Mr. J. G. Walton, of Newcastle, was next examined:-

The Chairman: You are going to speak for the provinces, I think?

A. Yes, my lord.

Q. You are a postman yourself ; what is your position?

A. I am a postman acting as a stamper, my lord.

Q. Do you receive any allowance for that?

A. Yes; 4 s.

Q. What do you get as a postman?

A. $28 \mathrm{~s}$. as a postman, $2 \mathrm{~s}$. for stripes, and $4 \mathrm{~s}$. allowance ; in all $34 \mathrm{~s}$.

Q. Is that at Newcastle?

A. Yes, my lord.

Mr. Walpole: What is the $4 \mathrm{~s}$. allowance for?

A. It is the allowance paid to stampers in 2nd class offices.

The Chairman: What are your hours of duty there?

A. We have 8 hours within 12 . The stampers' duties are chiefly late night duties, and we go on at midnight or come off at midnight.

Mr. Walpole: When do you go on yourself? What are your hours?

A. I go on from 12 till 2.

The Chairman: Is that in the middle of the day?

A. Yes, my lord ; and then I go on from 5.45 till 11.45 p.m.

Q. Do you do that always as a regular duty?

A. No, my lord; I rotate through five other duties. The second duty begins at 11.30 p.m. and ends at 7 a.m.

Q. Do you get extra pay for night duty beside what you have already told us?

A. No, my lord; but we work only 50 minutes to the hour on night duty.

Q. You get a time allowsnce in lieu of pay then?

A. Yes. No. 3 duty ranges from 11.50 a.m. till 7.50 p.m. The next duty is 9.30 to 12 , and 2 to 7.30 p.m., and the fifth duty is 1.15 to 7.30 , and 9.15 to 11 p.m.

Q. Are your duties confined entirely to stamping letters?

A. No, my lord; I do a variety of duties. On the night duty I sort forward papers and act as mail messenger and bagman. The other duties are chiefly stamping and mail messenger duties.

Q. Do they keep you pretty continuously at work the whole time?

A. Yes, my lord; it is very leavy work.

Q. Now, you wish to speak about promotion, do you not?

A. Yes, my lord.

Q. In the provinces?

A. Yes.

Q. Are there many such cases of employment as your own?

A. There are a tremendous lot over the country. I believe in Manchester there are over 100 men.

Q. Employed in the same way as you are?

A. Yes, sir ; there are 29 at my own office.

Mr. Walpole: I think you a little exaggerate that. I don't think there is anything like that number.

A. They are classed as office men.

The Chairman: Do you say that there are 29 men of your class on these duties at your office? 
A. Yes; but they are divided into different sections. There are Parcel Post men, porters, station messengers, stampers, and holiday relief men. They are all classed as one, and they are looked upon as stampers. They are simply divided into different sections to do the different classes of work while on duty.

Q. But still doing these duties involves a distinct increase of pay?

A. It is an allowance in lieu of Christmas boxes; that is what it is.

Mr. Walpole: That is what you call it. It is not what the Department calls it, is it?

A. I think it is, sir. I will give an instance that happened 12 months ago. I asked the Postmaster if the position as a stamper was promotion, and he said, "No, it was not." I asked him if it were in lieu of Christmas boxes, and he said, "Yes."

Q. Are these positions very much sought after by postmen?

A. No, my lord.

Q. Don't they like them?

A. In our office the men won't have them. Nine years ago, when I used to sign for these allowances (they only amounted to $2 \mathrm{~s}$. then), the sheet stated that they were in lieu of Christmas boxes. I believe there was a question asked in the House of Commons on this subject, and after that the heading "In lieu of Christmas boxes" disappeared. (Laughter.)

Q. Would you consider that $4 \mathrm{~s}$. was a fair allowance in lieu of Christmas boxes at Newcastle?

A. Well, I do not know about that; it is such a long time since I received a Christmas box. I really do not know what they amount to.

The Chairman : These things are probably talked about in the offices?

A. Yes; I have heard some of the men say that they had 30 s., some say that they get $£ 5$, and some even $£ 10$, but we do not look at it in that light. I may tell you that this subject will be fully dealt with under the heading of "Indoor men's allowances" by Mr. Wright.

The Chairman : Please go on with your statement.

\section{PROMOTION.}

Witness : Promotion in the provincial offices is a very burning question, and on behalf of the provincial postmen I am requested to ask your lordship's honourable Committee to give it due and careful consideration. We as postmen cannot admit that the work of a sorting clerk is superior and in some cases even equal to that of a postman. The postman has undoubtedly the most responsible and arduous portion of the work to perform, especially in large centres, where he is the first and last to handle letters transferred to the care of the Department; therefore we cannot admit of superiority in the sorting of a road to the sorting of a postman's walk. We maintain that, no matter in what light the subject is viewed, in no case can the work performed by sorting clerks be superior to that of a postman; therefore we urge that 2 nd class sorting clerks should not be officially recognised as superior to postmen.

Mr. Walpole: Your argument is that you would not recognise 1st class sorting clerks as superior to postmen?

A. I am not dealing with 1st class sorting clerks, but if it comes to that point I do not think they are. (Hear, hear.) We further contend that the duties, being similar, are of equal value and importance to the Department as those of the sorters, and that if anything the postman is slightly more responsible, inasmuch as he is left to control his own work on outdoor delivery, whilst the sorter is supervised by two or three controlling officers every time he is on duty. Practically speaking, the postman is performing duties of equal value outdoor to the Department, whilst the sorter is performing sorting duties under more favourable and comfortable conditions, not being exposed to the inclemency of the weather, and, under these conditions, we urge that all distinctions, such as sorting clerks and postmen be swept away, and all be placed on an equal footing and respect as between man 
and man should be. I will, with your lordship's permission, draw attention to the official prefix of "Mr." given to a boy sorter, and withheld from a postman of over 30 years' service. A man, having faithfully served the Department, and grown old in the Service, must officially humble himself to address a mere boy as "Mr.," whilst the boy can, with impunity, address within the walls of all Post Office buildings any man of the postmen staff as "Jackson," "Brown," "Smith," etc. This state of official conditions, I submit to your lordship's Committee, is both disrespectful and degrading. In support of this our contention, to show what little difference at present exists between the sorting clerks and the postman's work will be clearly defined under the question of postmen performing special duties. The duties and responsibilities of postmen's work brings into active operation more mental faculties and greater physical energies than that of any other body of men in the circulation department of the Post Office, inasmuch as a postman is the first to receive a letter and the last to dispose of it. He collects the letters, conveys them to the office, stamps and in some cases sorts them. Postmen have to exercise the greatest care in delivering to avoid complaints, :nd, as they are brought directly in contact with the public, it devolves upon them to display a large amount of tact and diligence; they must always be civil and obliging, and possess a sound knowledge of the local district and postal matters in general, and they are responsible for and have to keep a careful record of all changes of addresses, and re-direct all communications to the new addresses. In summer time the postman is responsible for the re-direction of all correspondence during the holiday season, and some postmen have over 50 letters per day to re-direct, and as all money and other valuables sent through the Post Office have to pass through the postman's hands, and all supplies of stamps for town sub-offices have to pass through the same source, he is the sole protector, for the time being, of a large amount of valuable public property, and is still held responsible for its delivery. Other important functions performed by postmen I will not enumerate. I think I have said sufficient to show that the nature of a postman's work is more arduous and responsible than is generally supposed. Now, what is a 2nd class sorting clerk? He is practically nothing more than a sorting postman. When he enters the Service his first duty is general sorting, and then bag opening; from that he will probably be put on to despatch a road, and the most difficult part of his work is that of local town sorting-a class of work that the postmen have at their finger ends. Let me here illustrate what we consider one of the anomalies of the present state of affairs. Two lads enter the Service from similar schools as telegraph messengers, and, we urge, belong to the same class of the community as sorters and telegraphists. At the age of 19 both are appointed on the staff, one as a sorter and the other as a postman; the sorting clerk rises to the head of his class, then passes to the 1st class, next into the rank of clerk, and finally will probably become a 1st class Postmaster at a large salary, retiring on a large pension.

Mr. Walpole : All of them? (Laughter.)

A. A good number do, sir. On the other hand, the postman advances at the rate of $1 \mathrm{~s}$. per year until he reaches the maximum of $22 \mathrm{~s}$. to $30 \mathrm{~s}$. per week, according to the classification of the office to which he belongs, and then goes on all his life at the same rate. There is no advancement for him, and I submit that this, in the best interests of the public service, should be changed. It is unfair; "once a postman always a postman" is a state of things that should not hold good. A man's fitness is the best rccommenda. tion a private employer can have, and why should not this be the rule in the Post Office? Instead of this what do we find? Superior appcintments are monopolised by the sorting force, and the greatest curse of all-favouritism -holds full sway.

Mr. Smith: When showing the identity of conditions under which the two lads entered the Service, you said they were appointed at 19. Now, as a fact, did they not pass the same examination?

A. We want them to have the same examination. 
Q. But that is not a description of existing facts, is it?

A. There is very little difference in the examination for postmen and that for sorting clerks; that is the examination I mean.

Q. The old examination?

A. Yes, sir.

Mr. Walpole: As a matter of fact, at Newcastle, I presume, the Postmaster makes a careful selection from among the telegraph messengers, and picks out those who are best qualified for postmen and those who are qualified for sorting clerks?

A. We find that nearly all the selections come from outside the Department altogether, on the recommendation of squires; they come entirely from that source.

Mr. Walpole: I think you agree with the previous witness that Mr. Hunter was a very fair Postmaster?

Witness : I am not prepared to admit that, sir. I admit that he was willing to meet the men and discuss their grievances, but that is all. We respectfully submit all this should be done away with, and the way to promotion would then be thrown open to all from the bottom to the top. Our views as regards promotion, my lord, are that all positions over $£ 2$ per week should be thrown open to postmen, and not monopolised by one section as at present. I mean 1st class sorting clerks, inspectors, assistant-superintendents, superintendents, and Postmasterships. In large towns inspectorships of postmen are supposed to be given to postmen, but some Postmasters have gone so far as to debar us from even those positions. In Liverpool there are 22 inspectors to 634 postmen, or 3.4 per cent. of promotions. Of these Messrs. Williams and Wilkinson were promoted inspectors from junior 2nd class sorting clerks ; two only of the 22 were admitted to inspectorships when the age of 40 had been attained, viz., Messrs. Tipping and Barrard. The first-named was over two years acting, and passed over by several junior men; he had great difficulty in overcoming the Postmaster (Mr. Rich's) prejudice against age, and I understand the average number of senior postmen passed over by Messrs. Robinson, Wiliams, Wilkinson, Gerrard, Roberts, Goffey, Lambert, Hicks, Thompson, Henderson, Fuller, Matthews, and Raistel would be 250 . Were the reasons in each promotion against these hundreds of postmen stated in compliance with Rule 105 in the Postmasters' Book of Instructions? In the case of Mr. Robinsen, he was placed to act as inspector while yet an assistant-postman of about three years' service; he must have been promoted over more than 300 postmen while having had no experience as to the ways of men, and exercising no influence while a postman. I understand his whole course has been to exercise the power vested in him as-a severe and irritating disciplinarian; he is disliked more than any inspector in Lirerpool by the men under him.

Mr. Walpole: Is this at Liverpool?

A. Yes, sir.

Q. And is Robinson the man's name?

A. Yes ; Mr. Robinson.

Q. And you say he was promoted to an inspectorship after three years' service?

A. Yes, sir.

Q. How long ago was that?

A. I have not the date of it, sir.

Q. He was promoted straight to an inspectorship?

A. Yes, sir. In the case of Mr. Hicks, the Postmaster-General, in answer to a question in the House of Commons, stated that Rule 105 had been complied with, and Mr. Hicks was the fittest candidate. The rule is :-

(Copy of Rule not in present Postmasters' Rule Book, issued for the enlightenment of the staff) :-

On page 105, Postmasters' Book of Instruction-“ Except to clerkships of 1st class, all promotions from class to class, whether in the major or 
minor establishment, are governed by seniority, combined with full competency and good character.

"Thus, on a vacancy occurring in a higher class, not being the 1st class of clerks, recommend for promotion that officer of highest standing in the class next below, who is qualified for the efficient performance of the duties of the higher class, and has conducted himself with diligence, propriety, and attention in his present class to your satisfaction.

"If, on the other hand, you feel it incumbent upon you to recommend some officer other than the one of highest standing in his class, furnish a tabular statement after the following specimen, giving the names and dates of appointment of those you propose to pass over, and your reasons. These reasons must be stated with precision in the column set apart for observations, such entries as "scarcely qualified," "has not given satisfaction," being insufficient in so important a matter."

The tremendous discrepancy between the prospects of postmen and clerks was shown to Mr. Rich about five years ago, and he said men should be trained into supervisors from an early age. He stated as to Mr. Meals, now chief clerk of Manchester, I believe, "Mr. Meals would be less favourable to you than I am." Mr. Meals replied, "I would not, if I had my way, promote postmen even to inspectorships." The witnesses of this are Messrs. George Lunn and John Dodd.

Mr. Walpole: When was this?

A. Five years ago.

Q. What was the occasion?

A. My statement will show that. Mr. Lunn was a senior postman, and acted at one spell for two years as assistant-inspector, but, being passed over by several junior men, he asked, when withdrawn, if he had given satisfaction, and was told he had. Mr. H. H. Parrot acted as inspector eight years, and was repeatedly passed over by juniors.

Sir F. Mowatt: Juniors in what?

A. Junior postmen in the Service.

Mr. Smith: Do I understand that your claim is that promotion to inspectorship shall be by seniority?

A. Yes, sir; with competency. Mr. M. Wilson, a well-educated and long service officer, has repeatedly acted as inspector, but has been passed cver by men he assisted to educate. Mr. John Dodd has acted as inspector, but has been passed over by juniors. The method, then, in Liverpool, has been for 19 years past to put senior postmen out of bounds for promotion, so that no postman is eligible if over 40 years of age.

Mr. Smith: You state that a senior man, even if he is efficient, is passed over?

A. Yes ; even if an efficient man.

Q. But not necessarily the best man?

A. I say if he is an efficient man to take up the position of inspector he is passed over.

Q. But he may not be the best man, and in that case he would be passed over. Is that so?

A. Quite so.

Q. You would take him even if he were not the best man? Is that so?

A. Quite so. It should be governed by Rule 105 in the Postmasters' Book of Instructions.

Q. You would take the senior man, although he might not be the best man?

A. If the senior man is an efficient man, and able to do the duty, he naturally thinks he is entitled to the position.

Mr. Smith : Just so.

Mr. Walpole : But is there to be no reward for special merit?

A. Well, that is where the opportunity for favouritism comes in, in what is termed "special merit" in the Service. 
Q. I presume there is such a thing as special ability, is there not?

A. Quite so.

Q. And do you think that should go for nothing in the Service?

A. Well, I have not seen much of it among the postmen.

Mr. Smith: You say there is no special ability among the postmen?

A. Of course we have clever men among postmen-some of the cleverest in the Service-but they have no chance to show their ability.

Mr. Walpole: You referred just now to your late Postmaster, Mr. Hunter?

A. Yes, sir.

Q. How did he begin life?

A. As a postman in Liverpool.

Q. And did he not rise to a very high position in the Department?

A. Yes; I believe after being a postman some time he became a sorter, and then went out as a postman again.

Q. But he has not passed all his life as a postman?

A. Not much of it.

Q. He was some time of his life a postman?

A. Yes.

Q. And he rose to one of the highest positions in the Department?

A. Quite so; but when he entered the Service a very different state of affairs prevailed then to now.

Mr. Smith: According to your plan he would not have been able to do this unless through seniority?

A. I take it that according to the Departmental plan his appointment was by seniority.

Mr. Walpole: Which appointment?

A. The Postmaster's appointment. I believe that such appointments went by seniority when Mr. Hunter was appointed.

Mr. Walpole: Do you mean that Mr. Hunter was senior postman before he was made sorting clerk?

A. I presume so, sir. He was but a very short time a postman, then he went in as a sorter, and then came back again as a postman.

Q. And after that he became something else?

A. Yes.

Q. Do you think he was senior postman in the Service?

A. Prior to 1865 there was no distinction between the two classes. If we go back 50 years at Newcastle we should find, I believe, there were only 10 postmen, whereas we have now 153. Fifty years ago it would not take very long to become senior postman, and you did not want many supervising officers in those days. To show the kind of promotion postmen get in liverpool, when six sorting postmen were appointed sorting clerks they each forfeited 7s. per week allowance. In Cardiff, during the past few years, there have been five vacancies for inspectorships. Postmen made written application for these, and-and I wish to emphasise this-never even received an acknowledgment. Sorting and telegraph clerks from other towns were appointer. The present inspector was a telegraph clerk-an assistant. Mr. Dennis was never in the Service before he came to Cardiff; he was employed as a 2nd class sorting clerk for a few months, and then appointed as assistant-inspector. This gentleman, I believe, came from the same part of the country as the Postmaster; a third inspector was a sorting clerk at Newport. In Cardiff there are about 150 postmen, and I ask-Are all these men totally unfit for promotion?

Mr. Walpole: Who is this gentleman you are referring to?

A. Mr. Dennis, an inspector at Cardiff.

Q. Was his case mentioned on a previous occasion?

A. Not that I am aware of, sir.

Q. Do you know where he did come from?

A. I think somewhere not very far from Cardiff; I can get you the information. 
Q. If he came "not very far from Cardiff" he could not have come from the same country as the Postmaster?

A. I am informed that it was the same part of the country.

Q. But the postman came from a place a long way away from Cardiff?

A. Yes, Worcester, I believe. It has never been known for a postman to be promoted at Cardiff. I can give other cases where postmen have applied for positions as 2nd class sorters, and the treatment they have received, but I fear I would detain the Committee too long if I gave them all. I will take Brighton as an example. The present Postmaster of Brighton, Wilson A. Hetherington, Esq., in reply to the question "How many Brighton postme had been promoted during the past five years?" gave the number as four. We have analysed these four cases of promotion. The names of the postmen (promoted during the past five years) are Mr. A. Mantell, Mr. J. Mantell, Mr. F. Dunstone, and Mr. W. Stenning. We have nothing to say regarding the cases of Messrs. A. and J. Mantell. We believe them to be genuine cases of promotion. For reasons given below we think the cases of Messrs. F. Dunstone and W. Stenning are not quite clear from the suspicion of influence. First I will take the case of William Stenning. This man entered the Brighton Office some years since-roughly speaking from five to seven years ago. For a short time he did parcel delivery work, and afterwards letter delivery. After that, and for some considerable time, he performed indoor duty in parcels depot. While working upon this indoor duty he received an appointment as town postman. I may say, my lord, with reference to this case that I very much regret having to refer to it. But we have evidence showing the state this man was in when he was appointed sorter. This would be about four years ago. From the date of his appointment as town postman until he was promoted to the appointment of sorting clerk, William Stenning never once performed a postman's duty.

The Chairman: What was the object of appointing him as a town postman if he were not to do any of the work? What did he do?

A. He would be employed in the sorting office, or as assistant clerk, perhaps. Indeed, for months previous to his appointment as postman he had not performed the work of that class. Further, during the whole time of his service he never once wore the uniform. He was eccentric in his behaviour previous to his appointment to a sorting clerkship. After spending several months in the Sussex County Lunatic Asylum he was invalided from the Service.

Mr. Walpole: You say he was eccentric before his appointment?

A. Yes, sir. I am sorry to illustrate this case, but our evidence proves that this man was in an unfit state when the Brighton Postmaster appointed him as 2nd class sorting clerk.

The Chairman: What was the motive of the Brighton Postmaster?

A. Favouritism. It seemed a very strange thing to appoint him to do responsible work when he was only fit for an asylum. This clearly proves that this Postmaster does not pick the best men. He picked a man who was very eccentric, and who used to go out into the streets and try to mesmerise horses and that sort of thing.

Mr. Walpole: When did this happen?

A. About two years ago; we have evidence to prove it.

Q. Evidence to prove what?

A. That the man was not in his right senses when he was made a 2nd class sorting clerk.

Q. Have you evidence to prove that the Postmaster knew that fact?

A. I don't know about the Postmaster; no doubt the superintendent did.

The Chairman: Was that the reason he was not sent into the town to deliver letters-that he was not in a fit condition to do so?

A. That would give the postman a more responsible position than the 2nd class sorter. If he could not deliver letters he would not be fit to be a 2nd class sorter.

Mrr. Walpole: It seems to me that your grievance against the Postmaster 
is not that a hardship was inflicted on any particular postman, but that a man was selected who was unfit for the appointment?

A. Yes ; I will prove that. This man, too, was not a senior man. He was a long way down on the staff. He had only been in the Service five jears altogether. Next I come to the case of Frank Dunstone. F. Dunstone was at one time a rural postman at Hassocks gate (under Brighton). He was transferred to Brighton and immediately placed upon sorter's duty. He has never done a day's work in Brighton as a postman. Like W. Stenning, he has never worn the uniform since he came to Brighton. After a year or two on sorting clerks' duties, and after having been rejected by the official medical man, by reason of his heart or something else being affected through rheumatic fever, he received an appointment as sorting clerk.

Mr. Walpole : After being rejected by the official medical officer?

A. Yes.

Q. Then how did he get the appointment without a medical certificate?

A. I do not know, sir. He might have got another doctor to pass him. It is evident he did get in. After short service as sorting clerk he is given the post of assistant-inspector of postman, a position he now holds. His brother, Mr. Walter Dunstone, is a superintendent in Brighton in the same office. Considering that vacancies on the sorting sheet are never advertised, how is it possible by means other than that of influence for a rural man to be brought in, as Dunstone had been, and placed immediately on clerical duties? Certainly not by reason of any dearth of postmen material in Brighton that could be utilised for the filling up of vacancies such as these. So much for promotions from the ranks of postmen during the past five years. I shall refer to F. Dunstone again when dealing with the cases of inspectorship and assistant-inspectorships of postmen. Since the death of Mr. Corney, late inspector of postmen, Brighton, about eight years ago, the post of inspector of postmen here has been filled by Mr. Geo. Wood, one time a clerk there, now Postmaster of Poole, Dorset; Mr. C. Weller, one time a sorting clerk, now assistant-superintendent; and Mr. F. Antram, one time a sorting clerk, 2nd class, then assistant-inspector, and finally inspector, a post he is now holding and has held since Mr. Weller's promotion. The post of assistant-inspector has been created during the past two or three years. Nothing was known about this until the post was filled. Afterwards they learnt that applications for this post had been invited from the 2nd class sorting clerks ; that Messrs. Coleman, Dunstone, and Antram had applied, and that Antram had been successful?

Mr. Walpole: Who was successful?

A. Antram, a 2nd class sorting clerk. When the postmen heard that Mr. Weller had been promoted to the post of assistant-superintendent they at once petitioned for the post of inspector; they at the same time petitioned for promotion generally. The Postmaster granted them an interview, at which there were present Messrs. Braby (E.), Measor (E.C.), Cox (W.C.), Trigwell (Hove), and Barnes (indoor postman). This interview took place some eighteen months ago, therefore we cannot quote verbatim, but this is something like what occurred-" Postmaster said that he would nominate a postman directly for promotion, but gave it as his opinion that the postmen of Brighton had not the education or ability to warrant him nominating any of their number. He also declined to put postmen to a practical test, such as allowing them to work the holidays of the inspector or his assistant. With reference to sorting clerkships promotions for postmen, he did not think that they could pass the new examination. He was immediately asked if he had ever tried a postman at that examination, and if not, how he came to suppose that they could not pass it? He replied that having left school some time they must necessarily forget. He was answered to the effect that all postmen did not forget, and no doubt the men in the postmen's class in many instances knew a deal more than they did when they left school. In conclusion, he stated that he would carefully consider all that the deputation had urged, and that he might be relied upon to do justice in the matter." 
Result-Last October F. Antram, late 2nd class sorting clerk, late assistantinspector, promoted to the inspectorship ; F. Dunstone, late 2nd class sorting clerk, promoted to the post of assistant-inspector; both inspectors are very young in service and in age; both have relations in the Service. F. Dunstone, as previously stated, is brother to one of the assistant-superintendents. F. Antram is the nephew of Geo. Wood, one time clerk, one time inspector, and one time superintendent there. Mr. Geo. Wood left Brighton to take up the Postmastership of Sheerness. He is at present Postmaster of Poole, Dorset. The inspectors' holidays are performed by a 2nd class sorting clerk. So much for the way in which inspectorships of postmen are filled up in Brighton. We will now look into some other causes that have worked, and are working to the detriment of postmen at Brighton. Nearly half the number of sorting clerks at present on the Brighton staff have been brought from other towns; some have been fully established previous to taking local appointments, others have received their appointments at Brighton. Indoor postmen have helped these men, and are still helping some of them towards a proper knowledge of local sorting. An instance of how postmen are inconvenienced by the inefficiency of sorting clerks and learners performing sorting clerks' duties-No. 27 S. clerk and No. 8 indoor postman sort newspapers (local) together from 11 p.m. to midnight, into six divisions (E., E.C., W.C., W., N., and H.P.O.) elementary local sorting. The papers are supposed to be finished before midnight, at which time the postman is booked off duty. The clerk is off duty at 1.30 a.m. Sometimes the S.C., or learner, performing the sorting clerks' duty, knows so little of the local sorting that the postman is called upon to stop half-an-hour overtime (gratis) to clear up the work. The sorting clerk will sometimes call out thirty or forty per cent. of the addresses. The postman takes part credit in any bad sorting. We have seen a postman sorting locals with a learner on each side of him asking almost every address. The postman has his duty to perform, which requires his attention, without having his mind drawn from his work by the questions put to him by lads who will eventually take appointments that are denied him, but which he helps to qualify them for.

At this point the Committee adjourned for luncheon, and on returning

The Chairman (addressing the witness) said: You are going to produce cases of other men in the office whom you consider worthy of promotion?

A. Yes, my lord.

Q. Are you still on the Brighton case?

A. Still on that case. I will take the case of Frederick Paul. After performing duty as a telegraph lad, mail messenger, stamper, etc., Paul entered the Parcel Post Depot 1st August, 1883, where he remained until '1895-12 years. Besides performing sorting and despatching duties during the whole of this time, he has been placed upon clerk in charge or superintendent's duty for several months in the year from 1888 to 1891 . I will, with your lordship's permission, describe the duties he is called upon to perform. No. 3 duty, 5 a.m. to 11.30 a.m., 4.30 p.m. to 6 p.m. He has in that time to open office, receive coach, check bills, deal with charges or registered parcels, total "S." bills for number of parcels delivered previous day, also check sub-office and Brighton bills, responsible for the whole of sub-office bills during day, also "N." bills during time on duty from 5 a.m. to 8.30. Sole charge of depot from 5 a.m. to 8.30 a.m., 4.30 p.m. to 6 p.m., responsible for the whole of the in and out mails. On No. 2 duty, 5.30 p.m. to 1 a.m., he has much the same duty, heaviest despatches of the day to supervise, sole responsibility from 6 p.m. to finish of duty, make all entries in despatch book, any irregularities enter in diary, make up dead bag, supply information for confidential inquiry branch, missing or damaged parcels, etc., and lock up depot at $1.30 \mathrm{a} . \mathrm{m}$. When not performing these superintendent's duties, Paul has been for the last nine years employed on sorting and despatching, making over 70 despatches a day. Recently these superintendents' duties have been made much lighter by the addition of an extra clerk, a 
properly-appointed superintendent has also been placed in charge. When Paul made application for promotion he was refused. He was told that holding a postman's appointment did not warrant him expecting promotion.

Mr. Walpole: Who was he told that by, do you know? Was it by Mr. Hetherington?

A. No ; by the superintendent, Mr. Bennett. When Paul made the application the Postmaster referred it to the chief clerk, Mr. Bennett, who replied that he was a very good man in his way, but not sufficiently qualified for even a 2nd class sorter's position.

Mr. Walpole: That was not the answer given to us just now. You said he was told that, "holding a postman's appointment would not warrant him expecting promotion."

A. Yes; and that was the reply he got.

Q. But you have just now told us that the answer was that he was a very good man, but not qualified for the position.

A. Quite so.

Q. But there is a difference between the two?

A. The facts are these. He applied to the Postmaster in the first place. The Postmaster referred the application to the chief clerk, Mr. Bennett, and Mr. Bennett answered that he was a very good man, but had hardly sufficient qualifications for appointment even as a 2 nd class sorter.

Q. That is a totally different thing from what you put in the body of your evidence?

A. But that is the reply he got from the chief clerk.

Q. How did you get hold of a reply which was presumably confidential, being a conversation between the chief clerk and the Postmaster?

A. I beg your pardon.

Q. How did you get hold of the reply?

A. It was supplied to me from Brighton; but I do not think that that is a fair question to ask me.

Q. But it was presumably a confidential conversation?

A. It is information supplied to me; I can go no further than that. Considering the responsible duties Paul had performed, he was naturally upset over the refusal of his application. Indeed, it preyed on his mind to such an extent that, acting on medical advice, he took six weeks' holiday, visiting various places at great expense to himself and friends.

Mr. Walpole: He took six weeks' holiday? Visiting friends?

A. He went to various places at great expense. His health broke down.

Q. But he went away on holiday?

A. Yes; on medical advice. On his return, still suffering with mental debility, he was forced to go outside-the medical man saying that it was absolutely necessary for the sake of his health. Even then he had great difficulty in getting permission to go out. He has an excellent character, and has never once been booked late in 12 years.

The Chairman: When you talk of going outside you mean to deliver letters?

A. Yes, my lord. Next I will take the case of George Bristow, one time a telegraph lad, mail messenger, etc., now appointed postman (indoor). He, too, has an excellent character. He has performed, besides duties of his own class, from 18 to 20 different S. clerks' duties, and there is not the slightest question as to his ability. He applied for promotion and was refused it. He was told by Postmaster that holding the appointment of postman did not warrant him expecting promotion.

Mr. Walpole : Have you any proof of that? That is the same thing?

A. Y is.

Q. Have you examined into it?

A. Yes; these men are quite willing to prove each case.

Sir F. Mowatt: You say he was told that by the Postmaster, Mr. Hetherington?

The Chairman: Who also told Paul the same thing? 
A. Quite so, my lord; and I may tell you that a late Postmaster at Glasgow made the same statement to a Glasgow postman some years ago. Here is the case of H. L. Barnes. During the past few years he has performed as many S. clerks' duties as any other postman. Nothing is wrong with his character. He applied in answer to advertisement in P.O. Circular, some four or five years ago, for a vacancy of S. clerk at Great Grimsby, and received no reply. He applied for promotion as S. clerk at Brighton some 18 months ago. His application was again ignored.

Sir F. Mowatt: When you use the expression "application ignored," you mean that there was no answer at all.

A. There was no answer at all.

Mr. Walpole: This man saw the advertisement in the Post Office Circular, intimating that there was a vacancy, and applied for it?

A. Yes, sir.

Q. Are you aware that no answer is ever given to such applications? The only answer is the filling up of the appointment.

A. Yes; but nobody knows who gets the vacancy, and a man may be kept in suspense 12 months. If I apply for a sorting clerkship at Hastings in this way, am I to wait 12 months? Yet that is the usual course. No notification is given, and nobody knows who gets the appointment. To sum up, I have shown you that postmen have performed the majority of sorting clerks' duties there, and I have a statement to hand in which shows that postmen at Brighton practically teach the sorting clerks their duties. Bearing this in mind, and also that some of the sorting clerks here have not performed anything like this number of duties, we think that this shows clearly that the argument of lack of ability thrown at them by the Postmaster is untenable, especially as one of their number has performed superintending duties.

Mr. Smith: If the postmen perform all the duties of sorting clerks, and there are from 18 to 20 indoor men, what work are they doing?

A. Counter duties.

Mr. Smith: Then in that case they would be under the head 1st class clerk, and would not be performing sorting duties at all?

A. They are 1st class sorting clerks.

Mr. Walpole: Have they done registration duties?

A. I believe there is a list of the duties performed by them.

Mr. Walpole : As a matter of fact, they have not done registration work?

A. No. Another difficulty, and doubtless, if the truth could be known, the key to all this injustice anent promotion, is the one of "relationship." It is hardly to be expected that local authorities in the provincial offices who may have sons, relations, or friends in the office as learners, are going to recommend postmen for positions which they wish their friends to fill. The son of the chief clerk at Brighton (H. Bennett) is a learner. The nephew of an assistant-superintendent (C. Weller) is also a learner there. These lads, or young men, go into the Service perhaps about 17 years of age; they receive no wages for about a fortnight, and then they are put on sorting clerks' duties. They are what are called learners. At Newcastle we have what are called "half-timers." Telegraph messengers come up to learn, and they are paid 3d. per hour for learning their duties as sorting clerks, but in Brighton it is the other way, I believe.

Sir F. Mowatt: I do not understand your argument.

A. They have never been in the Service before; they are not paid for about a fortnight or three weeks, and then they are put on the permanent staff.

Mr. Walpole: They are kept on as learners until a vacancy arises on the permanent staff?

A. I should like to refer to the case of Bennett. Bennett is always employed on clerk's duties. Weller was placed on the duty of news examiner before he had been in the office two weeks. I do not think that that in 8, duty a boy should be placed on. 
Sir F. Mowatt: Have either Bennett or Weller been promoted?

The Chairman : No ; they have only just come in.

Witness : They came in as learners.

Q. When did they come in?

A. I think with the last six months; I can easily get the information.

Q. Are they learners now?

A. No; they are on the staff now. Only a fortnight elapsed before they were put on the staff. One of them is a news examiner, and he was learning the duties only two weeks.

Mr. Walpole: That is, his duty is to seek for surcharges, etc. ?

A. Yes; and these are duties often performed by sorting clerks.

Sir F. Mowatt: They attended a fortnight, and then went up for examination?

A. No; they are on the staff, but not appointed.

Mr. Walpole : But they are not appointed yet?

A. Not yet; but they get wages.

Q. In fact, they are paid learners instead of unpaid learners?

A. They are receiving full pay-the minimum wage.

Q. Are you certain of that.

A. I understand it is so from the information $I$ have received.

Sir A. Godley: What is the difference between a man appointed and one unappointed?

A. The latter is unestablished.

Mr. Walpole : I suppose that technically he is still a learner acting as a substitute for another man away on leave?

A. He cannot be a learner when he is doing a full man's duty.

Q. $\mathrm{H}_{\Theta}$ is doing duty as a substitute, is he not?

A. I cannot answer that; but the position of news examiner involves duties which are generally done by 1st class sorting clerks. Then there are two other cases-Harris and Belward. Harris came into the office a middleaged man. The Postmaster tried to obtain for him the post of assistantinspector of postmen, but he was too old. He holds no proper appointment, but has been placed on the staff.

Mr. Walpole: Has he got an unestablished appointment?

A. Yes ; as a sorting clerk.

Q. He will never get beyond the small pay he is receiving. I presume?

A. Not unless they can find some other place for him, sir. Belward was first engaged two years ago as a temporary hand during the Christmas pressure in the Parcel Depot. After that he was brought into the sorting office, and immediately placed on bag opening and news examining-a duty which he still continues to perform. He had not the slightest knowledge whatever of the duty when placed on it. $\mathrm{He}$ is old and feeble, and between the age of 55 and 65 . He has been sent home three times for being the worse for liquor. The men say that they can prove this. He is now doing sorting clerks' duties.

The Chairman: What I want to know is this, why have you brought this Brighton case so specially forward?

A. To show the discrepancy existing between postmen and sorting clerks.

Q. Then it is not with the view of making any special charge against the men at the Brighton office?

A. Well, yes; to a great extent it is. These men have applied for promotion which they are competent for, and they are denied it.

Q. Do you allege that in many offices practices are frequent such as you describe as occurring at Brighton?

A. Yes, my lord; and Mr. Wright, who follows me on the same question, will supplement this case by further prooffs.

Mr. Walpole: You mean deliberately to say such practices as those you have described at Brighton ato pretalent? 
A. Yes, very.

Q. In your own office?

A. I cannot say so much for my own office since wo have got a new Postmaster.

The Chairman: We shall hear the other side of the case even as regards Brighton. Do not suppose, because I ask you this question, that I shall take what you say as being a necessarily correct description of what is taking place. Do you allege that in many offices throughout the country promotion is given to men having relations in the office in a high position?

A. Yes, my lord, we can prove it; we have ample evidence. Mr. Wright will bring this out, I believe. He will produce al list of towns where the office staff is largely made up of relations of the supervising staff. He will substantiate a lat of these charges as to the relationship question. I have a case from Hastings which I had intended to bring before the Committee, but as the names have not been supplied to me I will not quote it. My lord, what chance has the postman against such abuse of local power? At Stafford, T. Mountford and S. Powell performed sorting clerks' duties for a long period. They applied for appointments as sorting clerks, and were told they were not adapted for that class of work; in the event of sickness or pressure these men are repeatedly called upon to perform these duties such as they have been informed they are not adapted for. To show the discrepancy existing between postmen and that of every other body of public servants as regards promotion, the following is a tabulated statement of the number of the police force of Newcastle and Middlesboro', and the staff of postmen. This table is to show the difference in the number of promotions open to the police force according to the total number of the force, and the number of the staff of postmen and the number of promotions open to postmen :-

\section{NEWCASTLE-ON-TYNE.}

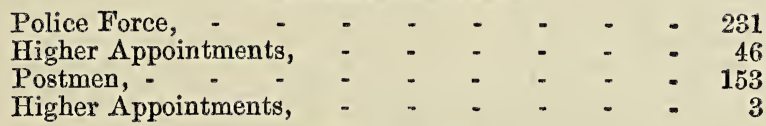

HIGHER APPOINTMENTS IN THE POLICE FORCE.

Chief Superintendent, - - - - - - 1

Superintendents, - - - - - - $\quad$ - 4

Inspectors of Police, - _ _ . . . . 4

Inspector of Detectives, - - - - - - 1

Sergeants, - - - - - . . - 36

HIGHER APPOINTMENTS OPEN TO POSTMEN.

Inspector, - - - - - - - $\quad$ - 1

Assistant Inspectors, - _ _ - - _ . 2

Mrdolesborougr.

Police Force, - - - - - - - - 86

Higher Appointments, - $\quad-\quad-\quad \cdot \quad-\quad \cdot \quad 15$

Postmen, - - - - - - - - - 42

Higher Appointments, - - - - $\quad-\quad-1$

HIGHER APPOINTMENTS IN POLICE FORCE.

Chief Constable, - $\quad-\quad-\quad-\quad-\quad-1$

Superintendents, - $\quad$ - $\quad$ - $\quad$ - $\quad$ - $\quad . \quad$ - 1

Detectires, - - - - - - - - 2

Inspectors, - - - $\quad+\quad \cdot \quad \cdot 3$

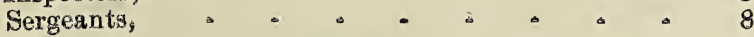

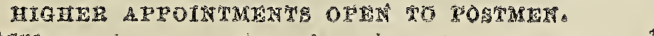


Policemen acting as clerks are allowed 2s. per week in lieu of uniform.

Detectives receive an additional allowance of $10 \mathrm{~s}$. per week; vacancies are filled up by seniority with efficiency.

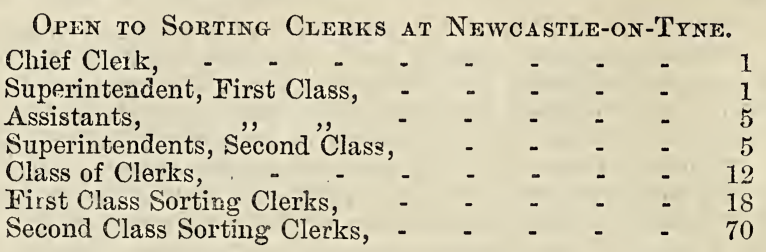

The Chairman: When you entered the Service the prospect of promotion held out was one of the inducements to join, was it?

A. We do not know what the conditions are when we enter the Service. We do not know what promotions are open to us. But Mr. Arnold Morley said, in the House of Commons last May, that promotion was one of the benefits of the Service.

Q. What was he speaking about then?

A. On the Estimates, my lord.

Q. Whai class?

A. The postmen's class, my lord.

Mr. Walpole: No, no, he was not; he was talking about the Service generally.

A. I think he quoted a list of men who had held the position of postmen and had become Postmasters.

Q. Rising to Postmasters?

A. Yes, sir; but you must remembêr that there are sub-postmasters at $£ 10$ a year.

Sir A. Godley: You say that when you enter the Service you do not know what your prospects are?

A. We do not know what promotions are open to us; we do not know because we have no means of finding out.

Q. No means at all of finding out when you enter the Service?

A. No.

Mr. Walpole : You entered the Service as a postman, did you not?

A. Yes, sir.

Q. And knowing what advancement a postman has in his scales of pay?

A. Quito so.

Q. You had no reason to know whether there was any prospect of promotion beyond these scales at all?

A. No; that is not known.

Mr. Walpole: Is that not exactly what you said?

A. Not with refererce to London. I supposse that in the provinces a man naturally has an ambition; he wants to advance. "Once a postman always a postman" is not what he aims at, and we do not think it is right.

Q. Is it not the case that when you entered the Service you knew what were your prospects as a postman?

A. Yes ; but I did not know what else was open to me in the Post Office. When I entered the Newcastle Office there were only 50 postmen employed there. Now there are 153, and promotion does not advance proportionately with the number. I can show yeu a discrepancy between the position of the sorting clerks and the postmen at Newcastle.

Sir A. Godley: Do you think it is usual to enter the Service without making inquiry as to future prospects?

A. Well, new entrants are generally telegraph lads, who have had some opportunity of knowing what is open to them.

The Chairman: What did you expect when you entered the Service as a postman? 
A. I thought I might be a Postmaster some day, my lord, and I have that ambition yet. (Laughter.) Now, my lord, I now draw the Committeo's attention to a revision just passed at Manchester. I find that two 1st class inspectorships have been given to the 1st class sorting clerks. This, I submit on behalf of the Manchester staff, is a monopoly of the sorting office. Looking through the Post Office Estimates for 1895-1896, you will see that out of 398 sorting clerks in Manchester and district, 178 of them are in receipt of over $£ 100$ a year, whilst the Manchester postmen, who number 610 , have only 23 positions ranging. from $£ 100$ to $£ 230$. In connection with the paper on promotion sent us a short time ago from Man. chester, I would like to add that great dissatisfaction prevails here owing to several senior postmen of ability and of good character being passed over by junior men for assistant-inspectorships.

Mr. Walpole: You say "passed over by junior men." Do you mean postmen?

A. Yes, sir; this is taking place at the present time.

Q. Your charge just now was that sorting clerks got the inspectorships; now you say it is the junior postmen?

A. Yes, sir; the chief inspectors of postmen have been created from 1st class sorting clerks, and in Manchester, under the new revision, that reduces the prospect of promotion again. That is the present position of affairs throughout the provinces. Postmen have nothing to hope for, nothing to look forward to, but remain in the same groove for the rest of their career. This we ask your lordship's Committee to remedy. We are of opinion it can be easily accomplished in such a manner that would benefit both the Department and the country. What we would suggest, my lord, is that every man should enter the Service as a postman, and that one examination should qualify him for any position of the Service, as the case with sorters at present. Let every man do so many years as an outdoor postman, and then take up the indoor work according to his sorting capabilities. If such a plan were adopted, we are confident the Service would materially improve; the staff having qualified in all its branches would naturally attain a greater all-round efficiency. It would, in our opinion, be one of the most economical reforms the Department could introduce -and one of the most just and beneficial acts towards its servants. I am specially requested to draw your lordship's Committee's attention to the small number of vacant Postmasterships given to postmen, and would suggest that all sub-offices, both town and country, with salaries of from $£ 100$ per annum, be open to postmen. These could all be made appointments which would be looked upon as promotion for postmen. Mr. Armour, in his evidence on behalf of the telegraph clerks, stated in three years-from 1890, '91, and '92-160 Postmasterships became vacant. Of these 142 were given to the postal branch; not one of these appointments was received by a postman. I have also here a table showing the number of postmen, and the number of promotions open to them.

Mr. Walpole: Before you come to that, I would like to ask a question about the Manchester case. I think you said that at Manchester two 1st class sorting clerks were promoted to be inspectors?

A. Yes.

Q. Is it not a matter of fact that these appointments were filled up by the promotion of assistant-inspectors?

A. The information I have is that 1st class inspectorships have been given to 1st class sorting clerks.

Mr. Walpole: As a matter of fact, they were assistant-inspectors who were promoted?

A. I cannot say that. The information I have is that these two positions have been given to 1 st class sorting clerks.

Q. In respect to the appointment of postmen to the smaller head offices; I presume you know that a head Postmaster usually has to have a know' ledge of telegraphic work? 
A. Well, I think the advance of science is such that we shall get rid of the telegraphs; they are being killed by the telephones. I believe that the Government are already introducing telephones in the sub-offices to a great extent. Even on the Tyneside alone we find lots of offices that are worth at least $£ 120$ a year, with commission.

Q. The head Postmaster at these offices is required to have a knowledge of both the telegraph and postal business?

A. Some do not know telegraphy at all; they get a girl in to do it. I am referring, of course, to the sub-offices.

Q. But sub-offices are usually given to tradesmen, are they not?

A. Yes; and we want that abolished. We have in Newcastle postmen, stampers, station messengers, and others who understand telegraph work. Only the other day a station messenger was on the railway platform when the railway telegraph clerk asked him to send a message for him, and he did it.

Mr. Walpole: I am not questioning the competence of some of the postmen to do the work; I am only venturing to doubt whether the great majority of these men have had an opportunity to qualify for it. You must remember they would be responsible for telegraph business.

A. Postmen are drawn from telegraph messengers, and they would have a knowledge of the work. We have plenty of them amongst us.

The Chairman: Telegraph messengers have no knowledge of telegraphy?

A. Yes ; they get a knowledge.

Q. They could not get much knowledge of the manipulative work?

A. I do not say that they could take the position of a test clerk, but some of them go into the telegraphic school.

Mr. Walpole: They are simply telegraph messengers taking out messages?

A. The difficulty about their going into the school is that the places are taken up chiefly by female labour.

The Chairman: Thank you ; that will do.

The witness then withdrew. 
The following tables were handed in by Mr. Walton :-

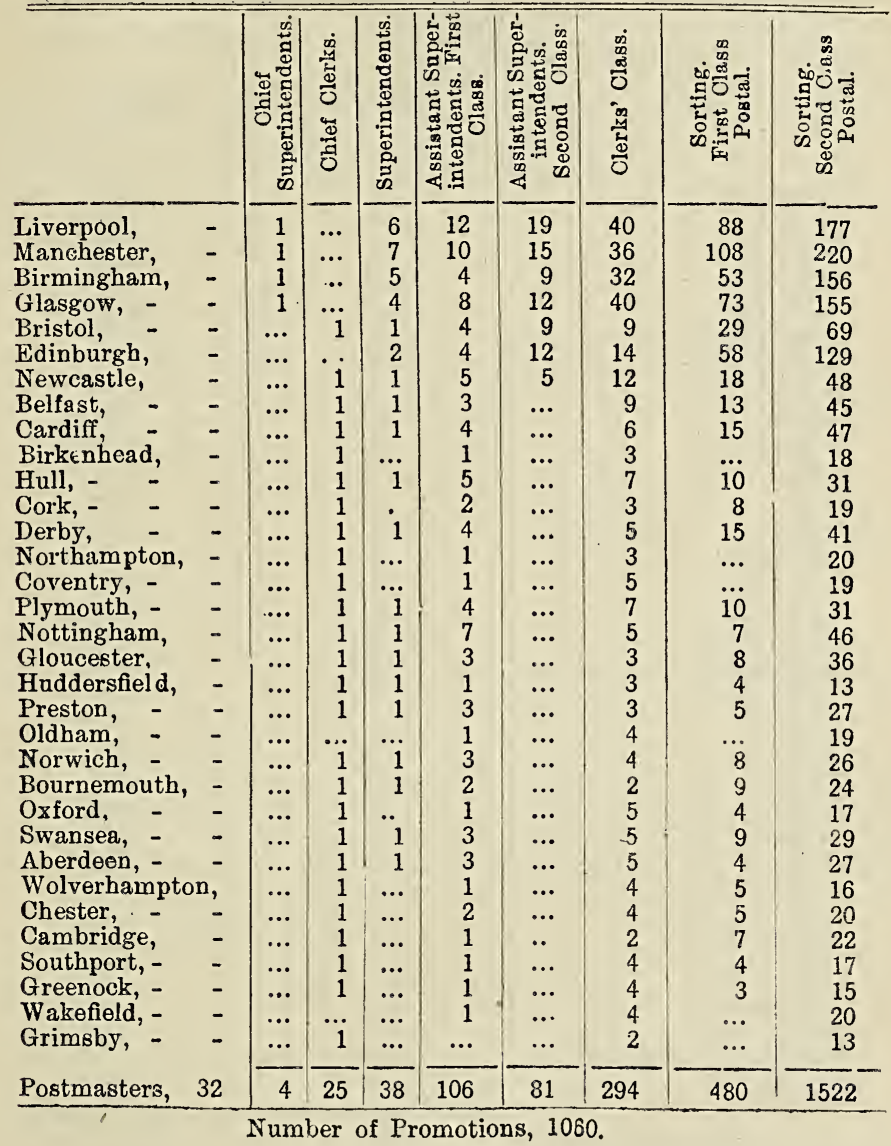


Statement showing the Numeer of Promotions open to Postmen.

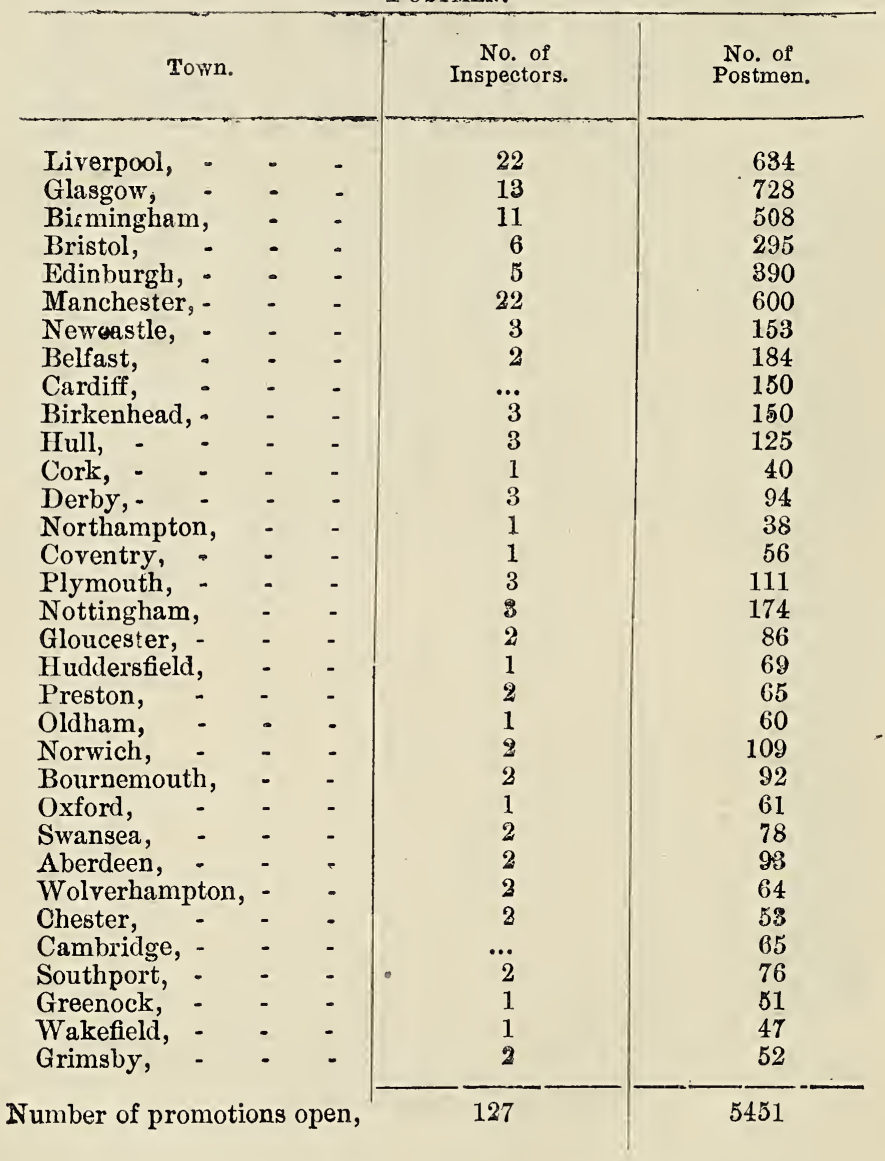




\section{SAMUEL WRIGHT, Leeds.}

Promotion.

Westumnster, Monday Feb. 24, 1896.

Samuel Wright next took his seat at the witness table, and was thus examined : -

The Chairman: You are a stamper, are you not?

A. No, sir; I am a postman in charge of the largest district office in Leeds.

Q. How many men have you under you?

A. 32 .

Q. You are head of the office there?

A. Yes, my lord; I have full control. My duties are purely clerical.

Q. Have you control over the telegraph side of the office?

A. No, my lord; that is done at another office a few yards away, and there a female telegraph clerk is in charge.

Mr. Walpole: Do you do counter work?

A. No, sir ; the female clerk in charge does counter work.

Q. Then you are not responsible for the counter work?

A. No, sir; I am responsible solely for the deliveries and other duties appertaining to postmen.

Q. For strictly postmen's work?

A. Yes, sir.

The Chairman: You are a postman?

A. Yes, my lord; I was appointed letter-carrier under the old name, socalled.

Q. Do you get any special allowance?

A. Yes; 5s. a week.

Q. Do you look upon that as extra pay for your particular work, or is it in lieu of Christmas boxes?

A. Yes ; but I have been an allowance holder ever since my first year's service. I have been performing duties indoors appertaining to the postmen class.

Q. Have you done deliveries?

A. Yes, I have done all postmen's work; I have done every duty that can be mentioned.

Mr. Walpole: Do you reside at your office?

A. Yes, sir.

Q. And have free quarters in addition to the allowance?

A. Yes, sir.

Q. With coals and gas?

A. Yes, sir.

Q. Then you get free quarters, coals, and gas in addition to an allowance?

A. Yes; but I must impress upon you before we proceed any further that my wife, who has an allowance for cleaning up the offices, and for cooking for the telegraph clerks and boy messengers, earns fully double the sum that is paid to her.

Q. Has your wife an allowance made to her for this work?

A. Yes; she has an allowance of $5 \mathrm{~s}$. a week, but-

Q. I am not saying you are overpaid.

A. No. 
Q. But you get free quarters, coal, gas, 5s. a week for yourself and $5 \mathrm{~s}$. for your wife. I suppose you also get payment for stripes?

A. I get $28 \mathrm{~s}$. a week, $3 \mathrm{~s}$. for my stripes, and then there is a $5 \mathrm{~s}$. allowance. Sir F. Mowatt: That is 36 s. altogether?

A. Yes; 36s, altogether.

The Chairman : Well, what are you going to tell us, Mr. Wright?

A. I am going to speak on the question of promotion, and to show that it is practically a dead letter. The question I am requested to bring before your notice is promotion for postmen. With your permission, as examples of provincial offices, I will give the return of postmen promoted in the Leeds Office since 1880, whilst the places of over 80 per cent. of the present sorting force rave been.vacant or created.

Sir F. Mowatt: What percentage?

A. Eighty per cent.

The Chairman : Are you not going to tell us very much what Mr. Walton has told us already?

A. I think you will find as we proceed that I take a different view.

Q. But which is the view of the Association?

A. I am representing the Association.

Q. Does not Mr. Walton represent the Association?

A. Yes, my lord; he also represents it.

Q. Then which of you is giving the view of the Association?

A. Both of us, my lord. (Laughter.) These vacancies have been filled over the heads of postmen "who were eligible" by outsiders on the nomination of the local authority:-Number of postmen who have received sorting clerkships appointments, 6 ; number of postmen who have received assistant-inspectorships, 3.

Mr. Walpole: What do you mean by local authority?

A. The Postmaster; he has full power to nominate whom he thinks fit.

Mr. Walpole: I only want to know.

Sir F. Mowatt: When you say "outsiders" do you mean telegraph clerks and messengers?

A. No, sir; as I proceed you will find out what I mean by outsiders.

Mr. Walpole: You mean that he brings young men into the sorting branch fresh from school?

Sir F. Mowatt: I am afraid I must ask you again, what do you mean by "outsiders"?

A. I mean the sons and relatives and friends of the controlling officers. It used to be a rule of the Service that the postmen's ranks should be exhausted of competent officers before the Postmasters had resort to outside ranks.

Mr. Walpole: What for?

A. For sorting clerks.

Q. When was that a rule of the Service?

A. It was in the old order book. I have the rule here.

Mr. Walpole: I shall be glad to see it.

Mr. Smith: Is an outsider necessarily a relative of the Postmaster?

A. I am informed that the rule is out of date; it went out of date only two years ago. I have been in possession of this order for about five years, and $I$ brought it under the notice of Mr. Lee, but he ignored its existence.

Mr. Walpole: What is the order?

A. It is one addressed to superintendents and clerks, and says that when an officer belonging to either grade is absent his duties shall devolve upon the officer next below him, provided he is competent to do the duty, and that that officer's immediate inferior shall, subject to the same condition of competency, do his work, and so it is to go to the lowest class.

Mr. Walpole: I thought you said it was an order under which postmen wero to be nominated to places as sorters before outsiders. I may have misunderstood gou? 
A. It is a rule on page 105 in the Postmaster's Book of Instructions. (Rule already put in.)

Mr. Walpole: That rule applies to promotion, does it not?

A. I am informed there is another rule in the same book that states explicitly that the sorting clerk class can only be filled from the postmen's class.

Mr. Walpole: That is the rule I ask you to read to me, not this rule. I have already said I was unaware of that rule.

A. But, sir, you must understand that I have never seen this Postmaster's Book of Rules. In the provinces we have not had access to it.

Mr. Walpole: You quote a rule. I was quite unaware of its existence, and my advisers are unaware of it. I ask if you have got it? Where is it?

A. My friend, Mr. Maclaren, will undertake to supply you with a copy of the rule.

Sir F. Mowatt: I thought you said you had the rule in your possession, and that you tried to impress it upon your Postmaster two years ago, and he ignored it?

A. This is the rule I was referring to.

Sir F. Mowatt: Then it is not the rule of which you gave us the substance?

A. There are so many rules I cannot understand them all.

The Chairman: I do not think you strengthen your case by talking of a rule you evidently do not understand.

A. I will read the rule when I come to the paragraph.

The Chairman: You have shown us completely your utter ignorance of the rule. You cannot give your evidence without being prompted by some one else.

A. Yes, my lord, but-

The Chairman: Why bring it forward if you do not understand it? You have not been giving your own evidence, Mr. Wright. Every word you have said has been prompted by Mr. Maclaren from behind you. I have not interfered because I wislied to give you every latitude.

Witness (continuing his statement) said: From the returns received I find other large provincial towns are placed at a greater disadvantage than Leeds, as the following list will show the number of years since a postman received promotion at any of the following offices, viz., Brighton, 4 years; Gloucester, 8 years ; Halifax, 8 years ; Cork, two within 20 years ; Huddersfield, 12 years; Middlesborough, 10 years ; Plymouth, 18 yeans; Cardiff, promotion unknown. Mr. Morley, replying to a memorial from the Leeds Office on the subject of promotion under date February, 1892, stated that promotion for postmen was open up to and including Postmasterships. To prove how completely this explicit statement of the Postmaster-General is ignored, I would respectfully point out to this honourable Committee that higher appointments are filled without being made known amongst the postmen's staff. I am referring now to sorting clerks. In Leeds Office, for example; the same obtains in the majority of provincial offices. I have never known it to be the case yet that a postman had been placed on the board for a higher appointment at Leeds, nor for the last five years has a postman been promoted at this office, with one exception, viz., the brother of an assistant-inspector to an inspectorship of postmen at Doncaster. This promotion was given without notification to the staff, and over the heads of 24 officers senior to himself. Now, my lord, we are told that we have a ccurt of appeal, and to show you how totally it is ignored, I will draw your lordship's attention to the matter. To this appointment I personally entered an official protest against the manner in which it was given, but to this day I have not received an acknowledgment.

Mr. Walpole: How long ago was that?

A. Two years ago; tho day before Mr. Sallsbury camo to teeds-the 28th

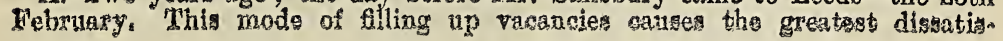


faction throughout the staff, nor does it move in a direction of improving the efficiency of the public service. Mr. Morley, speaking in the House of Commons on the appointment of this Committee, laid special emphasis on the fact of so many entrants to the public service being sons, etc., of those already in the Service. This principle we, the postmen, should be in full sympathy with, provided it operated equitably with all grades; but to show the pernicious effects of placing local nominations entirely in the hands of the local authority, I will quote the percentage of higher appointments above postmen held by blood relations, such as sons, etc., of the controlling force, and compare them with those held by postmen, as per example, in the offices of Liverpool and Leeds. Appointments held by blood relations of controlling officers in the Liverpool Office:-Mr. Robinson (chief clerk), 1 son; Mr. Whittingham (late D.), 1 son; Mr. Barrat, 1 daughter; Mr. Hall, 1 daughter; Mr. Jefferson, 1 daughter; Mr. France, 1 son; Mr. Isley, 1 son; Mr. Salkeld, 1 son; Mr. Walker, 1 son; Mr. Mawson, 2 sons ; Mr. Nottingham, 1 son; Mr. Turner, 1 son ; Mr. Sargentson, 1 nephew; Mr. Jefferies, 1 son, 1 daughter; Mr. Salder, 1 son; Mr. Henderson, 1 son;. Mr. Barker, 1 son; Mr. MTnighter, 1 daughter; Mr. Hall, 1 daughter; Mr. Scott, 1 son; Mr. Davies, 1 daughter; Mr. Pordham, 2 sons ; Mr. Barker, 1 son; Mr. Smith, 1 son ; Mr. Pacher (late inspector), 1 son; Mr. Dannett (Postmaster of Wigan), 2 sons; Mr. Dufton (pensioned superintendent), 1 son; Mr. Scott, 1 son; Mr. Burkett, 1 nephew; Mr. Hughes, 1 son; Mr. Webbs. 1 son; Mr. Lascelles (Postmaster of Ashton-under-Iyne), 1 son; Mr. Pierce (Superintendent, Shrewsbury), 1 son. Only 1 son and 1 daughter of postmen occupy positions above postmen. Leeds Office:-Mr. Carthage (chief clerk), 2 sons; Mr. Fawcett (superintendent), 1 nephew; Late Mr. Cawood (first-class supt.), 2 sons ; Mr. Dickinson (first-class supt.), 1 daughter; Mr. Hart (first-class supt.), 1 nephew ; Mr. Roberts (first-class supt.), 1 son; Mr. Metcalf (firstclass supt.), 1 nephew; Mr. Lockwood (second-class supt.), 1 son; Mr. Britton (second-class supt.), 1 son-in-law ; Mr. Green (first-class supt., tely.), 1 son and 1 daughter; Mr. Graham (second-class supt., tely.), 2 sons ; Mr. Stones (second-class supt., tely.), 2 sons; Mr. Green (clerk, Circulation Branch), 1 son. Sons of postmen :-Mr. Bentley (stamper), 1 son; Mr. Westerman (stamper), 1 son; Mr. Hellewelli (Parcel Post porter), 1 son.

Sir F. Mowatt: When you say "blood relations," do you include sons, nephews, and cousins?

A. I include sons, nephews, and cousins.

The Chairman: You have not included cousins. They are all sons and daughters. Do you contend that all these people in these lists are receiving undue promotion?

A. I quote them because I think they have been brought in by the influence of the head Postmasters.

Mr. Walpole: You mean that "Mr. R." has got one of his sons into the office. Is that so?

A. Yes, sir.

Q. And "Mr. W." has got one son in, and "Mr. B." a daughter?

A. Yes, sir.

Q. Do you object to the fact that a gentleman in a high position in the Liverpool Office has brought his son into that office?

A. I do not object to the system of bringing into the office. I object to their being pitchforked into the position of sorting clerks.

Q. There is nothing in this table to show that?

A. Most certainly there is.

The Chairman: What is the position of the people named in these lists?

A. They are all of the controlling force.

Mr. Smith: Do you mean that the sons as well as the daughters of the gentlemen nained are of the controlling force? I see that they occupy all 
sarts of positions. They are sorting clerks of the 1st and 2 nd class and telegraph clerks.

Q. Do you know any trade or occupation in which fathers do not introduce their sons?

A. I do not know; but I say that we should all have the same chance.

Q. The table does not show whether the chances are fair or not. As it happens, I imagine that these things occur in every occupation.

A. My contention is that they should join the staff at the bottom.

Mr. Walpole: But if they came in as sorting clerks and telegraphists, do they not start at the bottom of their respective classes?

A. Yes; at the bottom of those classes. We have applied frequently for promotion, and have been told that there are no vacancies, but perhaps a week or two later these men are put into the position.

Mr. Smith: You think they should start on the postmen's scale?

A. Yes ; at the bottom of the whole Service.

Mr. Walpole: As a matter of fact, the Liverpool Office is one where a great many postmen are raised to sorting clerks, is it not?

A. I am not disputing that.

Mr. Smith: Do you mean to say that everybody entering the Service and having a relation in it must always enter at the bottom of the lowest paid class in the Service?

A. Certainly.

Q. Whatever his or her qualifications?

A. Yes; whatever qualifications they may possess.

Q. If the entrant has not a relation in the Service, may he take any position?

A. No, sir.

Q. Everybody must enter the Service at the bottom, and you say there should be no way of getting into the Service but by the lowest class?

A. Yes; at the bottom of the lowest class.

Q. And that is your position?

A. That is my position.

Sir F. Mowatt: Have all these people, all these sons and daughters, to pass an examination for sorting clerks?

A. Yes, sir.

Q. And it is a different examination to the postman's?

A. Yes; it is a different examination to the postmen's.

Mr. Walpole: Would you have everybody enter the postman's class, and permit nobody to become a sorting clerk or telegraphist without?

A. Yes.

Q. But that would involve that nobody could get these appointments until they came to a comparatively advanced age?

A. I do not siay that; what I do say is, that until they have proved that they are efficient for higher appointments they should act as postmen.

Mr. Smith: The previous witness suggested that it should be done by seniority. Do you agree with that?

A. Yes; I think it should.

Mr. Walpole: Then if it were done by seniority they would not get promotion to sorting clerkships or telegraphic appointments until they were comparatively advanced in years, would they?

A. I cannot answer that question, not knowing the number of vacancies which would occur.

Q. But is it not a fact? Must it not be so?

(This question was not answered.)

The Chairman: You say there is nothing to prevent the sons and daughters of postmen coming into the Service in the same way as these other young people have done, provided they can pass the examination?

A. Yes, my lord; but that is where the difficulty comes in. I have a case here of a stamper in Leeds, named Porteous. He had a daughter in a high grade school, who has obtained a scholarship there. She is very 
clever. She tried to get into the Service as a telegraphist at the Leeds Office; she went to the telegraph school and passed the necessary preliminary examination, and they then told her there were no vacancies, but that they would send for her when one occurred. About a month after, Mr. Tuckett, then assistant-superintendent at Leeds, and now Postmaster at Gateshead, brings his daughter in as a telegraph learner. She attended the same school as the other girl, but had been unable to pass the same standard in the high grade school. Upon her father being transferred to Gateshead she gets in as a counter clerk, but there is no vacancy given to the postman's daughter, although several are open. This is, I think, a proof that influence has brought this to pass.

Sir F. Mowatt: What has been brought to pass? I do not quite understand?

A. I am complaining that the postman's daughter was qualified by examination, and was not appointed, while the superintendent's daughter did not qualify for the situation, and was appointed. As I said, the postman's dapughter won a three years' scholarship in the high grade school at Leeds, and the other could not win a scholarship.

Mr. Smith: Did she try?

A. Yes; she tried and failed. But the other girl, being a postman's daughter, she was completely ignored. I say that this is a proof of undue influence being brought to bear in the case of the other girl.

Sir F. Mowatt: What do you say was done in the case of the superintendent's daughter?

A. She came in as a telegraphist.

Q. And it was as a telegraphist that the other girl wanted to get in?

A. Quite so; and then the superintendent's daughter was transferred as a counter clerk to Gateshead-on-Tyne, her father having been appointed Postmaster of that place. I shall be able to give proof in every one of these cases from the Liverpool Office. Now I come to Leeds, and I find that the same conditions exist. I wish, however, first to draw attention to this important fact, that at the city offices at Liverpool there is only one son and one daughter of a postman occupying higher appointments, while at Leeds there are three. The first two went in years ago as office-messengers, or they would never have been in at all. The third is a very shady case, and a thing I would rather not go into.

The Chairman: I think we had better have it out. We had better go into every shady case.

Mr. Walpole: I would rather have it out, rather than have this Committee think there are shady cases.

Witness : I do not wish to do the man a personal inury in the eyes of the public.

Mr. Walpole: You need not give the name.

A. I can give the name.

Sir F. Mowatt: Give us the facts without the name.

A. Well, I will call him Mr. H. This man came in at the introduction of the Parcel Post. He is at pensioner from the army.

Q. What did he enter as?

A. As a Parcel Post porter, and he nolds that position to this day.

The Chairman: At what age did he enter?

A. Just under the age to be appointed on the establishment. I think he was about 42 or 45 years of age.

The Chairman: I think the limit is 32.

Witness: Yes; but it has been revised since then. He entered on the introduction of the Parcel Post. This man has got a house, and everything free of cost. He has the house of the House Inspector, but does not perform the duties of that inspector. Another man performs them, and gets an allowance of $4 \mathrm{~s}$. a week, without the privilege of living in the house free. This man made particular friends, and was rather more familiar 
than I should be tempted to be with Mr. Leal, when he was Postmaster. Mr. Leal was pensioned off two years ago.

The Chairman: Go on.

Witness : He used to dig up Mr. Leal's garden, and do such work as that, and the result was that he exercised great influence over Mr. Leal, and by means of that influence he got his son into the Service over the heads of several men with long service, who had applied for positions for their sons.

Sir F. Mowatt: What did he get him in as?

A. As a sorting clerk in the Parcel Post department.

Mr. Smith : Do you know whether he is doing his work efficiently?

A. I am not prepared to say that.

Q. You don't know whether he is a man of exceptional promise?

A. I might say he had no more exceptional ability than 100 postmen in Leeds Office.

Mr. Smith: You have not answered my previous question. You don't know whether he does the work efficiently or not?

Witness : I beg your pardon.

Q. I want to know whether he is doing the work efficiently or not?

A. I do not know.

Q. And you cannot say whether he is exceptionally promising or not?

A. I suppose he would be put on junior duties; he would by degrees become more efficient, the same as the rest of us.

Q. Do you know this case of your own knowledge?

A. Yes; I know every individual connected with it, and I can prove all I have said.

Mr. Smith: I understand you complain somebody was taken on, and not that other people were rejected? Do you know whether the man who was appointed was the best of those who applied?

A. We have men in Leeds Office who applied for this position; they were men of service, and have shown they were efficient by performing the duties.

Sir F. Mowatt: In this case you are not complaining of the appointment of the son or daughter of a superintendent, but of the son of a porter?

A. Yes ; of a porter, sir.

Q. And you explain his being appointed by the fact of his father assisting to dig the Postmaster's garden? (Laughter.)

A. I do, sir.

Sir F. Mowatt: All right; I very much doubt it, but that is your explanation?

A. Well, I think it is a proof of undue influence.

Mr. Walpole: Mr. Leal is no longer Postmaster, is he?

A. No, sir.

Q. And he has not been so for some years?

A. $\mathrm{He}$ has only been gone for two years, sir.

The Chairman: And the lad was appointed before Mr. Leal went away?

A. Yes, previous to the appointment of Mr. Salisbury. My lord, the postmen's contention is that individual interests are considered before the interests of the public service. I humbly submit, on behalf of the postmen of the United Kingdom, that the present mode of filling up vacancies as sorting clerkships is a violation of the Postmaster-General's statement.

Mr. Walpole : What statement?

A. That promotion was open to postmen.

Mr. Walpole: On that point, perhaps you will allow me to read the rule which we were looking for. It states that- "Subject to the approval of the Postmaster-General, who reserves to himself the right to nominate to any vacancy he thinks proper, the Postmaster is entrusted with the nomination of sorting clerks, telegraphists, and town postmen, and it is incumbent upon him to discharge his trust by getting the best qualified persons to act." Perhaps you will accept it from me that that is the rule which governs these matters? 
A. I should like to know the date of that. I cannot accept it. It does not seem to have been in existence at the time the rule I referred to was in force.

Mr. Walpole : I believe you will find that I have read it correctly.

A. But that is in the new book?

The Chairman: The date of the book is 1893.

Witness: If a return of higher appointments open to postmen for the past ten years wøre made, showing how these appointments were conferred, it would clearly be demonstrated that the time has already arrived, in the best interests of the public service, for a clearly-defined system of promotion to be introduced, whereby every person entering the public service commenced at the bottom class, and would feel assured that through his own perseverance and industry a just reward would await him. After showing these returns on behalf of the postmen of the United Kingdom, I humbly ask your lordship's Committee-Is it unreasonable for us to assume that if local authorities confer positions on those who surround them, they in elevated positions will be proof against the influence of private friends, or that influence in individual favour will be resisted? I will now give a return of the number of vacancies to sorting clerkships in the following provincial offices within the last two years, of which none have fallen to the postmen's lot. Return of towns showing the number of vacancies as sorting clerks within two years :-Gloucester, 6; Darlington, 3 ; Huddersfield, 4 ; York, 4; Stockport, 1; Scarboro', several ; Northampton, 3; Bradford, 4; Wolverhampton, 4; Leeds, 19; Derby, 2; Great Yarmouth, 4 ; Widnes, 2 ; West Hartlepool, 3; Bedale, 3; Doncaster, 4; Grimsby, 2; Swindon, 2; Lowestoft, 5; Beccles, 2; Wakefield, 5; Shrewsbury, several ; Rothesay, 3; Llanelly, 2; West Bromwich, 3; Shipley, 1; Chorley, 1; Maidstone, 5 ; Stockton-on-Tees, 3 ; Limerick, 5; Preston, 5 ; Harrogate, 1 ; Kilmarnock, 2; Ayr, 2; Tiverton, several ; Worthington, 1; Aberdeen, 12 ; South Shields, 1; Stourbridge, 1; Croydon, 1; Rochdale, 3; Newport, Mon., 3 ; Motherwell, 1; Stailybridge, 3; Wrexham, 3; Paisley, 2; Dalkeith, 1; Blackpool, 2 ; Chester, 5.

Mr. Walpole: What are these vacamcies?

A. Sorting clerkships, sir.

Q. In how many towns?

A. 49. In provincial offices postmen have made repeated applications for promotion without success, the official reply to their applications appearing to be universal, viz.-a blank negative in these terms:-1st, That there are no vacancies ; 2nd, that the applicant has no knowledge of sorters' duties; 3rd, that sorting clerkships should be filled by a better class of men than is found in the postmen's ranks ; and 4th, that postmen are not sufficiently educated for these positions, not being able to perform clerical duties. To the first answer I am requested to say that every vacancy for a higher appointment should be exhibited amongst postmen in the Postmen's Department. The replies 2 and 4 will prove fallacies, because postmen to-day perform the duties of the sorters, and act as such whilst sorters are on sick or annual leave, which will be shown under the question of allowances paid to postmen who perform special duties. To the third reply I say that candidates for sorting clerks to-day are drawn from similarlyeducated lads of the same class and schools as postmen, the only difference being, that one is locally recommended, whilst the other has to fight his own battle in the struggle of life. Seniority as a safeguard was formerly some limitation; that has been entirely set aside as regards postmen, and is now looked upon as a condition more potent "than a black official record" to prevent their promotion. That this restriction was needed the present mode of filling up vacancies clearly shows. The rule is aimed at selection or arbitrary choice, not cnly as a protection to applicants who have made repeated applications to their respective chiefs for promotion, but every senior officer should have been shown as unfit for promotion "as per riule," and his unfitness defined. If thousands of postmen are in a chronịic 
state of unfitness for promotion, I humbly request your lordship's honourable Committee to examine closely the treatment which has robbed them of all inducement to self-improvement, for at present it would appear the rule is "once a postman always a postman." The present staff of inspectors and assistant-inspectors of postmen have been chiefly drawn from the sorting force, a great many having never performed postmen's duties, and they show clearly, upon assuming such duties, they are totally unfitted for the positions, having no experience, nor can it be expected they can command the influence over men under their control like a man of experience, whose long and honourable service proves his title to full respect and submission, and, in addition, improves the efficiency of the public service. I am also requested to draw your attention to the higher educational test imposed upan future candidates for sorterships, issued under date April, 1893. Persons employed as temporary sorters prior to that date have, up to very recently, been admitted under the former lower edīcational test. Officers thus admitted under the lower standard, when promoted to inspectors, clerks, superintendents, Postmasters, etc., have not afterwards the slightest higher test imposed. If necessary, from postmen to sorters, some higher standard must also be necessary for such positions, and on these grounds I claim that postmen who were on the establishment prior to the higher standard coming into operation should be exempt from it, and come under the standard obtaining when they were placed on the establishment. To depart from this tends to demonstrate partiality, and also commits a breach of faith virtually upon the older members of the postmen's staff, from whom an educational test should not be required any more than from the members of the major staff on their elevation.

Mr. Walpole: What do you mean by "partiality"?

A. By importing their own relations direct from school.

Q. Do you say their having to pass a higher examination, which is applicable to everybody, implies partiality? How can it imply partiality when it is applicable to everybody?

A. Yes, I do. You must understand this. A man may have been serving the Department for years, and may have proved himself quite competent to perform the duties. Yet you bring in a boy fresh from school; he can pass an examination which a man who has been long in the Service will have practically forgotten, because he will have no incentive to go forward, knowing that it would be practically useless to do so.

Mr. Walpole: I only wanted to know what you meant.

Witness: I maintain that it is a great hardship for men who have served the Department faithfully for years "to have imposed upon them" when asking for promotion a higher educational test than the one obtaining when they entered the public service. Moreover, I contend that an ounce of practical experience is worth more than any theoretical knowledge. Now, my lord, I will show the great discrepancy at present existing as between the numbers of higher appointments in the circulation branches and the postmen's department, showing the cost in each case of the following ten provincial offices. I must impress upon the Committee to take special note of the great percentage of promotion open to sorting clerks at present above postmen in each respective department. I do not include either chief clerks or Postmasters in this return. I commence with the class of clerks and superintendents only:- 


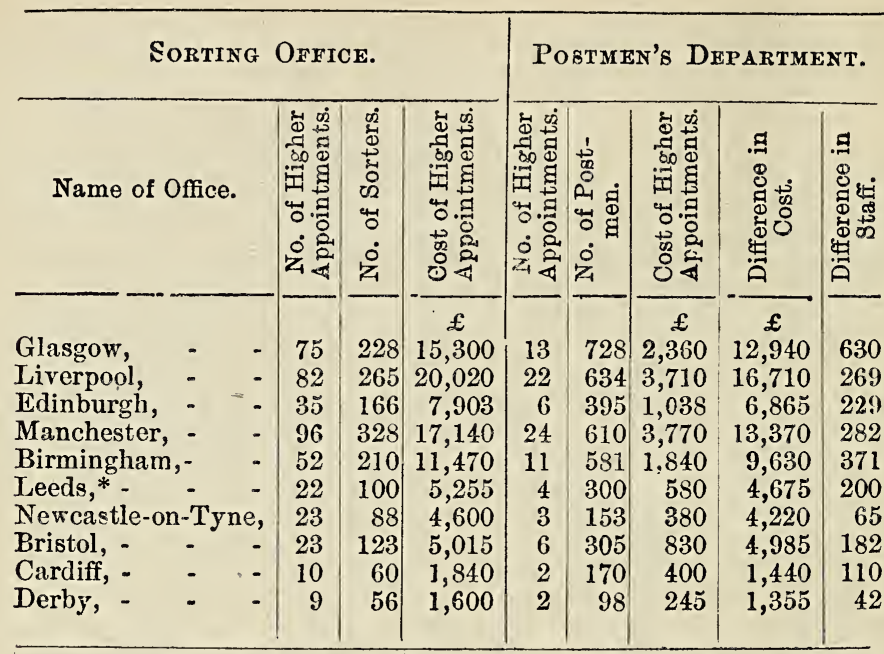

* In the case of Leeds one of the four is an Out-Door Inquiry Officer, and does not perform any Inspector's duties, so the number is practically three.

Q. Naturally, in your calculation you have not reckoned among the positions to which postmen can be appointed any number of sorting clerks' positions?

A. No; because wo do not have any. We are practically debarred from them.

Q. But don't postmen get made sorting clerks at all in the provinces?

A. I have shown we have not had one in five years at Leeds. I might draw attention to this fact, that at Manchester two postmen have possessed a higher appointment, carrying with it $7 \mathrm{~s}$. a week, and they are now willing to go in as sorters at $7 \mathrm{~s}$. a week less wages than they are getting now.

Mr. Walpole: You mean they have an allowance as sorting postmen?

A. Yes; and they will lose that if they go in as sorting clerks.

Mr. Smith: But they gain enormously increased chanoes of promotion?

A. In some offices they are allowed to carry with them their allowances and stripes, but these are told they have to drop the allowance.

Mr. Walpole: In any case they will carry the allowance for sorting postmen with them?

A. Yes, sir; the last stamping postman appointed at Leeds carried his allowance with him.

Sir F. Mowatt: When was that? How long ago?

A. About eight years ago.

Mr. Walpole: You think, as far as I gather, that the Department has been extremely liberal to the sorting clerks?

A. Yes; it has been over-liberal to them at our expense.

Q. And therefore you think that, whatever we do, we ought to do nothing for the sorting clerks?

A. Oh, no I I have not said that. (Laughter.)

The Witness (continuing): My lord and gentlemen, whilst such anomalies as those exist, I ask, on behalf of my brother postmen of the United Kingdom, can the Department expect a contented Service, can it expect an efficient Service. whilst postmen are to be kept out of all advancement, and continue to be hewers of wood and drawers of water to the Islimaelites of the 
public service? On behalf of the future and the best interests of the Department, I appeal to this Committee to recommend a complete reorganisation of the Service, and to begin to raise the status of new entrants by raising the examination for future postmen's appointments. Further, I appeal to your lordship's Committee to recommend to the PostmasterGeneral an equal percentage of higher appointments in the postmen's class to compare favourably with the number of higher appointments already in existence in the sorters' class. This I ask as a just reparation to hundreds of deserving men in the public service, who, if it is not granted, must remain postmen to the end of their days. Also, I would impress upon this Committee the desirability of not allowing any officer's name to be submitted for promotion who has less than ten years' service.

This finished the witness's evidence.

The Chairman: We will adjourn now till Thursday.

\section{JUNIOR POSTMEN'S CASE.}

Westminster, Thursday, Feb. 27th, 1896.

Lord Tweedmouth's Committee resumed their Inquiry into the grievances of Post Office employees at the House of Lords' Committee-Room to-day, all the members being present.

Mr. S. Wright was again called to speak on the case of the junior post. men, and the special duties performed by postmen. He said :-

\section{JUNIOR POSTMEN.}

I am specially allotted to bring under your notice the question of creating junior postmen.

Mr. Walpole : Junior postmen?

A. Junior town postmen. I must, with the permission of your lordship's Committee, refer back to the year 1890. At that period memorials were forwarded from all parts of the United Kingdom, asking for the total abolition of classification in postmen's rauks. 'This request the then PostmasterGeneral (the late Mr. Raikes) granted. Upon announcing his revision on July 23rd, 1891, in the House of Commons, the Postmaster-General informed the House, "that on and from August 2nd, 1891," classification in the postmen's ranks would be abolished, and only one class would form the establishment, beginning with a minimum wage of $17 \mathrm{~s}$. per week, a reduction of 1s. weekly on the former second-class minimum. We now come to Novenber, 1891, when, to the astonishment of the provincial postmen, a junior class was created in several provincial offices, beginning with a wage of $12 \mathrm{~s}$. and $14 \mathrm{~s}$. per week, rising by $1 \mathrm{~s}$. per week annually, to $16 \mathrm{~s}$. per week maximum. After the promises given by the then Postmaster-General on behalf of the establishment to the House of Commons, your lordship's Committee will pardon us if we urgently urge upon you to inquire closely into the authority obtained from Parliament for the creation of this class. We feel agreed strongly that the creation of junior postmen is a breach of faith to Parliament, also virtually a breach of contract to the Service. I would also draw your lordship's Committee's special attention to this fact: these men already served the Department about six years-that was prior to their entering as junior postmen, having entered as boy telegraph messengers at 14 years of age, and thus practically serving an apprenticeship to the advantage of the Department.

The Chairman : This is a very small class, is it not, Mr. Wright?

A. I do not know exactly the number, my lord, but when I prepared this paper there were 204 of them. Our contention is that, there was no authority to create this class.

The Chairman: As a matter of fact, there are only 200.

Mr. Walpole: I cannot accept your statement that we had no authority to create this class. I am quite willing to say this: the Department is at 
one with you about this class, and no further appointments will be made to it. That will save time, will it not?

A. Yes, sir. I am quite willing to save the time of the Committee, but the question is: what about back pay, and the service counting for stripes? That is the next question I should like to put in.

(The witness then handed in several tables relating to the service of junior postmen at Hull, Leeds, Portsmouth, and Manchester.)

Q. These junior postmen have only done six hours' work. In no case did they do a full day's work.

A. In the case I have here they did from 7 hours 45 minutes to 8 hours a day, I think.

Q. I do not wish to contradict you, but I think it is hardly so. I did look into the Leeds case some time ago. But I do not want to stop you. If you wish to, go on.

A. The duty ranged from 4.30 to midnight at a Leeds District office; junior postmen worked 8 hours 30 minutes alternate weeks.

The Chairman: I think, Mr. Wright, that you might at any rate drop so much of the junior postmen's case as refers to the question of the class, and confine yourself to stating any points with regard to which you think the existing junior postmen have a right to be considered.

A. My lord, if I could have the promise of the Secretary that these men's cases will be looked into with regard to back pay, which we say they are entitled to, I will withdraw the case immediately. There is also the question of the service counting for stripes.

Q. I do not think you can expect such a statement to be made by the Secretary. I think the best plan will be for you, so far as you have any particular point to urge on behalf of the existing junior postmen, to do so. You had better tell us shortly what you have to say.

A. My point is that the class have a right to back pay from the date of the statement of the Postmaster-General in the House of Commons. They ought to receive the difference as between $14 \mathrm{~s}$. and $17 \mathrm{~s}$.

Sir F. Mowatt: What was that statement?

A. The Postmaster-General's statement in the House of Commons on July 23rd, 1891: - "That on and from August 2nd, 1891, classification in postmen's ranks will be abolished, and only one class would form the establishment, beginning with a minimum wage of 17s. a week," a reduction on the existing 2nd class letter-carriers in the provinces of 1s. a week.

Q. Then you hold that, after that, the Postmaster-General had no authority to vary the rates of pay, or terms of employment of postmen?

The Chairman: The witness's first point is, that the Postmaster-General had no right to appoint this class of junior postmen at all.

Sir F. Mowatt: And I am asking whether there is no right to vary the terms of the appointment of postmen. Does the witness say that the Postmaster-General made a contract with Parliament, and should never depart from it?

A. We contend that it is a violation of the pledge given to the then House of Commons.

Q. Would you say, when a statement of that sort is made, you hold that the Postmaster-General has no power, without the direct authority of Parliament, to make any change in these terms? I do not want to press you unduly-I want to understand if that is your point.

A. That is our contention in the provinces.

Q. Then your contention is that he would have no power either to increase or decrease the wages of the postmen?

Mr. Walpole: I should be glad if you would give us an exact reference to the quotation on which you rely. We have had search made for it in the office, and been unable to find it. I do not dispute its truth, but we want an exact reference to enable us to find the statement.

A. I took the statement out of the "Times."

The Chairman: Of what date? 
A. July 24th.

Mr. Walpole : 1891?

A. Yes ; 1891.

The Chairman : I dare say you can get it in the library here.

Mr. Walpole: I am not defending the action of the Department. These things are totally different to what the Postmaster-General had in contemplation in 1891. At the time that he made that statement, I think it was the fact that he was bringing men into postmen's places who had served in the army, and therefore they were older men, whom it was very unfair to put on low rates of wages. When the junior class of postmen was revived, it was revived because our medical officer thought it was unwise to put telegraph messengers, who were growing lads, on a full eight-hours' duty. He advised, therefore, for medical reasons, the establishment of an intermediate class of junior postmen, to work short duties at low rates of pay until their strength was matured.

A. Very often those you think boys are young men.

Mr. Walpole: I am quite aware of that.

A. Their ages run to 23, 24, 25, and 26. Yet they are appointed junior town postmen.

Mr. Walpole: I am quite aware what their age was at Leeds, and that is one reason why we want to abolish the class. They passed through the auxiliary class first, and then became junior postmen.

Witness : I am not referring to the Leeds case ; I am quoting the case of Hull. The ages are similar at various towns in the provinces. These men have been in the Service six or seven years.

Q. As auxiliaries?

A. As boy messengers and auxiliaries.

Mr. Walpole : I am not attempting to defend it; I want to get rid of it.

Sir F. Mowatt: I want to understand what the witness's exact point was, so as to save time, and I think now I've got that.

The Chairman: I think you might go on at page 6 with your evidence, Mr. Wright.

Witness: I earnestly urge that each junior shall be paid in full back pay from his junior appointment; that is to say, the difference between the $12 \mathrm{~s}$. and $14 \mathrm{~s}$. and the $17 \mathrm{~s}$. per week. This I consider a just reparation due to these men from the Department.

The Chairman : Of course you only make that claim, even from your own point of view, in the case of men who have been doing a full eight-hours' duty?

A. Yes, my lord.

Q. I mean that if a man has only been doing a six-hours' duty, you would not expect him to be paid? He surely would not have the same claim.

A. Our contention is that this thing had no right to be done.

Q. No, no ; that is not the point. I can see that you may have a prima facie case in favour of men who have been doing an eight-hours' duty to receive the same pay as other men who were doing a similar eight-hours' duty, but if a man's duties were confined to $5 \frac{1}{2}$ or 6 hours per day, it does not seem to me he would have the same prima facie case as the man who did the eight-hours' duty.

A. Probably not; they would not have the same claim on the Department if they worked only 6 hours per day as the men who worked 8 hours. I must acknowledge that in justice to the Department.

Q. That, of course, limits the amount of back pay to be claimed very much.

A. Yes, my lord, it would limit it; but the point I wish the Committee thoroughly to understand is this : that the juniors appointed prior to the Raikes' revision are deprived of the stripes until they have been five years on the full establishment, as it is termed, although these men have practically worked eight hours per day.

Sir F. Mowatt: I do not think you can make any claim for an increasing 
rate of pay on the ground that the appointment itself was an improper one, and that the Department had no power to make it. That would be a very good case for not paying at all-(laughter)-and I do not see where your claim for altering the rate of pay comes in. I do not for a moment dispute your claim, but I suggest that you should consider the matter from the point of view that if there was no power to appoint, and if it were a wrong appointment altogether, then the consequence of that is, that the payment of wages was wrong. (Laughter.) But if you say that for certain reasons these men have been made to do more work than was justified by the smaller rate of wages, that is a good argument for asking for an increase of wages, and that I understand you to be doing.

A. That is my contention. Our point is this: We contend that the Department had no power to create this class.

Sir F. Mowatt: Very well; then they had no authority to pay the men in it. (Laughter.) Don't get yourself into unnecessary difficulties.

Mr. Walpole: On behalf of the Department, and to reassure the junior postmen, I may say that if there were no authority to pay, Parliament has condoned our action by passing the pay every year in the Estimates. (Laughter.)

Sir F. Mowatt: I do not want to destroy the force of the witness's arguments. I only want to put it on this ground in self-defence.

Witness: I will presently show you the force of the argument, and also that the position was practically recognised at Leeds-by a most unusual proceeding apparently. We now come to August, 1893 . Leeds junior postmen were employed on relief duties, and to somewhat allay the smouldering discontent, 12 auxiliaries, transferred from boy messengers, were called upon to perform the duties hitherto performed by the juniors. These auxiliaries signed the poy-sheet weekly for $17 \mathrm{~s}$. per week, and were ordered to hand over $3 \mathrm{~s}$. per week to the juniors; this practice was continued for some time, when, ultimately, these men refused to countenance such a practice any longer, and, consequently, the juniors had to sign for 3 s., as receiving an allowance to that amount. This practice was continued up to the introduction of a revision of the establishment on April 1st, 1894. Mr. Morley, replying to a memorial on the subject of junior postmen, under date 10th February, 1892, stated that the question had been brought before his notice, and, in all probability, provision would be made for the total abolition of the class on the next revision of the establishment at Leeds. The next revision of the establishment took effect on April 1st, 1894. My lord, to our astonishment, the junior class was increased from 12 to 20 . (Here the witness made a pause, apparently in order to allow the mind of the Committee to grasp the effect of the statement.)

The Chairman: Go on; these pauses do not make your evidence more weighty. Just follow on more quickly.

Witness: The greatest indignation pervaded, and a further memorial was forwarded, pointing out the previous promise, the result being that the Treasury have sanctioned a reduction from 20 to 6 . I will now draw your lordship's Committee's attention to this-that the time served as junior at present does not count for stripes; the actual service begins only when a man is transferred to the senior class. These men pass the same examination, and receive the same certificate of appointment as men on the senior establishment. They pass no further examination, medical or otherwise. They receive full privileges equal to senior established men in other respects.

The Chairman: That is the case always, I suppose. The practice is that only the service done by full-time men does count for stripes. That is the rule of the Department, whether rightly or wrongly. It does not apply to juniors only; it applies to auxiliaries, and very much the same point was brought forward by them.

Witness: The point is that the juniors, prior to the Raikes' revision, did full-hours' duty for two or three years in the junior service, and this 

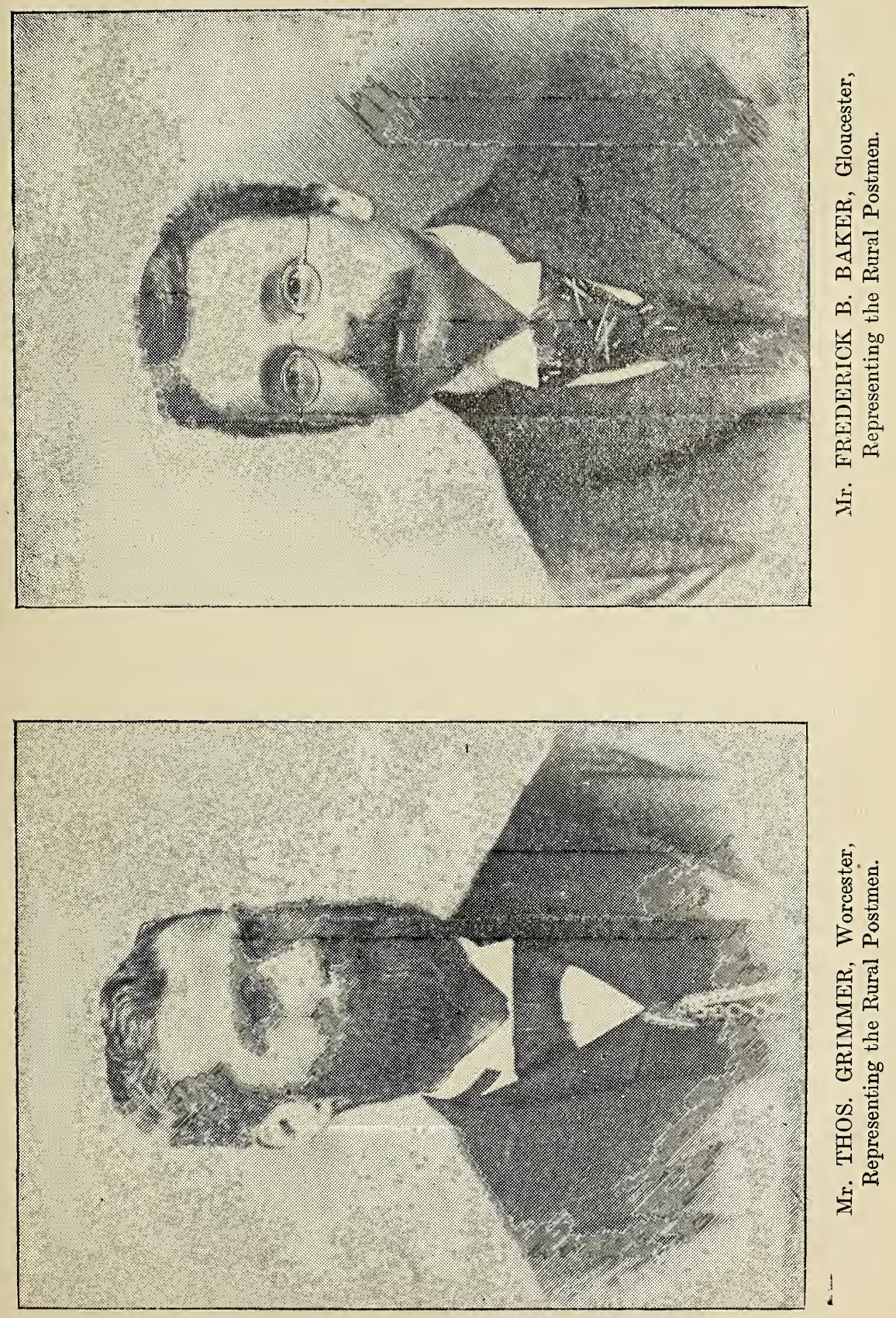

does not count for stripes. We have cases of this from Newcastle and Manchester. Our contention is that this time should count for stripes. To illustrate this, let me point out that a man who has been three years on the junior class has to serve the Department eight years before he gets his stripe.

Thie Chairman: Go on with your statement, please.

Witness: Rule 93 states the full conditions. No mention is made of junior service as to the conditions of such service not counting for stripes. I submit the names of two officers of past junior service, whose service - up to now is not counting for stripes. On behalf of the juniors, both past and present, I ask this Committee to recommend to the Postmaster-General that such service count for stripes, and that they receive full recompense of whatever amounts are due to them for such services, providing their conduct has been satisfactory. I next come to the question of postmen performing special duties.

The Chairman: You are going into the case of the indoor postmen?

A. Yes, my lord.

\section{THE CASE FOR THE INDOOR AND ALLOWANCE CLASS.}

I am also requested to bring under your notice the special duties postmen perform, and the important positions of trust and responsibilities these duties involve upon those occupying them, also the great discrepancy paid in allowances, as between town and town, for performing similar duties of equal value to the Department, which are classed under several heads, as follows, viz. :-

(1) Charge takers and assistant charge takers.

(2) Senior or assistant-postmen.

(2a) Inspectors of telegraph messengers.

(3) Sorting postmen.

(4) Stampers.

(5) Bagmen.

(6) Mail porters.

(7) Parcel Post packers.

(8) Holiday and sick relief men.

To show your lordship's Committee the responsible positions occupied by this portion of the postmen's staff throughout the provinces, I will, as briefly as possible, describe the nature of their duties and responsibilities.

\section{CHARGE TAKERS AND ASSISTANT CHARGE TAKERS.}

Charge takers are postmen occupying positions of full control of the delivering force attached to the district offices belonging to such towns where district offices are established.

The Chairman: That is what you are yourself?

A. Yes, my lord. They receive and desputch all mails to and from the head office, deal with surcharged letters for their own district, receive all registered letters posted within their district, check off and give out, and are hcld responsible for all registered letters received for delivery within their respective districts, arrange the duties of postmen under their control, deal with official correspondence referring to their districts, answer inquiries referring to complaints, make out wage schedules, and pay wages. Assistant charge takers perform these duties in the absènce of the charge taker, and assist in the control. I should like, with the permission of the Committee, to draw the Secretary's attention to the number of registered lotters that postmen in this position have to deal with. I have tak n my figures from the returns of registered letters received for delivery during the months of December and January last. I received 877 in December and 765 in January, and surcharges to the amount of $£ 110 \mathrm{~s}$. per week. I state this because the Secretary made capital out of the Brighton case by saying that the postmen had nothing to do with registered letter work. 


\section{POSTMEN ACTING ASSISTANT INSPECTORS OF TELEGRAPH} MESSENGERS.

These men have a large amount of clerical work to perform. They make out wage schedules, arrange duties, record dockets to the credit of the messengers, and keep the following books:-Drill register, uniform, express letter, late attendance, sick staff, diary, and book of instructions. They have also to inquire into the delay and non-delivery of telegrams.

The Chairman: What do you mean by drill register?

A. It is a military drill and the attendances at it, as I understand it.

Mr. Walpole: Do you mean for telegraph messengers?

A. Yes, sir; for telegraph messengers. We have to register the number of times they attend drill. Senior or head postmen perform similar duties, and assistant-inspectors at small towns where no district offices are established. Sorting postmen's duties are considered locally to deal with correspondence posted and received for local delivery to which town they belong. To show your lordship's Committee the little difference which exists between the sorting clerk proper and the sorting postman, I will give you examples of the practical work performed by the two classes in the offices of Liverpool and Leeds and Glasgow :-

Liverpool, H.-All correspondence posted and received in Liverpool is first dealt with by the postmen, who divide it into divisions; the forward goes into the C.B., whilst the local is dealt with by the postmen.

GLASGOw, H.- Town sorting postmen deal with all correspondence posted or received for the local deliveries. Previous to this work being taken up by postmen, it was done by first-class sorting clerks only. At present, on the Glasgow and Carlisle Sorting Tender, where the work is done wholly by sorting clerks, only first-class men are allowed to deal with the letters, the junior men being confined to the news. Now, my lord, I wish to press upon the Committee this point, that the postmen in the provinces are performing the very self-same duties as the first-class clerks are doing.

LEEDs, S.-Correspondence posted within the chief office district only is first dealt with by the sorting clerk. The local is sent out in bulk to be dealt with by the sorting postmen. Each district office deals with its own local posted correspondence, sub-divides the forward into districts and divisions, picks out certain towns, labelling the same which is forwarded direct, this work being performed by postmen only. Now, my lord, we come to what is called sub-offices, i.e., country offices under the control of chief offices. In Leeds, what do we find? The sorting clerk making up and despatching these mails, but, owing to the large percentage of letters which would be mis-sent, the postmen have to go through and check the sorters' work to avoid mis-sending and complaints of delay. There is one-to us a very important point-which I must press upon this honourable Committee, viz.. the mails run late, and consequently time is limited to the outgoing mail. What do we find? Sorting postmen and stampers, etc., are used to sort up the correspondence which should be dealt with by the sorting clerk. A postman at $f 1$ s. per week is performing duty side by side with the sorter of $£ 140$ per annum, giving the same value, and owing the same responsibilities to the Department.

The Chairman: Do you mean to say that in the same office you find sorting postmen and sorting clerks standing side by side doing exactly the same work?

A. Yeŝ; standing side by side, or rather, sitting side by side, doing corresponding duties.

Mr. Walpole: Is that a preliminary division of the correspondence?

A. Yes ; that is the preliminary division of the correspondence. Stampers' duties are to change all stamps to proper time and date stamp all correspondence, assist in the despatch of mails, performing the responsible duties of sealing and sacking of bags into their respective divisions, detecting surcharges, sort forward newspapers, and perform similar duties to that of a second-class sorter, with equal hours of night and day duty. He must have 
a thorough knowledge of the train service in his respective districts, and in small towns does most of the local sorting of letters, work sorting clerks' holidays, and have a general knowledge of all the work in the circulation department. The duties of bagmen are to take charge of all empty mail-bags, and distribute them to the various roads, or send them back to their office of circulation. The men performing these duties must have a thorough knowledge of the various "roads," and the circulation of many offices where enclosures are circulated to.

The Chairman: Is the bigmen's work in the provinces all done by postmen?

A. Yes, my lord; all the bagmen's work.

Q. Is there no special class of bagmen in the provinces at all?

A. No, my lord; they are postmen receiving allowances. The duties of mail porters are very arduous, owing to the heavy mail bags and Parcel Post work combined. The gravest responsibility is also attached to this important work. As an illustration, take a railway junction-say Normanton or York. Railway connections are limited, trains run late, the mail porter on duty has bags for north, west, and south. Trains are arriving and departing from three or four different platforms; the total time is perhaps limited to three or four minutes; bags have to be exchanged, unsacked, and re-sacked. I ask, on behalf of these men, this Committee to look at the terrible anxiety passing through these men's minds for the short time. They know the full responsibility attached to forwarding a wrong bag in the excitement of the moment; they also know the Departmental view, and that punishment generally follows in the case of one being sent wrong. Can a sorter's position be of more value to the Department than this? The sorter is under the direct control of the superintendents on duty, whilst the mail porter controls his own work. He must also record all irregularities, report all bags out of course, advise by wire offices of failure of letter and parcel mails, and report to the surveyor of the district causes of failures; as a rule the mail porter performs more clerical duty than the ordinary sorting clerk. Parcel Post packers perform similar duties to sorting clerks - sort parcels in several towns, and despatch and receive parcel mails, their duties heing equal to sorting clerks. In the provincial offices there is a certain percentage of the outdoor force called holiday and sick or relief postmen. This class of postmen is employed on every duty belonging to the postmen's department. They perform the duties of assistant charge taker, stampers, sorting postmen, and all other duties which postmen generally perform, when officers are absent on sick or annual leave. The question of the stopping of allowances when off sick and on annual leave in the offices where such a rule is in force creates the greatest discontent.

The Chairman: Is it not a universal rule at some offices to pay allowances to men when they are away on holiday or sick leave?

A. At some they do, my lord, and at some they do not. I know of a case of a Manchester clerk who got none.

Q. Then the practice varies?

A. Yes; the practice varies, my lord.

Mr. Walpole: Do you know of any instance where, in the case of illness, the allowance of a charge taker was knocked off?

A. Not in the present day, but I could give cases two years ago where it was knocked off. It is only about three years since it was allowed at Leeds. I would draw the attention of your lordship's Committee to the PostmasterGeneral's decision on the question of full pay during sickness. Reg. No. 171,074 , June 16th, 1894, under regulation C., paragraph 2 , reads :- “ That wliere such illness is due to causes beyond his own control, no deduction will be made from the officer's pay." After such an explicit statement, clearly showing that wages are to be paid in full, and allowances being officially recognised as wages, and paid on both Sunday duty and overtime rate, how can this paragraph be construed for allowances to be stopped on 
sick or annual leave in several provincial offices-to note, Manchester, Birmingham, Cork, and Liverpool?

Mr. Walpole: Your whole contention appears to be that the pay covers the allowances?

A. Yes; I say it does. If a duty is paid for as overtime at the Sunday rate, as is the case, it must be considered as wages. My lord, I appeal to this Committee to inquire into these cases, and refund whatever money is due to everyone who has had the allowance stopped since June 6th, 1894. This I ask as a just reparation to these men.

Mr. Walpole: Somebody would have these allowances, even if they were stopped?

A. That is a question I cannot answer.

Q. Don't you know, as a matter of fact, that if the allowance is stopped from one man it is paid to another?

A. No; I cannot answer that question.

The Chairman: Why do you take the date June 6th, 1894 ?

A. I think that was the date it appeared in the order-book. I am also further requested to bring before your lordship's Committee the question of advising that all sub-office mail despatches be performed by sorting postmen, and the work be wholly attached to the postmen's department. In support of this I would draw your lordship's Committee's attention to the fact that postmen to-day have to check off a great percentage of the suboffice correspondence, or the sorting clerk's work, before it is despatched, to avoid mis-sents and official complaints of delay. A considerable cost of labour would be saved to the Department.

Mr. Walpole: Do you mean to say that these men had to check the sorting clerk's work?

A. I mean that the sorting clerk divides the revision, and that the postman has to check and pick out the mis-sorts.

Q. In Leeds?

A. Yes, and in many other offices. I have instances of postmen receiving, with allowances, about $24 \mathrm{~s}$. a week, the allowances amounting to $4 \mathrm{~s}$. or $5 \mathrm{~s}$., who have to check first-class sorting elerks' duties, who malse up the suboffice mails during the day, and also during the night. Further, I ask that the efficiency of performing their special duties be looked upon as an avenue to promotion before the claims of any person outside the Service are taken into consideration, thus throwing open all future vacancies to a deserving body of men, whose claims to higher appointments to-day are ignored.

Mr. Walpole: Is it not the case that this checking of letters sorted by a sorting clerk is only to find certain cases where there has been an alteration in the district? Take your own case, for instance: I am advised that in order to prevent delay at the head office, the practice has been to sort the bags from Armley and Wortley, which have just been added to the city area, in the district offices. They have been examined in the presence of a sorting clerk by postmen well acquainted with the district, to find out any letters which may have been mis-sorted. The postmen have a local knowledge which the sorting elerk has not. Is that not the check to which you refer?

A. Yes, sir. Armley and Wortley are in the district offices.

Q. Yes, they were, but they have just been brought within the city area?

A. Yes; about six months ago.

Q. And the sorting clerks had not the local knowledge of these places which some postmen had?

A. There are other offices mentioned here.

Q. I am only taking one case as an illustration; I do not want to go through the wliole list.

Sir F. Mowatt: I should like to ask one question. I observed that you read out the words "checked by postmen in the presence of the sorting clerk"? 
Mr. Walpole: Yes, it is so. They are checked in the presence of postmen well acquainted with the district.

Witness : There are about half-a-dozen offices at Leeds where this is done.

Mr. Walpole: There are some other offices, I know. I have only taken the case of one; it is the same thing. In provincial offices we find that allowances vary from 2s. to 9s. per week, according to the classification of the office.

The Chairman : Nine shillings a week?

Sir F. Mowatt: What does that represent?

A. A sorting postman at Manchester receives 9s. a week.

Mr. Walpole: That is merely retained by the existing holder, is it not?

A. I do not so understand it.

Q. That is an instance in which the Department has been exceptionally liberal, has it not, and it has to mend its ways in the future. (Laughter.)

A. If the Department has been excessively liberal on one side, it has been rather niggardly on the other. Our contention is that all officers performing similar duties and equal responsibilities to the Department should be paid on an equal footing, whether they be located in large or small towns. In support of this I would draw your lordship's Committee's attention to the high rents and cost of living in such towns as Harrogate, where the men's total maximuin wages are only 22s. per week. Harrogate is a much more costly place than Manchester, yet the allowance is only 2s. per week.

Mr. Walpole: The Harrogate case has been mentioned before in this Committee. Is it not a fact that a memorial has been addressed to the Postmaster-General asking for an increase of pay to the Harrogate postmen? Do you know that?

A. I have no recollection of it.

Q. It is a fact. I will ask you-I do not expect you will be able to answer-is it not the case that the Postmaster-General did not reply to that memorial because he said the matter was pending before this Committee, and he could not interfere with it?

A. I have no knowledge of that. In conclusion, my lord and gentlemen. on behalf of the future. and the best interest of the public service by the postmen of Creat Britain and Ireland, "with few exceptions," I am directed from a Conference held last year in the city of Glasgow, to urge upon this honourable Committee to recommend that allowances as now paid be incorporated into the weekly wage, and made equal to those of sorting clerks, their duties and responsibilities being indentical. In support of this I will quote a case of injustice which has recently occurred in Brighton. William Carter, acting sorting clerk, failed to pass on the old examination, and was offered and accepted a postman's appointment about October last year. In December he is given three weeks' annual leave, and returning to duty a week previous to Christmas, is given $3 \mathrm{~s}$. weekly allowance, which is taken from A. Talmey, his senior, who has been performing the duty for months as indoor postman satisfactorily. Talmey is pushed out on late collecting duty.

Mr. Walpole : Let me look at this case, will you?

A. Yes, sir.

The Chairman : Do you know of this case of your own knowledge?

A. I know it of my own knowledge; I saw the man on Saturday.

Q. Who? Talmey?

A. At Brighton, I saw a man $w$ ho gave me the information.

Q. Do you say it was 'Talmey, or Carter?

A. No; I saw Paul.

Q. Then you do not know the case of your own knowledge?

A. I will vouch for the accuracy of it.

Mr. Walpole: What office is he at?

A. Brighton.

Q. What rank does Talmey hold? 
A. Talmey is a postman.

Q. Do you allege this as another instance of favouritism at Brighton?

A. It shows on the face of it it is a case of favouritism. I am told this was done by the order of the Postmaster at Brighton. Here is a man who fails to pass as a sorter. He wishes to stay as an indoor man, performing indoor duties, but another man is pushed out of his place to make room for him. It shows, on the face of it, that it is a gross case of favouritism. In conclusion, I may say that, appealing to your lordship's Committee, I feel confident that they will investigate this case, and give full protection in future against the whims of capricious officials.

The Chairman: Thank you.

The witness then withdrew.

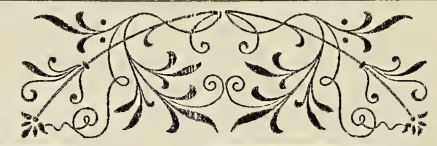


J. G. WALTON, Newcastle-on-Tyne.

Indoor and Allowancm Postmen's Case.

Westminster, Thursday Feb. 27, 1896.

Mr. Joseph G. Walton was next re-called, and further examined. He said:My lord, supplementing the previous witness on behalf of the case on postmen performing special duties, I will draw your Committee's attention to the fact of a return taken in the city office of Newcastle-on-Tyne of missorted letters sorted into walks by sorting clerks during one night's work on January 16th. No. 2,512-I may tell you, my lord, that in Newcastle the town sorters are divided into 20 walks, and the sorting is entirely done by sorting clerks. I have here a list showing the mis-sorts. On No. 1 walk there were 148 mis-sorts; on No. 2, 303; No. 3, 124; No. 4, 134 ; No. 5, 89.

Mr. Walpole: Do you mean that these were mis-sorted into the wrong walks, or were they mis-sorts in the walk itself?

A. They were mis-sorted into the wrong walks. In No. 6 there were 74 ; in No. 7, 73 ; in No. 8, 122; No. 9, 136; No. 10, 135; No. 11, 65; No. 12,90 ; No. 13,76 ; No. 14,107 ; No. 15,111 ; No. 16,30 ; No. 17,198 ; No. 18,160 ; No. 19 , 85 ; No. 20,134 ; No. 21,84 ; at Benwell, 63 ; and at Gosforth, 11 ; total, 2,512.

The Chairman: Are these in one single night, or in one delivery?

A. The early delivery (early morning post).

Q. What was the total number of letters dealt with?

A. I cannot give the total number, my lord.

Mr. Walpole: You say there are 2,000 odd mis-sorts?

A. Yes ; 2,000 odd mis-sorts.

Sir F. Mowatt: Are these mis-sorts by sorting clerks checked by postmen?

A. Yes, sir.

Mr. Walpole: You mean that the postmen put these all right afterwards?

A. They sent them back again to the sorters to be re-sorted. The men have been much delayed in getting out on their deliveries.

Q. The sorting to which you refer is primary sorting, is it not?

A. No, sir ; it is local town sorting.

Q. It is not merely primary sorting?

A. No.

Q. Why is it done at Newcastle by the sorting clerk?

A. I do not know. We had petitioned to get it altered for years, but could not get satisfaction. My lord, this system of sorting postmen has been described as an extravagant one by a witness from another class, but $I$ submit that if postmen in Newcastle were wholly employed on local sorting duties, it would be a great saving to the Department. First, a considerable cost would be saved in labour through the correspondence being correctly sorted, while a considerable amount would be saved in travelling expenses on T.P.O. work, as the following example of what is paid in allowances as between the sorter and postmen will clearly prove:-Newcastle 1: 1 st sorting clerk, 18s. per week each; Newcastle 2: 2nd, 18s. Brighton 1: 1 st sorting clerk, $£ 14$ s. per week each ; 2nd, 18s. ; 1 postman, 12s.

The Chairman: Do you mean a man gets an $18 \mathrm{~s}$. allowance? 
A. Yes; for T.P.O. work.

The Chairman: Do you mean to say that postmen would be content to do the same work a sorting clerk would do with a much lower allowance?

A. I do not say they could have a smaller allowance; I do say that they would do the work in a more efficient manner.

Q. You say it would be a great saving to the Department. Surely if the pay were the same to the postmen as to the sorting clerk, there would be no saving of money?

A. You would not then have 1st class sorting clerks to do the work.

Q. You do not propose to give them a smaller allowance?

A. I am working on the allowance received by postmen at the present time.

The Chairmain: Exactly.

Witness: At Brighton No. 9 indoor postman's duty on T.P.O. is as follows :-On duty 9.30 p.m., leaving Brighton 10.50 p.m. for London Bridge, and returning to Brighton at $8.30 \mathrm{a.m}$. the following morning.

The Chairman: What! 11 hours?

Mr. Walpole: What is his duty? Is he an indoor postman at Brighton?

A. Yes. His duty was from 12 p.m. to 8.30 a.m. on Monday, and from 9.30 p.m. to 12 p.m.

Mr. Walpole: Was this on Tuesday?

A. No ; Monday night.

Mr. Walpole : Monday night?

A. Yes; he comes on duty at 12 Sunday night, which is practically Monday.

Mr. Walpole : Was he on on Sunday night from 9.30 till 12?

A. No; he came on at midnight, and stayed till 8.30 a.m.

Q. And again on Monday night from 9.30 till 12 ?

A. Yes, sir. The duties are the same all the week, except on Saturdays.

He works $8 \frac{1}{2}$ hours on Saturdays, and that brings him up to $63 \frac{1}{2}$ lours.

I may say here, my lord, that he gets no allowance.

Mr. Walpole: I cannot make it out at $63 \frac{1}{2}$ hours. I only have from half-past nine to midnight, which is $2 \frac{1}{2}$ hours?

A. Yes, sir.

Q. What other hours are there?

A. From midnight to 8,30 a.m.

Q. Is there any interval between?

A. I believe there is an interval of two hours at London Bridge?

Q. Then this is a travelling duty?

A. Yes, sir; he is a travelling postman. He does local travelling and sorting.

Sir F. Mowatt: You said there was an interval of two hours?

A. Yes, at London Bridge, but then this man is 52 miles from home.

Sir F. Mowatt: You said he worked 11 hours a day?

Mr. Walpole: His duty is to go to London Bridge and back, is it not?

A. Yes, sir.

Q. Surely he cannot take 11 hours to travel 150 miles?

A. This man goes on duty two or three hours before he leaves Brighton.

Q. Possibly?

A. He takes on duty earlier.

Q. It is utterly impossible that the man should be kept on duty all that time if he is chiefly doing T.P.O. duty; the train would not take more than two hours.

A. He has over two hours' sorting at London Bridge Station before he leaves. He takes up the duty at London Bridge Station at $4.30 \mathrm{a.m}$. This man, I take it, works $21 \frac{1}{2}$ hours' extra duty, and receives nothing for it. He simply gets $12 \mathrm{~s}$. travelling allowance.

The Chairman: 2s. a day?

A. Yes, sir. 
Sir F. Mowatt: Have you any particulars with you? You say he goes on duty at 12 o'clock Sunday night?

A. Yes.

Q. That is at Brighton?

A. Yes.

Q. Do you know at what time the train goes to London?

A. I cannot give it to you now, as I have not it here, but I will produce the oorrect time.

The Chairman : Go on, please.

Witness : I will give a full description of his duties, which are as follows :- Open mail-bags, viz., Brighton to sorting carriage, Steyning, Henfield, Beeding, Uckfield; also Portsmouth line of bags, 9 in number. Hand letter bills and register bags to sorting clerks. On the return journey he sorts the Northern District correspondence, which is the largest division of Brighton.

Sir F. Mowatt: What is the man's name? This should be looked into.

Mr. Walpole: I think I shall identify the man easily.

A. There are several men who rotate on the duty. The man who was on duty last week was Barnes.

The Chairman: When you compare the allowances, you are comparing the allowances of postmen with those of 1st class sorting clerks?

A. Yes, my lord.

Q. You told us that the ordinary allowance apparently was 18s. per week, or 3s. per day. There are several special circumstances in which some 1 st class clerks are given 24 s., I believe?

A. Our men don't get 24s., and I believe there are some cases where men travelling with the mail only receive 9s.

Mr. Walpole: Have you those cases?

A. I have not.

Q. The first postman at Brighton gets 12s.?

A. 9s. is the allowance for postmen. I will draw attention to a sorting clerk having double the allowance given to a postman, each performing similar hours of duty, and having equal responsibilities.

Mr. Walpole: You want to extend that practice?

A. Yes; we want to extend that practice.

Witness: I now hand in a list of towns where forward news are sorted by stampers, who are held responsible for mis-sents. They are as follôw's:- Northampton, Southsea, Norwich, Dundee, Oldham, Wakefield, Greenock, Cambridge, Bury, Grimsby, Ashton-under-Lyne, Stirling, Woolwich, Halifax, Paisley, Sunderland, Darlington, Perth, Southport, Windsor, Chester, Devonport, South Shields, Wolverhampton, Birkenhead, Hull, Cardiff, Torquay, Liverpool (all foreign news correspondence is sorted by stampers), Oxford, Bournemouth, Preston, and Sheffield. Herewith also is a list of towns where local sorting is done by postmen:-Liverpool, Manchester, Glasgow, Gainsboro', Birmingham, Leeds, Bristol, Sheffield, (Bhester, Swansea, Brighton, Bradford, Woolwich, Wolverhampton, Hull, Halifax, Preston, Huddersfield, Gloucester, Norwich, Belfast, and Cardiff. My lord, with your permission, we hand in a correction to the statements of Mr. Latimer, of Birkenhead. Mr. Latimer is reported to have said that postmen who were promoted to sorting clerks senior to men holding head postmen's positions in Birkenhead, are only in receipt of $£ 1$ 4s. per week, whilst the head postman is in receipt of wages, etc., equal to $£ 24 \mathrm{~s}$. per week. This, we submit, is a gross misrepresentation, inasmuch as it is impossible for any postman to obtain wages equal to that amount with anything under 16 years' service.

Sir F. Mowatt: What? Less than 10 years' service?

A. Yes ; under 16 years' service. Whilst, on the other hand, we find sorting clerks at 10 years' service receive the full maximum of a secondclass sorter equal to $40 \mathrm{~s}$. per week. Postmen occupying such positions as head postmen must be of exemplary character. 
Mr. Walpole: Your point is, Mr. Latimer said that the head postman at Birkenhead receives $44 \mathrm{~s}$. per week, and you think he does not.

A. That is so; his allowance is only $5 \mathrm{~s}$. He has $30 \mathrm{~s}$. a week, if he is at the top of the maximum, and that would be 15 years' service; so he cannot have it. I say he gets $£ 110$ s. wages, $5 \mathrm{~s}$. allowance, and $3 \mathrm{~s}$. stripes; in all 38s.

Q. Are you sure he has only a $5 \mathrm{~s}$. allowance; there are some $7 \mathrm{~s}$. allowances in Liverpool?

A. In Liverpool, but I do not think there are any in Birkenhead.

Q. Then you allege there is a mistake of $6 \mathrm{~s}$. ?

A. Yes; a mistalke of $6 \mathrm{~s}$.

Q. Do you think Mr. Latimer was taking into consideration the revenue from Christmas boxes, uniform, etc.?

A. Charge takers do not get Christmas boxes.

Sir F. Mowatt: So you are speaking of a charge taker?

A. Yes. Charge takers, stampers, etc., do not get Christmas boxes.

Mr. Walpole: As a matter of fact, the head postman does get Christmas boxes at Liverpool?

A. I think not.

Q. I am told he does ; I do not wish to press it.

The Chairman: Mr. Latimer did include it; his statement was that the head postman received the maximum of $30 \mathrm{~s}$., stripes $3 \mathrm{~s}$. , and an allowance of $5 \mathrm{~s}$., while his boots and uniform he valued at $2 \mathrm{~s}$. per week, and his Christmas boxes at $4 \mathrm{~s}$. a week, making a total of $£ 24 \mathrm{~s}$, , against $£ 2$ for the sorting clerk. That is the way he makes it up.

A. Well, that is not correct, my lord.

Mr. Walpole: What is incorrect in it?

A. The Christmas boxes.

Q. Don't you think Mr. Latimer knows better about that than you do?

A. No, no! And then as to the question of uniform, I do not see why that should be treated as wages.

Sir F. Mowatt: You are only contradicting the evidence so far as the amount of the estimate is concerned.

The Chairman: The thing is, you do not agree with Mr. Latimer on two points? You say it is not fair to count in boots and uniform and Christmas boxes?

A. Yes; we count boots as wages, but not uniform; boots are as requisite in one case as the other.

Mr. Walpole: You count uniform as wages when it comes to the question of pension, don't you?

A. I think the Department do. (Laughter.)

Q. And you take advantage of that?

A. Well, we take all we can get. (Laughter.)

The Chairman : Thank you; that is all you want to say, I suppose?

A. Yes, my lord.

The witness then withdrew. 
GEORGE GREGORY, of Portadown.

Rurar Postmen's Case-Wages-Dispartty betwegn Town and RdRal.

Westmunster, Thursday Feb. 27, 1896.

George Gregory, of Portadown, was the next witness called and examined:-

The Chairman: You are a rural postman yourself?

A. I was, sir, for 15 years.

Q. Where? At Portadown?

A. Yes; at Portadown at one time, and at Ahory at another time.

Q. Fior 15 years?

A. Yes ; 15 years.

Q. When did you enter the Service?

A. I entered the Service in December, 1872, and was appointed on the 16th February, 1873.

Sir F. Mowatt: Appointed as what?

A. Rural postman.

The Chairman: What wages were you taken on at?

A. 8s. per week.

Mr. Walpole: How long was your duty?

A. About 4 hours and 20 minutes was the actual time of my walking.

Mr. Walpole: Were you an established postman or an auxiliary?

A. I was an established postman.

The Chairman: What was the length of your walk? How many miles did you cover?

A. About 12 miles.

Mr. Walpole: And was that the whole of your day's duty?

A. Yes.

Q. A walk of 4 hours and 20 minutes?

A. Yes; but $I$ had to be in the office at 5.30 in the morning, and did not reach home till 10 past 8 . I reached the end of my walk at 8.10 a.m., and started on the return journey at 5.50 p.m.

The Chairman: What time did you get back to Portadown?

A. At 10 past 8 .

Q. And your walk was about 6 miles each way?

A. Yes; 12 miles ai day. Then, after 14 years, I was transferred to another walk.

Q. You were on that walk till 1887 ?

A. Yes.

Q. The walk was altered, but did not go on at the same rate of wages all the time?

A. No, sir; I got 1s. a. week rise about two years after I was appointed, and I remained at $9 \mathrm{~s}$. a week, and I had $2 \mathrm{~s}$. for good conduct stripes in 1883 , I think it was. 
Q. Then you had two good conduct stripes?

A. Yes ; and that made my wages 11 s., and I was transferred to a longer rural walk extending to abont 17 miles.

The Chairman: 'That was in 1887, was it?

A. Yes; that was in 1887. I was only on it for about 8 months, how. ever.

Q. How many miles?

A. 17 miles.

Q. And how many hours?

A. $6 \frac{1}{4}$ hours was the actual time of walking, not counting the time I was sorting letters before I started, or sorting them after I came back.

Q. Then I suppose you did nearly 8 hours?

A. Yes, sir.

Sir F. Mowatt: And what were you paid for that?

A. I had 16s.

Q. Including stripes?

A. Yes ; including stripes. I had 14s. wages and 2s. stripes; the third stripe was due at that time, and it was only when the surveyor saw me and noticed that my stripes were bright, that he asked, "Was I not one of the men recommended for another stripe?" At that time I had held two stripes for seven years, and I told him so, and he asked why I had not got more stripes. I said I did not know. He asked why I didn't know. I told him I had made application. Then he asked me if there was anything against me. I replied, "I think not." And then he said, "I will look into it. He did so, and in a few weeks I got my third stripe, with \&2 17s. back pay.

Mr. Walpole: Then they treated you pretty fairly?

A. Yes, they treated me pretty fairly; but when I asked about the stripe in the post office, they told me that when it was due to me it would be sēnt to me. I do not look upon such an answer as that as satisfactory to a man.

The Chairman: You were only eight months on that long walk, were you?

A. Yes. I was next transferred to the Parcel Post department at Portadown, as a packer and porter.

Q. When was that?

A. In A pril, 1888. I took the long walk in August, 1887.

Q. What wages did you then get?

A. 16s. a week with stripes, and a 2 s. allowance.

Q. The wage was then exactly the same?

A. Yes; 14 s., with 2s. allowance, and 2s. for stripes. I remember I made a mistake just now. It was after I came to the Parcel Post department that I got my third stripe.

Q. What point have you reached?

A. I am not at the maximum.

Q. You are still increasing then?

A. Yes.

Mr. Walpole: Your pay rises from 16s. to 22s.?

A. Yes.

The Chairman : By 1s. increments?

A. Yes.

Q. Now you are getting 20s.?

A. I am getting 21s. a week wages, which, with the allowance and stripes, makes 26s. a week.

Mr. Walpole: I thought you said you were transferred in 1888?

A. Yes, sir.

Q. And you could not be at the maximum now, then?

A. No, sir; I have 23 years' complete service. I completed the 23 years yesterday fortnight. I ain now in my 24 th year.

Mr. Walpole: I am glad to see you are not looking very exhausted from your labours after 24 years. 
Witness : I have done a great deal of labour in my time, but I am thankful to say I am blessed with a strong constitution. I was never off a day sick, except when I had typhus fever, and then I was off for eight weeks; that was about eight years ago. I had very hard work to do at that time. I think my complaint in reference to being kept so long on a rural walk will bear out some of the statements made by these men. There were, when I entered the Service, boys at school in the town to which I belong, who got into the P.O., and are now sorting clerks, having passed over the heads of postmen. I do not say by farouritism exactly, but still they were pushed on.

Sir F. Mowatt: They came in as postmen?

A. Yes; as postmen.

Mr. Walpole: At Portadown?

A. Yes; and they got these opportunities of promotion, while I was kept on a rural walk. They were put in as town postmen, and whenever I made an application I was told that telegraph messengers had a prior claim to me. That was the answer I got to the applications I made. I know that when the Parcel Post commenced in 1883, I thought I had a chance, but strangers were taken in who had never had any connection with the Post Office at all, and these were given 16s. a week, while I only had 13s. I had already got two good conduct stripes.

Q. Do you know any telegraph work?

A. No, sir.

Q. I presume that at Portadown a sorting clerk is of necessity required to know telegraphic work?

A. Yes.

Q. Might not that be the reason why you were not chosen for a sorting clerk's place?

A. Well; the application I made was for a town postmanship.

Q. I beg your pardon; I thought you made application to be made sorting clerk?

A. No ; town postman. These other men got in, and were allowed to learn telegraphic work while doing postmen's duty, and they were then transferred to the sorting clerk's duties.

Q. Your complaint then is, that these men were appointed town postmen with a shorter service than you had?

A. Yes, sir.

Mr. Walpole: I quite understand that.

Witness: I now come to the question of the disparity of pay between town and rural postmen. As to why there should be such a disparity between the wage of town and rural postmen located at the same office has never received a satisfactory reply, officially or otherwise. To examine the matter in detail. The cost of living is just as expensive for the rural man as for the town man. Rents are equally high for the one as the other. If the town postman's wages are inadequate-as they undoubtedly are-what is the case of the rural postmen, with from $2 \mathrm{~s}$. to $7 \mathrm{~s}$. per week less?

The Chairman: Doing the same hours?

A. Yes ; and doing the same class of work.

Q. Is that at Portadown? Have you a town postman there?

A. Yes.

Q. And what is the difference?

A. The difference there is $3 \mathrm{~s}$. , and $19 \mathrm{~s}$. is the maximum for the rural postman, and 22s. for the town postman. This, of course, excludes stripes and other allowances.

$\mathrm{Mr}$. Walpole: It rises from $15 \mathrm{~s}$. to $19 \mathrm{~s}$. for rural postmen then?

A. Yes, sir.

Q. And from 16s. to 22s. for town postmen?

A. Yes, sir. If the one is inadequate, the other must be starvation 
wages. If the town man finds it difficult to make both ends meet, when he is always at home for his food, how must it be with the rural man, who is obliged to keep a home near the head office, and pay for lodgings and meals away from that home every day? On the ground of responsibility no difference can be justly made. The rural postman has just as much responsibility as the town postman. Rural postmen require a more varied knowledge of postal arrangements than town postmen. They are the means of distributing the information on postal matters which is done by counter clerks in town. The public in these districts prefer to ask the rural postman rather than the sub-postmaster, as they get a more satisfactory answer from him. If the questions that a rural postman has to answer on behalf of the Department in a year were tabulated, they would form a goodsized book. The postal conditions are always varying, and in order to keep himself informed of these varying conditions, a considerable portion of his leisure is occupied in making himself acquainted with the questions which he knows may be asked. With matters of this kind, a town postman has no trouble. He can refer his questioners to the counter clerk. The property entrusted to his care may not be as much in quantity, but the value in proportion will be higher, and he will have it longer in his possession away from the controlling eye of the officials at headquarters. Taking these things into consideration, it is bad policy on the part of the Department to pay men several shillings per week lower than town men for no other apparent cause than that they do their work in rural districts. The Department gives these men responsible work to do, and entrusts them with valuable property for delivery; it also recognises them as doing a full day's work. Now, to pay these men from 2s. to 7s. per week less for doing exactly the same class of work is simply, to say the least of it, pubting temptation in their way, and such conduct is not creditable to a public Department.

Mr. Walpole: When you say from 2s. to 7s. a week less, you mean that the maximum is from $2 \mathrm{~s}$. to $7 \mathrm{~s}$. less?

A. Yes, sir.

Q. Not that they are paid that?

A. In Portadown the rural man gets $15 \mathrm{~s}$. , the town man 16s.; then the latter rises $3 \mathrm{~s}$. higher than the former.

Mr. Smith : Is it usual in other places?

A. Yes ; in Belfast, for instance, there is a difference of $7 \mathrm{~s}$. in the maximum.

Q. Is there usually a difference in the minimum between rural and town postmen, or is it peculiar to these cases?

A. There is a difference of from 1s. to $3 \mathrm{~s}$. Having in view the fact that the cost of living is the same for town and rural postmen, and that the responsibility is identieal, while in some respects rural postmen's conditions of service are more exacting, we consider that circumstances justify similar treatment to town and rural postmen in the matter of wages and other emoluments. I now come to the case of rural postmen and their hours of duty. The question of rural postmen's duties is a burning one, and I will ask this Committee to give a very careful consideration to it on behalf of the rural postmen of England, Ireland, and Scotland, as I have some cases which I can quote which will show that the complaint is justly made. In the case of any postman, the hours of duty are spread over too many when they exceed 12 hours daily. Is there any public need for it, as far as the rural postmen are concerned? In a few districts it may be necessary, but when examined closely these districts will be found to be few and far between. I have always been of opinion that a 12 hours' day on a rural walk, if made a rule of the Department, would satisfy the public generally, and it is long enough, year in and year out, winter and suinmer.

Mr. Smith: Do you mean a 12 hours' day? Do you mean the duties to be spread over that period? 
A. Yes, sir.

Q. You do not mean 12 hours' work?

A. No, sir.

Q. What, in your opinion, is the advantage of having it confined to 12 hours instead of 13 or 14 ?

A. I will explain that further on.

Q. You are going to develop it, then?

A. Yes ; I am going to develop it. Most of these walks are early morning and evening walks; a man has to leave home early in the morning, and cannot return until the evening, and he is expected to stay out in the country all day.

Mr. Smith : Cannot he get home?

A. No, sir, he cannot get home; and some men who are on these duties are obliged to have lodgings out in the country, where they can spend the time they have to wait.

Q. Then they have to be away from home the whole period?

A. Yes. When I was on a country walk I had to leave home very early. I was obliged to be in the office at 5.30, and it took me ten minutes to get there, and I did not get back until about 8.30 in the evening.

Q. Where did you spend the intervening time?

A. Wherever I could. When not engaged at anything, 8s. or 9s. was my wages, but I may say I had a special advantage, because I knew something of the linen trade, which at that time was very good, and I was able to get some work to do at it; still, under the circumstances. I did not get half the value of my work.

The Chairman: What was the name of the place where you ended your walk?

A. Crabtree Lane.

Q. Were there linen works there?

A. Yes; hand-loom linen weaving works. I gained a knowledge of the trade as a boy, but I was only half-paid for what I did, because I could not give my whole time to it. I was doing double what I should have done for the money.

Mr. Walpole: Your work for the Department lasted $4 \frac{1}{2}$ hours, did it not?

A. Yes; the walk took $4 \frac{1}{2}$ hours.

Q. You had leisure at this place where you stopped from 8.10 in the morning till 6.10 at night?

A. Yes, sir.

Q. And during that time you worked at the hand-loom weaving?

A. Yes, sir.

Mr. Smith: I understand that your objection to a longer period than 12 hours chiefly turns on the fact that a rural postman, by reason of the nature of his duties, cannot get home in the middle of the day?

A. That is so.

Q. And you advance it as a special reason in the case of a rural postman?

A. Yes, sir. And another point is that this limitation would give them a better opportunity for social enjoyment and self-improvement, an opportuuity which every young man should have, if possible. In order to meet any objection that might be made by those who are opposed to allowing the rural postman to return to his head office in the 12 hours from starting in the morning, let them make out their claim for consideration, and if they are in earnest, and want special facilities, let them pay a proportion of the cost towards giving the rural postman overtime pay for the number of hours he is detained through them from returning to the thead office over 12 per day. If this were done, it is wonderful how many grievances (called public ones) disappear when they require paying for, if even a small proportion of the cost is asked for.

Sir F. Mowatt: Do you think it would have the same effect on the Post Office to state grievances thus? (Laughter.) 
The question was not answered.

Witness : When a question of this kind is raised, there are to be found, in every district, eccentric persons who have hobbies of their own. Very probably one of these is in opposition to change of any kind, however beneficial it may be to the public in general, but if such changes are for the benefit of the few, they raise that very pointless, but convenient cry-"Tlie public interests will suffer from the proposed change." Some of these persons, if they had their way, would keep our rural postmen out till midnight if it served some hobby of their own, and call it a public grievance, if it were not granted. We lay strong emphasis on tliese points, but while we do so, we as strongly protest against anything detrimental to the public selvice being in our minds. We declare ourselves willing to serve the public to the best of our ability, individually, and as a body. But we respectfully ask that the public be served, and not a few favoured individuals. If the public service requires it, we are prepared to yield without a murmur to the long hours, and do our duty to the public to the best of our ability. But we maintain that in the vast majority of cases the public do not require the services of rural postmen longer than the time mentioned. To go into particulars. A rural postman has his delivery over within four hours from the time he leaves the head office. If his day was to be completed in 12 hours, that would allow four hours for replies to be made to letters he delivered in the morning at the end of his walk. That is, supposing a man to be four hours on the outward journey, which is not always the case. It is a general rule to finish the outward walk in from three to three-and-a-half hours, which would leave from five to six hours for replies at the end of the walks. These hours would allow ample time for rephies. None would have less than four hours at the extreme end of the walks, and some would have as much as six, and yet the rural postman's day's work could be completed in 12 hours. We ask for the rural postmen of the United Kingdom the most careful consideration of this Commission, as to their long hours of duty. Another phase of the question is that a rural postman does not walk or work eight hours per day. We consider that any man doing 11 miles' walking per day, and being absent from head office for 12 hours, should be considered to have done a full day's work, and that 16 miles should be the limit of a walk - for a travelling rural postman.

Sir F. Mowatt: What is the limit now? Is there any limit?

A. There appears to be no limit.

Mr. Walpole: Can you give us some of these extensive walks?

A. I liave 42 here.

Q. Over 17 miles?

A. Yes ; 17, 18, 19, and 20. There is one at Skipton which is 17 , and another 20 miles per day. One at Slough 18, and a second 20, each of these representing a walk. One at Grimsby of 18 miles.

The Chairman: Are these cases where the postmen have to go on their feet?

A. Yes, my lord.

Q. Have they no cart?

A. They have no cart; they are not even mounted.

Mr. Walpole: Are you sure of that?

A. I know of it in one or two cases. I had the information from the men themselves.

Mr. Walpole: One of the regulations is that Postmasters in rural districts shall be asked to report any cases in which they have reason to believe the walk of rural postmen in rural districts exceeds a distance of 18 miles a day, or involves actual walking for over 6 hours. It is laid down that these should be the maximum limits in any office, and where the roads are heavy and the districts difficult ones to traverse, these limits should not be reached. That is the rule of the Department. 
A. I was not aware of that rule. However, I can give you a few 20-mile walks that might be looked into. I will hand in my list.

\section{Examples of Long Watiss.}

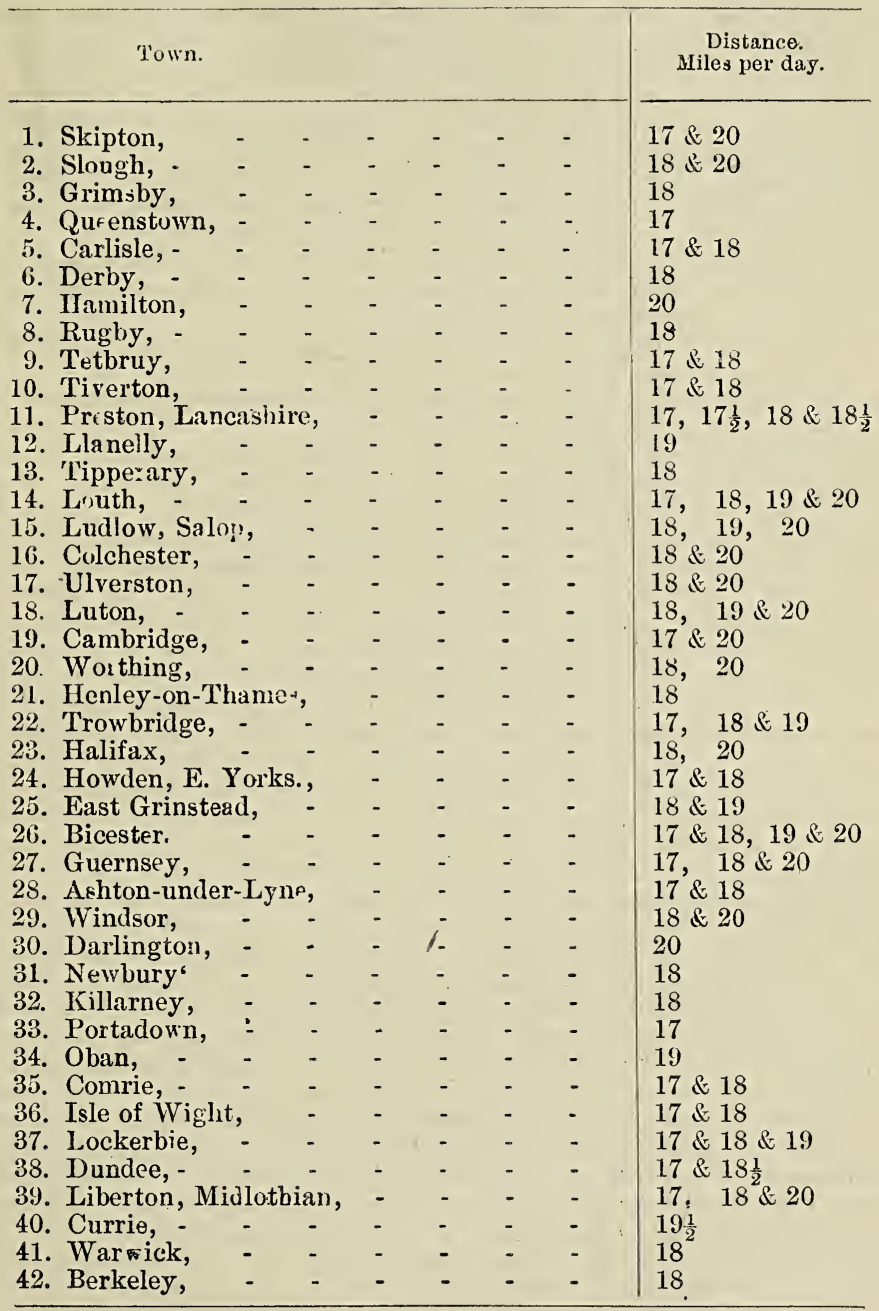

Mr. Walpole : You have no particulars about these walks, have you? For instance, you cannot give me the Colchester walk, can you? I happen to have seen the Colchester office, and know that many of the rural postmen there are mounted.

A. I took these from a list of cases supplied to me as being walks on which the men were not mounted. I find in one or two instances that the men are mounted for a short distance; they are walking rural postmen 
with 20-mile walks. That is according to the information that has come into my hand. I can get you more particulars if you wish.

Mr. Walpole: I think the Colchester men must be mounted part of the way.

A. We distinctly asked them at Colchester whether they were mounted or not, but they have not given us the information.

Q. Then they have not said they are unmounted?

A. They have not said they are unmounted. I will try and supply papers on this point after the adjournment for luncheon. You will see at Darlington there is a walk of 20 miles.

Mr. Walpole: If there is any particular case you want me to look into, perhaps you will try and identify the walks. That will help us very much. There are a great many rural walks in each town.

A. The papers I took this information from are at my hotel, and I will bring them here; they will show the name of the man, the length of his service, his pay, and other particulars.

Mr. Walpole: I only want to remedy any grievance you can point out. You are aware of that?

A. Thank you, sir. I will bring the papers with me this afternoon.

Mr. Walpole: Thank you.

Witness: Now we have dealt with the disparity of pay and the hours of duty, and I propose next to take into account the social question, and $I$ wish to draw the attention of the Committee to the social disabilities under which rural postmen labour. Take the rural postman as a social being in relation to his duty; 14 hours represent the time a day's work is spread over for a large number of rural postmen. Of course, this is only a medium case. He leaves home shortly after 5 o'clock in the morning, and does not return till after 8 at night. When he gets refreshments it is about 9 o'clock. It is then too late for any social enjoyment, or to attend classes for his improvement; besides, he has only about 8 hours to rest before he commences the same weary round again, and this goes on from week to week, 13 days out of 14 (speaking generally), from one year's end to the other, the only relief from it being his short annual leave. To a young man it is very tantalising io see others enjoying themselves, while he is debarred, owing to the nature of his duties, from the same enjoyment, and no certain hope of change. Such a change, if it does come, will be by happy chance rather than any right he may have to claim it, and even others, with less service, pass him in the race and obtain the coveted change. Again, take a rural man with a family, and perhaps sickness in it; he leaves home about 5 o'clock a.m., and does not return till 8 or 9 at night. What changes may have taken place there in that time, as 16 or 17 hours make great changes, particularly in diseases to which children are liable? He is inactive for 7 or 8 hours of this time, and naturally turns over the question in his mind why he should be kept out so long, but can find no reasonable answer. Owing to the nature of his duties he is debarred from:-(1) Self-improvement; (2) social enjoyment; and (3) home comforts; and (4) performing social obligations. These things go on year after year without hope of redress. We have already recommended that the covering time over which the rural postmen's daily work is spread should be contracted, and in the majority of cases we see no bona fide difficulty in accomplishing this. But in those exceptional cases where it would be found impossible to compress the day's duties within the 12 hours, we recommend that the rural postmen on those bad duties should have first claim on vacancies of other duties where the day's work was compressed within narrower limits. At present telegraph messengers are preferred for town duties to rural postmen, and we are of opinion this should not be the case.

Mr. Walpole: Now, in your own experience when you were a rural post man, you started on the return walk at 5,50?

A. Yes, sir. 
Q. What do you think the public would have said if the Department had directed you to start at 3 o'clock instead of 5.50 , in order that you might get home at 5.30 ?

A. My impression is that they would have met the case without a murmur. (Laughter.)

Mr. Walpole: Then the public around Portadown are much more amenable than the public in most places, for we have had murmurs when we have altered a post by only 5 or 10 minutes.

Witness : Was that a rural post?

Mr. Walpole: No; a town post.

Witness: That is a different thing altogether. A place where you have business men requiring to send letters up to the last moment, and possibly not knowing what they are going to do till the last moment, is very different from a country district: My experience with town work has been that business men up to the last do not know exactly what they are going to do; they have to wait to get the closing prices of the market; but in country districts it is different. They get their letters in the morning; they can soon decide what they are going to do, and in almost every case their letters are ready hours before the postman is allowed to start home. I may say that on one occasion during the winter, some of the people on my walk thought it was a pity I should be kept out so late, so they approached the Postmaster and asked if the arrangement could not be altered. One argument they argued was that there was no mail going out for three hours after I came back to Portadown, whereas there was a mail going out half-an-hour before I arrived. That was the Scotch mail, and it was suggested that it could be arranged to catch that, but the reply was that it could not be done.

The Chairman: Would it be convenient to you to have returned at 6 or 7 o'clock when you were working in the linen factory?

A. I would have been glad to have dropped that in order to get an opportunity of improving myself. I should have considered it a boon. The same complaint is made by others. If I had been allowed to return by 7 o'clock the Department would not have been inconvenienced, and the ruial postmen would have reaped the benefit.

Q. Do you suggest that a rural postman's duty is harder than a town postman's duty?

A. The duties are in many ways harder. They are harder in this way: they have a longer stretch to walk, they are exposed to the weather at least 3 or 4 hours at a time, and, suppose it is raining, they have no shelter for themselves, whereas, in a town or city like London, much of the men's work is done under cover. Again, if there is snow on the ground, they find the walking very heavy. They feel they are subjected to unjust treatment, and consider it very hard. They have to tramp with a lieavy load of parcels, and deliver them in the dark. In my own case, for three months in the year at least, the greater portion of my delivery was over before it was daylight at all. I consider that, in that respect, too, our duties are much harder. I now come to the next point, which deals with the want of accommodation at the end of our walks. Many rural postmen have to wait more or less time at the end of their walks before they make the return journey to the head office. When rural postmen arrive at the end of their walks, of course they are free to go where they like, but, in nine cases out of ten, where can they go? Their scanty wages will not allow to pay for accommodation at the outward end of his walk, and provide for a home at the starting point. To return home is out of the question, in fact, impossible. Where a walk terminates in a rural district it is principally farmers' houses that are in the vicinity, and they will not allow a stranger to be always hanging about the place. It may be tolerated for a while, but, as the rural postman is not an occasional visitor, but a daily one from one year's end to another, they soon tire of him, or bear with him as a necessary evil which must be put up with. When this state of affairs arrives, 
these people are not long in making the rural postman feel that he is tolerated in a place for charity's sake; his better nature revolts against it, and his manhood will not allow him to accept a charity grudgingly given, no matter what the consequences may be to his health. Take a man arriving at the end of his walk after travelling eight or nine miles on a wet morning, probably wet to the skin, and obliged to go about under the hedges or any other shelter he can find, getting more wet perhaps, and remaining in that state from five to ten hours, according to the time for starting on the return journey.

Mr. Smith: Have you known any case of that kind?

A. Yes; I have known cases of having nowhere to go to.

Q. Having nowhere to go to?

A. Yes; I have known such cases. It might have been my own case if I had not possessed the knowledge I did of the linen work; it was only that which enabled me to stand it.

The Chairman: Could you make any arrangements at the end of your walk by which you could change your clothes?

A. No, my lord; I hadn't any clothes down there.

Q. Didn't you keep a change down there?

A. No, my lord; but when I made arrangements to work at the linen business I used to take clothes down. If, however, I had not been able to pay for a place to stop in, I should have had nowhere to go to.

Q. Then you took a room there yourself?

A. Yes, my lord. Trip allowances are made to men employed in the travelling P.O., and rightly so, when they are away from home for their meals. Provision is also made by the Department in many cases where men are prevented by the nature of their duties from getting home for their meals. If this is done for one class of postal employees who are on a higher scale of pay, we are of opinion that the rural postman is equally w urthy of consideration. He leaves home very early in the morning, and does not return till late in the evening. Yet no provision is made for this man by the Department; the only thing it does for him is to pay him from two to seven shillings per week less than postmen on town delivery, who can get home to their meals. The health of these men and their ability to perform their duties with freedom from preventible illness, caused by exposure to the weather, wet clothes, with uncomfortable and irregular meals, should be carefully looked after, from a financial point of view, by the Department.

Q. Have you any estimate showing the amount of sickness among rural postmen?

A. I have not a return showing the difference, but this I do know, that rural postmen are oftener off on sick leave than town postmen, and that this is one of the causes. Through their constant wettings they get stiffness in their joints after years of exposure such as this. These things contribute to the rural postman's difficulties.

The Chairman: You do not know anything about the average death rate amongst rural postmen, do you?

A. I do not, my lord. The only evidence I have as to that was the testimony of Dr. Wilson, who did not draw any distinction between town and rural postmen.

Sir F. Mowatt: Do the Department supply waterproof capes to the rural postmen?

A. Well, they call them waterproof capes. (Laughter.) They are called waterproof capes, but when you are out in a shower the inside of the cape is equally as bad as the outside.

Mr. Walpole: Are you referring to tle new capes issued last year?

A. No; we have never seen any of those at Portadown.

Q. 'They are given you every second year, are they not?

A. No ; every third year. 
Q. As a matter of fact, we have issued a new pattern cape, which I hope will prove more satisfactory.

A. I am very glad to hear that. I found it very difficult to carry my parcels safely with the old cape, for if the inside got wet and rubbed against any cardboard boxes, the latter would break open and the contents would be lost.

Q. Well, we are trying some new ones, and I hope you will get one some day.

A. I do not want one so much now. At the same time, I should be glad to know, on behalf of my rural comrades, that they are to be put in a better position in this respect than I was.

Mr. Walpole: We are trying two patterns.

A. I am very glad to hear it. There is another class of men who are m.cre dangerously situated still. These are the men whose walks termirate in villages, or where there are public-houses in the vicinity; the temptation is to go there and spend the time at their disposal. They will be sheltered from the weatler, but the landlord of the public-house will not give much countenance to a man hanging about his place who is not leaving him some money, and, meeting with acquaintances, the man naturally falls into the trap, and habits of intemperance are formed which would never have been contracted had the Department done its duty by these men. The recommendations which find most favour with the men are as follows:-(1) An allowance of 2s. 6d. per week to provide a room and fuel to cook his food and dry his clothes, etc.; or (2) an alternative payment at the rate of $1 \mathrm{~d}$. per hour for every hour they are obliged to wait at the end of their walks.

Mr. Smith : Can they always get a room? I thought your point was they could not?

A: No, they cannot always; and therefore I suggest there should be some compensation for not being able to get a room.

Q. It would not be so useful for him as a room, would it?

A. It would not.

The Chairman: Which of the two recommendations do you suggest?

A. I think that where a room can be got the allowance of $2 \mathrm{~s}$. 6d. a week would be best. That is my own opinion, my lord. Those in favour of the first proposition argue that if an apartment is taken the postmen will have just as much to pay for it if he only occupies it two hours daily as if he occupies it continually. Those in favour of the second proposition argtie that those who have the longest to wait get a corresponding allowance. There is still a large body of rural postmen, probably 800 to 1,000 scattered over the country, who, when they get to the end of their walk, can find no suitable place wherein to stop. There are cases where they would have one, two, or more miles to walk before they could get a suitable place. In such cases a rest or hut should be erected at or near the end of such walks, of such dimensions as would enable them to have a small stove for heating and cooking purposes, and keep a change of clothing and other necessaries for his comfort and convenience. In cases where the rests are provided, the allowance asked for rent and fuel would be changed to allowance for fuel, which would amount in these cases to 1s. 6d. per week. Another point before leaving this very important subject. If these moderate recommendations should be sanctioned, the men receiving them should give guarantee and proof that the sums granted for these purposes were expended for their comfort, health, and convenience, and not for their own personal gain or other purposes. We recommend for the benefit of the Service that something of this kind should be done by the Department. $W e$ are only asking as a body what is reasonable for the conditions of service we are called on to perform, and we do not countenance for a moment any individual diverting to his private use what is intended for his health, comfort, and convenience. I now come to the case of the auxiliary rural postmen. I heard Mr. M'Taren's statement, and I thoroughly 
concur with all he said, but still I think there are one or two points in which the case of rural men has not been brought out so well as it might be. These are a class of men that are to be commiserated. They are to all iutents and purposes servants of the State, but oh! what a mockery, when their pay and position are examined. They do a few hours' work in the day, and are obliged to be on at the same hour every day, speaking generally, for which they receive a miserable pittance-it can not be called pay. They are saddled with all the responsibilities of postmen, and they receive about $4 \mathrm{~d}$. per hour, and some even less. In many cases their walks are laid out, and arranged with such regard to time that, from the start to the finish, it is almost a race to accomplish it in the time allowed. The lot of auxiliary rural postmen attached to sub-offices is not a happy one. The Department sets such a bad example of sweating to the sub-postmasters and sub-postmistresses that they prove very intelligent pupils, and are very quick to apply the knowledge so gained to their own pecuniary advantage. For example, should the S.P.M. be a farmer, the auxiliary, or auxiliaries, as the case may be, have to or are expected to do a lot of menial work usually performed by a maid of all work, such as carrying water, preparing food for cattle, and, in some cases, milking. Again, should the S.P.M. be a grocer or a general dealer, as a great many of the rural S.P.M. are, the auxiliaries are looked upon as sort of light porters attached to the establishment, and they have to convey the parcels of the S.P.M's. customers, and put up with all the whims of both the S.P.M. and his customers.

Mr. Walpole: Are these auxiliaries men who deliver letters under an allowance to the sub-postmaster?

A. Yes; in some cases.

Q. We make an allowance to the sub-postmasters for the delivery?

A. Yes, sir.

Q. And he gets the letters delivered by his servant, or by one of his family, or does it himself?

A. Yes; but some of these men I am referring to only get $3 \mathrm{~s}$. $6 \mathrm{~d}$. I am informed that $3 \mathrm{~s}$. 6d. is allowed to sub-postmasters, and that nothing above $3 \mathrm{~s}$. 6d. comes under the term of "auxiliaries, or unestablished postmen."

The Chairman: In these cases do not the sub-postmasters pay the men anything in excess of the allowance?

A. No; I have no knowledge of any case where that is done. I have inquired of a lot of men all over the country, and they tell me they do a lot of this extra work in order that they may be allowed to do the work in connection with the Post Office If any objecion is made by these men to this state of affairs, they are told by the sub-P.M. that if they do not like the conditions they can leave; and if a man is independent enough to refuse to do the work, the sub-P.M. contrives to have him removed shortly after such an unpardonable action as refusing to do their menial work.

The Chairman: But if the postman makes an official complaint it must be forwarded?

A. Ah! but the sub-postmaster generally talks the rural postman out of the idea of forwarding the report.

Mr. Walpole: It is the Irish sub-postmasters that do that. (Laughter.)

A. I suppose it is the Irish sub-postmasters I am talking about just now, but I am sorry to say there are as many bad cases in England and Scotland as in Ireland. (Hear, hear.)

Mr. Walpole: What I ventured to suggest was that the English Postmaster had not the same capacity for talking as the Irish. (Laughter.)

A. Well, some gentlemen in England have quite an equal capacity. I need not go any further than to mention Mr. Gladstone; who is master of them all. (Hear, hear, and laughter.) I do not like to hear anything said against Irishmen in that respect if it is intended for a slight, but I suppose 
I may take it as a compliment when you suggest that they are able to talk the auxiliaries out of the idea of forwarding the reports?

Mr. Walpole : Certainly. (Laughter.)

Witness: If complaints are made the sub-P.M. thinks he has no right to forward such, and generally gives a plausible excuse for the complaint made, and shows the complainant that if he follows the course indicated in the report he will land himself in a worse plight than he thinks he is in now. By means similar to this, reports never come to light, while a glaring injustice is done to the auxiliary class, and glossed over by the sub-P.M's. to their own advantage. Most of these men have gone to the sub-offices as boys, and have continued on from year to year, in the hope of one day being recognised and put on the established service; thus they have drifted on from year to year, losing heart and hope, and doing their work in a half-hearted manner, believing, in their own minds, if not using the language audibly, that the Department knows nothing, and cares less about them, if it can only manage to get the few hours' work it wants done every day out of them at the sweating rate it pays them. The Department allows these men a tunic and trousers once a year, together with a cap, and an overcoat once in two years. These are very good arrangements as far as they go, but they are not supplied regularly, sometimes not at all. What has been said about misfits supplied to appointed inen applies with almost double force to the auxiliaries, as they only receive once a year part of a suit, and often when misfits come and have to be sent back they are never heard of again. (Laughter.) If application is made to the sub-P.M's. they will hardly think it worth their while to forward such application on behalf of this down-trodden class of public servants, thus in one way or another he is done out of some of the benefits he is allowed by the Department. All the hope and pride which those men should take in the Service is taken out of them by the two sweaters under which he serves, i.e., first the Department, which pays them from $3 d$. to 4d. per hour for doing very responsible work, and, after having performed that part of it, the sub-P.M's. finish what the Department commenced in the way already described. I would here put in a few examples of rural unestablished and auxiliary duties:-Dudley-Hours of attendance, 6.30 a.m. to 10 a.m., and 3.30 p.m. to 5 p.m. ; wages, 17s. Exeter-Hours of attendance, $6.45 \mathrm{a} . \mathrm{m}$. to $10.40 \mathrm{a.m}$., and $5.30 \mathrm{p.m}$. to 7.25 p.m.; wages, 18s. ; length of service, 25 years. Campden (Glos.)-Hours of duty, 7.45 a.m. to 11.40 a.m., and 3.30 p.m. to 5.30 p.m.; wages, $14 \mathrm{~s}$.; length of service, 20 years. Campden (Glos.)-Hours of duty, 7.14 a.m. to 10 a.m., 3.30 p.m. to 5.30 p.m.; wages, 9s.; length of service, 5 years. Rillinsdrisk (Co. Cork)-Hours of duty, 9.35 a.m. to 1.40 p.m., and 3.15 p.m. to 4.25 p.m. ; wages, 17s. 6d.; length of service, 35 years. Taunton-Hours of duty, 5.30 a.m. to 9.20 a.m., and 3 and 4 p.m., also collection 8 p.m. to 9 p.m. ; wages, 14s. Barnard Castle-Hours of duty, 8.40 a.m. to 12.15 p.m., and 1 p.m. to 4 p.m.; wages, 15s. King's Langley, R.S.O. (Herts.) Hours of duty, 7 a.m. to 9.50 a.m., and 3.35 to 6.40 p.m. ; wages, $16 \mathrm{~s}$. Preston (Lanc.)-Hours, 5.30 a.m. to 9.15 a.m., and 3.30 p.m., 6.15 p.m.; wages, 17s. Limavady-Hours, 7.40 a.m. to 11.10 a.m.; wages, 7s. ; length of service, 20 years. Portadown-Hours, 6.40 to $9.35 \mathrm{a.m}$, and 4.50 to 7.10 p.m. ; wages, 11s.; length of service, 10 years. Dundrum-Hours, 7.55 a.m. to 9.50 , and 11.45 a.m. to 12.25 p.m., and 3.30 p.m. to 4.25 p.m., and 7.45 to 9.45 p.m. ; wages, $13 \mathrm{~s}$. ; length of service, 9 years.

Notw.-In some of the foregoing cases the interval of duty is really of no use to the men concerned, as it occurs at the outward end of their journey, and, even in the case of those who are able to return home, their day's work is so broken up that it is out of the question to expect other employment.

The Chairman: Are these auxiliaries employed to do the same walks as the established men?

A. They do similar walks and similar work; they may not be doing 
exactiy the same walk as the established man, but they are doing similar walks which require as much time.

Q. In the first two of these cases they have higher wages, have they not?

A. Yes; but that does not occur in many cases. The unestablished men get their hours occupied; they have no leisure hours and very short pay. The instances $I$ have cited are taken at random from the papers I have received. In some cases they have to make two or three attendances, and in some there are even four attendances spread over the whole day, some of them extending to 16 hours; yet they are not established, they cannot get either holidays, pensions, or stripes; they have to stand still, for they can rise no higher.

Mr. Walpole: Are these town postmen you are referring to?

Witness : No ; rural.

Q. But surely no rural postman does five attendances a day?

A. Well, there are several with three attendances-two in the country and a station delivery. It is complained that, though they are called auxiliary rural postmen, and are clothed as such, they ought to come under the head of town postmen, as they do part of town postmen's duties.

The Chairman: The list you have put in shows mostly two attendances?

A. Yes; but some of them show three attendances. These hours in a good many cases represent the time when the men arrive at the end of their walk, and not the time when they retarn. The note attached to the list I liave put in shows that these men, although they receive very small pay, and unestablished, yet from the nature of the duties they perform, it is utterly impossible for them to obtain other employment. I am referring, of course, to the broken nature of their duties.

The Chairman: Do you wisl this put in?

A. Yes, decidedly; I have put in cases of long walks, giving examples of the hours which men have to do.

The Chairman: In none of those cases did you say how many hours the men are employed?

A. No, sir ; the table only shows the distance for each walk.

Q. What men are they?

A. Established men.

Q. Established rural postmen?

A. Yes.

Q. This refers to the first part of your case?

A. Yes; I should have handed you the list when I was dealing with that part of iny case.

\section{RECOMMENDATIONS.}

(1) What is asked for on behalf of these men is that they be paid 6d. per hour for every hour they are on duty, and, should they be required to come on duty a second time with one hour or less between them, that it be reckoned continucus duty.

(2) That they be paid for Sunday duty the same as the established force.

(3) That there is no obstacle in the way of amalgamating four-fifths of the rural auxiliary postmen's. work, and thereby absorbing them into the established force as vacancies occur.

(4) While they are auxiliaries they should have one complete suit of uniform every year, and cape, overcoat, and leggings at the same time as established men.

(5) 'That they should be made free from the control of the sub-P.M's. after their duty is done to the Department.

(6) That they be allowed one week's holiday in the year, with half sick pay and the boot money allowed to the established men.

Mr. Walpole: But, Mr. Gregory, a postman who is an auxiliary postman, would not be at the disposal of the sub-postmaster, as you call him, after his duty was performed, would he? 
A. He has to be more or less.

Q. Are you not confusing two men, the auxiliary man and the man employed by a sub-postmaster under an allowance?

A. I am including both cases. When a sub-postmaster employs a man under an allowance, he expects him to do certain work.

Q. You say there is no difference between the case of the auxiliary proper who is the servant of the Department and the man who is paid under an allowance, and who is the servant of the sub-postmaster?

A. Yes; you will find in the country districts that the sub-postmaster influences the postmen under him to do certain work, and without a rule to the effect that that is not allowed, the general impression will continue that a man must do it-that he is expected to do it.

Mr. Smith: You mean to say that if an auxiliary who is a servant of the Department works alongside an auxiliary who is a servant of the subpostmaster, there is no difference, and the sub-postmaster makes the servant of the Department work for him?

A. Well, you can hardly say he makes him work for him, but he makes him feel that he ought to give assistance to the other.

Q. And they consider that for their protection there should be some ruling on the point?

A. Yes; there should be a definite ruling that when the work is done to the satisfaction of the Department the man should be entirely free, and the sub-postmaster should have no control over him. I may be allowed to say I think that if the Postmaster-General did issue an order to that effect the money voted for the purpose of paying these men would have a tendency to find its way into the hands of those who do the work.

Mr. Walpole: You mean that the Department should interfere? As a matter of fact, if we do hear of cases where men are unjustly employed, we take notice of it.

A. I think there should be a general order that no advantage should be taken of the men by curtailing their pay or ordering them to do certain work.

Mr. Walpole : Have you anything further to ask?

A. Nothing, except that a new rule be made to the effect that when the work is done to the satisfaction of the Department the man should be free. It he does other work it should be of his own free will. There should be no pressure put upon him. It is difficult to define how sub-postmasters can manage to get certain things done which really should not be done. It is a well-known fact that these things are done.

Mr. Smith: Do you mean that they are done without extra pay?

A. Yes; done without extra pay.

Mr. Walpole: That sort of thing is difficult to guard against by rules.

A. Yes; but if there is a rule the postmen could understand-they would know they could not be punished for refusing to do this extra work. The last part of my statement deals with a point which does not require much argument. It is a small change we ask for, which will not require a Treasury minute or anything of that sort.

Sir F. Mowatt: By all means let us hear that part. (Laughter.)

Witness: I will. As I say, it does not require a Treasury minute, but I may tell the Committee that in the provinces we find great complaint and a strong undercurrent of feeling on this matter. That is why $I$ have put it in at the close of my statement. It is the question of the payment of wages and holiday money. In the provinces it is found very inconvenient to the men that they are not paid until Saturday night in a great many cases. This is peculiarly so with rural men who do not return to the head office until after 8 o'clock at night. They have to return home, and when their money gets into the market they have to buy what has been rejected by earlicr customers, and thereby get an inferior quality of goods for their money. Saturday is the usual day in the rural districts (and small towns may be included in this case) for buying the following week's provisions; 
this practice of paying wages on Saturday night is therefore very inconvenient for the men, and, besides, it is a depreciation of value in money spent of from 5 to 10 per cent., as he gets an inferior article for his money at the close of the market than he would earlier in the day.

Mr. Walpole: Your first point is that you want to be paid on Friday, is it not?

A. Yes, sir.

Q. And in the first week you are paid on Friday would you be content to receive only six days' pay instead of seven? (Murmurs of dissent in the room.) That would be fair, would it not?

A. In our office we appointed a deputation to wait on the Postmaster, and he asked if we would be willing to leave a day's pay in his hands provided the men were paid on Friday. I pointed out that in my case I was paid in the middle of the day on Saturday, so that I had no complaint to make.

Mr. Walpole: I have made arrangements in one case for paying the men on Friday, a day's pay to be kept in hand.

A. Here is the difficulty. In other towns they are paid on Friday. At one time at Portadown we were paid on Fridays. In a great many other towns the wages are paid on that day. In the case of sub-offices the money is sent to the Postmasters on Friday nights, and paid to the men on Saturday mornings. Our own men at Portadown head office are not paid now till Saturday, but at Belfast, Derry, and other places they are paid on Friday. That is the case in a great many other towns in Ireland. But in the district to which I belong they are not paid till Saturday, and the particular complaint of the rural postmen is that they are not paid till Saturday night late. I think the rural postmen should be paid on Friday night. The town postmen do not complain, as they are paid on Saturday afternoons or in the middle of the day, but the rural postman is very generally away at that time. The next point on which emphasis is placed by both town and rural postmen is that when they get their holidays they kelieve they should get their pay advanced if it is to do them any good. Their pay is not large enough to put by a sum for holiday expenses, and when they only get their usual week's pay they find it difficult to go to any place that will be a change of air. If their fortnight's holiday pay were advanced to them it would be a boon to them, more particularly in the case of men who are married and have families. The postmen look upon ho'iday pay being due to them when they are entitled to the holidays, as they have to serve one year before they receive any holiday at all. Our recommendations are:-(1) That all postmen be paid on Friday in each week; (2) that all postmen who get annual leave be paid their holiday pay in advance.

This finished the witness's evidence.

\section{RURAL AUXILIARIES' CASE FOR SOUTH COUNTY DUBLIN.}

\section{(Handed in by Witness.)}

We respectfully beg leave to submit for your kind consideration a statement with reference to the many grievances under which we labour. With regard to our duties, we beg to inform you that they are heavy and laborious, and in many cases equal to that performed by established men, some of us doing as much as 7 hours and 30 minutes per day. On each delivery we take out the parcels, and have to carry them a long distance before disposing of them-in some cases over 5 or 6 miles-and on the return journey take back a heavy collection of parcels, sealed bags, and letters. We have also to attend three and four times a day at the office. Our duties are so arranged that our day's work extends over 14 and 15 hours per day. We 
have to work on Sunday, in some cases for over 5 hours, without any extra pay for it. We walk on an average $14 \frac{1}{2}$ miles per day. We have in soine cases, after walking a distance, to wait for three or four hours before making the return journey home, and without any allowance for shelter while waiting to do so, but are forced to depend on the charity of some neighbour to protect us from the inclemency of the weather, and often compelled to wear our wet clothes for four and five hours without a change.

For this laborious work we are paid at the rate of $3 \mathrm{~d}$. and $3 \frac{1}{2} \mathrm{~d}$. per liour. such, we consider, a most unfair remuneration for such work. We ask to be paid at the minimum rate of established postmen, and in no case less than sixpence per hour. We also ask to be paid for Sunday work, and be allowed off every alternate Sunday, the same as the established men. We also ask to be admitted to the privileges enjoyed by the established men, such as annual leave, boot allowance, sick pay, medical attendance, and payment for Bank Holidays. We also wish to point out that in consequence of the way our duties are arranged that our off-duty time is simply worthless to us. Moreover, it is difficult for us to employ whatever time we may have between our duties. Many complaints have been made against us competing in the labour market against the unemployed, on account of us being in receipt of Government pay. Public meetings have been held to protest against us, and threats used to bring the matter before Parliament.

We also wish to call your attention to the fact that in some offices there is ample employment for auxiliaries to be put on full time. There are cases where the Parcel Post is held over from 9.15 a.m., the time it arrives, until it is taken for delivery by the established men on the midday duty, thereby causing a delay of five and six hours, also the holding over of the English mail for hours in order to avoid putting a few auxiliaries on full time, as by so doing they (auxiliaries) would have a claim to be placed on the established class. We also wish to put before you the long service some of us have to put in before getting on the established class-in some cases 7,8 , and 11 years. This we regard as a great hardship. We ask that all auxiliaries of five years' service be called up for examination to qualify for the estahlished class, and should they he successful that they be plased thereon, and that their probationary term be six months insteal of, as at present, two years, which latter term we consider unfair after serving a term of five years. We also beg to call your attention to the fact that there are in eight sub-offices in South County Dublin 39 established postmen and 38 auxiliaries. Many of the latter are employed for 6 hours $30 \mathrm{~min}$. , and in some cases for 7 hours $45 \mathrm{~min}$. per day. The postal authorities, in order to avoid returning these (auxiliaries) men for a full day's work of 8 hours, have adopted a device which, to say the least of it, is far from being just. They compel the auxiliaries to sign two receiptsone for their standing pay, and another for $2 \mathrm{~s}$. or $3 \mathrm{~s}$. which is termed overtime, notwithstanding that they are doing this overtime every day for the whole year.

We also desire to call attention to an incident which has very recently taken place in one of the sub-offices in this district. We sent out forms for the men to enter the particulars of their day's work for the information of the Committee of Inquiry. One of the men handed the form he received to the local Postmaster, with a request to be allowed to take his time from the attendance-book. The Postmaster sent the form on to the surveyor for his information. The surveyor had the duties of the auxiliaries revised, and took off some and transferred them to the established men. He then sent out the form with permission for the men to take the revised time from the attendance-book. But by chance the men received a second form which they had filled up and duly returned before the revision took place.

We will mention one more incident of injustice before finishing this statement. It is the case of an established man in Kingstown Post Office, who applied for the usual allowance due to inside men or men debarred from 
participating in the Christmas gratuities given by the public, and was refused it. This man works 8 hours $25 \mathrm{~min}$. per day, and on duty every Sunday. He attends on station duty and on the Kingstown and Holyhead Paclet. He likewise does one delivery of letters, etc., etc., every day. Just a week or so before Christmas lie was taken off the delivery, so that he is deprived of his Christmas boxes, which the Postmaster-General estimated, when he was fixing the maximum pay of the established class. as equivalent to $5 \mathrm{~s}$. per week per man.

We sincerely hope these matters will receive the generous consideration of the Committee, for which we beg to say they will earn the lasting gratitude of a miserably paid body of men in the Postal Service.

[Since Maher's case was brought under the notice of the Committee of Inquiry he has been granted an allowance of $2 \mathrm{~s}$. per week in lieu of Christmas boxes, which the Department deprived him of by taking him off his regular walk during the Christmas-time. He is now about applying to have the amount increased to 5s. per week, the estimated value by the P.M.G., and to have it made retrospective, in order to cover his losses since December, 1892, when he was first deprived of them.]

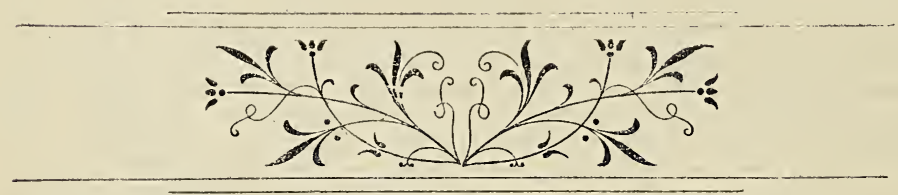


FREDERICK B. BAKER, Gloucester.

\section{Mounted Rurals-Hours of Duty-Lone Walks.}

Westminster, Thursday, Feb. 27, 1896.

Mr. Frederick B. Baker, of Gloucester, was next called to the table.

The Chairman: You are a postman from Gloucester?

A. Yes, my lord.

Q. What is your service?

A. I entered the P.O. about November or December, 1884.

Q. What as?

A. Rural auxiliary.

Q. When did you become a postman? Or are you still a rural auxiliary?

A. I was about a month auxiliary, then I was placed on other duties. On the 16th May in the following year I was appointed rural postman. It was in 1884 that I entered the Service. In the following year I was established and put on a rural walk, on which I continued until Feb. 24, 1895, when I was transferred to the town class.

Q. Will you tell us how long your hours were during that time? In 1884 as a rural auxiliary what were your hours?

A. I have no recollection of that time. I think $T$ only had one morning delivery, and I probably finished abont 9 or 10 o'clock.

Q. Do you know how many hours you worked on that walk?

A. It was probably from $3 \frac{1}{2}$ to 4 liours.

Q. What were you paid at that time?

A. I believe I was receiving $10 \mathrm{~s}$. 6d. a week. I am only speaking from memory.

Q. Then in 1885 you becamè a full-timer?

A. In 1884. In 1884 I was placed on a rural walk and received full pay. At that time it was $16 \mathrm{~s}$.

Mr. Walpole: On a scale rising to 22s., or what?

A. That was introduced later on.

The Chairman: What are you receiving now?

A. My wages are 21s., and two stripes.

Q. You do not include the stripes in the 21s. ?

A. No, my lord.

Q. You supplement the evidence of the last witness, don't you?

A. I wish to deal more particularly with the mounted men and their duties, but I should like to ask your indulgence if I to some extent touch upon subjects dwelt upon at more length by the previous witness, as I may explain that it has been difficuls to prevent our evidence overlapping altogether, but as far as possible we have avoided this.

Q. You have heard the evidence of Mr. Gregory. Do you approve of it? Do you agree with it?

A. Yes, I agree with it; but as I go on my evidence will bring out other points. There has been some indecision as to the number of witnesses, and at the last moment we had to cut out part of $m y$ statement altogether. 
The Chairman: I do not want to stop you. Which subject are you going to speak on first?

A. The work of the rural postman. I think that in the evidence of the last witness some misunderstanding arose as between the sub-office men and the auxiliary men. I was a rural auxiliary before I was appointed to a rural walk, and these men, I believe, are suffering from some injustice as to their duty. There is a case in point I wish to bring forward.

The Chairman: You are speaking of sub-office men?

A. I am not certain whether he is a sub-office man. I believe he is a rural auxiliary between Askern and Campsill. He is described as an auxiliary postman, sir. The man's duty, according to the table, is 6 hours 25 minutes, for which he has been in receipt of 10s. a week. It only came under our notice last week by a letter sent to me saying that the wages have been increased $4 \mathrm{~s}$., and the officer receives back money. That takes the case out of our hands.

Mr. Walpole: Then you have nothing more to say about that case?

A. No, sir; but I think the fact of his getting a jump of 4s. a week at once shows that he has been dealt with very hardly previously. (Hear, hear.)

The Chairman: Do you think he would be more satisfied if the increase had been limited to 2s.? (Laughter.) He has got back money too?

A. Only for one month.

Mr. Walpole: The increase may have been dre to an alteration of duty?

A. I believe not.

Q. Was his a full appointment?

A. He ought to have been a fully appointed man.

Mr. Walpole: I will look into the case if you wish to put it in. You must state it or not.

The Chairman: In a case where a man does $6 \frac{1}{2}$ hours you think he should have a full appointment? Is that it?

A. Yes; here is a list of the duties.

Mr. Walpole: And according to the list his time was 6 hours 25 minutes?

The Chairman: That is the time stater, and lie gets $14 \mathrm{~s}$. a week.

Mr. Smith: If he paid by the sub postmaster or by the Department?

A. I do not know.

Witness (continuing): Bearing in mind the possible opposition to our demands on the ground of their not being acceptable to the public, we fully appreciate the hazard of rousing the ill-will of the public in this matter, which any attempt to withdraw any of the facilities they-the suburban and rural residents-at present enjoy, might be expected to do. But we hopefully look to this, the first opportunity probably they have ever had of obtaining an adequate knowledge of the conditions of our service, to quicken their readiness in accepting an abbreviation of these facilities, and we confidently rely on those who have ever sympathised with us, that they will not offer serious opposition to our desires. I am emboldened to take this view by the absence of any opposition to the town sub-office half-holiday early closing, and to the discontinuing of the last delivery in some towns on the half-holiday evening. I refer particularly to the facility given for so long an interval to elapse between the incoming of the morning post and the despatch of the evening post, prolonged on an average to some six hours, but often prolonged to eight hours, which it can be readily conceived is much too long, and which would be willingly allowed to be shortened. But I feel more sure that the opposition would be more likely to come from the Department than from the public, for in some cases the public has taken the initiative in suggesting improvements in this respect, but the difficulty has been assumed to be too great for anything to be done. As an instance, I may mention that the vicar of the parish at the extremity of my journey, viewing with alarm the risk attending a journey on the Cotswolds during the winter, when the blinding 
snowstorms render it extremely perilous, opened up a correspondence with my Postmaster, and suggested that my return journey, or that part of it that lay on the hills, should take place in daylight through the winter months. The conditions under which the Department could see their way clear to allow this humane concession was that the gentleman should undertake to get the consent of the different villages on my route to the proposed change, a condition sufficient to deter him from prosecuting his kind intention. Had this been a suggestion for a somewhat earlier delivery, or for the inclusion of some place in the delivery, I believe more earnest efforts would have been made 1.2 act upon it, and $I$ feel convinced that these difficulties which arise in the event of a suggested change for the bettering of a man's duty are easily overcome if the alteration is suggested from some influential resident pleading on behalf of the public, suggesting it may be some facility to catch a certain mail or to get his letters at an earlier hour. Yet, if it be a Sunday delivery to be taken away or an alteration, as was suggested in my case, a canvass must be taken and a large majority obtained before it can be recommended.

Sir F. Mowatt: A Sunday delivery to be taken away?

A. Yes, sir; in some rural districts.

Q. That was not the suggestion of the clergyman?

A. No, sir.

Q. It was another suggestion?

A. Yes, sir; it was only an alteration of time suggested in my case. It is very hard to discriminate in these cases as to whether the alterations are only for the benefit of a favoured one or two individuals. The Department have no wish to have any complaints whatever from the public. I may point out that in the case of rural postmen they are forbidden to get anyone to intercede on their behalf. That is prohibited in the Rule Book. Therefore the feeling obtains among the men that their interests are deemed to be only secondary. I shall not attempt to dwell upon the manner in which these extended duties affect the men, but will point out that from the lateness of their return home, and, particularly in the case of a mounted man, after which some time has to be devoted to the comfort of his horse, rural men are debarred from entering into social relations with their fellow. townsmen, or, in the case of the younger men availing themselves of the facilities offered, either by evening classes, elementary and technical, now so abundantly offered, for improving themselves and enabling them to fit themselves for other duties. Also that in the winter months these late duties are bound to trespass on the men's time on the Sabbath to some extent, when some little matter regarding his horse, his cart, or harness, has to be attended to that may demand daylight, or for which there is no time in the evening, and this irrespective of the necessary grooming and feeding. We would recommend that, where it can possibly be done, these duties should be confined within a 12 hours' day.

\section{WAGES.}

We would earnestly direct your attention to the disparity between the wage of the rural and that of the town postman located at the same office, and we would submit that there is no reason that can be adduced in its justification, where men doing work equally as responsible, and which needs to be done equally as intelligently, should be in receipt of wages so unequal. It may be pointed out that in some cases the amount of correspondence is still very small, but, on the other hand, there are some deliveries in the suburbs of our large towns where the amount of correspondence dealt with is as great as within the town, independent of their other varied work; yet these deliveries are still defined as rural. In sub-offices a great part of the station duty is performed by rural men, and it frequently happens that the rural men take a part of the town delivery on their route, We maintain, therefore, that there is no reason for this anomaly, 
The duties of a rural postman require even a more general knowledge of postal work than a town man, they not being confined to the delivery and collection of letters. Those duties include the accepting and giving receipts for registered letters and parcels, for which he must be responsible while they are in his charge, and on circular walks these remain for some hours in his possession. He must have a knowledge of the charges for these articles to be able to make proper charges for whatever is tendered to him. Further, he has also to accept and deliver to their destination letters without their having passed through a Post Office, and this without being under any supervision whatever, a freedom of action nct permitted to any other class. In introducing this into the rural districts I see a greater compliment to the men's trustworthiness than has ever before been paid them. He must necessarily have a knowledge of the regulations referring to registration, Parcel Post, and postal and money orders, to enable him to satisfy the many inquiries that will be made of him during his journeys. This refers more particularly to those men who are appointed to a district that is largely patronised by summer visitors, and here I would call attention to the efforts made by the railway companies to popularise our picturesque villages, which must influence the influx of summer visitors and emphasise the need of an intelligent class of servants. The present wage (minimum) for appointed men-15s., 16s., and 17s. per week, and maximum wage of 19s., 20s., and 21s.-is inadequate, for we would observe that these men have to reside in town, and their expense of living is as great as, if not more than, that of the town postman; he has to pay the same rent and taxes, and has the additional expense of living the whole of the day away from home. Our wage will not bear favourable comparison with any service requiring the intelligence and bearing the same responsibility, for we find there are men with 30 years' service who are only receiving 20s. as wages. The assertion that our wage will compare favourably with that of the agricultural labourer in the district in which we are situated is not an equitable comparison, and we strongly resent comparing us with this most ill-paid of labour, with whom our responsibilities and our oost of living are in no way identical. We would ask that all returning to a head office be classed as postmen, and that the present distinction be effaced; that our minimum wage be equal to this class; and that on town apprintments becoming vacant they be offered to the rural men, according to their seniority. We feel that there would be no difficulty in this; in fact, in those cases where there are two and three deliveries daily it is unreasonable that they are regarded as of an inferior class to town postmen. For a case in point, I may say that there are 15 rural postmen at Bolton performing two deliveries daily. One of these so-called rural walks has three deliveries daily, served by two men on the morning delivery, and the other deliveries being worked alternately by these same men. Another man has two deliveries and a night collection, extending his duty to some 15 hours.

The Chairman: You mean the duties are extended over a period of 15 hours, not that they take 15 hours to perform?

A. Yes, my lord; the limit is 15 hours. Some of these men deliver a portion of the borough not half-a-mile from the head office, whereas the town men in other directions deliver $1 \frac{1}{2}$ miles from the head office. Yet, in the face of this and of the fact that, within a few miles of Bolton, and as for that any other town, there are sub-offices, strickly speaking, more rural where the men are appointed as townsmen. These men consider themselves entitled to be classed as town men as they return to the head office on the completion of each delivery, and they have petitioned the PostmasterGeneral against being classed rural, but the Department, while allowing them $2 \mathrm{~s}$. increase of wages over the rural maximum, refused to acknowledge their claim, thus denying them all prospect of promotion, for by offering men junior vacancies on the town staff (which is usually done), it would mean placing men with over a dozen years' service, and in pos- 


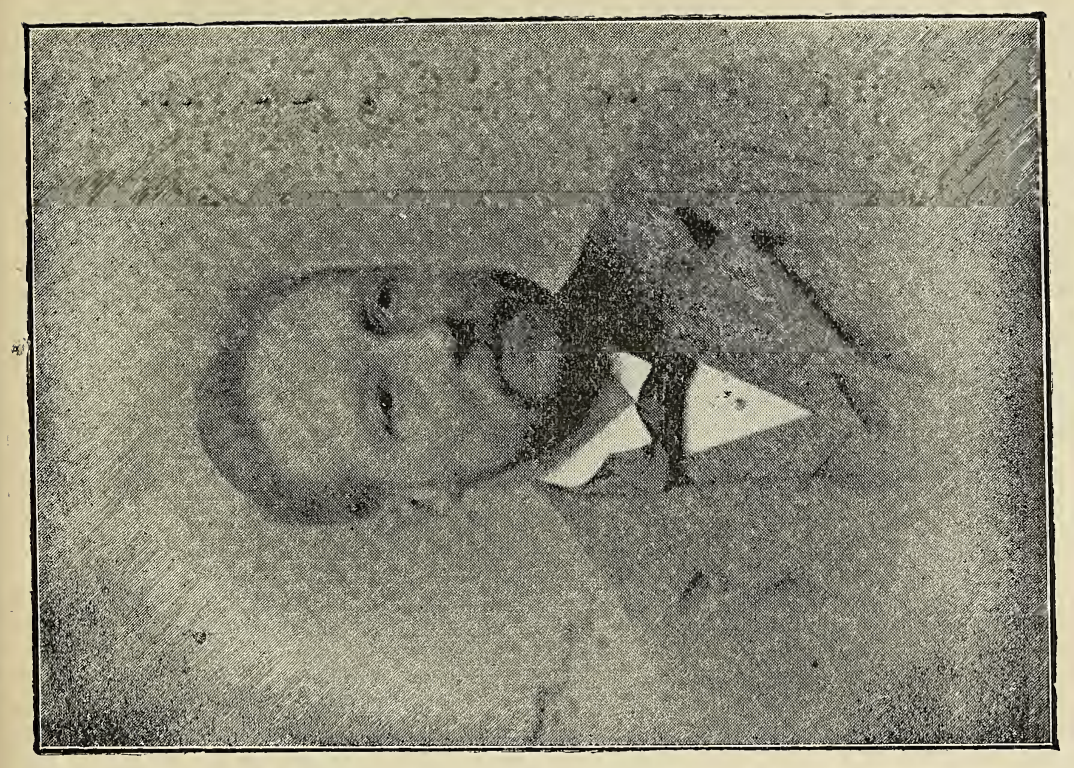

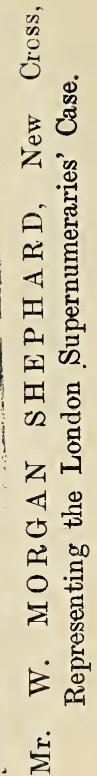

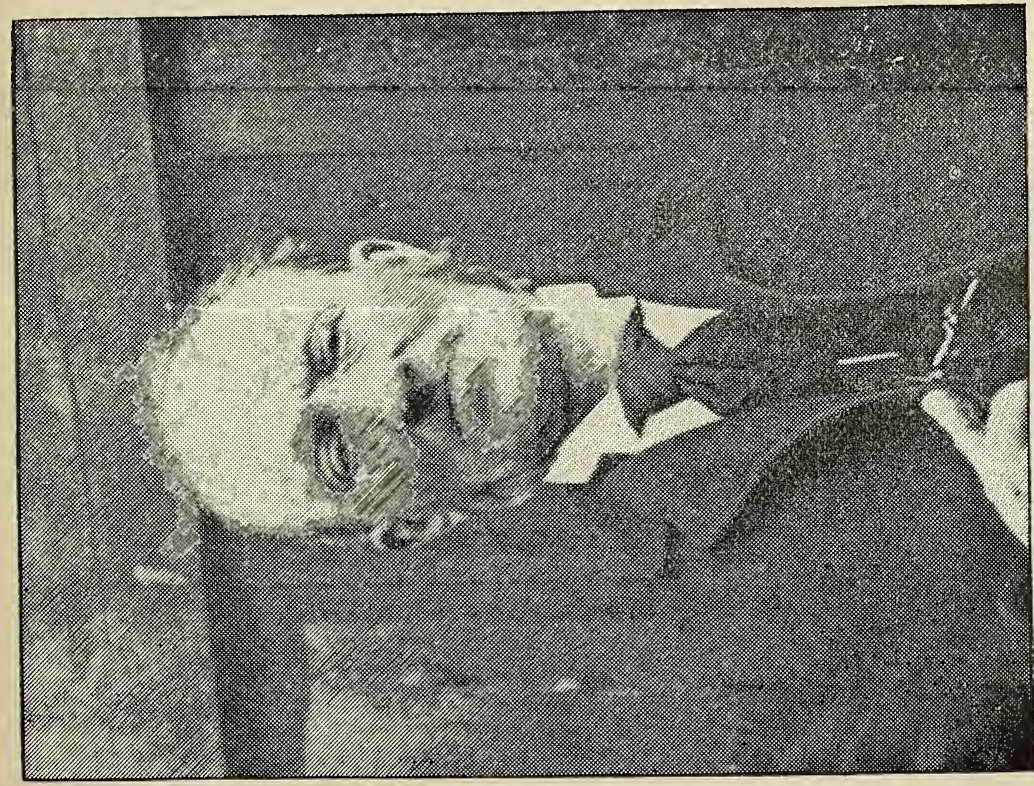

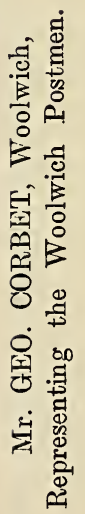



session of two stripes, as junior postmen. This is a condition they refuse, claiming that they are to all intents and purposes town men.

Mr. Walpole: That cannot take place now. There are no more junior postmen to be appointed, so it cannot be.

A. You have put a wrong definition on the term. I did not mean junior postmen. I meant juniors in the town postmen's class.

Q. What is the objection to that?

A. That their previous service is not taken account of.

Q. How can that be? They carry it with them.

A. In some respects; but it does not count for seniority.

Q. It makes no difference to the men, does it, how they rank among themselves?

A. In their daily intercourse, do you mean?

Q. They have the same wages and advantages. What difference does it make?

A. In an office where there are only a small number of men, it means they must serve several more years before they regain senior position.

Q. What do you mean by senior position-a head postman?

A. Yes, sir. I shall refer to this again.

The Chairman: You are going to explain it presently?

A. Yes; I refer to it again later on. So much more unfavourable are the conditions under which the rural man performs his duty that were the wages made equal no town men would seek rural appointments, for a rural man, after having an arduous journey-it may be through a deep snow which he may have to trudge through for days-is in a state of exhaustion such as is unknown to a town man, whose walk is through swept streets. I would further emphasise this matter by asserting that this low minimum wage, and the strict rules referring to his late attendances and other matters, all tend to keep it down at this minimum, which is not a living wage sufficient to enable the men to withstand temptation.

\section{ACCOMMODATION FOR DAY'S LODGINGS.}

Rural postmen having from one hour upwards to remain at the end of their walk, should have some provision made for their day's lơdging by the Department, on whom should rest the responsibility of this, or make an allowance sufficient to meet the expense of this accommodation, inasmuch as this affects the efficiency of the men, and the absence of it randers the men susceptible to contract disease and injuriously affects their longevity. A question was asked of the last witness as to the arduous nature of his duties. I should say emphatically that I consider the rural man's duties a great leal more arduous than those of a town man. A town man has no experience of the exhaustion that a rural man experiences after ending his long w:lk, more particularly if that is in a hillo district. [ have a copy of a report from the Postmaster in regard to my own experience in the snow. It reads :-

\section{(Copy.)}

\section{Mr. GodBX-}

The Brimpsfieid rural postman, who is due to reach this office at 7.15 p.m., did not arrive until 9.5 p.m. to-night.

Baker states that after proceeding about half-a-mile on his journey he lad to return to Brimpsfield with his horse and trap, finding it impossible to proceed in consequence of the state of the weather. He then made a second attempt on foot, and reached here at the above-stated time in a very exhausted condition.

Between 30 and 40 letters for the north of England will suffer detention.

George St., 18th Nov., 1893.

(Signed) H. C. DAwE, Åssistant-Superintendent. o 


\section{To the Assistant-Sdperintendent,-}

I am glad to learn that the man arrived safely in Gloucester; it shows he has considerable pluck and interest in the Service to face such weather.

20th Nor., 1893.

(Signed) W. H. GodBY.

The Chairman: After all a walk in the snow is the exception and not the rule?

A. Yes, sir; but on the other hand the walks in hilly districts are laborious enough.

Mr. Smith: You have not had a personal opportunity of comparing the duties of town and rural postmen, have you? You are not a town postman, are you?

A. Yes; I am a town postman now. I am speaking from personal experience of the two, and I say I do not now feel the fatigue I did after my rural walks.

Mr. Walpole: You are in a town where there are no heavy flights of stairs to be worked?

A. Yes, sir.

Q. There are no staircases on your walk?

A. No more than the steps outside houses.

Q. You have not the laborious work which has been described to us by some witnesses?

A. No, sir ; but arduous duties are not the exception to the rule.

The Chairman: What I said was that deep snow is an exception to the rule.

A. I should like to point out that in some services exceptions prevail and are recognised.

Mr. Walpole: What, snow?

A. No, sir; exceptions to the rule. In the course of some evidence given previously it was brought forward that the policeman's pension was granted him on account of his exceptional duties. It must be an exception for him to get a brick thrown at him.

Sir F. Mowatt: Quite so. But it is a rather more frequent exception than he cares for. (Hear, hear, and laughter.)

Witness : Well, I consider there are seasons during which a postman, especially in the rural parts of Scotland, has to trudge through the snow more often than the number of times a policeman gets a brick thrown at him.

Sir F. Mowatt: That is no compliment to the Scotch climate.

The Chairman: I think a Scotch postman has something more than his own legs to get about upon. That is my experience.

A. I am referring to exceptional cases. In my own case, which I have quoted, I considered that my life was in peril.

The Chairman: The report records sympathy for you.

Mr. Walpole: Were you walking from Gloucester, or was it the return journey?

A. From Brimpsfield to Gloucester. I began the journey in a blinding snowstorm and a very low temperature. After going a short distance I was almost incapable of proceeding further, and it was only by an effort that I turned my horse's head round. He carried me back in an exhausted condition to the place I started from.

The Chairman: I expect you would have done better on your own legs than on a cart?

A. Yes, sir ; I completed the journey on foot.

Witness (continuing): We think that when the rural man remains at a village during the day the accommodation available (generally that of a labourer's cottage) would not exceed $2 \mathrm{~s}$. 6d, per week, though for even this 
small sum to be subtracted from his low wage is no small consideration, and the picture is presented of men wandering about lanes or fields awaiting their return journey, and this too frequently in the case of men having a family dependent upon them, and with a high town rent. Granting that there are a number who manage to pay a small sum for the luxury of a cottage to stay in during the day, still this is not a very desirable state of things where there are generally a numerous family, and these in bad weather crowding the home so that the privacy needed for changing his clothing is not obtainable. Others again have to put up at a blacksmith's or a cobbler's shop, while others are allowed the shelter of the squire's saddle room, or as an alternative to this a man has to drag out his long stay at the village alehouse with all its temptations towards intemperance and evil associations, an alternative which it is most earnestly to be wished it should be the endeavour of the Department to remove from their servants, as a condition of things which may lead their servants to that indulgence which meets with most severity from their superiors. We would offer the recommendation that some efficient provision should be made to engage a room for the exclusive use of the postman, to ensure its privacy as is done for sub-offices.

Mr. Walpole: May I ask you what arrangements you made yourself when you were a rural postman? What did you do?

A. My case was not a typical case.

Q. I only want to know what you did in your own case?

A. I finished my journey at a village where there were a number of cottages. Many men finish their walks at places where they can nover get accommodation.

Q. Quite so. I am only asking you as to your own case?

A. I was able to get a room at a cottage where I could put up.

Q. Did you get any work there?

A. I preferred to rest.

Q. Did you pay for the room?

A. Yes; I had to pay for it. But in the case of a man with a family dependent upon him, and paying a high town rent, he could not afford to pay, and so it is that a great number of the men wanler ahout the fields awaiting the time for their return journey.

Sir F. Mowatt: What do you mean by "as is done for sub-offices?" What is the meaning of that?

A. I mean by that that in cases where there is a sub-office in a village they engage a room for the postal work. Should that plan not be adopted I would suggest that an allowance be made to the men in lieu thereof, or as an alternative in those cases where accommodation was not obtainable-and we would prohibit the village alehouse - the men should be allowed to return to a village or more populated district nearer home, there to await the hour of their return journey, the collection of the letters from the end of the walk being the subject of a special collection from the S.O. in the village, where the postman remains. Another suggestion is that in thinly populated districts the erection of shelter boxes should be the subject for consideration, as instance at Moreton Valance. In this case the man erected a hut at his own expense. We feel that hitherto our demand for consideration in this respect has been entirely ignored, whether it be that it is proposed to add some two or three miles to a man's walk, or a new district to be embraced, and as the area over which the rural postmen travel has been extending in every way, there are few places, however out of the way, to which the facility of free delivery is not given. Yet in this increase of area, or it may be increase of the length of time before the departure of the postman, owing to later trains becoming serviceable, or it may be a proposition that a man give up his home in the country and reside in the town, or leave town and live in the country-in none of these matters is any consideration given as to how it may affect the man's convenience, or in one case has it been considered necessary to ask the rural 
man how much more remuneration he is entitled to for the added distance or time, or in the other if he is entitled to any compensation or increment to meet his enhanced expenses.

\section{DEFINITION OF RURAL MAN'S DUTY.}

We think it should be more clearly defined what constitutes a rural man's appointment, and that it should be made clear whether it can be altered with disregard to the man's comfort or interest. As an instance-one of many-Thomas Ames, for 27 years, till June 20th, 1890, was on the walk to Llangwylley, R.S.O., Anglesea, but a delivery was effected to Llangefrui, on the application of a gentleman having an interest in the place, though not a resident, and he was transferred to Llangefrui, where he is unable to get a cottage nearer than four miles of his starting place, which distance he must traverse morning and night. This necessitates as early rising as 4 o'clock a.m. to be at the office in time, and not returning to his family till 8.40 p.m., and, to use his own word, "Making my life quite miserable."

The Chairman: Are you certain of that case? Will you give me some reference to it?

A. Yes; I will get particulars. (Statement handed in.) We think that a clearer definition of a rural man's daily duty should be laid down, over which he is entitled to overtime, as at present there is apparently no limit to what he can be expected to perform without any overtime being allowed. Men may be several hours delayed through heavy snow or floods, or those men having station duty through late trains or through a heavy delivery of circulars, election or other kinds, or at Christmas, when men have been called upon to perform an extra delivery, meaning a continuous duty of over 14 hours, without receiving any payment for the work, as their average daily duty did not amount to 8 hours for the week.

Sir F. Mowatt: You say it is 14 hours' continuous duty?

A. Yes, sir.

The Chairman: You mean 14 hours from home?

A. No, my lord; I mean 14 hours' continuous duty.

Mr. Walpole: Not continuous duty?

Witnes: The rural postmen at Gloucester at previous Christmases have been instructed to hire a trap to return to H.O. after the first delivery, with which they had to take out an afternoon delivery, so that they had scarcely time for a meal hetween $5.30 \mathrm{a.m}$. and $7.30 \mathrm{p.m}$. 'This was discontinued last Christmas. We petitioned the Postmaster at Gloucester for overtime, but we never received it; instead he pointed out it was done in the interests of the men, so that they might have more time for themselves on Christmas Day to spend with their families.

The Chairman: That was only one day?

A. Yes, my lord; the days before Christmas 1892, 1893, and 1894.

Q. Did you not have to work on Christmas Day?

A. Yes; We had the usual work on Christmas Day.

$\mathrm{Q}$. Did they not give you time to make up for it?

A. No; the men had no compensation at all. We think that a man's duty should be the time he is timed to perform that duty, which time should be entered in his rule book, and any other work which exceeds that time above one hour should be paid as overtime. I shall refer presently to how even this does not fully include a man's whole duty if he is mounted. We think it desirable that a man having a journey of more than sixteen miles daily should be mounted; also, it should be made clear how far a man is expected to walk before entitling him to an allowance for a horse and cart. On what calculation this is considered, whether the distance travelled, the amount of correspondence, or the population, comparisons with different duties in different districts does not reveal any defined rule, for we find in Gloucestershire and other agricultural districts that some men are mounted, travelling 16 miles or so daily, 
whereas in other counties men on foot travel as man as 26 and 30 miles daily; so this does not suggest any explanation of such inequality of labour.

Mr. Walpole: Can you give me any case where a man travels 26 or 30 miles on foot?

A. I believe there is a case in the Bradford district. I had some doubt about this man, and I corresponded with the men there as to the duties. I have got this answer:- "The statements are correct as near as we can reckon. The districts are what you may call thinly populated. J. B. litts, Idle, 34 miles. I understand his duties rotate every other week, and I think it was the heaviest duty. But it is all done on foot."

The Chairman: 34 miles a day?

A. Yes, sir; and they tell me there are other duties of 24 and 26 miles.

Mr. Walpole: Are you sure this man Pitts is not mounted?

A. So I am informed.

Q. Do you mean he does 34 miles every day?

A. Yes; for a week.

Q. Every day for a week 34 miles?

A. Yes.

The Chairman: Then he must do 11 hours' absolute walking every day?

A. I shall be able to confirm the statement.

Mr. Walpole: I will look into the case.

The Chairman: Have you his duties?

A. Yes; I have them here.

Mr. Walpole (examining the duties): This man is on duty $7 \frac{1}{2}$ hours, so that if he does a 34-mile walk he must go at the rate of 5 miles an hour. That shows there must be a mistake in your figures. Do you really think that a man walks 34 miles and delivers letters in $7 \frac{1}{2}$ hours?

A. I have tried to get the accurate facts.

Q. Oh! I am not complaining of you.

A. I will give cases where min have exceptional work.

The Chairman (examining the daties): You have a case here of 32 miles, but that man is partly mounted.

Mr. Walpole: I should donlt these facts. The witness said distinctly this man Pitts was unmomnted.

Witness: I will give the duties of a man at Denbigh.

The Chairman: He is off duty at 7.30 in the evening, and goes on at 7.30 in the morning.

Mr Walpole: Pitts' duty is a litile over 7 hours. What is your experience? Does a man when he is on a walk delivering letters do more thar. $2 \frac{1}{1}$ to $2 \frac{3}{4}$ miles per hour?

A. That depends entirely on the number of houses on the walk.

Q. I admit that. But would not the average be $2 \frac{1}{2}$ to 3 miles?

A. I believe that a man is expected to walk more than that.

Sir F. Mowatt: More than 3 miles an hour?

Mr. Walpole: More than 3 miles while delivering letters?

A. Yes, sir. In the matter of collections he has to cover 3 miles an hour;

I have only taken turnpike miles. He has to go up and down gardens.

The Chairman: Then that makes Pitts' walk more than 34 miles?

Si. F. Mowatt: The simplest way will be to have this case inquired into.

Mr. Walpole: Have you anybody else who does any walk with these "Spring-heeled Jack" boots? (Larghter.) Anyone who does such a walk as that?

A. I should like to point out in confirmation that papers have been sent to me showing that a rural man at Denbigh wallss 23 miles, one at Kendal 23 miles, one at Southampton 26 miles, and one at Weston-super-Mare 23 miles.

Mr. Smith: What is that walk?

A. I have no particulars.

The Chairman: Can you give me the number of hours these men are on duty? I think you should give that as well as the distances? 
A. I can get the number of hours. (Handed in.) I now come to the disadvantages attending transfers, and wish to ask that the transfer of a rural postman to the town class be freed from the disadvantages at present attending it. I am aware that this phase of our grievances has been before your lordship with regard to another class, and that it has been pointed out that this prevails in every other service, the army being instanced, but I fail to see that the case is a parallel one, or the conditions the same, for here we have a branch of the Service starting as either telegraph boys or auxiliaries, entering the P.O. on the same conditions, yet whose future is to be left to mere chance, the capabilities of the men being without any weight, for they obtain a town or rural appointment on its becoming vacant at the time they were eligible. Thus the first opportunity or chance overweighs any ability the man may possess, for if he be rural then promotion is practically unobtainable. I would not say that if a man be transferred to another office for his own advantage he should retain his seniority, but where a man commences his career in one office (where the date of liis entry is kept) and is afterwards transferred to the town, that he should lose all his vears of service and become junior again is injust, whereas in such trivial matters as selecting his holidays, etc., he is allowed to retain his seniority. Surely if it is practicable to retain it in one matter it would be so in the more important one of promotion.

Mr. Walpole: What is the disadvantage?

A. I am endeavouring to explain it.

The Chairman: Is it a fact that at this moment when a rural lettercarrier becomes a town letter-carrier he loses all his time in the Service?

A. Yes, sir; he has to take a position at the foot of the town postman's class.

Sir F. Mowatt: He carries with him the salary he liad been having?

A. I believe so ; in my own case I carried my existing wages with me.

Q. And does his previous service count for pension?

A. Yes ; but in promotion it counts for nothing.

Q. But not as regards promotion?

A. But the result is that a man who might have entered the Service only two or three months before I was transferred might be my senior, though I had served 15 years.

Mr. Smith: We have heard from other witnesses that promotion does not go by seniority. 'That has been a source of complaint.

A. I should qualify that. There should also be capacity.

Mr. Smitll : I don't know what ought to be. The complaint is that seniority is entirely neglected. Do you agree with that complaint?

A. I don't see wi.at you wish to elicit. A man loses in the selection of the walks, etc.

Mr. Walpole: And you complain that by the loss of seniority he loses his chance to get the head postmanship?

A. Yes.

Q. But the head postman is selected because he is the best man. He is not necessarily the senior postman?

A. I am unable to answer that. The head postman gets the choice of walks.

The Chairman: I see; you mean you lose the opportunity of choosing particular walks in a town when you become town postman?

A. Yes; there are other minor disadvantages. It is a lamentable fact that there are men who have served 10 and 15 years with two and three stripes as guarantees of their trustworthiness, and whose transfer has beels recommended by their Postmaster (a recommendation only too tardily given) and been obtained, who are now junior to youths just making their start in life, and with a comrade who mayhap had entered the office with him away above him, with better prospects while he remains in the office and has only his pension to hope for. But if this is a regrettable circumstance, how much more so the picture of men performing rural walks, yet feeling them- 
selves capable of better employment, with a future of continual toil, or perhaps a pension that spells poverty, but who cannot accept this price of their transfer. Or, again, of men who, feeling that, however they may strive to perform their duty conscientiously, the opportunity of transfer will never come to them, see boys and strangers coming and taking positions for which they feel they have first right. What wonder, then, if men feel they have grievances? That the clothing is not sufficiently durable will be demonstrated by Mr. Grimmer. I may say the new issue of greatcoats for mounted men, however, meets with some approbation, and fills a longfelt want, the old pattern being quite insufficient to keep a man warm, as alse the cape, but which should have armholes (as the pattern for the walking men).

Mr. Walpole: Armholes left out?

A. Yes, sir; and when he is buttoned right down his arms are underneath.

Q. That is to give protection to the arms, I suppose, is it not?

A. I do not know. Why it should have been left out for the mounted men is inexplicable, for it is very inconvenieut to button, and wh $\mathrm{n}$ buttoned both hands must be at liberty to extricate himself, which he is not at all times able to do with safety, and retain control of his horse.

\section{PARCEL POST.}

The introduction of the Parcel Post imposed duties on the rural postman in a manner we believe that was not premeditated by its introducer, $\mathrm{Mr}$. Fawcett, who, in his most sanguine moments, could hardly have anticipated the increase (and I believe it is still increasing) of this branch of the Service as a gigantic carrying concern throughout the rural and suburban districts. $\mathrm{He}$ surely never dreamed of the picture of a rural man burdened as he is day by day with cumbersome weighty parcels, suffering from fatigue and exhaustion till he more resembles a coolie or a labourer of a like nature than a servant of the most profitable of this country's undertakings. The rule that a rural man should be expected to carry $35 \mathrm{lbs}$. weight before he is entitled to get assistance might not have been so peculiarly irksome had this part of the Department business kept to any modest dimensions, and this maximum weight been but seldom attained by the rural man, but in view of the strides the branch has made in the eyes of the public as the most direct and economical means for the conveyance of parcels to anywhere outside a town or easy rodiu of a railway station, and, as a consequence. the use made of it, and the frequency with which this maximum is attained, we feel that the time has arrived when it is necessary to reduce this maximum to $28 \mathrm{lbs}$. I am unable to give any exact estimate for this increase, and $I$ doubt if it would be possible for the Department, unless some account has been previously taken of the parcels received and delivered in these rural and suburban districts separately from that of town parcels, but probably I could assert with some degree of exactness that a rural man delivers some 1,200 parcels, and collects say 1,000 (23 and 19 weekly) annually on the average, though, of course, for some localities this is too low an average, as, from a return kindly taken for me at an office with 15 rural men, the number of parcels carried outwards by these men in one week (at an ordinary period) amounted to 453 . Thus it will be apparent that the maximum is often reached and exceeded. In an office of 16 or 18 rural men assistance is probably given from four to six times per week. Happily there are offices where this assistance is generously given, but it is to be regretted that there are instances where this rule is not adhered to, where men are not allowed assistance when their load has been in excess of $35 \mathrm{lbs}$, but instead of this they have had their letter bill signed "heavily loaded," which exonerates them if they are late in the completion of their delivery in consequence. In other offices the men are expected to take them out in a handcart; this latter of the two ways of procedure is scarcely preferable to carrying them, and in bad weather would undoubtedly add to the labour. 
Again, in others-I arlmit these are exceptions-whe I it happens that parcels are numerous on the evening down delivery, they have been kept back and handed to the rural man whose outward walk is over this town walk, to deliver on his outward journey, and to these men, if they appeal against this, the consolation is offered that their weight does not come up to the prescribed $35 \mathrm{lbs}$. limit. Against these deviations of the rules we would protest as not tending to encourage a spirit of content. To treat a man as a beast of burden, and load him up to the utmost limit without any regard for the exhausting nature of this work, whether sweltering in the heat of summer or through the bad roads of winter, when, perhaps, lie has to go nearly the end of his journey before appreciably reducing his load, or on his return journey, during the latter part of it exceeding its prescribed límit. Then on what are termed circular walks : a man may have to carry the greater part of his load round the whole journey. There is yet another way in which the Parcel Post has affected the men, and which efforts were made to obviate at the time it was introduced. I refer to the privilege which rural postmen previously enjoyed of carrying private parcels, and which, in some instances, materially supplemented their income, and for the withdrawing of t'is privilege compensation was given. The men were invited to state their weekly earnings in this way, and, upon these statements a nominal sum officially calculated to meet the case was granted, from $6 \mathrm{~d}$. per week upwards, which allowance would be discontinued on the appointment becoming vacant and a new man being appointed.

Mr. Walpole: But the men were asked themselves to state what they were receiving, were they not?

A. Yes, sir; but I may point out they were not told the purpose of the inquiry.

Q. They were asked to state what they were earning, and then we gave them compensation for the amount?

A. Yes, sir.

Q. And if they did not state what they were earning that was their fault?

A. It was not known whether it was intended to punish them for carry. ing the parcels.

Sir F. Mowatt: Do you mean that, fearing punishment, they withheld the information?

A. I think that a number of men withheld the information, or in some cases said they were not receiving anything in that way.

Sir A. Godley : And do you complain of that?

A. I complain that in these cases where the men's wages were calculated in that way they were done out of it.

Q. But a man who has sent in a false return has no cause for complaint?

A. I do not know that it was false. I have cases in my mind where the officials calculated the earnings of certain men and then they did not get it. Mr. Walpole: What did not the men receive compensation for?

The Chairman: He says the officials calculated that they had received a certain amount.

Mr. Walpole: Do you say they did not receive compensation?

A. According to my information certain of them did not.

Q. If you give me particulars I will look into those cases.

A. Thank you, sir. This compensation, though felt to be calculated too low, we think gave satisfaction where it was carried out, but in soine instances the men were never allowed this compensation, and suffered from the loss of it, and feel that the Parcel Post has imposed on them. They estimato their weekly loss at some $3 \mathrm{~s}$. per week.

\section{MOUNTED MEN.}

The increase of the Parcel Post and its consequent additional burden to the rural men the Department have endeavoured to cope with by increasing the number of mounted men, for by thus providing the men with a horse and 
cart they are able to take out on delivery an additional weight, and also embrace a more extended area. This has everything to recommend it, and we would further recommend that this course should be followed much more generally than even is the case now, so as to include all walks that exceed 16 miles per day, for walks which are more than that too severely tax the men's strength. I would make but few exceptions, the chief one probably would be in the case of a locality where this might seriously delay the introduction of a separate Parcel Post delivery, which, where the weiglit warrants it, is the nost desirable. The present condition whereby men heavily loaded have to walk 20 and even exceeding 20 miles each day must certainly induce immature old age.

Mr. Walpole: I do not admit the 20 miles a day. If they do walk that distance it is against the express rule of the Department.

A. I have submitted walks which are over 20 miles a day.

Q. You have given me one of 34 miles. I have checked it. It is impossible. There is another case of 20 miles within $5 \frac{1}{2}$ hours. No walk extends over $5 \frac{1}{2}$ hours. You will find that the man is on duty only $5 \frac{1}{2}$ hours.

A. The man says he goes on duty at 7.30 , and he walks 21 miles. It is the Weston-super-Mare case.

Mr. Walpole: I am not referring to the Weston-super-Mare case.

Witness: The mode of procedure patronised by the Department when introducing this change from the walking to a mounted man I wish to bring under notice. The official word "provide" in this respect would seem to be a misnomer when it is really the men themselves who have to provide this horse and cart. The rural man receives an intimation that he must provide a horse and cart. This to a man who has up till then been in receipt of from $17 \mathrm{~s}$. to $20 \mathrm{~s}$. per week, or, as came under my notice recently, an auxiliary who had been receiving $11 \mathrm{~s}$. per week, who, on applying for an appointment, was nffered a mounted man's vacancy, on accepting which he would be expected to furnisi a horse and cart, is an order at which the men are frequently nonplussed at the largeness of, for what reserve funds can such a man be expected to have in hand out of his wage, with which he has had to support himself and family, and pay a high town rent, to meet the expenditure of some $£ 35$ or $£ 10$ ? I am aware this is done by contractors in some cases, but this is not much favoured by the Department for economical reasons. If a man has been thrifty and unmarried, it means the investing of his hard-earned savings in a hazardous undertaking. Or if otherwise he must have recourse to moneylenders or obtain the things on credit, to even which the Department gives countenance by offering to see that a part of his salary is kept back for the repayment. So we have the servant here disbursing his savings in the furtherance of his employer's business, and paid, too, at such a rate that it is only by constant striving that he can eventually replace his invested funds, a matter of impossibility if he is unfortunate; he cannot free himself of his debt and the demoralising feeling of being insolvent. For the alleviation of these conditions we would urge that the Department should advance these men who are without funds a sum of money to meet this expense, free of interest; this if they are still of opinion that it is not within their duty to provide the carts as in the case of the hand-carts.

Mr. Walpole: And suppose a man does not provide the horse and cart?

A. It is not pointed out to a man what will become of him if he does not accept the change, or whether he will be removed to another walk. But when it is suggested to him it is to his interest to fulfil these suggestions if possible.

Q. It is usually to his great advantage to be mounted?

A. Yes; if he gets sufficient remuneration

Q. Can you give me a case where a man has been forced to be mounted against his will? 
A. No; but I can, on the other hand, give cases where men have declined to be mounted.

Q. Were they removed to other walks?

A. No, sir; the proposal to make the walk a mounted one has not been carried out.

Sir A. Godley: They have done on foot the walk it was intended should be a mounted one?

A. Yes, sir.

Mr. Walpole: They preferred to do the work on foot, and were allowed to do so?

Sir A. Godley: I suppose there are walks which cannot be worked on foot?

A. Yes, sir.

Q. And you suggest that if a man is offered a walk of that kind it practically means that he must get a horse and cart?

A. Yes, sir; unless the area of the walk is amended.

Q. And although there is no compulsion for a man to accept such a walk, if he does it means that he must have a horse and cart?

A. Yes; if he had previously been a mounted man he would accept it. It is only in recent years that this plan has been extensively adopted.

Mr. Walpole: Since the introduction of the Parcel Post, is it not?

A. Yes, sir. The average amount for these allowances is about 5s.-a rather high average-for they vary from 6s. to $£ 1$ per week, a sum we earnestly represent as being most insufficient remuneration.

Mr. Walpole: What do you represent as insufficient-the average of 15s.?

A. No, sir; everything below 18s.

Q. You represent that the average of $15 \mathrm{~s}$. is too low?

A. I do not wish to speak of the average being too low. Any man receiving $15 \mathrm{~s}$. or under would be too low.

Q. Irrespective of the length of his duty?

A. Yes, sir; irrespective of the length of his duty. I do not take that into consideration.

Q. Is it not the case there are 6s. allowances given to auxiliary postmen?

A. I believe so; but $6 \mathrm{~s}$. is an extreme limit. That would be an exception.

Q. But the 6s. duty would probably be a duty where a man had a donkey cart?

A. No, sir ; that does not necessarily follow at all. Men have received 12s. for donkey-cart duties.

Q. Is that illiberal?

A. It is fair, sir.

The Chairman : Go on, please.

Witness : I mean to say that the average even on those shorter walks is not enough. I would not accept it. There is no guarantee that the walk will remain a short one, or that it will not be added to in a year or two. These men have the same liabilities as others. It is quite as possible that thoy may meet with an accident as the men on other mounted walks. The only thing in these cases is the question of the wear and tear of the horse.

Sir F. Mowatt: But if the walk is increased would not the allowance for the horse be increased?

A. I believe not, sir.

Sir A. Godley: Have they no means of insuring their horses against accident?

A. They can scarcely do that on the allowance made.

Sir F. Mowatt: My impression is that when a walk is increased there is an increase of wages.

Witness: This difference in the amount allowed varying from the 6 s. to the higher one of $£ 1$ it is difficult to discover a reason for, unless one is prepared to believe it is from sordid motives of economy practised by the Department towards the class of their servants, a policy of "as cheaply as possihle." For we find it is not from the distance travelled by the men that the allowance is estimated, for whereas one man probably in one case 
receives $£ 1$ per week for an 18-mile daily journey, another man may only receive 12s. for a 25 -mile journey, and 12s. for a 22-mile journey. That some levelling up of these allowances is urgently needed and dawning upon the Department may perhaps account for some town receiving an increased allowance during the last year. In support of my representation that the allowance is insufficient, I have calculated that in some of these most illpaid cases the amount allowed is about 1-24th of a penny per mile, less, I believe, than the amount allowed to a cavalry trooper for provender alone, remuneration that will not bear comparison with any other vehicular hiring of a similar nature; and this is demonstrated in the tenders sent in in reply to inquiries as to what horse hirers would supply a horse and cart to do relief work during holidays, etc., which in every case exceeded the highest allowance, and in some cases doubled them.

Mr. Walpole: In the case of the men sending in tenders, were they not for drivers as well as horses and carts?

A. No, sir ; merely for the horses and carts.

Q. No driver?

A. No, sir; the substitute would do the driving. This fact is interesting as showing the disparity between the estimate of the Department and that of practical men as to what is adequate, and it calls for some explanation of the cutting down of the allowance so far below these public tenders. I myself have had to pay precisely the amount I have been allowed -for hire, viz., 3s. per day, above which $\bar{I}$ have had to find the animal's feed, and have had my own pony on my hands on the sick list.

Mr. Walpole: What is your allowance?

A. 18s. per week.

Q. And what distance do you cover?

A. 18 miles. But I have a case of a man receiving 12s. and doing 25 miles. This was previous to the privilege of a substitute horse for holidays being introduced; since then the men at Gloucester are fortunate in having one hirer who provides an aged pony for $£ 1$ weekly. A man who is on his holiday has to pay the stabling of the substitute at the end of the journey. There are men in our office who, in addition to having to keep their own horses, have to pay the substitute's stabling at the end of the journey, and their allowance is probably only $15 \mathrm{~s}$.

Mr. Walpole: You say that during the short time they are on leave the Department has to pay more highly for horse hire?

A. Yes; I mean that the horse hire is far above the amount allowed to the men. I have an instance where a man has to pay $24 \mathrm{~s}$. a week, and may probably be getting only $15 \mathrm{~s}$. or $16 \mathrm{~s}$.

The Chairman: You think he should get much more?

A. Yes, my lord. This arrangement of providing a substitute for $£ 1$ a week is an advantage to the men, even if much more than their allowance, for it is a much lower tender than anyone will give in, and one which the owner declares he is out of pocket by, which can readily be believed when we note that ordinary hire is $9 \mathrm{~s}$. or $10 \mathrm{~s}$. per day for a horse and trap. When we consider the cost of provender of late years-which has been so high that this item in the winter of '93 and '94 and spring of '94 absorbed all the allowance, and meant special contracts for the army without any increase for the rural postman-the cost of keeping in a state of efficiency the harness and cart with its everyday use, farriers' and veterinary expenses, and the cost of stabling at both ends of his journey, and the extra time and work to be devoted to the animal's comfort, we feel we are justified in representing these allowances as insufficient. These expenses affect all the men more or less, for as in the case of veterinary expenses it is rare that animals working continually day after day escape all the ills and mishaps to which they are subject. but there are numerous instances where the men are attended by serious ill-luck with their horses, and consequently their veterinary bills run to a serious item. Even where these expenses have swallowed up their whole savings of years, no matter the cause-illness 
or accident-if your horse fails with the men's punctual attendance, so must his horse or a substitute attend, no matter at what price it may have to be obtained. Again, farriers' expenses during our late severe winters have - ften meant as much as $4 \mathrm{~s}$. per week for weeks together, for roughing, etc. This is felt severely in a hilly locality. The stabling accommodation, meaning the rent of a house with stable at a high rent, or renting a separate stable in town, and also a stable at a farmhouse at the end of his walk, is a serious drain on the meagre allowance, and a matter which is attended with inconvenience apart from the difficulty of procuring suitable stabling, which is generally granted with a show of obligation. It can easily be perceived that the men are not in a position to pay a great deal, so it follows he is frequently expected to oblige by commissions which are regarded as irregularities by the Department, and if he declines these he is termed disobliging, and probably has to seek fresh accommodation. I would observe also that the allowance does not include any recognition of the time the men are occupied in grooming or otherwise attending to their horses and carts, whether it be at early morning, during the day, or on the completion of his day's duty. This work generally necessitates the man rising at either $4.30 \mathrm{a} . \mathrm{m}$. or at the latest $4.45 \mathrm{a} . \mathrm{m}$. to be on duty at 5.30 a.m., and if he can conclude this work in the evening at 8.30 p.m., which I feel sure is not often possible, his day's work has spread over the length of 16 hours. Of course, there are men who are in a much worse position, men who do not reach their head office till 8.30 p.m. We consider that this extra labour and risk should be recognised in calculating the allowance, and also that a fair estimate of this time be taken, and that it should be included in the men's duty, and thus remove the present anomaly of these men being debarred from any claim for overtime-no matter from what reason or to what extent their duty is prolonged-as their average does not amount to 48 hours per week. To include this extra time to the men's credit instead of -as at present-the actual time he is timed to come on duty in the morning, begin and finish his outward and inward journey. This might be allowed to include $\frac{1}{2}$-hour during the day, and 1 hour after his return journey, or in all 2 hours per day. Althongh this would not repre- $n$ t the whole time spent in the work of grooming, harness cleaning, and trap washing, etc., we would favour this low estimate of the time, so that a mounted man should be regarded as performing an 8 hours' day. I would state that, in my opinion, the minimum allowance for the maintenance of a man's horse and cart should not be less than 19s. per week. Out of this sum I would suggest that $1 \mathrm{~s}$. be deferred pay as a provision for the contingencies that invariably occur. This deferred sum should be retained in the hands of the Department, and should be allowed to accumulate and form a fund wherewith the men could replace any damage caused by accident to either cart or harness, or for the paying of expenses of veterinary, or the hiring of a substitute during the casual laying up of their animals. This fund should be available on the men making application with explanation of the need for it. This fund could also be used in the furtherance of $\mathrm{my}$ previous suggestion to the effect that the money requisite to provide a man with a horse and cart should be advanced by the Department to the men, for this deferred pay could be appropriated in paying off the loan. I think this fund might be retained until the end of every five years, at which time the amount due to each man, less the amount withdrawn in the interval for emergencies, should be paid to him to aid him in the purchase of new. carts or fresh animals or new harness. This, I feel sure, would act beneficially on the efficiency of this branch of the Service, by attracting applicants for this work of a more desirable character, and, by enabling the Department to insist on the one pattern and one regulation size. It would make their mounted men a credit to their offices, and do away with the "all sorts and conditions" kind of conveyances that have done duty for this work, and which constitute visible object lessons of the Department's economv.

The Committee at the close of the witness's evidence adjourned till Monday. 
THOMAS GRIMMER, Worcester.

Rural Case--Wages-Uniform-Parcel Post.

Westminster, Monday, March 2nd, 1896.

Present:- The Right Hon. Lord Tweedmouth (Chairman), Sir Francis Mowatt, K.C.B., Sir Arthur Godley, K.C.B., Spencer Walpole, Esq., H. Llewellyn Smith, Esq., and Robert Bruce, Esq., Secretary.

The first witness was Thomas Grimmer, rural postman, of Worcester, who was examined as follows:-

The Chairman: What is the length of your service as a rural postman?

A. I joined the Department as a rural postman on approbation on the 20th November, 1892, and I was appointed on the 25th April, 1893.

Q. You were formerly in the army?

A. Yes.

Q. How many years' service had you in the army?

A. 22.

Q. And what age were you when you became a postman?

A. 38 .

Q. What were your wages then?

A. I started at $16 \mathrm{~s}$. per week.

Q. And what was the length of your walk?

A. My walk, as laid down by my regulations, is $16 \frac{1}{2}$ miles- $-11 \frac{1}{2}$ miles for delivery and 5 miles of collection-but I have myself corrected the distance of my walk; I believe it is measured by the surveyors' map, but I reckon that the walk is really between 17 and 18 miles per day.

Q. About a mile more than the Department calculate?

A. Yes ; about a mile-and-a-half or nearly two miles more than the Department allows.

Q. How is the difference caused?

A. By walking round farmhouses and going up to cottages which lie off the road.

Q. How long does it take you to complete that walk?

A. I am allowed 4 hours all but 5 minutes to do the $11 \frac{1}{2}$ miles of delivery, and $I$ am allowed 2 hours all but 10 minutes to do the 5 miles of collection.

A. It is nominally a 6-hours' day?

A. Yes.

Q. Is it your experience that you are generally able to do it within the time allowed?

A. Yes; I am able to do it in the time allowed, but I am often placed in rather an awkward position; I go out 5 miles, but cannot return till I ccme back in the evening, otherwise if I came back in the afternoon the distance would be more like 28 miles.

Q. What time do you start in the morning?

A. I go out at a quarter-to-six in the morning, and get back at five minutes to seven in the evening?

Q. What is the end of your walk? 
A. It is five miles distant.

Q. What is the place?

A. It is a village.

Q. What is its name?

A. Crowle.

Q. What do you do when you get there? Have you a place where you put up during the interval of waiting?

A. No; I have no place. I have sometimes walked part of the way back and occasionally have picked up a ride, but on other days I have nothing to do during part of the afternoon but to walk about the village; there is a sub-post office there, but it would, of course, be intruding for mo to attempt to remain in it.

Q. Then you are there for about 8 hours?

A. Yes, when I stay there; sometimes I walk part of the way back for my mid-day meal, and stand a chance of picking up a ride on the road.

Mr. Walpole: Is that your usual practice, to try and get a lift back?

A. Yes.

Q. Have you no place to go to?

A. No, I have no place there; I live right in the middle of the city of Worcester.

Q. Have you no friends at Crowle?

A. I am not a rative of the place. I have none.

Q. I thought that being there so much you might have friends with whom you could pass some of the time?

A. No, sir.

The Chairman: What is the particular point you wish to submit?

A. The wages of rural postmen, uniform, lodgings, etc. I beg leave to appeal to you on behalf of the rural postmen of the United Kingdom for your kind consideration on the following subjects, viz. : wages, Parcel Post, uniform, and lodgings, which we consider to be a great hardship inflicted upon us by the rules of the Department. I do not propose to dwell any louger than it is actually necessary on any one of these points, but simply to lay before you the plain facts.

\section{WAGES.}

We consider that all rural postmen should be paid the wage of a town postman; we have to do the same work as a town postman, our hours are much longer, our walks much longer, the roads are much heavier, and it is often the case that our load is much heavier; we have to be away from our homes all day, and during the winter months it takes one all his time to get through, the roads being so very heavy, and the fields that we have to cross to effect our delivery are almost impassable; we have to live in the same neighbourhood as the town postmen, so we have to pay the same for house rent and provisions, which we find very hard with the high rates and taxes. Our work as rural postmen certainly must be considered heavier than a town postman's for several reasons:-1st, When the town man does not leave the office till 7 o'clock in the morning, and as a rule finishes by 9 or a little after, and goes to breakfast at his home, a rural postman leaves the office at 6 o'clock, and finishes about 10 or a little after, having walked about 10 or 11 miles, and has to have his breakfast at the village inn or the roadside. What chance has the rural man of having a warm meal? 2nd, A rural postman is also a counter clerk; that is to say, his duties are similar. to those attaching to that office (vide "Rules for Rural Postmen," 26, 27, 28c, and 56), which makes his position of more importance than a town postrian.

The Chairm ın : He does that sort of work on his walk?

A. Yes; for the convenience of the public he has to. supply postage stamps and registered letter forms, and he has to collect parcels and weigh them for the public, telling the senders the amount of postage, and he has to give 
receipts for registered letters. He is supplied with the necessary materials to do this. During the winter months it is very trying with most rural postmen. A number of us have to pay a weekly rent to some person in the village to allow us to stay during the day, and then we have our rough journey home. We do think our case is hard, and trust that the Committee will give this subject their utmost consideration. Although I have not fully taken up the subject of hours of attendance-as that was done by a previous witness-I wanted to say something on that point here, thinking that it would bear out our contention with regard to the wages question.

Q. Do you propose to deal with your own attendance?

A. I propose to deal with the hours of attendance of rural postmen generally. Rural postmen, as a rule, commence work at 5.45 a.m., and many of them do not complete their work till 7.30 p.m. This we consider is a very long day for winter and summer, and we do not know of any class of working men whose hours are as long. We admit that he is not working all the time, but then, the Department places him in this position, and, with the distance he has to travel, it is next to impossible for him to return until he commences his inward walk. This is every day (Sunday excepted). We do not know of any town whose rural men have the halfholiday during the week, which we consider could be done by working Saturday the same as Sunday. A number of town's men get the halfholiday, but we don't know any town where the rural postmen get the half-holiday on Saturday. The rural men have still to go into the country, and they find that the collection is much smaller on Saturdays than upon any other day of the week, because the country people as a rule come to market, and we think Saturday could easily be worked with the Sundays. The rural postmen might stay only one hour at the end of the delivery, and then return, and thus get half-a-day off the same as the town men. The public would not be put to much inconvenience by it, and we feel certain they would do all in their power to assist us in getting it. We most earnestly plead for a proper definition of a full day's time for rural postmen. We are of opinion that the percentage of sickness is far greater with rural postmen than with the town postmen. There has been some question about answers given with regard to the 18 miles per day or 6 hours' walk, but in my case I can challenge anyone to doubt the distance of my walk. I maintain that the surveyor's map is not a fair way to test the point at all, unless a good allowance is made for the time going up to cottages and round farmhouses.

Mr. Walpole: There must be many days when you do not go up to all the cottages?

A. There are certain cottages we go up to some days and others we do not. I think it would only be fair that the postmen should have the advantage of such difference of distance as that might make.

Q. I presume there is hardly any day on which you have to go to all the cottages; there must be some average in the matiter?

A. As a rule we go to all the cottages three or four times a week.

Q. I dare say that is so. When a walk is fixed the surveyor's clerk walks the whole distance with you, does he not?

A. No, sir.

Q. Are you sure of that?

A. He goes to the houses for which there happen to be letters on the day of his visit.

Q. In fact he goes over the walk with you to all those houses for which you have letters?

A. Yes.

Q. He does not simply stop at the gate while you go to the cottages?

A. No, he does not; but I have heard from several offices that the surveyor's clerk generally tests the walk on a Monday morning, which is not a fair day to test a rural walk, because in the Midlands we don't get the London mail till mid-day, and it is not delivered in the country district till 
Tuesday morning; we get no London letters to deliver on Monday morning, and therefore our delivery is much smaller on that day than on any morning in the week, so it is hardly fair for the delivery to be tested on a Monday.

Q. So far as I see from the diaries of the surveyors' clerks, they are walking every day of the week except Monday ; indeed, I think they would neve: get through their work if they only tested the walks on a Monday.

A. That is the case in several offices. I have been in communication with some rural men at places elose to Worcester, and they tell me that they never have their walks tested in winter time, but simply in the summer, so that the clerks have a delightful walk, and do not have to contend with heavy roads and ploughed fields. In fact, they go for the principal object of seeing the country. (Laughter.)

Mr. Smith : Still the distances are the same?

A. They don't consider the distance. They want to see the country, but they don't, for these reasons, take a day in winter, when it would be much heavier walking.

Mr. Walpole: Surely you don't mean to say th.it the surveyors' clerks are not doing their work in winter?

A. I don't wish to cast any reflection on them, lut $\mathbf{I}$ say that the walks are usually tested on a Monday, which, we contend, is not a fair day. We have spoken upon this matter repeatedly. Then again, even if we admitted that it was a fair way of testing the round, let it be remembered that the rural postman has to carry lis load, whereas the visiting clerk has nothing to carry on the walk, and can therefore go much quicker than the postmani.

Mr. Llewellyn Smith: Does your remark about the testing on Monday apply to your own office only, or is it the result of information collected from various parts of the country?

A. I have collected the information round about my own district office, where I have been in contact with the men.

Mr. L. Smith: I think that is a matter to be looked into.

Mr. Walpole: So far as the Dep.rtment knows, the presumption would be that the surveyor's clerk would not test walks on a Monday morning. It is his instruction that he should, if possible, be at, headquarters on Monday, so that he could not test the walk on that day, but no doubt there are some cases in which the clerk stays away from headquarters in order to test the walk.

Witness: With regard to the Parcel Post, we feel sure that no person suffers so much as the rural-postman under this subject. The advantages given to the public by the Department incresses the burden on us as rural postmen largely. Our contention is that we were intended for letter-carriers, and not for carriers of burdens such as the Department has contrived to put on us. We are of opinion that the parcel delivery and collection should be done by mounted men in rural districts, and as the Post Office have become public carriers they could then raise the maximum weight from 11 to $28 \mathrm{lbs}$, and in this way serve the rural districts in a proper manner, and separate parcels not exceeding $1 \mathrm{lb}$. from other postal matter for walking rural postmen. Anything heavier should be handed over to be delivered by mounted men. By raising the maximum of the weight as suggested the Department, in a few years, would be recompensed for the extra outlay, as the public every year seem to appreciate the care and punctuality with which parcels are delivered by Parcel Post, compared with those that are carried by railway companies. Those who made the carrying of parcels by a walking rural postman a part of his duty must have never thought of, nor surely never experienced what it was to carry a lot of parcels such as children's chairs, parts of machinery, hat boxes, dress boxes, and portmanteaus.

Mr. Walpole: I think there are not many portmanteaus that weigh less than 11 lbs.? 
A. I have had a portmanteau and a small Gladstone bag to take out in my short experience.

Q. Full or empty?

A. They would not be full as they were passing through the post. Such parcels a rural postman has to carry 10 or 12 miles on a dark winter morning, and protect them from the weather, and at the same time deliver letters, newspapers, and other postal matter. He starts with a maximum of $35 \mathrm{lbs}$.; of this weight he will have on an average from 150 to 200 letters, newspapeis, circulars, etc., and an average of four parcels. The postal matter will very likely almost fill his pouch, some of the small parcels may fit into it also, but if so, he must take them out to get at his letters wlien he comes to the place for deliving them. In the nast there has been a great outcry at our soldiers being so buckled up with their equipment and that like, that they were unable to march to any great. extent, but, my lord and gentlcmen, I should like you to see some of our rural postmen going on their morning walks, pouches full, and parcels strapped all round them. The appearance of a rural postman when he is in the condition above described is ludicrous in the highest degree. Besides all this, his pace or rate of walking is impeded, and extra exertions on his part have to be made to keep time. No allowance as to time is made for carrying parcels, as in the majority of cases the time allowed remains the same as when there were no parcels to carry. We consider the weight limit too high. Having been accustomed to carry loarls before I became a postman, I can assure you that $28 \mathrm{lbs}$. hang heavier on my shoulders when I get to the $6 \frac{1}{2}$ miles' limit of my route than heavy loads that I have carried in my army career. It is a regular drag and bearing-down weight over a long distance, especially when you have to walk over heavy roads, and it tends to knock a man up altogether.

The Chairman: What was the weight of your accoutrements when you were a sollier?

A. I was in the garrison artillery, and, of course, so far as our accoutrements were concerned, we seldom had to carry them, bat we had heavy projectile to carry for short distances.

Q. The urdinary accoutrements of a soldier in full marching order would weigli a goo.l de.il more than 28 lbs.?

A. But he has not the roals to contend with like a rural postman. If you take a regiment route marching, soldiers go on their route twice a week, but a rural postman is at it every day.

Q. But a rural postman has not always $28 \mathrm{lbs}$. to carry?

A. No more has a soldier.

Q. He has more when in full marching order.

A. He does not carry that every day.

Q. I mean for regular route march ing. When i full marching order a solüier has a good deal more in weight than a postman at the worst of times?

A. That is only at certain times, but we are loaded every day, as it were.

Sir F. Mowatt: But you are unloaded as you go along?

A. Yes; as a rule we lose a portion of our load as we go along, but I may recall the old saying that when you are in a hurry everything goes contrary, and when a rural postman gets a heavy load he has usually to take it to the end of his journey. It may seem strange to illustrate the point in this way, but such is the case. Where people live far from towns they take advantise of the facilities given by the Department to have nearly everything sent to them through the post, and we therefore find that as a rule the big parcels have to go to the end of our journey or to some byelanes. It may appear small at first sight, and if it could always be in compact form, or easy to distribute over the body, it would not be nearly so bad, and mitht be tolerated under certain circumstances; for example, if heavy parcels were got rid of early on the walk, or in collecting parcels if the heary ones were handed to us when we were near the head office; but experience shows that two-thirds of the heavy parcels go to, and are 
received from districts furthest from the head office. It hardly seems possible, but such is the case. It is from experiences such as these that the recommendation is made to reduce the weight limit to $28 \mathrm{lbs}$., and the delivery to be done by mounted men. The unwieldy shape of some of the parcels, and the flimsy nature of others, prevent them being strapped together. The light ones have to be strapped together and put on one side, and the heavy ones on the other. These have to be supported while you get at your pouch of the letters, etc., for delivery. Perhaps a corner of a heavy box gives you pain on one side, and yet it cannot be moved suddenly lest the box marked "Fragile" on the opposite side should be injured, the red label of which is turned up to the postman when he received the parcels, as it is the duty of every postman to be careful to a greater degree if possible with parcels having this label affixed to them. I would like to point out here that railway companies as a rule see that packets and parcels are securely packed. I should like, my lord, to quote an experience of my own on this point. I was bringing a bag from an office on a round, and there was evidently a parcel in it which was fastened with one of those big shawl pins, and this shawl pin was pressing into my back, although I had to carry it 2 miles. The public, so long as they get their parcels passed in, don't care, but it is very awkward to carry a load of from 30 to 35 lbs. with a pin sticking into you.

Q. Surely you could alter the position of that parcel with the pin?

A. No; I was bringing in a sealed bag, and if I had shaken it up I might have broken something inside of a fragile nature.

Mr. Walpole: But could you not turn the bag, and so at worst get only the other end of the pin?

A. Yes; but then I had suffered the first shock. I only mention this in order to illustrate the awkwardness of the position in which we rural postmen are sometimes placed. I should like to point out that some rural postmen have a portion of a town round to do on their outward walk, and in many cases have to carry parcels the whole of their journey. I will give a case in point. A rural postman commences his walk 1 mile from the head office; he has 13 houses to supply in the city boundary, and also parcels to deliver. During the winter months these people are not up, nor will they get up to receive them, so he has te carry them the whole journey round, and deliver them on his return at 6.30 p.m. He reports this to his superior officer when he returns, but is told there is no remedy, that the surveyor has power to allot portions of town to rural walks. These people get a delivery of letters and parcels after the rural man goes in the morning-at 12 and 4 o'clock. That is to say, certain parcels for these people are kept back.

Q. Where is this particular delivery?

A. In Worcester.

Q. Does the rural postman go to these houses at 6 in the morning?

A. He goes to the Post Office at that hour.

Q. At what time does he call at those houses?

A. After leaving the post office at 6 in the morning. The distance is about a mile, so he would get there from a quarter-past-six to half-past-six.

Q. Are there no letter-boxes to the houses?

A. There may be; but I am speaking with reference to parcels.

Mr. Walpole: How often would there be parcels at that hour for these people?

A. During Christmas week this rural postman had a parcel for one place which had a postage of $10 \frac{1}{2} \mathrm{~d}$., and another for a second house out of these 13 houses which had a postage stamp of $6 \mathrm{~d}$. He rang the bell to call up the servants, but they would not come, so he continued on his rounds and had to carry these two parcels a distance of 12 miles, unnecessarily as we hold, because they could have been left in the office and sent to these people by the 12 o'clock town delivery.

Q. Did he complain? 
A. Yes.

Q. To the Postmaster?

A. To the inspector.

Q. Was any remedy suggested?

A. He was told it could not be altered, as the surveyor had full power to add a portion of a town delivery to the rural postman's walk.

The Chairman: Could it not have been arranged to have these parcels sent out by the 12 o'clock town delivery?

A. We thought so, but we were told to continue delivery.

Mr. Walpole: You mean that the inspector did not carry the appeal further?

A. He told the man that he would report the circumstince, but the parcels still came in, and the postman wanted them to be left behind for town delivery, but was told, "No ; you must take them."

Q. How long ago was that?

A. In Christmas week.

Q. That was an exceptional time?

A. It was not an exceptional case; it has continued since.

Q. And it has not been remedied since?

A. No.

Q. How many rural postmen are there starting from Worcester?

A. There are seven of us from the head office.

Q. How many of them have any delivery in the town.

A. Only this one.

Q. The other six have no town delivery?

A. No; I don't think the other six have any town delivery. We think that 35 lbs. is rather a heavy load, bearing in mind the distance that a rural postman has to walk. We have cases where men are made to carry more than their $35 \mathrm{lbs}$., which we desire to bring to your notice. The regulation states that he shall not carry more than $35 \mathrm{lbs}$, and yet the Department use their persuasive powers to get a man to carry a greater weight rather than get him assistance, and cases are known when the load has weighed 76 lbs. They have to call in a small telegraph messenger tc take a portion, saying, "You cannot have two assistants." The officer says it is not worth while bringing on another person for one or two parcelsof course it saves him trouble - and the postman may not like to refuse him. The weight should be made definite and the rule adhered to.

Mr. Walpole: Can you tell us about this case of the $76 \mathrm{lbs}$ ?

A. Yes; it was the case of a rural postman who found that his weight came altogether to 76 lbs. We have not any big boy messengers in the provinces as in London, but two or three parcels were taken out of the bag and given to a little boy messenger, the rural postman taking the remainder, so that the rural postman had still about 45 or $50 \mathrm{lbs}$. to carry.

Sir F. Mowatt: So that the little boy had to carry $30 \mathrm{lbs} . ?$

A. I will not say the exact weight he had to carry, but according to the rule there should have been two assistants in such a case.

Sir F. Mowatt: If there were $76 \mathrm{lbs}$. to be carried, and the boy had two or three parcels, you cannot have brought the man's weight down to 50 lbs.?

Witness : I am not speaking on behalf of the little boy, but on behalf of the rural postman.

Q. I was rather putting a question on behalf of the little boy-(laughter) - and it seems to me as if you had shunted $30 \mathrm{lbs}$, on to him.

The Chairman: It was 35 lhe

A. It was the Department that did it; if there was any cruelty it was theirs, but I think I said that the rural postman had from 45 or $50 \mathrm{lbs}$. left to carry.

The Chairman: What is the greatest weight you have had to carry as a rural postman? 
A. When I was on my old round I have carried at night time as much as $56 \mathrm{lbs}$.

Q. That was a collection?

A. Yes ; that was a collection.

Mr. Walpole: How far had you to carry that?

A. Alout two-and-a-half miles. I don't say that I was compelled to carry it. It was in this sense-I had to make a collection through the village, and the rule says that when the weight exceeds a certain amount assistance may be obtained, but it is often practically impossible to take advantage of that rule. Assistance may be employed if it can be obtained, but in collecting on? would rather carry the weight some time than go back to the sub-office for help.

Q. You burden yourself with this load rather than go back to the suboffice?

A. Well, one cannot get any assistance in a country lane, or very seldom, and if I ask a man's help the first thing he asks is, "What will you give me for doing it?" The Department allows 8d., but one cannot engage a man to carry the load that distance for $8 \mathrm{~d}$., and therefore, being unable to pay the extra money out of his own pocket, the rural postman has to carry the weight, excessive though it may be, several miles.

Q. The Department allows 8d.?

A. Yes ; in this particular case.

Mr. Llewellyn Smith: And you find that not sufficient?

A. Yes.

Mr. Walpole: How far is the distance?

A. About two miles or two miles and a half on the main road from the sub-office. I remember asking a man to help me there, and he said he would if I gave him a "bob," but I carried it myself.

Q. You could not bring him down to 8 d. ?

A. I could not. It caused a bit of a row. He would not stand it, and if I were a civilian and were asked to-morrow to carry a similar load for several mil as I would not do it for $8 \mathrm{~d}$. I had to say that was all he could get. He demanded 1s., and I was not prepared to pay the extra 4d. out of my own pocket. Our recommendations are that the limit of weight for rural postmen be $28 \mathrm{lbs}$. on starting from their head office. This weight to include letters, poüches, parcels, newspapers, circulars, or other postal matter. And we hope that the Commission will see their way to recommend that the parcel work be done by mounted men in the rural districts. That is with reference to heavy parcels, my lord.

Mr. Walpole: There must be many places where the number of parcels received by post is so small that it would be practically impossible to naintain mounted men for the delivery. Is that not so?

A. Of oourse I can scarcely give you a definite answer to that, because I have not traversed sufficient ground over England; but where I' lave been and where $I$ have taken notice of the postal work I don't think it would be impossible. Of course, the Postal Department is an increasing department; it is increasing daily.

Q. And in consequence the mounted men are also, I believe, increasing daily?

A. I have not seen any.

Q. As a matter of fact, we are increasing the force nearly every week.

A. I could not say as to that.

Q. They don't come round your way. Do any of you use bicycles?

A. Yes, some of the rural postmen do, but there is a great deal of bother about them; and as the Department don't pay for bicycles the use of them would be wearing out a man's own property for the public service. We had a case of a walk of six miles where a postman has been forbidden to ride a bicycle under any pretence whatsoever.

Q. How long ago was that?

A. Three months. 
Q. Do you know the reason?

A. No.

Mr. Walpole: The orders of the Department are very strong that permission is not to be refused without good reason.

A. Well, I have not made inquiries into this case. I did not take up this branch of the subject.

Q. But if the Department made an allowance for bicycles, as it does in certain cases, would that not be a relief?

A. Yes ; in some cases.

Q. I suppose you have tolerably good flat roads near Worcester?

A. On tlie contrary, I should say we have about the hilliest parts, except in Wales; there are some nice hills our way, where the National Cycle Association have put up boards to say it is dangerous to go down.

The Chairman: That is generally done on account of some sharp turn of the hill?

A. It is owing to the steepness.

Mr. Walpole: You have some flat land as you go down towards Tewkesbury, in the valley of the Severn?

A. I have never been that way. We hold that the $28 \mathrm{lbs}$. net weight, if agreed to, or recommended by the Commission and adopted by the Department, should be adhered to. Turning now to another subject, I should say that great dissatisfaction exists among t!:e rural postmen with regard to the inferior quality of uniform supplied to them, as well as the unsuitable shape of it; the quality and colour are almost identical witl that supplied to the inmates of workhouses in Ireland.

Q. Do you know yourself what is supplied to the inmates of workhouses in Ireland?

A. I have received that information.

Q. From whom?

A. From one of the witnesses already examined, but the point was left to me as a practical man, for I am a tailor by profession.

Q. What is the colour of the workhouse clothing in Ireland?

A. The information was supplied to me. Our colour is grey. What interest can a man take in the Service when he is supplied with uniform which gives ill-natured people the opportunity of making such remarks as follows:- - There goes the poorhouse chap"; "How much does the Poor Law Guardians pay for them clothes"; or "There will be another penny in the pound on the poor-rates for that new suit"? In rural districts when phrases such as these get into common use they do not die out as soon as they do in towns. In the matter of rural postmen each new suit renews remarks such as I have quoted as far as Ireland is concerned. Apart from the economy, we fail to see any good administrative reason why rural postmen should be clothed different from town postmen. There should be one uniform for all classes of postmen, in shape, colour, and quality.

Mr. Walpole: You are talking about Worcester?

A. I am giving evidence on behalf of the whole of the rural postmen.

Q. What is the colour of your uniform?

A. Dark grey.

The Chairman : Is that universal in the provinces?

A. Yes, my lord.

Q. And do the town postmen in the provinces also wear grey?

A. No; they wear blue, the same as the London postmen.

Q. And you wish to have blue lather than grey?

A. I think it would be more suitable and more serviceable. We want to have the same as the town postmen.

Mr. Walpole: Is it the grey colour you object to?

A. Yes; and its present quality.

Q. What is the matter with the quality?

A. It is very inferior.

Q. Is it inferior to the blue clothing the town postmen wear? 
A. Much.

Q. Are you talking of the winter or the summer uniform?

A. I am talking of both; they are made of the same material. The topcoat, the summer coat, winter coat, and waistcoats are all of the same material ; the trousers for rural men in the winter are of a heavier material, and the trousers in the summer consist of a blue serge.

Q. Would you prefer the town postmen's uniform?

A. Yes ; much.

Q. Is that the general opinion?

A. Yes ; as regards the colour and quality.

Q. And as regards the serge; is that better for you for summer wear?

A. Yes, if we had it bigger; at the present time they are too close fitting.

The Chairman: Is that the case with all the men that the clothing are cut too scrimply?

A. I have been informed that that is the case with nearly all the postman, that the clothes are cut too closely; I know it is the case with the rural postmen down our way. It is a sad complaint right through our office as regards the fit and style of clothing.

Q. When your uniform gets wet does it shrink much?

A. It does much, my lord. The clothes get wet very quickly; there is not a particle of waterproof quality in it; in fact, the rural postman's clothing is nothing but shoddy material. To prove that if you take any new garment for them from the stores and let it be worn for 24 hours by even the most careful man, so that the atmosphere can get into it, and then beat it on a table with a stick, you will find as much dust come out of it as if it had been in wear for six months; it is nothing but shoddy, but it is different in the case of the clothing of the town postmen.

Mr. Walpole: Should we remove this grievance if we gave you the same uniform as the town postmen had?

A. We would be satisfied with that, provided it were a better fit.

Mr. Walpole: Of course, the things ought to fit properly.

Sir F. Mowatt: As to the sorting out of sizes, are the men measured for their clothing, or is it served out in sizes?

A. Yes; we are measured and get the clothing afterwards. But in nine cases out of ten the clothes do not fit. Some time last year the agent came to our place and superintended the measurement. We then thought we were going to have a better fit, but we have got rural men in our office nowand I prefer to keep to the case of the rural men, for I know much less about the town postmen-who, when they put out their arms, find their sleeves several inches too short. It is a common fault apparently right through the Department with regard to the rural men that their clothing is too tight fitting.

Mr. Walpole: I am afraid that that is a complaint all through the Service, that the uniforms are too tight fitting. We have had a committee on that subject within the last two years, and recommended that the clothing should be made looser. We have specially dealt with that, and I hope they will be more to your satisfaction in the future, but in the case of thousands of uniforms it is rather difficult to make all right. Would you be satisfied with the town postman's uniform. properly fitted; that is what I wanted to come to?

A. Yes; we would be satisfied with the town postmen's uniform if it fitted properly.

Q. Do you want a different shaped jacket?

A. It has been suggested by one or two that we should have a different shaped jacket, but, speaking for myself, I believe it would be satisfactory if we were supplied with a proper fit of the same jacket as the town postmen.

Mr. Walpole: I find that the Department would save money by giving you the same uniform as the town postmen, as the rural postmen's uniform costs more. There is really no desire on the part of the Department to skimp the material. 
Witness : In theory the rural postmen are supplied with two suits in the year-a summer suit in April and a winter suit in October. These arrangements would be suitable as to time if they were adhered to all over the United Kingdom, but some towns think themselves fortunate if they receive their uniform within six or eight weeks of the stated time. I have heard of cases where misfits were sent back and no more supplied for that issue. These things are very irritating to men who are entitled to and expecting uniform. They lose heart trying to keep up the appearance of good uniform, and the seeds of slovenly habits are sown in the lives of these men, which would not have been there but for the neglect of the Department in not having their contracts fulfilled at the proper time. The material that our summer coats are made with is the same as the winter coat, and the topcoat, instead of being somewhat heavier. The whole of the clothing is too close fitting, and the coats should be lined with some woollen material instead of the cotton stuff. The top-coat requires to be lined throughout, and it would be a greater inducement to comfort if they had pockets outside, with a different style of cut. The head-dress is too hot and heavy in summer and not suitable for the winter, for rural postmen who have the open country to contend with. It is rather an awkward shaped hat. We had an advantage, if it can be called an advantage, of wearing a straw hat of our own during the summer weather, but in many of the towns we had to adhere to a uniform pattern, which made it rather awkward for rural postmen.

Q. When you talk about a uniform pattern, was not the rule simply that it should be a clean white straw hat, with a plain black ribbon round it?

A. Yes.

Q. There was no other uniform requirement with regard to the hat?

A. But a number of the men had already straw hats with different colours.

Q. Do you think it was unreasonable on the part of the Department to say that if you preferred to wear white straw hats they must be clean and have plain black ribbons round them?

A. I don't think there was any necessity of publishing an order that they must be clean straw hats, as every postinan who had any respect for his profession would want to have a clean hat. Even here in London, when I have been up for my summer holiday, I have not seen many people wearing dirty white hats, and the rule puts a man to the extra expense of getting new ribbons.

Q. That would not be much?

A. It would be $4 d$., 5 d., or 6 d., which totals up for a rural postman.

Mr. Walpole: You don't think it would look so well to see a lot of post. men starting off with different coloured ribbons round their straw hats?

A. If the Department wanted something different, the Department should supply what it wanted.

Q. It does not supply straw hats, but only says that if you wear them you should have a plain black ribbon round them. The wearing of straw hats was conceded to you as a relief in hot weather.

A. If it was necessary for us to be so relieved the Department should have provided us with the means of relief.

Mr. Llewellyn Smith: The Department does not compel you to wear them at a!!?

A. But we were labouring under a terrible trial in the very hot weather.

The Chairman: What is the particular fault you find with your uniform caps?

A. The hat is too heavy and hot in summer and not suitable in winter.

Q. Have you any suggestion to make as to what would be more suitable?

A. I would simply suggest a kind of tweed helmet, and the same thing in winter with ear-laps.

Sir F. Mowatt: But would you not be afraid of the criticism of the people on the road, who seem to have rather hurt your feelings by your remarks? (Laughter.) 
A. No, sir; the rural postman is exposed to the weather more than a town letter-carrier. In the office I come from there are at present two men who have frost-bitten ears, and I have no doubt there are others elsewhere, so the fact of having ear-laps or something of that kind would be a certain protection. We have to go into the open country, and in keen frosts or cold winds we often find the weatlier very biting. The waterproof capes do not keep you dry should you get caught in a shower of rain, and it is not long enough for any man.over $5 \mathrm{ft}$. 4 in., because the rain runs off it and soaks in the knees of his trousers, exposing him to the danger of rheumatism and colds. That is another point I should like to dwell upon a little, viz., with reference to the waterproof capes. I heard remarks in expectation of a new pattern cape, but I have already got one different from what I received two years ago, and I find that it is quite as wanting in the waterproof quality as the old one. I have found in my experience that ordinary calico is waterproof provided you place it in such a position that nothing touches it underneath, but as soon as anything touches it underneath the water soaks through; it is the same with these waterproof capes. If you wear one of them for half-an-hour in a shower of rain you can take it up and wring it.

The Chairman: The new ones?

A. Yes; my new one that I got about two months ago is just the same. If you have a pressure like that of a man's shoulder against it in wet weather the rain will soak through just as if the material was not waterproof at all, and in the case of a tall man like myself the rain runs down, and just catches me at the knees above the short leggings.

Q. If the cape were to hang below your knees it would be very awkward to walk in and mucli heavier to carry.

A. We make a complaint with regard to the leggings; we want a shorter waterproof cape and longer leggings-leggings which will keep our legs dry.

Q. Do you mean like what the policemen in London wear?

A. I have not noticed what the London policemen wear in wet weather.

Q. I mean leggings of waterproof like the legs of trousers?

A. Yes ; coming right up.

Q. You would not be prepared to wear long capes, would you, to protect your knees?

A. It would drown some of the postmen to have a long cape, as we vary in height.

Q. I don't mean the same length of cape for everybody; but, supposing each man had a cape long enough to protect his linees, he would find it rather awkward to walk in, would he not?

A. He might find it awkward with the present style of cape, as it is not waterproof, but he would find it much less awkward if it were waterproof ; the capes are very broad round the bottom-they are cut in a circular form, and they would to a certain extent keep the wet from the knees so long as the water running down tliem did not drip on to the trousers where they gather just above the leggings. For outside wear a light serviceable waterproof coat to cover the knees, and if good material were used it should last for three years. The ordinary overcoat should be made of dark or blue woollen material, single-breasted, and with two pockets in the outside, buttoner close up to the neck, with the tab fasten d with buttons, and should be cut with the allowance for making up on the front, the metal badge of G.P.O. to be worsted. Postmen have to carry a bag, and the strap of that bag passes over the shoulder and gets into contact with the metal badge, which sometimes tears the clothing. The leggings should be made of material to cover the knees and be supplied every two years. A wide waterproof cape similar to that supplied now, but shorter, for the protection of the parcels, and should be supplied to each rural postman to be carried in his pouch, so as to be prepared for any sudden changes in the weather. It has been already stated that the present shape of clothing is a cause of dissatisfaction, but when taken in conjunction with the fact 
that only about one mon in ten gets a satisfactory fit out of each issue, and that many of them are wearing the summer uniform in January, and the winter uniform in July, there is just cause for the irritation that is so general on this head among both town and rural postmen. We recommend: -That the Department contract for the supply of the cloth materials and trimmings, and the cutting of them according to the uniform pattern, and that each head Postmaster be supplied with the number of suits, etc., required for the men under his charge, at least one month before they are due to be worn. That they be made locally to fit each man, the Postmaster to be responsible for the make according to the uniform pattern before they are paid for. As to the dates of issue and wearing summer and winter uniform for rural men, the following seem to be satisfactory if adhered to:-Rural postmen, summer uniform, April to October; winter uniform, October to April. The reason we put that in is that some of the rural postmen's clothing for winter does not reach them until about the time when they ought to be getting their summer clothing, and so vice versa. If these matters were looked after closely in this way a great deal of the irritation would be allayed, and if looked after in a business-like way little, if any, additional expense would be required to carry out these reforms, and the result would be a contented Service, so far as uniform would be concerned.

The Chairman : You told us, Mr. Grimmer, that you were a tailor?

A. Yes, my lord; I was a battery-sergeant tailor.

Q. Do you find yourself able to do a certain amount of tailor's work now?

A. Not now, my lord.

Q. Have you dropped it entirely?

A. Yes, my lord.

Q. Were you a tailor when you were in the Artillery?

A. On joining the Artillery I commenced it. I was tailor for 15 years, and out of that time I was about 12 years battery-sergeant tailor.

Q. You do not attempt to practise it now?

A. No, my lord.

Q. What pension have you now?

A. I have a sergeant's pension.

Q. How much do you get?

A. 2s. 3d. per day.

Q. Don't you do anything except Post Office work now?

A. Unless I do anything for myself. I do little jolss for mysclf.

The witness then withdrew. 
THOMAS CARMICHAEL, Heckmondwike.

Sub-Office Postmen. -

Westminster, Monday, March 2nd, 1896.

Thomas Carmichael, S.O. postman, called and examined :-

The Chairman : Are you a rural postman?

A. I am a sub-office postman.

Q. What particular work do you do?

A. Indoor work and deliveries, as well as other outdoor duties.

Q. You are going to speak in regard to medical attendance?

A. That is the question, my lord.

Q. Do you speak in regard to medical attendance for postmen all over the country, or only rural postmen?

A. I shall speak for the postmen generally all over the country. I have important evidence which has been sent to me in respect of complaints that are made of medical treatment. I am anxious to place these before your lordship, and I wish to say at the same time that I have had no experience myself in matters of this kind, as the system has not yet reached our sub-office.

Q. The evidence has been supplied to you on these points by your comrades, has it?

A. Yes, sir; it has been collected and given into my hands to be dealt with.

The Chairman : Go on, please.

Witness : The statement I have to submit to your lordship's Committee for consideration is that of free medical attendance as affecting postmen employed at head offices, sub-offices, and other small offices. It is true that in head offices in London and provincial towns provision is made by the Department for free medical attendance and medicine to be given to postmen employed at these offices; whereas at sub-offices, only a very small number have the privilege extended to them, and those who have rarely take advantage of it owing to the hardships, expenses and inconvenience which accompany its application, making it thereby practically useless for its real purpose. Dividing the subject into two parts for a moment, we have on the one hand sub-office postmen contending that its advantages should reach all sub-offices (but under a more satisfactory basis) than that now in existence, and of which I intend to offer some suggestions later on. On the other hand, we have postmen at sub-offices complaining very bitterly at the manner in which in its operations its usefulness is often robbed, and its proper object totally disregarded by members of the medical staff, and of the arbitrary power these gentlemen are permitted to exercise over postmen without let or hindrance. Now, if in the eyes of some of these medical gentlemen a postman fills a minor position, I would respectfully remind them that like themselves he is nevertheless a servant of the Department, whose duties are equally important, entitling him to receive such consideration, care, and attention as would be meted out to those in a higher rank, and for this purpose, I believe, the authorities deemed it necessary that doctors should be appointed; and I am of opinion that if the interests of the Department in this particular branch have to be safeguarded, medical pfficers had better be instructed to equalise matters more creditably than 
has hitherto been the case in respect of postmen, making all alike without mark or distinction, as all are admittedly constituent parts, and go to make up and complete the whole machinery of the Post Office system. Postmen at large centres cannot balieve that the Department is aware of the pauperised treatment meted out to their servants. Government officers, your lordship will adnit, should not be treated thus. One man in particular had to appeal to the Secretary before sick leave was granted him, and another had to obtain the assistance of the local chief clerk before the doctor's stiffness could be removed.

Mr. Walpole: Doctor's stiffness?

A. Yes, sir ; his obdurate manner.

The Chairman: Is it your contention that postmen receive worse treat ment from the medical officers than sorting clerks and telegraphists?

A. Yes, my lord; and I think the evidence which I am about to place before the Committee will bear me out in that respect. At Liverpool, for instance, many of the postmen would prefer to have their own "family doctor" on account of the P.O. medical officer's treatment, which is certainly not so good as that of sick club doctors, and they are bad enough. The cost of their prescriptions is simply nominal. A chemist dispensing for one of our medical officers informed Postman S. Dowling that he had agreed to dispense prescriptions for Post Office employees at 3d. per case, except under circumstances of a special character, when the cost might be a little more.

The Chairman: I suppose you would not say it was $3 \mathrm{~d}$. per case; you mean it was $3 \mathrm{~d}$. per bottle or box?

A. Yes, my lord; I understand it is such.

Mr. Walpole: Is there any objection to that arrangement? If the medical officer is able to make such an arrangement with the chemist would you object to it?

A. I think, sir, it shows without a doubt how much interest the Department take in their servants' welfare.

Q. What do you mean by that?

A. I mean that even a bottle of medicine which may only cost $3 \mathrm{~d}$. and give to the dispenser out of this a large share of profit carnot reasonably be expected to contain ingredieints of much value.

The Chairman: I do not see that that follows. At any rate in that respect apparently other servants of the Post Office are in the same position as postmen. You do not say this merely applies to postmen? Is it not the case with Post Office employees altogether?

t. I am onls dealing with the postmen's case, my lord.

Q. You do not say so here. You told me when you began that the postmen were not aware of the position of other employees of the Post Office. Apparently they are all put on the same line in regard to the drugs dispénsed?

Witness: Postman J. Walsh had a prescription given him by Medical Officer Dr. M'Allister, to take to a charitable institution in Beaufort Street, and, his sister calling there to Kave it dispensed, was ordered to go round to a back slum to be served with other poor people.

The Chairman: Is this at Liverpool too?

A. Yes, my lord.

Mr. Walpole: What do you mean by "back slum?" I should like to know what it means. Do you mean she was sent round to the doctor's back deor?

A. I understand it is some kind of $\mathrm{c}$ nvenienc? commonly mate by parochial doctors for serving pror neople in the district in which they a re concerned.

Q. You mean that the doctor has two doors, and sees some patientsas many doctors do-at the door at the back of his premises?

A. The fact of the postman's sister or friend having been sent round to such a place is decidedly lowering to the Department. I do not think that 
the authorities, if they knew of such a case, would allow the doctor to do arything of the kind.

Witness: Occasionally the hideous and inhuman practice adopted towards candidates for appointments in the matter of teeth extraction in some cases is most revolting, is uncalled for, is unnecessary, and certainly inexcusable. How can it affect the Department if a candidate has to submit to one or a dozen teeth being taken out? If the object in view is to ensure for the public a more pleasing appearance of the man wlo is to be a representative of the Department, surely it is not too much to ask the Department to encourage this by supplying a new set of artificial ones, and so save the new entrants a needless expenditure of $£ 5$.

Sir F. Mowatt: Encourage what?

A. Good appearance in the street, for the authorities must know that young men being thus deprived will strive hard to have them replaced as soon as possible.

The Chairman : Is it not the fact-I am not defending the rule in regard to the extraction of teeth-is it not a fact that the reason for examining the teeth is that it is supposed that a man must masticate his food properly in order to digest it properly, and, therefore, knowing the importance of a man having good general health, it is desirable he should have good teeth in his head?

A. Yes, my lord; but when a man previous to his appointment receives a notification that he must have a certain number of teeth extracted before he can receive his appointment, I think something should be done for him by the Department for being so deprived.

Mr. Walpole: No other men will receive such a notification in the future. (Continuirg, Mr. Walpole said he did not know the witness was going to speak on this subject, and intimated that that rule was abolished last Saturday.)

Witness: I lave the following report regarding teeth extraction from 'T' rquay:In order to pass the medical officer's examination candidates for the appointmont of postmen are obliged to have new teetl .put in; the expenses incurred in endeavouring to carry out the whims and eccentricities demanded thus have cost some of the men from 50 s. to £5. Fuller particulars will be sent on if desired.

Mr. Walpole: They have never required teeth to be put in; they hive required teeth to be taken out. Do you know of any case where the men have been required to put in teeth?

A. Cases have been reported to me.

Q. Of the Department requiring teeth to be put in?

A. No, sir ; but where the men have gone to that expense.

Q. A good many of us do that. (Laughter.)

A. But it was through the compulsory extraction of the teeth provious to their app intment.

Sir F. Mowatt: They had them put back again afterwards. (Laughter.)

Witness : Two others were refused on similar grounds, one of whom, however, has since been passed in, although at that time he was told that, in addition to the above, he was suffering from heart disease, and therefore no good for Post Office employment.

The Chairman: Is it worth while going into the question of teeth extraction now that Mr. Walpole has told you the rule has been abolished? The rule was abolished on Saturday.

Mr. Walpole: I did not know you were going to speak about it to-day. I am not prepared to hear it. Perhaps you would not object to handing in the medical evidence.

Lord 'Tweedmouth followed up with a similar request, and the witness, after being assured that justice would be done to it, complied. 


\section{WAGES.}

Witness : Generally speaking, the home liabilities of sub-officc postmen, if carefully considered, are certainly much greater than a casual glance would lead us to believe, for, on examination, I find that house rents in many small towns with populations varying from 8,000 to 12,000 and upwards, for such habitations as the authorities would desire that their servants should occupy, cannot be had for less sums than 4s. 6d., 5s. 9d., and 7s. 3d., and some are even giving higher than this. An instance in my own neighbourhood-The L. and N. W. Railway are extending their system through Spen Valley; the new line is now in course of construction, and, in consequence of this, many dwelling-houses have had to come down. In my own little town, with its popnlation of under 10,000 , upwards of a 100 houses have had to be pulled down. But the railway company, in providing for this wholesale demolition, have erected others-in equal numbers-and whe lowest rent a-ked for these is $4 \mathrm{~s}$. $6 \mathrm{~d}$. per week, which does not include rates, as these are paid separately as follows :-Poor rate, $3 \mathrm{~s}$. per $\mathcal{A}$; 'general district rate, $3 \mathrm{~s}$. per $£$; general district water, 1 s.; water rent, 10s. per arnum. These cheap back-to-back houses are not now so much sought after, since local sanitary authorities look upon them with disfavour, and condemn them as being very unhealthy.

'The Chairman: What is the total amount of your own rate bill, do you know?

A. About 50 s.

Mr. Walpole: What is your own rent? Do not answer that if you would prefer not to.

A. I would rather not answer it. I am obliged to live in a house according to my circumstances; I have a large family, and I could do with more accommodation than what I can afford to pay for. Food, clothing, and the necessaries of life generally, as a matter of fact, are more expensive in small towns owing to competition being less keen than at large centres. Taking these things into consileration, together with the prospects sub-office postmen liave of promotion, their condition is, indeed, most pitiable. So insignificant are our claims for a step up the ladder that, I believe, however deserving of promotion anyoue of our number may be, he is invariably about the last person our liead Postmaster would ever think of recommending, or considering, in a matter so important. How to account for this neglect of duty, this total absence of the one thing which is encouraging, the indifference manifested with regard to the welfare and future prospects of deserving subordinates, is a problem I have tried many times to solve, but I can conceive no other reason for it than the degrading uniform, for such it is in the eyes of those above us.

The Chairman: Do you want to do away with uniforms altogether, or do you, like the last witness, want a uniform the same as the town postmen?

A. I should prefer to do away with it aliogether if we did not receive better treatment than is accorded to us. It seems to be general, too, all over the country. This is one thing in particular which we want to bring prominently before your lordship's Committee: we think we are entitled to greater respect than what is given to us.

Q. By whom? The public?

A. No ; by our superiors.

Mr. Walpole: How do you mean greater respect? Are you treated disrespectfully?

A. I will come to that by and bye. Our superior officers, if pressed. would very likely admit that their indifference and disregard of the just claims of the postmen generally to adrance by way of promotion, is not on account of their character or incapah:.1. : it is not because they are illiterate, for that would not correspond with the duties they liare to perform; it is not, in fact, the man himself, because at church or chapel, dressed in 
his own attire, he resembles so much of a sameness with the rest of the congregation that even his superiors might run the risk of calling him "Mr." without loss of dignity. 'Then what on earth is it if it is not the "cloth?" Anxious, t'erefore, to maintain all under our roof with comfort and respectability, we find it utteriy impossible under present conditions, because $22 \mathrm{~s}$. or $27 \mathrm{~s}$. is positively inadequate, and falls much below the real value the situation ought to command. The importance of our work and the consequences likely to follow any negligence or carelessness in the discharge of those duties are so exceptionaliy severe in character that it would b? impossible to find a parallel case out of the many branches which go to make up the great industrial classes of this country. These particulars should not be lost sight of, because, when the question of wages has been discussed, the authorities have endeavoured to justify themselves in the matter of making comparisons with certain of these outside classes. I trust, therefore, I have said sufficient to convince your lordship's Committee that a recommendation should be made on our behalf for a substantial increase in wages, seeing that we have both medically and educationally qualified ourselves for the position, according to the requirements of the Department; and in the readjusting of wages I trust, therefore, that the great disparity now existing between sub-offices and head offices will be a thing of the past.

Mr. Walpole: May I ask what is your scale of wage?

A. $24 \mathrm{~s}$.

Q. From $17 \mathrm{~s}$. to $24 \mathrm{~s}$ ?

A. Yes, sir.

Q. Your head office is Normanton, is it not?

A. Yes, sir.

Q. What is the scale of the head office at Normanton?

A. I believe it is $24 \mathrm{~s}$.

Q. There is no disparity in your case, then, between the sub-office wage and the head office wage?

A. It is not so generally. At Normanton, I believe, there is only one town postman. It is simply a village, and should not be compared at all.

Q. I was taking your case as a test case. In your case there is no disparity between the sub-office wage and the head office wage?

A. We are classed in the first scale of $24 \mathrm{~s}$. I think there are something like 1,590 sub-office postmen, of which only 326 are in receipt of the first scale. The following are my reasons for making this claim:-1, That in many small towns house rents are exceptionally high in comparison to the wages S.O. postmen are in receipt of ; 2, that owing to less competition in smaller towns living, as a matter of fact, is much more expensive; 3 , that promotion for S.O. postmen is unquestionably a dead letter; 4 , that we have no Departmental M.O., and therefore out of our scant wages have to pay our own doctor's bills; 5 , that S.O. postmen between duties may be asked to leave the office, in consequence of which he is obliged to hang about the streets, no retiring-room being provided for his accommodation.

The Chairman: What is the scale of wages you ask for sub-office postmen?

A. I would saggest, my lord, that we go up to 36s. (Hear, hear.) I do not think $I$ am asking too much in that. I would also suggest that the annual increment should be $2 \mathrm{~s}$. per week.

Q. You now go from 17s. to 24s.?

A. Yes, my lord.

Q. You do not ask for any increase in the minimum?

A. Yes, my lord; I should recommend that the minimum start at 20 s.

Q. Then you ask for 20 s., rising to 36 s.?

A. Yes, my lord.

Q. Rising by 2s. a week?

A. Yes, my lord. 
Mr. Walpole: Is that 36s. to be exclusive of stripes?

A. Stripes, of course, are given as extras.

Q. I am only asking you the question.

A. Yes; exclusive of stripes, which are, of course, given only to deserving ones.

The Chairman: Or rather they are withheld from undeserving ones? (Iaughter.) I think that is the better way to put it.

Witness : At this point I should like to relate a little incident that transpired a short time ago in respect to myself. I have three stripes, and although I got the first two without any trouble, the third was overdue 18 months, when a gentleman, believed to have come from London, came upon the scene, and made it his business to inquire into the matter.

Sir F. Mowatt: Into your particular matter, as to why you were kept without the stripe?

A. Yes, sir; they are at times exceptionally good.

Q. Had you complained?

A. Yes; and he came to investigate the matter before awarding the stripe.

Mr. Walpole: I hope he did not come all the way from London?

A. I believe so; it was the first time we had seen him.

Q. Was he not one of the surveyor's clerks in your district?

A. I do not know, sir; I have never seen him before or since. After he had gone the Postmaster told me he had had a lot of trouble with him, that in giving emphasis to the truth of his statement on my behalf he had to strike the desk several times. (Laughter.) The dispute arose over a late attendance of a quarter-of-an-hour, for which I was asked to give an explanation. I had only been late once in $6 \frac{1}{2}$ years.

The Chairman: Was that the only time you were late?

A. Yes, my lord; a quarter-of-an-hour in $6 \frac{1}{2}$ years. He wanted an explanation, and I told him I could not remember the occasion, which indeed I could not, but that would not satisfy him; I must make an explanation of some sort. When I examined the time-book I found that the late attendance was in the month of December, eight or ten days before Christmas, and at that time each year we have, as a rule, excessive deliveries of correspondence, and no doubt on that account I must have felt overworked, and, in consequence, overslept myself in the morning.

Mr. Walpole: It was hardly worth sending an officer from London for that?

A. Hardly worth while investigating a case so frivolous.

Q. I think not.

A. The stripe was put off, however, for a further pericd if three months, so that altogether $I$ had to wait 1 jear and 9 months for it on account of this late attendance.

The Chairman: But when you got it, it dated back?

A. Yes, my lord: but that does not: remove the injustice attached to the delay in awarding them as they become due.

\section{ACTING HEAD POSTMEN AT S.O'S.}

The Department has not yet seen fit to appoint a head postman at all S.O's., but I would like to recommend this change, believing that its adoption would be accepted at S.O's. with much satisfaction, for in addition to creating a fecling of contentment, it might also be accepted as a kind of promotion, not only by the senior men, but also by the others following up, and from which, together with our comrades at head offices, head postmen, inspectors, etc., might with advantage be drawn. The experience and usefulness of the senior postmen at S.O. is very helpful, and can best be appreciated by their respective S.P.M., whose hours are long and continuous, their duties arduous and confining, and, if absent only for a little while, the office, for the time being, is practically without a head. The S.P.M. cannot rely on punctuality, accuracy, and good management from a 
boy clerk, who perhaps but a short time before was only a telegraph mes enger. It is absolutely inconsistent, and it is cruel to attempt to place a youth, even temporarily, over the heads of a number of intelligent men, any one of whom, it may be, is old enough to be father to the lad.

Mr. Walpole: What?

A. A boy clerk misht be left occasionally in charge of connter work, seeing that the uniform is objected to behind the counter. A surrey.r's clerk, calling one day, observed a postman on the other side of the counter sctually serving. This was too much for him, so he pro ested. The Postuaster ex. plained, however, that the uniformed man was his son, and a request was made that he would not allow him to appear again at the counter in uniform. It is again a question of covering. He may do these duties in his own clothes, but not in uniform. The senior postman should be appointed assistant 10 the sub-postmaster, and control in his absence. The boy clerk would then have more confidence in his work, knowing that there is some one senior to himself in authority. At H.O. there is the H.P. inspector and assistant-inspectors, according to the number of men employed. The surveyors, or their clerks, when they pay us a visit, they have the system in vogue at larger offices so well ground into them that an attempt is often made to work smaller offices on similar lines-in my opinion an utter impossibility. The sub-office with its six, eight, or more men, no established clerk, S.P.M. opens the mail-bags; the senior postman may have 10 or 15 years' service in, but it avails him nothing. His stripes in a matter of this kind are set down as of no value, he is distrusted just as though he had entered the Service the day previous. His character all along may be irreproachable, but alike indifference is meted out to him. What is the reason? "Uniform!" The S.P.M. may be taken ill during the night; what have we to do? The boy assistant perhaps is not on duty, yet it is laid down under any circumstances postmen are strictly forbidden to open mail-bags, or to sort letters other than their own. The boy arrives with a look of satisfaction flitting over his infant countenance-(laughter)-no doubt at the thought of his usefulness and importance, and proceeds to accomplish the great act which not even his father dare do, because he is only a postman.

The Chairman: What you want is that the senior postmen at these suboffices should be recognised as assistants to the Postmaster?

A. Yes, my lord. It seems inconsistent to place a boy over the heads of a number of men. I think that senior postmen at sub-offices generally would accept it in that way.

Q. That is with an extra allowance for it?

A. They would not object to that.

Mr. Walpole: To having no extra allowance? (Laughter.)

A. No; to receiving one.

The Chairman: What you want to arrive at is this : you want a recognition of position? That is what you are asking for?

$\Lambda$. Personally, I should prefer that, even without an extra allowance, rather than the existing arrangement should remain unattered. In a S.O. near Leeds the following incident transpired:-6 a m., surveyor's clerk enters (unexpectedly). The sub-postmaster not feeling well was a little later than usual, and to save time the respectel senior nostman opened the mail-bags; he is a man of unimpeachable character, highly respected, is looked up to by all with whom he comes in contact, his length of service is 18 years, and is the wearer of three good conduct stripes. He has never been reported for any offence, he is a Sunday-school teacher, and a deacon in the church connected therewith. A week later this man is informed by his sub-postmaster that although he has in him implicit confidence, he must not in future open any mail-bag, as oriers to that effect had been received, thit this must be done by himself or his assistant, a boy whose age is about 15 , promoted from the telegraph messenger staff. Imagine the man's feelings then, when asked to step on one side to make room for 


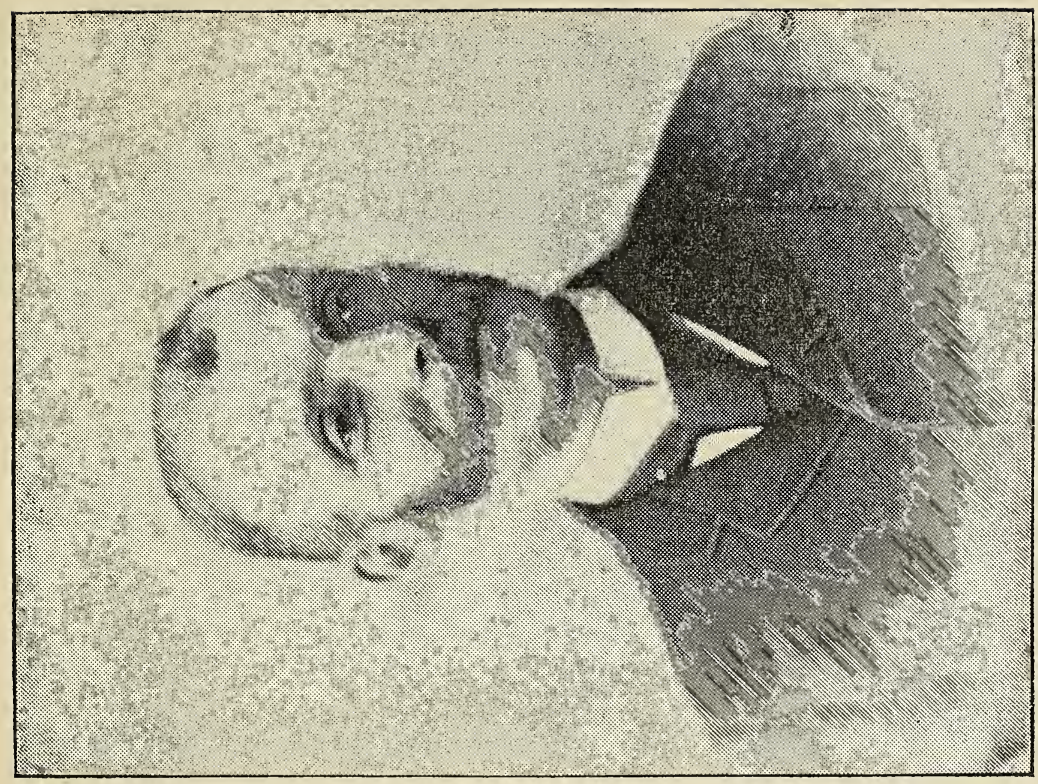

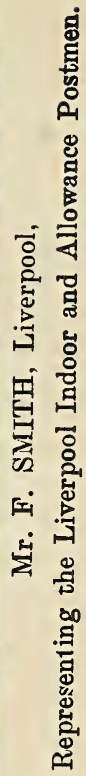

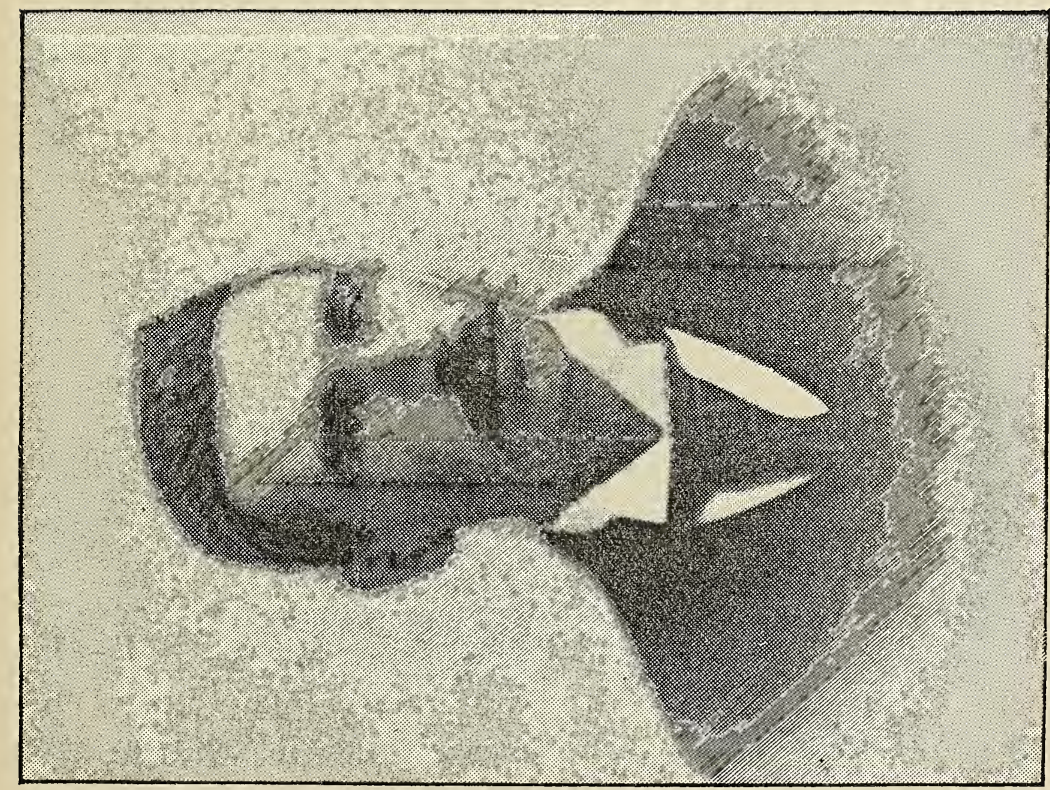

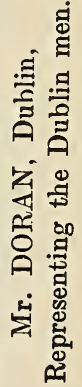



a boy who had not been born for three or four years after this man had received his appointment.

Mr. Walpole: The Department actually told the Postmaster to do his own work; was that it?

A. It was certainly a case of sickness; he was not by any means enjoying good health at the time, and it would only have been consistent for an officer of mature age to do a thing of this sort rather than a boy of tender years. This does not appear to be confined to one particular quarter; several complaints of a similar character come from S.(). in Kent. One from Erith S.O., Woolwich, says he has been established 20 years, and was sent from Woolwich head office 17 years ago purposely to take up the duties of acting head postman at Erith S.O. After 13 years' service as such he asked that he might be placed on the head postmen class, but was told this could not be granted, because much of the work he was doing could be done by the sub-postmaster. Two years later an order was issued forbidding acting head postmen opening bags, dealing with registered letters, etc., so that the work he had been sent to do, and had done for a period of 15 years without complaint, was taken away from him, and is now being performed by the sub-postmaster's assistant-a young (unestablished) officer. Why more confidence is placed in the unestablished is a problem. No justification can be assigned for the contemptuous and insulting method adopted in addressing postmen, not only by some in authority, but also by boy clerks. A case was brought under my notice a short time ago which happened at Batley, i.e., a report of a frivolous character had been written out, intended for one of these youths who had in the meantime asked to be transferred to the auxiliary class, with a view to obtaining an appointment as postman The report was made out with due respect towards those who are permitted to labour outside of the official uniform shell, and was endorsed "Mr." "o-and-so, but directly it was made known that he had joined the postman's ranks the report was sent to him with the "Mr." struck out.

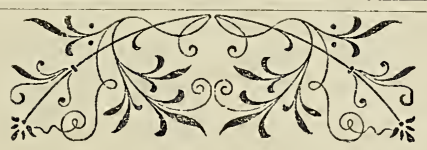




\title{
STATEMENT ON BEHALF OF THE ESTABLISHED POSTMEN OF THE SUB-OFFICES OF SOUTH COUNTY DUBLIN.
}

\author{
Handed in by Mr. Carmichael, Heckmondwike.
}

The first matter which we respectfully beg to submit for your consideration is the important one of wages. We consider that our present wages are a very unfair remuneration for the duties which we perform, and altogether inadequate to maintain us and our families in decency, much less in comparative comfort, considering the present cost of living, house rents, etc., etc.

The maximum wage in the majority of offices in South County Dublin is $24 \mathrm{~s}$. per week, in a few it is $20 \mathrm{~s}$. and $22 \mathrm{~s}$. The minimum is $17 \mathrm{~s}$., and in a few 16s. And, considering the responsibilities we are under and the arduous work we have to do, which in the majority of sub-offices in South County Dublin is more laborious than that in London, Dublin City, Manchester, Liverpool, Glasgow, and Edinburgh, as we have to take out on each delivery of letters all parcels for delivery without any assistance whatsoever, and in many cases we have to carry these parcels a distance of from $2 \frac{1}{2}$ to 5 miles before finishing our delivery, and then in some cases to wait at the end of our journey for over two, three, and four hours before returning to the office with a heavy collection of letters and parcels. We therefore respectfully claim an equal right to be placed on the same scale of pay with them. We earnestly hope the Committee will see the justice of recommending one scale of pay for all established postmen throughout the United Kingdom, with a minimum of 20 s., increasing by $2 \mathrm{~s}$. a year to a maximum of 40s. per week.

With regard to those so-called gratuities which postmen receive at Christmas-time from the public, we beg to say that we regard the system as degrading to the sccial chrracter of postmen, and we sincerely hope the Committee will strongly recommend its abolition.

With regard to this matter, the Postmaster-General (at the time) stated, in reply to a question put on the subject in the House of Commons a few years ago, that he estimated the value of those gratuities as equivalent to $5 \mathrm{~s}$. per week per man. and that he was influenced by it in fixing the maximum wage of established postmen.

Such ar estimation, as far as the sub-offices of South County Dublinand we firmly believe 90 per cent. of provincial postmen-are concerned, is most unjust to us.

We are prepared to prove that the average value of these so-called gratuities does not amount to more than 1s. 6d. or $2 \mathrm{~s}$. per man per week, and in many cases it is under 1 s.

We therefore earnestly hope that this begging, degrading system will be abolished, and that the Committee will recommend the PostmasterGeneral to make it prohibitory, and if necessary under a penalty, for all postmen to solicit or accept in future those questionable free gifts at Christmas-time, and that their estimated value by the Postmaster-General be added to our regular wages. Such a departure from this system will be unanimously approved of by all postmen, as it will undoubtedly tend to raise the social and moral character of the men, and save them from many and painful humiliations, and perserve to them their spirit of self-respect and independence. 
We therefore again express the hope that the Committee will recommend the speedy abolition of this degrading and humiliating practice.

With regard to promotion, we can assure you that there has not been one postman promoted to any of the higher grades from the sub-offices in South County Dublin within the last 24 years. We are practically shut out from promotion from the rank of postman.

As regards medical attendance, we wish to point out that in many of the offices the men are excluded from free medical aid when ill, and have to pay the local doctor for attendances and certificates. This we regard as most unfair.

As to punishment, we consider it excessive to deprive a man of his stripes or stripe for five years, which means a fine of $£ 212 \mathrm{~s}$. a year, amounting in all to $£ 13$, for some offence which would be sufficiently punished by extra work or a reasonable fine. We 1 egard the present system as simple tyranny.

As to the hours of duty, we beg to call the Committee's attention to the fact that many of us are doing over eight hours, and in some cases nine hours per day. We also feel the present arrangement of our duties a grievous hardship, as they are spread over 14, 15, and 16 hours per day. We ask that our day's work be so arranged as not to extend beyond 12 hours per day. We also wish to call your attention to the number of attendances which many of us have to make per day. In many cases we are put off duty for 10, 15, and 20 minutes between the duties, and are forced to remain about the office, as we cannot return home. The majority of us have to attend five, six, and some seven times per day. The average number of miles walked per day by us is 18 .

We also wish to bring under your notice the hardship some of us have to undergo by having to walk a distance of six or seven miles on a delivery of letters and heavy load of parcels, and when finished perhaps wet through with rain, having to depend on the charity of some neighbour for shelter for three or four hours before commencing the return journey home with a heavy collection of letters, sealed bags, and parcels. We claim that we should be credited with the time our outward journey begins until we return to the starting-point, or at least granted some allowance for shelter while waiting to return to the starting-point.

With regard to the present Superannuation Act, we consider it most unsatisfactory. Under the present system a man receiving his appointment at 18 years of age must serve a term of not less than 42 years before he can claim to retire on pension, unless he is medically unfit or totally incapacitated. We also consider that 1-60th of our pay for each year of service is insufficient to keep us in comfort when beyond our labour. We therefore hope the Committee will recommend that the present Superannuation Act be amended in such a way as to leave it optional for a man to retire at 25 years' service on a pension of two-thirds of his pay, and that his retirement be compulsory at 30 years' service on a pension of threefourths of his pay, instead of, as at present, half-pay.

We beg leave to add that within the last ten years there have been only two men superannuated in South County Dublin. We wish to point out that it is optional with the Irish Police to retire on pension at 25 years' service, and at 28 on a pension of three-fourths of their pay. 


\section{SUPPLEMENTARY EVIDENCE LODGED WITH THE COMMITTEE BY MR. MACLAREN, GLASGOW.}

In the course of his evidence, Mr. S. Wright (of Leeds) referred to the old rule of the Service which directed that sorterships in the provincial offices should be reserved exclusively for letter-carriers. It is now impossible to give in extenso the rule referred to, as the old Rule Book has been superseded by 1893 edition, in which it appears in a modified form.

The part of the old rule which concerns us is as follows :-

"Vacancies in sorter's class should be filled by direct appointment only in the event of no one of the letter-carriers desiring to succeed to the vacancy and being qualified to perform the duties required."

In our view of the case, we do not admit the justice of the disparity between the wages paid to sorting clerks and those paid to postmen. We do, however, suggest that when this distinction was first introduced it was the intention of the Department that the sorting branch should be an avenue of promotion open to the postmen's class. Our complaint is that local Postmasters were allowed to treat as their own private patronage the bestowal of sorterships which ought by strict letter of rule to have been reserved exclusively for letter-carriers, so long as any of the latter class were able and willing to succeed to the vacant sorting duties.

Lest it should be contended by the Department that the rule in question had long since been rescinded. I beg to submit the following extracts from official papers, which go to show that the rule remained in force-at least nominally-till 1893. The following extracts also illustrate by concrete example the grievance complained of, and the steps taken to obtain redress officially :-

\section{1.-EXTRACT FROM GENERAL PETITION.}

"That the injustice perpetrated upon postmen through the absence of a clearly-defined system of promotion can never be adjusted unless an independent Committee be appointed to consider this question with powers to act: we therefore pray that you will ensure for your petitioners this reasonable request."

(The Glasgow copy of this petition was dated 16th Jan., 1893, and signed by 644 postmen.)

\section{2.-THE POSTMASTER-GENERAL'S DECISION.}

"In the country there is no restriction upon the promotion of such postmen as possess the necessary qualifications. This condition being fulfilled postmen can rise to the class of sorting clerks and telegraphists, and even higher appointments. As a matter of fact, many of the present sorting clerks and not a few of the Postmasters entered the Service as postmen. In this respect, therefore, no change appears to the Postmaster-General to be necessary."-19th Feb., 1893.

\section{3.-REJOINDER FROM THE GLASGOW POSTMEN TO THE POSTMASTER-GENERAL.}

"Your memorialists beg to state that they are at a loss to understand the full import of your references to the higher appointments which are seemingly open to postmen: they therefore beg to give herewith a tabulated list 
of all the promotions to higher appointments which have taken place at this office within the last ten years, viz. :-

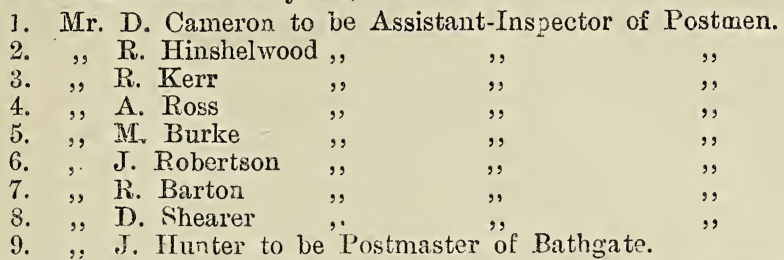

"With regard to transfer's to the sorting branch, your memorialists admit that theoretically there may be no restrictions, but experience has shown otherwise. For though, during the last 10 years, about 150 vacaut sorting clerkships have been filled up at Glasgow, so far as your memorialists can ascertain, only two bona fide postmen have been selected. They are James Turner and Jas. W. Langmuir. Your memorialists are aware that there is a rule in the Book of Rules to Head Postmasters bearing on this subject, which directs that vacancies in sorter's class 'should be filled by direct appointment only in the event of no one of letter-carriers desiring to succeed to the vacancy and being qualified to perform.' But this rule has been practically disregarded at Glasgow for the last ten years, as your memorialists have already shown by the statistics furnished. Cousidering that there are now over 500 established postmen at Glasgow, your memorialists respectfully submit that nine promotions to higher appointments and two transfers to the sorting branch in ten years do not afford adequate opportunities of promotion. In these circumstances your memorialists are still of the opinion that an independent inquiry is necessary."-April, 1893.

When presenting the memorial containing the disputed quotation, our local Postmaster (Francis Brair, Esq.) took exception to the quotation, and expressed some doubt as to whether such a rule really existed, and, producing his own working copy of the Book of Rules for Head Postmasters, he challenged me to find it. I turned up the rule and read it aloud, and after doing so the Postmaster and Mr. D. Beaton (who was also present) scrutinised the rule in question, and compared it with quotation in the memorial. Ultimately the Postmaster was forced to admit both the accuracy and the fairness of the quotation.

Putting the construction which we did on this rule-and by implication making a charge of favouritism against such Postmasters as had disregarded it - we contend that it was the Postmaster-General's duty to have informed us in the event of our having quoted in support of our case any rule which had authoritatively become obsolete. In absence of such a disclaimer, we take it that we established a clear case of rule being disregarded. Instead of enforcing the rule, however, the Department saw fit to modify it to suit the practice which prevailed, thereby condoning the conduct of such Post. masters as had bestowed sorterships on their own friends. It may be urged in defence by the Departinent that the postmen's class are not now expected to furnish candidates for vacancies in the better paid posts in the Service. We admit that some change was effected in 1893; for example, the entrance examination to the sorting clerk's class was raised somewhat. It is also quite true that in 1891 a change was effected in the condition of entrance to postmen's class, which is calculated to lower the status of the postmen. We refer to the reduction from 18s. to $17 \mathrm{~s}$. of the initial wage of established postmen.

We confess that we have at times entertained some suspicion that this policy was conceived and carried out by the Department in the full knowledge that it tended towards deteriorating efficiency of the force. For when well-to-do working men come to understand the real state of matters-the low commencing wages, the prolonged unestablished service, etc.-they will 
show greater and greater reluctance to make either telegraph messengers or postmen of their sons. In this way one of the most important fields for recruiting the Service will be put out of bounds. It is, therefore, only to be expected that the continued application of the policy will leave its mark on the personnel of the force.

We do not admit that the filling up of sorterships by direct appointment has resulted in any material improvement in the sorting force. Speaking particularly of my own office, I desire to state that some of the ablest an! most efficient officers in the sorting branch are men who have been postmen; and it is our complaint that the process of promotion by which these men attained their present position has been allowed to fall into disuse.

In fairmess to the Department, we must frankly confess that at Glasgow the postmen are not so rigorously excluded from the sorting branch as they used to be. Formerly the rule of the Service gave preference to postmen over everyone else, but this rule was never carried out. Nowadays the postinen have no preference over others for vacant sorting clerkships, neither are they boycotted as they used to be. In fact, since the sorting clerks' entrance examination was raised in 1893, the Postmaster of Glasgow has seen his way to allow postmen to secure a fairish proportion of the vacancies, and we contend that the experiment has justified itself, inasmuch as that the postmen's branch proved able to supply suitable recruits.

It may be added that the experience gained on letter-delivering duty would be in the nature of good training for sorting duty. In saying so we do not in the least admit that sorting is in itself a superior duty which ought to be more highly paid than letter-carrying. On the contrary, we maintain that letter-delivery is equally responsible as sorting. But the sorting on account of its being indoor duty, physically less fatiguing, etc., will always have attractions for some of the postmen's class, even supposing the pay and prospects of promotion be the same. But the restrictions which obtain at Glasgow put the majority of postmen out of bounds for transfers to the sorting office. These restrictions are that postmen candidates must be under 22 years of age and in receipt (if appointed) of less than 20 s. per week.

The loss of sorterships is not, however, the only respect in which the postmen have been encroached on. The sorting branch has been allowed, not merely its own proper quota of higher appointments, but, in ardit.10n, it has monopolised a number of promotions which ought in fairness to have been open to the postmen's branch. This, we suggest, is the true explanation of the disproportionate number of higher appointments possessed by the sorting branch as compared with the telegraph branch. In support of this contention, the following statements concerning the Glasgow Office are offered as being typical of other large provincial towns:-

\section{TABLE A.}

Showing list of certain duties (higher appointments and clerical duties) the filling up of which is not participated in by the postmen's branch :-

OFFICE WHERE LOCATED.

Number of Appointments held by Sorting Branch
Number of Appointments held by Telegraph Branch.

Accounts Branch,

Public Enquiry Office, \&c., $\ldots .$.

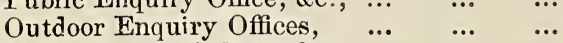
Rural Postmen's Branch, $\quad \ldots \quad \ldots \quad \ldots$ Returned Letter Branch, $\quad \ldots . \quad \ldots . \quad \ldots$ $\begin{array}{llllll}\text { Storekeeper, } & \ldots & \ldots & \ldots & \ldots & \ldots \\ \end{array}$ Clerk in Charge, Govan B. O., $\quad \ldots . \quad \ldots$ 
TABLE B.

Showing details of salaries of officers quoted in Table A :-

\begin{tabular}{|c|c|c|c|c|c|c|c|}
\hline \multirow{2}{*}{ No. } & \multirow{2}{*}{ RANK. } & \multicolumn{3}{|c|}{ Annual Salary. } & \multicolumn{3}{|c|}{ Wages. } \\
\hline & & Min. & Ine. & Max. & Min. & Inc. & Max \\
\hline 1. & Superintendents, ... $\ldots$ & $£ 310$ & $£ 15$ & 400 & $\ldots$ & $\ldots$ & \\
\hline 2. & Assist.-Supts., 1st Clas:, & 260 & 10 & 310 & $\cdots$ & $\cdots$ & $\cdots$ \\
\hline 3. & $,, \quad, \quad 2$ nd $\quad$, & 200 & 10 & 260 & $\cdots$ & $\ldots$ & $\ldots$ \\
\hline 15. & Clerks, $\quad \ldots \quad \ldots \quad \ldots$ & 150 & 8 & 190 & $\ldots$ & $\ldots$ & $\ldots$ \\
\hline 7. & Sorti g Clerks, 1st Class, & $\ldots$ & $\cdots$ & $\cdots$ & $40 /-$ & $2 /-$ & $56 /-$ \\
\hline & Telegraph Clerks, , , & $\cdots$ & $\ldots$ & .. & $40 \%$ & $2 /-$ & $56 /-$ \\
\hline
\end{tabular}

In the case of some duties enumerated in foregoing tables, the work consists almost entirely of overseeing matters connected with the postinen's branch, yet the officers themselves are not men who have risen rhrough the postmen's ranks. For example-(a) There are two clerks whose time is mostly taken up with postmen's wages-sheet; (b) there are two sortiug clerks whose work chiefly consists of checking postmen's delivery lists ; (c) there are one assistant-superintendent and three clerks whose principal duty is to oversee postmen employed at the sub-offices under Glasgow; (d) there are three clerks employed on outdoor inquiry duty-a duty which formerly devolved on the inspectors of postmen.

The transfer of the outdoor inquiry work from the postmen's branch to the sorting branch was-and is still-regarded as an unwarrantable encroachment on the postmen's proper field of promotion. On grounds of proportional representation alone the postmen might reasonably lay claim to some of the duties enumerated in the foregoing tables. But we do not base our claim entirely on these grounds. We attach quite as much importance to the fact that our branch could produce a sufficient supply of competent officers ; and admitting, as we do, the right of the Department to receive a fair day's darg from each of its employees. we regard it as being of the highest importance that the supervising officers should be practical men with a capacity for organisation-men capable of giving the best service to the public consistent with a just consideration of the needs of the Department's servants. By this we mean the true economy which avoids wasted force, and not false economy, which merely saves money by grinding down the lower and more helpless grades of the Service.

Although, so far, we have deemed it our duty to simply uphold the claims of the postmen, we are far from considering the matter as a mere question of postmen $v$. sorting clerks for the promotion incidental to the Service. On public grounds we take leave to express our serious doubts as to the scundness of the policy which fostered such flagrant nepotism as was brought out in evidence in the Liverpool, Leeds, and Brighton cases. In this connection the following quotation will, doubtless, be interesting:-

"In December, 1787, the Commission of Inquiry commenced its labours. Exactly a century had elapsed since the Post Office had undergone a similar ordeal, a period far too long for any public Department to be left to itself, and meanwhile abuses had taken root and flourished."-H. Joyce, "History of the Post Office."

Concurring in the dictum expressed in this quotation, the postmen have consistently striven to have the Post Office establishments overhauled by an independent Committee of Inquiry - a Committee that could bring to bear a fresh and unbiassed judgment on the matter at issue. 


\title{
THE CASES SUBMITTED BY NON-FEDERATION WITNESSES.
}

\author{
WILLIAM CHARLES HERBER'T, of the E.C.D.O.
}

Westuinster, 9th March, 1896.

William Charles Herbert was next called :-

The Chairman: I understand you are an E.C. postman?

A. Yes, my lord.

Q. And you are not a member of the Association?

A. No.

Q. You are going to speak to us from a rather different point of view, are you not?

A. Yes, my lord; with respect to wages and Christmas boxes. Before proceeding with my statement on these subjects I desire to correct in one point the statement I furnished, and to express regret for the occurrence of a mistake. The error to which I refer was an assertion that the Federation has less than 100 members in the E.C. Branch, whereas I should rather have said not more than 100 members. The E.C. postmen, in seeking to supplement the evidence tendered by the representatives of the Postmen's Federation, desire to explain that that body cannot be considered in any sense as representative of postmen of the E.C.O., since the E.C. Branch of the Federation has not more than 100 members, whereas there are over 900 postmen in the E.C. Therefore they-the E.C. postmen -feel they have a riglit to be heard in support of their own case, and independently of the Postmen's Federation. The evidence they propose to offer is as follows:- In respectfully asking for an increase of the minimum to $24 \mathrm{~s}$., and a maximum of $40 \mathrm{~s}$. by annual increments of $2 \mathrm{~s}$. per week, they desire in the first place to protest against the comparisons that have frequently been made of their pay and position as postmen with that of certain other grades of labour outside the Post Office.

Q. That is exactly the same request as is made by the Federation.

A. Then I will pass that over.

Q. I do not see the good of your repeating what the Federation has already said.

A. We contend that this class is most unfortunate.

Mr. Llewellyn Smith: Who do you represent?

A. I represent a large number of the senior men.

Q. Were you authorised by a meeting to give this evidence on their behalf, or are you simply stating your own view?

A. I was authorised by a large number of those whose signatures are appended to the memorial we handed in. They submit that such comparisons are most unfair, because none of those classes of labour referred to demands of its entrants that searching inquiry into their past lives, character, education, and physical fitness that is exacted by a Civil iervice examination, and which postmen have to pass in order to attain to their position. They also submit that no class of labour outside the Post Office resembles in any respect the work they are called on to perform, demanding, as it does, qualifications of the highest standard in the matter of energy, accuracy, and discretion. They therefore claim for their position and work that it is of a special and most responsible kind, demanding a special and superior wage. The postmen submit that in estimating the quality and value of the work they perform it should be done by comparison witl that of other grades of the Service; and they think that the quality and value of their work as E.C. postmen will not suffer by comparison with the quality 
and value of the work performed by E.C. sorters; for, while the work of the sorters consists of London district sorting and the despatch of correspondence to the respective districts, that of E.C. postmen embraces London district sorting, and the sortation and disposal of the whole of the correspondence for the City of London, without doubt the most important and valuable that passes through the post. They also maintain that responsibility should be considered in estimating the value of work performed, and claim that postmen's work in the E.C. is in many respects more and in no case less responsible than sorters'. In the case of sorters the most responsible part of their duties consists in despatching "roads," the work of which is to examine the correspondence to prevent any mis-sorts being sent, although should any escape their notice or through error be allowed to pass, it is important to bear in mind that such correspondence does not pass beyond official protection and ratification. But in the case of postmen of the E.C., who have to work at the highest pressure in sorting and arranging correspondence for delivery to the public, should they by an oversight or misconception of an address inadvertently misdeliver a letter, there is always the possibility of it falling into dishonest hands, and of its not being recovered; or, even should it eventually reach its destination, of complaint from the public, which brings in its train an amount of discredit that reflects upon the whole of the Department; hence the greater responsibility and the necessity of absolute accuracy on the part of a postman in the discharge of this important portion of his duty, which in the case of a sorter, although necessary, at least cannot be regarded as so important, since delay is the worst that can happen as a result of an error on lis part. As further proving the responsibility of postmen's work compared with that of sorters, they-the postmen-would point out that sorters who deal with ordinary correspondence have not to deal with registered letters, a class of sorters being appointed for that purpose, who receive an allowance for the extra responsibility considered to be incurred. But postmen have to deal with both classes of correspondence, and in the city of London, where the registered correspondence is very considerable, as well as valuable, it not infrequently occurs that some postmen have to deal with 50 to 100 registered letters in addition to the ordinary correspondence at a single delivery, and for which responsibility they receive no allowance whatever, although, should they lose sight of one in the course of duty-and which even the most scrupulous care will not always prevent- they are practically put under arrest until it is found, or they have been able to satisfy the Department that it has been genuinely lost.

Sir F. Mowatt: Put under arrest?

A. That is so. In the event of a postman losing a leiter or being unable to account for it, he is not allowed to leave the office.

Q. I suppose until he gives an explanation?

A. Until full inquiries have been made into the matter.

Mr. Walpole: $\mathrm{He}$ is detained in the office while search is being made for the letter?

A. Yes.

Sir F. Mowatt: That is during the day?

Mr. Walpole: During his duty.

Witness : They would also urge that postmen incur great risk in the discharge of their duty, in support of which statement they would mention the case of a man named Blake, formerly a letter-carrier in the E.C.D.O. Among other correspondence he had a register for delivery; he obtained a signaturs for it, and returned the receipt in the ordinary course. Some time after the firm for whom it was intended complained that they had not received it. Blake was called on to recognise the person to whom he had delivered it, but, being unable to do so, was dismissed the Service on suspicion. Some years after an employee at the firm was found to be dishonest, and among 
other things confessed to having stolen this register, hence the risk to which postren are exposed in the discharge of their duties, and which cannot be said to apply to any other grade of the Service.

Mr. Walpole: When did this occur?

A. This case occurred about 17 years ago-I think about 16 or 17 years ago.

Q. Is it not rather prehistoric?

A. Perhaps. Nevertheless, it bears on the point that there is a risk and a serious risk in this particular respect.

Q. But it has not happened for 17 years?

Witness: Other reasons the E.C. postmen would advance in support of their claim for an increased wage are that high rents and insufficient accommodation prevents them living within the district of their work, while as a result of the early hour at which their duties commence, most of them having to attend at 5 a.m., they are prevented from availing themselves of the privilege of workmen's tickets, in consequence of which their travelling expenses are additionally heavy. Finally, they submit that the wages of pcstmen have not advanced in proportion with other grades of the Service, and that they have not had an equitable share in the several advances in wages that have taken place in recent years. 'They would point out that during the last 14 years the maximum wage of a 1st class sorter has increased 11 s., that of a 2nd class sorter 15s., while that of a postman has only advanced $4 \mathrm{~s}$. Such a disparity in the reward allotted these grades they consider to be most unfair, because they feel that whatever increase has occurred in the value and responsibility of work performed as a result of the development and prosperity of the Service applies to postmen as much as sor'ters, while the cost of living is as great to one class as the other. Therefore, as a result of this statement of their case, the E.C. postmen trust your Committee will see reasons to recognise the responsibility and importance of their work, and in their recommendations advise the concession of their request, and by so doing place the postmen on a more equitable footing with other grades of the Service. That is the statement I had prepared to sabmit to this Committee.

The Chairman: I should like to say, Mr. Herbert, that the only use which it seems to me to be is to prove how excellently well the Federation have got up their case and presented it-(hear, hear)-as you have not told us one single thing we have not had in evidence already.

Witness: I wish to add to that portion of the statement dealing with registered letters that the Eastern Central postmen feel very sore that responsibility should be recognised by an allowance being made to sorters dealing with registered correspondence, while in their-the postmen's-case, no account of it whatever is taken into consideration. They submit that the responsibility and risk incurred in dealing with registered correspondence is much greater in the case of postmen than sorters, because in most cases the postman doesn't know the person whose signature he has obtained when delivering a registered letter, or whether the signature is a correct one or not; but in the case of a sorter who receives an allowance, the Department guarantee him a check about which there can be no question. In the statement I have just read, it says some postmen have to deal with 50 to 100 registers at a single delivery. Perhaps I should modify that statement somewhat, and say from 40 to 80 . I have here a return of the number of registered letters for 12 months delivered by an Eastern Central postman, from which you will observe that in 289 deliveries he disposed of 31,178 registers : but, let me add, he only dealt with registers on these particular deliveries, nevertheless they had to be signed for and signatures obtained from the public when distributing them, so that there was an immense amount of risk and responsibility incurred, and altogether I don't think it would be difficult to show that there is no district or town throughout 
the country in which postmen deal with such a considerable amount of registered correspondence as in the city of London, and this is one of the main reasons why we think our wages should be increased. The arduous nature of our work is another reason we would urge should be taken into consideration. I may say that a return of some of the walks and the number of registered letters delivered in them was taken this morning, with the following result:- Mincing Lane, 1st section, 18 registered letters; 2nd section, 28; 3rd section, 24; 4th section, 53. Cornhill, 1st section, 14; 2nd section, 43; 3rd section, 50; 4th section, 46. Bishopsgate Street, 1st section, 32; 4th section, 48; 6th section, 14; and 7th section, 13. In Leadenhall Street there were 169 registered letters take out amongst the various sections. In Old Broad Street the 1st section took out 22 , 2nd 77, 3rd 16, 4th 46, and 5th 41. Lothbury, 1st section, 18 ; 2nd, 65 ; 3rd, 42; 4th, 40. I may now go on to give you the particulars of Austin Friars.

The Chairman: I don't think you need go into all that. It stands to reason that in the central business parts of the City you will find registered letters for delivery more frequently than elsewhere. We would all agree that that is the natural course of things.

A. I should like to state that in Lothbury last week a man who had two sacks of letters went out with 101 registered letters, and another man with a sackful of letters had 90 registered, and bearing in mind that these letters have all to be intermingled with their correspondence, you will at once see the amount of risk a postman runs from having to deal with these registered letters.

Q. As a matter of fact, the complaints of the loss of registered letters are exceedingly rare, are they not?

A. That is so, my lord; and it shows the care which a postman takes in discharging that very important part of his duty. In the Fastern Central Office most of the postmen have to attend at 5 a.m., and it is only by working at the highest pressure that they can manage to cope with the work or hope to get out with the 1st delivery in reasonable time. Then they have very heavy loads to carry, in some instances amounting to from 50 to 70 or more pounds, but it is due to the Department to say that in the case of the heavier loads when men are available assistance is given, but unfortunately men are not always available, in which case the postmen have to bear the burden of these loads themselves. We therefore submit that the continuous early rising, high pressure when working, heavy load carrying. combined with heavy stair work during the clay, make our work very ex hausting, so much so that only the very fittest is able to survive it, and if proof is needed of this, we submit it is to be found in the very small percentage of the E.C. postmen who survive the maximum of service required before retiring on pension.

The Chairman: Is there not a rule as to your being able to receive assistance if there is more than a certain weight to be carried?

A. Quite so ; and I have mentioned that it is due to the Department to say that when men are available assistance is given.

Q. You are not giving us any figures in proof of your statement as to the age postmen retire on pension. I suppose you have none?

A. I have not any figures, but I know, my lord, that during the last 22 years only one postman has reached his maximum of service upon retirement.

Mr. Walpole: Is it not possible that some postmen have been promoted, and have retired from the higher ranks as officers?

A. That may be so; but I know of only one case, and he had not aitained a service of 40 tears on postman's duty. Q. Tou think it rather hard lines not to get promotion befoten 40 yeare of
A. Quite an. 
The Chairman: "There are 900 men in your office?

A. 945, my lord.

Q. Can you tell me how many men have died out of this number each year during the last five years?

A. No, my lord, I cannot; but I can tell you that of those who have taken their pensions during the last five years a large percentage are young men.

Q. I understood you to say that they were killed off without being able to get a pension or anything else?

A. No, my lord. That was not my statement. I wished to point out that very few survive their maximum service.

Mr. Walpole: Then they must die?

A. That does not follow. They may have been obliged to take their pension through ill-health before attaining their maximum of service, and this is the result of the heavy work they have performed.

The Chairman: You do not contend that it kills, but you say it tires them out early?

A. It incapacitates them from work.

Mr. Walpole: How long have you been at it?

A. 22 years.

Q. It has not tired you out yet?

A. No, sir. We also desire to draw attention to the fact that in most cases 1-5th of the time of E.C. postmen is occupied in primary sorting; we wish it to be understood we do not complain of this, as we regard it as the easiest portion of our work; only that we say it is properly sorters' work, and as the scale of pay of sorters is considerably higher than that of postmen, the fact that we perform this work we submit should be a reason why our scale of pay should be higher. I come now to the question of Christmas boxes, and I think you will acknowledge my authority to speak on this matter when I tell you I am the secretary of a committee elected by the walk-holders of the city of London to represent their interest in cornection with this question, and as such I am instructed to tell you that the Postmen's Federation, in asking for the abolition of Christmas boxes, do not express what is the desire of the city men on this matter. The city postmen have not asked for the abolition of the boxes, and neither would they be prepared to surrender them unless a full equivalent was given to each man for what he would lose thereby, and to give them this would necessitate an expenditure on the part of the Department of $f 4,600$ a year for the City alone.

The Chairman: I imagine that Christmas boxes in the City are very beavy, are they not?

A. Well-

Q. I want an answer to that question.

A. They are, my lord; and I will deal presently with what it amounts to.

Q. Wait a moment. I think that this argument of yours rather goes against your earlier contention. You claim that the E.C. postmen should receive much higher wages on account of their much harder work. Now, it seems to me they already get higher wages, talking into consideration the Christmas boxes?

A. Well, my lord-

Q. Is not that so?

A. By that contention you are recognising Christmas boxes as wages.

Q. I am only asking at the present moment is it not the fact that $\mathrm{E}$.C. postmen are paid higher than any other postmen in London?

A. If we took that view we should admit that Christmas boxes are part of our wages. We contend they are not. (Hear, hear.)

Q. I do not say whether they are wages or not; all I say is that the 
position of the E.C. postman at this moment-taking all things into consideration-is much better than that of another postman?

A. In some cases it is, my lord. Mr. Warner, in his evidence before this Committee, said if the Department gave an immediate increase of $2 \mathrm{~s}$. per week the men would be satisfied. I may tell you the city men would not be satisfied, and that they regard such a statement as an effort on behalf of those who are getting very little or nothing to reap an immediate benefit at the expense of those who are getting something more substantial. Whatever may be the objection or dislike of the district and other postmen to collect Christmas boxes, it is not shared by the city postmen. In the City it is the custom of firms to enter in a book, of which the cashiers have charge, sums of money to be given for different purposes; amongst these are the postmen's Christmas box, which they esteem it a favour to give, so that with the city postmen it is not a question of solicitation, but of simply receiving what is offered. Again, it is largely the practice of city postmen to leave unpaid correspondence and call later on for the money; this they are under no official obligation to do, but they do it to save delay to the firms-in many cases weekly, monthly, and quarterly credit is given-so that what they receive at Christmas is rather a reward for special services given than a Christmas box in the ordinary acceptation of the term.

Sir F. Mowatt: When you say "unpaid correspondence," do you mean correspondence which has not been stamped?

A. That is so, sir.

The Chairman: You said you were going to tell us presently how much these Christmas boxes amounted to?

A. Yes, my lord, and I have told you; I have pointed out what it would cost the Department to compensate us for the loss of them in the City alone.

Q. What are they worth to individual City postmen? That is what I want to know.

A. Do you mean those who collect them?

Q. Under what system are they distributed?

A. The system is this-The men on the walk collect them, and pay 20 per cent. upon what they collect towards the Assistants' Fund. The remainder the walk-holders divide among themselves.

Q. Is that distributed over the whole number of men?

A. No ; only over the City men

Q. How many men have shares?

A. There are about 400 section walk-holders and 200 assistants.

Q. Then to compensate these 400 men you say it would cost $£ 4,000$ odd? A. Yes.

Mr. L. Smith: But what about the other 300 men? You told us there were 900 City postmen?

A. Oh, they would be collectors and the floating staff.

Q. And they get nothing?

A. They get nothing. The floating staff, however, participate in the assistants' share-the share of those who are performing supernumerary duties.

The Chairman: And do the other men share and share alike all through the City?

A. No, my lord; the men on each walk share what is gathered in after deducting the amount paid to the Assistants' Fund.

Q. How many men on a walk are there as a rule?

A. They vary somewhat; in some cases there are only four, and in some cases there are six, and even eight.

Q. And then the difference between the different walks is very great, is it not?

A. Yes, my lord, it is. 
Q. What is the most valuable walk in the City?

A. Lombard Street; there they collect somewhere about $£ 150$.

Q. And between how many men is that divided? How many men are there on that walk?

A. There are six men on that walk, and out of the amount they would pay' 20 per cent. on $£ 115$ to the Assistants' Fund.

Mr. Walpole: Why do they only pay on $£ 115$ ? They collect $£ 150$ ?

The Chairman: I take it that they deduct 20 per cent.

A. No; the circumstances are these-They collect $£ 150$, they dedluct 25 per cent. for collecting, and then they pay 20 per cent. on the remainder to the Assistants' Fund.

Q. What is the 25 per cent. collecting for? Who gets that?

A. The collectors, my lord.

Q. Then the men who go round and collect the boxes get an extra 25 per cent.?

A. Yes; but I may point out that in the event of the postman being away ill, and the assistant doing his duty, he charges him 25 per cent. for collecting it in for him.

Q. Then it comes out at an average of about $£ 20$ a man?

A. 'That is so.

Mr. Walpole: And the man who is fortunate enough to collect gets 25 per cent. on $£ 150$ ?

A. That is so.

Q. And $£ 37$ 10s. would be the share for collecting? Is there more than one collector?

A. The whole of the six men collect.

Q. Then, besides sharing up the net amount, they get 25 per cent. on the collection?

A. That is so.

Q. And they take 25 per cent. from the grand total before sharing with the assistants?

A. Yes.

Q. And the result is that Lombard Street postmen receive a very large sum in Christmas boxes?

A. That is so.

Q. Something like $£ 20$ ?

A. Yes, sir.

The Chairman: Don't you think, Mr. Herbert, that if the system of Christmas boxes is to remain in force, the fair thing would be for all men to receive an equal share?

A. Well, my lord, I cannot admit that, and for this reason, that we look upon these walks as a kind of promotion.

Q. I do not wonder at it.

A. When we enter the Post Office we take these walks by seniority, and as we get more senior we get a more valuable walk.

Mr. Smith: How many assistants are there on this Lombard Street walk?

A. I think there are three.

Q. And these are in addition to the six?

A. Yes, sir.

The Chairman: But, after all, it seems to me that no very large sum would be involved to give compensation to all the City men for the money collected for Christmas boxes in the City. You tell us there are 950 postmen in the City, and that to those men the Department would have to pay compensation for Christmas boxes to the extent of something like $£ 4,000$ odd, therefore that would be under $\$ 5$ per man. That is to say, $2 \mathrm{~s}$. per week would do away with the whole thing?

A. But then you would be giving the $2 s$. a week all round, and by so 
doing you would be simply paying the younger men at the expense of the senior men.

Q. The young men would become senior men eventually, and you would get the 2s. a week all round?

A. But that would not compensate us senior men, who have suffered from the system in the past.

Q. But, after all, you have been reaping considerable advantages lately?

A. Quite so; but it has taken me 22 years to attain my present position. I shared $\$ 17$, and if you took that away from me, and paid me only $2 \mathrm{~s}$. a week in lieu of it, you would be taking away a considerable part of what I contend I have earned by my service in the past. You will be giving to the younger men who are just entering the Service all the advantages it has taken me these many years' service to earn, and you would be doing it, not at the expense of the Department, but at my expense.

Q. I quite admit that from that point of view your contention is perfectly reasonable, but $I$ do not say that it is a patriotic one from the point of view for the Service. Have you anything else to lay before us?

A. I should like to put in a return of some of the loads our men took out this morning.

Q. Very well.

A. Taking the Mincing Lane walk, I find that in the first section the bag weighed $50 \mathrm{lbs}$., and in the second section $80 \mathrm{lbs}$.

Mr. Walpole : 80 lbs.? How far would the man have to carry it before he got rid of some of it?

A. He would take it from the General Post Office to Mincing Lane, a walk of 15 or 20 minutes. On the third section the weight of the bag was $70 \mathrm{lbs}$.

Q. Was that man sent out with that alone?

A. We canrot obtain any information about that.

Q. But that is the important point. Cannot you say whether or not the man had assistance?

A. I cannot.

The Chairman: Unless you tell us that the men had to carry this weight unassisted I do not think you have any case?

A. I have already said that when men are available the Department give assistance, but men are not always available, and in that case the men have to carry the loads themselves.

Mr. Walpole: You have taken considerable trouble to get a particular return this morning, yet you cannot tell us whether assistance was or was not given with the heavy weights.

A. I may say that we were very pressed to get these returns this morning; we hardly had time for the purpose.

Q. But then there is no value given to the return, because a number of men are set aside each morning to give assistance on these walks?

A. The Department could supply the return. A number of men are no doubt sent out each day, and it will be quite possible for you to get the information as to whether assistance was given on these particular walks.

Q. I did not know you were going to bring this matter forward, or I would have had the information here.

A. I have some further instances. I will take the Billiter Square walk. On the 1st section the weight was $60 \mathrm{lbs}$., on the 2 nd section $65 \mathrm{lbs}$., on the 3rd section $72 \mathrm{lbs}$., and on the 5th section $43 \mathrm{lbs}$. On the Cornhill walk the weights were-1st section $45 \mathrm{lbs}$., 2nd section $70 \mathrm{lbs}$. , 3rd section $65 \mathrm{lbs}$., and 4th section $56 \mathrm{lbs}$. On the Bishopsgate walk the figures are1 st section 62 lbs., 4th section 84 lbs., 6th section 65 lbs. I suppose it is not necessary to go through any other returns?

Mr. Walpole: If you will hand it to me, I will see how many assistants were sent out. 
A. With pleasure.

Q. Is that the whole question you wish to raise?

A. Yes; if you will look at the paper you will see it represents the number of registered packages carried, the weights of each bag, and the number of bankers' bags made up by each postman.

Q. Does that finish your case?

A. It does, sir.

Q. I should just like to mention that I have looked into the pensions granted last year, and have worked them out, and I find that 6 City postmen were pensioned last year, 3 of whom were below 50 years of age, and of the other 3, 2 were 57, and the other one 61 years of age. It does not look as if they were worn out.

A. What were the ages of the first three?

Q. The first three were 45,42 , and 33 respectively. One who retired at 57 had done 39 years' service, the one who retired at 61 had 36 years' service, and the other man at 57 had 33 years' service. The man of 45 had 26 years' service, the one at 42, 23 years' service, and the one at 33, 16 years' service. They were the whole of the E.C. pensions granted last year.

A. And I think it will be seen from that that the average age is comparatively young.

Q. The average service is 29 years, and the average age is a little under 50 .

A. Surely that is a very low age for men to be worn out to such extent as to have to leave the Service?

Q. But three attained the comparatively respectable age of 57.

A. But then there is the case of a man who was worn out after 16 years' service. It is to be presumed he passed the medical examination when he entered.

Mr. Walpole: I do not know what the cause of his illness was. No doubt he contracted some illness.

The witness then withdrew.

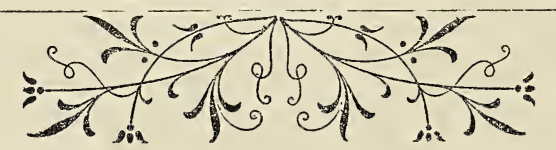


FRED. SMITH, of Liverpool.

\section{Special Case for hiverpool Allowance Men.}

\section{Westuinster, 9th March, 1896.}

Fred. Smith was then called and examined.

The Chairman: You are a Liverpool postman, I believe?

A. No, sir; I am a stamper.

Mr. Walpole: A Liverpool postman employed on stamping duties, is it not?

A. No, sir; I am not a postman, and never was.

Q. Were you never a postman?

A. No, sir.

The Chairman : How did you enter the office then?

A. I was an auxiliary acting as messenger when I became established, 19 years ago.

Q. An auxiliary acting as messenger?

A. Yes, my lord; and since I have been on the establishment I have always been in the position of a stamper, bagman, messenger, or porter. I may say in connection with this matter that several of my colleagues in the Liverpool Office are situated in a similar way. They held, I understand, the position of 4th class clerks, and it shows a retrogression in their case, as they have been designated postmen now for some years, although they do duty as stampers and messengers. I believe that in official papers they are designated as stampers and inessengers.

Mr. Walpole: Surely that is not so, Mr. Smith?

A. Yes; we are designated as stampers and messengers in conjunction with postmen.

Q. I have a copy of the Estimates here, and I see nothing of the kind.

A. It so appeared in my copy at Liverpool.

Q. Well, here is my copy, as you see.

A. Well, that is different from the copy I had; there distinctly the terms "stampers, messengers, and postmen" were used.

The Chairman: You have come to speak on one or two points on which certain of your colleagues disagree with the case already put forward by the Federation. Is that not so?

A. Yes, that is so. I appear for the bagmen, hall porters, mail messengers, mail porters, stampers, and their substitutes. We desire this opportunity to state briefly the reason that prompted us to submit a case independent of the postmen. I beg also, my lord, to ask your permission to mention in a few words four subjects, which we regard as unsatisfactory, in the course of the statement I have to submit. First, the eastern hall door from a messenger's point of view ; secondly, payment for Bank Holiday; thirdly, a concession granted by Sir A. Blackwood to the Liverpool staff in March, 1886; and fourthly, the possibility of injury caused by heavy bags. We were strong in our belief that the position we hold in the Service, the duties we perform, and the responsibility of those duties, entitle us to a position on the establishment, similar to the position held by the sorters in the London E.C. Office. On these grounds, the messengers, stampers, etc., felt that our case would not receive that consideration which we felt it demanded by being amalgamated with the postmen's. We have, my lord, reviewed the evidence given by the postmen's representatives, with a.view of narrowing down the statement we wish to submit to the narrowest possible limits. Before dealing with the details of our duties, etc., I desire to call attention to the persistent closing of the "Eastern Hall Door," which was mentioned by Mr. Walsh in his evidence. The messengers consider that in this matter they have an even greater grievance 
than the postmen; they regard the closing of this door as unnecessary and unjust; it entails on them additional walking and labour in order to despatch the mails. If it were allowed to be open it would save them walking 200 or 300 yards. At Exchange Station the guard's van, when marshalled at the north end of Exchange Station, cannot be reached without the greatest difficulty should the despatch be made a few moments late; the regulation time does not permit the van being reached without a desperate struggle. These struggles are of frequent occurrence, owing to the small margin allowed to work off the correspondence, and in the opinion of the men engaged on these duties, some modification of the existing rule may be permitted by the hall porter not allowing any officer to pass through not authorised by the Postmaster. On the question of "payment for duty performed on Bank Holidays," we wish to point out grievances connected with the working of the existing rules, and I would ask that this Committee recommend that payment be made for all times served on Bank Holidays. An officer who performs 8 hours' duty on Bank Holiday is often compelled to take a day off in lieu at the convenience of the Department.

Sir F. Mowatt: You ask for payment for duty performed on Bank Holiday? Is that instead of having holidays given you in lieu of Bank Holidays? Do you wish to be paid instead of that?

A. Yes; I think we should be paid for Bank Holidays.

Mr. Walpole: Is that not what is done row?

A. No ; recently men have been instructed to take their time off in lieu of Bank Holiday, and our grievance is that we have to do so at a time when we have no place to go to.

Q. You say a man was recently instructed to do that?

A. Yes, sir; and we say that the punishment falls the more heavily on the man according to the number of hours' duty he has to do. If he is an eight-hours' duty man, he suffers more than a five-hours' duty man.

The Chairman: This is very much like what we have had already. I would rather like you to confine yourself to points which have not been put before us, or on which you disagree with the views of the Federation.

Witness: I have one or two other points to lay before you.

Q. We only allowed you to give evidence at all because we supposed there were certain points which you thought had not been put effectually before us, and on which you differed from the Federation. Now, you are going into points which have already been put before us by the Federation.

A. I understand the question of Bank Holidays has not been dealt with.

Q. It has been dealt with over and over again.

A. Well, I do not wish to press the point, my lord. I will only remark that an officer who only performs 6 hours' duty receives the same consideration as the officer who performs 8. And all officers performing less than 6 hours' duty become entitled to payment. These arrangements, in our opinion, are infringements of the concession, and we call for their discontinuance. As regards promotion in the Postal Service, our opportunities are practically limited to an inspectorship of postmen, and a secord-class sorting clerksbip in the major establishment. With reference to the former, when a vacancy occurs, the one objection urged against our application, and which militates against our success, is our inexperience of postmen's duties, though we are classified with them, and only in one instance during the last ten years has an applicant from our ranks been successful.

The Chairman: Really, Mr. Smith, I must ask you to confine yourself to tho points upon which you do not agree with the Federation. I do not want to go over these subjests again. I have given you a great deal of latitude; in fact, I have given a great deal more latitude to the postmen than I ought to have done; I must take steps to close the evidence.

A. My statement was greatly mutilated through the correspondence with Mr. Bruce. It will not take me more than a few moments to read it. 
Q. I am glad Mr. Bruce has mutilated it. I simply consented to your coming here to state the points on which you do not agree with the Federation.

A. But there are points in connection with this that do not affect the postmen in any way.

Q. I shall stop you at once if I find you are going over ground which has already been covered; of course, I cannot say beforehand if you are covering old ground again.

A. I should like to be allowed to proceed. I should like to put in this case on behalf of 70 men; it is a burning question with us. About two years ago a vacancy arose for an inspector of postmen, for which I made arplication. I was sent for by the chief clerk, who questioned me as follows:- "How long have you been in the Service? What experience have you had in postmen's duties? How long were you a postman?" This conversation conveyed to my mind the idea that lack of knowledge in any branch of postmen's duties would act against my success. I mention this circumstance, not in the nature of a complaint, but to show how impossible promotion from a stamper to an inspector of postmen is to officers situated in the Postal Service as we are. As regards promotion to a sorting clerkship, notwithstanding admitted ability to perform the duties of a sorting clerk, we are precluded from taking advantage of the promotion through the restrictions respecting the question of income. These restrictions, which prevent promotion to clerkships, are unprecedented in character and unjust in their operation. A bagman, stamper, hall porter, or mail messenger, having arrived at his maximum rate of wages, with three good conduct stripes, would suffer a reduction of $8 \mathrm{~s}$. or 9s. per week in his income on promotion to a clerkship. I think it will be seen that exemplary service of 15 or 20 years in this particular branch of the Civil Service stands out as a beacon of blighted hope to the stampers, bagmen, mail messengers, etc., employed on indoor duties at Liverpool.

Mr. Walpole: That statement of yours is not accurate. The men carry with them their allowances on their promotion to clerkships.

A. No, sir, they do not carry with them. I, myself, would lose $8 \mathrm{~s}$. a week on promotion to a clerkship.

Mr. Walpole: I think you are wrong.

A. I think rot, sir.

Sir F. Mowatt: Do you not carry your stripes with you?

A. No, sir ; we are not allowed to carry any of them.

The Chairman: Have you any stripes?

A. I have three stripes, my lord.

Q. Then if you have stripes how on earth do you contend that you are not a postman?

A. My contention is that I have never done a delivery since I entered the Service.

Q. Are not stripes an essential distinction of postmen? Are they not given as a badge of honour and reward to postmen alone?

A. We are classed as postmen, but we do not do postmen's work.

Q. You are postmen employed on indoor duty; that is what you are.

A. You might as well call a common brick a plum-pudding. (Laughter.)

I have never done a delivery during the 19 years I have been in the Service.

Q. Would you state that a postman employed on sorting work is not a postman?

A. They are different altogether. They do postmen's work, which is indoor work; we do indoor work which is not postmen's work.

Q. Still, you are postmen for all practical purposes?

A. I do not agree with that, my lord.

Mr. Walpole: You wear a postman's uniform?

A. Yes, sir.

The Chairman: You really mean, then, that though you are classified 
as postmen by the Department you want the Department to set up another class to cover your case?

A. My statement will lead up to that.

Q. Then it is a pity to begin by trying to make out that you are another class.

A. I was putting my personal case forward when you put the question to me, and $I$ said I was not a postman, for the simple reason that $I$ had never done postman's work since I got on the establishment.

Q. If your contention that you are not a postman is correct, then your demand that a separate class shall be set up falls to the ground, because, according to your version, you are already a seprarate class: but if you start on the ground that you are a postman and are not satisfied, but want to be made into a separate class, then you have something to go on in putting forward your case.

A. I am prepared to submit that though we are recognised as postmen by the Department, our duties are not identical in any way with those of postmen. If the above limitations and restrictions could be removed, or the formation of a separate class for the above-named, it would open out to all pestmen the advantage of 70 promotions in Liverpool, which they do not at present enjoy, thereby reducing their grievances under that head to a minimum. In support of this, our claim for a new classification, we would enumerate the nature of our duties, which differ materially from those of postmen :-

1. Bagmen regulate and deal with all inland mail bags for the inward and outward despatches, numbering about 29,000 per week; they also perform the duty of stencilling mail bags, a most important one, necessitating perfect reliability on the part of those officers. They are also charged with the examination and oversight of all mail bags, withdrawing those which are worn out, and replacing them with new ones, and are alone responsible for the supply and maintenance of the stock of bags; thereby the Department is saved the cost of supervision, which is entailed at other large offices, to keep this branch of their work in a state of efficiency.

2. Mail messengers and mail porters regulate at railway stations the arrival and despatch of all mails. In connection with the regulating of mails, I would ask this Committee to recommend the discontinuance of heary sacking. The rule is that no sack, when made up, should exceed $80 \mathrm{lbs}$. in weight. We-contend that $80 \mathrm{lbs}$. entail too great a strain on one man's body to lift alone, which we very often have to do. I have seen men stagger and faint under the weight of some of the sacks and bags which arrive at the Liverpool Office. Officers have been compelled to retire from the Service through hemorrhage, in some cases resulting in death, caused, in my opinion, in no small degree by this abuse. The Committee will not doubt my statement when I inform them that the Controller of Stamps sends out stock in bags over $90 \mathrm{lbs}$. in weight daily. The railway post offices are the chief offenders in this respect. A case in point-I weighed bags from 130 to $150 \mathrm{lbs}$. arriving at Liverpool on the 25th of February, in transit from the Continent to the United States. I may say in connection with this that some years ago the chief clerk at Liverpool took steps to modify these weights, and he was successful for a short time, but we have now reverted to the old system. We ask the Committee to recommend that under no circumstances shall any sack exceed $60 \mathrm{lbs}$. in weight, and mail bag 50 lbs. And whenever it is found that a mail bag, which in due course should be enclosed in a sack, and that it exceeds $40 \mathrm{lbs}$. in weight, that bag should be sent outside. I may say, my lord, that from the railway travelling post offices on the London and North-Western Railway, the weight of the bags coming into our offices is often over $120 \mathrm{lbs}$; and I have seen some bags from the Caledonian Railway which have taken three men to lift out of the van. Now, there are not men available at all times 
to give this assistance, and therefore much more labour and greater hardship is entailed on the men when they have to lift these heavy bags. In our opinion this would alleviate much suffering and unnecessary pain, not only amongst those engaged on these duties in our own service-it would b. a surprising and unlooked-for relief conferred on a body of railway employees already overworked. About 2,000 mail bags per day are dealt with by the messengers without any supervision, and they also despatch important late fee correspondence, poster in the late fee box at the railway station, and deal with registered letters "posted out of course," and paid lats fee in precisely the same manner as is done by first and second-class sorting clerks at head office. They take charge of American and African mails, and transfer them to the proper authority on board ship, checking with the mail officer before receiving a receipt; they inquire into and report at head office all late arrivals of mails. Travelling duties of the greatest importance are performed by mail messengers taking charge of the night mails, transferring and disposing en route. I should like to place before this Committee a few details concerning their day and night duties :-

1. Day duty.-Clear late fee box at 9.45 a.m., 11.5 a.m., 12 noon, and 2 p.m. Examine and sort out the late fee letters for London and the Continent; enter all registered letters "posted out of course," on the letter bill, and also express letters. Sign the letter bill and enclose in late-fee bag with the correspondence before despatching by train. They also despatch important correspondence paid late fee for the United States and Canada on the days of sailing. Duties such as I have mentioned, to a great commercial city like Liverpool, whose interests are in constant touch with every Continent where commerce is known, are of grave importance to the community.

2. Night duty.-Early morning papers brought to the station from the various newspaper offices are examined, sorted, made up, and despatched in bags for the North of England and Scotland. This important duty was formerly performed under the supervision of a clerk. The mail messengers have now the whole responsibility of this duty resting upon themselves.

3. Travelling duties.- In sole charge of night mails for London, South Wales, and Yorkshire mails to Warrington. Transfer to limited mail London and South mails. Receive from limited mail North for Yorkshire. At Stockport transfer Yorkshire mails to Bristol, Shrewsbury, and Normanton T.P.O., and assist in mail tender to Stalybridge and Normanton-the return journey made on the following day being of the same character.

4. They are also called upon at times to take charge of heary American mails to London, Chester, and Holyhead. The above important and responsible duties are performed without incurring the cost of a penny in supervision; for the Committee will note that when a mail messenger or porter leaves the office in charge of a mail, he alone is responsible for its safe disposal.

5. Stampers face and stamp all correspondence posted at the head office, and at the Exchange Branch Office; they also tie and seal all outward mail bags, a duty which requires careful attention and involves considerable danger and risks to the contents of a mail in transit, should any of the 6,000 bags per week be overlooked. During the week ending January 25th, 1896, the total number of letters, etc., stamped by the stampers in the circulation branch with the outward date stamp was about 900,000, which, allowing $1 \mathrm{~d}$. per missive, would mean the perfect effacement of postage stamps to the amount of $£ 3,750$. The responsibility of cancelling $£ 3,750$ of postage labels effectually is a matter of great seriousness in these days of sharp practices, for if the labels are not properly defaced it encourages fraudulent persons re-using them. In addition, large numbers of circulars are frequently received prepaid in cash. In October, 1894, the numbers -were 1,193,864; in October, 1895, 1,343,600. In connection with the posting of large numbers of circulars, we ask for greater consideration in disposing of them. At present, no matter what numbers happen to be 
posted, they are disposed of by the staff, who, under ordinary circumstances, work at high pressure. The principle adopted by the late Postmaster was one of no overtime under any circumstances. This principle, we contend, frequently led to the overworking of the staff. The continued concentration of the eye and mind in the performance of this duty must seriously affect the organs of the body. They also stamp all inward correspondence-about $1,000,000$ per week-and are responsible for such legible and clear impressions of dates, etc., in stamping that will account for any mis-sent or delayed correspondence. Should the stamper fail in this particular part of his duty, serious inconvenience to the Service and the public would necessarily follow. Foreign office work stampers and messengers in the packet office stencil and prepare all foreign mail bags, stamp all inward and foreign direct mails, sort all newspapers, books, circulars, and important commercial papers for all the most important cities (and their divisions) in the United States and Canada (also its dependencies), South America, Newfoundland, Bermuda, Havana, Mexico, West and South-West Africa; weigh and check the weight of these mails ; tie and seal the bags (the average weekly numbers for the United States and Canada are about 250). From an official return for the month of January, 1896, the number of bags sorted and made up and despatched by stampers in the foreign office was about 2,065 , and the weight 112,050 lbs. They also sort all newspapers, books, etc., for the Continent prior to the despatch to London. This correspondence is made up in separate bags, such as Indian, Australian, Colonial, and Continental, the average weekly number of bags forwarded are between 80 and 90 ; we also convey ship-letter mails to their respective offices or place of embarkation; make inquiry and obtain the requisite information respecting the sailing, arrival, etc., of all United States and other mails. I desire, on behalf of this part of our duties, to say that this work has been performed by the stampers and messengers with the greatest care and satisfaction for over 30 years, with the greatest advantage to the Service.

The Chairman: You do not wish to cease performing these duties, do you?

A. No, my lord, but an effort was made by a previous witness to take them from us. We consider that they are our duties, and we wish to draw attention to the satisfactory way in which we have done the work in order that we may still be allowed to do it. A great effort is being made at present to deprive us of them.

Q. On the contrary, the evidence put forward on behalf of the postmen was rather to hold up the employment of postmen on indoor work at Liverpool as an example of what ought to be done in many instances in many other parts of the country.

A. I am referring to the position taken up by Mr. Lascelles. He appeared for the clerks, who are making a desperate effort to take all the sorting work.

Q. And that point has already been dealt with. The postmen dealt with the very self-same subject, and proposed that the retention of this work in the hands of the indoor men at Liverpool was an exception to the system.

A. They were referring to what the postmen did. That is quite distinct from what we do.

Q. They referred to the very things that you do.

A. Well, I shall only occupy a few moments. On the arrival of unsorted American mails, all the before-mentioned officers $(1,2,3,4)$ are frequently called upon at all lours of the day and night to assist in their disposal, regulating the transferring of the London and forward portion, and sorting both letters and newspapers bronght to this office, withdrawing correspondence subject to a tax through insuficient postage (a similar course is often taken with reference to posting, etc., of inland correspondence). The roal shown by the stampers in this respect frequently prevents surcharges 
of a large amount escaping detection. To verify my statement, I may mention that during the late chief clerk's term of office monthly returns were prepared showing the amount of over-weight correspondence detected by each member of the staff; reference to these rturns will corroborate my statement. As an instance just recently, several hundred books were posted by W. P. Hartley, Esq., of Aintree. 'The interest shown by the stampers in the direction $I$ have spoken of was again manifested. On this occasion these books, through a stamper, were found to be underpaid. In urging on the Committee the desirability of an extension of leave of absence from two to three weeks, we may say that the medical officers expressed great astonishment when they became aware that the bagmen, hall porters, mail messengers, mail porters, stampers, and their substitutes, who perform so much night duty, partial night, divided and irregular attendances, were not erititled to three weeks' annual leave. The Committee would better understand the nature of our duties by the perusal of this attendance-sheet. I beg to remind the Committee that postmen employed at health resorts throughout the United Kingdom, and not in any way subjected to the same confinement, irregular attendances, and unhealthy atmospheres, are allowed precisely the same facilities for recuperation as we are. In order that the Committee may understand the irregular attendances and duties we are subjected to, I may mention that on the 23rd of February, 1896, the Cunard steamship "Aurania" arrived at Liverpool with over 500 sacks of mails. The disposal of these mails necessitated attendance for duty at 11 a.m., being detained until after 6 p.m. The Committee will probably note that an attendance of this kind would deprive us of the only day we look forward to, to spend with our families and friends. It also deprived many officers, who were summoned that day, from both dinner and tea at the regular times. I, myself, had practically nothing between breakfast-time and the time I reached home at night. On the last occasion that this boat arrived at Liverpool we were ordered by special messengers at $5 \mathrm{p} . \mathrm{m}$. to attend at 9 p.m., and then being detained until after midnight. I would also like to mention a more recent case. On Saturday, February 29th, the Royal Mail steamer "Etruria" arrived at Liverpool with 900 odd bags. To meet the pressure caused by the extra work, officers were summoned for duty about 9.30 a.m., having previously gone off duty at midnight, not arriving home again until after midnight. The Committee will note that on that occasion a number of the men were on duty about 23 hours out of 32. Friday, February 28th, on duty 4 p.m. to midnight, reaching home just before 1 a.m. Saturday morning. Left home in answer to a summons at 10 a.m., arriving home again just before 1 a.m. on Sunday morning. For such inconveniences as these we are rewarded by the payment of our ordinary overtime rate, whilst officers employed on Sunday duty in the London Office receive double pay. The arrival of these mails being regarded as exceptional work, we consider that we ought to receive a corresponding remuneration by being paid the double rate. In addition to the arrival of unsorted mails, I desire to mention the concession granted to the Liverpool staff in March, 1886, and withdrawn by the late Postmaster in 1895.

\section{Extract from Order Book, dated 1886.}

"The Postmaster has much satisfaction in announcing that the Secretary has been pleased to express his willingness to regard the duty done at this office on Sunday in connection with the disposal of unsorted American mails as constituting a claim for special payment; and also as regards the duty done on Saturdays. to concede that after 9 p.m. the ordinary foreign mail duty of the day shall be considered ended, and that any such duty done after that hour shall be specially paid for."

March 9th, 1896.
(Signed)
J. D. RICH. 
Extract from Order Book, dated 1895.

"With reference to the Postmaster's minute. dated 9th March, 1886, at page 112 of Order Book, it is pointed out that the privilege therein announced of overtime payment on Sundays, and after 9 p.m. on Saturdays in connection with the arrival of unsorted American mails was annulled by the revision of 1890 , and as a consequence no claim for overtime payment on week-days can be allowed to clerks, sorting clerks, etc., until a full day's duty of 8 hours has been performed."

7th Narch, 1895.

(Signed)

W. R.

The foregoing are copies of orders issued to the Liverpool staff in 1886 and 1895 respectively. The concession announced in the first order was the result of a petition to the Secretary, whose attention was directed to the peculiar circumstances under which the Liverpool officers were frequently deprived of a partial holiday on Saturdays owing to the arrival of American mails. As no other office was subject to a similar disadvantage, the Secretary considerately decided that payment should be given for all time incurred in disposing of unsorted mails on Sundays or after 9 p.m. on Saturdays. In the second order it is urged that the concession was annulled by the revision of 1890. But it is difficult to see that the concession is in any way minimised by the revision. The revision extends the application of Sunday payment to all Sunday work, but the subject of Saturday overtime remains unaffected. When the revision was announced, no reference was made to the concession, and it was not until five years had elapsed that the concession was discovered to have been annulled. If, however, the privilege really is annulled by the revision, we beg to point out that the circumstances under which it was granted have not altered, that we are still deprived of partial relief on Saturdays when American mails arrive, and that the same reasons exist now as existed in March, 1886, for giving exceptional treatment to the Liverpool Office. We also beg to point out that the privilege was granted by the Secretary, but the order, dated 7th March, 1895, appears to have been issued by the Postmaster without the Secretary's authority. I hope this Committee will take this matter up. It is a great hardship for us at Liverpool that, after dealing with the heavy work on Saturdays, we should be deprived of our half-holiday. Saturday is the heaviest day in the week, and some Saturdays we have to work desperately hard in order to get a few hours relief. Yet, by the arrival of these mails, we are deprived of that relief. I wish to bring under the notice of the Committee the allowance question and the application, the great disparity, and the unsatisfactory working of the principle. It admits injustice and hardship to those men whose duties are identical, whose responsibilities are similar, and whose conduct is good. Instances can be stabed where an officer receives a less allowance than men junior in service, which these men view as a grievance. The late Mr. Fawcett stated that the allowance received by those men performing indoor duties was equivalent to the loss sustained in not receiving Christmas gifts. Later, in the House of Commons, Sir James Fergusson said that the allowance was given for duties not performed by postmen. It is refreshing to note the reformed tendency exhibited through Sir James by the Department since the days of Mr. Fawcett. The estimation of our duties shows conclusively that our demand for equal treatment for all officers performing indoor duties is reasonable, and in accordance with official declaration, and we ask the Committee to recommend the restoration of equal rights to all indoor men. In asking for the maximum of $50 \mathrm{~s}$. per week, we beg to submit the following reasons :-

1. That the nature and responsibilities of our duties, which are at present acknowledged by an allowance, entitles us to a higher remuneration. 
2. Owing to the enforced confinement when on duty, it becomes necessary to reside at some distance from the office, where health and respectability may be obtained, and which our present income will not reasonably permit.

3. That the commodities and necessaries of life are exceptionally dear, and that our present income will not permit of our obtaining the quality and class of things essential to nourish and strengthen our bodies, which are so much reduced by the nature of the arduous and responsible nature of our duties, approximating to, if not identical with, those of 1 st and 2 nd class sorting clerks, we trust that the claims set forth-

(a) The formation of a new class different from postmen.

(b) The extension of our annual leave to three weeks.

(e) That an increased pay on the basis of the scheme suggested in our first petition may receive the Committee's favourable consideration.

Mr. Walpole: You ask for a maximum of 50s. per week?

A. Yes, sir.

The Chairman: Then you differ from most witnesses whom we have had before us as to the abolition of classification and the simplification of the various classes in the Post Office? You wish, in fact, to add one more class to the existing classes in the Post Office?

A. Yes, my lord; we conceive that t?e abolition of classification would benefit materially a large number employed in the Service. No doubt it would benefit the younger men, but the men whose ages rank from 35 to 45 will receive no benefit at all from the abolition of the classes.

The Chairman: Thank you. The witness then withdrew, and the Committee adjourned for luncheon.

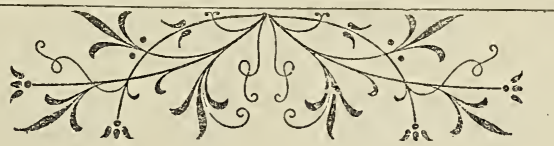




\section{Mṛ. DORAN, of Dublin.}

\section{The Dublin CASE.}

Westminster, 9th March, 1896.

Mr. Doran (Dublin) was the final witness called this day.

The Clairman: I am afraid I must ask you to be as brief as you possibly can.

Witness: I have condensed my statement as much as I possibly could. I am satisfied with the way in which the case has been presented, except on two or three points.

The Chairman: Deal with those points, then.

Witress: One of those points is that no mention is made of the fact that Dublin has no town sorting post:nen or stampers, and I wish to say a little on that.

The Chairman: You, like Mr. Smith, waut some men put on a new scale or class?

Mr. Walpoole : Do you mean that stamping is not done by postmen in Dublin?

A. I lade a mistake there. There are four stampers, whereas ten are reauired.

Mr. L. Smith: And who does the rest of the stamping?

A. Sccond-class sorters, etc.

Mr. Walpole: Second-class sorters doing stamping? Are you certain of that?

A. Yes; I can give instances which will show that.

The Chairman: You are an outdoor postman yourself?

A. Yes, my lord. I will give you instances showing the number of stampers employed at various times of the day, and that will show that four is not a sufficient number of establislied stampers. From 4.30 to 5.20, 17; from 5.20 to 8.30, 9; from 10.40 till 2, 11 ; from 4 till 5.15, 19; and from 5.15 to 7 p.m., 28. This is the number of stampers eniployed at different times of the day, while the number of postmen stampers is only 4.

Mr. Walpole: The others are auxiliaries, are they not?

A. No, sir; they are all classes of sorters, so far as I know. In fact, the head stamper at Dublin is a first-class sorter at 56s. a week. The stamping in other places is done by postmen, but I think I had better take that in my statement. But before proceeding to that, I have been asked to say a word or two on the question of the dual certificate. In regard to that, the Dublin men seem to have been treated differently from the London men. In placing the case of the Dublin dual certificate men before you, I refer to those who between 1885 and 1887 succeeded in obtaining the certificate qualifying them for the positions of postmen and sorters. When appointed they were placed on duty as postmen (they, prior to appointment, occupied the position of auxiliary postmen), but understood as vacancies occurred they would be drafted on to the sorting staff. This not having been realised up to the end of the year 1893, except in the case of about five men, the remainder drew up a petition praying for a transfer, and having presented it to the superior officer, after some time were informed that their request could not be granted, the statement being made that the holding of a dual 
certificate did not suffice for a sorting clerkship, a direct contradiction to their action in placing the aforesaid five men on sorting duties. Besides, the London and Elinburgh men of the same class were officially invited to accept transfer to the sorting staff, whereas the men in Dublin have no knowledge of any written intimation, nor were they ever verbally invited to accept transfer. What they now contend is that the privilege of becoming sorting clerks should be granted them, for had they been notified, as they believe the men in London and Edinburgh were, they would have arailed themselves of the opportunity. Now, I will take the case of the Dublin established postmen. There are, as I have already said, but four stamping postmen employed in \$.O., although there is ample work for 12 stampers. The stamping is principally done by sorting clerks, who are taken from the roads and primary sorting to do this work. The head stamper's duty is performed by a first-class sorting clerk at 56s. per week. When he is on leave his duties are performed by the senior stamper, but no allowance is made. We ask that the staff be increased to the above number. In 1892, Mr. Morley stated, in answer to a memorial, that he was inclined to grant local town sorting, but would first give the matter his careful consideration, with a view of ascertaining if it would be practical in Dublin. Application was again made six months later, and Mr. Morley replied that he was still considering the matter. Since that time nothing has been heard of it. Considering that postmen from their knowleage of the city and district are fully qualified for this duty, that their employment at this work would have meant a saving to the Department, and that this duty is being performed by postmen in all the other large towns, it is hard to see any justifiable cause for denying it to Dublin. About the time of the above-mentioned petition, and for some time previously, the primary sorting of newspapers and letter-packets for the night inails was being done by postr.en. Some time after this practice was discontinued, and the postmen put to the facing table. This may have been a coincidence, but the belief among the postmen was, that it was done for the purpose of preventing them from making any claim to the S.O. on that ground. In determining the minimum wage it must not be forgotten that auxiliaries are much longer in reaching a full-time duty than in London or Glasgow. Even with increased facilities of promotion, none of the present auxiliaries can hope to obtain their appointment before reaching 25 years of age, so that five years hence the wages of a postman of that age would vary considerably in different towns. For instance, in London he would be paid $34 \mathrm{~s}$, in Glasgow 30s., and in Dublin 20s. This difference would be altogether unjustifiable.

Mr. Walpole: How do you mean 34s. in London?

A. After five years' service, because the postman is appointed at 19 years of age.

Q. They get $24 \mathrm{~s}$. in five years?

A. No. They get $24 \mathrm{~s}$. at starting at 19 years of age, and they will get $34 \mathrm{~s}$. in London at 25 years of age; that is, supposing those increases be granted.

Q. But you are supposing something that has not occurred?

A. But even a shilling makes a difference-the difference would then be $5 \mathrm{~s}$. instead of $10 \mathrm{~s}$.

Q. I can understand that if you get appointed at a later age you get somewhat slower to your maximum salary than the man appointed at an early age; that is all your argument comes to.

A. That is all I am contending for.

Mr. Walpole: Well, I will admit that.

Witness: House rents in Dublin are second only to those of London. Rates and taxes are $10 \mathrm{~s} .6 \mathrm{l}$. in the $£ 1$, and tenements are consequently very dear. 
The Chairman: What does that include?

Witness: That is the total of what is paid by the householder in the youndage of his tenement. I have taken it from the P.O. Directory. It includes police tax, and all these things put together.

The Chairman: Water rate and gas rate?

Witness: Yes; it includes all that. A drawing-room in a respectable house will cost at least $4 \mathrm{~s}$. 6d., and one room is not sufficient to accommodate a family, if decency and health are considered. Consequently, a man must pay at least 5s. 6d. for a small three-roomed cottage, or a pair of rooms in a tenement. If these sums are deducted from $20 \mathrm{~s}$. or $22 \mathrm{~s}$., the nargin for living is rather small. If a Dublin postman is an hour late, he is sent off duty, and must pay a substitute. He is then reported and must work the time lost, although there is probably no loss to the Department, considering that the work has been done, and the substitute paid. This counts in the annual total against his increment, and possibly against his stripe. This rule is of recent introduction, and the men fear that should they be late on two other occasions in the same month, the first-mentioned offence may be added so as to render them liable to a further extra duty. Postmen from district offices must do these extra duties at the Central Office, and as they are almost all employed on four duties daily, and have therefore very little spare time, their punishment is more severe, for to their two hours is added a possible two mi'es' walk to the G.P.O., and the same in returning.

Mr. Walpole: What is the rule as to late attendances? Is it a recent instruction?

A. The rule is, I an informed, that a man must pay his substitute, and afterwards work in the time lost. It is also asked that we be supplied with a book of rules defining our various duties, such as we understand is supplied to other: offices, as the rules supplied to us under local authority are insufficient, and we may at any moment be called upon to explain our conduct in matters where we had no rule to guide us.

Mr. Walpole: You have the ordinary book of postmen's rules, have you not?

A. I never saw it. It is a local book we get supplied with.

Q. But have you not also the postmen's book of rules?

A. I never saw it. It is also asked that documents relating to irregularities be accessible to postmen, before giving explanation. We complain of being sent to perform labourers' duty in the unloading of mails. Our uniforms are not fitted for such work, the men appointed for it being supplied with linen overalls. We come on duty clean, and are compelled to go out on duty dirty through the performing of this work. It does not happen often, but we ask that it be prohibited. In Dublin no established postman finishes his day's work inside of 13 hours, and three-fourths of the duties extend from 14 to 15 hours. In the districts matters are much worse than in the Central Office. They must attend in almost all cases four times daily, and their duties extend over 15 hours, beginning at $6.30 \mathrm{a.m}$., and finishing as late as $9.40 \mathrm{p.m}$. The English mail arrives at G.P.O., Dublin, about 5.30 p.m., and is not sent out for delivery until 7.10 p.m. in the town, and $7.30 \mathrm{p} . \mathrm{m}$. in the districts. It could be sent out by a 6 p.m. delivery from the latter, by which could also be delivered the correspordence collected at $4.15 \mathrm{p} . \mathrm{m}$. This would be of great benefit to the public, would admit of the postmen at district offices having an early week in turn (the duties being made interchangeable), and would enable the men or the $7.30 \mathrm{p}$.m. delivery to finish earlier. The same results could be obtained in the Central Office by keeping back the 5.30 p.m. delivery until 6 p.m., and sending out two men on that delivery instead of one, as at present. I have also to ask that the duties in G.P.O. and district offices 
which exceed 8 hours should be revised, so as to bring them within that limit. Here is a typical case from Fairview, D.O.:-

6.30 to 9 o'clock a.m.

1 to 1.30 p.m.

2.30 to 5 o'clock p.m.

6.30 to 9.45 p.m. -8 hours and 55 minutes.

The postmen on commercial walks must make a second delivery of registered letters, after they have finished the morning delivery. If they finished at 8.45 a.m., and were kept until 9.30 delivering these letters, they would not be allowed to sign the latter time, but must sign 8.45 as the time of finishing their duty, so that they actually do work which the Department refuses to recognise. They ask that this time should be counted into their day's work. Postmen who make van collections complain that (in wet weather) they must sit on the uncovered seat of the van. No cushion or covering is provided. A collection may take three-quarters of an hour, and during that time the water from the roof of the van is flowing over the seat on which the collector is sitting. The seats of the accelerator are also left uncovered, and on a wet morning, during the 20 minutes' wait for the postmen, are exposed to the rain. This must result in injury to health, and they ask that it should be remedied. I now come to the evidence on behalf of the Dublin auxiliary postmen. The proportion of auxiliary to established postmen is greater in Dublin than any other of our large cities. Taking Glasgow as the highest, we find that the auxiliaries form 28 per cent. of the total staff of postmen in that city. In Dublin they form 41 per cent. In my statement I will endeavour to show how this percentage may be reduced by the amalgamation of a number of auxiliaries' duties, so as to form full-time duties, by the establishment of a staff of town sorting postmen, by increasing the number of postmen, stampers, and by adding the 11 p.m. collectors to the full-time staff. The necessity for some sucl revision is urgent, for promotion in Dublin is almost at a standstill. At the age a telegraph messenger auxiliary is obtaining his appointment in London, a messenger in Dublin has just taken up his 8s. duty. During the past $3 \frac{1}{2}$ years there were but 30 postmen appointed in Dublin, or an average of 8.5 annually, so that the last of the 85 junior auxiliaries cannot hope to obtain his appointment, under present conditions, before 1906, at which time he will be about 30 years of age. It is idle to expect that these men can be contented in the Service. The age limit at present debars the older men from obtaining their appointment, and they have consequently no future before them. They may continue in the Service until old age renders them unfit for work, when they must retire without one penny compensation for their time. Auxiliaries consider the examination into their qualifications, after they have passed several years in the Service, altogether unnecessary, considering that during that time they have been performing all the duties of postmen, and must be fitted to perform them, otherwise the Department is not acting fairly to the public in allowing unqualified men to perform duties on the careful discharge of which so much depends. It has been stated that auxiliaries are not medically examined upon taking up their duties. That is not so in Dublin. Examination for appointment should take place before taking up the duties of postmen, and an auxiliary should become fully appointed, even though he were only oil a part-time duty, after the expiration of a 12 months' probationary period. He would not then be at the loss-so far as pension, stripes, and promotion are concerned-of his years of service previous to his obtaining full-time duty, and should he fail to qualify, would not be too old to obtain other employment. As it is, if he should leave the Service at 24, the average of nomination, he is too old to learn any other business, and is practically, in the present scarcity of employment, without any future 
before him. As a case in point, I may mention Robert Fleming, who entered the Service in 1885 as telegraph messenger, became auxiliary in 1890, at about 20 years of age, and failed in his examination through being medically unfit in 1894 . He was then told to resign, and had to leave the Service at 24 years of age. He has since been unable to find employment. The age limit should be abolished so as to admit of the adult auxiliaries obtaining their appointments, which, in consideration of their long service, should be given to them without examination. The system of nominating for appointment men who have performed no auxiliary duty, except, perhaps, a qualifying period, deprives men of seven or eight years' service of the priority which is their right, and contributes to the stagnation of promotion, and it is therefore asked that all auxiliary and established postmanships should be confined to those who have passed through the telegraph messengership, exceptions being made in the case of the present staff of auxiliaries. There are 16 anxiliaries on early collection duty. Their duties are very heavy, requiring that they leave their homes at 3.30 a.m., and do not finish until about 9 a.m. Some of them have very long service-as much as 20 years. Their wages are 15s. weekly. They are not paid any extra for Sunday, though they work five hours, doing the same duties as on weekdays. Ten are employed at the parcels depot from 4 to 7 o'clock p.m., but they have no certainty of this duty, and fear that it may be taken from them at any moment, in which case they would be compelled, in the majority of cases, to finish their time in the Service at 15s. per week. Their duties should be added to, so as to bring their day's work up to 8 hours, and the older men should obtain their appointments without examination. Eleven of the 12s. class make 11 p.m. collections from town and district letter-boxes. Their duties-occupying 6 hours, and extending over 17should be considered full-time. These men are paid $5 \mathrm{~s}$. for the collection, making their wages equal to the present minimum of the established class, but from some unknown reason the $5 \mathrm{~s}$. is considered an extra allowance. This has made it possible for appointed men, at the maximum of their class, to hold these collections, thus depriving many of the miserably-paid auxiliaries of the chance of obtaining this so-called allowance. Appointed men cannot hold these collections without injury to their health-a conse quent loss to the Department by the increase in sick pay. If they were held by auxiliaries they would, upon their obtaining appointments, have reverted to other auxiliaries, whereas an established man may hold them as long as he remains in the Service. Recently these collections were reduced from 18 to 15, but instead of taking them from the better paid established men, they were taken from the auxiliaries, thus reducing the latter from $17 \mathrm{~s}$. per week to $12 \mathrm{~s}$. The auxiliaries feel this very much, and hope, through your recommendation, to obtain redress.

Mr. Walpole: When was this done?

A. About a month ago. There are 16 of these collections, and four are held by appointed men. Recently the number of collections was reduced by the amalgamation of two or three of them.

Mr. Smith: Is there a special allowance of $5 \mathrm{~s}$. for this collection?

A. It is called a special allowance, but it is in reality pay for work performed.

Q. It is a payment for work during the collection?

A. Yes.

Mr. L. Smith: Does the established man get the 5s. in addition to his ordinary pay?

A. Yes; four of these men get it.

Mr. Walpole : Are you certain of the facts, for they are quite new to me?

A. Yes; I am quite certain.

Mr. L. Smith: It is outside the ordinary pay?

A. Yes; and in addition to their ordinary hours. They have to work from a quarter to 6 in the morning till 12 p.m. 
Mr. Walpole: Are you certain of your facts?

A. I am quite certain; and bitter complaint is made about it.

Mr. Walpole: I will look into it.

Witness: The number of auxiliaries can be reduced, and the number of full-time postmen increased with very little difficulty. By a readjustment of duties, work at present performed by two auxiliaries could be done by one established man, and one auxiliary. For instance, the $15 \mathrm{~s}$. class perform morning and midday delivery and one collection, their duty averaging $5 \frac{1}{2}$ hours. The $12 \mathrm{~s}$. class perform two deliveries, generally morning and night. On a $12 \mathrm{~s}$. duty becoming vacant, the night delivery could be added to the $15 \mathrm{~s}$. duty, thus making one full-time duty and one $8 \mathrm{~s}$. duty, or the midday of the $15 \mathrm{~s}$. duty could be added to the $12 \mathrm{~s}$. duty with the same result. This would add about 20 to the full-time class, bringing the number to 174 , and reduce the auxiliaries by about 20 , thus increasing the facility of promotion.

Mr. Walpole: What number of hours would that spread over?

A. It is spread over 15 hours.

Q. And do you think there would be no objection to that?

A. The men would rather have it than be as they are.

Q. They would rather have a duty spread over 15 hours and have more auxiliaries appointed? Do you say they would rather amalgamate the two duties?

A. I am speaking for the auxiliaries, and I say they would sooner have the duties amalgamated, although they are spread over 15 hours.

Q. Which do you think would be the best yourself?

A. I should prefer the amalgamation of the duties. There are three auxiliaries at parcel depot doing 8 hours daily who could also be appointed. That the appointed staff has not been so increased is due to the fact that auxiliary labour can be had cheaper. There is no increase of pay, and few extras, while the appointed man is entitled to all such advantages. If the appointed or full-time staff were increased as above suggested, and town sorting and sorting clerkships thrown open to postmen, the present stagnation of promotion would disappear, and the future prospects of auxiliaries be considerably improved. Upon being promoted to auxiliary postman, a Dublin telegraph messenger is put on a one delivery duty, for which he is paid 8s. if employed at a district, and 7s. if employed at Central Office. In the evening he does duty as telegraph messenger, at which he earns about $4 \dot{s}$. weekly. While on this duty he is allowed boots, sick pay, and annual leave (from telegraph branch). On taking his next step-11s. or 12s. duty - he loses all these extras, and finds himself after one year's service in a worse condition than at the beginning. On passing from the 11s. (one delivery and one collection) to $12 \mathrm{~s}$. duty (two deliveries), he finds his work increased out of all proportion to his pay. On the 11s. duty he is paid a fraction more than $5 \frac{1}{4} d$. ; on 12 s. duty about $4 d$. per hour. There should be a. minimum rate of $6 \mathrm{~d}$. per hour for all postmen performing part-time duties. It is unjust that they should receive no increment while on these duties. Their services increase in value with time, and if other branches are entitled to such an increase, they also are entitled, and for the same reasons. The absence of any inducements to good conduct-in the case of adult auxiliaries - cannot be beneficial to the Service, and is not for the good of the public. Take the case of R. Gilligan and E. Reaney. The former entered the Service as telegraph messenger in 1872, became auxiliary in 1876, failed in medical examination in 1882, and is now 36 years of age, and after 20 years' aux. iliary service, in receipt of $16 \mathrm{~s}$. per week.

Mr. Walpole: He failed in the medical examination?

A. Yes; he failed.

Q. And could not therefore be appointed?

A. Yes; he could not be appointed.

Q. Do you hold the Department to blame for that? 
A. No, for nothing of that nature; but I hold it to blame for only paying him 16s. a week after 20 years' service.

Q. Perhaps the Department would have done better to have got rid of him altogether?

A. At the time, perhaps, but not after 20 years' service. E. Reaney ertered the Service as messenger about, 1877, and became auxiliary about 1879, failed in educational test in 1881, is now 38 years of age, and has 17 years' auxiliary service. He works about 7 hours daily, and is paid 17s. a week.

Mr. Walpole: There, again, is a case in which it would have been wiser for the Department to have said to the man, "You must go, as you have not passed the examination."

A. Although this man failed educationally he has been performing the auties of postman, though he is supposed not to be qualified to perform these duties; but supposing the man is not put on full-time duty, he should be allowed some increment, and have some encouragement to keep on in the Service. Had these men been allowed an annual increment, no matter how small, it would have cheered them up by the hope of a better future, and encouraged them to make a good name for themselves in the Service by the desire to earn it. But there was no such hope for them, and their long years' service must have been cheerless ones indeed. An auxiliary must pass at least three years on the $12 \mathrm{~s}$. class, and at least 18 months on the $15 \mathrm{~s}$., or other duties, before being nominated for appointment. If he passes, he must begin after about 9 years' (telegraph messenger and auxiliary) service at 17s. per week, and is not secure in his position until two years have passed; this lengthening of the probationary period is a great hardship. We ask that examination be held before taking up 8s. duty, and a yearly increment of $1 \mathrm{~s}$. be given until obtaining full-time duty, or until reaching the minimum of that duty. Upon reaching that duty, to rise by annual increments of $2 \mathrm{~s}$. to the maximum of that class. At present a Dublin postman must pass 18 years (inclusive of auxiliary service) before obtaining thr maximum. Dublin auxiliaries are on the same footing as regards Christmas boxes as the established men, and they would not be satisfied that they should be abolished without compensation. A minimum of $6 \mathrm{~d}$. per hour would add about $3 \mathrm{~s}$. to all (except the 4 a.m. collection class), their wages, and the Sunday pay, if granted, would be equal to $10 \mathrm{~d}$. weekly. These, with the other extias, would be sufficient satisfaction for the loss they would sustain. The 4 a.m. collector's could be compensated by bringing their duties up to full time. Atxiliary postrren should receive full pay when on sick leave. Their wages do not admit of saving, and the case of an auxiliary detained from work by any lengthened illness is pitiable. His recovery is retarded by want, and by anxiety for those dependent on him. This is a great hardship, and on behalf of the Dublin auxiliaries I ask for full payment when on sick leave. I have also to ask that all auxiliaries be granted a fortnight's holiday; and that boot money be given in proportion to duty; that is, $10 \mathrm{~s}$. $6 \mathrm{~d}$. for $11 \mathrm{~s}$. and $12 \mathrm{~s}$. classes, and $21 \mathrm{~s}$. for heavier duties. It is almost impossible for auxiliaries to keep themselves in good foot wear on their wages, and some auxiliaries have more outdoor work than appointed men.

Sir F. Mowatt: Is no boot money allowed to auxiliaries?

A. Nots to those under $17 \mathrm{~s}$. per week.

Mr. Walpole: But when they get $17 \mathrm{~s}$. per week they are full-time men?

A. No, sir; I think it is 18 s. a week. There are only one or two men doing that. With the exception of late arrival of English mail, and overtime worked at Christmas and Good Friday, anxiliaries are not paid for extra duty. The 12s. duty is understood to occupy $4 \frac{1}{2}$ hours, but few of that class do under 5, and delivery of circulars sometimes keeps them much longer, but they are paid nothing extra. 


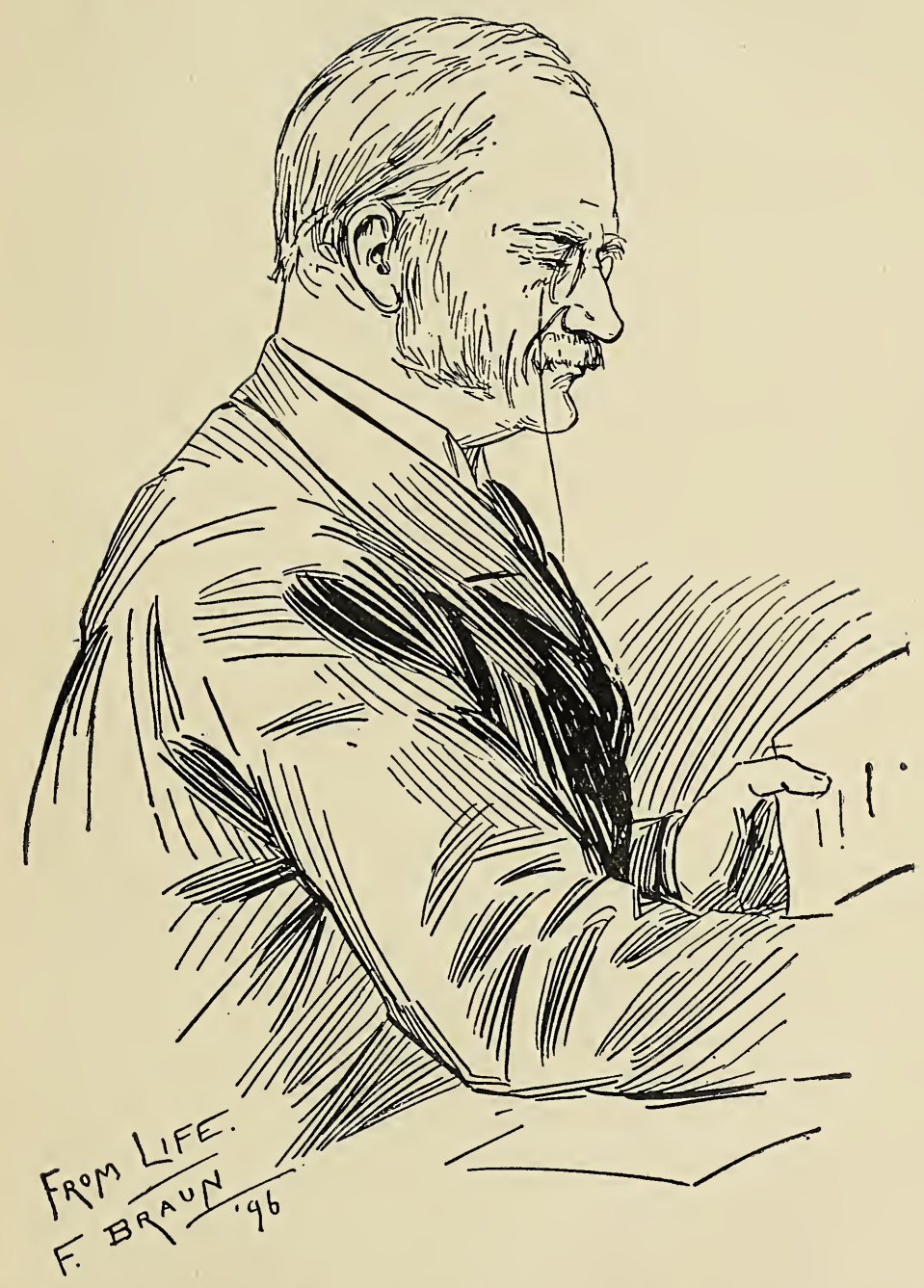

JASSPER C. BADCOCK, Esq.. Chief Controller of the London Postal Service. Departmental Witness for the London Case. 

Mr. Walpole: It is part of their contract.

Witress : But the auxiliaries think they should be paid as in the case of established nen. Auxiliaries attached to the Central Office are paid extra for Sunday work. In the districts they are not paid. In these latter, on any Sunday r.crning, an auxiliary may be seen working beside an established postman, doing exactly the same work, and doing it equally well. On the following Saturday the appointed man will be paid from 1s. 6d. to 2s. $6 \mathrm{~d}$. extra, while the auxiliary is paid nothing.

Mr. Walpole: You say he is paid nothing, but it is in his pay.

Witness: It was also in the pay of the established class, but the Department changed that. The auxiliaries want to have their work in 6 days, the same as the appointed men. This is a great source of discontent amongst the auxiliaries, and they ask for payment for Sunday work in proportion to their rate per hour. In considering the wages of Dublin auxiliaries, it must not be forgotten that outside employment is the exception. I know of but three auxiliaries who hold employment outside the Post Office, and to a considerable number their earnings as postmen constitute the only means of support. So it is really necessary in justice to the public that these men to whom its property is entrusted s?ould be raised above actual want, anc the wages I have stated will do nothing more. The following statement has been supplied to me from the postmen of the Dublin Parcel Post Depot: --The men of this depot desire to lay before you the main cause of discontent as briefly as possible. They are as follows:-Promotion for postmen at this depot is actually at a standstill, and we suggest that transfer to sorting clerkships at this office should be the rule, as the postmen emplcyed at parcel duty have performed in the past, and are called upon at present, to satisfactorily perform certain sorting duties. On a number of deserving postmen being transferred to the sorting staff their places on the postmen's list could be filled by auxiliary postrien being appointed as established men. At times of exceptional pressure the men here have to perform the primary sorting duty, five men being told off for this important work from the 20th to the 25th December, 1895, inciusive, without receiving the allowance usually granter to "relieving and sorting postmen" at other offices, which amounts to $7 \mathrm{~s}$. weekly. They therefore cannot see why the other branches are not open to them. The Department has already transferred postmen to the sorting staff without their undergoing any educational test other than that which they had previously undergone for a postmanship, and they have proved themselves capable of the performance of such duties, and even higher positions in the Service, which we would be glad to see in a better state of efficiency. On the admission of outsiders to this department, we have noticed a tendency to belittle the postmen on all rossible occasions. but believe that this policy is mainly confined to auxiliary and unestablished sorting clerks, such a practice not being sanctioned or encouraged by men who have risen from our ranks. We consider it the duty of the Department to discourage such a policy, which surely is not calculated to lead to the better performance of duties at this depot. We may in this respect draw your attention to the fact that, unlike the letter sorting office, there are postmen employed on every parcel sorting division, and they being in direct contact with the sorting clerk, you can easily come to the conclusion that such a state of things should not exist. We also believe that a revision of duties would be calculated to afford us a more even basis as compared with our brethren in English provincial offices, as there is no such person known here as a head postman, head bagman, head mail messenger, storekeeper's assistant, vard officer, or other such-like positions, which bring an increase in the ordinary wages, although there are duties incorporated with the ordinary work of supervising and other officers drawing much larger salaries than ours, which could with advantage to the Department be performed by postmen with the aforesaid designations. Another matter which calls for redress is the system of 
stopping the allowance granted for the performance of parcel post duty when we are on sick leave. This calls for an immediate change, especially when you take into consideration the fact that our work is of a very laborious nature, and its hardship is added to by having also to perform from 11 to 12 hours' duty fortnightly without rasment for overtime.

Mr. Walpole: Do you mean that the men have 11 or 12 hours' duty in one day?

A. I will explain that as it goes on. The cause of this state of things is the system which allows six indoor postmen to be off duty on each Monday morning, and then entails a midday duty on any of the six days for the purpose of making a return of the time previously allowed; we hare noticed a tendency to effect a change making this fall to each postman tri-weekly, but considering the severe work during our eight hours (which extends over 15), it is at any time a hardship, and we ask for its entire abolition, on the grounds of its being likely to militate against our health. My explanation as to the 11 or 12 hours' duty a day is this :-Six men of each class are let off on Monday morning, but they have to make it up by doing a midday duty, which takes $3 \frac{1}{2}$. or 4 hours, and that brings their total duty on that day up to $11 \frac{1}{2}$ hours. We may also mention as excessive labour the duty of loading and unloading parcel mails at the depot and at railway stations. These parcel hampers usually weigh from 8 to 10 stone. Surely this should be classed as labourers' work, and does not tend to make our uniforms present a neat or clean appearance, and also consider that we are bound by rule to "appear on duty clean and presenting a neat appearance," failure to do so entailing probable loss of good conduct badges. We would be thankful for a revision of all our duties, which would bring the performance of our eight hours within a twelve hours' limit.

Mr. L. Smith: But I thought you proposed a change for the purpose of absorbing auxiliaries, which would involve spreading the duty over 15 hours?

A. $\overline{\bar{I}}$ did in the case of auxiliaries, as the only possible means of getting these men established. It would be better for these men to be appointed than be as they are now.

Q. But now you are asking to have the duties confined to 12 hours. That is not quite consistent, is it?

A. I admit that; but this is the application of the parcel office only.

Mr. Walpole: Would you have one rule in one part, and another rule in the other?

A. 'The desire of the postmen is to get their duty within 12 hours, but in some cases it would be an advantage to have them spread over 15 hours.

Q. But surely you must have one or the other?

A. I should say as far as possible it should be done. I suppose a change will not be made, except as far as possible. The statement continues:Considering the hours we have mentioned, you cannot wonder at the men complaining of the excessive punishment meted out for late attendance. which in the case of the indoor men takes the form of a midday duty of three hours' duration, as compared with the letter-carrying branch with two hours for a like offence. This has been the practice up to the end of 1895; we believe it is intended to effect a change, making us work up time lost. With that mode of punishment we could agree, as it would be but fair to the Department, but time lost on Sundays, with consequent loss of extra pay to us, we should not be asked to work up. We may mention that late attendance on such days also count against our annual increment, good conduct badges, etc., aud we contend a change should be made in this rule. We are in accord with the letter-carrying postmen generally in their request for the abolition of Christmas boxes, and ask that an allowance similar to that already granted to indoor postmen should be conceded to the parcel post deliverers, who, you are aware, are not allowed to solicit Christmas gratuities. Regarding those men, we do not believe it is within your know- 
ledge that a system prevails here of allowing them time off instead of payment for overtime, and taking into consideration their present scanty wage, which is not added to by an allowance of any kind from the Depariment, and seldom from the public, we ask that they be paid for their work As showing the severe nature of our work generally, we may mention that a letter-carrier who came to this depot, although granted the allowance for indoor duty, found it necessary to apply for transfer back to the lettercarrying branch. The majority of the men here are only deterred from making similar application by their sense of what is due to their own selfrespect, as they desire to have no connection with the system of privileged begging at Christmas time. The postmen in this depot who were employed exclnsively on parcel post duties should have been in receipt of the Treasury grant of $5 \mathrm{~s}$. per week from the time they took up duty in the parcel depos as established postmen. Although in a number of cases they replaced men who had this allowance, they did not receive it until a lengthened period had elapsed, and then only when they had petitioned the Postmaster-General in 1890. The Department has certainly deprived these men of the money they should have been receiving whilst doing parcel post duty, and they now ask that the matter be taken into consideration with a view to their being compensated, as they believe the Treasury grant dated from the introduction of the Parcel Post in 1893. In conclusion, we would ask a careful consideration of all the facts we have mentioned, and whatever revision may be the outcome of your honourable Committee, we expect it to be for the benefit of the public, the Department, and the men. Now, I have to submit the case of the sub-office established class. I beg to present the case of the postmen employed at Dundrum, Malahide, and Howth sub-offices (under Dublin), and Botterstown. These localities are fashionable suburban and seaside resorts, and consequently the cost of living and house rents are high, while the duties performed are very arduous and trying, often extending over a period of 13 hours per day, while the maximum wage in Dundrum and Malahide for the established class is $24 \mathrm{~s}$. per week, which is considered inadequate for a man to keep his family and live in decency and comfort. At Howth Office the wage is a fixed one of 20 s. per week for established class, the duties requiring two attendances daily, viz., from 7 a.m. to 11.15 a.m., and from 2 p.m. to 6 p.m.

Mr. Walpole: Do you say the wages are fixed at $20 \mathrm{~s}$. a week?

A. Yes, sir.

Q. I think you must be wrong?

A. Well, $I$ am informed it is so.

Q. Is it on the established class?

A. So I am informed by Postman P. Connell.

Q. He must be wrong.

A. Possibly. In summer time the duty occupies 9 hours per day, in consequence of the increase of correspondence in this district, and in addition to the collection and delivery of letters, the parcel post, weighing about 2 cwt., has to be wheeled on a truck from railway station up a steep hill, akout half-a-mile in length, without any help, by one man, P. Connell, and afterwards the number of parcels taken out by him with the ordinary delivery of letters are from 7 to 15 , some of which often weigh $11 \mathrm{lbs}$. weight, and complains that he is often bent to the ground after traversing a distance of nearly 10 miles with those heavy parcels before his delivery is completed, as two walks are merged into one, on second delivery, and also, that there is an allowance of $3 \mathrm{~s}$. per week for station service, and $2 \mathrm{~s}$. per week for collections which he does not receive, and the remuneration received for alternative Sunday duty is 11d.

Mr. Walpole : Do you complain of the allowance of $3 \mathrm{~s}$. a week?

A. It is an error in the punctuation ; the statement is not mine. He states that it is allowed, but that he does not receive it. 
Mr. Walpole: That is very Irish, certainly.

Witness : It is allowed but the man does not receive it; that is, he does not get it though it is allowed for the duty.

Q. Why does he not get it?

A. I do not know. He says it is allowed for the duty, but he does not get it. A certain sum is allowed, but it does not get into the hands of the men.

Mr. Walpole: Quite so.

Mr. Smith: You suggest it has stuck somewhere on the way. Is that your point?

A. Yes; that is quite right. The duty performed in Dundrum and Malahide sub-offices are eyually arduous, and the number of attendances required to perform the duties, as arranged, are four and five daily, spread over 13 and 14 hours per day, and we claim that, as the work is identical, and in every way as important, performed by the postmen in all the suboffices of Dublin, they should be placed on the same scale of pay as G.P.O. and district offices, as they occupy a similar position to the zone system in London, and have on an average as large an amount of correspondence to deal with as the men in the city. We also contend that there should be a uniform scale of pay for all established postmen in city and County Dublin, commencing with a minimum of $24 \mathrm{~s}$. per week, and a maximum of $40 \mathrm{~s}$., rising by an annual increment of $2 \mathrm{~s}$. per week. I would also wish to point out that in some offices no medical attendance is provided for either the established or auxiliary class, and they are obliged, consequently, in case of illness, to provide such at their own expense, or seek relief from the local poor law dispensary of their district, notwithstanding the advantages the Department claims they derive through this item. They also in most cases have to dispose of the parcel post entirely, without any regard to weight, as long as they would be able to carry them. This is due to the fact of the local authority working on lines of strict economy. I also beg to draw attention to the case of the auxiliary postmen of sub-offices. The salaries, though small, would appear to them on entering the Service to be a fair remuneration for the time required of them by the Department, along with the inducement held out to them of being put on the established class at a later period, and naturally they are led to believe that their position will be equal eventually to other working men in the district. But after spending nine or ten years as auxiliary, and arriving at years of maturity and manhood, they often find themselves in the same position and receiving the same wages as they did on entering the Service, and their prospects of being placed on the established class as far off as ever, thereby causing discontent and disappointment, having forfeited the time they could have applied to learning a trade or other business, by remaining in the Service. Auxiliary postmen in sub-offices have not even the advantage of supplementing their scanty wages as their brethren in the city, by making collections at night, performing extra duties that arise casually, for which they receive payment in addition to their usual wages. Although not working an eight-hour day, the number of attendances in the day required in most cases would entirely exclude them from obtaining other employment, even if such was to be had, and in this respect they have suffered gross injustice, by the Department calculating that their spare time is devoted to other employment, which is not the case as a general rule. Also, that the system of auxiliary labour is encouraged by the Department rather than diminished in County Dublin, even in cases where an eight-hour day has been worked, and application made for appointment, the hours of duty have been reduced, so as to nullify all claim to be placed on the established class. They have also to work every alternate Sunday without receiving any extra payment, although in some cases between three and four hours are worked by them on Sunday, requiring two attendances, including morning delivery and evening collection. 
Mr. Walpole: Have you any instance of a man's full-time duties having been reduced?

A. Yes; I have an instance here, and I believe a Federation witness mentioned a case. The case I have is that of James Pratt, who, when an auxiliary, applied for an appointment, but instead of getting it had some of his duties taken off, and his wages reduced to 16s. His duties were:-

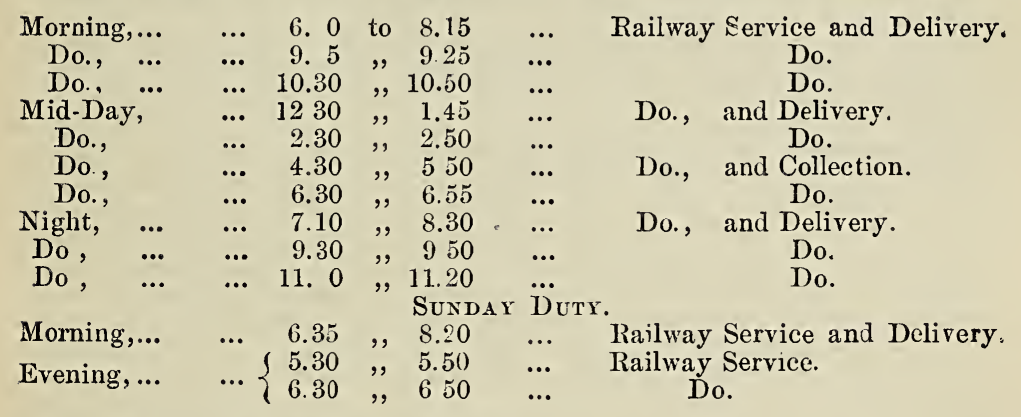

Mr. Walpole : How long ago was this?

A. Eleven years ago. But it is a case in point, as showing the Department does reduce the hours when application is made for appointment on the establishment. This man lost 1s. $6 \mathrm{~d}$. on his wages. This concludes the case I have to put forward.

The Chairman : Thank you. We will now adjourn until Thursday.

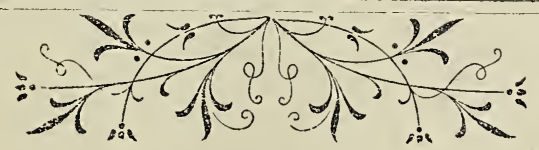


JASPER C. BADCOCK, LsQ.

Rebuting the Case put forward on benate ce the London Men.

Westminster, 19th March, 1896.

Mr. Jasper C. Badcock, Chief Controller of the London Postal Service, was then called on behalf of the Department to give the official reply to the case put forward by the Jondon postmen. He was examined as follows :-

The Chairman : Has this case of Roberts been brought under your notice?

A. No, it has not; but while Mr. Churchfield was giving evidence I sent an express letter to the N.W. District in order to obtain particulars. I should just like to inention the case of another witness-I will not give names-which was brought under my notice from a certain district for an irregularity committed, and to explain that in returning it to the Postmaster, I specially requested him, in the case of any witnesses, or anybody who supplied information to this Committee, to treat ordinary lapses of duty rather more leniently if possible than in the case of a man who had not given evidence, so that there might be no cause for alleging intimidation. That was the instruction to the Postmaster, and I hope I shall be able to afford an equally satisfactory explanation of what bas occurred in the case of Roberts.

Q. Your general instruction to your subordinates with regard to witnesses coming before this Committee has been that they are to have free and full opportunity of stating exactly what they wish?

A. Just so.

Q. And you would not sanction any sort of hindrance being put in their wiy of doing so, or any results occurring to them on account of the evidi nce being brought before the Committee?

A. Certainly not.

Q. Whether that evidence was absolutely true or false, or whatever it was, your view would be that every man had a perfect right to say absolutely and fully what he likes here, leaving it to the Committee to judge what credence shall be put in the statements that he lays before us?

A. Certainly; and I think it is proved by the instruction I gave to the Postmaster in the case I referred to just now.

Q. Now, I think the most convenient way will be for me to ask you some general questions about the men under your charge, and then run through the evidence and take up particular cases afterwards. I should like first to ask you how many postmen have you under your charge in London?

A. I cannot say exactly; I think about 4,500.

Q. And in what classes are they divided?

A. Of classes there are none now; in saying 4,500 I was only referring to established postmen.

Q. You have certain other classes, I think; you have a number of head postmen, have you not, and you have established postmen, supernumeraries, and auxiliaries?

A. Yes; there are 124 head postmen. I find the total nurnber of established postmen is 5,314 . Would you like to have them divided into zones? Q. If you please.

A. There are 3,049 town postmen; 784 postmen in Zone $1 ; 1,243$ in Zone 2; 217 in Zone 3 ; and 11 in Zone 4.

Mr. Walpole: These figures do not make up 3,049?

A. No; the 3,049 are town postmen. There are 277 auxiliary postmen in the town districts, and 2,204 suburban auxiliary postmen.

Mr. Smith : They are not divided into zones?

A. No; the rate of pay is the same throughout. 
The Chairman: What about the supernumeraries?

A. The supernumeraries stand against established vacancies, so that they would be included in the number of postmen in the different zones. There are 91 supernumeraries standing against the town postmen vacancies, but the 91 are included in the 3,049. There are 9 in Zone 1,13 in Zone 2, 7 in Zone 3.

Q. Now, will you give us the mode of appointment of these various men?

A. The mode of appointment of all established men is the same. They are generally telegraph messengers. They have to pass a qualifying examination consisting of writing tolerably a few lines, reading MS., and simple and compound addition. The telegraph messengers have the first claim on the appointments, the next claim is on the part of auxiliary postmen who entered the Service before the army scheme of employment was introducedsomewhere about 1892-and under this scheme men from the reserve who are auxiliary postmen have the next claim.

Q. What rules have you with regard to the limits of age?

A. The limits of age of postmen are from 18 to 30 , with an extension to 45 for a man who has been in the army.

Q. I should like to ask you for some information with regard to telegraph messengers. How are they appointed? How do you clioose them?

A. A boy makes application, and his home is visited with a view to seeing whether his parents are respectable, and so on: He has to furnish the ordinary references as to character, and then when a vacancy occurs he is appointed if everything is favourable.

Sir F. Mowatt: Is there no examination?

A. No; but it is a condition that he shall have passed the 5th Standard at a Board School.

The Clairman: What certainty is there that a telegraph messenger, if he conducts himself properly. will in due course receive an appointment as a postman?

A. Up to the present very few of the telegraph messengers have been got rid of at the age of 18 or 19, because we have been able to appoint. them all as postmen or sorters. The old plan was to appoint sorters from telegraph messengers, but since the institution of open competition the sorters' vacancies are not enough to go round. There has not been very milch inconvenience up to the present, but I am afraid in the coming time that we shall not be able to provide nearly so well for the boys as we have done in the past.

Q. Then it will be the case that, after employing these boys for three or four years, you will turn them adrift?

A. Yes, at the age of 19 ; the limits of age of entry are from 13 to 15.

Mr. Sinith: Are there a certain number of sorters' appointments reserved for them?

A. Yes; one-fourth are reserved for the telegraph messengers for limited competition amongst selected boys of exceptionally good character; a fourth of the vacancies are also reserved for limited competition amongst postmen. The remaining half are filled up by open competition.

Q. You say that the telegraph messengers have the first chance?

A. Yes, for every vacancy.

Q. And whether he is over age he has first claim in proportion to the number of vacancies reserved for his class?

A. Yes ; that is so.

Sir F. Mowatt: May we take it that it is possible in the future that all the appointments will go to the telegraph messenger boys who have the first claim, and that there are not enough to meet outside claims? Will they have exhausted all the appointments?

A. Yes, that is so; and even then we shall not be able to provide for the whole of the boys. I may mention that there is a weeding-out process carried on at the age of 16 , and if at that age the record of a telegraph messenger is not fully satisfactory we get rid of him then in preference 
to doing so at the age of 18 . We do so because he has a better chance of getting other employment at the earlier age.

Mr. Smith : How many are weeded out? Have you the figures?

A. I have not here, but I can supply them.

Mr. Smith : It would be rather interesting to have them.

The Chairman: They had better be obtained and put in later on.

Mr. Smith: How many telegraph messengers are there in London of all ages?

A. Nearly 3,000.

Q. How many come in the course of a year?

A. I will get those figures and supply them.

The Chairman: How'many vacancies have you in the ranks of postmen during the course of a year?

A. I cannot say.

Q. I only mean on the average?

A. I will get the figures for you, my lord. Generally speaking the postmen are promoted to one-fourth of the vacancies amongst sorters, and a fcurth is reserved for telegraph messengers. Of course if a postman is promoted to a sortership that makes a vacancy for a postman.

The Chairman: What I really want to know is what proportion of openings filled by telegraph messengers is to the number that becomes vacant?

Mr. Walpole: Therefore you must include the sorters' vacancies competed for by telegraph messengers.

The Chairman: I want to arrive exactly at what the position and chances of the telegraph messengers are, and whether, provided they behave themselves properly, they are practically certain of continuous employment in the Post Office?

A. I understand.

Q. I understand from what you have told us that in the future there will be no room for any old soldiers among the postmen?

A. I am afraid not; that is to say, among the established postmen. There will be room in the auxiliary class.

Q. Then, following that up, how are the auxiliaries appointed? In what classes?

A. From ordinary applications from people who have some other occupation, and who apply to be taken on as auxiliary postmen to give them work part of the day.

Q. And you insist upon auxiliary postmen having other work?

A. In London, yes, provided their wages are less than $18 \mathrm{~s}$. a week.

$\mathrm{Q}$. The auxiliary postmen are less in number than they used to be?

A. Yes.

Q. Do you believe that every auxiliary postman has another trade?

A. Yes; he has another trade or another means of occupation, but whether he always gets work at it I cannot say. I may mention that all the vacancies for auxiliary postmanships are offered in the first place to the Agent-General for Recruiting, in order that they may be filled up by army men if possible. It is only failing a supply of army men that we appoint an outsider.

Q. And in regard to army men, do you still insist on the same conditions as to other employment, or are you satisfied with the fact of their having a pension?

A. Well, they generally have reserve pay or pension.

$\mathrm{Q}$. And do you consider that sufficient to count as other employment?

A. Yes.

Mr. Walpole : If it makes up to 18s. a week, I suppose?

A. Yes.

Mr. Smith: You do not ever appoint telegraph messengers as auxiliaries in Fondon. as we understand it is done in the provinces? 
A. Yes; when there is a prospect of there being any established vacancy, then they are appointed, but if there is no such prospect we do not.

Q. Is that done to any large extent in London?

A. Yes.

Q. And do the telegraph men get the same wages as an established postman?

A. Yes.

Q. Would they form a large proportion of the auxiliaries?

A. No.

Mr. Walpole: It would be rather a small proportion, would it not?

A. I think it would; I can supply the exact figures.

Q. Would it be possible to extend that proportion very largely, and to recruit the auxiliary class from the telegraph messengers?

A. No, I am afraid not; because there would not be a sufficient flow to take them out of the auxiliary class, and if you did so appoint them you would have boys for years doing only purt time work, and so being a drag upon their parents.

Mr. Smith : You are speaking of the future when you say you think there wili not be enough places for telegraph messengers. At present there are enough, you say?

A. No; that is our difficulty now.

Q. Have you arrived at that already?

A. Yes. If we were to put them in the auxiliary class it would be to our interest on their having arrived at the age of 18 to get them into the established class as quickly as possible.

Mr. Walpole: Would it not be a great advantage to a telegraph boy to be on comparatively short duties in his first years as postman, and not to have to do a full eight-hours' duty? Could you not pass him through the auxiliary class so as to do that?

A. I rather think not. I think a boy of 18 wants a full day's work or else he gets into mischief. (Laughter.)

Q. Do you think he is strong enough for a full eight-hour duty in London?

A. Yes; I think so.

Q. And that is your opinion?

A. Yes.

Sir F. Mowatt: Does that include early morning work?

A. The postmen have not very early work. They usually come on at 5 a.m.

Q. Nothing before that?

A. No ; besides that, where there is an all-night duty it is done indoors.

Q. Would that be done by an auxiliary?

A. No.

The Chairman: Now let us come to the case of the supernumeraries.

A. Yes. In former years, after the establishment of the Parcel Post, there were a certain number of unestablished men who were called supernumeraries, and it was decided in $\mathbf{1 8 9 0}$ to abolish that class altogether. The supernumerary men are the men who were on that old class employed on full time, and who cannot be placed on the establishment either for a medical reason or age limit, or educational defect.

Q. It is a class, then, which in a comparatively short time will die out?

A. Yes, it is a redundant class ; in fact, for every supernumerary man now at work we have an established place against which he stands, and as he drops out that established place will be filled up.

Q. It has been suggested to us more than once that these telegraph messengers are employed as reliefs for absent postmen. Is that so?

A. That is so.

Q. On what terms do you employ them?

A. A boy is not employed under $17 \frac{1}{2}$ on postman's duty, but between $17 \frac{1}{2}$ and 18 ; he is then paid 17s. a week; if he is 18 or above he is paid the minimum postman's wage of 18s. per week. 
Q. Have you many of these boys so employed as a rule?

A. Yes ; a fair number.

Q. And then do they go back to their position of telegraph messengers when the occasion for their employment ceases?

A. Yes ; they go back to their work.

Q. And to their own pay, although they have been receiving a higher rate of pay?

A. Yes.

Mr. Walpole: Would there be many cases in which they go back to their usual employment? You see they are not put on this work until $17 \frac{1}{2}$ ?

A. Yes; they are only brought out to work a sick man's duty or to assist in a time of pressure.

Q. A time of pressure like Christinas, do you mean?

A. Yes; they are brought at a time of pressure like Christmas, but then they are not supposed to do a postman's full duty; they are merely assisting, and they are not paid at the full rate; they are paid 12s. a week, with bonus.

Q. Besides the literary examination, have you a medical examination for postmen?

A. Yes.

Q. Not for every class in it?

A. No.

Q. Not for the auxiliary class?

A. No.

Q. But the established postman has to pass a medical examination?

A. Yes.

Q. What is it?

A. I am afraid I can hardly say that.

Q. I do not want you to explain what the medical man does, but I want to know the rules, and how often a man has to go before the medical officer?

A. He has to go before him on being nominated for appointment as established postman; he has to go again at the end of six months, and again at the end of 22 months, with a view to the appointment being confirmed.

Q. Do you look upon that two years' probation as a purely medical probation, or do you look upon it as a conduct probation?

A. We also look upon it as a conduct probation.

Q. As a matter of fact, how many men are rejected at the end of six months? Are there many?

A. No.

Q. On medical grounds?

A. I think not.

Q. Do you have a great many rejections at the first examination?

A. Yes ; a great many.

Q. What sort of proportion would the number be of those rejected to those examined?

A. I am afraid I cannot say. I do not see the nomination cases until the men have passed through the hands of the medical officer.

Q. Has an auxiliary, before becoming an established postman, to undergo the same medical examination?

A. Yes.

Q. And to pass through the same period of probation?

A. Yes.

Q. In spite of the fact that he may have been employed a considerable number of years by the Department?

A. Yes; but he would only be on part time work.

Q. Do vou think it is necessary to have two years' probation in the case of that man-in the case of a man who has been a long time in the employment of the Department? 
A. I should think it was not so necessary as in the case of a man brought fresh to the work.

Q. You are well aware what the man's conduct has been?

A. Certainly.

Q. Do you find you get the supply of men that you require? You have not any lack of applications for postmanships generally?

A. Oh, no; we have more than we can satisfy.

Q. Now, with regard to the quality of the men coming in, do you think it keeps up to the standard, or have you any reason to be dissatisfied with the quality of the men you get as postmen? I mean, is the raw material such as you would wish to have?

A. Yes; I think so on the whole, since we have taken to weeding out the unsatisfactory telegraph messengers.

Q. But when you speak of weeding out, are these messengers not subject to dismissal at any time?

A. Yes.

Q. They are not on the establishment, are they?

A. No.

Q. Then in addition to the periodical weeding out there is the power of dismissal which the Postmaster has?

A. Yes ; there is constant weeding out going on, and if a boy does not turn out quite satisfactory we get rid of him.

Q. You mean that if a boy mirconducts himself frequently he is dismissed at discretion?

A. Yes; but at 16 we revise the boy's service and see if he is likely to make a satisfactory servant or not; if not we get rid of him.

Q. In that way you ought to have a considerable knowledge of the greater part of the men or boys who are passed into the postmen's class?

A. Yes.

Mr. Walpole: And in those cases you would be content with a shorter probation than two years?

A. I think not as regards the medical examination, because at the age when a man is appointed a postman his constitution is changing, and one does not know what may occur.

Q. Now, will you give us the pay of postmen?

A. Yes; for head postmen the scale of wages is $23 \mathrm{~s}$., rising by $1 \mathrm{~s} .6 \mathrm{~d}$. to $38 \mathrm{~s}$. Every postman commences at a minimum of $18 \mathrm{~s}$, rising by an increment of 1s. to 34s. for town postmen, 32s. for Zone 1, 30s. for Zone 2, 26s. for Zone 3 , and $24 \mathrm{~s}$. for Zone 4 . Zone 4 is made up of the outlying. districts, such as Manor Park, Chingford, and Woodford. They are semirural districts, in fact.

Q. Do you think that the present amount of increment is a fair one, or do you think that the time a man takes to reach his maximum is too long?

A. I think the time he takes to reach his maximum is too long, and that the increment ought to be increased. (Hear, hear.)

Q. I should like to ask you what your own opinion is with regard to the maximum and minimum rate of pay at present in force among the town postmen?

A. The question of the minimum rate of pay is rather a general one, and would depend on the rate of pay for adult labour generally. There is no reas on why the postman's minimum rate of pay should be higher than the sorter's minimum rate of wages.

Mr. Smith : Are not their ages different?

A. No.

Q. Is the average arge at which they come in the same?

A. Yes; about the same. As regards the maximum, I certainly think that there is room for an increase. (Hear, hear.)

Q. You would bo inclined to put thege postnen very müch on the footing of ?ind clags gorters? 
A. I think so. I think their duties are equal in importance, and if any. thing the postmen's duties are more arduous than those of 2nd class sorters; they have more split attendances.

Q. What are the sorters' scale of wages?

A. $18 \mathrm{~s}$. by $1 \mathrm{~s}$. to $20 \mathrm{~s}$., and then by $2 \mathrm{~s}$. to $40 \mathrm{~s}$.

Sir F. Mowatt: You are speaking of the town postmen now?

A. Yes.

Q. As distinct from zone postmen?

A. Yes.

The Chairman: Now, there is another question I should like to ask you, and it is this-Do you think there is a difference in the work and responsibility of postmen in the different parts of London such as to warrant the great differences in the maximum which are found between those of town postmen and those of the postmen in the various zones?

A. I think not quite; but there should be a difference for the different zones. That would be quite justifiable, as the men who live in the higher class districts have considerable difficulty in securing suitable lodgings close to their work, and some allowance should be made for the travelling expenses they have to incur.

Q. Then the difference I understand you to put it is in the amount the man would have to pay for rent and travelling, rather than in the nature of the duties?

A. Certainly.

Q. But would you be in favour of maintaining the zone system in its integrity, by having as many different zones as at present?

A. I think so. I believe the number is right, but whether there might not be some adjustment necessary in some cases I am not prepared to say.

Mr. Smith: I see there are hardly any established postmen in Zone 4; is that because it is so very small?

A. Yes, it is a very small one; it only consists of Manor Park, South Woodford, and Chingford; they are really places built out of provincial offices. Manor Park was part of the Ilford delivery.

Mr. Smith: Is it possible to distribute these 2,204 auxiliaries over the different zones. It would be interesting to see where they are placed.

A. I will supply the particulars, certainly. I have not here the distribution for the different zones.

The Chairman: You have told us what you thought should be the scale for town postmen, but you have not told us what you suggest with regard to the zone postmen. Have you thought of that?

A. I think their scale should be adjusted to a corresponding extent.

Mr. Walpole: You would increase the maximum of the town postman 6s., would you not?

A. I have not gone quite so far as that.

Q. Well, would you say 3s.?

A. I said that I would put them somewhat on the same scale as 2nd class sorters ; I have not committed myself to any definite amount.

The Chairman: I rather understood you to say that you thought the duties of the postmen in the various zones were practically identical with those of the town postmen, but that their expenses were less, and that therefore the ratio of their maximum should be settled by a consideration of what their expenses are?

A. Yes ; and that is the principle on which the present condition of things is based.

Q. You say the duties of postmen are identical?

A. I do not think I can go quite so far as that. There are certain differences, but there are also compensating differences. For instance, the work of the postman in one zone would be more important than the corresponding work of a man in a town district, whilst certain of the work of the men in the town district would be more important than the work of the men in the zone. 
Q. Still, if you put all the men on an equality with regard to the necessaries of life, then you say they ought to be paid on an equal footing?

A. Yes, that is so; and as illustrating the difference, I may mention that one day last week I was in the S. Kensington Office, and I looked through the address book there to see where the men employed in that office lived. I found that a great number of them lived at Fulham, a large workingclass neighbourhood having sprung up there, and houses having been built which are let to two families, and that kind of thing. Now, the life of a man in the S. Kensington Office who lives at Fulham and has to go backwards and forwards three times a day is harder than that of the Fulham postman whose work lies at his own door, so to speak.

Q. Then, besides the question of pay and regular increment, the postmen have a further advantage in the shape of good conduct stripes?

A. Yes.

Q. At present there are three-one for every 5 years' service-provided the man has a good record?

A. That is so.

Q. Would you be in favour of an extension of this system? I mean does it not seem a little bit hard on a man who goes on to 20,25 , and 30 years not to get any increase of his stripes?

A. I think so.

Q. Would it be your view that so long as a man is a postman and remains in the postman's class he should get a stripe for every 5 years' satisfactory service?

A. Well, a man serving 40 years as a postman would be all stripes! (Laughter.) Still, I think the principle is right.

Sir F. Mowatt: But what is more important than that, is that it would be all shillings. (Renewed laughter.)

A. That is the Treasury point of view. The difficulty of too many stripes could be got over by some other device.

The Chairman: It would not be a very probable thing that a man who had served 30 years and had been of good conduct all that time, so as to secure all the stripes due to him, would remain a postman, would it?

A. I do not know that. There are a good many worthy postmen who would not be fit for any higher position.

Q. I understand you to say your view would be that some extension of the stripe system might well be adopted?

A. I think so.

Q. Then besides the stripes there is the uniform. I do not think that from the London postmen we have had any complaint with regard to the uniform itself; I do not remember to have heard any complaints with regard to the quality of the uniform supplied?

A. No, not in regard to the quality ; the complaints have been more in regard to the fit; the uniform is made too tight for the men to wear comfortably.

Mr. Walpole: You are aware that a Departmental Committee sat upon that subject and recommended that the uniform should be made looser?

A. Yes.

Q. Do you happen to know whether the new uniforms are more comfortable?

A. I have not heard; I have not had any complaints, but I am not quite sure that the recommendation of the Committee came in time for the making of last winter's uniform. My own impression is that it did not.

The Chairman: What is the amount of uniform given-I do not mean the value, but how often do the men get uniforms?

A. They get two suits a year.

Q. One thick suit and one thin suit?

A. Yes; and then they get a greatcoat.

Q. How often?

A. Every two years. 
Q. And a cape?

A. I think every three years.

Mr. Walpole: I fancy it is every two years.

The Chairman: Do you have any complaints in London with regard to the quality of the waterproof capes?

A. Not recently; there were many complaints in former years, but I have not seen any since the new pattern was introduced three or four years ago.

Q. What is your rule with regard to boot allowance for established postmen?

A. The boot allowance is a guinea a year.

Q. Now, besides these various emoluments, are there any allowances given to london postmen?

A. No; the only allowance is where a man is acting as head postman; he gets 3s. a week for supervision.

$Q$. And that is the only special allowance given to postmen?

A. Yes.

Q. Have you formed any opinion as to the possibility of prohibiting Christmas boxes?

A. Of course it is possible to prohibit them, but I have not formed any opinion as to whether the prohibition would be effective.

Q. When I say the possibility of enforcing a prohibition of Cliristmas koxes, I mean a prohibition of solicitation?

A. Yes; but whether that would not be evaded to a very great extent 1 am not sure.

Mr. Walpole: Do you mean that the solicitation would be evaded?

A. Yes, I am afraid so; there are many ways of asking for Christmas boxes without actually soliciting them. I do not think that a railway ticket collector asks for one, but he becomes uncommonly civil just before Christmas. (Laughter.)

The Chairman: What proportion of the sorting work do the London postmen perform?

A. rhat would differ at the different offices or zones. As a rule the town postman sorts the collection which he brings in; he also performs the London district sorting, and picks ont the provincial, Irish, Scotch, and foreign letters ; in some cases he will sort for the railway divisions.

Mr. Walpole: You mean that the town postman sorts the letters he brings in, and does, in fact, the primary sorting?

A. Yes; he does the primary sorting. For instance, in the W.C. District the postman bringing in a collection would sort the railway divisions; he would take out the letters for the N. Western, Midland, Great Northern, the Great Eastern, the South Eastern, and the South Western, etc.; he would also pick out the foreign, the Irish, the Scotch, the Liverpool, Manchester, Birmingham, Brighton, Londor district and suburban district, and he might also take some other large towns, such as Dublin. Hastings, etc. ; in addition to that he does his own walk-sorting for his own delivery.

Q. What is done with letters coming into the office?

A. In the W.C. District Office they are divided by the postmen to the respective walks, and arranged for delivery by them.

Q. Then a great deal of the postman's work is admirable training for a sortership?

A. Yes; for the simpler forms of sorting work.

Mr. Walpole: They do the primary sorting of the letters they collect; they sort for the London district, and do their own walk-sorting?

A. Yes; they do three branches of sorting.

Sir F. Mowatt: In fact, a complete sorting of the Londion letters?

Mr. Walpole: They do the sorting for districts?

A. Yes, they do the sorting for districts; but then they are thken to the despatching sorter, who examinas thom to sed that they ate will whe befor they ase despatohed. 
Mr. Walpole: But I wish specially to refer to the provincial sortingthe sorting for railway divisions.

A. I should like to supplement what I have said about the postmen in zones. You understand that a torn postman does no actual despatching work, but in the suburban offices in the different zones the case is quite different. There the postmen deal with all the letters, and all the despatches that are made from the office by the postmen themselves. I will take a specimen office. At South Kensington, in Zone 1, the postmen stamp the correspondence collected throughout the day, sort for all London postal districts and railway divisions, select letters, etc., for local delivery, and for despatch in direct bye-bags to the following adjacent offices:-Chelsea, Earl's Court, Fulham, West Brompton, Hammersmith, Kensington, Paddington, and West Kensington. Now I will take an office in Zone 2. There the postmen stamp all the correspondence collected throughout the day, sort for all London postal districts and railway divisions, select letters for local delivery and for despatch in direct bye-bags to the following adjacent offices :-Brixton, Clapham, South Lambeth, Camberwell, and Peckham. Clapham is much the same; they send direct bye-bags to Balham, Brixton, South Lambeth, Stockwell, Mitcham, and Sutton. Coming to an office in Zone 3, the postmen stamp all the correspondence collected throughout the day, select letters, etc., for local delivery, and letters out of two collections are also selected for despatch to the adjacent sub-districts. At Stratford letters for two collections are only sorted for the London postal districts and railway divisions; at other times they go unsorted to the district offices.

Mr. Walpole: When you say that the postmen at S. Kensington are doing a large amount of sorting work, is it done by the whole force of postmen stationed at Kensington, or by a selected force?

A. No; it is done by them indiscriminately. When you come to Zone 4 the men at Woodford just sort the letters for the district, and for London forward. These are specimens of the work done in all the London subdistrict offices, of which there are about 100.

The Chairman: And now as to the pay of the auxiliaries; what is it?

A. The rate of payment is $6 \mathrm{~d}$. per hour.

Mr. Walpole: Before we pass away from the sorting, I should like to ask you whether, as you get into the outer zone, the work of the postman is a little simpler than the work of the postmen in the inner zones?

A. It is a little simpler because there are not so many direct despatches.

Q. Quite so. The work of Zones 1 and 2 involves despatching duties which a town postman does not do. Is that so?

A. That is so.

Q. And in that respect they have a greater responsibility?

A. Yes; but on the other hand town postmen have other important duties, and so, more or less, the one thing is compensated for by another.

The Chairman : Now let us come to the question of auxiliary rates of pay.

A. Yes. The rate of pay for auxiliary postmen between 5 a.m. and 10 p.m. is $6 \mathrm{~d}$. per hour; between $10 \mathrm{p} . \mathrm{m}$. and midnight it is $8 \mathrm{~d}$. per hour, and from midnight till 5 a.m. it is $9 \mathrm{~d}$. per hour, and there is a limitation that no man who is brought on duty for a single collection shall be paid less than 6d., or for a single delivery less than 1s.

Q. Are most of the London auxiliaries pretty fully employed?

A. 'No; the rule is not to employ a man more than 5 hours a day.

Q. Are most of the auxiliaries employed as much as 5 hours per day?

A. No, by no means ; many are employed for only one delivery.

Q. The morning delivery?

A. Yes.

Q. Can you tell me how many in London are employed simply for the morning delivery out of the three thousand odd?

A. I have not the information with me, but I can put it in. 
Mr. Smith: Is it a rule not to employ auxiliaries over 5 hours a day? Surely some are so employed? We liave heard evidence to that effect.

A. That is a survival of the old system.

Q. They are not new duties then?

A. No; with the new duties we confine the work within the 5 hours per day, and if it is necessary to work a man more than 5 hours a day then it is made an establisled postman's duty.

Q. And then you would fill it up with other work?

A. Yes.

Q. Are these London auxiliary duties being done away with?

A. Yes, at the present time, and they would be done away with at once but for the hardship to the men who have been on them some years.

Mr. Walpole: But occasionally auxiliaries do more than 5 hours a day, do they not? Take Hampstead, for instance; there are a good many men there who are working 6 hours per day, are there not?

A. Yes, I dare say there were; but when we can find continuous work we ask for authority to employ full-time men, and at once make them established duties.

Mr. Walpole: Some interval necessarily takes place before you get the authority, does it not?

A. Not a very long one; it is generally given almost at once. Whenever we see our way to make a full-time duty without any great hardship to the men who have hitherto worked it we do so, and I can get authority for that in a couple of days.

Mr. Smith : I was going to ask whether it would be possible to reduce the number of lours still further, and make the maximum not 5 , but 4 or 3 .

A. No ; we reduce the number of auxiliaries as far as we can now, by appointing full-time men when we can possibly do so.

Q. You are gradually then reducing the maximum number of hours for which the auxiliaries are employed?

A. Not necessarily; it may be that we have to employ men on the first delivery in the morning and the last delivery at night, and those two duties occupy nearly 5 hours.

Q. Then in your opinion it is difficult to go beyond the reduction already made?

A. Yes, without having an established force, which would be wasted.

M. 11 alpuie: Would it be possible for these longer auxiliary duties to be done by telegraph messengers?

A. Yes ; but they would not get adult pay.

Q. Why not, if they were working 5 or 6 hours, would they not then get full pay?

A. Five hours would represent 15 s. per week.

The Cliairman: And is that not so much as he would receive as a telegraph messenger?

A. Oh, yes; 11s. is the maximum of a telegraph messenger's pay.

Sir F. Mowatt: What you mean is that it could be done and the pay would be 15s. per week, and that if a telegraph messenger were temporarily employed on these longer hours he would not get adult pay?

A. No ; because he would not be doing a full day's work.

Mr. Smith: Are these longer auxiliary duties of 5 or 6 hours which are still surviving at mostly bad hours of the day for lads? Are they very early or late hours?

A. I think they are not bad. We have endeavoured as much as possible to avoid employing the same men on the last delivery at night and the firšt delivery in the morning, but there are some cases in which it cannot bs avoided.

The Chairman: What is the pay of the supernumeraries?

A. The supernumeraries were paid 18s. per week in the old time, when they were supernumerary men, and then a scale was established giving them an increment of 1s. for two years, and now recently it has been ex- 
tended to 26s. This has not been done with, as was suggested, the object of taking the wind out of the sails of the witnesses on this point, but it was decided upon before the Committee was appointed.

Q. What advantage do you give the postmen with regard to holidays?

A. Each postman has a fortnight's holiday on full pay, and the holidays are confined within 36 weeks of the year; they are not taken in the winter months. I think they run into the last week in February and the first week in November, but they are practically confined to 8 months.

Mr. Walpole: Then the postal force of London is better off than the provincial force in regard to the season in which their holidays are taken?

A. I think so.

The Chairman: Then we have lad several complaints about the practice of working Bank Holidays. What is your practice with regard to Bank Holidays?

A. The practice as regards Bank Holidays is that if a man is employed for six hours he is granted a day's holiday at some other time, but if he is employed less than six hours he is paid at extra duty rates for the time he is actually employed, unless he himself wishes to have the time off instead.

Q. Do you think there is any objection to paying the men for work done on Bank Holidays, if you required their services on such days? Do you see any objection to giving them pay for it instead of time off afterwards?

A. Of course the man receives a day's pay under any circumstances.

Q. Do you wish to suggest the giving an additional day's pay?

A. It is a mere question of expense.

Sir F. Mowatt: Up to six hours he gets it now?

A. No; he gets time off for six hours.

Q. For six hours he gets it already?

A. Yes.

Q. And therefore it is merely a question of extending the system?

A. Yes.

Mr. Walpole: The intention of a Bank Holiday is to give a holiday, is it not?

A. I thought so.

Q. We have had complaints that where a day is given in lieu of Bank Holiday it is given at an inconvenient time. Is there any rule in London under which when a day is given the man is allowed a choice in any way?

A. No. I think he must take it when the opportunity comes.

Q. Do you give them any notice of the day?

A. I should think so.

Q. Do you not happen to know?

A. I do not. It would be a short notice in any case.

Mr. Walpole: Then it would not be very convenient to the man?

Mr. L. Smith: Would it not be possible to have a certain minimum notice given?

A. Of course it might be arranged that no man should have less than three days' notice. But it might not always be possible to give it.

Mr. Walpole: Can you go one better and say 10 days' notice? Are there any cases in which men are allowed to add the Bank Holiday to the end of their annual leave? Does that take place in London?

A. An order has just been issued that that may be done unless there is any reason to the contrary. But the general adoption of such a plan would very much interfere with leave duties, as a man might accumulate three or four Bank Holidays and take them in addition to his annual holiday. It would mean that additional provision must bo made to cover those days, as it would not be fair to postpone the holiday of the next man due to go.

The Chairman: At present the auxiliaries have no advantage in regard to stripes?

A. No, sir. 
Q. Do you see any objection to extending the stripe system to the auxiliary class? If you do, what is it?

A. No; I do not see any objection. The point to be considered is that an auxiliary only works part time.

Mr. Walpole: Would you extend it to auxiliaries making only one collection or delivery?

A. I do not see where you are going to draw a line if you extend it at all.

Q. Do you think that a man doing one delivery or collection would have the same claim to a stripe for 5 years' good conduct as an estublished man doing full duty?

A. As regards the good conduct stripe the payment might be adjusted according to the amount of duty.

Sir F. Mowatt: Would you say that where a man is employed on the full auxiliary time of 5 hours that that should count towards a stripe?

A. Yes; you might give him 9d. instead of 1s. a week. And a man doing one delivery or one collection might have $3 \mathrm{~d}$. or $4 \mathrm{~d}$. It might be adjusted in that way.

Mr. Smith: Of course you see a difficulty in confining the stripe to auxiliaries doing 5 hours, as it would bring great pressure from the men doing 3 or 4 hours to get their duties extended to 5 hours?

A. Yes; there would be the same objection to drawing any line between half-time and full-time.

Q. You are trying to avoid employing auxiliaries for 6 hours?

A. Yes. Now you have a definite line that no man not on full duty shall have a good conduct stripe. I do not see how you could draw any other line.

Sir F. Mowatt: You have a better knowledge of a man's conduct when he is in your employment all day than when you only employ him an hour in the morning or an hour or two late at night?

A. That is so; but then you have only a proportionately better knowledge of his conduct if he is employed 5 hours instead of 1 .

Q. The knowledge would not be so exhaustive, but still it is sufficient. I do not know that there is much difference between 5 hours and 8 hours?

A. Very often the man on the shortest time-on the first morning delivery-is more liable to make late attendances.

The Chairman: The next point is with regard to sick leave-absence on account of sickness. What are your definite rules on that subject?

A. The postmen, like all other officers in the Service, are granted sick leave on full pay for six months, and half-pay beyond that time.

Q. What requirement have they to satisfy before you grant sick leave?

A. A medical certificate has to be sent in immediately a man is absent. $\mathrm{He}$ has to give notice of his inability to do duty, and the medical officer of the Department countersigns the certificate if there is no reason for suspicion?

Q. Has the original certificate to be obtained from the medical officer in charge of the Department, or may a man get it from a private practitioner?

A. If he gets it from a private practitioner it has to be countersigned by the medical officer of the Department.

Q. Does the medical officer visit him at his own house, or must he put in an appearance at the office?

A. Very often he visits him at his own house, but the rule is that the man must come to see the doctor if he is able to do so.

Q. Do the same medical officers attend the postmen as attend the sorters?

A. Yes.

Q. And with regard to shorter indispositions, what do you do if a man is off duty for only a day or two?

A. He gets a certificate in the same way. We must cover every absence by a medical certificate. 
Q. And what advantages in the way of medical attendance do you give your men? Do they get free medical attendance?

A. Yes; free medical attendance.

Mr. Walpole: And free medicine?

A. Yes, of course.

Q. What are the hours of duty of established postmen?

A. Eight hours during the day: But that is necessarily split up into more or less frequent attendances.

Mr. L. Smith : Do you mean 8 hours' actual work?

A. Yes; not more than 8 hours.

Q. In the case of sorters, does it mean 8 hours' actual work?

A. Yes.

Q. In the same way-not including intervals?

A. No; if a man has continuous employment for eight hours he has one interval.

Q. That does not apply to postmen?

A. Well, a postman has an opportunity of getting a cup of tea or some. thing of that sort. He is not kept hard at it all the time.

Mr. Walpole: I suppose that when one duty begins a short time after the termination of another there is an interval which is counted part of the duty?

A. Certainly.

Q. He is not on the stretch the whole time?

A. No; any interval less than an hour would be counted part of the duty.

Sir F. Mowatt: Less than an hour?

A. Yes, less than an hour; but then, of course, the man would be expected to do any odd work that might turn up in the time.

The Chairman: Have you any case of a man who has an interval of as much as 45 minutes counted in his duty?

A. Yes.

Q. Counted in his 8 hours?

A. Yes.

Mr. Walpole: I think we have had some in evidence here?

A. Yes, that is so. Of course we don't let it occur if-

The Chairman: Oh, of course, I know you try to avoid it. (Laughter.)

A. If a postman is working on continuous work he has to wait for the letters to come down for delivery. He would then be doing nothing. Probably the first bags would be sorted off before the second lot arrive, and again the men would have an interval of five or ten minutes.

Q. Within what range do you endeavour to confine the London post. men's duties-within what range of hours?

A. The rule is to confine them within 12 hours, and we are working to that as quickly as we can. At the present time out of 5,221 established postmen we have 3,680 whose duties are confined within 12 hours, or 70 per cent of the total.

Mr. Walpole: Are you sure of the number?

A. Yes.

Q. I have it here- $-3,934$ ?

A. That includes the reserve. Between 12 and 13 hours there are 658 men; 13 and 14 hours, 415 men; 14 and 15 hours, 197 men; 15 and 16 hours, 134 men; and over 16 hours, 15 men. I should explain that as regards many of the attendances extending over 12 and under 14 hours there are two attendances only, and the men prefer such a duty as that to the more frequent attendances, which would confine it to 12 hours, as it affords them a longer break in the middle of the day.

Mx. Smith: I presume that the cases where the duty is spread over 16 hours the lintertal for gleep cectits in the middle of the day?

A. There are ouly 15 of them, $x$ eannot oxplain them: 
Q. When was this policy of reducing the number of hours for day duty to 12 adopted? 1891.

A. It was one of the recommendations of the Postmen's Committee in

Q. Do you find the operation of the rule makes it difficult to find full-time places for auxiliaries?

A. Certainly.

Q. And you think the rule creates obstacles? You could replace a number of auxiliaries by full-time men if it were not for the necessity of confining the duties within 12 hours?

A. That is so ; decidedly.

Q. I should like to ask your opinion as to the relative advantage of the two? Take the two alternatives-confine the duties to 12 hours, or convert more auxiliary duties into full-time duties-which would you prefer?

A. Officially, or in the interests of the men?

Q. Both.

A. I think the best arrangement is the one we are aiming at-to confine the duty to 12 hours.

Q. You think it would be more advantageous even if it leaves outside the established force a large number of auxiliaries?

A. I think so.

Q. Do you think it would lessen the benefit to the men if the period over which the 8 hours' attendance is spread were extended from 12 to 13 hours? I observe that 658 men work between 12 and 13 hours?

A. That is where we have just exceeded the 12 hours. I think that of those 658 men 450 men's duties are under $12 \frac{1}{4}$ hours.

Q. Then in order to materially reduce the number of auxiliaries you would have to spread the hours of duty over 14 or 15 hours?

A. 15 hours; and not only that, the men would have to make more frequent attendances.

Mr. Smith : I see.

The Chairman: Do you think that the weight of split duties falls as heavily on the postmen as on the sorters?

A. I should think it is about the same. The sorters have only two attendances at most, but the time over which the day's work is spread is longer. The postmen's duties are more frequent, but they are confined to shorter hours.

Mr. Walpole: There is nothing among the postmen's duties so serious as the early and late attendances of the sorters?

'A. I am afraid we have still some unrevised attendances, but these will be wiped out as opportunity offers.

The Chairman: I take it that on the whole the postmen have not got to attend as early as the sorters? What have you to say to that?

A. If anything the postmen have not. In the chief office the sorters have to attend at 4 o'clock, while the postmen do not go in till 5. I beg your pardon; in the E.C.D.O. the postmen go on at 4 as well.

Mr. Walpole: But the postmen who go on at 4 o'clock in the E.C.D.O. do not work after 8 o'clock at night?

A. No.

Q. Then the sorters' position is distinctly worse than the postmen's?

A. Yes ; but against that the postman may have to go on at 4 o'clock in the morning, and may have to do a day attendance, which the sorter has not. So he would have three attendances against the sorter's two.

The Chairman: What allowance do you give in respect of night duties?

A. To postmen?

Q. Yes.

A. A certain number of postmen are employed inside the office at night, and they get 7 hours' attendance against 8 . That is the only allowance.

Q. Do you make a proportionate allowance when it is not a full duty? 
A. Only when the duty is continuous.

Q. What are the hours you count as night duties, and in respect of which you make this allowance of one-eighth?

A. I think the only continuous attendances for postmen are from 10 to 5 or from midnight till 7 a.m.

Q. That is not what I mean. Supposing a man does two or three hours in the night between 10 and 5, would that count for the allowance of oneelghth!?

A. I think no allowance is made for a broken duty of that kind.

Q. Don't you give a proportionate allowance for hours in the night?

A. Not as a rule; but when a postman's duties are revised 8 hours is not fully worked up to.

Q. In the sorters' case do you give that allowance?

A. Yes, that is so; but even then we are entitled to the full 8 hours for split duties. It is only on the sorters' night duty - a continuous one-that the allowance is made.

Q. Is it from 10 to 5 ? Is that the range of hours considered to be night duty?

A. Yes.

Mr. Walpole: Is it not the rule that you do not make any reduction for night duty unless it exceeds 2 hours?

A. No; I do not think there is any rule to that effect.

The Chairman: What facilities do you give postmen who wish to exchange duties among themselves-if a man wants to get off for any reason? If he has a friend who will take it do youl allow that?

A. The man has to provide an approved substitute-a man who is perfectly competent to do the work. He has to get the approval of the secondclass overseer in the sorting office or the inspector, as the case may be. The superintending officer has discretion to allow it three times in the month, but beyond that number he has to refer the matter to his superior officer. The instruction is that it should always be allowed where satisfactory reasons are shown.

Q. Are many such applications made?

A. Oh, yes!

Mr. Smith: Who are the substitutes?

A. They may be auxiliaries or established postmen.

Mr. Walpole : It is usually another postman, is it not?

A. Yes.

The Chairman: The most frequent cause of complaint is on account of late attendances, I fancy, is it not? Thle most frequent fault found with the men is that they do not attend at the right time?

A. No; I do not think that the attendance is so very much worse.

Q. I do not want to put it in that way. But are not more faults found with late attendances than with any other kind of irregularities?

A. I think not.

Q. What are the most common irregularities that you complain of?

A. The mis-delivery of letters.

Q. You are speaking now of the postmen?

A. Yes. Then there is loitering, and sometimes, though not very frequently, a violation of the rule which lays it down that no postman should go into a public-house during his delivery. Then there is the omission to properly endorse letters when the addressees have gone away, and to note removals, etc. Sometimes, too, a man will not follow his delivery on the prescribed route. There are various little things like tliat.

Q. What is your system of punishment for these irregularities?

A. The man is called upon to explain, and if he does not give a satisfactory explanation he is reprimanded. It is only when the offence is frequent that there is punishment by extra duty or in the shape of suspension of pay. 
Q. Have you any system of fines for irregularities?

A. No. Except so far as a suspension of pay for a day might be called a system of fines.

Q. Then you do suspend pay for a day or more?

A. Yes; when the offence is a bad one.

Sir F. Mowatt: And do you suspend the work at the same time?

A. No. (Laughter.)

Q. Then that is a fine.

A. It is very seldom resorted to.

Mr. Walpole: You very seldom suspend except the offence is serious?

A. Just so. I have a case here of a man demanding a Christmas box in the S.E. District, and I am afraid delaying correspondence because he did not get one. I propose that that man's pay shall be suspended for two days to mark the gravity of the offence. It is a serious offence, for which punishment should be inflicted. There is a system of inflicting extra duty without pay as punishment.

The Chairman: And besides what that involves, there is following it as a consequence of the punishment a probable loss of stripe?

A. Yes; a loss of a stripe already granted.

Q. That is not exactly what I was referring to. I was rather thinking of the grant of the next stripe being deferred?

Mr. Walpole: I presume that a stripe already granted cannot be taken away without the authority of the P.M.G.?

A. No.

Q. And that would only be done in the case of a very serious offence?

A. Yes ; the same applies to a suspension of pay.

The Chairman: What number of irregularities would involve the nongranting of a stripe?

A. The rule is that a man shall have practically a clean record for 5 years. He would be judged both by the number of his late attendances and the other irregularities which are recorded against him.

Mr. Smith: Must the clean record be for the 5 previous years, or might it be 4 good years, then a bad one and then a good one?

A. No; he must have a fairly clean record for the previous 5 years.

The Chairman: Who records the various irregularities?

A. One of the clerks in the P.O. or in the sub-controller's office.

Q. In the first instance, who takes note of them-the head office, or the particular office to which the man is attached?

A. If a man is reported for an irregularity he is called upon to explain, and if necessary reprimanded or cautioned, and the matter, of course, is entered in the conduct record.

Q. But who reports him in the first place?

A. It may be a public complaint, or it may be a street inspector or officer.

Q. Have you a system of street inspectors-men going about the streets watching the postmen?

A. Yes; amongst other duties they do that.

Q. Are they in uniform?

A. No. (Laughter.) I have a case here-I will not mention names-of a man riding on a mail van-that is against the rules; smoking on duty, postcard not properly endorsed, mis-delivery of letters, gossiping in a public-house while on delivery, insolent conduct to one of the public, improperly endorsing a letter not known although addressed to a numbered court, etc.

Q. Is that all against one man?

A. Yes.

Mr. Walpole: Over what period does that spread?

A. Tour years.

Q. Would that involve a loss of atripe?

A. Yes; that is a case in points 
Q. Has that stripe been suspended?

A. It is being suspended.

Q. It is not a case of a stripe being taken away?

Mr. Walpole: No; a stripe would not be taken away when once granted except for a more serious offence, would it?

A. No. Taking away a stripe is regarded as a punishment, while not granting it is a matter of reprimand. That is the distinction we draw.

Mr. Smith : Do the auxiliaries get any holidays?

A. No, sir; except a few of them who are doing full-time duty.

Q. Do you see any reason why they should be treated differently in point of holidays from the others?

A. The only difference is that which applies to the question of the good conduct stripe-you must regulate it according to a man's amount of duty.

Q. Why so? If a man works 4 hours a day you would be letting him have a fortnight off of 4 hours a day. It would regulate itself in that way.

A. Yes; that is so.

The Chairman: What is your experience of the result of the establishment of the Parcel Post so far as the men are concerned?

A. In what way, sir?

Q. Have you found that the men take great objection to Parcel Post work?

A. There is a certain amount of dissatisfaction at having to deliver parcels with letters, but I am bound to say that I think it is a merely sentimental grievance. Many of these small parcels which are now taken out by postmen were, before the Parcel Post was established, sent by letter post or book post. The public now send them by Parcel Post because the rates are cheaper. But it involves extra work for the postmen, because time is allowed for the delivery of these parcels, and if the time were not taken up in that way the walks would be extended. The men would have to give the same time to the delivery of letters.

Q. In London is it rare among the men under you to have to deliver bulky parcels?

A. Certainly; no man takes out a bulky parcel with letters. The rule is that he should not take out more than 5, and the weight of these is not to exceed $11 \mathrm{lbs}$. He would not take out any bulky or inconvenient parcel which would hamper him in the delivery of letters.

Q. Have you any rule with regard to the total weight a man is to taks out in London?

A. Of both parcels and letters? Well, that would depend upon how far the man had to carry the lot. For instance, a postman starting from the G.P.O. with a delivery for Paternoster Row would take out almost as much as he could carry. But a man who had to go some distance before he commenced to deliver would be given some allowance for it.

Q. Do you frequently give assistance to postmen?

A. Oh, yes ; in the City offices there is a reserve of 30 or 40 men ready to give assistance on the first morning delivery.

Q. Are they generally called upon?

A. Not to the full extent. I should mention that in the E.C. District a good many postmen decline to ask for assistance when they might fairly ask for it. They seem to prefer to do their work in their own way. I will give the numbers. On the 2nd March (Monday) there were 55 bag carriers supplied. Monday is often a heavy morning. On the next morning there were 6. On the fifth, when there was an American mail, there were 18; on the next, when also there was an American mail, there were 21; on the Saturday morning, the 7th, there were 19 assistants; on the ninth (a Monday) there were 41 ; on the 16th there were 61 for bagcarrying alone, besides 113 assistants for the delivery of registered letters.

Q. When you go into the more remote parts of London does the same rule prevail there?

A. The question never arises. The lads there never come up to $35 \mathrm{lbs}$. 
Q. I was not thinking so much about the total load, but about the difference about parcels?

A. Oh, yes; where there are parcels even in the sub-districts to interfere with the due delivery of letters or to incommode the postmen, a special delivery of parcels would take place, and they would be kept back for the purpose.

Q. I take it your view is that there is no ground for complaint as to the delivery of parcels?

A. I think not.

Mr. Walpole : In London?

A. Yes, in London. Evidence was given on that point. I do not know whether you would like me to take that now?

The Chairman: Is it a particular case? I would rather leave that when we come to deal with those cases.

A. One of the witnesses said he had to take out 5 parcels every morning.

Q. Was that the experience of Mr. Boaler?

A. Yes. He said he had to take out 5 parcels with every morning walk, and that caused delay. I was rather struck by that evidence, and I got the number of parcels that were taken out on his walk for the three mornings he was relieved in order to come here. Take the month of February. During that month only once did he have 5 parcels, three times there were 4, six times there were 3 , eight times there were 2 , and six times there were 1 , while once there was no parcel at all. He complained that the delivery of parcels caused him to finish his delivery later than the recognised time of finishing the delivery. The recognised time in a town district is 8.45 , and this witness finished at 8.35 once, 14 times at $8.40,6$ times at 8.45 , and once only did he exceed that limit, when he finished at 8.50. On the three days that he was relieved from duty in order that he might attend here a substitute who did not know the work was employed in his place, and that substitute on each occasion finished earlier than he himself did any morning in that month. Then he said also that there were a good many parcels brought back. I find that the parcels taken out on the first delivery in the N.W. Town District in that month numbered 3,942, or an average of 154 a morning, and as there were 70 postmen to deliver that gives an average of rather more than 2 a beat for each postman. The number brought back during the month, or returned because no answer could be obtained because the house was not open was only 24-that is, 1 in 265 or something of that sort, or less than one each among the 70 postmen.

Q. Do you often find that the correspondence and letters are damaged by the breaking of boxes containing perishable articles?

A. No; there is no experience of that sort. It may occasionally happen, but a postman has no right to take out a bulky parcel or one that he has reason to think might damage the correspondence. $\mathrm{He}$ would be quite within his duty in handing that up to the superintending officer for special delivery.

Q. Yंou do not get any complaints from the public on that subject?

A. No, sir.

Sir F. Mowatt: But boxes containing flowers, etc., are sometimes smashed?

A. Yes, because they are generally packed in such flimsy boxes. I think the fault will generally be found in the packing rather than in the treatment of the boxes.

Q. Are the general conditions of service of the parcels postman the same as those of a letter-carrier?

A. Yes.

Q. And are the advantages of all sorts similar?

A. Yes ; except as to the solicitation of Christmas boxes.

Q. There is a rule specially applied to them. Why was it made in their case? 
A. When the Parce? Post was established, and it is to a certain extent the same now, the limils for the parcels delivery were not the same as for the letter delivery. The parcels were delivered from a separate office, and the delivery was extended over a greater area, and it was thought that the public would resent being importuned by two postmen for Christmas boxes, while there might be endless disputes as to one man having got what was intended for another.

Mr. Walpole: And it was thought also that it was undesirable to extend a system which was not desirable in itself, I presume?

A. Yes, that is so. The fear was it would double the demand.

The Chairman: What prospect of promotion has the London postman?

A. I have a note here of the actual promotions of postmen during the three years ended the 31st December, 1895, when the average force of town postmen was 2,863. There was one 1st class overseership, one 2nd class, 17 lobby officers, 4 messengers, and 2 head postmen. Among the suburban postmen, who numbered 2.090, there was 1 lobby officer and 6 head postmen. Besides this, 160 town postmen and 8 suburban postmen were made 2nd class sorters during the three years, after a limited competitive examination.

Mr. Walpole : 'A definite number of sorters' places are kept open for them?

A. Yes; one-fourth of the vacancies. Of course, you will understand that it is the juniors who generally get these, so it is hardly promotion.

The Chairman: Is it not worth the while of a senior to take such a position?

A. No

Mr. Walpole: But still it is an opening for the more intelligent junior men?

A. Yes.

The Chairman: And yet you think the duties of a postman are equal in importance to those of a sorter?

A. Yes ; a 2nd class sorter.

Q. Therefore it would not really be an opening for the more intelligent men, but an opening for everybody who was capable of performing a postman's duty?

Mr. Walpole: It would be for the more intelligent because they have to pass a competitive examination.

A. And they would be young men who have only just left school.

The Chairman: A postman has not, as a matter of fact, got a very great chance of getting out of his own rank?

A. He has not.

Q. What is your view of the effects of the employment of a postman on his general health?

A. I do not think that a postman suffers more from sickness than any other class of P.O. officials. It may be he has a little more rheumatism, but I think the average sickness is much about the same as every other class. It is slightly higher, I think.

Mr. Smith: About the system of sick pay to the auxiliaries-do they have no pay when sick?

A. Not as a rule.

Q. Would it not be possible to have a proportionate sick payment in their case?

A. In exceptional cases we give them two-thirds sick pay.

Q. What kind of case constitutes an exceptional case?

A. Well, an auxiliary who is broken down and is laid up and has nothing to live on.

Q. That would be treated quite as a special case?

A. Yes.

Q. And rather as a compassionate allowance?

A. Yes. 
Q. It is merely a question of cost whether he should have it?

A. Yes ; that is so, sir.

Q. You do not see any difficulty in the way otherwise?

A. No, sir.

Q. Of course a man in ordinary employment might run the risk and be more liable to sickness?

A. Yes.

Mr. Smith : Of course he might contract a sickness which might be attributable to his other employment, and then he would want to be paid by the P.O.?

A. Yes, sir.

The Chairman: I wanted to ask you the reason of taking Woolwich out of the London district?

A. That is rather ancient history. (Laughter.)

Q. But still a complaint has been raised. It is a typical case.

A. There are other suburban districts which possibly might be included within the London zone and are not.

Mr. Walpole: It was not taken out alone?

A. No; other places were taken out?

Q. Woolwich, Croydon. Sutton, and Mitcham?

A. Yes. I think the fact was that the area of London had become too large for one control.

The Chairman: It was not a question of the difference in the work? But the effect of taking these districts out of London management was to reduce the rate of wages paid to the postmen?

A. Yes; but at the same time the sorting work, which is done by London postmen is done at Woolwich by sorting clerks, who are paid more highly for it than is paid for the same work to London postmen. It is not a loss to Woolwich, although it may be to the postmen.

Mr. Walpole: The postmen at Woolwich are not doing such high-class work as the London postmen?

A. Quite so.

Sir F. Mowatt: Did the change affect the men who were serving at the time the change was made?

A. No.

Mr. Smith: What is the maximum of the Woolwich postmen?

The Chairman: $17 \mathrm{~s}$. by $1 \mathrm{~s}$. to $28 \mathrm{~s}$. The postmen in adjacent London districts begin at 18s. and have a higher maximum. The real object then, Mr. Badcock, was to relieve the London office of work which was growing too much for it?

A. Yes.

Mr. Walpole: I presume that the work in London does not grow lighter?

A. Certainly not.

Q. Do you think we ought to avoid anything to increase the work?

A. I think so.

Mr. Smith: Is it a fact that North Woolwich is within the London postal district, and there the maximum is $36 \mathrm{~s}$.?

A. North Woolwich is a different district to Woolwiclı itself in the way of rents, etc.

Sir F. Mowatt: I should like to take you back and ask you a single question in order that we may be quite clear as to the meaning of an answer you have already given, namely, the answer in which you said, I think, that the duties of town postmen were as important and as responsible as those of 2nd class sorters?

A. Yes.

Q. Do you mean that you think the entire advantages of the one class should equal the advantages of the other. or were you speaking only with reference to the scale of salary received by each, for, of course, the town postman has stripes and boot money, etc., which the sorter has not? The point I wanted to get at was whether we should understand the effect of your 
recommendation to be that the combined advantages of all sorts of the one class should be equal to the combined advantages of the other class, and that you were not speaking merely of the rate of wage paid to each?

A. As regards the boot question, I think the advantage is rather on the side of the sorter; I don't think that the guinea a year which is given to the postman quite compensates him for the excessive use and wear of shoe leather due to his calling, so I think that question might be left out of account, but I should certainly not propose the full scale of $40 \mathrm{~s}$. with stripes.

Q. Speaking generally, you thought that the total advantages of the one class sliould be about equivalent to the total advantages of the other class?

A. That is so, having regard to the boot allowance being peculiar to the postmen.

Mr. Walpole: The 2nd class sorter gets a blouse. I suppose the uniform would represent something like 1s. a week to the postmen, whereas it would be a little less in the case of the blouse for the sorter?

A. It would; but I think the blouse sufficiently protects the 2nd class sorters' private clothes, so that there is not much difference on that score. The postman would only use his uniform when he was on duty, and therefore he would probably have as much use for his own personal clothing as the 2nd class sorter would have.

Q. Do you suppose that a postman only wears his uniform when he is en duty?

A. I find that all the postmen witnesses here attended in mufti.

The Chairman: Now we will run through the evidence. If I pass any point you wish to remark upon just stop me. There are two or three little points upon which I understand you can give some evidence with regard to memorials as to sanitation of some of the offices?

A. There are two offices mentioned-Sydenhain and Anerley-where the w.c. accommodation is somewhat defective; in both these cases arrangements are now being made to build new offices: the Sydenham office was one which we were obliged to rent; it was the best we could get at the time, but ground has been acquired, and other arrangements are being made for a. new office there. At Anerley the present office is provided by the town sub-postmen, and there also we have acquired a site and are about to build a new office. Something was said about the office at Maida Hill, which was inconveniently situated on the first floor of a mews, but there also a new office has been provided, and it was actually occupied last Monday.

Mr. Walpole: That is a fine office?

A. Yes; a very nice office indeed. In all the new offices they are building the sanitary arrangements are of the most perfect description, as they are not built as temporary stop-gaps, but so that they may last many years.

The Chairman: I think some evidence was given with regard to the offices at Notting Hill, West Brompton, and South Kensington?

A. At Notting Hill the men lived so close to the office that the kitchen in that office is very little made use of, and at West Brompton the case is somewhat similar. With regard to South Kensington, we have acquired a new site in Queen's Gate on which to build a new office. Concerning the case of Holloway Sorting Office there was some swamping and flushing on account of some defective drain in the street, but that occurred also in other places in the immediate neighbourhood, and not only in the Post Office. I should say that this question of sanitary accommodation in the offices has been taken up very promptly of late years, and very great improvements have been made. The offices now being provided are quite adequate for the work, and liave all proper sanitary conveniences and improvements up to date.

The Ohairman: Mr. Churchfield in his evidence laid great stress on the number of registered letters that London postmen have to deal with. It seems to me he speaks of a very large number? 
A. I think it is also repeated by Mr. Herbert in the last day's evidence, but the statement that the postmen have hundreds of registered letters is quite an exaggeration; whe 1 there is a large number to deliver they are sent out specially, and in such a case the postman who takes them has no other letters to deliver. The statement was, I think, that postmen sometimes had as many as a hundred registered letters to deliver in addition to their ordinary mail matter. I find that the number of registered letters for the first delivery in the City is about 2,700, and there are 332 postmen employed in the delivery, so that it would work out at an average of about 8 per man.

Mr. Walpole: I suppose the number would be very unevenly distribute!?

A. Certainly, that would be so.

Q. A man might have as many as 30 registered letters in some walks, I presume?

A. Yes ; but where a man had so many as 30 , many of them would be what we call listed-that is, entered in a list and tied up in one bundle os one delivery, so that he could not treat them as separate registered lettens. I have a statement of a day's delivery of registered letters and the number of men on each walk. The highest number is in the Lothbury walk, where there were 146 registered letters divided amongst five postmen.

Q. That would bring up the average in that case to about 30 each per man?

The Chairman: But might they not be rather unevenly distributed in the walk?

A. No; they are pretty evenly distributed in such a walk, but in Bartholomew Square there were only 4 registered letters amongst 4 men delivering, whilst in Bunhill Fields there was only 1 registered letter amongst 4 men delivering. (Laughter.)

Q. I think the same witness (Mr. Churchfield) drew a comparison between the wages of park-keepers and postmen. Have you looked into that at all?

A. Yes; at the time the announcement was made as to the minimum wage of $24 \mathrm{~s}$. a week to men employed at the parks, I got information from the Office of Works as to what that really meant, and I was told that the announcement applied to labourers and not to park-keepers. The memorandum which I got from the Office of Works is as follows :-

\section{WAGES OF LABOURERS.}

"Hitherto these labourers (some 400) have been paid from $3 \mathrm{~s}$. to $3 \mathrm{~s}$. 9d. or $4 \mathrm{~s}$. per day, according to their skill. There have been a few paid from $2 \mathrm{~s}$. to $4 \mathrm{~s}$. per week more as gangers, and about 8 foremen paid from $30 \mathrm{~s}$. to $53 \mathrm{~s}$. per week. There has been no regular increment for labourers, and no scale of pay, and no limits of age. Labourers have no right to pension. If invalided after 15 years' continuous service a gratuity is granted of one week's pay for each year of service (under S. 4 of Super. Act, 1887). The daily hours are those of ordinary horticultural and gardening establishments (more than 8 hours certainly), the Saturday half-holiday, the Bank Holidays, and two days extra annually are given.

Sick pay is allowed as follows:-Under 1 year's service, nil; over 1 and under 10 years' service, half-pay; and over 10 years' service, threefourths pay.

The work done is the rough and unskilled work of the parks, e.g., digging, wheeling, road-mending. These men are constantly coming and going. It has just been decided that the minimum pay in future shall be $4 \mathrm{~s}$. per day (24s. per week) in London, and 3s. 6d. per day in the suburban parks. This will practically be the maximum pay also. The other circumstances of the employment are unchanged. These men are, it will be seen, in a very different position from pensionable Post Office men on scales of pay." 
I find also that the pay of the park-keepers is very different. The following is the communication which I received from the Office of Works on that subject:-

\section{"PARK-KEEPERS (ENGLAND).}

1. The park-keepers in the Royal Parks under the Office of Works are chosen from ex-sergeants of the army, or of corresponding rank in the navy, under 45 years of age.

2. Their duties are to enforce the rules, under the Parks Regulation Act, and are also indicated in the annexed code of regulations. The hours vary with the season, being about 60 hours per week; but this is a rough estimate.

3. The emoluments are as follows:-

(a) Uniform.

(b) Lodges-for a small number only, however.

(c) Wages (leaving out of consideration a few men appointed by the Ranger of Hyde Park and Richmond Park).

(1) In Hyde Park, Kensington Gardens, and the St. James's and Green Parks, 26s. per week-increased from 24s. in 1889 on account of the greater expense of houses for these men.

(2) In the other parks $24 \mathrm{~s}$. per week. The wages of the Kew Garden park-keepers were increased from 20s. to $22 \mathrm{~s}$. in 1893, and then to 24s. in 1895. The Kew men are nonpensionable.

(d) Pensions-under the Superannuation Acts.

(4) Sick pay is granted, with free medical attendance, under the following conditions:- Under 1 year's service, nil; over 1 and under 10, half-pay; over 10, three-fourths pay-for a period not exceeding two months in any year.

5. Ordinary leave is as follows:- Six week days; one Sunday in four off duty, and in consideration of Sunday duty, one day's leave out of 28 working days; the Bank Holidays (or days in lieu).

6. There are in England 3 inspectors (at $£ 91$ per annum), 7 sergeants (4 at 27s., 3 at 30s. per week), promoted from the park-keepers; 97 parkkeepers."

Mr. Walpole: So that both as to duty and pay the position of a parkkeeper is inferior to that of a London postman?

A. Very much, I think.

The Chairman: Is there anything else you wish to say before we go on to the zone question?

A. Well, a question was asked whether many men failed at the end of their probation. I have got particulars of 590 postmen who have been appointed at the chief office since August, 1891, and only 7 were rejected on medical grounds at or near the end of the two years' probations. That is 1.18 per cent. 'The question was as to the permanency of service owing to two years' probation.

Q. A witness gave some instances of anomalies in the zone system, and i!lustrated his point by supposing that this Committee got into an omnibus drive on Brompton Road, where different wages might be paid for delivering letters on the two sides of the road, or at the end of the road, as compared with the beginning. He said that on one side the delivery was by a town postman with a maximum of $34 \mathrm{~s}$, , on the other side the postman's maximum was 32s., while in Fulham Road it was 30s.?

A. Yes; but these differences are due to the varying cost to the men of providing themselves with lodgings. In this particular case at the end of 
such a 1d. omnibus drive the passenger would be in the Fulham District, where the postman lives near his office, whereas he might start his 1d. drive from a town district, where men had to live nearly 3 or 4 miles from tlieir office.

Mr. Walpole: As a matter of fact, would not the men delivering on both sides of the Brompton Road be paid the same rate?

The Chairman: The witness said not.

Mr. Walpole: I have the map here, and I think it is so.

A. There might be some overlapping boundary.

Q. But, speaking broadly, they would be paid the same rate on both sides of the road?

A. Yes.

Q. Then it is not the case that the men might be paid 34s. on one side and on the other 32s. ?

A. Perhaps what the witness meant was that a delivery at No. 23 might be at one rate and at 25 at another rate. There might be inequalities in the numbering of the road ; that is, the odd numbers might not be exactly opposite the even numbers on the other side; in fact, I believe they are not. There may be something in that.

Mr. Llewellyn Smith: In any case. whether or not this happens, if you have zones you must have some point at which the line has to be drawn?

A. Yes; the line must be drawn somewhere.

Mr. Walpole: I was rather impressed with what you said as to the case of Notting Hill, which is in Zone 1. You said that there the men live close to the office?

A. Yes; that is the case. Notting Hill is a district that has, I think, gone down very much, and many of the large houses are now let in floors. Perhaps at the time when Notting Hill was included in Zone 1 there were reasons for that which do not exist now.

The Chairman: Have you anything to say with regard to the number of duties in the E.C. District, and also in the Hampstead Division?

A. As regards the E.C.' District, I should say that the existing plan of working the postmen's duties was based mainly upon proposals put forward by the men themselves as to what would be to them the most acceptable method of working. Their proposals were not adopted in their entirety, but an endeavour was made to work as closely as practicable on the lines they suggested. Instances were given in evidence where certain sections were stated to attend at the office at 5 a.m. and to continue, with some intermissions, till 7.30 or 8 p.m., covering a period of 15 hours, but I find on looking into the matter that the whole time actually worked by these sections is 7 hours a day. Another attendance mentioned is from 5 to $7.30 \mathrm{a} . \mathrm{m}$., and from 2.30 to 8 p.m., the whole time covered being 15 hours, but this is one of the cases where the men preferred two attendances, although extending over a longer time, to confining the day's work within a narrower compass with more frequent attendances.

Mr. Walpole: I should like to ask you on that point, do you think that this is a very objectionable duty from 5.30 to 7.30 , and from 2.30 to 8 ? It extends over 15 hours certainly, but it appears to me a duty that many men would like?

A. It gives a man the opportunity of doing something else in the middle of the day and also late in the evening, while still leaving him time for sleep. He would have considerable leisure.

Q. I was rather asking you with reference to Mr. Llewellyn Smith's question as to whether a 12 hours' limit could be always maintained?

A. It is only in the E.C. District, and perhaps in the W.C. District, that you could provide work for the men which would occupy the 8 hours in two attendances, but that would never apply in the suburban offices. Where it cannot be done I see no objection to extending two duties over 15 hours. 
Q. Where the work of postmen can be concentrated in two attendances you see no objection to extending it beyond the 12 hours-say to 14 or even 15 hours?

A. No; because there is sufficient interval between the two attendances to admit of rest or recreation. I should mention in regard to the illustration from Hampstead that the whole of the duties there are under revision, and a proposal is before the Treasury which, if sanctioned, will provide that 54 of established postmen will complete their day's work within 12 hours, 6 within 13 hours, and 17 within 14 hours, whilst only 4 will range beyond 14 hours. An illustration was also given as regards Kilburn, where

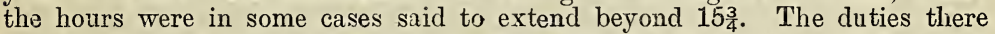
are also under revision; the proposals are well advanced, and if carried out as now arranged all the established postmen at Kilburn will have their work confined within 12 hours.

The Chairman: You are endeavouring to bring all within the 12 hours as far as possible?

A. That is so. There are 108 districts and sub-districts, and the difficulty is that all the revisions cannot be done at once; they all take time.

Q. Complaint has been made that an allowance that used to be made at Christmas or at times of exceptionally heavy work has been withdrawn?

A. I don't think that is the case. On one occasion, 4 or 5 years ago, when it was a very bitter winter, just at Christmas-time, when the snow was very deep on the ground, an arrangement was made that the men should be paid for protracted attendance at the extra duty rate, but that was quite an exceptional arrangement. It applied to the delivery on New Year's Eve and on New Year's morning, which were very protracted. That is always the case more or less. That has been met for many years by an additional allowance of $6 d$. where necessary to all men employed on these deliveries, and that is what was done last year, with the proviso that the 6d. was not to be paid where the duty was not protracted. An instance was quoted as regards Kentish Town, and I find that in that sub-district 21 men were on duty for the last delivery on New Year's Eve ; 6 completed their duty within the fixed time before 10, and the other 15 between 10 and 11 . With regard to the first delivery on New Year's Day, 33 men were employed. One finished within an hour after the appointed time, 9 within an hour-and-a-quarter, 8 within an hour-and-a-half, 9 within an hour-and-threequarters, and only six were more than that, but less than two hours late, so that there was no very serious prolongation as a whole.

Q. No man was more than 2 hours late?

A. No; although mention is made by witness of a case where a man was 3 hours late.

Q. Complaint was made, I think, by the same witness with regard to the delivery of circulars, which he thought a hardship. Do you often find that great stress is put on the men by the delivery of circulars?

A. No ; the delivery of circulars is part of the ordinary duty of the postmen, but where there is very great pressure of circular work a special delivery of the circulars ought to be made so as not to delay the postmen in the completion of his ordinary deliveries. That rule, so far as I know, is always acted upon, but it is unreasonable to expect that all circulars shall be excluded from the delivery.

Q. I understand the men have only to take a certain proportion of circulars, and that when there is really an overwhelming proportion of them an extra man is put on the work?

Mr. Walpole : A postman has in ordinary course to take an average proportion of circulars, but when there is an exceptional quantity you assist him?

$$
\text { A. Yes. }
$$

Sir F. Mowatt: Do I understand that when he has to deal with an extra quantity he has a paid assistant?

A. No: they are sent out by another man by a special delivery. 
Q. Does the man have an additional delivery-one for letters and the other for circulars?

A. The same man may come back in time to get them, or another man may be put on to do it.

Mr. Walpole: If he did, it would be done within his 8 hours' duty, or else he would be paid extra for it?

A. Yes ; certainly he would be paid for it.

The Chairman: One of the witnesses on behalf of the auxiliaries (Mr. Wilson) pressed very much for the abolition of auxiliaries altogether, and thought the whole work should be done by established men?

A. Everything that can be done to create a full day's duty is done, but the number of men employed on the first delivery in the morning, and on the last in the evening, is so very much greater than those employed at other parts of the day that it is necessary to employ part-time men. Take. for instance, the case of Hampstead itself, of which Mr. Wilson was speaking. On the first delivery 72 men are engaged, on the 2 nd 17, on the 3rd 20, on the 4th 19 , on the 5 th 18 , on the 6 th 22 , and on the last 52 , so that it is impossible to spread the attendances of these men equally over the whole day and have full-time men on all the deliveries.

Mr. Llewellyn Smith: How long do the auxiliaries work at Hampstead? Are they chiefly 5-hours' men?

A. I have not that information at hand at the moment.

Mr. Walpole: At present there is a large force of auxiliaries at Hampstead whom we are trying to get rid of to a great extent.

A. That is so. The present numbers at Hampstead are 42 established men and 76 auxiliaries, but under the proposal we have made the number of auxiliaries would be reduced to 52 , and the number of established men increased from 42 to 55 .

Mr. Llewellyn Smith: Could you tell in regard to the 52 auxiliaries left whether they would be employed chiefly on single deliveries or would they have two deliveries?

A. I think perhaps on two deliveries.

Sir F. Mowatt: Morning and evening?

A. Not necessarily.

Mr. Walpole: They would be employed three or four hours a day on the average?

A. Yes.

Q. The 76 auxiliaries were employed considerably more than that time?

A. Yes.

Mr. Llewellyn Smith: So that by the revision you reduce not only the number of your auxiliaries but the average duration of their duty?

At this stage Mr. Wilson asked to be allowed to correct the witness.

The Chairman: No, no; you have had your turn. It is Mr. Badcock's now.

Mr. Wilson: Well, what he says conveys a very wrong impression of the real facts.

Witness (replying to Mr. Smith's question) : I should not like to say that, but I could put in a copy of the present and proposed working.

The Chairman: Even under your new scheme the proportion of auxiliaries to established men in that district is very great?

A. Yes; that is accounted for by the large number who have to be employed on the morning and night delivery.

Q. How is it you are able to dispense with a comparatively large number of the auxiliaries in the central part of London?

A. Because the collections and deliveries are so much more frequent. In the E.C. District, for instance, we have no auxiliary postmen, but during the busy part of the day there is a collection every half-hour, so that we can employ a large number in the first delivery and then work them for the rest of their time almost continuously in collection, besides which there 
is a large amount of indoor work, the correspondence brought in by the postmen being sorted by the postmen themselves. They can thus be employed usefully indoors.

Mr. Walpole: The greater number of collections and deliveries in the course of the day make it easier to employ full-time men?

A. Yes; that is so.

Q. Therefore the nearer you get to the centre of the town the easier it is to make full-time duties? Is that so?

A. Yes, that is so; assuming, of course, that the correspondence is equal in proportion.

Q. Mr. Wilson says that when he was appointed an auxiliary he had no recollection of signing a form?

A. Yes; but I have here the form which he signed on the 26th of March, 1879. It is as follows :-

"I, Henry Mark Wilson, having been appointed auxiliary letter-carrier at Fiampstead, with wages of 12s. 6d. a week, am fully aware that no advantage or payment other than these wages attaches to the appointment; that my services may be discontinued at any moment, and that, when discontinued, whether after a short or a long period, they will give no claim whatever to another appointment, compensation, gratuity, or pension; also that on leaving the Service I must return the official uniform supplied to me. In token that I fully understand, and agree to these terms of employment, I hereto set my name, and in doing so I do also declare that I have other means of subsistence than those to be derived from my appointment as auxiliary letter-carrier."

The Chairman: You had better hand that statement to Mr. Wilson. He may like to see it.

Q. When Mr. Wilson said he had signed no such paper as that his recollection was at fault?

A. I think so. But not only that, he also said that "is rather more explicit than was told me when I entered the Service. I had no such paper."

Mr. Llewellyn Smith: It was suggested to us that this was not a guarantee that the man had other employment, because although he might originally have had other employment and had fallen out of it, it was too much to expect that he should record that against himself, with the consequent prospect of losing his Post Office employment?

A. There is, no doubt, a good deal of temptation on that score, but the mere fact that a man was temporarily out of other employment would not be allowed to stand against him.

Q. Do you think, as a matter of fact, that the mere signing of that paper is any guarantee to the Post Office that the auxiliary really has any other employment?

A. I think it is to a certain extent.

Q. Can you see any other method of arriving at the same result?

A. Not unless by a more inquisitorial investigation.

Q. You do not think any other means than requiring such a declaration should be taken?

A. I think not.

The Chairman: Reference was made to the case of Joseph Noyes as one of considerable hardship?

A. It is a case of hardship, inasmuch as a part-time man when he becomes unfit for further service has no claim for pension or gratuity. This man was kept on until complaints were received from the public more than once of the inefficient way in which his duty was done, and, in the end, although he was kept on as long as possible, there was no alternative but to get rid of him. From the Controller the Postmaster was requested several times to keep him on and give him another chance, but the Postmaster at last reported that he was so infirm as to be absolutely incapable of discharging his duties. So we had to dispense with his services. 
Mr. Walpole: Then, in the Postmaster's opinion, the man was not a hale man for his age, or as capable as Mr. Wilson said he himself was for his work?

A. There is some conflict of opinion upon that point between Mr. Wilson and the Postmaster.

The Chairman: As a matter of fact, is a man retired at 50?

A. No.

Q. At 65 ?

A. Not even at 65 if he is able to do his duty.

Q. The 65 age rule is not applied to postmen?

A. No.

Sir F. Mowatt: Then you do not accept the statement that this man was told that he must retire because he was over 60 ?

A. Yes; he was told that under a misapprehension, but that misapprehension was at once corrected.

Q. But the witness stated that the reason given was simply that he was over 60 years of age.

A. The Postmaster, on the 7th July, 1891, reported that Noyes was over 60 years of age, and that, as he was not performing his duties in a satisfactory manner, his services must be dispensed with. On the 22nd July the Postmaster was told by the Controller, "I think we may continue Noyes' employment yet a little longer, notwithstanding his having reached the age of 60 . Let it make no difference as far as age is concerned." And so it went on, the Postmaster trying to get rid of him, and the Controller trying to keep him out of mercy, until it was reported that he was absolutely inefficient.

Sir F. Mowatt: Then take the case of Whickers. He, too, had to resign we are told?

A. Yes; but he was kept on till he was 76.

Mr. Walpole: Till he was 76 ?

A. I think so.

Q. He was an old pensioner when he began, was he not?

A. Yes. He was over 72 .

The Chairman: The witness Wilson also said that at Hampstead the army reserve men did not sign the paper you have quoted in his case?

A. I have here the papers signed by all the army reserve men employed at Hampstead.

Q. How many signed papers have you there?

A. Forty-two papers signed by 22 men.

Mr. Walpole: Some men have signed more than one paper?

A. Yes; when any change is made in their duty or pay they sign a fresh declaration.

Mr. Llewellyn Smith: It was said they had not signed these papers till 5 months ago, when the papers were sent round to them, but that inothing of the kind was signed by them when they entered the Service. Is it a fact that they were only signed 5 months ago?

A. The first of them came in April, 1892, and signed declaration on the 11th of that month. Others signed in November, 1894 (when their wages were altered from 15s. 9d. to 16s.), May, 1892, June, 1892, December, 1892, and October, 1892, etc.

Mr. Walpole: Then Mr. Wilson's evidence on that point was quite inaccurate?

A. Yes ; quite.

The Chairman: Reference was made to the case of a man who came into the Service as an anxiliary at $15 \mathrm{~s}$. per week, but was said to have been led to believe that at the end of 12 months he would receive an established appointment. Is that the fact?

A. Yes. The man, whose name is Kitchen, adheres to the statemeat th'it he was misled at the Army Recruiting Office, but he acknowledged that he was not misled in any way at the district post office. He asserts that 
he was told that he might obtain an established appointment in his orrer; but he found that the number of men in front of him was so large that his order was a long way off.

Mr. Walpole: So he had fair warning?

A. Yes.

Sir F. Mowatt: Before he joined?

A. Before he joined. He says he went to the district offise, and was told he would get his appointment in order of seniority. He understood that to be about a year, but I am satisfied that no such definite fromise was made, it being well known that there were a number if auriliaries waiting for appointment, as well as a number of telegraph mossengersi, so tha: it would not be at all likely for Kitchen to obtain añ appointiuent $f(r)$ a long time to come. He admitted that a few days after taking his appointment he saw from the great number of auxiliaries in front of him that it would not be possible for him to obtain an established appointment within a year, and then he did not think it worth while to write about the matter. He makes no complaint now, and is annoyed at his case being brought before the Committee.

Mr. Walpole: Was it not brought before the Committee with his authority?

A. It comes to this-he states that his grievance was "fished" for.

The Chairman: And now I come to the Hackiney case, where it whas stated that certain duties were performed, and that the men were not paid in respect of them.

A. That was entirely owing to a misunderstanding. I examined into the whole auxiliary duties at Hackney, and found that the proper rates were being paid. You will remember that when I was giving the rates of pay to auxiliary postmen, I said the rule was that they were to receive not less than 6d. for an isolated attendance for collection, and not less than 1s. for a delivery. The men employed on continuous work at Hampstead have construed that as a condition that they should be paid $6 \mathrm{~d}$. for each collection, and 1s. for each delivery insteal of on the time rate.

Mr. Walpole: In the case of a continuous collection extending over two or three hours, you will pay on the time rate?

A. Yes, that was the intention, and that was what was being done in every other district in London, including Hampstead, where, according to the witness, the auxiliaries were satisfied with their rates of pay.

The Chairman: Has this been explained to the Hackney men since the evidence was given?

A. Yes, and before. It is right I should say I believe that the witness Wilson gave this evidence in good faith, and that he was supplied with incorrect information.

Q. Now I' will come to the case of Powell and Waters. Have you anything to say about that?

A. I think the complaint in the case of Powell was that he got 15s. a week for auxiliary employment extending over the whole of the day, and that practically he had no time for making anything else. His hours of duty were as follows:- $\mathrm{He}$ makes a collection from $8.50 \mathrm{a} . \mathrm{m}$. to $9.40 \mathrm{a} . \mathrm{m}$., a delivery from $12.45 \mathrm{p} . \mathrm{m}$. to $2.45 \mathrm{p} . \mathrm{m}$., and another delivery from $4 \mathrm{p.m}$. till 6 p.m. He is thus on duty for a total of 4 hours 50 minutes per day.

The Chairman: Still the duties are very much scattered over the day; it does not give him any length of time to work outside.

A. That is so; but he has all the evening to himself, and if he pursues the trade of a waiter, or anything of that sort, he would be able to acceps emiployment.

Mr. Walpole : But your evidence practically confirms the evidence.

A. That is so. As regards Waters, it was stated that 9d. was given him for taking a bye-bag from St. John's Wood to Kilburn between every delivery. The witness stated that the Hampstead, Kilburn, and St. John's Divisions were so mixed up that it was practically impossible for each 
man in sorting always to know exactly where the respective divisions ended, and so that there might not be any delay in the correspondence, the man was paid 9d. per week for taking the bag backwards and forwards the whole week. Now, the facts of the case are that the conveyance of this bye-bag to Kilburn forms part of the man's regular duties. He has to do one duty from 6.40 to 7.40 , for which he gets $3 \mathrm{~s}$. a week, and he has two deliveries, for each of which he gets $6 \mathrm{~s}$. a week. He is occasionally employed to assist an overloaded postman, and that is where, perhaps, the $9 \mathrm{~d}$. per week comes in. His regular pay is $15 \mathrm{~s}$. per week.

The Chairman: Now, if a telegraph messenger is doing auxiliary duty as postman, is he required to sign one of these forms?

A. No; not if he is living at home with his parents.

Q. The witness also referred to the duties at the Northern District Office. Do you know anything of them?

A. The complaint there was, I think, that certain of the old auxiliaries had to take up mid-day work after the revision, and as they had something else to do, it broke into their time, and "these poor old auxiliaries "were told that, except they took this duty, they must go. They did go. Now, the revision took place rather more than six years ago, and the leading feature of it was the conversion of auxiliary into full-time established labour. A number of the auxiliary letter-carriers were put on full time on the established class. The number of auxiliaries was reduced from 47 to 24,23 being thus displaced, and of these 23, 17 were made established postmen, 2 were transferred to another district as auxiliaries, one declined nomination, and 3 resigned, because they could do nothing but evening duty. I expect these three are the "poor old auxiliaries": they were all of them under 30 years of age. (Laughter.)

Q. You do not know how they were employed in the day-time, do you?

A. No ; I have no information before me as to that.

Q. Wilson gave us his own hours, and said they were fully 8 hours.

A. He acknowledged that the actual hours of working were not fully 8 hours, but said that the rest of the time was occupied in going to and fro. The full allowance would be 45 minutes for a morning collection, and 25 minutes for an afternoon collection. His total attendances work out, I believe, at 7 hours and 35 minutes. It is hardly a full 8 hours, but still it is only a little under.

Mr. Walpole: Is that allowing the man time for walking to and fro?

A. Yes; it allows time for him having to commence duty at a distant point.

The Chairman: Now we come to the complaint that special duties are pressed upon the auxiliary men by the officer in charge, and that in consequence of having to attend at the offices for special duties a man has to set aside his private employment?

A. Yes; and a specific case was given. It was the case of a man named Alderman at Blackheath. The man was stated to be a waiter, and he had an opportunity of a job, by which he could earn 7s. 6d., in the middle of the day. Now, the rule is not to call upon auxiliary postmen to perform compulsorily any duty but the duty which he engages to do day by day. It is stated that owing to the General Election an order was sent down to Blackheath that no man-not merely the established men-but no man was to be let off on that day. I have copies of the circulars which were issued at that time, and I will read them. The first ran :- "It is of special importance that great care should be exercised in the disposal of election notices and polling cards, so that no delay may occur in their delivery. The postmen especially should be warned in the matter; any delays that may be caused through inattention or carelessness will be severely dealt with." The other one read as follows:- "Be good enough to note that election circulars should, as far as possible, be sent out with the regular deliveries. Each postman should take out a fair proportion, and every effort must be made to get the circulars and polling cards delivered as quickly as pos. 
sible. Large numbers of polling cards may shortly be posted, and it is essential that proper and ample arrangement should be made for their delivery." Now, these are the only circulars that were issued to Blackheath, so that there was no keeping the man on duty except for his regular work.

Mr. Walpole: Do you mean that no order was given that no man should be let off duty on that day?

A. No order was given to that effect. I have read the only orders we had, and they simply emphasised the necessity for the proper delivery of the election circulars. As regards Alderman, his regular duty is the morning delivery, a 5 o'clock collection, and a 6 o'clock collection. On the 13th July he provided a substitute for his 5 o'clock collection, changing duties with another postman who did the 9 o'clock collection. He paid another man to do his 6 o'clock duty. I am assured that there was no difficulty in dealing with the election work at Blackheath, and I am also told that Alderman's services were neither asked for nor required in connection with it.

Q. Is an auxiliary ever requested to do a duty against his will?

A. No; except the duty he engages to do day by day.

Q. He does no extra duty; he only does that which he has undertaken to do?

A. That is so.

Mr. Walpole: Then the whole of that case falls to the ground?

A. I think so.

Sir F. Mowatt: He explains that he was let off when he asked?

A. Yes; but before that he made out that he was compulsorily kept in, and that he had great difficulty in getting off.

Q. On examination, I think the witness felt that the case could not be maintained?

A. Yes.

Mr. L. Smith : One point made by the witness was not that he was compelled to stay on, but that the men generally found it a disadvantage if they declined to do so, because afterwards it was remembered against them. That was what he suggested.

A. Yes; but in this case the man was not requested to stop beyond his regular duty.

The Chairman: You have the same rule with regard to the intervals between duties for auxiliaries as for established postmen, have you not?

A. No; the rule is to allow a greater license to auxiliaries, for the reason that they have other reasons to be employed outside, and it is necessary that they should do so.

Q. Does an auxiliary get any allowance for boots?

A. No, sir. As regards an auxiliary providing a substitute, there is a guiding rule directing the overseers. It is necessary that auxiliaries should have occasional indulgence to a greater extent than established men, as it is recognised that they are partly dependent on services other than post office work.

Q. The witness suggested that the way to remedy matters was to increase the number of deliveries and collections at Hampstead, so as to be able to employ more full-time men. Do you think that would be possible?

A. I think that Hampstead is pretty well served now. There are seven deliveries a day, and fourteen collections, one of them being a Parcel Post one.

Q. The witness next came to the question of the remark of a medical officer to an auxiliary as to the probationary period, and he quoted a conversation which he said he had had with the medical officer, in which the question was put to him, "Are you on two years' probation?" His reply to that was in the affirmative, and he says that the medical officer then abserved, "I never heard such an absurd thing in all my life!" Have you inquired into that? 
A. Yes; I thought it was a strange thing for a medical officer to say, so I made inquiry on that, and the medical officer's reply is that the statement of Wilson is untrue. As it happened, it was his partner who saw the man Wilson, and he says he has no recollection of making any such remark as is ettributed to him. In fact, it was so unlike any expression he ever used that he could not understand how Wilson came to suggest that he had used it.

Sir F. Mowatt: In fact, he never heard such an absurd thing in all his life. (Laughter.)

The Chairman: Now we come to the cases of two men-Akerman and Hunt-who got into the army after being refused by the Departmental Medical Officer?

A. Yes; it is stated that they were refused by the medical officer at the end of two years' probation. 'That is not the case; they were both refused by the medical officer on nomination for appointments as established postmen; they did not serve as established postmen at all. The medical officer in this case is a retired army surgeon-major. He was not satisfied that one of them had not a lung defect, and he found that the other had varicose veins. They were neither of them rejected; the medical officer simply postponed giving a definite opinion for six months. One man resigwed voluntarily one month afterwards, and the other about four months later.

Q. They did go into the army afterwards?

A. Yes.

Mr. Walpole: But they had not been rejected by the Post Office medical $\operatorname{man}$ ?

A. Not actually rejected. I may mention that this medical officer, an old army man, expresses the opinion that in view of the pension, etc., granted to postmen, the examination should be more strict for the Post Office Service than for the army. All that he has to certify for in regard to an army man is that he is a man likely to last the time for which he has enlisted, but in the ease of the Civil Service he has to bear in mind the fact that the man may have to come on the pension list.

Sir F. Mowatt: When men are rejected by the medical officer, is the reason for the rejection given them, or are they merely told they are unfit?

A. The reason is not given to the men themselves.

The Chairman: I now come to the case of George William Emeny.

A. Yes; that also was a rejection on nomination, and not at the end of probation. The Departmental Medical Officer at Walthamstow reported that on examination he found considerable dullness at the apex of the right lung, and indication of old mischief. The man was examined later on by another medical man, who reported that there were no signs of activs distase, and that the lung condition had not extended. Then the man was examined by the Chief Medical Officer, who reported that Emeny was not fit to be an established postman. The man appealed, and forwarded the two certificates which were put in by the witness Wilson. The Chief Medical Officer again examined the man, and reported that he was unable to alter the opinion he arrived at on the previous occasion.

Mr. Walpole: In a case of that kind, the candidate would have a further appeal now, would he not?

A. Yes; if he chooses to exercise it.

Q. And he would be able to appeal to an independent medical man, not one of our own officers?

A. He may appeal to a man outside the Department, and I think for that purpose certain medical men are appointed by the Civil Service Commissioners.

Q. They are recommended by the College of Physicians, are they not?

A. Well, at any rate, they are not recommended by the Post Office. 
The Chairman: The next point raised was a suggestion that the medical officers of the Post Office were liable to be influenced by special orders given to them, to deal in a particular way with certain cases?

A. I made inquiry upon that point while the evidence was being given, and I have here the observations from the medical officer in question. It appears that the practice is one in vogue at the S.W. District Office, and the names of four men were mentioned in connection with it. They were Harper, Mendall, Bowles, and Barnes. I first asked the medical officer what he understood by this endorsement on the order to see him, and he says in reply. "The rule of endorsing the orders to see the medical officer was instituted about eight or nine years ago by Mr. Angell (the then Postmaster), and it was specially made owing to the conduct of the postman Mendall and a small number of men who, with him, were suspected of systematic malingering. Mendall, more especially, was constantly absenting himself from early morning duty, and attending here afterwards with trivial complaints of having been ill in the night, and as he enjoyed remarkably good health, he was frequently refused sick certificates to cover his absences. The result in his case was marked, for, as far as I know, he is now an exemplary officer, and certainly never troubles me unless really ill. Most of the other suspected men have left the Service, but the rule has always remained, though now very rarely enforced (I believe two or three times in 1895 amongst a staff of over 1,000). The instructions I received from the Postmaster were:- 'That when an order was endorsed by the inspector on duty, to withhold sick leave in cases where I could satisfy myself that there was nothing in the state of the applicant's health to justify his absence from duty.' My discretions would, therefore, be fettered only in so far that I should feel it my duty to withhold a sick certificate when I was perfectly satisfied that the officer had absented himself without sufficient cause of illness, and if I thought there was any doubt in the case, I should give the patient the benefit of it. I am bound to say that officers have from the first very much resented the rule, as they generally consider that it throws some doubt on the genuineness of their complaints. T. H. Brabant, Medical Officer, S.W. District." Harper's case was a simple one: he had a tooth extracted on Saturday evening, and therefore absented himself from duty on the following Monday morning. I failed to discover any sufficient reason for his absence, so he was not given a sick certificate. The following day he complained of some pain in the jaw due to the extraction, and as it seemed somewhat swollen I advised fomentations, and then put him off duty, to enable him to carry ont the suggestion." I have here the details of the other cases. I do not know whether you will wish me to go into them.

The Chairman: I do not think you need go into all the details; all we want is the general conclusion.

Sir F. Mowatt: As I understand it, the endorsement was to the effect that the man was absent from early morning duty, and it would show that the certificate was required to cover an absence which had already occurred?

A. Yes.

The Chairman: Now we come to the cese of Duncan.

A. Yes; that is another case in which it is suggested that the man was put upon a two years' probation, and then rejected. The fact is, he was rejected on nomination for appointment. He was examined by the District Medical Officer in February. 1893, and it was reported that he had flat feet. Still he was appointed as an auxiliary postman. In June, 1893, he enlisted, and his friends bought him out, and an appeal was again made to the Post Office for a re-consideration of his case. He was examined by the Medical Officer-in-Chief in July, 1893, who reported that although his

["The above statement $r e$ my absence from duty through illness, as supplied by the Medical Officer (I presume), is a bsolutely inaccurate from beginning to end." - G. H. HARPFR, S. W.D,O, - June 8th, 1896.] 
trouble was only slight at present, still the nature of a postman's duty would no doubt increase it, in consequence of the walks he would have to do, and that it would probably involve his retirement from the Service at an early age on a medical certificate. On that he was rejected.

Q. It seems that the Post Office Medical Officer is more strict than an army medical officer?

A. Yes; as I said before, an army doctor has only to certify as to a man's probable health during the few years for which he has enlisted, while the Post Office Medical Officer has to look to a life-long service.

Q. Then we come to the complaint that postmen are hampered by having to carry parcels?

A. I think we already dealt with that in the early part of the day.

Sir F. Mowatt: I should like to ask you a question on that. I meant to have done so at the time. You stated the number of parcels that a postman has to deal with at any one time is limited to five, and the witness complained that that would often add 10 or $15 \mathrm{lbs}$. to the weight the lettercarrier has to deliver?

A. The limit of weight is $11 \mathrm{lbs}$.

Q. But the man said that five parcels would often add 10 or $15 \mathrm{lbs}$. to an already heavy delivery of letters. Do you say it is fair representation that parcels would weigh on the average 2 "lbs.?

A. No ; certainly not.

Mr. Walpole: There is a limit of $11 \mathrm{lbs}$. for the total weight of parcels a man may lave to take?

A. Yes; the five parcels must not exceed $11 \mathrm{lbs}$. in weight.

The Chairman: You do give assistance by way of hand-carts for the delivery of parcels, do you not?

A. Certainly.

Q. Is there any rule as to when a hand-cart may be given?

A. Hardly a rule; the delivery is systematically made by hand-cart, as parcels do not vary much either in bulk or number.

Q. Do you sometimes have to send out a hand-cart on a delivery where ordinarily a postman carries them?

A. A parcels delivery covers the whole of the area always. A parcels delivery is made for the heavy parcels, besides a delivery by the letter pastman with his letters. It is only a question of keeping back the larger parcels for the parcel delivery, and of sending ont with the letter delivery the smaller parcels.

Sir F. Mowatt: Is wheel delivery miversal? Is there a heavy parcel delivery all over England?

A. I am speaking of London; there is always a hand-cart in reserve for parcels' delivery in suburban districts. A man may, if he likes, take the parcels out in his bag over his shoulder, or he may use a hand-cart. In some districts the hand-cart is always used.

The Chairman: Now we come to the case of the Wallington and Carshalton coach?

A. Yes; that is the case in which the man, according to the witness, had to wait at Carshalton 4 hours. It is a case of a split duty, and it does not seem to be much worse than the case of postmen.

Q. Do you mean the case of rural postmen who take out a morning delivery, and wait at the end of the walk until it is the time of the evening collection?

A. Yes; but I may also add that it is not very different from the case of the London postman who has daily two intervals of two hours each.

Sir F. Mowatt: But he might go home?

A. Hardly within two hours, unless he lives very close. I do not think there is any ground for special complaint in this matter.

The Chairman: Do town postmen in many cases have to stay out in the post offices, or in the neighbourhood during the day? 
A. Undoubtedly; men with three attendances do, as very often there is not sufficient time for them to get home in the intervals.

Q. And in such cases do you provide them with any place to go to at the head office?

A. Yes; there is always a postman's kitchen, as we call it-a postman's retiring-room. In some offices it is better than in others, but we give the best accommodation we can. During the summer, in fine weather, the gardens at St. Paul's Cathedral are very much used by City postmen.

The Chairman : They would not go there on a wet day?

Mr. Smith: They might go inside.

Witness: They could not smoke there. (Laughter.) I may mention in regard to the Wallington case, we tried to get accommodation for that man, but could not succeed in doing so; we could get nothing nearer than at Carshalton.

Q. And is the man allowed to go back there in the coach?

A. The coach goes back, and he arrives in it.

Mr. Walpole: He suggested that it was rather against the rule of the Department to do so?

The Chairman: Well, he said it was by favour of the driver he did it.

Mr. Walpole: Is there any objection to doing so?

A. Not at all; the coach is empty.

The Chairman: Now we come to the case of Chapman and Howe.

A. Yes. These men were passed over for promotion from the then second to the then first-class for generally unsatisfactory conduct, and the contention seems to be that the punishment that they so sustained should not be a permanent one. But it is the case throughout the Service, that when a man does not get promotion in his ordinary course through misconduct of his own, he loses his turn, and has to suffer for it through his career. Now, there is nothing exceptional in their cases.

Q. It is on general grounds that they were passed over?

A. Yes. It is alleged that it was owing to their connection with the socalled Postmen's Union; but according to the papers sent to me, no mention was made at the time of that agitation. Their conduct was described as "generally unsatisfactory."

Mr. Walpole: At any rate, the reason given by the Postmaster to the members of the local branch is not the reason given officially?

A. Stated to have been given? The man who was Postmaster at the time is dead, and consequently there is no means of correcting the statement, but the man who was chief clerk at the time says that no such reason was ever given.

Q. Can you tell me what are the existing rules with regard to the attendance at meetings?

A. There are no restrictions at all now. Originally the rule was that men were forbidden to attend public meetings held outside the Post Office building on subjects connected with their duty or pay. That was modified in April, 1890, and a notice was issued to the effect that Post Office servants might hold meetings outside the Post Office buildings for the discussion of official questions, provided that ample notice was given to the Department, the meetings to be confined to Post Office servants interested, and an official shorthand writer to be present if required by the authorities. In September, 1893, the whole of these restrictions were removed.

Q. And now they are free to meet as they like?

A. Yes; as they like and with whom they like.

Q. And where they like?

A. Yes.

The Chairman: Then Mr. Boaler says he was punished two years in succession for late attendances. I asked him how many late attendances, and he said there were 18 the first year. He also stated that he was late on an average 20 minutes each time. Can you tell me how far that was correct? 
A. Yes; I have a history of the case here. The increment which was arrested was the final increment from $33 \mathrm{~s}$. to $34 \mathrm{~s}$., and we are more particular with a man's last increment, because if he gets over that, there is no means of punishing him in the same way for future offences. He must either not be punished at all, or the punishment must be very much greater. In January, 1889, Boaler had been 18 times late during the preceding year, and his increment was deferred for three months. In April, when it came up for consideration again, and it was found that in the interval he had been late twice only, the increment was allowed. Then he went on all right till June, 1893, when the question of his final increment was considered, and as it was found that he had been 23 times late in twelve months, it was deferred for six months. During that deferred period he was reported for loitering and drinking in a public-house while on duty. At the end of the six months it was found that he had been 14 times late, and the final increment was then arrested. The matter came up for consideration again in the following June, and it was then found that he had been 18 times late, but as that was only 4 times within the second period of six months, the increment was not arrested on that occasion, but it was deferred for six months. During that six months he was six times late, and as thus he was going back, his increment was again arrested. In June, 1895, he was again reported for being 10 times late during the preceding year, and as the attendance was not considered quite satisfactory, the increment was deferred for six months, while during the probationary period of six months he was only four times late, and at last the final increment was allowed.

Q. Can you tell us what was the amount of the lateness of his attendances?

A. Yes; I will take the case of the final increment. The year in which he was 23 times late gave a toal loss of time of 12 hours and 16 minutes; 14 times late, 4 hours 30 minutes; 18 times late, 6 hours 30 minutes; 6 times late, 2 hours 40 minutes; 10 times late, 3 hours 53 minutes; 4 times late, 2 hours 3 minutes.

Q. Roughly speaking, that is haif-an-hour for each late attendance?

A. Yes.

Sir F. Mowatt: Is not that rather an unusual sort of lateness? We have had cases before us of men being two or three minutes late, owing to a journey being too long, or the weight to carry too heavy. Half-an-hour ate seems rather a substantial amount.

A. Well, if a man oversleeps, himself at 5 o'clock in the morning it is not a question of two or three minutes. I think the short late attendances are usually those made on collections during an ordinary duty.

The Chairman: The next case is somewhat similar. It is that of a man named Cox, and it is complicated by the fact that he had a sick wife.

A. Yes. It was said that the original bad attendance was due to the fact that he was unable to afford a nurse for his wife, and that since she had died he had been able to make better attendances. Now, this man was 19 times late in 1889, 19 times in 1890, 21 in 1891, and 27 in the period ending August, 1891, when the increment was stopped. His late attendances spread over the whole year, but his wife's illness did not extend over the whole year. The witness alleges that after the wife's death the man's attendances were very much improved. Now, he was 6 times late in 1892, 7 in 1893, 4 in 1894, and 3 in 1895, so that the attendances did not very much improve, for his wife did not die till 1895, and it was 1891 when the increment was arrested.

Q. Was it in 1891 she was ill?

A. In 1891 illness was alleged as an excuse for the late attendances, but at the same time it was admitted that they were spread over the whole year, whereas the wife's illness was not. 
Mr. Walpole: And his wife lived four years after the increment had been arrested?

A. That is so.

Q. And has the attendance improved practically during the four years?

A. Yes.

The Chairman: What have you to say about Buchanan's case?

A. I must admit in that case that there had been a misunderstanding owing to an error in the records, and I think that misunderstanding was not sufficiently remedied, and that the man's stripes ought to date back to the original date. I will have that seen to. 'The mistake aruse through there being two Buchanans in the office, and a certain irregularity was credited to the wrong man.

At this stage the Committee adjourned until Monday.

The Committee met again on Monday, March 23rd, when there were present: The Right, Hon. Lord Tweedmouth (Chairman), Sir Francis Mowatt, K.C.B., Spencer Walpole, Esq., H. Llewellyn Smith, Esq., and Robert Bruce, Esq., Secretary.

Mr. J. C. Badcock was re-called, and further examined, as follows :-

The Chairman: I think the last case you dealt with was that of Robert Charters. The next batch of cases has reference, I think, to a number of men who complained of delay with regard to stripes?

A. Similar complaints were made in various parts of the evidence. It was a question whether service as assistant-letter-carriel should count for stripe allowances. Mr. Churchfield has given me the names since his evidence, and the men have now received their third stripe, as it has been decided by the Secretary that their time as assistant-letter-carriers should count. It dates from the completion of their fifteen years' service, including their service as assistant-postmen.

$\mathrm{Q}$. Is there any case now in London where a man is waiting for a stripe because there is no vacancy?

A. No. The first and second stripe classes are unlimited. It is only in the third stripo class where the number is limited, and there is no place in London where the men are now waiting for it.

Q. What is the limit for the third stripe in London?

A. There are 30 badges for every 100 men. In each 100 there are not to be more than 30 three stripes.

Mr. Walpole: That is the rule all over the country, is it not?

A. Yes.

The Chairman: And as a matter of fact, that limit is not reached in London at the present moment.

A. No.

Mr. Walpole: Has it ever been reached in London? Or are present circumstances exceptional?

A. So far as I know, it has never been reached in London, speaking from my own memory. Reference is made to some men at Hampstead who have had 15 years' service, and who have not yet received their stripe; the fact is that the case of these men was reported with the cases of one or two doubtful men, and it is the inquiry into the case of the doubtful men which has led to the stripe for the others being deloyed, but, when granted, it will be granted as dating from the commencement of their service.

The Chairman: I think we have already dealt with questions of promotion, but have you anything more to add under that head?

A. It was stated that there was a regulation laid down in the Iondon district that the appointment to overseerships should be in the proportion of two to sorters and one to postmen. I have had very full inquiry made, and I can find no trace of any such regulation or understending. 
Q. Do you think it would be desirable to increase the difficulty of examinations for the postman's class on entry?

A. I see no reason for doing so.

Q. It was suggested by some of the men themselves in evidence as if they would rather like it.

A. Ah, but these men are already in the Service. (Laughter.) It is a very old argument for men in the Service to adrocate the increase of difficulty in examination, and then to make that increased difficulty in examination the basis of claims for more pay.

Q. Then we come to the question of the Parcel Post. The men who assisted in starting the Parcel Post, or some of them, seem to think that they had promises held out to them which were not fulfilled.

A. Their evidence is that Mr. Blake informed them that in return for their attendance they should be the first to receive appointments in the established sorting class. This promise is not admitted by Mr. Blake or by Mr. Hunter, the Chief Superintendent referred to. And, as a matter of fact, when a class of sorters for the Parcel Post was established, they were third-class sorters, on the scale of $18 \mathrm{~s}$. by $1 \mathrm{~s}$. to $20 \mathrm{~s}$., and it would not have been worth the while of postmen already in the Service to be transferred to that scale.

Q. The claim seems to have been that those men who were transferred to the Parcel Post should be made sorters.

A. They expected to be made sorters.

Q. Yes, and now, as a matter of fact, postmen of a certain number of years' service would have been losers, as I understand, by becoming sorters in the Parcel Post Branch.

A. Not at present, but they would have lost at the time, as the class of sorters first established for the Parcel Post were only third-class sorters. A transfer from the position of postmen to a second-class sortership now gives a higher increment and a higher maximum.

Q. Would he not even then have been suffering a loss?

A. No. The postman would have carried his wages with him. In the case of any transfer made for the benefit of the Service, the existing wages are carried.

Sir F. Mowatt: I should like on that point to ask you a question illustrating a difficulty which I felt in understanding some of the evidence at the moment it was given. The alleged promise was that these men should be promoted eventually to be sorters, but there were at that time no sorters at all in the Parcel Post branch.

A. No.

Q. Therefore I could not understand, and the witness did not succeed in clearly explaining to me how it was that they expected to be made sorters in a branch of the Service in which there were no sorters.

A. When the Parcel Post was established, it was unknown what it might develop into, and, as Mr. Walpole puc it, a "scratch crew" was engaged in the first instance, and I think what may have led to some of their expectations may have been that one of the overseers may have said, "Now, men, put your back into it, and very likely something will come out of this, and you may stand a good chance of getting something by-andby."

Q. There seems to have been no definite place of promotion promised?

A. No, there was not. There were no places to promise at the time.

The Chairman: Is there any rule that no postman is allowed to compete for a clerkship?

A. No ; certainly not. When I am asked to nominate candidates for competition for clerkships, I send to each London District Postmaster or Superintendent in charge of a division, asking him to recommend the men under 
his charge whom he considers best qualified for the position, and I don't care whether the man so recommended is a porter, messenger, sorter, or what he may be.

Q. Have there been postmen appointed to clerkships?

A. No, not direct. There was one man who entered as a postman and became a sorter, and was afterwards nominated for a clerkship.

Sir F. Mowatt: You say that although the offer is open to all upon recommendation, yet in practice, it is generally not the postmen who are recommended?

A. Quite so.

Q. Could you explain why that is so?

A. The sorters pass a higher examination at entering, and therefore, presumably, the postman is less intellectually fitted for a clerkship, and in these cases it is making a selection of one man from a force of 300 or 400 under the maximum rate.

Q. So we may assume the explanation to be that there are generally better educated men to be found among the sorters?

A. Yes; among the sorters and counter-men and telegraphists.

Q. Than among the postmen?

A. Yes.

Q. That is your explanation?

A. Yes; it is the probable explanation.

The Chairman: I understand a man does not become a clerk right off, and that the nomination only gives him the right of competing for a clerkship?

A. Yes; but it is a limited competition, about three men being nominated for each vacancy.

Q. They compete between one another?

A. Yes, before the Civil Service Commissioners.

Mr. Walpole: Might you not go one better? Is it not the case that the more intelligent postmen presumably compete in the beginning of their carcer for the sorters' places, and so reduce the proportion of remaining postmen best qualified for clerkships?

A. Yes; that is so.

The Chairman: Have you anything to say about the answer to the question, where a man said he had been appointed as head postman, and had been turned off?

A. He was not appointed as head postman; he was tried on head postman's duties, but the trial showed that he was not equal to them, and, in fact, although I hardly like to mention it, he was deprived of one of his good conduct stripes.

Q. While he was being tried as a head postman?

A. No, two years afterwards; in fact, last December, for misconduct.

Mr. Walpole: But it was before the evidence was given here?

A. Yes, it was in December last.

Q. Then there is Worth's case. It is stated that he had been working head postman's duties on and off for the last nine years?

A. He has done head postman's work for some years, during the annual and sick leaves of the regular men, but the Postmaster states that he cannot be recommended for promotion, as he is shifty, unreliable, and careless.

Mr. Walpole: Is that not a reason for not employing him to act as head postman?

A. It was thought better to give him a chance, instead of letting him have the grievance of complaining that he had not had an opportunity of showing
whether he was qualified.

Q. But if he showed himself shifty, unreliable, and careless for several years, ought not his trial as a head postman to cease?

A. I must confess that I think so. 
Q. It is also stated in the evidence that each vacancy at New Cross has been filled up by men from the Head District Office?

A. There have been three vacancies for head postmen there in the last nine years, and only one was filled up from the Head Office.

Q. Then there was a complaint with regard to the case of a man named Coslett, of his application for a lobby officership having been passed over.

A. He was passed over because of his quarrelsome disposition. The lobby officer has to exercise control over the men bringing in the bags from the sorting office, and over the mail-cart and van drivers. And it wants a man of very peaceable disposition to control those two different elements.

Mr. Walpole: There was no favouritism in the matter?

A. Oh, no.

Q. Unfortunately, he had not a good enough temper for the place?

A. That is so, and every man above the one who was promoted was duly reported on and reasons given.

The Chairman : Some points were raised by Mr. Symes, arising out of the abolition of classification. Do you want upon that point to supplement at all what you have already told us?

A. The great grievance was that the system of classification was abolished without any alteration being made in the amount of increment. I do not know whether I am disclosing official secrets, but I believe that the Postmen's Committee in their report, when they recommended the abolition of classification, contemplated an increase in the increment. The PostmasterGeneral in his wisdom, however, adopted the abolition of classification, but did not adopt the increase of increment. If the recommendation of the Committee had been adopted in its entirety, I think there would have been little cause for grievance.

Sir F. Mowatt: The form in which the grievance came before us was this: I think that the men near the top of the line dividing the first and second-class would have passed over that line more quickly if classification had not been abolished.

A. By the abolition of classification the jump which they formerly obtained was abolished, but that would have been made up to them in great measure if the increase of increment had been granted. But, of course, it would not have got rid of this grievance that these men just before the abolition got the jump, whilst the men just after did not get it.

Mr. Smith: It was the men near their maximum who felt the grievance?

A. The case showed the advantage the men enjoyed before the abolition of classification in obtaining this jump.

Mr. Walpole: The existence of classification gave them a distinct leap in a certain portion of their career?

A. Yes ; as a rule.

Q. And this abolition did away with that?

A. Yes.

Q. Assuming that we decided to recommend that classification be abolished, that would abolish the jump equally in other branches of the Service, would it not?

A. Certainly, but that must depend on the Committee,

Q. Do you think that would constitute a grievance?

A. I don't know; that would depend entircly on the state of the lower class.

Q. Which would vary in different classes and the different offices?

A. Yes. I should mention that in order to remedy grievance as far as possible, we got authority to fill up every vacancy which existed on the first-class, and there were many at the time of the abolition of classification.

Sir F. Mowatt: But if the promotion was not very quick, the effect of doing away with the jump would be merely this: that on the take-off side the men would proceed by increment until they had bridged the line.

A. That is so; but it was not the case with ithe postmen in practice. 
Q. As regards the future, the jump would disappear by the men crossing the line by means of increment?

A. Certainly ; it would do away with the grievance about which we heard in evidence of so many men standing at the maximum of the second class.

Q. On the take-off side, as it were?

A. Yes.

The Chairman: IFr. Symes made a strong charge to the effect that it seemed to be the rule of the superiors in the Department never to give a moment's careful consideration to the complaints and representations of their subordinates.

A. I think that was the case in which we were said to have given the answer four days before the memorial was received. (Laughter.) I have gone into that case very carefully, and got the purticulars. The allegation was that on April 4th, 1892, a meeting of postmen was held in the Eastern District, and three delegates were elected to lay their case before the Controller. There is no trace, either in my own office or in the office of the Sub-Controller of the Circulation Department, to which these men belong, of any application made by the men in the E.C. District previous to the 19th September, 1892. Applications were received from men similarly situated in the Western, W.C., South-Western, North-Western, Paddington, and South-Eastern Districts at various times between September, 1891, and July, 1892. These applications were placed together before the Postmaster-General on the 2nd September, 1892, and a decision was given by him on the 6th of September, which was promulgated on the 15th of September to the district from which the application had been received. The first application from the E.C. District was dated the 19th September, and was sent to me on the 20th. It was reported by me by the Secretary on the 21st, and by him placed before the Postmaster-General on the 26th. The Postmaster-General decided on the 6th January that the decision given in the other districts applied eçually to them, and this was communicated to them in the E.C. District on the Joth of January. A copy of the memorandum of 15th September was enclosed, and no doubt this is what is referred to as the answer given before the memorial was sent in.

Sir F. Mowatt: It was an enclosure in an answer dated the 10th of January the following year?

A. Ÿes.

The Chairman: The answer the Postmaster-General had given to the previous memorial was deemed to be a good answer to the subsequent memorial from the E.C. District.

A. That is so. The answer given by the Postmaster-General on the 9th January, 1893, was as follows :-

"The Postmaster-General has had before him the accompanying memorial from certain postmen in the Eastern Central District, representing that they have suffered by the formation of postmen into one class, instead of there being two classes as formerly, and asking that the present arrangements may be relaxed in their favour. Similar applications have already been made by postmen in other districts, and after due consideration of the circumstances, Mr. Morley had given his decision; a copy of that decision is herewith. Having reviewed the matter on the appeal from the E.C. men, the Postmaster-General is of opinion that the decision already given must be adhered to, and he directs that the memorial is to be answered accordingly."

The Chairman: I think your account is quite borne out by the evidence that was given.

A. But it was conveyed by the evidence that $I$ had had application from the E.C. District in 1892, and had taken no notice of it.

The Chairman: But when you were dealing with the memorial it practically came out as you have stated?

A. Yes. 
Q. An assertion was made by one of the witnesses that the stripe or increment had been stopped because a man had been 8 times late in one year?

A. Yes, that was two years ago; it seems to be rather ancient history. No particulars are given, and it is rather difficult to meet a charge of that kind in consequence.

Mr. Walpole: But is it a fact that a stripe was ever stopped because a man was 8 times late?

A. I think it may have been in the past, when the stripe regulations were interpreted more strictly than they are now.

Mr. Smith: In this case it was pointed out that the stripe was stopped for a man being 8 times late, although his annual attendances were over 900

A. I do not believe any man's increment was stopped for merely being 8 times late in one year. I expect there must be greater irregularities in previous years.

Sir F. Mowatt: You are speaking of the increment as distinct from the stripe?

A. Yes.

The Chairman: It was further stated that increased difficulties are found in the way of getting sick leave?

A. That is a matter for the medical officer.

Q. Is it not brought under your supervision?

A. No.

Mr. Walpole: Do you believe there is any truth in it?

A. Not the slightest.

Q. Not the slightest?

A. No.

Sir F. Mowart: A statement was made that the men preferred going about suffering because they knew that the medical officer would only give them leave in cases where they were suffering from infectious disease or a very serious illness. Do you think that is an accurate statement?

A. My own impression is that it is not. I believe that if a man is genuinely ill the doctor gives him every consideration.

Mr. Walpole: As a matter of fact, the average sick leave of the staff is 7 or 8 days a year, is it not?

A. Yes. I take it that if the medical officer is anxious to keep down the sick leave, it would not be to his interest to keep a man on duty when he was becoming ill, as that might lead to a long illness, whereas a short period of absence given at once might set him up.

The Chairman: Then reference is made to a memorial from some of the E.C. postmen, in which they suggest that they have suffered in consequence of the abolition of classification, and by not being allowed to choose their duties by seniority?

A. Not being allowed to choose according to seniority?

Q. Yes. You will see that they complain that they are not allowed to choose their duties according to seniority, and that, in some cases, they are thus deprived of their share of the Christmas boxes.

A. I think that that memorial had to do in great measure with the question of Christmas boxes. It was from the junior men in the Central Office, and asked that they might be allowed to choose their duties. I looked the matter up on receiving it, and referred it to the Sub-Controller, who is the arbiter in such cases, and he made an arrangement which had my approval, and which resulted in juniors getting a somewhat larger share of Christmas boxes than they had had in the past. I have heard no more of it, and I thought it was all settled until this evidence was given.

Q. In March last a further memorial was presented, and apparently that was on the subject of the abolition of classification and the loss of the jump wages on promotion from the second to the first class.

A. I do not think it followed on the first memorial; I think it was merely a shot at the Controller on the ground that he had not given the men a fair hearing. 
The Chairman: I thought it was a double-barrelled shot?

A. No ; I think it was aimed mainly at the loss sustained by the abolition of classification. On the 21st March they sent in a further memorial to the Postmaster-General asking for 4s. a week addition to their wages to compensate them for the loss they considered they had sustained by the abolition of classification, and the Sub-Controller, in sending that memorial to me, enclosed a tabulated statement showing that the abolition of classification had not been so prejudicial to them as they suggested. On receiving this memorial I pointed out to the men through the Superintendent how the matter really stood, and said that I saw no hope of this memorial being acceded to, but still, if they wished it, I would send it on to the Postmaster-General. The men replied on the 22nd, tendering me their hearty thanks for my kindly consideration, and stating the reasons why they still wished the memorial to be sent on. I sent it on, and it was decided on by Mr. Morley on the 23rd. I think that after tendering me their hearty thanks for my consideration, it was hardly fair to charge me with having no sympathy with them.

Q. What was Mr. Morley's decision?

A. He maintained the old decision. He pointed out that the change which had been effected had undoubtedly been advantageous to the postmen as a whole, and even in their own case, they had a higher maximum salary than they would otherwise have been able to attain.

Q. Is it a fact that the men are punished for not knowing about removals on the walks on which they hare just been put?

A. No; unless it is by some extreme inadvertence.

Q. Do you know anything of the alleged case given us of such a punishment being inflicted? I think the man's name was Wolverton?

A. Yes. In that case there was a dispute about a delivery for a Mr. Child, who had, I think, left his office and gone to another place, or had started business on his own account in the same building. Special instructions were given as to how his letters were to be dealtwith, and these instructions were signed by all the postmen on the walk. Wolverton, the postman who complains that he was punished, himself signed the instruction, and he has acknowledged that he read it, and afterwards delivered the letter contrary to the instruction.

The Chairman: His statement was that he had been off the walk for a week or a month before he made the mistake?

A. I think he had been continuously on it for a month.

Mr. Walpole: He no doubt worked on it, and signed the instructions.

The Chairman: The next case is a somewhat similar one. A man named Farrant complains of having been punished for not knowing the way in which a wall had to be worked?

A. In that case I am assured that the letters were properly arranged for delivery by a man who knew the walk, and that this postman had nothing to do but to take the letters out in the order in which they were given to him.

Q. And he preferred to do it in his own way instead?

A. Yes; he preferred to do it in his own way.

Q. And was it for this his stripe was arrested?

A. No; the stripe was arrested for general want of care in the performance of his duties. In the year 1895 there were 8 irregularities recorded against him. He was cautioned, then reprimanded, then warned, again cautioned, again cautioned, then he got extra duty, and twice again was he cautioned during the year.

Q. Then his stripe was arrested entirely on other grounds than those put forward by the witness?

A. Yes; for general want of care.

Sir F. Mowatt: I observe that in the description of the case given in the evidence, it was suggested that the man was never on the walk before, and that there was no one in the office to give him information, so that he 
was left entirely to himself to decide how to deal with the correspondence. That is not quite on all fours with the explanation now given.

A. The report given at the time-on the 25th July-was that Farrant was a man suitable for this particular sor' of duty, and that the letters were sent to him properly arranged for ordinary delivery.

Q. The witness also told us in answer to Mr. Walpole's question as to whether any man had been dismissed the Service on mere suspicion, that a man named Morris was so dismissed 18 months ago. Have you any explanation as to that?

A. Yes; I remember that case very well. It was the case of a cheque being stolen, and Morris was dismissed for being concerned in an attempt to negotiate the cheque, which another postman named Jones had stolen. Morris's case was re-considered on appeal, and it came out that there had been some sort of conversation between the two men as to how they could get the cheque changed. The cheque was enclosed in a letter which could not be delivered, and Jones did not return that letter. Instead of doing so, he consulted Morris as to how they could get the money for it, and I believe they were going to halve the proceeds.

Sir F. Mowatt: Was that proved to the satisfaction of the PostmasterGeneral?

A. Yes.

Mr. Walpole: One man was actually convicted of stealing the cheque, so that that part was proved to the satisfaction of the Court, was it not?

A. Yes; it was so far established that the man pleaded guilty, and was bound over to come up for judgment when called upon.

Mr. Smith : Then he was not punished?

A. No. The Common Serjeant remarked that Jones appeared to have yielded to a sudden temptation, the letter having been handed to him, and his attention having been called to the valuable security which it contained. He, therefore, bound him over in his own recognisances to come up for judgment when called upon.

The Chairman: Then some evidence was given with regard to the length of the walk and to the mis-delivery of letters in consequence. A man complained of having been punished for a mis-delivery, in spite of the difficulties he had to face.

A. Yes. He took a registered letter which was addressed to the AngloAustralian Bank, and wrongly delivered it to the Hong-Kong Bank. The letter was fully addressed, and apparently he delivered it without reading the address. It was a registered letter, and he had to obtain a receipt for it. He had the receipt prepared for them, with a full address upon it, and he was reprimanded for the mis-delivery. His complaint was that he was punished twice over for one offence. Now, complaint was made to the Department that the letter had been mis-delivered, and he was reprimanded for that. It turned out eventually that the letter had been lost, and the result of the inquiries that had been made was that it was felt that a simple remand was not sufficient, and so the man was punished with four hours' extra duty.

Sir F. Mowatt: When you say that the letter was lost, was it not admitted that it was delivered to the Hong-Kong Bank?

A. No. They could not tell what had become of it. It was lost as far as the addressee was concerned.

Q. He was both reprimanded then, and had extra duty?

A. Yes. He goes on to say that such a mistake was easily made in the hurry of his duty. His stripe was stopped for want of general satisfaction in the performance of his duty.

The Chairman: Then the witness put forward the exceptional difficulty of duties in certain districts performed by the man with special registered carts?

A. Yes, it is a responsible duty, but it is one of the simplest duties in the office. The registered letters are made up in bags, which are entered on 
a bag list, and two men are sent out with the cart in which they are conveyed: one man to take charge, and the other man to do the delivery.

Q. Are these generally valuable letters? I see you have hero a list referring to a delivery for the London and Provincial Bank?

A. Undoubtedly they are valuable letters, for they are remittances from the branch banks to the head offices, as a rule.

Q Q. Are they cheques?

A. Yes; and notes and nogotiable securities to some extent. I do not think, however, that they are securities which a man would find it easy to get rid of. They would not be of much, value to him.

Q. Practically they are not negotiable, then?

A. I think not. Of course, it would cause some little inconvenience if they were lost, but there would not be much in them that a man could make much use of.

Q. You dealt with the question of supernumeraries in the first part of your evidence, did you not?

A. Quite so.

Q. We have had a man here named Herbert who came to give evidence rather in opposition to the Postmen's Federation, and his first point was as to the sorting work performed by the postmen?

A. I think that was with regard to the town postmen generally. The amcunt of the sorting work in the E.C. District does not differ materially from work done in the other districts of London. The postmen do the primary sorting in four of the divisions in which the E.C. District is divided, and the letters for the suburbs for each district are placed by them.

Q. Mr. Herbert claims that the postmen's work in the E.C. District is in many respects more, and in no case less, responsible than that of the sorters.

A. I should assume that he was referring to the second-class sorters.

Q. The next point was as to the number of registered letters dealt with ?

A. Yes; he states that from 50 to 100 . registered letters are taken out by a man on his ordinary delivery.

Q. What have you to say about that?

A. It is very seldom that a man takes out 50 registered letters without having assistance given him. Again, they are not single registered letters; they are in a great measure entered on one list, and tied up in one bundle. They should, therefore, be treated as one letter.

Q. There would be so many registered letters go to one firm?

A. Yes. I will put in a copy of a list showing that.

Sir F. Mowatt: And this list shows the delivery for one firm?

A. Yes.

The Chairman: In giving an example, the witness said that the E.C. postmen had to dispose of 31,178 registers.

A. That is so, but then he was referring to the case of delivering registered letters only. It is a man who delivers in the stockbrokers' quarters at Draper's Gardens, and I believe that more than half the letters so delivered go to about 14 firms.

Q. Is it not the rule that a man on delivering a registered letter should obtain a receipt?

A. Yes; and in addition to that the man who is responsible for this delivery is always accompanied by an assistant.

Sir F. Mowatt: I suppose he puts them together in their respective bundles before he goes out on his walk? Does he do that himself or is it done for him?

A. He does it himself.

Q. Before he starts?

A. Yes; but they are listed before they are placed in his hands.

The Chairman: He re-arranges the bundles?

A. Yes.

Sir F. Mowatt: Is it dono by the sorter, then? 
A. Yes; it is first done in the registered letter section.

The Chairman: What is the rule with regard to giving assistance on these registered letter deliveries?

A. Whenever a man has a large number of registered letters, and sees that it will hamper him in the delivery of the ordinary correspondence, he would ask for assistance.

Q. And is it given in all cases of that kind?

A. Yes. I have here the return for Bishopsgate Street. On the first walk there were 32 registered letters, on another there were 48 , on a third 46 , and on a fourth 65 . In each of those cases on the day mentioned assistance was given.

The Chairman: The witness also gave us instances of a very large number of registered letters which had to be delivered by one man-in one case 101, and in another 90 .

A. That would be altogether abnormal.

Sir F. Mowatt: Do you know whether this man had assistance?

A. I cannot say whether he had assistance on that occasion, but no doubt he would have been granted it if he had asked for it.

The Chairman: Do you keep a good reserve of men for this assistance?

A. Yes; 30 to 40 men are always available.

Q. Are they generally employed?

A. Yes; to a fair extent.

Q. And what do they do when they are not so employed?

A. A great many of them are on the second delivery commencing at 8.30 ; they are at work in the office; they have to attend at 6.30 .

Q. Then we have had some evidence with regard to the hardships of a postman's lot, causing him to drop out of the Service at an early age. Can you give us any statistics as to the age at which men do drop out?

A. I find that in the E.C. District, that in 1891 there were 5 postmen who died out of a force of nearly 1,100 men; their average age was $43 \frac{1}{2}$. In 1892 two died, and their average age was 30 years and 10 months; in 1893 nine died, the average age being 38 $\frac{1}{2}$; in 1894 four died, and the average age was 273. Last year five died, and the average age was 35 years and 5 months. During the same years the pensioners from the postmen's class in the E.C. District were as follows:- In 1891, six, with an average age of 54 years and 9 months; in 1892, two were pensioned at an average age of 56 years 8 months; in 1893, four, with an average age of 58 years 8 months; in 1894, eight, with an average age of 52 years and 8 months; and in 1895, six, with an average age of 44 years and 11 monthsthe total being 26, with an average age of 52 years 5 months.

The Chairman: Can you give us the average age of the men in the Service?

A. I am afraid not.

Sir F. Mowatt: Those figures do not take into account the men who are passed out of the postmen's class, and subsequently pensioned off?

A. No ; but still the evidence was that the postmen's work kills a man off, or wears him out. I do not think it is borne out by these figures.

Sir F. Mowatt: When I said "passed out of the postmen's class," I meant into the upper classes.

A. They would not be passed into the upper classes if they were worn out.

Q. Then your figures do not show the full field in which these 5, 2, 9, 4, and 5 deaths occurred?

A. No.

The Chairman: Would you be inclined to agree with the proposition that the E.C. postmen are better off than the other postmen?

A. In what way?

Q. Generally, both as regards emoluments and duties.

A. No, I should think not; there may be a few cases perhaps, say the men on the Lombard Street walks. 
Q. It would be confined to a very few, then?

A. Yes, comparatively few, but take them all round, I should say that the London District Office men are more favourably situated than are the men in the E.C. District.

Q. Would you be inclined to admit that the E.C. men have harder work to do than the men in other districts of London?

A. No ; I should think not.

Q. Then you do not think they have any claim to be better paid than the men in the other districts?

A. The only ground on which such a claim could be based would be, I think, the greater value of the registered letters they have to take out in many cases.

Q. Now, do not answer this if you prefer not to, but do you not think that if the Christmas box system is to continue, the whole body of postmen should share in it, and not only a few men? Or do you prefer the present arrangement by which the senior men get it?

A. Are you speaking of the E.C. District only?

Q. I was rather putting it as a general proposition.

A. Well, the system of dividing Christmas boxes is settled among themselves, and it differs in different districts. In my opinion, the proper way would be to have an equal share throughout an office. It does not matter to the public whether a postman delivers or he collects; their idea is to give the Christmas box. On the other hand, the senior men in the E.C. District, for instance, have borne the heat and burden of the day for years: they had but a small share when they were juniors, and it would be rather hard to take it away from them just when they are about to reap the benefit of their long service. This is where the difficulty comes in.

Mr. Walpole: Do you say there would be no practical difficulty in saying that the Christmas boxes should be shared equally in an office?

A. I think not.

Q. No difficulty in enforcing such a regulation?

A. Oh, no; but I do say it would be rather hard on the senior men who have had to take a small share in the past; it would constitute a hardship in their case.

The Chai man: Then some question was raised as to the heavy weights carried by the E.C. postmen? Have you any rule in regard to assistance being given in the case of postmen carrying out weights in the E.C. District?

A. No; there is no hard and fast rule. The point of commencement of the different deliveries is, of course, very different in districts. A man might take out a very heavy load and begin to get rid of it directly. $\mathrm{He}$ might go, for instance, from the G.P.O. to a delivery in Paternoster Row ; we should not give that man assistance so readily as a man who had to go to Mincing Lane before he got rid of any portion of his load. Some examples were given. The first was the Billiter Square delivery. In the first section of that the weight carried was $60 \mathrm{lbs}$, in the second section was $65 \mathrm{lbs}$., and that man got assistance; in the third section it was 72 lbs., and that man got assistance; in the fifth section was 43 lbs.; then at Cornhill the weight in the first section was 45 lbs., that man got assistance. In the second it was 70 , in the third 65 , and in the fourth 66. Then in the Bishopsgate walk, in the first section the weight was 62 lbs., and that man was assisted; in the fourth section it was 84 lbs., and he was assisted; and in the sixth it was 65 lbs., and he was assisted, so that assistance was given pretty freely, it will be seen. I may say that all the postmen do not go out at the same time, and it is therefore possible that a postman who starts early with a moderately heavy load may ask for assistance and get it, whereas a man who starts later with as heary a load would be unable to get assistance, as all the men would be engaged. Still, as a rule, the men who start late are the men who deliver 
close to the office, and, therefore, they would not have the same need for assistance.

Q. Do you generally have men enough to give the assistance asked for?

A. I think so.

Q. Are you often obliged to refuse it?

A. No ; a great many of the men do not care for assistance. They would rather take out their bag and do the work their own way, than be bothered by some one helping them.

Q. I think that concludes the evidence to which we have to call your attention. Are you prepared to go into the case of the labourers to-day?

A. I am afraid not.

Q. Or the points raised by the ladies we had before us?

A. No.

Q. There is one question I was going to ask you ; it was on a different subject. Can you tell me anything as to ai recent rule with regard to the employment of auxiliary sorters?

A. Yes. In the E.C. Circulation Office we had some auxiliary sorters mainly in the newspaper branch, and it has been decided to do without assistance of that kind, and to fill the places by established appointments.

Q. Are there many of these men?

A. About 30, I think.

Q. Are they of considerable service any number of them?

A. Yes. If you remember, you had one here-Richardson.

Q. Yes; he had been a long time in the Service. What are you going to do in their case?

A. It has been decided that men of that standing may be allowed to stand against established vacancies, but they must have had at least 7 years' service. The Treasury tell us that if the men have not been there 7 years they must go.

Q. Is theie no discretion as regards individual cases. A man might be a good and useful man, and of good character, and it seems rather hard to turn him away because he has not done 7 years' service?

A. No. The Treasury have laid it down that if a man has not been there 7 years he must go. We are asking for kind forbearance for two of the men, but so far we have not succeeded in convincing the authorities that their services should be retained.

Sir F. Mowatt: Was not what the Treasury said, not that they would not promote the men, but that they would not give them a gratuity? There is an Act of Parliament which says that where a person who is not entitled to a pension leaves the Servic before he has been 7 years in it, there is no power to give him any gratuity on his leaving.

A. No; I think the Treasury decision was that they could not allow these men to block other created employments.

Mr. Walpole: That is so.

The Chairman: Is there anything else vou wish to add, Mr. Badcock?

A. I should like to mention, if I might be allowed to, the case of Roberts, of Hampstead, which was brought before the Committee by lifr. Churchfield on Thursday. It is a case of alleged intimidation. The charge was that because reference had been made to Roberts not being supplied with uniform, he had been told that he must seek other employment. I am assured by the Postmaster that that had nothing whatever to do with his case. Roberts, since the evidence was given, was acting as the opener of parcels receptacles, and one of the first duties of an opener, indeed, one of his most important duties, is to immediately look for the letter bill or parcel bill; that is the only way of proving that the despatch has not been tampered with. It is his first duty to find that bill, and if he cannot find it he should immediately report the fact to his superintending officer, in order that he may satisfy himself that it is not there. Well, on this particular occasion, the bill could not be found, and Roberts failed to report 
it. On being questioned, he said that no bill came, but subsequently the bill was found under the string of a parcel sent out for delivery. It was an act of gross carelessness. He was an unestablished man; he thad applied for a permanent appointment, but his history was this :-In October, 1895, he was reported for treating parcels receptacles in a rough and reckless manner, and smashing the parcels. He was reported by the inspector, and punished by extra duty, and warned that his services would be dispensed with unless his conduct improved. In November, 1895, there was a parcel for him to deliver; it was addressed to No. 1 in a certain road. To save himself the trouble of delivering it, he altered the number to 37 , thus causing it to be put into the hands of another postman to deliver, and consequently the delivery was delayed.

Mr. Walpole: Was that proved?

A. Yes; he admitted it.

$\mathrm{Q}$. And was he dismissed on the spot?

A. No; the overseer described him as totally unreliable, and he was finally warned.

Q. Why was he not dismissed?

A. Well, he ought to have been. On the 31st January he was cautioned; on the 24th February he failed to attend on his morning duty, and was seriously cautioned again; and in March came this case of not reporting a bill being lost. Then the Postmaster directed that he should be cautioned, and also that he look out for other employment. He had been informed that under the revision at Hampstead a number of established appointments had been created, but it had been decided not to recommend him for one.

Mr. Walpole: The main fact you have brought out is that he ought to have been dismissed last November?

A. I think so. There is just one other case I should like to mention. When I was giving my evidence last Thursday, Mr. Wilson tried to intervene. I was dealing with the number of postmen at Hampstead. I now find I mis-stated that number, and that I mixed up the number of the proposed established men with the present number of auxiliary men. Mr. Wilson at once saw the error. The mistake was quite unintentional. I was simply trying to show at the time that in this division we are endeavouring to abolish part-time duties. I gave 11 less for the established places under the revision than I should have done. I said there were 42 established men and 76 auxiliary, and that there would be 65 established and 52 auxiliary under the new revision. I should have said there would be 76 established and 42 auxiliary.

Mr. Smith:. You said you would obtain for us information as to the number of auxiliary postmen in the different zones.

A. Yes; I have here a statement showing the number of the auxiliary postmen grouped in zones. I may mention that this has been compiled from the records of the Controller's office, and it may not be strictly accurate, but it would be so within a little.

Q. In general terms what does it show?

A. It shows that in the town offices there are 3.049 established postmen and 295 auxiliaries. In Zone 1 there are 785 established and 619 auxiliaries. In Zone 2, 1,254 and 1,328 respectively. In Zone 3, 217 and 294; and in Zone 4, 11 and 17.

Q. May I take it as a general rule the proportion of auxiliaries to established men increases as we get further from the centre?

A. I think so; the reason being that the duties there are much less frequent.

Q. And there is more difficulty in making them into full-time duties?

A. Yes; we have to get a larger force on the first delivery in the morning in order to cover the larger area of ground. 
Q. Are there many telegraph messengers waiting for appointment?

A. Yes; there are 140 at present.

Sir F. Mowatt: 140?

A. Yes; they are employed as auxiliary postmen pending their appointment on the establishment.

Q. Is that in the whole of the zones-140 among the lot?

A. Yes; in the London district.

The Chairman: That is all at present, Mr. Badcock. I am much obliged to you.

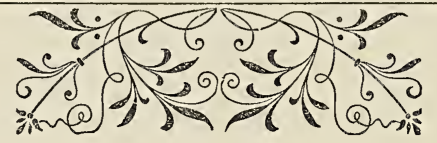


E. B. LEWIN HILL, EsQ.

Rebuts the Provincial Case.

Westminstek, 19th March, 1896.

Mr. Lewin Hill was then called and examined in regard to the case of the prorincial postmen.

The Chairman: You are commander-in-chief of the provincial postmen, I thive?

A. Yes; under the Secretary I deal with them.

Q. Can you tell me the total number of men for whom you are responsible?

A. In the provinces? Shall I give them in each class?

Q. Please.

A. The number of established postmen is 11,778 ; the number of suboffice postmen who really are town postmen in the sense that they do not deliver long rural walks, is 1,592 , and the number of rural postmen is 7,044 -that makes a total of 20,414 established postmen. In addition to that, the number of auxiliary postmen is 10,563, making a total of 31,067 established and auxiliary postmen in the provinces.

Q. Does this comprehend everybody you employ?

A. I'es, everybody we employ under these designations. We havè an allowance to sub-postmasters of $£ 4$ per year, for a man who works half-anhour or an hour per day, or whatever it may be, but we regard that as a duty provided for by the allowance.

Q. And these men are absolutely under the control of the local Postmaster, and are not under your control?

A. Yes; that is so.

Q. And your payment is made to the Postmaster, and not to the man direct?

A. Exactly so.

Q. And you leave him to make whatever arrangements he likes as to whom he employs?

A. Yes, broadly speaking.

Mr. Walpole: Except that you insist on his paying the allowance?

A. Yes; if it is an allowance of as much as $5 \mathrm{~s}$. per week, we make the sub-postmaster produce a receipt, but when it is an allowance of less per vear we do not. The duty may be done by his daughter, his son, or even himself, and we do not trouble about that.

The Chairman: Then with regard to the various classes you have given us, are they not again sub-classified?

A. Yes, they are; now, with regard to established town postmen on a scale, there are 11,628, and of junior town postmen on scale there are 107, of town postmen at fixed wages there are 43, These are men who are too old or who for some other reason cannot be put on the establishment; the total is 11,773. As to the class of junior town postmen, which, as you are aware, is a moribund class, we are getting rid of the men as opportunity offers.

Sir F. Mowatt: Are the whole of the town postmen established town postmen?

A. I was not quite correct in what I stated just now. I am reminded that some of the town postmen on fixed wages do not do a full day's work, they only work 6 hours, and therefore we do not put them on scale. They are not called auxiliaries; I do not know why.

Q. We may take it that eventually the whole of the established town postmen will be on scale? 
A. Certainly, I think so. A more proper designation for those men who do not do a full day's work would be auxiliaries. Of the sub-office postmen, the number established on scale is 1,504, and the number established on fixed wages is 88, making a total of 1,592. Of the rural postmen, the number established on scale is 6,573 , and on fixed wages 371 . With regard to the majority of the 371 on fixed wages, the reason that they are not on scale is that their work is not considered to be a full day's work. We have great difficulty in defining what constituted a full day's work, and among the definitions we have made most of these men do not come in so as to get on the scale.

The Chairman: In what proportion are the auxiliary postmen divided among the three classes?

A. I have not the figures by me, but probably about one-half of the auxiliaries work in towns, and the other half are what are called rural auxiliaries.

Q. What are your methods of appointments to the various classes?

A. I may say there is no difference. Before I deal with that I may mention that a large number do outdoor postal duties, which are provided for in the country by men who have a small allowance.

Mr. Walpole: Before you leave this point, let me ask you whether out of the 20,414 established postmen, 19,805 are not on scale?

A. Yes, I will take that from you. The town postmen are recruited now from the telegraph messengers and from auxiliary postmen who have been some time in the Service. Failing these, they are recruited by exsoldiers and ex-sailors?

The Chairman: Do you find that you have an adequate supply of suitable men?

A. I think we have more than an adequate supply; the dificulty is to provide for our telegraphic messengers and our auxiliaries-those men who are doing a double duty.

Q. As a matter of fact, are almost all your established appointments given to telegraph messengers and auxiliary postmen?

A. I believe so.

Mr. Walpole: Would that not be the case in the towns, but not in the rural districts?

A. I have guarded myself by confining my statements to town postmen. In Sir James Fergusson's time the rural postmanships were largely reserved for old soldiers.

Q. Now we have altered that, and give the first claim to our own people. And, as a matter of fact, are not our own force tending more and more year after year to absorb the vacancies?

A. Yes.

Q. Three years ago they absorbed about half of them?

A. Yes; the rural postmen in Sir James Fergusson's time were recruited almost entirely from old soldiers, and it was not held that our own people had any claim to them.

Q. In the rural districts soldiers are still frequently appointed.

A. Yes, I think so.

The Chairman: Can you readily tell me how many telegraph messengers you have in the country?

A. I can put that in.

Q. Does the same rule prevail in the country as in London with regard to the appointment of telegraph messengers as postmen?

A. Yes ; I should say the same rule.

Q. Is there a weeding-out of the telegraph messengers at 16 years of age?

A. We have ordered it, and I think the weeding-out is already in existence in the provinces, but in London it has not been carried so far, I think, owing to the paternal feeling at the appointment branch of our office. Every effort seems to be made to keep in anybody who can possibly scrape through; but the arm of that branch is not long enough to 
reach the country Postmasters, who get rid of the unsatisfactory lads before the boys become too old, and so they never come under the notice of the appointment branch of the Secretary's Department.

Q. Can you tell us what certainty a telegraph messenger has of becoming a postman, if he is of good conduct and gives satisfaction to the Department?

A. Hitherto I think there have been more than enough vacancies to provide for good telegraph boys.

Mr. Walpole: Is it not the case at Birmingham that they have been unable to provide for the whole number of telegraph messengers, and that in consequence the Postmaster has made a strict weeding-out at 16?

A. That is not in accordance with my recollection. Until recentlythat is, until the last three or four years-at Birmingham the telegraph messengers were regarded as a very unsatisfactory body of persons to make postmen of, and the Postmaster was so loth to take them that he used to bring young men in from the country in preference.

Sir F. Mowatt: For medical reasons?

A. Yes, for medical and general reasons. The boys were not a good enough class. In a thriving city like that, where there is such ai great variety of employment, the pay we offered was not enough to get a class of boys fit to make into good postmen; but Birmingham is perhaps rather an exceptional town in that respect. The Postmaster, who is a very capable man, seeks to get rid of the superfluous or unsatisfactory boys early enough to give them an opportunity of getting on elsewhere, instead of keeping them until they are too old.

The Chairman: Are any proportion of the sorting clerks' pläces open to telegraph messengers?

A. Yes, in the country; open in a sense, that a Postmaster, if he has a telegraph boy who gives good promise of being fit for a sorting clerk's place, might get him such an appointment. And, so far as I have observed, the smaller the town the better the class of boy we get for telegraph messenger. In the large towns-take London, for instance-many people don't like the lads to have the run of the streets at 13 or 14 years of age. At Dublin, there is, in addition, such a dislike of wearing uniform that you cannot get a good class of boys as telegraph messengers, but in a country town like Colchester, or towns of that size, we get a good many telegraph messengers, whose fathers are tradesmen in the place, and who have had a decent education. In the aggregate, many telegraph messengers have been appointed sorting clerks, or have been made telegraphists.

Q. You have no fixed proportion of the sorting clerkships set aside for telegraph inessengers?

A. No.

Mr. Walpole: That is left in the country entirely to the discretion of the Postmasters?

A. YES ; the Postmaster would naturally take an intelligent and wellbekaved boy whom he knew in preference to a stranger.

Mr. Llewellyn Smith: I presume the scale for telegraph messengers is not the same all over the country?

A. No.

Q. Then it can be adjusted in order to get the best boys?

A. In the main, they are paid by results, say $\frac{1}{2} \mathrm{~d}$. or $\frac{3}{4} \mathrm{~d}$. for each telegram delivered, or even 1d. in some cases, or less than $\frac{1}{2} d$. in other cases, according to what we call the docket rate. It is fixed at such an amount as will secure us the boys we want in different towns.

Q. When it breaks down in a city like Birmingham, that object is not realised?

\section{A. Yes.}

Mr. Walpole: But you have power to raise the docket rate?

A. Yes; certainly we can raise the docket rate where necessary. I think that Birmingham stands by itself. 
Mr. Smith: There you have a very large number of small workshops where boys can find employment?

A. Yes.

The Chairman: Have you any complaints from telegraph messengers of being turned adrift after being some time in the employment of the Post Office?

A. No.

Q. Of course I mean without proper cause?

A. I think I should have heard it if there had been such cases. I may mention here that it seems to me that the proper way out of the difficulty of finding places for telegraph messengers is for the office in London, or whatever it may be, to ascertain the probable number of vacancies in the ranks to which telegraph messengers can rise, and to weed out the staff at 16, so as not to have more left at that age than can fill those vacancies.

Mr. Llewellyn Smith: You would squeeze out more at 16 years of age?

A. Certainly, so as not to have many boys for whom we cannot find places, or whom we have to make auxiliaries for a considerable time.

Sir F. Mowatt: You would discontinue a boy at 16 for fear you should have to discontinue him at 18 ?

A. Yes; that seems to me the best way out of the difficulty.

Q. When do they enter as a rule?

A. From 13 to $15 ; 13$ is the minimum, I think.

Mr. Llewellyn Smith: You get them straight from school in many cases?

A. Yes, subject to examination.

The Chairman: What are the limits of age for appointing provincial postmen?

A. From 18 to 30 years, with an extension in the case of pensioners and army reserve men.

Q. Does that apply to all the different classes you have mentioned?

A. Yes ; I believe so.

Q. You require them to pass an examination?

A. Yes, a very simple one. Writing tolerably a few lines, reading manuscript, and addition-simple and compound. These subjects seem to us exceedingly simple, but I remember 30 or 35 years ago we had often difficulty in getting postmen to pass that examination. The rule was that if the vacancy was in England or Scotland, we nominated two or three men, because if we had only nominated one, and he had failed, we should have had the trouble of a second examination. In Ireland a candidate was more sure to get through, but was not worth so much when he had passed; we would often much rather have an Englishman or Scotchman who could not pass than the Irishman who could. (Laughter.)

Sir F. Mowatt: The Irishmen, then, have a large faculty for passing examinations?

A. Yes, for passing examinations, but not for being useful. (Laughter.)

The Chairman: Do you have many cases of rejection for not being able to pass an examination?

A. I cannot conceive that we have. This educational examination is the commonest drug in the market, and it would be rather difficult to get any person who could not pass it. A man who did fail might be entitled to some superior appointment. He would be a remarkable person. The candidates are much more frequently rejected on medical grounds, or on account of character.

Q. What are your rules with regard to medical examination in the provinces?

A. Exactly the same as in London. The candidate is examined by the local medical officer.

Q. The same period of probation?

A. Yes ; two years.

Q. Can you tell us what are the ordinary duties of a country postman?

A. The ordinary duties consist of the collection and delivery of postal 
packets of all kinds. In large towns in the provinces some postmen are specially selected to act as stanpers, messengers, and sorters, and they receive special allowances ranging from 2s. to $7 \mathrm{~s}$. a week. The higher allowance of $7 \mathrm{~s}$. is usually confined to postmen who divide the letters into walks for a number of postmen. They have to do really good work, and night work. Some men divide 20 or 30 lots of letters for different walks. There may also be one or two men who get $7 \mathrm{~s}$. a week for acting as foreman mail porters, as at Crewe or Stafford, and who take charge of the other mail messengers: otherwise the allowances are from $2 \mathrm{~s}$. in the small towns to $5 \mathrm{~s}$. in such towns as Liverpool and Manchester.

Q. Can you tell me what are the scales of payment for these different classes of men?

A. Yes; taking first the provincial town postmen, the highest scale is $17 \mathrm{~s}$. rising by $1 \mathrm{~s}$. to $30 \mathrm{~s}$., and the number of men on that scale is 2,888 ; the next scale is $17 \mathrm{~s}$. by 1 s. to $28 \mathrm{~s}$, , and the number on that scale is 1,994 ; the next scale is $17 \mathrm{~s}$. by $1 \mathrm{~s}$. to $26 \mathrm{~s}$, , at which the present numbers are 2,308 ; then come those at $17 \mathrm{~s}$. by $1 \mathrm{~s}$. to $24 \mathrm{~s}$., total 1,$842 ; 16 \mathrm{~s}$. by $1 \mathrm{~s}$. to $24 \mathrm{~s}$., total 784 ; next, 16s. by 1 s. to $22 \mathrm{~s}$., total 1,732 ; next, $16 \mathrm{~s}$. by 1 s. to $20 \mathrm{~s}$, total 3 ; then there is a scale of $15 \mathrm{~s}$. by $1 \mathrm{~s}$. to 20 s., total 64 , which latter is confined to Ireland.

Q. Can you tell me on what principle these various scales are based?

A. They are based, so far as we could, according to the value of labour in the several towns and the cost of living. Up to the time of the Fawcett revision in 1882-in which about $\$ 100,000$ was spent on the postmen-the wages in each town were fixed independent of any other town, according to what it was found necessary to pay in that particular town. As long as we could get a sufficient supply of qualified men, we did not increase the pay. Mr. Fawcett's scheme was really in disregard of that standard, and the wage of the postmen in each town was raised by 2s., so that those towns where the wages were already high, having been fixed at a higher amount owing to difficulty in getting the people we wanted, remained relatively high. In the revision of Mr. Raikes in 1891, as regards the town postmen, we followed pretty much the same practice, and added $2 \mathrm{~s}$. all round, and with the same result-that the large towns where we knew the cost of living was greater got the higher scale.

Q. Is it not possible that as the result of that scheme you are in some places paying more than the value of the labour, while in other places you are paying less than the value of the labour?

A. I should say that in all places we are paying more than the value of the labour, but in some places less so than in others.

Q. As I understand, your principle in calculating wages has been based not on the value of the services but on what you consider to be the rate of wages in the particular plae $\mathrm{s}$ for analogous duties?

A. All the revisions before Mr. Fawcett's time have followed from ex. perience.

Q. It seems to me that you pay a different rate of wage in two different towns of a somewhat similar character for exactly the same work?

A. Yes. We are always getting applications, and we are always trying to put people on an equality, but it is a very difficult matter to decide.

Sir F. Mowatt: The expenses of living are different in different towns?

A. Yes; but in every town the men one and all declare-and, I think, honestly believe-that their town is the very dearest in the whole of the United Kingdom. I have never been in a place where they did not tell me that. They always say that, and they always think it.

The Chairman: In these different revisions have you taken any means to ascertain what is the difference in the cost of living in these various places?

A. Yes; we have collected a great deal of information, which will be found in the appendices to the report of the Committee on Postmen of 1890-91. 
Mr. Walpole: When these applications for increased pay come before us, don't we take care in every case to find out what is the pay of the police, or other typical kinds of labour in those places and compare them?

A. Yes, we do ; and we endeavour so far as we can to deal equally with the postmen in towns of like importance, but it is very difficult to decide whit constitutes equality. In the old days we gave more pay when we found that we could not get men, and it was easy then to find out what we must pay; but practically in all towns at present we are already paying more than we need to in order to get and keep the class of men we want.

The Chairman: You have nine different scales for town postmen in the provinces. Don't you think it is possible to simplify these scales and reduce their number?

A. I think they could be reduced somewhat, but it seems to me that there ought to be a marked difference between the pay of postmen in very large towns and the pay of postmen in smaller towns. The value of labour and the cost of living are greater in the large towns.

Mr. Walpole: Have you observed from the general report on the wages of the labouring classes in the United Kingdom that there are in it similar variations in the price of labour as there is in our Service? Are there not varying rates of labour in different trades in different parts of the country, such as Lord Tweedmouth has referred to in the Post Office?

A. Yes.

Q. In the case, for instance, of the masons, do not their wages vary from $29 \mathrm{~s}$. to $39 \mathrm{~s}$. $5 \mathrm{~d}$. per week, and so in other trades?

A. Yes.

Mr. Llewellyn Smith: I suppose the smaller number of scales you have the greater will be the certainty that you will be paying too much in some places and too little in others, considering the enormous number of variations in the cost of living and in the rates of wages throughout the country.

A. I don't think we ever pay too little to get the class of people we want.

Q. That depends on what you want. There might be the alternative of paying low and getting bad services, and paying dear for good services.

A. We have always paid enough to get and keep the men we wanted.

Mr. Walpole: Is it not the case that the wages of masons in Lancashire vary from $29 \mathrm{~s}$. to $35 \mathrm{~s}$. 9d., a difference of $6 \mathrm{~s} .9 \mathrm{~d}$. ?

A. Yes.

The Chairman: But your variations are more; they are from 20s. to 28s.?

A. That may be so at the maximum, but not at the minimum. I may mention a kind of case we have not infrequently to consider.

Mr. Walpole: There are only three mén at 20 s.

The Chairman: There are also the Irishmen.

Witneśs: In a large town in the West of England there are postmen who ask for more wages, and they point to the fact that similar towns in the North of England have perhaps better pay than themselves. We are perfectly well aware that in these towns in Lancashire, all within moderate distance of Manchester or Liverpool-great manufacturing centres-the value of labour is higher than in the West of England, even though the town in the West of England be larger than some of the Lancashire towns to which I have referred. So far as I have had any voice in settling such a demand, I have adhered to the value of labour. It does not matter so much what the size of the town is as what the value of labour is. In the Lancashire towns, if we were to cut down the pay to the lowest scale, we could not get the people, although very likely we could get them in the west country.

Sir F. Mowatt: With regard to the two lowest scales, 16s. to 20s., and $15 \mathrm{~s}$. to $20 \mathrm{~s}$., there appear to be only 67 men in both of them together? 
Q. So that we may take the real minor scale as 16 s. to 22s.?

A. Yes. The junior town postmen are a small moribund class at certain large towns in England and Wales.

\begin{tabular}{cccccccc} 
& Scales. & & & & \multicolumn{3}{c}{ No. on Scale. } \\
$15 \mathrm{~s}$. & $1 \mathrm{~s}$. & $17 \mathrm{~s}$. & $\ldots$ & $\ldots$ & $\ldots$ & $\ldots$ & 29 \\
$14 \mathrm{~s}$. & $1 \mathrm{~s}$. & $16 \mathrm{~s}$. & $\ldots$ & $\ldots$ & $\ldots$ & $\ldots$ & 34 \\
$13 \mathrm{~s}$. & $1 \mathrm{~s}$. & $16 \mathrm{~s}$. &. & $\ldots$ & $\ldots$ & $\ldots$ & 8 \\
$12 \mathrm{~s}$. & $1 \mathrm{~s}$. & $16 \mathrm{~s}$. & $\ldots$ & $\ldots$ & $\ldots$ & $\ldots$ & 36 \\
& & & & & & & $\frac{107}{107}$
\end{tabular}

Q. You are abolishing that class altogether?

A. Yes; nobody in that class is supposed to do a full day's work-probably $6 \frac{1}{2}$ hours in a day-but it has been regarded as a stepping-stone.

Q. Have they had other employment?

A. They are supposed to be telegraph messengers who were not quite strong enough to give a full 8 hours' attendance. This scale gave them rather better pay than they got as telegraph messengers, so that it was a rise for the messengers.

Q. You are making no new appointments to that class?

A. I believe not.

Q. You have now something to tell us about the rural postmen?

A. Yes. These were all fixed on weekly wages (not on scale) up to the year 1891.

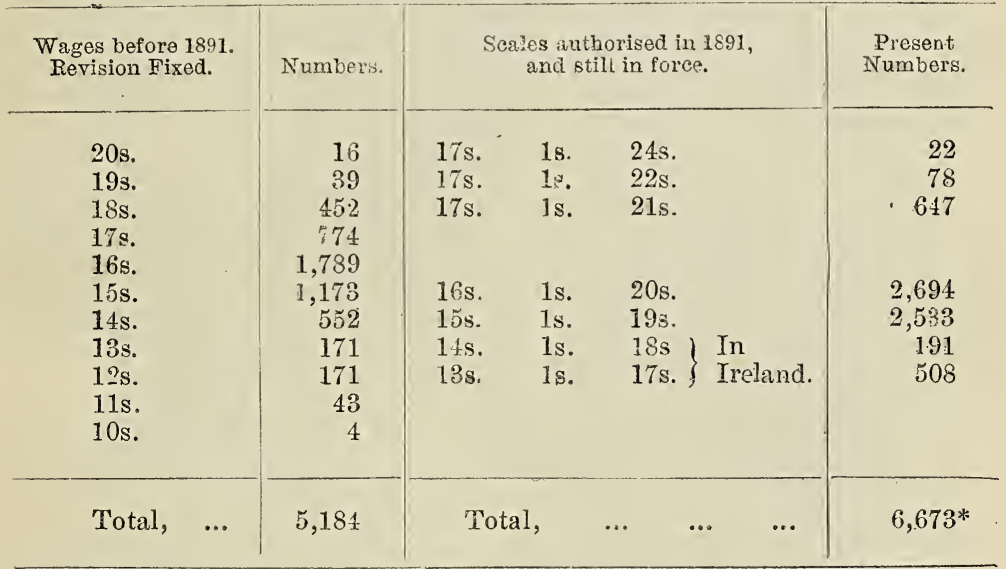

* It will be seen from this that there are five scales applicable to England and two which are only applied to Ireland.

Witness: Perhaps I may mention the fact that Mr. Fawcett's revision of postmen's wages in 1882 was confined to town postmen, and that practically the only advantage which these rural postmen obtained out of that revision was good conduct stripes; of course that was a great advantage. From what the papers in the office show, we know that Mr. Fawcett intended to follow up the revision of the town postmen by a revision of the rural postmen. But this was not done, and from various causes that revision did not come until 9 years later. In the interim a great deal was done to incrwase the pay of the rural postmen one by one, even for 10 years prior to the revision of 1891 we had done a good deal, for we learned 
that in many cases the rural postmen were not paid enough to induce them to stay in the Service. That was a case of being guided by the law of supply and demand. I have already quoted the scales authorised in 1891 and still in force.

Q. In these scales I suppose you are governed by the same general ideas?

A. Yes; we fixed the scales for the rural postmen in relation to those of the town postman.

Q. Do not the classes of town postmen and rural postmen sometimes tail into each other ; in the case, for instance, of rural postmen starting from a town office and doing similar work?

A. Yes; in the Committee of 1891 we recognised that there were no sufficient grounds for paying rural postmen who started from a town office less than town postmen who worked in the town, but their pay previously was so very much less that we were afraid to propose to put them on an equality.

Q. Still, so far as you have gone, you would be of opinion that the rural postman who lives in a given town and starts from the head office of that town to deliver in the rural districts ought to be on the same scale of pay as the town postman there?

A. Yes, certainly.

Mr. Walpole: In certain cases we promote the rural postmen starting from a town to town postmen's places?

A. Yes.

Q. So that practically such a man has a chance of reaching the town postmen's maximum?

A. Yes; but when a man has been a rural postman for 8 or 10 years he is often not well fitted for the position of town postman. He does his own work well enough, but he is slower and quieter, and the Postmaster does not always like to bring in a man who would not be quick enough for the town work.

The Chairman: Then what is your rule with regard to the pay of auxiliaries?

A. Our rule, I think, is this-At present we pay not less than $4 \mathrm{~d}$. an hour, but when a man does two duties, or even when he is in a large town, or where labour is scarce, we pay somewhat more; but with regard to auxiliaries we adhere much more strictly to the plan of fixing the pay at what we can get suitable persons for than we do in the case of the town postmen.

Q. What is your maximum pay per hour to an auxiliary?

A. A little over $5 \mathrm{~d}$.

Mr. Walpole: That is in the provinces?

A. Yes ; a little over 5d. is the highest.

Q. Whether in town or country?

A. Yes.

Q. It runs from $4 \mathrm{~d}$. to $5 \mathrm{~d}$.?

A. Yes; that is below the mean, and much below the maximum rate of pay per hour for established men, who have many advantages which the auxiliaries have not, but in the case of the auxiliaries we have gone on a different principle, and we have fixed their pay according to the market value of labour.

After a short adjournment the examination of the witness was resumed :-

The Chairman: Besides these wages, what other advantages in the way of allowances, or stripes, or uniform, etc., do they get?

A. In the first place they are entitled to three good conduct stripes under the terms already described, two being certain, and the third being given according to the number of vacancies.

Q. Then you have a limit also for the rural postmen as to the third stripe?

A. Yes ; the same limit-one-third. 


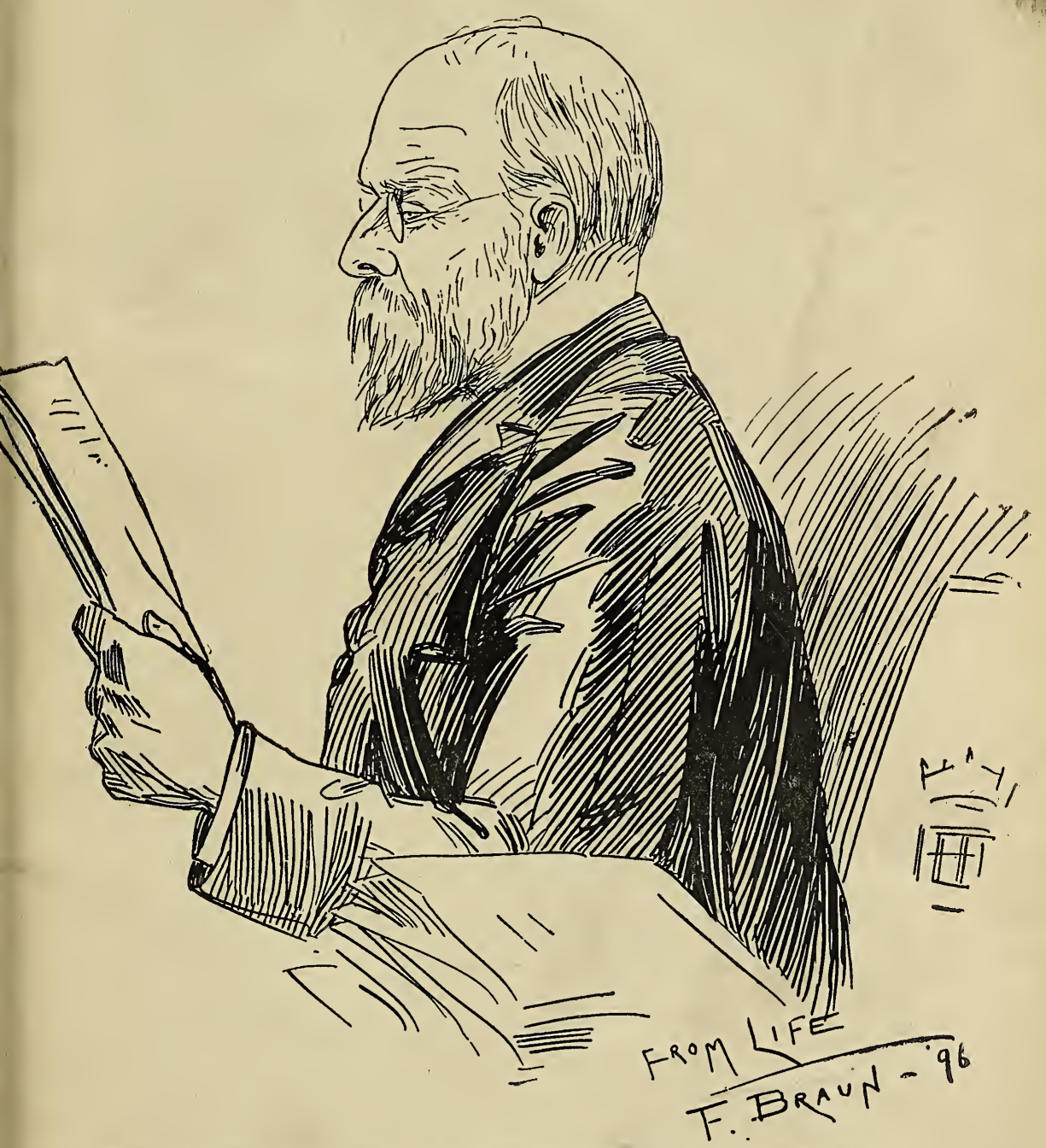

E. B. LEWIN HILL, Esq., Joint Third Secretary to the Post Office.

Departmental Witness for the Provincial Cuse. 

Q. Amongat the rural men have you any who have been refused the third stripe?

A. I think there are some in one or two districts.

Mr. Walpole: Is it not the case that we are altering the whole system, and, instead of breaking up the country into so many districts for the purpose of apportioning these stripes, we are treating the whole country as one district?

A. Yes; so as to secure equality in the allotment of the stripes.

The Chairman: Your axiliaries have no stripe?

A. None.

Q. The auxiliaries have none of these advantages except the uniform?

A. That is the only advantage they have; I think in some places they are allowed to see the doctor.

Q. The established men invariably have medical attendance?

A. Except in the very small towns, where there is not a sufficient num. ber of postal patients to induce a doctor to accept our terms of $7 \mathrm{~s}$. or $8 \mathrm{~s}$. per head.

Mr. Walpole: The established men have access to a doctor whenever there is a medical man to have access to?

A. Yes. In addition to free medical attendance and free medicine, the postmen have full pay during sickness, and pensions, and-what is still more important-permanency of employment. In that respect all of us in the Postal Service stand in a unique position. From top to bottom our men are certain, as long as they conduct themselves reasonably well, to retain their maximum pay down to the last day they remain in the Service, and whatever their class may be, whether postmen or sorting clerks, or telegraphists, or officers of higher grade, they continue, failing misconduct, to rise to the maximum pay of their class quite regardless of whether they are worth the higher pay that they get from year to year. When a postman gets past the bast of his work, and can no longer get the same full duty, he is allotted easier and let down easily, so that he may hold on to the Service with the maximum pay given to the class so long as there is any pretence for doing so. And that certainty of employment seems to me to be the most marked advantage that we Civil Servants have over outside employees. We never fear the failure of our employers. We never fear the caprice of our employers, but we are as certain that week by week we shall get our pay-that is, in the cases where it is paid weeklyas we are that the sun will rise to-morrow; in fact, the only doubt is whether we shall be alive to receive it. Then, as the Chairman asked me as to what the advantages are, I should add that there is the fortnight's holiday.

Q. I was asking more about the money advantages at the moment, leaving over the holiday question for the present. Your view is that the provincial postmen are paid a full wage already?

A. I hold that the provincial postmen and the London postmen, too, as a body, are not only paid fully up to the market value of their labour, but in excess of the market value of their labour. ("Oh, oh.")

Q. Have you any comparative evidence of the wages paid to postmen in other countries?

A. The Committee have already heard a statement of the rate of postmen's pay in the United States. Some witness showed that the wages there are much higher than here. I was recently in Belgium and in Paris on Post Office business, and I learned the rate of wages paid in each country, but I am sorry that I omitted to note with sufficient care the rate of wages in France. They were, I think, a little higher than in Belgium. In Brussels, Antwerp, and Gihent, and a few other of the larger cities, the postmen's pay is a little under 16s. a week to start. They get 1,000 francs a year to begin with, and rise to a maximum of $21 \mathrm{~s}$. 6 $\mathrm{d}$. per week. The increment is not given to then every year, but when it is given it is an increment of $1 \mathrm{~s}$. 6d. As a rule, a postman there does not reach his maxi- 
mum of $21 \mathrm{~s}$. 6.d. a week until after about 20 years' service. The increment there is given according to the state of the Budget, and the Budget is wa.tched with much closer interest than the accounts of almost any other Grvernment department that I ever heard of. The postmen, at all events, are always very eager to know whether it is a good Budget. In Belgium and France the postmen have much greater money responsibility than our pastmen, because they collect commercial bills. At a little town, about 10 miles from Brussels, I found there were four rural postmen. These men, like others of their class, collect commercial bills, more especially about the middle and end of the month. I was at that office just after the end of the month, and I found that in the preceding week these four rural postmen had brought in $£ 1,200$ in negotiable securities, bank notes, and such like. Those who bring in large sums get a little allowance for it. It was very small-I forget how much-but the responsibility of the men in that respect is proved by the fact that every rural postman there is bound to carry a revolver, because he might be murdered.

Sir F. Mowatt: They were probably not paid the full rate of wages paid in a larger town?

A. No; I think they were not. The authorities divide the towns into three or four classes; Brussels, Antwerp, and Ghent were, of course, reckoned among the large towns; I forgot to ask what their scale was in th:ese places.

Mr. Llewellyn Smith: Do you remember the scale in Paris?

A. Not the particulars; it was a little better than in Belgium, but not very much.

Q. The general rate of wages in Belgium is much lower than here?

A. Yes, no doubt; but as some evidence was given as to the rate of wages in New York, I thought it only fair to quote the rate much nearer home. One may, perhaps, have as little bearing as the other as to what would be the proper rate of wages here.

The Chairman: What ground do you put forward for believing the present rate of wages here to be sufficient?

A. These grounds:-We are always beset with requests from persons who, so far as we can judge, are really suited for the work, to be allowed to enter the Service as postmen, and the same applies to sorting clerks and telegraphists. I think that would be the experience of most of the men in the higher grades in London as well as in the country. We know from wide experience that any number of people will be delighted to come into our employ, people who are fitted for the employment, and who are greatly disappointed when they learn that there is no chance of their admission.

Q. At the present rate of wages?

A. Yes ; certainly.

Q. And in all classes?

A. Yes; not only with postmen, but all through.

Q. I am pointing rather to your lower paid classes, such as the rural postmen and auxiliaries?

A. I might not get so many applications for auxiliaries. I do occasionally get some and send them to Mr. Badcock. Another piece of evidence in my mind is, that very few postmen resign except on account of ill-health. I have got a return here with reference to the E.C. District, and last year the number of resignations of postmen there is stated to have been only five, of whom two resigned to escape dismissal, two obtained better places, and with regard to the fifth I am not clear why he went. Now, the number of postmen in the E.C. District is over 1,000 - between 1,000 and 1,100. Then we know that if a postman is threatened with dismissal he makes a most earnest appeal to be allowed to stay on, and if he is once dismissed we are beset with requests from all his friends that he may be restored. That would not be the case if the situations were not valuable to the men.

Mr. L. Smith : Still, nobody likes being dismissed. It is rather a slur, . 
A. They don't like being called on to resign.

Q. If they applied for other employment would they not be asked the cause of leaving the Postal Service?

A. I suppose they would. When we had the postmen's strike in 1890, which took place before the improvement in scale introduced by Mr. Raikes was carried out, some hundreds of postmen were dismissed for actually striking, or for gross insubordination, and with scarcely an exception these men did their utmost to be taken back; in fact, only the men of really bad character were in the long run excluded from the Service. Even men who were on the unestablished class who came on at 18s. per week, and could not rise above 19s. per week, were most anxious to be restored. I remember in one case the son of a carpenter was being dispensed with, and his father was so eager to get him taken back that he walked some seven miles to my house to plead for the boy's restoration. I pointed out that the boy's prospects were very poor even if he were taken back, as he could only get 19s. a week, but the father said that he considered 18s. a week was very good pay at the boy's age for the work he had to do.

Q. Where was this?

A. In the London District. He worked at Mount Pleasant.

Mr. Ilewellyn Smith: The rates of pay for carpenters in the London District are much better, and therefore I suspect that the lad could not have been very bright, or the father would have brought him up to his own business.

A. The lad looked a nice young fellow enough, and, of course, some account was taken by his parent and himself of his chance of getting on the establishment. The lad was restored, but was got rid of, as he could not pass the doctor.

Q. Does this case not prove too much? You would not suggest that 18s. or 19s. is not below the usual London rate of wages?

A. No; but many persons are desirous of getting into a service where they get such wages. Coupled with other advantages, there is good reason to believe we are paying more than the market value of labour.

The Chairman: Do you think there is any other particular class of employment which is particularly comparable with that of the postmen?

A. I thought of railway servants, whose work in many respects resembles the work of our employees. If they have not the same permanence as our people have, they have continuous employment so long as they are efficient, but our people have continuous employment whether they are efficient or not practically.

Q. Railway men are not very comparable with postmen, are they?

A. No. I mention them as a class of men who have permanent employment. I should say that a common carrier is not unlike a postman; a good comparative case might be made from one of Carter Paterson's men, who undertake to carry and deliver valuable packets and parcels, as well as collect the money for them. They collect the money on delivery, and receive parcels, and, I suppose, act as a kind of Carter Paterson Post Office Guide to their customers.

Sir F. Mowatt: Do you know the scale of pay for these men? Do you quote them as being much better off than the postmen?

A. No ; they are much worse off. I have some particulars of a case of a railway man whom I know personally. His work is not only more responsible and difficult than that of a postman, but more responsible and difficult than the work of an ordinary sorting clerk and telegraphist. He is called a parcel porter, but he is in reality in charge of the parcel work at his station, which has a considerable traffic-say 1,000 parcels a week. He takes in and sends out for delivery all parcels. For the parcels taken in he receives the money, and has, of course, to see that the right amount is paid in each case. He deals with all cases of delay or lost parcels at his station. He keeps all the accounts relating to his work. He corresponds direct with the public, and signs all ordinary letters to them-it being left 
to his judgment which letters he shall get the station-master to sign. His hours are between $60^{\circ}$ and 70 hours a week, including Sunday work, for which no extra pay is given. He has been in the service for 15 years, and is about 40 years of age. His wages are $23 \mathrm{~s}$. a week, and he has no chance of any further rise. In his town a sorting clerk of 15 years' service gets 40 s. a week, and a postman 27s. a week. He gets no pay whatever when away sick, gets no free medical attendance like other people, and has no claim for a pension, but may, if he lives to 60 years of age, perhaps get as an act of grace a retiring allowance of $7 \mathrm{~s}$. or $8 \mathrm{~s}$. a week. As he gets to be old and less useful his pay may be cut down. He gets three days' holiday a year and no overtime pay except at Christmas. This man is much above the average in intelligence. I think the man's pay miserably low, especially as the railway company is very prosperous. Still, the man will not throw up his appointment because he does not know where he can earn more. He was astonished to learn of the pay our people get, and wishes that he were fortunate enough to be in the service of the Post Office. He and other railway employees have told me that the pay and conditions of work in the Post Office Service are known to be exceedingly good. I remember, many years ago, that the late Sir Rowland Hill, in the course of a discussion on the question of wages, pointed out to us one effect of raising wages above the market value. It was this-While thus to raise wages was an undoubted benefit to the individuals in employment at the time, it was equally an undoubted injury to their class, as the inevitable effect of a rise of wages under such circumstances was to bring another class with superior qualifications into the field, and thus to oust from employment men who were able to do the work required sufficiently well, but who were not able to do the superior work which those who superseded them could do. The tendency is to drive these men into what is, I think, called the submerged tenth.

Mr. L. Smith: Do you consider that that effect has been brought about in the Post Office?

A. I don't think it has. We have been compelled to take telegraph boys, and that has handicapped us. I am sure we could have got better men than we have got if we had had a free hand.

Q. Why are you handicapped? Why not get a better class of telegraph boys? They know their prospects?

A. I think that as a rule decent people who take care of their households strongly object to the street life of the telegraph boy. That is a great obstacle to our getting a better class of boy. When a youth reaches 19 or 20 years of age there would not be the same objection on the part of parents to his doing the street work of a postman.

Q. Do you think that objection is well founded-that the work is bad for the boys?

A. I think it is to some extent. I have been told so.

Q. You think that boys deteriorate under it?

A. So I am told.

Q. Do you think the boys in London deteriorate?

A. Some years ago they could scarcely deteriorate, they were so bad. I think it is injurious for a boy to be out on the streets at 13 or 14, to be chaffed and to be larking about.

Q. More than in the case of errand boys?

A. People are not generally fond of their sons being errand boys.

Q. Still, a large number on leaving school pass a certain portion of their time as errand boys, even if they are going into a trade?

A. Yes.

Q. Is there any particular disadvantage attaching to being a telegraph boy which would make parents who are quite willing to let their sons be errand lads be reluctant to let them become telegraph messengers?

A. They meet in large numbers; an errand boy may not have another boy in the same shop with him-that is all. 
The Chairman: But in the large towns there is considerable control exercised over the boys by the Department?

A. Yes; but in the bigger towns I think we get the inferior boys. The smaller the town the better the class of boy.

Mr. L. Smith: How is that, with other splendid prospects and advantages which you have pictured?

A. I think the more you raise the wages the more you will raise the class of telegraph boys. Reverting to the larger question, I ask myself what significance should be attached to the general demand of the postmen and sorting clerks and telegraphists for higher wages? Does this demand warrant the kelief that the pay is a hole is insufficient by any standard you like to adopt? I think not. Postmen, in common with other Post Office employees, are well aware that in asking for more pay or for other like advantages, they do not run any risk of losing their situations, while there is always the chance of getting some concession. Under these conditions they naturally put forward demand after demand, and in my opinion they will continue to do so whatever concessions may be made to them from time to time. It is my full belief that if one and all of the present demands were complied with, fresh demands would spring up in a short. time, if successful or not, to be followed by others. I don't blame the men for it; any man who by asking may get something and will not lose anything is sure to ask. When the Committee on the Indoor Staff under Mr. Raikes, in 1890, considered their proposals, which were adopted, the opinion was expressed by the majority of the Committee that if these concessions were made that would be the end of all agitation. I remember myself saying, "Whatever else happens that will not happen; don't delude yourselves with the notion that the men will cease to ask." Mr. Raikes' improvements were received with the greatest gratitude, and there were any number of letters of thanks from the staff, but the ink was scarcely dry when the demands began again, and they have been going on ever since, and will go on. The conditions of private employment are altogether different. A man knows perfectly well that on asking for more pay his employer may not only refuse to give any, but may go further and give the man notice to quit on the ground that he does not choose to have discontented employees, and can easily supply himself with workmen for the wages he pays. There is, unfortunately, a growing habit among the main body of Post Office servants to use their voting power at elections to get higher pay for themselves, and it is well known that in constituencies in which political parties are at all evenly balanced, the Post Office servants can turn the election. My own view is that the time las come for telling the postman, in common with the members of the rest of the manipulative staff, in answer to their demand for a general rise of wages, that the Department is satisfied that the wages already paid are in excess of the market value of their services; that this being so no general addition to pay will be given, and that if the staff are dissatisfied and can do better for themselves outside the Post Office. they are, as they know, at perfect liberty to seek employment elsewhere. (Hisses, which were sternly repressed by the Chairman.) That, at any rate, is my view.

Mr. Walpole: You will admit, I suppose, that there are cases where the pay is too low?

A. Yes; I admit that. I was speaking of general demands. The Department Committee of 1890-91 recommended that the increments for town postmen in large provincial towns with the higher maximum of $26 \mathrm{~s}$. and upwards should, after the first two increments, be 1s. 6d. instead of 1 . In the case of the London postmen who were on the scale rising to $30 \mathrm{~s}$, , the Committee recommended that they also should have the 1s. 6d. increment. I imagine the reason was that they began at $18 \mathrm{~s}$., whereas those in the provinces began at $17 \mathrm{~s}$. I was on that Committee, and concurred in their recommendations.

The Chairman: You think the increment is too small? 
A. Yes. Mr. Burnett, the labour correspondent of the Board of Trade, gave evidence before the Committee of 1891, and his evidence might be useful to your Committee. He expressed the opinion that with the minimum which we give the rise was too slow, but he also expressed his opinion that the maximum we give in the large towns was sufficient-that was before we raised the maximum. He thought the postman ought to reach the maximum in five or six years, and that it was not necessary to pay any more after that.

Mr. Walpole: The gist of his evidence was that the minimum was too low and the maximum sufficiently high?

A. Yes; and that the increment ought to be larger. The cost of improving the provincial postmen's scales would, at the mean of 17 rea"s" service, be $£ 15,802$ a year, and 7,190 positions would be improved.

Q. That is for the provinces only?

A. Yes. The cost of improving the London postmen's scales as recrimlmended by the 1890-91 Committee would be £21,206 a year, and 5,083 positions would be improved. If the maximum limit carrying the improved increment were fixed in London as in the provinces at 26s. per week. the cost would be £21,417 a year, and 5,298 positions would be improved.

The Chairman: That leaves the rural postman entirely out of consideration?

A. Quite so. The total cost of giving an improved increment to all town postmen in London and the provinces whose wages rise to as muci as 26s. per week would be $£ 37,219$ per annum, and 12,488 positions would be improved. Of course, the increased cost of $£ 37,219$ would not be reached for some years to come, as many of the postmen are now well on their way to the maximum of their scale. It would only occur when the class of postmen was entirely composed of new-comers.

Q. Is the practice of Christmas boxes usual throughout the provinces?

A. Yes.

Mr. Walpole: You said you were in favour of a higher increment in certain cases?

A. Yes.

Q. Do you think our minimum wage is sufficient in all cases?

A. I rather doubt it.

Q. Do you think if we were to take in hoys possibly it is sufficient?

A. Yes.

Q. Even when, for some reason or other, a boy is kept at auxiliary work for two or three years until he is 20 ?

A. I think it would be a great convenience if we had an entrance wage according to a person's age.

Q. You do not think our wage is sufficient for adult labour?

A. Not in some cases. Very often a young fellow of 18 is tempted to marry.

Q. I understand your position. You think the initial rate is sufficient for a lad of 18 , but not for a man of 22 or 23 years?

A. Yes.

The Chairman: And you think we had better keep it low in order to remove from him the temptation of marrying?

A. Yes.

Mr. Llewellyn Smith: You would graduate it according to age?

A. Yes.

Q. And go on to a certain scale?

19

A. Yes; suppose a telegraph boy ceases to be a telegraph messenger at

Q. What wage would he then be getting?

A. 11s. per week.

Q. That is in London?

A. Yes; it would not be so much in the country.

Q. He would go in as a postman at 18s.? 
A. Yes.

Q. After that would you increase his increment?

A. Yes; every year or every two years.

The Chairman : And now as to the Christmas boxes in the provinces.

A. Yes.

Q. Is it usual to give them?

A. In the provinces about one-fourth of the men in the postmen's class get no Christmas boxes at all. Their duties as stampers, railway messengers, etc., preclude them from getting any.

Q. They would get a special allowance?

A. Yes; they get an allowance instead of Christmas boxes, and it is such as to make the men willing to forego the Christmas boxes and take indoor duties.

Q. Are there any special rules about the solicitation of Christmas boxes?

A. They are the same as in London.

Q. You allow it on the part of letter-carriers?

A. They are allowed to ask, but not to insist.

Q. Do you think it would be possible to prohibit Christmas boxes?

A. I think it is possible to prohibit solicitation, and I think it possib'e also that the effect of not allowing our people to ask for them would be that gradually the practice of giving them would cease.

Q. You think it is quite possible by regulation to practically destroy them?

A. Yes; if one judges from what has occurred in the cases of other classes. For instance, the police are not allowed to ask for them, and I think they get very few.

Mr. Walpole: But the police go round for other objects-to sell tickets for charitable institutions?

A. Yes ; for orphanages and things of that kind.

Q. They go round and sell tickets for entertainments, and we should not allow our men to do that.

A. But postmen do sell tickets in the City. I buy some every year. I may also point out that the parcel postmen have no right to solicit Christmas boxes, and they practically get none.

The Chairman: I quite agree that they are not allowed to ask, but I do not think it has been proved they received none

A. I think one man said he got 1s. $6 \mathrm{~d}$. a year.

Sir F. Mowatt: 'No doubt that was absolutely correct as he put it. $\mathrm{He}$ was asked "How much do you get?" To that he made no answer. Then he was asked, "How much do you get without solicitation?" and he replied, "1s. 6d."

The Chairman: Supposing Christmas boxes were abolished, would you recommend some allowance in lieu of them?

A. Yes.

Q. What do you suggest?

A. I do not think the men should have an equivalent in wages for not receiving Christmas boxes. In the first place, wages count for pension, and in the next place they count for overtime. Wages are a certainty, and Christmas boxes are not, as the men have told us, and I believe it. The collection of Christmas boxes is disagreeable-the men are finding it increasingly disagreeable. I think they ought to have some compensation for the loss of them. Then I think it should be borne in mind that to whatever extent the prohibition of solicitation of Christmas boxes prevents them being given, the money spent by the Department to compensate for them is not lost to the country, but is returned in one form or another.

Mr. Smith: I think we have been told that in some towns in the north of England and in Scotland the men do not collect them?

A. In some Scotch towns the men will not ask for Christmas boxes, but that, perhaps, is because they have no chance of getting them from Scotchmen. (Laughter.) I am sure that the indisposition to ask for Christmas 
boxes, and the feeling of humiliation in doing so, are feelings that will grow on the part of our people. It is a right feeling for the men to have. We cannot deny that, although the Christmas box system has not been officially recognised, yet it has been taken into account in fixing the wages. While looking at the market value of wages, we used tlso to look at the Christmas boxes and other perquisites.

The Chairman: How much sorting work do the provincial postmen do?

A. A great many postmen do it.

Q. What is your view of extending the practice?

A. I see no harm in the postmen doing the sorting.

Q. Do the postmen become sorting clerks to a large extent in the country?

A. They do to some extent, but I do not know whether it is to a large extent. Of course, a sorting clerk in the country has to do counter work, and postmen cannot do that.

Q. You do not think it would be possible in the provinces to recruit the sorting clerks largely from the postmen's ranks?

A. I think we should get a very inferior class of persons to what we now get. In a large country office even professional men go in for sorting clerkships. But they would not go in for postmen's places. The examination which sorting clerks have to undergo is a very easy one, but I do not think that postmen would find it possible to pass it.

Mr. Walpole: Yet you reserve a number of sorting clerks' places to be competed for by postmen?

A. I do not see any objection to that, provided you have a proper standard. The man must show whether he is fit or not.

Q. Would you not get over a great many of the duties with regard to the allocation of duties if you were to dovetail the postmen and sorting clerks into one another? A man might combine certain sorting work with his deliveries, and you could then give him a continuous duty?

A. That is possible; but as for counter work, I do not think the postmen could do it.

The Chairman: I was thinking more about the sorting work.

Sir F. Mowatt: Would they be competent to do the sorting work?

A. Yes; the postmen at Liverpool do it. They do the primary sorting.

Mr. Walpole: At Liverpool it is very much the same as at the E.C.D.O., in London?

A. Yes.

The Chairman: Is it possible to extend that system largely in the provinces?

A. Yes ; I think it is.

Sir F. Mowatt: Do you think that by practice a man could become an adept at both postmen and sorting clerks' work?

A. Yes, easily at both the sorting clerks' and postmen's work.

The Chairman: The postman has to deal with the actual manipulation of letters to a very considerable extent, has he not?

A. He has not to have the very extensive general knowledge which the sorter who has to make the despatches must have.

Q. But the sorter has it not when he first comes into the office?

A. We find that the number of men who have got memories which enable them to make despatches quickly and accurately is comparatively small.

Q. Do you find that in the case of sorters a good many are unable to do it well?

A. Yes. I think Mr. Badcock will bear me out in that. (Mr. Badcock dissented.) I find that a number of men are not sufficiently accurate to sort correctly and quickly.

Q. It is a wonderful thing, then, that our letters reach us so well. (Hear, hear.)

A. Yes. 
Q. Now, I would like to go into the question of holidays?

A. Yes.

Q. What are your rules with regard to holidays?

A. The men have a fortnight's holiday.

Q. Does that apply to all classes?

A. Yes.

Q. But not to the auxiliaries?

A. No, only to the established postmen; but there are some auxiliaries who may get a holiday-such as telegraph messengers waiting appointments. We regard them as part of the establishment.

Q. Have you any rule as to the time of the year when a provincial postman shall take his holidays?

A. They have to take them when they can be spared.

Q. And possibly in the smaller towns, where there are not many postmen, they get what are known as good holidays?

A. Yes.

Q. In London, I think, the postmen get their leave within 8 months?

A. Yes; I believe it is easier to spare them in the summer than in the winter. In London, therefore, the holidays come within 36 weeks.

Mr. Smith: Easier in the summer than in the winter?

A. Yes ; for instance, we do not allow anybgdy to go on leave in December, even if he wishes it. He cannot be spared because of the pressure of business. Among the telegraphists, however, the work is heavier the other way. It should be mentioned that in many provincial towns-whereever we are able to do so without expense-we bring the postmen's leave within 8 months, or we do so even if it causes a very little extra expense.

The Chairman: What is your rule with regard to Bank Holidays?

A. The same rule as has been described for the indoor staff. If a man works on Bank Holiday he has a day off later, but if we cannot give him a day off he is paid for the work. He also gets money if he only works part of the day, unless he prefers to have part of a day off another time. It is the same arrangement as in London.

Q. Would it be practicable in all cases to give a man the choice of either getting the pay, tle holiday, or the time off?

A. I think it would be practicable.

Q. You see no otlier reason against it?

A. It is like giving a man a day's leave.

Q. You already have that rule in regard to a portion of the day?

A. Yes; that is so.

Mr. Walpole: It is always practicable to give a man money, but is it always practicable to give him a holiday?

A. No; I do not think it would be always practicable.

Sir F. Mowatt: But you always give it as an alternative now?

Mr. Walpole: If we can do it.

A. If a man prefers the money he gets it; it does not save us much.

The Chairman: It was suggested to us that provincial postmen might have Saturday half-holidays.

A. I do not think that would bo practicable. We have suspended one delivery in the afternoon in many towns, and where the local authorities agree to it, there is no objection to doing it, but that is not the same as giving a half-holiday to the men; they might get off two or three hours, but in many cases the local authorities object altogether to a complete Saturday half-holiday on the ground that it interferes witl business, and that they cannot do without a delivery of letters.

Q. Even on Saturday afternoons?

A. Yes; and with regasd to the deliveries on Saturday afternoons and evenings, Mr. Arnold Morley objected to the half-holiday, because he thought it might increase the work on Sunday if the last delivery on Saturday were suspended. 
The Chairman: Do you think a suspended Saturday evening delivery would greatly increase the number of letters to be delivered on Sunday morning?

A. Of course it would mean that the letters kept over from Saturday would have to be delivered on Sunday.

Mr. Walpole: And in many cases that would be a serious thing; it would be a serious increase in the number of letters to be delivered?

A. Yes.

Mr. Walpole: In many towns the local half-holidays are taken on Thursdays and other days, are they not?

A. Yes.

Q. And in these cases would the municipal authorities object to the sus. pension of deliveries on those half-holidays?

A. Yes, they have objected, and we have had to restore the deliveries in consequence.

Q. In consequence of local complaints?

A. Yes. I wish to mention something about pensions, with reference to a statement which has been made by one of the witnesses. It was to the effect that postmen rarely lived to enjoy the benefit of the pension offered to them by the Department. The following figures are cited:The total number of pensioners under the Post Office at the present time is 3,873 ; of these 1892 , or nearly 49 per cent., are ex-postmen. In addition to this many officers who served for a great part of their time as postmen appear in the pension list as overseers, inspectors, etc. The established postmen in 1885 numbered 13,500, or 26 per cent. of the total established force. In 1895 they numbered some 26,000, or about 45 per cent. of the established force, so that the postmen, it will be seen, as compared with other Post Office servants, have considerably more than their proper pro. portion of pensions. That the unduly large proportion of pensions is not attributable to early retirement on the part of the postmen appears from the fact that the average age at which a postman takes his pension is 52.7 years, whereas the average age for the rest of the Service is 51.7. I wish next to draw a comparison of pay and attendances as between the police and postmen. The pay of the whole of the police force, including inspectors and superintendents, taken at the maximum of the scales in each case at Birmingham, Liverpool, Manchester, Edinburgh, Glasgow, Leeds, Bristol, Bradford, and Newcastle-on-Tyne, works out on an average of £86 10s. a year per man. The pay of the officers on the postmen's establishment at these towns, calculated on the same basis, works out on an average of $£ 93$ a year per man-an average of $\$ 610$ s. a year per man in favour of the postmen's establishment.

Mr. Walpole: Who are you including in the postmen's establishment?

A. We have taken the maximum. Policemen begin at a higher minimum, but they come in as older men. We have taken in the police, the ordinary constable, the sergeants, the inspectors, and the superintendents; and, on the other side, we have taken into account the postmen, the assistantinspectors, the inspectors, and the special allowances.

Sir F. Mowatt: What do you allow for the postmen?

A. We take the maximum of the scale. Of course, officers belonging to the rank and file in the police are relatively more numerous than in the postmen's class. The actual figures for the several towns are as follows:- 


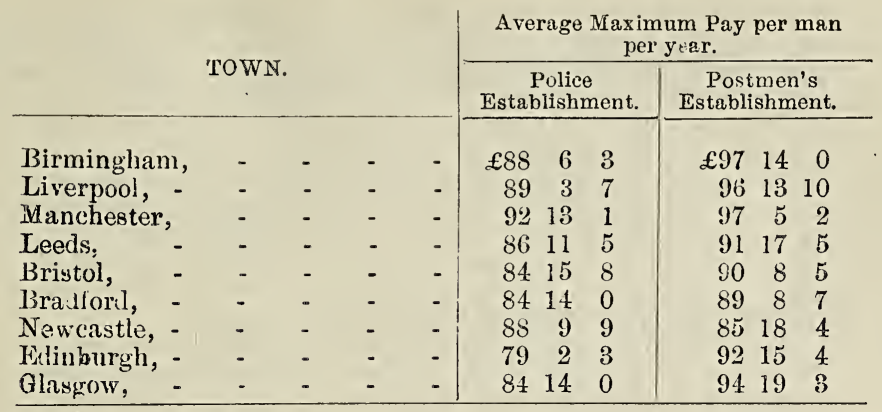

Sir F. Mowatt: How do you arrive at the constable's pension?

A. I did not say pension; it is pay. The average weekly attendance of the postmen at these offices is 50 hours for an average maximum wage of 33s. 8d. a week, whereas the average weekly attendance of the police-constables is $53 \frac{1}{2}$ hours for an average maximum wage of $31 \mathrm{~s}$. a week. This includes good conduct pay for both police and postmen. It does not include allowances for special duties performed by postmen. The annual leave of the police is seven or eight days, whereas the postmen have 12 days a year, and, in addition to this, Bank Holidays, or pay in lieu thereof, and extra pay for Good Friday and Christmas Day.

Sir F. Mowatt: Have you made any allowance for the deduction of $2 \frac{1}{2}$ per cent. from police pay for superintendents?

A. No. The physical standard required for the police is much highe: than that required for postmen. For instance, at Liverpool, the minimum: height is 5 feet 10 inches; at Manchester, 5 feet 9 inches; for the Royal Irish Constabulary, 5 feet 8 inches, or 5 feet 9 inches. The chest measurement required is also much greater in the case of the police. For instance, at Manchester, it is 35 inches, and for the Royal Irish Constabulary 36 ir.ches, or about $2 \frac{1}{2}$ inches more for the same height and age-20-24 yearsthan is the average for the postmen. Height does not affect the selection of candidates for postrien's appointments, e.g., a man of 5 feet, if otherwise suitable, would be, and has been accepted.

The Chairman: Have you any rule with regard to chest measurement?

A. No; we have no restriction.

Q. But a man has to pass a medical examination; would not the chest measurement be considered?

A. No doubt that would be one of the factors upon which the decision would depend.

Dr. Wilson (intervening): We do not take any limit of chest measurement at present; we simply take the general physique.

Sir F. Mowatt: In giving the figures just now, you said that in the Royal Irish Constabulary the chest measurement was $2 \frac{1}{2}$ inches more than that required for postmen.

A. Yes.

The Chairman: We had better now deal with the question of uniforms. I would like to ask you a few questions. Do you get many complaints with regard to uniforms?

A. No; very few.

Q. What number of uniforms do you give in a year?

A. I have prepared a statement on the question of uniforms in reply to the evidence given by Thomas Grimmer, rural postman, of Worcester. I had better read that:-Specimen suits of uniform worn by provincial town postmen and u ural postmen for summer and winter wear are displayed in the room. The colour is not like workhouse grey. In Irish Unions the 
material most in use is, for coats and vests a rough freize of a rather light grey colour, and for trousers a light drab corduroy. The District Surveyors report that they have never heard anything of a feeling of dislike to "wearing a workhouse uniform" as that mentioned. The rural postmen's clothing is modelled on that of a gamekeeper, rather than that of a soldier, as in the case of uniform for town postmen. It is not true that the grey cloth is inferior to the blue, as the patterns and prices show. Each piece of cloth is closely inspected by the experts of the Army Clothing Department before being accepted, and is well shrunk before being made up. Provision is made in the present contract for putting more cloth into the garments.

The Chairman : We are told the uniforms were too tight?

A. Yes. There is no foundation for the statement that the grey cloth is shoddy. It is a good Cheviat cloth. Under the circumstances described, the only dust that would come out would be superficial dust, which any cloth garment will pick up.

The Chairman : The complaint was also made that it would shrink.

A. I deny that. There is practically no difference in quality between the blue and grey cloths. The question of reducing the number of misfits is receiving very careful consideration, and a scheme is being develcped which it is hoped will do away with much of the present inconvenience. The next summer issue of garments will be found to be much looser. At present rural postmen's uniform costs $£ 210 \mathrm{~s}$. a year, and a provincial town postman's £2 5s. 6d. Allowing for leggings, which presumably would still be given, the saving by giving rural men provincial town uniform would be about 2s. 11d. per annum each. There has been but little delay in the issue of rural postmen's uniform; what delay there has been is mostly in the way of misfits. It is a fact that the rural postmen's summer and winter coats are made of the same material. This was considered to be bes's, having regard to their exposure to weather. It would save about $3 \mathrm{~s}$. $8 \mathrm{~d}$. a postman to give a serge coat and vest.

Mr. Walpole: In the summer?

A. Yes. To line the overcoats with woollen material instead of cotton would add considerably to the cost. They are considered to be quite heavy enough as they are. Pockets cost 9d. each-only the London postmen have them at present.

The Chairman: Are these in the greatcoat?

A. Yes. A new summer shako of much lighter material is to be issued in London this summer. If successful, there is no reason why it should not be extended to the provinces. "Ear laps" for men exposed to weather have been considered, but they have not been thought suitable. They would give a very "unsmart" appearance; and it is doubted whether the men generally would like them. We did not use the shako covers which were supplied. Oil-skin capes are now supplied instead of indiarubber, and are found to be much better in quality. Practically no complaints have been received. The capes are designed for the protection of letters and parcels, and could not be worn down to the knees. The "cape recently supplied," referred to by Grimmer, was probably one of old pattern.

The Chairman: The oil-skin capes have not long been issued, have they?

A. No; quite recently. The capes underwent very exhaustive examination, both at the Army Clothing Department and at the Laboratory, Somerset House, where they were pronounced to be excellent and waterproof. Apparently they do not stand the hard wear put on them. The question of supplying overalls has been considered, and the experiment of supplying about 500 of them is about to be tried. A waterproof coat to cover the knees would be expensive, and would soon wear out. The ordinary overcoat is now made of grey woollen material. Worsted badges instead of metal badges are not approved. They soon fray and become indistinguishable.

The Chairman: Do most of the postmen have leggings? 
A. No, I think only the rural postmen have them. That was laid down in 1891.

The Chairman: You do not know anything as to the issue of overalls?

A. No; they have not been issued yet. They are not yet made.

Q. Not tried yet?

A. No.

Mr. Walpole: Were they not tried on a limited scale two years ago, and we abandoned them?

A. I do not remember.

Mr. Walpole: It is so, and now we are going to try the experiment on a larger scale.

The Chairman: The drift of your evidence as regards clothing is that on the whole it is satisfactory, although there have been cases of misfits, Still, the number of complaints have not been very large.

A. Yes, sir.

Q. Now, what are the hours of work of provincial town postmen?

A. They are the same in the provinces as in London-8 hours.

Q. Have you a statement on that?

A. Yes.

Q. Dealing with the attendances beyond the 8 hours' limit?

A. Yes.

The Chairman: Read it, please.

Witness: Cases of prolonged attendance beyond the 8 hours' limit are, it is believed, extremely rare. The instances which have been quoted in the evidence given are in the main found to be at offices where the duties are at present under revision, such as Stalybridge, Liverpool, and Birmingham, or are explained by rotation with shorter duties, as at Devonport, Rawtenstall, Dingwall, Newcastle, Liverpool, and Jersey. As soon as the attendance of the postmen generally is found to exceed the normal 8 hours, a scheme for the revision of the duties is prepared, and pending the consideration of the proposals, temporary relief is afforded where desirable. The duties when revised are usually fixed to occupy rather less than the 8 hours-generally about 7 hours 30 minutes, so as to allow a margin for growth of work. Such revisions at the larger offices as a rule take place every three or four years, and any time beyond the 8 hours which the postmen may work when the revision is about to take place is probably fully made up by the lighter attendance when the revision comes into force. The several offices throughout the country are frequently visited by the surveying staff, and any readjustment of the duties which may be necessary can hardly fail to be discovered, should the Postmaster have failed to report the matter. Periodical surveys are made of the duties of the whole staff at each office, and any irregular attendance is adjusted. The Postmasters are quite aware that should the men under their supervision be overworked they must at once report the matter to the surveyor of the district. Every Postmaster has to answer the following questions in his annual report to the surveyor:-

"Does the average daily attendance of any of the town postmen exceed 8 hours? If so, state the hours of duty in each case.

"Does the daily attendance of any of the auxiliary postmen exceed 6 hours? If so, state particulars."

In connection with this point it should be added that at several of the large provincial offices, such as Bristol, Leeds, Edinburgh, Glasgow, Sheffield, Cardiff, Nottingham, Huddersfield, Belfast, Portsmouth, Leicester, and Preston, many of the postmen, especially those residing at some dis: tance from the office, are allowed the free use of the tramways or omnibuses, for which the Department pays a yearly sum to the company, and thereby obtain considerable relief in making their collections and deliveries. That such relief is of great benefit to them is proved by the fact that the granting of it has led to an improvement in the general health of the men in several instances. In some cases on the first delivery (the heaviest of 
the day) the postmen are conveyed, by means of covered brakes, to the starting-points on their walks. The accompanying extract ( 1 , see footnote) from the report of the surveyor at Glasgow shows how largely this relief is afforded to the postmen there, a typical instance of what the Department is doing in such cases for the benefit of the postmen :-

\section{EXTRACT FROM REPORT OF SURVEYOR OF GLASGOW,} 20th February, 1896.

"In Glasgow all the postmen except those whose delivery commences within a short walk from the head office, are conveyed by railway, tramway car, omnibus, or brake to, or near to, the point at which they commence delivering. There is no fixed limit, but there are not many men who have to walk thereto much above half-a-mile.

"It may perhaps be well to mention that 135 railway season tickets are held by postmen here, and these men enjoy the privilege of returning to the office, or reaching their homes where suitable by train. Wherever a train service can, with advantage, be substituted for any other conveyance, I have obtained the Secretary's sanction for the change, one of the special reasons for so doing being the benefit of return this affords to the holder. (2, see footnote.) Sanction for 78 of these season tickets has been obtained by myself since taking up duty here."

Sir F. Mowatt: Do the men use the tram cars and omnibuses in going to and from work, and also in delivering their letters?

A. Yes. (3, see footnote).

The Chairman: Can you tell us whether the season tickets are paid for by the office?

A. Yes; they are paid for by the office. They are given in cases in which postmen have to carry heavy bags, and therefore they have season tickets, which they can use at other times. Moreover, within the last few years the postmen at several towns have been given a partial holiday on one day a week by the suspension of some of the services with the consent of the local authorities. Here are some examples:-Accrington 2, Bacup 1, Bingley 3, Blackburn 2, Bolton 1, Bradford 1, Brighouse 1, Bury 1, Colne 5, Darwen 2, Dewsbury 1, Hadifax 1, Huddersfield 1, Keighley 3, Nelson 5, Preston 1, and Rochdale 1. In certain towns also where special local holidays, generally in the summer months, are observed, arrangements have been made with the consent of the local authorities for the suspension of several of the collections and deliveries, so as to admit of postmen sharing in the holiday. Instances of this are furnished in the margin. Taking all things into consideration, the postman's lot does not appear to be an unhappy one. $\mathrm{He}$ is far better off in these respects than the policeman, who, as a rule, has half the postman's annual leave, longer attendance, a full duty on at least every other Sunday, without extra pay, no leave or extra pay for Bank Holidays, Christmas Day, or Good Friday, and no partial holidays.

1.-The Brakes in use at Glasgow are not "covered in." The men who find it necessary to ride in them are fully exposed to the weather, of whatever kind.

2.-Those Postmen who are supplied with Season Tickets by rail (to be used by a Postman only) to the outlying districts find them useful in returning to their homes should they be domiciled near to the line of Railway for which the Ticket is available, otherwise they have no advantage.

3 - This answer is entirely wrong, so far as Glasgow is concerned. None of the Postmen in the Glasgow Office have the free use of the Tramway System in going to and from their work. A number of the Postmen on walking collections are the only men who are supplied with a limited number of checks to travel outwards for, or inwards with, their collection.

[A little too much has been made of this Season Ticket business, the advantages to the holder being more imaginary than real.] 
Dr. Wilson was then re-called and examined as follows:-

The Chairman: I want to ask you one question upon a point with regard to which I questioned Mr. Badcock. A statement was made by Mr. Symes that the postmen go about in suffering because they know that the official medical officer, unless they complain of infectious illness, will not give them leave, and they preferred thus to go about rather than lay themselves open. to a suspicion of malingering?

A. There is no truth in that at all. The average absence for 1895 is higher than it was for 1894, and it is worthy of note that more sick leave was granted after the introduction of the system of allowing full pay.

Q. As a rule you think the medical officers of the P.O. are considerate to the men?

A. I am sure of it.

Q. In the way of granting leave?

A. I am quite sure of it.

Q. Are the instructions of the Department that they should be so?

A. Yes.

Q. Of course you have to prevent any abuse of the privilege given?

A. Quite so.

Mr. Lewin Hill again re-called and further examined :-

The Chairman: Mr. Churchfield told us the other day that a postman at Windsor, who had given evidence before this Committee, had been watched or shadowed, or something of that kind, in consequence. I think that was the purport of his complaint? Can you give us any information?

A. Yes. Inquiry has been made by the surveyor; he has not been able to visit the office personally, but he sent one of the surveyor's clerks down to visit the Post Office, and he was informed that no difficulty whatever had been made on account of the evidence tendered before the Committee. The surveyor writes:- "I am of opinion that this assurance may be accepted. It seems probable that the statement made to the Committee is founded on a case which is now under consideration. It is a case in which I think the inspector was not discreet, but I see no reason to doubt at present that his sole object was to secure a proper performance of the duty under his immediate control. The inquiry is not yet completed; the case seems to be one which can be best settled by personal inquiry, and I have not yet had an opportunity of making it; but, so far as the case has gone, it would appear that while there was a want of judgment locally in dealing with it, and while there was unwise interference on the part of the inspector, at the same time the postman Riley acted in a manner calculated to interfere with the discipline of the office. I propose to visit Windsor next week, and I have no doubt I shall ba able to prevent anything of the kind occurring again."

Q. That takes us no further. I think it would have been better to wait until the inquiry could have been completed.

A. It was peported that Riley was insolent.

The Chairman: You had better bring the matter forward when the case has been settled.

The Commiltee then adjourned until Thursday.

Lord Tweedmouth's Committee held its last sitting before Easter to-day (Thursday, 26th March), and was engaged for four-and-a-half hours in com. pleting the examination of Mr. Lewin Hill, who was called by the Department to reply to the case put forward on behalf of the provincial postmen.

The Chairman: There are some points on which you wish to supplement your evidence on the subject of the wages of postmen?

A. There is one general consideration bearing upon the question of raising salaries and wages to which I omitted to call attention on Monday. It is this:--The expenditure of the Post Office divides itself into two classes, i.e., expenditure which is remunerative and expenditure which is 
not. The first class comprises expenditure for such improvements of service as lead to a growth of profitable business sufficient to cover the expen. diture incurred, and also, I think, such increase of pay up to the full market value of labour; because expenditure on this head conduces to the efficient, and, therefore, economical performance of the Service. In the second class is included expenditure which is not remunerative, and in this category I include increase of pay beyond the full market value of labour. Now, all additional unremunerative expenditure has to be paid for by taxation, and to whatever extent the wages-earning class contribute to the general taxation any increased unremunerative expenditure by tuhe Post Office comes out of the pockets of a large class of persons, very many members of which are less well off than our people. With regard to the question of the wages of postmen, I stated on Monday that I thought the present wages of town postmen are, as a rule, quite sufficient. Fully adhering to this opinion, I still think that our present system of paying the postmen on rising scale of wages is, as regards the postmen in the larger towns, susceptible of improvement. In the case of the smaller towns the maximum of the scale is reached in 6 or 7 years, but in the case of the larger towns the maximum is not reached until a much longer period. Thus, in the case of an office with the scale of 16s., 1s., 22s., the postman reaches his maximum after 6 years of service. But in the case of an office-Liverpool and Manchester, for instance-with a scale of 17s., 1s., 30s. a week, the postman does not reach his maximum until after 13 years' service. During the first seven years of his service he is paid only one shilling a week more than the postman at a town like Axminster or Congleton, where the scale of 16s., 1s., 22s. applies, although the cost of living and the value of labour are in all probability decidedly greater. I think that it may fairly be assumed that a postman after 6 or 7 years' service has, as a rule, reached his full value, and I think it would be better by the time he has reached his full value to give his maximum pay, as we do, indeet, in the case of the postmen in the smaller towns. Assuming that a town like Liverpool the postman during, say the first 20 years of his service, receives in the aggregate sufficient payment for his first 20 years' work, I would suggest that his scale of wages should be arranged as shown in the tabular statement $\mathrm{E}$. The seven tables-A to $\mathrm{G}$-show the effect of the application of the suggested plan to each of the long scales whether in London or the provinces. It will be observed that the efect of such a re-arrangement of the scale would be to give the postman in the earlier years of his service much more than he receives at present, but, on the other liand, to give him less than he receives at present in the later years of his service. The following tables were then handed in by the witness:- 


\section{Londoy Town Postrien.}

Present Scale, - - - - 18/ by $1 /$ to $34 /$ a week.

Proposed Scale, _ _ $\quad 18 /$ by $2 /$ to $30 /$ a week.

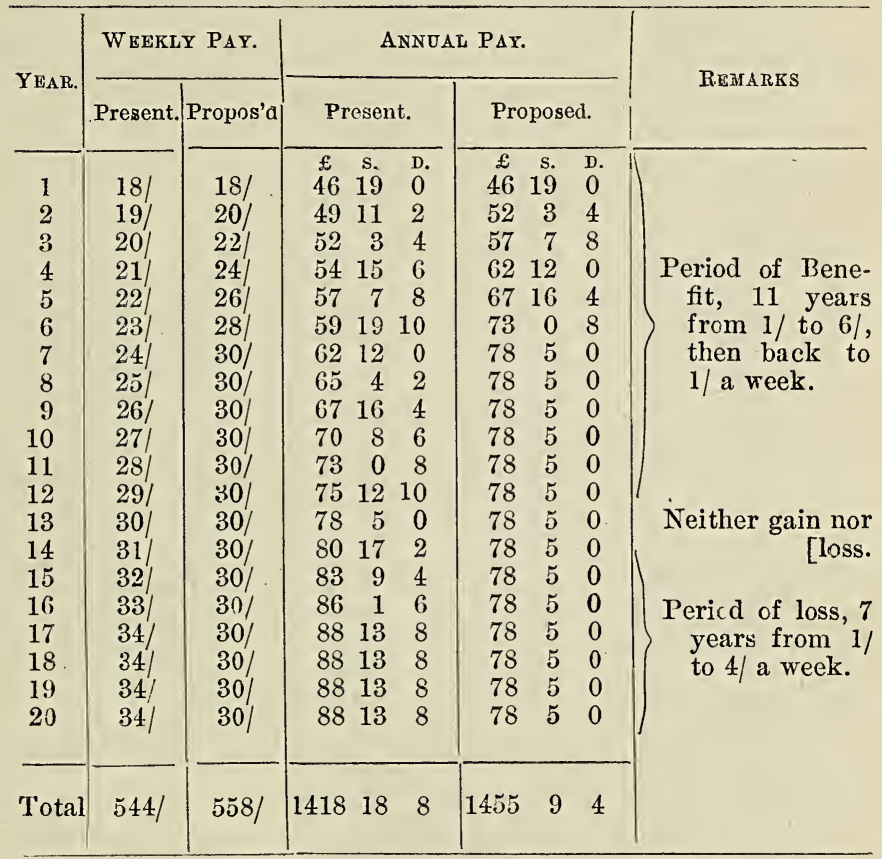

Total gain in 20 years, $£ 3610$ s. $8 \mathrm{~d}$ or $£ 116 \mathrm{~s} .6 \mathrm{~d}$ a year (8d. a week). Under the present scale a Postman reaches his maximum of 34/ a week after 16 years' service.

Under the proposed scale a Postman reaches his maximum of $30 /$ a week after 6 years' service. 
London Postmen-Zone I.

Present Scale, - - $18 /$, by $1 /$ to $32 / \bar{a}$ week.

Proposed Scale, - - $18 /, 19 /$, by $2 /$ to 29 / a week.

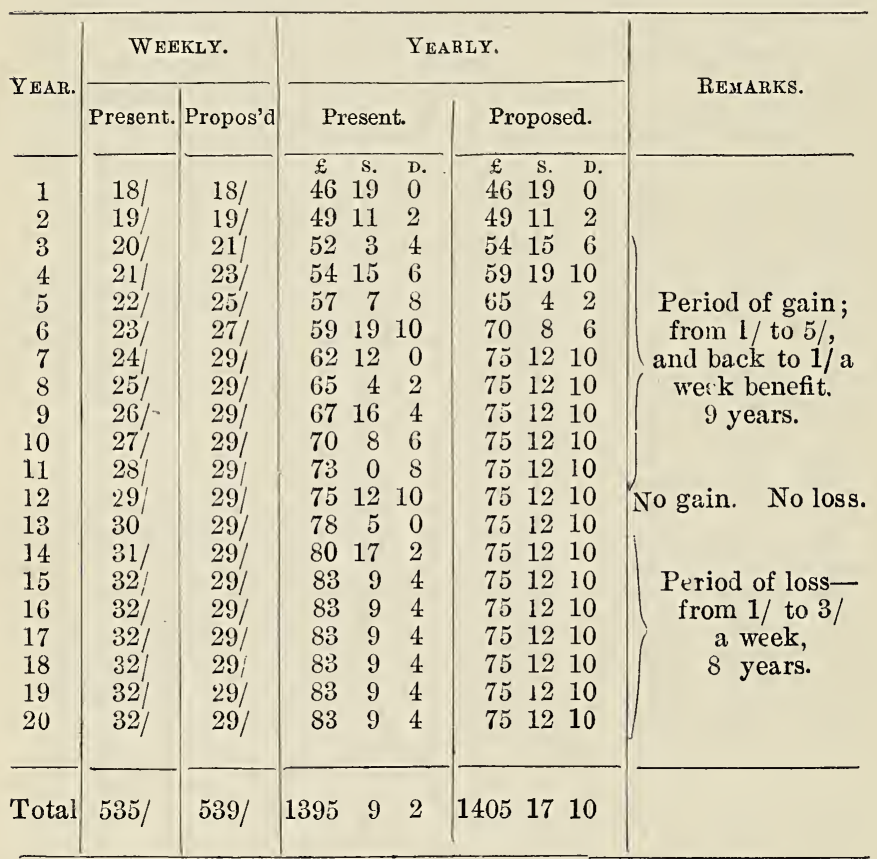

Total gain in 20 years, $£ 10$ 8.. 8 d., or $10 / 5$ a year, about $3 \mathrm{~d}$. a week. Under the present scale a Postmen reaches his maximum of $32 / \cdot$ a week after 14 years' service.

Under the proposed scale a Postmen reaches his maximum of $29 / \cdot$ a week after 6 years' service. 
London Postmen-Zone II.

Present Scale, - - - $18 /$ by $1 /$ to $30 /$ a week.

Proposed Scale - - - $18 /, 19 /$ by $2 /$ to $28 /$ a week.

\begin{tabular}{|c|c|c|c|c|c|c|c|c|}
\hline \multirow{2}{*}{ Year. } & \multicolumn{2}{|c|}{ WEEKLY. } & \multicolumn{5}{|c|}{ YEARLY. } & \multirow{2}{*}{ REMARKS. } \\
\hline & Present. & Proposed & \multicolumn{2}{|c|}{ Present. } & \multicolumn{3}{|c|}{ Proposed. } & \\
\hline 1 & 181 & $18 /$ & $\begin{array}{cc}£ & \text { s. } \\
46 & 19\end{array}$ & D. & $\begin{array}{ll} \pm & 5 \\
46 & 1\end{array}$ & $\begin{array}{l}\text { s. } \\
19\end{array}$ & & \\
\hline 2 & $19 /$ & $19 \%$ & 4911 & 2 & 491 & 11 & 2 & \\
\hline 3 & $20 \%$ & $2 ! 1$ & 523 & 4 & 541 & L.j & 6 & \\
\hline 4 & 211 & 231 & 54.15 & 6 & 591 & 19 & & Period of gain 8 \\
\hline$\check{5}$ & $2 \because 1$ & $25 /$ & $57 \quad 7$ & 8 & 65 & 4 & 2 & years from $1 /$ to \\
\hline 6 & $2 \%$ & $27 /$ & $59 \quad 19$ & & & 8 & 6 & $4 /$ and back to \\
\hline 7 & 24 & 231 & $62 \quad 12$ & 0 & 73 & 0 & 8 & i/ a week. \\
\hline 8 & $25 /$ & 231 & (i5 4 & 2 & 73 & 0 & 8 & \\
\hline$y$ & 261 & 231 & $67 \quad 16$ & 4 & 73 & 0 & 8 & \\
\hline 10 & 27 & 281 & 708 & 6 & 73 & 0 & 8 & \\
\hline 11 & 281 & 231 & 730 & 8 & 73 & 0 & 8 & No gain. No loss. \\
\hline 12 & 291 & 281 & $75 \quad 12$ & 10 & 73 & 0 & 8 & \\
\hline 13 & 301 & 281 & 785 & 0 & 73 & 0 & 8 & \\
\hline 14 & $30 /$ & 281 & 785 & 0 & 73 & 0 & 8 & \\
\hline 15 & $30 /$ & 281 & 735 & 0 & 73 & 0 & 8 & Period of loss 9 \\
\hline 16 & $30 /$ & 281 & $7 \lesssim \quad 5$ & 0 & 73 & 0 & 8 & years, $1 /$ and 2 \\
\hline 17 & $30 \%$ & $28 /$ & $78 \quad 5$ & 0 & 73 & 0 & 8 & a week. \\
\hline 18 & 30 & 231 & 785 & 0 & 73 & 0 & 8 & \\
\hline 19 & $30 /$ & 281 & $78 \tilde{\text { o }}$ & 0 & 73 & 0 & 8 & \\
\hline 20 & $30 /$ & 281 & $78 \quad 5$ & 0 & 73 & 0 & 8 & \\
\hline Total & $522 /$ & $525 /$ & $1361 \quad 11$ & 0 & 1369 & 7 & 6 & \\
\hline
\end{tabular}

Total gain in 20 years, $£ 716$ s. 6 d., or 7 s. 10 d.a year, nearly $2 \mathrm{~d}$ a week.

Under the present scale a Postman reaches his maximum of $30 /$ a week after 12 years' service.

Under the proposed scale a Postman reaches his maximum of $28 / \mathrm{a}$ week after 6 years' service. 
London Postren-ZoNe III.

Present Scale, - - $18 /$ by $1 /$ to $26 /$ a week.

Proposed Scale, - 18/ by $1 /$ to $22 \%$, then $2 /$ to $26 /$ a week.

\begin{tabular}{|c|c|c|c|c|c|c|}
\hline \multirow{2}{*}{ YEAR. } & \multicolumn{2}{|c|}{ W EEKLY. } & \multicolumn{3}{|c|}{ YEARLY. } & \multirow{2}{*}{ ReMarks. } \\
\hline & Present. & Propos'd & Present. & & Proposed & \\
\hline $\begin{array}{r}1 \\
2 \\
3 \\
4 \\
5 \\
6 \\
7 \\
8 \\
9 \\
10 \\
11 \\
12 \\
13 \\
14 \\
15 \\
16 \\
17 \\
18 \\
19 \\
20\end{array}$ & $\begin{array}{l}18 / \\
19 / \\
20 / \\
21 / \\
22 / \\
23 / \\
24 / \\
25 / \\
26 / \\
26 / \\
26 / \\
26 / \\
26 / \\
26 / \\
26 / \\
26 / \\
26 / \\
26 / \\
26 / \\
26 /\end{array}$ & $\begin{array}{l}18 / \\
19 / \\
20 / \\
21 / \\
22 / \\
24 / \\
26 / \\
26 / \\
26 / \\
26 / \\
26 / \\
26 / \\
26 / \\
26 / \\
26 / \\
26 / \\
26 / \\
26 / \\
26 / \\
26 /\end{array}$ & \begin{tabular}{crr}
\multirow{1}{*}{} & s. & \\
46 & 19 \\
49 & 11 \\
52 & 3 \\
54 & 15 \\
57 & 7 & \\
59 & 19 & 1 \\
62 & 12 & \\
65 & 4 \\
67 & 16 & \\
67 & 16 & \\
67 & 16 & \\
67 & 16 & \\
67 & 16 & \\
67 & 16 & 4 \\
67 & 16 & 4 \\
67 & 16 & \\
67 & 16 & 4 \\
67 & 16 & 4 \\
67 & 16 & \\
67 & 16 & 4
\end{tabular} & $\begin{array}{r}\text { D. } \\
0 \\
2 \\
4 \\
6 \\
8 \\
10 \\
0 \\
2 \\
4 \\
4 \\
4 \\
4 \\
4 \\
4 \\
4 \\
4 \\
4 \\
4 \\
4 \\
4\end{array}$ & \begin{tabular}{crr}
\multirow{2}{f}{} & s. & 1 \\
46 & 19 & 0 \\
49 & 11 & 2 \\
52 & 3 & 4 \\
54 & 15 & 6 \\
57 & 7 & 8 \\
62 & 12 & 0 \\
67 & 16 & 4 \\
67 & 16 & 4 \\
67 & 16 & 4 \\
67 & 16 & 4 \\
67 & 16 & 4 \\
67 & 16 & 4 \\
67 & 16 & 4 \\
67 & 16 & 4 \\
67 & 16 & 4 \\
67 & 16 & 4 \\
67 & 16 & 4 \\
67 & 16 & 4 \\
67 & 16 & 4 \\
67 & 16 & 4
\end{tabular} & $\left\{\begin{array}{l}\text { Period of gain, } \\
3 \text { years } 1 /, 2 /- \\
\text { and } 1 / \text { a week }\end{array}\right.$ \\
\hline Total & $484 /$ & $488 /$ & $1262 \quad 8$ & 8 & 127217 & 4 \\
\hline
\end{tabular}

Total gain in 20 years, $£ 10$ ss. 8 d. or 10 s. 5 d. a year, about $3 \mathrm{~d}$. a week.

Under the present scale a Pustman reaches his maximum of 26/

a week after 8 years' service.

Under the proposed scale a Postman reaches his maximum of 26/ a week after 6 years' service. 
Provicial Town Postmen.

Present Scale, - - - - $17 /$ by $1 /$ to $30 /$ a week.

Proposed Scale, - $\quad-17 /$ and $18 /$ by $2 /$ to $28 /$ a week.

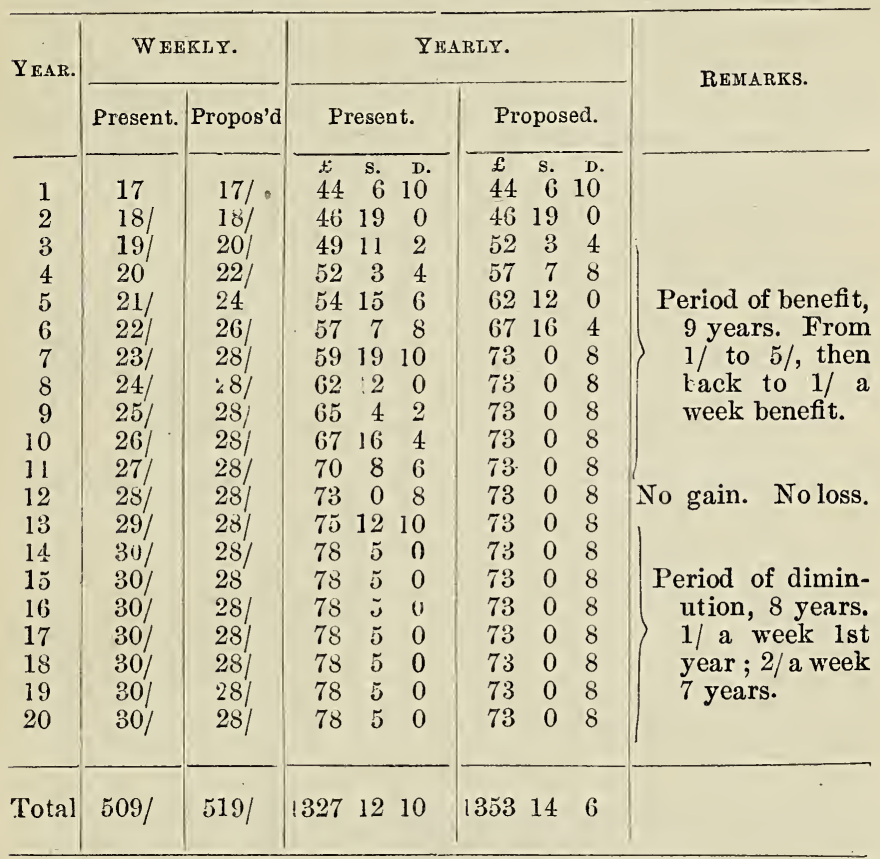

Total gain in 20 years $-£ 26$ 1s. 8 d. or $£ 16$ s. 1 d. a year, or 6 d. a week. Under the present scale a Postman reaches his maximum of $30 /$ after 13 years' service.

Under the proposed scale a Postman reaches his maximum of 28/after 6 jears' service. 
Prcvincial Town Postmen.

Present Scale, - 17/ by $1 /$ to $28 /$ a week.

Proposed Scale, $17 /$ by $1 /$ to $19 /$, then by $2 /$ to $27 /$ a week.

\begin{tabular}{|c|c|c|c|c|c|c|}
\hline \multirow{2}{*}{ YEAR. } & \multicolumn{2}{|c|}{ WEEKLY. } & \multicolumn{3}{|c|}{ YEARLY. } & \multirow{2}{*}{ REMARKS. } \\
\hline & Present. & Propos'd & Present & & Proposed & \\
\hline $\begin{array}{r}1 \\
2 \\
3 \\
4 \\
5 \\
6 \\
7 \\
8 \\
9 \\
10 \\
11 \\
12 \\
13 \\
14 \\
15 \\
16 \\
17 \\
18 \\
19 \\
20\end{array}$ & $\begin{array}{l}17 / \\
18 / \\
19 / \\
21 / \\
22 / \\
23 / \\
24 / \\
25 / \\
26 / \\
27 / \\
28 / \\
28 / \\
28 / \\
28 / \\
28 / \\
28 / \\
28 / \\
28 / \\
28 / \\
27 /\end{array}$ & $\begin{array}{l}17 / \\
18 / \\
19 / \\
20 / \\
21 / \\
23 / \\
25 / \\
27 / \\
27 / \\
27 / \\
27 / \\
27 / \\
27 / \\
27 / \\
27 / \\
27 / \\
27 / \\
27 / \\
27 ! \\
27 /\end{array}$ & $\begin{array}{ccc} \pm & \mathrm{s} & \text { n } \\
44 & 6 & 1 \\
46 & 19 \\
49 & 11 \\
52 & 3 \\
54 & 15 \\
57 & 7 \\
59 & 19 & 1 \\
62 & & \\
65 & 4 \\
67 & 16 \\
73 & 0 \\
73 & 0 \\
73 & 0 \\
73 & 0 \\
73 & 0 \\
73 & 0 \\
73 & 0 \\
73 & 0 \\
73 & 0 \\
73 & 0\end{array}$ & $\begin{array}{r}10 \\
10 \\
0 \\
2 \\
4 \\
6 \\
8 \\
10 \\
0 \\
2 \\
4 \\
8 \\
8 \\
8 \\
5 \\
8 \\
8 \\
8 \\
8 \\
8 \\
8\end{array}$ & $\begin{array}{crr} & \text { s. } & \text { D } \\
44 & 6 & 10 \\
46 & 19 & 0 \\
49 & 11 & 2 \\
54 & 15 & 6 \\
59 & 9 & 10 \\
65 & 4 & 11 \\
70 & 8 & 6 \\
70 & 8 & 6 \\
70 & 8 & 6 \\
70 & 8 & 6 \\
70 & 8 & 6 \\
70 & 8 & 6 \\
70 & 8 & 6 \\
70 & 8 & 6 \\
70 & 8 & 6 \\
70 & 8 & 6 \\
70 & 8 & 6 \\
70 & 8 & 6 \\
70 & 7 & 6 \\
70 & 8 & 6\end{array}$ & $\begin{array}{l}\text { Period of Bene- } \\
\text { fit, } 7 \text { years } \\
\text { from } 1 / \text { to } 4 / \\
\text { a d back to } 1 / \\
\text { a week. }\end{array}$ \\
\hline Total & $494 /$ & $501 /$ & 128810 & 4 & $\begin{array}{lll}1306 & 15 & 6\end{array}$ & - \\
\hline
\end{tabular}

Total gain in 20 years, $£ i 8$ ss. 2 d., or 18 s. 3 d. a year-a little over 4 d. a week.

Undes the present scale a Postman reaches his maximum of 28/ s week after 11 years' service.

Under the proposed scale a Postman reaches his maximum of 27/ a week after 6 years' service. 


\section{Provincial Town Postmen.}

Present Suale, - - - $17 /$ by $1 /$ to $26 /$ a week.

Proposed Scale, $17 /$ by $1 /$ to $20 /$, then by $2 /$ to $26 /$ a week.

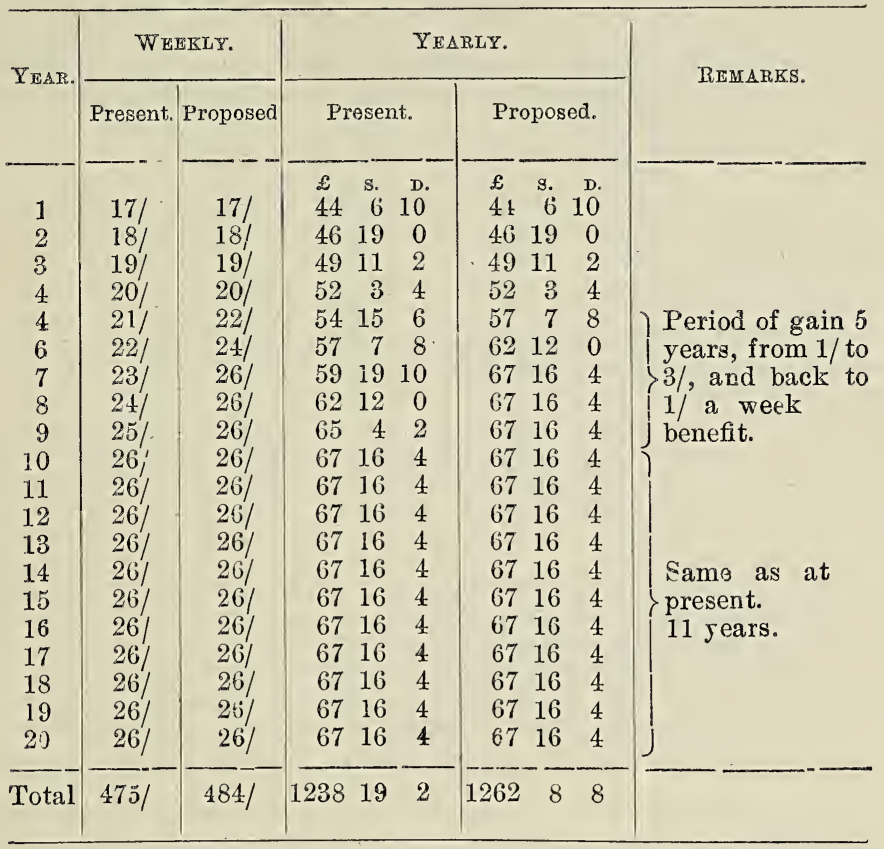

Total gain in 20 years, $£ 239$ s. 6 d., or $£ 13$ s. $6 \mathrm{~d}$. a year, nearly $5 \frac{1}{2} \mathrm{~d}$. a week.

Under the present scale a Postman reaches his maximum of $26 /$ a week after 9 years' service.

Under the proposed scale a Postman reaches his maximum of 23/ a week after 6 years' service.

The Chairman: Practically your proposal is to reduce the maximum and to increase the annual increment?

A. Yes.

Q. You would double the annual increment and decrease the maximum?

A. Yes. It is on the assumption that the present pay is regarded as sufficient as a whole. It seems to me that if the present pay is not regarded as sufficient, the better way of increasing it is to increase it in the earlier stages of a man's service, and not in the later.

Q. Have you formed any estimate as to what the cost of this would be?

A. Yes; that appears in the tables annexed to my statement and already put in. I have worked out the scheme on the basis of giving the postmen during the first 20 years of service about as much as he now gets. I will take here the case of a London town postman. These men are on the scale of $18 \mathrm{~s}$., rising by $1 \mathrm{~s}$. to $34 \mathrm{~s}$., and the scale which I suggest is $18 \mathrm{~s}$. . rising 
by 2 s. to 30 s. You will find that on such a scale as I suggest that during his first 20 years of service he would get on the aggregate about 8d. per week more.

Q. But after 20 years' service he would be a considerable loser, would he not?

A. Yes, he would lose. I ought to have obtained the average length of the service of postmen, but I have not done so. If, however, such a system of payment as. I suggest is adopted, my view is that it should be optional to each man in the Service either to stay on the present scale or to adopt the new scale.

Q. Up to about 13 years' service he would be a gainer?

A. Yes.

Q. But after that he would be an increasing loser every year?

A. Yes, after 14 years' service. At present he is getting $\$ 8017 \mathrm{~s} .2 \mathrm{~d}$. in the 14th year.

Q. And you are proposing that he should have $£ 785$ s.?

A. Yes.

Mr. L. Smith: Do I understand that these figures are merely given to iliustrate your contention, and that they do not represent a definite proposal?

A. No. It seems to me that at present our postmen in the large towns get too little in the earlier stages of their work, and although a man in 14 years gets $80 \mathrm{~s}$. a week, that does not provide him with sufficient money for lodging and food when he most wants it.

Q. You wish to distribute the aggregate in a different way, whatever that aggregaite may be?

A. Yes; whatever it may be fixed at. I have gone on the assumption that the present pay is sufficient, but if it is not then my idea would be to increase it in the earlier stages, and not in the later.

The Chairman: You put it in your evidence on the ground that a man reaches his full value at an early stage; but I understand that in your later remarks you are taking a different ground, i.e., the considerable expense of lodgings, etc. Now, I wish to ask, which is the ground you rely on?

A. I put it mainly on the ground that the man reaches his full value at an early stage.

Mr. L. Smith: The two principles, if worked out, might give very different results. Which do you think is the sound one?

A. I think the sound one is that of reaching full value at an early stage.

Q. But in a service in which a man continues almost necessarily for a long time, is it desirable always to pay him in each year the market value of his labour through that year? Would you rather not have regard to the growth of his expenditure?

A. In the case of postmen-and this applies also to telegraphists and sorting clerks-they constantly compare their pay with the scales of pay given outside the Department. "It is true," they say, "that outside the Department a man gets what he is worth." That is so, and if he is an apprentice he has to serve in that capacity so many years, but when his apprenticeship comes to an end, and he is deemed fit for his work, he at once gets full pay for it.

Sir F. Mowatt: That carries with it the consequence, does it not, that you cannot recognise long service?

A. Certainly.

Q. And if you pay a man what he is worth when he becomes worth it, he cannot afterwards plead that he has been a long time in the Service, and he should on that account have an increase of wages.

A. Certainly not. In the case of the postmen we do recognise long service up to 15 years by giving, at intervals of 5 years, good conduct stripes, each of which carries with it an allowance of 1 s. a week.

The Chairman: Do your tables and calculations include the stripes? 


\section{A. No.}

Mr. L. Smith: I want to ask you one question bearing on the general statement. At the beginning of your evidence you used the term " market value " rather freely. Do you mean by that the price it is necessary to pay in order to attract and keep in the Service people of sufficient efficiency to carry it on?

Q. And I gather you consider that if any class of people are paid above maarket value that immediately has the effect of attracting people of superior efficiency; that is to say, people who are too good for the place?

A. Yes; it would if you go into the open market.

Q. I understand that that effect is not, as a matter of fact, produced anıong postmen for reasons which you gave us last time?

A. Yes.

Q. And one reason is that during the earlier stages of what I may call the apprenticeship-that is, the telegraph messengers' work-parents do not consider it suitable for their boys that they should be sent into the streets, and that that in itself acts as a bar to getting a flow into the Service of what I might call the higher classes?

A Yes; but at the same time if you raise the pay of the postmen sufficiently high, the objection to the street service would not be so strongly felt by the parents. They would possibly put up with it in view of the future prospects of the boy.

Q. Supposing you went into the open market for postmen, according to your view, should we be able to get the same efficiency at a lower cost than we now pay for our telegraph messengers?

A. I think you would get telegraph messengers perfectly well by doing as Messrs. Smith and Sons, the news agents, do ; they employ many hundreds of boys (I do not know how many), they take them on for 2 or 3 years, and pay such wages as enables them to get a good class of boy, and at the end of the 2 or 3 years the boys have to go.

Q. But that involves the necessity of paying the market rate for telegraph messenger boys?

A. Certainly; and I think we do now.

Q. What, already?

A. That is a matter of opinion. I think so.

Q. Do you mean to say we should get the same class of telegraph mes. sengers for the same pay if there was no prospect of obtaining established postmen's wages?

A. I do not think we should get quite so good a class; probably we should have to pay a little more.

Q. Therefore if you brought down the posimen's wages to what you hold to be the market wage, you think we should have to increase the present pay of our telegraph boys?

A. Well, I think there is less reason for lowering it in their case than in the case of the other classes. I simply judge by what Messrs. Smith pay their boys. Two or three years ago I was told that they have very few vacancies above those of the boys who carry out the papers.

Q. But the boys later on get employment on the railways, don't they?

A. They may, but they have no claim on the railway companies, and our boys could just as easily get on to the railway as Messrs. Smith's boys.

Q. I understand the present conditions are not good enough in many cases to attract the kind of messengers we want, and I suppose if you give a worse pay you will get a worse ciass?

A. Certainly.

Q. Having regard to the Service as a whole, and beginning from the time that the boy commences at the messenger rate, is there not some compensation in the fact of his becoming eventually a postman?

A. Yes.

The Chairman: I think you have now the information with regard to the pay of telegraph messengers? 
A. Yes. The following statement shows approximaltely the present number of telegraph messengers in the employment of the Post Office:-

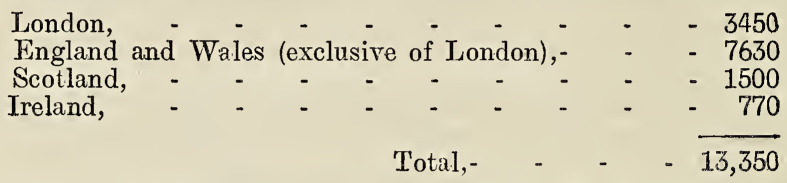

I was asked on Monday whether, if we reserve all our situations of postmen-rural as well as town-for telegraph messengers, there would be any situations left for retired soldiers, and I replied that there would be practically none. I find, however, on further inquiry, that in 1895 the Department was able after providing for telegraph messengers and auxiliary postmen to find places as postmen for 141 retired soldiers.

The Chairman: Do you think that up to 1895 you were able to provide for all the legitimate claims on behalf of telegraph messengers?

A. I doubt it. For instance, take the case of London-

The Chairman: I rather want to know about the country; we have already dealt with London pretty fully.

A. 'The point is this, that if in London there are more boys than we can find places for, we have not offered them situations in the country. The same thing applies, I fancy, to our large towns. Supposing at Manchester we have too many boys for the places, and at Liverpool we have more places than boys, we do not offer to transfer the boys from Manchester to Liverpool.

Q. Are places for the London boys found in the provinces?

A. I believe not at all.

Q. I should like to know whether in the provinces the legitimate claims of telegraph messengers have been met during the past year?

A. I believe that, taking each town, they have been met as far as possible, but in some towns we could not find places for the boys, and consequently those lads have to go, although at other towns there might have been vacant places which they could have filled. If we had hard a system of filling up all vacancies for the boys wherever they might be, I doubt whether we should have appointed 142 soldiers.

Mr. Walpole: Is it not the case that in London we do practically provide for all the legitimate claims of telegraph messengers whom we employ?

A. That is for Mr. Badcock to say.

Q. Is it not the case also that in those country towns where a large expansion of postal business is going on we do, as a general rule, provide for the telegraph messengers?

A. It is difficult to say.

Q. Will you take it from me that it is so?

A. Certainly.

Q. And in those towns where postal business is stagnant we cannot so provide for them?

A. I expect that would be the case.

Sir F. Mowatt: Where did the 141 retired soldiers find vacancies?

A. In towns where there were no telegraph messengers old enough to be put on, and where there were no auxiliaries.

Q. In the smaller towns?

A. Not necessarily. It might be in any town. It might be the case that no one had a claim to a vacancy, and, as the business was incrasing rapidly, and there were no boys available, soldiers were appointed.

Mr. Walpole: And some of these soldiers, I presume, were appointed in country districts where there were no telegraph messengers?

A. Ẏes.

The Chairman: I suppose you have no figures showing the comparative 
proportion of places filled up by telegraph messengers and by auxiliary postmen?

A. Yes; we have a return from 70 of the large towns. Shall I read it? The Chairman: No; I do not think we need go into the details. Give the totals.

A. The return shows the number of the established postmen in 70 large towns. The total is 6,738, while the number of auxiliary postmen is 1,258 , and of auxiliaries who are ex-telegraph messengers 906, so that apparently 906 telegraph messengers could not at once get established appointments as postmen.

The Chairman: What proportion of the established men were telegraph messengers, and what proportion were anxiliaries?

A. We have no record to show that. I may go a little further and point out that in 1895 the number of vacancies for postmen, including vacancies occasioned by the creation of new situations, was as follows:-London 440 , and the rest of the United Kingdom 1,520, making a total of 1,960 vacancies for postmen.

Q. Cannot you tell us how these were filled up?

A. No; but in the main they were filled up by telegraph messengersI am sure of that. We know, of course, that 141 were filled up by retired soldiers, but I should say that the rest were filled up absolutely by telegraph messengers or auxiliary postmen doing double duty.

Sir F. Mowatt: I was trying to get at that; I do not myself quite understand how it is. We have received-I will not say complaints, but-representations from several witnesses that the auxiliary postmen do not get their fair share of the appointments because they are given to the telegraph messengers?

A. The auxiliary postmen, did you say?

Q. Yes; and I want to know, if possible, how far the figures bear that out. I understand that the first claim is in the telegraph messengers, that failing them come the auxiliary postmen, and failing them the retired soldiers?

A. Yes.

Q. I should like to know, if you can tell us, how many of these 1,960 appointments (less the 141 given to soldiers) went to auxiliary postmen, and how many to telegraph messengers?

A. You want me to distinguish between the two, but then I must find out how many of the auxiliary postmen were in the first place telegraph messengers?

The Chairman: Yes; the auxiliary might cover both. A telegraph messenger might pass into the auxiliary ranks while waiting for an appointment as established postman.

Sir F. Mowatt: Then you have not got.the information I want?

A. No.

Q. I do not say it was a complaint, but it was a representation to us that auxiliary postmen who had not been telegraph messengers rather felt that they were ousted by the telegraph messengers, and did not get an equal chance of admission into the established postmen's ranks.

A. I think we could get the information from one of the surveyors.

Mr. Walpole: Is it not a fact that the complaint to which Sir F. Mowatt has alluded chiefly emanated from the London auxiliaries?

Sir F. Mowatt: Oh! Is that so?

A. Yes; I think so.

Q. Does the same complaint arise in the country, where it is usual to appoint telegraph messengers as auxiliaries?

A. I suppose not; but we have a great many auxiliaries in the Service who never were telegraph messengers.

$\mathrm{Q}$. In the provinces.

A. Yes.

Q. Are they not as a rule men who ususlly are not applicants for established places because they have other trades? 
A. In the case of postmen doing single deliveries they doubtless are; they would have other trades. Mr. Seton could give you more information on that point. I am informed by one of our surveyors who is present that in the case of an auxiliary who does more than one duty-the double aux iliary, as we call him-he is considered to have a prior claim to the telegraph messengers.

Sir F. Mowatt: In the provinces?

A. Yes; in the districts which Mr. Seton controls. I also know that, as a rule, the double auxiliary is desirous of taking an established place, although in some cases the man has a private business, and would prefer to "stick to it.

Q. I am only speaking of those who desire appointments. Are we to take it that the complaint that the telegraph messenger is supposed to have a prior claim for appointment as established postman, as compared with the auxiliary, would not apply to the whole of the provinces?

A. I am unable to answer that question beyond the information $I$ have just given to the Committee.

Q. Perhaps you will reconsider that point, and put an answer in subsequently?

A. Certainly.

Mr. Walpole: I want to ask you a question about wages. You have handed in a very important proposal with reference to the wages of postmen, and you have told us you have put it in merely as an indication of how we might alter those wages without materially increasing the expense. You do not mean it is a definite proposal, do you?

A. No.

Q. You served on the Postmen's Committee in 1891, did you not?

A. I did.

Q. And concurred in the report?

A. I did ; certainly.

Q. The Committee recommended at that time an increase in the maximum pay?

A. Yes, we did, all through the country.

Q. And you recommended an increment of 1s. 6d. instead of 1s.?

A. Yes.

Q. You recommended also more liberality in the stripe allowance?

A. Yes; we did.

Q. Do you still agree with the recommendations you then made?

A. Yes, I do. I must remind you that our recommendations with regard to the postmen followed the scheme adopted for the indoor people-the sorting clerks and telegraphists.

Q. You do not think now that the recommendations with which you concurred in 1891 were too liberal?

A. No; having regard with what was done for the indoor force.

Q. I rather want to remove the impression that may have arisen from your evidence that you thought the postmen were overpaid.

A. No ; I said they were paid in excess of the market value.

Q. You do not think they are paid with excessive liberality, then?

A. No; not having regard to what the indoor staff receive.

Q. You say that the lower scales are sufficiently ligh, and that the higher scales are too high? I should like to ask you, do you really think so? Talking of the provinces, do you adhere to your statement that the lower scales in the provinces are sufficiently high in all cases?

A. What I intended to say was this: That our experience since 1891, when the present scales were adopted, is that even the lower scales are sufficient to get us the class of people we require, and to induce them to stay in the Service when once they are there.

The Chairman: The case of Harrogate has been mentioned to this Committee, where the postmen are paid from 16s. to $22 \mathrm{~s}$. Do you think, considering the circumstances of that town, that the scale is sufficiently high? 
A. The Harrogate town postmen are now on the scale $16 \mathrm{~s}$. by $1 \mathrm{~s}$. to $22 \mathrm{~s}$., and the rural postmen $15 \mathrm{~s}$. by $1 \mathrm{~s}$. to $19 \mathrm{~s}$. The postmen at Harrogate, both town and rural, applied for a better scale in 1894, and at that time the surveyor reported that there was no difficulty whatever experienced in obtaining suitable men as town and rural postmen at the rate of wages then paid at Harrogate. He therefore did not recommend an improved scale for the present. Since that time we have given a better scale in many towns in which, as far as we can judge, the value of labour is not greater than at Harrogate. This is the case with many towns in Lancashire. Last May the postmen at Harrogate again applied for a better scale. In the interim I may say we had given the scale to better towns, and on this further application it was decided that it should await the decision of your Committee.

Mr. Walpole: During the last few montlss we have rather held our hands in the matter of altering scales of pay until it could be known what the report of this Committee would be.

A. That is so.

Q. And the Harrogate men have suffered in that respect?

A. Yes ; they have.

Q. Were you of opinion they did make out a case for an increased scale?

A. I think they made out a case, having regard to the higher wages paid elsewhere.

The Chairman: You have drawn out a memorandum with regard to the various scales of pay in force in the case of country postmen, and your suggestion is that there might be a simplification and a reduction in a number of scales?

A. Yes; I think that you yourself called attention to the multiplicity of scales, and asked whether they could not be reduced in number. I have here a statement showing the number of scales for both town and rural labour in the provinces. There are 13 scales.

Q. At present in force?

A. Yes; at present in force.

Q. In the provinces alone?

A. Fes.

The Chairman: Will you put it in?

A. Yes ; that can be added to my evidence.

The following is the memorandum put in by Mr. Hill :-

Scales of pay for established (full duty) postmen, town and rural, in the

United Kingdom. There are $a^{\frac{t}{5}}$ present 13 such scales, viz. :-

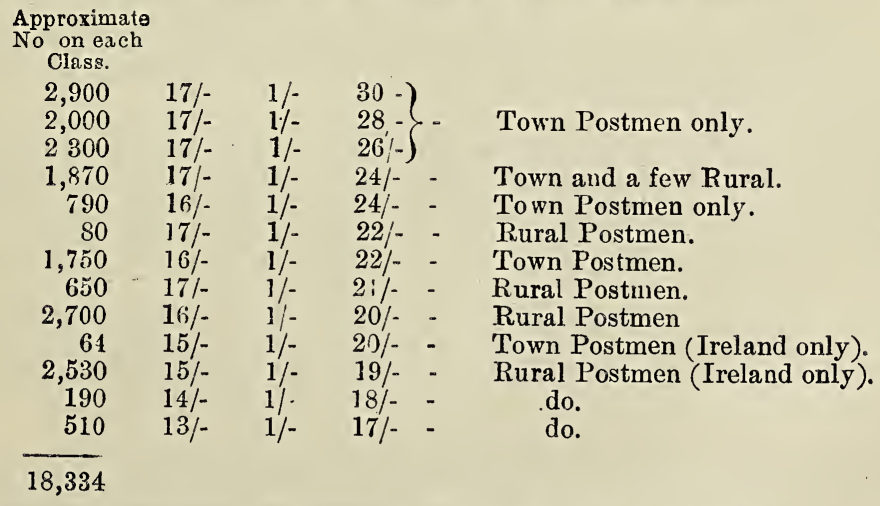

If the rural postmen be placed on the scales of pay in force for, or proper to town postmen and sub-office postmen at the offices to which they are 
attacned, tne numper of scales of pay would be reduced from 13 to 7 . A further reduction in the number of the scales could be made by placing the postmen (about 800 in number) now on the scale of $16 \mathrm{~s} .1 \mathrm{~s} .24 \mathrm{~s}$. on the scale of $17 \mathrm{~s} .1 \mathrm{~s} .24 \mathrm{~s}$. Of this the estimated cost is $£ 1,000$ a year.

There would, therefore, be six scales of pay only, viz. :-

Approximate No. on

each Class,

\begin{tabular}{|c|c|c|c|}
\hline 2,900 & $17 /-$ & 1/- & $30 /-$ \\
\hline 2,050 & $1 /-$ & $1 /-$ & 28 \\
\hline 2,440 & $17 /-$ & $1 /-$ & $26 /-$ \\
\hline 4,40 & $17 /-$ & $1 /-$ & $24 /-$ \\
\hline 5,780 & $16 /-$ & $1 /-$ & $22 /-$ \\
\hline 764 & $15 /-$ & $1 /-$ & $20 \%$ \\
\hline
\end{tabular}

18,334

Estimated cost of altering the scales as shown above-

$$
\begin{aligned}
& \text { For Rural Postmen, - - } \quad £ 30,00 \text { a year. } \\
& \text { "Town Postmen, - - 1,000 ", } \\
& \text { Total, - } £ 31,000 \text { a year. }
\end{aligned}
$$

The Chairman: Of course in this proposal you have not combined your suggestion with regard to an increase of the increment?

A. No; this is merely an attempt to meet your view.

Q. Supposing you had a combination of these two schemes, you might then still further reduce the number of scales, I should think?

A. It may be fairly remarked that, although the scales set forth in this memorandum look very numerous, we do not find any difficulty in applying them.

Q. But surely it is difficult to make a man understand why he should receive one scale of pay, while another man in the same town and doing apparently the same number of hours' work is receiving a different scale of pay?

A. Yes; but that difficulty would still remain, but not to so large an extent.

Q. Not to the same extent?

A. No; but there would still be some difficulty.

Sir F. Mowatt: Some of these classes are extremely small; one, I see, has only 80 men in it. They are disappearing, are they not, as a class?

A. Yes.

Q. In Ireland on a scale $15 \mathrm{~s}$. by $1 \mathrm{~s}$. to $20 \mathrm{~s}$. there are 69 , and in another class there are only 190 , so that really 7 or 8 would represent the total number of large classes now?

A. Yes; certainly.

Mr. Smith: On the other hand, would it be your view that the more you reduce the number of scales the more difficult it would be to avoid pay rates about the market value in some towns, and below the market value in others, seeing that in an immense number of localities the wages differ?

A. I think that seven or eight scales would enable us to avoid that near enough.

The Chairman: I asked you a question with regard to the promotion of provincial postmen and of telegraph messengers to the position of sorting clerks, and you told me that in many instances such promotions take place.

A. Yes.

Q. Have you any further information on the point?

A. Yes; I desire to add that during the last 15 years I have had many opportunities of consulting provincial Postmasters about the work of their offices, and their general experience is postmen and telegraph messengers so promoted do the less important duties of the indoor staff fairly well, but that very few of them prove to be fit for the higher work of the office. 
Postmasters, therefore, prefer to recruit the indoor staff from outside the Service, and from persons with a better general mental training.

Q. Then that would account for the comparative rarity of these ap. pointments?

A. Certainly.

Q. Now, as to the wages paid to the provincial auxiliary postmen. What are they?

A. The rate is $6 \mathrm{~d}$. per hour between 5 a.m. and 9 p.m., $8 \mathrm{~d}$. between 9 p.m. and midnight, and $9 \mathrm{~d}$. between midnight and 5 a.m. There seems to be no reason why the Department should pay a common rate of auxiliary wages throughout the United Kingdom. The auxiliary wages, like the established wages, depend in a great measure on the cost of living and the value of labour in a locality, and rates which are proper for cities and towns like Glasgow, Manchester, Birmingham, and Liverpool, would obviously be too high for a town in an agricultural district. The most equitable method of fixing the wages of auxiliary postmen is to pay them at a rate calculated to represent as nearly as possible 6d. per hour on the weekly wages of the men on the established scale, with a proviso that in no case should the rate be less than $4 d$. per hour. I am not sure whether the men on any appointed scale get less than 4d. per hour. The wages should be fixed for attendance on week days only, and the attendance on Sundays should be paid for with a separate allowance calculated at rate-and-aquarter. Those attending between $10 \mathrm{p} . \mathrm{m}$. and $5 \mathrm{a} . \mathrm{m}$. should have the same allowance as established men, viz., that $52 \frac{1}{2}$ minutes should count as an hour, and an attendance of $3 \frac{1}{2}$ hours in the night should be paid for as an attendance of 4 hours. The attendances on early morning and late evening duties should be given only to auxiliaries other than ex-telegraph messengers, and should not exceed 4 hours, and the employment should cease in all cases when the auxiliary reaches the age of 50 years.

Q. Fifty years of age?

A. Yes; I suggest that a single duty auxiliary should cease to come in to work when he is 50 years of age on the ground that at that age he becomes less useful to us. At that age he is rather apt to give up his private business and depend on the $6 \mathrm{~s} ., 7 \mathrm{~s}$., ox $8 \mathrm{~s}$. a week he gets from the Department. Still, I do not attach much importance to this recommendation.

Sir F. Mowatt: But a single delivery does not involve much strain on a man.

A. No; but at 50 a man gets slow and less useful to us.

Q. What is the age at which a man gets slow?

A. I got slow many years ago. (Laughter.) I do not hold that a man who works for us only 3 hours a day has a claim on us for ever. If the system of admitting that every man you employ has a claim on you is to continue, nobody will employ anybody, even for housework or to black one's boots, as there is no telling where the liability of the employer would stop. However, I do not attach much importance to this point.

The Chairman: It is rather hard to turn a man away from his work because he is 50 years old. (Hear, hear.)

Mr. Smith: Your proposal that an auxiliary should cease at 50 is confined to those who would be employed on a single duty?

A. Certainly.

Q. And you would make a definite rule that he should not be employed on more than one attendance?

A. Certainly.

Q. And your object is to get some guarantee which at present you have not got that they are not dependent solely or mainly on the Department for their living?

A. Yes.

Q. They would be simply people engaged in other trades whom the Department pays to do a job for it? 
A. Yes.

Q. And you think it would be an additional safeguard if a man knew he would not be kept on the job after he reached 50 years of age?

A. Yes.

Q. It would not be a case of dismissing a man. You would not regard him as permanently in the Service?

A. Yes. I repeat I do not attach much importance to it. But there is a tendency, as a man gets too old, for him to give up his private work; then something may happen, and the P.O. is abused for employing a person who has nothing else to do, and giving him only $7 \mathrm{~s} ., 8 \mathrm{~s}$, , or $9 \mathrm{~s}$. a week, as the case may be.

Sir F. Mowatt: Under the arrangement you suggest do you think you could always find sufficient men?

A. I have no doubt we could, especially at the better wages we give. At the present time we have no difficulty in finding auxiliary postmen in the country.

Q. To do a single delivery?

A. Yes; cobblers and tailors, and men in a small way of business, in which they would not be occupied at the time we want them. They are very glad to get the exercise and to be paid for doing it. "Then, too, they make a little connection for themselves on their delivery. They are a very good body of men indeed, and I am very glad to have them. They should, on taking up their appointment, sign a statement to the effect that they have independent means of subsistence which would, with the I..O. pay, bring them in 18s. a week at least. That should be done in the provinces as well as in London.

Mr. Smith: Do you think the declaration is found to be of any value in London?

A. That is for Mr. Badcock to say.

Q. I do not think that Mr. Badcock attaches much importance to it. Yet you propose to extend that to the country?

A. Yes; but only to protect ourselves against the charge that we give our men too small wages. When a man has nothing else to do he is tempted to steal.

Q. Would not the effect of introducing such a rule rather tend to encourage the employment of auxiliaries?

A. I do not see that it would. We must have auxiliaries on morning deliveries.

The Chairman: But is not the proper policy to reduce the auxiliaries to the lowest possible number consistent with the interests of the public service?

A. Yes, certainly. When we can make a full duty we do. We prefer to employ a man the whole of his time, because then we have a better hold over him. As far as I can see, however, we shall never be able to do away with the auxiliary force without employing people only half a day and giving them a full day's pay. They must fully understand that they can look for no further remuneration from or advancement in the Post Office, that their employment is only temporary, that it is subject to be terminated at a week's notice, and that under no circumstances will it be continued after they are 50 . However, to that last condition I do not attach much importance. As many auxiliary duties as possible should be allotted to ex-telegraph messengers who are desirous of becoming established postmen; the attendance should amount to 5 or 6 hours a day. The maximum attendance should in no case exceed 5 hours a day; and no lad of less than 18 years should be employed between 10 p.m. and midnight, and not less than 20 years of age between midnight and 5 a.m. That is our present rule. As far as practicable outsiders, i.e., auxiliaries other than ex-telegraph messengers, should be employed only in the early morning or late evening, with one attendance not exceeding 4 hours, and then employment should cease in all cases at 50 years. As regards counting aux- 
iliary service towards entering the established class above the minimum, the arrangement described will no doubt lead to more rapid promotion for the ex-telegraph messengers. These lads should, it is thought, be distinguished from outsiders. Half of their service beyond one year might perhaps be allowed to count as full-time service as regards the commencing wage on the established class, and for every year of full service thus formed they might be allowed one increment on entering the established scale. Every such full year of service might also count towards good conduct stripes. Annual leave of two weeks might also be allowed them, but as their wages would be fixed rateably at the mean of the established scale, it is thought that the higher proportionate pay should compensate them for receiving no sick pay or boot allowance, which are at present confined to persons doing a full day's work. With regard to annual leave, I find that telegraph messengers are very often allowed a fortnight's holiday.

The Chairman: I understand that, but they cannot claim it?

A. No; it has not been given as a general rule, but where it is asked for it has been allowed.

Q. You told us last time that the average pay of an auxiliary was $4 \mathrm{~d}$. or $5 \mathrm{~d}$. an hour in the provinces?

A. A little more than 5 d.

Q. Do you consider that that payment secures exactly the class of men that you want?

A. I doubt it. I think that if we paid a little more we should get better service. The Confidential Inquiry Branch at our office tell me that a large proportion of the thefts and other acts of dishonesty are committed by auxiliary rather than by established postmen, and I think that that points to the fact we are not getting as good a class of auxiliary as we require.

Q. Then you think that by increasing the rate we should get a better class of men?

A. I think we should.

Q. Do you consider it is necessary to get a better class of men in the auxiliary service?

A. I think it is desirable.

Q. In the interests of the public?

A. Yes. I base that statement on the fact that there is more dishonesty among the auxiliaries than in the established class.

Q. So far as the provinces are concerned, you give no extra pay for Sunday or night work?

A. As regards Sunday work, it has been roughly included in the pay. An auxiliary who works six day gets $6 \mathrm{~s}$., and one who works seven days gets a shilling more.

Sir F. Mowatt: I thought we had had it in evidence that Sunday work was counted in by the hour at the same rate of payment as week-day work?

A. If a man works on Sundays he is paid at a higher rate.

The Chairman: I understand not. You said if he worked on Sunday he would receive more than the man who only worked on week days?

A. Yes; his pay is higher in that case.

Q. Surely it would naturally be so if he worked a day more per week? Is no extra consideration given for his Sunday work?

\section{A. No.}

Mr. Smith: You said he got a shilling a week more?

A. We give $5 \mathrm{~s}$. for six rays', and $7 \mathrm{~s}$. for seven days' work.

The Chairman: So that if he does Sunday work he gets exactly the same rate of pay as for Monday's work?

Mr. Smith: Would an auxiliary doing 12 hours a week, including some on Sunday, get more than a man doing 12 hours, none of which fell os Sunday?

A. No.

The Chairman: A man who works seven days a week naturally gets rather more than a man who does six days' work? 
Mr. Smith: I was mistaken just now in saying that Mr. Badcock attaches little or no importance to the declaration signed by the auxiliaries in London regarding outside employment. I see now that he said it was a guarantee to a certain extent.

Mr. Walpole: You say that telegraph messengers employed as auxiliaries have in a great many instances received annual holidays?

A. Yes.

Q. We have it in evidence from Glasgow that a very large number of telegraph messengers are employed as auxiliaries, and in no case do they receive holidays. Has your attention been drawn to that fact?

A. No; it has not.

Q. It was also said that out of 200 auxiliaries, probably not more than 24 have outside employment, and that they are mostly ex-telegraph messengers waiting for established appointments. These telegraph messengers, when acting as messengers, get a fortnight's holiday, but when they are promoted to be auxiliaries the holiday privilege is withdrawn. What have you to say as to that?

A. I understand that the giving to the ex-telegraph messengers who are now auxiliaries a holiday has been recently introduced, and is only being gradually introduced.

Mr. Walpole: I imagine you would agree with me in thinking that some rule should be laid down in the matter one way or another?

A. Oh, certainly. I was asked by Lord Tweedmouth on Monday if I knew what was the pay of persons employed as carriers, with whom 1 was comparing the postmen.

Sir F. Mowatt: Are you speaking of Carter Paterson's, and people of that sort?

A. Yes; of the servants of such firms generally in London. I have made some inquiries, and so far as I can learn they are paid 21s. to 25s. a week, but they also get some little percentage on part of their work in addition. I am here speaking generally of carriers in London, and not particularly of Carter Paterson's men.

The Chairman: That is quite up to the postmen's standard, is it not?

A. The 25s. is not up to the London standard.

Q. Yes, I think so, with the gratuities. They start at 21s. instead of $18 \mathrm{~s}$. , and although they stop at 25s. they get some gratuities.

A. Yes, some little percentage; but the postmen get a good deal beyond their wages. They get uniform, free medical attendance, medicine, full pay when sick, a fortnight's holiday, and pension, and the carriers get none of these advantages, besides which the postmen rise to $34 \mathrm{~s}$. As to the attendance being brought within the 12 hours' limit, it is the practice as far as practicable to restrict the covering period over which the 8 hours' attendance is spread within about 12 hours a day. That practice was, I think, begun about 1890 in consequence of representations by the postmen.

Mr. Walpole: It is one of the recommendations of the Committee of $1890-91$.

A. Yes; and it arose out of the requests repeated here that the atten. dance should be brought within 12 hours. To do so, however, in all cases would necessitate the employment of a large number of auxiliary postmen, as the morning and evening duties, being as a rule the heaviest, render necessary the employment of more men at those times than during the rest of the day. The interests of the present established men and of the auxiliary postmen are therefore opposed to each other, and the witnesses on behalf of the established men ask for the 12 hours' limit to be strictly applied, while the auxiliaries ask that more established duties may be formed, and auxiliary labour in the Post Office be reduced as far as practicable. Uniless the 8 hours' attendance be allowed to spread over a covering period of more than 12 hours it will not only prevent in many cases additional full duties being performed, but it will be necessary in some cases to convert on vacancies present established situations into auxiliary ones-a step which 
would be most injurious to the interests of the large number of telegraph messengers who hope to obtain established appointments as postmen. Moreover, it has been ascertained from experience that the postmen not infrequently prefer a duty spread over about 14 or 15 hours, with a long interval in the day-time, to one involving three or four attendances within the 12 hours' limit. Such, for instance, is the case at Brighton, Eastbourne,

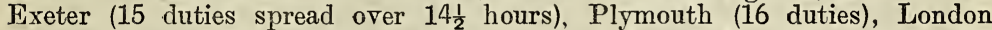
Eastern Central District, and at many other places. I may mention with regard to the case of Brighton I made a report to the Committee on Postmen of 1890-91, dated the 17th November, 1890. I was then sent to visit the large offices to learn as far as I could what the postmen wanted, what was the value of their labour, and their general conditions of service. At Brighton $I$ inquired whether the postmen desired to have their duty brought within 12 hours, and upon that point my report was as follows:- "The duties of one section of the town postmen are spread over about 15 hours, with an interval during the middle of the day of from five to six hours. The duties of the other section are spread over a period of $10 \frac{1}{2}$ hours. It is thought that the postmen do not desire any limitation of the period over which their attendance is spread. The men working on the 15 hours' period attach much value to the long interval in the middle of the day, which enables them to earn money in window cleaning, etc." On February last I asked the Postmaster at Brighton whether what I had described as the state of the facts in 1890 still held good, and he replied on the 28th of last month:- "The circumstances are unchanged. Before I reported on the last revision of the outdoor force I caused a ballot to be taken amongst the postmen, and I found that a large majority were in favour of the present system." As an illustration of the working of the 12 hours' limit, if strictly applied, the following instances now or recently under consideration may be mentioned:-At Edinburgh the postmen are, the Department is assured, perfectly satisfied with the present arrangement, which admits of suitable intervals for rest in the day-time, when the attendance is spread over more thin 12 hours. To apply the rule strictly would necessitate about 100 additional auxiliaries being employed at a cost of about $£ 2,300$ a year, and the present established postmen would have considerably lesis than a full day's work.

The Chairman: Would it be possible more largely to make the postmen do sorting and such other work?

A. Yes; I have something to say with regard to giving more sorting work to postmen. During the last few months we have introduced a change of system in the training of our indoor staff. We have arranged that all persons entering the provincial offices on the indoor staff should be first trained in telegraph work and then in postal work. They begin the telegraph work at an early age, and then go on to the postal work. The object of that is twofold. First, that our indoor staff should be able to do both sides of the duty, or at least to have sufficient acquaintance with both sides, and in the next place that the two sides of the Service as regards entrants should be on an absolute equality in the matter of wages. It would be impossible for us to train experienced postmen in telegraph work, as they are too old, and to employ them much in sorting work would, I think, upset existing arrangements, or would, at all events, to some extent upset them.

The Chairman: I must say it seems to me that you have an enormous force of men of one sort or another, and that by keeping great bodies of them so much apart for individual duties you waste a great force.

Mr. Walpole : Is not one of the objects of this alteration you have mentioned to prevent the very waste of force to which the Chairman has alluded?

A. That is so as regards the indoor staff.

Q. We want to have the men available and competent to do other work, according as the exigencies of the Service demand? 
A. Yes; other indoor work.

Q. And would it not be possible to employ a certain number of postmen on a certain portion of the sorting duties as at Liverpoel, because the sorting postmen would not be got rid of under this scheme?

A. Yes. I think it would be possible so to employ them; but it would not be possible to give the whole of the sorting work to postmen.

The Chairman: I mean that you might perhaps distribute the duties more over your whole force, and by that means have a larger proportion of established men, and dispense as far as possible with auxiliaries, and also give your established men more continuous duty?

A. Yes; exactly. At Cardiff the attendances of 90 postmen are restricted within a limit of 13 hours, those of the remainder-67 in number-are within 14 hours, with intervals during the day-time of from $3 \frac{1}{2}$ to 5 hours for rest. A large number of auxiliaries would have to be employed at a cost of about $£ 1,100$ a year, and the established men would necessarily in many cases have less than a full day's work, if the 12 hours' limit were strictly applied. At Waterford the force would have to be altered from 9 established and 2 auxiliary postmen to 5 established and 10 auxiliary postmen to apply the 12 hours' limit.

Mr. Walpole: In all those cases that you have cited where additional cost would arise from this scheme, I presume it would only arise if you kept the same number of established men as now?

A. Yes; only you would not be able to give your established men a full day's work.

Q. But you could reduce the number of established men where necessary, and increase the number of auxiliaries? That would involve no increase of cost?

A. The opinion of the practical officers is that you could not arrange a full day's work for your established men.

Q. Is it not rather the fact that you could not arrange a full day's work for the same number of established men that you could for a certain number?

A. Yes. I should here add that I am not responsible for these estimates, as they are given to us by our provincial staff. The surveyor reports as regards Perth, that if he is permitted to disregard the 12-hour limit, but not otherwise, established force could be substituted for auxiliary postmen.

The Chairman: Is the 12 hours' limit in force there?

A. Yes. Another surveyor reports on a case where 8 auxiliaries are employed as compared with 12 established postmen:- "This case affords so strong a proof of the evil effects of the endeavour to restrict rigidly the duties of town postmen within a period of 12 hours that $I$ beg for the Secretary's authority, when considering the question of a revision, to proceed on the old established line of providing as many fully employed duties as possible, due regard being, of course, paid to the desirability of consolidating the duties as far as possible."

Mr. Walpole: I understand that you cannot lay down a general rule as to the desirability of consolidating the duties, because in cases like those of Brighton or Eastbourne, the postmen themselves would object to that very consolidation, would they not?

A. Yes.

Q. In the cases of Brighton and Eastbourne they did object?

A. Yes.

Q. They prefer separating the duties?

A. Yes. At Bradford the auxiliary force could be reduced on vacancies from 28 to 10 if the 12 hours' limit be not applied. So also at Rochdale, where the auxiliary force could be reduced from 8 to 1 . The surveyor of the North-Western District reports as regards Bradford, Huddersfield, and Keighley:- "These cases, I think, fully prove the impracticability in the great majority of cases of restricting the town postmen's duties within a 
covering period of 12 hours, except by the employment of an excessive number of auxiliaries. There are other similar cases in the district." The surveyor of the Western District reports:- "It is absolutely impossible to find full duties and confine the attendance within the limit of 12 hours. To effect this the number of auxiliary postmen must be largely increased throughout my district." At Newport (Mon.) it will probably be practicable under a revision of the duties already in hand to reduce the auxiliary force considerably and create several additional established appointments, buf this cannot be done if the 12 hours' limit be applied. Another surveyo i reports as follows respecting the number of attendances of established post men:- "It is a very ordinary thirig for a postman to give four attendances a day, and in many cases it would be inexpedient and inconvenient, even from the man's own point of view, to reduce the number. A postman who comes on duty, as the Deal postmen do, at 6 a.m. or 6.15 a.m., has usually only a light breakfast before he starts, and it is desirable for his health's sake that he should have an interval for rest and refreshment at 9 a.m. or 10 a.m. before commencing his second delivery. The men also like an interval for dinner in the middle of the day, and another for their tea before commencing their evening delivery. Indeed, in outdoor revisions, it is very important to allow a sufficient number of breaks so that the men may not have too long stretches of walking:" In view of these facts, it would be most undesirable to lay down a strict 12 hours' limit as the longest period over which the attendance of an established postman should be spread. At the smallest offices it would be utterly impossible to observe such a rule, and the result would be that auxiliaries would have to be substituted for established force, while at the larger offices the strict application of the rule would not only prevent auxiliary duties being in a large number of cases converted into established ones, but would also necessitate a reduction in the established force in many instances. Of course, by employing additional auxiliaries, and giving the present established postmen considerably less than a full day's work, the rule could be applied in most cases to the existing established men, but the cost would be very large, and such a step could not be recommended. The arrangement would not only be extremely wasteful, but would lead to a large increase in auxiliary labour, which would be highly undesirable. There is no doubt that the postmen would object to such an increase in the auxiliary force. Under all theso circumstances it is thought that the practice to be followed should be to form as many full-time duties as possible within the 12 hours' limit, and then to frame as many additional full duties as practicable in such a manner as to allow a good interval for rest at night of from 8 to 9 hours between the last and first duties, the attendances in such cases being arranged as far as practicable so as not to exceed two a day, with a long interval for rest between them. Postmen frequently prefer duties with a long interval between them in the day-time, and on a revision the duties could be selected according to seniority. A Dublin postman said he was in favour of making more full duties, even if they be spread over as many as 15 hours, as the auxiliaries would prefer to be made established and have these duties rather than remain auxiliaries. The following question is asked in the report furnished by the surveyor at every general revision of the town postmen's duties :- "Will the attendance of the full-duty postmen be restricted within a covering period of 12 hours? If not, would the cost of so restricting it be excessive, and would the postmen have less than a full duty?" We have not asked the further question whether the postmen want it, but we might ask that.

Mr. Walpole: If your evidence is adopted would you recommend the omission of this question in future?

A. Yes; I should be disposed to recommend the omission of it. I don't think it is worth spending money on it seeing how often the postmen do not desire it. 
Q. The gist of your evidence is, upon that point, that it is undesirable to make a hard and fast line?

A. Yes ; there is a great difference between the condition of men in small towns where they live near their offices and in large towns where they have to live far away.

Mr. Llewellyn Smith: Do I understand that the proposal sketched out would involve a departure from the present policy of the Post Office, or is it a description of the poliey you at present pursue?

A. It is in the main a description of the policy we at present pursue. I think we have worked the 12 hours' limit rather too much.

Mr. Walpole: Is it not the fact that we regard the 12 hours' limit as the ideal, and that we strain after it, but that in many cases we cannot attain it?

A. Yes.

Mr. Llewellyn Smith: Of the two things-the 12 hours' limit and the reduction of the number of anxiliaries-you would prefer to regard the latter as the ideal to be sought?

A. Yes.

Mir. Walpole: That is rather contrary to the recommendations of the Postmen's Committee, is it not?

A. Yes ; I think it is.

Mr. Llewellyn Smith: Your experience of the working of that recommendation is that you have got to a point at which if you press the thing too far you incur greater evils than you remedy?

A. Yes.

The Chairman: Have you any rule with regard to the amount of interval between different duties which is counted or not counted in the provinces?

A. I think the interval is from a quarter to half-an-hour. At the same time, from the replies to some of the complaints I have notices that there have been intervals of something like an hour which have been allowed ti) count as duty, but.I think from a quarter to half-an-hour is more common.

The Chairman: You have no regular rule?

A. I think we have no hard and fast line.

Q. What rule have you with regard to the exchange of duties among men in the provinces?

A. Are you speaking of when a man desires to be absent?

Q. Yes; when he wants to be off and gets a friend who is willing to take his duty. Do you allow that in the provinces?

A. I think that would be described better by Mr. Joyce, who is going to take questions of discipline.

Q. At the last sitting I asked you what special allowances a provincial postman had, and what is their amount?

A. There are about 2,420 such allowances paid to established provincial town postmen at about 300 provincial head offices out of a total number of 914 provincial head offices. These allowances amount in all to about $£ 24,100$ a year, or an average of about $£ 919$ s. 2 d. a year (equivalent to $3 \mathrm{~s}$. $10 \mathrm{~d}$. per week per recipient. If the total number of provincial established town postmen be taken as about 12,000 , about 20 per cent. are receiving special allowances. Of the whole number of provincial established postmen (town, sub-office, and rural), about 12 per cent. are receiving special allowances.

Q. Practically all the allowances are given to the provincial town postmen?

A. Yes.

Q. The rural provincial postmen get very few, if any?

A. That is so, because they do not do the special work which we require, and for which the allowances are given. But the rural postman still has his Christmas boxes? 
Q. I assume he has.

A. The object of these allowances from the country is to induce certain postmen to do indoor work, and to undertake station service, and they naturally would object to take that duty if they were on that account to lose their Christmas boxes.

Q. Do you give special remuneration for night duty in the provinces?

A. Night duty counts shorter; each hour of the night duty is counted as rather more than an hour, and that is the only advantage.

Q. Is that given in all cases of night duty, whether short or long?

A. I should say that substantially that is so; but, of course, it might not be so if a man does say a quarter-of-an-hour's night duty.

Q. But if he does a couple of hours of night duty?

A. It ought to be done in all such cases. I am now told that the rule is that when the night duty is less than two hours we do not count is as such.

Q. What hours do you reckon as night?

A. 10 p.m. to 5 a.m.

Q. We have had a good many complaints about the inconveniences of parcel delivèry to the postmen, especially from the provinces, and from rural letter-carriers?

A. The present rule that only a few of the lighter and less bulky parcels are to be delivered with the letters is, it is believed, unles stood and acted on generally. Inquiry is made at every revision of force whether this rule is being observed. Any postman who considers that he is overburdened with parcels or letters can ask for relief, and this is afforded whenever the circumstances in the opinion of the controlling officer are considered to warrant it. Hand-carts or vans are used for delivering and collecting parcels where necessary, and the present arrangements are considered to be satisfactory. To support their plea that the parcel delivery may be separated entirely from the delivery of letters, many statements have been made in the evidence which are either totally without foundation or have much exaggerated the actual facts. For instance, the statement made as to the postmen at Manchester having to take out 14 or 15 parcels with their letters is thus explained in an extract from report of surveyor, Manchester:- "The revision of outdoor duties at Manchester was only carried into effect on the 3rd February, and owing to the pressure and confusion caused by the new working arrangements a number of parcels which should in proper course have been delivered by postmen with hand-carts were delivered by postmen by hand. I cannot, however, find out that any postman carried as many as 14 or 15 parcels. There is no doubt, however, that some of them carried more than the usual number at first, but the matter was put right after the first day or two. In the Central District of Manchester at the first delivery all parcels are taken out by horse and van, and by hand-cart; at the other deliveries the heavy and bulky parcels are taken out by horse and van, and the smaller and lighter parcels by the postmen with their letters. The parcels delivered by the postmen with their letters are few in number, averaging less than one per man for two deliveries. It sometimes happens, however, that a postman will have more than the regulation number of parcels at one of his deliveries, and in such a case assistance is given to him. In the other districts of Manchester the whole of the parcels are delivered by postmen, the smaller parcels being mainly delivered with the letters, and the larger parcels separately, after the completion of the letter delivery. The time occupied in the separate parcel delivery is regarded as part of the postman's 8 hours' duty. Under this arrangement relief is not necessary, as full provision is made in the duty schemes for the delivery of all parcels, small or large. The witness's statement in this paragraph is not correct. The arrangement as regards the number and weight of parcels delivered with the letters is in accordance with the rule (i.e., 4 or 5 of the lighter and less bulky parcels per man of a total weight of not more than $11 \mathrm{lbs}$.), the only exception being when a 
postman is allowed to carry more than the ordinary number with his letters in order to save him the labour of making a special delivery of parcels after the completion of his letter delivery. It frequently happens that a postman wishes to take out a few extra parcels with the letters in order to save himself trouble during the subsequent special parcel delivery. This slight departure from the general rule, which is entirely in the interests of the postmen, is only allowed when the delivery of letters will not be retarded thereby."

Witness: Inquiry has been made in several instances as regards the statements that postmen at certain towns deliver surplus parcels as best they can or leave them over until the next delivery, or deviate from their ordinary route to dispose of heavy parcels, thus causing irregularity of service, with the result that it has been ascertained at the special towns selected at random that there is no foundation for the statements. One of the questions which every surveying officer on making the periodical survey of an office has to answer is- "Are the deliveries of letters and parcels combined, and is any delay caused thereby to letters or parcels?"

Q. Do you generally get complaints that the letter delivery is embarrassed and made difficult by the number of parcels that the postmen, and particularly the rural postmen, have to carry out?

A. I should say not. I do not see the rural postmen so often, but I should say not as regards the town postmen.

Q. Then you think that the demand made to us by some of them that there should be a separate delivery in all cases of parcels is not one that can be sustained?

A. Certainly not; it would involve a very large expense. Some of the men seem to be ashamed to carry parcels, but I think that if they are they had better seek some other employment.

Q. And now you will, perhaps, deal with the wages of rural postmen?

A. The minimum of the scale for a rural postman is generally fixed at the same amount as that for the postmen employed in the town from which the rural postman starts. Thus, if the town scale is $17 \mathrm{~s} .1 \mathrm{~s} .26 \mathrm{~s}$, , the rural scale would be 17s. 1s. $21 \mathrm{~s}$, or $17 \mathrm{~s}$. 1s. $22 \mathrm{~s}$.; if the town scale is $16 \mathrm{~s}$. 1s. $22 \mathrm{~s}$, the rural scale is 16s. 1s. 20s. This rule is not always, however, observed. But inquiries on the subject are now being made, and it is in contemplation to level up where a lower minimum has been given by inadvertence to a rural postman. In considering the question of the wages of rural postmen it should not be overlooked that these men have received a very substantial increase of pay, amounting in many cases to $4 \mathrm{~s}$. or $5 \mathrm{~s}$. a week, or as much as 25 or 30 per cent. on their former wages, at the maximum, under the general revision of 1891.

(1) The chief reason for paying rural postmen on a lower scale than the town postmen, though both may live in the same town and pay the same rent is, no doubt, that the rural men are actually employed for fewer hours in the day.

(2) Having also, as a rule, an urbroken interval of several hours between delivery and collection, they have opportunities of earning money in other ways.

(3) They are supposed to obtain perquisites of one kind or another.

(4) Moreover, the volume of their work is less, and it is not performed ur.der such pressure as that of the town postmen.

The arguments for raising their scale are:-

(1) That their work involves more responsibility than that of the town postmen, since they are not under direct supervision.

(2) That it requires in some respects greater knowledge of details, for they have to register letters, weigh parcels, sell stamps, etc.

(3) That the men are put to greater expense, and are subjected to greater hardship through exposure on account of having to remain away from home all day.

In view of all these considerations I think that- 
(1) Rural postmen starting from a town (head office or sub-office) where there are town postmen on scale, should be placed upon the same scale as the town postmen.

(2) That the scales for rural postmen starting from the smaller towns and villages, where there are no town postmen on scale, should be raised so as to preserve approximately the same proportion as at present to the postmen included in Class I.

Class I. includes about 4,600 rural postmen, and the expense of raising the scale as suggested would amount at the arithmetical mean to about $£ 19,000$ a year. The true mean would, however, be considerably higher than this. Class II. includes about 1,900 rural postmen, and the cost of raising the scales as suggested, calculated at the arithmetical mean, would be about $£ 8,000$ a year.

The Chairman: As regards your first point, you must set the fact that the rural postmen of ten find themselves set down at some place far from their home, in the middle of the day, with 3 or 4 hours that he has no passible use for.

A. I quite accept that view.

Q. Then it is not very much good putting forward the point you were mentioning?

A. No, I don't think it is. The consideration is that a rural postman as a rule has an unbroken interval of several hours, which affords him an opportunity of earning money in other ways.

Q. Your second point as to their other opportunities of earning money would be true if they were generally to be found in their own home during these hours.

Mr. Walpole: I presume that in the rural districts there are a great many cases of men who get employment at the end of their walk?

A. Yes ; undoubtedly they earn something on a farm or in a cobbler's shop.

The Chairman: We have not had such cases given to us?

Mr. Walpole: There was the man who was employed in a linen weaving factory.

The Chairman : Not at the present moment. He said it was 10 years since he had done that work.

Witness : I don't think they would be given. There was the case of one witness-Grimmer, I think-who said he was a tailor and worked as such.

The Chairman: No; he told us that he had ceased for some years to do tailoring; he only put forward the fact of his being a tailor in order to show that he was a man who could give us reliable information about uniforms and clothing. What you have suggested may possibly be common, but it has not been brought before us in evidence to any extent. But I liad better ask you the question-Do you know, as a matter of fact, that a great many rural postmen find other employment at the end of their walk?

A. I believe that to be the case.

Mr. Walpole: Is not that the experience of officers of our Department who have been out inspecting these walks as surveyors, etc.?

A. Yes ; I believe it is.

Q. Are they not unanimous in saying it is the case?

A. I never knew people unanimous on any question. There is this to be borne in mind, that if a man has walked 16 miles in a day and carried parcels with him, he has done enough work, and if he works at the end of his walk at anything except sedentary work, he is doing what is not desirable for his health.

Q. And perhaps not desirable for the office, as he may not be so well able to walk the 8 miles back?

A. I am sure that the ordinary 16 miles' walk with the weights they carry is enough. Many of them have told me that, and I believe it to be 
true. Another point-the third on my list-is that these rural postmen are supposed to obtain perquisites of one kind or-another.

The Chairman: What perquisites do they obtain? We know about the Christmas boxes, but what other perquisites are there?

A. Well, I think the squire often gives them a dinner, or lets them dine with the servants; but there are not, perhaps, so many squires who do that sort of thing now.

Q. Surely that is not a question you are going to put forward as a thing to be considered by the Department with regard to these men's pay?

A. Well, I think it is perhaps one of the questions which are regarded as some justification for having in the past given them rather less; moreover, the volume of their work is less, and it is not performed under such pressure as that of the town postmen. The number of hours they are actually at work is less. The arguments for raising their scales are, first, that their work involves more responsibility than that of the town postmen since they are not under direct supervision.

The Chairman: What rules have you for the transfer of rural postmen to town situations?

A. Prior to 1891 rural postmen were nominated by the Treasury, and the nomination for town postmen vested in the Postmaster. Naturally the Postmasters preferred to nominate telegraph messengers and others who had some claim on the Department, and who would otherwise have been left unprovided for; so that it would seldom happen that a rural postman succeeded in obtaining a place on the town establishment. Now, however, that rural postmen enter the Service under the same conditions as town postmen, the claim of any rural postman who wishes to be transferred to the town establishment is duly considered. As a matter of fact, a rural postman who is in other ways suitable would be considered to have a claim prior to that of a telegraph messenger or auxiliary. if he applied for a vacancy on the town establishment. Such applications have not, up to the present, been very numerous, and many rural postmen, especially after they have been on a walk for some years, are disinclined to change their occupation. Some men, indeed, express a preference for rural duties. But it seems likely that more rural postmen would apply, at any rate in the earlier years of their service, for transfer to the town class, if they were aware that their applications would be likely under the existing conditions to be favourably entertained.

The Chairman: Do you find these men good material for town postmen?

A. I think the general experience is that after a man has acted for some years as a rural postman he is better fitted for a rural than a town appointment.

Q. I am speaking of a man in the earlier years of his service?

A. Then I think he is just as good.

Mr. Llewellyn Smith: Is the rule that a rural postman has a prior claim to a telegraph messenger or auxiliary universally known?

A. Well, it is known in the London Office, and we act upon it, but whether Postmasters generally do I cannot say.

Q. Have they not been instructed to observe it in any way?

A. I am not able to say.

Sir F. Mowatt: I do not quite understand the last answer. It seems of considerable importance. As a matter of fact, you say that a rural postman, if he is in other ways suitable, is considered to have a prior claim over telegraph messengers and auxiliaries for vacancies on the town establishment. Do I understand you to mean that if a man just outside London applied for an established postman's place within the London District, his claim would be considered before that of a telegraph messenger in the Iondon District?

A. No; I am spealking of rural postmen. They are not the same as provincial postmen.

Mr. L. Smith: You do not speak for London? 
A. When I speak of London I do not mean it in the sense of the London Postal Service-I refer to the Secretary's Office.

The Chairman: Now, what are the average hours of duty for rural postmen?

A. The hours of duty are necessarily spread over a long period in order to afford the public in rural districts a delivery of letters as early as possible, 'and a reasonably late collection. A postman who is kept away from the head office on official duty for 12 hours daily is regarded as doing a full day's work. As far as possible, the time spent by each man in actual walking is restricted to 6 hours a day. To restrict, however, the rural postman's duty to 12 hours would mean a serious curtailment of the accommodation now afforded in remote districts, and would lead to complaint; the public, moreover, would not consent to make a payment for the maintenance of the existing hours of collection, as suggested by one witness. Fffforts have from time to time been made to bring the men back to their head offices by 7 p.m. The proportion of cases in which postmen return as late as 8 p.m. is not large.

The Chairman: What is the average pace a rural postman walks?

A. About $2 \frac{3}{4}$ or 3 miles an hour?

Sir F. Mowatt: That is not the actual pace he walks, but the amount of ground he covers, including going up to the houses, is it not?

Mr. Walpole: Is it not $2 \frac{3}{4}$ miles?

Mr. Seton: My experience is that it is $2 \frac{3}{4}$ miles.

A. Well, I will say $2 \frac{3}{4}$ miles. With regard to the matter of the pace at which the postman goes, of course it includes stoppages at houses to deliver parcels, etc., and it may be to get a receipt for a registered letter.

The Chairman: Now, we have had some complaint as to the weight carried by these men. Have you anything to say as to that?

A. The precise maximum of weight in a particular case should, it is thought, depend upon the distance walked before the postman gets rid of any considerable portion of his load. A man should not, say, be required to carry $35 \mathrm{lbs}$. beyond 2 miles, or more than $30 \mathrm{lbs}$. beyond 3 miles. Perhaps the best plan would be to give a discretion to the surveyors to fix the maximum at the starting point somewhere between $28 \mathrm{lbs}$. and $35 \mathrm{lbs}$., according to the distance to be travelled before the load is materially reduced.

The Chairman: What rules have you with regard to giving assistance to men with heavy loads?

A. If a rural postman at the start has more than $35 \mathrm{lbs}$. to carry he is entitled to assistance, but, of course, it is not always possible to provide it, as the man goes out at 6 in the morning?

Q. Does the Postmaster get the assistance or the man himself?

A. I think either the Postmaster himself or the officer in charge at the office.

Q. I understood one witness to say that a man could get assistance for himself?

A. That is on the return journey only, I think.

Q. Following that up we have a good many complaints about the length of the rural postmen's walks?

A. Yes. The maximum distance for a rural postman's official journey on foot is 18 miles, but in the great majority of cases the distance actually walked falls considerably short of 18 miles.

Q. Would you say that in no case now in the United Kingdom is the 18 miles exceeded?

A. I do not think I could say that, because I found out on examining into some particular complaints that a man was walking 19 or 20 miles.

Sir F. Mowatt: Again, do you mean 19 or 20 miles of road, excluding the distance up to the house?

A. No; we allow for that. If a postman has to go a bundred yards to a house that is set back-it is taken into account. 
Mr. Walpole: We should not, except by inadvertence or error, approve of a man's walk exceeding 18 miles?

A. Certainly not.

Q. When a new walk is submitted for approval, is it not usual for the surveyor's clerk or some one to walk it with the postman?

A. Yes. Many men walking less than the maximum distance receive an allowance for horse-keep, or are otherwise relieved if their loads are sufficiently heavy.

Sir F. Mowatt: What do you mean by sufficiently heavy? You have a rule it should not exceed 35 libs.?

A. Yes; that is the rule. The man's load at the start must not exceed 35 lbs.

Mr. Walpole: But when the Parcel Post was instituted was there not a rule issued that the maximum weight should not exceed $35 \mathrm{lbs}$, according to the distance walked?

A. Yes. Comparatively little difficulty has been experienced in finding postmen willing to supply themselves with a horse and cart on receiving an allowance for the purpose. The allowance, which varies according to circumstances from 12s. to 20s. a week, is held to cover not only cost of provender, stabling, shoeing, and veterinary attendance, but a small sum towards replacement of capital. No postman is compelled to provide a horse and cart, but a refusal may involve removal to another walk, if it is necessary that the post should be made a mounted post. The suggestion made by one witness that a portion of the allowance for horse-keep should be retained by the Department as a reserve fund for the postman to draw upon in case of special outlay seems a good one, but the sum which the witness named-1s, a week-would perhaps be scarcely large enough for the purpose.

The Chairman: Do you encourage the use of bicycles?

A. In some cases where a load is greater than a walking postman should carry. or where an appreciable acceleration can be secured, the Department has granted rural postmen an allowance for providing and maintaining a cycle. The route in such cases must lie along roads in good condition, and there can be no taking of short cuts across fields, etc. The results obtainable from the use of cycles vary greatly, and many of the experiments made in the past have been disappointing. Quite apart from any benefit to the Service, a number of rural postmen who are in possession of a cycle and accustomed to ride it obtain permission to do so, so long as irregularity is avoided.

Q. What amount is granted?

A. $4 \mathrm{~s}$. a week, I think.

Mr. Walpole: There are very few cases in which it is granted, are there not?

A. There are under 100 cases.

Q. The rule now is that where a postman wishes to ride a cycle permission to do so is not to be refused arbitrarily. He is not to do it without the permission of the surveyor, but it is not to be arbitrarily refused. Is that not so?

A. Yes.

Q. And the same applies to where a rural postman has a horse and cart and wishes to use it?

A. Yes.

The Chairman: We had a good deal about the difficulty experienced by rural postmen in obtaining shelter at the end of their walks. Have you ever endeavoured to meet that difficulty?

A. In many places rural postmen find no difficulty in obtaining shelter at the end of their walk. Some render slight services-gardening, etc- -in part payment. Others follow their trade as shoemakers, etc., and can thus afford to rent a room. If a payment of $1 \mathrm{~d}$. were made, as suggested by a witness, for each hour the postman spends at the end of his walk, some 
would receive as much as $4 \mathrm{~s}$. a week, which is more than they need. The Department thinks that the wages should be fixed to cover any outlay for this purpose.

Mr. Walpole: Can that be so? The 4s. a week would represent 48 hours. and that is 8 hours a day for six days a week. It implies that a man would stay at the end of his walk 8 hours. Is that possible?

A. I think it is possible but not usual. A man may get to the end of his walk by 9 in the morning and leave at 5 p.m.

The Chairman: Have you ever considered the proposal that the Post Office itself should erect shelters under certain circumstances?

A. A few shelters have been erected, but it is not general.

Q. Can you tell us whether in the case of the shelters that have been erected they have given satisfaction? Have the men approved of the arrangement?

A. That hardly comes within my province.

Sir F. Mowatt: Perhaps I might afford the Committee some information on that point. I put a shelter up myself at an expense of about $£ 13$, and that seems to have suited for a long time.

A. I am told that there are not above half-a-dozen provided by the Department.

The Chairman: I think the request came from one of the Irish witnesses; it was suggested that it would be a great convenience to rural postmen if the practice were adopted of paying their wages on Friday?

A. There is no objection to paying the rural postmen on Friday instead of Saturday, if they are willing to accept payment for five days instead of six on the first occasion. Indeed, this arrangement has already been carried out, at the request of the men, in the case of the town postmen at Bury and elsewhere. To advance the pay for the holidays would not, it is thought, be desirable, since it would in many cases lead to the men getting into debt.

Sir F. Mowatt: Do you know on what ground that argument is founded? It seems to me that instead of an advance of pay for the holidays leading a man into debt, it would rather help to keep him out of it.

A. I suppose it means that if a man had his money in advance he would spend the whole of it and get into debt the other end, as well as be short of cash when he came back.

Sir F. Mowatt: I think it would be more likely to be the case that he would get into debt because the money was not advanced to him.

Mr. L. Smith: What Mr. Hill means, I take it, is that a man would spend all his money on a holiday, and when he came back would be without cash, and would have none to receive.

Sir F. Mowatt: But what is a man to do on his holiday if he has no money?

Mr. L. Smith: It is presumed he has saved money for his holiday.

The Chairman: When the practice of allowing postmen to carry private parcels was done away with did you give compensation?

A. The Treasury sanctioned the payment of a sum equal to two-thirds of the men's earnings from the carrying of private parcels, and, moreover, allowed the sums to count towards pension. If the men did not send in returns, or sent in inaccurate returns, they have only themselves to blame. It would be impossible to verify amended claims if they were now furnished.

Mr. L. Smith : Do you suggest that the average given to each individual man represented two-thirds of the sum he himself said he had earned?

A. Yes, what he himself said he had earned. That is to say, if we were satisfied his statement was accurate.

Q. Then nobody could have been injured by a false return being sent in except the people who actually sent such a return in?

A. Quite so; a man would not have injured his fellows by reducing the average. I think, according to my recollection, each man was called upon 
to state what he had earned, but the reason for putting the question to him was not given, and so he took it into his head that he had better say as little as possible.

The Chairman: We have been talking about the established rural postmen; I should like you now to tell us what is the position of the auxiliary rural postman?

A. Before I answer that I have something to say in reply to question 9,933. in which a suggestion was made for a weekly half-holiday. This suggestion for a weekly half-holiday for rural postmen could only be acted on if the residents on the posts expressed their willingness to have their letters ready for the post some hours earlier on that day. Saturday would be a bad day for curtailing posting facilities in cases where there is no Sunday post, and in many cases the residents in rural districts would suffer more inconvenience than town residents by the holiday given to town postmen.

The Chairman: I think I asked you questions on this subject last Monday, and we had quite a discussion on it?

A. We have thought the matter over since then, and have felt it to be desirable that I should make this additional statement on the subject.

The Chairman: And now let us get to the case of the auxiliary rural postmen.

A. Certainly. Auxiliary rural postmen are the servants of the Department, not of the Postmasters at the offices to which they are attached, and they cannot be dismissed by the Postmaster without authority from his surveyor.

The Chairman: Who appoints them?

A. The Postmaster.

Q. The local Postmaster?

A. Yes; he nominates them, and he has to get the approval of the surveyor for the nomination. Postmasters or sub-postmasters have, of course, no claim on the free services of an auxiliary in their private business, and this is generally understood throughout the Service.

Mr. Walpole: That is rather weakly put. Is it not the fact that it is the rule throughout the Service?

A. Yes ; that is the rule.

Sir F. Mowatt: And the Postmaster cannot pay the auxiliary rural postman out of the official allowance for doing the Postmaster's private work?

A. No.

Mr. L. Smith: You do not say it is not the practice sometimes?

A. No.

Mr. Walpole: But if we discovered any case where a Postmaster was so employing an auxiliary we should drop upon that Postmaster, should we not?

A. Certainly.

Mr. L. Smith : Have you discovered any such cases?

A. I am told that several such cases have come to the knowledge of the Department.

Q. And when they do, I suppose you always take measures to put a stop to the practice?

A. Certainly. Persons employed under allowances to sub-postmasters are the servants of the sub-postmasters, but the Department takes steps to prevent sub-postmasters taking advantage of their position. In the case of allowances of 5s. and upwards in England, Wales, and Scotland, and of allowances of $3 \mathrm{~s}$. $6 \mathrm{~d}$. and upwards in Ireland, the regulations are that the person employed by the sub-postmaster shall be paid the full allowance. shall himself sign the receipt for the allowance week by week, and shall not be superseded without the surveyor's authority. In the case of smaller allowances it is not practicable to enforce the same conditions, but steps are taken to ensure that the persons actually employed understand what they are entitled to receive, and that they do actually receive it. Annexed is 
a specimen of the Form 114, to be signed both by the sub-postmaster and by the person to whom the allowance is paid.

(Form put in.)

The Chairman: These men do get uniform?

A. Yes; in all cases the persons termed auxiliary postmen do.

Q. Even a man not getting so much as $5 \mathrm{~s}$.?

A. No ; these are duties provided for by allowances to sub-postmasters.

Mr. Walpole: With reference to the memorandum you have just read, that rule does not apply to what we call auxiliary postmen, does it?

A. No.

Q. It applies only to persons employed under an allowance?

A. Yes.

Mr. Walpole: We draw a broad distinction there; Mr. Hill's answer does not apply to these men.

The Chairman: I want to ask you this-In the case of men with an allowance of $5 \mathrm{~s}$. and upwards in England, and 3s. 6d. upwards in Ireland, do the men wear uniform?

A. No; they have a badge or stripe on the arm to show that they are in our Service.

Q. I do not understand quite even now about these auxiliaries. I want to know exactly how the rural auxiliaries are appointed?

A. Persons termed rural auxiliaries are nominated by Postmasters or subpostmasters, who have to get the approval of the surveyor.

The Chairman: Are they included in your list of auxiliaries, these men?

A. Yes; those described in the first paragraph are. They have the title "rural auxiliaries." and they get a uniform.

Mr. Walpole: Is it not the case there is a broad distinction between them and the auxiliary postmen who are the servants of the Department?

A. Yes.

Q. Then the persons employed under an allowance are the servants of the Postmaster, are they not?

A. Yes; that is so.

Q. But when an allowance gets so much as $7 \mathrm{~s}$. a week we insist on his being an auxiliary?

A. Yes; that is the case.

The Chairman: Then at what rate do you pay the auxiliary proper?

A. The men have asked to be paid 6d. per hour, but we have not considered it necessary to fix so high a rate of pay as 6d. an hour for auxiliary work in rural districts. Indeed, this rate is found to be sufficient even in London for work performed in the day-time. In the country there is rarely any difficulty-except in mining districts, etc.-in obtaining suitable persons for the present rates, i.e., from $4 \mathrm{~d}$. to $5 \mathrm{~d}$. an hour. If, owing to the high rate of wages prevalent in the district, difficulty is found in providing suitable persons at the ordinary rate, the allowance is suitably raised.

Sir F. Mowatt: Your present rate is $5 \mathrm{~d}$., you say?

A. It comes to this: if the surveyor says he cannot get men to do the duty under a certain sum, we have to pay that sum, be it $5 \mathrm{~d}$. or $10 \mathrm{~d}$. an hour.

The Chairman: Have you known of any case where 10d. has been demanded or paid?

A. No; but the pay is much more in a district where trade is very good, and we have to pay whatever is demanded in order to get the men. It is the practice of the Department whenever possible to amalgamate auxiliary duties, and thus form full duties. This practice involves slightly greater expense, but the evils of auxiliary labour, and the increased risk of inefficiency and dishonesty arising therefrom, are held to justify the increased cost. That there are still so many auxiliary duties which cannot be amalgamated is due to the fact that the bulk of the work of delivering letters is necessarily performed in the early morning. The supply of uniform 
clothing is renewed at longer intervals than is the case with full-time men since the auxiliaries are onlv employed officially for a portion of the day. It is not, of course, desirable that auxiliaries should wear their uniform whilst engaged on their private occupation.

The Chairman: Do they only get one suit of uniform a year, or something of that sort?

A. They get it less frequently than other postmen; I think it is about one suit a year. It would be against the general principles regulating employment in the Civil Service to grant holidays, sick pay, or pension, to persons giving only a portion of their time to the public service. Nor is it considered desirable to give boot allowances or stripes to such persons.

Q. I understood you to say in your evidence the other day that you thought stripes might be given to auxiliaries under certain conditions, and that the value of a stripe might be made commensurate with the amount of duty a man did?

A. I think that was Mr. Badcock's evidence, but still I agree with it.

The Chairman: We will now adjourn for a little while.

Upon resuming, the evidence was continued:-

Q. You have no supernumeraries amongst the rural provincial class, have you?

A. No persons bearing that name; but we have some not established, and not entitled to pensions because they cannot pass the doctor or for some other reason.

Q. Have you many of these?

A. No; one here and there. They are chiefly persons who, when they first began with us, were not doing a full o'ay's work; but the du ies increased until $i$ : became a full day's work; but by that time, however, they were too old to be put upon the establishment, so we give them fixed wages and a holiday, and do the best we can for them.

Q. I believe you have now a statement to make upon the subject of supernumeraries?

A. Yes; I wish to say something on that. The supernumerary postmen have complained before the Committee on Post Office Establishments that they have to choose their walks and periods of annual leave after all the established postmen of the class or zone to which they are attached, no matter how short the service of some of these may be. There are now in London 188 supernumeraries, who block a corresponding number of vacancies on the establishment, thus:-

$$
\begin{aligned}
& \text { Employed as sorters, - } \quad \text { - } \quad \text { - } \quad \text { - } \quad \text { - } 11 \\
& \text { Employed as porters, - } \quad \text { - } \quad \text { - } \quad \text { - } \quad \text { - } 42 \\
& \text { Employed as town postmen, - } \quad \text { - } \quad \text { - } \quad \text { - } 92 \\
& \text { Employed as Zone } 1 \text { postmen, - - - - } \quad \text { - } 6 \\
& \text { Employed as Zone } 2 \text { postmen, - } \quad \text { - } \quad \text { - } \quad \text { - } 29 \\
& \text { Employed as Zone } 3 \text { postmen, - - - _ } \quad \text { - } 8 \\
& \text { Total, - - } \quad-\overline{188}
\end{aligned}
$$

The supernumeraries are a diminishing class, and as vacancies occur in their ranks they are filled by the appointment of established officers. It is obvious, therefore, that if the supernumeraries are to continue to choose their duties and annual leave after the established men, their circumstances in this respect will tend to get worse rather than better as time goes on. In two ur three offices where the number of supernumeraries is considerable they are allowed to sign for annual leave on a separate list. This arrangement is no doubt satisfactory to the men who share in it, but it could hardly be maintained if the number of supernumeraries were much reduced; and, moreover, it provokes unfavourable comparisons from the supernumeraries in other offices who have to sign after the established men because they are not sufficiently numerous to have a leave list of their own. It would be 
better, I submit, to establish some practice which should be not only fair to the supernumeraries but uniform in its application. We have proceeded hitherto on the assumption that an established officer, as such, should take precedence of any unestablished officer, and I do not recommend that the privileges of men already on the establishment should be interfered with. The superuumeraries, however, are men of considerable service, and I do not think any one need feel aggrieved if it were decided to let them rank-as regards choice of duties and annual leave-before all future entrants on the classes to which they are attached. I recommend this course for the Secretaly's approval, and, if it be adopted, I propose that it shall apply to all the supernumera ies, whatever their present arrangements may be.

The Chairman: Now you have to say something as to the Windsor case?

A. Yes. Wich regard to the Windsor case, the district surveyor, Mr, Rushton, reports as follows:- "I visited Windsor to-day, and made personal inquiry into the statement made before the Committee that the postmen at Windsor were suffering from a surt of petty intimidation through being watched about in consequence of evidence offered before the Committee. The postman concerned is W. J. Riley, and I questioned him as to the facts. He expressed surprise that it should be supposed that he or any of the men were complaining of being watched about. He said that there was no intention of making any complaint as to the testing of the duties of the rural postmen, and, moreover, that it was quite understood that the recent tests of the rural posts were made for ordinary reasons. As a matter of fact, they were undertaken chiefly with a view of ascertaining whether the men needed any relief. Riley did think, however, that in accusing him of interfering with the test of two rural postmen on one occasion and in what followed, the inspector of postmen was influenced by the fact that he had furnished evidence to be put before the Committee. Upon my pointing out to Riley that, although there was no proof that he had warned the men, there was good ground for the inspector's suspecting him of doing so he readily admitted that his own impression was no doubt a wrong one, and that the view taken by the inspector was a very natural one. Riley added that he was quite ready to withdraw the suggestion. The only other reason Riley had for supposing that he was being harshly treated vias a small incident that occurred on the 22nd February last. On this occasion Riley was preparing to start on a parcel delivery. The two other postmen engaged on this delivery had already sta ted, and the Postmaster, who was in the sorting office, said to the senior clerk on duty, "See that man out of the office." Riley regarded this as indicating a harsh feeling, but the matter is, on the face of it, very trifling. Riley admits this, and says he did not himself propose to allude to it, but the local Federation Committee thought it better to do so. The Postmaster of Windsor is on leave, but it may be safely assumed that the words showed nothing but a wish to start the delivery in good time. I am quite satisfied from my inquiry to-day, and from the inquiry made on the 21st instant by Mr. Griffith, one of my assistants, that there is no ground whatever for the statement that the men have been subjected to petty tyranny because of the evidence given before the Committee. Indeed, the chief clerk and inspector of postmen inform me that, by direction of the Postmaster, they have been particularly careful to avoid doing anything which could possibly give colour to such a suspicion."

Q. 'The first point I made a note of was with regard to the complaint made at Liverpool on two or tbree different points; they referred to difficulties connected with some of the walks in Liverpool, and the weights carried?

A. To some extent Mr Walsh's evidence was answered at the following meeting, when we obtained a report from Liverpool?

Q. What is your view with regard to the statements as to excessive weights carried in Liverpool?

A. As shown in the re-examination of the witness Walsh, the statements made as regards the heavy weights carried by postmen at Liverpool and the 
injurious effects on certain postmen were much exaggerated. All reasonable complaints on this score have now been removed by the use of a lift indoors, and hand-carts out of doors, and a periodical check of the weights carried on the heavy walks has been established in the Liverpool District. The surveyor reports that the postmen everywhere show a reluctance to ask for assistance, the reason being, he is informed, that they think it would affect their Christmas boxes. A rule will be inserted in the revised edition of the Book of Rules for Town Postmen to the effect that any postman who thinks that he is overburdened may apply to the controlling officer for assistance.

Q. A difficulty arises in Liverpool in consequence of the arrival of the American mails?

A. When an American mail falls into the morning delivery the extra work is not much felt by the men; what they complain of is that when a heavy American mail is included in one of the afternoon deliveries it causes their attendance on that particular day to be prolonged beyond 8 hours. This prolongation, however, rarely exceeds an hour, and is to some extent compensated by light deliveries on other days.

Q. Following up that same point with regard to the Liverpool practice. will you now go to the question where a point is raised about prolonged deliveries?

A. The surveyor reports that he cannot find it is the practice at Liverpool to unduly prolong duties in disposing of circulars of halfpenny matter. When large quantities of tradesmen's circulars are posted for local delivery the inspectors ascertain by examination whether the circulars require immediate delivery, and if so, arrangements are made either by overtime or by employing temporary force. If the delivery of circulars (such as Mother Siegel's) is not regarded as urgent, the inspectors arrange for a few to be taken out at each delivery during the day; on such occasions a postman does not receive orertime pay, but the inspector is careful to arrange as far as possible for the delivery to be completed within usual limits.

Q. In another question we have evidence given with regard to split duties at the Liverpool office.

A. At the southern district office on the date named, postman R. Abberley served No. 14 walk, and the actual attendance as entered at Abberley in the attendance sheet was :-

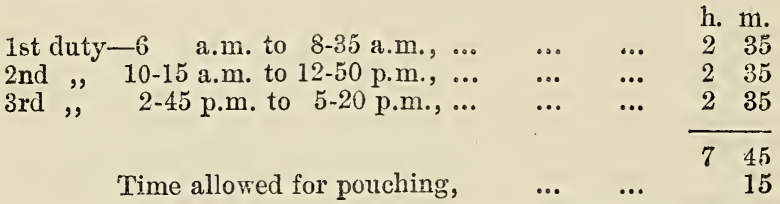

$$
\begin{aligned}
& \begin{array}{llllll}
\text { Total, } & \ldots & \ldots & \ldots & 8 & 0
\end{array}
\end{aligned}
$$

Mr. Walpole: There is an evident mistake there in the man's evidence, for he puts the second duty as ending at 1.50 instead of 12.50 .

A. Yes. With regard to the case of Postman W. Rourke, whose time worked was given as 9 hrs. 35 min., I may say that on the date named, viz., Nov. 30, 1895, the 7th walk in the Western District Office was served by Postman Rourke and his attendance as stated by himself was :-

$$
\begin{aligned}
& \text { 5-57 a.m. to } 9-15 \text { a.m., } \quad \text {.. } \quad \ldots \quad \quad \ldots \quad 3 \text { hrs. } 18 \text { min. }
\end{aligned}
$$

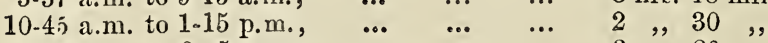

$$
\begin{aligned}
& \begin{array}{l}
2-45 \mathrm{p} . \mathrm{m} . \text { to } 6-5 \mathrm{p} . \mathrm{m} ., \\
\text { (Usual time for finishing, } 5 \mathrm{p} . \mathrm{m} .)
\end{array} \cdots \quad \cdots \quad \frac{3,, 20,}{9 \mathrm{hrs},}, \frac{\mathrm{min}}{}
\end{aligned}
$$


With regard to the statement that no time is allowed for pouching, no time is necessary for pouching. The inspector of the Western District reports as follows :- "Pustman W. Rourke, due on the 30th Nov. at 5.30 a.m., did not arrive before 5.57 a.m., 27 minutes late; to some extent his morning delivery was prolonged in consequence of his late attendance. The work on that day appears to have been exceptionally heavy, but Saturday is always a heavy day on his walk. In the morning we liad an American mail, and the fact that it was the last day of the month accounts also for some of the extra pressure. Apart from all this, however, Rourke, who is 55 years of age, is, in consequence of weak health, not anything like being smart in the performance of his duties. A younger and a stronger man could, I am satisfied, have completed the whole duty in about 8 hours. There are four men attached to the waik, each with a different attendance, and these four men rotate weekly. The average attendance of the four during the week ended Nov. 30 was, I find, 8 hrs. 2 min., and out of this time the man on B duty had quite 45 min. each morning for breakfast, and the man on the $\mathrm{D}$ duty had about $30 \mathrm{~min}$. each afternoon for refreshments. In order to show what the attendances of the men on this walk really are, I submit a return giving each man's attendance during last week, and I do not think that it can well be said that they are in any way unreasonable. The bags carried by the men are not heavy. The return shows that the average attendance is $8 \mathrm{hrs} .2 \mathrm{~min}$., including in the case of two men intervals of about $1 \mathrm{hr}$. and of about $45 \mathrm{~min}$. respectively, and the average covering period about 12 hrs. 10 min."

The Chairman: It has also been stated that a postman at Aberayon, father of five children, gets 7s. per week for 48 hours' hard work, and that a telegraphist at the same place gets $40 \mathrm{~s}$. for 48 hours' work. Do you know about such a case? Is there any postman anywhere working 48 hours and getting for it $7 \mathrm{~s}$. per week.

A. I don't believe it is a fact. Such a case is certainly not known in the Secretary's office.

Q. Do you think it is possible that there could be such a case?

A. I cannot conceive it to be possible.

Q. Would it be possible that any of these men we have heard of quasiauxiliaries employed by Postmasters could be doing anything like 48 hours' work for $7 \mathrm{~s}$."

A. Certainly not. I don't believe a man would do anything like it. I think the witness should have produced the precise case if he makes the statement.

Mr. Walpole: He did produce the case.

A. No; he said it was a hypothetical case.

Mr. Walpole : It was afterwards put as a hypothetical case, and no proof was offered.

The Chairman: In reply to my question the witness said that such cases were known in Ireland, or were stated to be known in Ireland and other places over the country, and were afterwards proved.

Sir F. Mowatt: You are not aware of such cases having been proved?

A. Certainly not.

Q. Are you aware of such a case ever having been proved to exist?

A. Certainly not in my time in the Service.

The Chairman: You don't believe such a thing is possible-for that is the real point I want to arrive at?

A. I do not.

Q. Then we come to a series of cases quoted in connection with split duties. The case quoted is one of Devonport, where it is alleged that a man works 8 hours and a half in four attendances, spread over rather more than 16 hours? 
A. There are no such duties at Devonport; the actual duties are as follows, and are performed by 20 men, 10 on each, and rotating in alternate weeks :-

$$
\begin{aligned}
& \text { 6- } 0 \text { a m. to 9- } 0 \text { a.m. } \\
& \text { 1-45 p.m. to 4- } 0 \text { p.m. } \\
& \text { 7- } 0 \text { p.m. to } 10-15 \text { p.m. } \\
& \text { (Including interval of hali-hour). } \\
& \text { Total, 8-30. } \\
& \text { 6. } 0 \text { a.m. to } 9-0 \text { a.m. } \\
& 11-15 \text { a.m. to } 1-45 \text { p.m. } \\
& 4-45 \text { p.m. to } 6-45 \text { p.m. }
\end{aligned}
$$

\section{Average attendance, 8 hours.}

Sir F. Mowatt: I noticed that an interval of half-an-hour is mentioned in the first set of duties, as occurring between 7 and 10.15 p.m., but is not mentioned in the second case. Can you tell me whether the half-hour is included in both cases?

A. I should think not in the second case.

Mr. Walpole: What has huppened is that the witness has taken the first two duties on the second rotation and added them to the third duty of the first.

The Chairman: Then a somewhat similar case is quoted in Birmingham.

A. No such duty exists at Birmingham; it was revised in December last, the arrangement being only a temporary one. A general revision of the postmen's duties at Birmingham is under consideration, and in accordance with the general practice endeavours will be made to keep as many duties as practicable within a covering period of $12 \mathrm{hrs}$. I should have stated that at Devonport the duties are under revision.

Mr. Walpole: There is nothing in the duty at Devonport that we are not prepared to stand by, is there?

A. No.

The Chairman: But a duty beginning at 6 a.m. and ending at 10.15 p.m. is a little awkward, even although there are long intervals between. We should if we can avoid it.

A. No such duty exists at Birmingham.

Q. Previous to the revision it was in existence, I suppose?

A. The arrangement was only a temporary one.

Q. Then there was such a duty?

A. Yes, I suppose so; but a general revision at Birmingham is now being considered, and in accordance with the general practice, an endeavour will be made to keep as many duties as possible within a covering period of 12 hours.

Q. Then there is a case from Lough mentioned, where it is alleged that six attendances were worked, amounting to 8 hours and 35 minutes.

A. There are five established postmen at Lough with an average daily attendance of 8 hours. The duty here referred to occupied $8 \mathrm{hrs}$. $15 \mathrm{~min}$., ircluding the interval between 10.20 and 10.30 a.m., and in ordinary course it should have rotated with a short duty of 7 hrs. 15 min., but the man performing the short duty was old and feeble, and his duty could not well have been increased. He has now been pensioned, and arrangements will be made to readjust these duties in a satisfactory manner.

Sir F. Mowatt: I think the next question arises with regard to Stalybridge?

A. That is coupled in my notes with Lark Lane, Liverpool, and it is stated with regard to both that the duties were already under revision, and the necessary relief has now been afforded.

Q. Then the circumstances prior to the revision were correctly represented to us?

A. I dare say the duties were correctly stated, but the revision was in hand before the witness came on.

Q. It is not contested that the duties which the uritaess specified were such as he described previous to the revision? 
A. They were prolonged, no doubt.

Q. There is a case from Lark Lane, Liverpool?

A. The answer is the same as in the case of Stalybridge, namely, that the duties were already under revision, and the necessary relief has now been afforded.

Q. It is only fair to the witness that we should know that he correctly represented the matter up to the time of the $\mathrm{r}=$ vision.

A. I dare say he did; I don't know to the contrary.

Q. There are two points in connection with Hebburn R.S.O. and Southport?

A. With reference to the first, two postmen attend between 6.40 a.m. and 9 p.m., and two between 6.40 p.m. and 7.40 p.m. The duty is rotating. A revision of the postinen's duties will shortly be taken up, and relief will be afforded at once if necessary. Circulars are spread over several deliveries.

Mr Walpole: Then, Mr. Hill, on your showing, a case is made out for relief.

Sir F. Mowatt: It is an extraordinary length of time-14 hours 20 minutes. It is stated that the men are often employed delivering circulars, for which they receive no pay?

A. We deny that.

Q. Then reference is made by the same witness to a case in which it is said men have to meet trains at the end of the delivery, and in consequence of late despatches have to turn themselves into harriers in order to be in time for their bags at the station?

A. This presumably refers to rare occasions-mostly at the Christmas season-when some of the morning mails arrive irregularly, and the postman concerned has to hurry to meet the train. The postmen's duties will be revised very shortly.

Mr. Walpole: Why has the postman to hurry to' meet the train?

A. It means that owing to the late arrival of the train on which a despatch of mails from the office depends, he has little time to get back for the outgoing train. The interval between the arrival of the incoming train and the departure of the outgoing mail may srmetimes be very short.

Sir F. Mowatt: One train having arrived too late, the men have to hurry back to catch the outgoing train, which may start in time?

A. Yes ; or that may start in time.

Q. Another case follows with regard to Southport, where it is stated that men have themselves paid cab fares in order to reach the office in time with their collection. Here, again, it is a matter of time apparently?

A. The rule in force at Southport is that when any postman has a heavy delivery, and considers that he will not finish it in time to make a collection, he should call the supervising officer's attention to the fact. If the latter considers that relief is necessary the ${ }_{2}^{\mathrm{a}}$ collection is provided for specially. Only one instance is known of a man paying his own cab fare under the circumstances mentioned. He had an accident on delivery, and upset the arrangement of his letters, and seriously delayed his return. Rather than have the case reported, he elected to take a cab at his own expense to make his collection.

Mr. Walpole: In connection with that will you refer to the case of Southport where it is stated that the inspector considered it necessary to make special provision for the delivery of large quantities of circulars, but on presenting the claim the Postmaster refused to meet it, and the inspector has been obliged to pay it out of his own pocket?

A. Yes; I have an answer to that. It was not necessary to supply assistance in delivering these circulars, and the inspector of postmen acted wrongly in authorising assistance. The cost was 1s. 8d., and had relief been necessary it could have been afforded for a fourth of that sum. The Postmaster refused, under the circumstances, to allow the claim, but he perhaps acted somewhat injudiciously in doing so, as the expense had been 
incurred, though improperly. The inspector and the three postmen concerned agreed among themselves to pay the amount between them.

Sir F. Mowatt: There is, too, a complaint of auxiliaries at Cambridge working seven attendances at 19s. per week?

A. These auxiliaries-four in number-perform during term time about 8 hours' work for 16s. a week as their proper duty, and one delivery a day during vacation for $7 \mathrm{~s}$. a week. In addition to this they are allowed to perform a collection at $3 \mathrm{~s}$., which is provided for under an allowance, making their pay 19s. and 10s. a week respectively. This causes their attendance during term time to exceed 8 hours, and to average between 9 and 10 hours. Their average weekly wages throughout the year are 14s. 6d. for an average daily attendance of $6 \mathrm{hrs} .30 \mathrm{~min}$. The present men have been employed on this duty for about 17 months, and those who are eligible $f: r$ established appointments will be placed on the established class under a general revision of the duties which will shortly take place, and which has been under consideration for some months.

Mr. Walpole: At the term time in Cambridge the postal duties are much heavier than at other times?

A. Yes.

Sir F. Mowatt: These men then average from 9 to 10 hours a day?

A. Yes.

Mr. Walpole: They are paid extra ender an allowance to the Postmaster for at least a portion of their extra work?

A. Yes.

Q. It is the usual arrangement?

A. Yes. There is a small allowance for the work to be done. The Postmaster can employ whom he likes, and I suppose these men ask to be employed and get the money.

Q. Would 16s. be the normal pay for an auxiliary working 8 hours at a place like Cambridge?

A. I should it is low. The minimum of the scale for town postmen is $17 \mathrm{~s}$., so that it is $1 \mathrm{~s}$. below the scale.

Q. It ought to be up to the minimum scale at least.

A. I think so. It is low.

Sir F. Mowatt: There is a complaint of unduly prolonged duties at Windsor. The duties were given as follows : -12 to $1.45,6.15$ to $9.15,6$ to 8 , and 8.45 to 11 , and the witness suggested it was difficult to know when the man got his sleep?

A. The duties have increased since the last revision in 1893. These three. attendances referred to by witness averaged $6 \mathrm{hrs}$. 40 minutes each-wages 15s. a week, with alternate Sunday attendance. The attendances are at present:-

(1) 6.15 to 9 a.m., 10.15 to 11 a.m., 6 to 7.45 p.m., 8 to 9 p.m.; 6 hours 30 minutes.

(2) 9 to 11.30 a.m., 6 to 7.45 p.m., 9 to 10 p.m., 12 night to 1.45 a.m.; 7 hours.

(3) 10 to 11.50 a.m., 6 to 8 p.m., 9 to 10 p.m., 12 night to 1.45 a.m. ; 6 hours 35 minutes; rotate average, 6 hours 40 minutes.

Intervals at night-(1) 9 hours 15 minutes; (2) 7 hours 15 minutes; (3) 8 hours 15 minutes.

Long interrals during day-(1) 7 hours; (2) 6 hours 30 minutes ; (3) 6 hours 10 minutes.

The men have not complained of their duties or pay. Under a revision which is in progress these men, if eligible, will probably obtain established appointments.

Mr. Walpole : 15s. a week is very low pay for duties of that kind, is it not?

A. Yes; I think it is low.

Q. Please direct your attention now to the complaint that six men are working an hour and a half on Sunday for nothing. Is there no fixed rate 
acknowledged by the Department for provincial auxiliaries, the same as we have in London?

A. No, there is not. Six auxiliaries attend 1 hour 30 minutes every Sunday, and their wages are fixed to cover this attendance. This the men quite understand when first engaged. They have begged that no alteration be made in their attendance or wages. If they were taken of the Sunday duty their pay would have to be reduced. The auxiliaries who have Sunday duty are paid at a higher rate.

Mr Walpole: In fact, in this case we are apparently paying rather liberally?

A. Yes.

The Chairman : Later on the witness put in a list of provincial auxiliaries doing full-time duties and receiving $24 \mathrm{~s}$. He remarks on one case that 18s. $7 \frac{1}{2}$ d. a week for a man 24 years of age is not an excessive wage. Have you anything to say with regard to his typical cases of extremely low wages?

A. Yes. The case of Llanelly refers to one man only. The duty occupies 5 hours 15 minutes, with no Sunday attendance. The question of raising the wage or reducing the attendance is being considered. Two other auxiliaries are paid $14 \mathrm{~s}$. a week of about 5 hours 40 minutes' attendance, including an alternate Sunday attendance of 3 hours. (2) Cosham (Hants)-The attendance of the two men is 4 hours, and 4 hours 15 minutes respectively. The wages are low, and have now been increased. (3) Bala, R.S.O.-The attendance is 2 hours 10 minutes on week days only. The wages have been raised to $4 \mathrm{~s}$. 6d., the usual rate. (4) Basingstoke- A revision of these duties was already in hand, and the question of placing these men on the establish. ment is already under consideration. Their wages and attendances are(1) 6 hours 50 minutes, 13s., raised now to 16s.; (2) 9 hours, 19s.; and (3) 7 hours 30 minutes, 16s. The auxiliaries have been allowed to perform duties provided for separately by allowances to improve their pay, which works out per hour as follows-(1) $3 \frac{1}{2} \mathrm{~d}$.; (2) $4 \frac{1}{2} \mathrm{~d}$.; and (3) $3 \frac{5}{8} \mathrm{~d}$. (5) Portsmouth-The question of affording relief was already under consideration, and has since been given. (6) Galashiels-The postmen's force is already under revision. There is only one auxiliary town postman. The wages have been suitably increased. (7) Dunblane-The duties are rural ones, occupying 6 hours in all, and the pay consists of 9s. regular wages and $5 \mathrm{~s}$. allowance. The postman is rather old and a slow walker. The question of forming these two attendances into a full-time duty is being considered. (8) Bridgnorth-This is wrong. The attendance of this man is $5 \mathrm{a} . \mathrm{m}$. to $6.15 \mathrm{a} . \mathrm{m}$. under an allowance of $2 \mathrm{~s}$. $6 \mathrm{~d}$. a week; $7.15 \mathrm{a} . \mathrm{m}$. to 9 a.m., and two attendances during afternoon and evening, occupying in all 4 hours 30 minutes, wages 10 s. ; total time 5 hours 45 minutes; total pay, 12s. 6d. These have now been raised to $13 \mathrm{~s}$. $6 \mathrm{~d}$.

Q. What have you to say with reference to the cases of Worksop and Creaiton?

A. 'These are cases of postmen being alleged to be greatly overburdened with parcals cn delivery. The cases cited are notably those of Worksop, Crediton, and Halkirk, and it has been ascertained that the men are not overburdened at these places.

The Chairman: The witness complained that the men at Worksop had to start cn their afternoon walks loaded like packmen?

A. With regard to this the Postmaster at Worksop reports that the arerage number of parcels per man is from 1 to 3 ; most of the parcels in the morning are specially delivered, the total weight of letters and parcels per man on the first delivery averages about $18 \mathrm{lbs}$, and less than that on the afternoon delivery. A relief is given when the parcels are more than the pcstman can reasonably carry. At Crediton in the first delivery the parcels are delivered by a special man and not with the letters. On the other deliveries (three in number) they are delivered with the letters, and average 1 to 3 per man. On those deliveries the average number of letters, etc., 
per man is about 70. A revision of the duties took place in November last, and it was then arranged for the parcels to be delivered separately. The number of parcels delivered in the Crediton town district averages about 37 a day, excluding Sunday, of which about 25 are delivered by the special postman. In the case of Halkirk these rural postmen (two in number) use ponies for their own convenience; there is no necessity for them to do so. Their walks are 15 and 16 miles respectively, week days only, but one of these attends for a short time-about an hour-on alternate Sundays. Their average weight carried is about $12 \mathrm{lbs}$. in winter and $23 \mathrm{lbs}$. in summer. One of them gets rid of two-thirds of the load at a sub-office two miles from Halkirk. When the weight exceeds 35 lbs. (which has been the case last year on only eight occasions on one post and three on the other) they are allowed the same amount for carriage of excess weight as would have been expended if an assistant were provided. They are both established postmen, and complete their day's work by 2.40 p.m. and 3.45 p.m. respectively.

The Chairman: A list of 20 offices was handed in, where it was alleged that postmen must deliver surplus parcels the best way they can or leave them over till next delivery, which the witness thought a very improper method of disposing of them. Does that correctly describe the practice anywhere?

A. We made inquiry at the following offices, which are among those mentioned by the witness, viz., Holyhead, Lowestoft, Stafford, South Shields, and Watford. These were considered to be fair samples, and in no case was the allegation found to be true.

Q. Is it a fact that at Formby parcels are delivered and collected together with letters, without regard to weight, half a hundredweight being frequently carried over 2 miles, two-thirds parcels?

A. We are assured that there is no foundation for that statement. The number of parcels delivered with letters is limited to a few of the lighter and less bulky parcels. The statement that a postman is frequently required to carry $56 \mathrm{lbs}$. over 2 miles is without foundation.

Q. What about the case of Hassocks?

A. The sub-postmaster of Hassocks did not consider that relief was necessary, the weight being so little over $35 \mathrm{lbs}$., and he would have had much difficulty in obtaining it at the early hour, viz., 6 a.m. The occasion cited is the only one remembered when relief has been required on this walk, which is $16 \frac{1}{2}$ miles, average weight carried between 20 and 30 lbs., about half of which is left at a sub-office distant about $2 \frac{1}{2}$ miles from Hassocks, the road to which is exceedingly good and fairly level. The Postmaster of Brighton reprimanded the sub-postmaster for not having provided in the first instance the assistance allowed in such cases, and he also reprimanded the postman, as in consequence of his having refused to obey the sub-postmaster's instructions some parcels were delayed till about mid-day.

Q. Then there is the case of Fakenham?

A. The rural postman, Huggins, is here referred to. He had already applied for relief, and arrangements for affording it are being made for giving him an allowance for a horse and cart.

Mr. Walpole: Then it is a fact that he walks $19 \frac{1}{2}$ miles daily.

A. I don't know; but he had applied for relief before the Committee heard of this case.

The Chairman: Are you going to deal with the Brighton cases of alleged favouritism?

A. No; that will fall to Mr. Joyce.

Q. Or to the allegations that promotions are sometimes due to men having relations in high positions in the Service?

A. Mr. Joyce will deal with that.

Q. A list was given us of examples of long walks by rural postmen?

A. Sixteen instances are quoted by the witness of rural postmen walking 
20 miles a day, and 10 of postmen walking 19 miles a day, but in most of these cases the length of the walk has heen exaggerated. At Ludlow, for example (No. 15 on the list), no postman walks over $17 \frac{1}{2}$ miles, and at Louth (No. 14) no man walks more than $17 \frac{3}{4}$ miles. At Bicester, Dundee, Llanelly, Trowbridge, and Worthing, there are no rural postmen walking the distance given by the witness. At Halifax (No. 23) a postman with an official walk of 15 miles walks home during the day and thus adds 7 miles to his walking distance. In one or two instances the postmen referred to have at their own request received additional work, involving a total walking distance exceeding 18 miles, for the sake of the additional pay, but these arrangements will not be allowed to continue. Several of the postmen whose cases seem to be referred to have been relieved in some cases months ago, on the recommendation of the district surveyors. There remain a few cases where, through the building of new houses or through miscalculation of distance, postmen at places named by the witness have walks of over 18 miles, and instructions have been issued for their immediate relief. This would have been done before if the men had complained through the ordinary channel.

Q. I understand that the object of the Department is that 16 miles should be the rule of the day's walk, although it may in some instances be ex. tended to 18 miles as a maximum?

A. Yes.

Mr. Llewellyn Smith: I understand you that complaints have not been made previously of these long walks.

A. If they had been they would have been rectified.

Q. As a matter of fact, complaints have not been made, but the cases have been brought direct before this Committee?

A. Yes.

Sir F. Mowatt: Extra distances have sometimes been given at the men's own request?

A. Yes. But they are no longer allowed to take excessive additional work simply because they want to do it.

The Chairman: Please refer now to the question in which reference is made to the payment of $3 \mathrm{~d}$. or $4 \mathrm{~d}$. an hour to auxiliaries for doing very responsible work, as I understand $4 d$. per hour is the minimum you give to auxiliaries?

A. That is our rule, but I have found one or two cases where it does not work out quite to 4 d., though I was not aware of it. The rule is that it should be 4d.

Mr. Walpole: There are cases where inadvertently we are paying less?

A. Yes; where it works out at a little less.

Q. Then there is a list of examples of rural unestablished and auxiliary duties. Have you any remarks to make with regard to these?

A. Yes; but reverting for a moment to the previous question, I should say that so low a rate as $4 \mathrm{~d}$. per hour is only given in the case of the smaller deliveries, involving from 1 to $2 \frac{1}{2}$ hours' work per day; when the duty is as much as 3 hours the postman is paid at a higher rate ranging up to $5 \mathrm{~d}$. an hour or sometimes more. Any cases in which men are actually receiving less than $4 \mathrm{~d}$. an hour are no doubt due to the work having grown in extent since the wages were fixed, but the surveyor's attention has now been called to the matter. With regard to the examples of rural unestablished and auxiliary duties, I may say that case No. 1 from Dudley cannot be identified. With regard to case No. 2 from Exeter, this man is the sub-postmaster. He has been employed on full duty for about 6 years only. His wages in 1890 were 15s. only, and they have recently been raised to 19s. He has pay as sub-postmaster also. In case No. 3, Campden, the hours of duty have been exaggerated. The man is old (64) and somewhat infirm, and takes longer than an able-bodied man would do. In case No. 4 from the same place, the duties prescribed for this man occupy only 4 hours a day. Through a misunderstanding he has been doing 1 hour's 
duty which should belong to another postman. He has now been relieved of this extra work.

Mr. Walpole: In the case of No. 2 the man is at once a postman and a sub-postmaster, and gets two separate payments?

A. Yes ; that does occur occasionally.

Q. That is an arrangement we are trying to get rid of?

A. Yes. We find the discipline difficult in the dual capacity.

Sir F. Mowatt: As a sub-postmaster does he not keep himself in order as a postman? (Laughter.)

A. Yes; that is one difficulty; or as a postman perhaps he does not treat the sub-postmaster with sufficient respect. (Renewed laughter.)

Q. Have you anything to say as to the other cases?

A. Case No. 5 cannot be traced. In case No. 6 the man has three circular duties, the interval being spent at home. The pay seems sufficient. In case No. 7 this man walks 17 miles; he is on scale, and has just received an increment. $\mathrm{He}$ is quite satisfied. In case No. 8 the wages are now 17s. ; distance 16 miles. In case No. 10 (Limavaddy) the hours of duty are from 8 to 11.10 a.m.; the wages are considered quite sufficient. The youth employed is only 19 years of age, and cannot therefore have served for 20 years. In case No. 11 the wages were inadequate, but have now been raised to 13s. In case No. 12 (Dundrum), the hours of duty have been somewhat exaggerated. The duties occupy normally only five hours, but as there are five attendances the present wages seem insufficient. They have been raised to $15 \mathrm{~s}$.

The Chairman: Instances were given of the wide range of hours over which rural postmen's work is spread?

A. An exceptionally early commencement and late completion of the rural postman's work is occasionally unavoidable. But in such cases there are usually other circumstances which remove the apparent hardship. For instance. William Bond, at Gilford, County Down, is said to be on duty over a period of $16 \frac{1}{2}$ hours, but between his morning and evening work he has an interval of over 9 hours, which he spends at home. Mr. M'Crory, at Newton-Stewart, has an ordinary rural post duty with 9 hours' interval, and ending at 7.15, but he volunteered for a further hour's work in the erening, for which he received payment. Michael Twohig, of Cork, another of the cases mentioned, is free after 9.30 a.m. save for half-an-hour at noon, and half-an-hour in the evening. He could, of course, be relieved of the later duties, but there is little doubt that he would prefer to retain them together with the extra payment made for them.

Q. There is reference to a case of a Doncaster rural auxiliary in receipt of 10s. a week for a duty of 6 hours and 25 minutes?

A. The Doncaster rural auxiliary referred to had not an official duty of 6 hours, but he now has, and receives wages of 14s. a week for that duty.

Q. We now come to the case of Thomas Ames, as an example of long walks?

A. Thomas Ames' official walk is a short one, under 14 miles a day, but, it is true that he cannot find a house near his starting point, and has a long walk to and from home, besides travelling a short distance by train at his own cost. His total walking distance is, however, 19⿺ miles, not 24. He has an 8 hours' rest in the day, and his wages and emoluments amount to 25s. a week. He has declined an offer of a transfer to another walk Until he can find a house near his starting point or is transferred to another walk, it is proposed to pay his railway fare for the journey, by which Ames shortens his walk home after completing his official day's work at 7.10 p.m.

Q. Do you give any advantages to men who are kept long waiting for trains?

A. Yes ; it is expressly provided (Circular to Surveyors, 4th August, 1891) that overtime payment may be given when a postman is kept waiting for a train which is late by as much as two or three hours, or when he is 
detained by heavy snowstorms, or has an extra delivery to make, and surveyors are instructed to give the necessary authority.

Q. There is a tremendous walk mentioned in the case of the man Pitts, who is said to walk 34 miles a day?

A. J. B. Pitts, sub-postman at Idle, Bradford, does not walk nearly 34 miles a day as alleged. He and another postman change duties weekly; one duty involves 1 hour's indoor work and 6 hours' outdoor work, and the other $1 \frac{3}{4}$ hours' indoor work (including two short intervals) and $7 \frac{1}{4}$ hours' outdoor work. In order to equalise the duties an hour's outdoor work has been transferrer from the second duty to the first, and with this change Pitts admits that the duties are quite satisfactory. The actual distance walked cannot be stated, but it is not thought to exceed 18 miles.

Q. There were some further cases mentioned?

A. Yes; with regard to the alleged walk of 23 miles at Denbigh, no rural postman walks over $17 \frac{1}{2}$ miles. As to the alleged case of a 23-mile walk at Kendal, the postman's walk was reduced in October, 1894 . For a short time it had been 21 miles a day. With regard to the 26 miles' walk alleged at Southampton, one man walked 22 miles before February 17 th, and his walk was on that date reduced to $15 \frac{1}{2}$ miles. With regard to the 23 miles alleged at Weston-super-Mare, the walk of the postman who gave his distance as 23 miles is really $16 \frac{3}{4}$ miles, and that of the postman who gave his as 21 miles is $16 \frac{1}{2}$ miles. There are no special circumstances in either case.

The Chairman: It was stated by one of the witriesses that Monday is the day usually chosen to test these rural walks, being a day when the number of letters is comparatively small.

A. That is not the fact. There are fewer tests on Monday than on any other day in the week, but where there is no Sunday delivery the deliveries on Monday are usually rather heavy. I should add that testing of the walks is not confined to the summer-time, but goes on all the year round.

Q. With regard to the case of the witness Grimmer from Worcester?

A. The case referred to by Mr. Grimmer is his own. On his way into the country he delivers letters at a group of houses within the Worcester city boundary, and about 1 mile from the head post office. In December last, when this postman had to carry on to the end of his walk a parcel for one of these houses, where the people were not up when he passed, he was told that if any further difficulty arose he was to hand over any parcels to be sent out by the mid-day town delivery. A parcel was so treated on January 6th, so that Mr. Grimmer appears to be mistaken in saying that the matter had not been remedied.

Mr. Walpole: When he stated the circumstances as an ordinary thing in the experience of rural postmen, he seems to have been describing what happened on one occasion?

A. Yes ; so far as his own walk is concerned.

$\mathrm{Q}$. And he gave us that as the experience of rural postmen?

A. Yes. When he stated that no remedy had been applied he omitted to mention that on a certain day in January a remedy had been applied in his own case, as I have mentioned, for he had been allowed to hand back a parcel.

Q. If a man is already carrying $35 \mathrm{lbs}$. weight he need not accept any further parcels on his inward journey?

A. Certainly not.

Q. Several points were raised by Mr. Fred. Smith, a stamper at Liverpool, who gave evidence independent of that given by the Federation.

A. The main points in his evidence are as follows:-(1) Eastern hall door Liverpool Office-It has now been arranged for this door to be used by postmen bringing in collections, and by station messengers conveying bags, by which means from 70 to 100 yards walking will be saved in some instances. The door cannot be seen by the supervising officers, and when 
it was open to the whole staff some of the men used it to conceal late attendance, and to leave the office without permission. (2) With regard to the payment for Bank Holiday, the rule is the same at Liverpool as obtains elsewhere. (3) Concession granted in 1886 as regards special payment at overtime rates for work done after $9 \mathrm{p} . \mathrm{m}$. on Saturday in connection with the incoming American mails-A memorial from the staff on this point is under consideration. (4) Heavy mail bags, limit of weight asked forThis question will be duly considered. The station messengers at Liverpool are allowed to use a cab if the total weight to be carried exceeds $35 \mathrm{lbs}$., and no sacks are made up at Liverpool weighing more than from 80 to 100 lbs. Special assistance is provided for handling American mails, and care will be taken to prevent any undue strain upon the men on whose behalf this witness spoke. (5) Establishment of a separate class for stampers, station messengers, parcel packers, etc., at provincial offices-The multiplication of classes and of varying scales of pay is undesirable. The present system of selecting postmen and paying them a special allowance for these duties, regulated according to the importance and arduous nature of such duties, works well. Under it a man who is found to be unsuitable for the duty can be sent back to the ordinary delivery, etc., work, whereas if a special class were formed with special rates of pay for men performing these duties, this course could not be adopted.

Q. We have also had some evidence given by an independent Dublin man named Doran, who asked and received permission to give evidence. Will you answer the main points that he raises?

A His points were:-(1) That more postmen should be employed in Du" in on the stamping duties, and that postmen should be employed in suldividing the letters into the town walks, in each case receiving the special usual allowances. (2) That the number of auxiliaries should be reduced, additional full-time duties being formed, although such duties would in many cases be spread over about 15 hours. (3) That certain collection duties and allowances for them should be revised. All the above points are already being dealt with in a general revision of the postmen's duties at Dublin which is under consideration. (4) A higher minimum for the established postmen in Dublin, to correspond with the higher age on appointment to the established class-The average on appointment to the established class during the last four years was 24 years. I have already expressed an opinion that in such cases higher commencing wages should be given. (5) Higher wages-for the postmen at certain sub-offices near Dublin. This question will be dealt with separately in the usual course.

The Chairman: Doran makes a statement that at Dublin one day biweekly the men are called upon to perform an 11 or 12 hour duty?

A. I have not been able to get information on that point. We are having a general revision of the indoor and outdoor duties at Dublin. I will inquire further into the matter.

Q. What is the nature of the reports as to the general sanitary condition of the provincial offices?

Mr. Walpole: They would not come under the notice of Mr. Hill.

The Chairman: Thank you very much, Mr. Hill. We need not trouble you any further.

The witness then withdrew, and the Committee adjourned until the 27th April.

The two tables appended were put in by Mr. Hill in the course of his evidence :- 
Statement showing the Number of Town Postmen (Established and Auxiliary) at certain Towns, 70 in Number.

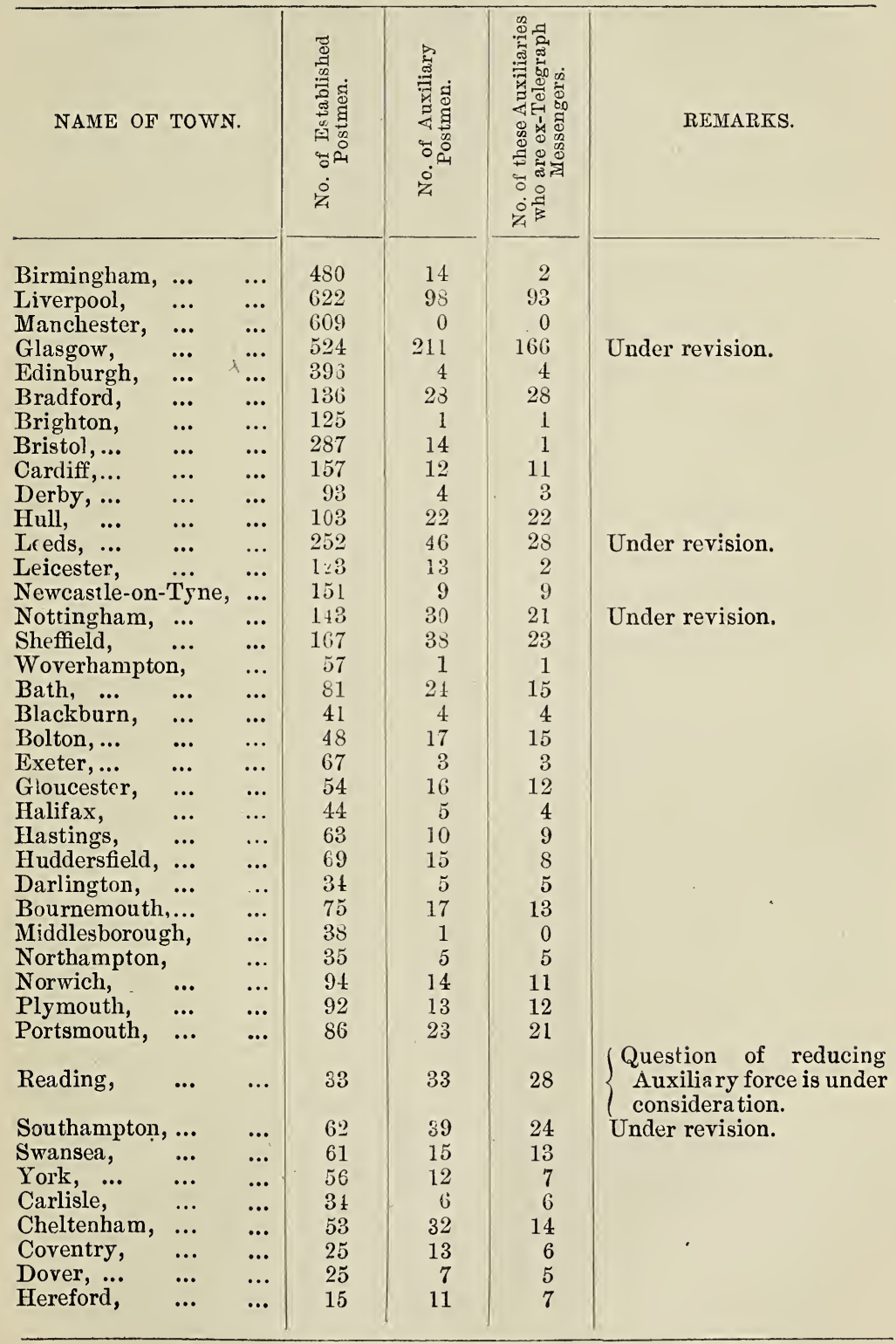


Statement showing the Number of Town Postmen (Continued).

\begin{tabular}{|c|c|c|c|c|c|c|}
\hline NAME OF T & TOWN & & 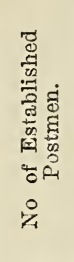 & 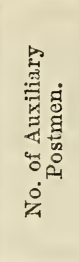 & 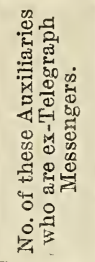 & REMARKS. \\
\hline Penzance, & $\ldots$ & $\ldots$ & 17 & 3 & 0 & \\
\hline Rugby,... & ... & ... & 13 & 4 & 2 & \\
\hline Ryde, ... & ... & ... & 17 & 7 & 4 & \\
\hline Taunton, & ... & ... & 24 & 3 & 3 & \\
\hline Torquay, & & ... & 46 & 4 & 3 & \\
\hline Tunbridge Wel & Ils, & $\ldots$ & 31 & 14 & 12 & \\
\hline Worcester, & ... & ... & 38 & 6 & 2 & \\
\hline Colchester, & & $\ldots$ & 30 & 7 & 6 & \\
\hline Great Yarmout & th, & ... & 27 & 16 & 3 & \\
\hline Guildford, . & ... & ... & 13 & 7 & 1 & \\
\hline Ipswich, & $\ldots$ & $\ldots$ & $4 \check{5}$ & 15 & 10 & \\
\hline Maidstone, & & ... & 19 & 8 & 1 & \\
\hline Peterborough,. & & $\ldots$ & 22 & 13 & 5 & \\
\hline Salisbury, & ... & ... & 17 & 8 & 1 & \\
\hline Shrewsbury, & ... & ... & 30 & 11 & 5 & \\
\hline Stafford, & ... & $\ldots$ & 31 & 4 & 3 & \\
\hline Winchester, & ... & ... & 18 & 11 & 8 & \\
\hline Aberdeen, & ... & $\ldots$ & 82 & 11 & 11 & \\
\hline Dundee, & ... & $\ldots$ & 75 & 12 & 12 & \\
\hline Paisley, & ... & ... & 24 & 20 & 1 & \\
\hline Falkirk, & ... & $\ldots$ & 10 & 2 & 1 & \\
\hline Inverness, & ... & $\ldots$ & 26 & 0 & 0 & \\
\hline Perth, ... & ... & ... & 23 & 10 & 10 & \\
\hline Stirling, & $\ldots$ & $\ldots$ & 13 & 6 & 2 & \\
\hline Dublin,... . & ... & ... & 160 & 116 & 98 & Revision in hand. \\
\hline Belfast, & ... & $\ldots$ & 105 & 33 & 24 & \\
\hline Cork, ... & $\ldots$ & $\ldots$ & 39 & 8 & 5 & \\
\hline Limerick, • & ... & ... & 21 & 3 & 2 & \\
\hline Londonderry, . & ... & ... & 13 & 11 & 4 & \\
\hline Total & ... & $\cdots$ & 6738 & $\begin{array}{l}1258 \\
\text { or } 18 \frac{1}{2} \mathrm{p} .\end{array}$ & $\begin{array}{c}906 \\
\text { or 78 p. c. }\end{array}$ & \\
\hline
\end{tabular}

During the last four years the average age of postmen on entering the established class at these offic's was $21 \frac{1}{2}$ years.

The average age of the police at these towns on entry is 23 years, and their average pay at starting is $23 \mathrm{~s}$, a week. 
Atmendance of Established Postmen at certain Large Towns.

\begin{tabular}{|c|c|c|c|c|c|c|}
\hline \multicolumn{3}{|c|}{ TOWN. } & \multirow{2}{*}{$\begin{array}{c}\text { Within } \\
\text { about } \\
12 \\
\text { Hours. } \\
194\end{array}$} & \multirow{2}{*}{$\begin{array}{c}\text { Over } 12 \\
\text { Hours. } \\
257\end{array}$} & \multirow{2}{*}{$\begin{array}{l}\text { Total. } \\
451\end{array}$} & \multirow[b]{2}{*}{ Under revision. } \\
\hline Birmingham, & $\ldots$ & ... & & & & \\
\hline Bradford, & $\ldots$ & ... & 107 & 29 & 136 & \\
\hline Derby, ... & ... & $\ldots$ & 25 & $* 68$ & 93 & * 46 within 13 hours. \\
\hline Hull, ... & $\cdots$ & ... & 65 & 29 & 94 & \\
\hline Leicester, & $\ldots$ & ... & 54 & 55 & 109 & \\
\hline Nottingham, & ... & $\ldots$ & 93 & $* 50$ & 143 & * 49 within 13 hours. \\
\hline Sheffield, & $\ldots$ & ... & 65 & *102 & 167 & $\begin{array}{l}\text { * } 23 \text { within } 13 \text { hours. } \\
\text { Revision shortly. }\end{array}$ \\
\hline Wolverhampt & ton, & $\cdots$ & 21 & 36 & 57 & \\
\hline Bath, ... & $\cdots$ & ... & 20 & 61 & 81 & Under revision. \\
\hline Exeter, ... & ... & $\ldots$ & 31 & 37 & 68 & Duties rotate. \\
\hline Hastings, & $\ldots$ & ... & 22 & 41 & 63 & \\
\hline Huddersfield, & $\cdots$ & $\cdots$ & 58 & 11 & 69 & \\
\hline Bournemouth & $\ldots$ & $\cdots$ & 33 & 41 & 74 & \\
\hline & $\begin{array}{l}\ldots \\
\ldots\end{array}$ & $\begin{array}{l}\cdots \\
\cdots\end{array}$ & $\begin{array}{l}49 \\
60\end{array}$ & $\begin{array}{l}43 \\
18\end{array}$ & $\begin{array}{l}92 \\
78\end{array}$ & \\
\hline $\begin{array}{l}\text { Portsmouth, } \\
\text { Swansea, }\end{array}$ & $\ldots$ & ... & $\begin{array}{l}00 \\
37\end{array}$ & $* 24$ & 61 & * 12 within 13 hours. \\
\hline Cheltenham, & $\ldots$ & ... & 19 & $* 32$ & 51 & * 22 within 13 hours. \\
\hline Aberdeen, & $\cdots$ & $\cdots$ & 58 & 23 & 81 & \\
\hline Dundee, & $\ldots$ & $\cdots$ & 28 & $* 47$ & 75 & $\begin{array}{l}* 13 \text { of these within } 12 \frac{1}{2} \\
\text { hours. Duties rotate. } \\
\text { Long interval. }\end{array}$ \\
\hline Paisley, & $\cdots$ & $\ldots$ & 13 & 11 & 24 & \\
\hline Greenock, & ... & $\ldots$ & 19 & 32 & 51 & \\
\hline Perth, ... & .. & $\ldots$ & 5 & 18 & 23 & Under revision. \\
\hline Belfast,... & $\cdots$ & $\cdots$ & 105 & $\ldots$ & 105 & \\
\hline Bolton, ... & $\cdots$ & $\cdots$ & $\dddot{\Omega}$ & $* 18$ & 48 & * All within 13 hours. \\
\hline York, ... & $\cdots$ & $\cdots$ & 35 & 15 & 50 & \\
\hline $\begin{array}{l}\text { Ipswich, } \\
\text { Sunderland, }\end{array}$ & ... & $\cdots$ & 11 & $3 t$ & 45 & \\
\hline $\begin{array}{l}\text { Sunderland, } \\
\text { Newport (Mor }\end{array}$ & & $\begin{array}{l}\cdots \\
\ldots\end{array}$ & $\begin{array}{r}* 25 \\
43\end{array}$ & $\begin{array}{r}25 \\
1\end{array}$ & $\begin{array}{l}40 \\
44\end{array}$ & 31 Auxiliaries employed. \\
\hline Newport (Mor & & & & 1 & 44 & Under revision. \\
\hline $\begin{array}{l}\text { Bristol,... } \\
\text { Cardiff, }\end{array}$ & $\ldots$ & $\cdots$ & 181 & 106 & 287 & \\
\hline Cardiff, & $\cdots$ & ... & 72 & $* 85$ & 157 & * All within 14 hours. \\
\hline Liverpool, & ... & $\ldots$ & 458 & 164 & 622 & \\
\hline Manchester, & ... & ... & $45 \check{\partial}$ & 154 & 609 & \\
\hline Brighton, & $\ldots$ & $\ldots$ & 55 & 70 & 125 & \\
\hline Newcastle-on- & -Tyne, & ... & 86 & 65 & $15 \mathrm{~L}$ & \\
\hline Norwich, & $\cdots$ & $\cdots$ & 53 & 41 & 94 & \\
\hline Inverness, & $\cdots$ & $\cdots$ & 12 & 13 & 25 & \\
\hline Leeds, ... & $\cdots$ & $\cdots$ & 190 & 62 & 252 & \\
\hline
\end{tabular}

\section{SumMary.}

Total number of established Town Postmen, $\quad \ldots \quad \ldots \quad$... $\quad 4,805$

Attending within covering period of about 12 hours, $\ldots . \quad 2,857$

Percentage within 12 hours' limit, over , $\quad$... 1,948

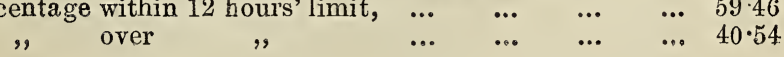


HERBERT JOYCE, EsQ.,

Late Third Secretary to the Post Office,

Rebuts the Cases of Promotion and Discipline.

Westuinster, April, 27th, 1896.

Lord Tweedmouth's Committee of Inquiry, after a recess extending over a month, resumed its sittings to-day, his lordship again presiding. There were also present Mr. Spenser Walpole, Mr. Llewellyn Smith, and Sir A. Godley, together with Mr. Bruce, the secretary. The first witness called was Mr. Herbert Joyce, one of the secretaries of the General Post Office, who spoke on matters of discipline, promotion, and punishment, but whose evidence was givan in so low a tone of voice as to render it extremely difficult to catch what he said.

The Chairman : Before going into the question of promotion and punishment, there are two little matters I should like to clear up. One is raised in a supplementary statement handed into me by Mr. M'Laren, in which attention is particularly called to part of an old rule, which lays it down that vacancies in the sorting class should not be filled up by direct appointment, in the event of any letter-carriers who may desire to succeed to it being qualified to perform the duties of the office. Will you tell me what is the fact with regard to that rule?

A. Yes. Since that rule was laid down it has been decided that for promotion to sorting clerkships there must in the interest of the Service be a fresh Civil Service Certificate obtained.

Q. Is that a Post Office rule, or is it a requirement of the Civil Service Commission?

A. It is a requirement under an Ordor in Council, which in respect to the Civil Service is equivalent to an Act of Parliament.

A. And therefore by an Order in Council the possibility of moving postmen direct into the sorting clerks' cliss without examination was done away with altogether?

A. Absolutely.

Q. And that is a matter on which the Post Office, as a separate department, has no control at all?

A. It has none.

Q. It is a part of a rule which applies to the Civil Service generally, is it not?

A. Yes.

Q. Now, I should like to ask you a question as to what is the rule with regard to the exchange of duties amongst the men in the provinces?

A. An exchange of duty is never refused if it can be consistently granted, and if application is not made too often. For Post Office purposes England is divided into many districts, and I have obtained a return from all of them. Speaking generally, and avoiding detail, the reply is that the applications are granted whén reasonable, and when not too frequently made.

Q. What conditions do you impose on the men who wish to exchange?

A. The conditions differ a little. In some offices it is required that the reason for the exchange should be given. Here I am speaking not of postmen but of sorting clerks. In other cases there are forms provided, which 


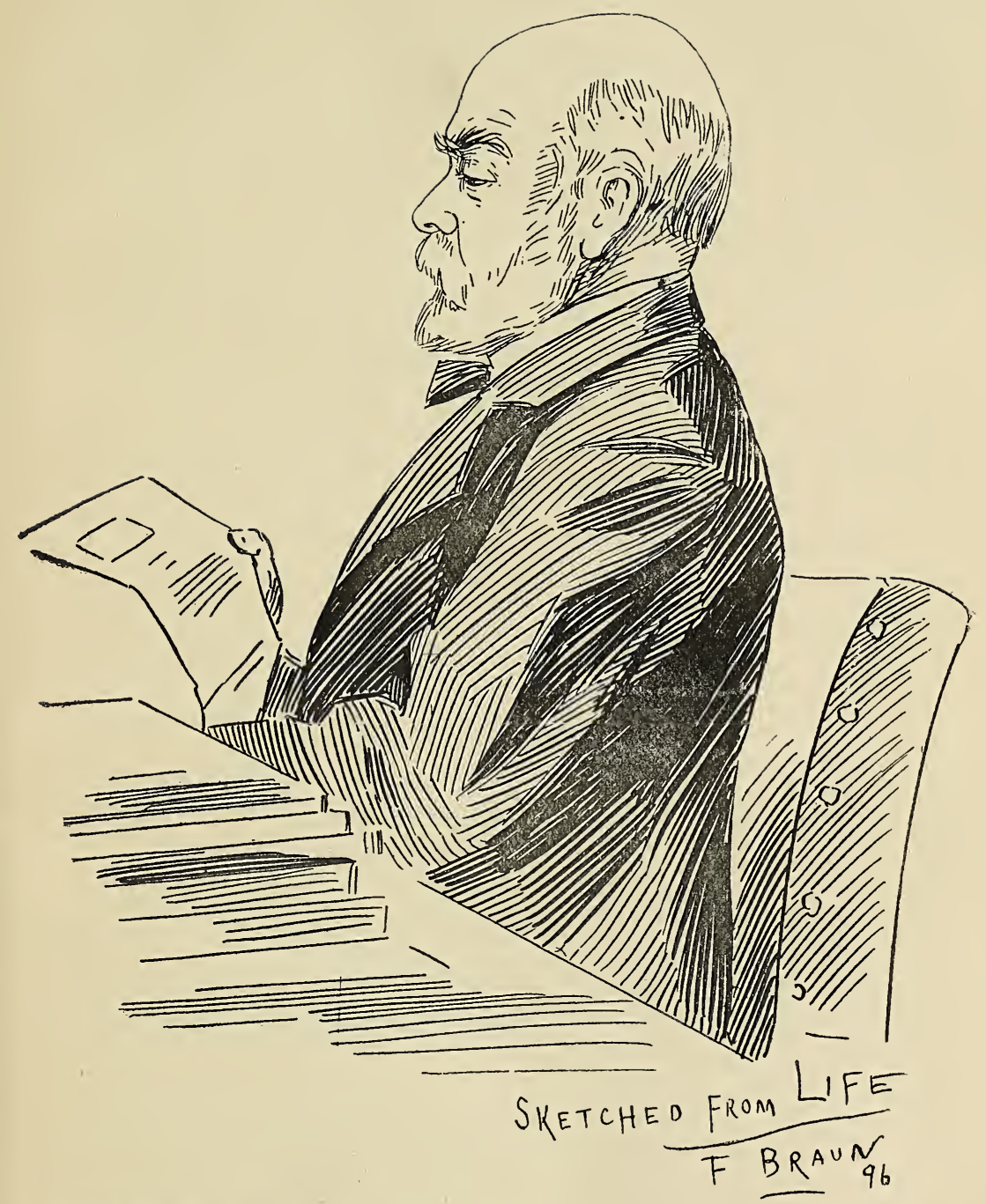

HERBERT JOYCE, Esq., Late Third Serretary to the Post Office. Departmental Witness on the question of Discipline and Promotion. 

have to be signed, not only by the man who asks to be allowed to exchange, but also by the man who is willing to take the duty. That form has to go to the superintendent or some other superior officer, and if he initials it, then permission is given.

Q. Is it required that the man who undertickes to do the substitute duty should be of the same class as the one who seeks relief?

A. Yes, almost always.

Q. And, with that exception, there is no check upon the individual sug. gested as substitute?

A. No; if he is a fitting substitute there is no check.

Q. And it is practically left to the two men to arrange it themselves?

A. Yes, practically.

Q. Then with regard to the postmen, what is the rule there?

A. Speaking generally, they are required to make written application to their inspector. In some cases the reason has to be specified. but I do not know if that is universal.

Q. Have you a general rule laid down from headquarters to govern the inspector's action with regard to these exchanges?

A. No. In some cases, no doubt, the inspectors or superintendents deal more indulgently with these applications than others, but we think it is a matter which should be left to the discretion of the local authorities to allow a man to get away if he has good reason for desiring to do so, even beyond the usual or prescribed number of days. We rather object to a rule, because if one were laid down, it must be adhered to in every case, and no exceptions could be made, even where the circumstances seemed to justify it. It is in the interests of the men themselves that a rule should not be laid down.

Q. Then practically it is very much in the local superintendents' discretion to refuse or grant leave for substitute service, and to decide the conditions under which particular leave should be given?

A. If you substitute "Postmaster" for "superintendent," that would be perfectly right. The superintendent deals with the ordinary cases, but cases of an extraordinary nature would be referred to the Postmaster.

Q. And in the smaller offices the Postmaster is the supreme authority, and would deal with all cases himself?

A. Yes.

Q. Is there anything further you wish to say on this particular point, Mr. Joyce?

A. No; I think there is nothing more. We have been talking of the exchanges of duty within a period of one day, but when a whole day is asked for or more than a day, then the case may be a little different. The officials are more particular in some offices, and even some districts, than others. But such applications are comparatively few, and are rarely refused. Speaking generally, the practice as regards applications for one day's absence would be much the same as that with regard to exchanges for part of a day.

Q. Passing from that question to the question of promotion, there has been a good deal of suggestion that it is possible for a man to receive promotion through favouritism rather than according to strict merit. Can you tell us generally your views upon that point?

A. Yes ; my view generally is this : that while human nature is as it is, there may be-indeed, I think I may say there are-most probably cases of favouritism, but that it is in any way whatever general $I$ do not believe for a moment-not for a single moment. I think the explanation of nuany of these charges of favouritism is this-It will be observed that almost every case relates to the promotion of men from the Postmaster's office. Well, the Postmaster's office has no special classification of its own. It happens in this way. The Postmaster when he requires any help must have recourse to the general office, and from there he naturally selects the most promising men with whom to surround himself. They are the best men- 
the picked men of the whole office-and it may be naturally expected that this picked lot, as time goes on, produces men more capable than those who remain in the general office. That I believe to be the true explanation of many of these charges.

Q. Then you do not think it would be possible, even in the case of any given office, that the practice of favouritism should be long continued?

A. No ; I think it is impossible. In a large office the chief officers are known to those about them. They are known not alone to the Postmaster, but to the surveyor of the district, and with the vigilance that is exercised at headquarters, it is quite impossible to suppose that as a rule Postmasters can make such promotions unfairly, or that they could hoodwink -for it is what that would amount to-both the surveyor and the headquarter staff.

Q. Are the promotions which are made from time to time in provincial offices reported to headquarters?

A. Yes. No promotion whatever is made in a post office except it passes first through the hands of the surveyor, and then it goes to head. quarters, where it is most vigilantly examined, not with the idea of favouritism, but to ensure that favouritism shall not be allowed.

Q. Do you think your provisions in that respect to be sufficiently strong, and to be exercised with sufficient vigilance to prohibit the chance of any long-continued practice of favouritism on the part of any subordinate officials of the Post Office throughout the provinces?

A. Absolutely, to prevent any long-continued practice of farouritism. I will not say that does not occur in any case. Indeed, I have in my mind a particular case with which I strongly think there was favouritism. But it is an exception. I am quite certain it is an exception.

Mr. Walpole: As a matter of fact, these promotions when they reach the head office are carefully analysed?
A. Yes.
Q. And when they pass through they go before the Postmaster-General?
A. They do.

Q. And they actually receive the written fiat of the Postmaster-General?

A. Every one of them.

Q. And, as a matter of fact, in the great majority of cases the fiat is not given lightly, but the Postmaster-General looks carefully into the facts?

A. Yes ; it is always a matter of the greatest grief to the PostmasterGeneral-it has been to every Postmaster-General under whom I have served-when he is constrained to pass over anybody in cases of promo. tion. I have seen Mr. Arnold Morley-I will not say in tears-but almost crying, and certainly much distressed, when he has had to pass anybody over. He has always done it with the greatest regret.

Q. Is there any difference in the treatment of the ordinary cases of promotion to the higher ones?

A. No; there is no difference whatever in the treatment of any case.

The Chairman then took the witness seriatim through the individual cases of grievances which had been laid before the Committee regarding sorting clerks.

The Chairman: Generally, in these cases we have gone through, you would say, I suppose, that though in one or two instances there may have been favouritism, on the whole the instances of men passed over were due to proper causes, and to causes which must be considered for the benefit of the Service?

A. Exactly; and, I should like to add, that I think the cases of farouritism, if they exist at all, exist very rarely.

Q. As a check on possible favouritism, it has been suggested in evidence that Postmasters should be required by the Department to warn men whom it is intended to pass over, so that the reasons may be stated, and protests accompany the recommendation.

A. I think that is absolutely out of the question. An overwhelming 
objection to letting men know before it is proposed to pass them over is that the Postmaster-General may not approve the proposal. No doubt this does not very often happen, but it does sometimes. It happened the other day. I well remember Mr. Fawcett's address to the head of a large department who had done this very thing; that is to say, having a large number of promotions to recommend, he had told the officers concerned whom he had recommended and whom he had not; and what made the natter worse, he had in his recommendation taken little account of seniority, whereas Mr. Fawcett, like Mr. Arnold Morley, had a perfect horror of passing anyone over. I only saw Mr. Fawcett angry on two occasions, and that was one of them. He summoned the head of the department, and, shaking his fist, he said, "What have you been doing? You have been telling all these men that they will be promoted, or that others will be passed over. Now, suppose that I don't approve of your recommendation, a pretty position you will be in then, and I have half a mind to put you in that position." Mr. Fawcett told the officer that it was a gross impropriety, and must not occur again. It is impossible to conceive anything better calculated to impair a Postmaster's authority than that one of his subordinates whom he has told that he would be passed over should be promoted, and that another who has been informed that he would be promoted has been passed over. It would really be out of the question to tell men beforehand of the intention to pass them over; indeed, it would not be in their own interests, because the fact of such an intention being made known to them might just turn the scale in the Postmaster-General's mind against them, whereas, otherwise, the Postmaster-General might possibly set the recommendation aside.

Q. Now, I think we may pass to the similar allegations put forward with regard to the postmen, and the first question I would ask is-Do the general propositions which you have laid down with regard to this subject in connection with the sorting clerks apply also in the case of the postmen?

A. I cannot answer that affirmatively, for the simple reason-and it is a melancholy fact-that among the postmen there is very little promotion. It therefore does not exist. I have already explained that the appointment of postmen direct to the position of sorting clerks is no longer possible.

Q. Do you think it is desirable that postmen should be transferred more freely from their own class to the class of sorting clerks?

A. If they proved themselves thoroughly fit I think it would be very desirable indeed, because it would give them promotion, but then fitness must be proved.' There are other things to be looked at.

Mr. Llewellyn Smith: Are you referring now to the possible extension of the sorterships open to limited competition, or to promotions to superintending posts?

A. I was speaking of promotion or transfer from the class of postmen to that of sorting clerks, under the Order in Council, as I have explained the appointment of sorting clerks must now be by new certificate, so that there cannot be promotion in the ordinary sense from the rank of postman to that of sorting clerk; it must be a fresh appointment.

Q. At present I think a certain number of sorters are chosen by limited competition from among the postmen.

A. That is so in London, but I am speaking solely now of the provinces, and in the provinces they cannot be so appointed without a fresh certificate.

Mr. Walpole : It is done in London also with a fresh certificate.

A. Yes, but with a limited examination-a limited competition.

Q. Yes. They have to get a separate certificate as sorting clerks from the

Civil Service Commissioners.

A. Yes.

Q. Would there be any reason why the same principle should not be applied to the large provincial offices?

A. Practically, I hope that it is applied and in existence there. 
Q. In the large provincial offices there is no reservation as to the number of places to be reserved specially for postmen.

A. No; I take it that if a postman proved himself thoroughly fit, the Postmaster would naturally be willing to give him a nomination.

The Chairman: We will now look to the evidence, where a few cases are given. The first case was at Liverpool, where Mr. Robinson is said to have been appointed to act as inspector while still an assistant-postman of about three years' service, and that he must have been promoted over more than 300 postmen.

A. If I may take in connection with this the case of Mr. Hicks, I think the one will explain the other better.

The Chairman : Certainly; do so.

A. They are both Liverpool cases. In the case of Mr. Hicks, out of a body of 500 postmen, all of whom had been invited to apply, only 15 offered themselves as candidates, and of these 15 Hicks, who had long acted as head postman, was by far the best qualified. If out of 500 postmen only 15 applied on the occasion of Mr. Hick's appointment, then I think it ceases to be a matter of surprise that Mr. Robinson was appointed over the heads of 210. I find that in 1885 Robinson stood 210 on his class, and he was promoted to be assistant-inspector. It was certified that no one standing above him was qualified for the duties. He had, when a young postman, been selected by his inspector as a superior and promising officer. He was temporarily employed as an assistant-inspector, and discharged the duties so efficiently that on a vacancy occurring he was promoted to it. The inspectors under whom he has worked think highly of his capacity. It is true that he is a strict disciplinarian, and not popular with the men, but there is no case on record or remembered in which he has shown want of judgment or consideration or has acted harshly.

Q. Still, it seems to have been rather a strong order to appoint an assistant-postman to such an office, and to give him such great promotion?

A. Yes, it certainly does seem so, but for the position of inspector or assistant-inspector of postmen there is no doubt that qualifications are required which are not ordinarily to be found in postmen.

Mr. Walpole: Is it a fact that Robinson was only an assistant-postman? Is not that a mistake?

A. He was a regular postman.

The Chairman: Was he a full-blown postman and not an auxiliary? It looks as if he were the latter.

A. No. He was a full-blown postman. Mr. Hicks passed over 500, and this Mr. Robinson passed over 210. He must have been in comparison not only a postman, but a postman of some years' service. Postmen do not always, or perhaps even often, possess sufficient power of control, aptitude for making inquiries, and ability to write an intelligent report. The present Postmaster of Liverpool states that at the town from which he has been recently promoted, out of a force of 300 postmen he found very few who were qualified for even the subordinate post of charge-taker, to which may be added that the fact already stated at Liverpool, that only 15 out of 500 applied for an appointment as assistant-inspector, which would seem to show on the part of the postmen themselves a distrust of their capacity.

Q. What have you to say with regard to the cases of Parrott and Lunn, who are stated to have been passed over, although it is added that both of them had actually acted as inspectors?

A. The last vacancy for assistant-inspector at Liverpool occurred in 1894, when both Parrott and Lunn were candidates. Parrott is a good and deserving officer, and had frequently acted temporarily as assistant-inspector at a district office, but of the candidates he was by no means the best. Lunn was a good postman, but was not possessed of the necessary qualifications for the position of assistant-inspector. 
Mr. Walpole: Is it true that Parrott had acted as assistant-inspector for 8 years?

A. No ; what I understand is that during 8 years he acted at intervals, when he was requested to do so, as assistant-inspector.

The Chairman: Then what about the case of Mr. John Dodd, who is stated to have acted as inspector, but was passed over by juniors?

A. He applied only on one occasion for the position of assistant-inspector. namely, in 1889, but he could not be recommended. It is true that as recently as 1894 he acted for several weeks as a substitute for assistant-inspectors on leave, but this employment was given because the man Dodd was suffering from diseased bone of the leg, and was unable to do his ordinary duty as postman.

$\mathrm{Mr}$ Walpole: You mean that through charity he was put on lighter work, and that a claim is founded upon that charity for his promotion to superior work?

A. Yes.

Q. Do you think, as a matter of fact, that a man suffering from diseased bone of the leg ought to have been allowed to take inspector's duty?

A. I think it was a matter of kindly consideration on the part of the Pestmaster, and I think it was perhaps natural, but it was clearly a makeshift.

The Chairman: The witness Walton said that the method in Liverpool had been for 19 years past to put senior postmen out of bounds for promotion, so that no postman would be eligible over 40 years of age.

A. For the position of inspectors and assistant-inspectors I think I may say that the local authorities, and also headquarters, are more particular than they are about any other promotion, and they are most anxious to select actually the best men. In almost every other promotion very great allowance is made for seniority, but in the case of inspectors it is not so, on account of the somewhat rare qualities required of inspectors, and the post is a most invidious one.

Q. Then with regard to these particular.cases, you would say that though they may be assumed to involve certain hardships to the men passed over, the cause of the passing over was simply the necessity of obtaining first-rate men for responsible situations.

A. Yes ; that is absolutely so.

Q. And that no question of favouritism arises with regard to these cases?

A. I have not the least idea that there was. I will say this, that if you go into the branch offices in London and see the inspectors of postmen, you would see at once that they are men with powers not ordinarily met with among postmen.

Q. Now we come to a long series of charges with regard to the management of the post office at Brighton. Would you prefer to deal with that as a whole or go into the individual cases?

A. If I may have my choice, I would rather deal with it as a whole.

Q. Then please do so.

A. Of course, I am also prepared, as far as I can, to go into the individual cases.

Q. I think you will be able to put the matter clearer in a general story rather than by going at once into the individual cases.

A. I think the true explanation of all these charges is that $\mathrm{Mr}$. Hetherington and the witness are in entire disagreement in a matter of principle. The witness holds that everyone should enter the service as a postman, whereas Mr. Hetherington strongly holds-and I am not expressing any opinion of my own on the matter-that the promotion of a postman to be a sorting clerk should be the exception and not the rule. His reasons for this opinion are (1) lack of education; (2) the inexpediency of ranking men of mature age among and below lads fresh from school, and (3) the fact that the qualities which make a good postman do not make a good sorting clerk. With this view he has endeavoured to keep in training a supply of 
well-educated lads to fill the vacancies as they occur, and meanwhile to act as substitutes for sorting clerks. This he calls his nursery.

Q. Does that practice hold good in other places besides Brighton?

A. It is not propounded in the same terms, but if it be the case that the postmen are not fit in other towns, then it would in practice be the same there.

Q. This is the first time I have heard the idea of any individual Postmaster keeping on his own account a sort of nursery for sorting clerks?

A. It cannot be uncommon at other offices. A young man must be learning his duty in the office with a view to nomination when vacancies oceur.

Mr. Llewellyn Smith : They are already employed?

A. Yes.

The Chairman: They are taken on the responsibility of the Postmaster to learn their work without the sanction of the Department, and not employed or paid by the Department, but taking advantage of the facilities placed at their disposal by the Postmaster to learn their work in order to obtain future appointments?

A. I don't suppose he would bring them into the office except as substitutes for absentees.

Q. When they are doing work as substitutes for absentees, what is their position-do they get paid or do they not?

A. Yes, they would get paid as substitutes.

The Chairman: Is it in the power of the Postmaster in the provinces to take men from outside the Service and employ their substitutes in the absence of the regular employees of the Department?

A. Yes.

Mr. L. Smith: Some might be employed as telegraph boys, might they not?

A. No.

Q. Then the custom in London as to them does not prevail in the provinces-I mean the custom of selecting clerks from ex-telegraph messengers?

A. Some might qualify, but that would not be the regular recruiting g:"ound.

Mr. Walpole: As a matter of fact, it has been the normal custom of Postmasters when any of the sorting staff were away from their duties for any cause, to bring in substitutes to do the work?

A. Yes; that must be done.

Q. And, in accordance with their instructions, it is their duty to do that?

A. Yes; in no other way could the work be done.

The Chairman: I thought I understood that the offices were provided with a sufficient number of officers to make provision for contingencies of this sort, and that there was a regular relief staff provided?

A. No.

Mr. Walpole: Is it not the case that in a revision we do provide a relief staff sufficient for all the normal business of the office?

A. Yes.

Q. But that, luckily or unluckily, the work is perpetually very fast growing, and in the course of a few months it outgrows the provisions which have already been made?

A. Yes.

Q. So that they have to wait for another revision and must fall back urion these substitutes for relief?

A. Yes

Mr. Smith: Some of the men so employed derive part of their income regularly through acting as substitutes in the same way as auxiliary postmen who derive part of their income from taking short duties.

A. Yes; in large offices they do.

Q. They would, in fact, be a kind of auxiliary sorting clerk?

A. Yes. 
Mr. Walpole: Would it not be the ease as it is with the rural postmen eniployed on substitute duty, that these men in time would be likely to be nominated for sorting clerks?

A. Certainly.

Q. And that is one of the objects in employing them?

The Chairman: I should like to draw your attention to the question which deals with the cases of H. Bennett, C. Weller, and others. The witness (Walton) states that Bennett is the son of the chief clerk at Brighton, and that Weller is the nephew of the assistant-superintendent, that they went into the Service as learners, and were soon put on sorting clerks' duties on the permanent staff.

A. They were admitted in the same way as the others. Bennett was admitted in April, 1894, and Weller in November, 1895. Neither has been nominated, and they both received pay only for acting as substitutes. Bennett was so acting almost continuously, but Weller received full pay for not more than three weeks in all.

Mr. Walpole: In the case of the employment of men engaged in other work to assist as auxiliary sorting clerks, is it not the fact that they would only be employed in times of pressure, such as Christmas time?

A. Yes ; I think they would only be employed at such times.

The Chairman: Have you anything further to say on that case?

A. No, beyond that I think that the explanation that I have given will go far to explain some of the charges of favouritism that have been made.

Q. Then there is another point in the evidence on this point to which I wish to call your attention. The witness complains that nearly half the present number of second-class sorting clerks on the Brighton staff have been brought from other towns; that does not seem to fit in very well with Mr. Hetherington's usual practice? His "nursery" seems to have been strangely deficient in that respect.

A. Yes; I was much struck with that statement, and $I$ inquired if it were a fact that nearly one-half of the sorting clerks now on the Brighton staff had been brought from other towns. I am informed that the total number of second-class sorting clerks at Brighton is 40 , while the number of these brought from other towns is 10 , and of these 10 four were imported by express instructions from London. I believe there was a reduction of the staff at Eastbourne. It was desired to reduce the number of learners there, and they were transferred to Brighton.

The Chairman: Then it was not on account of any deficiency in the supply of men at Brighton, but it was because the Postmaster had to provide places for these men by order of the General Post Office?

A. Exactly. He had to provide for the redundancy at Eastbourne.

Mr. Walpole: Then it cannot be sair that it was the fault of the Postmaster that men were brought from other towns instead of Brighton men being appointed? The complaint was on behalf of the Brighton men, who thought that some from among their own number should have been ap. pointed instead of men from other towns?

A. Yes; that is so.

Mr. Smith: I see that in the same answer there is a reference to the examination of sorting clerks, and that postmen do not think that they ought to be called upon to pass any fresh examination when they are transferred to the sorting class. It is suggested they could not pass the new examination.

A. I believe the standard of examination has recently been raised.

Q. Then there is an examination at Brighton for sorting clerks?

A. Yes; I have here a document which will show what the examination formerly was, and what it now is.

Q. Then it is not a case of open competition?

A. No.

Mr. Walpole: It is really a "pass" examination, is it not?

A. Yes. 
Q. An examination, the passing of which qualifies for the Service?

A. Yes.

The Chairman: Go on, please.

Witness: The other principles which underlie Mr. Hetherington's practice are rather a matter of speculation. It seems to me that a Postmaster who would not give a nomination to the son or nephew of an old Post Office servant, if fit for it, would be a positive churl. Mr. Hetherington and his predecessor, the late Postmaster, appeared to have given many such nominations. To say that of two persons promoted A is a son of an old Post Office servant, or that B is a nephew, proves nothing; the same might, and no doubt would be said of $\mathrm{C}$ and $\mathrm{D}$, or $\mathrm{E}$ and $\mathrm{F}$, if they and not $\mathrm{A}$ and $B$ had been promoted. There is no reason why such appointments should not be made if the person so appointed is fit for the place, and this seems to me to explain a great deal of the complaint as to the Brighton Office; without such explanation it would be unintelligible.

Q. Have you anything on the individual cases which were brought forward?

A. Yes. There is the case of W. Stenning, who, it was stated, entered the office five or seven years ago for a short time, had done parcel and letter delivery work, and had then performed indoor duty.

The Chairman: There is also the case of F. Dunstone, and it was alleged, I think, that both he and Stenning had never properly classified as postmen, and had never performed postmen's duty. In the case of Dunstone, the allegation was that he had never done a day's work as a postman, and had never worn the postman's uniform?

A. Yes; but I have not the slightest doubt it was not so. I believe there was an allegation also in the case of one of these men (Stenning) that he was of weak intellect, but I am informed that he showed no signs of that until about November, 1892.

The Chairman: Then it is a fact that he was sent to a lunatic asylum for some months?

A. I have taken that for granted. As regards Dunstone, he was appointed postman in October, 1887, and he was employed on the indoor duties until 1891, when he was promoted to be a sorting clerk. That was before Mr. Hetherington's time.

Mr. Walpole: Then Mr. Hetherington was not responsible for Dunstone's promotion, which, indeed, is against the principle on which he professes to act?

A. No ; because this took place in April, 1891, and Mr. Hetherington was not appointed until May, 1891.

The Chairman: Then, again, Mr. Dunstone's name (as well as that of Mr. Outram) is mentioned with regard to his promotion to an inspectorship, and it was complained that he got that promotion because he had a brother (Walter Dunstone) who was assistant-superintendent in the same office?

A. With regard to that, Mr. Hetherington says he was not aware at the time that any such relationship existed, and, in fact, the brother had left before Mr. Hetherington had got that promotion.

Q. The next case is that of Mr. Paul?

A. Yes; until recently Paul was employed as indoor postman or packer in the parcel office. Prior to 1891 his work was important, and possibly more responsible than it should have been, because the Parcel Post work was performed almost exclusively by the postmen, but at no time could his duty be defined as that of a superintendent, and in no case was he left in charge of the parcel office, except when acting as substitute. As regards the refusal of promotion to him, with the consequence that his health broke down, it is to be observed that the sick leave was granted him a year-an-ahalf after such refusal. He is not a man of superior ability, as has been suggested, and, indeed, he himself applied for outdoor work on the ground that the indoor work did not agree with his health.

The Chairman: Now we come to the case of Brostowe and Barnes, 
who complained that they were refused promotion. Are they cases which come under Mr. Hetherington's own responsibility?

A. Certainly.

Q. Then they may be taken as dependent on the principles which $\mathrm{Mr}$. Hetherington has laid down, and of which you told us just now?

A. Yes.

Q. There is the complaint that two men, Mountford and Powell, of Stafford, who applied for appointment as sorting clerks, and were told that they were not adapted for the work. Have you any explanation as to why they were passed over?

A. Yes.

Q. Has the practice which obtains at Brighton received the sanction at headquarters?

A. Only indirectly. Rightly or wrongly these matters are left in the hands of the local Postmaster, and there is not very much check exercised over them.

Q. Do you think that the postmen at Brighton have suffered? Do you think that if a different principle had been gone upon they would have received more of these places?

A. No, I do not; and I do not think there is anything to show that promotion has not been given in all cases where there was fitness for it. Indeed, I am not prepared to say that the proportion of promotions of postmen at Brighton is not as high as the proportion elsewhere. I am very much grieved to say that from a return which I have obtained with regard to the United Kingdom for the year 1894-1895, the number of postmen who were successful in passing into higher classes was very few indeed.

Mr. Walpole: Do you mean the number of postmen nominated as sorting clerks?

A. Yes; I should like to put in for the information of this Committee the return which $I$ have in my hands.

Q. It shows that only 27 postmen were nominated as sorting clerks and telegraphists during the year 1894-1895?

A. Yes.

The Chairman: Do you think the nominations of postmen for sorting clerkships are as numerous as they might be? Do you think that undue difficulties are put in the way of postmen obtaining these nominations?

A. No; I certainly do not think that undue difficulties are put in their way.

Q. Would a provincial postman, if he showed his fitness for the work, be practically assured of a nomination?

A. No, I do not think that he could be assured of that, and I am not quite certain that such an assurance could be given with propriety. Still, I think it would be desirable that where a postman is thoroughly qualified he should have the promotion. This lack of promotion is a very great drawback. Again, I am not quite sure whether, speaking generally, a postman's work is of a kind calculated to fit him for the duties of a sorting clerk.

Mr. Walpole: Would it not be possible to do in the provinces as we do in London, and reserve a certain number of sorting clerks' places for postmen in the large towns?

A. I should like to point out that there is a great difference between the work of a sorter and of a sorting clerk.

Mr. Walpole: Yes; a sorting clerk has to do a good deal more postal work than a sorter. He has counter work, for instance, has he not?

A. Yes, and speaking from experience, I may say that postmen have been found to do sorting work very well indeed, but difficulty has been found in fitting them for dealing with the money order and savings bank business.

Q. Counter work generally, in fact?

A. Yes, counter work. 
Q. But could we not meet these difficulties by imposing an educationa? examination?

A. Yes, possibly we might. Mr. Walsh put the case in regard to this extremely well. His arguments were strong, and he must have impressed the Committee by them, yet the fact remains that Mr. Walsh himself on two separate occasions was offered nomination as a sorting clerk, and that with becoming modesty he declined.

The Chairman: I think the wages in that case is a drawback. Still, the fact remains that a postman has a very small prospect of promotion, has hē not?

A. Yes; I feel that very strongly indeed.

Q. Does not your long experience enable you to give this Committee some suggestion as to the means by which this difficulty might be mitigated?

A. It is a very difficult subject to deal with, and I do not think I could make any suggestions now ; still, unquestionably, it is a matter which ought to be faced, and some means should be found of giving more promotion. I do not think it will be a very easy job.

Q. May I ask you to think the matter over a little, and favour us with a memorandum on the subject, which we may have an opportunity of considering?

A. Yes.

Q. Thank you. I quite understand you would not wish to answer such a question off-hand.

A. I will think the matter over.

Q. Now we will leave the Brighton case and come to the Stafford case.

A. Yes. In that case it was stated, I think, that the Postmaster at Stafford had informed the men that if they made themselves efficient in their duties and qualified for the Civil Service examination they should be recommended for promotion. Yes, the answer to that is, that the late Postmaster informed the men that if the men made themselves efficient at their duties, and qualified themselves for the Civil Service examination, he would, as vacancies arose, give them nominations for sorting clerkships. In order to form a judgment of their chances before the Civil Service Commissioners, he appears to have put some of the men through a test examination, and among those who came out badly were two men, Mountford and Powell. They were told that they would not pass the Civil Service examination until they had qualified themselves further. So it would seem to me that the Postmaster did all he could to help them through.

Mr. Walpole: He had, in fact, a sort of preliminary test examination?

A. Yes, in order to see what sort of chances the men had of passing. There was a third postman, Robinson by name, who came up to the Postmaster's standard, and so he got a nomination and passed the Civil Service Commissioners' examination. He has been a sorting clerk for nearly two years.

The Chairman: Before leaving that subject altogether, I should like you to look at a general question which has already been touched upon, with regard to the allegation that promotion is too often due to a man having relations at the top of the office. The witness in his comments on this point suggests that blood relations have better chances of appointment than others.

A. I do not think there is anything in that. I can quite see that there is strong ground for suspicion, and I think I know how the suspicion arises. There is no doubt some difficulty on the point, and it is very undesirable that there should be several relations in one office. But, on the other hand, as I have said, a Postmaster would be an absolute churl if he refused to give an appointment to the son of an old Post Office servant who was qualified for the post.

Mr. Walpole: Would you not go a little further, and say that supposing a Postmaster has an excellent officer under him as superintendent or clerk, 
and that officer has a son who is desiring an appointment, would you not say you see no reason why that son should not be nominated?

A. Yes. I see no reason whatever except that when the son comes up for promotion, if such promotion is not taken absolutely by seniority, there are always those who will say it is a case of favouritism.

The Chairman: The question raised here is not a question of nomination, but it is a complaint that a large percentage of the higher appointments are held by blood relations?

A. Yes.

Q. And you do not think that that would be found to be borne out by the facts?

A. No.

Mr. Walpole: Presumably the relations of high officers in the Service are rather better educated than the sons of postmen?

Q. And the better education would be the better qualification?

A. Yes.

A. Yes; the sons of postmen have not always the same opportunities for education as the sons of Postmasters.

Q. Have you anything else you wish to say on the point of favouritism in regard to appointments? If there is anything I have passed over perhaps you will say, and we will take that and leave the question of punishments until after the adjournment.

A. No; there is nothing more I wish to say on that branch of the question.

The Chairman: Then we will adjourn for twenty minutes.

Mr. Walpole (who during the temporary absence of Lord Tweedmouth occupied the chair when the Committee resumed after luncheon) said:

The witness described certain cases of punishment at Newcastle-on-Tyne, in one of which a postman who was ten minutes late was called upon to perform 30 minutes' extra duty. Do you know what the rule is?

A. Yes; it appears that at Newcastle extra duty has been allowed to accumulate, and that the men have been required to work it off in times of pressure-to do work, in fact, for which otherwise they would have received overtime payment. Until this evidence was given, the existence of such a practice was quite unknown at headquarters, and the Department have given orders to stop it.

Q. Have given orders that the accumulation of punishment shall be dis. continued?

A. Yes.

Q. There is also an allegation with reference to extra duty as punishment at election time? Do you know anything about that? They state that they do extra work, such as the election delivery of circulars, cheerfully, expecting to be remunerated for their labours at the overtime rate of pay.

A. That is the practice which I have said has been ordered to be discontinued.

Q. Then was this punishment duty inflicted both at election times and ordinary times?

A. Yes.

Q. And in both cases you have directed that the practice shall be discontinued?

A. Yes.

Q. Then in the next question the same point is again raised. We have the case of a Liverpool postman fined for every late attendance at the rate of $8 \mathrm{~d}$. per hour; if he is late 15 minutes or a part thereof, he is fined 6d., and if he is late one hour he is fined $8 \mathrm{~d}$., and he is specially called upon to work an hour extra in lieu of the hour he has lost.

A. Yes, that is so at Liverpool; but what this witness complains of specially is that the men are punished twice and even thrice for the samo offence. The case he puts is one of late attendance, and he complains that the man is punished first by fine, secondly by loss of increment, and thirdly 
by the loss of good conduct stripes. I do not think it is meant that he is deprived of these things, but that they ar arrested. Now there is obviously great confusion as to the increment and the good conduct stripe. The good conduct stripe has to be earned, and one condition of the earning is regularity of attendance. Take a similar case-take the case of a grocer, or any ordinary trader, who is fined for adulteration, the punishment is a fine, but the loss of custom which probably follows upon the conviction is a direct consequence of the man's own act, and has nothing to do with the penalty inflicted by the magistrate. Now this is the same with the postman. It is not the fact that the failure to earn increment or a good conduct stripe is the punishment for late attendance, it is merely the result of the man's own act, and the necessary consequence of his having imposed upon him the fine for irregularity of attendance.

Q. In fact, regularity of attendance being one of the conditions laid down for the receipt of increment, it has been impossible to avoid a duplication of punishment, unless, indeed, late attendances were not punished at all?

A. That is so.

Q. A man must be fined or punished in some way for being late. Is it the fact that for a certain number of late attendances it follows that he cannot receive the certificate which is necessary to entitle him to his increment?

A. Exactly. Before he can get his increment he has to get from the Post Office authorities a certificate. That certificate must be to the effect that he has given satisfaction by his conduct and been regular in his attendance during the preceding year.

Q What is the general position as to irregularity of attendance? Is it the fact that 16 late attendances in a year disqualify a man from getting his certificate?

A. I am not prepared to say that exactly. I do not think any number is fixed. I think the Department is always very indulgent, and before any penalty is inflicted, there must have been serious irregularity of attendance.

Q. Now we will pass on to another point. We have some specific instances of what are considered to be cases of harsh punishment. There is, for instance, the case of William Woodhouse, a postman of Norwich, who was appointed in the year 1872.

A. It is very difficult to deal with cases which are practically ancient history, and this complaint I see goes back a good many years. I have here the record of Woodhouse's case, and I think the Department will come to the conclusion that it is one not so much of harshness of treatment as of long suffering.

Q. On the part of the Department. (Laughter).

A. Yes, long suffering on the part of the Department. Here is Woodhouse's record:- In 1878, two days' suspension for irregular attendance, he having been 42 times late in one quarter. In 1880, three days' suspension, having been late no less than 173 times during the year. He was then stated to be "far from a good letter-carrier, very troublesome to the inspector, his manner almost amounting to insubordination, and setting a bad example to the younger postmen." In 1882 he absented himself from duty without leave. He was visited by the medical officer, and certified to be suffering from the effects of intoxication. He was grossly insubordinate to the Postmaster, and set him at defiance. Later on, at an interview with ${ }^{E}$ the surveyor, he was also very insubordinate. His di-missal was recommended, but with great-I had almost said undue-leniency, it was decided to give him one"more trial. In 1889 he was cautioned by the Postmaster for insubordinate conduct to the inspector. In 1891 the Postmaster was unable to recommend him for the good conduct stripe. In 1892 the same was the case. The Committee will be glad to hear that in 1894 there was a marked improvement; it is still maintained, and he has now been recommended for good conduct stripes. 
Q. Then it is utterly untrue that for the last 17 or 18 years Woodhouse's career has been of the most exemplary description?

A. Absolutely.

Q. What have you to say as to the case of Saunders?

A. In 1886 Saunders was fined three days' pay and cautioned for using profane and filthy laungage. In 1891 the Postmaster reported that as his general conduct had not been satisfactory, he could not recommend him for a good conduct stripe. In 1892 the surveyor informed him that he could not then recommend him for a stripe, but he should be pleased to do so when he obtained a good report as to his character and general efficiency. Subsequently inquiry showed him to be improving, and in 1894 the Postmaster reported of him favourably. The surveyor, however, thought that another year should elapse, and in the end recommended-a recommendation which has been approved-that Saunders should have three good conduct stripes, as from the 1st July, 1895.

Q. Three good conduct stripes, did you say?

A. Yes.

Sir A. Godley: To receive the three altogether-is that usual?

A. Well, there has been an improvement in his conduct. He is now certified to be of good conduct, and having served 15 years, he is in point of service eligible for them.

Mr. Walpole: But he has not served 15 years without a blemish?

A. No, still he has served 15 years.

Q. Then it is utterly untrue that as alleged he has 17 years' service as a postman with an unblemished record?

A. A bsolu'ely. I think that that allegation is made in Woodhouse's case.

Q. No, it is Saunders' case also; he has r:ow served 17 years, and it is suggested that the only instance wherein he may have incurred the displeasure of those in authority was in 1895, 10 years ago, when one of the postmen was charged with coming off his delivery in a state of intoxication. The postman in question made a charge against the chief clerk of being intoxicated on several occasions. Saunders was sent for to give evidence in the case, and it was reported subsequently that he had been heard to make use of obscene language in the sorting office, and at that time he was fined three days' wages.

Q. And you say that that man has now received three good conduct stripes?

A. Yes.

Q. And can you reconcile it with your conscience that they should be given him after your statement?

A. I am very sorry to say I cannot.

Q. But they have been given him?

A. Yes, as from the 1st July, 1895.

Q. Do you think it was right that he should receive three good conduct stripes?

A. To use your words, sir, I cannot reconcile my conscience to it. (Laughter).

Q. And this case of hardship therefore resolves itself into one of great indulgence apparently?

A. Yes.

Q. Then we come to the case of A. E. Carter, of Norwich.

A. Yes. This is a case in which it was asserted that the stripe was arrested for a misdelivery of letters in 1891. I have inquired into the facts, and $\mathrm{I}$ find that this was not one case, but many cases of misdelivery. He was reported to be extremely careless, and that it was impossible to recommend him for a good conduct stripe. Recently, however, he has very much improved, and has been recommended for one, but I am sorry to say that his conduct since not having been altogether satisfactory, it is doubtful whether the recommendation can be approved. Since this evidence was given, and 
he seeing his name in print appears to have turned his head, and I under" stand that he has been flaunting before his inspector what this Committee will do for him. Now, the Committee will, of course, understand that the stronger the influence he has, or thinks he has, at his back, the more important it is to show that nothing but good conduct will secure good conduct stripes. I wish it to be impressed upon the Committee that accordingly this man's name has been struck off the list of recipients, at all events for the present.

At this stage Lord Tweedmouth returned and took up the examination of the witness.

Q. We come now to the case of a man named Jordan, at Torquay, which was put forward as a typical case of punishment for late attendance.

A. That case speaks for itself. The attendance was very irregular, indeed, and the man could not therefore be granted either the increment or the good conduct stripes, which are only given in the case of regular attendance.

Q. The witness goes on to say that this man's increment was arrested two years, and that when it was granted he received an increment of only 1s., whereas he was entitled, as he thought, to $2 \mathrm{~s}$.

A. The explanation of that is very simple. When the increment was arrested the man was only 1s. short of the maximum scale. (Laughter).

Q. Is there any general rule with regard to the number of late attendances allowed?

A. There is a rule, but I am not sure that it is a general rule. It probably varies slightly in different offices. There is an objection to laying down an absolute rule, because there may be many cases in which a man may have been 20 times very late in the year, and whose attendance therefore would certainly not be good, while there might be other cases in which a man might have been 25 times late, and yet, on the whole, have made a good attendance. The headquarters staff allow a certain latitude to local authorities in granting an allowance in this respect.

Mr. Walpole: Is it not a fact that the headquarters staff, while allowing absolute discretion to Postmasters in the matter, has suggested to them that 16 late attendances in the day-time, or 20 in the night-time should be regarded as prima facie the number which should operate to stop a man's increment?

A. Yes, that is so.

Q. And has that been embodied in a circular which has been issued?

A. Yes.

The Chairman : I suppose you also consider there is not only a differenco between one late attendance and another, but you also consider the circumstances under which a man is late?

A. Yes, we consider all the circumstances. One man may be a few minutes late, and may use all his exertions to recover the time, while another man may treat it as a matter of indifference.

Q. Then you unhesitatingly asscrt that generally in the Department great discrimination is observed in judging between the causes and nature of the various late attendances?

A. In exceptional cases, yés. Of course as a general rule, a late attendance is a late attendance, so it must be a very exceptional case in which an excuse is accepted.

Q. Then following on the same subject, we have here a case of a man named Briers, a postman of Loughborough, who was put on to do an excessive amount of punishment duty by having to take the work of a postman who was absent on sick leave.

A. I have inquired into that. The facts are these: On December 2nd, 1894, a postman was absent cn sick leave, and no substitute being available, Briers was called upon to work off the ext a duty he had incur ed through late attendance. It was a case of emergency, or he would not have been re. quired ta do so on a Sunday. Briers has been seen. He says that during 
his service of eight years he 'never had any other cause of complaint, he and cther postmen having always been treated with kindness and considera. tion.

Q. This does seem to be a very large set-off to a late attendance amounting to 40 minutes. Surely the man ought not to have been required to do three hours and fifteen minutes' extra duty as a set-off to late attendance amounting in the aggregate to 40 minutes.

A. Yes, it is very heavy, indeed.

Q. Have you any special remark to make on this subject?

A. If I were asked, I should say it was far too heavy. As regards the remark of the witness that the men had held a meeting, and been quite indignant about this punishment being meted out, I am afraid unless that is explained, it will give rise to some misapprehension. No special meeting of the postmen was held. He incidentally mentioned the case at an ordinary meeting of the local branch of the Postmen's Federation, and he adds, had he known that it was intended to bring it under the notice of this Committee or to take any action upon it, he would not have mentioned it at all.

The Chairman: I must, however, say in my opinion it is rather a notable instance?

A. Yes, it is a very notable instance. I think it is a very excessive punishment, and far more than ought to be imposed.

Q. Then, there is the case of W. E. Jones, postman, of Oldham, who had two stripes withdrawn on the charge of losing a registered packet.

A. Yes, that is so; he was deprived of two good conduct stripes for dropping a registered letter. Of course, to drop a registered letter is a very serious matter, but he would not have been deprived of his stripes for that alone. As a fact, he had only just before been punished (in May, 1893), for losing a post-card while on his rounds, when he was reported for losing a registered letter. There is not the slightest ground for saying this postman had no opportunity of explaining before the verdict was given.

Q. I suppose there is no question he did lose the parcel himself?

A. Yes.

Q. Apparently it was found in quite another direction to his walk, and it was brought in by another postman?

A. Yes, that might be so; he probably dropped it, and it was piclred up by somebody else, who handed it to the other postman. With regard to the statement that he was not heard before the verdict was given, I should like to say a few words. It is not the casu that he has had no opportunity of giving an explanation on paper. It would be a very serious thing to say it was the practice of the Department to punish a man without hearing him in his own defence. As a matter of fact, in this case an explanation was given on the 3rd August, and the verdict was not given until the 28th August, therefore I am afraid I must say that in this respect the witness was not accurate.

Q. Then the postman did have an opportunity of explaining?

A. Yes; I have the document here in my hand. As I say, he made an expianation on the 3rd August, and the decision was not given in his case until 25 days later.

Q. Now; there is a very extraordinary statement made here as to a Postmaster acting as a matrimonial agent. Would it be possible for him to do so?

A. I do not think so. Of course we interfere with liberty as little as possible, and wo have certainly a number of appointments which Posto masters are prohibited holding, on the ground that they are objectionable. I do not know that that of matrimonial agent is one of the appointments which is on contemplation when the rule was laid down.

Mr. Walpole: I do not think that the allegation in this case is that the Postmaster acted as a matrimonial agent. 
A. No, I think not. Still, I am afraid that there is a case of a Postmaster in the North who acted as a matrimonial agent to a very large extent indeed. He produced a book a short vime ago, in which he kept a register of 200 marriages which he had taken part in bringing about.

The Chairman: He appears to be, then, a kind of successor to the Gretna Green blicksmith. (Laughter.) Now, is it a fact that the men are kept waiting a long time for the award of their stripes?

A. Yes, I am afraid we have been very guilty in that matter. I do not think there has been so much expedition in regard to it as there might have been at headquarters.

Q. Is it the practice, as suggested by this witness, to keep a man waiting for"his stripe as a sort of indusement to good behaviour? I think the man said in his evidence that "It was held like a sword over their heads."

A. No, I exclude that from my statement. A man cannot have a good conduct stripe until he has deserved it, and when he has earned it, then he is recommended for it. It certainly is kept as a sword hanging over his head until it has been earned.

Q. But after the stripe has been absolutely earned, is it then withheld for a certain time and not recommended, the Postmaster saying, "I do not think your conduct altogether satisfactory, but if you are good, then in six months I will recommend you for the stripe"?

A. The man must first establish a character for good conduct before he can be reported as entitled to the stripe, but as soon as he has established that character, then he ought to have it at once.

Mr. Walpole: But it must be a character for five continuous years?

A. 'That is the rule, but it is not rigidly insisted upon. I could instance many cases in which the full period of five years has not been insisted upon.

The Chairman: Then we come to the case of a man named Nevins, a postman at Gateshead. In this case the complaint is raised that it is not fair to punish a man for misconduct unless you give him the name of the witness upon whose testimony he has been adjudged guilty. I do not think there is any dispute in this case as to the guilt.

A. No; he was rolling about in the principal thoroughfare (Low Fell) at a quarter-past three in the afternoon in a state of intoxication, and he was then in uniform.

Q. I do not think that the justice of the action taken in the case was disputed.

A. Then I do not think that the giving of the name would be material when the facts are not disputed. Undoubtedly, it was a very serious offence.

Mr. Walpole: I believe that some very sensible postman when the "itness was dealing with this case, made the remark, "You are standing up too much for the boozers." (Laughter.)

A. Yes. And I am afraid I have had that charge made against myself. (Renewed laughter.)

Q. Nevins seems to consider that he was unfairly dealt with. But is it not a fact that he behaved most disgracefully?

A. Certainly; he was in uniform, and he was rolling along the thorough. fare in the afternoon in a state of intoxication.

The Chairman: Apart from that case, there also seems to have been a complaint that the Department receives complaints about men from outside, and that everything so told them is taken as gospel, while anything that the man may bring forward to repudiate the charge the Department looks upon askance.

A. There is only one word which will really express my feelings about that complaint, and that is "Rubbish!"

Q. The next case brought forward was that of a man named Etheridge, who was deprived of his stripes for an offence committed while he was away on leave? 
A. We cannot find any record as to this case, but at the same time, I seem to have a recollection of it. I will, however, take the facts as stated. If it is the case I am thinking of, the deprivation of the stripe was the act of the headquarters, and was not the act of the local authorities, who did not recommend that the man should not have his stripes taken away. If I remember aright he created a perfect scandal, and it was thought right that a man who had conducted himself in the way he did, should not wear a. good conduct stripe.

Mr. Walpole: The man was actually taken before a magistrate, was he not?

A. Yes, he was.

Q. Don't you think that under no circumstances whatever a man ought to receive a good conduct stripe for five years after he had so acted?

A. Yes, I think so.

Q. A point is made in comparing the punishment meted out to sorting clerks for their delinquencies, and those imposed upon postmen? The latter are looked upon as far too heavy, while it is suggested that the sorting clerks are dealt with comparatively ightly for an offence which would be heavily visited upon a postman. What have you to say with regard to that?

A. There is no ground whatever for the suggestion. I quite admit that it may to the postmen seem to be somewhat unjust, and for this reason: that in their case the punishment is more apparent. If you take the case of a sorting clerk, for instance, the ordinary punishment would be a suspension of pay, or a reduction of class, but if you come to the postman, there is no higher class to which he can succed. He has good conduct stripes under certain conditions, but he may fail to earn these, and if for intoxication they are suspended, and he loses his increment as well, of course he feels the punishment immediately. The loss to the sorting clerk is more in the form of loss of promotion in the future, and therefore the punishment is more immediately apparent in one case than in the otlser.

Q. In support of the argument the witness put forward on this ground, lie compared the cases of a sorting clerk named Freeling, and a postman named Webster. Can you give us any information on that?

A. Yes, I should like to make an explanation in regard to that. In the case of Webster, the punishment hardly seems to have erred on the side of severity. At any rate, from the Post Office point of view the wilful delay of a letter is a very serious offence, and one for which the law has provided heavy penalties. And not only this, but the case was a peculiarly bad one. In order to save themselves trouble Webster and another postman concerted together to deliver one another's letters, and when found out concocted an artfully-contrived tale in order to escape punishment. Thus far both men were equally to blame, but Webster, besides being older than the other one, was the more guilty in this:-1st, that the letters which he gave to his comrade to deliver he had delayed from a previous delivery, and 2nd, that the letters which he received from his comrade, and had undertaken to deliver, he did not deliver, but took back to the post office, and surreptitiously inserted among others waiting delivery. But he was not dismissed on that account. In 1884 and 1885 his increment was arrested for unsatisfactory conduct and irregular attendance. In 1886 he was reported for intoxication, and the same may be said of this offence on the part of a postman as of a wilful delay of letters. His conduct, however, improved. On February, 1891, he received his first stripe, in October, 1891, his second, and in June, 1892, his third. He seems, therefore, to have been treated with great leniency rather than with harshness.

Q. I do not think the allegation is that Webster was too lightly punished.

A. I thought it was put forward as a case of hardship.

A. No; a comparison was drawn between the offences of which Webster was guilty and the punishment he received for them, and the offences of 
which Freeling was guilty and the punishment he received, and it was suggested that, admitting both to be guilty, the punishment received by the sorting clerk was much lighter than that received by the postman.

A. Yes; that is so. It is a pleasure to me to be able to add that Webster's conduct since has greatly improved, and I think he has now got his good conduct stripes back.

Q. Has he all three now?

A. Yes. There is one other point I should like to mention before I leave the case. It is obvious that this occurred many years ago, for the date is given as November, 1890.

Q. I do not take it that it is a complaint qua the treatment of Webster; it is only given as a comparison of the treatment accorded to the two classes?

A. Well, with regard to the case of Freeling, I should like to say there is no evidence of wilful misconduct. On the contrary, the mistakes are just such as might be expected from a young beginner. One hour's extra duty is the usual punishment, and it appears to have been imposed with persistent regularity. He has not been promoted. He is still on the class in which he stood when he entered the Liverpool Post Office. It is probable that in withdrawing him from the sorting office and employing him in turn with other junior clerks on writing duties, the late Postmaster wished to give him an opportunity of gaining experience which would be useful in an examination he was about to undergo.

Q. You treat Freeling's conduct as of a very much lighter character than that of the postman?

A. No doubt. In his case there was no misconduct stated. His offence was simply a mistake-serious mistakes, no doubt-but they were punished in the way that all such mistakes are punished, by imposing hours of extra duty.

Q. Is there anything else you wish to say on the question of punishment?

A. No, I think not. There was one case brought forward, that of a man named Dain. In that it is made to appear that he. was deprived of one of three good conduct stripes for bringing out a sharp expression when he stumbled on the staircase. No doubt he did use a sharp expression. The report in his case is that he was said to be the worse for drink, and that he used very objectionable language, and as we do not know the exact words, I will accept the "sharp" expression he admits having used. That was not the only offence. He should have reached the house at which he had to make the delivery at 2.30 , but he did not reach it until 3.50 , leaving it to conjecture where he had been in the meantime. Even that is not all, for on the following day he was again reported under the influence of drink, and unfit to make the 1.30 delivery. That is the explanation of this case.

The Chairman: Thank you. I think that is all we have to ask you.

The witness then withdrew. 


\section{Mr. E. B LEWIN HILL.}

Controller of the Provincial Staff, was next re-called for the purpose of supplementing the evidence which he gave before the Committee.

The Chairman: You have one or two words to say with regard to the Aberayron case, which was brought before us by one of the witnesses?

A. Yes.

Q. Is it not a fact that this case was purely as a hypothetical case; that it was not stated by the witness that it was an actual one, but that it was put forward as a case that might occur?

A. I did not understand that.

Q. I think Mr. Walpole said to the witness: "Do you know this case of your own knowledge?" And the witness replied, "I put it forward as a hypothetical case"; and then I asked him "if there was a postman at the present time anywhere doing 48 hours a week for a wage of 7s. ?" To that he replied, "it was stated that was the case in Ireland, and therefore it might occur in other parts of the country." I then asked him, "Do you believe there is a postman in this country doing it?" and he replied, "I do not. I put it as a hypothetical case. But I have been informed that it has occurred in Ireland.

Witness: Perhaps it is not worth while going into the matter now.

The Chairman: We had better hear what you have to say, as you have inquired into it.

A. Well, it was stated that a postman at Aberayron, father of five children, gets 7s. per week for 48 hours' hard work, and that a telegraphist at the same place gets $40 \mathrm{~s}$. for 48 hours' work. I do not believe it is a fact; such a case is certainly not known in the Secretary's office. Inquiry made on the above matter at Aberayron shows: (1) That there is no postman there working 48 hours a week, or receiving wages of $7 \mathrm{~s}$. a week; (2) that the only married man employed is John Williams, rural auxiliary, from Aberayron to Llanarth ; and (3) that there is no "telegraphist" there at all, but merely an assistant for postal and telegraphic work (Miss Powell) who is paid 15s., not 40s. a week. John Williams is 33 years of age; he has five children, and has been employed as rural auxiliary from Aberayron to Llanarth with wages of $10 \mathrm{~s}$. a week since the 3rd September, 1893. His duties occupy from 10.40 a.m. to 2.30 p.m. (3 hours 50 minutes) daily, except Sunday, when he performs no duty at all, and a copy of the form (surveyor's, No. 83) signed by him at the time of his first employment is enclosed. Williams is a shoemaker by trade, and until three years ago was a sergeant in the county militia; he has had no other Post Office duties than those described above, and it has been ascertained that he actually receives the wages of 10s. a week. Another point I wish to touch upon is the evidence of Mr. J. F. Ray, second-class sorter in the newspaper branch. He said:- "I cannot remember that any gentleman from the newspaper section was asked to give evidence before the Committee as regards the value of his work. I never heard it mooted that any gentleman was called upon to give evidence upon that." Now, "The Post," which is the organ of the Fawcett Association, in the number for 24th May, 1890, speaking of the proceedings of the Committee in question, made the following statement: - "Everyone will remember how courteously and patiently the Departmental Committee under Mr. Lewin Hill's presidency allowed members of the sorting staff to describe exhaustively the quality of the work in their respective branches, and the classification which in their opinion would fairly remunerate the officers engaged in its performance." As a matter of fact, four sorters in the newspaper branch gave evidence before that Committee.

The Chairman: I think you have some comparison to make as to the present position of the staff, and what it was before the Fawcett revision, taken from the last report on the Post Office? 
A. Yes. I wish to direct the attention of the Committee to the last report of the Postmaster-General (for the year 1895), pages 5 to 13 . That gives the staff of the Department divided into sorters, telegraphists, and postmen, and there is also a tabular statement showing what has been expended since the year 1880 in improving the pay and position of the several branches of the manipulative staff. The statement shows as follows :- -

"The total expenditure thus incurred was stated to have been nearly $£ 750,000$.

"But this merely represents the increase of expenditure on the members of the staff at the times of each of the several revisions, and therefore much understates the increased expenditure now being incurred.

"Thus, Mr. Fawcett's revisions of 1881 appear in the statement in the Annual Report as costing-

$$
\begin{aligned}
& \text { For indoor staff, - } \quad \text { - } \quad \text { - } \quad \text { - } \quad \text { - } £ 210,000 \\
& \text { For outdoor staff, - - - _ - } \quad \text { - } 110,000 \\
& \text { Total, - - - - } £ 320,000
\end{aligned}
$$

"On the present numbers these revisions are now probably costing-

$$
\begin{aligned}
& \text { For indoor staff, - } \quad \text { - } \quad \text { - } \quad \text { - } \quad \text { - } £ 440,000 \\
& \text { For outdoor staff, - - - - - - 203,000 } \\
& £ 643,000
\end{aligned}
$$

“Again, Mr. Raikes' revisions of $1890-91$ are stated to have cost-

$$
\begin{aligned}
& \text { For indoor staff, - } \quad \text { - } \quad \text { - } \quad \text { - } \quad \text { - } \$ 265,000 \\
& \text { For outdoor staff, - } \quad \text { - } \quad \text { - } \quad \text { - } \quad \text { - } 126,000 \\
& £ 391,000
\end{aligned}
$$

"On the present numbers these revisions are now probably costing-

$$
\begin{aligned}
& \text { For indoor staff, - - - - - } \quad \text { - } £ 356,000 \\
& \text { For outdoor staff, - - - - } \quad \text { - } 156,000 \\
& £ 512,000
\end{aligned}
$$

"The result is that the two general revisions of Mr. Fawcett in 1881-2, and of Mr. Raikes in 1890-1, together with the smaller revisions shown on page 9 of the Postmaster-General's report, are probably costing at the present time about $£ 1,200,000$ a year, and not about $£ 750,000$ a year."

Mr. Smith: Can you tell us what is the total of the wage bill of the Department?

A. I cannot.

The Chairinan: Have you calculated what the increased profit to the Department has been? (Laughter.)

A. No; but I know that our profits have been going down. There is one other point on which I wish to make a statement. On the second day of my evidence I handed in a computation of what would be the cost of certain changes in the scales of pay, and it was based on the assumption that the average service in the postmen's class was 20 years. I stated at the time that it was pure assumption on my part that that was the average. Since then we have taken various measures in order to arrive at an opinion as to what is the average duration of the service of men on the postmen's staff, and I have here a return which is confined to the E.C. District, which 
dates back as far as 1870. This I propose to put in. Appended is the return :-

\section{POSTMEN, E.C. DISTRICT, LONDON.}

On the 1st January, 1870, there were 316 postmen in the E.C. District of London. On the 1st January, 1896, only 56 of these were still on the postmen's class.

The remaining 260 had left the class for the reasons given below :-

131 had retired on pension or gratuity.

43 had died.

53 had resigned or been dismissed.

33 had been promoted or transferred.

The average service of these men as postmen was as follows:-

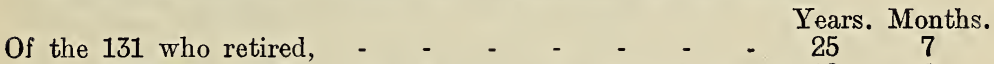
, 43 who died.
", 53 who resigned or were dismissed, -
," 33 who were promoted or transferred,-

$\begin{array}{rrr}- & 19 & 4 \\ - & 8 & 7 \\ - & 19 & 0\end{array}$

The average service for the whole of the 250 postmen who have left the Service was 20 years 3 months.

The average service at the present time of the 36 postmen who are still on the class is 30 years, and it is probable that they will remain for 5 years 5 months more, thus raising the average to 35 years 5 months.

If we then include these 56 men with the 260 who have left the Service, we find that the average length of service of the postmen is 22 years 11 months.

Of the 53 postmen who are entered as having resigned or been dismissed, it is found that 30 were dismissed, 18 resigned to escape dismissal, and 5 resigned, presumably to better their position.

I am having similar returns from the provinces, but they are not quite ready. I think, however, that when they are worked out it will be found that the average service is about 20 years.

The Chairman: This concludes the evidence for the day. We will meet again on Monday next at the Westminster Palace Hotel, there not now being any room in the House of Lords available for this Committee.

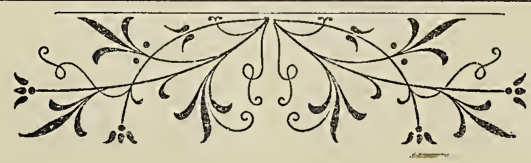




\section{REJOINDER LODGED WITH THE COMMITTEE ON BEHALF OF LONDON POSTMEN.}

To the Right Hon. LoRD Tweedmouth,

London, May 27th, 1896.

Chairman of the Committee on Post Office Establishments.

My Lord and Gentlemen of the Committee,-

We beg to submit for your consideration the following rejoinder to the Departmental evidence, but before doing so desire to tender you our heartiest thanks for the courteous and patient hearing accorded to us as representatives of postmen of the United Kingdom.

In dealing with the London questions first,

\section{WAGES.}

We note with great pleasure the suggestion by our Controller that we should be placed on an equal footing with the second-class sorters, and whilst we in every way appreciate the value of Mr. Badcock's statements, we are astounded and grieved that another Departmental witness, Mr. Lewin Hill, should, in presumably rebutting the evidence of the provincial postmen, go out of his way to belittle and minimise the claims of the London men by unfair comparison with Carter Paterson's carriers and railway porters. We endeavoured in our evidence to draw as few comparisons outside the Service as possible, feeling assured that having a class in the Service so nearly approaching our own-viz., the sorters-that to go cutside was both needless and unnecessary. We confidently hope that your C.mmittee, in its decision, will be guided more by a desire to see contentment in a Service where the "market value" policy has so long been tried, and, as we have endeavoured to prove, given rise to the greater portion of the abuses and anomalies that are still in existence.

\section{HOLIDAYS.}

We notice that the question of three weeks' holidays was not dealt with in the rebutting evidence submitted, and we eamestly hope that the omission of this important question signifies that postmen will be granted the same amount of leave of absence as is enjoyed by second-class sorters, telegraphists, messengers, and other bodies employed on less arduous duties.

\section{PROMOTION.}

In regard to this question we would say that, although no definite promise was forthcoming as to the ratio of promotions to the postmen's staff, we are still of the opinion that postmen should be entitled, with the sorting staff, to an equal proportion of the higher appointments.

\section{STATEMEN'T BY J. P. WORTH.}

With reference to this case, which was stated in the rebutting evidence to be "shifty, unreliable, and careless," we subjoin herewith Mr. Worth's statement in self-defence :-

"In answer to the first charge, I must say it is of no real substance, as I have always continued on a steady course.

"To the charge that I am unreliable: when I first received instructions to perform the duties of head postman at New Cross I had to do so under great difficulties, as the instructions were of a vague character. Moreover, I can furnish proofs that I am reliable. I would say that I worked the duty three years continuously, on one occasion during that period going through the Christmas pressure satisfactorily. "(Signed)-J. P. Worth."

\section{SUPERNUMERARIES.}

We would still iunpress upon you the loss of seniority of this class, and beg to bring under your notice the following order issued by the Secretary of the Post Office since our witness gave evidence:-

"The Secretary has decided in Reg. papers 118396/96 that supernumeraries 
blocking vacancies on the classes of sorters, postmen, and porters, shall be allowed to rank as regards choice of duties and annual leave after the men already appointed and before the new entrants on the classes to which they are attached. There will be no separate annual leave list for supernumeraries in future."-Dated 14th April, 1896.

We beg to point out that this Order in no wise touches the point raisedviz., that this class have in the past taken their seniority with established men by date of service, but in some cases this has been altered, and junior men have been placed on the sheet before them. We trust you will give this your favourabile consideration.

\section{AUXILIARIES.}

We note with satisfaction the admission by our Controller that men of this class transferred to the establishment should receive a higher minimum than at present in vogue, and we still assert that in no case should it be less than 24s. per week.

With regard to the pay of the Hackney men, we maintain that they do not receive the Raikes' scale of pay. Mr. Raikes' scheme makes no mention of the terms "isolated" or "continuous," but simply states that "no collection shall be paid for at less than sixpence." In proof that our construction of the scheme is the correct one, these men received the sixpence for each of these collections for three years after the promulgation of the Raikes' scale, and it was not until after the revision of the duties at Hackney Office that the present rate was brought into vogue. Again, with regard to $\mathrm{Mr}$. Badcock's statement "that no interval of less than half-an-hour is booked off"; this is inconsistent, as no interval of more than 15 minutes occurs between any of these continuous collections.

With regard to auxiliaries being called upon to perform duties in their spare time, whether convenient to them or not, it was never intended to convey the impression that orders to that effect were issued from the Chief Office, but that the superintending officers at the several zone offices put this construction upon them according to their own whims, and as these orders are never exhibited to the men they are unable to contradict them. As a further proof of this system, at Holloway Office on Boxing Day morning, 1895, there was a large influx of parcels for delivery, and the overseer (Mr. Glover) called for six volunteers to come back and deliver them; at first none would do so, but after some persuasion two men promised to return; finding no others would volunteer, he (the overseer) cut up a number of pieces of paper corresponding to the number of auxiliary postmen on duty, on four of which he wrote the word "on," and compelled the auxiliaries to draw lots, and those who drew the word "on" had to return and take out the parcels, upon threat of not being allowed to resume duty on the next day if they failed to return for the delivery of the parcels ; the names of the four auxiliaries who had to return were, Trew, Low, Fauliless, and Weller-notwithstanding the fact that it was Bank Holiday; and we would emphasise the fact that not a single established man was called upon to take part in this lottery.

In asking for the absorption of the auxiliary class into the ranks of the established class, it was suggested that this would be brought about by the assimilation of postal facilities (in the way of deliveries and collections) over the whole of London to that prevalent in the city at the present time, and not to only one district as implied by Mr. Badcock's reply.

\section{EXEMPTION FROM PARCEL DUTIES.}

We regret that this question was dealt with as a personal grievance, instead of as a general one. We think that the system of taking averages is unfair and misleading, as it is only upon the heaviest walks and during the heavy season that the grievance exists, more especially in the offices in the various zones. 


\section{MINIMUM RATE OF PAY.}

We find that the Department are still introducing casual labour at a lower rate than 6d. per hour. 'Three telegraph boys-A. Woolnough, High Street D. ; C. M. Mason, Rochester Road C. ; and H. A. Ellner, Regent's Park Road D., in the North-Western District-are at the present time performing established men's duties of eight hours daily for 9s. and 10s. per week. Auxiliaries are being asked to do established men's duties for a fixed wage of 18s. per week. At Earl's Court, two established men have been withdrawn from their regular duties to do the Exhibition work, while an auxiliary and a "casual" were requested, and consented, to do eight hour's work per day for 18s. per week. This we consider a clear breach of the Raikes' scheme, that nothing less than 6d. per hour should be the minimum rate of pay for unestablished labour.

\section{STRIPES.}

With regard to the statements of the official witnesses, that the delay in issuing stripes was solely due to local authorities not making application for the same, we find in the City there are about 30 men who are overdue for stripes, some of whom have been waiting 12 months and over.

\section{EXCESSIVE PUNISHMENT.}

We attach herewith the official records of Messrs. J. Chapınan and W. Howe, who were deprived of their appointments because they were members of the Postmen's Union :-

RECORD OF J. CHAPMAN.

\begin{tabular}{|c|c|c|}
\hline Date of Report. & $\begin{array}{l}\text { Subject and Registered Number } \\
\text { of Report. }\end{array}$ & Result. \\
\hline 5th July, 1887. & $\begin{array}{l}\text { Absent from duty without } \\
\text { leave, leaving his } 4-0 \text { p.m. } \\
\text { delivery unprovided for. }\end{array}$ & $\begin{array}{l}\text { Reprimanded and } \\
\text { cautioned. }\end{array}$ \\
\hline 24th Sept., 1887. & $\begin{array}{l}\text { Packed a parcel containing } \\
\text { eggs in a leaking condi- } \\
\text { tion for Shepherd's Bush, } \\
\text { whereby a parcel contain- } \\
\text { ing a dress was damaged. }\end{array}$ & Do. \\
\hline Transferred & from Paddington District to & West District \\
\hline on & promotion to 2 nd class Post & $\operatorname{man}$. \\
\hline 26th June, 1890. & $\begin{array}{l}\text { Neglect of Rule } 9 \text { of Instruc- } \\
\text { tions to Postmen. }\end{array}$ & Cautioned. \\
\hline $\begin{array}{l}\text { 27th July, } 1891 . \\
\text { 3rd Mar., } 1893 .\end{array}$ & $\begin{array}{l}\text { Date of Punishment. } \\
\text { Neglect of Rule } 9 \text { of Instruc- } \\
\text { tions to Postmen. }\end{array}$ & Do. \\
\hline 7th July, 1894. & $\begin{array}{l}\text { Misdelivered a letter ad- } \\
\text { dressed } 13 \text { Beaumont St } \\
\text { at } 64 \text { High Street. }\end{array}$ & Do. \\
\hline 27th July, 1894. & $\begin{array}{l}\text { Unpunctual attendance dur- } \\
\text { ing Increment year. }\end{array}$ & $\begin{array}{l}\text { Increment deferred } \\
\text { three months. }\end{array}$ \\
\hline 29th Oct., 1894. & $\begin{array}{l}\text { Improved attendance dur- } \\
\text { ing past three months. } \\
(383259) \text {. }\end{array}$ & $\begin{array}{l}\text { Increment due } 23 \mathrm{rd} \\
\text { July allowed. }\end{array}$ \\
\hline Transferred to & Paddington and re-transferred & to West District. \\
\hline 25th April, 1895. & $\begin{array}{l}\text { Misdelivered a letter at } 2 \\
\text { Adam Street. } \\
(134357) .\end{array}$ & Cautioned. \\
\hline 2nd sept., 1895. & $\begin{array}{l}\text { Non-compliance with last } \\
\text { paragraph of Rule } 9 \text { In- } \\
\text { structions to Postmen. }\end{array}$ & Do. \\
\hline
\end{tabular}

(Signed) H. H. Salmon, District Postmaster. Dated 26th March, 1896. 


\section{RECORD OF W. HOWE.}

\begin{tabular}{|c|c|c|}
\hline Date of Report. & $\begin{array}{l}\text { Subject and Registered Number } \\
\text { of Report. }\end{array}$ & Result. \\
\hline 23r Nuv., 1887. & $\begin{array}{l}\text { Erroneously treating as un- } \\
\text { deliverable a letter ad- } \\
\text { dressed "Lather," } 2 \text { and } \\
3 \text { Regent Place. } \\
\text { The letter was plainly ad- } \\
\text { dressed. }\end{array}$ & $\begin{array}{l}\text { Seen and seriously } \\
\text { cautioned. }\end{array}$ \\
\hline $\begin{array}{l}27 \text { th } J u^{7} y, 1891, \\
\text { 28th Dec }, 1893 .\end{array}$ & $\begin{array}{l}\text { Date of Punishment. } \\
\text { Mistelivered two letters at } \\
\text { 11 Hanover Square, W., } \\
\text { although plainly addressed }\end{array}$ & $\begin{array}{l}\text { Seriously cautioned } \\
\text { and warn } \mathrm{d} \text {. }\end{array}$ \\
\hline 9th Jan., is94. & $\begin{array}{l}11 \text { Hanover Square, Leeds. } \\
\text { Misdelivered letter addressed } \\
\text { Robertson \& Hart, (24) } \\
\text { Princes Street, Hanover } \\
\text { Square; at Robinson and } \\
\text { Green s, 9 Princes Street. } \\
(3535) \text {. }\end{array}$ & Cautioned. \\
\hline $\begin{array}{l}\text { 23rd June, } 1594 . \\
\text { 2nd Oct., } 1894 .\end{array}$ & $\begin{array}{l}\text { Do. do. (214884). } \\
\text { Delivered a letter for Messrs. } \\
\text { Geo. Roge s \& Eons, } 60 \\
\text { Berners itreet (Callers), } \\
\text { at the address instead } \\
\text { sorting to Callers Division. }\end{array}$ & $\begin{array}{l}\text { Do. } \\
\text { Do. }\end{array}$ \\
\hline 10th April, 1895. & $\begin{array}{l}\text { Placing a newspaper ia } \\
\text { letter box at } 56 \text { Berners } \\
\text { Street contrary to in- } \\
\text { structions given. }\end{array}$ & $\begin{array}{l}\text { Seriously cau- } \\
\text { tioned. }\end{array}$ \\
\hline 13th April, 1895. & $\begin{array}{l}\text { Placing a newspaper in } \\
\text { letter box at } 56 \text { Berners } \\
\text { Street instead of taking } \\
\text { to the office on first floor } \\
\text { as instructed. }\end{array}$ & $\begin{array}{l}\text { Two hours' extra } \\
\text { duty, and cau- } \\
\text { tioned. }\end{array}$ \\
\hline 19th Sept., 1895. & $\begin{array}{l}\text { Misdelivering letter instead } \\
\text { of endorsing it "Gone } \\
\text { away." (323280). }\end{array}$ & Cautioned. \\
\hline
\end{tabular}

\section{LATE ATTENDANCE.}

We view with regret that the rule laid down by Mr. Walpole, that 16 was the limit of late attendances, has not been brought into operation.

Trusting that these matters will have the careful attention of your Lordship's Committee. On behalf of the Postmen's Federation, I am,

Your obedient servant,

C. Churchrield, General Secretary. 
THE PROVINCIAL REJOINDER.

\author{
Letter-Carriers' Branch, Post Office, \\ Glasgow, June, 1896.
}

To the Fight Hon LoRD TweenmourH, Chairman,

Committee on Post Office Establishments.

Mx Lord,-After the courteous and patient hearing accorded to the witresses of the Postmen's Federation, it would be improper on my part to seek, without weighty reasons, to again engage the attention of ycur Committee. But some points have since been introduced in the Rebutting Evidence which call for further comment-particularly further comment and explanation from the postmen's point of view. To that end, therefore, this statement is principally prepared; and it will be my endeavour rather to clear up points already occurring in the Evidence than to introduce fresh matter.

Q. 11,642.-The Basis on which Postmen's Rate of Pay is Fixed.

Mr. Hill says that the various scales are based according to the value of labour in the several towns. In this connection a Limerick correspondent writes me as follows:-

"Here, in Limerick, labour is dearer than in any city in Ireland, both in the stores and at the docks, and $M r$. Hill adimitted this fact himself when on tour a few years ago. He was then so incredulous as to the statements we submitted to him, that he actually visited the stores himself, and found that we even under-estimated the wages rather than otherwise, and yet he could not see his way to pay the postmen of Limerick according to the market value of labour in Limerick."

In reference to the same question (No. 11,642), a Torquay correspondent writes as follows :-

"Some years ago Plymouth, Exeter, Devonport, and Torquay were on equal scale of wages. On petition, Plymouth, Exeter, and Devonport got increased maximum by $2 \mathrm{~s}$. But before Torquay had any definite reply the general rise of the Raikes' Revision took place. We were still 2s. behind our sister towns, for which no explanation was given. We have petitioned sereral times. We first showed the Department that the cost of living in Torquay is higher than any town in the West. After a good deal of correspondence on the subject, we were informed by the Postmaster-General, then Sir James Fergusson, that he admitted our arguments were correct, but if he gave it to Torquay he would have to give it to Bournemouth and other towns. We pointed out that that was not the point; if we were entitled to it we should have it. Then came the General Election and the accession of Mr. Arnold Morley to power; and one of his first acts was to grant Bournemouth and many other towns 26s. maximum. We took the opportunity of pointing this out, and stated that the same argument stood, viz., that if he gave it to Bournemouth, etc., he must accordingly give it to Torquay. To this we received the reply that Bournemouth and other towns had nothing to do with the case."

A Southport correspondent also writes :-

"Mr. Hill stated that when regulating the different scales of pay, the value of labour and cost of living was taken into consideration. On the authurity of Councillor 'Threllfall, J.P., late President of the Trades' Council, I beg to state that all trades are paid from $\frac{1}{2} \mathrm{~d}$. to 1d. more in Southport than in most towns, owing to the cost of living and high rents. The house 
occupied by myself, a very small one-2 rooms up and 2 rooms downamounts to, rent and rates combined, $7 \mathrm{~s}$. 3d. per week. As an instance of marked unfairness in the regulation of pay, I may quote Waterloo (a suboffice of Liverpool) in the same Parliamentary Division as Southport, with an estimated population of 11,000 , and with a complement of about 12 men, rents 20 to 25 per cent. lower, living 15 lower-with all these advantages the wages are $4 \mathrm{~s}$. per week more than at Southport, with an estimated population in the postal district of between 50,000 and 60,000, and, being a fashionable watering-place, is visited annually by thousands of visitors. Again, in all fairness, where does the consideration come in? Some months ago a petition was sent in, giving all these and other particulars, when the usual unfavourable reply was received, and it was stated that, 'No difficulty is experienced in obtaining suitable men at Southport as postmen for this remuneration, which is that given at other places of similar size and character, and compares not unfavourably with that of the police; and I regret therefore, that I am unable to sanction an increase of pay for these postmen.' We take it that Southport is a suburb of Manchester and Liverpool, hundreds of gentlemen living here who have their business in one or other of these towns. The auxiliaries are also paid on a very low rate at Southport, taking into consideration the above points, their pay averaging about 4d. per hour week days. Sundays, their duties consist of doubled walks-this is, two of the ordinary morning walks thrown into one, the time occupied being from $3 \frac{1}{2}$ to 4 hours every Sunday. They are paid 1s. 6d. every alternate Sunday. Their ordinary pay, $4 d$. per hour, is less than that paid to the commonest labourer, viz., 6d. and $6 \frac{1}{2} \mathrm{~d}$. per hour."

\section{Q. 11,658.-Junior Postmen.}

"Mr. Hill said "that nobody in this class (junior postmen) is supposed to do a full day's work."

In Leeds, until recently, the junior postmen were performing full-time duties of eight hours a day. This, however, is now admitted to have been a mistake on the part of the authorities, and that the full-time has been wrongly imposed on the Leeds junior postmen.

\section{Q. 11,696.-Wages Comparison with Railway Services.}

The case of the railway parcel porter is interesting evidence, as showing by concrete example what is a notorious fact, namely, that the railway companies are amongst the worst sweating concerns in the country. Had Mr. Hill pursued his inquiries further, he would also have discovered that the marked contrast is not confined to manipulative workers.

In the governing positions of almost any big railway company will be found experienced officers doing work for $£ 120$ and $£ 150$ a year which is analogous in character to that for which the Post Office pays $£ 250$ and $£ 300$ a year. If this law of supply and demand be a just one for fixing the rate of pay for postmen, it ought to be uniformly applied to the higher officials as well.

Decidedly interesting results would doubtless be obtained from a general application of the market value test to the higher posts in the Servicesay all above $\$ 300$ a year. Were the Department to go to the open market to fill up these posts, it is my firm conviction that there would be no great difficulty in obtaining men of good business training and a fair amount of administrative ability who would undertake the work for less than the present salaries. But I doubt if such a course would, in the long run, be a public benefit, although it might please cheese paring economists.

a public benefit, although it might please cheeseparing economists.

Q. 11,707, 11,713, 11,715.-The Inadequacy of the Commencing Wages.

Ever since the established postmen's initial wages were reduced from 18s. to $17 \mathrm{~s}$. a week, this question has given rise to a great deal of discontent. 
The ordinary channel for redress of grievances has been tried and found wanting. However, I note with satisfaction that Mr. Hill now admits the present commencing wage to be inadequate.

\section{Q. 11,726, etc.-Allowances in Lieu of Christmas Boxes.}

Mr. Hill mentioned that one-fourth or one-fifth of the men in the town postmen's class are in receipt of allowances in lieu of Christmas boxes. The Committee are liable to infer that the whole of the postmen who don't share in the Christmas boxes are thus provided for. (See answer to question 11,727.) Such, however, is not the case. In Glasgow, for example, there are upwards of 80 established postmen's duties which yield no Christmas boxes.

I refer to Parcel Post and collection duties, etc.

\section{Q. 11,736-7.-Christmas boxes.}

Mr. Hill admits that the Christmas boxes have been taken into consideration in fixing postmen's wages, and consequently postmen's wages are lower than they ought to be.

He also admits that some compensation should be given in the event of their abolition, but he is not prepared to give an equivalent to the wages, because an increased rate of wages would also carry with it increased rato for overtime and pension.

There is some inconsistency in this attitude.

\section{Q. 11,772-3-4.-Comparison with Police.}

As the duties of postmen and policemen are not at all analogous, we cannot admit the aptness of the comparison which Mr. Hill seeks to institute. In our view of the case a much fairer comparison would be with other manipulative branches of the Post Office Service, and particularly with the sorting clerks, whose duty, like that of the postmen, consists chiefly of the manipulation of letters. But even the comparison with the police fails when applied to large and small towns alike.

A Stafford correspondent writes me as follows:-

"Mr. Hill, in taking the average yearly wage of postmen and policemen, has taken the nine largest towns, and drawn the comparison therefrom. Had he included the smaller towns the result would have shown a very different aspect."

Several other correspondents write to the same effect.

Q. 11,775, etc.-Comparison with Police.

A Southport correspondent writes :-

"On various occasions during the giving of evidence, Mr. Lewin Hill mentioned the pay of the police, and stated that the postmen compared very favourably with them. As far as Southport is concerned, we must deny that such is the case. We have here 50 policemen, whose wages commence at 27s. 6d. per week and rise in five years to $32 \mathrm{~s}$. per week. There are also 6 sergeants rising to 38s. per week, also 5 inspectors rising to 50 s. per week, so that not only are they much better off as regards pay, but also as regards promotion, there being 11 higher appointments amongst fifty men. They have also far brighter prospects as regards pensions. They are pensioned after 25 years' service with two-thirds pay. During the last 12 months there have been five officers, inspectors, and others, who were pensioned at this rate. Also, as regards annual leave, we deny that we are as well off as the above. They are allowed seven days' annual leave, and also one day every fortnight. They also work the eight hours within the twelve, day duty. Night duty the eight hours is worked without a break, except for refreshments. 
"And now about the favourable comparison of the postman. We have at Southport 75 postmen whose pay commences at $17 \mathrm{~s}$. per week, rising by $1 \mathrm{~s}$. to $26 \mathrm{~s}$. Of course, there is the Sunday pay, which, for a new entrant, may amount to $1 \mathrm{~s}$. per week; therefore, it is clearly seen that the policeman for his first year's services has about $£ 26$ more than the postman. He also advances at a corresponding rate during his first five years' service, until the maximum is reached, after which, of course, the amount he receives more than the postman is less every year until the postman reaches his maximum.

"As regards promotion, we liave two higher appointments amongst 75 men, one of which-the assistant-inspector-is scarcely worth competing for. The next point is pensions. The only postman pensioned at southport is John Morris, who, after 17 year's' service, was pensioned at 4s. 6d. per week. Part of each year is spent by this pensioned Government servant in Ormskirk Workhouse. In these circumstances we cannot admit that a favourable comparison has been established.

"The following is on the question of deferred pay-another advantage the policemen have over the postmen. Some years ago a policeman died at Southport after about ten years' service, leaving a widow and family; some short time afterwards the widow received the deferred pay, amounting to between $£ 80$ and $£ 90$. About two years ago Jonathan Howard, a postmaan, died at Southport, having been appointed 17 years, leaving a widow and family, but according to the existing rule they do not receive a penny piece."

\section{Q. 11,794.-Postmen and Free Tramway Travelling.}

A correspondent writes :-

"Mr. Hill states that Cardiff was one of the places where postmen had free tram fares. We wish it were so. It would be a great boon to us. We had a free ride for one season about eight years ago. We have had to pay or walk ever since.

\section{Q. 11,796.-A Periodical Partial Holiday for Postmen.}

In response to representations as to the desirableness of securing partial holiday on Saturdays, Mr. Morley gave a favourable decision in 1893, the conditions being (1) that no extra expense was to be incurred; (2) that the local municipal authority signified its approval of one of the afternoon deliveries being suspended. Since then the boon has been extended to many towns. It should, of course, be understood that this is not a real weekly half-holiday. It never amounts to more than one-third of a day's work, and it is only shared on alternate weeks. But even this modicum of relief would be accepted gratefully by the postmen of those towns that have been hitherto left out of benefit. In this connection a Bingley correspondent writes me as follows :- "Bingley is erroneously included by Mr. Hill among the list of towns that share in the boon of a partial weekly holiday by the suspension of one of the deliveries."

Writing on 26th of April, 1896, a Bacup correspondent said:- "It is not true that the postmen at this office get a weekly half-holiday."

These errors in the rebutting evidence incidentally show that, notwithstanding their splendid machinery for gathering exact detail, the Departmental witnesses are not above making mistakes sometimes. Small wonder, then, that our witnesses who had no access to the official records of Service unintentionally committed errors of detail.

\section{Q. 11,805.-The Rate of Increment-Too Slow.}

Mr. Hill admitted that postmen took too long to reach the maximum wages, and he went on to say:- "In the case of an office-Liverpool or 
Manchester, for instance-with a scale of 17s., rising by 1s. to 30s. a week, the postman does not reach his maximum until 13 years' service."

The grievance might bo more strikingly exemplified by taking the case of Glasgow, where new entrants have to do about four years' auxiliary service and 13 years' established service before receiving the maximum wages.

\section{Q. 11,915.-Auxiliary Postmen's rate of Pay.}

Mr. Hill admits that-- "The most equitable method of fixing the wages of the auxiliary postmen would, perhaps, be to pay them rateably (calculated to the nearest $6 \mathrm{~d}$. on the weekly wages) at the mean of the established men's scale, with the proviso that in no case should the rate be lower that $4 \mathrm{~d}$. per hour, the present minimum."

The mean of the established postmen's scale at Glasgow is 23s. 6d. a week. Adopting Mr. Hill's basis of calculation, the "double-auxiliaries" at Glasgow ought to receive 18s. a week instead of 14s., the present rate. This admission goes to show that the auxiliaries are at present very much underpaid, and it also shows the moderate character of the claim put forward on their behalf.

\section{Q. 11,952.-Hours of Attendance at Brighton.}

A Brighton correspondent writes as follows:-

"Mr. Lewin Hill stated before the Committee that the postmen in Brighton did not wish their duties to be altered, as the long break in the middle of the day enabled them to earn money at window-cleaning, etc. This statement is without foundation. The facts are as follows:-Shortly after Mr. Hetherington came to Brighton, a paper was sent to each office, asking that those men who desired a change of duty would sign to that effect. No particulars were given, and no information could be obtained as to what the proposed change was likely to be. Men who had been a long time in the Service, and had picked their walks according to seniority, naturally objected to taking a step in the dark. The prevailing idea was that the duties would be made to rotate with the mid-day duties, which are, without exception, worked by men who are comparatively junior to the men on the other section. The men on these duties cover two, and in a few cases three, walks on the mid-day deliveries, and, further, it should be noted, do four consecutive deliveries between 6 a.m. and 4.30 p.m., with a short interval between. There is no doubt that these duties are very good ories, but, on the other hand, a man who has been accustomed to regard the men working them as in a sense inferior to him, as who had also been in the habit of receiving the lion's share of the Christmas boxes, would not care to be shifted from his regular duty. We would like to point out that the Christmas boxes are not shared here on the London system, but are given by the public to the man for whom they are intended. Naturally, the senior man comes in for the larger share. At the time the matter was brought up, we had no branch of the Federation in Brighton, and no means existed of calling the men together to discuss the subject. The case was mentioned to the Postmaster by a deputation which waited upon him about fifteen months ago, but he stated that as the men had declined to accept a change of duty, he could not discuss the subject until such time as a revision took place."

\section{Q. 11,967.-Compressing the Day's Work within 12 Hours.}

The witnesses of the Postmen's Federation made representations for compressing within 12 hours' stretch the postman's daily quota of eight hours' duty. But we never advocated that it should be done by increased employment of auxiliary labour. We rather looked forward to a re-organisation of postal work, by which the postmen's duties would be more dovetailed into 
the sorting work. We believe this to be capable of achievement, and that, in the end, it would be conducive to both true economy and efficiency of the public service. To deny the possibility of improvement in this direction would, in our view of the case, be regarded as a confession of weaknessa confession, in fact, that those in governing positions in the Service were unequal to the task of any extensive measure of re-organisation.

In any case, the witnesses of the Postmen's Federation are not correctly understood as advocating improved hours of attendance for established postmen by the creation of a new sweated class.

\section{Q. 11,933.-Auxiliary Postmen and Annual Holidays.}

In reference to auxiliaries' holidays, Mr. Hill said:- "Where it has been asked for, it has been granted." This statement is somewhat misleading. It is calculated to leave the impression that auxiliary postmen have hitherto been without annual holidays, simply because they have failed to ask for them.

At the time I gave evidence before your Committee, the rule of the Service on the matter was as follows:-

"Auxiliaries are not entitled to leave of absence at the cost of the Department, but the Postmaster can give them leave of absence not exceeding one fortnight in the year, provided they can, with the approval of the Postmaster, agree with some competent person to act as substitute."

By a general petition, dated 16th January, 1893, annual holidays and other advantages were asked for auxiliary postmen. That petition was refused. It was only when a fresh application was made in May, 1896, that authority was granted to give holidays to those of the Glasgow auxiliaries who have previously been telegraph messengers. For this instalment of justice we are sincerely grateful; but it falls short of the needs of the case. For, although I pointed out the treatment which telegraph messengers received on being promoted to an auxiliary postman's duty, I did not wish it to be inferred that ex-telegraph messengers had greater claims on annual holidays than other auxiliaries. My reasons for selecting the case of ex-telegraph messengers to illustrate my argument were:-(1) It was a truly typical case-the auxiliary postmen being mainly recruited from the telegraph messengers; (2) because it served to show more strikingly the ir.consistency and absurdity of the Departmental attitude on the question. Even the latest decision is not without its absurd features. Take, for example, the case of James M'Alpine, auxiliary postman, Glasgow. He joined the Service 36 years ago. At that time the Post Office had no telegraph messengers. Yet he is denied the boon of annual holidays, just because he did not pass through the ranks of a class which did not then exist. The only real solution of the question is for the Department to meet the case squarely by giving annual holidays to all auxiliaries.

\section{Q. 11,957.-Postmen's Hours of Attendance at Cardiff.}

A Cardiff correspondent writes :-

"It will be observed that there is a vast deal of difference between the evidence given by us and the rebutting evidence, as given by $\mathrm{Mr}$. Hill, regarding the hours of duty. A revision was the cause of the difference. At the time the statement was compiled our figures were rather underestimated than otherwise."

\section{Q. 11,985.-As to Postmen being Overburdened.}

The postmen's representatives made a complaint that postmen on letterdelivering duty had frequently to carry excessive loads. As the Parcel Post is the principal, though not the only cause of overburdening, a plea was put forward for the Parcel Post being wrought separate, as originally intended. In the rebutting evidence Mr. Hill pooh-poohed the complaint 
by saying: "Certainly not; it would involve a very large expense. Some of the men seem ashamed to carry parcels, but, I think, if they are, they had better seek some other employment." If the real Departmental view is accurately expressed by Mr. Hill, it partakes of an even more harsh character than our witness represented it. Surely Departmental countenance is not given to cases like the following:-

(1) Lochee Case.-On Sunday, 1st March, 1896, a sealed bag, which weighed over $70 \mathrm{lbs}$, had to be carried by one man from Dundee head office to Lochee, being a distance of about 2 miles, all up-hill. No assistance of any sort was given, and the complaint was lodged with the superintendent. 'The average weight of this bag is said to be about $60 \mathrm{lbs}$., and has to be "carried by one man.

(2) Inverleithen Case.-A postman at Inverleithen, N.B., has to convey with hand-cart the mails for despatch by the 9.20 p.m. train. The mail bags and parcel baskets weigh at times over $4 \mathrm{cwt}$. The weight of the hand-cart itself is about 2 cwt. This makes a gross weight of 6 cwt. to be propelled by one man for nearly half-a-mile. In November last, when this matter was brought under my notice, I caused a return to be kept for one week. On two of the nights the load exceeded 4 cwt.

At present there is a carrying-weight limit for collection duty, but it is not adhered to so well as it might. For example, at Glasgow an unestablished postman was required to answer a report, of which the following is a copy :-

[Copy of Report.]

Post Ofrice, Glasgow, 24th February, 1896.

"For JAMES Smith, Collector, 19 Walk.

"You are requested to furnish your explanation on the following points, with the least possible delay:-

"On arriving, on Saturday, 22nd inst., with collection due here at 11.45 a.m., you reported having employed a cab from St. Enoch's Square P.B. to head office. The weight of the collection was 42 lbs. mile?

"Why did you engage a cab, seeing the distance travelled was only half-a-

"Intd. A. W.

(Signed) A. Camernon, Pro. Postmaster."

The postman is here called upon to explain his action, just as if he had committed some grave irregularity, while, as a matter of fact, he only took adrantage of Rule No. 58 (Postman's Rule Book), which says: "You are allowed to employ a cab or other conveyance when the weight of your collection exceeds 35 lbs."

I cannot pretend to know what construction the reporting officer chose to put on this rule. I presume he held it to be a safeguard against the short shipment of mails, rather than a rule intended to protect the postman from being over-burdened. The superintendent who countersigned the report is a zealous and painstaking officer. I am free to credit him with having been influenced entirely by a sense of duty, and that in adhibiting his initials to the paper he had no intention to lend countenance to an act of petty oppression on a subordinate. But the mere fact of such a report being issued in an admittedly we!l-managed office like Glasgow is significant.

In the case of delivery duty, there is no definite carrying limit. It is left largely to the discretion of the inspector, or other superior officer, to give or withhold assistance as he sees fit. In some towns this discretionary mode of giving relief works fairly well, but in other towns the vested power is frequently abused. In no town. however, can it be said that the present 
haphazard method gives complete satisfaction. The experience of the Glasgow postmen may serve to illustrate the policy hitherto pursued by the Department with regard to the Parcel Post. In December, 1890, two Glasgow postmen gave evidence before the Departmental Committee then sitting. In the course of his evidence, one of the witnesses laid great stress on hardship imposed upon postmen through having to carry parcels up and down long flights of $\mathrm{s}$ airs, along with the ordinary letter delivery-for at that time there was scarcely any relief given, except to a few of the very heavy districts at the morning delivery. At other deliveries postmen had to struggle along with the parcels as best they could. This was, indeed, a very serious state of matters for postmen in a town like Glasgow, where stair-climbing enters very largely into the daily work. Mr. Joyce, who was Chairman of that Committee, innocently suggested to the witness that a postman could ease his work by leaving his bag at the foot of the stairs while he went to serve the upper flats of a building. That such a suggestion should be made by one of the Chief Administrators of the Department would lead one to infer that some of the higher officials don't really understand the service they are supposed to control-for to do as Mr. Joyce suggested would have rendered the postman liable to a penalty of $£ 20$ for leaving in an unprotected position the correspondence entrusted to his care. (See Post Office Offences Act, 1 Vic., Cap. 36, Sec. 7.) However, one of the immediate results of the representations then made was that authority was given to employ 20 additional postmen. The additional men were to be employed exclusively in relieving the letter-carriers of the larger and heavier parcels. It should be noted that this much-needed relief was only given after the Parcel Post had been in operation for seven years, and that it was not given as a spontaneous act of justice, but rather in consequence of pressure by agitation.

Since the Department refuses to grapple boldly with the question by adopting separate delivery, the postmen are quite justified in seeking to have a definite load-line fixed, beyond which no man would be required to burden himself. The postmen, therefore, urge that the following weight-limits be fixed and enforced:-1st, for a near-hand walk-that is, a walk in the immediate vicinity of the office-that the maximum carrying weight be $35 \mathrm{lbs}$. 2nd, In the case of a distant walk-that is, in the case of the postmen having to walk a mile, or more, before reaching the commencing point of his delivery - that a weight-limit of $28 \mathrm{lbs}$. be fixed. That this is only a moderate claim must be admitted when the attendant circumstances are impartially considered.

Q. 11,983, etc.-The Plea for Separate Delivery for Parcel Post.

A Watford correspondent writes as follows :-

"As Mr. Lewin Hill has stated that the allegation in reference to the disposal of parcels at this office is untrue, I wish to say that the statements contained in the forms for inquiry were correct in every detail at that date, viz., July, 1895. Had we known that Watford would be taken as an example, I feel sure that a much stronger case could have been made. At that date part of the town was served by hand-carts, which were despatched from the office at 7.30 a.m., but a large portion of the town, which inciuded Nos. 6, 7, and 11 walks, was not served at any period during the day by a parcel postman, therefore the men on those walks were compelled to deliver all the parcels with the ordinary correspondence. I have seen Archer on No. 11 walk take out 18 parcels for delivery among his ordinary correspondence, the reason he took so many being as follows:-Had he left any parcels back. he knew that he would have to take them out on his next delivery, and would therefore be compelled to carry them much further, as Nos. 6 and 11 walks are then merged into one. I am not quoting the above as an instance which merely occurred once in a wav, as I should say that the number of parcels delivered by this man would average from 10 
to 14 on each first delivery. The same may be applied to No. 7 walk, as the man on this walk had to deliver all parcels that arrived, although on this walk they would not be quite so numerous as on No. 11. As to the delay caused by leaving parcels over from one delivery to another, I may say that it was a frequent occurrence. I myself have delivered parcels at 4 p.m., which, in the ordinary course, should have been delivered by 8.30 a.m. It is only fair to the Department to say that the foregoing system has been remedied, although, at the present time, the surplus parcels are delivered by telegraph messengers, who are employed at this office at $5 \mathrm{~s}$. per week, and receive nothing extra for delivering parcels. If $\mathrm{Mr}$. Lewin Hill had stated that the evidence supplied was formerly correct, but had since been remedied, it would not appear so false; but when he says that there was no foundation for such statements, then it would appear that we are trying to manufacture a case by misleading statements."

\section{Q. 12,055.-Auxiliary Postmen's Uniforms.}

Mr. Hill mentions uniform clothing as one of the emoluments of auxiliary postmen. But one cannot depend on uniforms being issued when due. For example, Walter Dunbar, auxiliary postman, Glasgow, is still (at the time of writing) without his uniform, after 11 months' service in the Postmen's Branch. Others have 8, 9, and 10 months', and are still performing their official duties in mufti. Besides being an unnecessary expense to the lads themselves, it is in other respects undesirable. The public-especially in business parts-look askance on postmen who perform delivering duty without the uniform.

With reference to the Brighton Cases, a Correspondent writes :-

"The evidence given with reference to promotion is correct in every detail, and with regard to relationship with the inspector of postmen to the Postmaster of Poole, and also the relationship of the assistant-inspector to an assistant-superintendent here, we have nothing to add or retract.

"We have made inquiries at Hassocks, S.O., and have been informed that F. Dunstone, the assistant-inspector, was not a rural postman there, but was employed by the sub-postmaster as an assistant at a wage of six shillings per week. His duties consisted of making collections, occasionally doing a rural walk, etc. He held no appointment in the Service until he was appointed postman at Brighton.

"With regard to the statement that he was rejected by the medical officer, we wish to point out that an error was made with reference to this matter. His certificate of physical fitness was withheld for six months, owing to an affection of the heart, but was granted at the end of that time.

"Mr. Walton stated that the postman travelling on the T.P.O. between Londen and Brighton came on duty at midnight on Sundays. This was incorrect. The men came on duty at $10 \mathrm{p} . \mathrm{m}$. on Sundays, and on other nights at 9.30 p.m. Since the case was mentioned to the Committee the hcurs of duty have been curtailed to the extent of one hour each night. Clerks and postmen now come on duty at 10.30 instead of 9.30 p.m. The duty now extends over a period of 10 hours, i.e., from 10.30 p.m. until $8.30 \mathrm{a.m}$. There is an interval of two hours at London Bridge, but, seeing that they are locked in the railway station, it cannot be considered as time off duty.

"Upon the question of the allowance of $3 \mathrm{~s}$. given to W. Carter, we find that this sum had not been paid regularly to Talmey, but had been given to him in turn with three other men, Patching, Long, and A. J. Grimwood. When Talmey spoke to the inspector of postmen with reference to the matter, he was told that the allowance could be paid to whoever he (the inspector) thought fit. This is Talmey's statement. At present all of these men are deprived of any share in this allowance, as it is all paid to Carter." 
Q. 12,248.-As to Postmen being Shut out from Sorting Branch.

A Brighton correspondent writes :-

"As to the statement that the learners are only in receipt yf pay while they are filling the place of a sorting clerk who is absent, we sh ruld like to mention that as soon as they arrive at the age of eighteen years they are invariably nominated for an appointment, which proves that they are really filling vacancies on the staff which are being kept warm for them. The whole secret of the matter is this: the Postmaster of Brighton does not love the postmen, and if he can, by any pretence, keep them down and shut them out from every avenue of promotion, he is going to do it.

"His first argument (Q. 12,244) against them is lack of education. Brighton is supposed to be one of the best educated towns in the kingdom, and we have yet to learn that postmen have not derived some benefit from the spread of knowledge which has taken place during the last decade or so, and we are loth to believe that only the sons and nephews of chief clerks and superintendents have profited thereby. His second argument is not worth considering; indeed, it can scarcely be dignified by the name of an argument. The final argument can be made to cut both ways-"The qualities which go to make a good postman do not make a good sorting clerk." We know of sorting clerks who are absolutely incapable of being entrusted with the duties of a delivering postman. So satisfied is the Postmaster of Brighton with his theories that he has endeavoured 'to keep in training a supply of well-educated lads to fill the vacancies as they occur, and meanwhile to act as substitutes for sorting clerks. This he calls his nursery.' (Vide Mr. Joyce's evidence). The postmen are shut out accordingly. So long as the Department continues to bow down to the fetish of the educational as against the practical test, we suppose such things must be, but we feel positive that the Post Office, conservative as it is, will be bound to recognise the claims of those, who, by reason of long service and experience, have some right to be considered. We would like to quote the opinion of a well-known writer, who, in speaking of the tendency of the public to regard mere book education as the prime factor, so far as regards success in life, instead of as a casual accessor, says, that if we possessed the slightest sense of humour as a nation, we would not permit an educational test for the humblest employee in the Government Service, at which it is highly probable that Lord Salisbury. or any one of the heads of Departments would get plucked.

"At any rate, we think the time has come when Postmasters should be told that private opinions and deep-seated prejudices should not be allowed to operate against a body of men in the manner in which they have done in the past, and that is no part of a Postmaster's duty to provide positions in the Public Service for outsiders at the expense of men already in the Service."

\section{Q. 12,265-6.}

"If further proof of the state of affairs existing at Brighton were necessary, it has been supplied by those responsible for the defence of the system. Surely the irony of fate was never better exemplified. We endeavcured to state our case in as temperate a manner as possible, but we hesitated to describe the Brighton Sorting Office as a nursery. This has been done for us by the Postmaster of Brighton, and we hereby tender him our hearty thanks. Now that the official mind has unburdened itself as to the manner in which sorting clerks' appointments are filled at Brighton, we should like to point out the singular fact that nearly all of these lads are educated at the same school, and that the Postmaster of Brighton is a manager of that school. We may assume that the Postmaster is actuated by a keen sense of his 'responsibilities,' and feels that it is not only his duty to keep a watchful eye over the intellectual training of these youths, but also to provide them with the positions in the Public Service. 
"We have no doubt that the parents and guardians of the lads in question are deeply grateful to the Postmaster, and that they regard him as the beau-ideal of a school-manager. Whether he is actuated by a genuine desire to obtain the best possible material for conversion into Post Office officials, or whether he is influenced by a hankering after cheap popularity is, as Mr. Joyce would put it, 'rather a matter for speculation.' This we do know, that these lads are brought into the office knowing absolutely nothing of the routine, and are given every opportunity of learning the duties, and that postmen act in the capacity of "nurses' while they are in the nursery."

\section{Q. 12,265-6.}

A Brighton correspondent writes:-

"Mr. Joyce's evidence, presuming it to have been correctly reported, does not say much for the ability or honesty of purpose of those who have been responsible in furnishing him with his facts and figures. Mr. Walton stated on our behalf that "nearly half the number of sorting clerks at present on the Brighton staff have been brought from other towns; some have been fully established previous to taking local appointments, others have received their appointments at Brighton.' Mr. Joyce, rebutting, confesses: 'That he was very much struck with that statement,' and he inquired into it, and was "informed that the total number of second-class scrting clerks at Brighton is 40 , while the number of those brought from other towns is 10 . It was desired to reduce the number of learners at Eastbourne, and they were transferred to Brighton.' The only truth in this reported statement of Mr. Joyce is that the number of second-class sorting clerks here is 40 . Within the last ten years, the whole of the present staff of sorting clerks, and about one-half of those of the first-class, have received their appointments on the Brighton staff: Maidstone supplied 1; Ashford, 1; Margate, 1; London, 4; Burgess Hill, 3 ; Hassocks and Hurst, 4; Chatham, 2; Chichester, 1; Newcastle-on-Tyne, 1; Epsom, 1; Leeds, 1 ; Windsor or Datchet, 1 ; and Llandudno, 1 ; a total of 22 imported men. Of these one has left the Service, and one has gone to Tunbridge Wells, and three have received first-class appointments. Further, instead of Eastbourne supplying Brighton from its superabundant, embryonic, clerical material, exactly the opposite is the truth; not one of the present staff of second-class clerks or learners here have come from that town, whereas Brighton has actually recently lent Eastbourne a learner from its now far-famed nursery."

N.B.-(1) From information now at hand it would appear that the Brighton case has been understated. The total number of imported Sorting Clerks should be 28 instead of 22, as stated in the foregoing paragraph of the rejoinder.

(2) I find from the official copy of the evidence that the inaccurate character of Mr. Joyce's evidence with reference to Eastbourne has already been fully admitted at the commencement of the fortieth day of the Committee's sittings. 
Q. 12,265.-Detailed Statement as to Imported Sorting Clerks at Brighton. TABLE A.

The following tabular statement shows how the sorting clerks' class at Brighton has been recruited within the last ten years :-

\begin{tabular}{|c|c|c|}
\hline NAME. & Town of ORIgIN. & Remiaks. \\
\hline $\begin{array}{lc}\text { *Coleman, } & \ldots \\
\text { *Miller, ... } & \ldots \\
\text { *Groves, ... } & \ldots \\
\text { *Tupper, ... } & \ldots \\
\text { *Mascell, ... } & \ldots \\
\text { Baker, C., } & \ldots \\
\text { Baker, H., } & \ldots \\
\text { *Cook, R., } & \ldots \\
\text { *Kent, H, } & \ldots \\
\text { Habgood, } & \ldots \\
\text { *Brien, ... } & \ldots \\
\text { *Eouthey,... } & \ldots \\
\text { *Mann, ... } & . . \\
\text { Young, ... } & \ldots \\
\text { *M·Intyre, C. . B., } \\
\text { *Tappley, ... } & \ldots \\
\text { *Elliot, ... } & \ldots \\
\text { *Brice, ... } & \ldots \\
\text { *Dunn, ... } & \ldots \\
\text { *Sharp, ... } & \ldots \\
\text { *Snow, ... } & \ldots \\
\text { Carman,... } & \ldots \\
\text { M·Intyre, W. D., }\end{array}$ & $\begin{array}{l}\begin{array}{c}\text { Burgess Hill. } \\
\text { do. } \\
\text { do. }\end{array} \\
\ldots \quad \ldots \\
\text {...... } \\
\text { Hurst and } \\
\text { Hassocks Gate. } \\
\text { Chatham. } \\
\text { do. } \\
\text { Chichester. } \\
\text { Newcastle-on-Tyne. } \\
\text { Epsom. } \\
\text { Leeds, ... ... } \\
\text { Datchet or Windsor, } \\
\text { Llandudno. } \\
\text { Maidstone, } \\
\text { Ashford, } \\
\text { Margate. } \\
\text { Canterbury. } \\
\text { London. } \\
\text { do. } \\
\text { do. } \\
\text { do. }\end{array}$ & $\begin{array}{l}\text { Gone to Surveyor's } \\
\text { Office, Tunbridge Wells. } \\
\text { Left Service. } \\
\text { Now 1st Class. } \\
\text { Now 1st Class. }\end{array}$ \\
\hline
\end{tabular}

TABLE B.

Here also is a list of men who have come from other towns within or about the past five years, but have not been appointed either through lack of vacancies, failing examinations, or other causes :-

\begin{tabular}{|c|c|c|c|}
\hline \multicolumn{2}{|l|}{ Name. } & Whence Came. & REMARKs. \\
\hline *Wenban, & & Came from Worthing, & Went to 'Tunbridge Wells, received \\
\hline *Creigh, & $\cdots$ & Came from Cork, & $\begin{array}{l}\text { Failed at old examination, returned } \\
\text { to Cork; deceased. }\end{array}$ \\
\hline †Crain, & $\cdots$ & Came from Bedford, & Expecting to be nominated shortly. \\
\hline Weller, & $\cdots$ & Came from Rochester, & Expecting to be nominated shortly. \\
\hline Carter, & $\cdots$ & Came from Hassocks, & $\begin{array}{l}\text { Failed at old examination, now a } \\
\text { Postman, mentioned in the evi- } \\
\text { dence. }\end{array}$ \\
\hline Tester, & $\cdots$ & Came from Hassocks, & Had to resign. \\
\hline Dooner, & $\cdots$ & Came from Australia, & Returned there. \\
\hline
\end{tabular}


N.B.-The name of Dunstone, now assistant-inspector, who came from Hassocks, is not included in either of these lists. Those marked with an asterisk were previously employed in the Post Office at the towns opposite their names, and some of these men wore the uniform before coming to Brighton. It stands to reason that these men cannot be so well fitted for doing local sorting as local born and bred postmen.

\section{Q. 12,275.-Re Cases of Stenning and Dunstone, Brighton.}

\section{A Brighton correspondent writes :-}

"Mr. Joyce merely says, in reply to Chairman: "Yes, I have not the slightest doubt it was not so.' Mr. Joyce has every opportunity of giving dates, opportunities not available to us. Instead of giving a blank denial to our allegations, let him give the date of one day when Stenning or Dunstone, holding postmen's appointments, wore the uniform or did postmen's duty. He also states (Q. 12,278) that Dunstone's brother has left, and that he left before the present Postmaster got his appointment. The truth is that Dunstone's brother has not left, but is still holding an assistant-superintendent's appointment in Brighton. The cases of Belward, Harris, and Carter, Mr. Joyce, though given every opportunity to rebut, did not attempt to touch."

\section{Q. 12,279.-The Case of Mr. F. Paul.}

In reference to this case, a Brighton correspondent writes:-

"Mr. Joyce admits that his work, prior to 1891, was important. But why only prior to 1891 ? Is it because we, purposely understating the case, handed in that Paul's duties as clerk in charge only covered the years from 1888 to 1891 ? What can Mr. Joyce, or anyone else, for the matter of that, say to the following dates taken from the attendance books, showing that Paul was performing clerk in charge duties until two years after $\mathrm{Mr}$. Joyce says that he had ceased to perform them:- Jan. 18th, 1892, to Feb. 20th, 1892; Mar. 21st, 1892, to April 22nd, 1892; Oct. 10th, 1892, to Dec. 3rd, 1892 ; Dec. 11th, 1892, to Dec. 16th, 1892; Jan. 17th, 1893, to Jan. 31st, 1893; Mar. 20th, 1893, to July 1st, 1893; July 31st, 1893, to Aug. 26th, 1893 ; Oct. 16th, 1893, to Oct. 21st, 1893; Nov. 6th, 1893, to Nov. 18th, 1893.

"Almost, it will be seen, until the year 1894. Mr. Joyce also says that at no time could Mr. Paul's duties be defined as those of a superintendent. There was no difference but that of wage. What an exposition of Departmental economics-Paul performing duties by himself at a wage of about $£ 80$, that now requires a superintendent and clerk at an aggregate wage of $£ 350$, not including the salary of an odd learner! The remainder of $\mathrm{Mr}$. Joyce's evidence, so far as it affects Brighton, is made up,.with few exceptions-particularly with reference to relations having left the office before the present Postmaster came, and who, unfortuaately for the truth of Mr. Joyce's testimony, are still here-by an abuse of postmen for lack of educational ability. We respectfully call on Mr. Joyce for proof, and when he has proved it to reconcile his adrocacy of an educational test as the criterion of merit, with Mr. Hill's statement, that those who pass it bestIrishmen-make the worst officials.

"The Brighton evidence was carefully understated, and although there are generally two sides to every question, so far as this office is concerned, Mr. Joyce's rebutting evidence cannot be accepted as being a fair answer to the plain unvarnished statement made on our behalf before the Commission of Inquiry."

\section{Q. 12,290.-Postmen and Counter Duties.}

If counter duties are really so difficult that they exclude the hope of postmen being able to perform them, it may fairly be asked: Where do sub-postmasters gain their practical training and experience? 
Concluding Remarks.

In the course of Mr. Hill's evidence, the following sentence occurs :-

"Don't delude yourselves with the notion that the men will cease to ask." Although this was given in a reminiscent sort of way, I presume that it expresses Mr. Hill's views as applying to the present case. So far as the postmen are concerned, every claim put forward was, I hope, supported by fair argument. But even suppose it were the case that groundless claims had been put forward by any section of the Service, the Department must take to itself a great measure of the blame. From experience of former revisions, the Departmental policy may be said to foster a spirit of importunate asking, for Mr. Hill practically admits that every improvement granted was the result of pressure by agitation. And it will be observed that the classes that agitated most vigorously got the most prompt and substantial redress. As the postmen have hitherto adhered to comparatively mild methods of agitation, they were rewarded by redress coming more tardily and more niggardly. This deferential method of allaying discontent is further exemplified in treatment meted out to the various classes of postmen themselves. Town postmen, on account of feeble attempts at concerted action, in the way of simultaneous petitions, etc., fared better than their rural brethren. That this is a correct statement may be gathered from Mr. Hill's own admission when he says :-

"Mr. Fawcett's revision was confined to town postmen, and practically the only advantage which rural postmen obtained out of that revision was good-conduct stripes, which was, however, a great advantage. From what the papers in the office will show, we know that Mr. Fawcett intended to follow up the revision of the town postmen by a revision of the rural postmen. But this was not done, and from various causes that revision did not come till nine years later."

The moral here is obvious. Had rural postmen agitated more they would probably have fared better.

Again, in answer to Question 11,663:-

"In the Committee of 1891 we recognised that there were no sufficient grounds for paying rural postmen, who started from a town office, less than town postmen who worked in the same town, but their pay previously was so very much less that we were afraid to propose to put them on an equality." This is a curious way of reasoning. The Department should not have been afraid to do what was right.

Auxiliary postmen fared still worse. They were left out in the cold altogether.

Had the Department been actuated by motives of justice, the cases of the weaker and more helpless classes, such as telegraph messengers and auxiliary postmen, would be the first to get attention and suitable redress. Instead of that, we find Mr. Hill contemplating a step calculated to inflict further hardships of the telegraph messengers' class (see answer to Question 11,834-5). In our view of the case, it would be more creditable for the Department to have its policy based on principles of justice rather than mere expediency.

If, in the course of this statement, I have had occasion to criticise the Departmental ways with unusual freedom, it is not in the least through any desire to impair the discipline so necessary in the Service. It is rather because the present occasion is one which should be taken the fullest advantage of to state our case freely. This, indeed, is what we believe Mr. Morley would have desired when he said that "he desired to make the scope of the Inquiry as wide as possible, so as to include all practical grievances, and that the men might be encouraged to come forward and state them freely."

I have the honour to be,

Your obedient servant,

Alnaxander MacLaren, Postman, Glasgow. 


\section{REJOINDER FORWARDED BY MR. JOHN WALSH, LIVERPOOL.}

As an item, I contended the standard of education had been raised to keep postmen from sorting clerkships, and that the present standard is superfluous.

A standard similar to the police, with the educational effect of experience of postal work on the individual, is sufficient. Mr. Lewin Hill bears me out, for he implies that Irishmen, who can pass examinations because of their educational acquirements or surplus knowledge, are less useful than Englishmen and Scotchmen without such surplusage. The Irishmen are, if his statement be true, over-equipped with theory and under-equipped with practical parts. It is on competency demonstrated in practical parts that postmen rest their claims for equity.

No point has been urged by Mr. Hill as to his "market value" principle applying to pensioners; these, as shown by the number in a chronic state of poverty and helplessness, are not of great market value. The principle would meet with least resistance here, but he does not recommend direct application with gieater rigour than it at present operates. I will show his indirect intentions.

There is no contention against the collective and sustained force of our country, as Government employei', retaining small fractions from postmen's wages and distributing them again in increased pensions to the decreased fraction of men living to receive pensions; nor against provision for our widows and children, as set forth in our scheme. Our comparison to the favourable treatment of police officers is not said to be unreasonable. Neither is the inadequacy of our pensions and poverty of used-sp postmen disputed; but Mr. Lewin Hill, by asserting that overseers, inspectors, etc., now pensioned were once postmen, in some mysterious way seems to imply that the big pensions of high officials (once postmen) are a source of relief to the 12.3 per cent. of postmen pensioned under $6 \mathrm{~s}$. per week, and the 24.8 per cent. more pensioned under 10s. per week from '92 to '96. The greater age of postmen when pensioned (stated one year over all other pensioners of the P.O.) is misleading. In the '93 and '94 Estimates the average age of the postmen pensioned is 55.8 years, the average service 27.38 years. There are, however, 71 out of 156 men rural postmen. These average 57 years of age, and 27.7 of service, which reduces the average age of the other 85 postmen to 54.9 years, a difference of two years, though the service average is nearly the same. The explanation is, that the limit of age for rural men when joining is 45 years, and has always been higher than any other branch of the service. I am struck, however, with one feature of this:- The rural postmen are but 27 per cent. of postmen, yet in ' 93 and '94 had 45 per cent. of the postmen pensioned.

I would point out that Mr. Hill's comparison of maxima between postmen and police is an untrue basis of calculation; from minimum to maximum, with the rate of increase in actual wages affect all, and may be said, for calculating purposes, to be invariable. Allowances and promotion are accidental, and affect only certain individuals of a class, and are irregular as to times of bestowal. One-fourth, Mr. Hill says, have allowances in the provinces, three-fourths are therefore permanently withюut. In large towns the average service of a man commencing an allowance might be 10 to 15 years' service; the average life in harness, according to $\mathrm{Mr}$. Hill, is 20 years, therefore the number of years in receipt of allowance few. Your lordship said to Mr. Reid, inspector, "But still it (minimum) is a material point. When a man is first appointed it makes a vast deal of difference 
whether he gets $£ 80, £ 120$, or $£ 140$. I cannot adinit you are right in shutting out the question of minimum altogether." To show the weakness of his maxima comparison, I have only to divide his $£ 1,32712 \mathrm{~s} .10 \mathrm{~d}$. by his 20 years, to find that $£ 667 \mathrm{~s}$. 7d. a year, or $£ 15 \mathrm{~s}$. $6 \frac{1}{2} \mathrm{~d}$. per week, is the postman's average in Liverpool and the large towns. The police rate for the first year in Liverpool is $£ 15 \mathrm{~s}$. per week, the second $£ 17 \mathrm{~s}$. per week, as shown by the police circular I append, while the policeman's uniform is more expensive, his boot allowance greater, and his chances of promotion not to be compared. To a force of 1,442 constables there are 248 higher positions, worth from $£ 88$ ss. to $£ 440$ per annum. The police have no split duties-or none to speak of here-therefore work about one to two hours a day less than postmen, and have one day a fortnight off, in lieu of Sunday work. The policeman's height or weight would be no more use to him in the Post Office than the trade of a joiner or compositor. It is not the requisite smartness and intelligence are the quantities in demand, and big men have not a monopoly, as shown by the number of small men in governing positions. This argument, therefore, fails.

Mr. Hill's proposed manipulation of our wages would involve a loss to postmen in the second 20 years of $£ 104$ 4s. 4d., and a further loss on persion of one-fifteenth ; in the case of a 40 years' man receiving two-thirds this would mean 1s. 4d. per week for the rest of his life. I have shown our pensions now are only a little over half that received by the other sections for the same number of years' service.

His proposals would aggravate and intensify every existing form of discontent. Uniformity, as in the penny postage, the treatment of army, navy, and Irish Constabulary as to pay and promotion, is the only wise solution of our difficulties. The market value of labour (men).-The class whose bones are ground to powder by this principle (Scripture phraseology) is the poorest workers. The law or voice of the nation prohibits competition against postal work, and commands that charges for such service shall be uniform throughout the land-poor and rich district alike. Necessity impels the community to come in and buy postal service, but the greater necessity of one man or firm over another is no advantage to the Post Office in allowing higher charges or extortion. Greater demand is an increased opportunity for profit to traders. But this institution, so protected and so limited by law, takes the keenest advantage of the needs of the poor worker, and of the low market value of labour in his poor district.

Remunerative or profitable expenditure.-Suppose at Liverpool you have 10 per cent. profit on a postman receiving 30 s. per week, at Harrogate you charge the same for your service to the public, but pay your postman 36 per cent. less; your profit at Harrogate will be nearly 50 per cent., for you charge the same for the man's service, and require out of him a similar number of hours' service to the man at Liverpool.

. What is profit? It is the amount overcharged the public at the counter, to be returned to the same public in surplus as remitter of some other form of contribution or tax-a very expensive method of handing in money and allowing it to filter through many hands that you may get a portion of it back. Sir R. Hill is quoted to warn us that higher wages attract superior persons, and would have the effect of making our present positions precarious, but the late P.M.G's. report and Mr. Lewin Hill dispose of this, for they contend there are few resignations, and that our wages are as sure as the sun's rise; and yet the standard of education and wages have both risen!

$\mathrm{Mr}$. Hill also supports our claim for retirement at 50 , for he says that men become slow at 50 , and adds he himself became slow years ago. He cannot, then, consistently say our much heavier work would have a less enfeebling effect on us. Mr. Hill pleads that I have in the Liverpool case exaggerated: this is but opinion of degree, and not evidence of detailed fact. My statements are-except the mistake in dates-strictly and severely true. Seven 
hand-carts and seven big telegraph lads have been put on at the morning delivery to assist. Three walks have been split up, and extra men put on them. Two trollies have been invented to fit a hydraulic hoist, hitherto little used, and letters are now taken up, a whole section at a time. Parcels and papers are also taken up in this hoist, and these we have since found to weigh up to $170 \mathrm{lbs}$. in certain bags, yet even now the delivery at head office in the mornings is not started on several of the big walks until near 8 a.m., though due at 7 a.m. I have seen, years ago, every man able to go out with the work at 7 a.m.

The density of work under pressure.-The extra man added to 1 and 12 walks should reduce the time booked on each of these walks 8 hours. It will be found not to have reduced the time booked 2 hours. W. Young is another man who burst a blood vessel, no doubt through heavy work, and W. Taylor and J. Brown know something more on the Elliott case. The Aberayon case was reported to me by a postman, and as I regarded it as hearsay, I sent direct for particulars, as in the Formby case, enclosing a stamped envelope for reply. I received no reply, and merely mentioned it in order that if a vestige of truth was found in it the man might have justice done him. My real object in this phase of the case was, however, to prove the inter-dependence of workers on each other, and show how the weaker or poorer worker suffers through the indulgence granted aristocratic workers. The case was carefully worded as a suppository one. I might have used Cork or any other town, and given the actual wages to illustrate my point.

I regret extremely to say that Mr. Joyce has been misinformed. I have never been offered a nomination for a sorting clerkship. I would have declined one, however, these 12 years past, as I could not, with a growing family, have forfeited $7 \mathrm{~s}$ allowance.

It is also untrue that Mr. Dodd acted inspector the first and longest spell because of diseased bone. He had no disease or knowledge of diseased bone when first selected. Mr. Dodd has, however, been treated by $\mathrm{Mr}$. Birkett and all concerned with great kindness during his sickness, and I trust the introduction of this good officer's name, for the purpose of justice, will not cause a diminution of indulgence to him. The opinion amongst postmen here is that seniority in postmen's case, and theirs alone, acts against them às a crime. At this moment all the men acting as inspectors are juniors to hundreds of postmen in Liverpool.

- John WaLSII, Sorting Postman.

(Witness.)

The following has also been forwarded to and accepted by the Committee as evidence :-

Extract from "Liverpool Daily Post" of Tuesday, 9th June, 1896, showing a recent increase in police wages here:-

\section{THE PAY OF THE POLICE FORCE. RECOMMENDED INCREASE.}

Yesterday the Watch Committee of the City Council had under consideration the report which the Head Constable (Captain Nott-Bower) was directed to present in reference to the recent memorial from sergeants and constables 
asking for an increase of pay. The Head Constable recommended, and the committee approved of, the following-

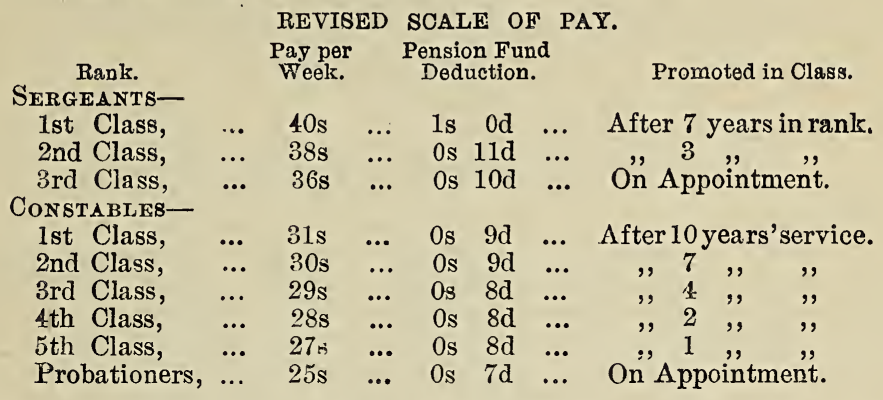

There will be a merit class for sergeants, carrying 2s. per week extra pay; the number of sergeants promoted to this class not to exceed 10 per cent. of the total strength. Constables on day point duty to receive 1s. per week beyond the above rates. There will also be three merit classes for constables, distinguished by badges, each badge carrying 1s. per week extra pay, constable to be eligible for the first badge after 15 years' service, 5 years' clean books, and certified efficiency, or for any specially meritorious conduct; for the second badge after 20 years' service, ten years' clean books, and certified efficiency, or for any specially meritorious conduct; and for the third badge, for specially meritorious conduct only.

The present rate of pay for constables varies from 25s. to $30 \mathrm{~s}$. per week as a maximum for class promotion, with a possible increase to $32 \mathrm{~s}$. for merit services. For sergeants the present rate is from $34 \mathrm{~s}$. to $38 \mathrm{~s}$, with $40 \mathrm{~s}$. for merit services. By the revised scale the maximum in both ranks of the force, apart from merit services, has been approximated to Manchester, where the sergeants recently received an increase of $2 \mathrm{~s}$. per week, and the older constables have been in a better position than in Liverpool. The cost of the increase is estimated by Captain Nott-Bower at $£ 1,980$ per annum, of which $£ 990$ would fall upon the Exchequer, and $£ 410$ upon the Dock Board.

It will be seen that these three merit shillings raise the police maximum to $35 \mathrm{~s}$. per week, without counting the $1 \mathrm{~s}$. given to day point duty men. The sergeants have been increased $2 \mathrm{~s}$. per week, and in addition a number of the men receive 2s. extra per week for acting as firemen. The higher positions are in the proportion of 1 to about 6 constables, and in every case raises the social status of the men; allowances to postmen do not, as they are mostly in lieu of Christmas boxes.

Yours obediently,

John WaLSH, Sorting Postman.

(Witness.) 


\section{REJOINDER BY THE NOTTING HILL BRANCH.}

The Right Hon. Lord Tweedmouth,

Notting Hill, S.O.

Chairman of the Committee on Post Office Establishments.

MY LORD,-

I am instructed by my colleagues, postmen at Notting Hill, to submit to your Committee's consideration the following reply to Mr. Badcock's statement with reference to Notting Hill, made before your Committee on March 19th :-

(1st) The reason that the kitchen is not more largely made use of is not because the men live close to the office, but because, owing to its gloomy and unhealthy state, the men do not use it more than they can possibly help. Excluding the two head postmen, there are 61 established men. Of these 14 live within half-a-mile of the office; 17 between half-amile and a mile; 20 between one and two miles; and 10 two miles and over. In addition to these are 24 auxiliaries, who mostly live at a distance of between one and two miles.

(2nd) The fact of several large houses being let out in floors is of no benefit to the postmen; rather the reverse, as these houses which formerly let for about $£ 300$ per annum, on being converted into flats, bring in from $£ 500$ to $£ 600$, the rent per flat being from $£ 65$ to $£ 170$ per annum, each house containing from five to six flats; and whereas formerly the postman delivered the correspondence at the front door, he now has to climb five or six flights of stairs.

(3rd) Three years ago, owing to the increase of the work, it was found necessary to open a new office at North Kensington, taking a large portion of the ground away. At the same time it was found necessary to greatly curtail the walks; since then, as showing the district still rises, another portion of the ground has been transferred to the Kensington ground, giving relief to some of the walks.

(4th) The rents for apartments suitable for postmen are about $8 \mathrm{~s}$. to $10 \mathrm{~s}$. per week for a floor, within a radius of a mile; farther out, at Queen's Park and Shepherd's Bush, where many of the men live, small houses can be got at from 10s. to $14 \mathrm{~s}$. per week.

(5th) The town delivery also in one part comes within about 500 yards of the office, which is itself in that important thoroughfare, Westbourne Grove. In several instances the local delivery overlaps the town delivery; for irstance, in delivering High Street, Notting Hill, the Notting Hill man would have to pass Pembridge Square, Pembridge Gardens, Linden Gardens, and Clanricarde Gardens, not merely touching them, but enveloping them.

Lastly; my lord, the official return of the correspondence delivered, taken the same week in each year, is as follows:-In 1893 the number was 202,502-this included the North Kensington portion; in '94, after North Kensington was a separate office, the numbers were 168,361; in '95 the numbers were 164,542 , when another portion had been transferred to Kensington; this year the return showed 184,996, being an increase from last year of 20,454 , the ground being the same.

I am, my Lord,

Yours obediently,

June 8th, 1896.

H. Rowbotнay, Local Sec. 


\title{
REJOINDER LODGED WITH THE COMMITTEE ON BEHALF OF
} WOOLWICH POSTMEN.

\section{The Right Hon. LoRd Tweedmourn,}

\author{
Chairman of the Committee on Post Office Establishments.
}

\section{My Lord,-}

The rebutting evidence given before your Committee by $\mathrm{Mr}$. J. C. Badcock, on the 19th March, having special reference to the case of the Woolwich postmen, has now been read and considered by my colleagues, and I am directed by them to submit to your Committee for their consideration the following reply thereto:-

(1st) The statement that Croydon, Sutton, and Mitcham were taken out of the Metropolitan area at the same time as Woolwich is the opposite of fact, and had Mr. Badcock consulted the Official Circular of the 19th August, 1879, he would have seen that his statement was incorrect, and further, Croydon, Sutton, and Mitcham are not in the County of London, and from information that came from authentic sources we assert that these places have never been within the Metropolitan area for postal purposes, at least not within the memory of the oldest of the postmen employed at the aforesaid offices.

(2nd) Sorting work at Woolwich is done by sorting clerks. This is also only true in part. The sorting clerks were not introduced at Woolwich until 1888, previous to which date the whole of the sorting-inward and outward, district and London forward, despatch of mails, the making-up of registered letter bags, etc.-was done by postmen, but for which work not one penny allowance was ever received by them, and to-day the whole of the inward sorting is still done by the outdoor postmen, who get no allowance for the work. The only sorting done by sorting clerks is the outward, which we think pretty well disposes of the suggestion of Mr. Walpole that Woolwich postmen are not doing such high-class work as the postmen in London.

(3rd) Mr. Badcock stated that the men serving at the time of the change suffered nothing thereby, but he admits at the same moment that the change has no doubt been the means of keeping down the men's wages, which means that the men have suffered, and will continue to do so until a change is effected.

The men here have a lower minimum and a lower maximum; all hope of promotion is absolutely destroyed, and there is no hope for men obtaining sorterships except by entering the open competition, a much less favourable position than men in other London offices occupy. We may also mention that the men serving at the time of the change were not offered the alternative of going to some other office in the districts, or remaining at Woolwich under the new order of things; in fact, they were not aware that a change was contemplated until the official announcement appeared eleven days prior to the transfer.

My Lord, we live in a district where rents are continually going up in consequence of the enormous number of hands employed in the Royal Arsenal, and, as has already been pointed out to your Committee, our expenses are as heavy as those of the postmen in the adjoining London districts. We do not admit that the responsibilities of London postmen 
are any greater than ours, and as Woolwich is in London for everything else, we ask from the Department that we be paid London rates of wages, a request which we hope will not be considered unreasonable, and we confidently rely on your Committee recommending our claim.

Lastly, my Lord, it is said that Woolwich was taken out of the Metropolitan area because it had become too large. To make any remark upon this is perhaps beyond our province, but we cannot help pointing out that a great part of the official correspondence for Woolwich travels from London via Tunbridge Wells and vice versa, thus travelling a distance of some 77 miles to reach a place about 8 miles from the General Post Office.

I am, my Lord,

Yours obediently,

G. Corbet.

Finis.

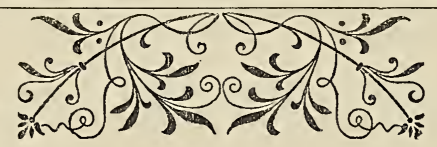




\section{N D EX.}

The London Case for Enquiry.

Abolition of Classification, H. Symes, E.C.D.O. (Floating Staff, \&c.), -

Pages.

142-171

Auxiliaries, H. M. Wilson, Hampstead S.O. $63-94$

$46-52$

Discipline, H. Boaler, N.W.D.O. (Punishments, \&c.), -

Floating Staff, The-H. Symes, E.C.D.O. ( $\Lambda$ bolition of Classification, \&c.),

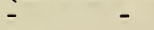

$110-122$

$142-171$

Hours of Duty, D. s. Boston, Kentish Town (Heavy Winter Work, Number of Attendances, Circulars), -

-

$52-62$

Parcel Post (From a Letter-Carrier's point of view), H. Boaler, N.W.D.O.,

-

95-98

Parcel Postmen, G. H. Stuart, S.W.P.P. Depot, - - - - $\quad$ - 99-109

Promotion, A. F. Harris, W.D.O.,- $\quad-\quad$ - $\quad$ - $\quad$ - 123-141

Punishments, H. Boaler, N.W.D.O. (Discipline, \&c.), - 110-122

Recognition of the Federation, C. Churchfield, E.C.D.O. (Wages, Minimum, Sanitation)

$21-34$

Sanitation, C. Churchfield, E. C.D.O. (Wages, Recognition of the Federation), -

Superannuation, John Walsh, Liverpool (London and Provincial),

Supernumeraries, W. M. Shephard, New Cross,

Supplementary Case (C. J. Roberts, Hampstead S.O.), C. Churchfield, E.C.D.O.,

Wages, C. Churchfield, E.C.D.O. (Minimum, Recognition of the

C. J. Warner, S.W.D.O. (Christmas Boxes),

Woolwich Case, The-Geo. Corbet, Woolwich, -

Zone System, T. G. Barnes, S.E.D.O.,

-

$$
\text { - }
$$

$180-183$

$35-45$

\section{The Provincial Case for Enquiry.}

Auxiliaries, Z. Howe, Sheffield,

, A. M'Laren, Glasgow, - - - - - -

Christmas Boxes (In relation to the Wages Question, the Initial Wage), A. M'Laren, Glasgow,

Discipline, J. S. Smith, Newcastle-on-Tyne (Citizen Rights, Recognition of the Federation, Punishments, Late Attendances),

Holiday and Casual Leave, S. Dowling, Liverpool (Hours of Duty, \&c.),Indoor and Allowance Class, J. G. Walton, Newcastle-on-Tyne,

$254-283$

391-394

S. Wright, Leeds,

- 385-390 
Junior Postmen-S. Wright, Leeds,

Medical Attendance, T. Carmichael, Heckmondwike (Sub-Office Postmen, \&c.),

Parcel Post-W. Martin, Manchester,

Promotion-J. G. Walton, Newcastle-on-Tyne,

S. Wright, Leeds,

Punishments, J. S. Smith, Newcastle-on-Tyne (Citizen Rights, Late Attendances, Recognition of the Federation), -

Recognition of the Federation, J. S. Smith, Newcastle-on-Tyne (Citizen Rights, Late Attendances, Punishments),

381-385

Rural Postmen, Geo. Gregory, Portadown (Wages, Disparity between Town and Rural, Rural Auxiliaries),

441-439

$315-324$

$353-370$

371-381

$325-352$

$325-352$

$395-412$

F. B. Baker, Gloucester (Mounted Men, Hours of Duty, Exampies of Long Walks),

$413-428$

Thos. Grimmer, Worcester (Wages, Uniform, Parcel Post),

South County Dublin Case,

Sub-Office Postmen, Thomas Carmichael, Heckmondwike (Medical Attendance)

Superannuation, John Walsh, Liverpool (London and Provincial),

Supplementary Evidence, A. M'Laren, Glasgow, . - -

Wages-A. M'Laren, Glasgow (Christmas Boxes, the Initial Wage),

, -John Walsh, Liverpool (Wages, Aggregate, Special Lirerpool Cases, Comparisons, Statistics),

$450-451$

$442-449$

236-253

$452-455$

187-196

$197-236$

Non-Frdeitation Cases.

Dublin Case, The-Mr. Doran, Dublin.

474-485

E.C.D.O. Case-W. C. Herbert, E.C.D.O.

$456-464$

Liverpool (Indoor and Allowance Staff), Fred Smith, Liverpool,

$4 € 5-473$

Rebuttixg the Case.

Jasper C. Badcock, Esq., rebutting the London Case,

E. B. Lewin Hill, Eqq., rebutting the Provincial Case on all cases

excepting Promotion and Discipline, -

-

607-627-629

Herbert Joyce, Esq., rebutting the Cases of Promotion and Discipline, - $608-626$

The London Rejoinder, -

RFJOINDERS.

The Provincial, , -

\begin{tabular}{cc}
\multicolumn{2}{c}{ RFionNDERS. } \\
- & - \\
- & - \\
Lirerponl, & - \\
- & - \\
- & - \\
- & -
\end{tabular}

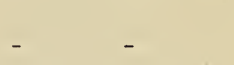

Rejoinder by Mr. John Walsh, Liverpo?l, - - - -

Notting Hill Rejoinder,

$630-633$

634-647

648-651

Woolwich

$-\quad-$

652

Preface,

$-\quad-$

653-654

A Chapter of Postal Service History, by A. M'Laren, Glasgow, 



(1)

sing 